University of New Hampshire

University of New Hampshire Scholars' Repository

\title{
Erosion and Accretion Trends of New Hampshire Beaches from December 2016 to March 2020: Results of the Volunteer Beach Profile Monitoring Program
}

\author{
Larry G. Ward \\ University of New Hampshire Center for Coastal and Ocean Mapping, Durham, Igward@ad.unh.edu \\ Rachel C. Morrison \\ University of New Hampshire Center for Coastal and Ocean Mapping, Durham \\ Alyson L. Eberhardt \\ University of New Hampshire Extension, Durham, alyson.eberhardt@unh.edu \\ Wellsley J. Costello \\ University of New Hampshire Extension, Durham \\ Zachary S. McAvoy \\ Eollowe this and fadditionahwarks athat:https://scholars.unh.edu/ccom \\ Part of the Environmental Monitoring Commons, Geology Commons, Geomorphology Commons, \\ Sedimentology Commons, and the Sustainability Commons
}

\section{Recommended Citation}

Ward, L.G., Morrison, R.C., Eberhardt, A.L., Costello, W.J., McAvoy, Z.S., and Mandeville, C.P., 2021. Erosion and Accretion Trends of New Hampshire Beaches from December 2016 to March 2020: Results of the Volunteer Beach Profile Monitoring Program. New Hampshire Sea Grant and University of New Hampshire Extension Technical Report, Durham, NH 03824. 420 pp. https://dx.doi.org/10.34051/p/2021.34

This Report is brought to you for free and open access by the Center for Coastal and Ocean Mapping at University of New Hampshire Scholars' Repository. It has been accepted for inclusion in Center for Coastal and Ocean Mapping by an authorized administrator of University of New Hampshire Scholars' Repository. For more information, please contact Scholarly.Communication@unh.edu. 


\section{Authors}

Larry G. Ward, Rachel C. Morrison, Alyson L. Eberhardt, Wellsley J. Costello, Zachary S. McAvoy, and Caitlin P. Mandeville 


\section{Erosion and Accretion Trends of New Hampshire Beaches from December 2016 to March 2020: Results of the Volunteer Beach Profile Monitoring Program}

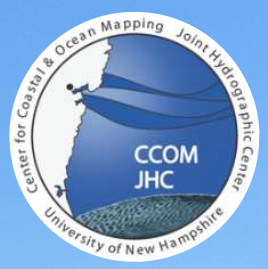

REPORT BY:

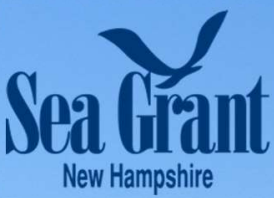

(1)

Extension

Larry G. Ward, Rachel C. Morrison, and Zachary S. McAvoy

University of New Hampshire Center for Coastal and Ocean Mapping

Alyson L. Eberhardt, Wellsley J. Costello, and Caitlin P. Mandeville NH Sea Grant Extension

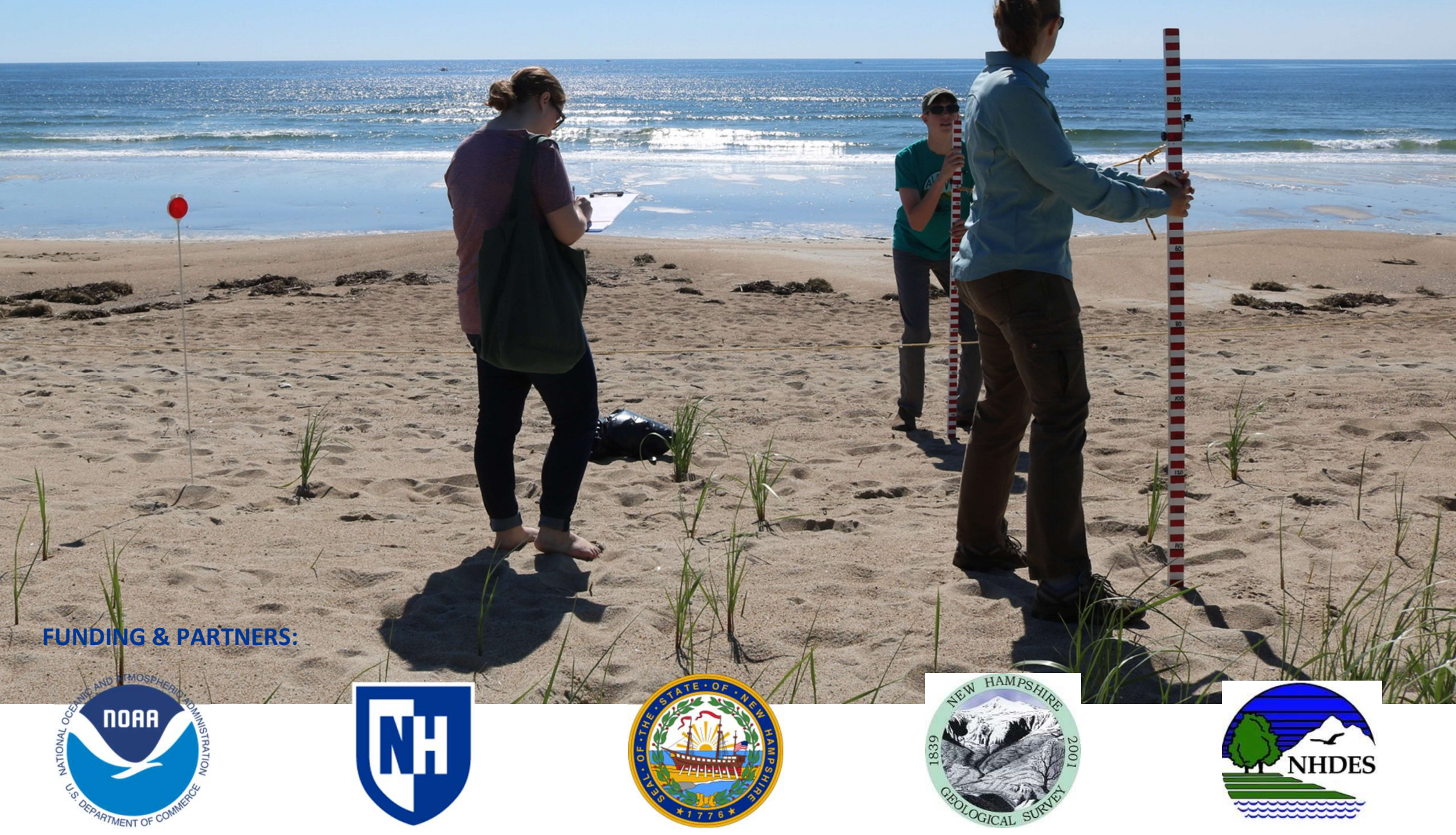




\section{Acknowledgements}

The project was funded, in part, by NOAA's Office for Coastal Management under the Coastal Zone Management Act in conjunction with the New Hampshire Department of Environmental Services Coastal Program. The grant was managed and technical support provided by the University of New Hampshire Cooperative Extension, New Hampshire Sea Grant, and the University of New Hampshire Center for Coastal and Ocean Mapping/Joint Hydrographic Center (CCOM/JHC) (NOAA Joint Hydrographic Center Award Number NA10NOS4000073). We are grateful to the community volunteers who collected the field data, often under very cold and harsh conditions. Their dedication is deeply appreciated. The volunteers include Alfred Ackerman, Tom Adams, Saarika Arthanat, Vidya Balasubramanyam, Dennis Barrett, Hank Bautzmann, Rebecca Beasley, Greyson Belliveau, Lauren Belliveau, Katharine Brown, Colin Canedy, Dave Canedy, Kathy Canedy, Leslie Cliche, Rick Cliche, Jonathan Cooper, Steve Couture, Mark Davidson, Molly Dennett, Hugh Evans, Eve Fralick, Claudia Gilmartin, Kirsten Howard, Craig Jaus, Kaye Jaus, Mike Jeans, Sue Lambert, Peter Leary, Jessica Li, Kevin Lucey, Don Maggs, Stephen McCarthy, Nathalie Morison, Sally Nickerson, Holly Oliver, Dave Perkins, Lee Pollock, Sylvia Pollock, David Ritchie, Ellen Saas, Dave Samara, Cathy Silver, Doug Silver, Barry Simard, Sally Soule, Joe St. Onge, Bryce Stetson, Jennifer Stetson, Mike Stockdale, Terry Stockdale, Ben Sweeney, Lisa Sweet, Marc Tosiano, Sherri Townsend, Bob Walsh, Dongmei Wang, Ryan Wang, Mary Wicklund, Hopi Wickson, Maverick Wickson, Chris Williams, Deb Wrobel, John Wrobel, and Dawen Zhou. This project would have been impossible to conduct without their steady assistance and often ingenious problem solving in the field. If anyone was omitted by mistake we apologize. A number of colleagues at the University of New Hampshire CCOM/JHC provided scientific and technical support, advice, and insight including the IT Group (Will Fessenden), Tom Lippmann, and Jon Hunt. We are also grateful to Kristen Grant, Maine Sea Grant and University of Maine Extension, and Jake Amman from the Wells National Estuarine Research Reserve for sharing their insights and experience with the Southern Maine Volunteer Beach Profile Monitoring Program.

\section{Map Projections}

All maps are projected in Transverse Mercator, horizontal datum NAD 1983 UTM Zone 19N.

\section{Recommended Citation}

Ward, L.G., Morrison, R.C., Eberhardt, A.L., Costello, W.J., McAvoy, Z.S., and Mandeville, C.P., 2021. Erosion and Accretion Trends of New Hampshire Beaches from December 2016 to March 2020: Results of the Volunteer Beach Profile Monitoring Program. New Hampshire Sea Grant and University of New Hampshire Extension Technical Report, Durham, NH 03824. 420 pp. https://dx.doi.org/10.34051/p/2021.34 


\section{Executive Summary}

New Hampshire's Atlantic beaches are extremely important to the Seacoast as they provide recreation and esthetic value and are vital to both the local and state economy. However, recent research has shown that over the years the beaches have lost elevation and size (Olson and Chormann, 2016) due to storm erosion and low sediment (sand) supply. This situation is exacerbated by climate change due to an acceleration in the rate of sea-level rise and an increase in storm intensity (Kirshen et al., 2014). Therefore, a monitoring project was initiated in December 2016 and expanded in 2018 to determine seasonal changes in the morphology and elevation of the beaches, assess the response of the beaches to storms with respect to erosion and subsequent recovery, and develop a baseline to determine long-term trends in beach size, elevation, and position. A unique aspect of this study is the involvement of community volunteers working together with the University of New Hampshire (UNH) Center for Coastal and Ocean Mapping, UNH Cooperative Extension, New Hampshire Sea Grant, and the New Hampshire Geological Survey.

The monitoring network consists of thirteen stations located at six of the major beaches, including each of the state beaches, along the New Hampshire (NH) Atlantic coast (Figure ES-1). Monitoring stations are located at Wallis Sands, Jenness Beach, North Hampton Beach, North Beach, Hampton Beach, and Seabrook Beach. At least two stations are located at each beach (Seabrook Beach has three stations). Beach elevation profiles were run routinely at each station at approximately threeto four-week intervals. Additional measurements were made following several major storms. Monitoring was initiated at three stations in December 2016 and ten stations were added in 2018. In total, approximately 400 elevation profiles were run at the thirteen stations between December 8 , 2016 and March 14, 2020. The beach elevation profiles were measured from a permanent station marker at the landward extent of the beach (either a point on a seawall or a stake in the dunes), perpendicularly across the beach to the low water line or swash zone. The elevation profiles were run using the Emery (1961) method which utilizes two calibrated rods and the horizon for leveling. Sediment volume calculations were made for each profile that approximated the amount of material in the intertidal zone for that profile at that point in time for a one-meter wide swath of the beach. Seasonal changes and storm impacts on beach elevations, profile characteristics, and sediment volumes are discussed in detail for each beach and station in Chapter 4: Results. Therefore, the details of each beach are not discussed here in the Executive Summary. Rather, an overview of the general characteristics of the NH Atlantic beaches is presented and the major conditions and processes that control their stability are discussed. 


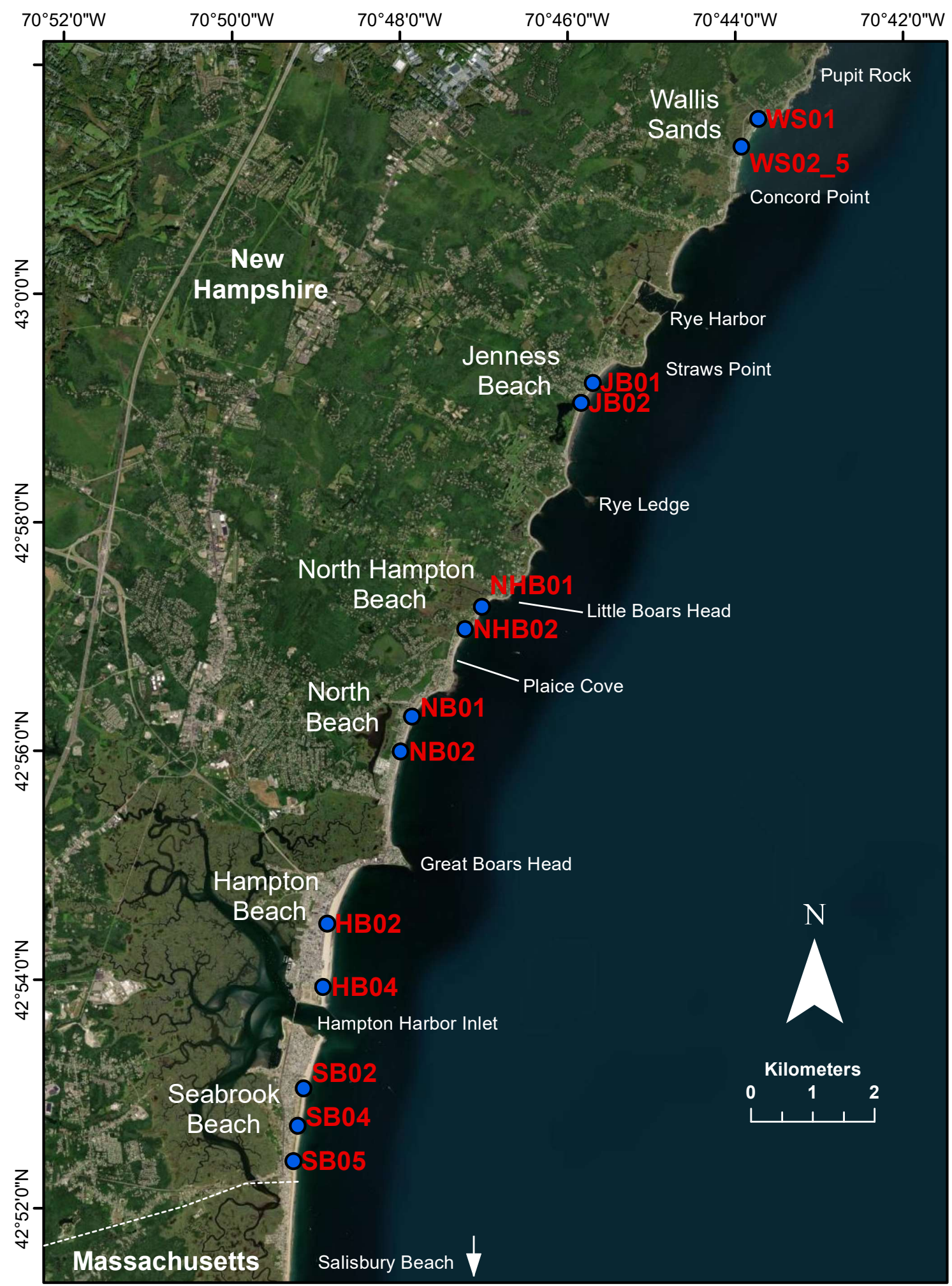

Figure ES-1. Location map of the New Hampshire coast and the thirteen beach elevation profile stations monitored during this study. 
The relatively short NH Atlantic coastline $(29.5 \mathrm{~km}$ or $18.3 \mathrm{mi})$ is located between the rocky Maine (ME) coast and the barrier island systems found in northern Massachusetts (MA). As a result, the NH coast tends to be rockier on its northern end transitioning into barrier islands in the south. The beaches north of Great Boars Head in Hampton, NH tend to be highly variable and include attached barriers, small pocket beaches eroded into the upland, and gravel beaches associated with headlands. Many of these beaches are composed of sand and gravel (bimodal) or totally gravel (shingle beaches). The headlands, which are composed of bedrock or more commonly bedrock covered with till, extend offshore and effectively separate the beaches and diminish the exchange of sediment between beaches via longshore drift. Beaches south of Great Boars Head are part of a barrier chain that extends from Great Boars Head to Cape Ann, MA. These barrier beaches are largely unimodal (sand) and have well-formed berms and broad intertidal zones. The southern end of Hampton Beach (South Beach) and Seabrook Beach both have dune systems which provide protection against storm erosion and flooding. However, historically the dune systems were far more extensive in Hampton and along the entire NH Atlantic coast (Eberhardt and Burdick, 2008). The larger dune systems unfortunately were lost due to development in the past. Today, dunes are protected as regulatory wetlands, but only a small percentage of their historic extent remains.

Most of the NH Atlantic coast has extensive seawalls or human-made berms built to protect the upland, except at the locations on Seabrook Beach and Hampton South Beach where large dunes presently exist. Seawalls and berms prohibit or reduce the ability of a beach to erode into the upland, diminishing another source of sediment. Thus, the seaward-extending headlands, coupled with the numerous seawalls and man-made berms, limits sediment movement on NH Atlantic coast beaches north of Great Boars Head to an onshore - offshore direction. As a consequence, the overall sediment supply is limited, leading to lower elevations, erosion, washover, and flooding.

A major observation apparent from examination of the elevation profiles and volumetric changes of the beaches is that there is considerable variability between profile measurements at a station over time and between different stations during the same profiling period. This is true even for profile stations at the same beach. In limited cases, this in part is due to uncertainty in the measurements and relatively small changes in elevation and volume often being measured. However, most of this variability is due to offshore features including the subtidal extensions of the headlands, bedrock outcrops, or eroded glacial deposits which create megaclast deposits. Therefore, it is prudent to be conservative with interpretations of the data from individual measurements which largely chronicle the effects of a single event. Here, trends in erosion or accretion, as well as losses or gains in elevation, are not based on profile-to-profile variability. Rather, trends are based on the overall changes over several months when beach elevation and sediment volume gains or losses become clearer.

Based on the time series record of the beach elevation profiles, mean elevations of the beach profiles, and intertidal sand volume calculations along the profiles, there were two periods of extended erosion and sediment loss during the study. The first period of major erosion was observed between late February and April 2017 at the three stations monitored during that period: Wallis Sands State Beach (WS01), Jenness State Beach (JB02), and Hampton Beach State Park (HB02). All three stations 
lost considerable elevation during this period due to a series of winter storms in February including Maya, Niko, and Orson, and were slow to recover (Figure ES-2). WSO1 and JB02 slowly increased in mean elevation as the beaches rebuilt through the spring and fall reaching maximum elevation in early December 2017. HB02 recovered earlier and regained elevation by late August 2017. The second major period of erosion occurred due to the impact of a series of severe nor'easters that occurred in March 2018 including Riley, Quinn, and Skylar. These major storms all occurred within a three-week period, which did not allow the beaches to recover between the storms. During the March 2018 nor'easters, all NH beaches were severely eroded and experienced major damage to the adjacent infrastructure due to storm surges, waves, and large sediment clasts including cobbles carried by the overwash (Figure ES-2 and see Chapter 4: Results). Similar to the impact of the 2017 storms, most $\mathrm{NH}$ beaches were slow to recover, undergoing the process of accretion from spring 2018 into early 2019. During 2019 and early 2020 there were several periods of erosion and recovery as well; however, the loss of beach elevation and volume was much less than occurred during the March 2018 storms and also did not occur at all stations.

There are a number of factors that control the stability and resilience of a beach system. Elevation is one measure of a beach's vulnerability to flooding, overwash, erosion, and damage to infrastructure (e.g., seawalls, roads, or homes). With only a few exceptions, each beach elevation profile measured during this study had the mean elevation calculated for its standard length (a constant profile length used to calculate volume or mean elevation for a station based on all of the profiles measured at that station, defined in the Glossary in Appendix A). The mean elevation for each station monitored during the study was determined by averaging all the profiles from that station from January 2018 through March 2020. The results show that, in general, beach profile stations located north of Great Boars Head had lower elevations (Table ES-1) relative to southern NH beaches. The lowest mean elevations observed occurred at North Beach, which floods on a regular basis up to the seawall during spring high tides, making it very susceptible to erosion, flooding, and storm damage (see Chapter 4; North Beach). Similarly, Jenness Beach and Wallis Sands both had low elevations and were very susceptible to storms, although the elevations were slightly higher than North Beach. By contrast, all three stations on Seabrook Beach had mean elevations that were on the order of one meter higher than the beaches north of Great Boars Head. The mid-Hampton Beach station (HBO2) had both the highest mean and minimum elevations of all profile stations monitored during this study. The station at the southern end of Hampton Beach (HB04) was lower than HBO2 and all three of the Seabrook stations, but was still greater than all of the northern beaches except North Hampton Beach, which is somewhat of an anomaly. The State Beach (NHB01), which is located on the northern end of North Hampton Beach, is very narrow, steep, and composed of sand with a very large pebble and cobble population (mixed sediment). As a result, the mean elevation is slightly higher than some of the other northern beaches but is still very susceptible to overwash and storm damage due to its narrow width. The station further south at North Hampton Beach (NHB02) starts in dunes and is partially protected by Godfrey's Ledge. As a result, it is highly variable and is not characteristic of the beaches to the north. The higher elevations of the barrier beaches south of Great Boars Head provide more protection from flooding and storm damage. 
Although more work must be done to assess the relationship between beach erosion, flooding, and mean elevation, the initial results agree with earlier studies done on NH Atlantic beaches. Previous work indicates that these beaches, when viewed over approximately the last two centuries, have undergone a slow retreat (landward migration) north of Great Boars Head, while Hampton Beach and Seabrook Beach have prograded (built seaward). Olson and Chormann (2016) compared charts, maps, and aerial photographs over a period from 1885 to 2015 . Their results are highly variable, but over the entire period Hampton Beach and Seabrook prograded at $\sim 0.2$ and $\sim 0.6 \mathrm{~m} / \mathrm{yr}$ (meters per year), respectively. Most of the beaches north of Hampton Beach were either very close to stable or retreating between $\sim 0.05$ and $0.35 \mathrm{~m} / \mathrm{yr}$. The exception was Wallis Sands which accreted $\sim 0.10 \mathrm{~m} / \mathrm{y}$. Olson and Chormann (2016) also examined volume loss based on changes in elevation of the beaches determined from lidar surveys between 2000 and 2014. The results of the volumetric analysis were consistent with the shoreline change analysis. Hampton Beach and Seabrook Beach varied significantly between surveys, but in general showed a trend of accretion. The beaches north of Great Boars Head also showed a great deal of variability, but by contrast lost sediment and elevation over the same time period.

Even at the higher rates of shoreline change observed by Olson and Chormann (2016), the overall horizontal movement of the $\mathrm{NH}$ Atlantic beaches was relatively small due to the low rate of relative sea-level rise in $\mathrm{NH}$ over the last century, the bedrock outcrops along the coast, and the extensive engineering structures (Blondin, 2016). However, the results of the study presented here have verified that the beaches have lost elevation north of Great Boars Head while gaining elevation at Seabrook Beach and Hampton Beach (discussed below). It is important to note that the rate of relative sea-level rise in the northeast is accelerating (Sallenger et al., 2012; Kirshen et al., 2014), which will make the NH Atlantic beaches and coastal infrastructure with low elevations more susceptible to erosion, flooding and storm damage in the future.

The time interval between measuring beach elevation profile changes during this study was short enough to document the effect of storm events on the beaches, and the length of the study period was long enough to advance our understanding of seasonal changes. However, a full understanding of long-term trends in erosion and accretion and elevation change will require monitoring to be maintained. Climate change and the acceleration in the rate of sea-level rise will increase the likelihood that the $\mathrm{NH}$ beaches will suffer high rates of erosion, increased flooding, and damage to coastal infrastructure including roads, businesses, and private homes. Going forward, a major goal of this study will be to identify the NH Atlantic beaches that are most vulnerable to erosion and storm damage and to develop a long-term monitoring plan that is tailored to providing timely results that can be used to make management decisions for mitigating the impact of storms and sea-level rise. Decisions regarding coastal resiliency plans, deciding where to place dredge sediments that are suitable for beach nourishment, developing beach nourishment plans for the future, and assessing the building of private and public infrastructure all need extended baseline data concerning beach erosion and elevation change. 

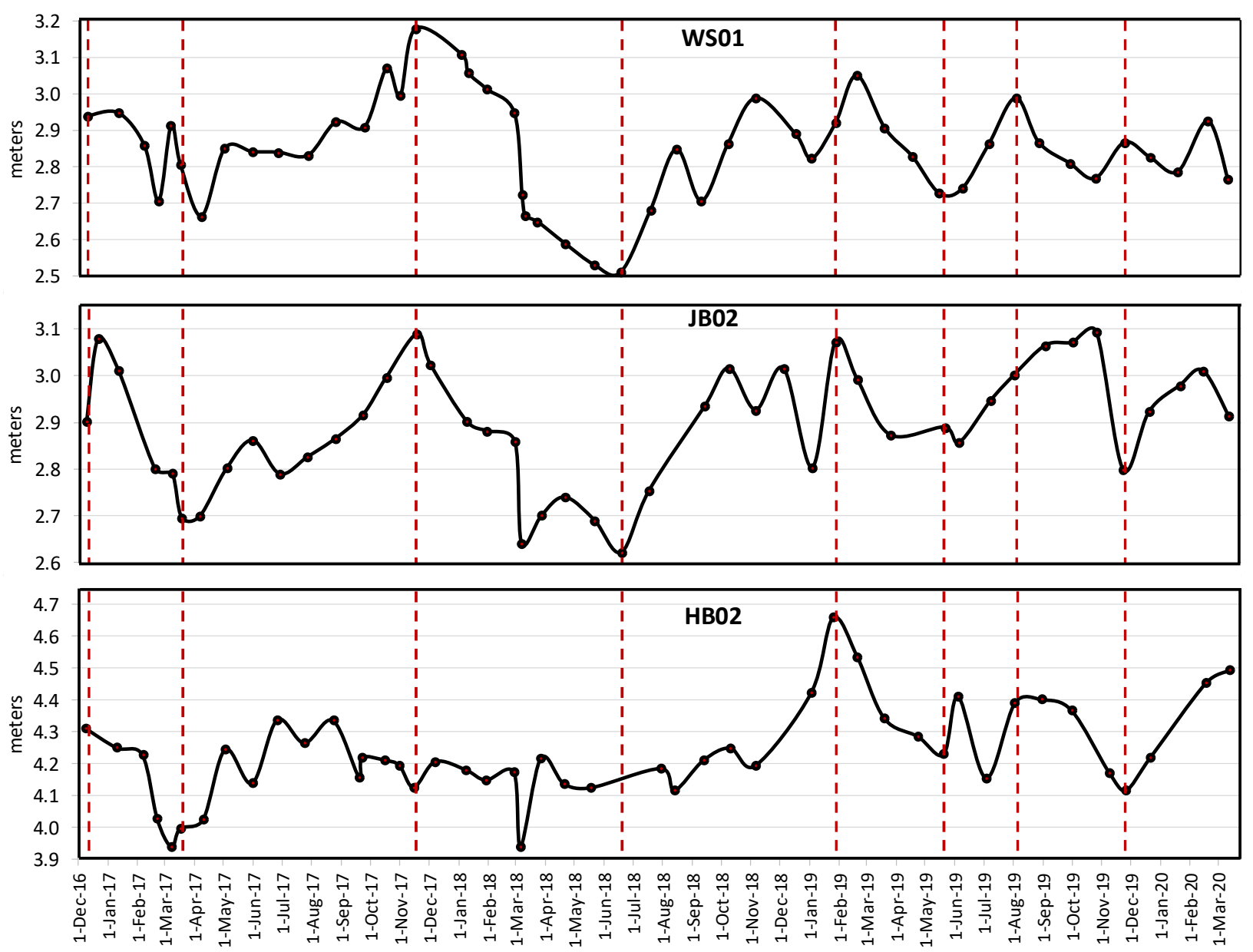

Figure ES-2. Time series of mean beach elevation at Wallis Sands State Beach (WSO1), Jenness State Beach (JB02), and Hampton Beach State Park (HB02) from December 2016 to March 2020. These stations were monitored for three full years and are representative of many of the study sites. The vertical axis units are in meters and referenced to the IGSO8 ellipsoid. Red dashed lines represent peaks or lows in elevation. 
Table ES-1. Mean elevations and profile lengths of the beach profiles measured between January 2018 and March 2020 for the thirteen stations along the New Hampshire coast. The elevations are presented in reference to MLLW and NAVD88.

\begin{tabular}{|ccccc|}
\hline Beach & Station & $\begin{array}{c}\text { Mean Elevation } \\
\text { MLLW }(\mathbf{m})\end{array}$ & $\begin{array}{c}\text { Mean Elevation } \\
\text { NAVD88 }(\mathbf{m})\end{array}$ & $\begin{array}{c}\text { Mean Profile } \\
\text { Length }(\mathbf{m})\end{array}$ \\
\hline North Beach & NB01 & 1.6 & 0.0 & 73.1 \\
North Beach & NB02 & 1.5 & 0.0 & 74.8 \\
Jenness Beach & JB01 & 2.1 & 0.6 & 148.5 \\
Jenness Beach & JB02 & 2.4 & 0.8 & 169.0 \\
Wallis Sands Beach & WS01 & 2.2 & 0.7 & 135.5 \\
Wallis Sands Beach & WS02.5 & 2.2 & 0.7 & 120.4 \\
North Hampton Beach & NHB01 & 2.4 & 0.9 & 70.7 \\
North Hampton Beach & NHB02 & 3.0 & 1.5 & 106.6 \\
Seabrook Beach & SB02 & 3.4 & 1.8 & 103.2 \\
Seabrook Beach & SB04 & 3.4 & 1.8 & 87.1 \\
Seabrook Beach & SB05 & 3.4 & 1.8 & 88.4 \\
Hampton Beach & HB02 & 3.8 & 2.2 & 164.4 \\
Hampton Beach & HB04 & 2.5 & 0.9 & 151.6 \\
\hline
\end{tabular}




\section{Table of Contents}

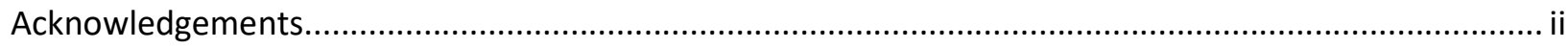

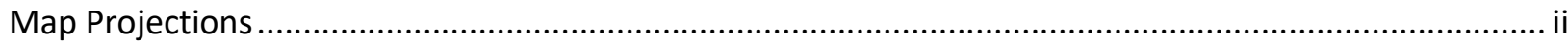

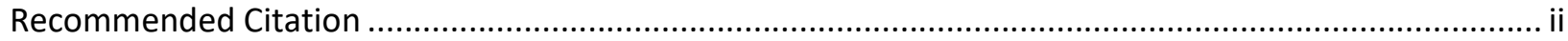

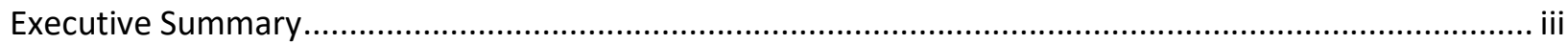

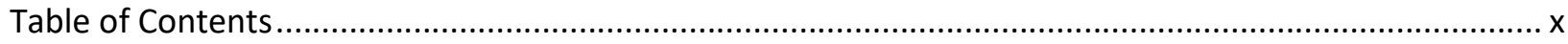

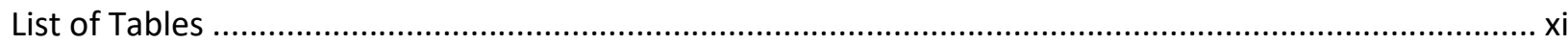

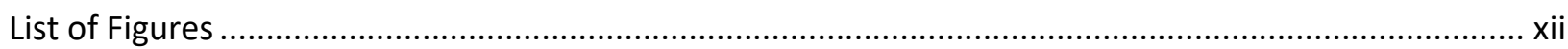

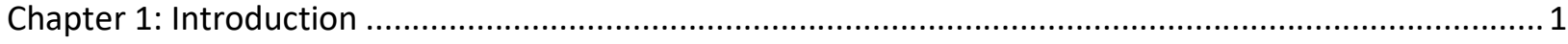

Chapter 2: Description of the New Hampshire Coast ..........................................................................

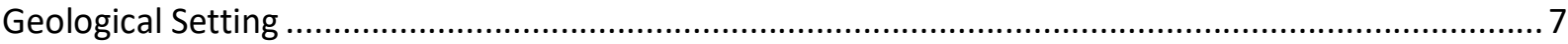

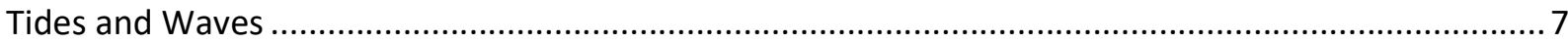

Climate

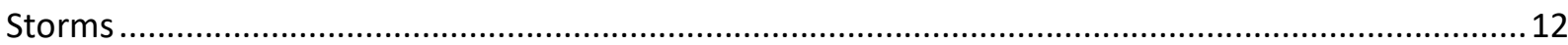

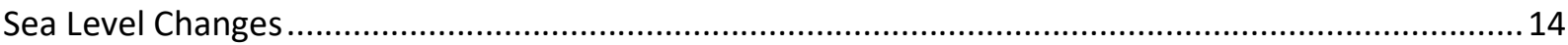

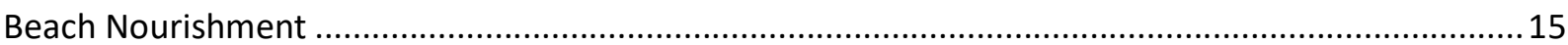

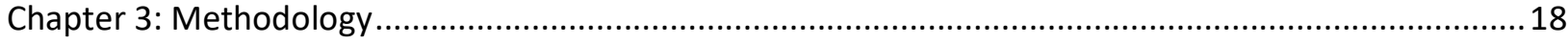

Establishment of the Beach Monitoring Stations ............................................................................ 18

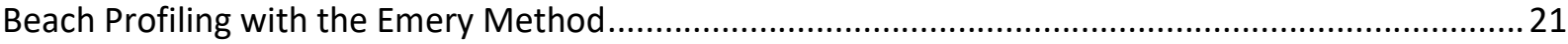

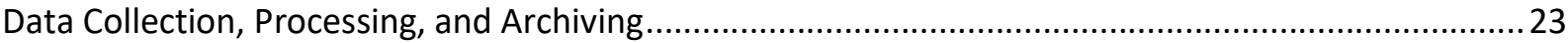

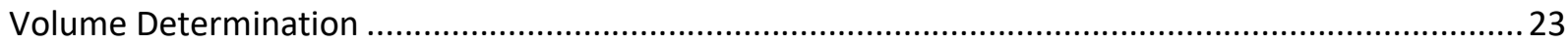

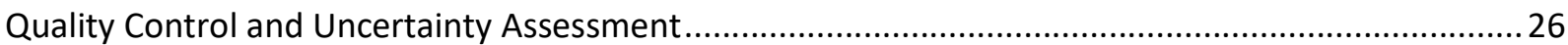

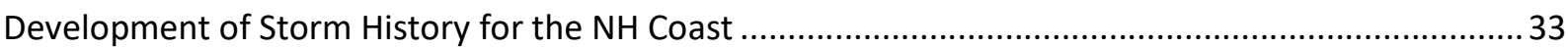

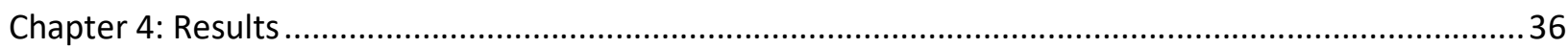

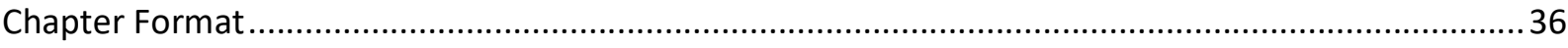

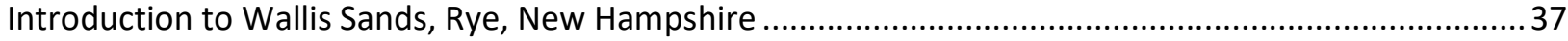

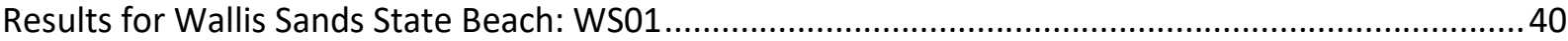

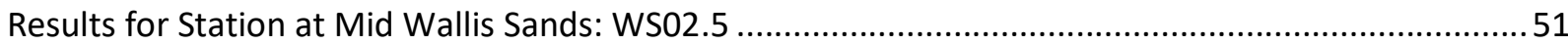

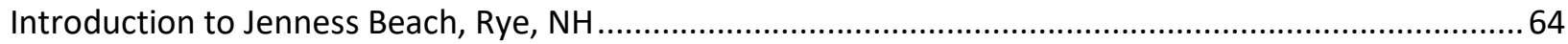

Results for Station at Northern Jenness State Beach (Cable Beach): JB01 .........................................68

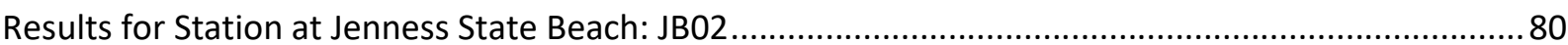

Introduction to North Hampton Beach, North Hampton, $\mathrm{NH}$..............................................................93

Results from Station at North Hampton State Beach: NHB01 ........................................................99 
Results for Station at Mid North Hampton Beach (Godfreys Ledge Tombolo): NHB02 119

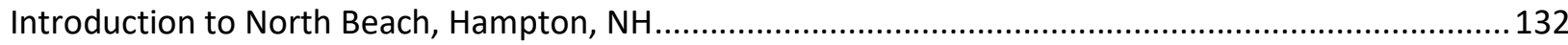

Results for Station at the Northern End of North Beach: NB01 …............................................... 141

Results for Station at Mid North Beach: NB02 …....................................................................... 160

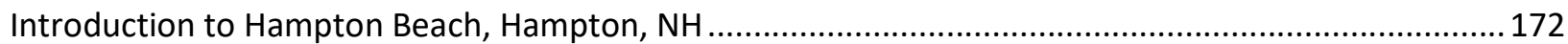

Results for Station at Hampton Beach State Park: HB02 …........................................................... 181

Results for Station at Hampton Beach State Park: HB04 ............................................................... 198

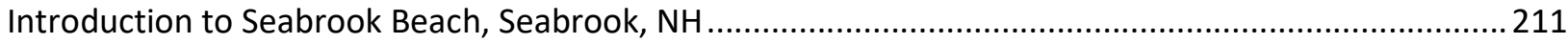

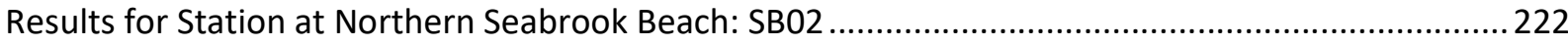

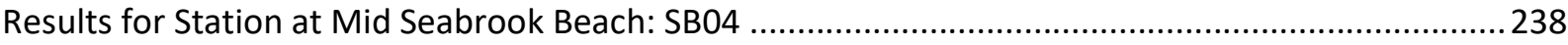

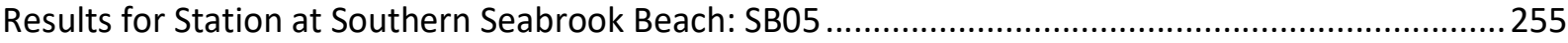

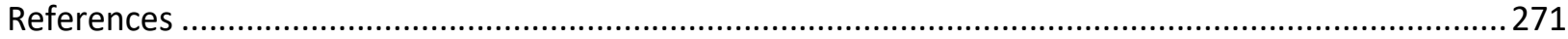

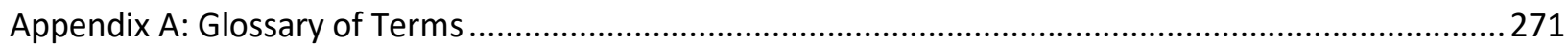

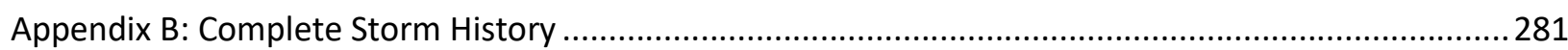

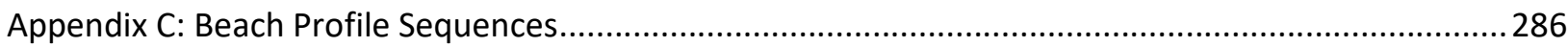

Appendix C(1): WS01 beach profiles from December 9, 2016 to March 12, 2020............................ 286

Appendix C(2): WS02.5 beach profiles from January 30, 2018 to March 14, 2020...........................296

Appendix C(3): JB01 beach profiles from January 28, 2018 to March 14, 2020.................................304

Appendix C(4): JB02 beach profiles from December 8, 2016 to March 12, 2020............................310

Appendix C(5): NHB01 beach profiles from January 27, 2018 to March 14, 2020............................319

Appendix C(6): NHB02 beach profiles from January 27, 2018 to March 14, 2020............................328

Appendix C(7): NB01 beach profiles from January 27, 2018 to March 13, 2020.................................337

Appendix C(8): NB02 beach profiles from April 18, 2018 to March 13, 2020.....................................346

Appendix C(9): HB02 beach profiles from December 9, 2016 to March 12, 2020.............................352

Appendix C(10): HB04 beach profiles from February 28, 2018 to March 9, 2020............................ 361

Appendix C(11): SB02 beach profiles from January 29, 2018 to March 9, 2020 ................................366

Appendix C(12): SB04 beach profiles from January 29, 2018 to March 9, 2020 ............................... 375

Appendix C(13): SB05 beach profiles from January 29, 2018 to March 9, 2020 ...............................383

\section{List of Tables}

Table ES-1. Mean elevations and profile lengths of the beach profiles measured between January 2018 and March 2020 for the thirteen stations along the New Hampshire coast ......................................... ix

Table 2-1. Mean and maximum significant wave heights (Hs) …......................................................

Table 2-2. Summary of air temperature, wind speed, and precipitation ..............................................11 
Table 2-3. The twelve highest storm surge events in 2017, 2018, and 2019 that occurred at the tide

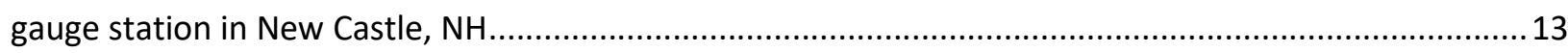

Table 2-4. Summary of known beach nourishment projects on the New Hampshire coast.....................17

Table 3-1. Station positions and elevations for the station markers for the NH VBPMP ........................ 19

Table 3-2. Differences between Mean Lower Low Water and -30 m (IGS08) on NH coast.......................24

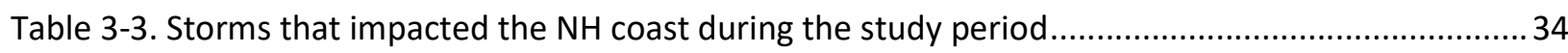

\section{List of Figures}

Figure ES-1. Location map of the New Hampshire coast and the thirteen beach elevation profile stations monitored during this study

Figure ES-2. Time series of mean beach elevation at Wallis Sands State Beach (WS01), Jenness State Beach (JB02), and Hampton Beach State Park (HB02) from December 2016 to March 2020 .................. viii

Figure 1-1. Wallis Sands State Beach (top photograph, looking north) and Wallis Sands town beach (bottom photograph, looking south from State Beach) on July 30, 2017............................................. 3

Figure 1-2. Storm waves at North Beach on March 3, 2018 following the severe Nor'easter Riley............ 4

Figure 1-3. Beach and dune erosion caused by Nor'easter Riley

Figure 1-4. Extremely high water and waves at Hampton Beach on March 3, 2018 (left photograph) and Jenness State Beach on March 4, 2018 (right photograph) during the Nor'easter Riley ...........................5

Figure 1-5. Damage that occurred due to Nor'easter Riley ..............................................................

Figure 1-6. Volunteers measuring a beach elevation profile at Jenness Beach (station JB01) using the Emery (1961) method on November 11, 2018

Figure 1-7. Volunteers measuring distance from the station marker to the beach surface to start the

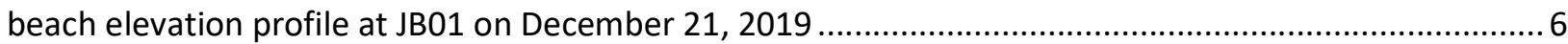

Figure 2-1. Beach nourishment at Seabrook Beach using dredged material from Hampton-Seabrook Harbor (December 11, 2012)

Figure 2-2. Beach nourishment at Hampton Beach State Park using dredged material from Hampton-

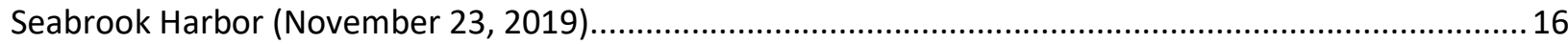

Figure 3-1. Station markers at Hampton Beach (HB04) on July 8, 2019............................................20

Figure 3-2. The station marker height above the sand is being measured with a profile rod during the

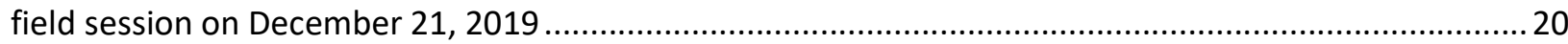

Figure 3-3. Seaward and landward profile station markers for station HBO4 on October 27, 2017..........21

Figure 3-4. Seaward profile station marker (wooden post) for station SB05 on April 17, 2019 ............... 22

Figure 3-5. Volunteers measuring a beach elevation profile in the field using the Emery method at Jenness Beach (JB02) on July 8, 2019

Figure 3-6. Volunteers measuring a beach elevation profile in the field using the Emery method at Hampton Beach (HB02) on January 2, 2019

Figure 3-7. An example of extending a relatively low amplitude (flatter) elevation profile is shown for Jenness Beach (JB02) on August 8, 2019 
Figure 3-8. An example of extending a steep beach profile to the standard length for sediment volume calculations is shown for SB02 (Seabrook Beach) on June 19, 2018

Figure 3-9. Comparison of Emery beach profiles completed on December 8, 2016 at station JB02 by two separate volunteer groups, representing the accuracy and repeatability of the method

Figure 3-10. Measuring a beach profile at Wallis Sands using the GNSS Rover system on August 3, 2016

Figure 3-11. Comparison of GNSS rover profiles and Emery profiles for Wallis Sands (WS01).................30

Figure 3-12. Comparison of GNSS rover profiles and Emery profiles for Jenness Beach (JB02) ...............31

Figure 3-13. Comparison of GNSS rover profiles and Emery profiles for Hampton Beach (HB02).............32

Figure WS-1: Location map of Wallis Sands with beach profile stations and shoreline structures (Blondin,

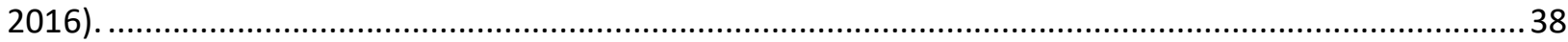

Figure WS-2. Wallis Sands beach looking south from Seal Rocks on November 11, 2012 ...................... 39

Figure WS-3. The southern end of Wallis Sands beach on August 1, 2019 ...........................................39

Figure WS-4. A seawall at the southern end of Wallis Sands beach on August 1, 2019.........................39

Figure WS01-1. Location of Beach Profile WS01 on Wallis Sands State Beach 40

Figure WS01-2. All forty-nine beach elevation profiles measured at WS01 over the entire study period from December 9, 2016 to March 12, 2020

Figure WS01-3. Maximum (November 16, 2017) and minimum (June 18, 2018) beach elevation profiles determined from volume calculations and mean elevation over the entire study period at station WS01

Figure WS01-4. Calculated sediment volume, mean profile elevation, and mean elevation change for station WS01

Figure WS01-5. Beach elevation profiles for WS01 on January 10, 2017, February 6, 2017, and February

21,2017

Figure WS01-6. Beach elevation profiles for WS01 on February 27, 2018, March 7, 2018, and March 10, 2018

Figure WS01-7. Wallis Sands State Beach shortly after Nor'easter Riley 46

Figure WS01-8. Beach elevation profiles for WS01 on April 21, 2018, May 21, 2018, and June 18, 201846 Figure WS01-9. Beach elevation profiles for WS01 on June 18, 2018, July 19, 2018, and August 15, 2018

Figure WS01-10: Beach elevation profiles for WS01 on August 15, 2018, September 10, 2018, and October 8, 2018

Figure WS01-11: Beach elevation profiles for WS01 on October 8, 2018, November 6, 2018, and December 17, 2018 .49

Figure WS01-12. Beach erosion at Wallis Sands State Beach on January 28, 2019 after a winter storm..49

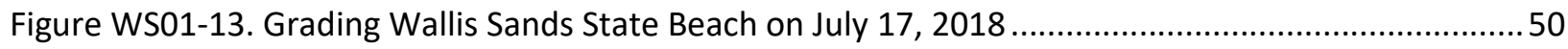

Figure WS01-14. Wallis Sands State Beach on August 19, 2018 with a large, wide berm .......................50 
Figure WS02-1. Location of station WS02.5, with the profile transect shown by the white dashed line in the photograph taken on May 21, 2018. 52

Figure WS02-2. Station marker and seawall at the landward end of the beach elevation transect at WSO2.5 52

Figure WS02-3. Dune grasses established in front of the seawall at station WS02.5 on February 27, 2018

Figure WSO2-4. Dune grasses seen in Figure WSO2-3 were removed during the severe nor'easters of early March 2018 as shown in the photograph taken on March 27, 2018 .53

Figure WS02-5. The dune grasses that were removed during the March 2018 nor'easters (Figure WS02-

4) were replanted as shown in this photograph taken on August 1, 2019. 53

Figure WS02-6. All twenty-eight beach elevation profiles measured at WS02.5 between January 30, 2018 and March 14, 2020

Figure WS02-7. Maximum (September 30, 2019) and minimum (June 18, 2018) beach elevation profiles by volume from the study period at station WS02.5......

Figure WS02-8. The maximum (September 30, 2019) beach elevation profile at station WS02.5 compared to the profile following the severe nor'easters that occurred in late winter 2018. 56

Figure WS02-9. Photograph of the sand ramp (arrow) on the upper beach south of station WSO2.5 on May 27, 2018

Figure WS02-10. Beach elevation profiles for WS02.5 on January 28, 2019, February 19, 2019, and March 25, 2019 57

Figure WS02-11. Calculated sediment volume, mean profile elevation, and mean elevation change for the beach profile at station WSO2.5 59

Figure WS02-12. Beach elevation profiles for WS02.5 on January 30, 2018 and February 27, 2018 .......60 Figure WS02-13. Beach elevation profiles for WS02.5 on February 27, 2018, March 15, 2018, and March 27, 2018 60

Figure WS02-14. Ridge and runnel system (arrow) at WS02.5 on March 27, 2018 formed after the major sequence of storms in late winter 2018. 62

Figure WS02-15. Beach elevation profiles for WS02.5 on March 27, 2018 and May 21, 2018. 62

Figure WS02-16. Beach elevation profiles for WS02.5 on May 21, 2018, June 18, 2018, and July 17, 2018

Figure JB-1. Location map of Jenness Beach with stations, geographic features, and shoreline engineering structures. 65

Figure JB-2. Jenness Beach from the Rye Ledge area looking north on October 25, $2020 \ldots \ldots \ldots \ldots \ldots \ldots \ldots . . . .66$

Figure JB-3. Northern Jenness Beach or Cable Beach on September 9, 2017 …...................................66

Figure JB-4. Jenness State Beach with its concrete seawall that separates the parking lot and bathhouse from the beach... 66

Figure JB-5. A large riprap seawall that separates the mid-Jenness Beach area from the upland. 67 
Figure JB-6. Manmade gravel berm separating southern Jenness Beach or Sawyers Beach from the upland

Figure JB01-1. Jenness Beach or Cable Beach looking north from JB01 on September 9, 2017

Figure JB01-2. Bedrock outcrops exposed on the low tide terrace (arrow) just south of the JB01 profile transect

Figure JB01-3. Station JB01 which starts at the lower corner of the seawall and extends to the low tide swash

Figure JB01-4. Station JB01 looking seaward on June 8, 2019 .70

Figure JB01-5. Mid-beach at station JB01 looking south on September 9, 2017 during accretional conditions

Figure JB01-6. Mid-beach at station JB01 looking south on March 25, 2018 after the series of storms in late winter 2018.

Figure JB01-7. All twenty-nine beach elevation profiles measured for station JB01 between January 28, 2018 and March 14, 2020

Figure JB01-8. Maximum (September 1, 2019) and first minimum (April 21, 2018; same volume as December 29, 2018) beach elevation profiles determined from sediment volume and average elevation from the study period at station JB01

Figure JB01-9. Maximum (September 1, 2019) and second minimum (December 29, 2018; same volume as April 21, 2018) beach elevation profiles determined from sediment volume and average elevation from the study period at station JB01

Figure JB01-10. Calculated sediment volume, mean profile elevation, and mean elevation change for the

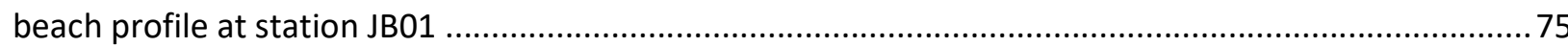

Figure JB01-11. Beach elevation profiles for JB01 on January 28, 2018 and February 24, 2018 ..............76 Figure JB01-12. Beach elevation profiles for JB01 on February 24, 2018, March 15, 2018, and March 25, 2018

Figure JB01-13. Seaweed washed up at JB01 following the series of winter storms in late winter 2018.. 77 Figure JB01-14. Upper beach by JB01 built up by the landward migration of sand ridges .78

Figure JB01-15. Beach elevation profiles for JB01 on March 25, 2018, April 21, 2018, and May 19, 201879

Figure JB01-16. Beach elevation profiles for JB01 on May 19, 2018, June 10, 2018, and July 18, 2018....79

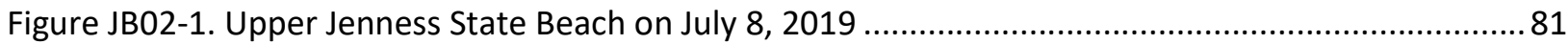

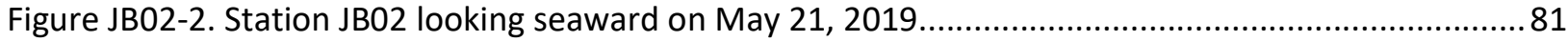

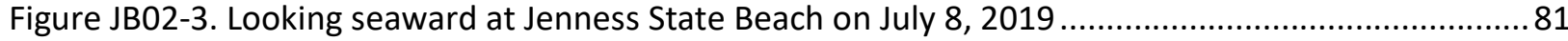

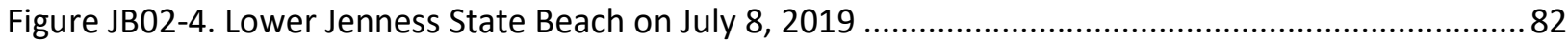

Figure JB02-5. Jenness State Beach after being mechanically raked and groomed 82

Figure JB02-6. Jenness State Beach looking south from JB02 during accretional conditions on July 17, 2018 
Figure JB02-7. Jenness State Beach looking north from station JB02 following Nor'easter Riley on March 2018

Figure JB02-8. Jenness State Beach facilities which were badly damaged by the late winter 2018 nor'easters

Figure JB02-9. A ramp created by overwash at Jenness State Beach on after the series of severe nor'easters in late winter.

Figure JB02-10. All forty-five beach elevation profiles run at JB02 between December 8, 2016 and March 12,2020 .85

Figure JB02-11. Calculated sediment volume, mean profile elevation, and mean elevation change for the beach profile at station JB02

Figure JB02-12: Maximum (October 26, 2019) and minimum (June 18, 2018) profiles by volume from the study period at station JB02 .87

Figure JB02-13. Beach elevation profiles for JB02 on April 20, 2018, May 21, 2018, and June 18, 2018 .. 87 Figure JB02-14. Beach elevation profiles for JB02 on June 18, 2018, July 17, 2018, and September 13, 2018 .88

Figure JB02-15. Beach elevation profiles for JB02 on January 29, 2018, February 27, 2018, and March 6, 2018 91

Figure JB02-16. Beach elevation profiles for JB02 on March 6, 2018, March 27, 2018, and April 20, 2018 91

Figure JB02-17. Beach elevation profiles for JB02 on January 3, 2019, January 27, 2019, and February 19, 2019 92

Figure NHB-1. Location map for North Hampton Beach, NH with stations, geographic features, and shoreline structures .94

Figure NHB-2. Little Boars Head, which forms the northern extent of North Hampton Beach ................95

Figure NHB-3. Little Boars Head during a storm on October 30, 2012 .............................................95

Figure NHB-4. North Hampton State Beach on September 2, 2019 after a stormy period when an excessive amount of seaweed washed onto the beach 95

Figure NHB-5. North Hampton State Beach looking south on September 2, 2019................................96

Figure NHB-6. North Hampton Beach and Plaice Cove on April 7, 2018 ...............................................96

Figure NHB-7. Headland at southern end of North Hampton Beach on August 2, 2020 .......................96

Figure NHB-8. Godfreys Ledge, which is a bedrock outcrop that is exposed off the southern end of North

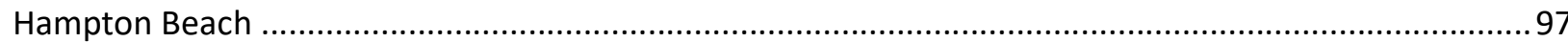

Figure NHB-9. Godfreys Ledge tombolo on February 17, 2019 following a stormy period .....................98

Figure NHB-10. Exposed tree roots (arrows) uncovered by erosion on Godfreys Ledge tombolo on April 11,2018 .98

Figure NHB-11. Close-up of exposed tree roots uncovered by erosion on Godfreys Ledge tombolo on April 11, 2018. .98 
Figure NHB01-1. North Hampton State Beach looking north from the southern end of the beach on January 27,2018 100

Figure NHB01-2. North Hampton State Beach looking north from the southern end of the beach on March 3, 2018 following Nor'easter Riley

Figure NHB01-3. All thirty beach elevation profiles measured during the study period at North Hampton State Beach station NHB01 from January 27, 2018 to March 14, 2020 102

Figure NHB01-4. Maximum (August 30, 2019) and minimum (January 17, 2020) beach elevation profiles during the study period at station NHBO1 103

Figure NHB01-5. Calculated sediment volume, mean profile elevation, and mean elevation change for the beach profile at station NHB01 104

Figure NHB01-6. Beach elevation profiles for NHB01 prior to the severe nor'easters in late winter 2018 on January 27, 2018 and February 24, 2018. 106

Figure NHB01-7. Beach elevation profiles for NHB01 on February 24, 2018 before the late winter 2018 nor'easters, followed by post-storm profiles from March 10, 2018 and March 28, 2018 107

Figure NHB01-8. Low tide terrace at station NHB01 looking north near the water line before and after the late winter 2018 storms 108

Figure NHB01-9. Mid-beach at station NHB01 looking south before and after the late winter 2018 storms 108

Figure NHB01-10. Large cobbles which were thrown over the seawall during Nor'easter Riley, damaging the seawall roadway and surrounding buildings 109

Figure NHB01-11. The seawall and parking lot at North Hampton Beach, which had to be repaired or replaced due to the damage during Nor'easter Riley. 109

Figure NHB01-12. A sand and gravel ramp which was pushed up against the seawall during the late winter nor'easters.

Figure NHB01-13. Following the severe nor'easters of late winter 2018, North Hampton State Beach was apparently graded in an effort to restore the beach

Figure NHB01-14. Beach elevation profiles for NHB01 on March 28, 2018, April 21, 2018, and May 19, 2018

Figure NHB01-15. Beach elevation profiles for NHB01 on November 4, 2018, December 1, 2018, and December 29, 2018.

Figure NHB01-16. Beach elevation profiles for NHB01 on December 29, 2018, January 26, 2019, and February 17, 2019

Figure NHB01-17. Beach elevation profiles for NHB01 on June 9, 2019, July 5, 2019, and August 3, 2019 115

Figure NHB01-18 (above). Beach elevation profiles for NHB01 on August 3, 2019, August 30, 2019, and September 28, 2019 116

Figure NHB01-19 (right). Mid beach at station NHB01 on August 30, 2019 (the maximum elevation profile for the study period at this station) 
Figure NHB01-20. Beach elevation profiles for NHB01 on December 21, 2019, January 17, 2020, and February 14, 2020

Figure NHB01-21. North Hampton State Beach on January 17, 2020 after being eroded during winter storms

Figure NHB01-22. North Hampton State Beach on February 14, 2020.

Figure NHB02-1. The beach elevation profile at $\mathrm{NHB02}$, which extends from narrow dunes and across the beach to the swash zone

Figure NHB02-2. Dunes extend landward from the beginning of NHB02 shown here by the wooden post

Figure NHB02-3. The upper transect of NHBO2 is usually composed of a sand and gravel mixture as seen here

Figure NHB02-4. The base of the sand and gravel ramp or berm at NHBO2 121

Figure NHB02-5. The mid and lower beach or low tide terrace at NHB02 122

Figure NHB02-6. The upper beach at NHB02 on March 10, 2018 after the severe nor'easters of late winter 2018

Figure NHB02-7. The mid and lower beach or low tide terrace at NHBO2

Figure $\mathrm{NHB02}-8$. The dunes landward of $\mathrm{NHBO2}$ were largely sand with scattered pebbles and cobbles following the severe nor'easters in late winter 2018.

Figure NHB02-9. All thirty beach elevation profiles measured at NHB02 from January 27, 2018 to March 14,2020

Figure NHB02-10. Maximum (August 30, 2019) and minimum (April 21, 2018) profiles by volume from the study period at station NHBO2

Figure NHB02-11. Calculated sediment volume, mean profile elevation, and mean elevation change for the beach profile at station NHBO2 126

Figure NHB02-12. Beach elevation profiles for NHB02 on February 24, 2018, March 10, 2018, and March 28,2018 128

Figure NHB02-13. Beach elevation profiles for NHB02 on March 28, 2018, April 21, 2018, and May 19, 2018 128

Figure NHB02-14. Beach elevation profiles for NHB02 on May 19, 2018, June 16, 2018, and July 15, 2018 129

Figure NHB02-15. Beach elevation profiles for NHB02 on July 15, 2018, August 15, 2018, and September 9, 2018 129

Figure NHB02-16. Beach elevation profiles for NHB02 on September 9, 2018, October 5, 2018, and November 4, 2018

Figure NHB02-17. Beach elevation profiles for NHB02 on June 9, 2019, July 5, 2019, and August 3, 2019

Figure NHB02-18. Beach elevation profiles for NHB02 on August 3, 2019, August 30, 2019, and September 28, 2019 
Figure NB-1. Location map of North Beach with stations, geographic features, and shoreline structures

Figure NB-2. The headland to the north of North Beach taken on March 18, 2017 134

Figure NB-3. North Beach looking south on June 6, 2019 134

Figure NB-4. The small gravel and rock beach located adjacent to the northern headland (arrow) ....... 134

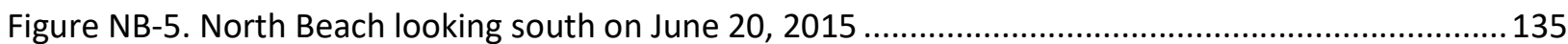

Figure NB-6. Storm waves following Nor'easter Riley at North Beach................................................ 135

Figure NB-7. During storm conditions waves push gravel up the beach and often form gravel ramps as shown in this photograph taken on September 5, 2016 136

Figure NB-8. During storms, sand can be eroded from the lower beach and transported landward building a sand ramp against the seawall as seen here at North Beach on April 7, 2018. 136

Figure NB-9. During storms sand and gravel can get pushed landward forming ramps as seen here..... 136 Figure NB-10. Megaclast platform (arrow) on the northern end of North Beach on January 26, 2019 .. 138 Figure NB-11. Bedrock outcrop with cobbles and boulders exposed at mid North Beach (arrow) .........138 Figure NB-12. Cobble and boulder or megaclast platforms (arrow) outcropping on the southern end of

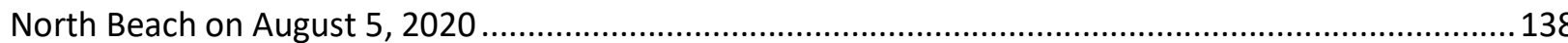

Figure NB-13. North Beach is composed of bimodal or mixed sediments including sand and gravel as seen here 139

Figure NB-14. Peat deposit outcropping on North Beach at station NB01 140

Figure NB-15. Close-up of peat deposit outcropping on North Beach at station NB01 on April 18, 2019

Figure NB-16. Tree stump exposed in the lower intertidal near the profile transect at North Beach NB01 140

Figure NB01-1. Station NB01, which is located at the northern end of North Beach 141

Figure NB01-2. Landward portion of the beach elevation profile at NB01 on January 26, 2019 142

Figure NB01-3. NB01 profile transect looking seaward 142

Figure NB01-4. Small bedrock outcrop along with scattered cobbles and boulders located a short distance from station NB01 143

Figure NB01-5. Bedrock outcrop and cobble and boulder platform located 100 m south of NB01 ......143 Figure NB01-6. All thirty beach elevation profiles measured at station NB01 between January 27, 2018 and March 13, 2020 145

Figure NB01-7. Maximum (August 4, 2019) and minimum (March 28, 2018) profiles by volume from the

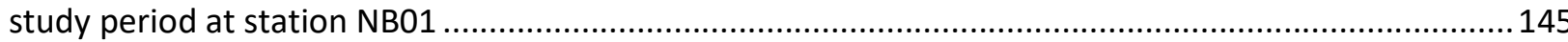

Figure NB01-8. Beach elevation profiles for NB01 on January 27, 2018 and February 24, 2018 147 Figure NB01-9. Beach elevation profiles for NB01 on February 24, 2018, March 10, 2018, and March 28, 2018 
Figure NB01-10. Beach elevation profiles on March 28, 2018, April 21, 2018, and May 21, 2018 following

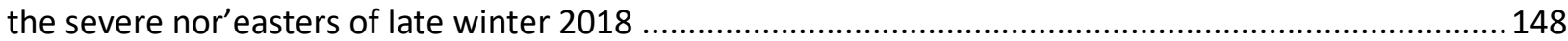

Figure NB01-11. North Beach, which was severely eroded during the late winter 2018 nor'easters ..... 149 Figure NB01-12. Post-storm beach at NB01 on March 18, 2018 following the severe nor'easters of late winter 2018.

Figure NB01-13. The lower beach by the swash zone, which was extremely eroded in late winter 2018

Figure NB01-14. Calculated sediment volume, mean profile elevation, and mean elevation change for the beach profile at station NB01 150

Figure NB01-15. Beach elevation profiles for NB01 on May 21, 2018, June 19, 2018, and July 15, 2018152 Figure NB01-16. Beach elevation profiles for NB01 on July 15, 2018, August 13, 2018, and September 8, 2018

Figure NB01-17. Beach elevation profiles for NB01 on September 8, 2018, October 7, 2018 and November 6, 2018 153

Figure NB01-18. Granite slabs at base of seawall and concrete landing at station NB01 153

Figure NB01-19. Beach elevation profiles for NB01 on February 23, 2019, March 20, 2019, and April 18, 2019 155

Figure NB01-20. Beach elevation profiles for NB01 on April 18, 2019, May 16, 2019, and June 7, 2019155 Figure NB01-21. Beach elevation profiles for NB01 on June 7, 2019, July 6, 2019, and August 4, 2019.156 Figure NB01-22. The beach at station NB01 looking south on August 4, 2019. .157

Figure NB01-23. The beach at station NB01 looking north on August 4, 2019 157

Figure NB01-24. Beach elevation profiles for NB01 on August 4, 2019, September 2, 2019 and September 28, 2019 158

Figure NB01-25. Beach elevation profiles for NB01 on September 28, 2019, October 26, 2019 and November 23, 2019 158

Figure NB01-26. Beach elevation profiles for NB01 on November 23, 2019, December 23, 2019 and January 21, 2020 159

Figure NB02-1. The beach south of station NB02 on September 29, 2019 160

Figure NB02-2. Location of beach elevation profile for NB02 161

Figure NB02-3. Stairwell (part of seawall), gravel ramp, and granite slabs at base of seawall at station NB02

Figure NB02-4. The beach elevation transect at NB02, which extends from the base of the stairwell seaward to the low water line 161

Figure NB02-5. Profiling North Beach at NB02 on September 29, 2019 162

Figure NB02-6. Mid and lower beach at NB02 on February 22, 2019 162

Figure NB02-7. Upper beach at NB02 on February 22, 2019 162 
Figure NB02-8. All twenty-one beach elevation profiles measured at station NB02 between April 18, 2018 and March 13, 2020

Figure NB02-9. Maximum (August 17, 2019) and minimum (May 20, 2018) beach elevation profiles for the study period at station NB02.

Figure NB02-10. Beach elevation profiles for NB02 on April 18, 2018, May 20, 2018 and June 17, 2018

Figure NB02-11. Eroded beach at station NB02 with exposed pebbles following the late winter 2018 nor'easters 167

Figure NB02-12. Lower beach at NB02 on June 17, 2018 167

Figure NB02-13. Calculated sediment volume, mean profile elevation, and mean elevation change for the beach profile at station NB02 168

Figure NB02-14. Beach elevation profiles for NB02 on October 7, 2018, November 4, 2018 and January 1, 2019 170

Figure NB02-15. Beach elevation profiles for NB02 on January 1, 2019, January 27, 2019 and February 22, 2019

Figure NB02-16. Beach elevation profiles for NB02 on April 19, 2019, May 16, 2019 and June 8, 2019.171 Figure NB02-17. Beach elevation profiles for NB02 on June 8, 2019, July 7, 2019 and August 17, 2019171 Figure HB-1. Location map of Hampton Beach with stations, geographic features, and shoreline structures

Figure HB-2. Great Boars Head (arrow), which forms the northern boundary of Hampton Beach ..........174

Figure HB-3. Concrete seawall which backs Hampton Beach

Figure HB-4. North of the large dune field at the southern end of Hampton Beach where there is a section without dunes or a seawall .... 175

Figure HB-5. Dunes located on the southern end of Hampton Beach 175

Figure HB-6. Large dune mounds located on the southern end of Hampton Beach 175

Figure HB-7. Cobble and boulder or megaclast platform at the northern end of Hampton Beach a short distance from Great Boars Head. 176

Figure HB-8. Bedrock outcrop on the northern end of Hampton Beach. 176

Figure HB-9. Groin on the northern end of Hampton Beach. 177

Figure HB-10. Large bedrock outcrop (arrow) at the southern end of Hampton Beach 177

Figure HB-11. Close-up of the large bedrock outcrop at the southern end of Hampton Beach 177

Figure HB-12. A large portion of Hampton Beach has a very wide backshore as shown in the photograph taken on June 17, 2015

Figure HB-13. Much of Hampton Beach has a very distinctive berm and a steep beach face (left arrow) fronted by a wide low tide terrace (right arrow) as seen here

Figure HB-14. Hampton Beach often has a wide, flat lower beach or low tide terrace as seen in this photograph looking north 
Figure HB-15. The southern end of Hampton Beach which has a large dune field (arrow) is typically very wide and flat

Figure HB-16. Large manmade berms (arrows) at Hampton Beach which serve as protection against storm waves and surges 180

Figure HB-17. Manmade berms being built on Hampton Beach 180

Figure HB02-1. Beach elevation profile at $\mathrm{HB} 02$, which is located approximately in the middle of Hampton Beach

Figure HB02-2. Following severe storms, sand can be washed into the sidewalks, streets, and business district behind Hampton Beach as seen here on March 5, 2018.

Figure HB02-3. Hampton Beach is regularly altered using bulldozers (seen here) and similar equipment to level the upper beach, build storm berms, and for other purposes 183

Figure HB02-4. Hampton Beach is regularly altered using bulldozers and similar equipment, as seen here where the upper beach is being extended and sand pushed down the berm 183

Figure HB02-5. All forty-six beach elevation profiles run at HBO2 between December 9, 2016 and March 12,2020 185

Figure HB02-6. Comparison of the maximum (January 25, 2019) and the first of the two minimum beach elevation profiles following a series of winter storms in early 2017 on March 8 for station HB02 ......... 186 Figure HB02-7. Comparison of the maximum (January 25, 2019) and the second of the two minimum elevation profiles following the severe Nor'easter Riley on March 6, 2018 at station HB02 186

Figure HB02-8. Beach elevation profiles for HB02 on February 6, 2017, February 21, 2017 and March 8, 2017 188

Figure HB02-9. Beach elevation profiles for HB02 on March 8, 2017, March 17, 2017 and April 10, 2017

Figure HB02-10. Hampton Beach at HB02 looking north on March 18, 2017 following a series of nor'easters

Figure HB02-11. Ridge or sand bar (arrow) migrating across the lower beach at HBO2 on April 10, 2017

Figure HB02-12. Calculated sediment volume, mean profile elevation, and mean elevation change for the beach profile at station $\mathrm{HBO2}$

Figure HB02-13. Beach elevation profiles for HB02 on May 3, 2017, May 31, 2017 and June 26, 2017.191 Figure HB02-14. Beach elevation profiles for HB02 on June 26, 2017, July 24, 2017, and August 23, 2017

Figure HB02-15. Beach elevation profiles for HB02 on September 22, 2017, October 16, 2017, and October 31, 2017

Figure HB02-16. Beach elevation profiles for HB02 on December 7, 2017, January 8, 2018, and January 29,2018

Figure HB02-17. Beach elevation profiles for HB02 on January 29, 2018, February 26, 2018, and March 6, 2018 194 
Figure HB02-18. Beach elevation profiles for HB02 on March 6, 2018, March 27, 2018, and April 20, 2018

Figure HB02-19. Beach elevation profiles for HB02 on January 2, 2019, January 25, 2019, and February

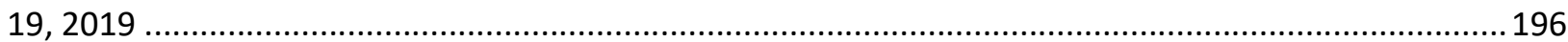

Figure HB02-20. Large berm (arrow) constructed near the seawall at HB02 to prevent overwash ........ 196 Figure HB02-21. Beach elevation profiles for HB02 on April 23, 2019, May 20, 2019, and June 4, 2019197 Figure HB02-22. Beach elevation profiles for HBO2 on August 30, 2019, September 30, 2019, and November 8, 2019 197

Figure HB04-1. Extensive dune system that backs the southern 0.4 km of Hampton Beach ................ 199

Figure HB04-2. The beach at HBO4 is typically wide and flat as shown here on November 8, 2019 .......199

Figure HB04-3. Approximate position of HB04 Beach elevation profile...............................................199

Figure HB04-4. Station HB04 following the severe nor'easters of March 2018 ....................................200

Figure HB04-5. Eroded dunes south of station HBO4 (southern end of Hampton Beach) after the March 2018 nor'easters 200

Figure HB04-6. All twenty-three beach elevation profiles measured at station HB04 between February 28, 2018 and March 9, 2020 202

Figure HB04-7. Maximum (September 17, 2018) and minimum (March 12, 2018) beach elevation profiles from the study period at station HBO4 202

Figure HB04-8. Calculated sediment volume, mean profile elevation, and mean elevation change for the beach profile at station $\mathrm{HBO} 4$ 204

Figure HB04-9. Beach elevation profiles for HB04 on February 28, 2018 and March 12, 2018..............205

Figure HB04-10. Ridge and runnel on lower beach at HB04 on March 12, 2018 .................................205

Figure HB04-11. Beach elevation profiles for HB04 on March 12, 2018, March 29, 2018, and April 22, 2018 206

Figure HB04-12. Beach elevation profiles for HB04 on April 22, 2018, September 17, 2018, and October

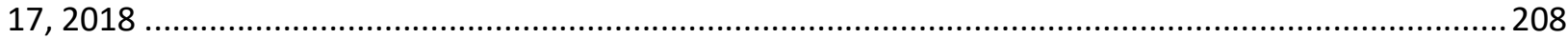

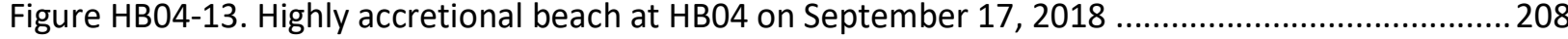

Figure HB04-14. Beach elevation profiles for HB04 on October 17, 2018, November 4, 2018, and December 1, 2018 209

Figure HB04-15. Beach elevation profiles for HBO4 on March 20, 2019, April 17, 2019, and June 21, 2019

Figure HB04-16. Beach elevation profiles for HBO4 on September 12, 2019, November 8, 2019, and December 21, 2019. 210

Figure SB-1. Seabrook Beach, NH, which is the northern half of the Seabrook-Salisbury Beach barrier island

Figure SB-2. Location map of Seabrook Beach with stations, geographic features, and shoreline engineering structures 
Figure SB-3. Seabrook beach dunes, the largest dune system in NH, looking south from near station SB04

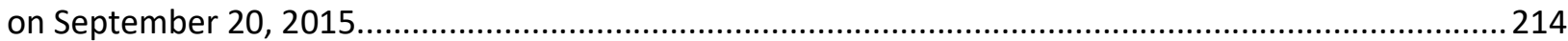

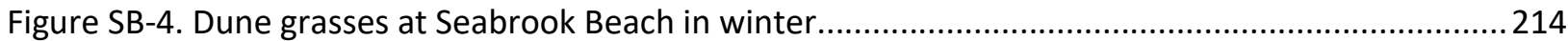

Figure SB-5. Homes north of the major dunes on Seabrook Beach, which are typically protected by a seawall (arrow) as shown in this photograph looking north from Hooksett Street on February 4, 2020215 Figure SB-6. The small section of northern Seabrook Beach where there is no seawall, but instead dune

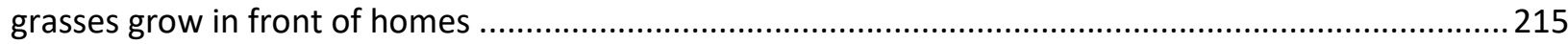

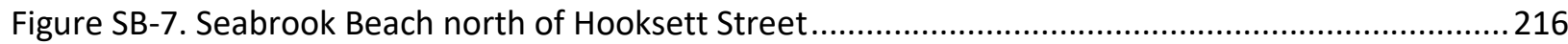

Figure SB-8. Seabrook Beach on September 5, 2016 looking south from near Hooksett Street .............216

Figure SB-9. Seabrook Beach north of Hooksett Street on December 6, 2015, showing the bedrock outcrops that are present in that area on the low tide terrace ..........................................................217

Figure SB-10. Bedrock outcrop on the low tide terrace on Seabrook Beach ........................................217

Figure SB-11. Small tombolo (arrow) located behind Round Rock....................................................218

Figure SB-12. Pipeline running from the dredging operation in Hampton-Seabrook Harbor to Seabrook

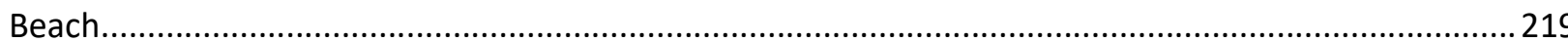

Figure SB-13. The sand placed on the beach during the beach nourishment project from the nearby harbor was graded with bulldozers

Figure SB-14. Dredge pipe outfall (arrows) and sand buildup on Seabrook Beach on October 26, 2019, where th 220

Figure SB-15. Redistribution of sand by power shovel and bulldozer continued into early 2020, as seen in these photographs taken on February 4, 2020

Figure SB02-1. Beach elevation profile transect for station SB02 on Seabrook Beach looking south (white dashed line)

223

Figure SB02-2. Beach elevation profile transect for station SB02 on Seabrook Beach looking east (white dashed line 223

Figure SB02-3. Mid and lower beach at station SB02 on February 24, 2018 .224

Figure SB02-4. Seabrook Beach at station SB02 looking south on March 7, 2018 following Nor'easter Riley.

224

Figure SB02-5. All thirty-two beach elevation profiles measured at station SB02 from January 29, 2018 to March 9, 2020 226

Figure SB02-6. Maximum (August 3, 2019) and minimum (May 18, 2018) profiles from the study period at station $\mathrm{SBO} 2$ 226

Figure SB02-7. Calculated sediment volume, mean profile elevation, and mean elevation change for the

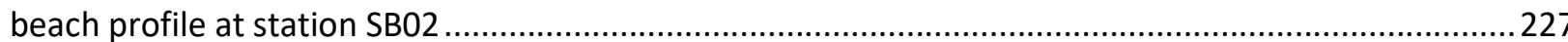

Figure SB02-8. Beach elevation profiles for SB02 on January 29, 2018 and February 24, 2018 ............ 229

Figure SB02-9. Beach elevation profiles for SB02 on February 24, 2018, March 7, 2018, and March 27, 2018 
Figure SB02-10. Swash zone at low tide at SB02 on March 7, 2018 during a stormy period 230

Figure SB02-11. Dune erosion and overwash that occurred during Nor'easter Riley 230

Figure SB02-12. During the March 2018 severe nor'easters the foredunes were eroded and sand transported further into the dunes 231

Figure SB02-13. Upper beach near station SB02 on March 7, 2018 following Nor'easter Riley ..............231

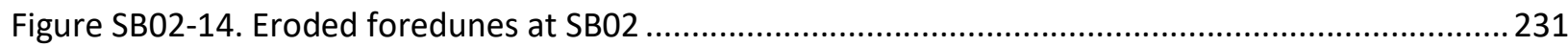

Figure SB02-15 (above). Beach elevation profiles for SB02 on March 27, 2018, April 21, 2018, and May

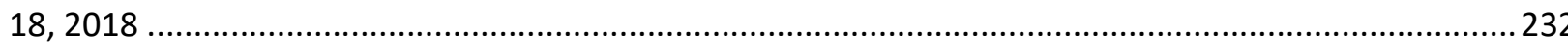

Figure SB02-16 (right). Rills formed on the low tide terrace after an erosive period at station SB02 ..... 232 Figure SB02-17. Beach elevation profiles for SB02 on March 20, 2019, April 19, 2019, and May 15, 2019

Figure SB02-18. Beach elevation profiles for SB02 on June 20, 2019, July 10, 2019, and August 3, 2019 234

Figure SB02-19. Beach elevation profiles for SB02 on September 29, 2019, October 26, 2019, and November 21, 2019 235

Figure SB02-20. Beach elevation profiles for SB02 on November 21, 2019, November 23, 2019, and December 25, 2019. 235

Figure SB02-21 (above). Beach elevation profiles for SB02 measured on December 25, 2019, January 20, 2020, and February 4, 2020 236

Figure SB02-22 (right). Ridge and runnel system (arrow) that started to form on the low tide terrace at station SB02 236

Figure SB02-23 (above). Beach elevation profiles for SB02 on February 4, 2020, February 17, 2020, and March 9, 2020 237

Figure SB02-24 (right). Ridge and runnel system (arrow) that continued to move landward on the beach at station $\mathrm{SBO} 2$ 237

Figure SB04-1. The upper and mid beach at SB04 under accretional conditions.................................239

Figure SB04-2. The lower beach at SB04 under accretional conditions 239

Figure SB04-3. The beach at SB04 frequently has large ridge (right arrow) and runnel (left arrow) systems

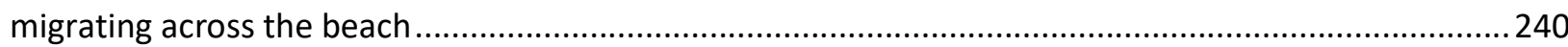

Figure SB04-4. Large ridge (right arrow) and runnel (left arrow) system on SB04..............................240

Figure SB04-5. Following storm events the beach often has a steep beachface with a concave-up profile

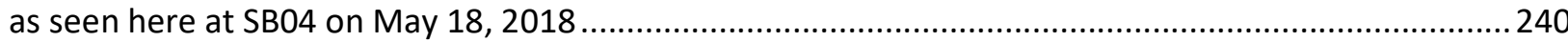

Figure SB04-6. Dune system on Seabrook Beach at SB04 on August 3, 2019 ........................................ 241

Figure SB04-7. Sand overwashed into dunes by winter storms, looking north...................................241

Figure SB04-8. Close-up of sand overwashed into dunes by winter storms ..........................................241

Figure SB04-9. The beach elevation profile at SB04 looking south ....................................................242

Figure SB04-10. The beach elevation profile at SB04 looking west toward the dunes ...........................242 
Figure SB04-11. The beach elevation profile at SB04 looking east.

.242

Figure SB04-12. All twenty-seven elevation profiles measured at station SB04 from January 29, 2018 to

March 9, 2020 244

Figure SB04-13. Beach elevation profiles at SB04 with the highest mean elevation (August 3, 2019) and with the lowest mean elevation (November 25, 2019) measured at station SB04. 244

Figure SB04-14. Calculated sediment volume, mean profile elevation, and mean elevation change for the beach profile at station SB04 245

Figure SB04-15 (above). Beach elevation profiles measured at SB04 on January 29, 2018 and February

26,2018 247

Figure SB04-16 (right). Seabrook Beach at SB04 on February 26, 2018 ............................................ 247

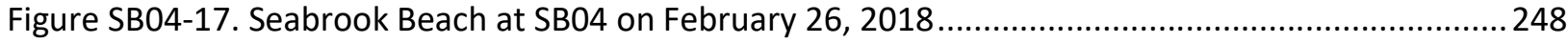

Figure SB04-18. The low tide terrace at station SB04 on February 26, 2018 248

Figure SB04-19 (above). Beach profile sequence for SB04 on February 26, 2018, May 18, 2018, and June 18,2018 249

Figure SB04-20 (right). The upper beach and dunes at SB04 after they were overwashed during the storms in late winter and early spring 2018

Figure SB04-21. The dunes at SB04 after they were overwashed during the storms in late winter and early spring 2018 250

Figure SB04-22. Beach elevation profiles for SB04 measured on August 17, 2018, September 7, 2018, and October 8, 2018 252

Figure SB04-23. Beach elevation profiles for SB04 measured on January 26, 2019, February 22, 2019, and March 25, 2019 252

Figure SB04-24. Beach elevation profiles for SB04 measured on March 25, 2019, April 17, 2019, and May 18,2019 253

Figure SB04-25. Beach elevation profiles for SB04 measured on June 7, 2019, July 3, 2019, and August 3, 2019 253

Figure SB04-26. Beach elevation profiles for SB04 measured on September 3, 2019, September 27, 2019, and November 8, 2019 254

Figure SB04-27. Beach elevation profiles for SB04 measured on November 8, 2019, November 25, 2019, and December 20, 2019 254

Figure SB05-1. The dune system at SB05, which is narrower than those at stations SB02 and SB04.....256 Figure SB05-2. The beach elevation profile at SB05, which starts in the foredunes 256 Figure SB05-3. The beach elevation transect at SB05, which starts at the seaward stake in the foredunes and ends at the water's edge

Figure SB05-4. The beach at SB05 during accretional conditions, when it often has a relatively wide backshore (arrow) and a well-defined berm 257

Figure SB05-5. During accretional conditions the beach at SB05 often has a well-defined berm (left arrow) and steep berm face (right arrow) as seen here on August 3, 2019. 
Figure SB05-6. The beach at SB05 often has a wide and flat lower beach or low tide terrace as shown here on August 3, 2019.

Figure SB05-7. Following storms the beach at SB05 often has patches of shells and pebbles (arrow) as seen here on March 12, 2018 following a series of storms. 258

Figure SB05-8. Seaweed washed up on the lower beach at SB05 (arrows) on January 29, 2018 following stormy conditions 258

Figure SB05-9. All thirty profiled dates at station SB05 from January 29, 2018 to March 9, 2020 .......... 260

Figure SB05-10. Calculated sediment volume, mean profile elevation, and mean elevation change for the beach profile at station SB05

Figure SB05-11. Maximum (August 17, 2018) and minimum (March 9, 2020) profiles for the study period at station SB05. 262

Figure SB05-12. Maximum (August 17, 2018) and post-storm (March 12, 2018) profiles for the study period at station SB05. 262

Figure SB05-13. Beach elevation profiles for SB05 measured on January 29 and February 26, 2018..... 264 Figure SB05-14. Beach elevation profiles for SB05 measured on February 26, 2018, March 12, 2018, and March 26, 2018 264

Figure SB05-15. During the nor'easters in March 2018 Seabrook Beach was severely eroded as seen here

Figure SB05-16. Extensive overwash and a large amount of sand was brought into the dunes after the severe nor'easters in March 2018

Figure SB05-17. Extensive overwash of the dunes at SB05 caused by the severe nor'easters in March 2018 266

Figure SB05-18. The dune grasses grew quickly through the sand that was transported into the dunes by storm surges during the nor'easters in March 2018, as seen here 266

Figure SB05-19. Beach elevation profiles for SB05 measured on March 26, 2018, April 18, 2018, and May 18,2018 268

Figure SB05-20. Beach elevation profiles for SB05 measured on May 18, 2018, June 18, 2018, and July 13,2018 268

Figure SB05-21. The beach at SB05 had a large volume of sand deposited on the mid and upper beach by May 2018 as shown in the photograph taken on May 18, 2018 269

Figure SB05-22. The beach at SB05 had rebuilt by May 2018 as shown by the large volume of sand deposited on the mid and lower beach on May 18, 2018. 269

Figure SB05-23. The lower beach or low tide terrace at SB05 had rebuilt by May 2018 as shown in the photograph taken on May 18, 2018

Figure SB05-24. Beach elevation profiles for SB05 measured on February 22, 2019, March 25, 2019, and April 17, 2019.

Figure SB05-25. Beach elevation profiles for SB05 measured on June 7, 2019, July 3, 2019, and August 3, 2019 


\section{Chapter 1: Introduction}

The New Hampshire (NH) Seacoast is visited by millions of tourists each year and is vital to the region's economy. The coastal communities (including all tidal areas) made up approximately 11 percent of NH's population in 2016 and accounted for $\$ 11$ billion of the gross regional product (summarized in New Hampshire Coastal Risk and Hazards Commission, 2016). Central to the esthetic and economic value of the Seacoast are the beaches, which are used extensively for recreation (Figure 1-1). As a result of climate change, sea-level rise, and storms (Figure 1-2), the beaches are frequently severely eroded (Figures 1-3 and 1-4) and coastal infrastructure is damaged (Figure 1-5). Therefore, to enhance coastal resiliency, the NH Volunteer Beach Profile Monitoring Program (VBPMP) was initiated in 2017 with the goal of documenting changes in beach elevation and sand volume that would reflect the effects of storms, seasonal cycles and long-term trends of erosion (loss of elevation and sediment volume), accretion (increase in elevation and sediment volume), or stability (no measurable change within limits of uncertainty) of the beaches. To achieve this goal six of the major beaches along the NH coast were monitored at thirteen sites at approximately three- to four-week intervals and on several occasions shortly before and after storm events (station locations shown in Figure ES-1). At each station during all monitoring periods a beach elevation profile oriented perpendicular to the strike of the beach was measured using the Emery method (Emery, 1961; Figures 1-6 and 1-7) and ground photographs were taken. Three of the profile sites were run for more than three years (40 months from December 2016 to March 2020) and ten profile sites were run for more than two years (27 months from the beginning of 2018 to March 2020). The time interval between measuring beach elevation profile changes during this study was short enough to document the effect of storm events on the beaches, and the length of the study period was long enough to advance our understanding of seasonal changes in the beaches. However, a full understanding of the storm effects, seasonal changes, and long-term trends in erosion or accretion (and at what locations) will require continued monitoring and analysis.

An important aspect of this study is that the field program was conducted almost entirely by trained volunteers who measured beach elevation profiles, took field photographs, and uploaded the data where it was retrieved and processed by the project management team at the University of New Hampshire (UNH). Similar community science programs are currently in place through the National Oceanic and Atmospheric Administration (NOAA) Sea Grant programs in Maine (ME) and California (CA). Since 1999, the Southern Maine Volunteer Beach Profile Monitoring Program has monitored beaches monthly between York and South Portland. The data collected from beaches in ME is used to monitor long-term changes in erosion and accretion and to help with beach management decisions. It is analyzed by the Maine Geological Survey and is used to help inform the National Weather Service (NWS) "wave run-up model". The Community Alliance for Surveying the Topography of Sandy Beaches (COAST SB) is a relatively new beach monitoring program and is run through the University of California at Santa Barbara (University of California, accessed February 2020). Since 2017, CoAST SB has made monthly surveys of local beaches in Santa Barbara and Ventura counties to 
monitor changes in erosion and the effects of natural hazards such as debris flows. As with $\mathrm{NH}$ and $\mathrm{ME}$, the CA monitoring program will be used to help with beach management and conservation decisions.

This study of $\mathrm{NH}$ beaches is timely in view of changing conditions due to climate change, sea-level rise, a projected increase in storm intensities (Wake et al., 2011), and increased development pressure on the coastal region. The database and knowledge gained through this study will provide municipal, state, and federal agencies and decision makers with important information on $\mathrm{NH}$ beaches for guiding beach management decisions including maintenance, restoration, or beach nourishment. Furthermore, the involvement of community scientists creates opportunities for incorporating volunteer knowledge, disseminating the results of this work to a broader public, and deepening their knowledge of the coastal environment. It is the goal of this study to continue the $\mathrm{NH}$ Volunteer Beach Profile Monitoring Program for a number of years to establish long-term trends in elevation and sediment volume at $\mathrm{NH}^{\prime}$ s major beaches. The program was temporarily suspended from mid-March to July 2020 due to the COVID-19 pandemic, but resumed once new guidelines were in place.

This report is focused on the results of the VBPMP for the period from December 2016 to March 2020. Included in the Results are the beach elevation profiles and volumetric calculations for each station. Also included are the general characteristics of the beach, identification of local engineering structures that affect the beach (e.g., seawalls), and a description of any unique features that would affect beach conditions. Review of the profile data includes the general profile characteristics during the monitoring period and storm effects, beach erosion, and recovery. There is a great deal of repetition, but the goal is to have the results for each beach be able to stand alone and be complete. In addition, a glossary of terms used throughout this report can be found in Appendix $A$, an assessment of the major storms impacting the $\mathrm{NH}$ Seacoast is given in Appendix $\mathrm{B}$, and all of the beach elevation profiles for all of the beaches is given in Appendix $\mathrm{C}$.

Other reports on the $\mathrm{NH}$ beaches by the authors include the following.

Ward, L.G., McPherran, K.A., McAvoy, Z.S., and Vallee-Anziani, M., 2016, New Hampshire beaches: Sediment characterization: https://dx.doi.org/10.34051/p/2021.29

McPherran, K.A., 2017, Seasonal Changes in Geomorphology and Sediment Volume of New Hampshire Beaches: Insights into a Highly-Engineered, Paraglacial, Bedrock Influenced Mixed Sand and Gravel Coastal System: https://scholars.unh.edu/thesis/1105

Ward, L.G., Corcoran, N.W., McAvoy, Z.S., and Morrison, R.C., 2021, Seasonal Changes in Sediment Grain Size of New Hampshire Atlantic Beaches: https://dx.doi.org/10.34051/p/2021.33 

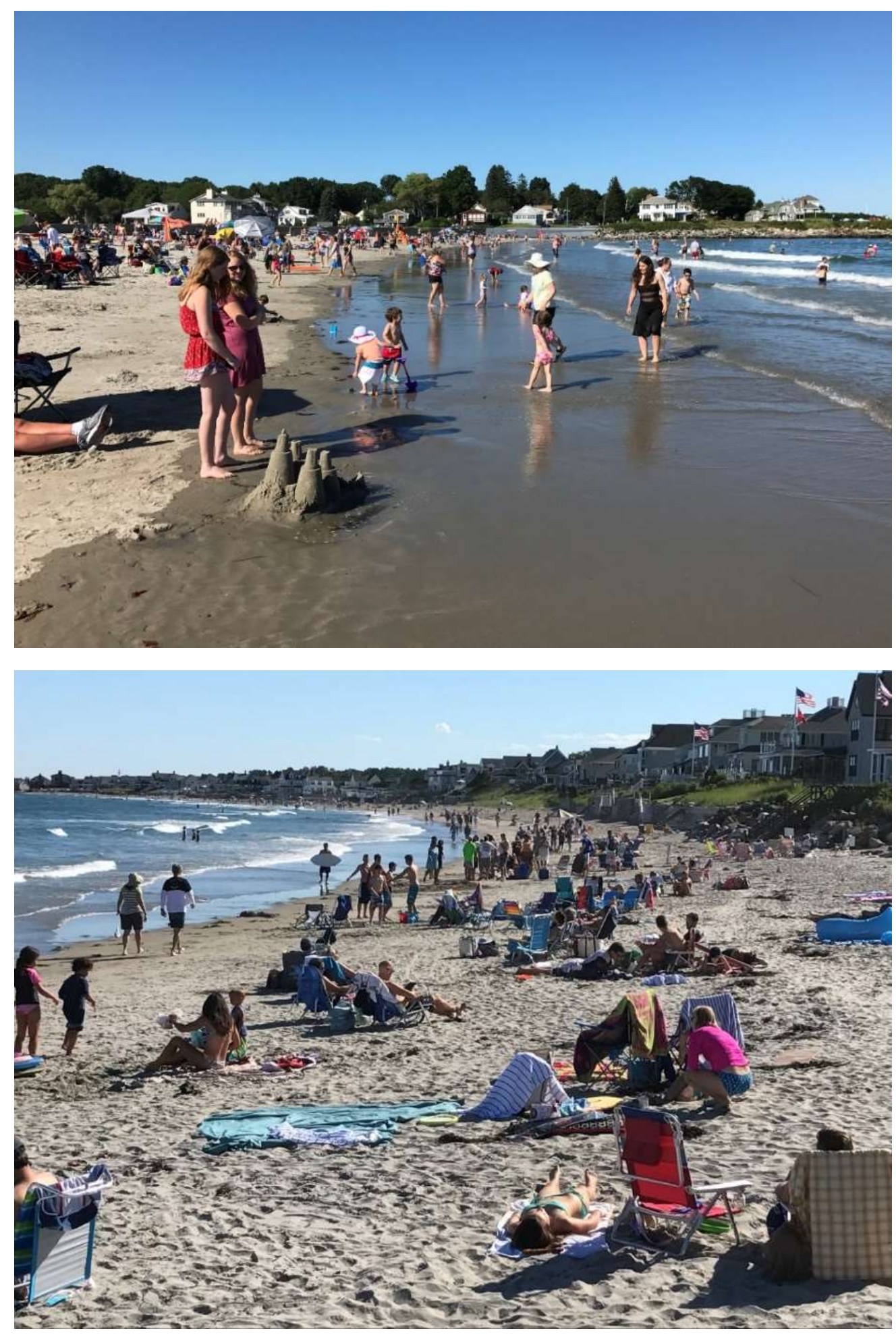

Figure 1-1. Wallis Sands State Beach (top photograph, looking north) and Wallis Sands town beach (bottom photograph, looking south from State Beach) on July 30, 2017. 

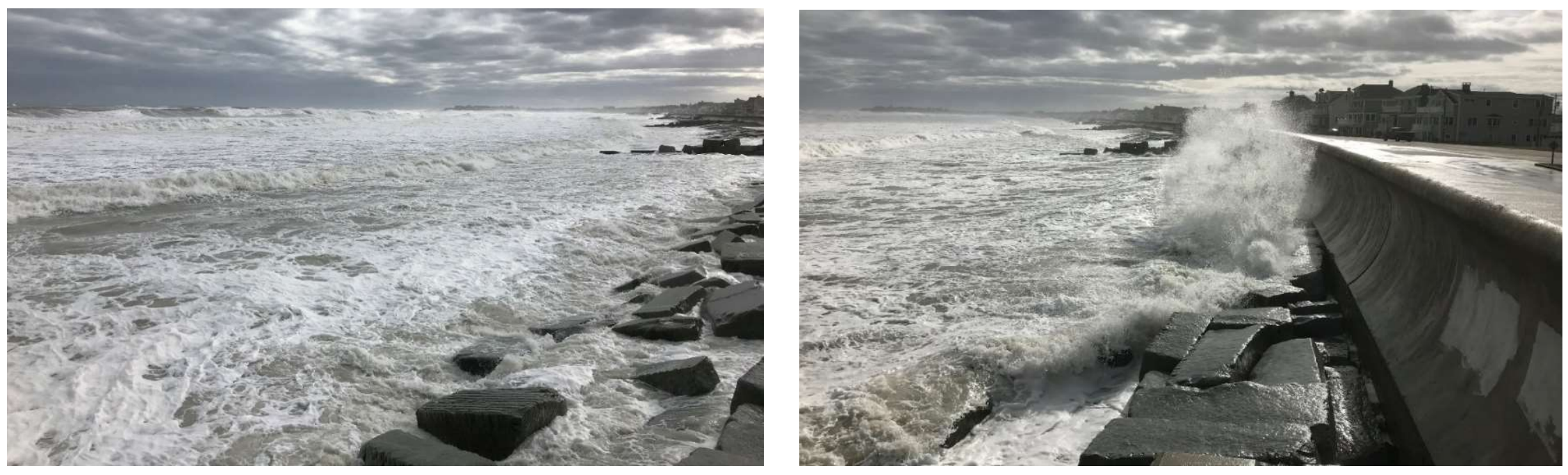

Figure 1-2. Storm waves at North Beach on March 3, 2018 following the severe Nor'easter Riley.
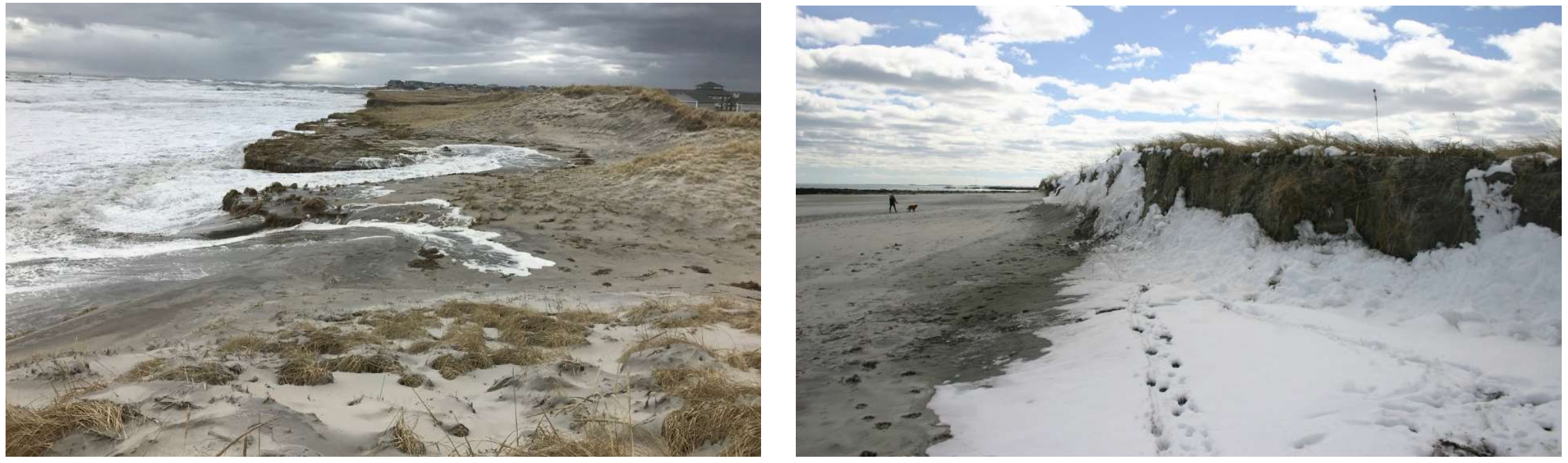

Figure 1-3. Beach and dune erosion caused by Nor'easter Riley at Seabrook Beach on March 3, 2018 (left photograph). The combined effects of the three powerful nor'easters that occurred in early March 2018 including Riley, Quinn and Skylar caused major beach and dune erosion as shown here at Hampton Beach State Park on March 15, 2018 (right photograph). 

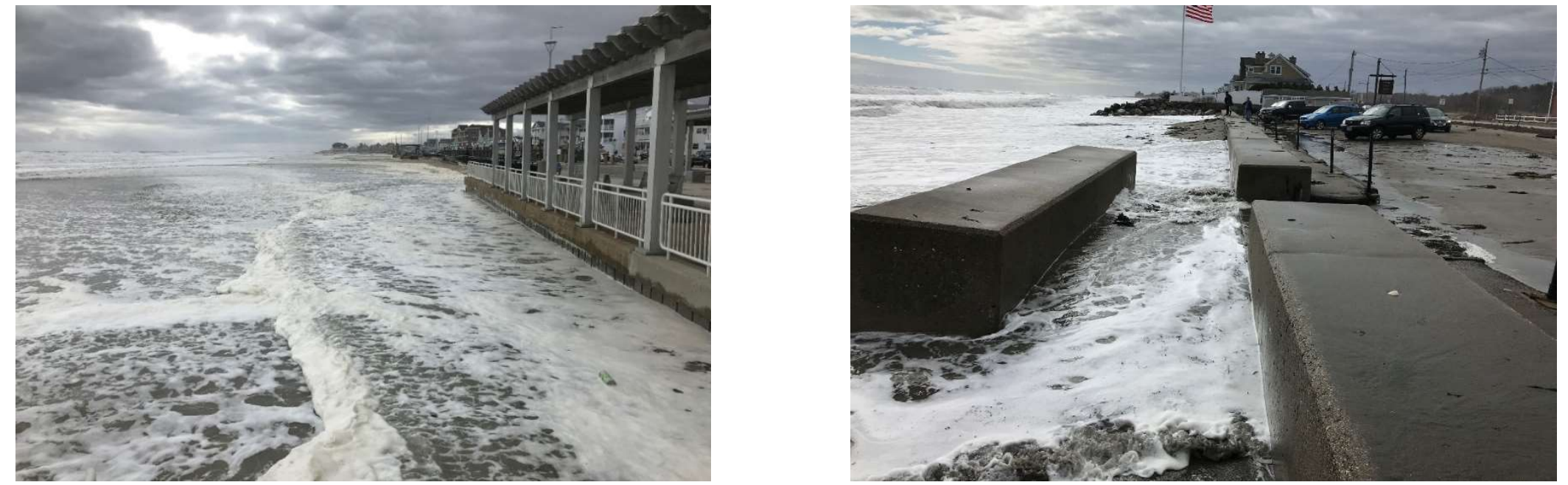

Figure 1-4. Extremely high water and waves at Hampton Beach on March 3, 2018 (left photograph) and Jenness State Beach on March 4, 2018 (right photograph) during the Nor'easter Riley which resulted in major beach erosion, washover, and damage to the adjacent infrastructure.
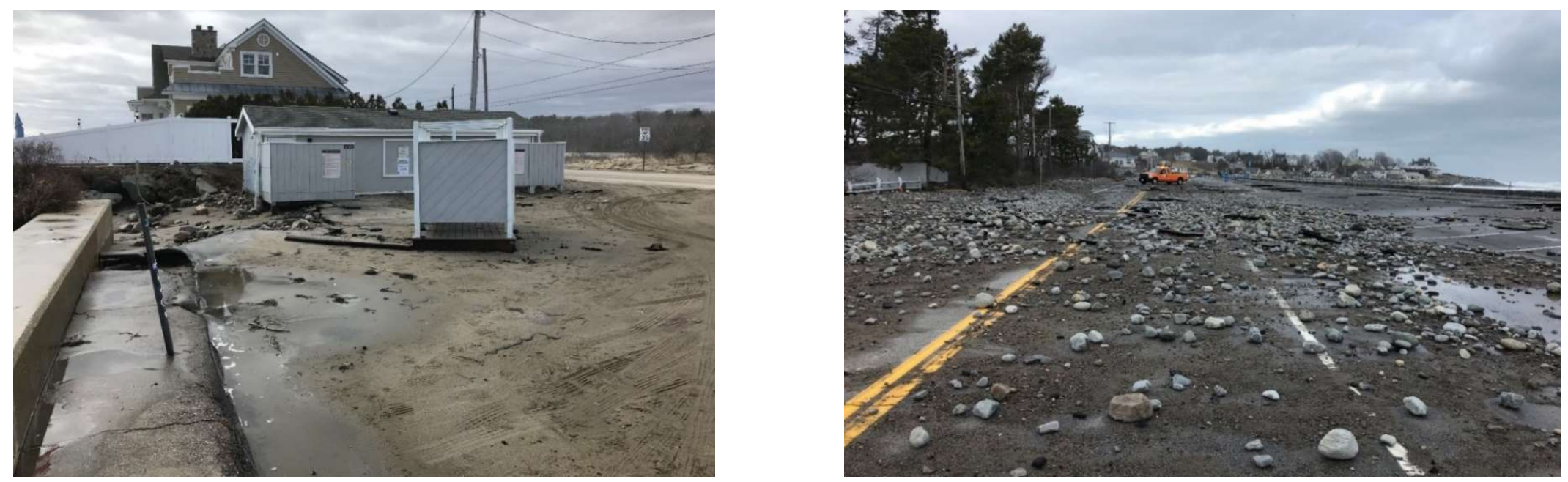

Figure 1-5. Damage that occurred due to Nor'easter Riley. Major damage occurred to the beach house, parking lot, and some surrounding homes at Jenness Beach (left photograph), and the intensity of the storm caused sand, pebbles, and large cobbles to be pushed over the seawall at North Hampton State Beach (right photograph) onto the parking lot and across the road. The photographs were taken on March 3, 2018. 


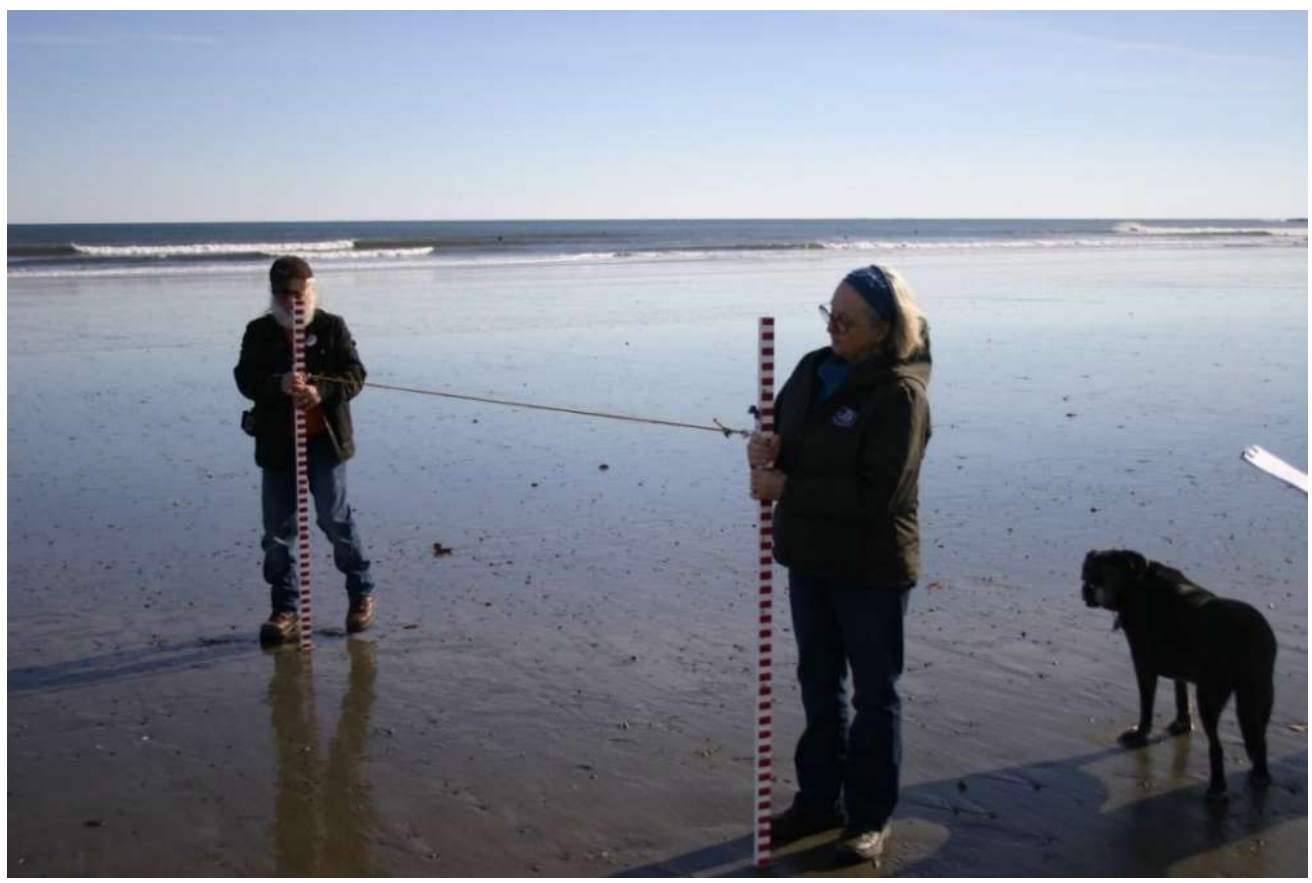

Figure 1-6. Volunteers measuring a beach elevation profile at Jenness Beach (station JB01) using the Emery (1961) method on November 11, 2018.

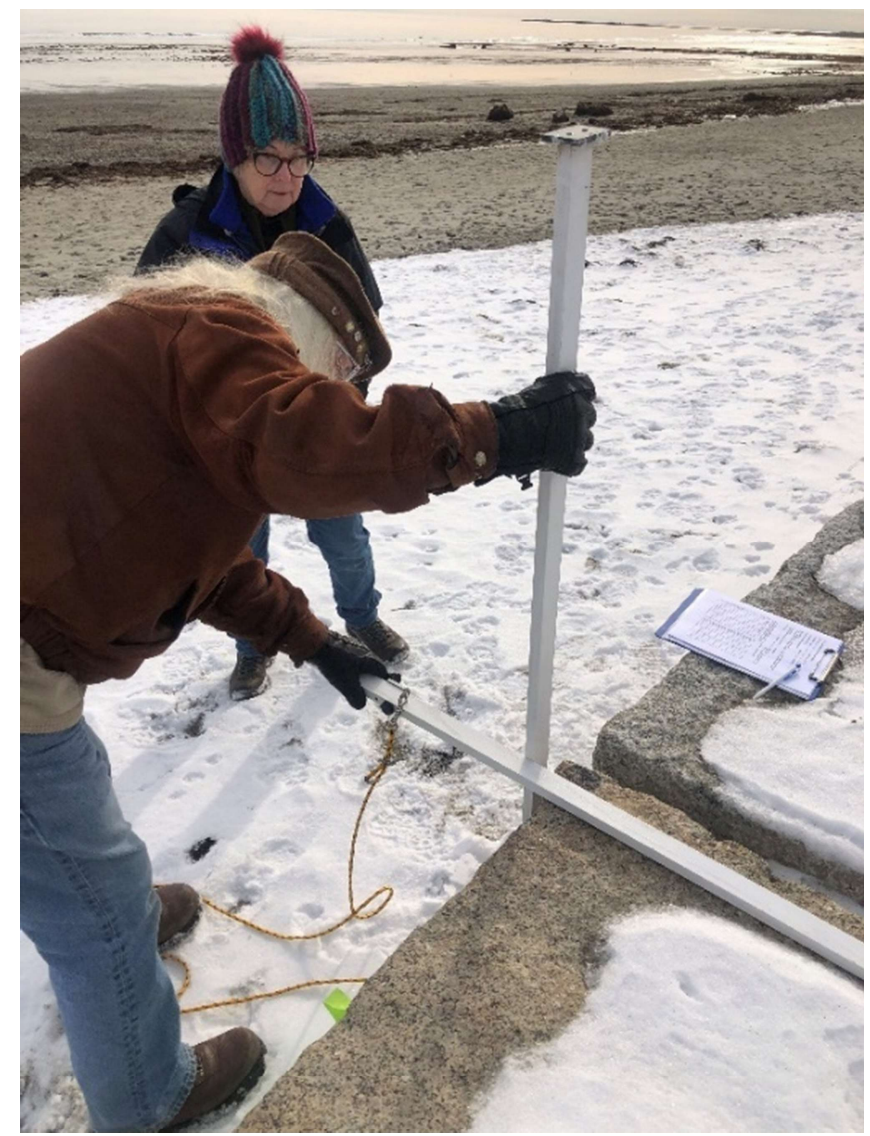

Figure 1-7. Volunteers measuring distance from the station marker to the beach surface to start the beach elevation profile at JB01 on December 21, 2019. The profiles were run during all seasons, often under cold and snowy conditions. 


\section{Chapter 2: Description of the New Hampshire Coast}

$\mathrm{NH}$ beaches are highly variable and change dramatically from the entrance of Portsmouth Harbor at the northern end of the study area to the southern end at Seabrook Beach. The beaches north of Great Boars Head (Figure ES-1) tend to be largely attached or welded barriers bound by headlands that extend offshore separating the beaches. Many of these beaches are bimodal and are composed of sand and gravel. The beaches are also separated from their back-barrier marshes and lagoons by seawalls, human-made berms, a major roadway (Route $1 \mathrm{~A}$ ), and near-continuous private homes and businesses. South of Great Boars Head, the beaches include a barrier spit attached to Great Boars Head (Hampton Beach) and the northern half of a barrier island (Seabrook Beach). As is the case with the northern barriers, Route $1 \mathrm{~A}$, private homes, and a beach resort (Hampton Beach) separate the barriers from the back-barrier marsh system. Hampton Beach has aeolian dunes at the southern end (Hampton Beach State Park) and Seabrook Beach is backed by extensive aeolian dunes over much of its length.

\section{Geological Setting}

The coast of $\mathrm{NH}$ is strongly influenced by the bedrock geology and glacial deposits. The major beaches north of Great Boars Head (a glacial drumlin) are separated by headlands that are composed of bedrock or, more frequently, till covering bedrock. The $\mathrm{NH}$ coastal region and nearshore shelf was heavily eroded by the advancing ice sheet during the last major glaciation that lasted from approximately 120,000 to 12,000 yrs B.P. (years before present), exposing bedrock in many areas. The Laurentide Ice Sheet extended across the Gulf of Maine terminating on Georges Bank 24,000 yrs B.P. The glaciation left extensive sediment deposits along the coast and inner continental shelf including tills and stratified drift found in drumlins, eskers, glaciomarine deltas, submarine groundingline fans, kettles, and moraines (Birch, 1984; Sinclair et al., 2018). These deposits are extremely important to the coastal system and are likely the major source of sediments that make up the beaches in $\mathrm{NH}$. The till deposits on and surrounding the headlands have been eroded, leaving behind large megaclast platforms (dominated by cobbles and boulders). The megaclast platforms are found seaward of the headlands offering protection against wave erosion, and on the adjacent beaches often underlying thin sand deposits.

\section{Tides and Waves}

Tides. The $\mathrm{NH}$ coast has semidiurnal tides with a strong diurnal inequality (difference in height between successive high tides and low tides). Mean tidal range at the Fort Point, New Castle, NH tide level station for the 1983-2001 epoch was $2.63 \mathrm{~m}$ (8.63') (Station 8423898 - Fort Point; NOAA COOPS, accessed January 2020). The great diurnal range calculated as the difference between MHHW (mean higher high water) and MLLW (mean lower low water) was 2.86 m (9.38').

Tidal heights and times often vary from predicted due to storm effects (storm surge). An extreme example is the storm surge associated with the "Blizzard of 78" which occurred from February 5-7, 
1978. The high tide level on February 7, 1978 was $0.82 \mathrm{~m}\left(2.69^{\prime}\right)$ higher than the predicted height at the tide gauge at Seavey Island, ME (Station 8419870; NOAA CO-OPS, accessed January 2020). This is one of the largest storm surges measured for the $\mathrm{NH}$ area. At the tide gauge in Boston, MA the largest storm surge for the "Blizzard of 78" on February 7 was $1.28 \mathrm{~m}$ (4.20') (Station 8443970). Storm surges in $\mathrm{NH}$ are discussed in more detail in the section on Storm Events.

Waves. Unfortunately, there are no long-term wave gauges located close to shore off the NH coast. Therefore, wave data was obtained for the two nearest wave gauges with extended periods of record: Cape Elizabeth, ME located $\sim 70 \mathrm{~km}$ ( 43.5 miles) northeast of Portsmouth Harbor, and Jeffreys Ledge located $\sim 53 \mathrm{~km}$ ( $\sim 32.9$ miles) offshore of the NH coast. The wave gauge off Cape Elizabeth is $\sim 6 \mathrm{~km}$ (3.7 miles) offshore in $\sim 26.5 \mathrm{~m}$ (86.9') of water (Station 44007 - Portland; 43.525 N 70.141 W; NOAA NDBC, accessed January 2020). The wave gauge located just seaward of Jeffreys Ledge is in $\sim 76.5 \mathrm{~m}$ (251.0') of water (Station 44098 - Jeffreys Ledge; 42.798 N 70.168 W; NOAA NDBC, accessed January 2020). It is likely that wave conditions along the NH coast are most similar to those in Portland, ME. Therefore, long-term averages and maximum wave heights available for the Portland gauge provide an overview of monthly, seasonal, and extreme wave conditions (Table 2-1). Waves measured at Jeffreys Ledge are likely larger than those close to the coast as shoaling would reduce the wave energy. However, Jeffreys Ledge is provided as a comparison and has data that provide insights to more recent events that occurred during the study period.

Mean monthly significant wave heights ( $H s$; average height of the highest one-third of all wave heights during a 20-minute sampling period, reported every half hour) for the period 1982-2008 at the Cape Elizabeth, ME wave gauge ranged from 0.7 to $1.1 \mathrm{~m}$ (2.3 to 3.6') with an annual average of $0.9 \mathrm{~m}\left(3.0^{\prime}\right)$. However, there was a strong seasonal signal (e.g., higher means and maximum wave heights in winter) (Table 2-1). Maximum significant wave heights (single highest 20-minute average that occurred during a given month) ranged from 2.6 to $9.6 \mathrm{~m}$ (8.5 to $31.5^{\prime}$ ). As expected, monthly means for Jeffreys Ledge were slightly higher than the Portland gauge ranging from 0.7 to $2.5 \mathrm{~m}$ ( 2.3

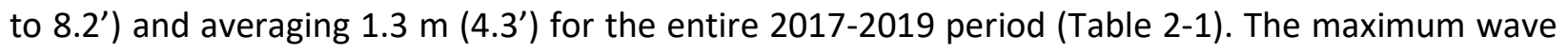
heights at Jeffreys Ledge ranged from 1.5 to $8.4 \mathrm{~m}$ (4.9 to $\left.27.6^{\prime}\right)$ for the 2017-2019 period. The highest monthly mean and maximum wave height was in March 2018 due to three severe nor'easters including Riley (Mar 1-4), Quinn (Mar 6-9), and Skylar (Mar 12-14). 
Table 2-1. Mean and maximum significant wave heights (Hs) for the wave buoy off Cape Elizabeth, ME for the time period between 1982 and 2008 (Station 44007 - Portland; 43.525 N 70.141 W; NOAA NDBC, accessed January 2020) and for the buoy at Jeffreys Ledge for 2017, 2018, and 2019 (Station 44098 - Jeffreys Ledge; 42.798 N 70.168 W; NOAA NDBC, accessed January 2020).

\begin{tabular}{|c|c|c|c|c|c|c|c|c|c|c|c|c|c|}
\hline \multicolumn{7}{|l|}{ Portland, ME } & \multicolumn{7}{|c|}{$1982-2008$} \\
\hline Significant Wave Height & $\operatorname{Jan}$ & Feb & Mar & Apr & May & Jun & Jul & Aug & Sep & Oct & Nov & Dec & Annual \\
\hline Mean Hs (m) & 1.1 & 1.1 & 1.1 & 1.1 & 0.9 & 0.7 & 0.7 & 0.7 & 0.8 & 1 & 1 & 1.1 & 0.9 \\
\hline Maximum Hs (m) & 6.2 & 7.3 & 7 & 9.6 & 6 & 4.5 & 2.6 & 5.8 & 6 & 7 & 7.3 & 8.1 & 9.6 \\
\hline Max Occurred & 2003 & 1988 & 1993 & 2007 & 2005 & 2002 & 1985 & 1991 & 1985 & 1996 & 1995 & 2007 & Apr-07 \\
\hline \multicolumn{14}{|c|}{ Taken from Station 44007 (https://www.ndbc.noaa.gov/station_page.php?station=44007) } \\
\hline \multicolumn{7}{|l|}{ Jeffreys Ledge, NH } & \multicolumn{3}{|c|}{2017} & & & & \\
\hline Significant Wave Height & Jan & Feb & Mar & Apr & May & Jun & Jul & Aug & Sep & Oct & Nov & Dec & Annual \\
\hline Mean Hs (m) & 1.8 & 1.7 & 1.6 & 1.5 & 1.1 & 1.0 & 0.8 & 0.8 & 1.3 & 1.2 & 1.3 & 1.4 & 1.3 \\
\hline Maximum Hs (m) & 5.3 & 5.2 & 7.1 & 4.6 & 3.3 & 4.0 & 2.9 & 2.7 & 4.6 & 5.6 & 2.8 & 4.4 & 7.1 \\
\hline \multirow[t]{2}{*}{ Max Occurred } & & & & & & & & & & & & & March \\
\hline & \multicolumn{13}{|c|}{2018} \\
\hline Significant Wave Height & Jan & Feb & Mar & Apr & May & Jun & $\mathrm{Jul}$ & Aug & Sep & Oct & Nov & Dec & Annual \\
\hline Mean Hs (m) & 1.8 & 1.3 & 2.5 & 1.3 & 0.9 & 0.9 & 0.9 & 0.7 & 1.2 & 1.4 & 1.6 & 1.3 & 1.3 \\
\hline Maximum Hs (m) & 7.8 & 3.0 & 8.4 & 5.5 & 2.0 & 2.5 & 2.0 & 1.8 & 2.7 & 6.5 & 6.2 & 4.1 & 8.4 \\
\hline \multirow[t]{2}{*}{ Max Occurred } & & & & & & & & & & & & & March \\
\hline & \multicolumn{13}{|c|}{2019} \\
\hline Significant Wave Height & $\operatorname{Jan}$ & Feb & Mar & Apr & May & Jun & Jul & Aug & Sep & Oct & Nov & Dec & Annual \\
\hline Mean Hs (m) & 1.6 & 1.4 & 1.4 & 1.4 & 1.1 & 0.8 & 0.7 & 0.8 & 1.0 & 1.8 & 1.6 & 1.7 & 1.3 \\
\hline Maximum Hs (m) & 4.1 & 4.9 & 3.8 & 3.1 & 3.4 & 2.5 & 1.5 & 1.9 & 4.2 & 6.8 & 4.8 & 6.3 & 6.8 \\
\hline Max Occurred & & & & & & & & & & & & & October \\
\hline
\end{tabular}

\section{Climate}

The NH Seacoast has a humid, continental climate with four distinct seasons (winter, spring, summer, and fall) (Kottek et al., 2006). Summers are typically warm and humid (June- September), while winters are cold with frequent snowstorms (December-March). The transitions between seasons are variable and linked to regional climate changes (Betts, 2011).

The meteorological station at the Isle of Shoals, NH (Station IOSN3 - Isles of Shoals, NH; $42.967 \mathrm{~N}$ $70.623 \mathrm{~W}$; NOAA NDBC, accessed January 2020) was used to characterize the air temperature and winds for the $\mathrm{NH}$ coast because of its proximity ( $10 \mathrm{~km}$ or 6.2 miles offshore) and long-term records. The mean monthly average air temperature at the Isles of Shoals for the $1996-2008$ period was $8.9^{\circ} \mathrm{C}$ $\left(48.0^{\circ} \mathrm{F}\right.$ ) but had a wide range (Table 2-2). Mean summer temperatures (June to September) averaged $17.9^{\circ} \mathrm{C}\left(64.2^{\circ} \mathrm{F}\right)$, while winter averaged $0.3^{\circ} \mathrm{C}\left(32.5^{\circ} \mathrm{F}\right)$. However, these averages can be deceiving as air temperatures can be very warm or very cold in any season. Wind speeds at the Isles of Shoals over the same period averaged $25.9 \mathrm{kph}(16.1 \mathrm{mph})$ with higher averages in winter months. Similar to the temperature, the average wind speeds are deceptive as very strong winds occur during storm events. 
Precipitation in the form of rainfall and snow was obtained from the National Weather Service station in Durham, NH which was the closest location to the coast with a long-term, continuous record (NOAA NWS, accessed January 2020). The average precipitation over three time periods (1996-2008, 20092019, and 2017-2019) shows longer-term averages and more recent conditions (Table 2-2). Overall, the annual precipitation averages for all three time periods were similar (ranging from 114.6 to 118.9 $\mathrm{cm}$, or 45.12 to $46.81^{\prime \prime}$ ) with strong differences between summer ( 40.7 to $42.8 \mathrm{~cm}$, or 16.0 to $16.9^{\prime \prime}$ ) and winter periods ( 28.7 to $34.4 \mathrm{~cm}$, or 11.3 to $13.5^{\prime \prime}$ ). Snowfall did increase over time with the most recent period (2017-2019) having the highest average (ranging from 103.6 to $129.5 \mathrm{~cm}$, or 40.8 to 51.0").

Mean annual precipitation in NH (whole state) increased 10\% or 12.7 cm (5") from 1895 to 2011, likely due to climate change (Kirshen et al., 2014). Extreme annual precipitation increased as well over the last century. The northeastern US, in general, has experienced a $53 \%$ increase in extreme precipitation since 1996 (Huang et al., 2017). This has primarily been due to an increase in frequency of tropical cyclones, extratropical cyclones, and fronts, occurring mostly in the months of September and October (Huang et al., 2017). Recent tropical cyclone activity accounts for about half of this observed increase in extreme precipitation. The mean annual precipitation and extreme precipitation events in NH are projected to increase by $20 \%$ for the period from 2071-2099 (Kirshen et al., 2014). 
Table 2-2. Summary of air temperature, wind speed, and precipitation. (Top) Average, minimum, and maximum air temperature and wind speed for the meteorological station at the Isles of Shoals located $\sim 10 \mathrm{~km}(6.2 \mathrm{miles})$ of the NH coast between 1996 and 2008 (Station IOSN3 - Isles of Shoals, NH; 42.967 N 70.623 W; NOAA NDBC, accessed January 2020). (Bottom) Yearly, summer, and winter precipitation and snowfall totals for the station in Durham, NH for the period between 1996 and 2008, for the last decade (2009-2019), and for the years encompassing the study (2017-2019) (NOAA NWS, accessed January 2020).

\begin{tabular}{|l|l|l|l|}
\hline Isles of Shoals, NH & \multicolumn{3}{c|}{ 1996-2008 } \\
\hline Air Temperature & Average & Minimum & Maximum \\
\hline Mean Monthly & $8.9^{\circ} \mathrm{C}\left(48.0^{\circ} \mathrm{F}\right)$ & $-1.7^{\circ} \mathrm{C}\left(28.9^{\circ} \mathrm{F}\right)$ (Jan) & $19.3^{\circ} \mathrm{C}\left(66.7^{\circ} \mathrm{F}\right)$ (Jul \& Aug) \\
Summer (Jun - Sept) & $17.9^{\circ} \mathrm{C}\left(64.2^{\circ} \mathrm{F}\right)$ & $5.3^{\circ} \mathrm{C}\left(41.5^{\circ} \mathrm{F}\right)$ & $33.3^{\circ} \mathrm{C}\left(91.9^{\circ} \mathrm{F}\right)$ \\
Winter (DeC - Mar) & $0.3^{\circ} \mathrm{C}\left(32.5^{\circ} \mathrm{F}\right)$ & $-22.5^{\circ} \mathrm{C}\left(8.5^{\circ} \mathrm{F}\right)$ & $22.9^{\circ} \mathrm{C}\left(73.2^{\circ} \mathrm{F}\right)$ \\
\hline Wind Speed & Average & Minimum & Maximum \\
\hline Mean Monthly & $25.9 \mathrm{kph}(16.1 \mathrm{mph})$ & $20.0 \mathrm{kph}(12.4 \mathrm{mph})$ (Aug) & $31.3 \mathrm{kph}(19.3 \mathrm{mph})$ (Jan) \\
Summer (Jun - Sept) & $21.4 \mathrm{kph}(13.3 \mathrm{mph})$ & 0 & $122.4 \mathrm{kph}(76.1 \mathrm{mph})$ \\
Winter (Dec - Mar) & $30.1 \mathrm{kph}(18.7 \mathrm{mph})$ & 0 & $93.2 \mathrm{kph}(57.9 \mathrm{mph})$ \\
\hline
\end{tabular}

Taken from Station IOSN3 data (https://www.ndbc.noaa.gov/station_page.php?station=iosn3)

Mean monthly average is the average of all values over the 12 year period

Mean monthly minimum is the month with the lowest mean values

Mean monthly maximum is the month with the highest mean values

Wind speed is averaged over a two-minute period and is reported hourly

\begin{tabular}{|c|c|c|c|}
\hline Durham, NH & 1996-2008 & 2009-2019 & 2017-2019 \\
\hline Precipitation Totals & Average & Average & Average \\
\hline Annual (over time interval) & $116.6 \mathrm{~cm}(45.9 \mathrm{in})$ & $114.6 \mathrm{~cm}(45.1 \mathrm{in})$ & $118.9 \mathrm{~cm}(46.8 \mathrm{in})$ \\
\hline Summer (Jun - Sept) & $40.7 \mathrm{~cm}$ (16.0 in) & $41.6 \mathrm{~cm}$ (16.3 in) & $42.8 \mathrm{~cm}$ (16.9 in) \\
\hline Winter (Dec - Mar) & $34.4 \mathrm{~cm}(13.5 \mathrm{in})$ & $33.7 \mathrm{~cm}(13.3 \mathrm{in})$ & $28.7 \mathrm{~cm}(11.3 \mathrm{in})$ \\
\hline Snowfall Totals & Average & Average & Average \\
\hline Annual (over time interval) & $103.6 \mathrm{~cm}(40.8 \mathrm{in})$ & $120.4 \mathrm{~cm}$ (47.4 in) & $129.5 \mathrm{~cm}$ (51.0 in) \\
\hline Winter (Dec - Mar) & $93.5 \mathrm{~cm}$ (36.8 in) & $113.5 \mathrm{~cm}$ (44.7 in) & $116.6 \mathrm{~cm}$ (45.9 in) \\
\hline
\end{tabular}

Calculated from data from the National Weather Service (https://w2.weather.gov/climate/xmacis.php?wfo=gyx)

Annual precipitation/snowfall is the total of the mean monthly precipitation totals over the specified time interval 


\section{Storms}

The major storms impacting the $\mathrm{NH}$ coast are tropical storms and, far more frequently, extratropical storms or cyclones (e.g., nor'easters), which typically occur several times per year. During this study, three severe nor'easters including Riley, Quinn and Skylar caused extensive erosion to the $\mathrm{NH}$ beaches and damaged infrastructure (Figures 1-3, 1-4, and 1-5). Tropical storms (e.g., hurricanes) are much stronger than extratropical storms, but occur far less frequently. However, periodically the northern New England coast is impacted by hurricanes. Notable examples include the $1938 \mathrm{New}$ England Hurricane, the 1944 Great Atlantic Hurricane, Hurricane Carol (1954), Hurricanes Donna and Edna (1960), Hurricane Gloria (1985), Hurricane Bob (1991), and Hurricane/Tropical Storm Irene (2011).

Storm Surges. Strong easterly winds associated with storms often create storm surges (difference in the predicted high-water level versus the actual measured water level). However, the magnitude of the storm surges, at least in $\mathrm{NH}$, tend to be much less than a meter. For example, the ten largest storm surges at Fort Point, New Castle, NH between 2003 and 2012 ranged from 0.25 to $0.62 \mathrm{~m}(0.82$ to 2.02') (Kirshen et al., 2014). However, as discussed previously, the "Blizzard of 78" storm surge at high tide on February 7, 1978 at Seavey Island, ME (Station 8419870, NOAA CO-OPS, accessed January 2020) was $0.82 \mathrm{~m}\left(2.69^{\prime}\right)$. In addition, the blizzard and storm surge occurred during a spring tide resulting in the flooding of broad areas of the $\mathrm{NH}$ coast.

The storm surge at Fort Point, NH ( $3 \mathrm{~km}$ or 1.8 miles from Seavey Island) was determined for the 2017-2019 period (Table 2-3). During March 2018 three severe nor'easters occurred (Riley, Quinn and Skylar). During Quinn the storm surge reached $0.80 \mathrm{~m}$ (2.62') on March 8, 2018. Fortunately, this was not during a spring tide (larger than average tides that occur twice each month), so the overall tide level was not as high as during the Blizzard of 78. The impact of storm surges is strongly affected by the phase of the tide (spring versus neap tide). 
Table 2-3. The twelve highest storm surge events in 2017, 2018, and 2019 that occurred at the tide gauge station in New Castle, NH (Station 8423898 - Fort Point, NH; $43.072 \mathrm{~N} 70.71$ W; NOAA CO-OPS, accessed January 2020). Events were chosen from all high tides over the year. Corresponding storm event is noted, if available.

\begin{tabular}{|c|c|c|c|c|c|}
\hline \multicolumn{6}{|c|}{ Highest Storm Surges 2017} \\
\hline Date & Time (GMT) & Predicted $(\mathrm{m})$ & Verified $(\mathrm{m})$ & Difference $(\mathrm{m})$ & Storm Event \\
\hline $1 / 4 / 2017$ & 8:00 & 1.108 & 1.609 & 0.501 & (Not named) \\
\hline $1 / 24 / 2017$ & $13: 42$ & 1.101 & 1.748 & 0.647 & \\
\hline $1 / 25 / 2017$ & $2: 12$ & 0.819 & 1.329 & 0.51 & \\
\hline $2 / 13 / 2017$ & 5:36 & 1.351 & 1.866 & 0.515 & Winter Storm Orson \\
\hline $2 / 14 / 2017$ & 6:18 & 1.304 & 1.731 & 0.427 & Winter Storm Orson \\
\hline $2 / 15 / 2017$ & 19:06 & 1.182 & 1.585 & 0.403 & Winter Storm Pluto \\
\hline $2 / 16 / 2017$ & 7:30 & 1.16 & 1.783 & 0.623 & Winter Storm Pluto \\
\hline $3 / 14 / 2017$ & 17:42 & 1.359 & 1.775 & 0.416 & Nor'easter Stella \\
\hline $4 / 4 / 2017$ & $22: 30$ & 1.109 & 1.527 & 0.418 & \\
\hline $4 / 7 / 2017$ & 1:00 & 1.177 & 1.599 & 0.422 & \\
\hline $10 / 30 / 2017$ & 11:18 & 0.995 & 1.621 & 0.626 & Tropical Storm Philippe \\
\hline $11 / 19 / 2017$ & 16:24 & 1.357 & 1.78 & 0.423 & \\
\hline \multicolumn{6}{|c|}{ Highest Storm Surges 2018} \\
\hline Date & Time (GMT) & Predicted $(\mathrm{m})$ & Verified $(\mathrm{m})$ & Difference $(\mathrm{m})$ & Storm Event \\
\hline $3 / 3 / 2018$ & $4: 48$ & 1.556 & 2.133 & 0.577 & Nor'easter Riley \\
\hline $3 / 4 / 2018$ & $5: 36$ & 1.552 & 2.072 & 0.52 & Nor'easter Riley \\
\hline $3 / 5 / 2018$ & $6: 18$ & 1.496 & 2.007 & 0.511 & Nor'easter Riley \\
\hline $3 / 6 / 2018$ & 7:00 & 1.401 & 1.922 & 0.521 & Nor'easter Quinn \\
\hline $3 / 7 / 2018$ & $20: 30$ & 1.053 & 1.647 & 0.594 & Nor'easter Quinn \\
\hline $3 / 8 / 2018$ & $8: 36$ & 1.164 & 1.967 & 0.803 & Nor'easter Quinn \\
\hline $3 / 13 / 2018$ & $13: 24$ & 1.018 & 1.601 & 0.583 & Nor'easter Skylar \\
\hline $3 / 22 / 2018$ & 7:12 & 1.429 & 1.986 & 0.557 & (Not named) \\
\hline $11 / 25 / 2018$ & 17:06 & 1.643 & 2.143 & 0.5 & \\
\hline $11 / 27 / 2018$ & 7:06 & 1.183 & 1.89 & 0.707 & Coastal Flood \\
\hline $11 / 27 / 2018$ & 18:42 & 1.551 & 2.051 & 0.5 & Coastal Flood \\
\hline $11 / 28 / 2018$ & 7:48 & 1.193 & 1.735 & 0.542 & Coastal Flood \\
\hline \multicolumn{6}{|c|}{ Highest Storm Surges 2019* } \\
\hline Date & Time (GMT) & Predicted $(\mathrm{m})$ & Verified $(\mathrm{m})$ & Difference $(\mathrm{m})$ & Storm Event \\
\hline $1 / 4 / 2019$ & $2: 42$ & 1.015 & 1.299 & 0.284 & \\
\hline $1 / 5 / 2019$ & $15: 42$ & 1.342 & 1.696 & 0.354 & \\
\hline $1 / 6 / 2019$ & $4: 12$ & 0.965 & 1.301 & 0.336 & \\
\hline $2 / 16 / 2019$ & $0: 24$ & 0.898 & 1.217 & 0.319 & \\
\hline $2 / 24 / 2019$ & $20: 12$ & 1.382 & 1.841 & 0.459 & High wind event \\
\hline $3 / 22 / 2019$ & 17:00 & 1.785 & 2.134 & 0.349 & \\
\hline $4 / 27 / 2019$ & 10:18 & 0.994 & 1.553 & 0.559 & (Not named) \\
\hline $4 / 27 / 2019$ & $22: 42$ & 0.822 & 1.111 & 0.289 & (Not named) \\
\hline $5 / 14 / 2019$ & 11:54 & 1.372 & 1.68 & 0.308 & (Not named) \\
\hline $5 / 15 / 2019$ & $0: 30$ & 1.388 & 1.671 & 0.283 & (Not named) \\
\hline 9/7/2019 & $10: 36$ & 1.004 & 1.417 & 0.413 & Hurricane Dorian \\
\hline $10 / 12 / 2019$ & $3: 12$ & 1.193 & 1.608 & 0.415 & Subtropical Storm Melissa \\
\hline $\begin{array}{l}\text { Calculated fro } \\
\text { Datum used } \\
\text { *2019 had no }\end{array}$ & $\begin{array}{l}\text { m Fort Point, } \mathbf{N} \\
\text { as NAVD88 } \\
\text { data for Nov ar }\end{array}$ & Station data (htt) & ps://tidesandcur & ents.noaa.gov/wat & terlevels.html?id=8423898) \\
\hline
\end{tabular}




\section{Sea Level Changes}

Water levels recorded at a specific location from a land-based gauge (e.g., the tide gauge is attached to the earth's surface) measures the change in ocean surface elevation and the change in the earth's crustal elevation (i.e. uplift or subsidence) over time. This is referred to as relative or local sea-level change. Conversely, changes in water elevations measured from satellites (in the past few decades) or from a tide gauge at a location where the crust is known to be stable (i.e., no vertical motion) is referred to eustatic or global sea-level change.

The average relative sea-level rise for the period from 1926-2018 measured at the tide station at Fort Point in New Castle, $\mathrm{NH}$ is $2.01 \pm 0.19 \mathrm{~mm} / \mathrm{yr}$ (NOAA CO-OPS, accessed January 2020). The tide station located a short distance away ( $3 \mathrm{~km}$ ) at Seavey Island, ME, is $1.76 \pm 0.30 \mathrm{~mm} / \mathrm{yr}$ for the period from 1926 to 2001. Unfortunately, both locations have several extended gaps in their records. However, the tide station in Portland, ME, located $\sim 75 \mathrm{~km}$ ( $\sim 7$ miles) to the north, has a complete tide record for the time period from 1912-2018. The rate of sea-level rise at the Portland station is $1.88 \pm 0.14$ $\mathrm{mm} / \mathrm{yr}$. The similarity in rates of the three stations and proximity between them gives confidence that the mean rate of relative sea-level rise along the $\mathrm{NH}$ coast was $\sim 1.8$ to $2.0 \mathrm{~mm} / \mathrm{yr}$ (0.071 to 0.079 inches/yr) for the period from early 1900s to 2018. However, this is the mean rate for the entire period. There is strong evidence the rate of sea-level rise is rapidly accelerating. For example, the tide station record at Portland, ME shows an increase in the rate from $1.9 \mathrm{~mm} / \mathrm{yr}$ during the 1912-1980 period to $2.3 \mathrm{~mm} / \mathrm{yr}$ during the 1980-2016 period (McPherran, 2017). This trend is seen elsewhere along the US East Coast (Wake et al., 2011; NOAA CO-OPS, accessed January 2020).

As a result of climate change, eustatic sea-level rise has been accelerating and will continue to do so for the rest of this century. The tide gauge records for the NH Seacoast and vicinity discussed above show that the rate of relative sea-level rise in NH is very close to eustatic or global sea-level rise. Wake et al. (2011) estimated that the difference between eustatic and relative sea-level rise for Portland, ME, which has a similar history as the gauges in New Castle, NH and Seavey's Island, ME, was only $0.05 \mathrm{~mm} / \mathrm{yr}$. The slightly higher rate of the relative or local sea-level rise over eustatic sealevel rise is likely due to crustal subsidence. Therefore, predictions for future sea-level rise scenarios are likely valid for the NH Seacoast region without adjustment for crustal movement (uplift or subsidence) (Kirshen et al., 2014).

Mean eustatic sea-level rise (the average for the world's oceans) was 1.7 $\pm 0.2 \mathrm{~mm} / \mathrm{yr}$ from 1901-2010 (IPCC: Intergovernmental Panel on Climate Change, 2014). However, the mean eustatic rate of sealevel rise increased significantly to $3.3 \pm 0.4 \mathrm{~mm} / \mathrm{yr}$ during the period from 1993-2010. The IPCC (2014) predicted that the rate of eustatic mean sea-level rise will increase significantly in the coming century due to climate change and anthropogenic greenhouse gas emissions. Kirshen et al. (2014) pointed out that projections of increases in sea level into the future are based on probabilities and as such have a wide range. At this time, it is not possible to give an estimate with certainty, but it is clear that future sea level will increase significantly over present sea level. IPCC (2014) and Wake et al. (2019) indicated the mean rate of eustatic sea-level rise for the most extreme scenario would be between 
8-16 mm/yr for the period from 2081-2100, a major increase over the 1971-2010 period (2.0 \pm 0.3 $\mathrm{mm} / \mathrm{yr}$ ). However, relative sea-level rise in many regions will be more or less severe than eustatic sea-level rise due to factors such as fluctuations in ocean circulation or regional tectonics. However, Sallenger et al. (2012) identified the northern half of the US East Coast as a sea-level rise hotspot.

\section{Beach Nourishment}

Periodically, some of the beaches have had sand brought in from other areas or pumped onto the beach during dredging operations (Figures 2-1 and 2-2) to alleviate erosion, increase elevation, or to extend the intertidal area. Determination of the beach nourishment projects (placement of sediment, usually sand, on a beach from an outside source) carried out on $\mathrm{NH}$ beaches is extremely hard to assemble as record-keeping in the past appears to be incomplete at best. Also, it is likely that smaller projects were conducted ad hoc and not carefully documented. Nevertheless, several efforts to assemble what is known about beach nourishment in $\mathrm{NH}$ have been made including Haddad and Pilkey (1998), Olson and Chormann (2016), USACE (2016a and 2016b), and McPherran (2017). An updated version of the NH beach nourishment projects between 1935 and 2020 is given in Table 2-4. 

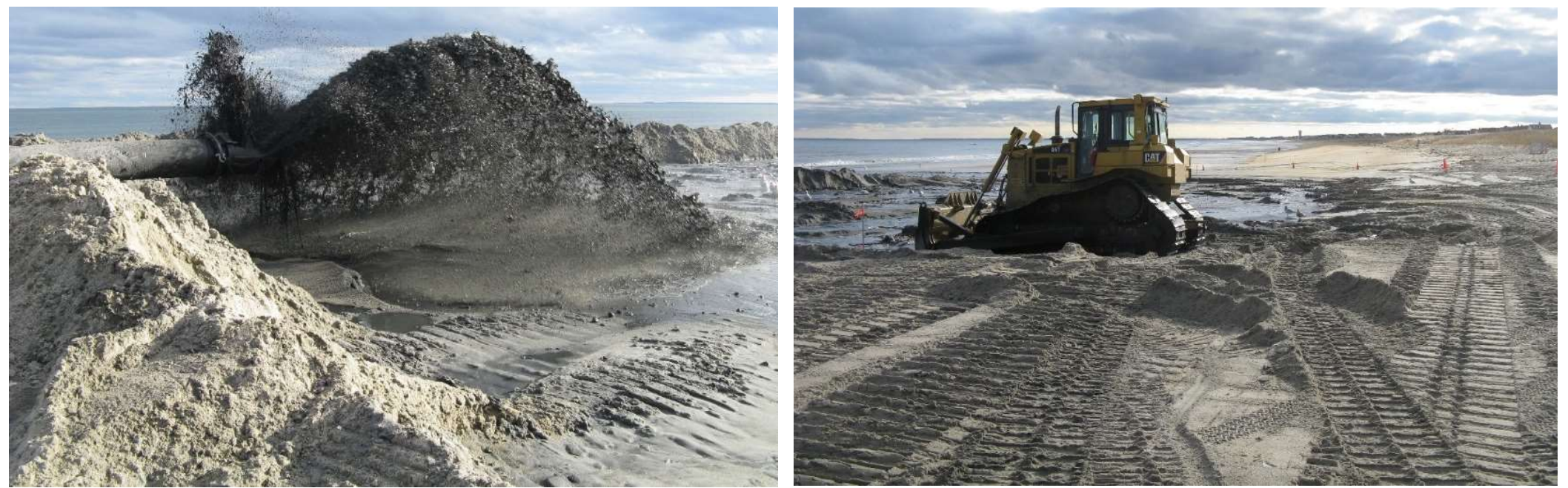

Figure 2-1. Beach nourishment at Seabrook Beach using dredged material from Hampton-Seabrook Harbor (December 11, 2012). The sand was pumped onto the beach via a pipeline (left photograph) and then graded with a bulldozer (right photograph).
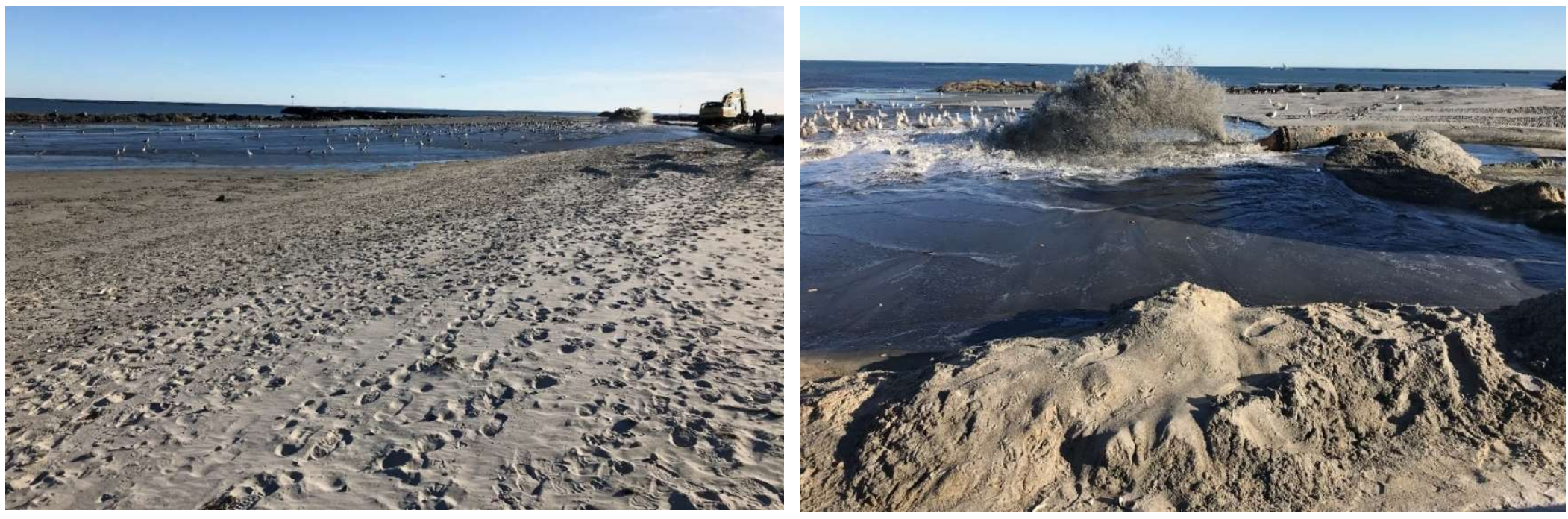

Figure 2-2. Beach nourishment at Hampton Beach State Park using dredged material from Hampton-Seabrook Harbor (November 23, 2019). The sand was pumped onto the beach via a pipeline (left photograph). Photograph on the right is a close-up of sand discharged from the pipe. 
Table 2-4. Summary of known beach nourishment projects on the New Hampshire coast. Modified (updated) from McKenna (2013) and McPherran (2017), and NHCP (personal communication, 2021).

\begin{tabular}{|c|c|c|c|c|c|c|}
\hline Location & Organization & Date & $\begin{array}{c}\begin{array}{c}\text { Nourishment } \\
\left(\mathrm{m}^{3}\right)\end{array} \\
\end{array}$ & Placement Location & Structure & Other \\
\hline $\begin{array}{l}\text { Wallis Sands } \\
\text { Beach }\end{array}$ & $\begin{array}{l}\text { USACE NH Shore and } \\
\text { Bank Protection } \\
\text { Projects (NHSBPP) }\end{array}$ & 1963 & 153,000 & $\begin{array}{l}\text { Northernmost } 800 \text { feet of } \\
\text { beach; } \\
\text { direct placement of sand }\end{array}$ & $\begin{array}{l}107 \text { m long } \\
\text { stone groin } \\
\text { emplaced }\end{array}$ & $\begin{array}{l}\text { Widened northernmost } 244 \\
\mathrm{~m} \text { of beach to } 46 \mathrm{~m} \text { width }\end{array}$ \\
\hline $\begin{array}{l}\text { Wallis Sands } \\
\quad \text { Beach }\end{array}$ & USACE NHSBPP & 1973 & 7,700 & & & $\begin{array}{c}\text { Part of restoration effort after } \\
\text { major storm in February } \\
1972 ; \\
\text { groin repaired }\end{array}$ \\
\hline $\begin{array}{l}\text { Wallis Sands } \\
\text { Beach }\end{array}$ & Unknown & 1983 & $\begin{array}{l}\text { Unknown } \\
\text { volume }\end{array}$ & & & \\
\hline $\begin{array}{l}\text { Wallis Sands } \\
\text { Beach }\end{array}$ & USACE & 1994 & 4,100 & $\begin{array}{l}\text { Wallis Sands State Park (900 } \\
\text { feet off the beach) }\end{array}$ & & $\begin{array}{c}\text { Material dredged from Little } \\
\text { Harbor entrance channel; } \\
\text { used to create a nearshore } \\
\text { "feeder berm" }\end{array}$ \\
\hline $\begin{array}{l}\text { Wallis Sands } \\
\text { Beach }\end{array}$ & USACE & 2001 & 31,000 & $\begin{array}{l}\text { Wallis Sands State Park (900 } \\
\text { feet off the beach) }\end{array}$ & & $\begin{array}{l}\text { Material dredged from Little } \\
\text { Harbor entrance channel and } \\
\text { anchorage; used to create a } \\
\text { nearshore "feeder berm" }\end{array}$ \\
\hline $\begin{array}{l}\text { Wallis Sands } \\
\quad \text { Beach }\end{array}$ & USACE & 2017 & 3,100 & $\begin{array}{l}\text { Wallis Sands State Park (900 } \\
\text { feet off the beach) }\end{array}$ & & $\begin{array}{c}\text { Material dredged from } \\
\text { Sagamore Creek; used to } \\
\text { create a nearshore "feeder } \\
\text { berm" }\end{array}$ \\
\hline $\begin{array}{c}\text { Hampton } \\
\text { Beach }\end{array}$ & State of $\mathrm{NH}$ & 1935 & 765,000 & & & \\
\hline $\begin{array}{l}\text { Hampton } \\
\text { Beach }\end{array}$ & USACE NHSBPP & 1955 & 306,000 & $\begin{array}{l}\text { From Haverhill Ave to the } \\
\text { north (northern and middle } \\
\text { part of beach); } \\
\text { direct placement of sand }\end{array}$ & & $\begin{array}{c}\text { Widened northern } 1981 \mathrm{~m} \text { of } \\
\text { beach }\end{array}$ \\
\hline $\begin{array}{l}\text { Hampton } \\
\text { Beach }\end{array}$ & USACE NHSBPP & 1965 & 130,000 & $\begin{array}{l}\text { From Church St to the north } \\
\text { (northern 2,200 feet of the } \\
\text { beach); sand dredged from } \\
\text { channel at Hampton Harbor }\end{array}$ & $\begin{array}{c}58 \text { m stone } \\
\text { groin emplaced }\end{array}$ & $\begin{array}{c}\text { Widened northern } 671 \mathrm{~m} \text { of } \\
\text { beach with Hampton Harbor } \\
\text { dredge material }\end{array}$ \\
\hline $\begin{array}{c}\text { Hampton } \\
\text { Beach }\end{array}$ & USACE & 1973 & 313,000 & & & $\begin{array}{l}\text { Part of restoration effort after } \\
\text { major storm in February } 1972\end{array}$ \\
\hline $\begin{array}{c}\text { Hampton } \\
\text { Beach }\end{array}$ & Unknown & 1987 & 16,000 & & & \\
\hline $\begin{array}{l}\text { Hampton } \\
\text { Beach }\end{array}$ & USACE & $2012 / 2013$ & 40,000 & & & $\begin{array}{c}\text { Maintenance dredging } \\
\text { project at Hampton-Seabrook } \\
\text { Harbor }\end{array}$ \\
\hline $\begin{array}{l}\text { Hampton } \\
\text { Beach }\end{array}$ & USACE & 2019 & 24,500 & $\begin{array}{l}\text { Southern end adjacent to } \\
\text { the jetty; } \\
\text { direct placement of sand }\end{array}$ & & $\begin{array}{c}\text { Maintenance dredging } \\
\text { project at Hampton-Seabrook } \\
\text { Harbor }\end{array}$ \\
\hline $\begin{array}{c}\text { Seabrook } \\
\text { Beach }\end{array}$ & Unknown & 2005 & $\begin{array}{c}\text { Unknown } \\
\text { volume }\end{array}$ & & & \\
\hline $\begin{array}{l}\text { Seabrook } \\
\text { Beach }\end{array}$ & USACE & $2012 / 2013$ & 92,000 & $\begin{array}{l}\text { Northern end of the beach; } \\
\text { direct placement of sand }\end{array}$ & & $\begin{array}{c}\text { Maintenance dredging } \\
\text { project at Hampton-Seabrook } \\
\text { Harbor }\end{array}$ \\
\hline $\begin{array}{l}\text { Seabrook } \\
\text { Beach }\end{array}$ & USACE & 2019 & 91,700 & $\begin{array}{l}\text { Northern end of the beach; } \\
\text { direct placement of sand }\end{array}$ & & $\begin{array}{c}\text { Maintenance dredging } \\
\text { project at Hampton-Seabrook } \\
\text { Harbor }\end{array}$ \\
\hline
\end{tabular}




\section{Chapter 3: Methodology}

\section{Establishment of the Beach Monitoring Stations}

Station Network. The present VBPMP station grid consists of thirteen stations spaced over six of the major beaches along the NH coast (Wallis Sands Beach, Jenness Beach, North Hampton Beach, North Beach, Hampton Beach, and Seabrook Beach) (Figure ES-1; Table 3-1). The locations of the stations were chosen based on several criteria including: coverage of the different types of beaches found in $\mathrm{NH}$ with regard to morphology and sediment types; accessibility by volunteers during all seasons; and availability of locations where permanent station markers could be established. Most of the thirteen stations chosen were part of a profile network established during an earlier study by McPherran (2017). Only Foss Beach was excluded from the present study due to lack of suitable locations to establish permanent station markers and station accessibility.

Station Markers. In order to locate the beach monitoring profiles easily, two types of station markers are used. At locations where the beach is backed by vegetated dunes, a wooden stake is driven into the beach dune margin or foredune ridge (Figure 3-1). A second stake is also established to act as a back site for the beach profile and a station marker in the event the seaward stake is lost. More commonly, a seawall is located at the landward boundary. At these locations, a black circle $(\sim 5 \mathrm{~cm})$ is painted on the top of the seawall (Figure 3-2). This marker and a back site (often a chimney or telephone pole) are used to establish a shore-normal profile line (at a right angle to the coast or upland). The station marker and back site are lined up and used as reference points to ensure the beach profile is straight along the seaward transect and consistent over time.

Station Marker Positions and Elevations. The position (latitude and longitude) and elevation of all station markers (painted markers on the seawalls and wooden stakes) were determined using the Global Navigation Satellite System (GNSS) (Figure 3-3). The GNSS signal was captured with an Ashtech (Proflex 500) receiver with a Zephyr model II antenna (or similar). The raw GNSS data were postprocessed with Continuously Operating Reference Stations (CORS) differential correction data using Ashtech's Precise Differential GPS Navigation and Surveying (PNAV) software (Ashtech, 1988) or RTKLIB (an open source program package; http://www.rtklib.com/; accessed January 2020). The CORS located in either Salisbury, MA or Durham, NH were used. The elevations were determined in reference to the ellipsoid (WGS84) and adjusted to NAVD88, Mean Water Level (MWL) and Mean Lower Low Water (MLLW) referenced to NAD83 (1986) using VDatum (NOAA NOS, accessed January 2020; http://vdatum.noaa.gov/). The station locations and elevations are shown in Table 3-1. 
Table 3-1. Station positions and elevations for the station markers for the NH VBPMP. The elevations of the markers were determined in reference to the ellipsoid (IGS08) and adjusted to NAVD88, Mean Water Level (MWL) and Mean Lower Low Water (MLLW) referenced to NAD83 (1986) using VDatum (NOAA NOS, accessed January 2020; http://vdatum.noaa.gov/).

\begin{tabular}{|c|c|c|c|c|c|c|c|c|c|c|c|}
\hline Station ID & $\begin{array}{r}\text { Date } \\
\text { Leveled }\end{array}$ & Type & $\begin{array}{r}\text { Latitude } \\
\text { IGS08 }\end{array}$ & $\begin{array}{r}\text { Longitude } \\
\text { IGS08 }\end{array}$ & $\begin{array}{r}\text { Height } \\
\text { IGS08 }\end{array}$ & $\begin{array}{r}\text { Latitude } \\
\text { NAD83 }\end{array}$ & $\begin{array}{r}\text { Longitude } \\
\text { NAD83 }\end{array}$ & $\begin{array}{r}\text { Elevation } \\
\text { NAD83 }\end{array}$ & $\begin{array}{r}\text { Elevation } \\
\text { NAVD88 }\end{array}$ & $\begin{array}{r}\text { Elevation } \\
\text { MTL }\end{array}$ & $\begin{array}{r}\text { Elevation } \\
\text { MLLW }\end{array}$ \\
\hline WS01 & $6 / 20 / 2017$ & Seawall & 43.027703 & -70.728421 & -23.81 & 43.027692 & -70.728416 & -22.61 & 4.03 & 4.13 & 5.56 \\
\hline WSO2_5 & $1 / 30 / 2018$ & Seawall & 43.023613 & -70.731603 & -22.96 & 43.023603 & -70.731598 & -21.77 & 4.88 & 4.98 & 6.42 \\
\hline JB01 & $12 / 6 / 2017$ & Seawall & 42.988737 & -70.760207 & -23.96 & 42.988727 & -70.760202 & -22.77 & 3.94 & 4.05 & 5.49 \\
\hline JB02 & $6 / 13 / 2017$ & Seawall & 42.985772 & -70.762434 & -23.97 & 42.985762 & -70.762429 & -22.78 & 3.93 & 4.05 & 5.48 \\
\hline NHB01 & $6 / 20 / 2017$ & Seawall & 42.955718 & -70.781270 & -23.55 & 42.955708 & -70.781266 & -22.35 & 4.40 & 4.52 & 5.96 \\
\hline NHB02_Landward & $12 / 7 / 2017$ & Stake & 42.952479 & -70.784601 & -22.65 & 42.952469 & -70.784596 & -21.46 & 5.30 & 5.42 & 6.86 \\
\hline NHB02_Seaward & $12 / 7 / 2017$ & Stake & 42.952426 & -70.784518 & -22.62 & 42.952416 & -70.784514 & -21.42 & 5.34 & 5.46 & 6.90 \\
\hline NB01 & $6 / 19 / 2017$ & Seawall & 42.939494 & -70.794637 & -24.97 & 42.939484 & -70.794633 & -23.78 & 3.01 & 3.13 & 4.57 \\
\hline NBO2 & $12 / 6 / 2017$ & Seawall & 42.934373 & -70.796721 & -23.77 & 42.934362 & -70.796716 & -22.57 & 4.21 & 4.33 & 5.78 \\
\hline $\mathrm{HB} 02$ & $8 / 4 / 2016$ & Seawall & 42.909014 & -70.810574 & $N / A$ & 42.909003 & -70.810569 & N/A & $\mathrm{N} / \mathrm{A}$ & $\mathrm{N} / \mathrm{A}$ & $\mathrm{N} / \mathrm{A}$ \\
\hline $\mathrm{HB} 02$ & $6 / 15 / 2017$ & Seawall & $\mathrm{N} / \mathrm{A}$ & N/A & -23.55 & $\mathrm{~N} / \mathrm{A}$ & $N / A$ & -22.36 & 4.47 & 4.62 & 6.07 \\
\hline HB04_Landward & $10 / 27 / 2017$ & Stake & 42.899808 & -70.811209 & -22.95 & 42.899798 & -70.811204 & -21.75 & 5.08 & 5.20 & 6.65 \\
\hline HB04_Seaward & $8 / 29 / 2018$ & Stake & 42.899795 & -70.811107 & -23.41 & 42.899785 & -70.811102 & -22.21 & 4.61 & 4.74 & 6.19 \\
\hline SB02_Landward & $10 / 19 / 2017$ & Stake & 42.885002 & -70.814999 & -20.55 & 42.884992 & -70.814994 & -19.35 & 7.49 & 7.61 & 9.06 \\
\hline SB02_Seaward & $10 / 19 / 2017$ & Stake & 42.884954 & -70.814532 & -21.81 & 42.884944 & -70.814527 & -20.61 & 6.23 & 6.36 & 7.81 \\
\hline SB04_Landward & $8 / 29 / 2018$ & Stake & 42.879484 & -70.815709 & -21.65 & 42.879474 & -70.815704 & -20.45 & 6.39 & 6.52 & 7.97 \\
\hline SB04_Seaward & $10 / 19 / 2017$ & Stake & 42.879470 & -70.815563 & -21.65 & 42.879460 & -70.815559 & -20.45 & 6.39 & 6.52 & 7.97 \\
\hline SB05_Landward & $10 / 27 / 2017$ & Stake & 42.874301 & -70.816577 & -21.51 & 42.874291 & -70.816572 & -20.31 & 6.54 & 6.67 & 8.12 \\
\hline SB05_Seaward & $10 / 27 / 2017$ & Stake & 42.874303 & -70.816304 & -21.69 & 42.874293 & -70.816300 & -20.49 & 6.36 & 6.49 & 7.93 \\
\hline
\end{tabular}




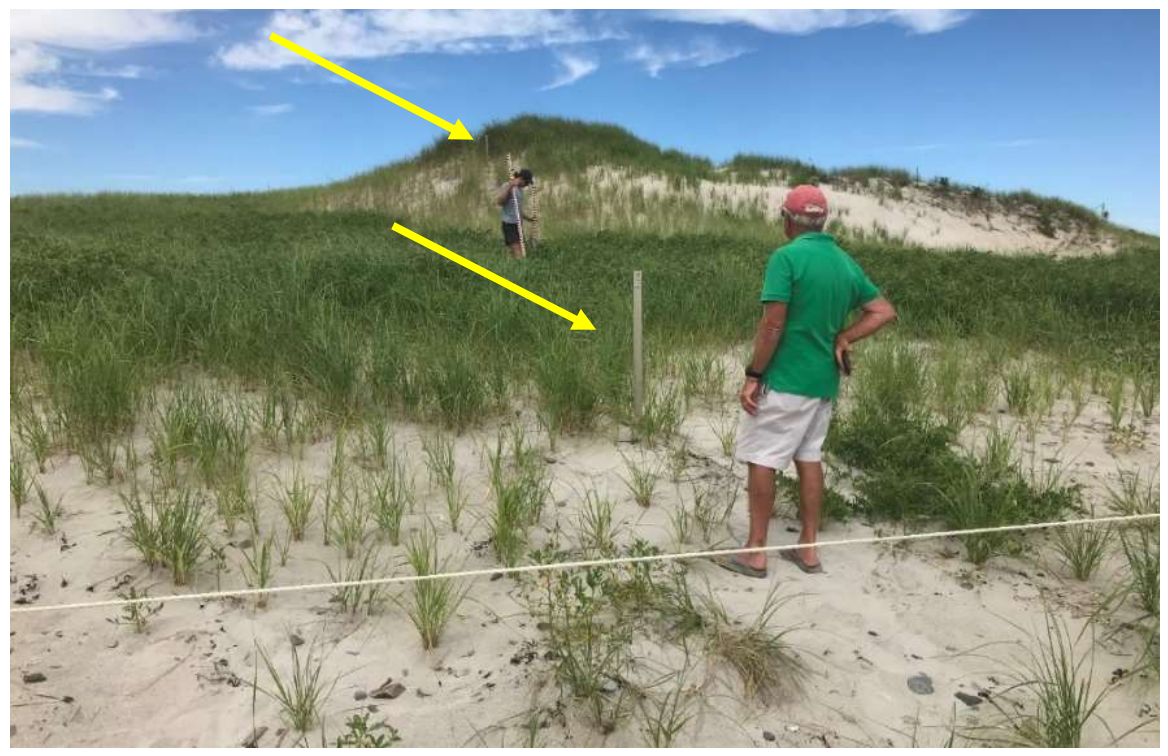

Figure 3-1. Station markers at Hampton Beach (HB04) on July 8, 2019. Two wooden stakes are used to mark the station (arrows). The beach elevation profile is typically run from the seaward stake. The landward stake is used to line up the shorenormal profile transect and help re-establish the station if the seaward stake is lost (i.e. due to storm erosion or vandalism).

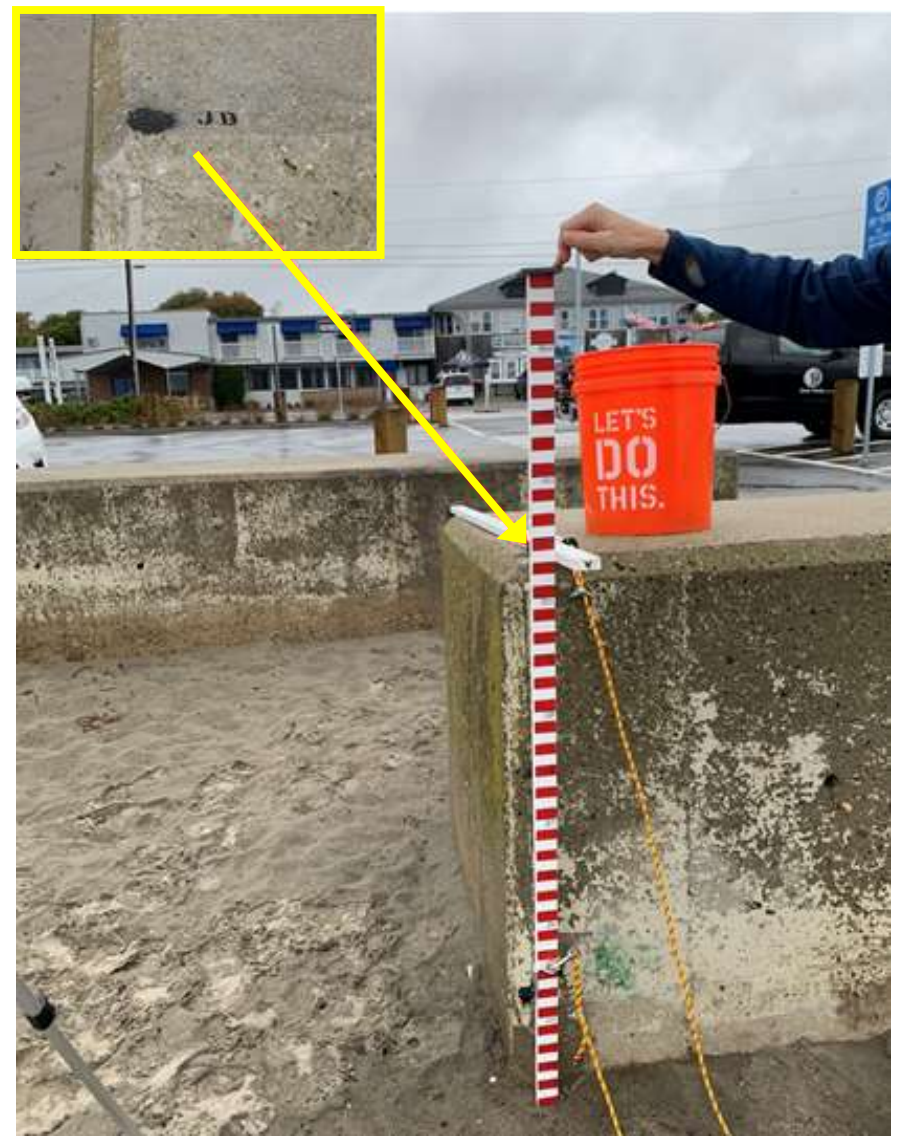

Figure 3-2. The station marker height above the sand is being measured with a profile rod during the field session on December 21, 2019. At profile stations where the landward boundary is a seawall or a hard structure, the station is marked by a painted circle on the seawall (upper left inset). At Jenness State Beach (JB02) the station marker is a painted black circle $\sim 5 \mathrm{~cm}$ in diameter on the seawall. 


\section{Beach Profiling with the Emery Method}

The elevation profiles of the beaches were determined by establishing a shore-normal transect from the station marker at the landward extent of the beach to the swash zone at low tide. The shorenormal elevation profiles (hereafter referred to as the beach profiles) were measured using the Emery method (Emery, 1961). First, the vertical distance from the station marker (marker on seawall or top of wooden stake at the beginning of the profile) to the beach surface is measured (Figures 3-3 and 3-4). All subsequent measurements are made relative to this point on the beach at the base of the station marker. Starting at the base of the station marker, two $1.5 \mathrm{~m}$ calibrated staffs $(2 \mathrm{~cm}$ increments) a known distance apart (usually $\sim 3 \mathrm{~m}$ ) are aligned on the transect (Figure 3-5). The profile rods are outfitted with bubble levels to help keep the profile rods vertical during measurements. Using a line-of-sight with the horizon as a level the relative difference in elevation between the rods is determined. The profile rods are then moved with the landward rod occupying the spot on the beach of the seaward rod. This process is continued across the beach on the transect until the swash zone or water is reached (Figure 3-6). The relative difference in elevation and distance between the profile rods is recorded for each jump (movement of the rods). The beach elevation profile is determined by summing the changes in relative elevation and distance between the profile rods for each jump (ignoring a very small error introduced due to the curvature of the earth over wide beaches). Since the station marker position and elevation were previously determined the beach profile can then be tied into a datum by adjusting the first elevation.

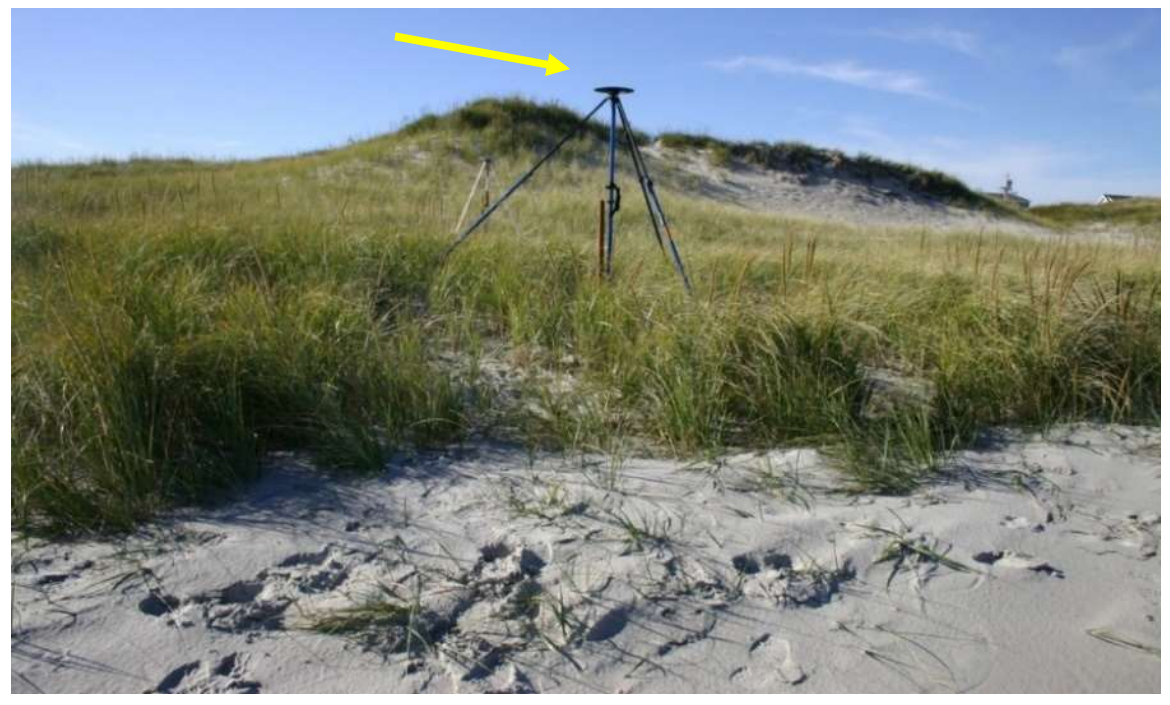

Figure 3-3. Seaward and landward profile station markers for station HB04 on October 27, 2017. The station position and elevation of the posts are being determined using GNSS antennas and receivers (indicated by the arrow). 

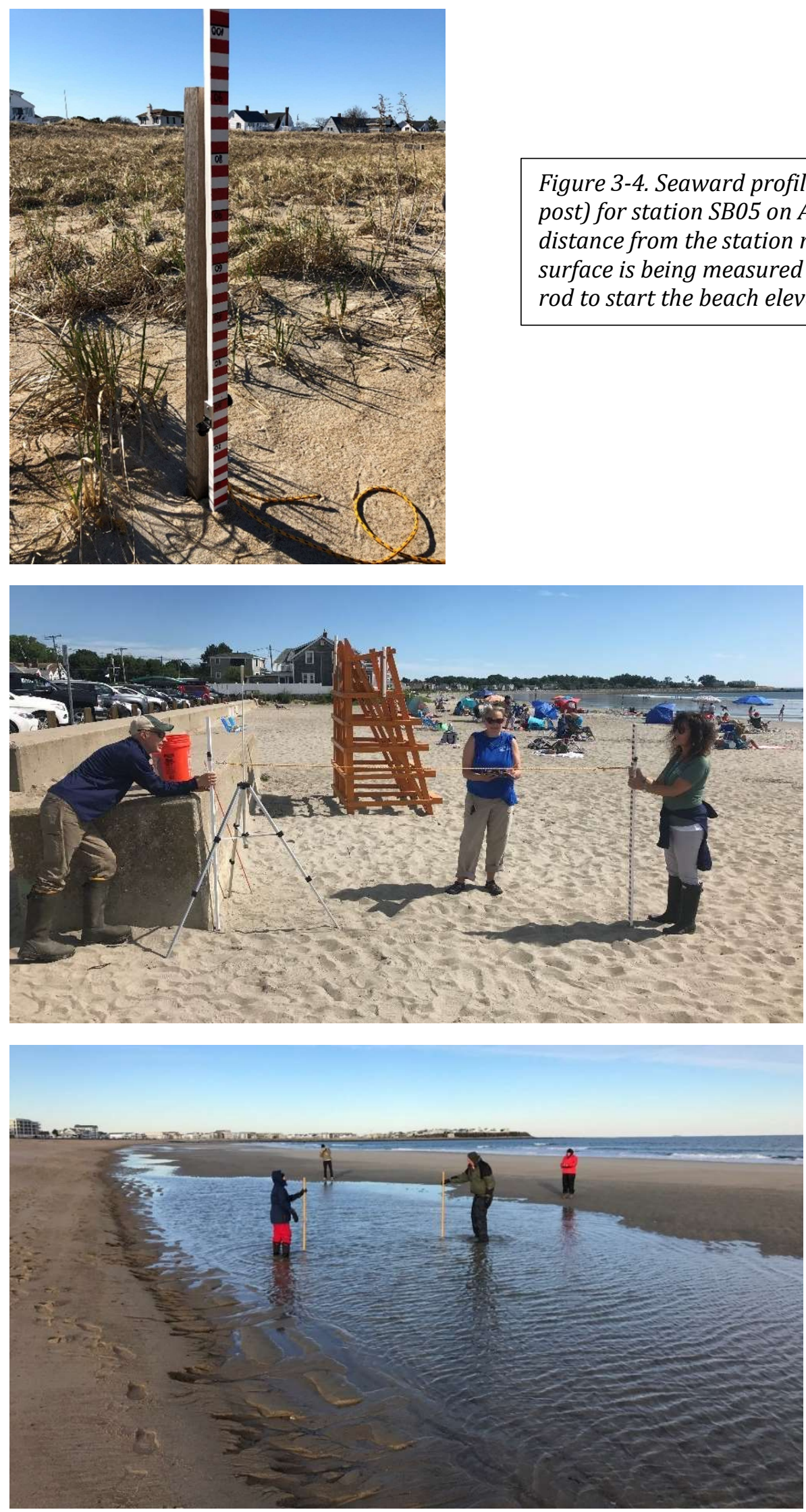

Figure 3-4. Seaward profile station marker (wooden post) for station SB05 on April 17, 2019. The distance from the station marker to the beach surface is being measured by inverting the profile rod to start the beach elevation profile.
Figure 3-5. Volunteers measuring a beach elevation profile in the field using the Emery method at Jenness Beach (JB02) on July 8, 2019.
Figure 3-6. Volunteers measuring a beach elevation profile in the field using the Emery method at Hampton Beach (HB02) on January 2, 2019. 


\section{Data Collection, Processing, and Archiving}

The VBPMP involved over thirty-five volunteers running profiles and taking photographs at thirteen stations at three- to four-week intervals. Consistency in data collection was maintained by periodic group workshops and individual training, as well as frequent visits in the field by the project management team. The transfer of the data from the field to the management team was accomplished by the volunteers uploading the profile data to Google Drive. This included the raw data sheet from the field and all photographs. The volunteers also entered the raw profile data into a Microsoft Excel spreadsheet. Subsequently, the data and photographs were examined to assure completeness and the Excel file was compared to the raw field data. If any questions concerning the data collection or photographs were identified, the volunteer group was contacted for clarification. Subsequently, the data was copied to a UNH Box site for archiving.

The profile data and field photographs were processed at the UNH Center for Coastal and Ocean Mapping (CCOM). The raw profile data was brought into an Excel spreadsheet where the cumulative distance along a profile and the relative elevations were calculated for that profile. Subsequently, the relative elevation values were converted to common vertical elevation datums including IGSO8 and NAD83 with reference to the ellipsoid, and NAVD88 and MLLW based on the NAD83 ellipsoid using VDatum (NOAA OCS, accessed January 2020; http://vdatum.noaa.gov/). Each profile at a station was brought into MATLAB and all profiles plotted at a $5 X$ vertical exaggeration for comparison and display. The volume of sediment above a reference datum (-30 $\mathrm{m}$ with reference to the IGS08 ellipsoid) for each profile was also computed and plotted in the Excel spreadsheet. The method to compute the volumes is discussed below.

\section{Volume Determination}

To facilitate comparisons between beach elevation profiles and quantify changes in the beach measured by the elevation profiles, the volume of sediment on the subaerial beach was computed. A standard elevation to serve as the base to the subaerial beach was defined as $-30 \mathrm{~m}$ with reference to the IGS08 ellipsoid. On the NH coastline, the -30.00 m IGS08 ellipsoid elevation is equivalent to $0.38 \mathrm{~m} \mathrm{MLLW}$ at Seabrook Beach close to the southern extent of the study area and $-0.63 \mathrm{~m} \mathrm{MLLW}$ at Wallis Sands State Park at the northern extent of the study area (Table 3-2). Therefore, the volume calculations approximate the volume of the intertidal beach from the landward seawall or foredunes to approximately MLLW.

Because the lengths of the beach profiles at each station varied, sometimes substantially, due to tidal conditions or erosion, a standard length for each profile was chosen to use for volumetric calculations. The standard elevation profile length was determined for each station by reviewing all the profiles from that station from approximately January 2017 (WS01, JB02, and HB02) or January 2018 (all the remaining stations) to March 2020 and determining a minimum length that captured most of the profiles. Due to the variation in profile lengths some were shorter than the standard 
length. In these cases, the profile was lengthened by assuming the profile continued seaward at a slightly lower elevation or flatter than the last few measurements (Figures 3-7 and 3-8).

To determine the subaerial volume of sediment from the Emery beach profiles, each horizontal step or jump on a profile transect (typically $\sim 3 \mathrm{~m}$ ) from the landward limit to the standard distance seaward was treated as an individual cell, the area of that cell determined, and the area of all of the cells summed. The area of each cell is calculated by multiplying the mean height or distance above the $-30 \mathrm{~m}$ IGSO8 ellipsoid of the landward and seaward boundary of that cell and the width of the cell. The width of the cell was calculated using the Pythagorean Theorem using the distance between the profile rods (hypotenuse) and the difference of the landward and seaward elevation of the cell (height). To convert the area of the profile to a volume, the profile was assumed to be representative of a 1-meter-wide swath of the beach. Subsequently, changes in volume between profile periods was determined.

Estimated volumetric changes along the profile line during the study period reflect similar trends as the beach profiles but allow a comparison of sediment loss or gain. In a sense, examination of the volume of sediment lost or gained provides a clearer picture of changes to the beach over time, although all details of the morphology are lost. Calculating volume data between surveys allows determination of whether the beach remained unchanged (volume and/or elevation changes within limits of uncertainty), accreted (positive increase in volume greater than uncertainty), or eroded (decrease in volume greater than uncertainty).

Table 3-2. Differences between Mean Lower Low Water and -30 m (IGSO8) on NH coast.

\begin{tabular}{|cccccc|}
\hline Station & Latitude & Longitude & & MLLW & Difference \\
& IGS08 Ellipsoid & IGS08 Ellipsoid & IGS08 Ellipsoid & IGS08 Ellipsoid & (S3) \\
\hline WS01 (Station Marker) & 43.027700 & -70.728417 & -30.00 & $-29.37 \mathrm{~m}$ & $0.63 \mathrm{~m}$ \\
JB02 (Station Marker) & 42.985772 & -70.762433 & -30.00 & $-29.46 \mathrm{~m}$ & $0.54 \mathrm{~m}$ \\
HB02 (Station Marker) & 42.909014 & -70.810574 & -30.00 & $-29.59 \mathrm{~m}$ & $0.41 \mathrm{~m}$ \\
SB04 (Seaward Stake) & 42.879470 & -70.815563 & -30.00 & $-29.62 \mathrm{~m}$ & $0.38 \mathrm{~m}$ \\
\hline
\end{tabular}




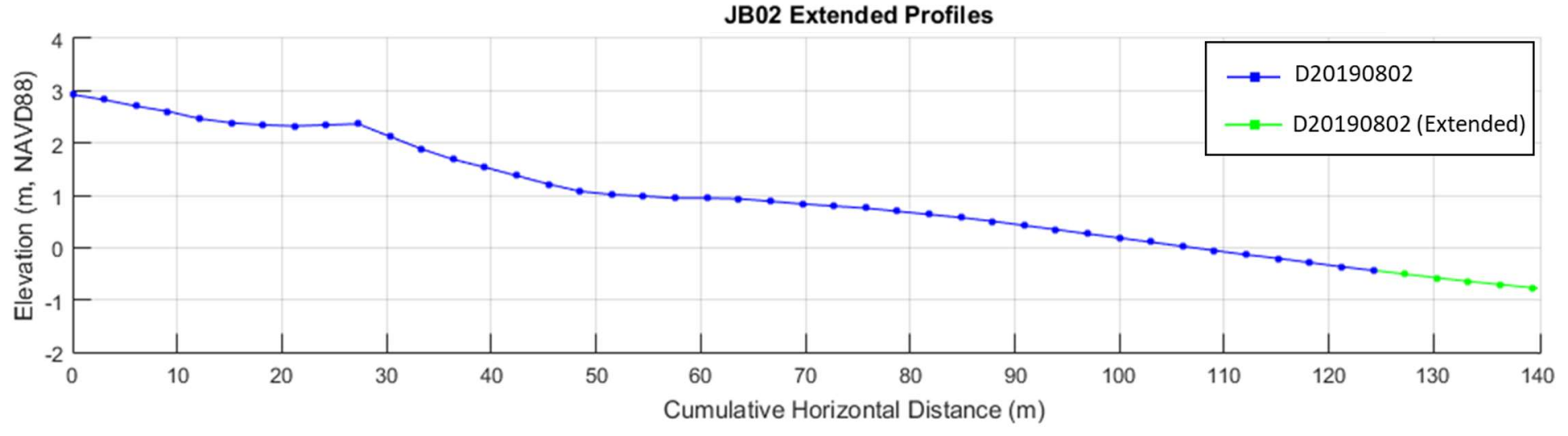

Figure 3-7. An example of extending a relatively low amplitude (flatter) elevation profile is shown for Jenness Beach (JB02) on August 8, 2019. In order to establish a standard length (or minimum) for all beach profiles for sediment volume calculations, some shorter profiles needed to be extended manually. Each station has its own standard length based on one or two years of data.

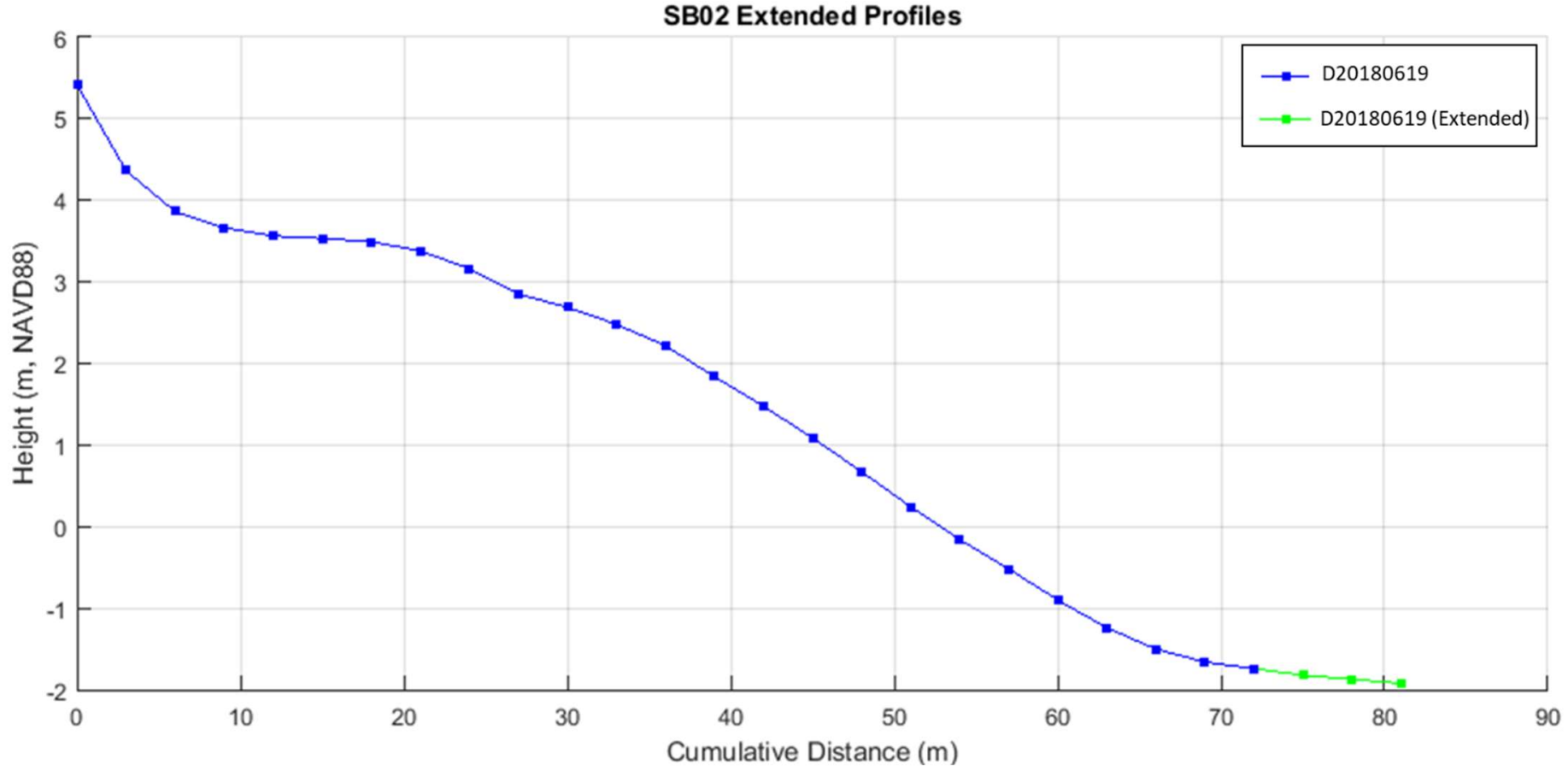

Figure 3-8. An example of extending a steep beach profile to the standard length for sediment volume calculations is shown for SBO2 (Seabrook Beach) on June 19, 2018. 


\section{Quality Control and Uncertainty Assessment}

Rigorous quality control was practiced for the data collection, data transfer for archiving and processing, and data processing. Quality control in collecting the data in the field was accomplished by thoroughly training volunteers, either in group sessions or individually prior to field work. Volunteers were trained in field methods, beach feature identification, and data entry protocols. Project team members joined volunteers in the field for initial data collection efforts until volunteers were confident in field methods. Ongoing quality control efforts include annual trainings to review methods, project evaluations (to assess volunteer motivation, volunteer learning as a result of the project, and opportunities for programmatic improvements), and frequent visits into the field with volunteers.

Transfer of the data to the project team by the volunteers was monitored by comparison of the uploaded data to the original field data sheets, which were obtained via photographs or handdelivered to the project team. Field conditions and visibility of the horizon were verified by field photographs uploaded by the volunteers. Quality control of data processing, archiving, and plotting was achieved by a second and separate review of both the recorded and uploaded data, and plotting of the beach profiles. Inconsistencies in the data and profiles were identified and if necessary, field volunteers contacted and queried. All profiles were examined to locate outliers and to verify accuracy or reject data.

Evaluation of Emery Method Precision. In order to assess the precision of the Emery method for measuring beach elevation profiles, one of the permanent stations in the profile network (JB02) was run twice consecutively on December 8,2016 by different personnel. The measured elevation profiles were nearly identical with the lines used to plot the profiles overlying each other for most of the profile (Figure 3-9). There was slight separation of the profile line in the lower $40 \mathrm{~m}$, but the maximum difference was $0.10 \mathrm{~m}$, and most were less. The average difference based on the volumetric calculations for the landward $95 \mathrm{~m}$ of the profile was $0.02 \mathrm{~m}$.

Comparison of the Emery Methods with GNSS Surveys. To obtain a sense of the uncertainty or accuracy of the Emery method for beach profiling, a comparison was made between beach profiles measured using the Emery method during this study and the same beach profiles measured with a GNSS rover which previously had an uncertainty assessment. The GNSS rover was a three-wheeled dolly with an Ashtech ProFlex 500 receiver and Ashtech Marine Antenna III mounted on a pole centered on the dolly (Figure 3-10). McPherran (2017) indicated the uncertainty of the GNNS rover system for profiling was on the order of $\pm 0.15 \mathrm{~m}$ for elevation and $\pm 0.20 \mathrm{~m}$ for horizontal position when strong satellite signals were received.

The comparisons between the Emery profiles and the GNSS profiles were made on two occasions in 2017 at three stations (Wallis Sands State Park at WS01, Jenness State Beach at JB02, and Hampton Beach State Park at HB02; see Figure ES-1). Unfortunately, the GNSS rover and the Emery profiles were not run at the same time, but rather the GNSS profiles were available from another study at the 
three stations that coincided with the present project. The GNSS profiles that were chosen were run between one to fifteen days from the Emery profile at the same station. No storm activity or periods of large waves occurred between the GNNS rover and Emery profiles selected for this comparison. Although not ideal, it provides some perspective, albeit not definitive. Other profiles were examined, but fifteen days was considered the limit between profiles for comparisons.

Overall, the comparison between the Emery and the GNSS profiles show a reasonable correlation (Figures 3-11, 3-12, and 3-13). All but one of the seven profiles compared were very similar, and differences were likely related to overall uncertainty of both methods and the time interval between surveys. It should be noted that the Wallis Sands and Jenness Beach profiles are relatively low relief. However, this is not the case for Hampton Beach which is relatively wide and steep at the berm face. At WS01 the February 21 Emery profile and the February 22 GNSS rover profile agree extremely well remaining within $0.20 \mathrm{~m}$ vertically with the GNSS rover profile at a slightly higher elevation (Figure 311). The August 25 Emery profile and September 5 GNSS rover profile at WS01 agree very well staying within $0.20 \mathrm{~m}$. However, the Emery profile is again slightly higher throughout the length. At JB02 the March 28 GNSS rover profile is less than $0.20 \mathrm{~m}$ different and for much of the profile less than 0.10 $m$ different than the March 17 and April 5 Emery profiles (Figure 3-12). At JB02 the September 9 GNSS rover profile is less than $0.20 \mathrm{~m}$ different compared to the August 24 Emery profile. At HBO2 the September 19 Emery profile and the September 18 GNSS rover profiles are very similar (Figure 3-13). The profiles are within $0.20 \mathrm{~m}$ over the whole length and often less than $0.15 \mathrm{~m}$ vertically. There is a slight offset in the berm crest likely due to a gap in the GNSS profile at the beginning. The one exception was the comparison between the GNSS profile done on February 3, 2017 and the accompanying Emery profile done on February 6, 2017 (Figure 3-13). There is a 10-15 m horizontal offset and a $0.40-0.60 \mathrm{~cm}$ vertical offset. However, the vertical offset would be reduced if the horizontal offset were removed. In this comparison, the Emery profile is likely correct as the GNSS profile has a gap near the landward boundary which was caused by weak satellite tracking and an intermittent signal that could not be enhanced in post-processing.

One striking difference that warrants further consideration for future work is the trend seen in the lower portion of each of the comparison profiles where the Emery profiles become slightly higher than the GNSS rover profile as the waterline is approached. The reason for this is not clear and may be coincidental. Also, the precision of the Emery profiles should ideally be determined by running several profiles consecutively at the same station. The accuracy of the Emery profile should be evaluated by running both an Emery profile and a GNSS rover profile at the same time at several stations. This should be done at stations that are relatively low relief (Jenness Beach or Wallis Sands) and at stations with high relief (e.g., Hampton Beach or Seabrook Beach).

Summary. The uncertainty of measuring beach elevation profiles using the Emery method is hard to determine. However, based on the comparisons described above and assuming all protocols are being followed, determining the accuracy and precision of a beach elevation profile using the Emery method is summarized below. 
The horizontal position uncertainty using the Emery method is not known except at the station marker which is determined with the GNSS (discussed below). The horizontal position is based on a measurement between profile rods for each reading or jump, which is a constant. The alignment of the transect is based on the volunteer profilers staying on the transect by visually lining up the station markers. The comparison of a 130 m long transect at station JB02 run two times (back to back) indicates the lengths only differed by a few meters (Figure 3-9). Therefore, the position error cannot be determined, but it is considered small or negligible.

The precision of the elevation profiles measured using the Emery method can be estimated from the profiles shown in Figure 3-9. The maximum difference in elevations between the profiles was $0.10 \mathrm{~m}$, and the average difference for the landward $95 \mathrm{~m}$ of the profiles was $0.02 \mathrm{~m}$. Although more profiles need to be run to better quantify the uncertainty, it appears it is on the order of $0.10 \mathrm{~m}$ to $0.15 \mathrm{~m}$. The absolute location and elevation is only known for the station marker or stakes and is determined using GNSS, post processing, and CORS stations. This error is likely similar to or less than the error discussed by McPherran (2017) and is on the order of $\pm 0.15 \mathrm{~m}$.

Although it is not possible to assign error estimates for this study, it is useful to recognize the comparisons discussed above. Based on this reasoning and to be conservative, the changes or differences in the elevations of profiles from the same station must be greater than $0.20 \mathrm{~m}$ to be considered different. The same estimate is used to compare mean elevations for individual profiles run at the same station. Finally, comparisons of mean profiles between different stations must take into consideration the error in leveling the station marker, as well as errors in measuring profiles using the Emery method. Here, $0.20 \mathrm{~m}$ is again used for the uncertainty. A final consideration is the uncertainty of the volume calculations. Assuming a $0.20 \mathrm{~m}$ vertical error and no horizontal positioning error, then the error in volume estimation for a one-meter-wide transect $100 \mathrm{~m}$ in length would be $\pm 20 \mathrm{~m}^{3}$ and the error for a transect $150 \mathrm{~m}$ in length would be $\pm 25 \mathrm{~m}^{3}$. Since all "standard length" transects are within this range, the uncertainty for volume is likely $\leq \pm 25 \mathrm{~m}^{3}$. Although these values cannot be quantified, it is useful to keep them in mind when comparing profiles and stations. 
Beach Profiling Repeatability Test

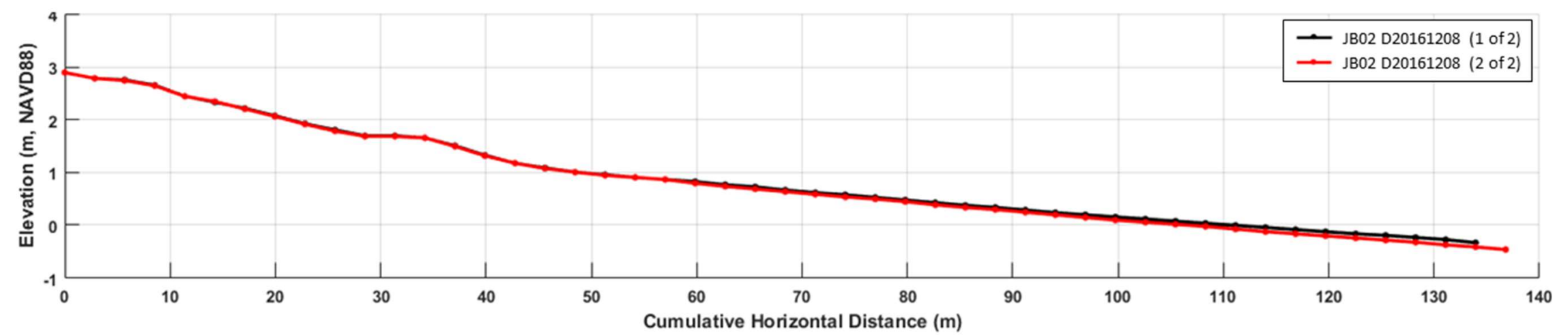

Figure 3-9. Comparison of Emery beach profiles completed on December 8, 2016 at station JB02 by two separate volunteer groups, representing the accuracy and repeatability of the method.

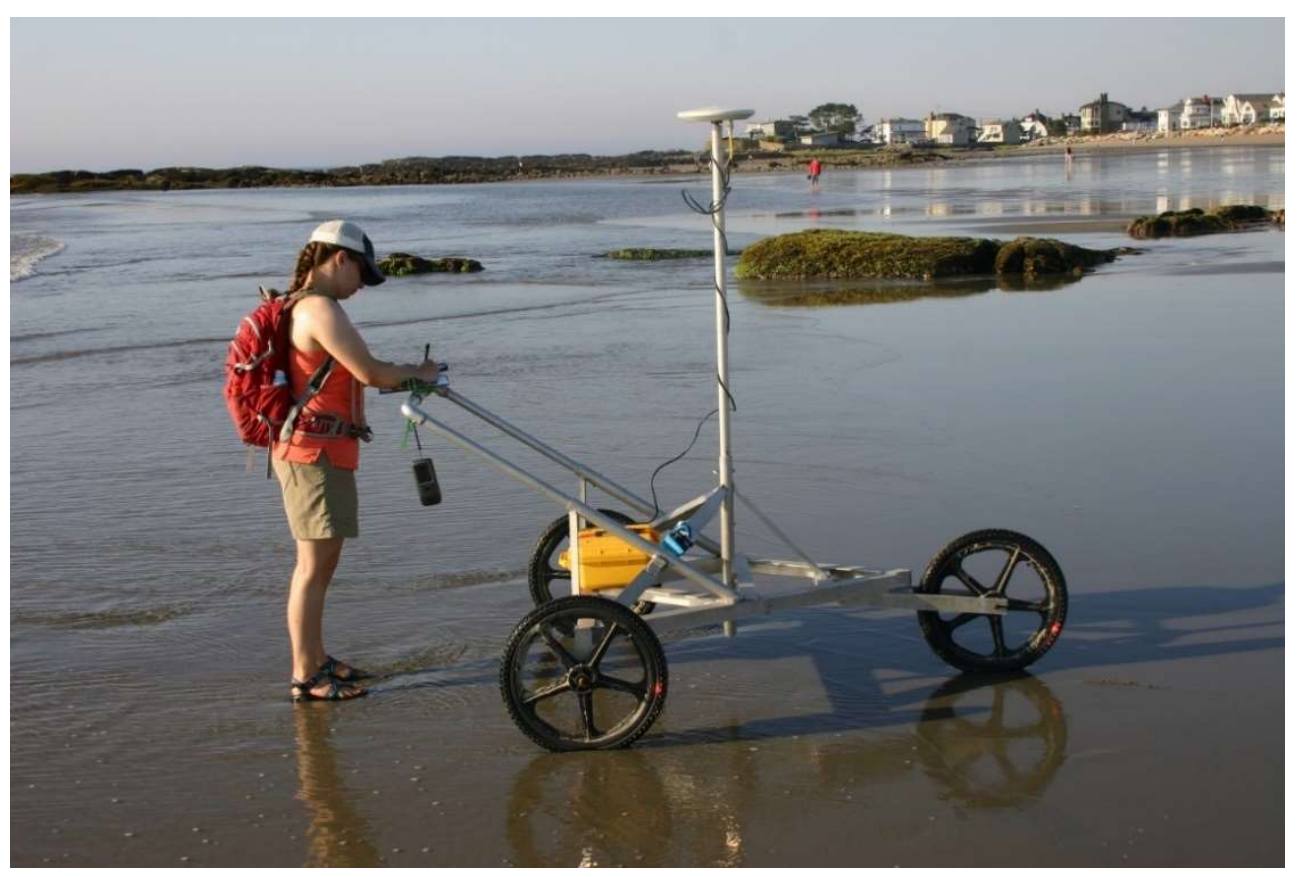

Figure 3-10. Measuring a beach profile at Wallis Sands using the GNSS Rover system on August 3, 2016. 


\section{WS01}
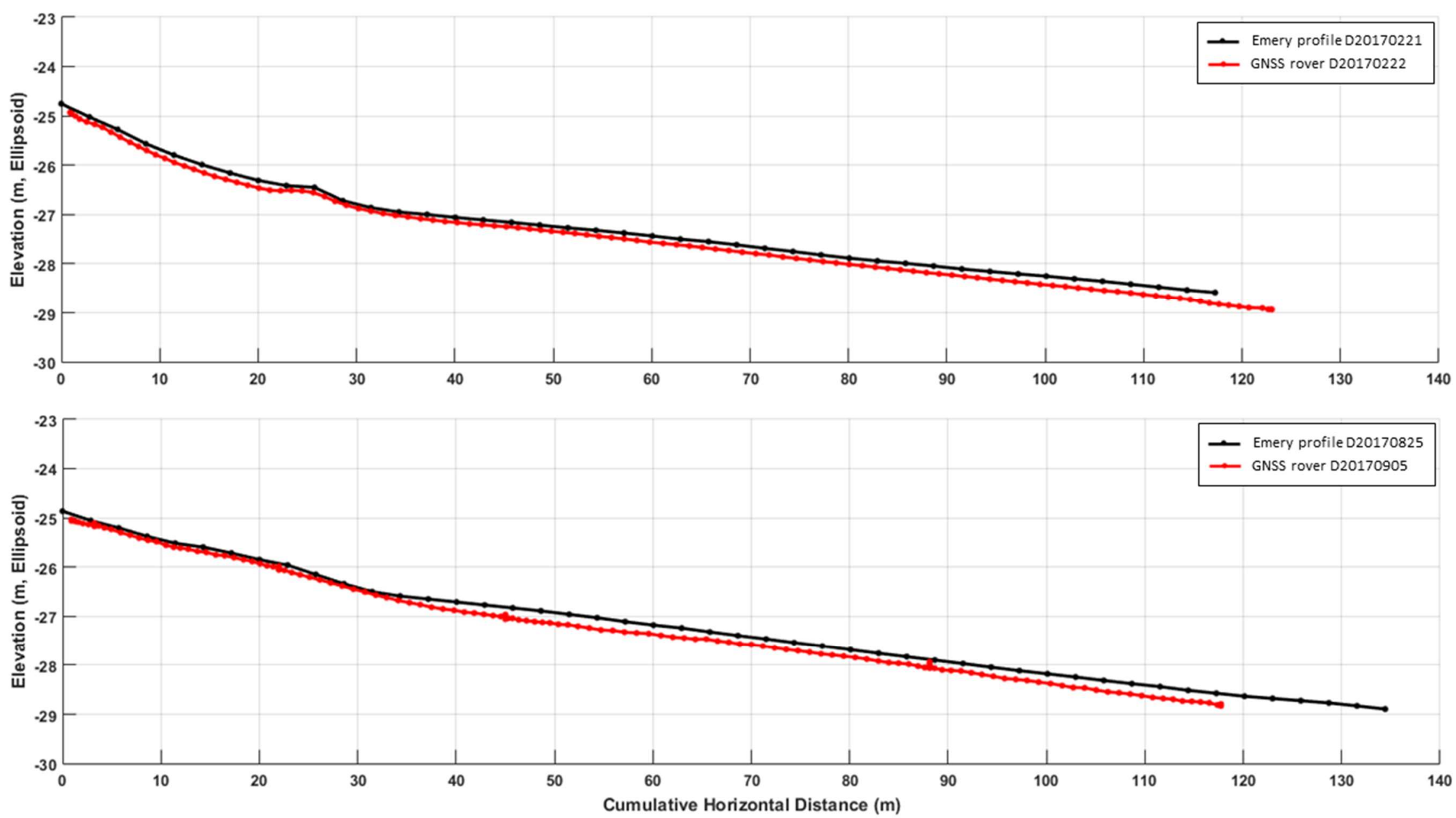

Figure 3-11. Comparison of GNSS rover profiles and Emery profiles for Wallis Sands (WSO1). 
JB02
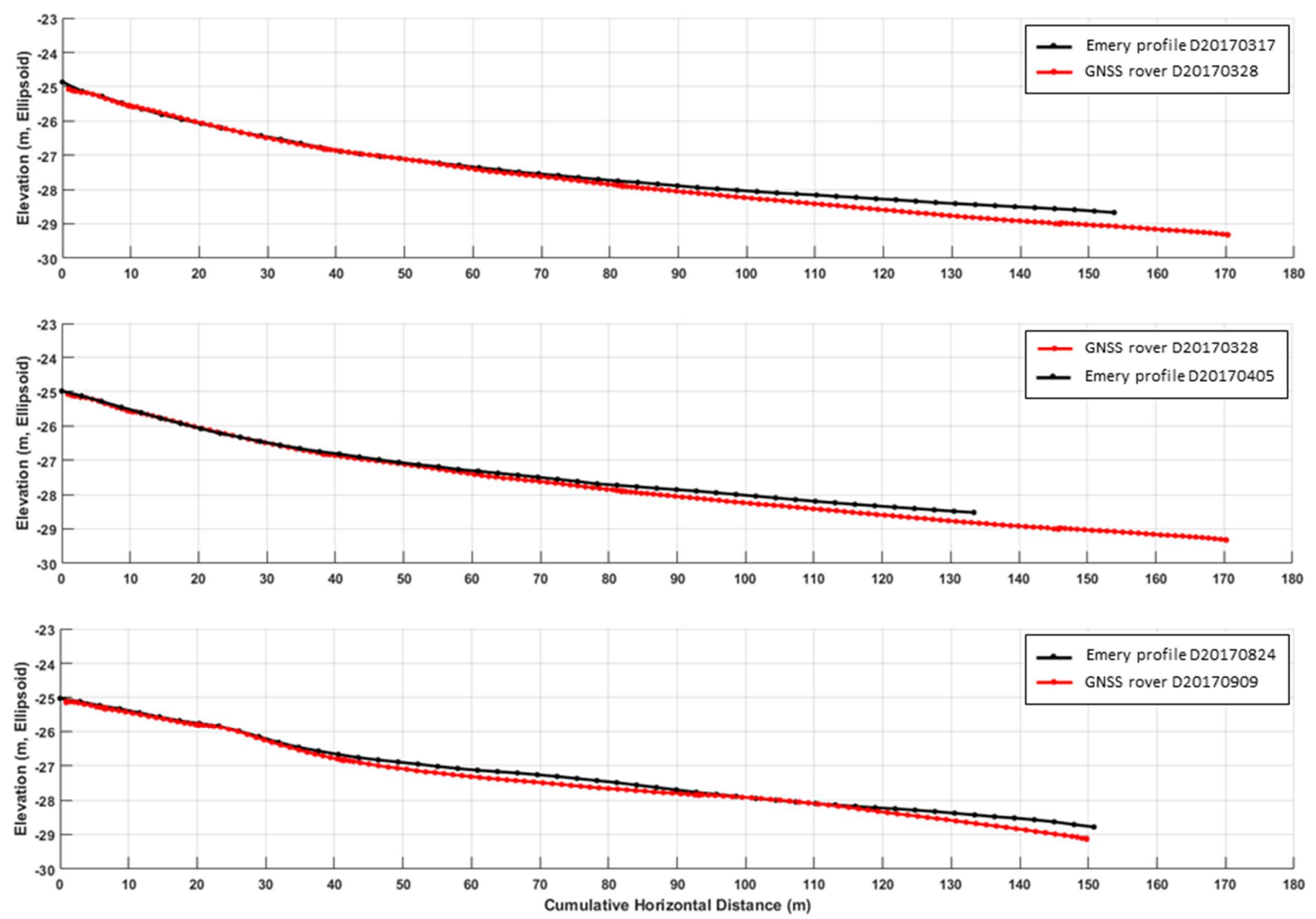

Figure 3-12. Comparison of GNSS rover profiles and Emery profiles for Jenness Beach (JB02). 


\section{HB02}
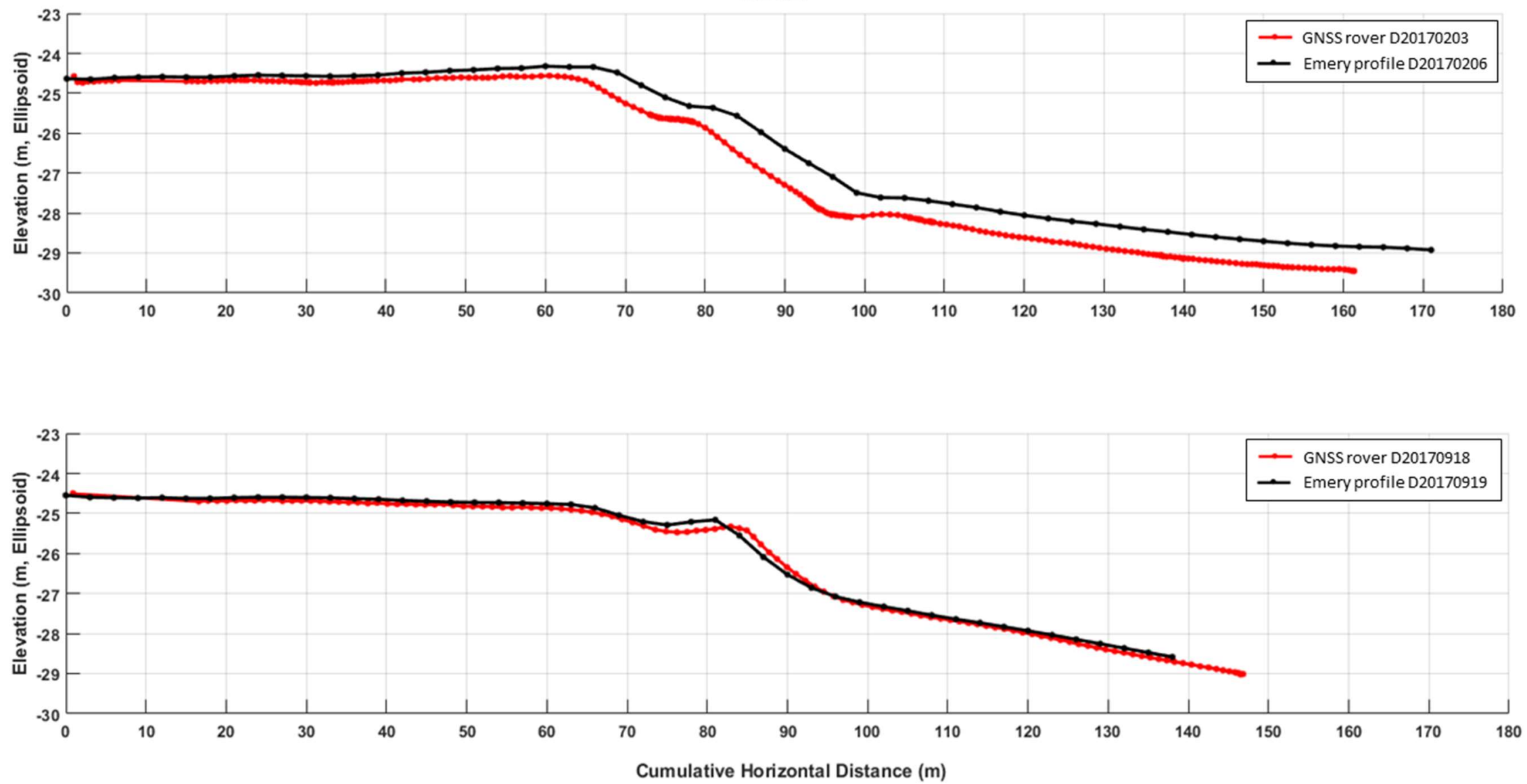

Figure 3-13. Comparison of GNSS rover profiles and Emery profiles for Hampton Beach (HBO2). 


\section{Development of Storm History for the NH Coast}

Wind and wave data from NOAA's National Data and Buoy Center (NOAA NDBC, accessed January 2020) were used to characterize storm events affecting the NH coast from December 2016 to March 2020. Wind data were obtained from the Isles of Shoals station (IOSN3) and wave data from Jeffreys Ledge station (44098). Dates of major storm events were first identified by combining data from NOAA's Storm Events Database (NOAA NCEI, accessed January 2020) with online searches which included local news stories and weather channel precipitation totals. Additionally, plotting of wind and wave data revealed more peaks in the data which were verified as weather events in online searches. The average, maximum, minimum, and direction of waves and wind were calculated for each storm event. The calculations focused on periods during the storms when the waves were the largest and the winds the strongest to look at peak conditions. This was done by using minimum thresholds: generally >8-10 m/s ( 18 to $22 \mathrm{mph}$ ) for wind speed and >1.5-2.0 $\mathrm{m}$ ( 4.9 to $6.6^{\prime}$ ) for wave height. The average and dominant wave periods were also calculated from the wave data.

The major storm events that occurred during the study period and impacted the $\mathrm{NH}$ beaches are summarized in Table 3-3 and more complete storm descriptions are given in Appendix B. 
Table 3-3. Storms that impacted the NH coast during the study period (December 2016 to March 2020). Significant wave height is the average height of the highest one third of all wave heights during a 20-minute sampling period and was reported every half hour. More complete storm descriptions can be found in Appendix $B$.

\begin{tabular}{|c|c|c|c|c|c|}
\hline $2016-17$ & Name & Type & Snow & \begin{tabular}{|l} 
Average \\
Wind Speed
\end{tabular} & \begin{tabular}{|l} 
Average \\
Significant Wave Height
\end{tabular} \\
\hline Dec 28-30 & Fortis & Winter Storm & $<5 \mathrm{~cm}\left(<2^{\prime \prime}\right)$ & $13.8 \mathrm{~m} / \mathrm{s}(30.9 \mathrm{mph})$ & $2.8 \mathrm{~m}(\mathrm{SE}$, then $\mathrm{W})$ \\
\hline Jan 3-5 & & & & $13.4 \mathrm{~m} / \mathrm{s}(30 \mathrm{mph})$ & $4.0 \mathrm{~m}(\mathrm{ESE})$ \\
\hline Jan 7-8 & Helena & Nor'easter & & $11.4 \mathrm{~m} / \mathrm{s}(25.5 \mathrm{mph})$ & $2.8 \mathrm{~m}(\mathrm{E})$ \\
\hline Jan 17-19 & Jupiter & Winter Storm & $13-20 \mathrm{~cm}\left(5-8^{\prime \prime}\right)$ & $10.8 \mathrm{~m} / \mathrm{s}(24.1 \mathrm{mph})$ & \\
\hline Feb 5-7 & Maya & Winter Storm & $15 \mathrm{~cm}\left(6^{\prime \prime}\right)$ & $11.6 \mathrm{~m} / \mathrm{s}(26.0 \mathrm{mph})$ & $1.6 \mathrm{~m}$ (WSW) \\
\hline Feb 7-9 & Niko & Nor'easter & $25-38 \mathrm{~cm}\left(10-15^{\prime \prime}\right)$ & $13.6 \mathrm{~m} / \mathrm{s}(30.4 \mathrm{mph})$ & $3.1 \mathrm{~m}(\mathrm{WSW})$ \\
\hline Feb 9-10 & & & & $14.1 \mathrm{~m} / \mathrm{s}(31.5 \mathrm{mph})$ & $3.4 \mathrm{~m}$ (NE, then WNW) \\
\hline Feb $12-13$ & Orson & Winter Storm & $15-41 \mathrm{~cm}\left(6-16^{\prime \prime}\right)$ & $14.0 \mathrm{~m} / \mathrm{s}(31.4 \mathrm{mph})$ & $3.6 \mathrm{~m}(\mathrm{E})$ \\
\hline Feb 15-16 & Pluto & Winter Storm & & $10.3 \mathrm{~m} / \mathrm{s}(23.0 \mathrm{mph})$ & $2.8 \mathrm{~m}(\mathrm{E})$ \\
\hline Mar 14-15 & Stella & Nor'easter & $30-51 \mathrm{~cm}\left(12-20^{\prime \prime}\right)$ & $19.5 \mathrm{~m} / \mathrm{s}(43.7 \mathrm{mph})$ & $4.6 \mathrm{~m}$ (ESE) \\
\hline Mar 19-21 & & & & $10.1 \mathrm{~m} / \mathrm{s}(22.6 \mathrm{mph})$ & $3.1 \mathrm{~m}$ (ESE) \\
\hline Mar 31-Apr 2 & Theseus & Winter Storm & $15 \mathrm{~cm}\left(6^{\prime \prime}\right)$ & $12.5 \mathrm{~m} / \mathrm{s}(27.9 \mathrm{mph})$ & $3.3 \mathrm{~m}$ (ESE) \\
\hline May 14-15 & & & & $11.7 \mathrm{~m} / \mathrm{s}(26.2 \mathrm{mph})$ & $2.6 \mathrm{~m}(\mathrm{E})$ \\
\hline May 25 & & Coastal Flood & & $12.3 \mathrm{~m} / \mathrm{s}(27.6 \mathrm{mph})$ & $2.2 \mathrm{~m}(\mathrm{E})$ \\
\hline Jun 5-7 & & & & $12.2 \mathrm{~m} / \mathrm{s}(27.3 \mathrm{mph})$ & $2.9 \mathrm{~m}(\mathrm{E})$ \\
\hline Sept 19-22 & Jose & Hurricane & & $11.1 \mathrm{~m} / \mathrm{s}(24.9 \mathrm{mph})$ & $3.6 \mathrm{~m}(\mathrm{E})$ \\
\hline Oct $29-30$ & Philippe & Tropical Storm & & $16.4 \mathrm{~m} / \mathrm{s}(36.6 \mathrm{mph})$ & $3.9 \mathrm{~m}$ (SE) \\
\hline $\operatorname{Dec} 5-6$ & & & & $13.5 \mathrm{~m} / \mathrm{s}(30.2 \mathrm{mph})$ & $2.8 \mathrm{~m}(\mathrm{SE})$ \\
\hline Dec 23-24 & Dylan & Winter Storm & $3-10 \mathrm{~cm}\left(1-4^{\prime \prime}\right)$ & $8.2 \mathrm{~m} / \mathrm{s}(18.4 \mathrm{mph})$ & $1.9 \mathrm{~m}$ (ESE, then WNW) \\
\hline Dec 25-26 & & & & $13.4 \mathrm{~m} / \mathrm{s}(30.0 \mathrm{mph})$ & $2.9 \mathrm{~m}$ (ENE, then WSW) \\
\hline \multicolumn{6}{|l|}{2018} \\
\hline Jan $3-5$ & Grayson & Nor'easter & $25-38 \mathrm{~cm}\left(10-15^{\prime \prime}\right)$ & $16.65 \mathrm{~m} / \mathrm{s}(37.2 \mathrm{mph})$ & $5.0 \mathrm{~m}$ (ENE) \\
\hline Jan $12-16$ & & & & $11.8 \mathrm{~m} / \mathrm{s}(26.4 \mathrm{mph})$ & $2.7 \mathrm{~m}$ (SSE, then $\mathrm{E})$ \\
\hline Jan 17-18 & Inga & Winter Storm & $10-20 \mathrm{~cm}\left(4-8^{\prime \prime}\right)$ & Low winds & \\
\hline $\operatorname{Jan} 29-31$ & & & & $11.7 \mathrm{~m} / \mathrm{s}(26.2 \mathrm{mph})$ & $3.4 \mathrm{~m}(\mathrm{E})$ \\
\hline Feb 7-9 & Liam & Winter Storm & $13-30 \mathrm{~cm}\left(5-12^{\prime \prime}\right)$ & $10.85 \mathrm{~m} / \mathrm{s}(24.3 \mathrm{mph})$ & $1.8 \mathrm{~m}$ (ESE, then NW) \\
\hline Feb $16-18$ & Noah & Winter Storm & $15-23 \mathrm{~cm}\left(6-9^{\prime \prime}\right)$ & $10.8 \mathrm{~m} / \mathrm{s}(24.2 \mathrm{mph})$ & $1.7 \mathrm{~m}$ (variable winds) \\
\hline Mar 1-4 & Riley & Nor'easter & Flooding & $16.24 \mathrm{~m} / \mathrm{s}(36.3 \mathrm{mph})$ & $5.9 \mathrm{~m}(\mathrm{E})$ \\
\hline Mar 6-9 & Quinn & Nor'easter & $25-46 \mathrm{~cm}\left(10-18^{\prime \prime}\right)$ & $14.63 \mathrm{~m} / \mathrm{s}(32.7 \mathrm{mph})$ & $5.1 \mathrm{~m}(\mathrm{E})$ \\
\hline Mar 12-14 & Skylar & Nor'easter & $61 \mathrm{~cm}\left(24^{\prime \prime}\right)$ & $15.59 \mathrm{~m} / \mathrm{s}(34.9 \mathrm{mph})$ & $5.1 \mathrm{~m}(\mathrm{E})$ \\
\hline Mar 21-23 & & & & $12.5 \mathrm{~m} / \mathrm{s}(28 \mathrm{mph})$ & $4.0 \mathrm{~m}(\mathrm{E})$ \\
\hline Apr 15-17 & & & & $13.8 \mathrm{~m} / \mathrm{s}(30.9 \mathrm{mph})$ & $4.0 \mathrm{~m}(\mathrm{E})$ \\
\hline Sept 18 & Florence & Hurricane & & Low winds & \\
\hline Oct 12 & Michael & Hurricane & & Low winds & \\
\hline Oct $27-28$ & & & & $17.2 \mathrm{~m} / \mathrm{s}(38.5 \mathrm{mph})$ & $4.5 \mathrm{~m}$ (ESE) \\
\hline Nov $10-11$ & & & & $13.3 \mathrm{~m} / \mathrm{s}(29.8 \mathrm{mph})$ & $2.9 \mathrm{~m}(\mathrm{E}$, then $\mathrm{W})$ \\
\hline Nov $15-16$ & Avery & Winter Storm & $13-20 \mathrm{~cm}\left(5-8^{\prime \prime}\right)$ & $17.1 \mathrm{~m} / \mathrm{s}(38.3 \mathrm{mph})$ & \\
\hline Nov 20 & & Snow Storm & $8-20 \mathrm{~cm}\left(3-8^{\prime \prime}\right)$ & $10.4 \mathrm{~m} / \mathrm{s}(23.3 \mathrm{mph})$ & \\
\hline Nov 27 & & Coastal Flood & & $15.7 \mathrm{~m} / \mathrm{s}(35.1 \mathrm{mph})$ & $3.8 \mathrm{~m}(\mathrm{E})$ \\
\hline Dec 16-19 & & & & $12.7 \mathrm{~m} / \mathrm{s}(28.4 \mathrm{mph})$ & $2.9 \mathrm{~m}$ (ESE, then NW) \\
\hline Dec 21-23 & & & & $12.5 \mathrm{~m} / \mathrm{s}(28.0 \mathrm{mph})$ & $2.4 \mathrm{~m}$ (SE, then variable) \\
\hline
\end{tabular}


Table 3-3. (continued).

\begin{tabular}{|c|c|c|c|c|c|}
\hline \multicolumn{6}{|l|}{2019} \\
\hline $\operatorname{Jan} 1-2$ & & & & $12.4 \mathrm{~m} / \mathrm{s}(27.7 \mathrm{mph})$ & $2.3 \mathrm{~m}$ (SE, then NW) \\
\hline Jan 19-20 & Harvey & Nor'easter & $20-30 \mathrm{~cm}(8-12 ")$ & $15.1 \mathrm{~m} / \mathrm{s}(33.8 \mathrm{mph})$ & $3.1 \mathrm{~m}(\mathrm{E}$, then NW) \\
\hline Feb $12-13$ & Maya & Nor'easter & $10-20$ cm (4-8") & $9.5 \mathrm{~m} / \mathrm{s}(21.3 \mathrm{mph})$ & $3.2 \mathrm{~m}(\mathrm{E})$ \\
\hline Feb 25 & & High Wind & & $17.0 \mathrm{~m} / \mathrm{s}(38.0 \mathrm{mph})$ & $2.8 \mathrm{~m}$ (ESE) \\
\hline Mar 3-4 & & Snow Storm & $10-20 \mathrm{~cm}\left(4-8^{\prime \prime}\right)$ & $10.1 \mathrm{~m} / \mathrm{s}(22.6 \mathrm{mph})$ & $2.4 \mathrm{~m}(\mathrm{E})$ \\
\hline Apr 3-9 & & & & $12.0 \mathrm{~m} / \mathrm{s}(26.8 \mathrm{mph})$ & $2.2 \mathrm{~m}(\mathrm{E})$ \\
\hline Apr 19-21 & & \multirow{3}{*}{\multicolumn{2}{|c|}{ Hazardous Weather Outlook }} & $12.9 \mathrm{~m} / \mathrm{s}(28.9 \mathrm{mph})$ & $1.9 \mathrm{~m}(\mathrm{SE})$ \\
\hline Apr 26-28 & & & & $10.9 \mathrm{~m} / \mathrm{s}(24.4 \mathrm{mph})$ & $2.2 \mathrm{~m}$ (SSE) \\
\hline May $13-15$ & & & & $9.9 \mathrm{~m} / \mathrm{s}$ (22.1 mph) & $2.5 \mathrm{~m}(\mathrm{SW})$ \\
\hline Aug 26 & & \multicolumn{2}{|l|}{ Rip current risk } & Low winds & \\
\hline Sept 6-7 & Dorian & \multicolumn{2}{|l|}{ Hurricane } & $12.5 \mathrm{~m} / \mathrm{s}(28.0 \mathrm{mph})$ & $2.7 \mathrm{~m}(\mathrm{E})$ \\
\hline Sept 20 & Humberto & \multicolumn{2}{|l|}{ Hurricane } & Low winds & $1.9 \mathrm{~m}$ (ESE) \\
\hline Oct $11-13$ & Melissa & \multicolumn{2}{|l|}{ Suptropical Storm } & $13.6 \mathrm{~m} / \mathrm{s}(30.4 \mathrm{mph})$ & $4.0 \mathrm{~m}$ (ESE) \\
\hline Oct $16-17$ & & \multicolumn{2}{|l|}{ Nor'easter } & $15.6 \mathrm{~m} / \mathrm{s}(34.9 \mathrm{mph})$ & $3.5 \mathrm{~m}(\mathrm{SE})$ \\
\hline Nov 18-19 & & & & $13.3 \mathrm{~m} / \mathrm{s}(29.8 \mathrm{mph})$ & $3.8 \mathrm{~m}$ (ESE) \\
\hline Nov $24-25$ & & & & $15.2 \mathrm{~m} / \mathrm{s}(34.0 \mathrm{mph})$ & $2.9 \mathrm{~m}$ (ESE, then WNW) \\
\hline Nov $28-29$ & & & & $12.8 \mathrm{~m} / \mathrm{s}(28.6 \mathrm{mph})$ & $3.3 \mathrm{~m}(\mathrm{NE})$ \\
\hline Dec 2-4 & Ezekiel & Winter Storm & $30-41 \mathrm{~cm}\left(12-16^{\prime \prime}\right)$ & $15.4 \mathrm{~m} / \mathrm{s}(34.4 \mathrm{mph})$ & $5.0 \mathrm{~m}(\mathrm{E})$ \\
\hline Dec 14 & & Flooding & & $12.4 \mathrm{~m} / \mathrm{s}(27.7 \mathrm{mph})$ & $3.0 \mathrm{~m}$ (SE, then variable) \\
\hline Dec 30-31 & Gage & Winter Storm & $10-20 \mathrm{~cm}\left(4-8^{\prime \prime}\right)$ & $13.6 \mathrm{~m} / \mathrm{s}(30.4 \mathrm{mph})$ & $3.6 \mathrm{~m}(\mathrm{E})$ \\
\hline \multicolumn{6}{|l|}{2020} \\
\hline Jan $16-18$ & Jacob & Winter Storm & $10-20 \mathrm{~cm}\left(4-8^{\prime \prime}\right)$ & $12.3 \mathrm{~m} / \mathrm{s}(27.5 \mathrm{mph})$ & $2.6 \mathrm{~m}$ (variable) \\
\hline $\operatorname{Jan} 25$ & Mabel & Winter Storm & & $14.3 \mathrm{~m} / \mathrm{s}(32.0 \mathrm{mph})$ & $2.8 \mathrm{~m}$ (ESE) \\
\hline Feb 6-7 & & Winter Storm & $5-15 \mathrm{~cm}\left(2-6^{\prime \prime}\right)$ & $12.2 \mathrm{~m} / \mathrm{s}(27.3 \mathrm{mph})$ & $2.4 \mathrm{~m}$ (ESE, then W) \\
\hline Feb 27-28 & & Winter Storm & $5-10 \mathrm{~cm}\left(2-4^{\prime \prime}\right)$ & $15.4 \mathrm{~m} / \mathrm{s}(34.4 \mathrm{mph})$ & $3.0 \mathrm{~m}(\mathrm{E}$, then WSW) \\
\hline March 6-7 & & Nor'easter & & $14.1 \mathrm{~m} / \mathrm{s}(31.5 \mathrm{mph})$ & $3.8 \mathrm{~m}(\mathrm{E})$ \\
\hline Mar 23-24 & Quincy & Winter Storm & $10-15 \mathrm{~cm}\left(4-6^{\prime \prime}\right)$ & $12.0 \mathrm{~m} / \mathrm{s}(26.8 \mathrm{mph})$ & $2.8 \mathrm{~m}$ (ESE) \\
\hline Apr 3 & & Coastal Flood & & $12.9 \mathrm{~m} / \mathrm{s}(28.9 \mathrm{mph})$ & $4.3 \mathrm{~m}(\mathrm{E})$ \\
\hline Apr 9-10 & & Winter Storm & & $11.8 \mathrm{~m} / \mathrm{s}(26.4 \mathrm{mph})$ & $2.1 \mathrm{~m}$ (SE, then W) \\
\hline Apr 13 & & High wind & & $15.2 \mathrm{~m} / \mathrm{s}(34.0 \mathrm{mph})$ & $2.8 \mathrm{~m}$ (SSE) \\
\hline
\end{tabular}




\section{Chapter 4: Results}

The results for the Volunteer Beach Profile Monitoring Program (VBPMP) for the period from December 2016 (for stations WS01, JB02 and HB02) or around January 2018 (for stations WS02.5, JB01, NHB01, NHB02, NB01, NB02, HB04, SB02, SB04, and SB05) to March 2020 are summarized in this chapter. For the most part, every profile station was measured at three- to four-week intervals over the entire study period on a routine basis. In addition, many stations were monitored at much shorter intervals centered on major storms (e.g., late winter and spring 2018). The exceptions to this schedule were at $\mathrm{HBO} 4$ and NB02. Any variances to the above schedule are explained within the results for those stations.

Included in the Results are the beach elevation profiles and volumetric calculations for each station. Also included are the general characteristics of the beach, identification of local engineering structures that affect the beach (e.g., seawalls), and a description of any unique features that would affect the beach conditions. Review of the profile data includes the general profile characteristics during the monitoring period and storm effects, beach erosion, and recovery. There is a great deal of repetition within this chapter, but the goal is to have the results for each beach be able to stand alone and be complete.

A major observation apparent from examination of the elevation profiles and calculations for volumetric changes for the beaches is that there is considerable variability between profile measurements at a station over time, and there is also considerable variability between different stations during the same profiling period. Therefore, trends in beach erosion or accretion, as well as losses or gains in elevation, are not based on profile-to-profile variability. Rather, trends are based on the overall changes over several months when beach elevation and sediment volume gains or losses become clearer and are not the result of a single event.

\section{Chapter Format}

The results from monitoring the elevation profiles and volumetric changes at each beach studied are presented in this chapter in the following format. A brief overview of the general physical characteristics of the overall beach system is given. Subsequently, each profile station is described in detail including an "Overview" and "Summary" for that station only, which is presented at the beginning of the discussion of that beach, followed by the "General Profile Characteristics" and "Storm Effects, Beach Erosion, and Recovery". The narratives for all the sections are broken into smaller segments to better align with the figures. The beach elevation profiles use the following format for dates: "DXXXXXXXX" or "'Date'YearMonthDay". For example, D20210401 stands for April $1,2021$. 


\section{Introduction to Wallis Sands, Rye, New Hampshire}

Wallis Sands is a small barrier spit $\sim 1.3 \mathrm{~km}$ long located between two rocky headlands (Seal Rocks and Pulpit Rock to the north and Concord Point to the south; Figures WS-1 and WS-2). The barrier is 200 to $250 \mathrm{~m}$ in width from the edge of the back-barrier marsh (Parson's Creek salt marsh) to the lower intertidal zone. Wallis Sands is separated from Concord Point by a small (20-25 m width) tidal inlet (Parson's Creek) that facilitates the tidal exchange with the back-barrier marsh. Parson's Creek is extremely shallow as it crosses the intertidal beach. Wallis Sands includes both a town beach owned by Rye, $\mathrm{NH}$ and a State Beach.

Wallis Sands State Beach, which forms the northern $200 \mathrm{~m}$ of the barrier (Figure WS-1), was originally the site of a Life-Saving Station of the United States Life-Saving Service $\left(19^{\text {th }}\right.$ and early $20^{\text {th }}$ century). Subsequently, the station became part of the US Coast Guard which was abandoned in 1938. In 1962, the US Army Corps of Engineers (UASCE) recommended widening the beach to $\sim 45 \mathrm{~m}$ $\left(150^{\prime}\right)$ along $244 \mathrm{~m}\left(800^{\prime}\right)$ of shoreline and constructing an impermeable groin. As a result of the USACE recommendations, the beach was widened to $\sim 46 \mathrm{~m}$ (150') and a $107 \mathrm{~m}$ (350') groin was constructed in 1963. The State Beach was established in 1964."

All of Wallis Sands including the State Beach and the town beach has some sort of engineering structure including vertical seawalls, riprap, and in a few locations a combination of hard structures and dune grasses (Figure WS-1 and WS-2). The beach is composed of primarily sand but may have concentrations of pebbles after high energy events (Figure WS-3). The southern end of Wallis Sands town beach near Parson's Creek does not have a beach profile monitoring station. However, visual evidence suggests there is significant beach erosion occurring as well as damage to the seawalls (Figures WS-4). 


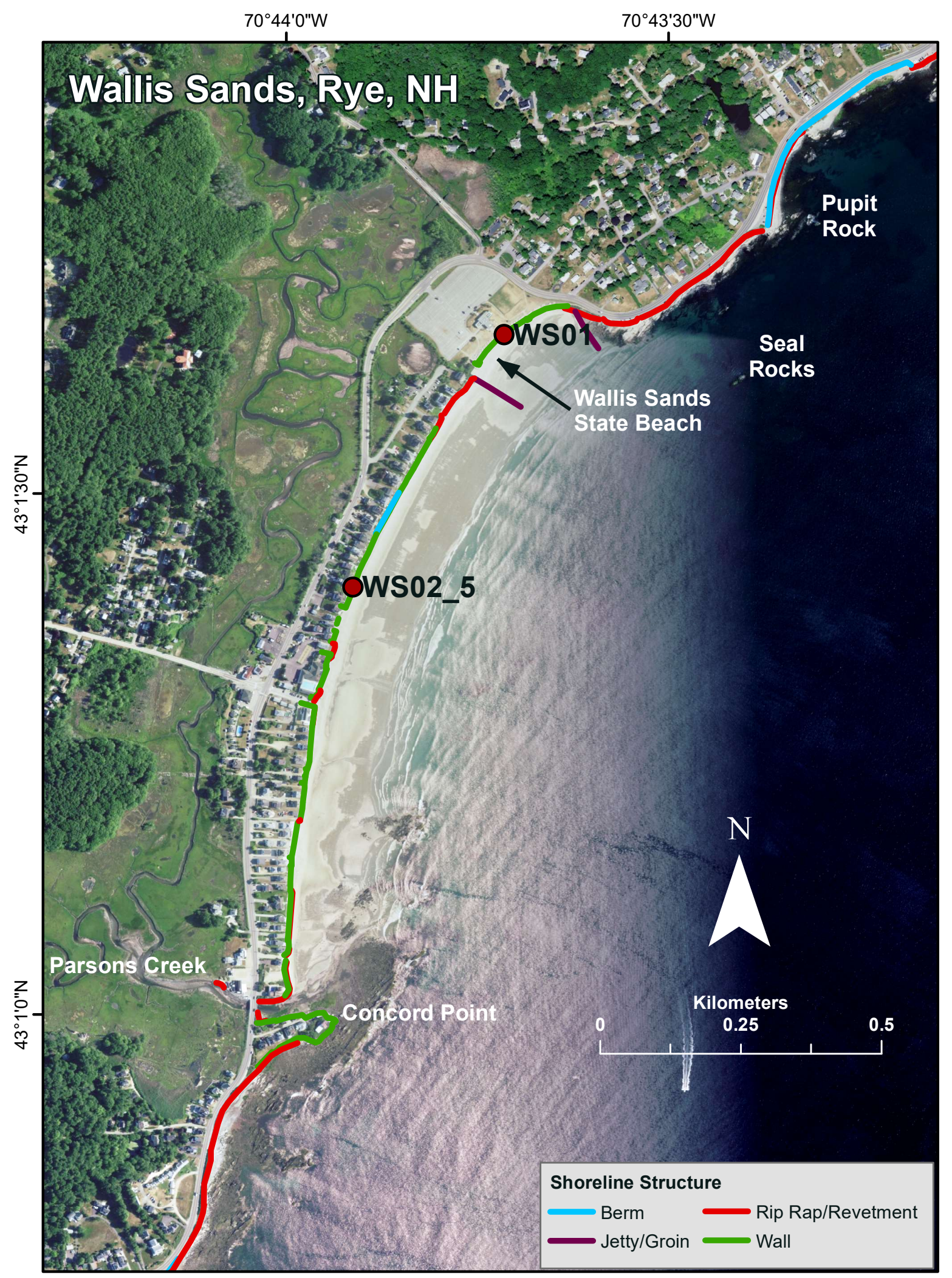

Figure WS-1: Location map of Wallis Sands with beach profile stations and shoreline structures (Blondin, 2016). 


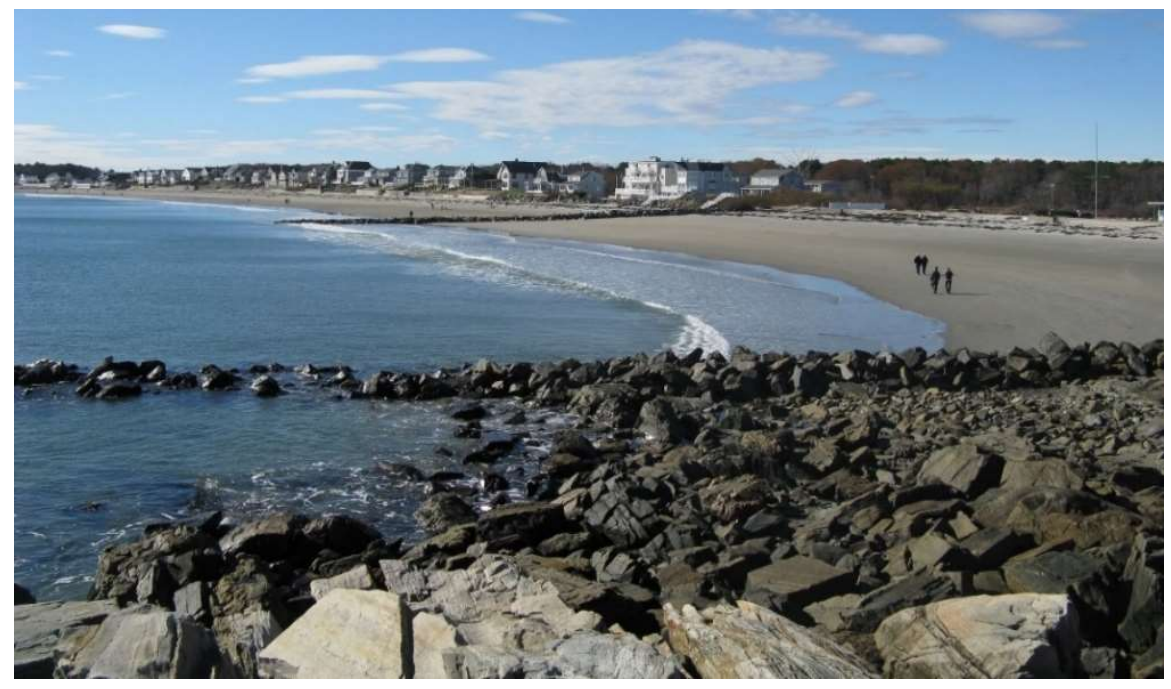

Figure WS-2. Wallis Sands beach looking south from Seal Rocks on November 11, 2012.

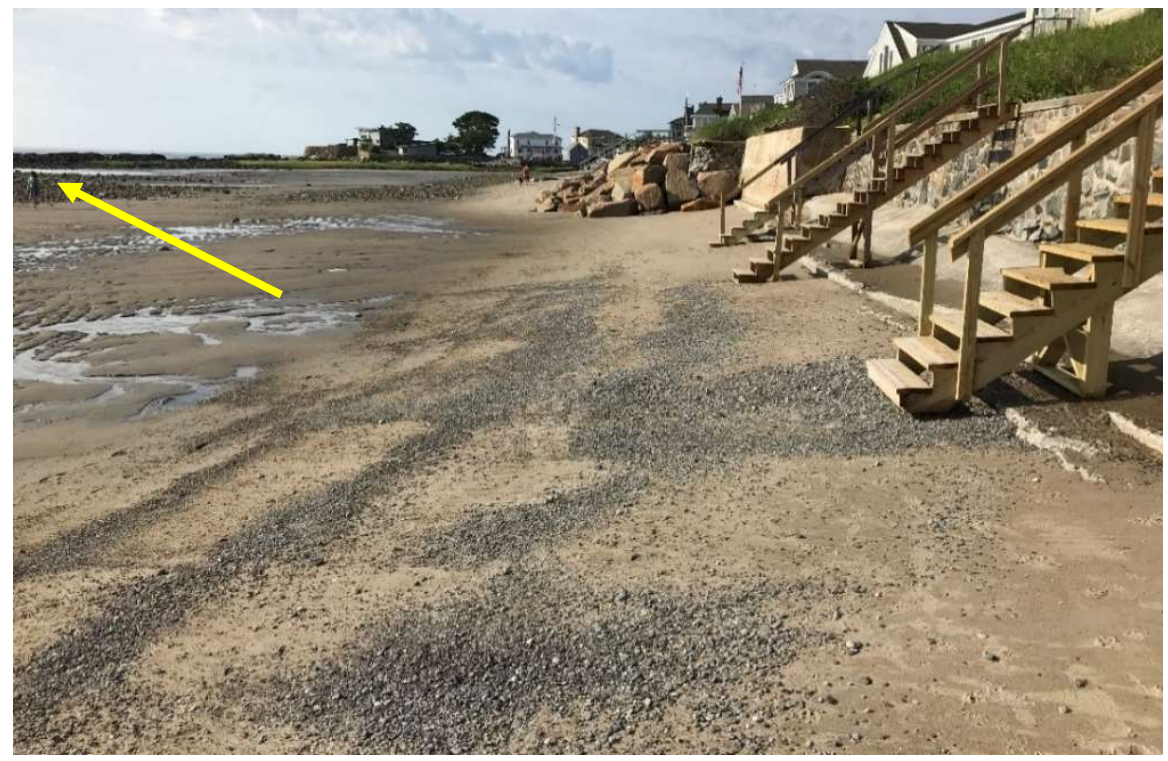

Figure WS-3. The southern end of Wallis Sands beach on August 1,2019 . Note the low elevation of the beach, the concentration of pebbles on the surface of the sand, and the exposed megaclast platform in the upper left side of the photograph (arrow).

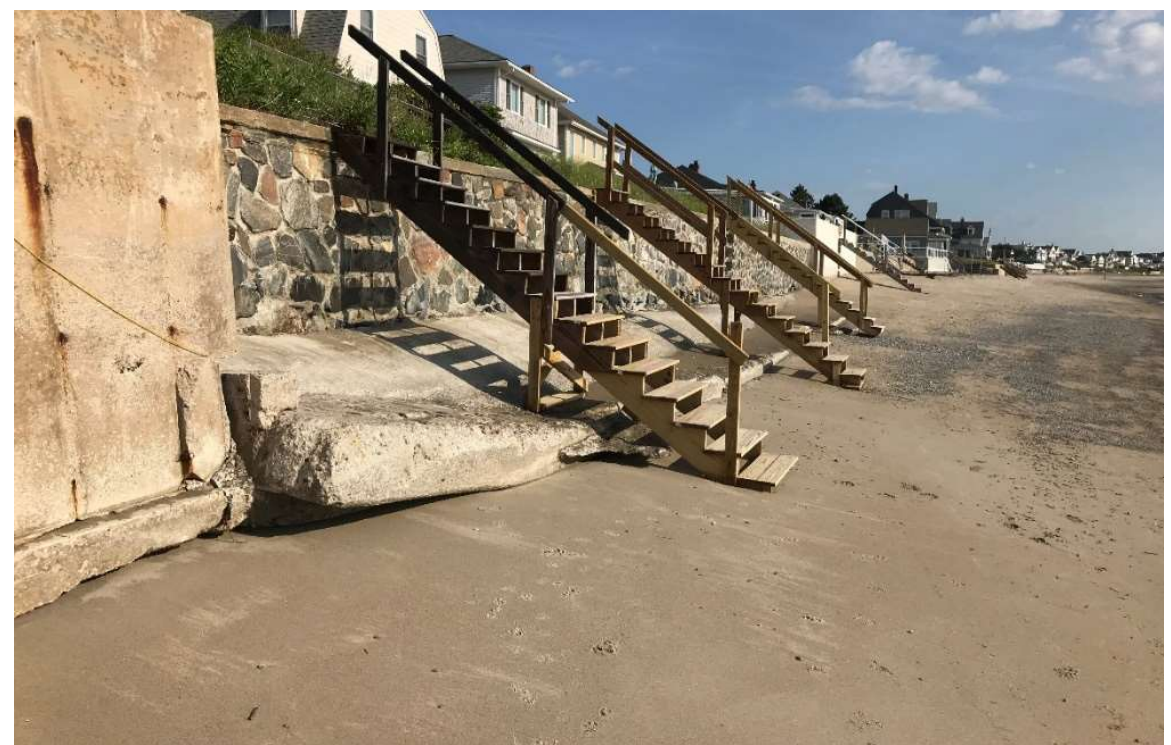

Figure WS-4. A seawall at the southern end of Wallis Sands beach on August 1, 2019. Note the base of the seawall is exposed and undermined indicating significant erosion. 


\section{Results for Wallis Sands State Beach: WS01}

Overview. Wallis Sands State Beach is located at the northern end of Wallis Sands and extends 200 $\mathrm{m}$ from a rock groin at the base of the bedrock headland (Seal Rocks and Pulpit Rock) southward to another large stone groin that is $2-3 \mathrm{~m}$ in height and extends across the entire width of the beach (Figures WS-1 and WS-2). A vertical concrete seawall separates the intertidal beach from a bathhouse and parking lot that was built where the dunes were once located. The seawall has stopped landward migration of the beach, but at the expense of a source of sand for the beach. The profile station is located near the center of the State Beach and extends from the seawall to the low tide swash (water line) (Figure WS01-1). The beach is typically composed of sand with a few scattered pebbles.

Summary. Based on the observations to date, an erosion and accretion cycle occurred in winterspring 2017 from February 6 to May 1. The beach continued to undergo accretion during summer and fall 2017 reaching the maximum average elevation and sand volume measured during the study period. However, the largest erosion cycle and impact to Wallis Sands State Beach was in late winter 2018 from March 7 to June 18 due to the impact of the severe nor'easters including Riley (Mar 1-4), Quinn (Mar 6-9), and Skylar (Mar 12-14). The impact of these storms was so severe because of the storms' intensities, but also because the beach had already been eroded and was at a lower elevation, making it more susceptible to erosion. Recovery during summer 2018 was weak but continued into the fall and early winter 2019. However, and somewhat surprisingly, another erosional cycle occurred in late winter-spring 2019 from March 20 to June 9. Only minimal recovery has occurred as of March 2020.

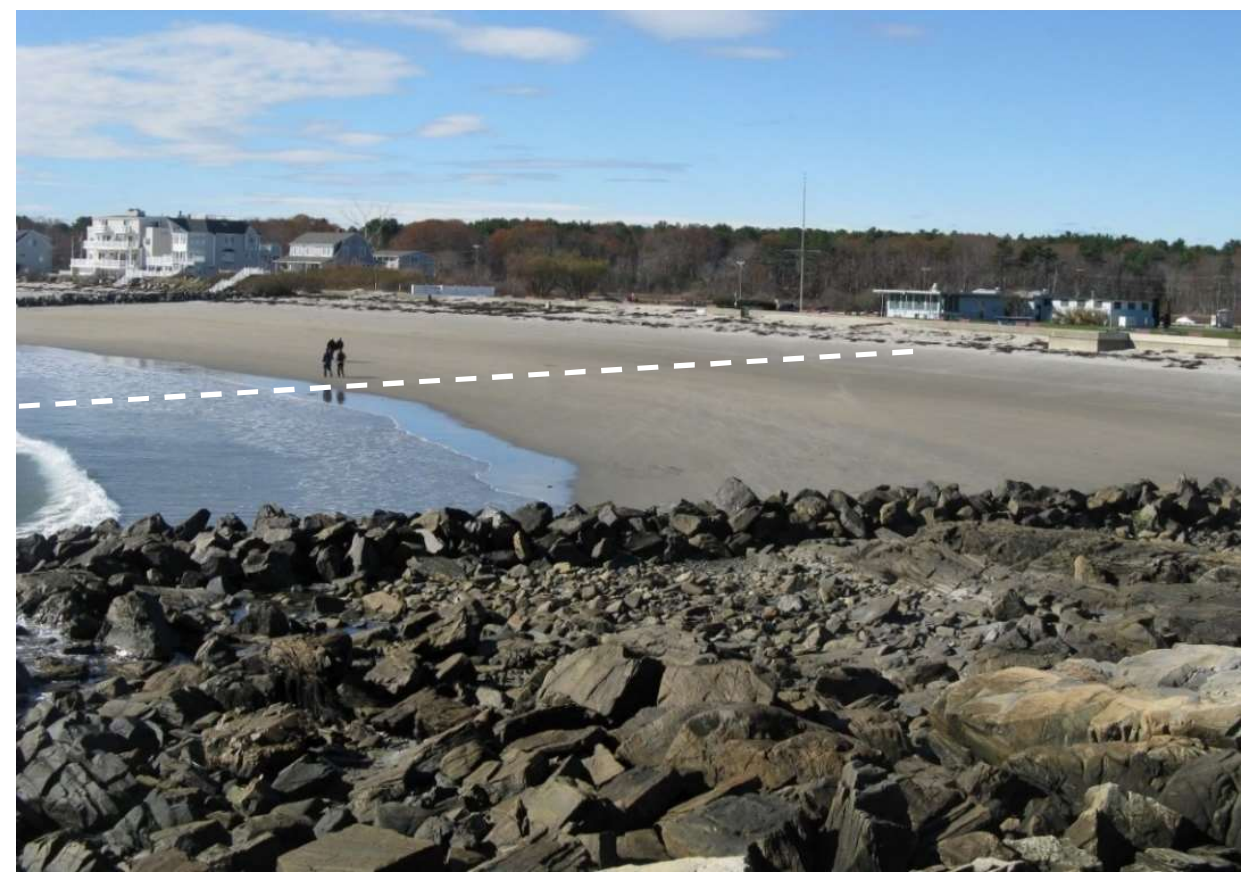

Figure WS01-1. Location of Beach Profile WS01 on Wallis Sands State Beach. Photograph taken on November 4, 2012. 
General Profile Characteristics. The elevation profile at WS01 was measured forty-nine times from December 9, 2016 to March 12, 2020. All plotted beach profiles can be found in Appendix C(1). The beach elevation profiles which extend from the seawall to the low tide swash typically were between $130 \mathrm{~m}$ to $160 \mathrm{~m}$ in length, with the shorter profiles occurring after storm events when the beach was eroded. Examination of the sweep zone (envelope all beach elevation profiles plotted together; see Appendix A: Glossary) shows the elevation of the beach varied $\sim 1.7 \mathrm{~m}$ in the upper beach (backshore) due to erosion of a berm (likely human-made, discussed below), but closer to one meter over the rest of the beach (Figure WS01-2). Comparison of the maximum average elevation profile (which occurred on November 16, 2017) with the minimum average elevation profile (which occurred on June 18, 2018) shows an average loss of $\sim 0.7 \mathrm{~m}$ ranging from $\sim 0.4 \mathrm{~m}$ at the seawall to $\sim 0.9 \mathrm{~m}$ at the low water line (Figure WS01-3). Maximum and minimum average elevations are also defined in Appendix A.

Considering the overall elevation of the beach is relatively low, the loss of a meter of elevation is important and results in much of the beach being inundated by the ocean during maximum spring high tides or storm surges. In general, the beach changed significantly in response to accretionary conditions (beach elevation and sand volume increased; Appendix A), erosional conditions (beach elevation and sand volume decreased; Appendix A), and human-induced changes (e.g., grading, seaweed removal, construction of a wide and flat berm on the upper beach). 


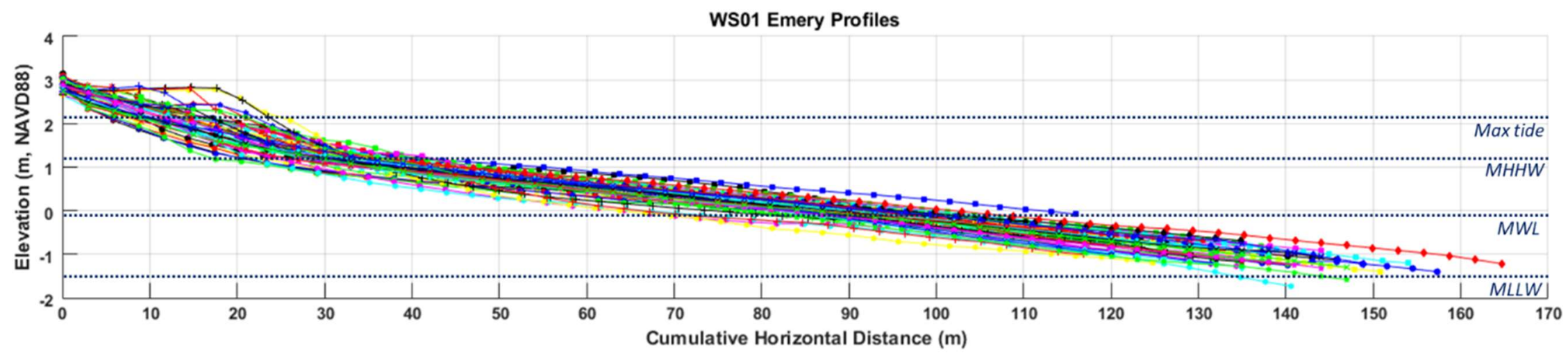

Figure WS01-2. All forty-nine beach elevation profiles measured at WS01 over the entire study period from December 9, 2016 to March $12,2020$. Examination of all the profiles together shows the maximum and minimum elevations of the beach. Maximum tidal elevation (max tide), mean higher high water elevation (MHHW), mean water level (MWL), and mean lower low water elevation (MLLW) are indicated by the dotted lines.

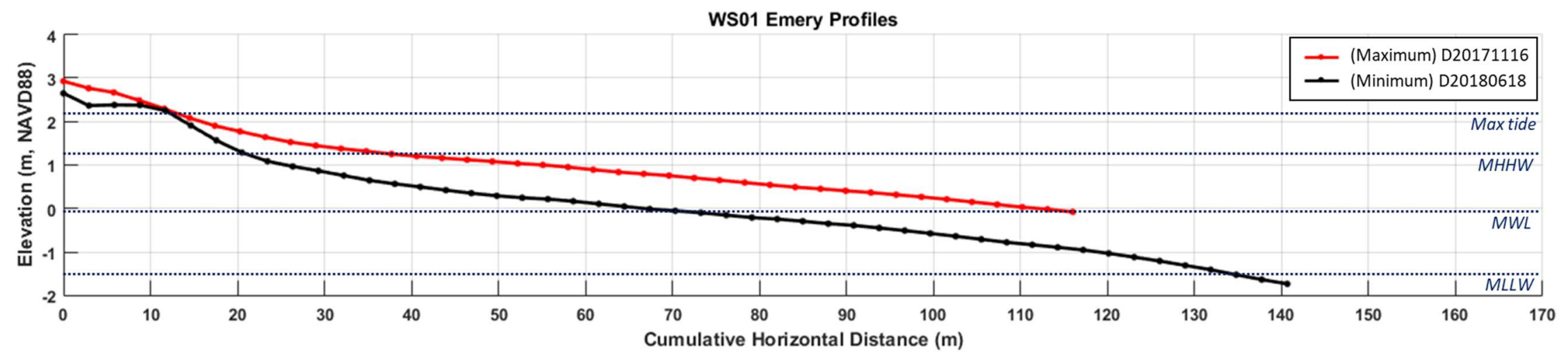

Figure WS01-3. Maximum (November 16, 2017) and minimum (June 18, 2018) beach elevation profiles determined from volume calculations and mean elevation over the entire study period at station WSO1. Note that this is not the impact of a single event as the profiles are not consecutive monitoring dates. Rather this comparison looks at the extreme of differences of beach elevation profiles over the entire study period. 
Storm Effects, Beach Erosion, and Recovery. Based on the beach elevation profiles and sand volume calculations, the beach accreted (increase in sand volume and beach elevation) during fair weather conditions and underwent significant erosion (loss of sand volume and elevation) as a result of major storms (Figures WS01-4). For example, the beach elevation and volume were relatively constant and the beach stable between December 9, 2016 and February 6, 2017 (Figure WS01-5). However, significant losses in beach sand volume and elevation occurred between the profiles measured on February 6 and 21, 2017 due to Winter Storms Maya (Feb 5-7), Niko (Feb 7-9) and Orson (Feb 12-13) (Table 3-3). The erosional effect of each storm was more intense as the beach had little chance to recover between storms.

After a short accretional period, the beach at WS01 was again significantly eroded by Stella (a blizzard with over a foot of snow and high winds from March 14-15) and Winter Storm Theseus (Mar 31-Apr 2) (Figure WS01-4; Table 3-3). Following these storms, the beach accreted and then changed little during spring and summer 2017. In fall, the beach built upward reaching the maximum sand volume measured at WS01 during the study period on November 16, 2017. However, continuous beach erosion occurred from January 3, 2018 to February 27, 2018 due to Winter Storms Grayson (Jan 3-5), Inga (Jan 17-18), Liam (Feb 7-9), and Noah (Feb 16-18) (Figure WS01-5).

Due to these early 2018 winter storms and resultant erosion, Wallis Sands State Beach was already at an overall lower elevation when the next series of severe nor'easters occurred in late winter 2018 including Riley (Mar 1-4), Quinn (Mar 6-9), and Skylar (Mar 12-14). Therefore, the impact of these nor'easters on top of an already eroded beach was extremely damaging (Figure WS01-4). The most significant erosion and coastal damage was caused by Riley with a significant loss of elevation and sand volume from the beach between February 27 and March 7, 2018 (Figures WS01-4 and WS01-6), and the effects were visible (Figure WS01-7). The beach continued to erode with Quinn and Skylar finally reaching the lowest elevation and sand volume measured during the study period on June 18 , 2018 (Figure WS01-8). 

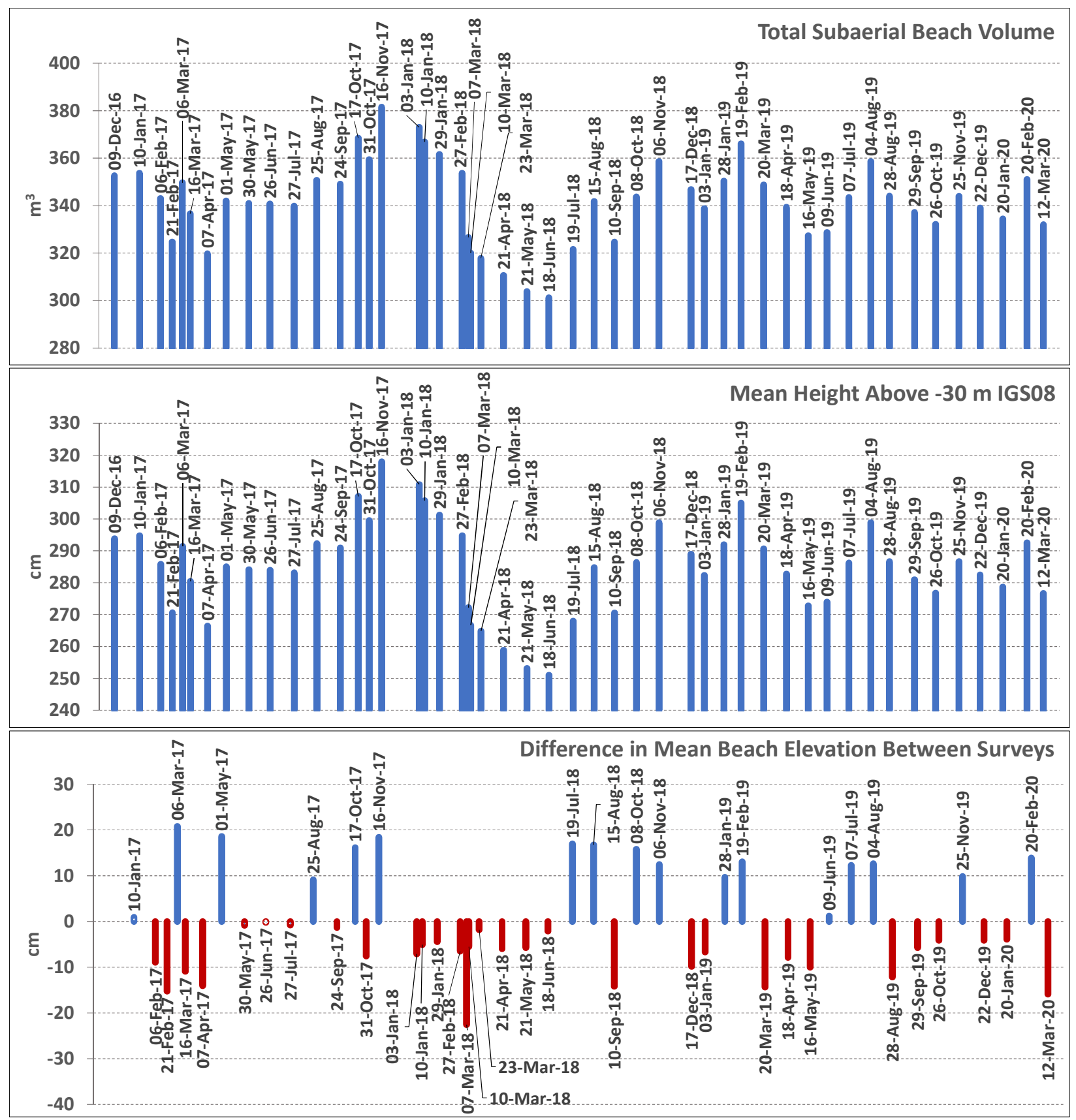

Figure WS01-4. Calculated sediment volume, mean profile elevation, and mean elevation change for station WS01. These parameters were calculated from 0-120 meters of the profile length. Seven of the forty-nine beach elevation profiles were shorter than the "standard profile length" for the station. The profiles were extended using the procedure described in Chapter 2: Methods. All but one extension was less than $10 \mathrm{~m}$ which is considered negligible (four were less than $5 \mathrm{~m}$ ). The longest extension $(31.8 \mathrm{~m}$ on December 17, 2018) was measured during a neap tide on a flat beach. 


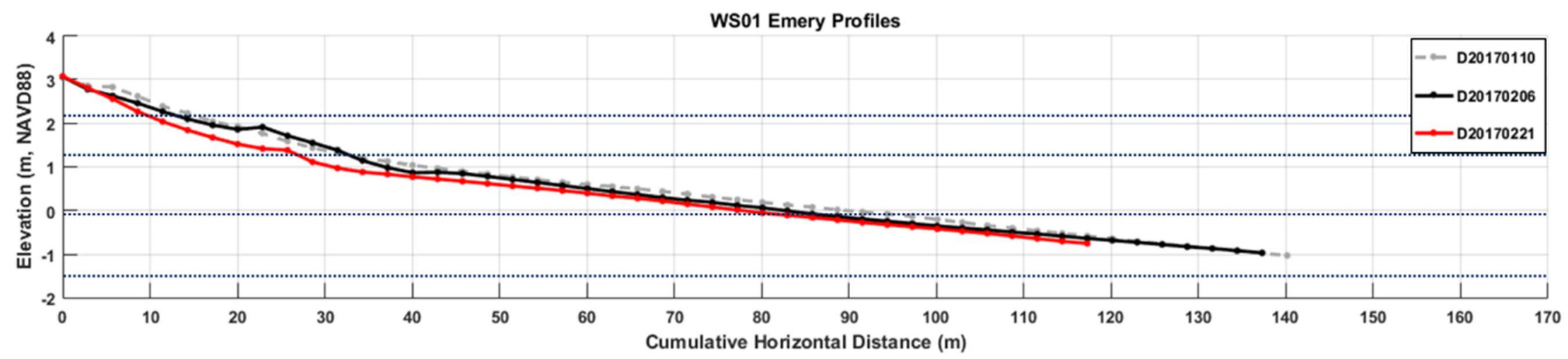

Figure WS01-5. Beach elevation profiles for WS01 on January 10, 2017, February 6, 2017, and February 21, 2017.

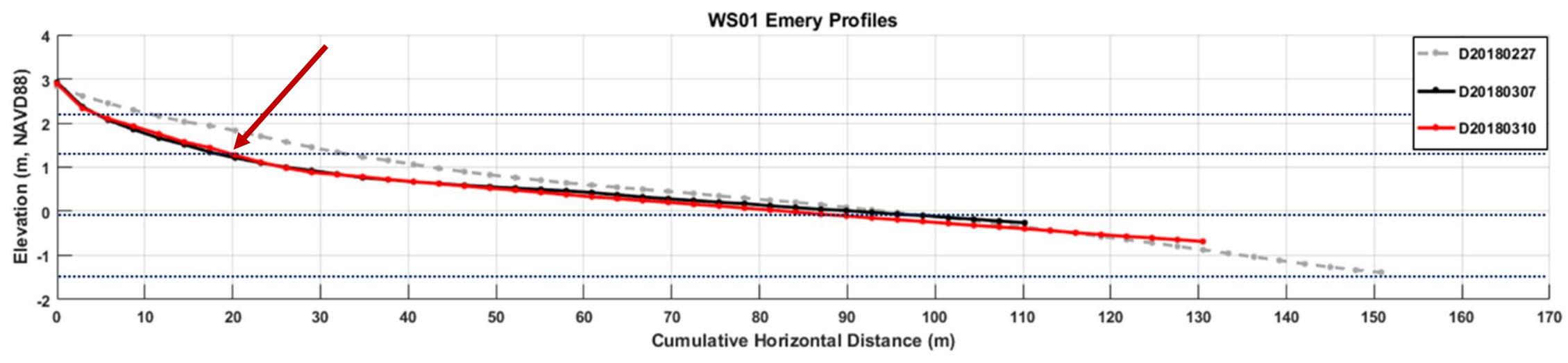

Figure WS01-6. Beach elevation profiles for WS01 on February 27, 2018, March 7, 2018, and March 10, 2018. Note the erosion that occurred following the nor'easters in March 2018 (arrow). 

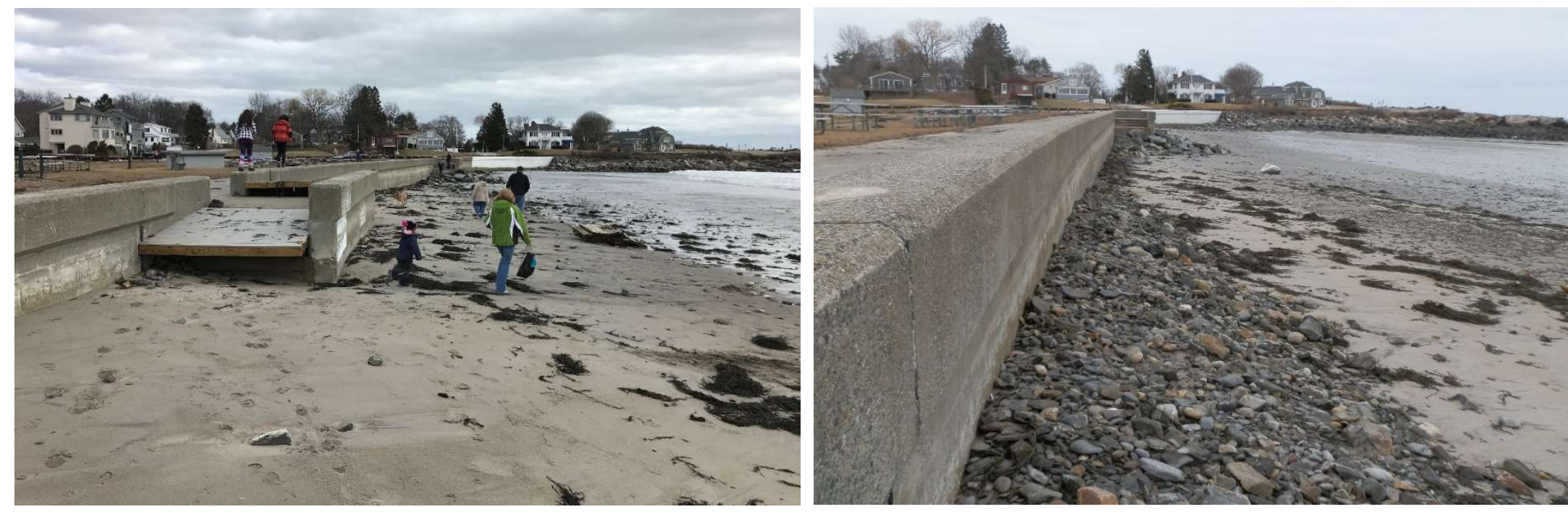

Figure WS01-7. Wallis Sands State Beach shortly after Nor'easter Riley. The left photograph was taken on March 4, 2018 and shows the beach by the seawall starting just south of the elevation profile station. Note the wooden walkways have been washed up onto the stairwell and the lower beach severely eroded. The right photograph was taken on March 7, 2018. The intensity of the storm waves removed the sand and concentrated gravel against the seawall.

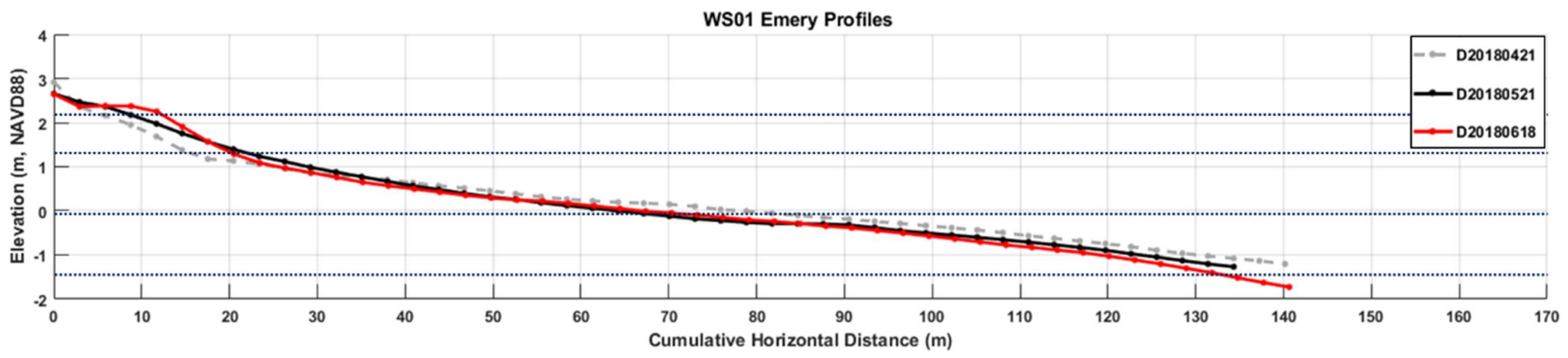

Figure WS01-8. Beach elevation profiles for WS01 on April 21, 2018, May 21, 2018, and June 18, 2018. 
The beach at WS01 did not start recovering until the next month in July 2018 (Figures WS01-4 and WS01-9). However, part of the recovery of the upper beach was likely due to anthropogenic alteration of the beach (discussed below). During summer and fall 2018 (July 19 to November 6 profiles: Figures WS01-9, WS01-10, and WS01-11) the beach accreted but did not reach the same overall volumes and elevations as during fall 2017 before the series of severe nor'easters occurred in late winter 2018.

During early winter 2019, erosion and accretion predictably occurred with relatively minor winter storms (Figures WS01-11 and WS01-12), but the beach recovered with a maximum volume for 2019 on February 19 (Figure WS01-4). However, an extended period of erosion occurred from February 19 to the beginning of spring reaching a minimum on May 16. This is puzzling as no major storms occurred (Table 3-3). Following the May 16 profile, a period of accretion occurred that extended through August 2019 (Figure WS01-4). The volume calculations and elevation averages indicate another period of overall erosion has initiated since that time, however. Small peaks of increasing volume were seen in both November 2019 and February 2020, but the subsequent months always decreased in volume again, producing a seesaw pattern (Figure WS01-4).

Human-made Changes to WS01 Beach Profile. Between June 18 and July 19, 2018, the WS01 beach profile elevation was dramatically increased on the backshore between the seawall and berm along with an increase in the volume of sand (Figures WSO1-4 and WS01-9). This was done by NH Division of Parks and Recreation to enhance the upper beach for storm protection to the landward facilities and to increase recreational value (Figures WS01-13 and WS01-14). The additional sand was redistributed by natural processes (wave action) over the next three months, despite the lack of any storm activity, to restore the beach to the fair-weather equilibrium profile seen on November 6 . 


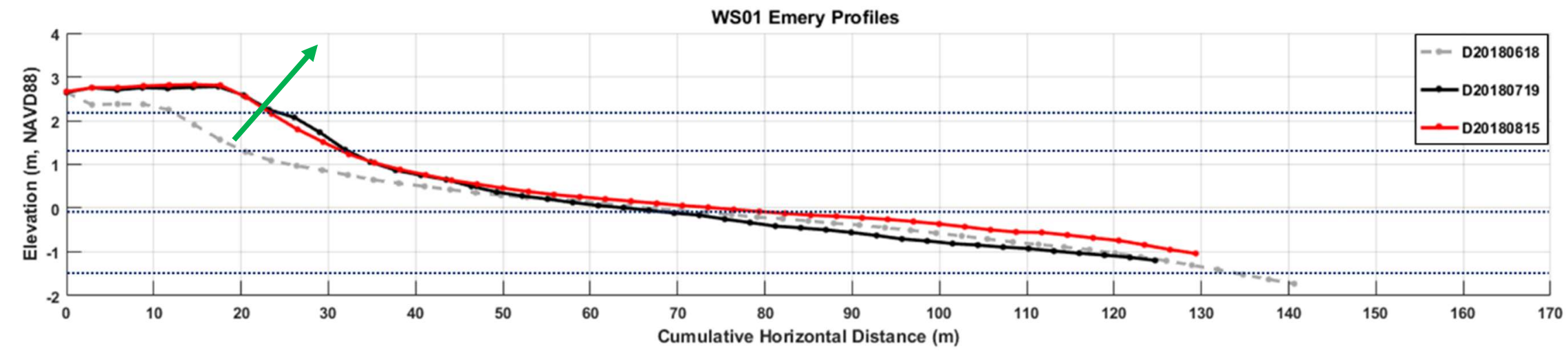

Figure WS01-9. Beach elevation profiles for WS01 on June 18, 2018, July 19, 2018, and August 15, 2018. Note the large increase in the upper beach (arrow), which was likely due to the NH Division of Parks and Recreation placing sand on the beach for storm protection.

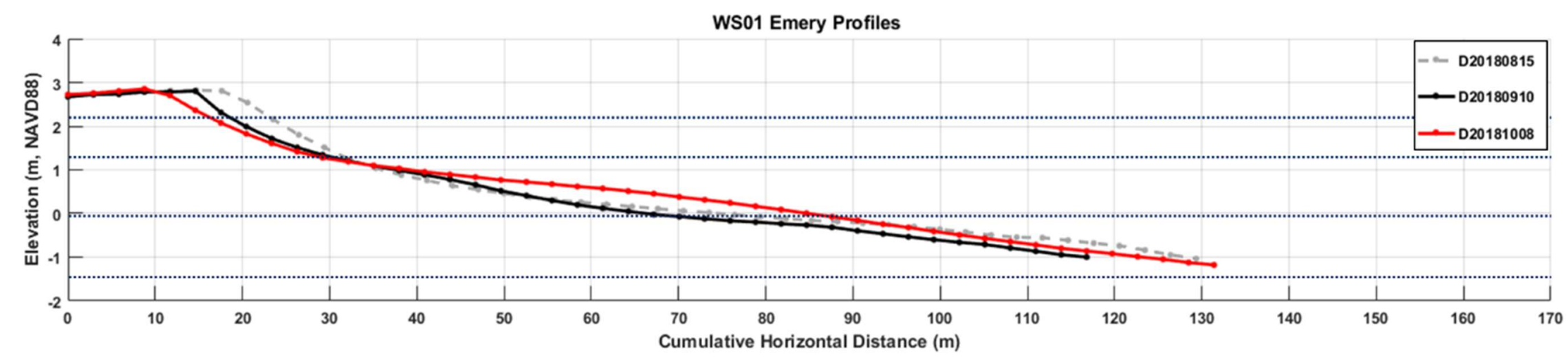

Figure WS01-10: Beach elevation profiles for WSO1 on August 15, 2018, September 10, 2018, and October 8, 2018. 


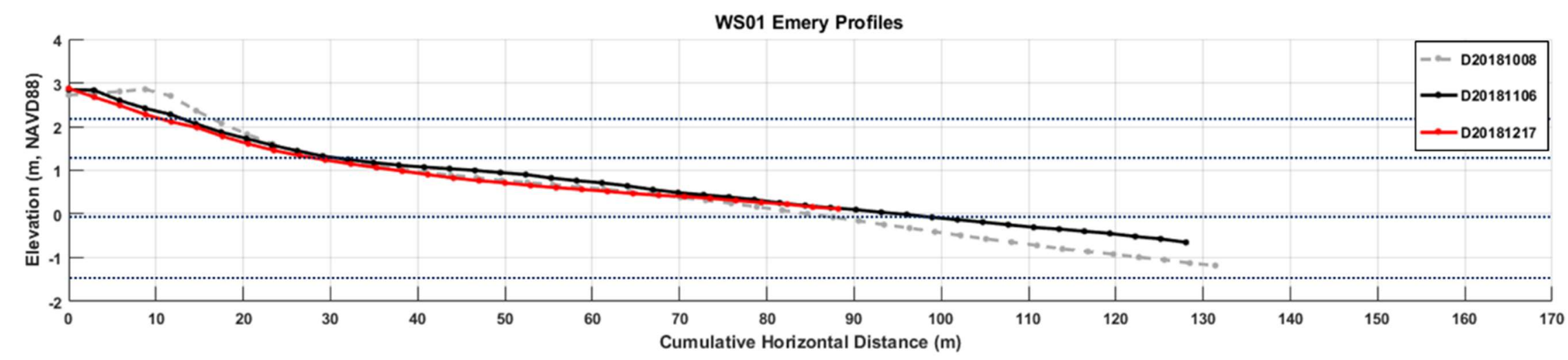

Figure WS01-11: Beach elevation profiles for WS01 on October 8, 2018, November 6, 2018, and December 17, 2018.

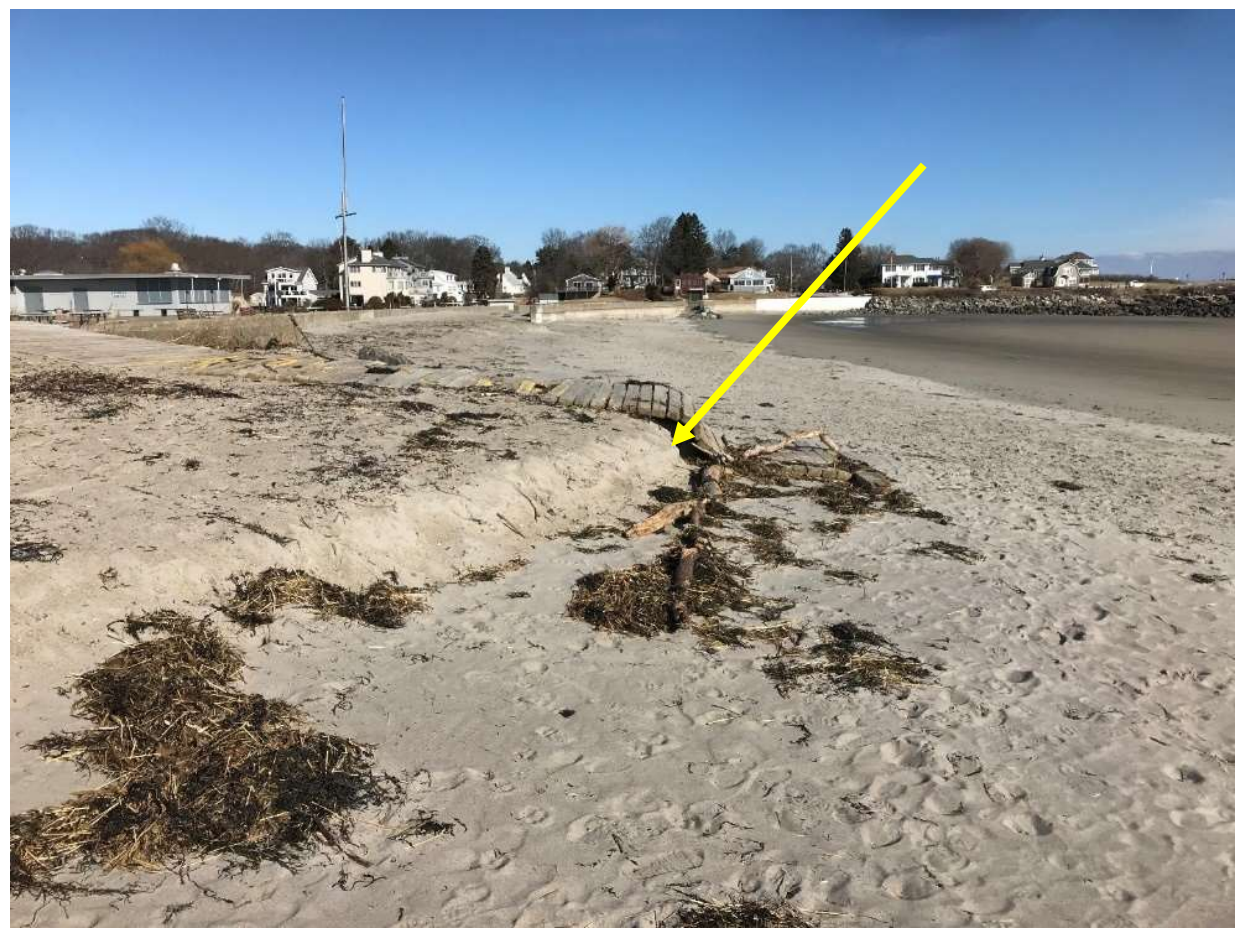

Figure WS01-12. Beach erosion at Wallis Sands State Beach on January 28, 2019 after a winter storm. Note large scarp cut into the beach (arrow). 


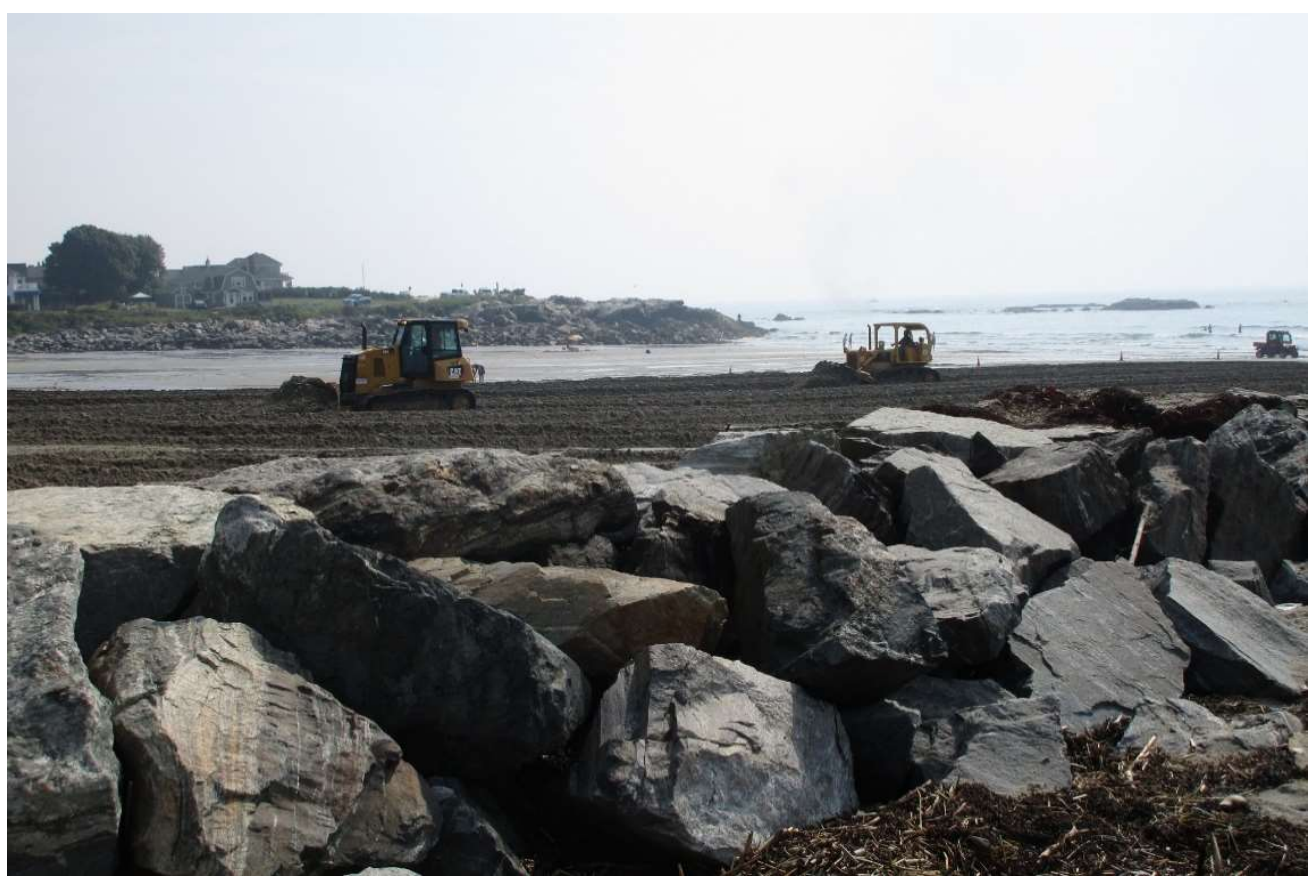

Figure WS01-13. Grading Wallis Sands State Beach on July 17, 2018. Note the associated beach profiles shown in Figure WS01-10 which illustrate the construction of a large berm. It appears that sediment was moved from the lower beach to enhance the size of the berm.

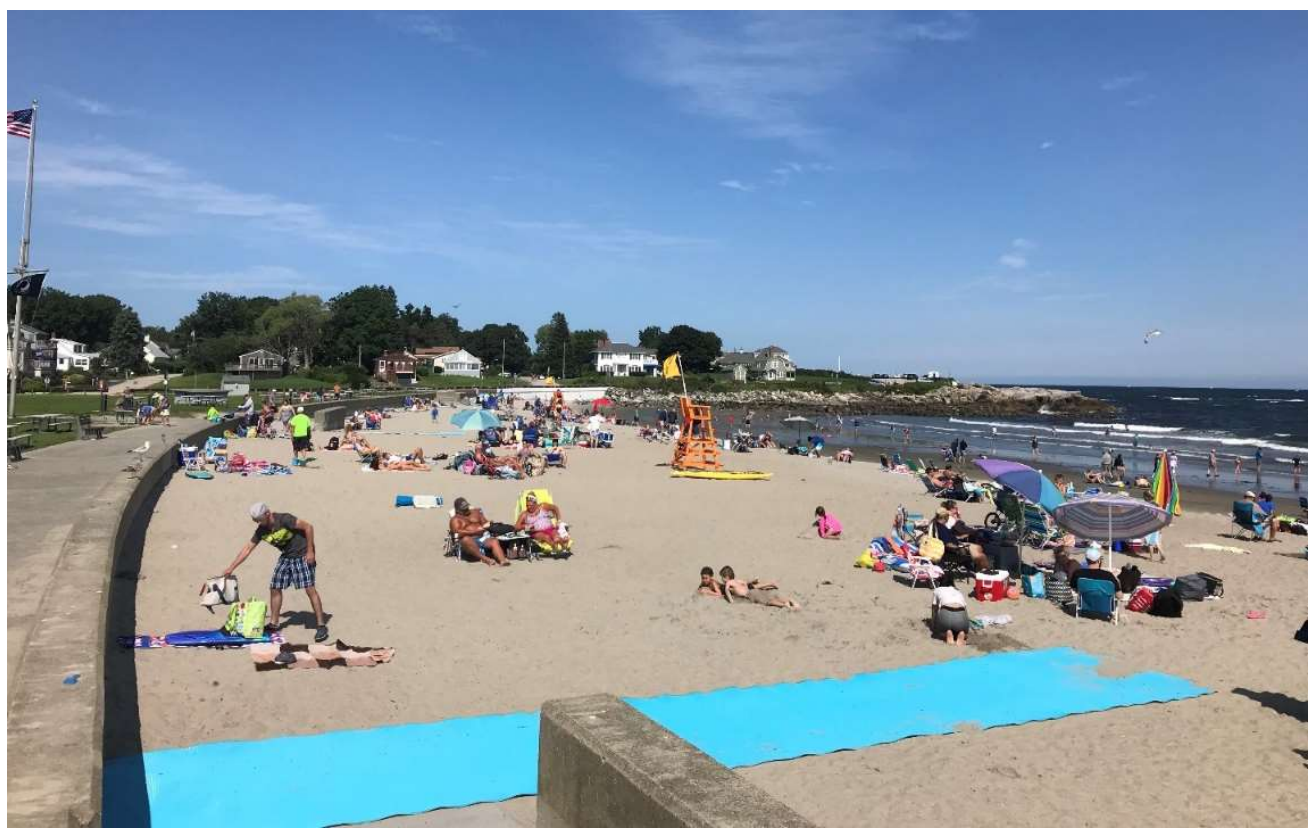

Figure WS01-14. Wallis Sands State Beach on August 19, 2018 with a large, wide berm. 


\section{Results for Station at Mid Wallis Sands: WS02.5}

Overview. Profile station WSO2.5 is located very near the center of Wallis Sands (south of the State Beach) where the effects of the headlands at either end of the beach are at a minimum (Figure WS1). Residential homes are located directly behind the beach on elevated parcels of land where the sand dunes were previously located (Figure WS02-1). Station WS02.5 is located directly in front of one of the residential homes at the base of a vegetated slope that extends from the house down to a low concrete seawall ( 0.5 to $1.25 \mathrm{~m}$ above the sand depending on beach conditions) (Figure WSO22). The profile extends from the base of the seawall 110 to $130 \mathrm{~m}$ seaward (depending on beach conditions) to the low tide swash zone. The beach is largely composed of medium to coarse sand but is frequently covered with scattered pebbles following storms. The pebble population is part of the beach sediment and remains behind as surface lag deposits when the finer sediment is eroded.

At the beginning of the study the seawall at WS02.5 was fronted by a sand mound vegetated with dune grass that extended $\sim 6 \mathrm{~m}$ seaward (Figure WS02-3). However, the sand mound and vegetation were removed during the late winter nor'easters in 2018 that included Riley (March 1 - 4), Quinn (March 6 -9), and Skylar (March 12 - 14) (Figure WS02-4). The dune vegetation was replanted in spring 2019 but has not rebuilt to previous levels (Figure WS02-5). The higher sand elevation stabilized by the dune vegetation prior to the major 2018 storms afforded protection to the seawall, likely minimizing wave damage and the impact of the storms on the seawall. Protection of seawalls with dune grasses is a valuable and environmentally sound strategy.

Summary. WS02.5 had two periods of erosion. The first was a major erosional period starting in late winter 2018 and continuing until June 2018, followed by a period of accretion until winter 2019. A second, less intensive period of erosion occurred in late fall 2018 to early winter 2019 (November 7, 2018 to February 19, 2019). Spring and summer 2019 were variable but with major accretion occurring in late summer and early fall. The maximum sand volume and accretion conditions for WS02.5 occurred on September 30, 2019. It should be noted that during the period of accretion in 2019 at WS02.5, Wallis Sands State Beach (WS01) lost volume. Visual evidence also suggests the southern end of Wallis Sands appears to be losing sand volume. It is not unreasonable to consider that sand lost from Wallis Sands State Beach (WS01) contributed to the accretion at WSO2.5 following Riley, Quinn, and Skylar. Alternatively, it is not unreasonable to suggest that the source of sand was from the southern end of Wallis Sands which is considerably narrower than the middle and northern reaches. These hypotheses warrant testing via wave refraction studies and other field observations or modeling. 


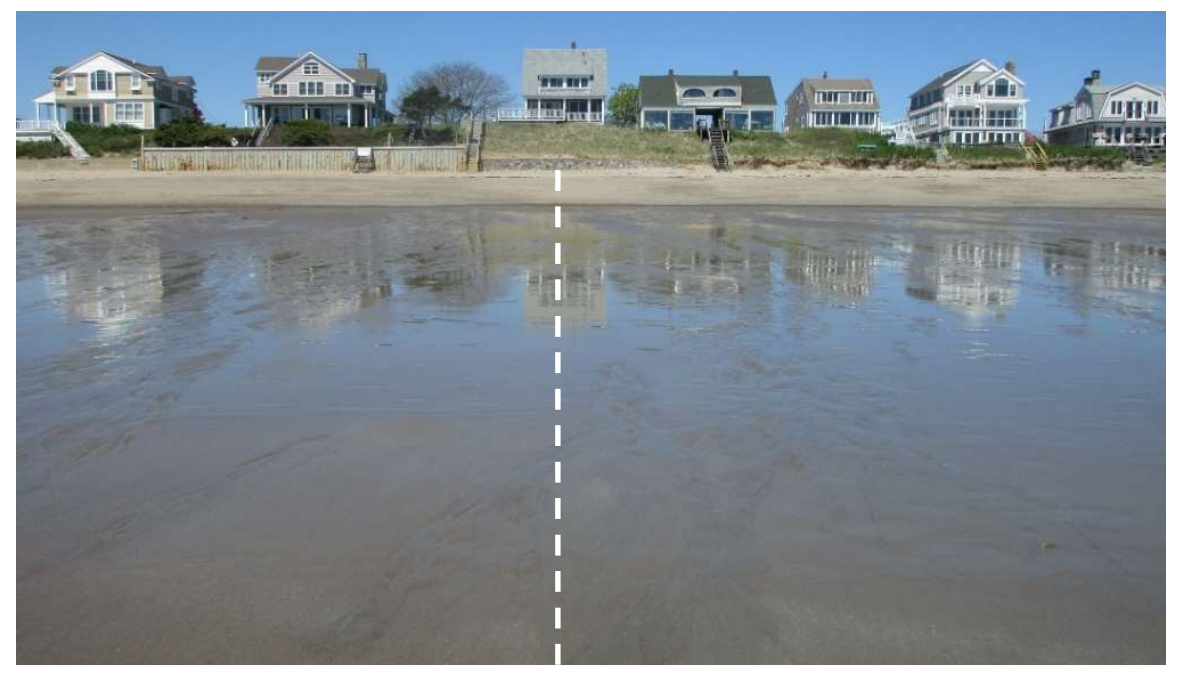

Figure WSO2-1.

Location of station

WS02.5, with the

profile transect shown by the white dashed line in the photograph taken on May 21, 2018. Note many of the homes are elevated and almost all have a seawall.

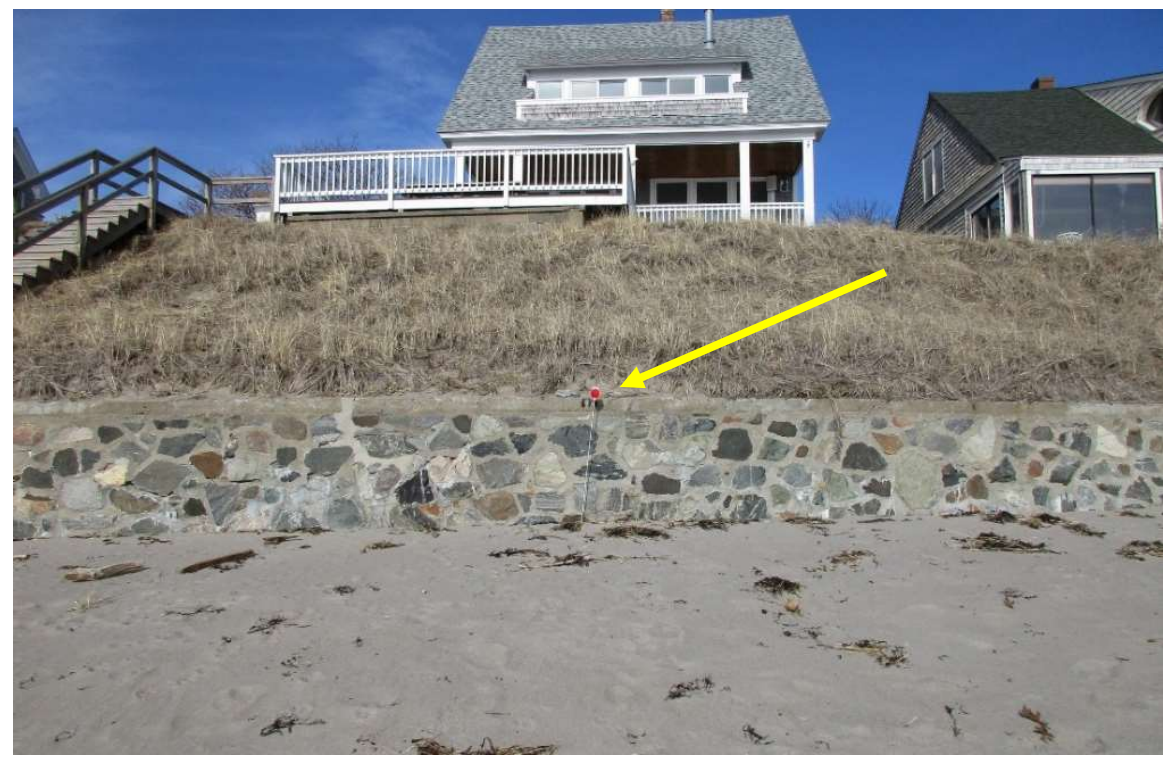

Figure WSO2-2.

Station marker and seawall at the landward end of the beach elevation transect at WS02.5. The station marker is directly behind the red reflector (arrow) in the photograph taken on July 17, 2018. Note the dune grasses planted on the slope.

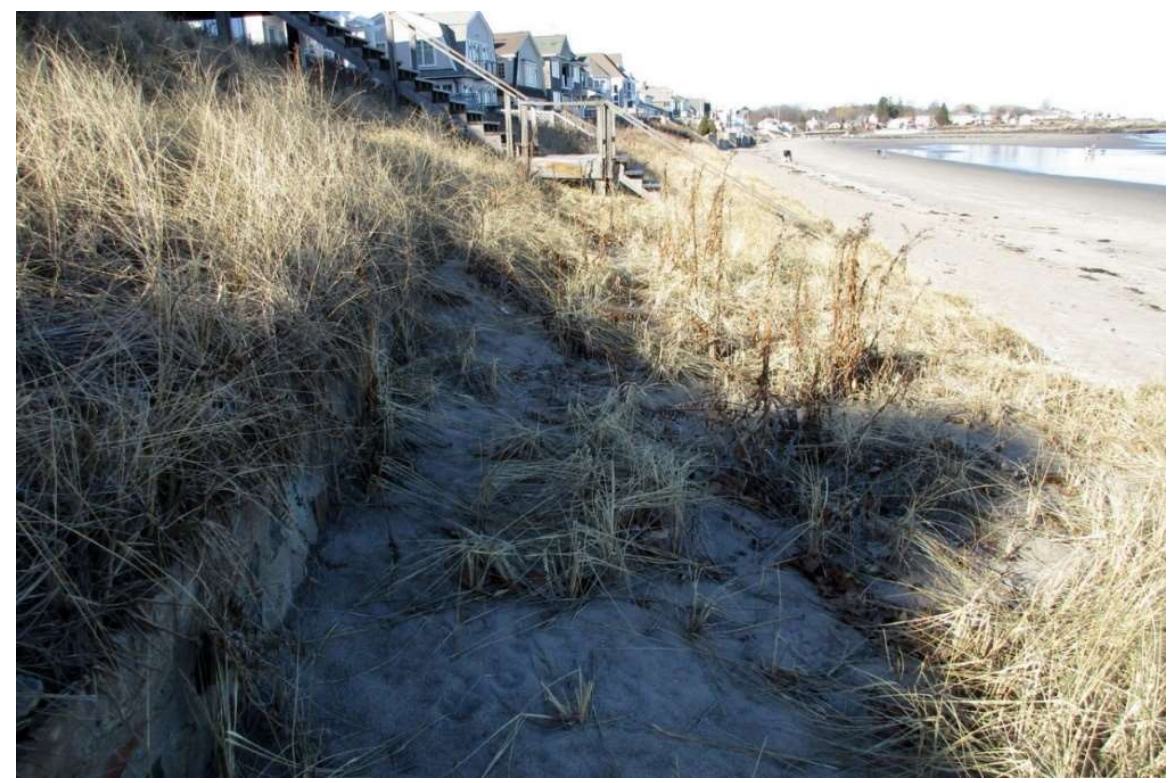

Figure WSO2-3.

Dune grasses established in front of the seawall at station WS02.5 on February 27, 2018. 


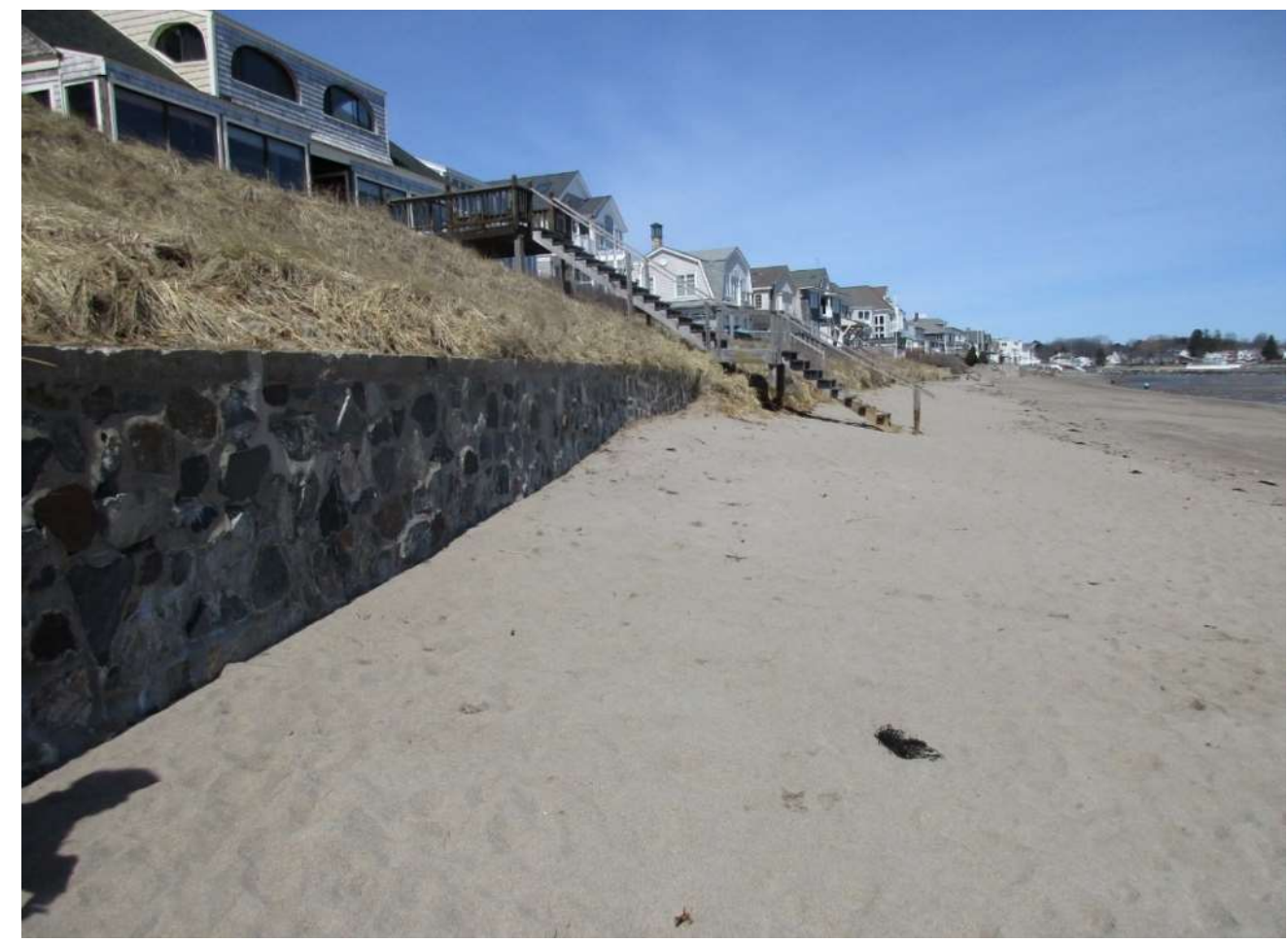

Figure WSO2-4. Dune grasses seen in Figure WSO2-3 were removed during the severe nor'easters of early March 2018 as shown in the photograph taken on March 27, 2018.

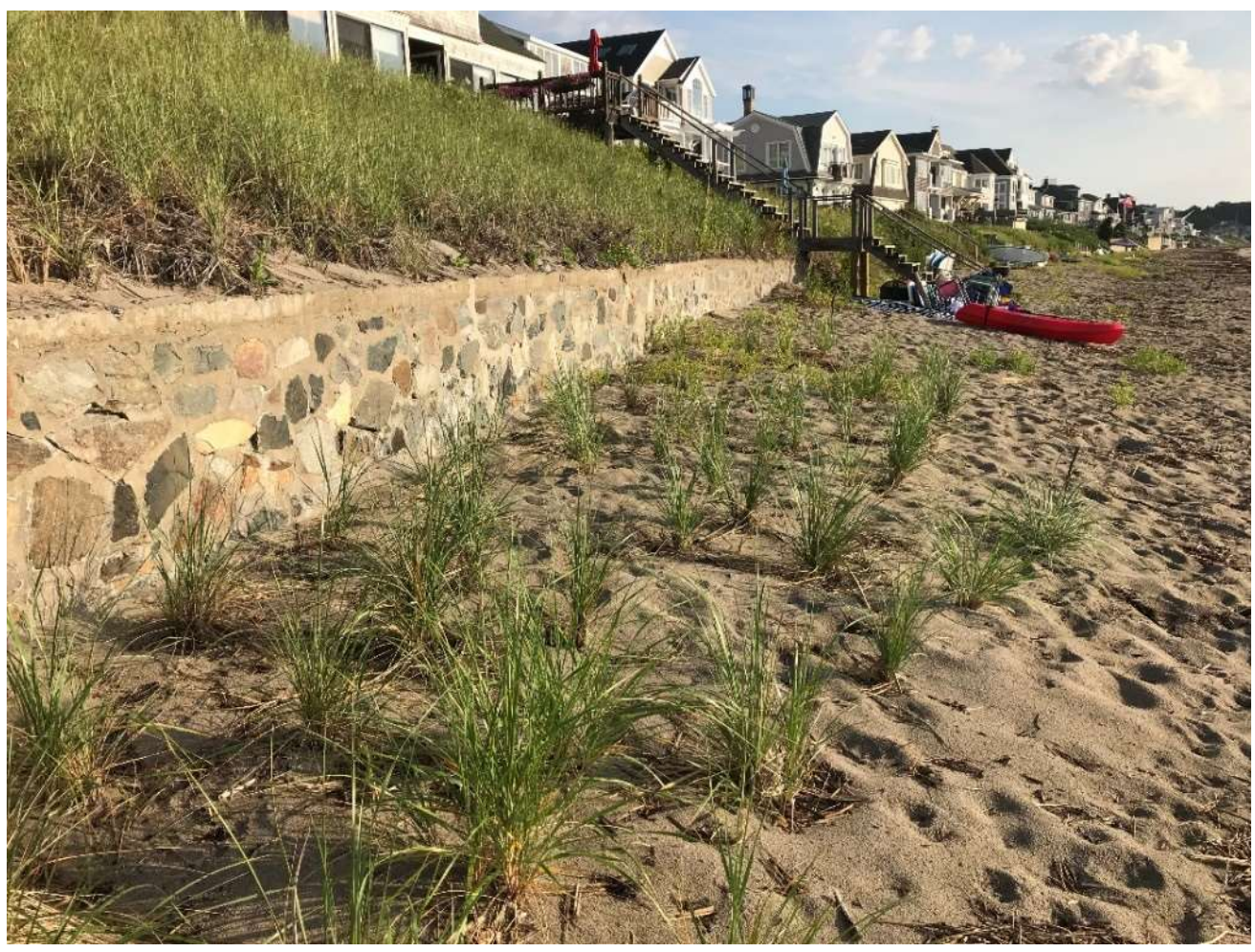

Figure WSO2-5. The dune grasses that were removed during the March 2018 nor'easters (Figure WSO2-4) were replanted as shown in this photograph taken on August 1, 2019. 
General Profile Characteristics. WS02.5 was measured twenty-nine times between January 30, 2018 and March 14, 2020 (Figure WS02-6). All plotted beach profiles can be found in Appendix C(2). The profile was typically 110 to $140 \mathrm{~m}$ in length from the seawall to the low tide swash but approached $170 \mathrm{~m}$ during a very low tide on February 19, 2019. The shortest profile length was $85 \mathrm{~m}$ on April 19,2018 largely due to neap tidal conditions. However, the length of the profile was $\sim 94 \mathrm{~m}$ on March 27, 2108 as a result of erosion after Riley, Quinn, and Skylar.

Examination of the sweep zone shows the elevation of the beach varied $\sim 1.4 \mathrm{~m}$ at the berm, $\sim 1.2 \mathrm{~m}$ at the base of the berm, and $\sim 0.9 \mathrm{~m}$ on the low tide terrace (Figure WS02-6). Comparison of the maximum average elevation profile which occurred on September 30, 2019 after a long period of accretion with the minimum average elevation profile which occurred on June 18, 2018 after several major late winter and spring storms shows an average loss of $0.6 \mathrm{~m}$ over the profile, with a maximum difference of $\sim 1.2 \mathrm{~m}$ in the runnel at the base of the berm (Figure WS02-7). Maximum and minimum average elevation are defined in Appendix A. The change in the beach at WS02.5 as a result of the late winter 2018 nor'easters is very close to the differences described above. Comparison of the maximum average elevation profile on September 30, 2019 with the elevation profile from March 15, 2018 (post-winter storms) shows an average loss of $0.5 \mathrm{~m}$ over the profile ranging from $0.3 \mathrm{~m}$ at the seawall, $0.7 \mathrm{~m}$ at the berm crest, and $1.2 \mathrm{~m}$ in the runnel at the base of the berm (Figures WS02-8).

A general characteristic exhibited at WSO2.5 (as well as at many of the NH beaches) is a "sand ramp" (Figure WS02-9). The sand on the beach in front of many seawalls tends to form a low-gradient ramp that can extend 10 or $20 \mathrm{~m}$ seaward. This increase in elevation of the upper beach likely results from the erosion of the lower beach during the stormy periods and the storm surge, along with wave runup, pushing sand up against the seawall (Figure WSO2-10). This is commonly seen along the NH coast where the response of the beach to storms includes building of a sand or gravel ramp in the upper beach. 


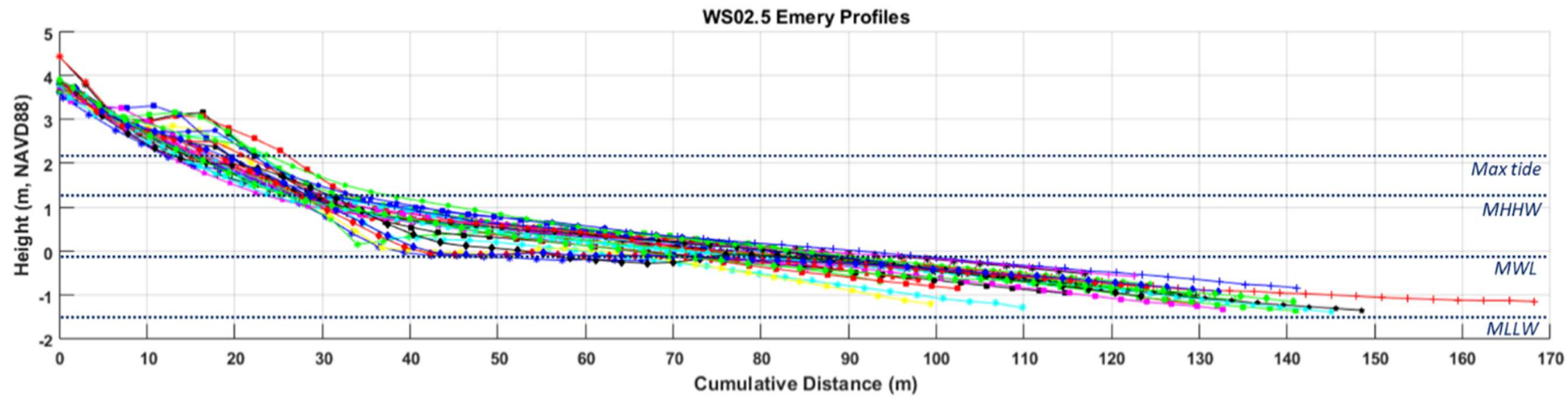

Figure WS02-6. All twenty-eight beach elevation profiles measured at WSO2.5 between January 30, 2018 and March 14, 2020. Examination of all the profiles together shows the maximum and minimum elevations of the beach. Maximum tidal elevation (max tide), mean higher high water elevation (MHHW), mean water level (MWL), and mean lower low water elevation (MLLW) are indicated by the dotted lines.

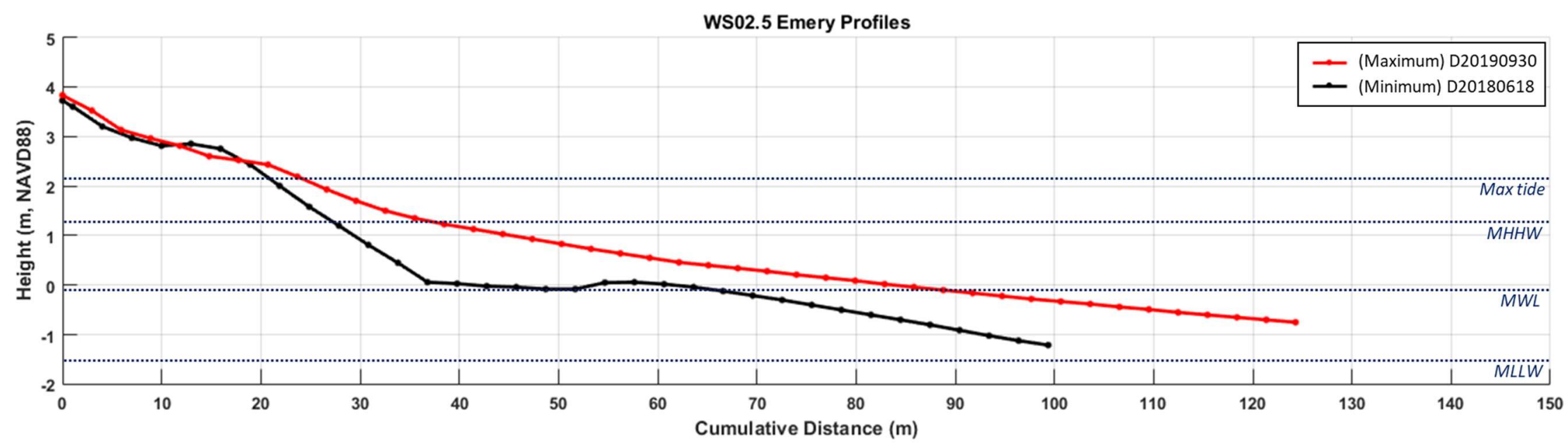

Figure WS02-7. Maximum (September 30, 2019) and minimum (June 18, 2018) beach elevation profiles by volume from the study period at station WS02.5. Note that this is not the impact of a single event as the profiles are not consecutive monitoring dates. Rather this comparison looks at the extreme of differences of beach elevation profiles over the entire study period. 


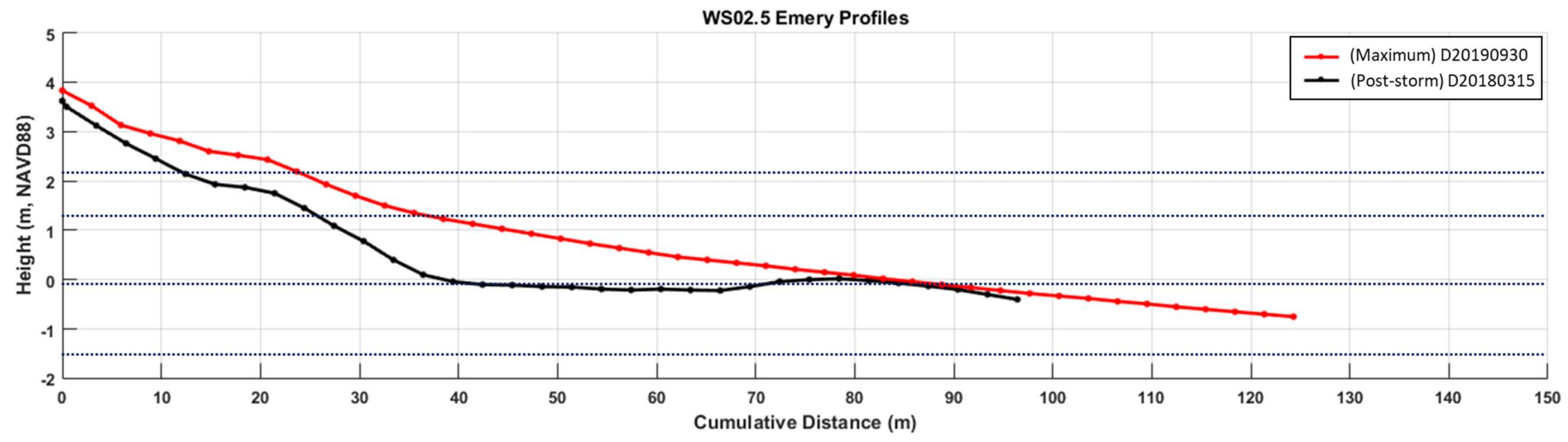

Figure WS02-8. The maximum (September 30, 2019) beach elevation profile at station WS02.5 compared to the profile following the severe nor'easters that occurred in late winter 2018 including Riley, Quinn, and Skylar.

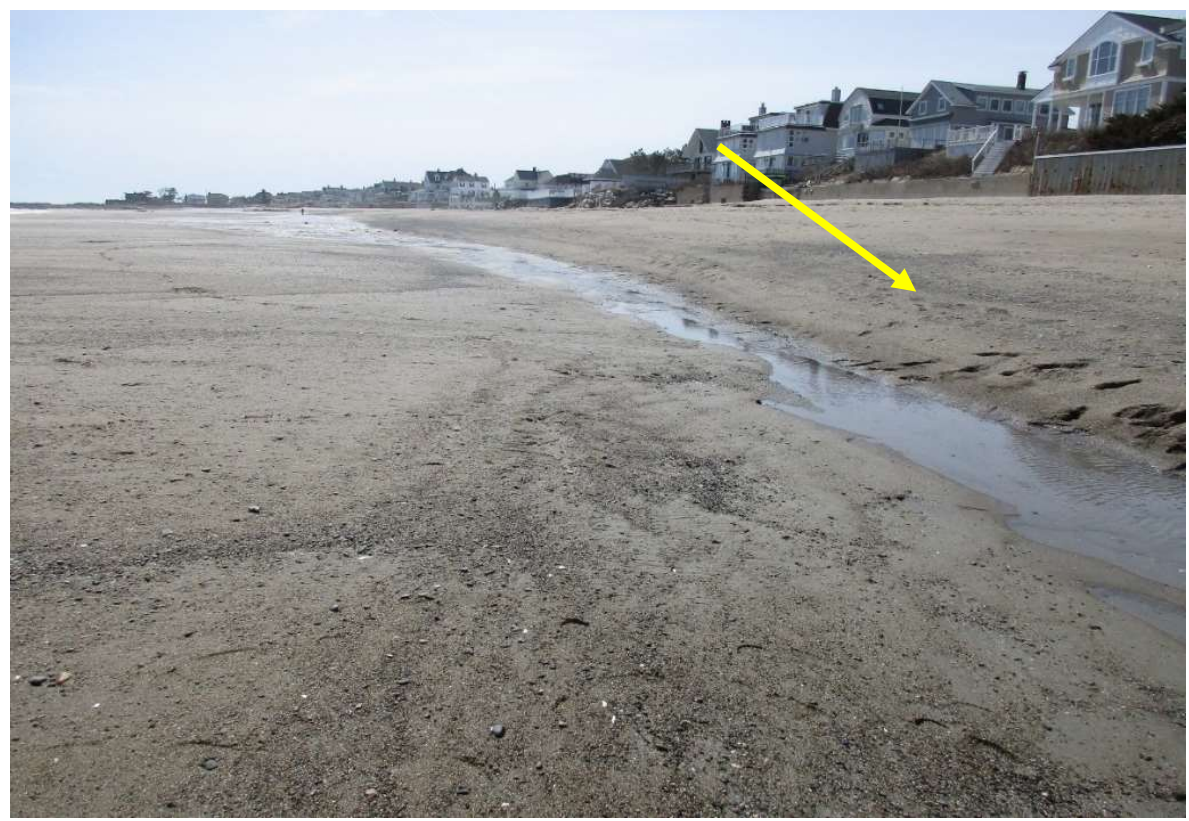

Figure WS02-9. Photograph of the sand ramp (arrow) on the upper beach south of station WSO2.5 on May 27, 2018. Many NH beaches have a sand ramp adjacent to the seawalls likely developed during storm activity. 


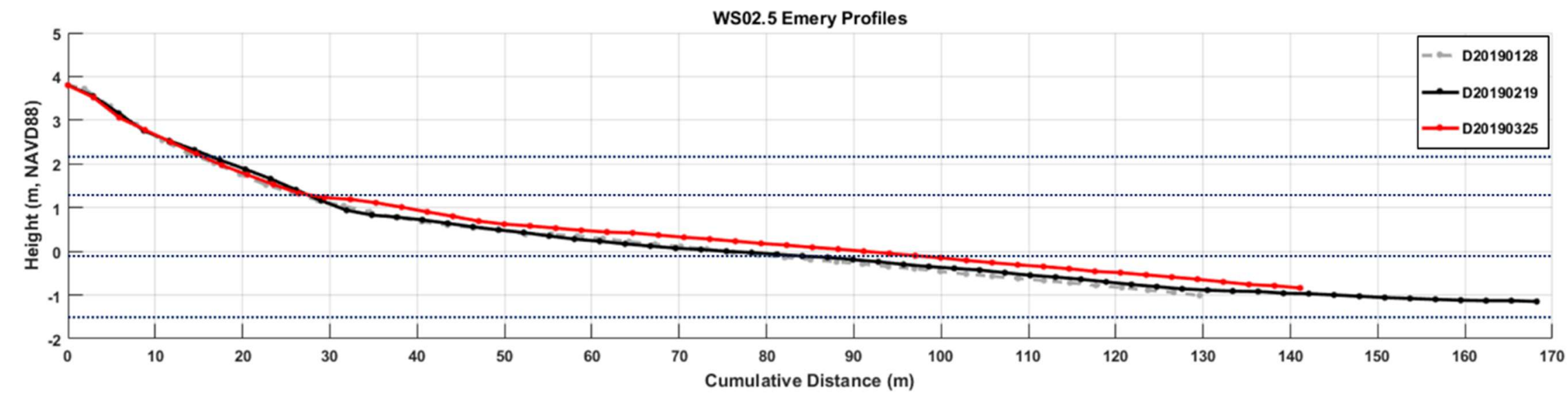

Figure WS02-10. Beach elevation profiles for WS02.5 on January 28, 2019, February 19, 2019, and March 25, 2019. Note the sand ramp in the upper profile ( 0-30 m). 
Storm Effects, Beach Erosion, and Recovery. Based on comparison of the beach profiles and the volume of sand from the seawall to $120 \mathrm{~m}$ seaward, beach accretion at WS02.5 occurred during fair weather conditions, while significant erosion occurred as a result of storms with relatively rapid recovery following these events (Figure WS02-11; Table 3-3). The beach profile at the beginning of the study for this station (January 30,2018 ) appeared to be stable or in equilibrium (Figure WSO212), although the sand volume was below maximum volumes seen in late summer and fall 2018 (Figure WS02-11). Presumably, the somewhat lower volumes measured along the profile on January 30 and February 27, 2018 resulted from earlier winter storms such as Grayson (Jan 3-5), Inga (Jan 1718), Liam (Feb 7-9), and Noah (Feb 16-18) that occurred prior to this station being monitored (Table 3-3).

The maximum erosion during the study period occurred during Riley (Mar 1-4), Quinn (Mar 6-9) and Skylar (Mar 12-14) and is reflected in the March 15, 2018 beach profile which shows 0.9 m of erosion mid-beach in comparison to the pre-storm profiles (Figure WS02-13). Based on the change in the volume of sand, the beach lost an average of $0.35 \mathrm{~m}$ along the entire profile transect (Figure WSO211). As discussed above, prior to the late winter nor'easters in 2018 the seawall at WSO2.5 was fronted by a $\sim 6 \mathrm{~m}$ wide sand ramp that was vegetated with dune grasses to protect the seawall (Figure WS02-3). The planted dunes and sand ramp were removed by wave erosion during the storms (Figure WSO2-4). 

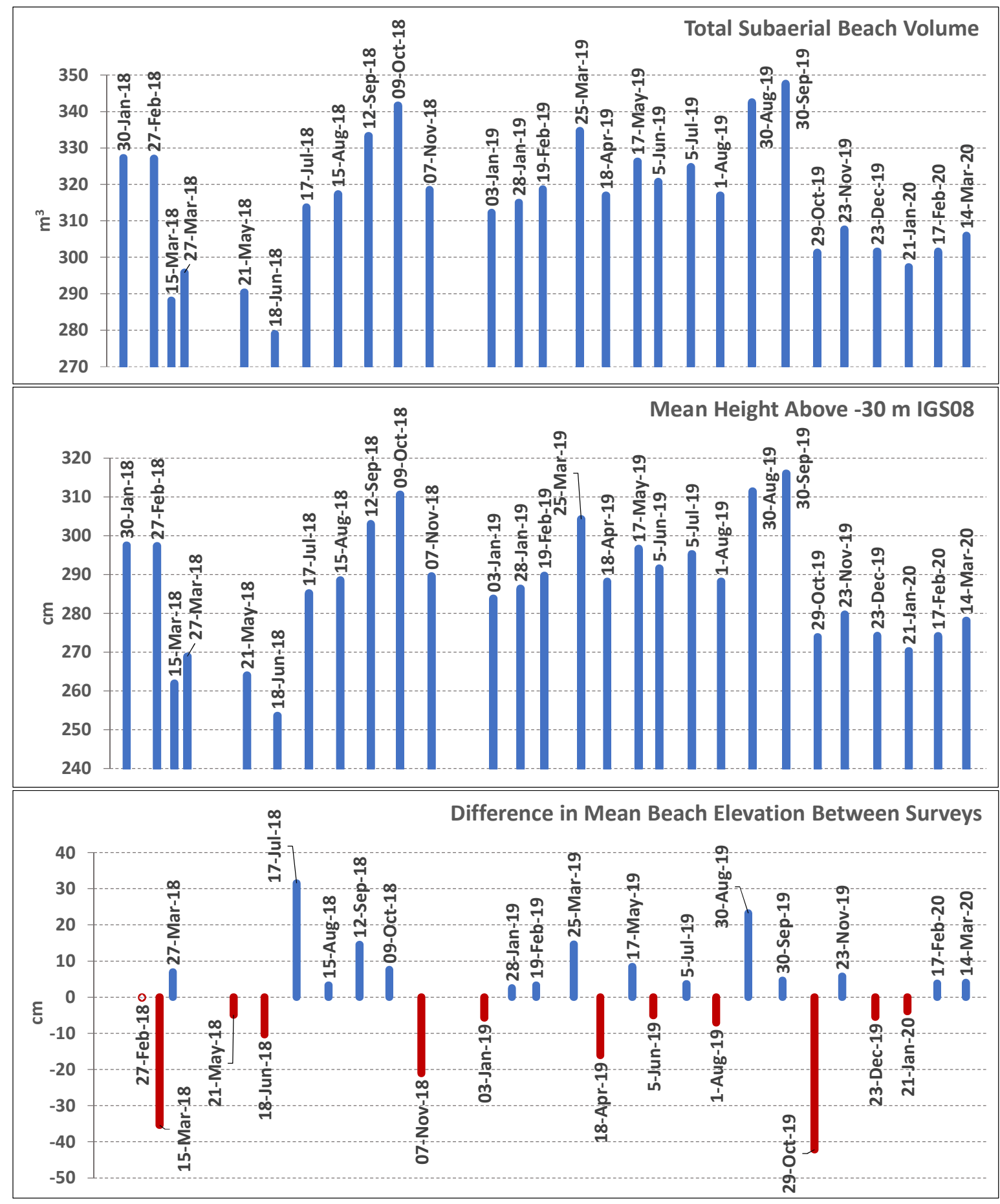

Figure WS02-11. Calculated sediment volume, mean profile elevation, and mean elevation change for the beach profile at station WS02.5. These parameters were calculated from 0-110 meters of the profile length. Ten of the twenty-eight beach elevation profiles were shorter than the "standard profile length" for the station (110 $\mathrm{m}$ ). These profiles were extended using the procedure described in Chapter 2. Five of the profiles were extended less than $10.6 \mathrm{~m}$ which is considered negligible (two of these were less than $1 \mathrm{~m}$ ). The longest extension ( $33.5 \mathrm{~m}$ on October 29, 2018) was measured during a neap tide on a flat beach. The other two extensions followed the March 2018 storms when the beach was eroded. There is high confidence in the calculations being representative of the station. 


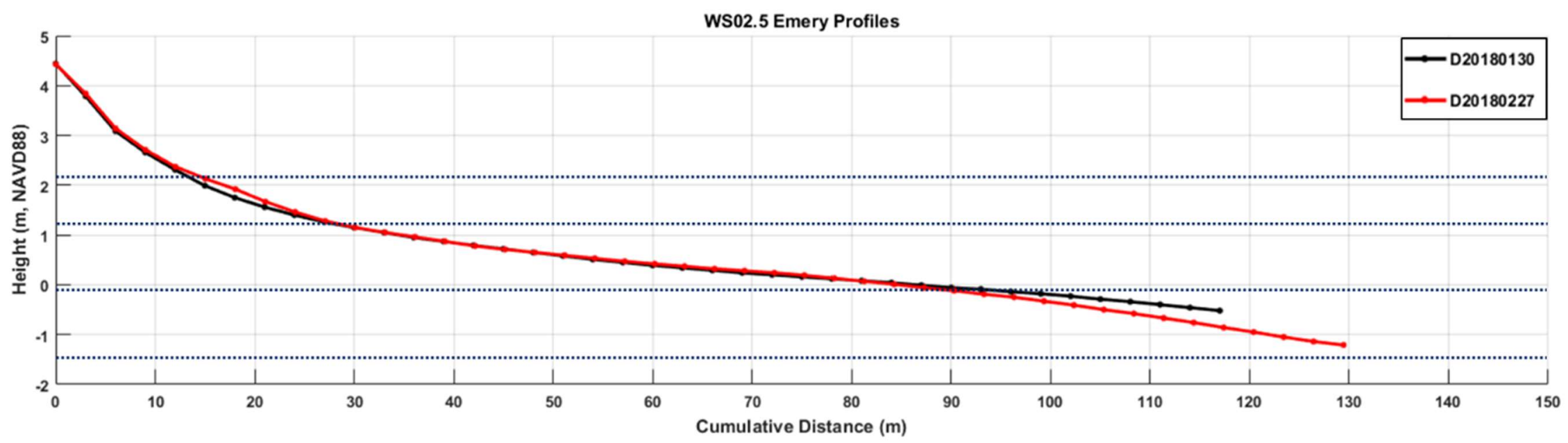

Figure WS02-12. Beach elevation profiles for WS02.5 on January 30, 2018 and February 27, 2018.

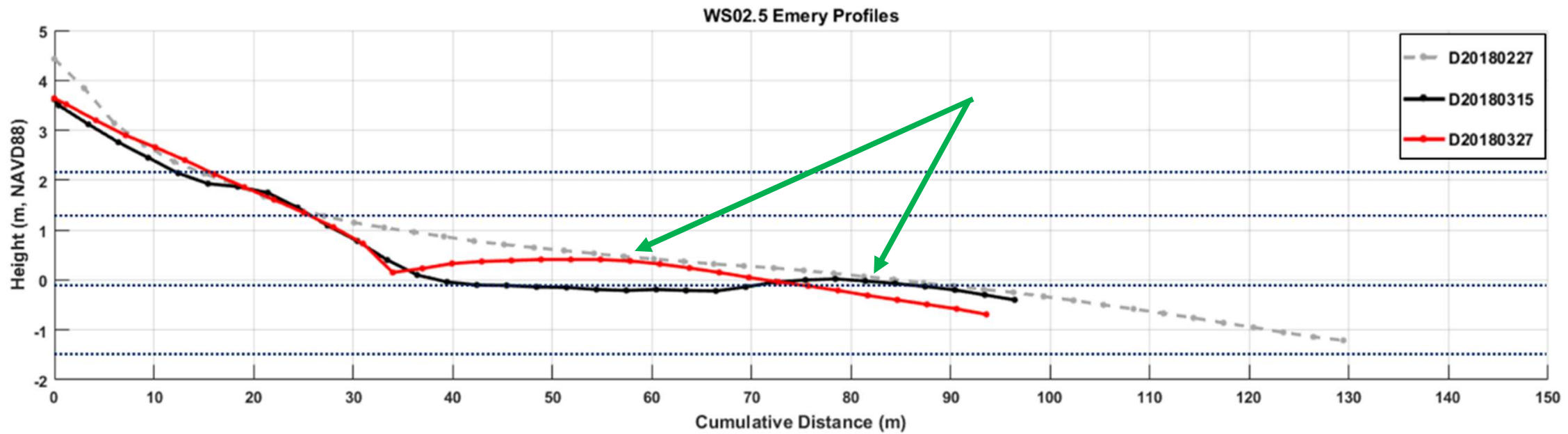

Figure WS02-13. Beach elevation profiles for WS02.5 on February 27, 2018, March 15, 2018, and March 27, 2018. Note the major erosion of the beach as shown by the March 15 profile. However, the beach was recovering by March 27 as evidenced by the major ridge that was migrating landward (see arrows). The ridge and runnel is shown in Figure WSO2-14. 
Following these storms, a ridge and runnel system formed which helped to somewhat restore the beach. The ridge and runnel system was apparent on the lower beach on March 15 despite the preceding period of erosion and grew in size and migrated landward by the time the profile was run on March 27 (Figure WS02-13). Unfortunately, marginal weather conditions make the results of the April 19 beach profile suspect due to an unclear horizon and it is therefore omitted here. By May 21 the ridge welded onto the upper beach (Figures WSO2-14 and WS02-15). The sequence of beach profiles and volumetric calculations from January 30 to May 21 shows the sequence from an accretional beach (January 30), to a highly eroded and flattened beach (March 15), to the development of a ridge and runnel (March 27), and the landward migration of a ridge and runnel system which formed a berm (May 21). This berm may have developed from eroded sand from the lower beach being pushed landward. The profile on June 18 shows the berm still present on the upper beach, while the lower beach is slightly lower and a ridge is migrating landward (Figure WSO2-16). The sand volume on June 18 is the lowest seen for this station for the study period.

Sand volume calculations (Figure WS02-11) and beach profiles for WS02.5 showed a continuous increase in elevation and sand volume during the summer and fall of 2018 reaching a value close to the maximum for the study period on October 9. Similar to WS01, a series of storms in late fall 2018 and winter 2019 eroded WS02.5, including Avery (Nov 15-16, 2018), Harper (Jan 19-20, 2019) and Maya (Feb 12-13), which removed sand and decreased the beach elevation (Table 3-3). However, the impact to structures, flooding, and erosion was far less than the sequence of storms in late winter 2018. Also, the beach showed a large amount of variability in summer 2019, and had accreted significantly by September 30, 2019, reaching the maximum sand volume and average mean height above MLLW for the study period (Figure WS02-11). During fall 2019 the beach eroded to a lower level, possibly initiated by a king tide and coastal flooding on October 28, 2019. Overall, the sand volume remained low through March 2020, likely caused by a series of winter storms including Ezekiel (Dec 2-4, 2019), Gage (Dec 30-31), and unnamed winter storms in February (27-28, 2020) and early March (6-7). 


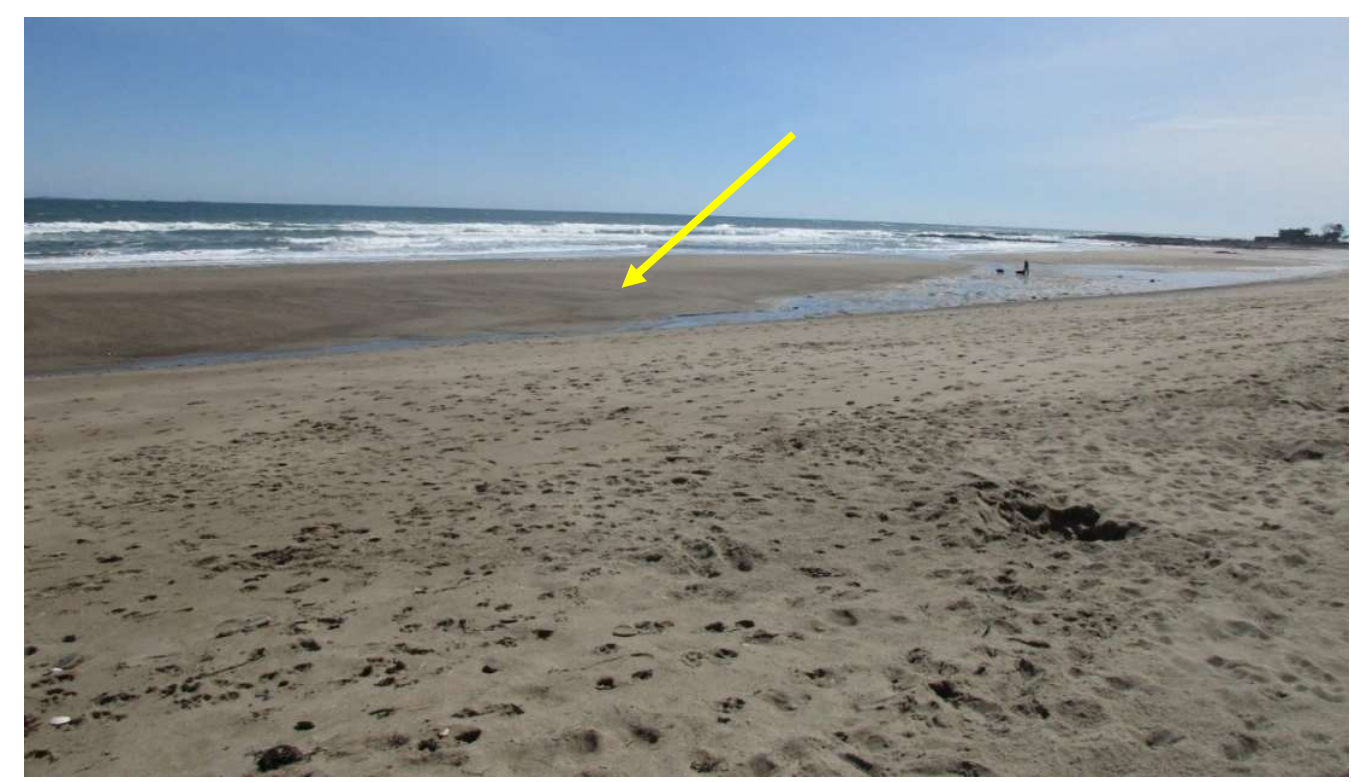

Figure WS02-14. Ridge and runnel system (arrow) at WS02.5 on March 27, 2018 formed after the major sequence of storms in late winter 2018.

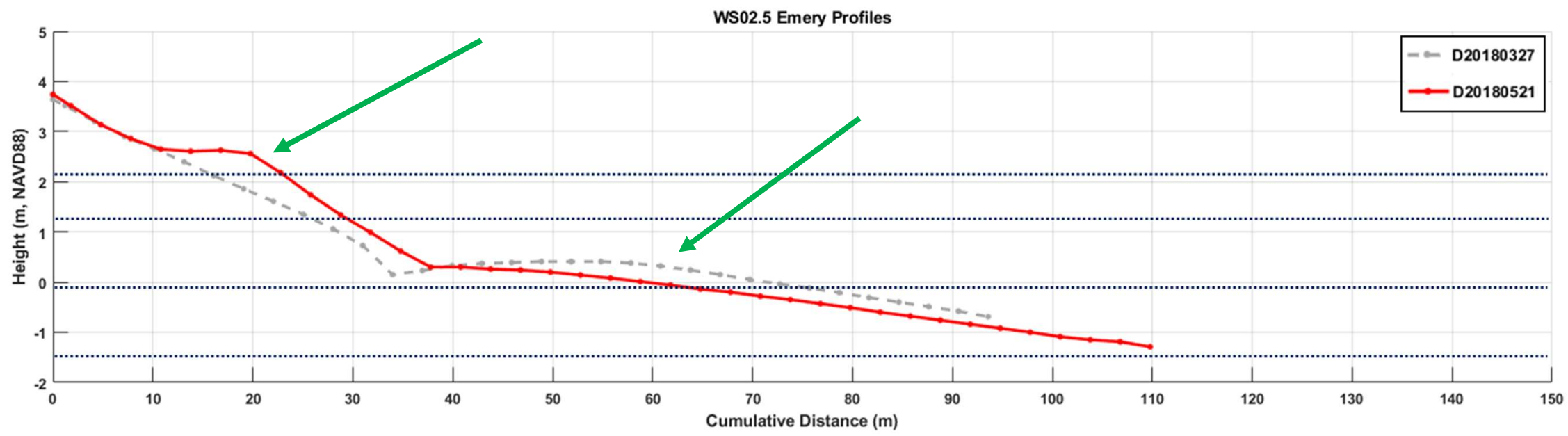

Figure WS02-15. Beach elevation profiles for WS02.5 on March 27, 2018 and May 21, 2018. Note the large berm (left arrow). The ridge and runnel shown in Figure WS02-14 is apparent on the March 27 profile (right arrow). 


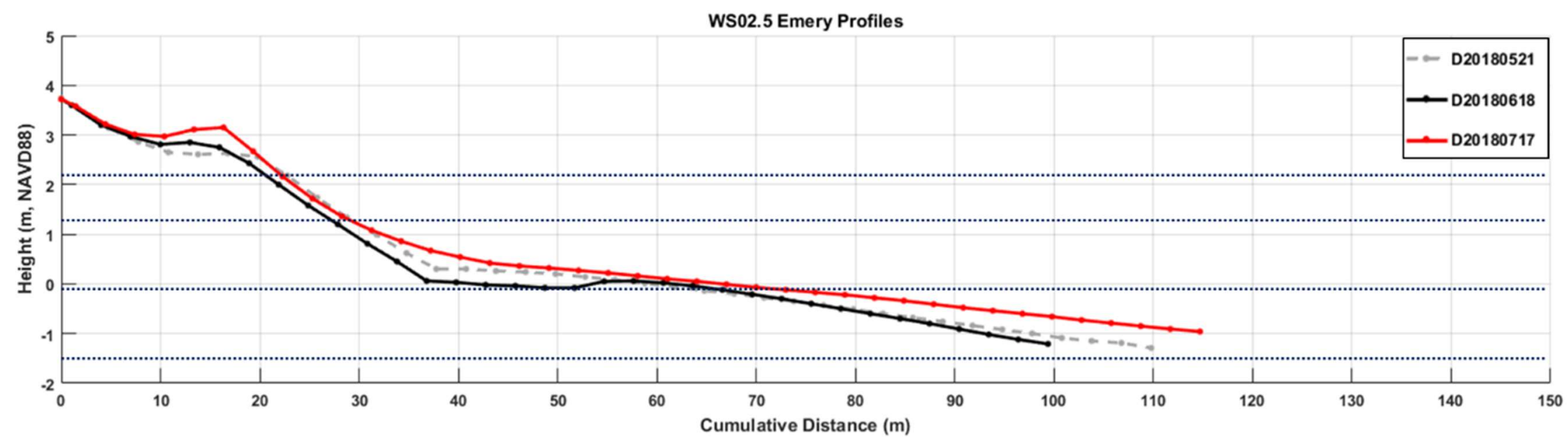

Figure WS02-16. Beach elevation profiles for WS02.5 on May 21, 2018, June 18, 2018, and July 17, 2018. 


\section{Introduction to Jenness Beach, Rye, NH}

Jenness Beach is $1.8 \mathrm{~km}$ in length. It is located between two headlands primarily composed of glacial till: Straws Point (also called Lockes Neck) to the north and Rye Ledge to the south (Figure JB-1). The beach is relatively flat and ranges from $\sim 150$ to $200 \mathrm{~m}$ in width (Figure JB-2). The southern half of the beach system is backed by an enclosed pond (Eel Pond). It is likely that Jenness Beach was a barrier spit extending from Straws Point but migrated landward and is now a mainland beach, at least on the northern half. Locally, Jenness Beach is divided into Cable Beach (northern end), Jenness State Beach (middle section), and Sawyers Beach (southern end).

Jenness Beach has a variety of engineering structures separating the beach from the upland (Figure JB-1). Presently, there are no longer dunes at the landward edge of the beach. On the northern end of the barrier at Cable Beach, residential homes are located where dunes once likely existed. These homes are fronted by a variety of relatively low seawalls, many built from rock blocks, as well as riprap. However, several homes have opted to plant dune grasses in front of their land providing additional protection from wave erosion and storm surge (Figure JB-3). Jenness State Beach is backed by a relatively low concrete seawall $(\sim 1.0$ to $1.5 \mathrm{~m})$ that separates the beach from the parking lot (Figure JB-4). South of Jenness State Beach a series of homes are located on a topographic high fronted by a riprap wall several meters in height (Figure JB-5). A culvert located at the southern end of the riprap seawall provides drainage for Eel Pond to the ocean. The southern end at Sawyers Beach is backed by a human-made gravel berm exceeding three meters in elevation (Figure JB-6). Eel Pond (now largely freshwater) is located landward of the barrier and at one time was likely a salt marsh (Figure JB-1).

Jenness Beach is composed of bimodal sediment. Typically, fine to medium sand covers the beach surface during accretional periods. However, after storms when the beach has been eroded and the veneer of sand removed, the beach is frequently characterized by pebble lag deposits in many locations, especially on the mid and lower beach. The source of the coarse material is likely the headlands that form the boundaries of Jenness Beach which are composed of eroded glacial tills and provide abundant gravel. 


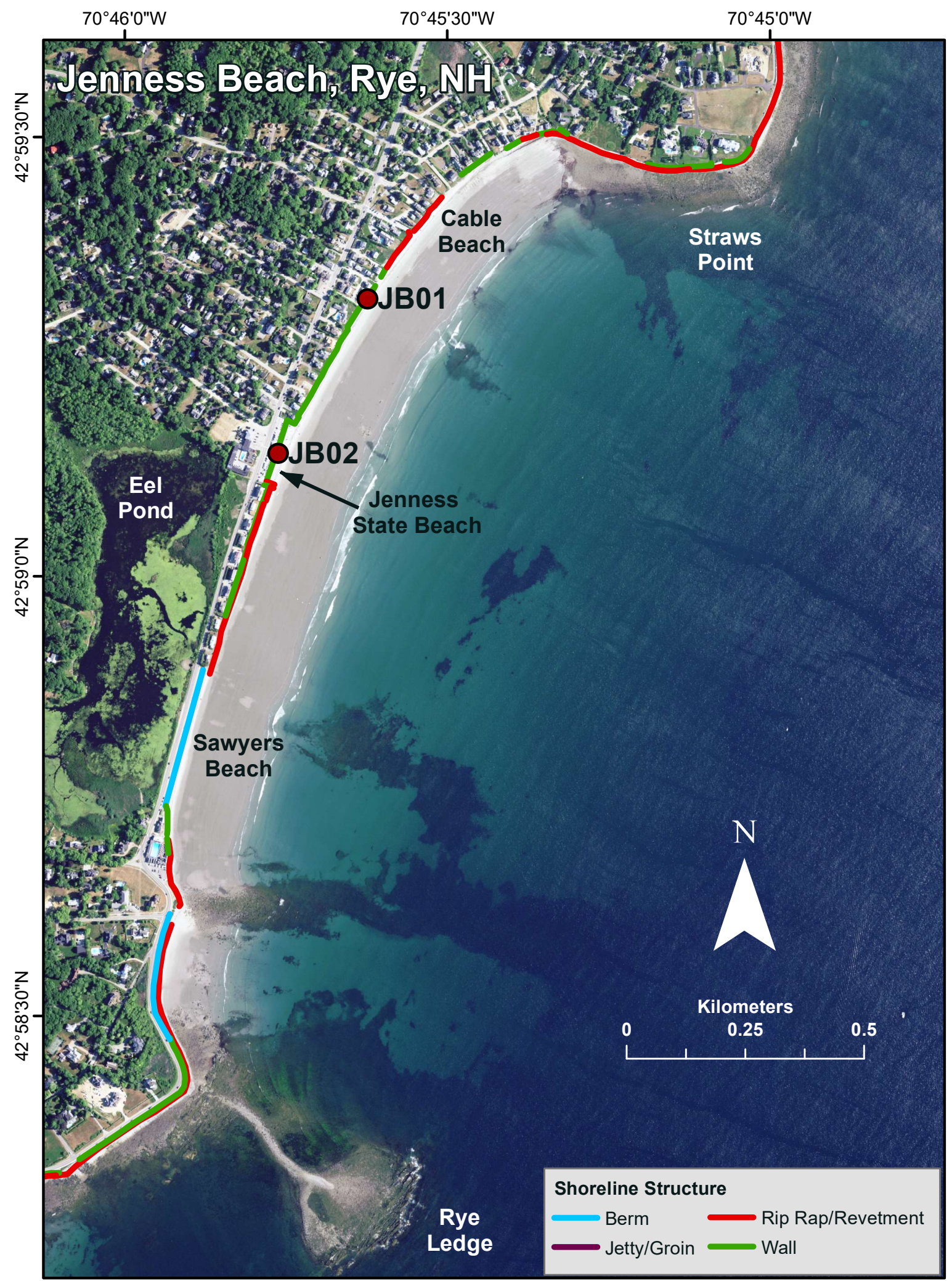

Figure JB-1. Location map of Jenness Beach with stations, geographic features, and shoreline engineering structures. 

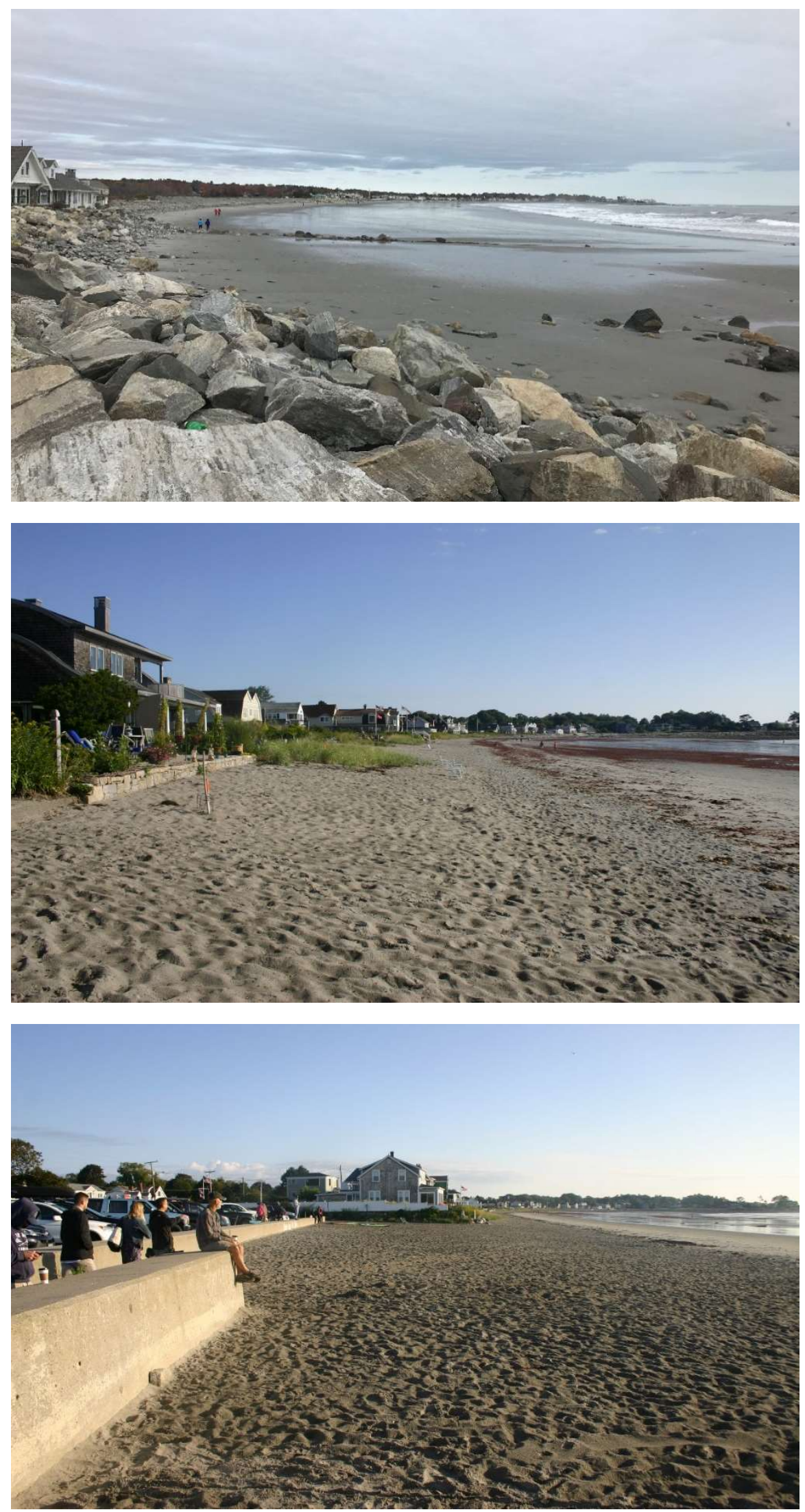

Figure JB-2. Jenness Beach from the Rye Ledge area looking north on October 25 , 2020.
Figure JB-3. Northern Jenness Beach or Cable Beach on September 9, 2017. Private homes are located at the landward boundary where dunes once existed. Many of the homes have dune grasses (with or without seawalls) protecting the upland which is a sound environmental practice.
Figure JB-4. Jenness State Beach with its concrete seawall that separates the parking lot and bathhouse from the beach. The photograph was taken on September 9, 2017. 


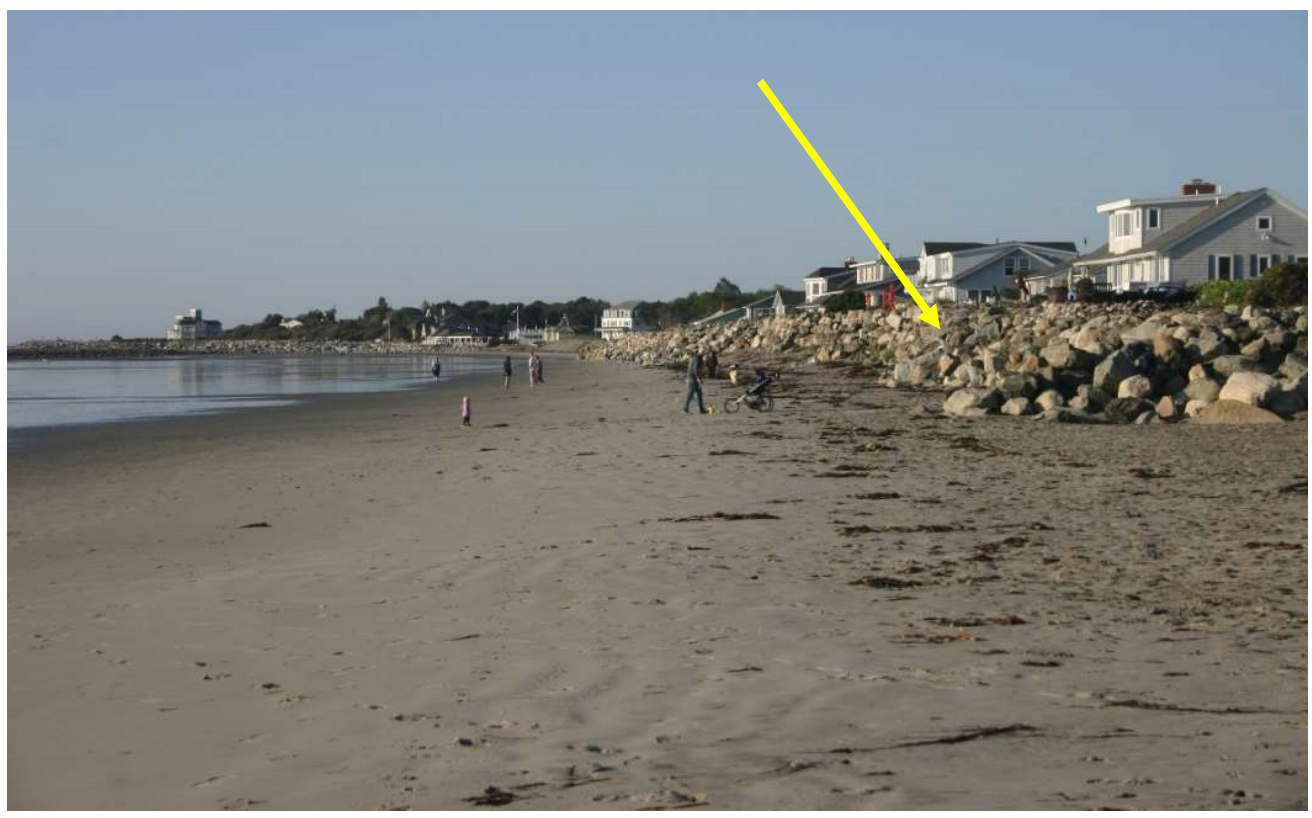

Figure JB-5. A large riprap seawall that separates the mid-Jenness Beach area from the upland (arrow). Private homes are located at the top of the seawall. The photograph taken on September 20, 2017 is looking south from Jenness State Beach towards Sawyers Beach.

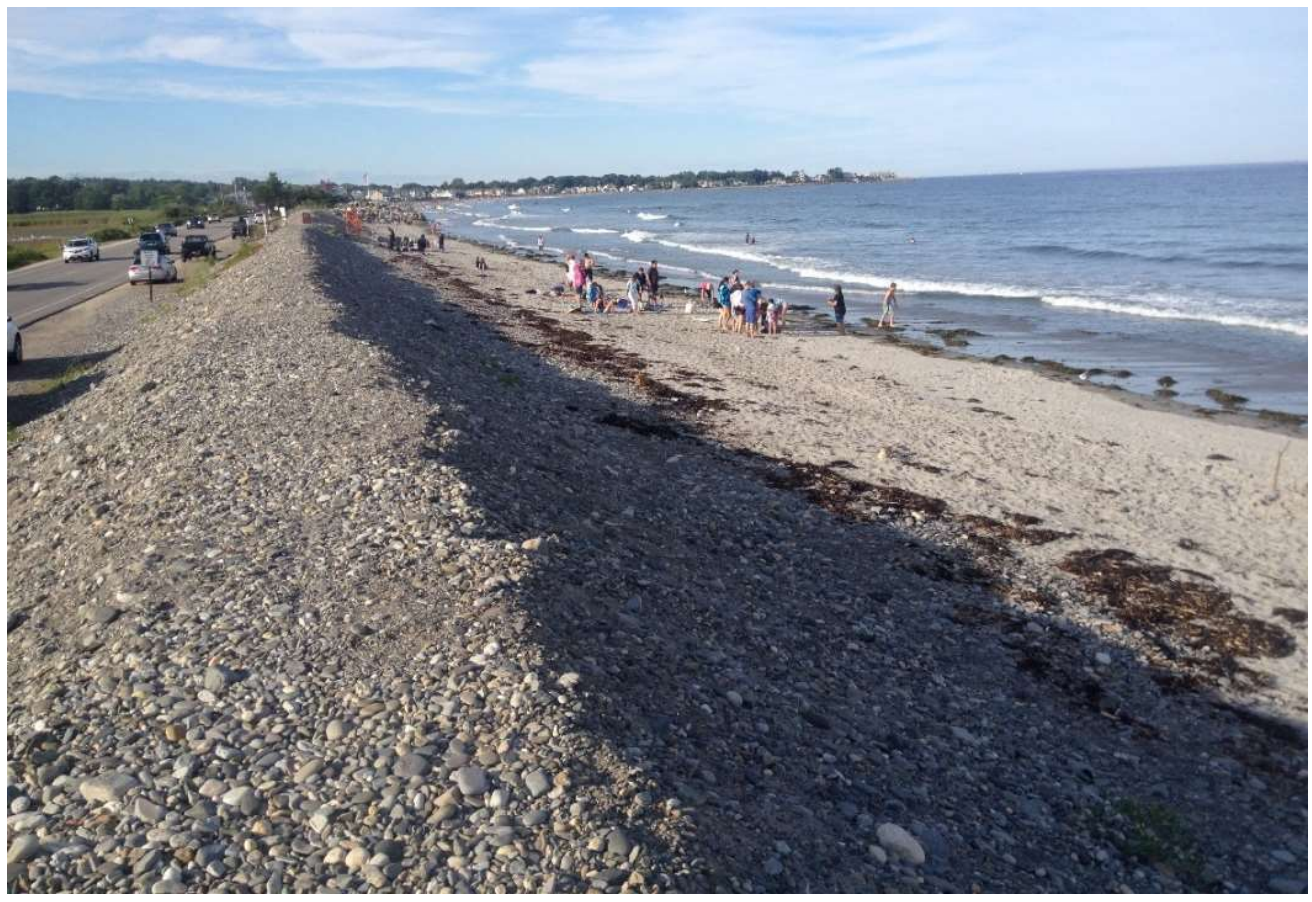

Figure JB-6. Manmade gravel berm separating southern Jenness Beach or Sawyers Beach from the upland. The photograph taken on August 8, 2015 is looking north. 


\section{Results for Station at Northern Jenness State Beach (Cable Beach): JB01}

Overview. JB01 is located on the northern half of Jenness Beach $~ 500 \mathrm{~m}$ from Straws Point (Figure JB-1). The beach is locally called Cable Beach. The backshore boundary is characterized by primarily private homes fronted by seawalls, some with a narrow fringe of dune grasses (Figure JB01-1). The beach is relatively wide with low amplitude $(<1 \mathrm{~m})$ morphologic features periodically forming (e.g., berms during accretional periods). The beach has a narrow backshore (landward of the berm or mean high water) normally composed of sand, relatively low elevation along its length, and small-amplitude features (Figure JB01-1). The low tide terrace is wide and relatively flat (Figure JB01-2). Bedrock or boulders outcrop on the beach $250 \mathrm{~m}$ south of the profile and offshore. JB01 extends from a stone seawall fronting a private home $\sim 150$ to 180 m seaward to the swash zone (Figures JB01-3 and JB014). Under accretional conditions the beach is usually composed of fine to medium sand (Figure JB015). However, following storms or other periods when large waves and erosion occur, the beach becomes bimodal and is covered with small pebble lag deposits (Figure JB01-6).

Summary. Overall, JB01 exhibited the typical erosion cycle for $\mathrm{NH}$ beaches with the beach profile showing a slightly concave profile with a sand or gravel ramp leading up to the seawall formed by sediment being pushed landward by storm surges and wave run-up. Following storms, the beach rebuilt itself with the development of ridge and runnel systems that migrated landward, eventually developing a berm and building the beach elevation up to create an accretional profile. However, the relatively dramatic changes seen at JB01 over the several-month period from March through July 2018 illustrates how rapidly these beaches can change. This is a clear example of the need for longterm monitoring (years) of relatively closely spaced observations (several weeks), and also supports the idea that determining trends requires looking at changes over several months grouped together, rather than month-to-month. 

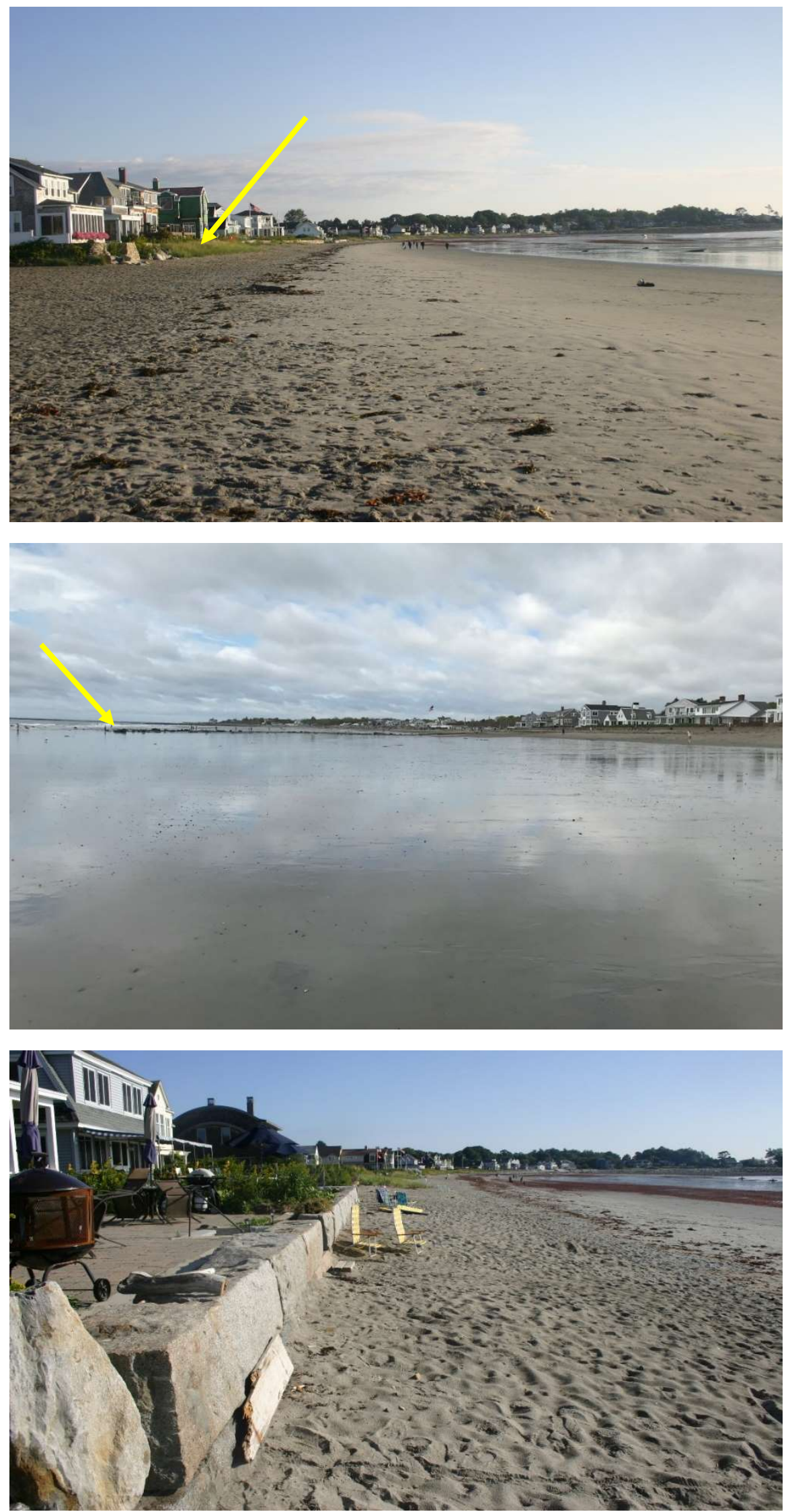

Figure JB01-1. Jenness Beach or Cable Beach looking north from JB01 on September 9, 2017. Note the narrow backshore (rough sand), dune grasses in front of some of the homes (arrow), and relative flatness.
Figure JB01-2. Bedrock outcrops exposed on the low tide terrace (arrow) just south of the JB01 profile transect. Photograph taken on May 19, 2018.
Figure JB01-3. Station JB01 which starts at the lower corner of the seawall and extends to the low tide swash. The photograph was taken on September 9, 2017. 


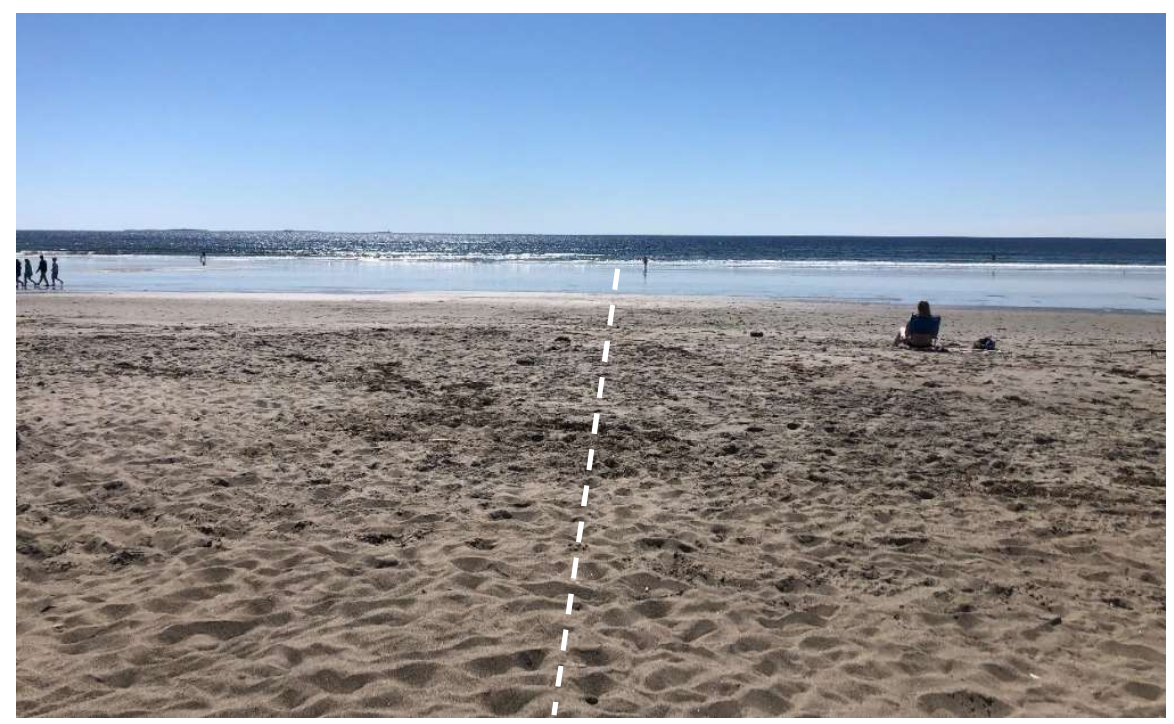

Figure JB01-4. Station JB01 looking seaward on June 8,2019 . The elevation profile transect is shown by the white dashed line.

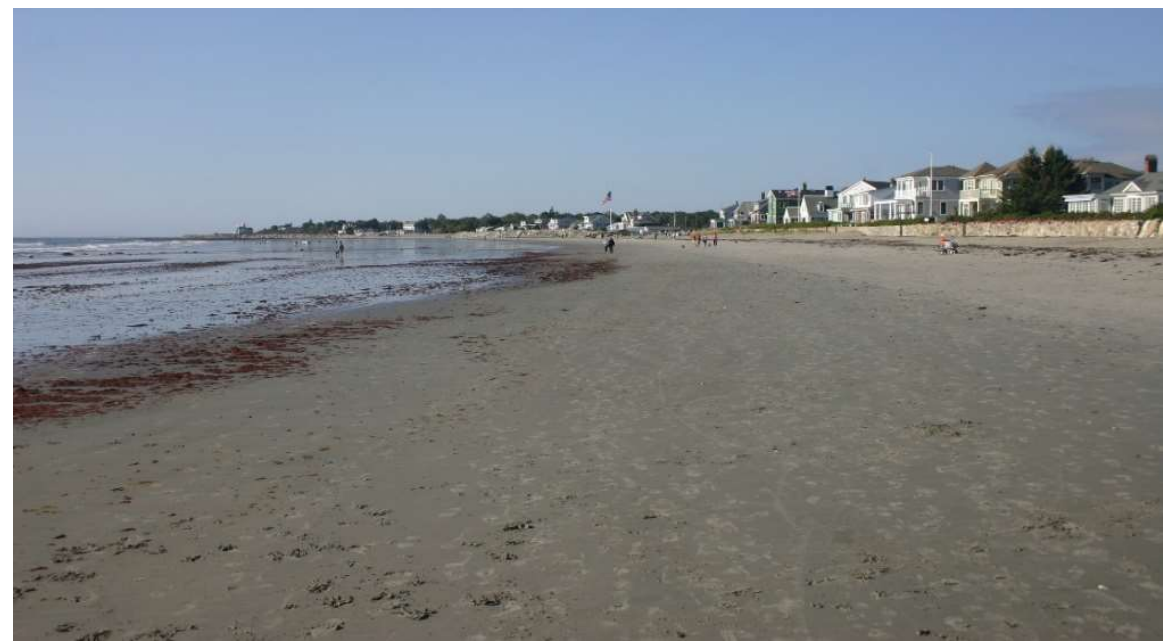

Figure JB01-5. Midbeach at station JB01 looking south on September 9, 2017 during accretional conditions when the beach is primarily composed of sand.

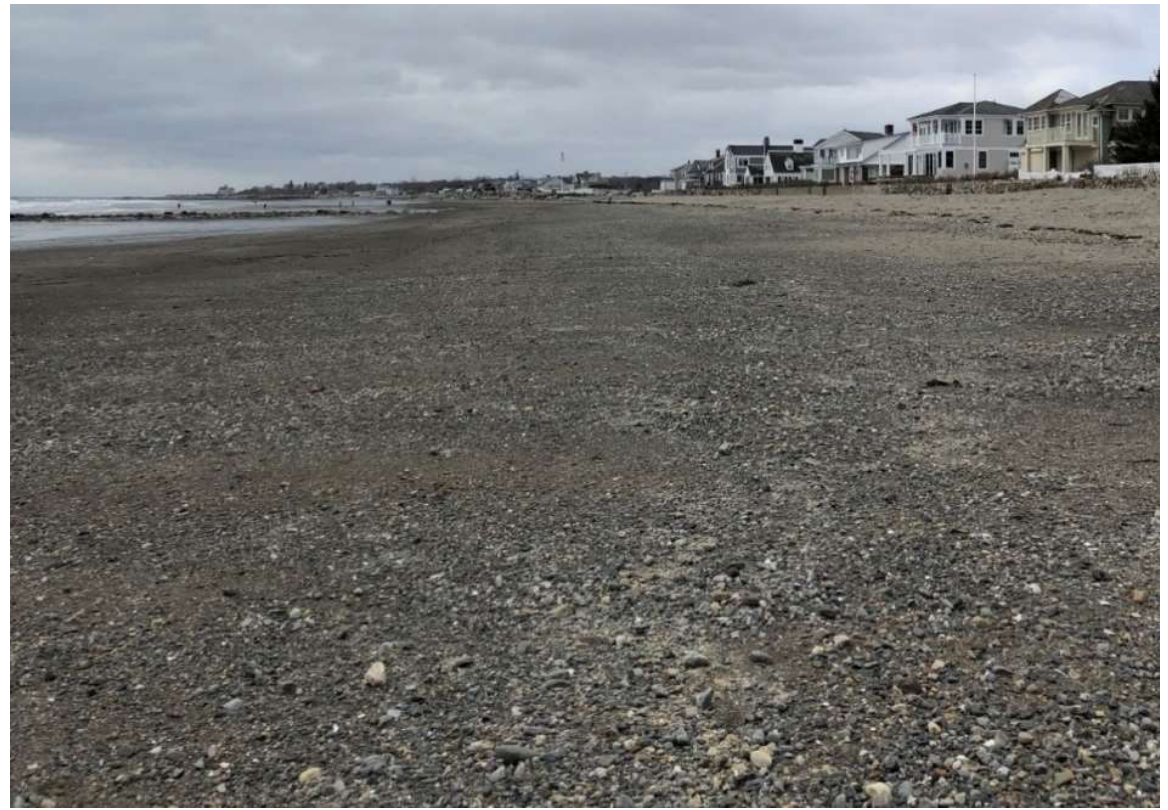

Figure JB01-6. Midbeach at station JB01 looking south on March 25, 2018 after the series of storms in late winter 2018 exposing pebble lag deposits. 
General Profile Characteristics. JB01 was part of the expansion of the VBPMP that occurred in 2018. The station was profiled twenty-nine times between January 28, 2018 and March 14, 2020. All plotted beach profiles can be found in Appendix C(3). The profiles were typically $130 \mathrm{~m}$ to $160 \mathrm{~m}$ wide from the seawall to the low tide swash. The sweep zone or the maximum elevation differences when all the beach profiles are examined together varied $\sim 0.6 \mathrm{~m}$ at the seawall and berm, $\sim 0.8 \mathrm{~m}$ at mid beach, and $\sim 0.9 \mathrm{~m}$ on the low tide terrace near the swash zone (Figure JB01-7).

Comparison of the maximum average elevation profile for the study period which occurred on September 1, 2019 with the minimum average elevation profiles which occurred on April 21, 2018 and December 29, 2018 (same sediment volumes) showed an average loss of $\sim 0.4 \mathrm{~m}$ on both dates (Figures JB01-8 and JB01-9). Even though the April 21 and December 29, 2018 average elevations are the same and are the result of major beach erosion, the elevation profiles show two different morphologic configurations. The December 29, 2018 profile has the classic post-storm profile for an eroded beach, and when compared to the September 1, 2019 maximum profile, shows the entire beach eroded from near the seawall to the low tide swash losing between 0.4 to $0.6 \mathrm{~m}$ in elevation (Figure JB01-9), although a small sand ramp formed by the seawall. Conversely, the April 21, 2018 and September 1, 2019 comparison (Figure JB01-8) shows the mid beach (loss of $\sim 0.8 \mathrm{~m}$ ) and lower beach (loss of $\sim 0.5 \mathrm{~m}$ ) were heavily eroded, while the upper beach formed a small berm seaward of the previous location and sand was pushed up against the seawall.

Despite the change in elevation at JB01 being on the lower end of fluctuations along the NH beaches, it is very significant due to the generally low elevation of the entire Jenness Beach system which allows it to be inundated to the seawall during storm activity or extremely high tides. The beach profiles at Jenness Beach were originally observed by Leo (2000) who attributed the consistently low elevations of the beach to be at its downcut limit. 


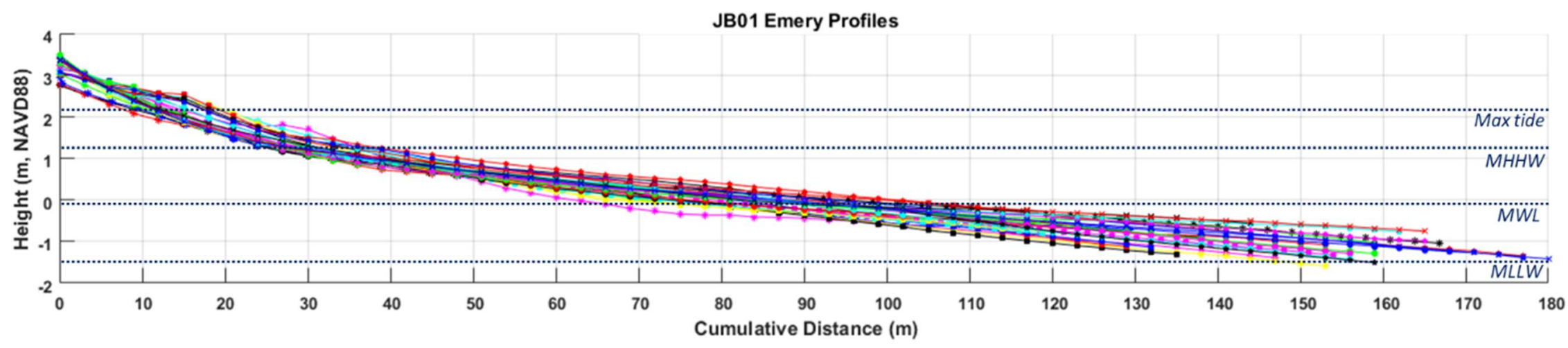

Figure JB01-7. All twenty-nine beach elevation profiles measured for station JB01 between January 28, 2018 and March 14, 2020. Examination of all of the profiles together shows the maximum and minimum elevations of the beach. Maximum tidal elevation (max tide), mean higher high water elevation (MHHW), mean water level (MWL), and mean lower low water elevation (MLLW) are indicated by the dotted lines.

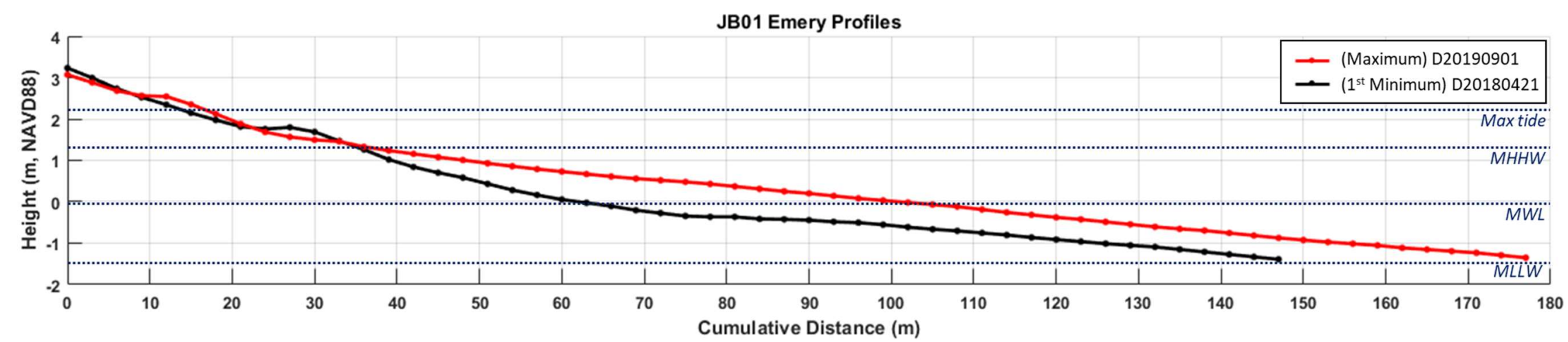

Figure JB01-8. Maximum (September 1, 2019) and first minimum (April 21, 2018; same volume as December 29, 2018) beach elevation profiles determined from sediment volume and average elevation from the study period at station JB01. Note that this plot extends to 180 meters, rather than the standard 170 meters for JBO1 profile plots. Note that this is not the impact of a single event as the profiles are not consecutive monitoring dates. Rather this comparison looks at the extreme of differences of beach elevation profiles over the entire study period. 


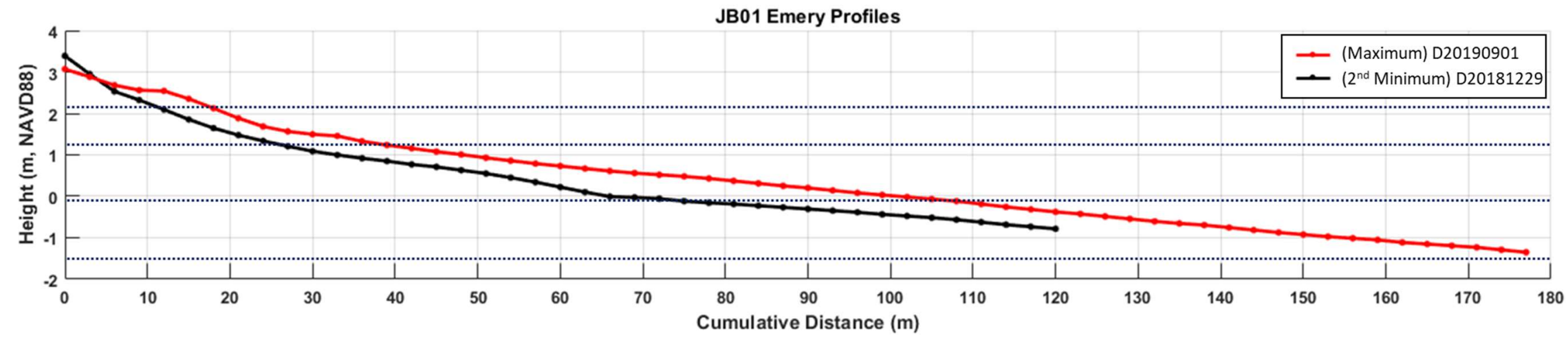

Figure JB01-9. Maximum (September 1, 2019) and second minimum (December 29, 2018; same volume as April 21, 2018) beach elevation profiles determined from sediment volume and average elevation from the study period at station JB01. Note that this plot extends to 180 meters, rather than the standard 170 meters for JB01 profile plots. Note that this is not the impact of a single event as the profiles are not consecutive monitoring dates. Rather this comparison looks at the extreme of differences of beach elevation profiles over the entire study period. 
Storm Effects, Beach Erosion, and Recovery. Review of the volumetric calculations and the beach profiles for JB01, for the most part, follow expected trends. Jenness Beach was slightly eroding at the beginning of the study as indicated by the sand volume decreasing between January 28 and February 24, 2018 (Figure JB01-10). In addition, the beach profiles for these dates were relatively flat reflective of an erosional profile (Figure JB01-11). During and prior to this period, the NH coast experienced a series of winter storms including Grayson (Jan 3-5, 2018), Inga (Jan 17-18), Liam (Feb 7-9), and Noah (Feb 16-18) (Table 3-3). Consequently, the beach was already at a lower elevation when impacted by the three powerful nor'easters in late winter 2018 including Riley (Mar 1-4), Quinn (Mar 6-9) and Skylar (Mar 12-14) (Table 3-3). JB01 was significantly eroded by these storms as verified by the loss of the volume of sand on the beach (Figure JB01-10) and lowering of the beach profile (Figure JB0112). Visual examination of the beach shows the sand veneer removed and a pebble lag deposit exposed which covered most of the mid to lower beach (Figures JB01-6; JB01-13). In addition, a sand ramp formed adjacent to the seawall which was likely pushed up by the storm surge. 


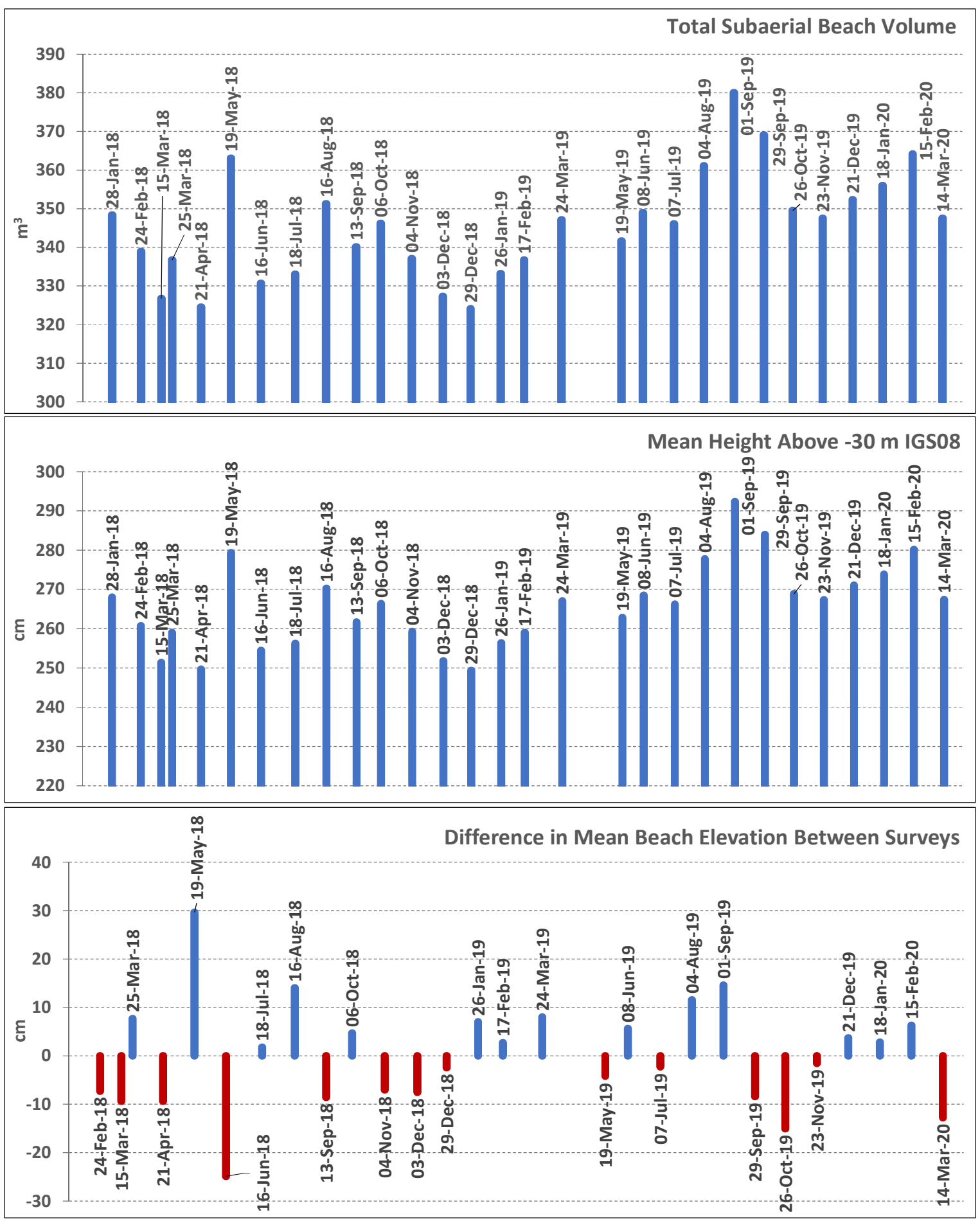

Figure JB01-10. Calculated sediment volume, mean profile elevation, and mean elevation change for the beach profile at station JB01. These parameters were calculated from 0-130 meters of the profile length. Eight of the twenty-nine beach elevation profiles were shorter than the "standard profile length" for the station (130 m). These profiles were extended using the procedure described in Chapter 2: Methods. Seven of the profiles were extended less than or equal to $10.0 \mathrm{~m}$ which is considered negligible (four were less than $1 \mathrm{~m}$ ). The longest extension (11.1 m December 3, 2018) was measured following winter storms when the beach was eroded. 


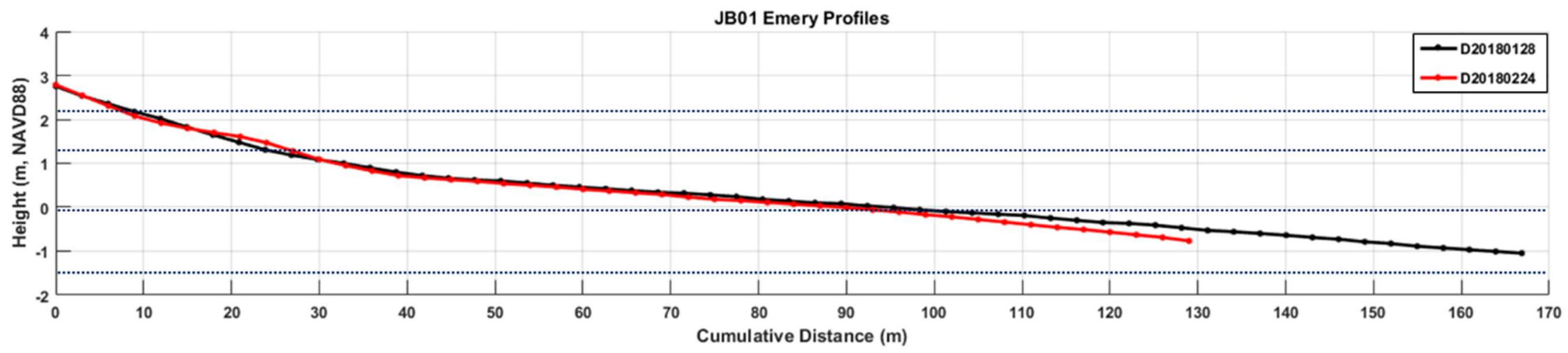

Figure JB01-11. Beach elevation profiles for JB01 on January 28, 2018 and February 24, 2018.

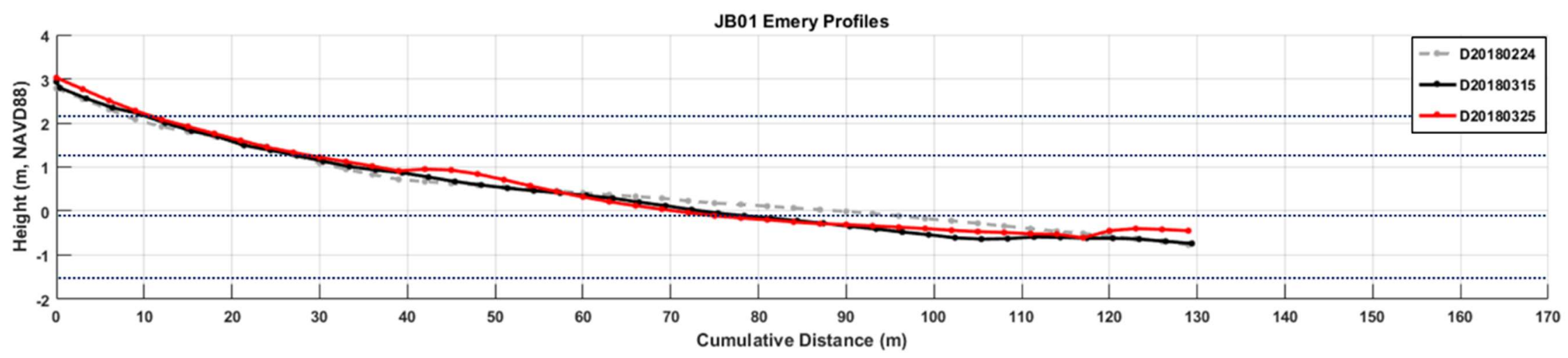

Figure JB01-12. Beach elevation profiles for JB01 on February 24, 2018, March 15, 2018, and March 25, 2018. 


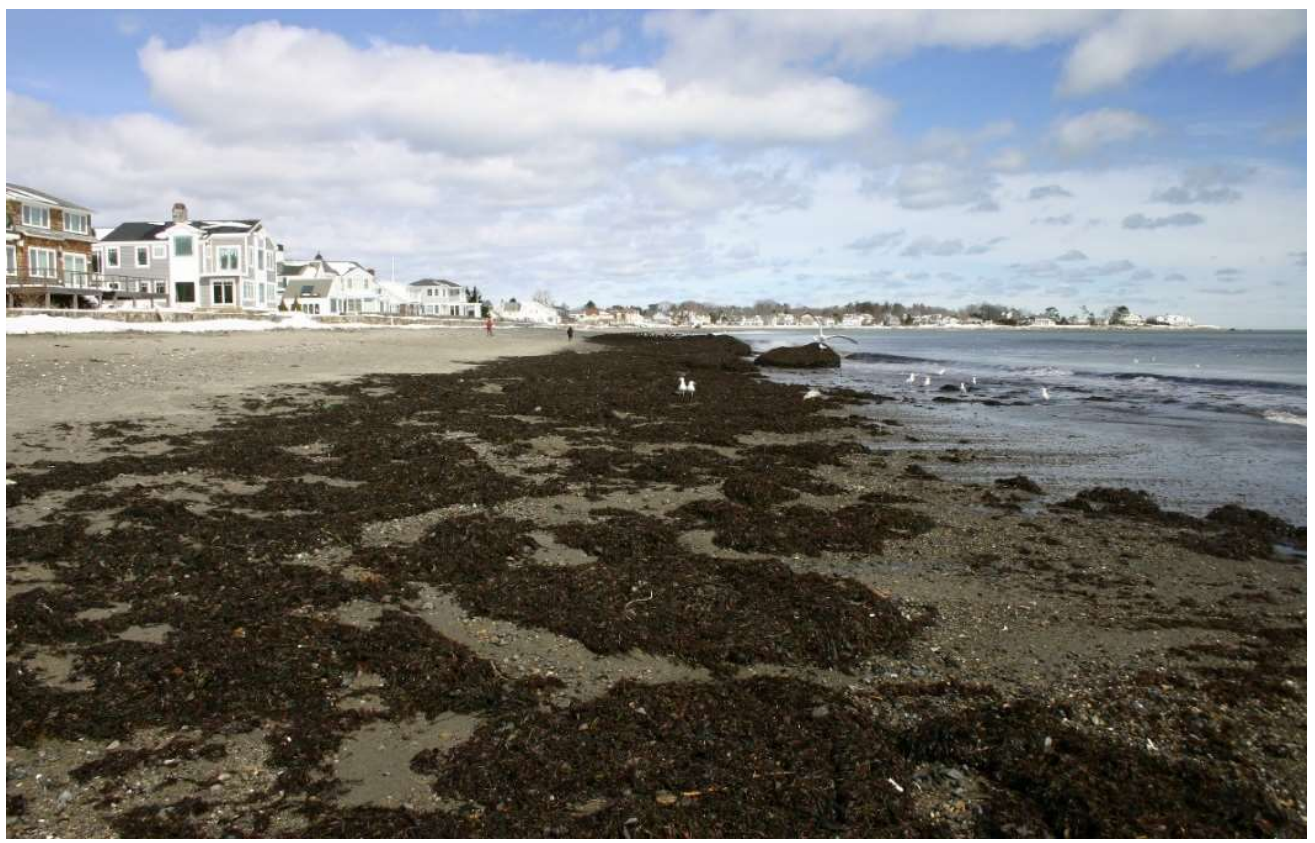

Figure JB01-13. Seaweed washed up at JB01 following the series of winter storms in late winter 2018. Photograph was taken on March 15, 2018.

Little change occurred in the beach elevation on March 25 with the exception of a small ridge located at mid-beach. On April 21, the ridge had migrated landward and a berm was forming. By May 19 the ridge had reached the upper beach and had largely rebuilt to pre-storm levels (Figures JB01-14 and JB01-15). An anomalously large volume of sand was computed for JB01 on May 19, 2018 (Figure JB0110) based on the beach profile. The volume of sediment is surprising considering that the previous and the following months' volumes were low. However, review of the field observations, photographs and notes indicate no obvious issues in the field protocol. In addition, the field photographs indicate the presence of a wide backshore and an accretional berm (Figure JB01-14). Therefore, the large volume cannot be discounted and may indicate a large volume of sand that migrated onshore and was subsequently redistributed. This process will be considered further as more field data is collected.

With the exception of the anomalously high volume of sand on May 19, the beach elevation and volume at JB01 remained low throughout the spring and early summer and only moderately increased in late summer and fall 2018 (Figure JB01-10). In late fall and winter 2018 and winter 2019, the sand volume at JB01 again decreased in response to the fall storms, including Avery (Nov 15-16, 2018) (Table 3-3). Sand volumes and average beach elevations increased through late winter until fall 2019 (JB01-7). In fact, the largest volumes and elevations measured during this study occurred on September 1, 2019. 
The beach elevation and sand volume decreased slightly from the very high values seen in September 2019 but were still relatively high overall compared to most of the previous year in 2018. From November 2019 to February 2020 the beach steadily increased once more despite a few winter storms with strong easterly winds and high waves including Ezekiel (Dec 2-4, 2019), Gage (December 30-31), and two unnamed winter storms in late winter 2020 (February 27-28 and March 6-7) (Table 3-3). The most recent profiling date in March 2020, however, decreased in volume. However, overall there were no periods of prolonged erosion in late 2019 and early 2020.

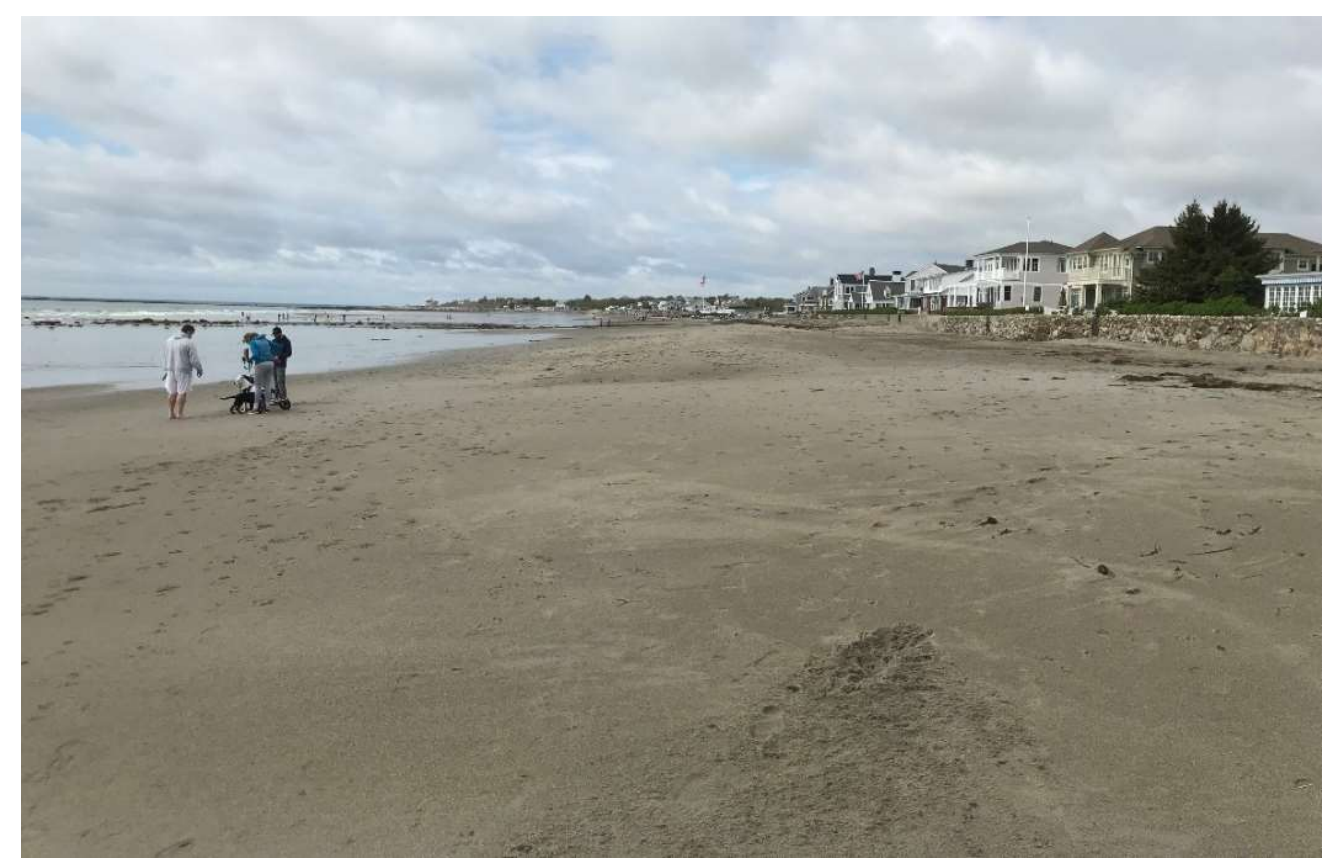

Figure JB01-14. Upper beach by JB01 built up by the landward migration of sand ridges. Photograph is looking south and was taken on May 19, 2018. 


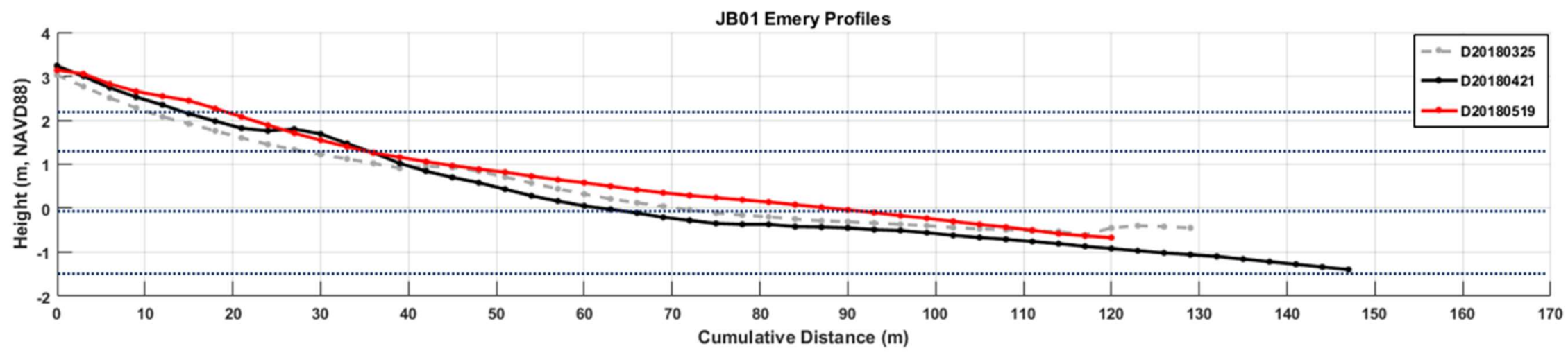

Figure JB01-15. Beach elevation profiles for JB01 on March 25, 2018, April 21, 2018, and May 19, 2018.

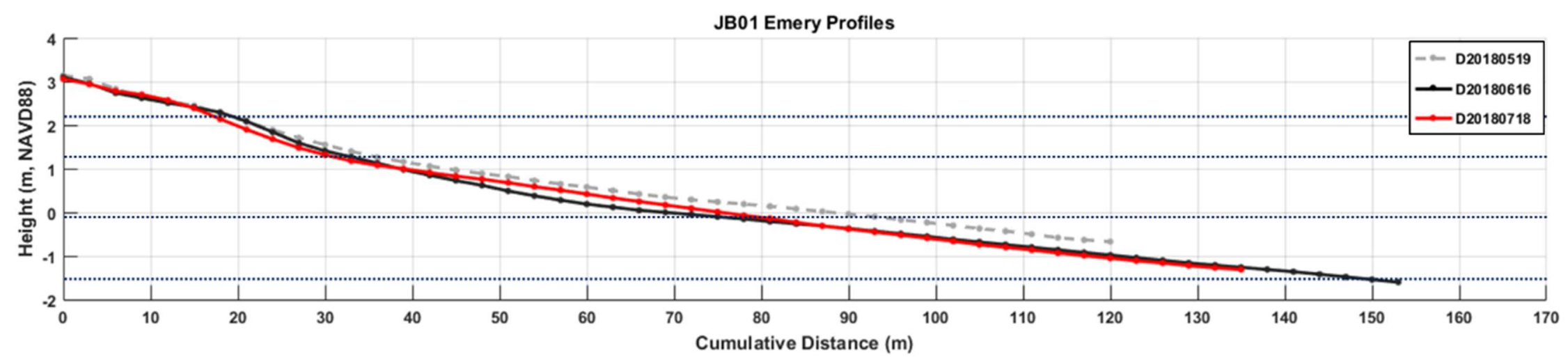

Figure JB01-16. Beach elevation profiles for JB01 on May 19, 2018, June 10, 2018, and July 18, 2018. 


\section{Results for Station at Jenness State Beach: JB02}

Overview. JB02 is located at Jenness State Beach (Figure JB-1). A concrete seawall separates the beach from a parking area and bathhouse (Figure JB02-1). The beach is relatively wide (typically 175 to $200 \mathrm{~m}$ ) with low amplitude $(<1 \mathrm{~m})$ morphologic features that are periodically present (e.g., berms during accretional periods) (Figure JB02-1). The profile transect extends from the seawall to the low tide swash (water line) (JB02-2). The backshore is relatively narrow and is normally composed of sand. The low tide terrace is wide and flat (Figure JB02-3). There are bedrock or boulders outcropping on the low tide terrace $\sim 100 \mathrm{~m}$ to the north of the beach elevation transect (Figure JB02-4). In order to maintain the beach for visitors, the upper beach is periodically mechanically raked or graded to remove seaweed and debris left by beach users, or to redistribute sand (Figure JB02-5). During accretional conditions the beach surface is largely composed of sand with a few scattered pebbles (Figure JB02-6). However, during stormy conditions, the fine to medium sand veneer is removed and a pebble lag deposit is exposed (Figure JB02-7).

Jenness State Beach was heavily damaged during the late winter 2018 nor'easters when waves overtopped the seawall causing damage to the bathhouse, parking lot, and general infrastructure (Figure JB02-8). A sand ramp was formed against the seawall, presumably by wave action during a storm surge, which allowed sand and gravel to be pushed into the parking lot (Figure JB02-9). Consequently, the bathhouse was replaced, the parking repaved, and the area refurbished. Construction started in November 2018 and was not completed until May 2019. According to New Hampshire State Parks, the cost of these renovations was approximately $\$ 1$ million. As a result of the construction, the back marker at station JBO2 was lost and the profile had to be aligned with a new back site. However, the beach elevation profile was located along the same transect with only a minor adjustment.

Summary. As stated earlier, it is important to recognize that month-to-month changes in the beach elevation and volumes can be relatively large, so it is more useful to look at trends over several months. Clearly, Jenness State Beach had three periods of erosion between December 2016 and March 2020: February 17 to June 27, 2017; March 6 through July 17, 2018; and a minor period of erosion from March 25 to July 8, 2019. The most severe erosional period was due to the late winter 2018 nor'easters. Between these periods the beach fully regained the sediment volume and elevation during summer to late fall. Equally important is to recognize that Jenness State Beach has a relatively low elevation overall. Consequently, even when in an accretional phase the beach is low and particularly susceptible to flooding and storm surges. 

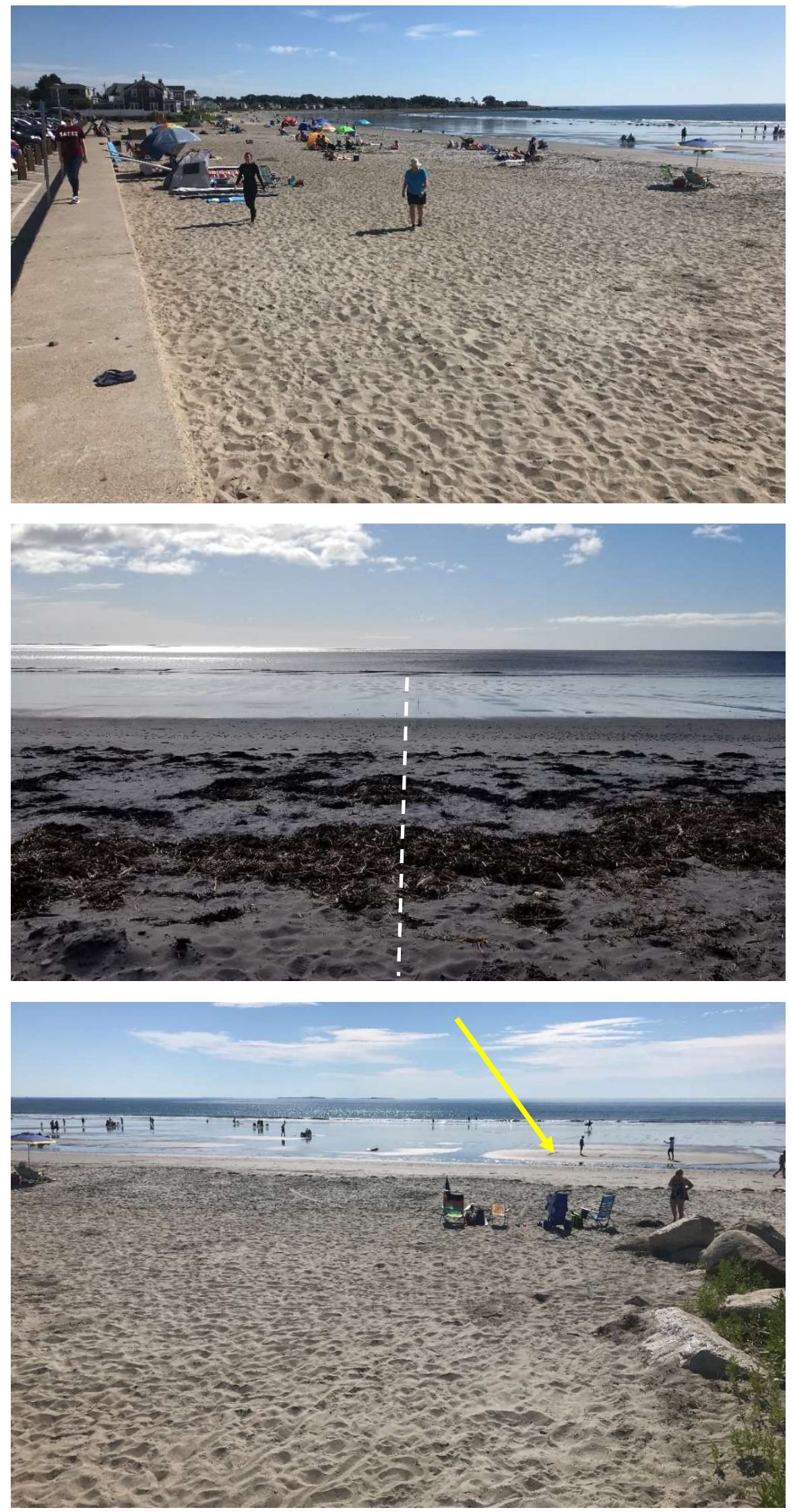

Figure JB02-1. Upper Jenness State Beach on July 8, 2019. A seawall separates the beach from the parking lot, bathhouse, and coastal roadway. Note the wide accretional beach with a small berm.
Figure JB02-2. Station JB02 looking seaward on May 21, 2019. The profile transect is marked by a white dashed line.
Figure JB02-3. Looking seaward at Jenness State Beach on July 8, 2019. Note the wide low tide terrace and small ridges migrating landward (arrow). 

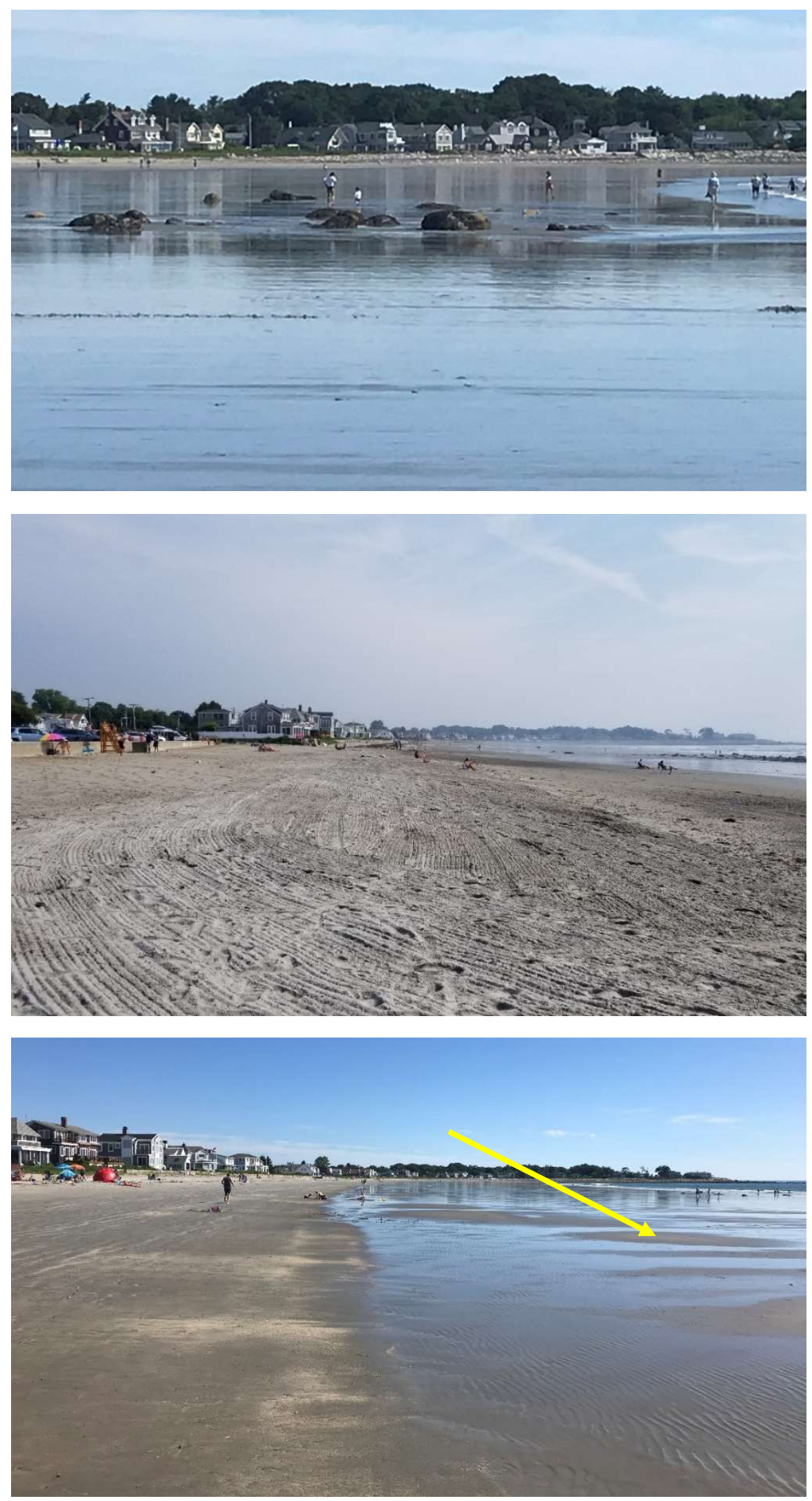

Figure JB02-4. Lower Jenness State Beach on July 8, 2019. Note the wide low tide terrace and exposed rocks. During highly eroded conditions much more of the rocks are exposed. During maximum accretional conditions the rocks are often nearly buried.
Figure JB02-6. Jenness State Beach looking south from JB02 during accretional conditions on July 17, 2018. The beach is largely sand with scattered pebbles. Note the low amplitude ridge and runnel on the low tide terrace (arrow) indicative of the beach building process. 


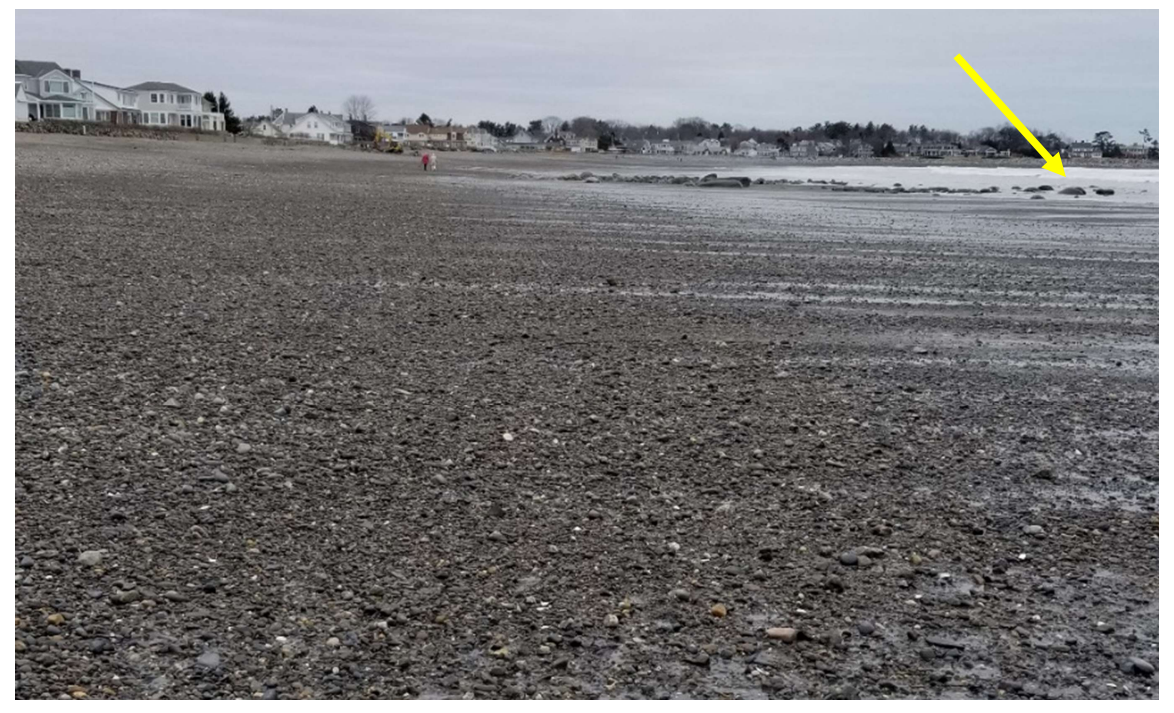

Figure JB02-7. Jenness State Beach looking north from station JBO2 following Nor'easter Riley on March 2018. The sand normally covering the beach has been eroded leaving pebble lag deposits. Note the rock outcrop (arrow) is more exposed than during accretional conditions (see Figure JB02-4).

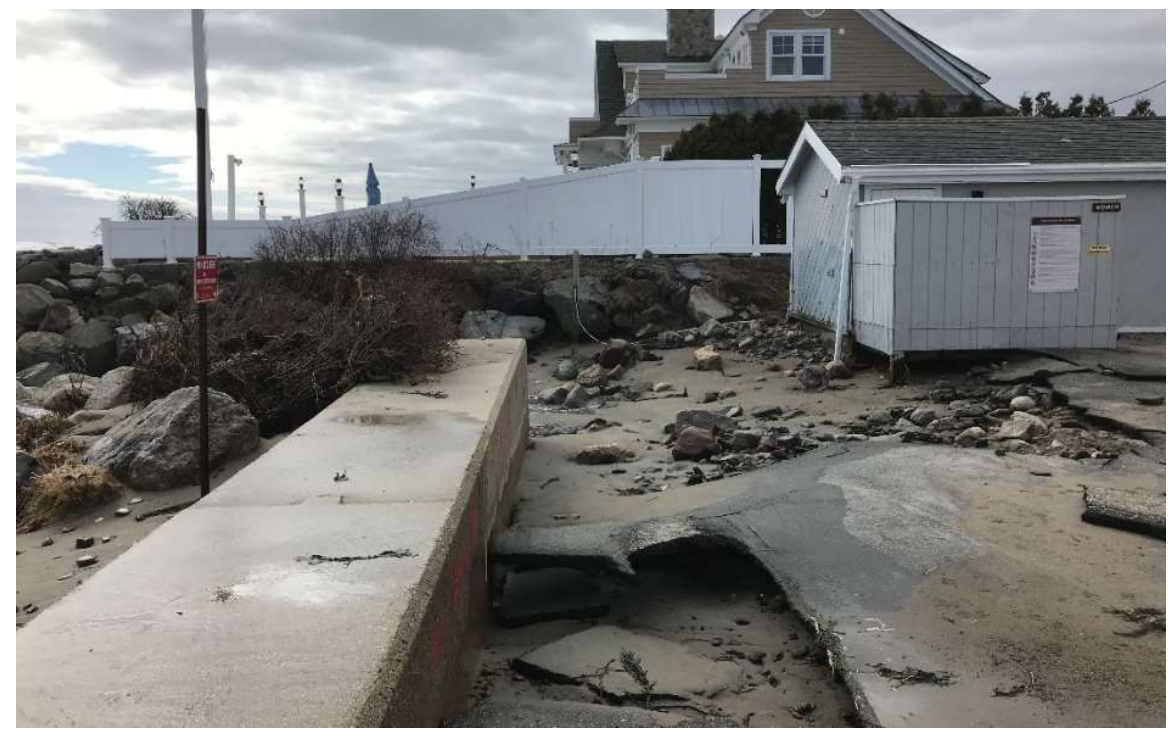

Figure JB02-8. Jenness State Beach facilities which were badly damaged by the late winter 2018 nor'easters. As a result, the bathhouse and parking lot had to be replaced. Photograph taken on March 4, 2018.

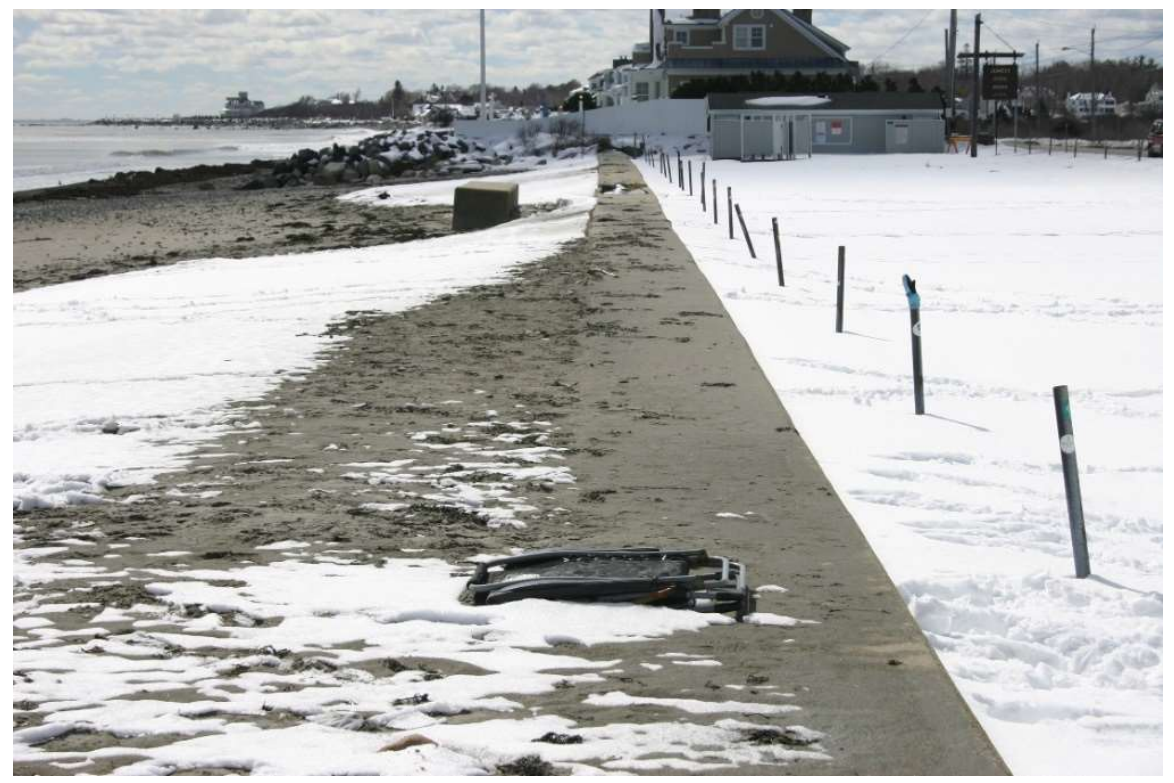

Figure JB02-9. A ramp created by overwash at Jenness State Beach on after the series of severe nor'easters in late winter, on March 15, 2018. This occurs when sand and gravel from the beach is pushed up against seawalls. The ramp facilitates sediment to be pushed over the seawall by wave action and storm surge. 
General Profile Characteristics. The station at JB02 is one of the original stations in the profile network and was established in late winter 2016. The elevation profile was run forty-five times between December 8, 2016 and March 12, 2020 (Figure JB02-10). All plotted beach profiles can be found in Appendix C(4). Review of the elevation profiles taken over the entire period showed limited variation in relief with a slight concave-up cross-section. However, the beach elevation profiles signaled major erosive events with changes in elevation. The beach profiles were typically $150 \mathrm{~m}$ to $170 \mathrm{~m}$ in length from the seawall to the low tide swash. A number of the profiles approached or exceeded $190 \mathrm{~m}$ in length with the longest being $216 \mathrm{~m}$ on February 19, 2019 during a very low tide. The shortest elevation profile was 95 m on March 6, 2018 following the Nor'easter Riley. Examination of the sweep zone shows the elevation of the beach varied from a minimum of $\sim 0.5 \mathrm{~m}$ near the seawall in the upper beach to $\sim 1.3 \mathrm{~m}$ in the lower intertidal zone (Figure JB02-10).

A useful comparison to assess extreme changes in beach profiles is to compare the maximum average elevation profile with the minimum average elevation profile. However, as often is the case, multiple dates have very similar extreme values. Such is the case for the maximum average elevation profile for JB02. The average elevations for the beach from the seawall to $150 \mathrm{~m}$ seaward are the same (within the uncertainty of the measurements) on December 20, 2017, November 17, 2017, January 27, 2019 and October 26, 2019 and the profiles are nearly identical (Figure JB02-11). Since all of these are similar, the October 26, 2019 profile was chosen to represent the maximum average elevation. This elevation and sand volume appear to be the equilibrium profile for an accretional beach at JB02. Similarly, there are several close minimum average elevation profiles, but June 18, 2018 is the lowest. The average difference between the October 26, 2019 and June 18, 2018 elevation profiles is $0.5 \mathrm{~m}$ ranging from near zero for the landward $40 \mathrm{~m}$ of the profile to $0.7 \mathrm{~m}$ at mid beach and $1.3 \mathrm{~m}$ in the lower beach (Figure JB02-12).

The June 18, 2018 beach elevation profile is particularly revealing. Due to an exceptionally low tide, the profile extends nearly $200 \mathrm{~m}$ seawards exposing a heavily scoured lower intertidal area (Figures JB02-12 and JB02-13). Mostly likely this occurred during other major erosive events like the sequence of severe nor'easters that occurred in late winter 2018 including Riley, Quinn, and Skylar in March 2018 , but the profiles completed in the months leading up to June did not extend far enough offshore to include the scoured area. Following this period, small amplitude ridge and runnel systems migrated across the lower intertidal to rebuild the beach as shown on July 17 and September 13, 2018 (Figure JB02-14).

The overall low elevation of the beach, except adjacent to the seawall, makes Jenness Beach highly susceptible to storm surge inundation and wave erosion. During storm surges the entire beach is flooded and the area landward of the seawall is vulnerable to flooding and sediment overwash, as evidenced by the damage sustained during the late winter 2018 nor'easters. 


\section{JB02 Emery Profiles}

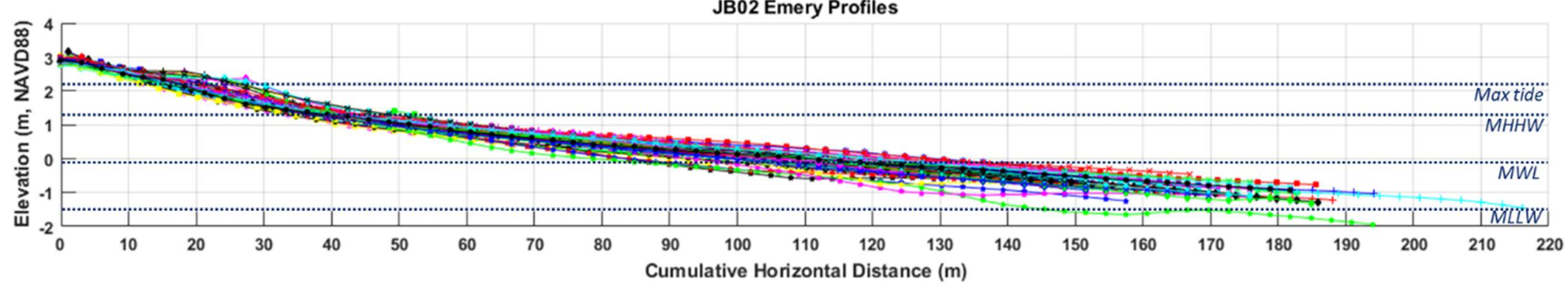

Figure JB02-10. All forty-five beach elevation profiles run at JB02 between December 8, 2016 and March 12, 2020. Maximum tidal elevation (max tide), mean higher high water elevation (MHHW), mean water level (MWL), and mean lower low water elevation (MLLW) are indicated by the dotted lines. 

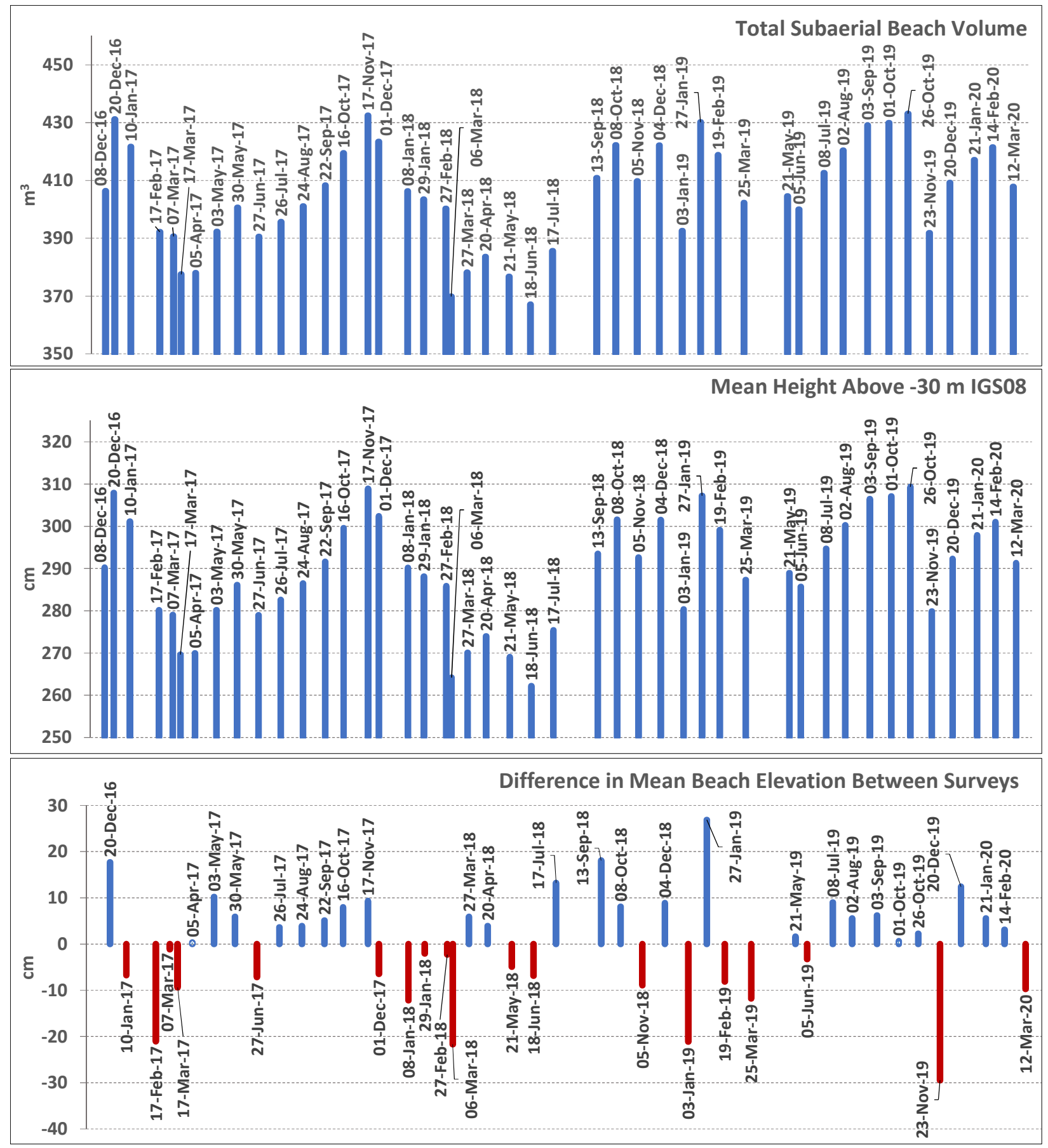

Figure JB02-11. Calculated sediment volume, mean profile elevation, and mean elevation change for the beach profile at station JB02. These parameters were calculated from 0-140 $\mathrm{m}$ of the profile length. Five of the fortyfive elevation profiles were shorter than the "standard profile length" for the station (140 $\mathrm{m}$ ). These profiles were extended using the procedure described in Chapter 2: Methods. Two of the profiles were extended less than or equal to $6.6 \mathrm{~m}$ which is considered negligible. One of the longest extensions (41.4 m on March 6, 2018) followed winter storms when the beach was eroded. The other long extension (44.3 m on August 2, 2019) was measured during a neap tide. 


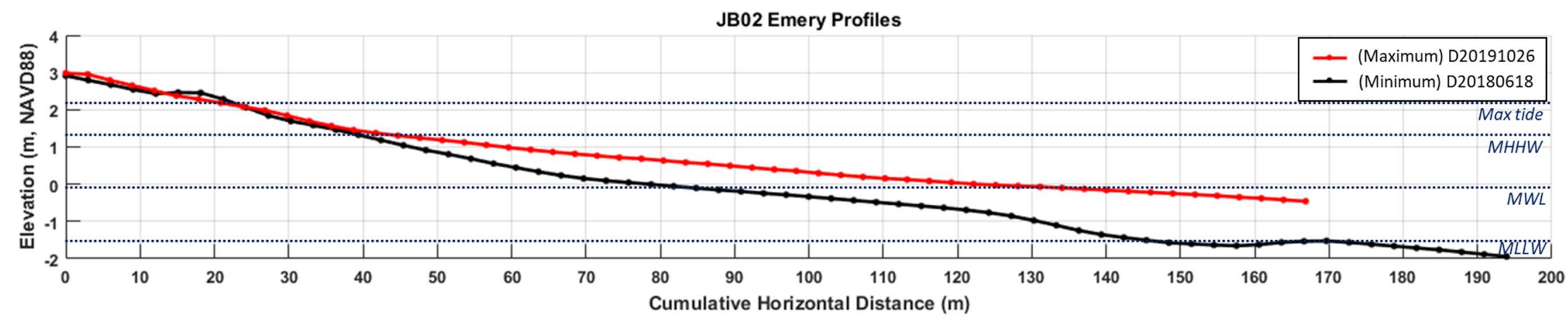

Figure JB02-12: Maximum (October 26, 2019) and minimum (June 18, 2018) profiles by volume from the study period at station JB02. Note that this is not the impact of a single event as the profiles are not consecutive monitoring dates. Rather this comparison looks at the extreme of differences of beach elevation profiles over the entire study period.

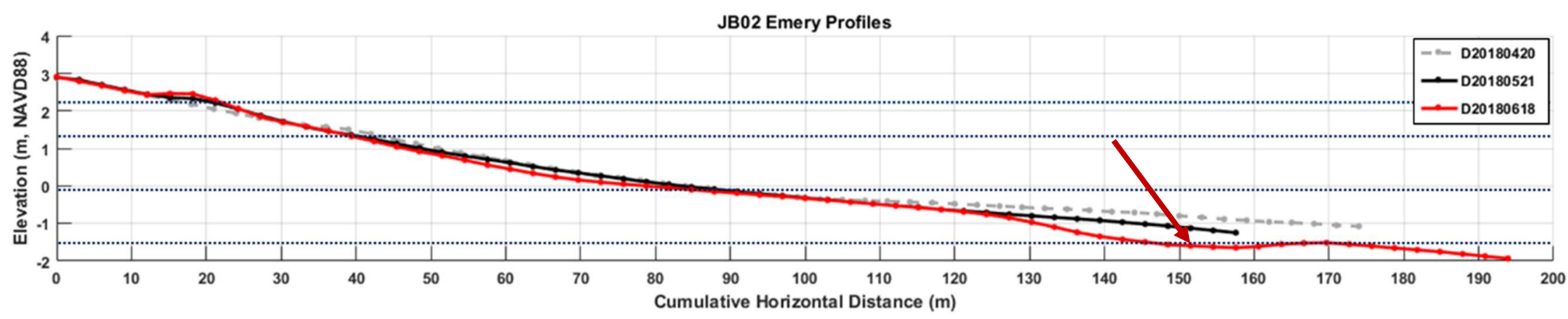

Figure JB02-13. Beach elevation profiles for JBO2 on April 20, 2018, May 21, 2018, and June 18, 2018. Note the scoured lower beach on the June 18 profile (arrow). 


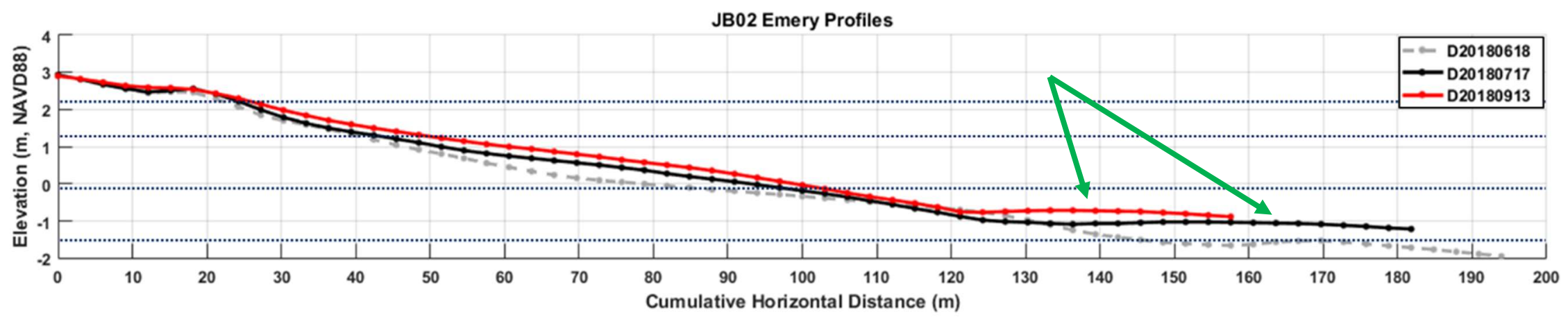

Figure JB02-14. Beach elevation profiles for JB02 on June 18, 2018, July 17, 2018, and September 13, 2018. Note the ridge and runnel systems migrating landward on July 17 and September 13 (arrows) signaling the recovery and accretion of the beach. 
Storm Effects, Beach Erosion, and Recovery. Review of the beach elevation profiles and volume of sand (and gravel) above approximately mean lower low water (MLLW) along JB02 from the seawall to $150 \mathrm{~m}$ seaward show Jenness State Beach experienced significant erosion and accretion during the monitoring period (Figures JB02-4, JB02-5).

In early winter 2017 the sediment volume and elevation was relatively high indicating an accretional phase (Figure JB02-11). For comparison, the highest volumes during the study period were fairly consistent. However, the series of winter storms from the end of December to the end of March 2017 including Fortis (Dec 28-30, 2016), Jupiter (Jan 17-19, 2017), Maya (Feb 5-7), Niko (Feb 7-9), Orson (Feb 12-13), Stella (a blizzard from Mar 14-15) and Theseus (Mar 31-Apr 2) (Table 3-3) significantly eroded the beach reaching a minimum volume for 2017 on April 5 . The erosional effect of each storm was more intense as the beach had little chance to recover between storms. During this period, the average elevation of the beach lowered nearly $0.4 \mathrm{~m}$. Although $0.4 \mathrm{~m}$ is a relatively small amount of erosion in comparison to losses suffered at other $\mathrm{NH}$ beaches during major storms (e.g., Hampton Beach), it is very significant at Jenness Beach due to its overall low elevation, which is characteristic for this location even under accretional conditions.

During spring, summer, and fall 2017, JB02 had a positive increase in sediment volume as the beach accreted. In fact, the relatively uniform and consistent increase continued between April 5 and November 17, 2017. However, once again with the increase in storm activity in winter 2018, JB02 suffered elevation and sediment loss as a result of the next series of winter storms including Grayson (Jan 3-5), Inga (Jan 17-18), Liam (Feb 7-9), and Noah (Feb 16-18). Similar to JB01, the beach was already at a lower elevation when heavily damaged by three powerful nor'easters in late winter 2018: Riley (Mar 1-4), Quinn (Mar 6-9) and Skylar (Mar 12-14) (Table 3-3). Therefore, the impact of the nor'easters was more damaging due to the lower elevation of the beach before the storms. Riley caused major erosion to almost all of the NH beaches. JB02 was significantly eroded as evidenced by the profile run on March 6, 2018 (Figures JB02-11, JB02-15). As discussed above, the storm with its very high tides and large waves flooded large areas of the coast and caused extensive damage.

The beach elevation and sediment volume fluctuated slightly but was overall significantly lower through the spring and early summer 2018 showing very little recovery (Figures JB02-11 and JB0216). For example, the June 18, 2018 elevation profile is the lowest seen throughout the study and shows that Jenness Beach had not yet started to recover from the nor'easters Riley, Quinn, and Skylar. As summer 2018 progressed, a modest increase in sediment volume and elevation started to occur as was seen on July 1 and continued throughout the rest of the summer and fall 2018 . Although there were fluctuations in volume and elevation including an erosional event shown in the January 3, 2019 profile, the beach had fully recovered by January 27, 2019 (Figures JB02-11 and Figure JB02-17). Late winter storms again took a toll on JB02 with the sediment volume decreasing to a low on June 5, 2019; however, the impact was minimal compared to the previous year. A likely factor in the differences between 2018 and 2019, besides storm intensity, is that the elevation of the beach had been significantly lowered before the 2018 nor'easters. At the end of summer 2019 in September, 
JB02 had accreted and gained elevation almost reaching the maximum measured during the study to date (Figure JB02-11). As expected, though, some beach erosion occurred in November 2019 at the beginning of the winter season, possibly due to a king tide coastal flood on October 28. Despite a few winter storms with strong easterly winds and high waves including Ezekiel (Dec 2-4, 2019), Gage (Dec 30-31), and two unnamed winter storms in late February-early March 2020 (February 27-28 and March 6-7: Table 3-3), the beach at JB02 accreted between November 2019 and February 2020 (Figure JB02-11). 


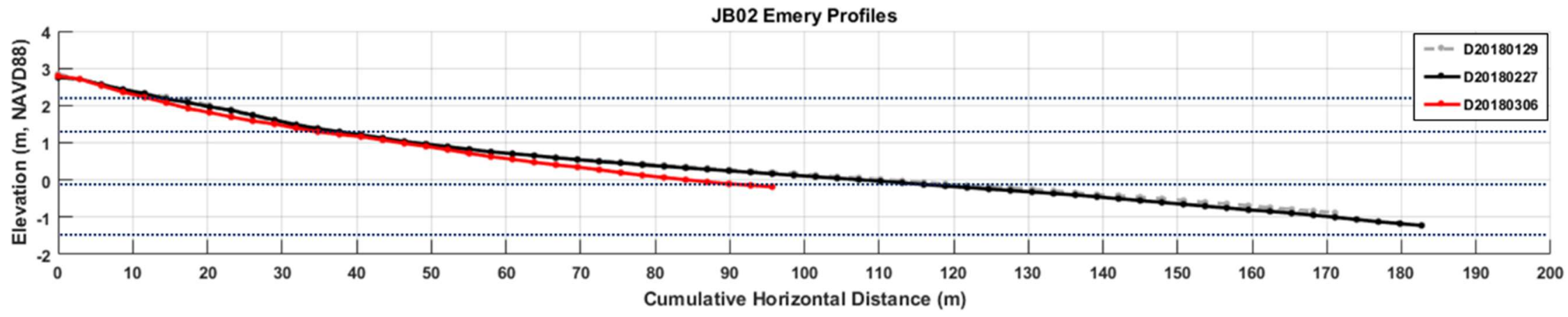

Figure JB02-15. Beach elevation profiles for JBO2 on January 29, 2018, February 27, 2018, and March 6, 2018.

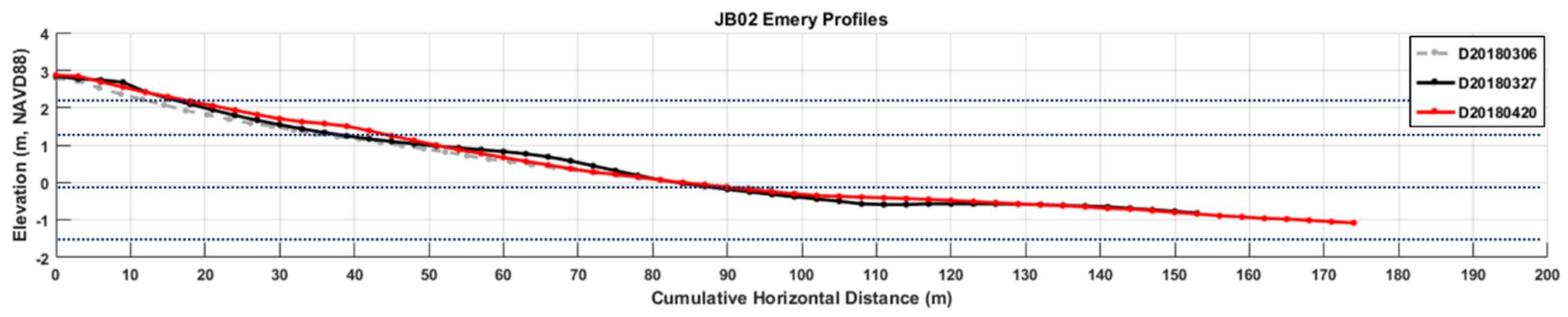

Figure JB02-16. Beach elevation profiles for JBO2 on March 6, 2018, March 27, 2018, and April 20, 2018. 


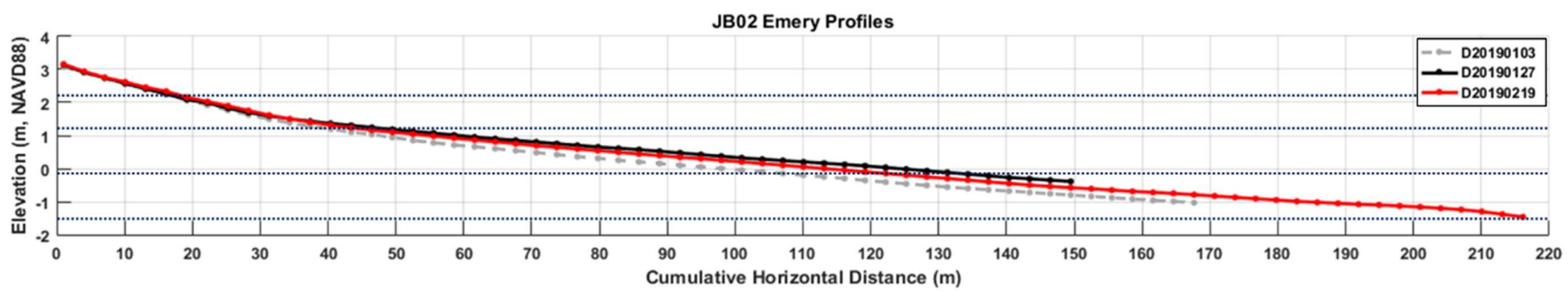

Figure JB02-17. Beach elevation profiles for JBO2 on January 3, 2019, January 27, 2019, and February 19, 2019. Note that this plot extends to 220 meters, rather than the standard 200 meters for JB02 profile plots. 


\section{Introduction to North Hampton Beach, North Hampton, $\mathrm{NH}$}

Note: In this report the southern end of the beach (south of Godfreys Ledge) is referred to as Plaice Cove. Locally it is also referred to as Northside Park.

North Hampton Beach and Plaice Cove form an attached or welded barrier that extends $1.4 \mathrm{~km}$ from Little Boars Head southward to the headland at Plaice Cove (Figure NHB-1). Although the system presently is a single barrier, it is composed of three very different beaches including North Hampton State Beach to the north, Plaice Cove to the south, and a tombolo (or a small isthmus) extending from the mid-beach area to Godfreys Ledge.

North Hampton State Beach (and the small section of beach at the northern end) is $~ 0.33 \mathrm{~km}$ in length and is strongly influenced by Little Boars Head to the north (Figure NHB-2) and Godfreys Ledge tombolo to the south. Little Boars Head, which is largely composed of unconsolidated glacial till covering bedrock, has been heavily eroded by wave action (Figure NHB-3) as evidenced by cobbleboulder or megaclast platforms that surround the headland and extend southward onto North Hampton State Beach (Figures NHB-2 and NHB-4). Overall, much of North Hampton State Beach is adjacent to or is underlain by eroded glacial till deposits providing an abundant source of cobbles and boulders (Figure NHB-4). The State Beach is backed by a concrete seawall that separates the beach from the parking lot and bathhouse (Figures NHB-1 and NHB-5). The northern $0.7 \mathrm{~km}$ of North Hampton Beach is lined with private homes that are fronted by riprap revetments.

Plaice Cove beach extends $\sim 0.7 \mathrm{~km}$ from the town boundary separating Hampton and North Hampton to the headland in the south (Figures NHB-1 and NHB-6). Similar to Little Boars Head, the eroded glacial deposits off the southern headland have formed a cobble-boulder platform that makes up the southern end of the beach (Figure NHB-7). Unlike North Hampton Beach which is bimodal with extensive cobble and boulder deposits, Plaice Cove beach is largely sandy. However, the sand supply appears to be very limited as Plaice Cove is relatively narrow with extensive engineering structures on the landward margin (Figures NHB-1). The entire length of Plaice Cove beach is either lined with riprap revetments or high concrete seawalls (Figure NHB-7). 


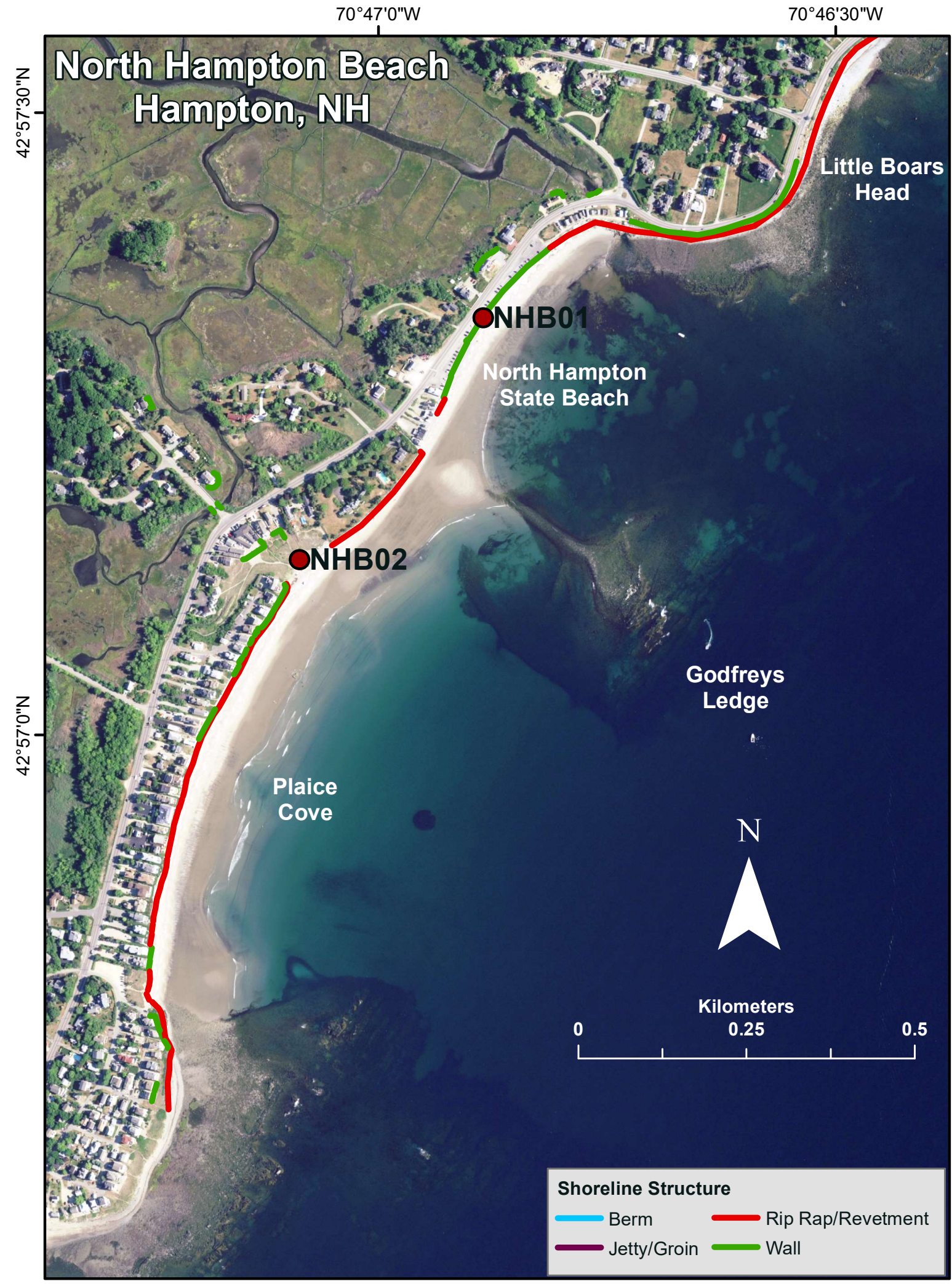

Figure NHB-1. Location map for North Hampton Beach, NH with stations, geographic features, and shoreline structures. 


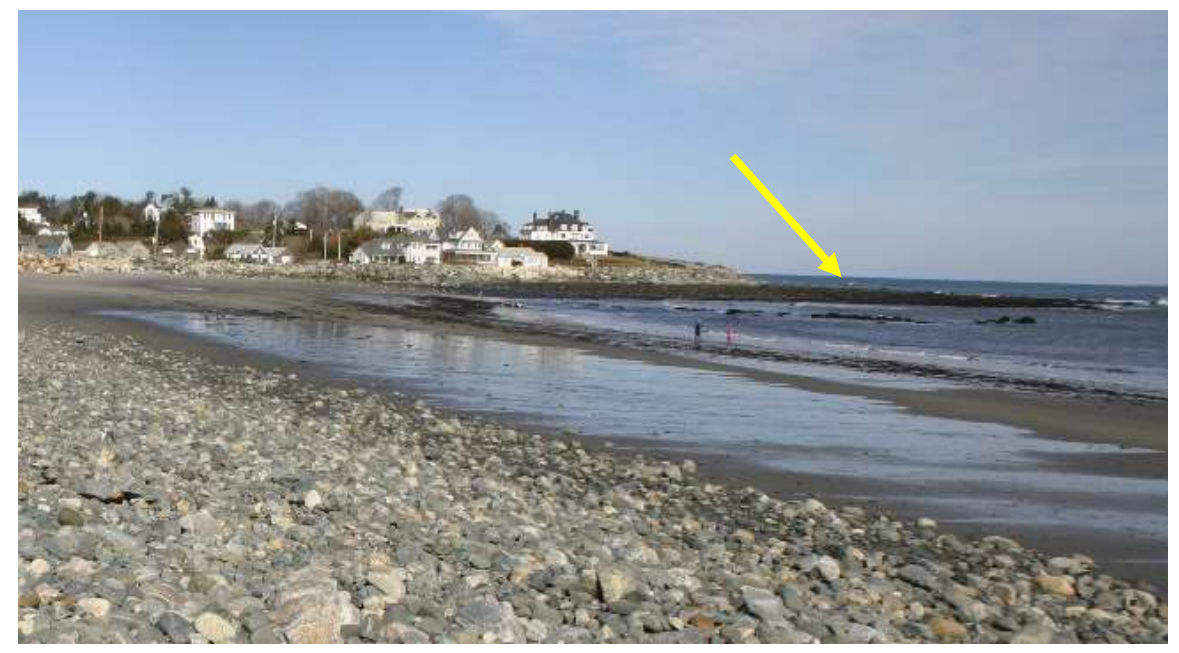

Figure NHB-2. Little Boars Head, which forms the northern extent of North Hampton Beach. Photograph is looking north from North Hampton State Beach on February 26, 2018. Note the pebble and cobble platform around the headland (arrow).

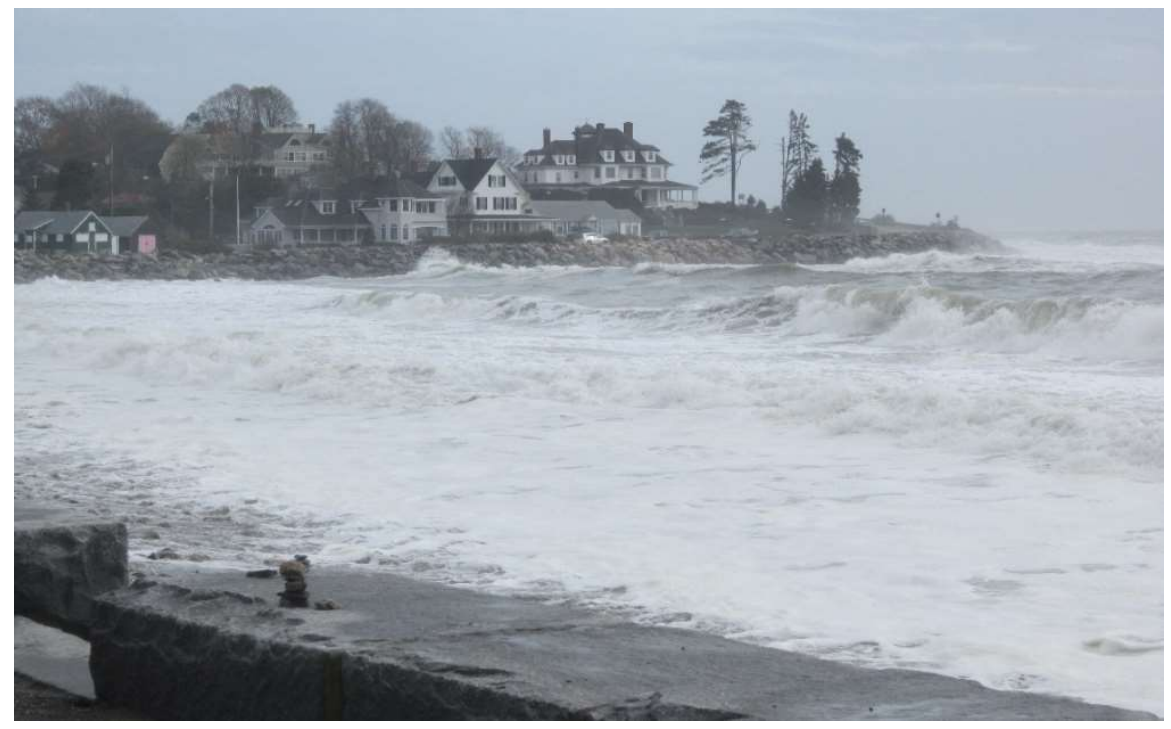

Figure NHB-3. Little Boars Head during a storm on October 30 , 2012. The photograph is looking north from station NHBO1.

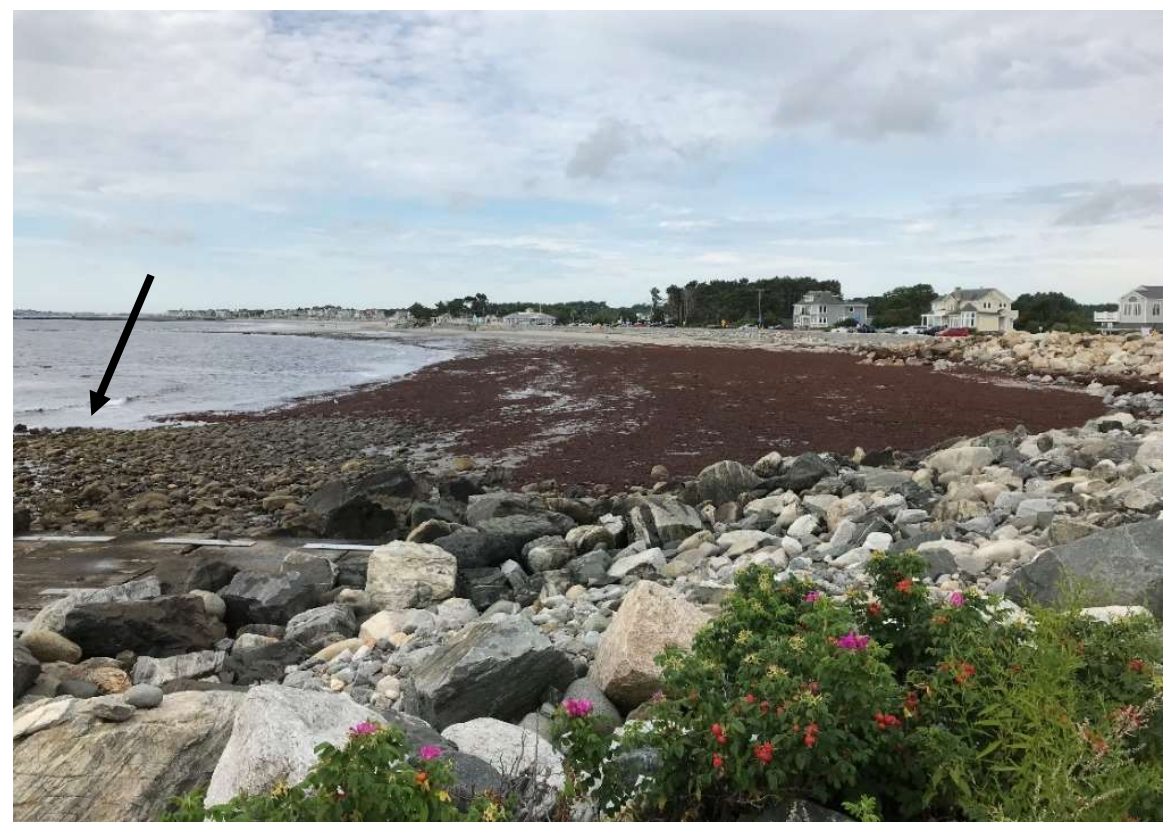

Figure NHB-4. North Hampton State Beach on September 2, 2019 after a stormy period when an excessive amount of seaweed washed onto the beach (dark red area). The photograph is looking south from Little Boars Head. Note the pebble and cobble platform adjacent to the headland formed by the erosion of till deposits (arrow). 



Figure NHB-5. North Hampton State Beach looking south on September 2, 2019. The bathhouse is shown by the arrow.

Figure NHB-6. North Hampton Beach and Plaice Cove on April 7, 2018. The photograph is looking south from station NHBO2. Note the narrow beach and the extensive rip rap seawalls (arrow).
Figure NHB-7. Headland at southern end of North Hampton Beach on August 2, 2020. The headland has a megaclast platform composed of cobbles and boulders (arrow) extending seaward. Note the sand veneer has been removed exposing the pebbles underneath. 
Godfreys Ledge is presently composed of bedrock. The sandy beach behind Godfreys Ledge tombolo is $0.32 \mathrm{~km}$ in length and bulges seaward (Figures NHB-1 and NHS-8). The widening of the beach here is a result of wave refraction around Godfreys Ledge causing longshore drift reversals and a reduction of wave energy leading to sediment deposition. Most of the beach and tombolo is composed of pebbles, cobbles, and boulders forming a platform that is exposed at low tide. Under accretional conditions the landward portion of the tombolo and the beach are covered with sand (Figure NHB8). Following periods of erosion, the veneer of sand that extends from the beach to Godfreys Ledge is sometimes removed exposing the pebbles, cobbles, and boulders underneath (Figure NHB-9). The shoreline south of North Hampton State Beach as well as part of Godfreys Ledge tombolo are also lined with private homes and riprap revetment separating the private upland from the beach.

During periods when the tombolo has been eroded, tree stumps are exposed in the intertidal zone (Figures NHB-10 and NHB-11). These tree stumps, which are found in several locations along the NH coast (Odiorne Point, Foss Beach, and North Beach) in intertidal areas, were formed when the beach transgressed landward with sea-level rise over previously forested areas. The remains of a drowned forest which are present in the intertidal zone at Odiorne Point, Rye, NH have radiocarbon age dates that show the tree stumps were killed by rising sea-level approximately 3,660-3,490 yrs B.P. (Lyon and Harrison, 1960; Harrison and Lyon, 1963; Kelley et al., 2010).

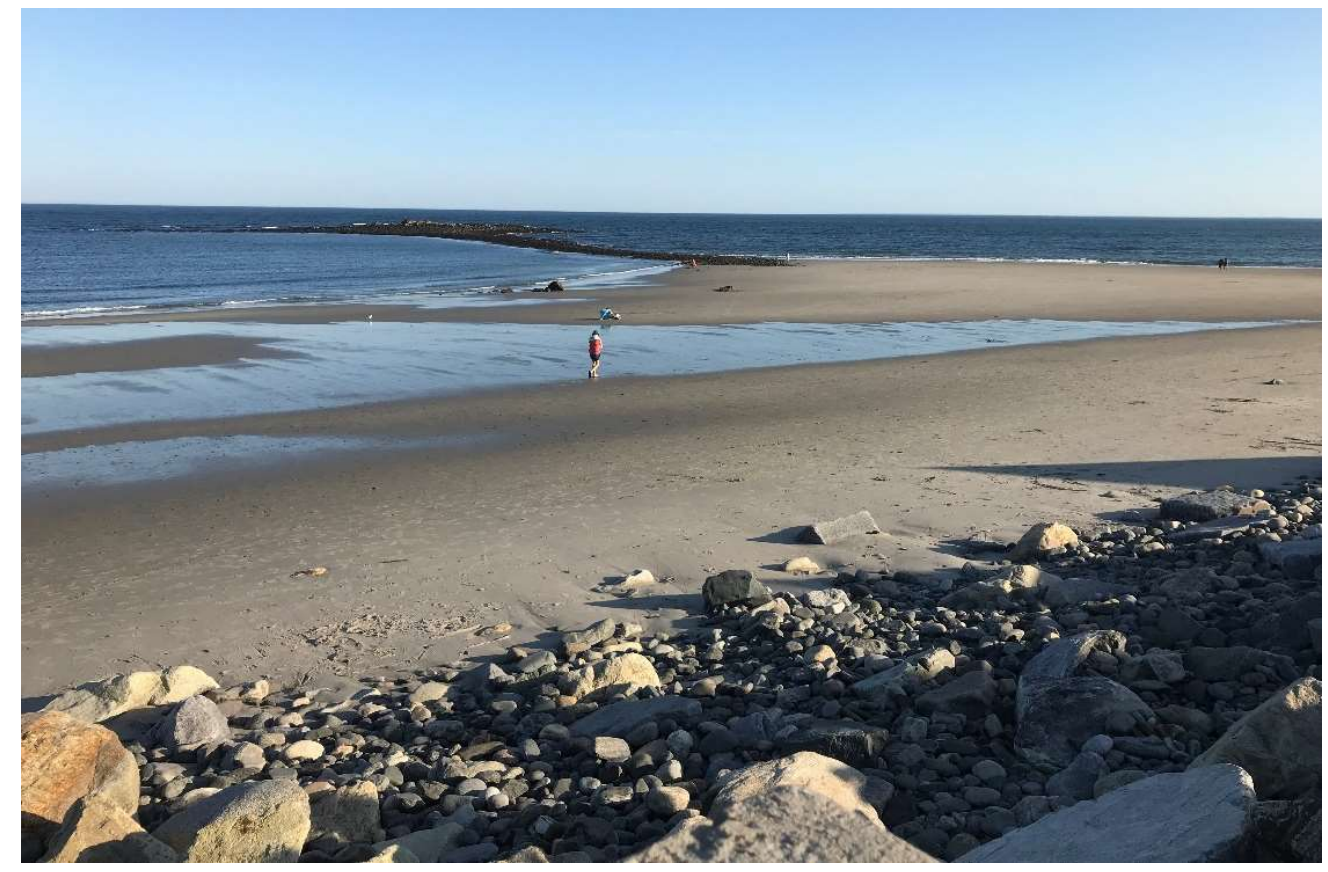

Figure NHB-8. Godfreys Ledge, which is a bedrock outcrop that is exposed off the southern end of North Hampton Beach. Wave refraction caused by the outcrop has formed a tombolo connected to the beach. The tombolo causes the beach to widen and is covered with sand during accretional conditions. During erosive conditions the underlying pebble and cobble lag deposit is exposed (see Figure NHB-9, below). The photograph was taken on September 28, 2019. 

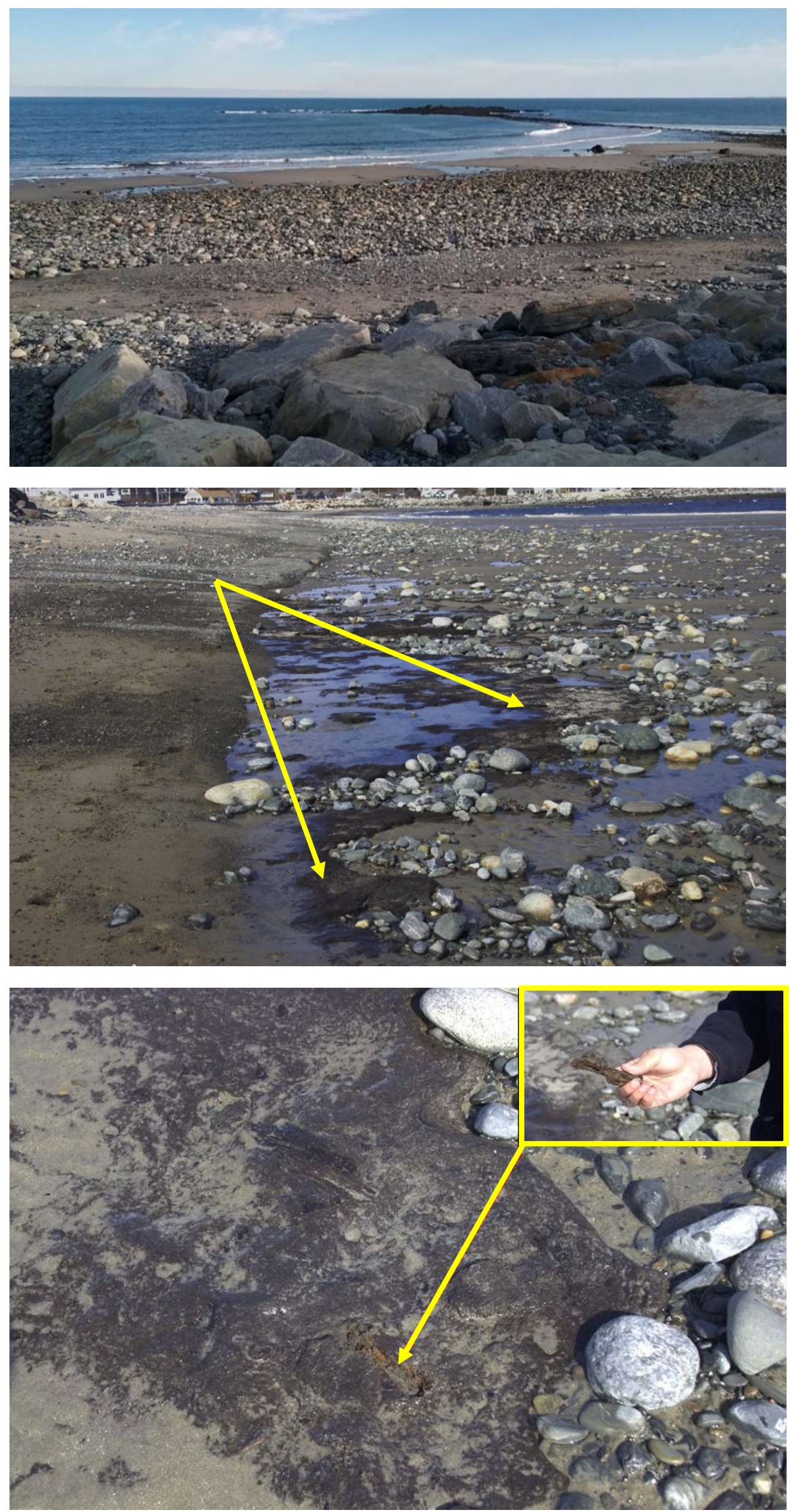

Figure NHB-9.

Godfreys Ledge tombolo on February 17, 2019 following a stormy period when much of the sand veneer was removed exposing the underlying pebble and cobble megaclasts.

\section{Figure NHB-10. \\ Exposed tree roots (arrows) uncovered by erosion on Godfreys Ledge tombolo on April 11, 2018.}

Figure NHB-11. Closeup of exposed tree roots uncovered by erosion on Godfreys Ledge tombolo on April 11, 2018. Note sample of the tree stump shown in the inset. 


\section{Results from Station at North Hampton State Beach: NHB01}

Overview. North Hampton State Beach is extremely complex due to the influence of Little Boars Head and Godfreys Ledge which form its boundaries (Figure NHB-1). As discussed above, pebble, cobble and boulder or megaclast platforms associated with Little Boars Head and Godfreys Ledge tombolo dominate the northern and southern portions, respectively, of the State Beach. In general, the beach cross-section elevation profile at NHB01 is extremely steep. The landward boundary of the beach is defined by a relatively low concrete seawall typically on the order of one meter in height above the sediment surface (Figure NHB01-1). A pebble-cobble ramp extends approximately three to five meters seaward from the seawall over much of the length of the beach. Prior to the series of severe nor'easters in spring 2018 including Riley (Mar 1-4), Quinn (Mar 6-9) and Skylar (Mar 12-14) (Table 3-3), the gravel ramp was largely composed of pebbles and cobbles. However, following these storms, which changed the character of the beach for the remainder of this reporting period, the gravel ramp was composed of pebbles and cobbles, but had a sand matrix (Figures NHB01-2).

As a result of the across-shore and alongshore variability in sediment, erosional and accretional trends are difficult to quantify from the single station at North Hampton State Beach. Overall, the area where NHBO1 is located tends to be sandier than both the northern and southern extents of the State Beach but is still characterized by cobbles and boulders in the lower intertidal.

Summary. North Hampton State Beach is somewhat unique for the NH coast. The beach is strongly affected by Little Boars Head to the north and Godfreys Ledge tombolo to the south which cause wave refraction and attenuation. Perhaps more significantly, Little Boars Head and Godfreys Ledge are composed of till or were covered with till which has eroded with sea-level rise and the Holocene transgression leaving extensive megaclast (pebble, cobble, and boulder) platforms which front the headlands and extend onto the beach. Therefore, the beach is bimodal with extensive gravel deposits, and is composed of megaclasts at the boundaries and underlying the lower intertidal. Also, the beach is often covered with a veneer of sand during accretional conditions that covers the megaclasts. This sand veneer is easily eroded, revealing the cobbles and boulders. Therefore, the mid and lower beach changes composition over very short time periods from sandy to very coarse gravel with cobbles and boulders. The cobble ramp at the seawall is a permanent structure. Overall, the beach tends to be narrow and steep.

As discussed above, North Hampton State Beach changed composition rapidly in response to storms. For example, a major increase in the height of the gravel ramp at the seawall accompanied by a dramatic lowering of the lower intertidal and a decrease in the cross-shore width of the beach occurred following the three severe nor'easters that occurred in late winter 2018. This storm sequence caused major beach erosion, changes in sediment grain size, and damage to infrastructure at NHB01. However, the maximum erosion and volume loss to the beach occurred during winter storms in 2019. It is also notable that the beach at NHB01 underwent a major amount of accretion in winter 2020 following a massive erosion event. 
The volume of sediment on the beach and the profile elevation at NHB01 recovered to pre-storm conditions relatively quickly following the late winter 2018 nor'easters (Riley, Quinn, and Skylar). However, this is not the case for the sediment composition. Field observations indicate the pebblecobble deposits on the beach, which were more separated prior to the storms, became extensively mixed during the storms. Part of this resulted from the beach being leveled or smoothed following these storms by large equipment which mixed the sand, pebbles, and cobbles.

Another trend observed at North Hampton State Beach is the development of an accretionary wedge, or a layer of sand which migrates onto the beach and covers the cobbles and boulders on the lower and/or the mid beach. The cobble ramp at the upper beach by the seawall seems to persist. This has been observed on other $\mathrm{NH}$ beaches as well, although not as pronounced as at North Hampton State Beach. This accretionary layer is somewhat ephemeral but is usually present to some degree after extended periods of relatively calm or depositional periods. Therefore, the response of this beach, and perhaps of mixed sediment beaches (sand and gravel) in $\mathrm{NH}$, is to have the sand veneer stripped off during higher wave energy, exposing the cobbles and boulders. During major storms the large clasts are eroded from the lower beach and form a ramp against the seawall. The ramp allows the pebbles and cobbles to overtop the seawall. Following these events, the sandy accretionary wedge returns.

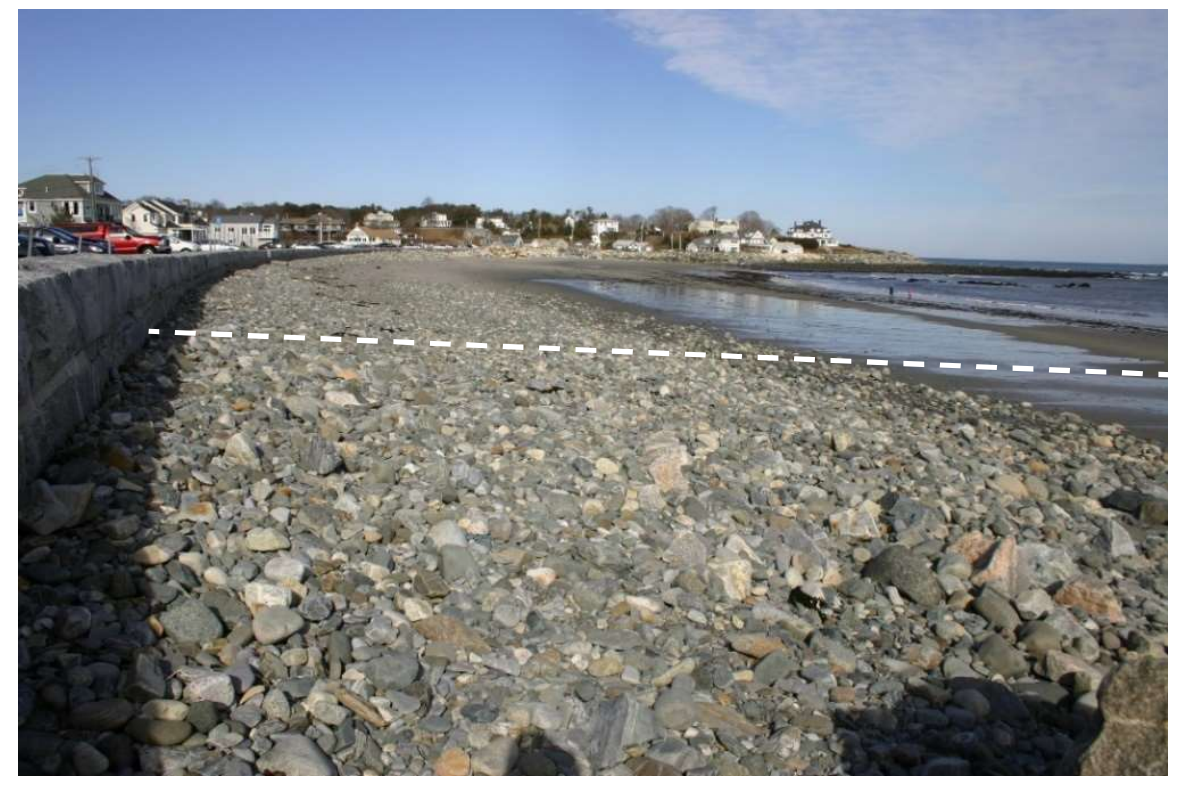

Figure NHB01-1. North Hampton State Beach looking north from the southern end of the beach on January 27 , 2018. The beach profile is typical for accretional conditions with a sandy cobble ramp against the seawall and the mid and lower beach covered with a sand veneer. Beach elevation profile transect NHBO1 is shown by the white dashed line. 


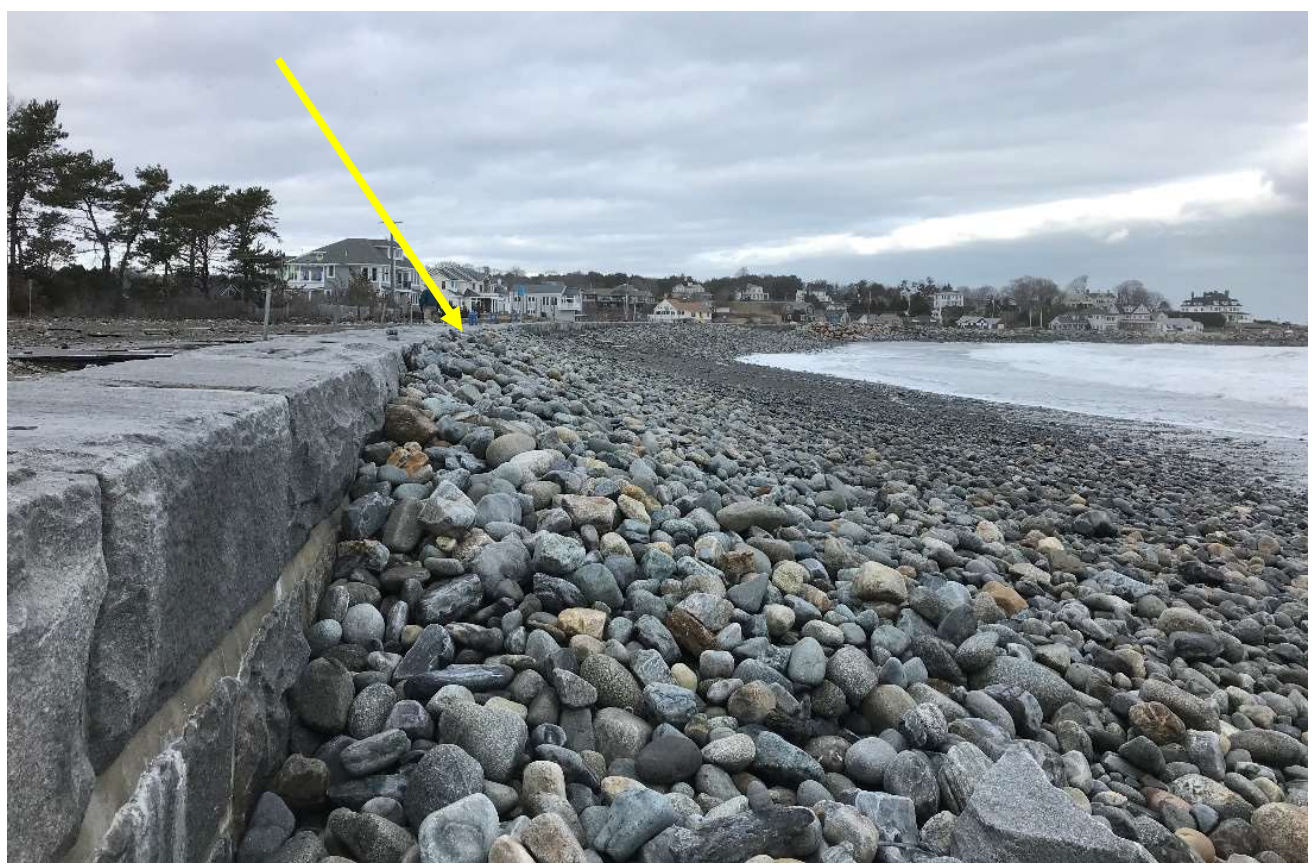

Figure NHB01-2. North Hampton State Beach looking north from the southern end of the beach on March 3, 2018 following Nor'easter Riley. Note the cobble ramp has built to the top of the seawall.

General Profile Characteristics. The beach elevation profile at NHB01 was run thirty times between January 27, 2018 and March 14, 2020. All plotted beach profiles can be found in Appendix C(5). Review of all of the profiles plotted together show that the beach was relatively narrow ranging from 60 to $80 \mathrm{~m}$ in width, extremely steep, and underwent very large vertical elevation changes (Figure NHB01-3). The maximum elevation differences of the beach varied from $\sim 0.6 \mathrm{~m}$ near the seawall, $\sim 1.1 \mathrm{~m}$ in the upper beach, to $\sim 1.4 \mathrm{~m}$ in the lower intertidal. Examination of individual beach elevation profiles for the maximum average elevation (August 30, 2019) versus the minimum average elevation (January 17, 2020) for the entire study shows extremes in the profiles from accretional to highly eroded conditions (Figure NHB01-4). The elevation profiles differed by $\sim 0.6 \mathrm{~m}$ at the berm crest, $\sim 1.4$ $\mathrm{m}$ at the base of the berm face, and $\sim 0.4 \mathrm{~m}$ at the swash zone (water line). Other elevation profiles had similar maximum and minimum elevations values including February 24, 2018 (similar maximum) and February 17, 2019 (similar minimum) (Figure NHB01-5). However, only two profiles are shown here for simplicity. 


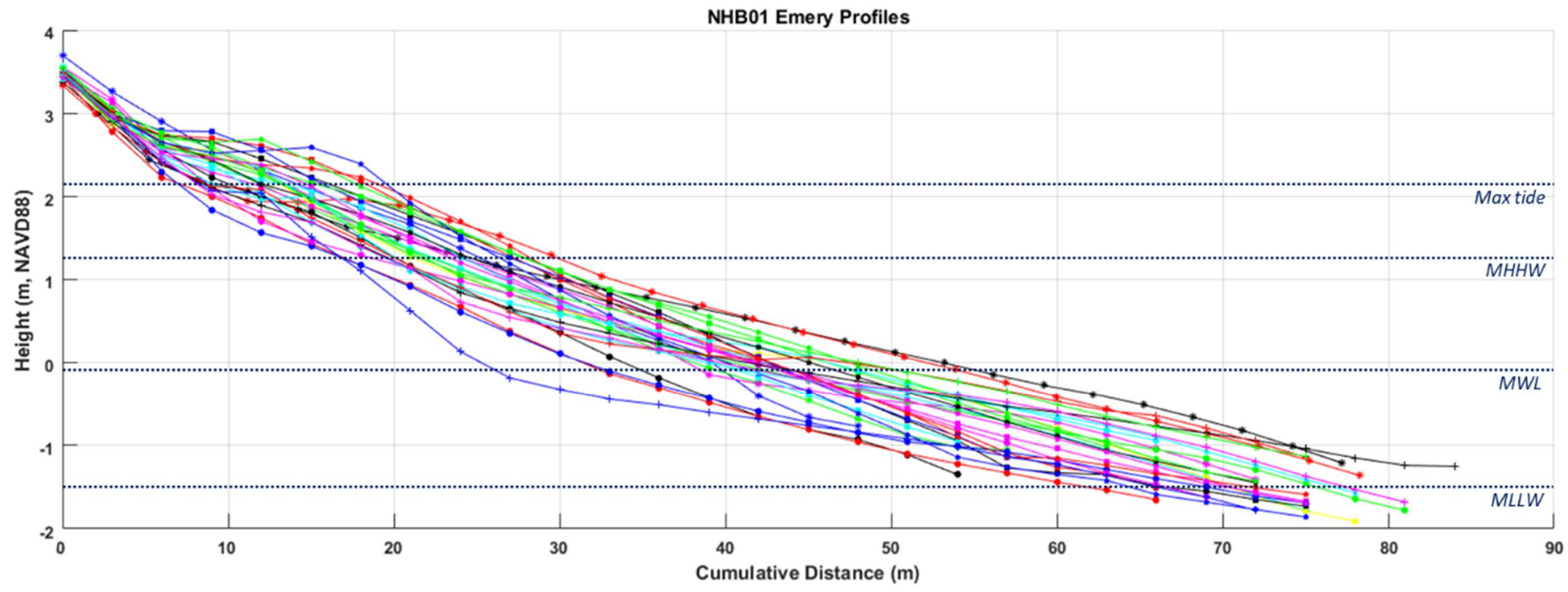

Figure NHB01-3. All thirty beach elevation profiles measured during the study period at North Hampton State Beach station NHB01 from January 27, 2018 to March 14, 2020. Maximum tidal elevation (max tide), mean higher high water elevation (MHHW), mean water level (MWL), and mean lower low water elevation (MLLW) are indicated by the dotted lines. 


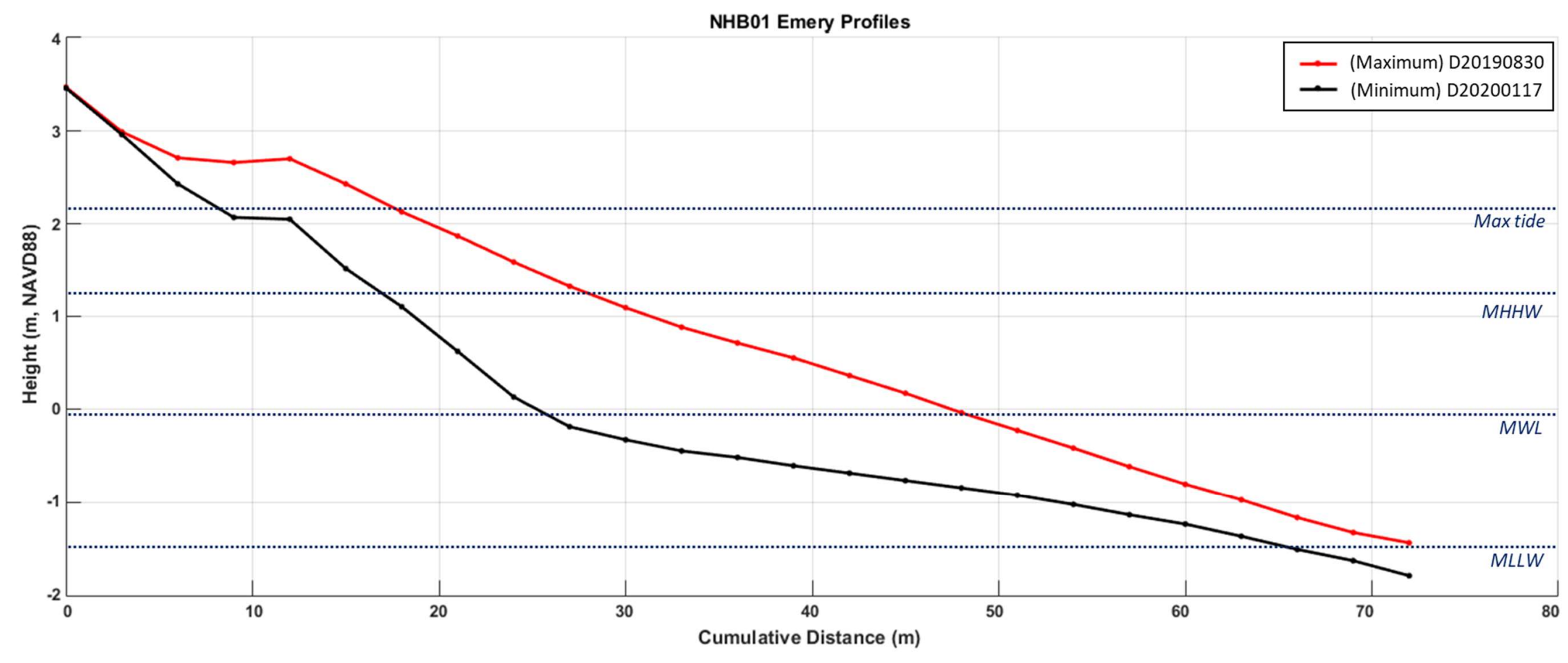

Figure NHB01-4. Maximum (August 30, 2019) and minimum (January 17, 2020) beach elevation profiles during the study period at station NHB01. Note that this is not the impact of a single event as the profiles are not consecutive monitoring dates. Rather this comparison looks at the extreme of differences of beach elevation profiles over the entire study period. 

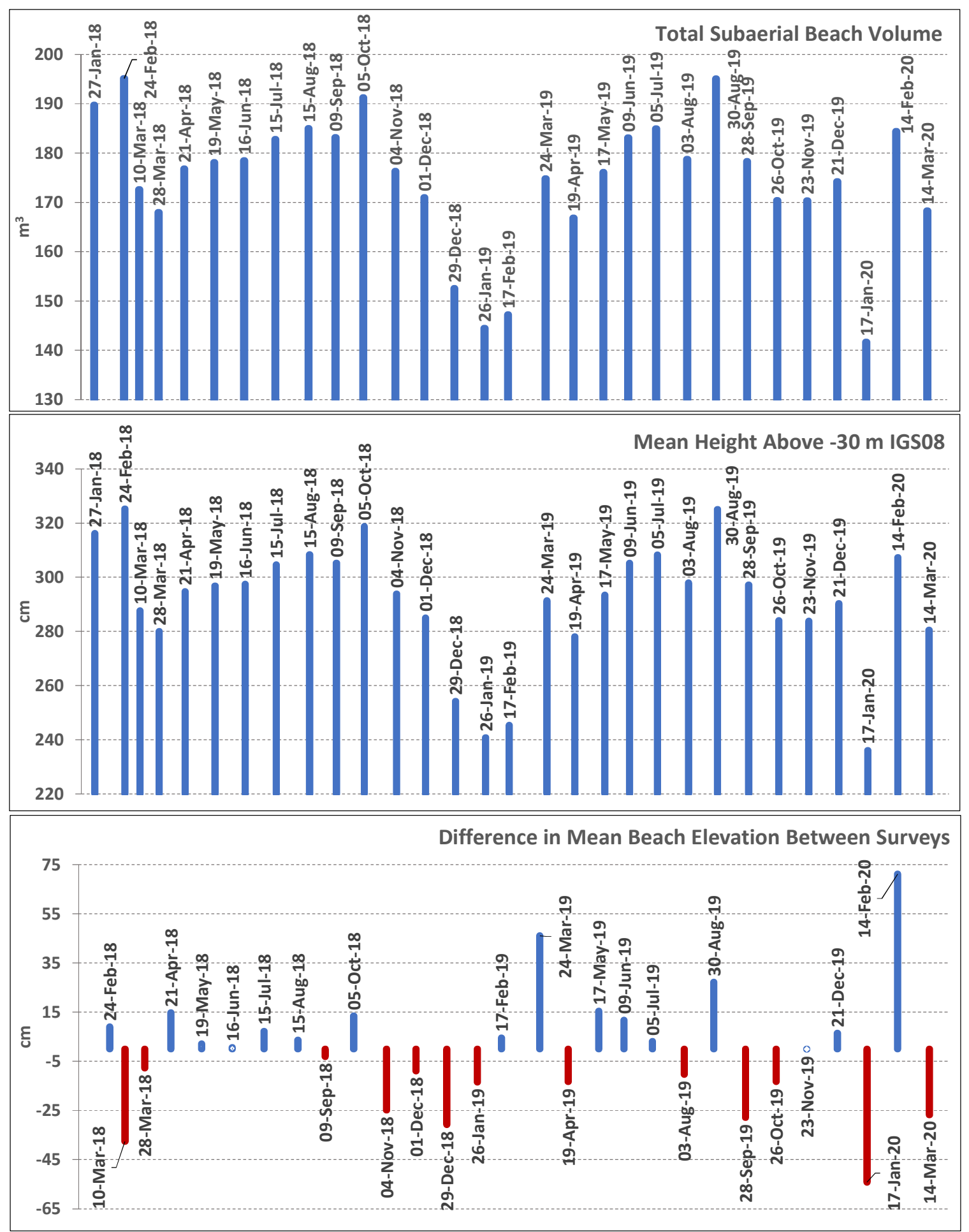

Figure NHB01-5. Calculated sediment volume, mean profile elevation, and mean elevation change for the beach profile at station NHB01. These parameters were calculated from 0-60 m of the profile length. Four of the thirty elevation profiles were shorter than the "standard profile length" for the station $(60 \mathrm{~m})$. These profiles were extended using the procedure described in Chapter 2: Methods. Three of the profiles were extended less than or equal to $6 \mathrm{~m}$ which is considered negligible. One of the longest extensions (12.0 m on March 10, 2018) occurred following the March 2018 nor'easters when the beach was extremely eroded. 
Storm Effects, Beach Erosion, and Recovery. NHB01 sediment volumetric calculations for the beach, as well as elevation profiles, show the expected trends of storm-induced erosion separated by periods of beach accretion and recovery. Extreme changes in the beach profile at NHBO1 were driven by major storm events. At the beginning of the monitoring period in late January 2018, North Hampton State Beach had an accretional profile and one of the largest sediment volumes observed at the station during the study period (Figures NHB01-5 and NHB01-6). However, the series of storms in early 2018 caused major erosion, flooding, and damage to the seawall (Figure NHB01-7). Based on mean elevation calculations, an average of $\sim 0.5 \mathrm{~m}$ of elevation was lost across the entire beach (Figure NHB01-5). The beach elevation profiles in Figure NHB01-7 show that $1.0 \mathrm{~m}$ was lost on the lower beach exposing the underlying megaclast platform composed of pebbles, cobbles, and boulders that previously had been covered with sand (Figures NHB01-8 and NHB01-9). During the late winter 2018 nor'easters, gravel was pushed landward against the seawall forming a ramp that allowed sand, pebbles, cobbles, and even small boulders to overtop the wall (Figures NHB01-2 and NHB01-7). As a result of the storms, major damage to the infrastructure at North Hampton State Beach occurred to the bathhouse and parking lot, as well as nearby private property (Figures NHB0110 and NHB01-11).

After the storms, sand and gravel were apparently removed from the seawall and the beach graded to reduce the steepness (Figures NHB01-12 and NHB01-13). Recovery from the storms began quickly, evidenced by a large ridge and runnel forming on the low tide terrace as seen in the April 21, 2018 elevation profile (Figure NHB01-14). Overall, the beach elevation and volume continued to recover from the storms throughout the spring, summer, and fall reaching a similar volume as the pre-storm values on October 5, 2018 (Figures NHB01-5). 


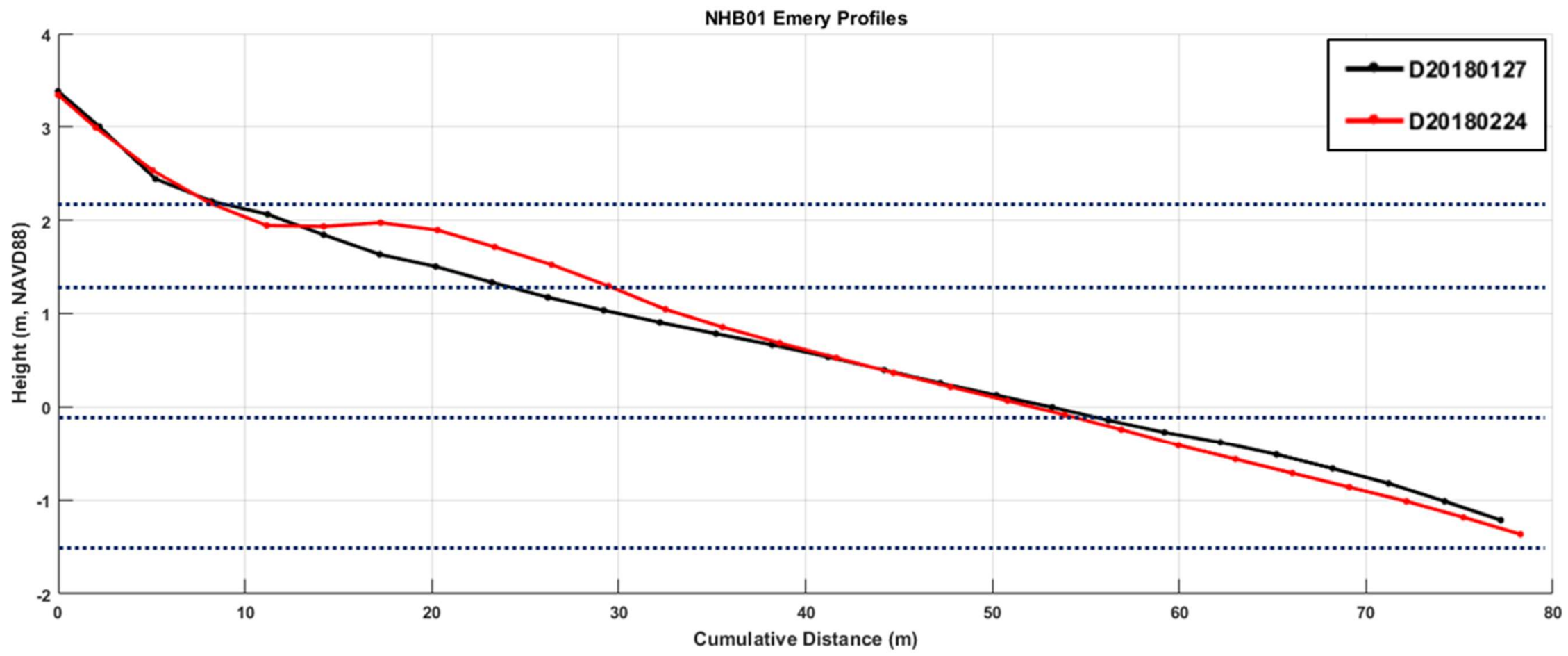

Figure NHB01-6. Beach elevation profiles for NHB01 prior to the severe nor'easters in late winter 2018 on January 27, 2018 and February 24, 2018. 


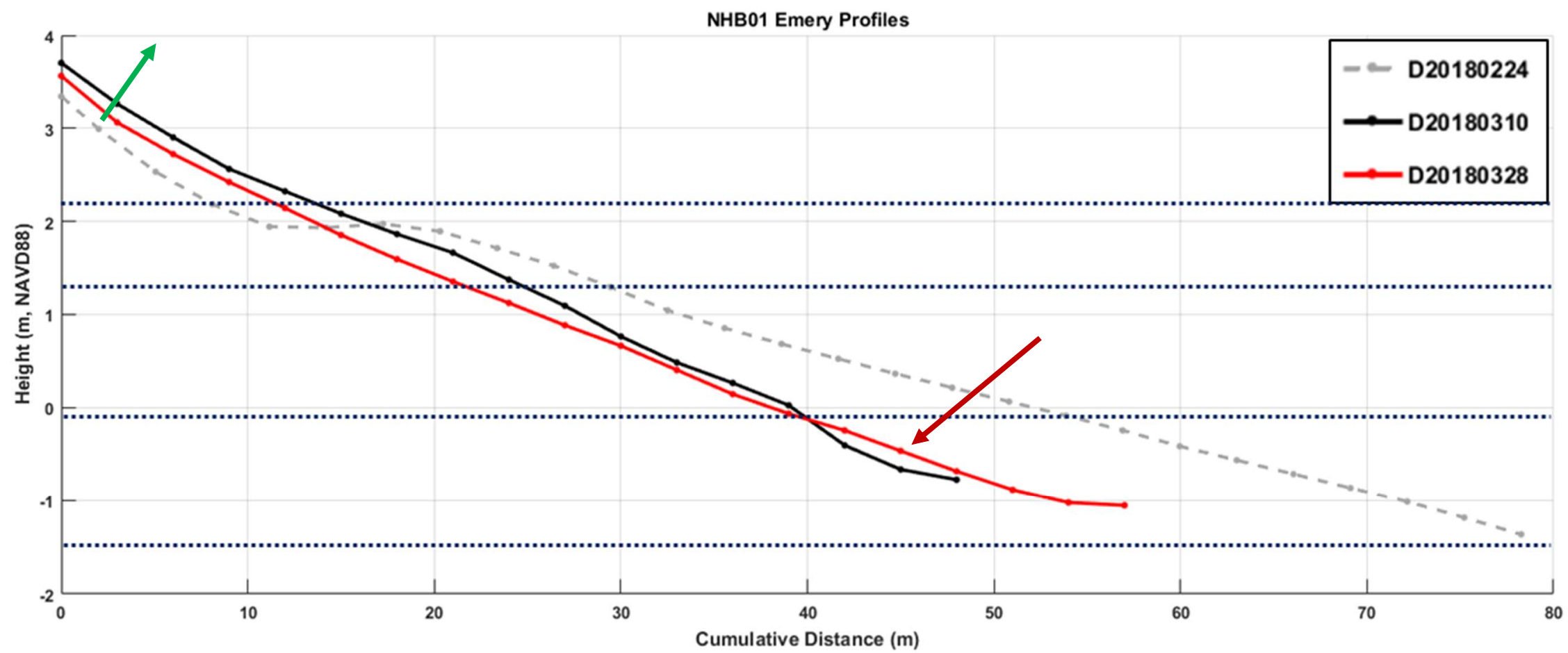

Figure NHB01-7. Beach elevation profiles for NHB01 on February 24, 2018 before the late winter 2018 nor'easters, followed by post-storm profiles from March 10, 2018 and March 28, 2018. Note the massive erosion of the lower beach (red arrow), but the increase in elevation at the seawall (green arrow). Apparently, sand and gravel was eroded from the lower beach and pushed landward against and overtopping the seawall. 

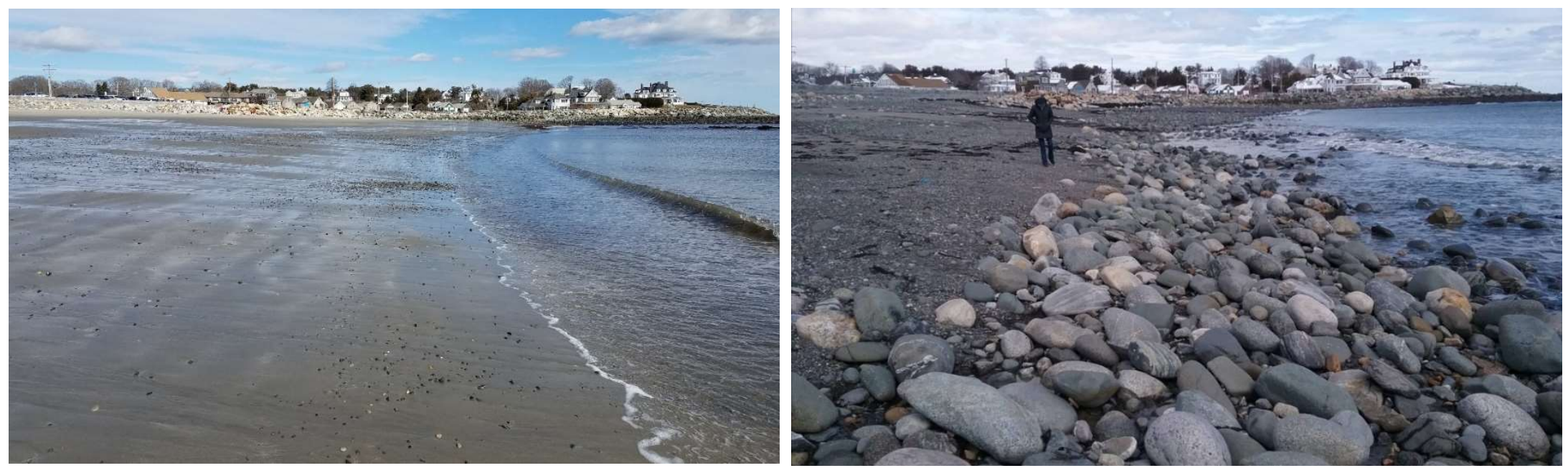

Figure NHB01-8. Low tide terrace at station NHB01 looking north near the water line before and after the late winter 2018 storms. The photograph on the left is looking north on February 24, 2018, when sand covered the cobbles and boulders that are located in the lower beach. The photograph on the right was taken on March 10, 2018, when the megaclast platform was exposed due to erosional conditions.
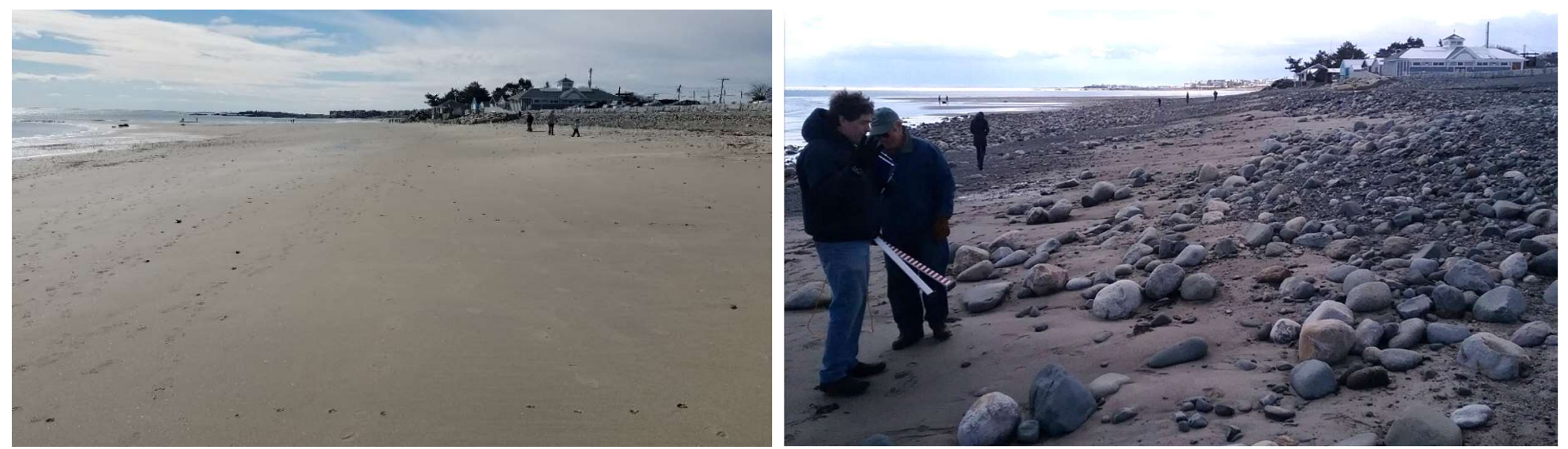

Figure NHB01-9. Mid-beach at station NHB01 looking south before and after the late winter 2018 storms. The photograph on the left is from February 24 2018 and shows an accretional beach with sand covering the cobbles and boulders. The photograph on the right is from March 10, 2018 and shows an eroded beach, where the sand veneer that covered the cobbles and boulders has been removed, exposing the megaclasts. 


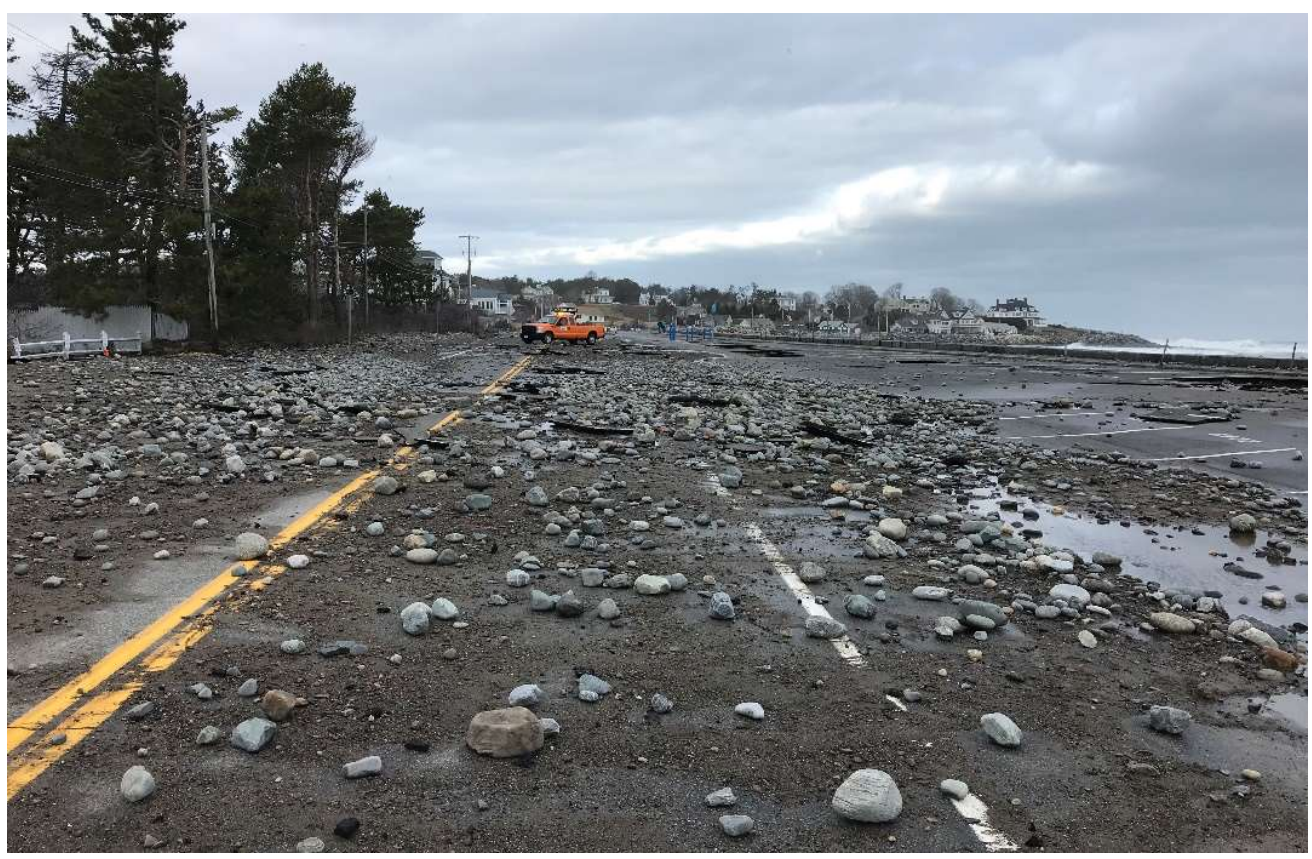

Figure NHB01-10. Large cobbles which were thrown over the seawall during Nor'easter Riley, damaging the seawall roadway and surrounding buildings. Photograph taken on March 3, 2018.

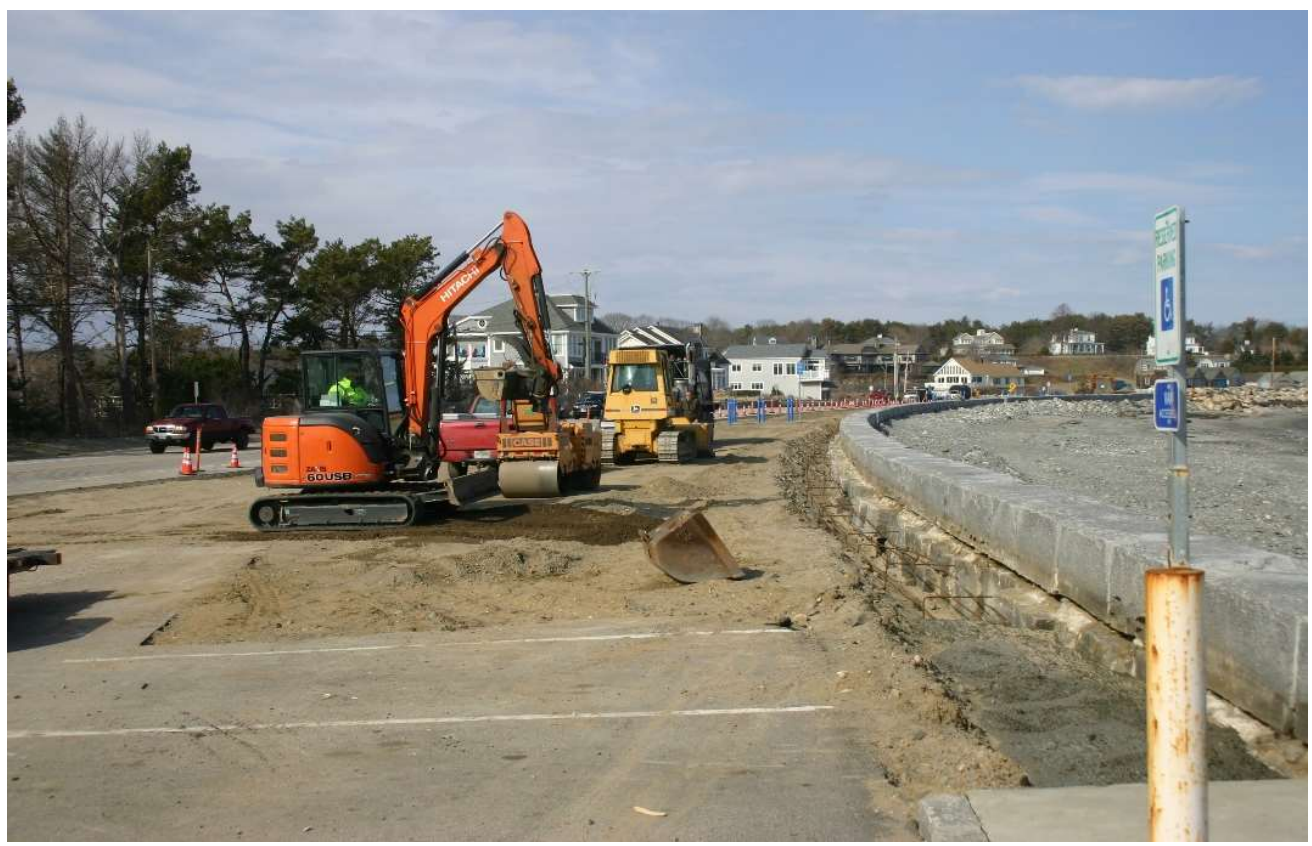

Figure NHB01-11. The seawall and parking lot at North Hampton Beach, which had to be repaired or replaced due to the damage during Nor'easter Riley. Photograph taken on April 11, 2018. 


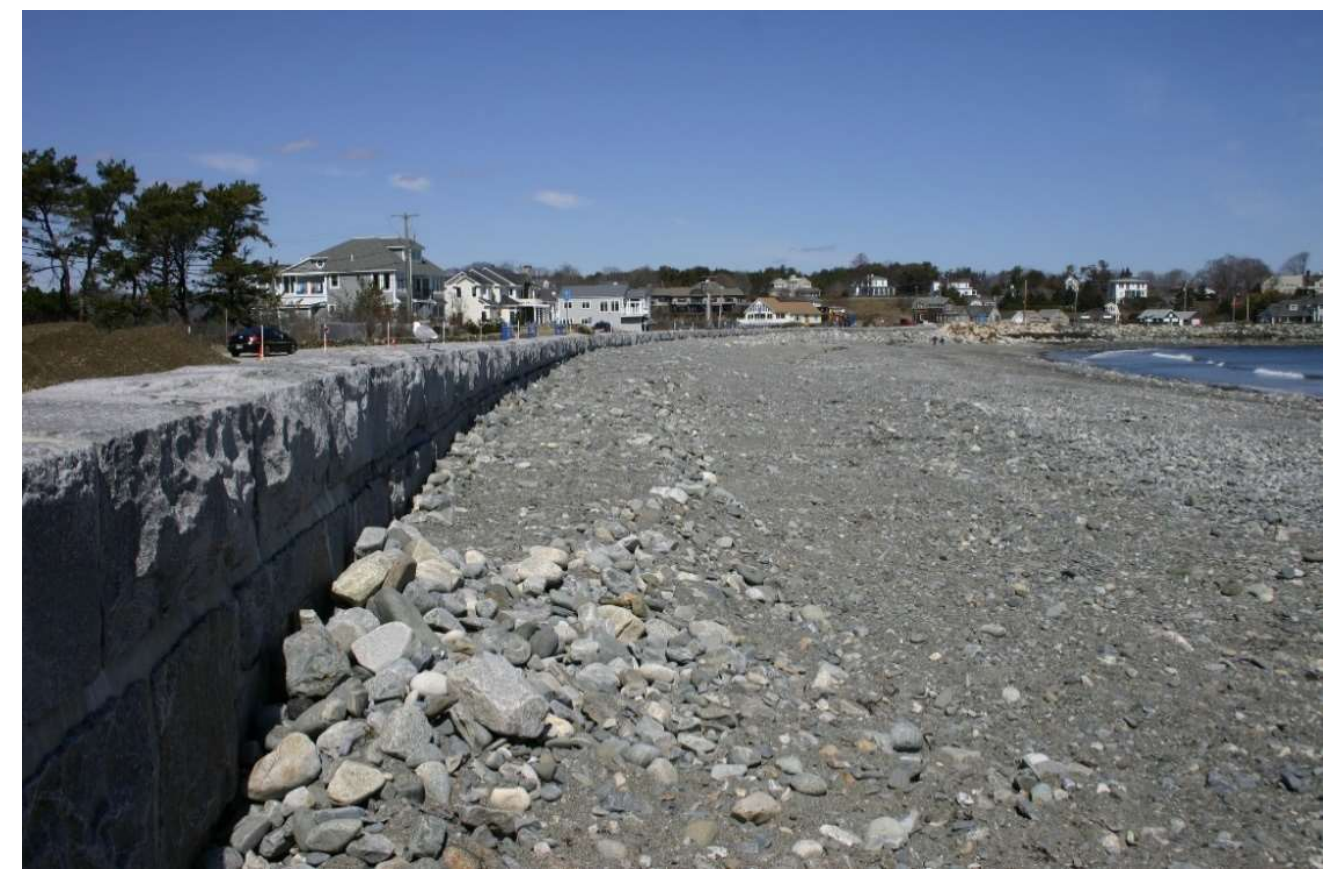

Figure NHB01-12. A sand and gravel ramp which was pushed up against the seawall during the late winter nor'easters. Following the storms, the beach was graded including moving sediment back from the seawall. Compare the photograph above taken on April 11, 2018 with the photograph in Figure NHB01-2 taken on March 3, 2018 which shows the ramp. Note the sand and gravel are mixed.

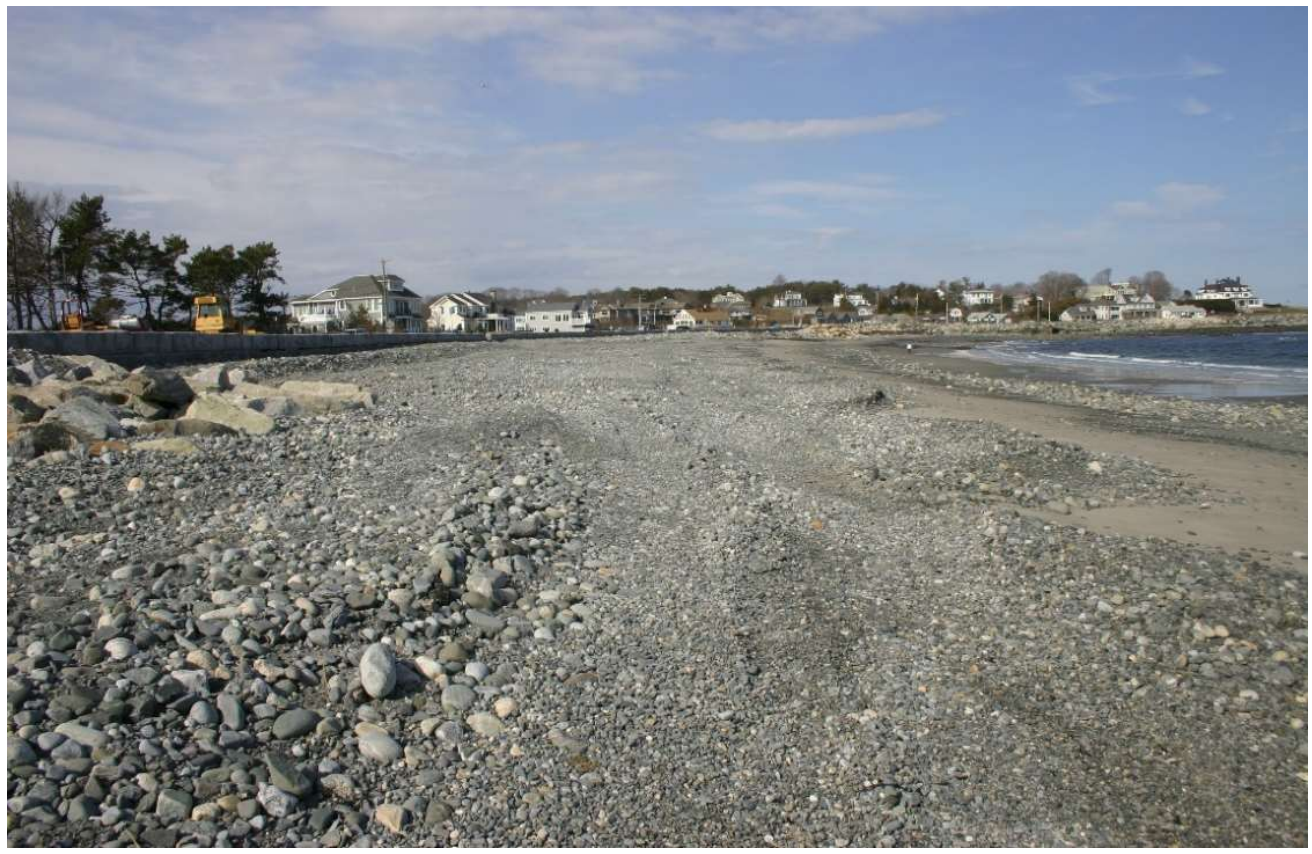

Figure NHB01-13. Following the severe nor'easters of late winter 2018, North Hampton State Beach was apparently graded in an effort to restore the beach. The photograph above was taken on April 11, 2018. 


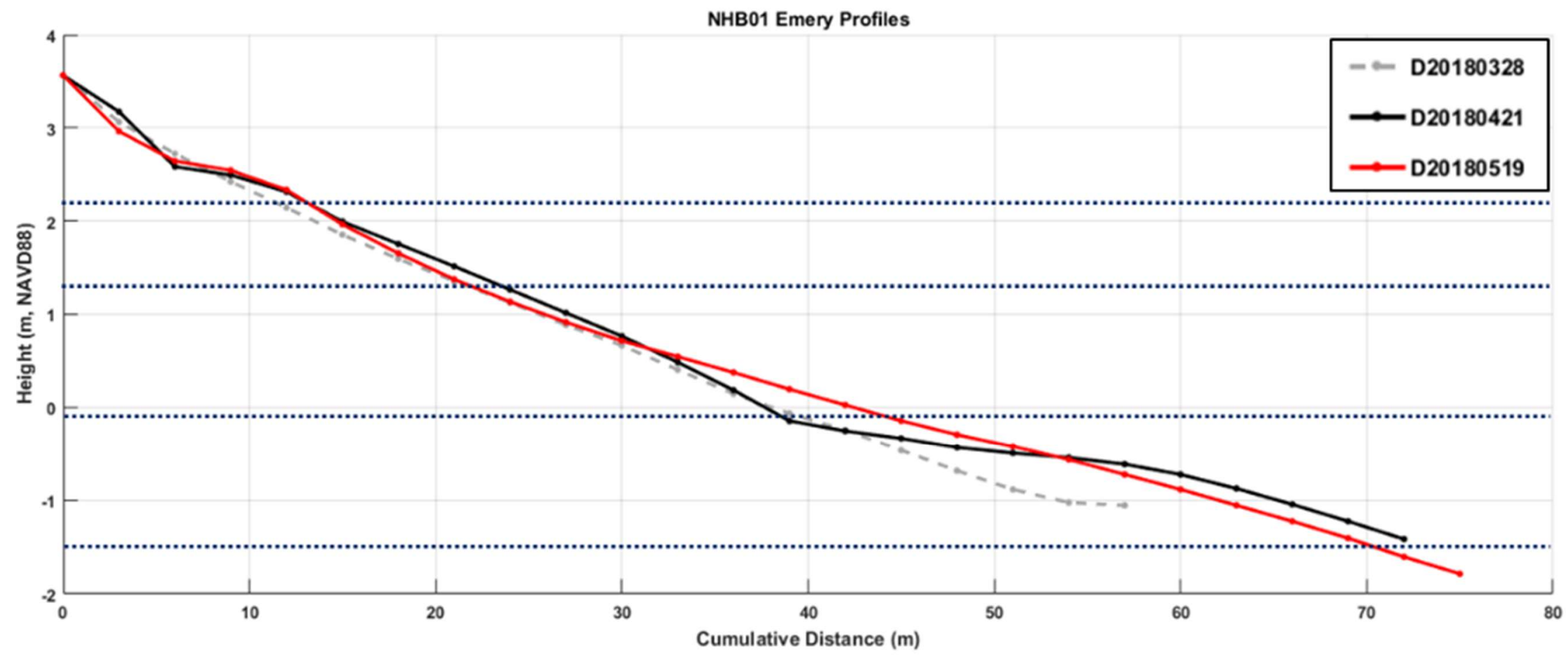

Figure NHB01-14. Beach elevation profiles for NHB01 on March 28, 2018, April 21, 2018, and May 19, 2018. 
During late fall 2018 and early winter 2019, a series of high wave energy events (unnamed storms), as well as Nor'easters Harper (Jan 19-20, 2019) and Maya (Feb 12-13) occurred causing a continuous decline in sediment volume from November 2018 to February 17, 2019 (Table 3-3). This extended period of storminess caused the beach to erode to its near lowest level for the study by January 26 and February 17 (Figure NHB01-5). The beach elevation profiles show dramatic loss as well during this period, with the average elevation of the beach from the seawall to $60 \mathrm{~m}$ seaward showing a loss of over $0.7 \mathrm{~m}$ (Figures NHB01-15 and NHB01-16). It is not clear why the volume of sediment lost from the beach at NHB01 in winter 2019 was greater than the late winter to early spring 2018 storms. However, it is possible the beach had not fully recovered from the 2018 storms and had not yet reached an equilibrium condition prior to the 2019 storms. Alternatively, and more likely, the severe nor'easters in late winter 2018 were so energetic that cobbles and small boulders were eroded from the lower beach and pushed to the upper beach creating a gravel ramp. Subsequently, the gravel ramp was removed by mechanical equipment (e.g., backhoe or bulldozer).

The beach once again recovered in terms of elevation by the end of summer 2019 (Figures NHB01-5, NHB01-17, and NHB01-18). In fact, the August 30, 2019 profile has the highest sediment volume and average elevation for the study and is covered in many areas with a veneer of sand (Figures NHB015 and NHB01-19) With the onset of late fall and winter, some elevation and volume were again lost from the beach, with a sharp drop to the lowest volume measured during the study period on January 17, 2020 (Figures NHB01-5 and NHB01-20). Conversely, by the next profiling date (February 14, 2020), the beach had accreted significantly to a volume similar to that seen in fall 2019. The amount of sediment volume loss is hard to fully explain but was likely forced by unnamed high wave energy events and two strong winter storms in December 2019 (Ezekiel: Dec 2-4 and Gage: Dec 30-31) (Table 3-3). However, the rapid recovery is puzzling. It is notable that the beach underwent major accretion during the winter. The magnitude of the erosion is shown in photographs of the beach taken on January 17, 2020 (Figure NHB01-21) and the recovery on February 14, 2020 (Figure NHB01-22). 


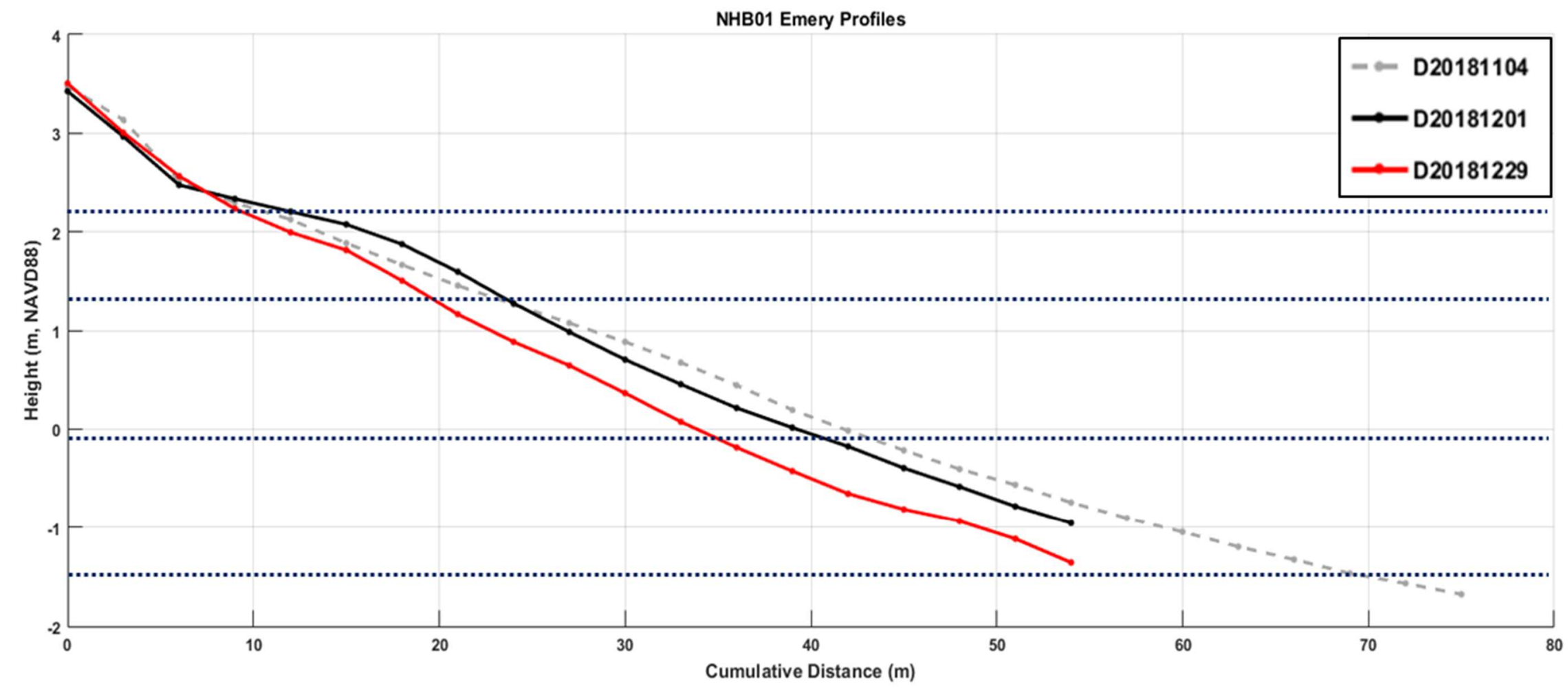

Figure NHB01-15. Beach elevation profiles for NHB01 on November 4, 2018, December 1, 2018, and December 29, 2018. 


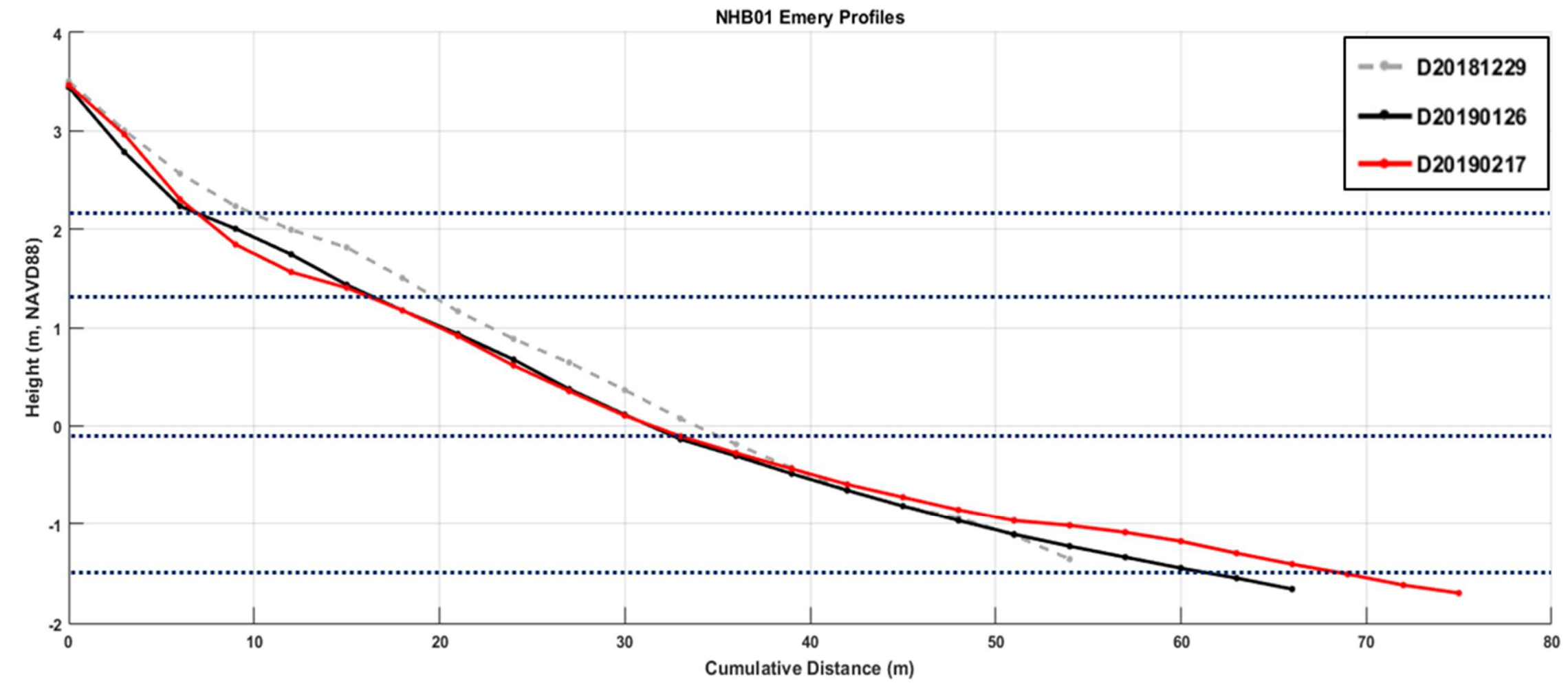

Figure NHB01-16. Beach elevation profiles for NHB01 on December 29, 2018, January 26, 2019, and February 17, 2019. 


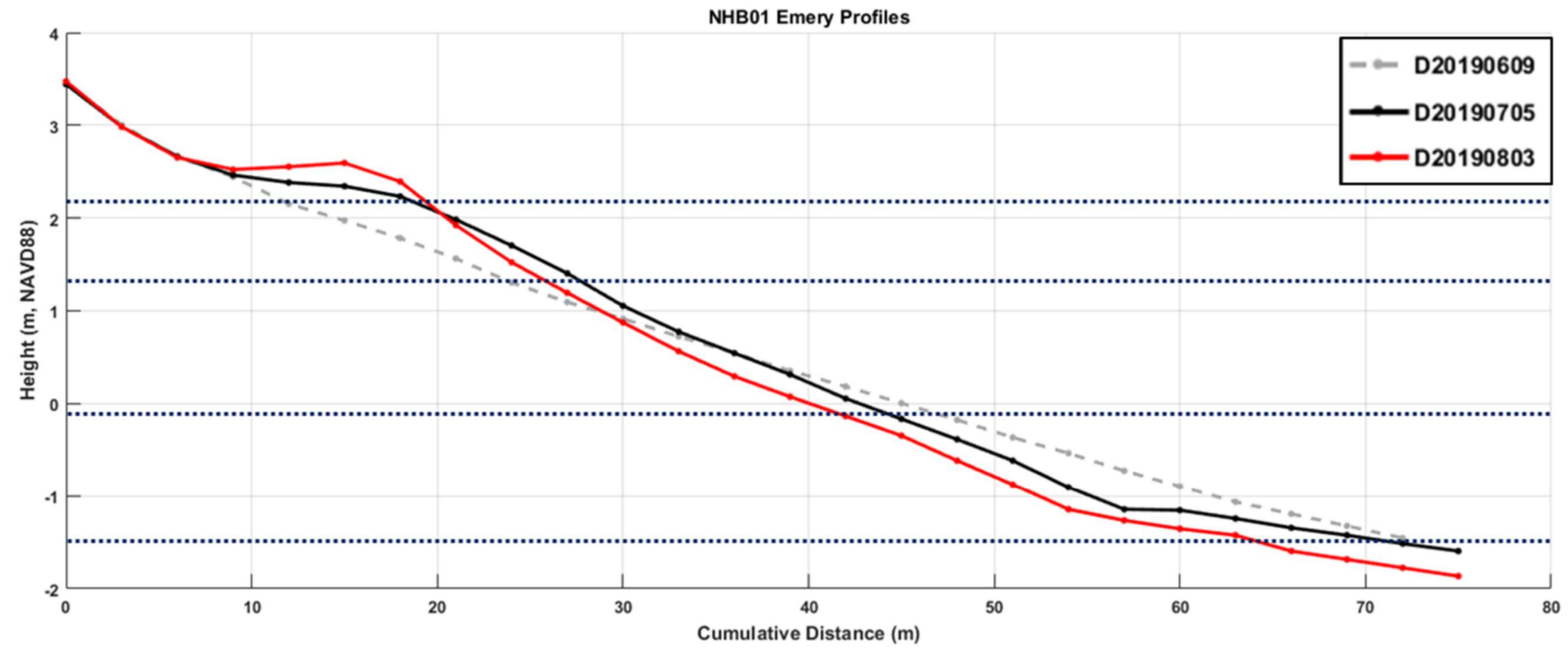

Figure NHB01-17. Beach elevation profiles for NHB01 on June 9, 2019, July 5, 2019, and August 3, 2019. 


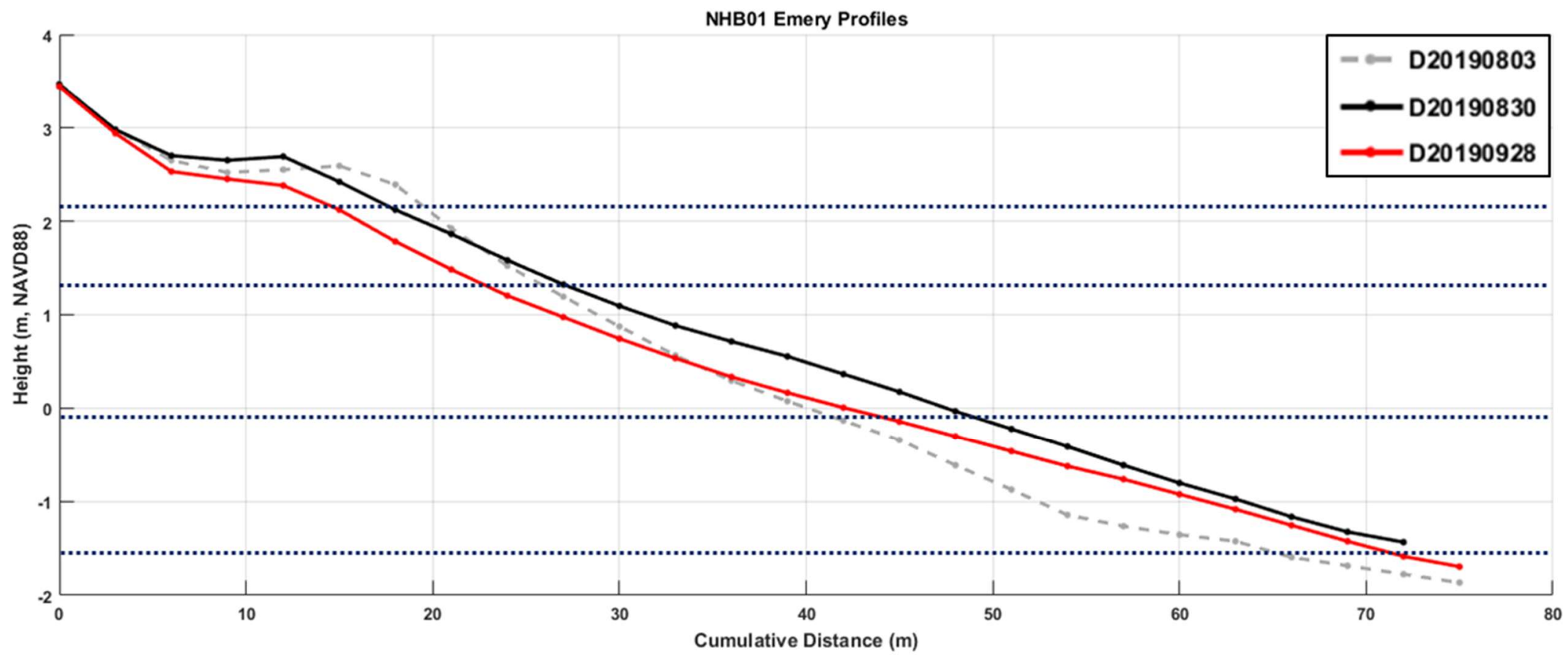

Figure NHB01-18 (above). Beach elevation profiles for

NHB01 on August 3, 2019,

August 30, 2019, and September 28, 2019.
Figure NHB01-19 (right). Mid beach at station NHBO1 on August 30, 2019 (the maximum elevation profile for the study period at this station). A veneer of sand is present on top of the beach, which occurs during accretional conditions.

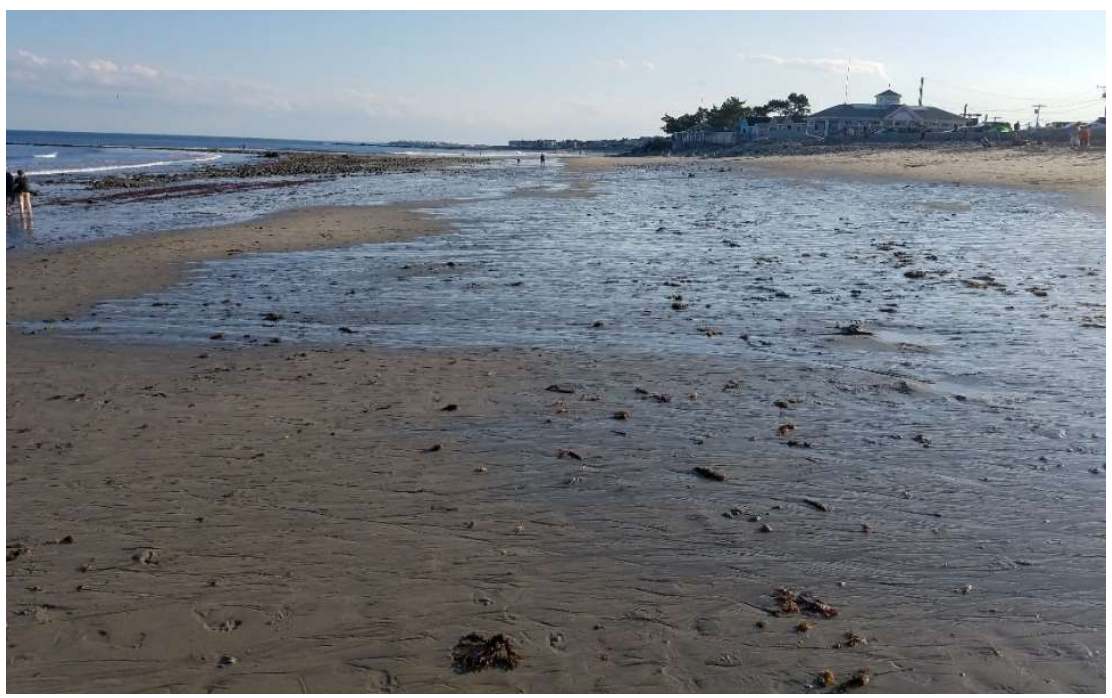




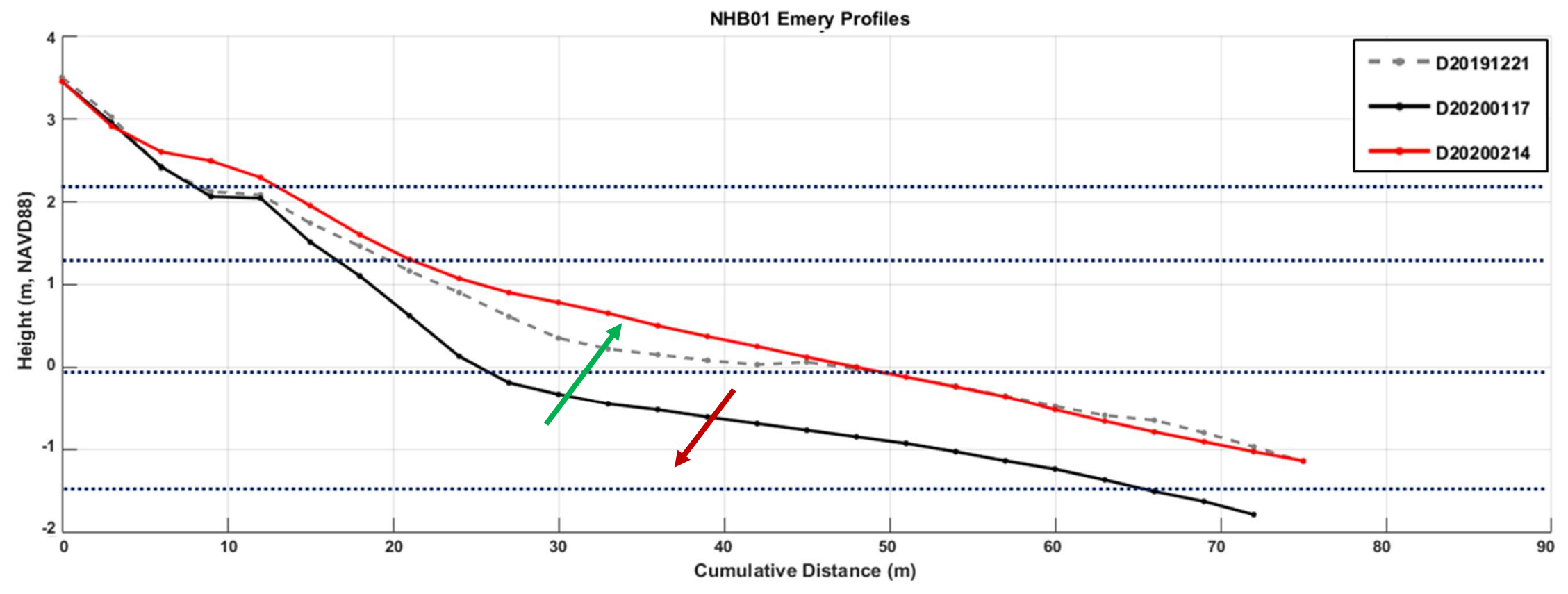

Figure NHB01-20. Beach elevation profiles for NHB01 on December 21, 2019, January 17, 2020, and February 14, 2020. NHB01 was severely eroded between December 21 and January 17 likely due to winter storms (red arrow). However, the beach quickly recovered between January 17 and February 14 (green arrow). Note that this plot extends to 90 meters, rather than the standard 80 meters for NHB01 profile plots. 


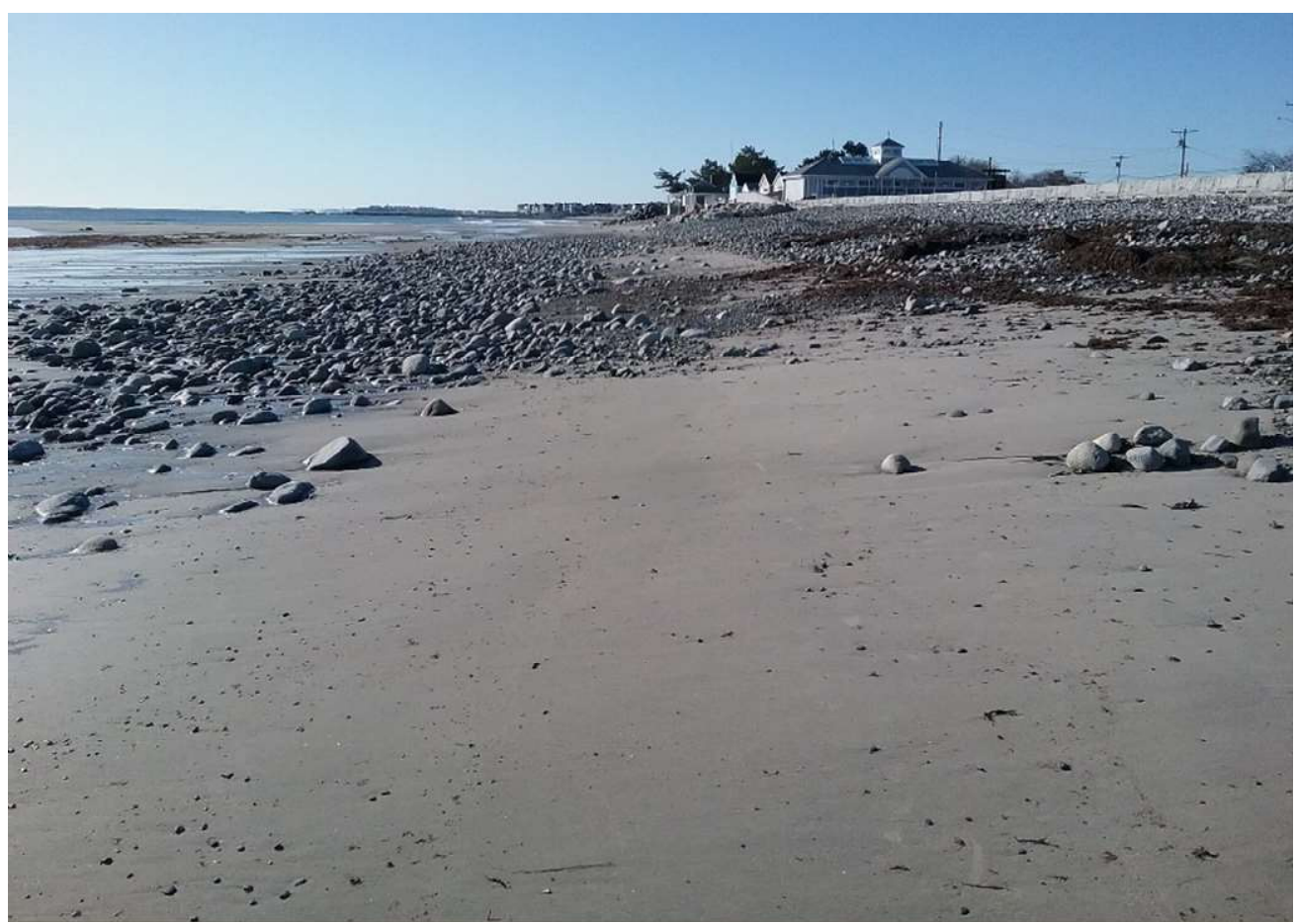

Figure NHB01-21. North Hampton State Beach on January 17, 2020 after being eroded during winter storms. Photograph is looking south from NHBO1.

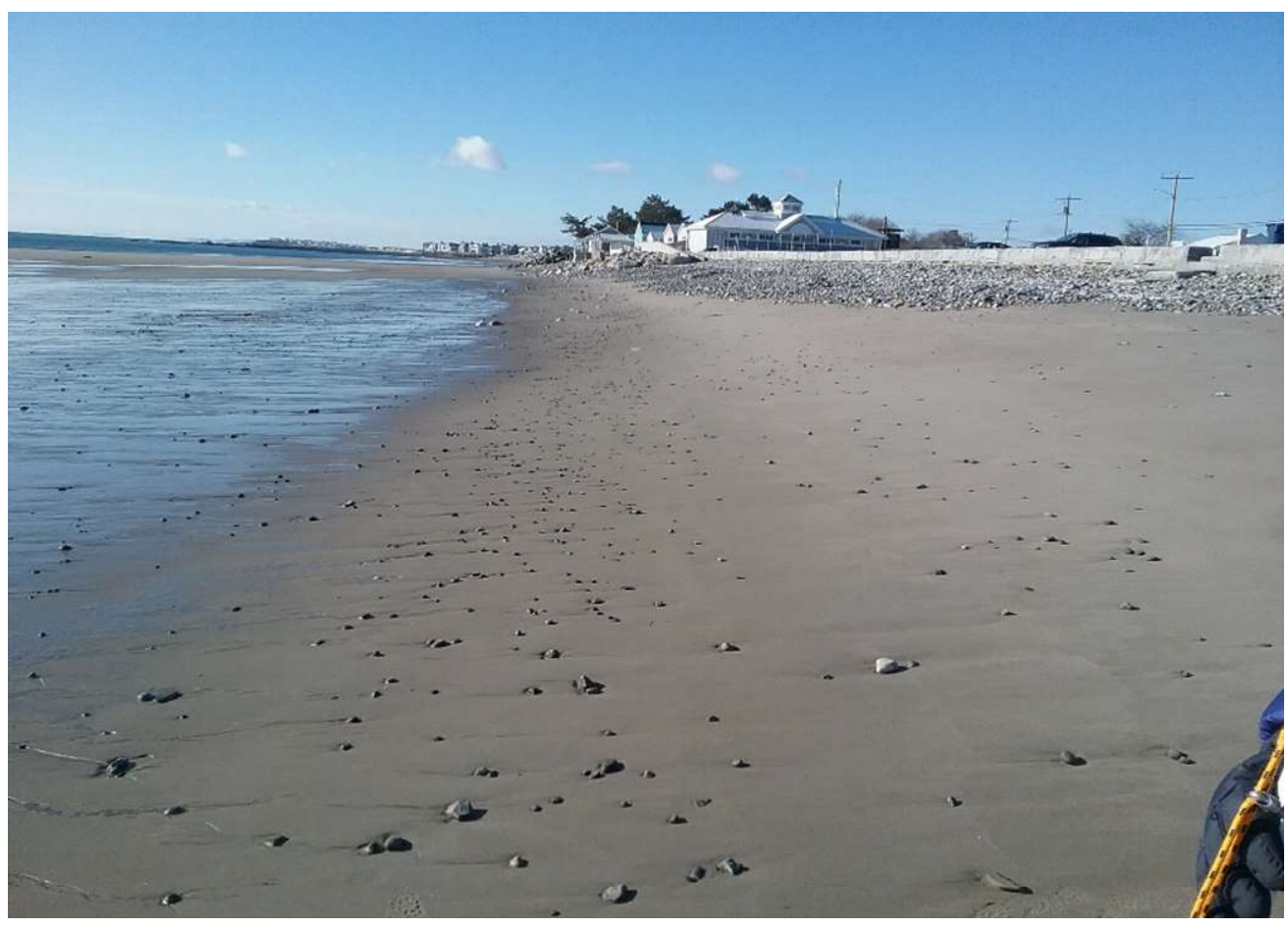

Figure NHB01-22. North Hampton State Beach on February 14, 2020. The beach was severely eroded on January 17 , but has recovered with a sand veneer covering the cobbles and boulders that were previously seen in Figure NHB01-21. Photograph is looking south from NHBO1. 


\section{Results for Station at Mid North Hampton Beach (Godfreys Ledge Tombolo):}

\section{$\mathrm{NHBO2}$}

Overview. Profile NHBO2 is located on the southern side of Godfreys Ledge tombolo (Figure NHB-1). Due to its position, $\mathrm{NHBO2}$ is somewhat protected from waves from the east and northeast. Unlike the rest of the North Hampton Beach-Plaice Cove system, NHB02 originates in dunes and is not separated from the upland by a seawall or riprap (Figures NHBO2-1 and NHBO2-2). The upper beach adjacent to the dune edge is composed of a pebble and cobble ramp (Figures NHB02-03 and NHB024). Seaward of the cobble berm the beach becomes sandy. The entire beach south of NHBO2 is sandy under accretional conditions (Figure NHB02-5). However, during storms the entire lower beach can become gravelly as was demonstrated during the severe nor'easters in late winter 2018 (Riley: March 1-4, Quinn: March 6-9, and Skylar: March 12-14) (Figure NHBO2-6 and NHB02-7). In addition, sand and gravel including cobbles and boulders were pushed into the dunes by storms surges and large waves developing an overwash deposit (Figure NHB02-8).

Summary. The beach at NHB02 underwent major changes in length, elevation, and sediment volume as a result of the severe nor'easters that occurred in late winter 2018. However, unlike many of the other $\mathrm{NH}$ profile stations, NHBO2 experienced a prolonged period of accretion where the beach almost doubled its length and sediment volume. Although speculative, the magnitude of accretion is likely related to the Godfreys Ledge tombolo altering wave approach and energy and enhancing sediment deposition. More work is required to verify the cause and controls of erosion and recovery at NHBO2, but it is very likely tied to the impact of Godfreys Ledge tombolo and related sediment processes. 


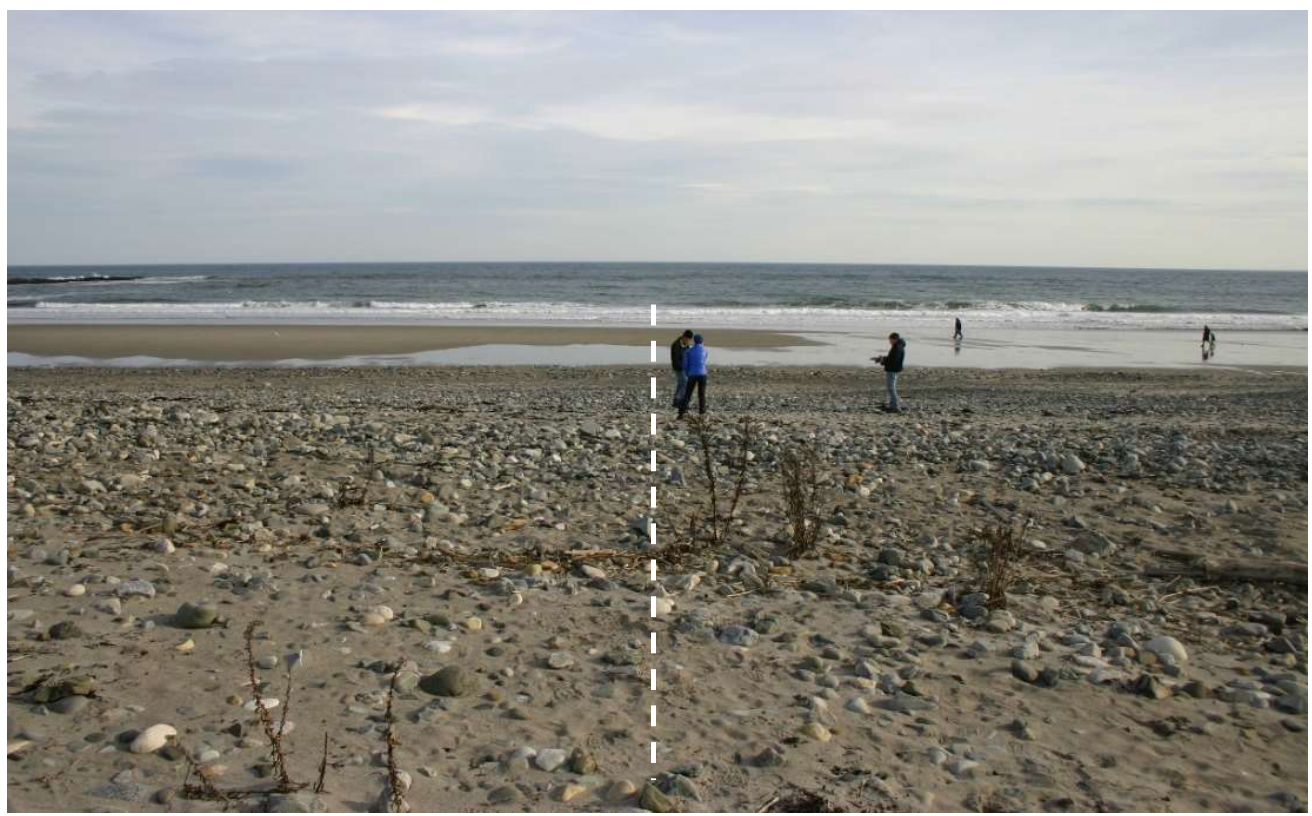

Figure NHB02-1. The beach elevation profile at NHBO2, which extends from narrow dunes and across the beach to the swash zone. The white dashed line in this photograph taken on January 27, 2018 shows the transect. The upper beach is a mixture of sand, pebbles, and cobbles.

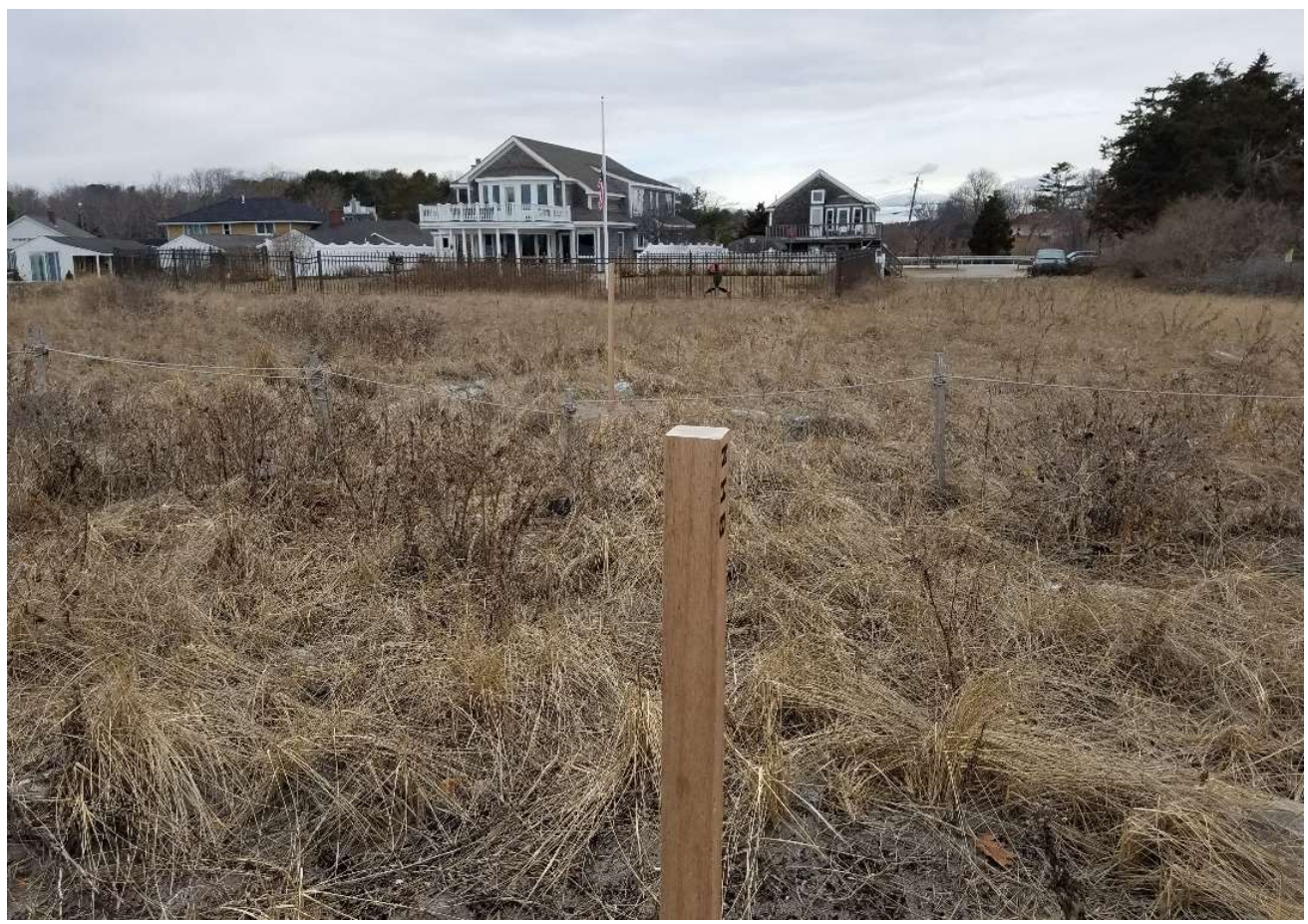

Figure NHBO2-2. Dunes extend landward from the beginning of NHBO2 shown here by the wooden post. Residential homes are located behind the dunes. 

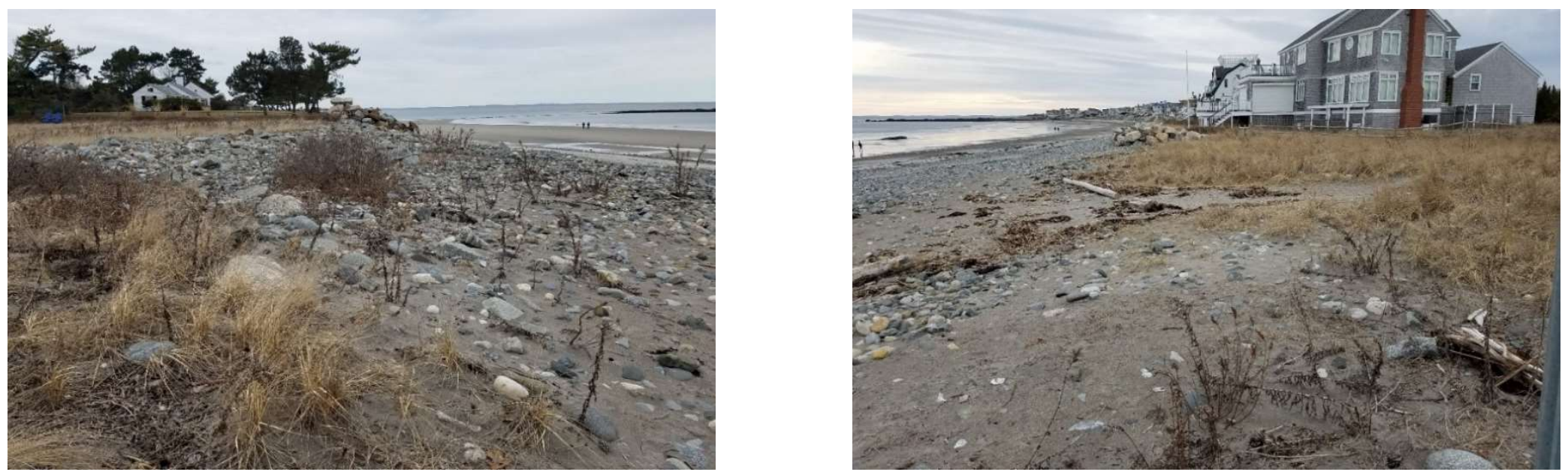

Figure NHB02-3. The upper transect of NHBO2 is usually composed of a sand and gravel mixture as seen here. The photograph on the left is looking north from NHBO2, and the photograph on the right is looking south from the station where residential homes are located which are fronted by extensive seawalls and riprap barriers. Photographs were taken on February 24, 2018.
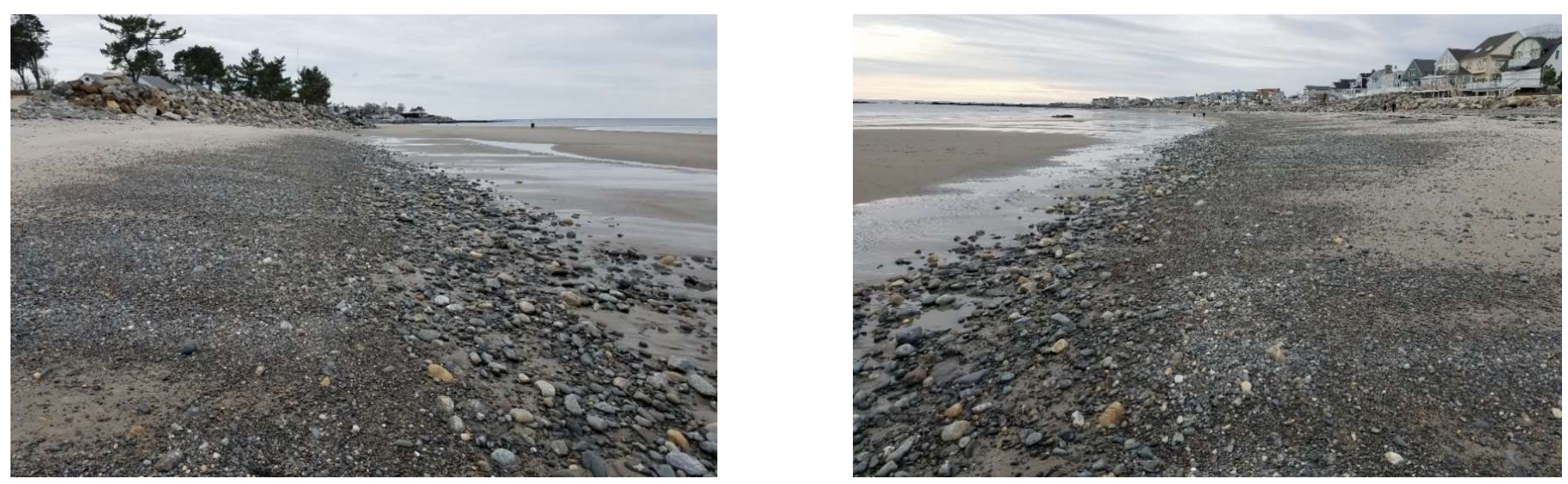

Figure NHBO2-4. The base of the sand and gravel ramp or berm at NHB02. The photograph on the left is looking north from the transect, and the photograph on the right is from the same view but looking south towards Plaice Cove. Note the exposed pebbles and cobbles in the base of the berm. During more accretional conditions the gravel is buried in sand. Photographs were taken on February 24, 2018. 


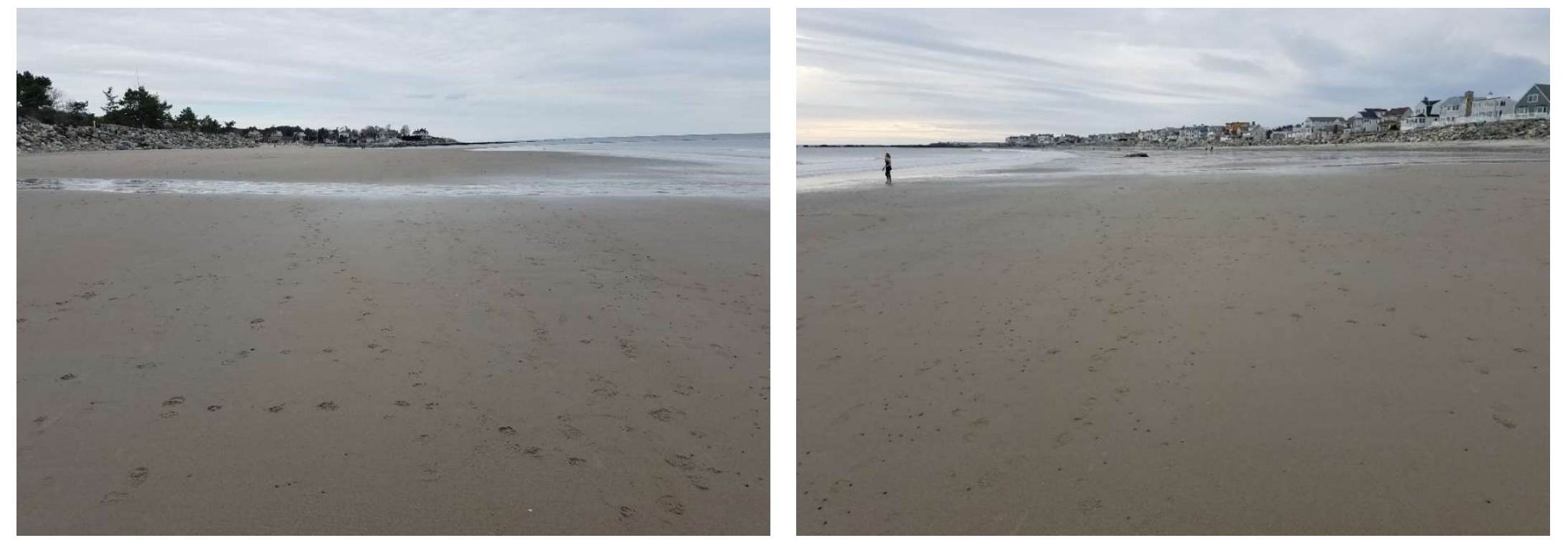

Figure NHB02-5. The mid and lower beach or low tide terrace at NHBO2. The photograph on the left is looking north from the transect, and the photograph on the right is looking south from the same location. Photographs were taken on February 24, 2018. 


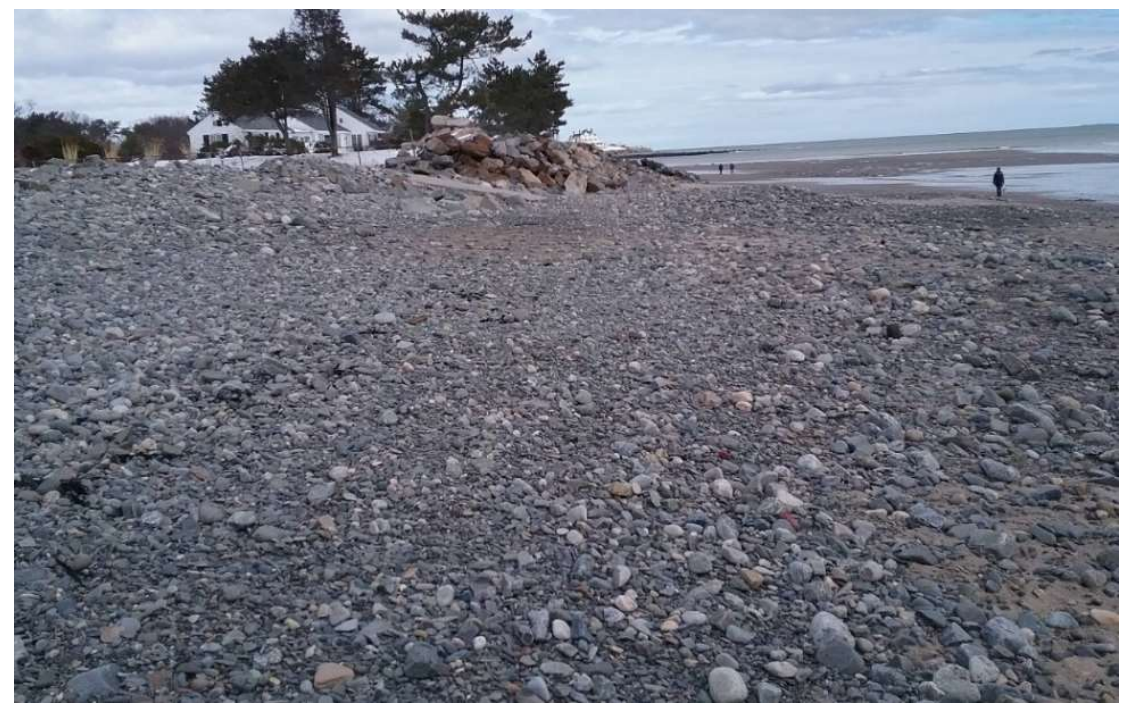

Figure NHB02-6. The upper beach at NHBO2 on March 10, 2018 after the severe nor'easters of late winter 2018. In this location the beach transitioned from $a$ sandy substrate with dune grasses to a cobble berm. Compare to Figure NHBO23.

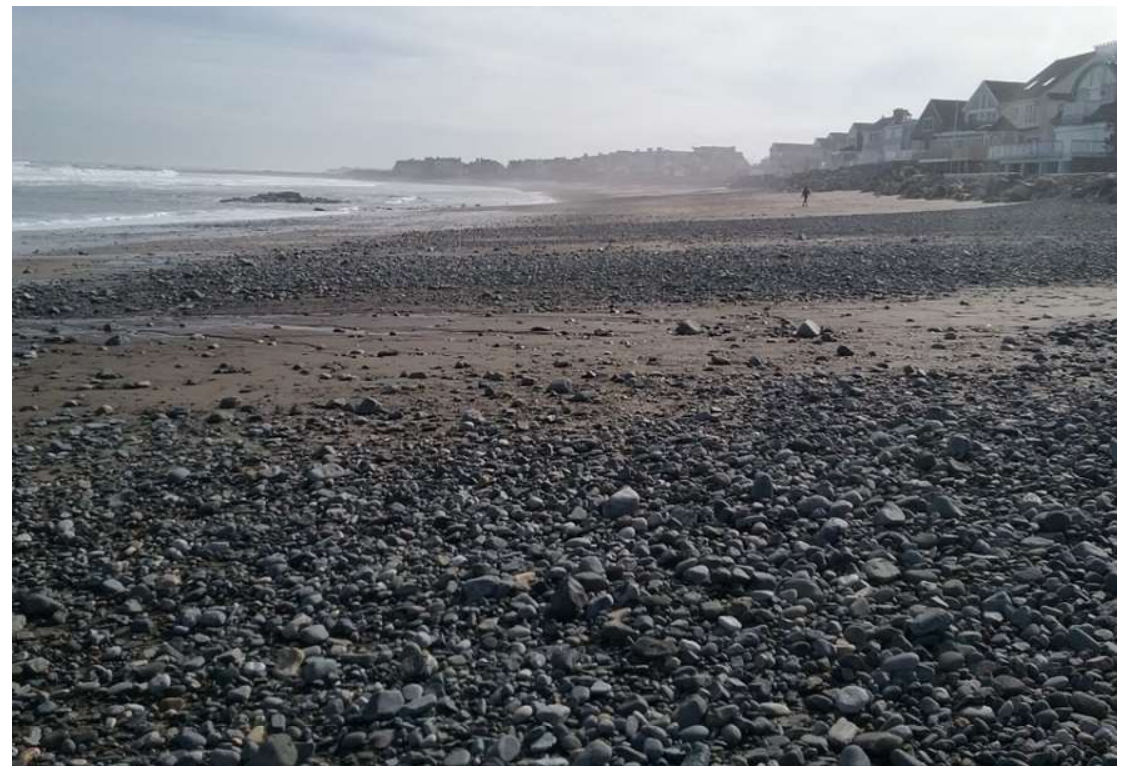

Figure NHB02-7. The mid and lower beach or low tide terrace at NHB02. The photograph is looking south from the transect on March 28, 2018. The sand on the lower beach was eroded leaving behind a gravel lag deposit. Compare to Figure NHB02-5. Sand from the beach, along with pebbles, cobbles, and small boulders was pushed up the beach and into the dunes (Figure NHB02-8, below).

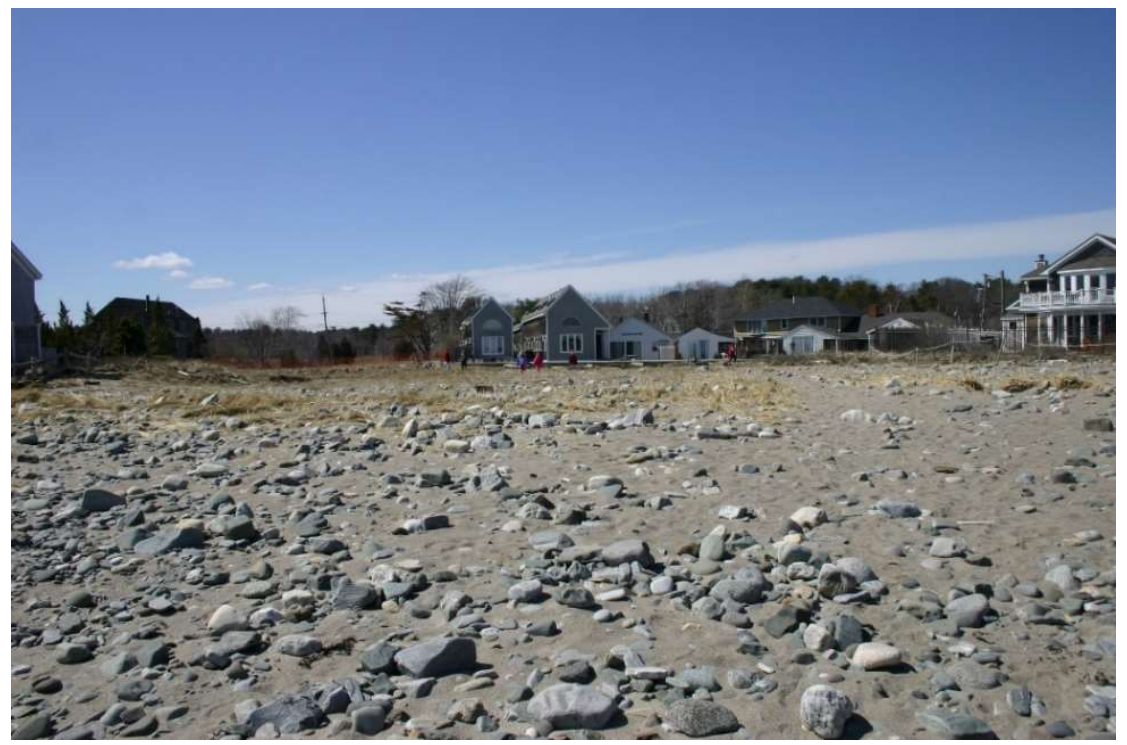

Figure NHB02-8. The dunes landward of NHBO2 were largely sand with scattered pebbles and cobbles following the severe nor'easters in late winter 2018. During the storms, extremely high tides and large waves pushed this material into the dunes as shown here on April 7, 2018. Compare to Figure NHBO2-2 which was taken of the same area before the storms. 
General Profile Characteristics. NHB02 was measured thirty times from January 27, 2018 to March 14, 2020 (Figure NHB02-9). All plotted beach profiles can be found in Appendix C(6). The beach elevation profile at NHB02 varies significantly in length, steepness, and composition over time. Part of the reason for this variability in morphology and sediments is likely the effect of the tombolo on wave approach, size, and energy. NHBO2 in general is very steep in the upper and mid-beach area but tends to flatten out or at least become less steep in the lower beach. The length of the beach profile at NHBO2 ranged from $60 \mathrm{~m}$ following late winter storms in 2018 to $135 \mathrm{~m}$ after an extended period of accretion in summer 2019.

Examination of the sweep zone shows the elevation of the beach varied $\sim 1.6 \mathrm{~m}$ in the lower beach and $\sim 2.2 \mathrm{~m}$ at mid-beach (Figure NHB02-9). These are some of the largest changes in elevation of the sweep zones (largest vertical variability) measured during this study along the $\mathrm{NH}$ coast. Comparison of the maximum average elevation profile (August 30, 2019) with the minimum average elevation profile (April 21, 2018) reveals the impact of the late winter 2018 nor'easters on the entire beach at NHBO2 (Figure NHB02-10). The elevation difference at the berm in the upper beach was $2.3 \mathrm{~m}$ and the elevation difference at mid-beach was $\sim 1.5 \mathrm{~m}$. The elevation difference at the lower beach was not measurable because the profile on April 21, 2018 was no longer intertidal (it became subtidal). However, it was likely large. In fact, the lower beach did not recover until fall 2018, as seen in the elevation and volume figures (NHB02-11). This is discussed below. 


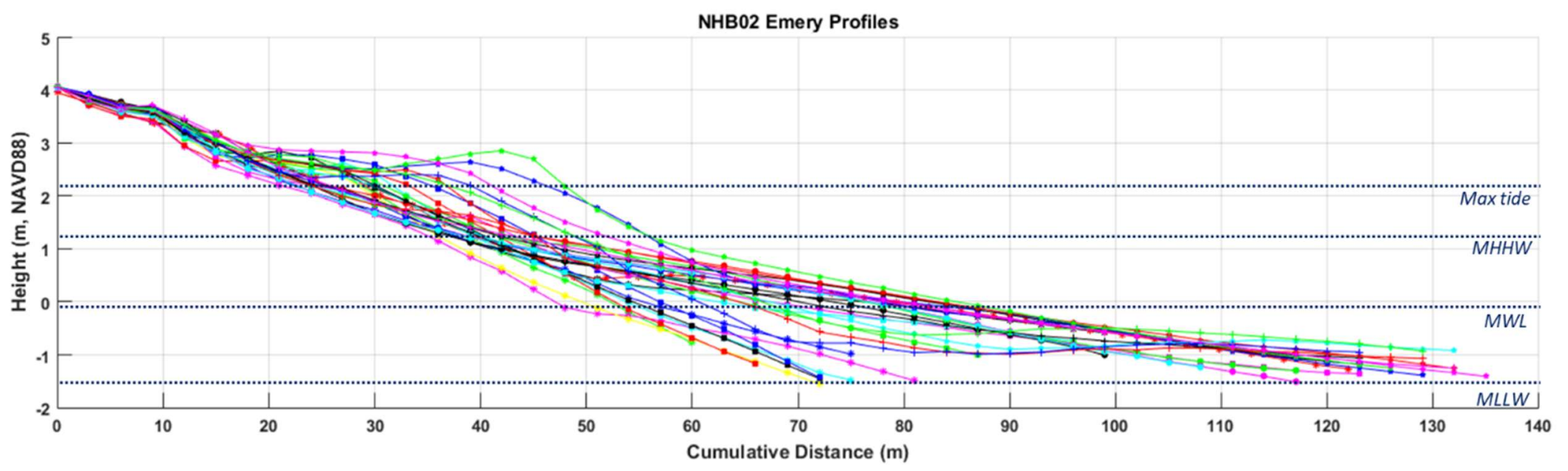

Figure NHB02-9. All thirty beach elevation profiles measured at NHB02 from January 27, 2018 to March 14, 2020. Maximum tidal elevation (max tide), mean higher high water elevation (MHHW), mean water level (MWL), and mean lower low water elevation (MLLW) are indicated by the dotted lines.

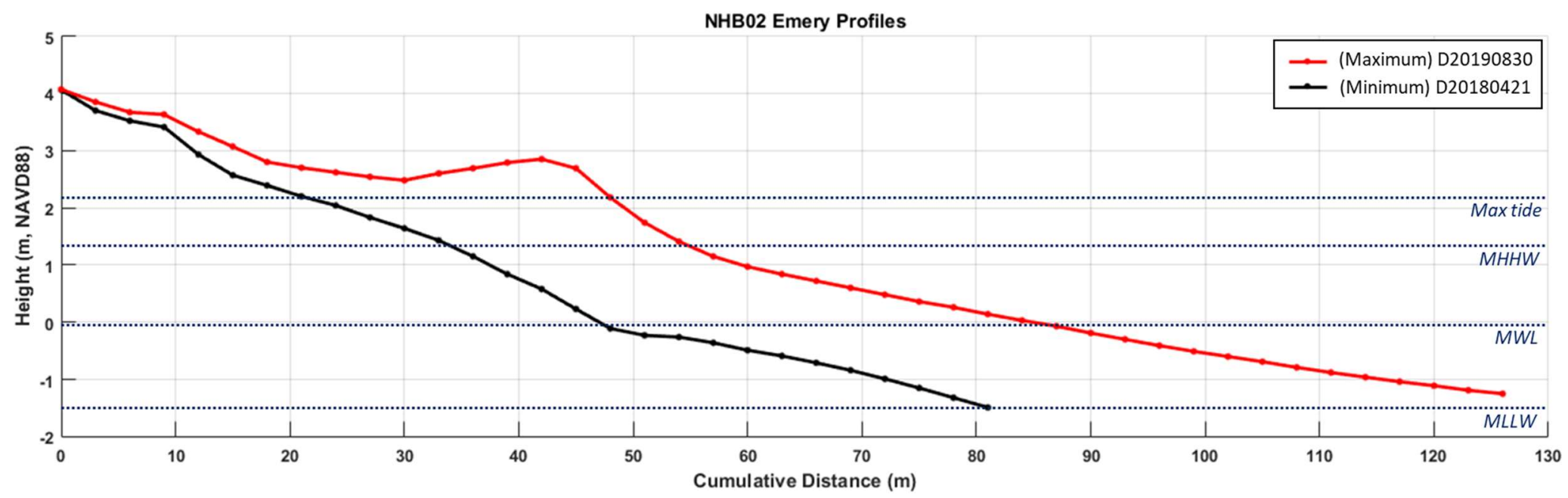

Figure NHB02-10. Maximum (August 30, 2019) and minimum (April 21, 2018) profiles by volume from the study period at station NHB02. Note that this is not the impact of a single event as the profiles are not consecutive monitoring dates. Rather this comparison looks at the extreme of differences of beach elevation profiles over the entire study period. 

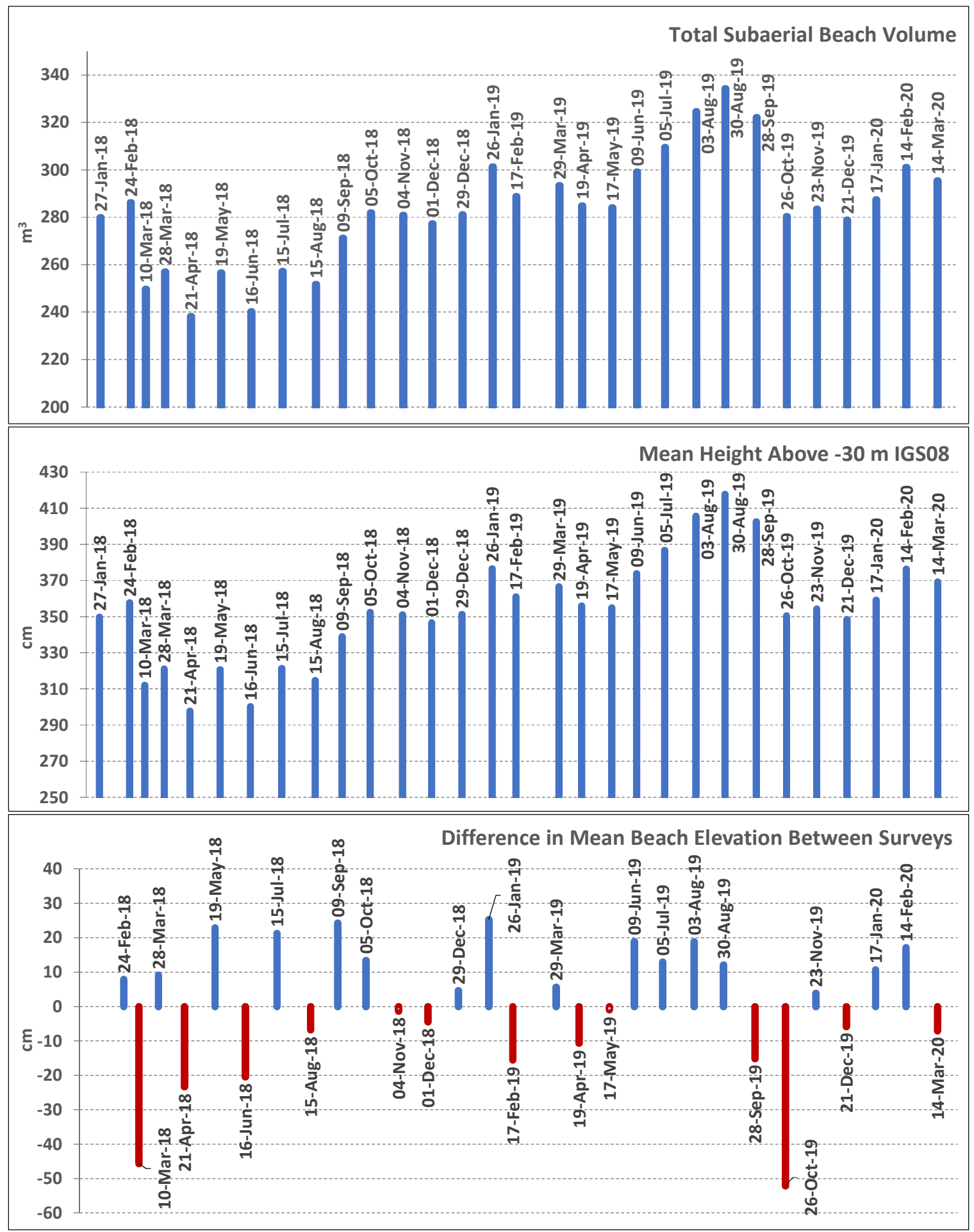

Figure NHBO2-11. Calculated sediment volume, mean profile elevation, and mean elevation change for the beach profile at station NHB02. These parameters were calculated from 0-80 m of the profile length. Seven of the thirty elevation profiles were shorter than the "standard profile length" for the station $(80 \mathrm{~m})$. These profiles were extended using the procedure described in Chapter 2: Methods. Five of the profiles were extended less than or equal to $8.0 \mathrm{~m}$ which is considered negligible. One of the longest extensions (20.0 m on March 10, 2018) occurred following the March 2018 nor'easters when the beach was extremely eroded. 
Storm Effects, Beach Erosion, and Recovery. The extreme erosion of the lower beach at NHBO2 by the late winter 2018 nor'easters (Riley, Quinn, and Skylar) is revealed in the February 24 to March 28 elevation profiles (Figure NHB02-12) and volume calculations for the first $80 \mathrm{~m}$ of the profile (NHB0211). The sediment volumes at the beginning of the study in January and February were somewhat lower than fully accretional conditions indicating some erosion had occurred in late 2017 before profiling had begun. However, the impact of the nor'easters caused major erosion of the beach and loss of elevation. The average beach elevation for the area where the sediment volumes were calculated (the landward $80 \mathrm{~m}$ of the transect which extended from the station marker at the edge of the dunes to the low tide terrace) lost approximately $0.6 \mathrm{~m}$ (NHB02-11). The impact of each storm was more severe due to the lack of recovery time between these high energy events. Comparison of the beach elevation profiles prior to the storms (February 24, 2018) and after (March 28, 2018) shows the beach lost $\sim 0.2$ to $0.5 \mathrm{~m}$ in the upper beach, but almost $1.2 \mathrm{~m}$ at the base of berm (Figure NHB0212).

As stated above, the beach profile elevation at NHBO2 remained very low and the beach width very narrow throughout the spring, summer, and early fall 2018 and did not rebuild until October and November 2018 (Figures NHB02-13, NHB02-14, NHB02-15, and NHB02-16). The upper beach at $\mathrm{NHB02}$ transitioned from a sandy substrate with pebbles, cobbles, and dune grasses to a cobble berm following the late winter 2018 storms (Figure NHB02-7). In addition, sand and cobbles were eroded from the upper beach and pushed landward into the dunes by overwash during the events (Figure NHB02-8). The cobbles remained in the dunes and on the berm for the remainder of the study period. Although the beach at NHB02 was extensively eroded during the late winter 2018 nor'easters and took almost six months to rebuild, the beach continued to build with minimal periods of erosion from fall 2018 through fall 2019. In fact, the fall 2019 profiles have the longest lengths, highest mean elevations, and largest volumes measured during the study period (Figures NHB02-11 and NHB0216). The beach at NHBO2 maintained its length and developed a large depositional berm in summer 2019 (Figure NHB02-17). In September the beach elevation profile was eroded (Figure NHB02-18) and the sediment volume decreased (Figure NHB02-11) which continued through winter. However, the volume and elevation lost or the amount of erosion that occurred in winter 2019 was far less than winter 2018 to spring 2019. 


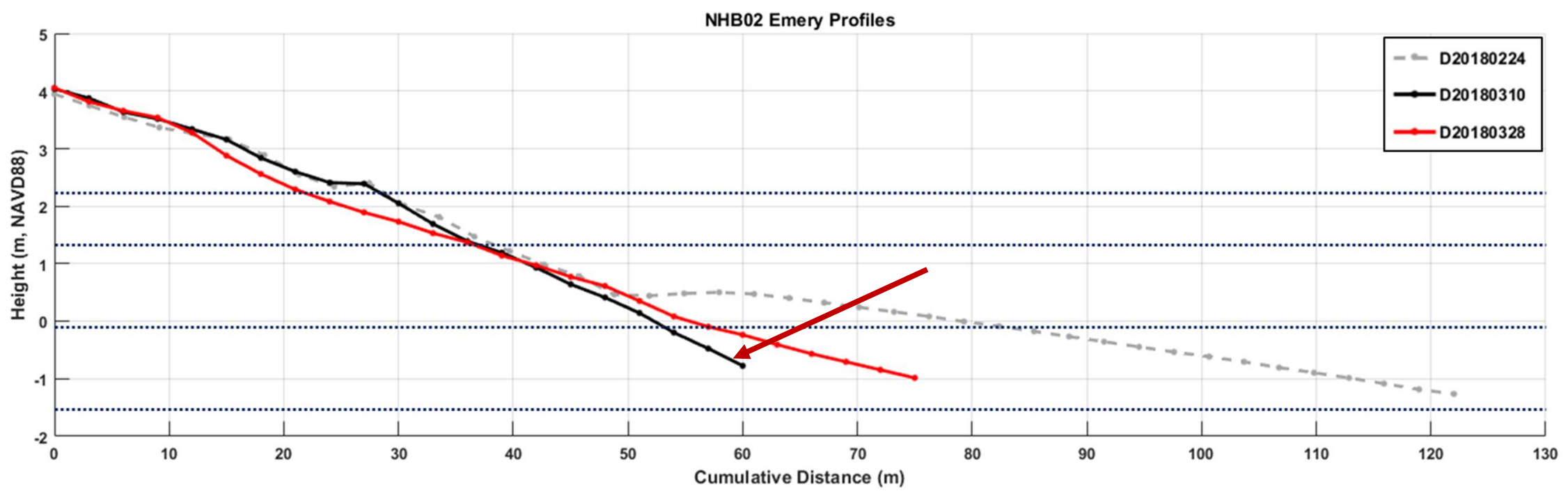

Figure NHB02-12. Beach elevation profiles for NHBO2 on February 24, 2018, March 10, 2018, and March 28, 2018 shows the extreme erosion (arrow) due to the severe nor'easters of late winter 2018 (Riley, Quinn, and Skylar).

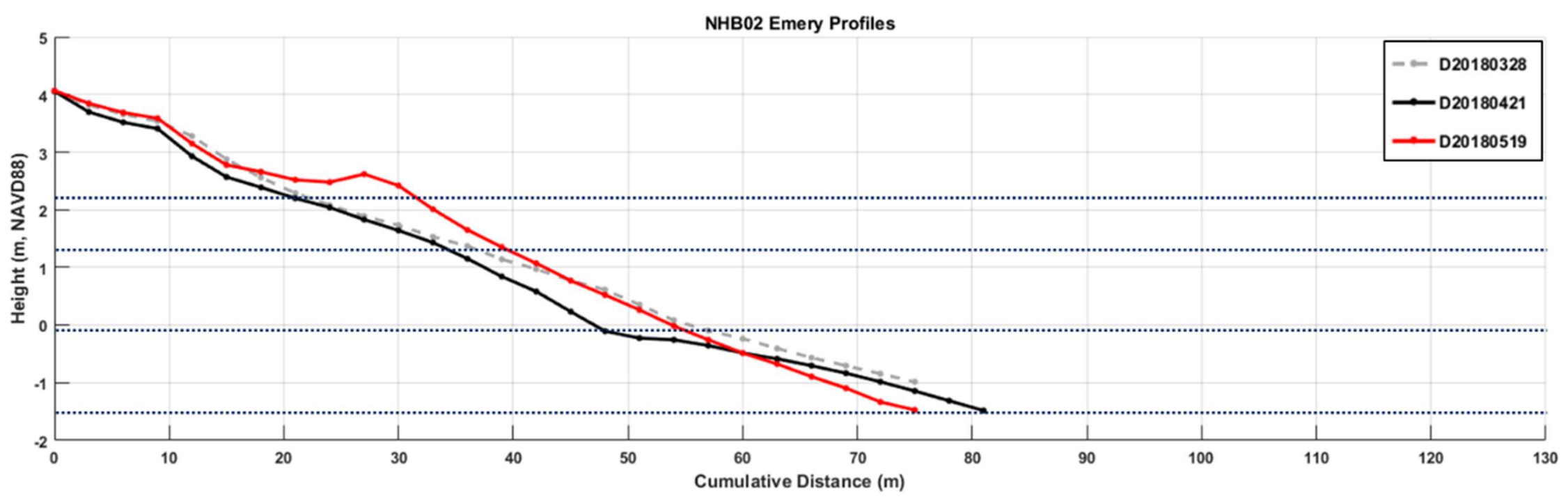

Figure NHB02-13. Beach elevation profiles for NHB02 on March 28, 2018, April 21, 2018, and May 19, 2018. 


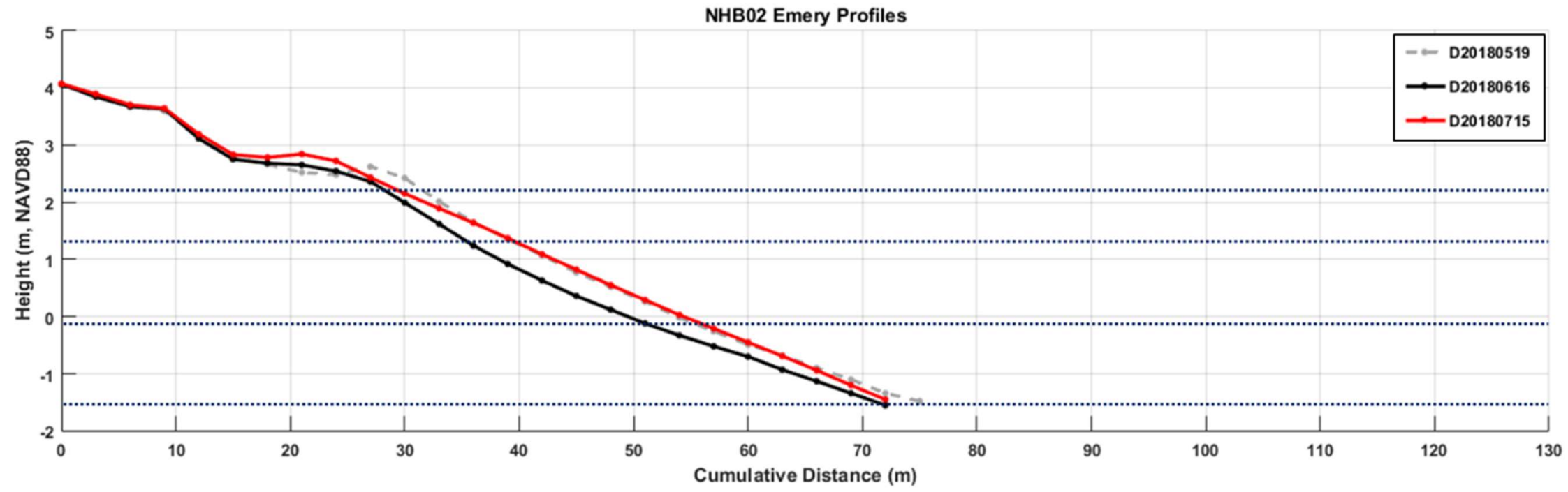

Figure NHB02-14. Beach elevation profiles for NHBO2 on May 19, 2018, June 16, 2018, and July 15, 2018.

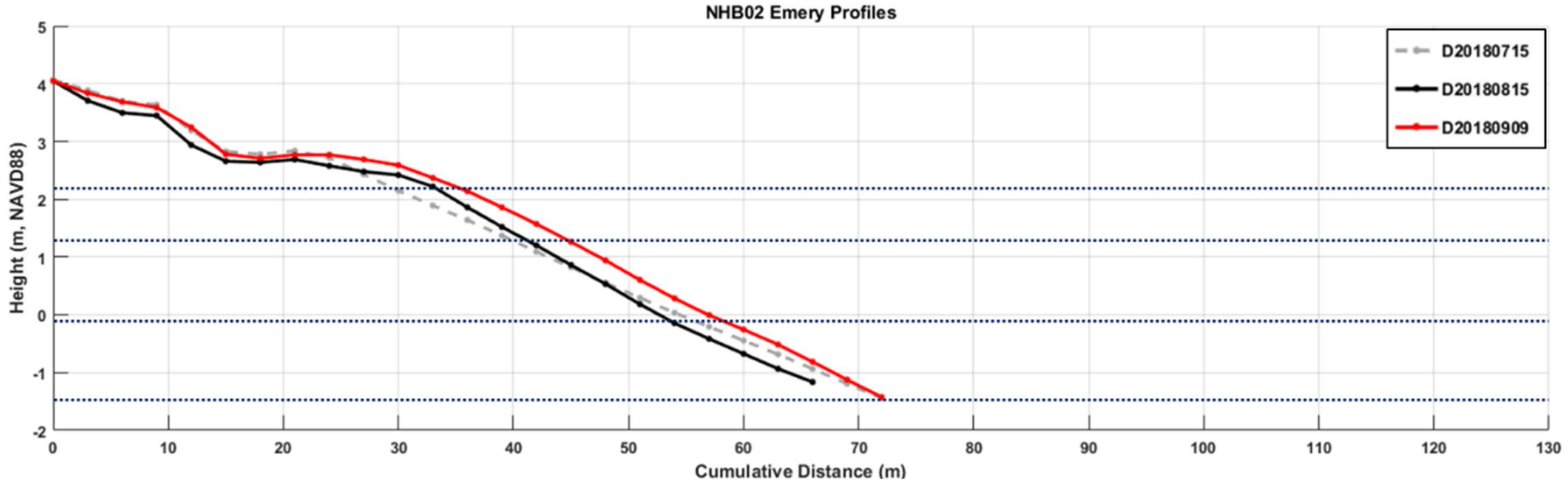

Figure NHB02-15. Beach elevation profiles for NHBO2 on July 15, 2018, August 15, 2018, and September 9, 2018. 


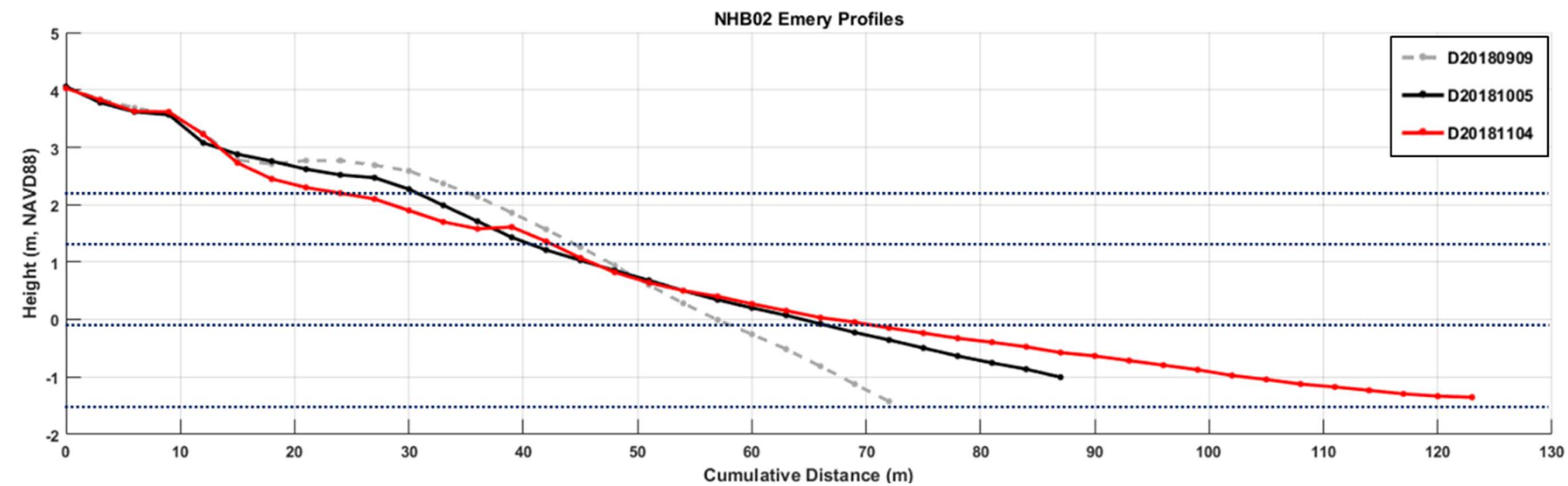

Figure NHB02-16. Beach elevation profiles for NHB02 on September 9, 2018, October 5, 2018, and November 4, 2018.

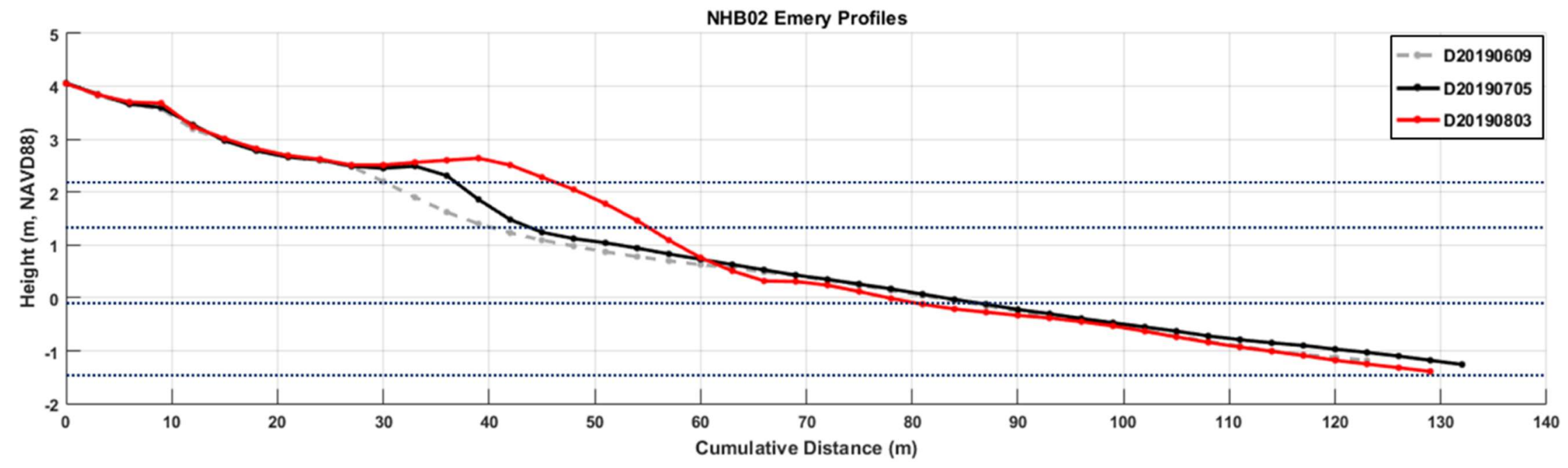

Figure NHB02-17. Beach elevation profiles for NHB02 on June 9, 2019, July 5, 2019, and August 3, 2019. Note that the y-axis of this plot extends to 140 meters, rather than the standard 130 meters for NHBO2 profile plots. 


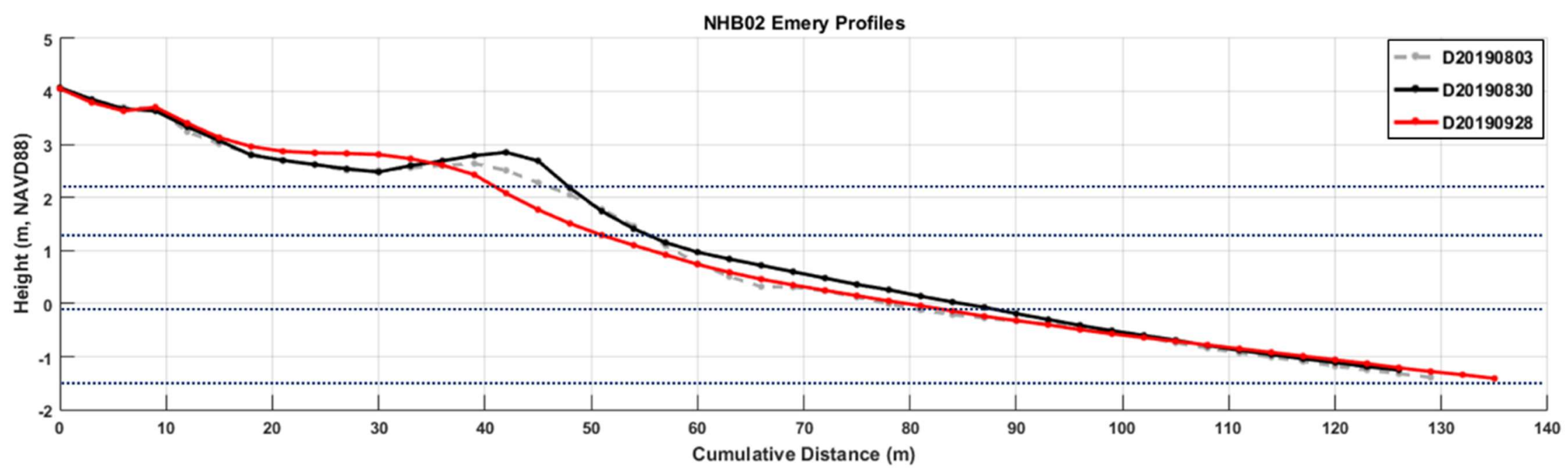

Figure NHB02-18. Beach elevation profiles for NHBO2 on August 3, 2019, August 30, 2019, and September 28, 2019. Note that the y-axis of this plot extends to 140 meters, rather than the standard 130 meters for NHBO2 profile plots. 


\section{Introduction to North Beach, Hampton, $\mathrm{NH}$}

North Beach, a NH State Park, is an attached barrier extending 2.7 km from the headland at Plaice Cove southward to Great Boars Head (Figure NB-1). Landward of North Beach there is an impoundment (Meadow Pond) and extensive salt marshes (Hampton Salt Marsh Conservation Area). The major coastal highway along the NH Seacoast (Route 1A) separates North Beach from the salt marshes and Meadow Pond. Presently, tidal flow to the back-barrier marsh is through Hampton Harbor Inlet, but is significantly constricted by culverts under Route 101 (Exeter-Hampton Expressway) and Route 101E (Winnacunnet Road).

The northern end of North Beach directly adjacent to the headland is locally referred to as Plaice Cove (Figure NB-1). The headland extends seaward and continues offshore onto the continental shelf and essentially isolates North Beach from North Hampton Beach, prohibiting or at least interrupting sediment transport from the north (Figure NB-2). Great Boars Head at the southern end of North Beach extends seaward onto the continental shelf separating North Beach from Hampton Beach (Figure NB-3). Similar to the northern headland by Plaice Cove, Great Boars Head likely prohibits the transport of sediment from Hampton Beach to North Beach. Thus, the headlands cut off any longshore transport of sediment to North Beach from either the north or south. This has important implications to North Beach as it limits new sediment from longshore transport. Furthermore, both headlands likely were an important source of sand to North Beach in the past. However, erosion of the headlands has left cobbles and boulder platforms that now provide protection from waves. Also, rip rap (stones) has been placed at the base of the headlands and has stopped or slowed present day erosion and cut off this valuable source of sand.

A small, gravelly beach is located adjacent to the headland (Figure NB-4). A riprap wall separates the small beach from the private homes. North Beach is a long, narrow beach with low elevation (Figure NB-5). A large concrete seawall extends nearly the entire length of North Beach, separating the homes, businesses, and roadways from the beach (e.g., Ocean Boulevard or Route 1A). The infrastructure was built where the dunes were once located. The seawall is fronted by large stone blocks that were placed there to slow down erosion at the base of the seawall (Figure NB-5). The wall is several meters in height from the beach surface and access to the beach is via concrete staircases. North Beach has a relatively low overall elevation and tends to lack large physiographic features such as berms. However, gravel or sand ramps are found adjacent to the seawall.

Due to its overall very low elevation, North Beach frequently becomes totally inundated with water during large spring tides and storm surges (Figure NB-6). During storms, sand and gravel are eroded from the beach and pushed landward to form gravel ramps (Figure NB-7), sand ramps (Figure NB-8), or a combination of both (Figure NB-9) against the seawall. 


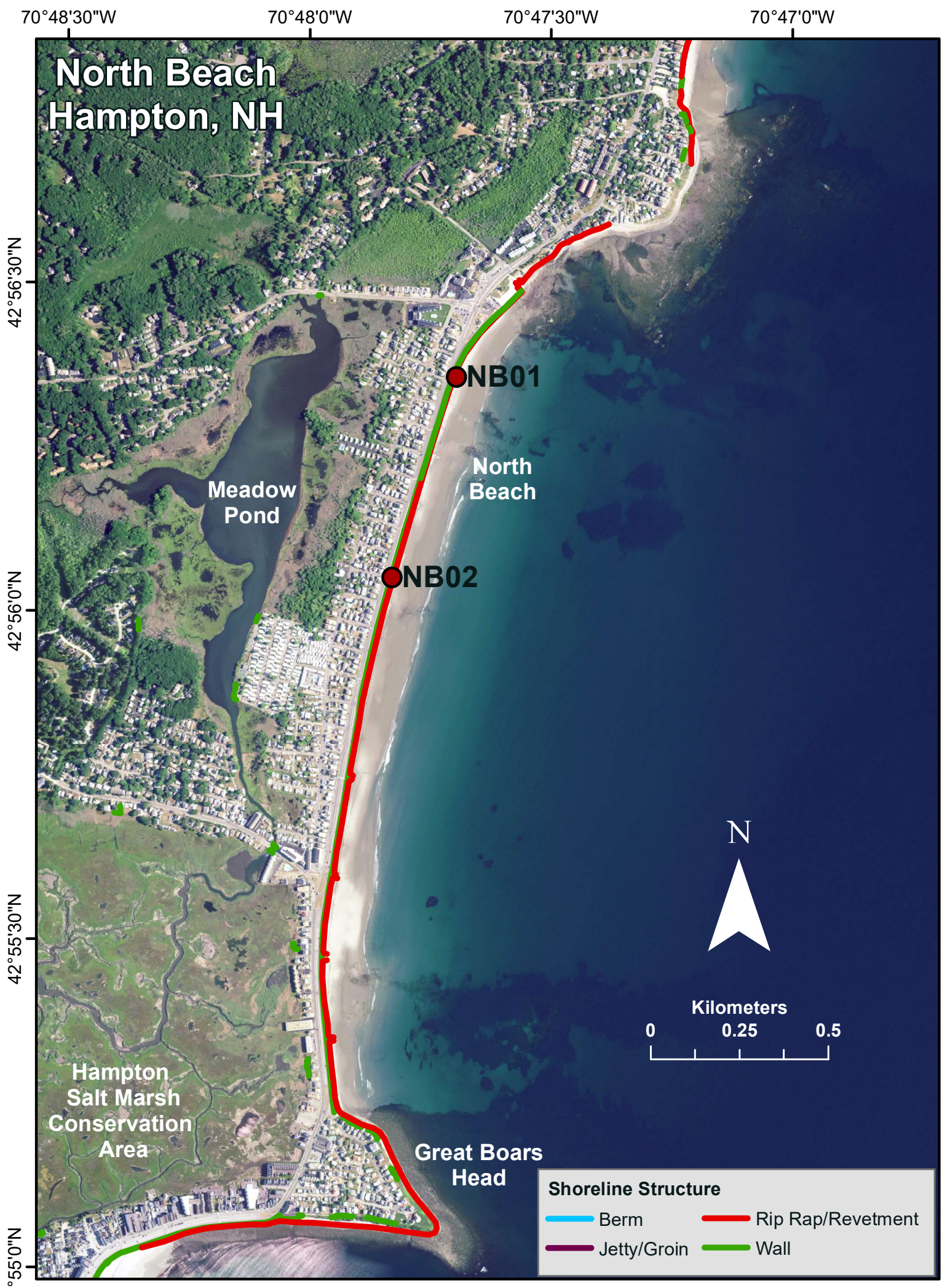

Figure NB-1. Location map of North Beach with stations, geographic features, and shoreline structures. 


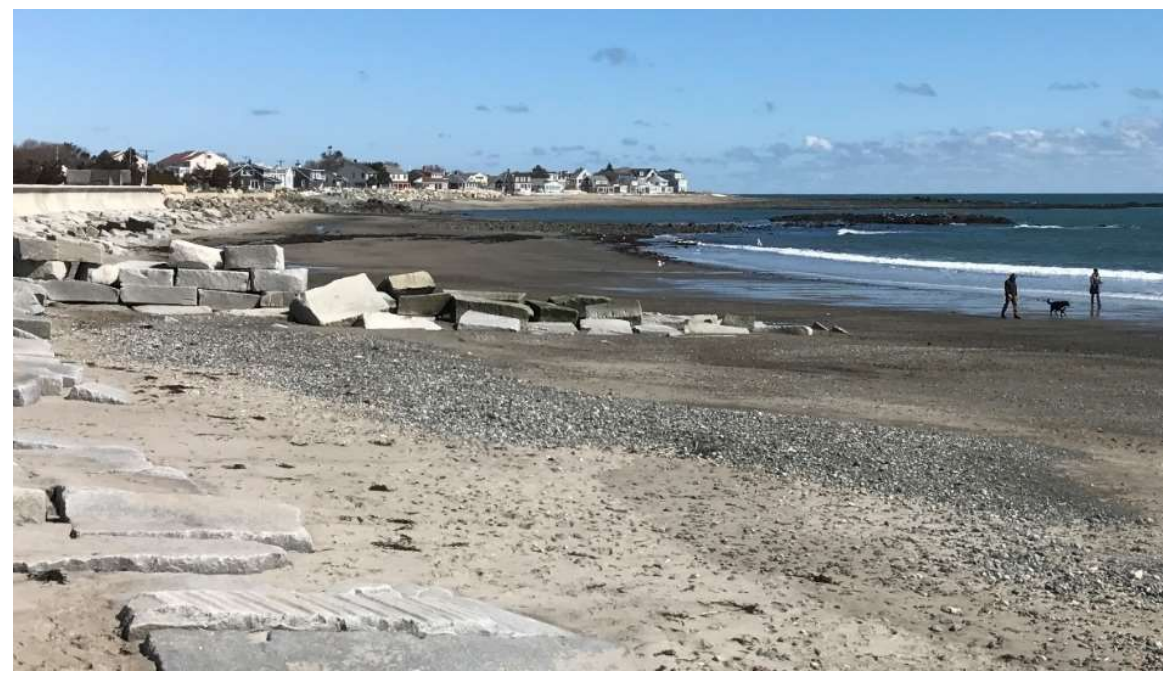

Figure NB-2. The headland to the north of North Beach taken on March 18, 2017. Note stone groin in the foreground in disrepair and the stone blocks at the base of the seawall.

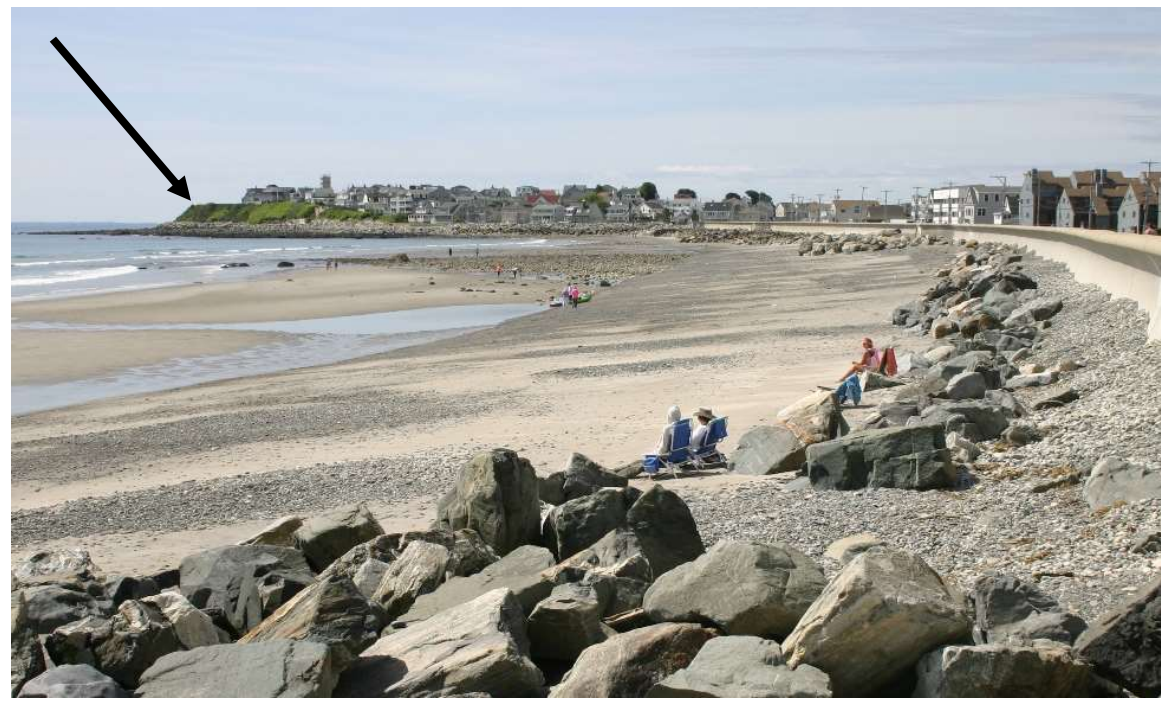

Figure NB-3. North Beach looking south on June 6, 2019. Great Boars Head (arrow) forms its southern boundary, and a long and high concrete seawall extends the entire length. Note the riprap at the base of the seawall placed to diminish wave impact to the seawall and protect private homes.

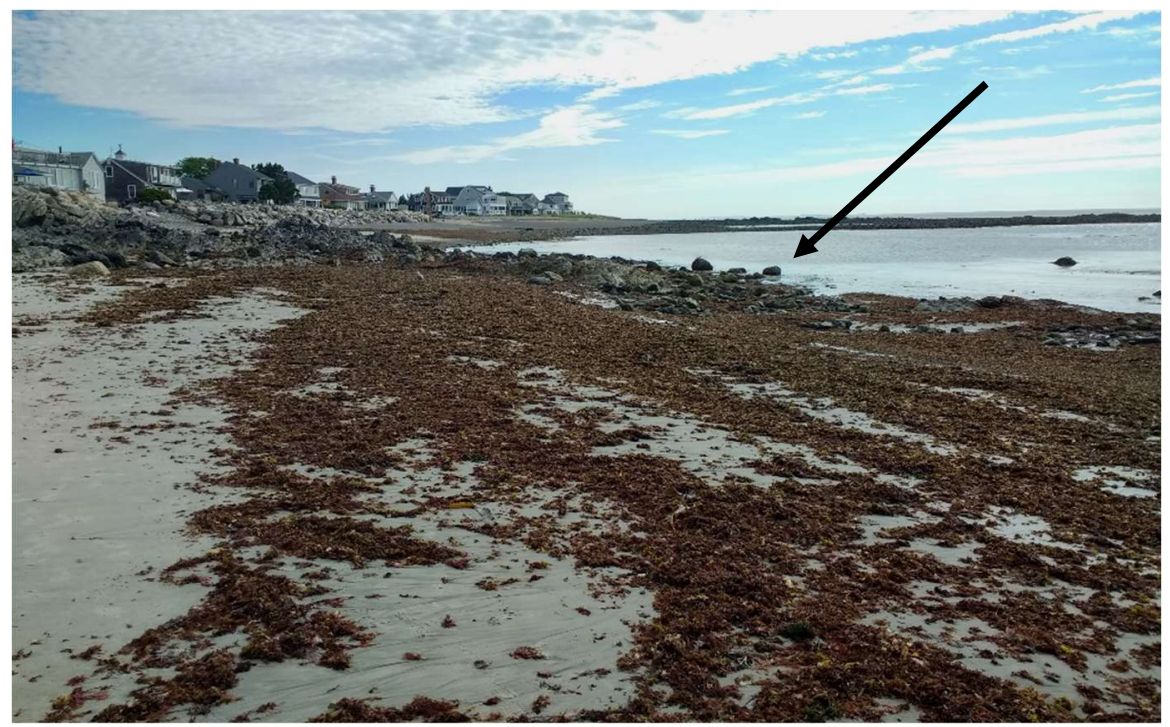

Figure NB-4. The small gravel and rock beach located adjacent to the northern headland (arrow). The photograph was taken on August 5, 2020. 


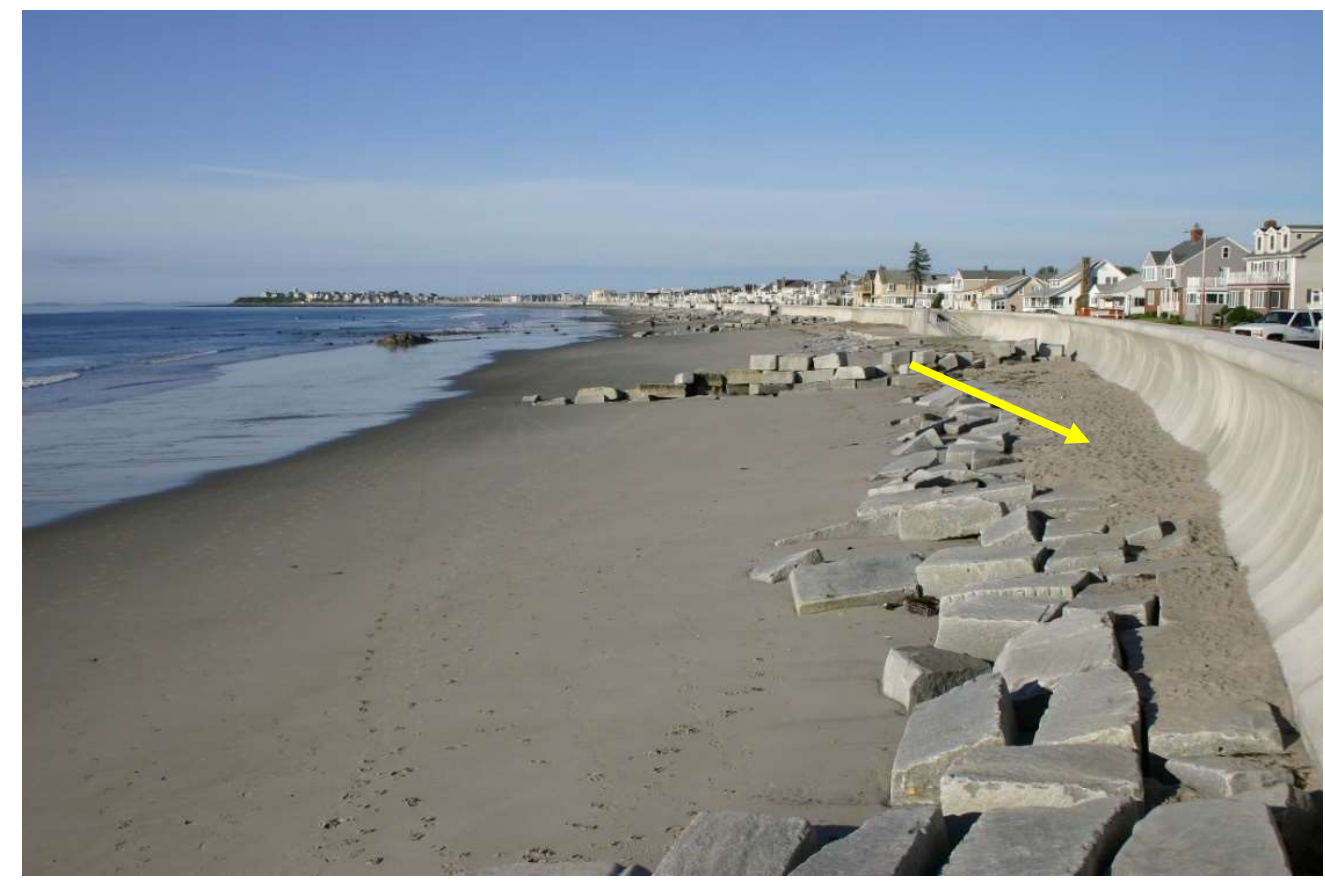

Figure NB-5. North Beach looking south on June 20, 2015. Great Boars Head is in the background. The beach is long, narrow and backed by a high concrete seawall. Note the granite blocks at the seawall placed to mitigate wave impact to the wall. Also note the sand trapped behind the blocks (arrow).

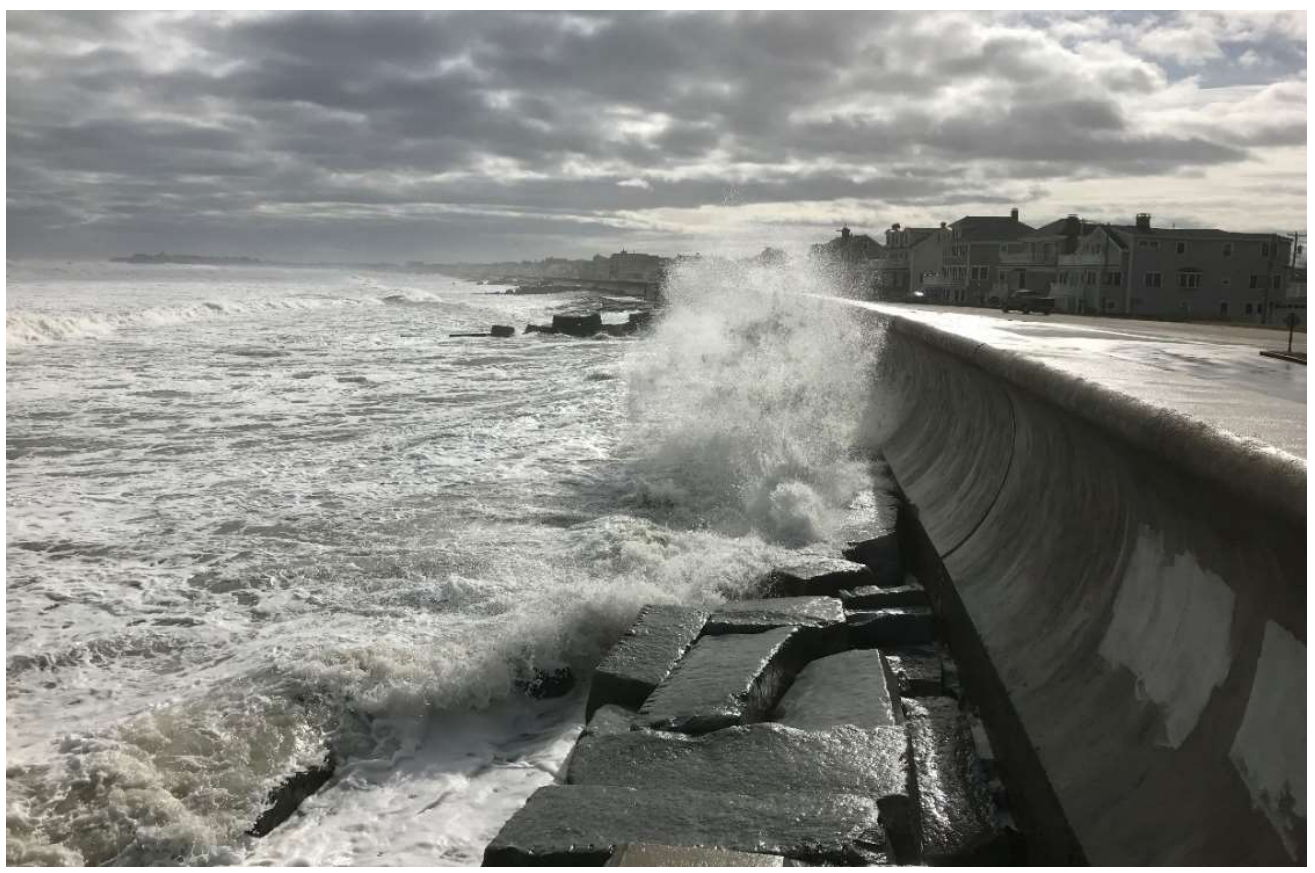

Figure NB-6. Storm waves following Nor'easter Riley at North Beach. The low elevation of the beach along with the storm conditions resulted in the seawall being impacted by waves. The photograph here taken on March 3, 2018 after the peak of the storm and the largest waves. 

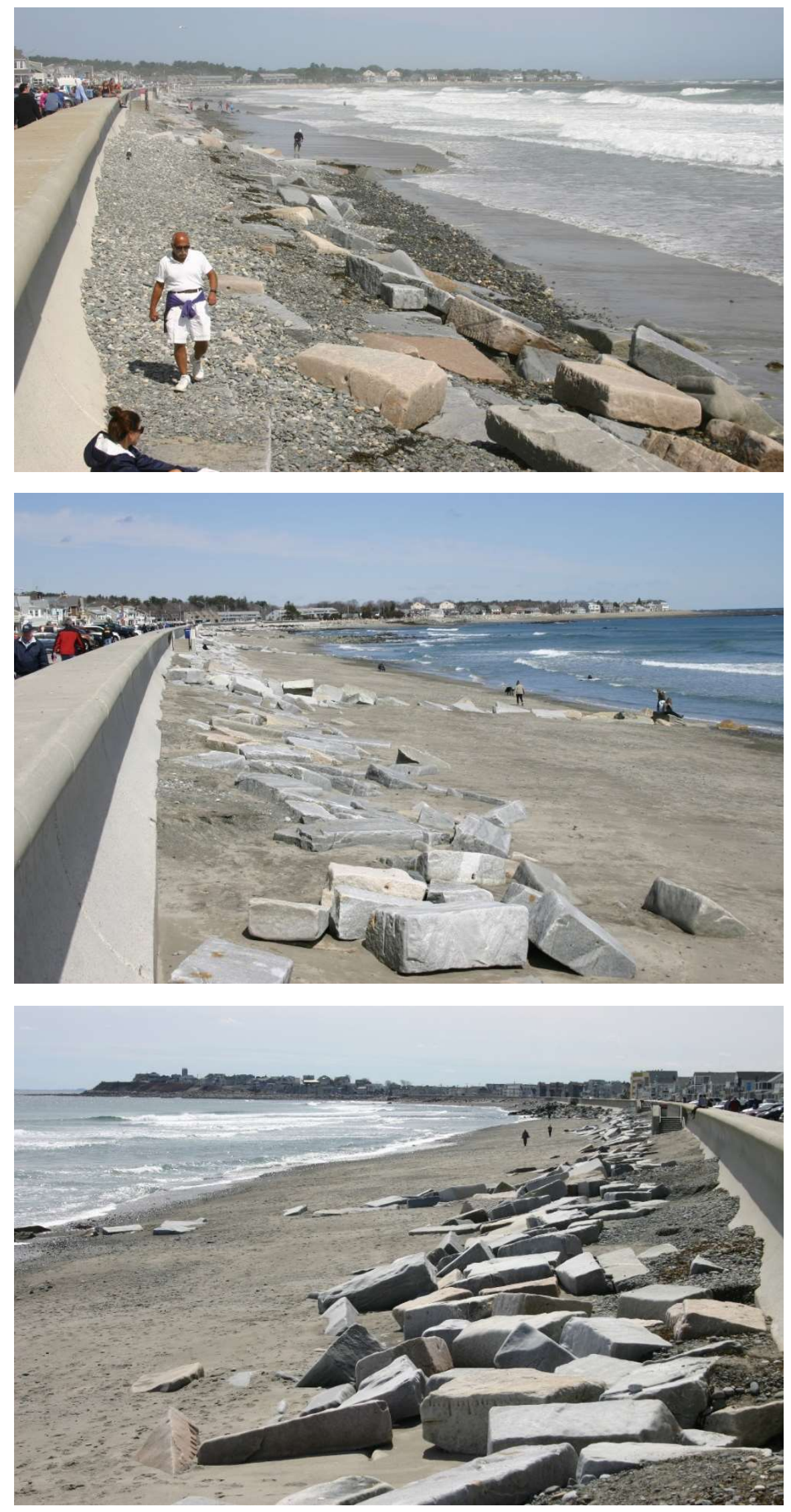

Figure NB-9. During storms sand and gravel can get pushed landward forming ramps as seen here. In this case the gravel is against the seawall and the sand has formed $a$ large ramp mid-beach. The photograph is looking south on April 7, 2018 following three severe nor'easters (Riley, Quinn, and Skylar). 
The headlands that isolated North Beach have a major influence on the morphology and sediment composition of the beach. Both the headland to the north and Great Boars Head to the south are largely composed of glacial till. Great Boars Head is a glacial drumlin. Tills are composed of a mixture of mud, sand and gravel including cobbles and boulders. As the headlands eroded, the mud and sand were transported elsewhere leaving behind the larger clasts including cobbles and boulders. The sand was likely distributed to the adjacent beaches and to the nearshore shelf. The cobbles and boulders were too large to be transported long distances and formed megaclast platforms around the headlands. Apparently, there were other till deposits as there are several large megaclast platform deposits found on North Beach including large platforms on the northern end of North Beach (Figure NB-10), at mid beach south of NB02 (Figure NB-11) and on the southern end toward Great Boars Head (Figure NB-12). As a result of the influence of the glacial till deposits, the sediment on North Beach is bimodal and composed of sand and gravel. During erosional periods the beach becomes coarser and is often covered with pebbles (Figure NB-13). During accretional periods, a veneer of sand is deposited on the beach (Figure NB-5).

As stated above, North Beach is likely an attached barrier that has migrated landward with sea-level rise to its present position from a location further seaward. Evidence of this migration are what appear to be peat deposits that outcrop on the beach periodically following storms. A large peat outcrop was exposed at the northern end of North Beach at station NB01 in the lower intertidal zone on at least two occasions: April 18, 2019 (Figures NB-14 and NB-15) and October 26, 2019 (Figure NB16). Similarly, tree stumps and peat have also been exposed in the intertidal at Odiorne Point and North Hampton Beach (located south of North Beach along the NH Seacoast).

Presently, the headlands likely diminish or prohibit any longshore transport of sand to the North Beach (as explained above). In addition, the headlands are now armored with riprap and other materials essentially reducing or cutting off any new sediment source. Since the seawall forms the landward boundary, the only natural source of sediment to North Beach is from offshore. Therefore, it appears that North Beach has a limited source of sediment and as result has a low elevation, little morphologic features such as berms, and is susceptible to flooding, erosion, and storm damage. The exposure of the underlying peats is also evidence that the thickness of sand is limited. 


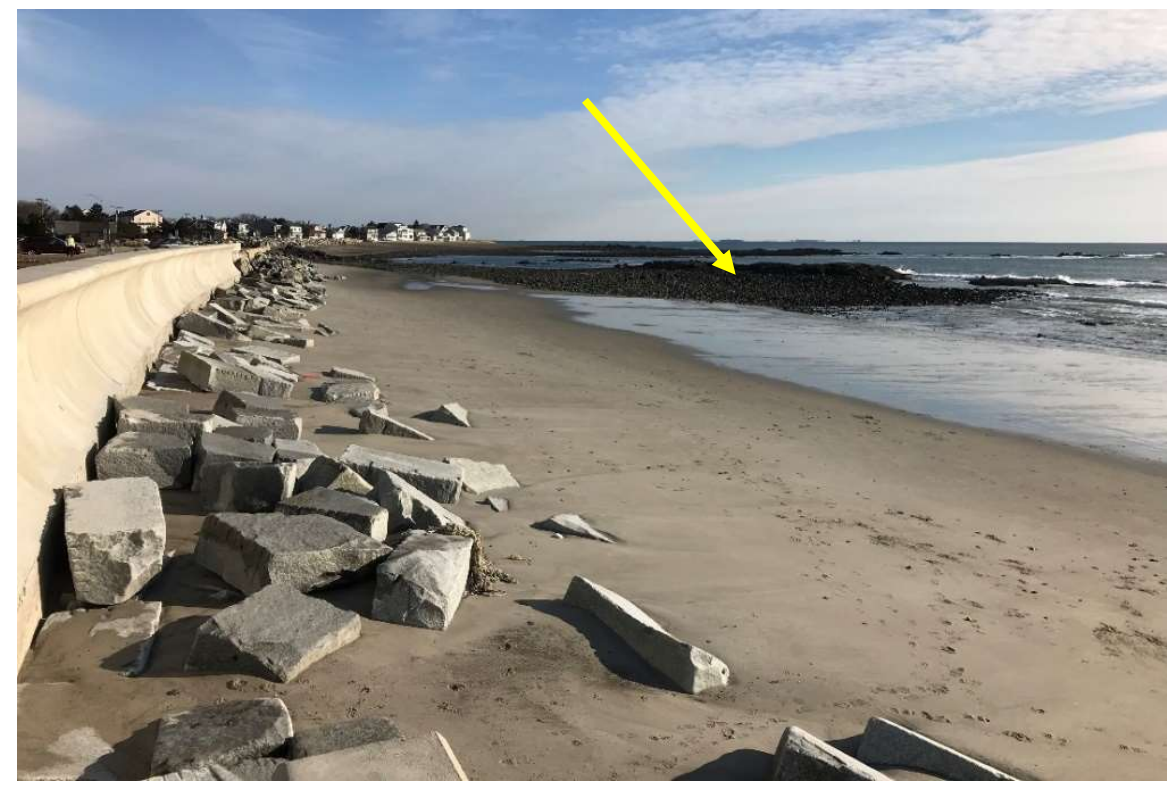

Figure NB-10.

Megaclast platform (arrow) on the northern end of North Beach on January 26, 2019. The headland and surrounding area is composed of till which was eroded during the last sea-level transgression leaving behind the cobbles and boulders forming the apron around the headland and on the beach.

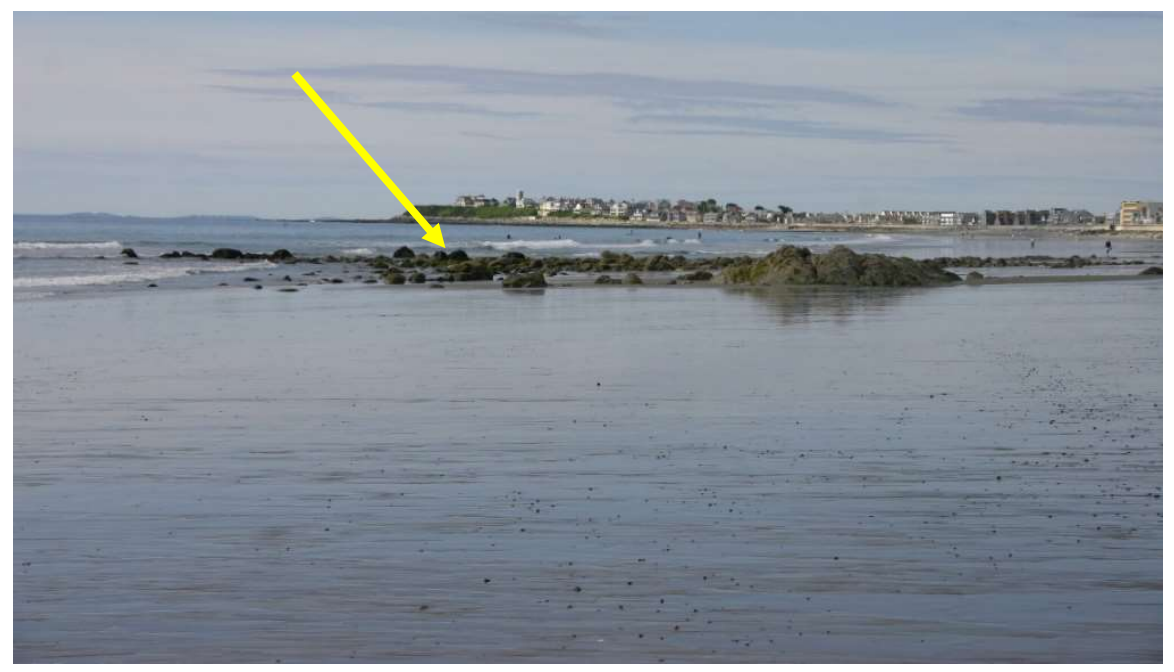

Figure NB-11. Bedrock outcrop with cobbles and boulders exposed at mid North Beach (arrow). The photograph was taken on July 7, 2019.

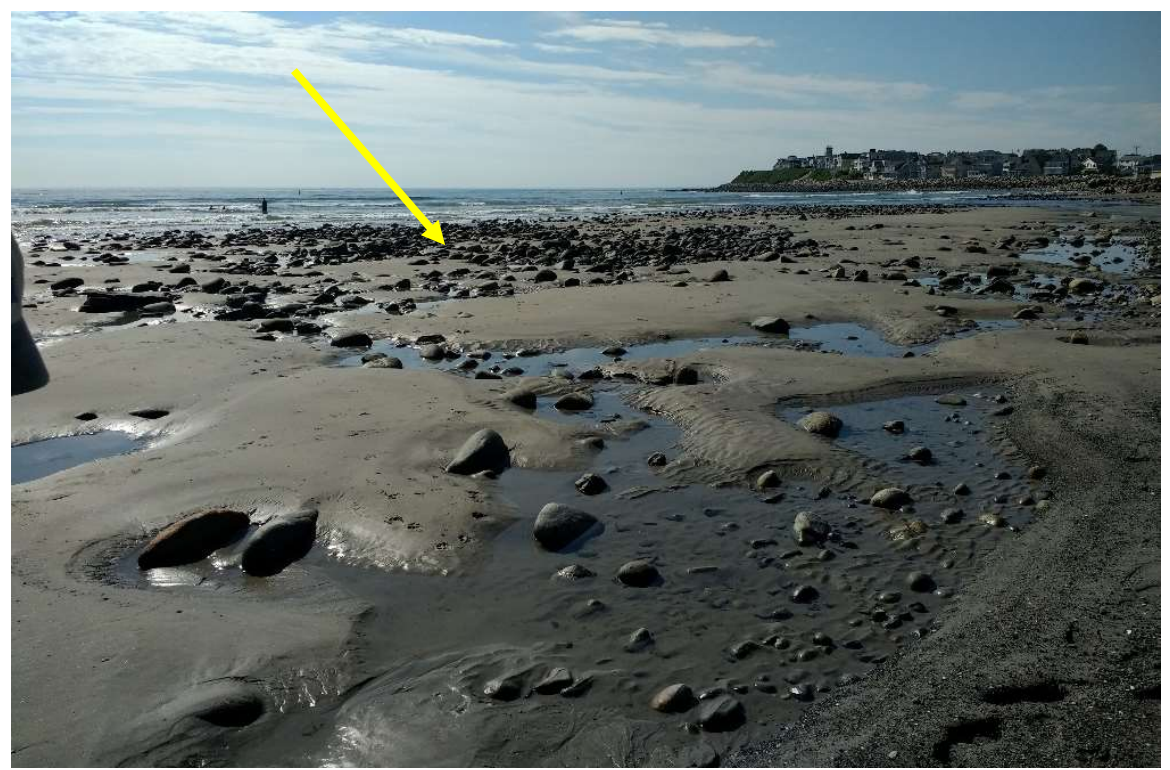

Figure NB-12. Cobble and boulder or megaclast platforms (arrow) outcropping on the southern end of North Beach on August 5, 2020. Great Boars Head is in the background and is surrounded by a megaclast apron. 

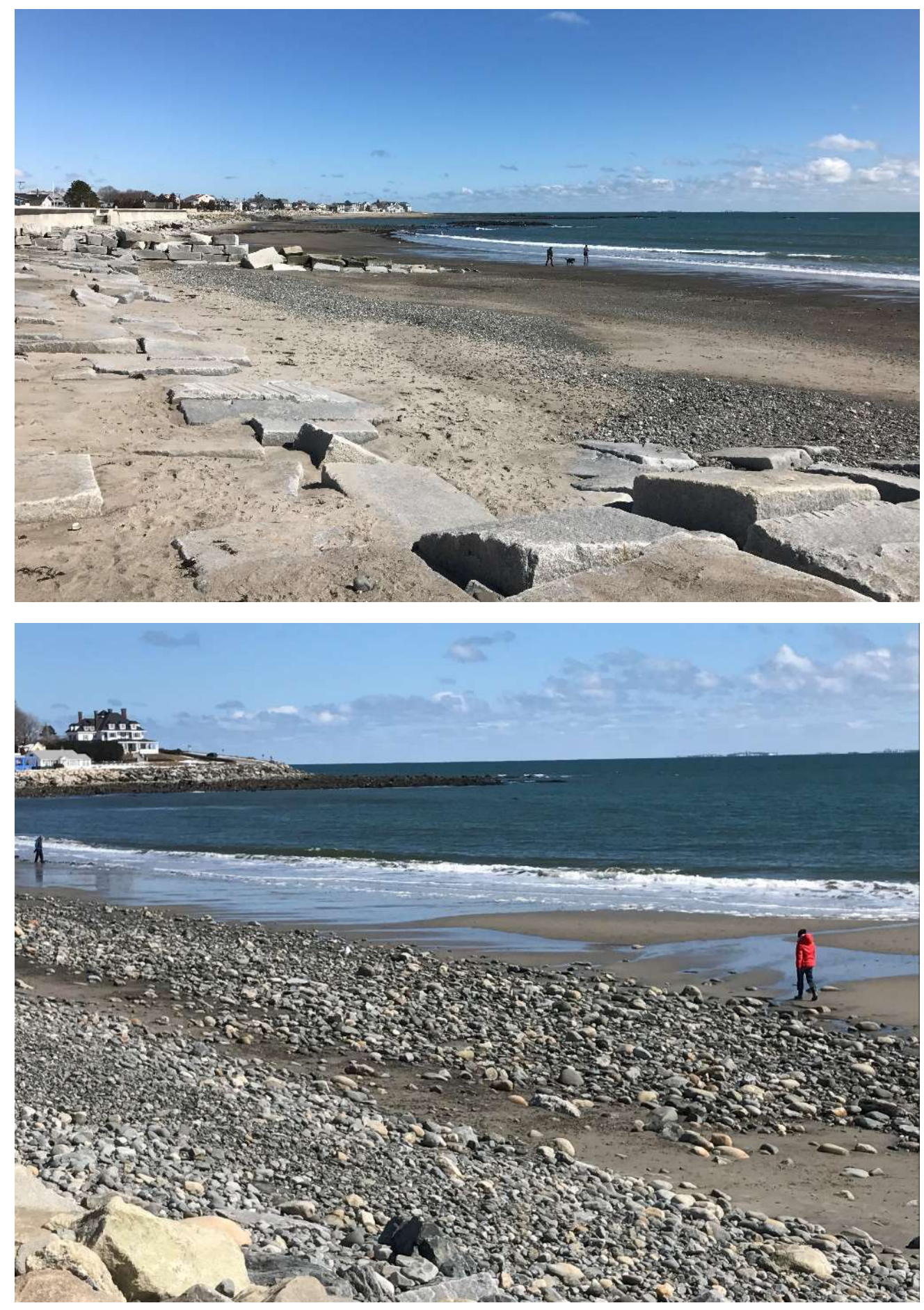

Figure NB-13. North Beach is composed of bimodal or mixed sediments including sand and gravel as seen here in these photographs of northern North Beach on March 18, 2017. During storm periods the gravel can become more concentrated as finer sediments are eroded. 

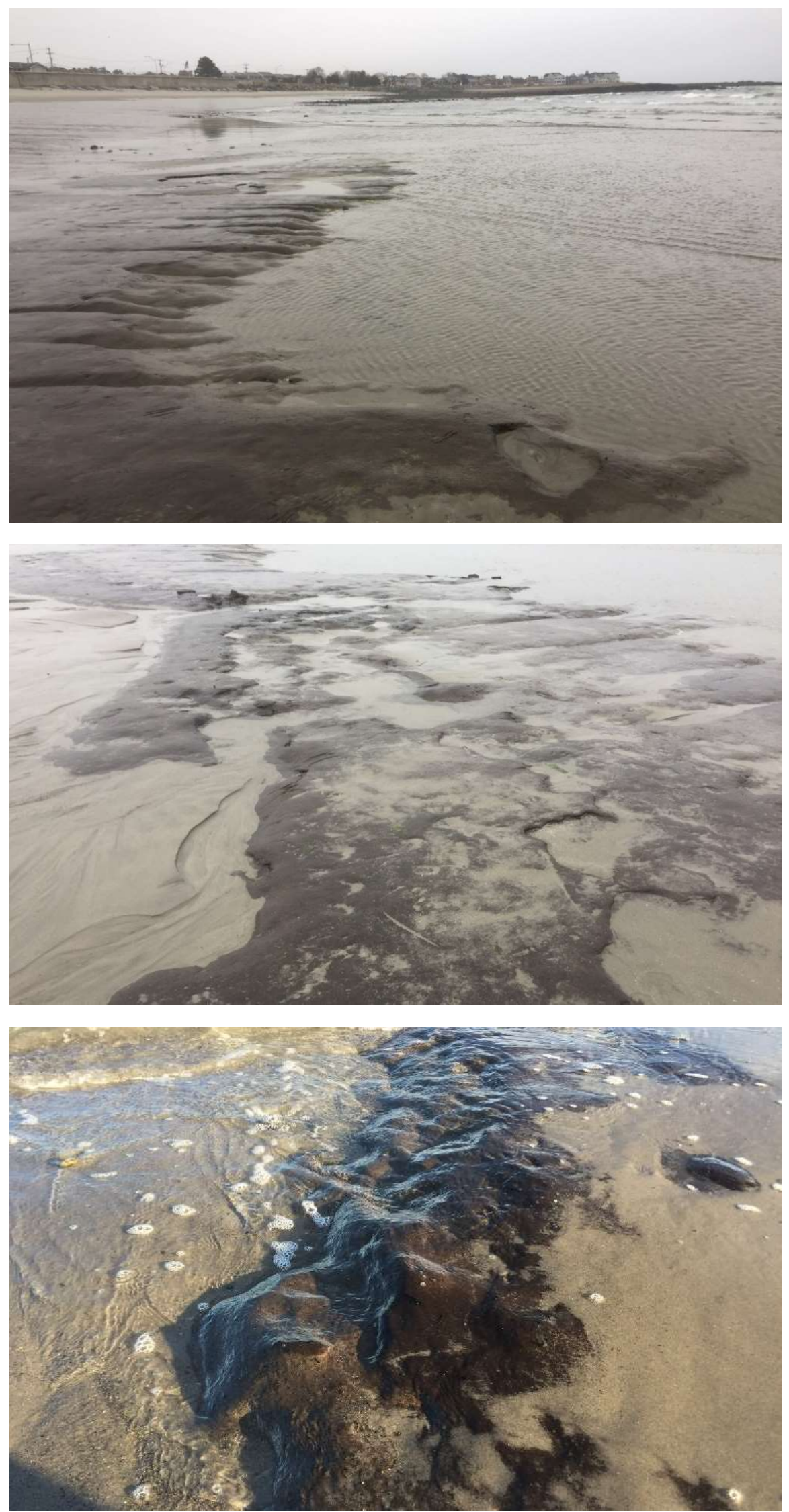

Figure NB-14. Peat deposit outcropping on North Beach at station NB01. The peat is periodically exposed after stormy periods when the covering layer of sand is removed. The photograph was taken on April 18, 2019.
Figure NB-15. Close-up of peat deposit outcropping on North Beach at station NB01 on April 18, 2019.
Figure NB-16. Tree stump exposed in the lower intertidal near the profile transect at North Beach NB01. Photograph taken on October 26, 2019. 


\section{Results for Station at the Northern End of North Beach: NB01}

Overview. Profile station NB01 is located $\sim 0.6 \mathrm{~km}$ from the headland that forms the northern boundary of North Beach (Figure NB-1). The profile extends seaward from a large concrete landing at the base of the seawall that is $\sim 30 \mathrm{~m}$ in length and $\sim 6 \mathrm{~m}$ in width (Figures NB01-1 and NB01-2). Granite slabs (on the order of one or two meters in length and width) are located along the base of the seawall and the concrete landing to prevent wave scour (Figure NB01-3). The landward two to three meters of NB01 traverses the granite blocks. However, periodically the concrete blocks are covered with sand, often after storms when sand is eroded from the lower beach and forced landward. Bedrock or cobble and boulder fields are common in the vicinity of NB01. Approximately 150 to $200 \mathrm{~m}$ north of the station cobble-boulder fields or platforms are found (Figures NB-10 and NB01-4). Approximately $100 \mathrm{~m}$ south of the station there are outcrops of either bedrock or scattered cobbles and boulders (Figures NB-11 and NB01-5). The beach sediment is highly variable ranging from sand to mixed sand and pebbles following erosive events. Following extended periods of storms or large wave conditions when the beach is highly eroded, peat-like deposits are exposed in the lower intertidal zone (discussed previously in the "General Characteristics of North Beach") (Figures NB-15, NB-16, and NB17). The peat deposits were likely part of the upland landward of the beach at a lower sea level (discussed in the previous section).

Summary. North Beach at NB01 suffered major erosion including significant elevation and sediment volume loss during the severe nor'easters in late winter 2018. However, the beach rebounded and maintained its elevation and volume for the remainder of the study period with short erosive events, some extreme, followed by rebuilding of the beach. NB01 appears to be very dynamic with losses and gains of elevation and movement of sediment. However, this apparent stability of erosion followed by accretion may not be as positive of a trend as it would seem. The overall elevation of North Beach is low, so even rebuilding the beach during the accretional periods still leaves it extremely vulnerable to storms. The entire beach becomes inundated during large spring tides and storm surges. It is likely that North Beach has lost significant elevation over time as sediment sources have diminished (discussed above). Erosion is clearly a very significant problem at North Beach.

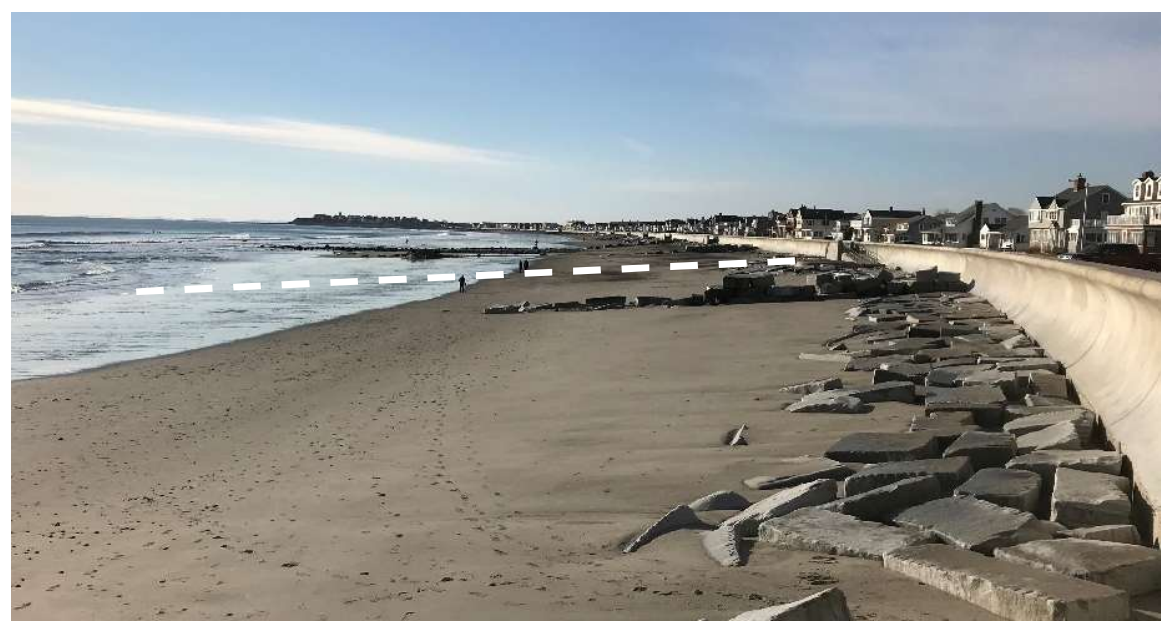

Figure NB01-1. Station NB01, which is located at the northern end of North Beach. The beach elevation profile transect is shown by the white dashed line in the photograph taken on January 26, 2019. 


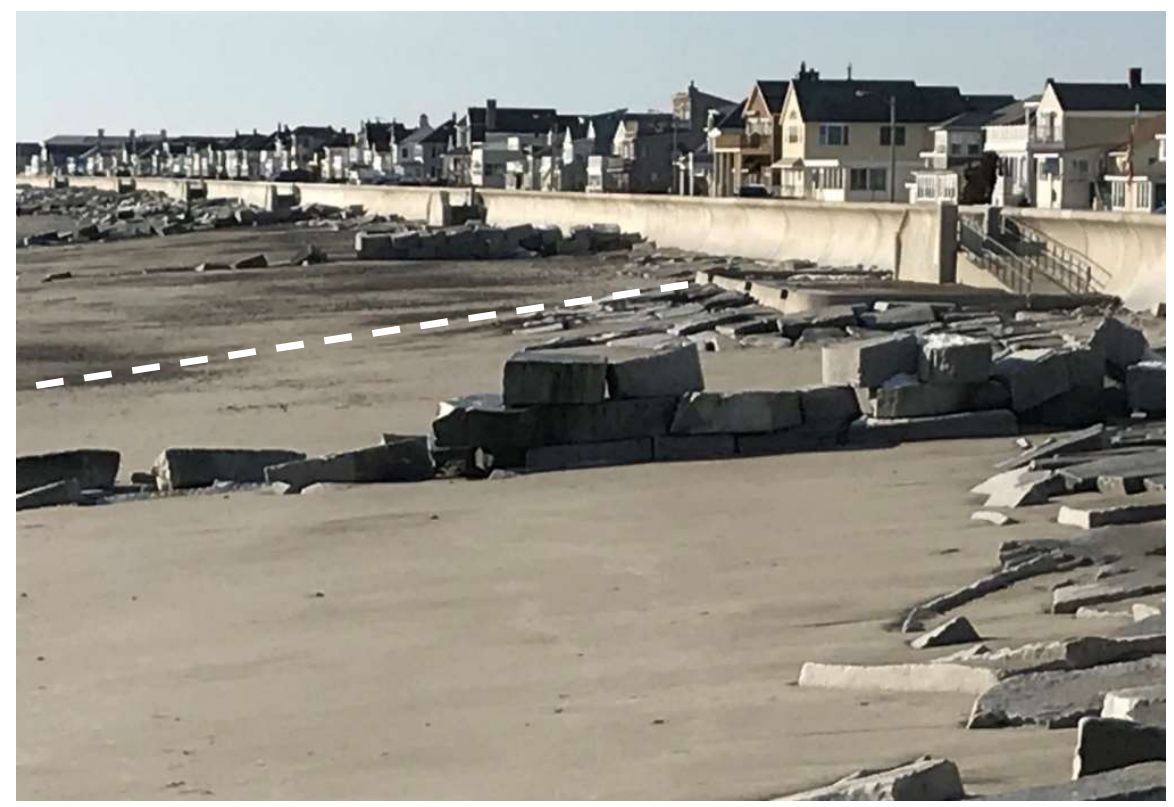

Figure NB01-2.

Landward portion of the beach elevation profile at NB01 on January 26, 2019. The white dashed line shows the profile transect that extends seaward across the beach. The photograph is looking south.

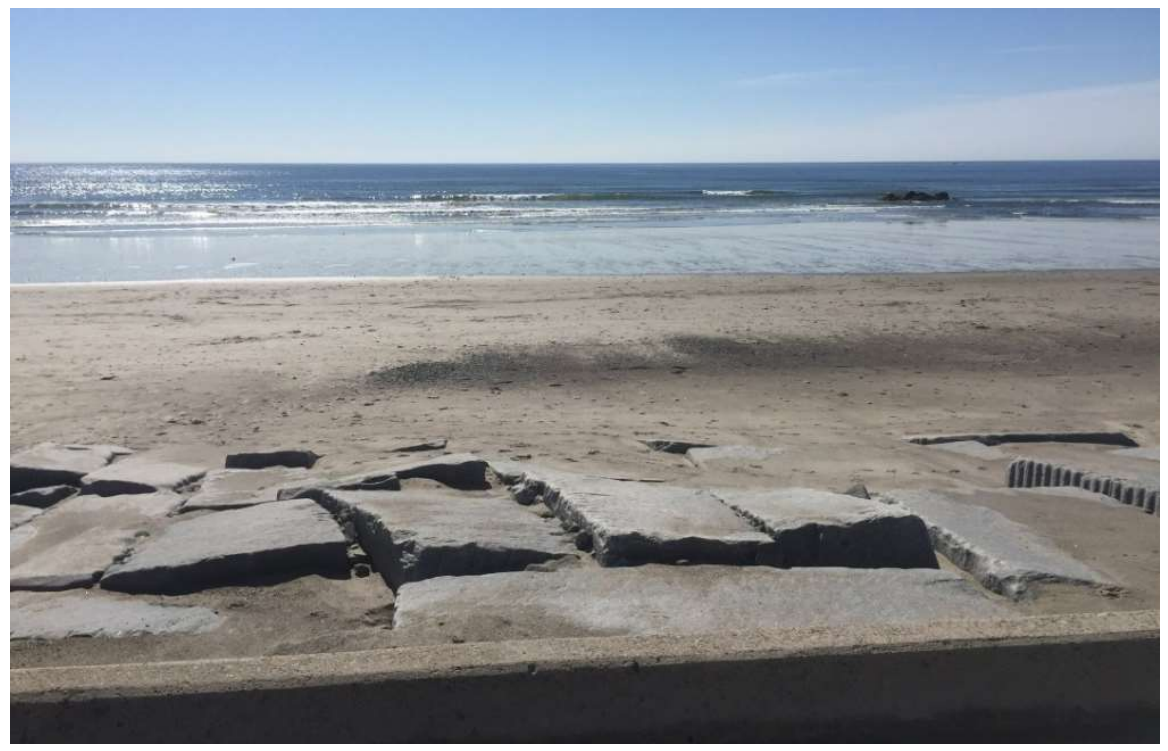

Figure NB01-3. NB01 profile transect looking seaward. The photograph was taken on June 7, 2019. 


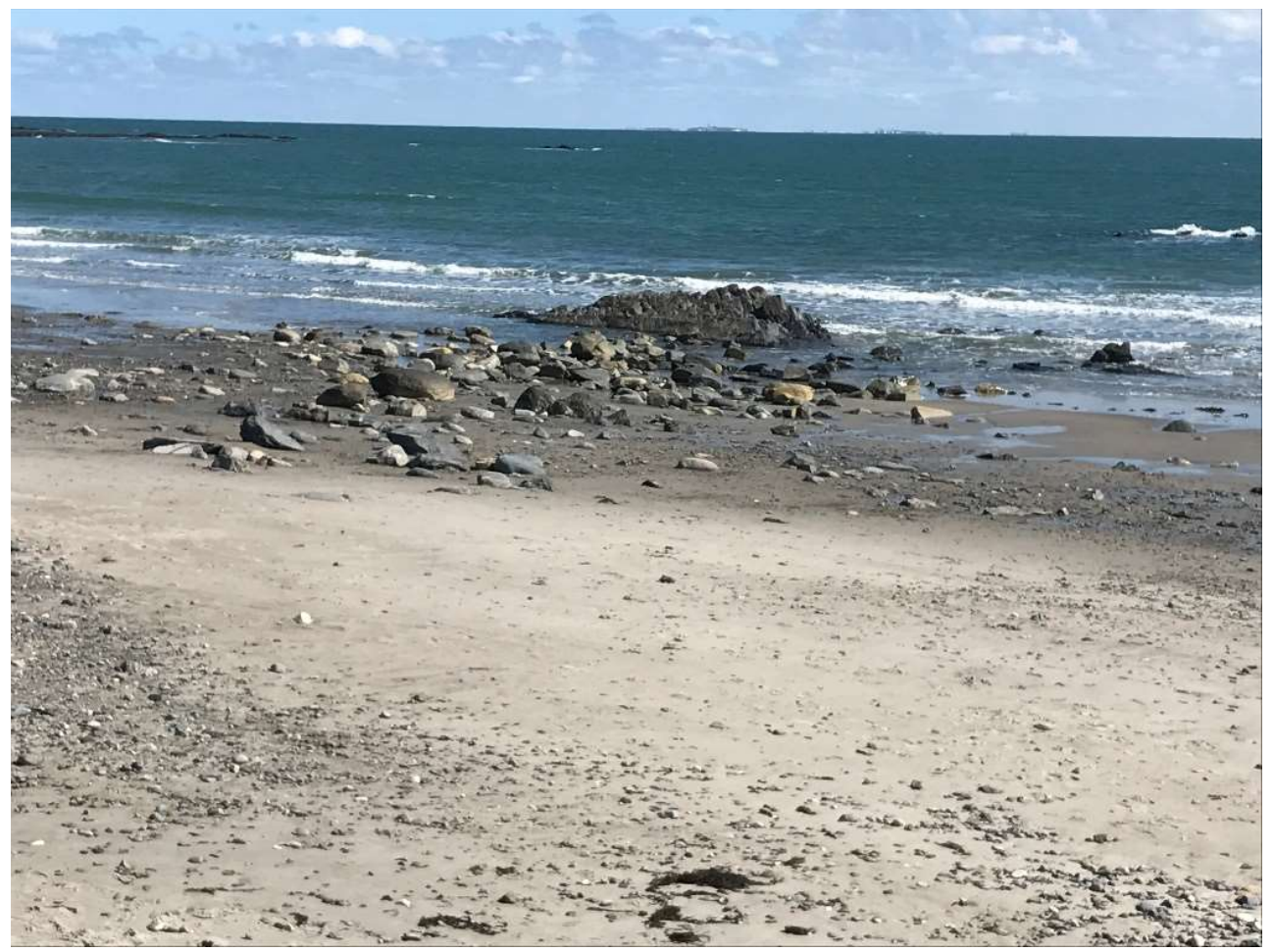

Figure NB01-4. Small bedrock outcrop along with scattered cobbles and boulders located a short distance from station NB01. Photograph taken on March 18, 2017.

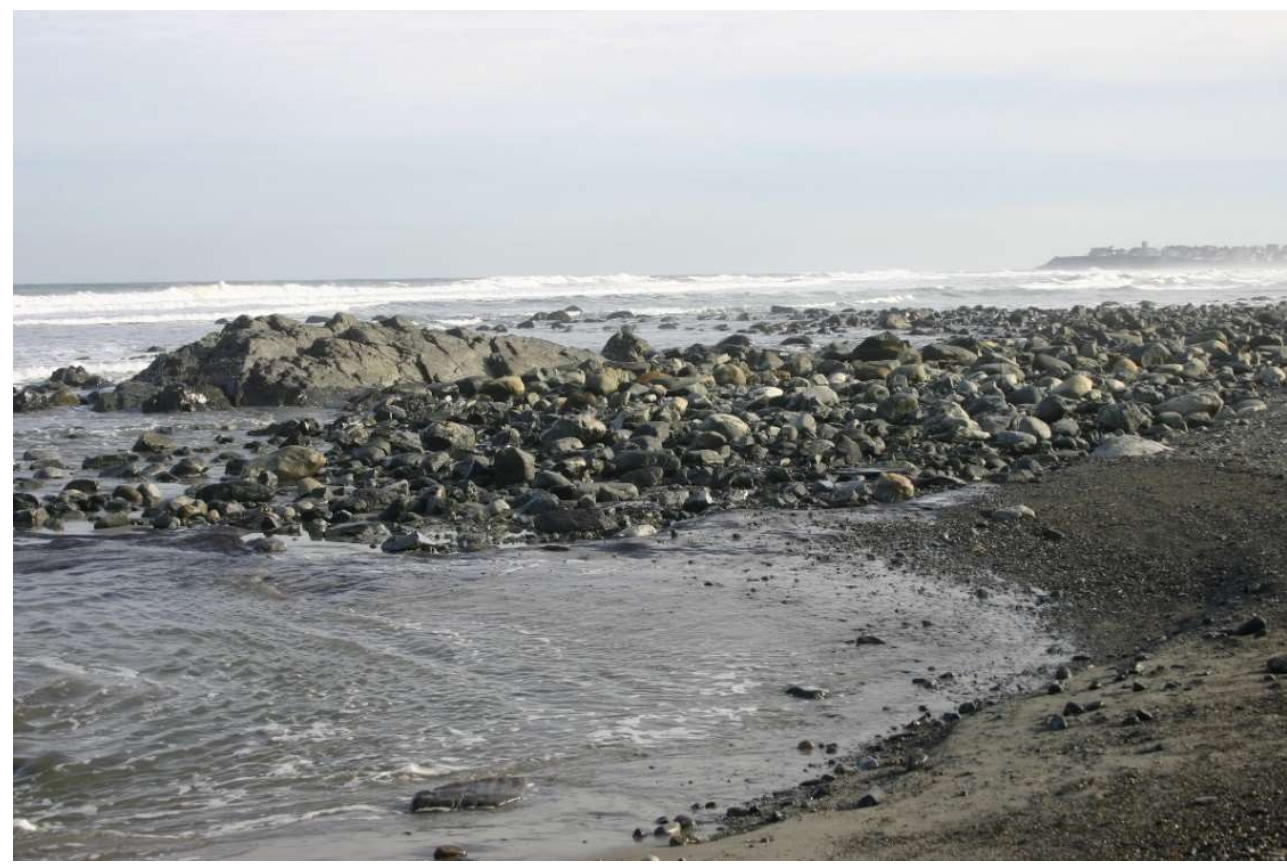

Figure NB01-5. Bedrock outcrop and cobble and boulder platform located $100 \mathrm{~m}$ south of NB01. The photograph was taken on March 28, 2018 following the severe nor'easters of late winter. 
General Profile Characteristics. The profile at NB01 was measured thirty times between January 27, 2018 and March 13, 2020 (Figure NB01-6). All plotted beach profiles can be found in Appendix C(7). The width of the beach from the concrete landing to the low water line varied from a maximum of $99 \mathrm{~m}$ on February 24, 2018 during an accretional period to a minimum of $33 \mathrm{~m}$ on March 28, 2018 following three severe nor'easters in late winter 2018. Examination of the sweep zone shows the elevation of the beach varied $\sim 0.6 \mathrm{~m}$ at the start of the profile at the landing near the seawall, $\sim 1.7$ $\mathrm{m}$ at a point $33 \mathrm{~m}$ seaward of the starting point, $\sim 1.5 \mathrm{~m}$ at mid beach, and $\sim 1.2 \mathrm{~m}$ in the lower beach (Figure NB01-6).

Comparison of the maximum average elevation profile for the entire study period (which occurred on August 4, 2019) with the minimum average elevation profile (which occurred on March 28, 2018) illustrates the magnitude of change between individual profiles (Figure NB01-7). During the accretional conditions on August 4, 2019, the intertidal beach elevation profile was $\sim 87 \mathrm{~m}$ long with sand covering most of the beach. However, following three major nor'easters in late winter 2018 the beach was severely eroded with major elevation loss. The beach elevation at $\sim 33 \mathrm{~m}$ from the start of the profile was $\sim 1.8 \mathrm{~m}$ lower when compared to the maximum profile. Furthermore, the measurement could not be made at the lower beach because the elevation was below the low water level indicating severe erosion in the lower intertidal as well.

Both examples show that there was a large range in the beach elevation over the two-year study period. This is especially significant because the beach has an overall low elevation with respect to sea level even during periods of accretion. Therefore, the beach is frequently inundated. 


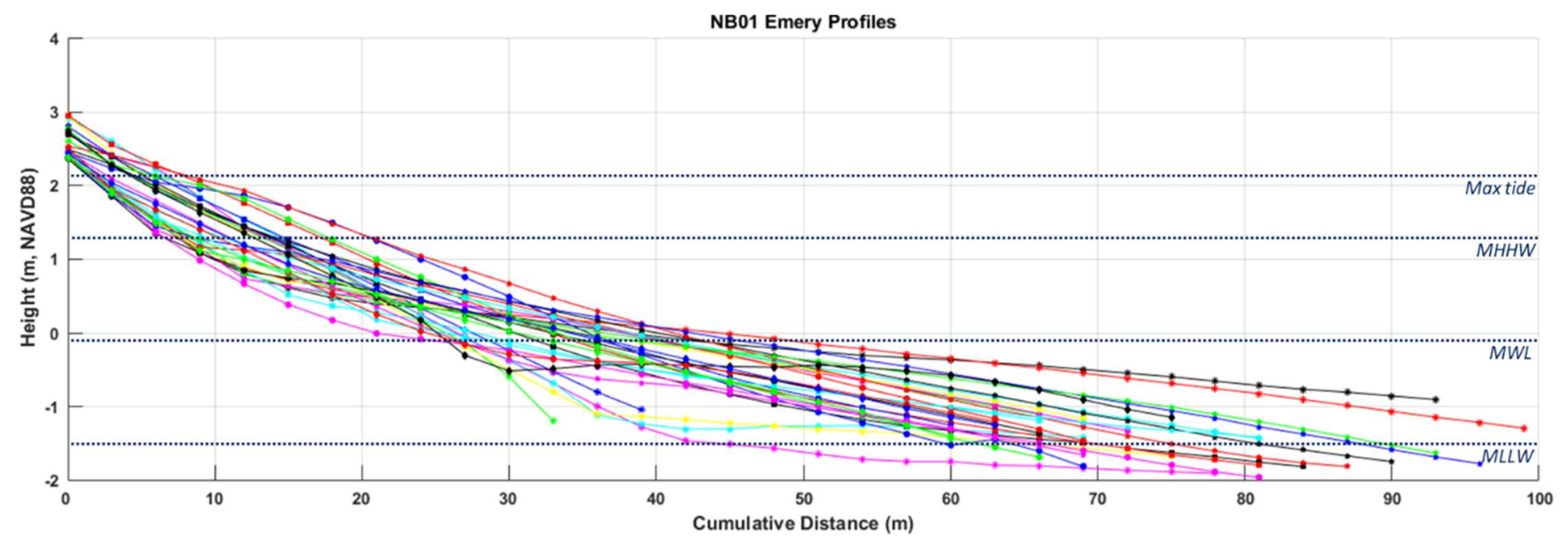

Figure NB01-6. All thirty beach elevation profiles measured at station NB01 between January 27, 2018 and March 13, 2020. Maximum tidal elevation (max tide), mean higher high water elevation (MHHW), mean water level (MWL), and mean lower low water elevation (MLLW) are indicated by the dotted lines.

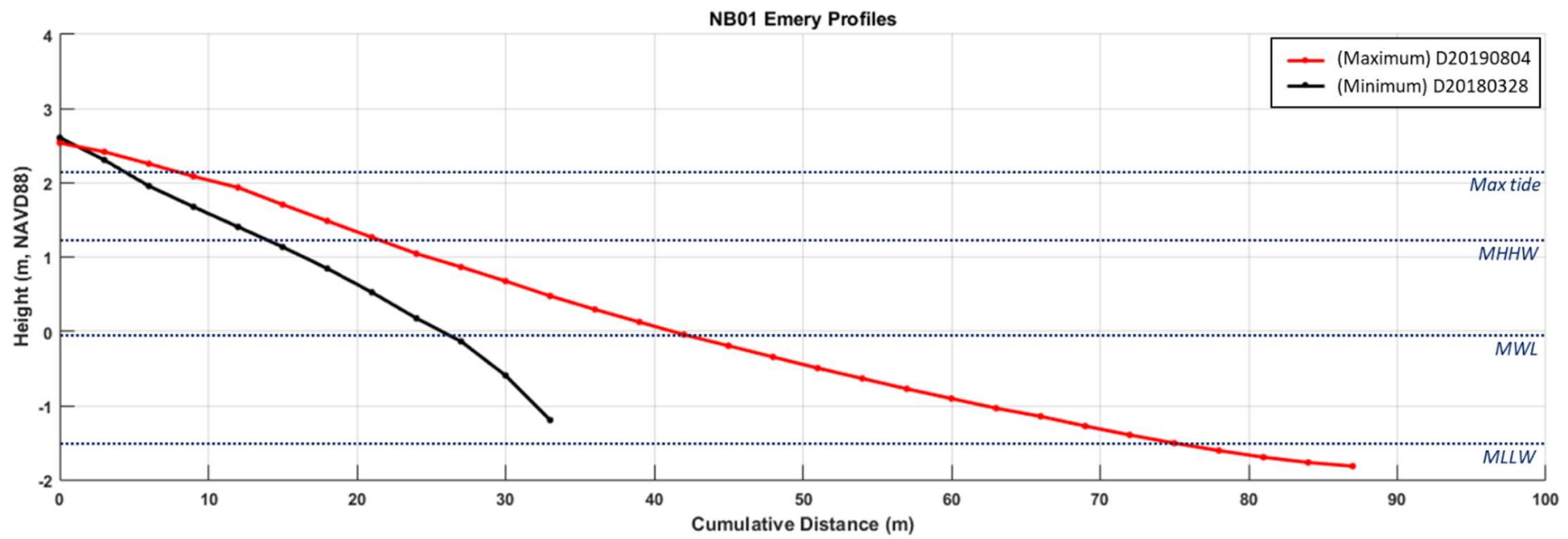

Figure NB01-7. Maximum (August 4, 2019) and minimum (March 28, 2018) profiles by volume from the study period at station NB01. Note that this is not the impact of a single event as the profiles are not consecutive monitoring dates. Rather this comparison looks at the extreme of differences of beach elevation profiles over the entire study period. 
Storm Effects, Beach Erosion, and Recovery. The impact of high-energy events on North Beach at NB01 are clearly illustrated by the sequence of severe nor'easters that occurred in late winter 2018 including Riley (March 1-4), Quinn (March 6-9), and Skylar (March 12-14) (Table 3-3). More than $1 \mathrm{~m}$ of sediment was eroded from the NB01 profile during Riley and the beach continued to erode and lose elevation during Quinn and Skylar (Figures NB01-8, NB01-9, and NB01-10). The beach profile became very steep due to sand being eroded from the lower beach and subsequently pushed landward against the seawall by waves (Figures NB01-11 and NB01-12). Sand also was likely transported seaward. As a result, the lower beach was badly eroded, covered with a pebble lag, and in a number of areas the underlying megaclast platforms and peat deposits were exposed (Figure NB01-13).

The volume calculations at NB01 also illustrate the impact of these 2018 storms on the beach at NB01 (Figure NB01-14). Based on the computed sediment volume, in January and February 2018 the beach was built up and in an accretional phase despite early January storms including Grayson (Table 3-3). However, the three subsequent nor'easters caused major erosion and volume loss of the beach with the minimum for the entire study reached on March 28, 2018. The occurrence of three major storm events with large waves within a short period with no time for the beach to recover between storms led to a significant loss in the mean elevation $(\sim 0.8 \mathrm{~m})$ and up to $\sim 1.3 \mathrm{~m}$ elevation loss in the lower profile between February 24 and March 28. 


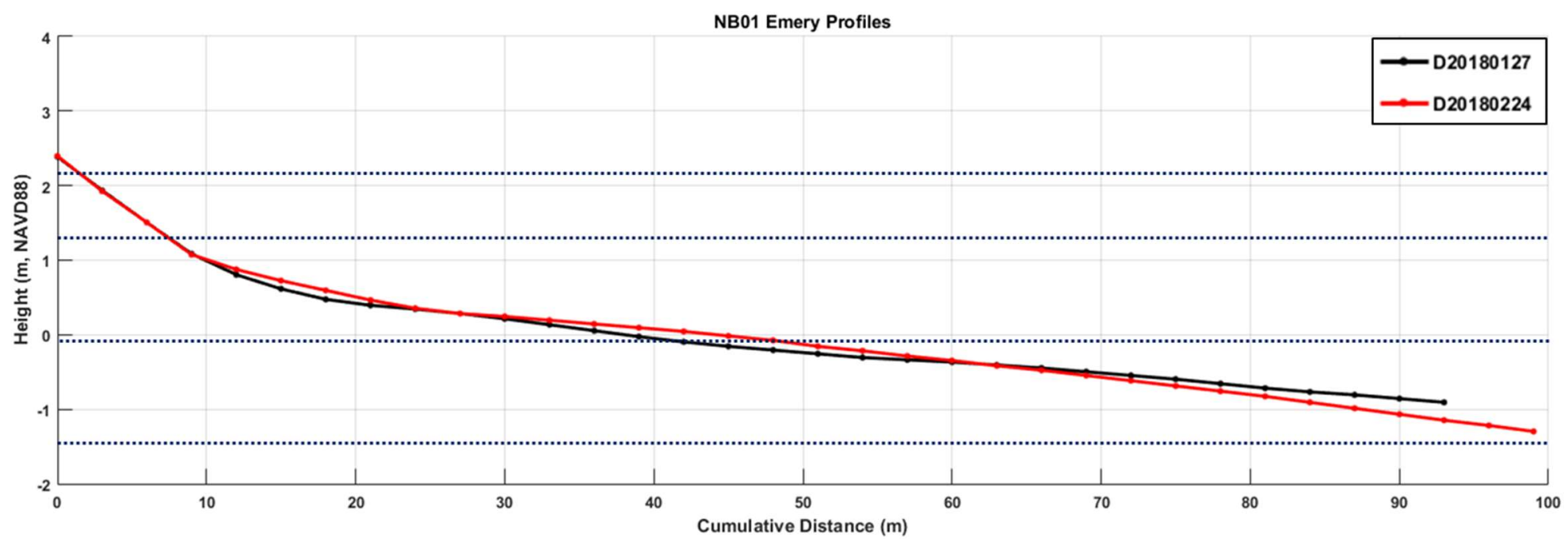

Figure NB01-8. Beach elevation profiles for NB01 on January 27, 2018 and February 24, 2018.

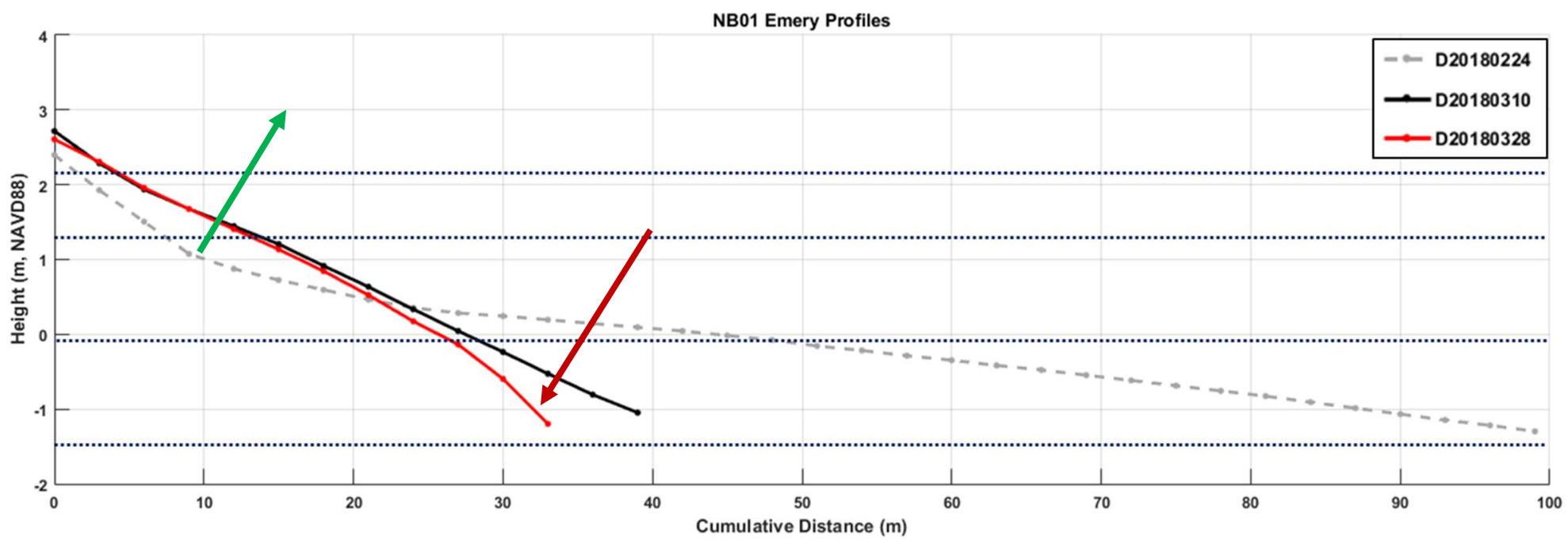

Figure NB01-9. Beach elevation profiles for NB01 on February 24, 2018, March 10, 2018, and March 28, 2018. The beach was badly eroded by the late winter 2018 nor'easters leading to dramatic elevation loss. Note the massive erosion in the lower beach (red arrow) and the accretion in the upper beach (green arrow) due to part of the sediment eroded from the lower beach being pushed landward. 


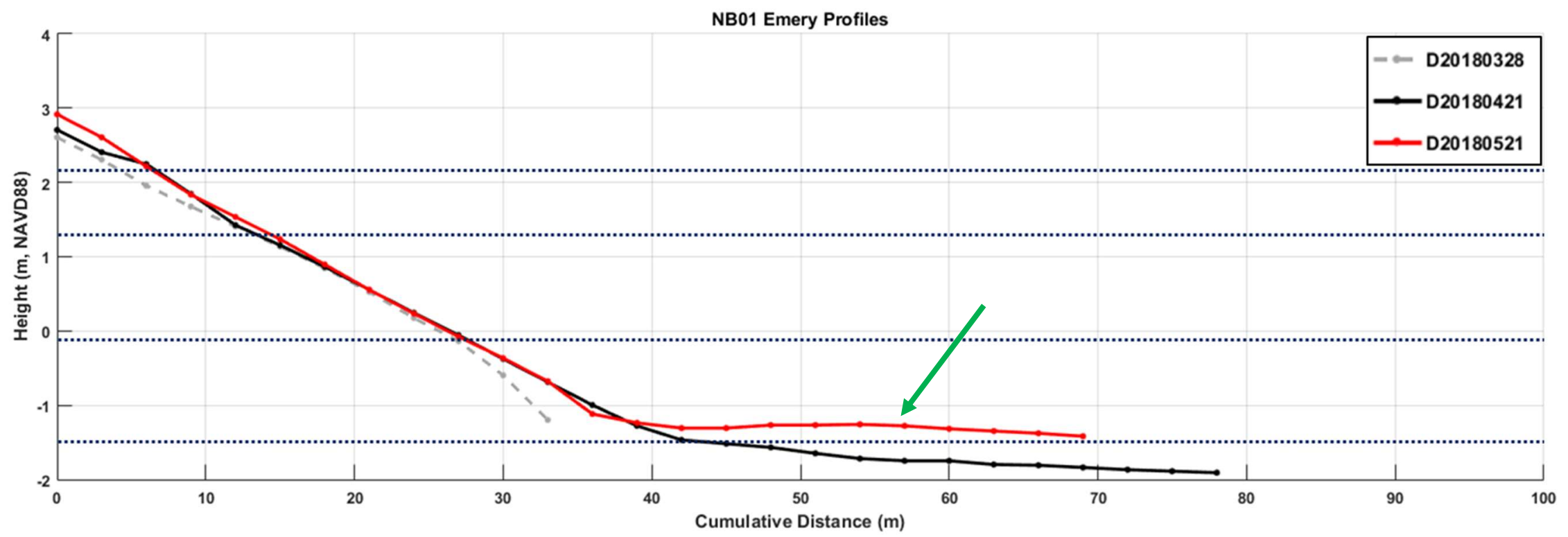

Figure NB01-10. Beach elevation profiles on March 28, 2018, April 21, 2018, and May 21, 2018 following the severe nor'easters of late winter 2018. The beach was beginning to recover on the April 21 and May 21 profiles. Note small ridge on low tide terrace which is a sand bar migrating landward (arrow). 


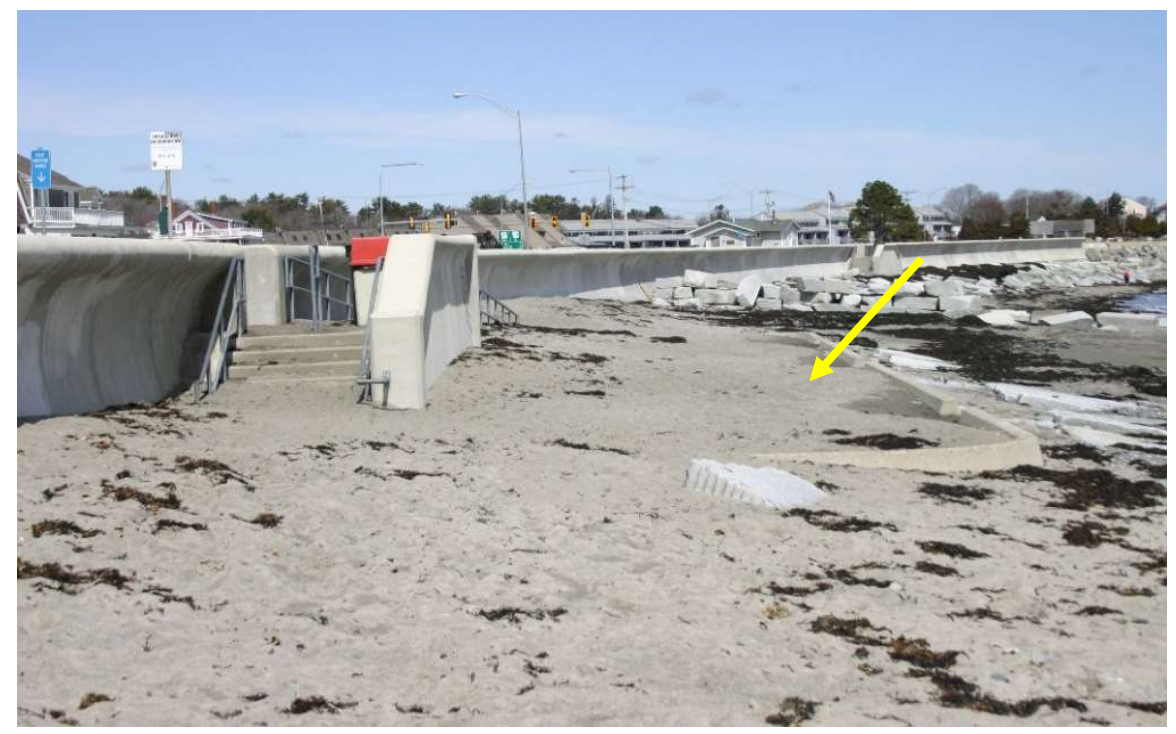

Figure NB01-11. North Beach, which was severely eroded during the late winter 2018 nor'easters. Sand from the lower beach was eroded and pushed landward creating a sand ramp shown in the photograph taken on April 21, 2018. Sand is covering the concrete landing at NB01 (arrow).

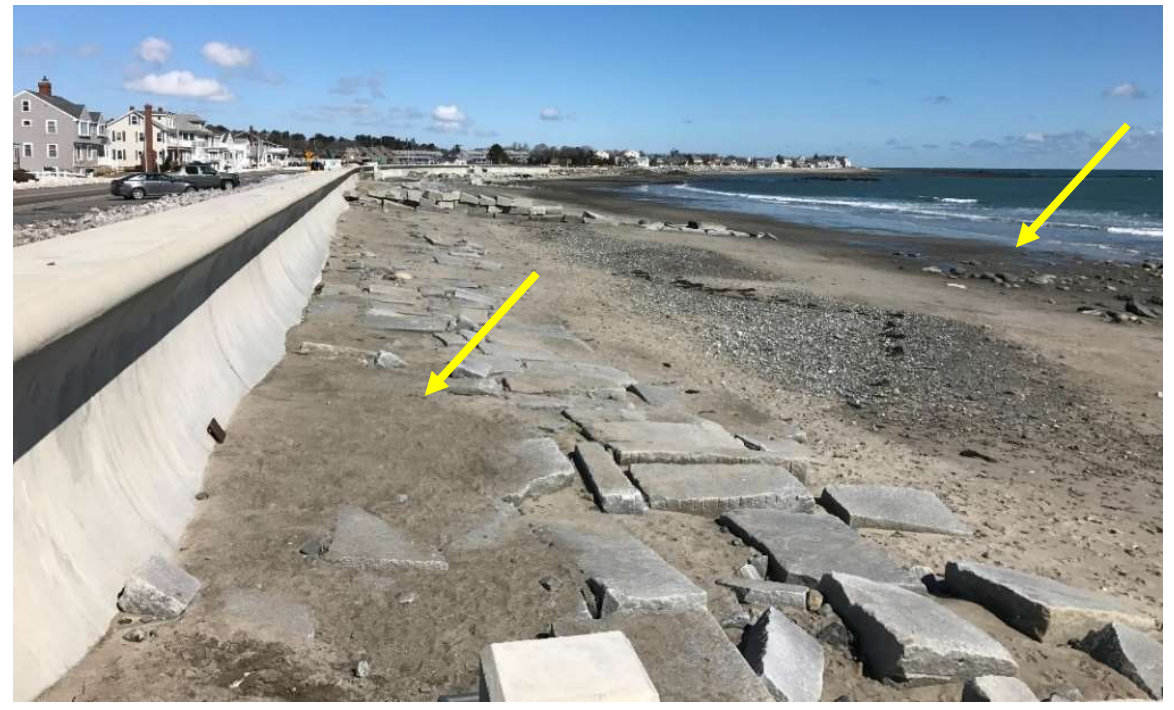

Figure NB01-12. Poststorm beach at NB01 on March 18, 2018 following the severe nor'easters of late winter 2018. Sand was eroded from the lower beach and pushed landward against the seawall (left arrow). Note the highly eroded lower beach (right arrow).

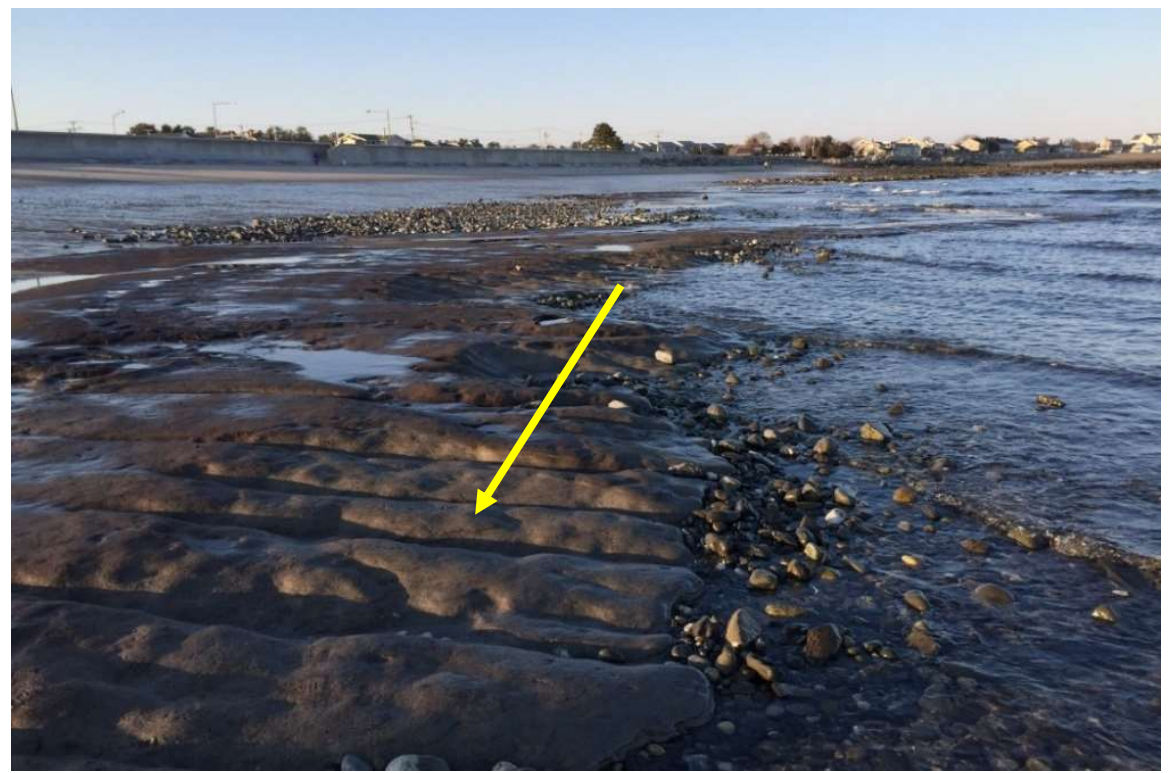

Figure NB01-13. The lower beach by the swash zone, which was extremely eroded in late winter 2018. The photograph shows the beach on March 20, 2018 looking north from the NB01 transect. The sand has been stripped and transported landward and seaward. Underlying peat deposits appear to be exposed (arrow). 

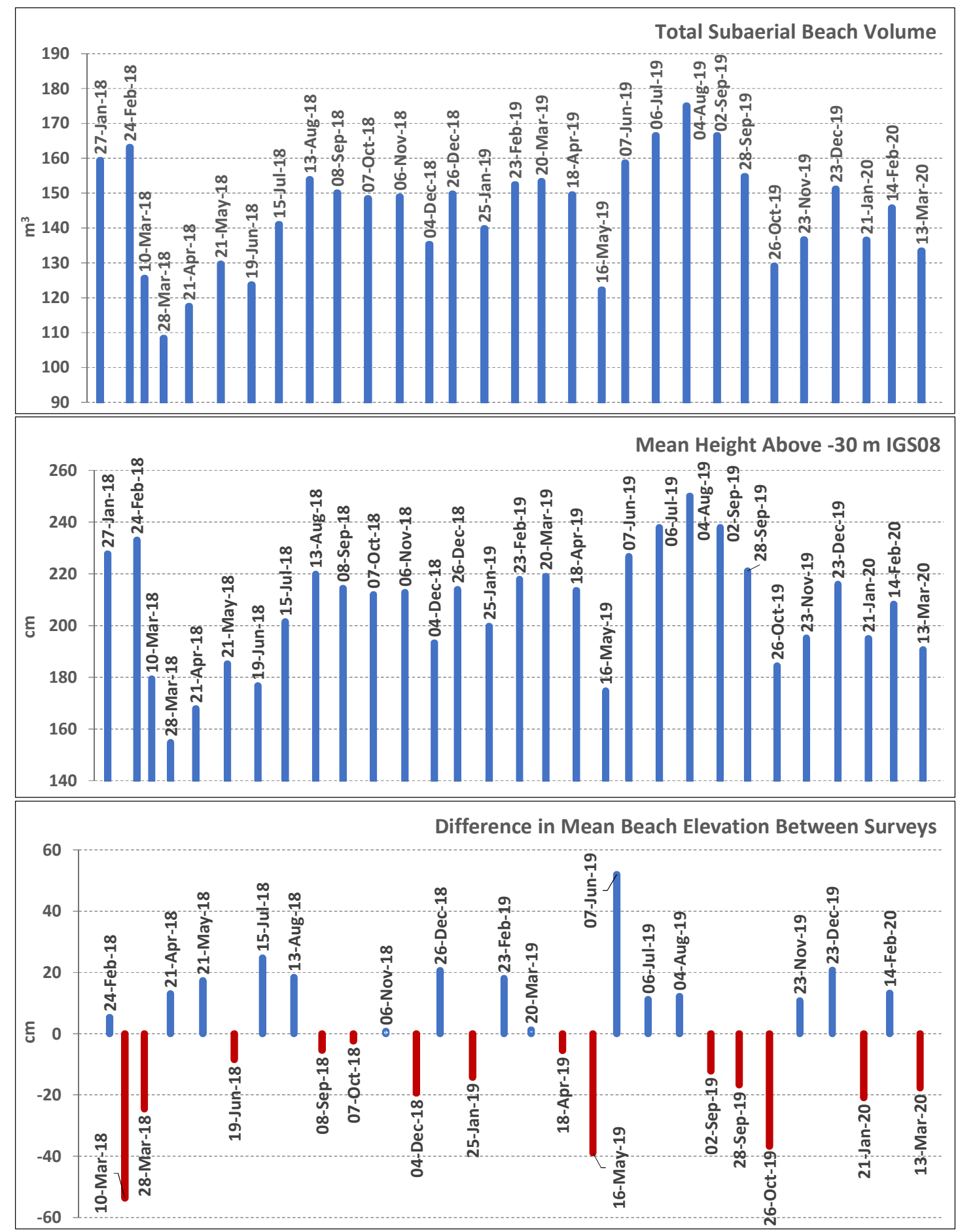

Figure NB01-14. Calculated sediment volume, mean profile elevation, and mean elevation change for the beach profile at station NB01. These parameters were calculated from 0-70 $\mathrm{m}$ of the profile length. Fourteen of the thirty elevation profiles were shorter than the "standard profile length" for the station $(70 \mathrm{~m})$. These profiles were extended using the procedure described in Chapter 2: Methods. However, twelve of the profiles were extended less than or equal to $10.0 \mathrm{~m}$ which is considered negligible (eight were less than or equal to $4 \mathrm{~m}$ ). The two longest extensions (31.0 m on March 10, 2018 and $37.0 \mathrm{~m}$ on March 28, 2018) occurred following the severe nor'easters of March 2018 when the beach was extremely eroded. 
The beach at NB01 started a slow recovery from the late winter 2018 severe nor'easters by April 21 that continued until late summer 2018 (Figure NB01-14). During the period between March 28 and April 21, the lower beach was accreting, reforming the low tide terrace. By April 21 and May 21, the lower beach had built vertically and had become intertidal (Figure NB01-10). Accretion continued with the mid beach building upward and the sediment volume at NB01 increasing, approaching prestorm levels by August 13, 2018. The beach maintained this equilibrium accretion profile through September 2018 (Figures NB01-15 and NB01-16). In the fall, the beach adjusted its elevation profile, whereby the sand that had previously been pushed onto the upper beach and against the seawall appeared to have been transported to the lower beach, which resulted in a lowering of the upper part of the profile and an increase in elevation of the seaward part of the profile (Figures NB01-17 and NB01-18). Evidence that the sand did not leave the beach but rather redistributed itself is that the sediment volume remained relatively constant during this period (Figure NB01-14). It would appear that the September and October 2018 profiles were more in equilibrium. 


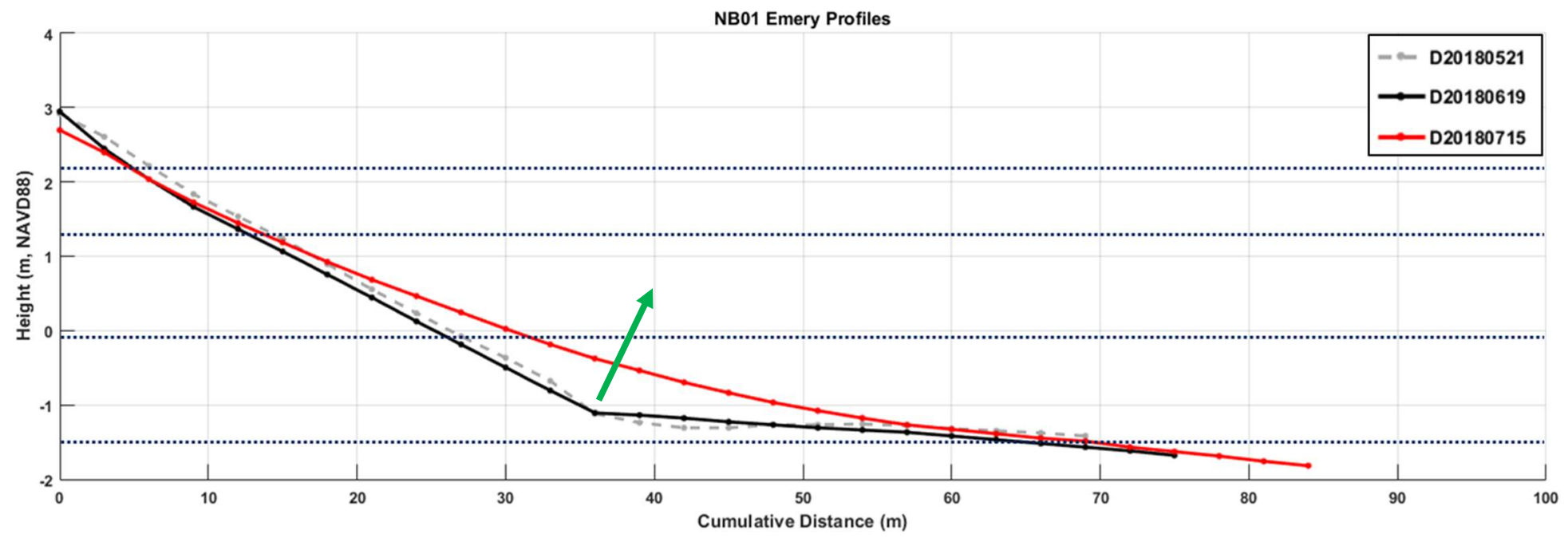

Figure NB01-15. Beach elevation profiles for NB01 on May 21, 2018, June 19, 2018, and July 15, 2018. Note the significant amount of accretion on July 15 (arrow).

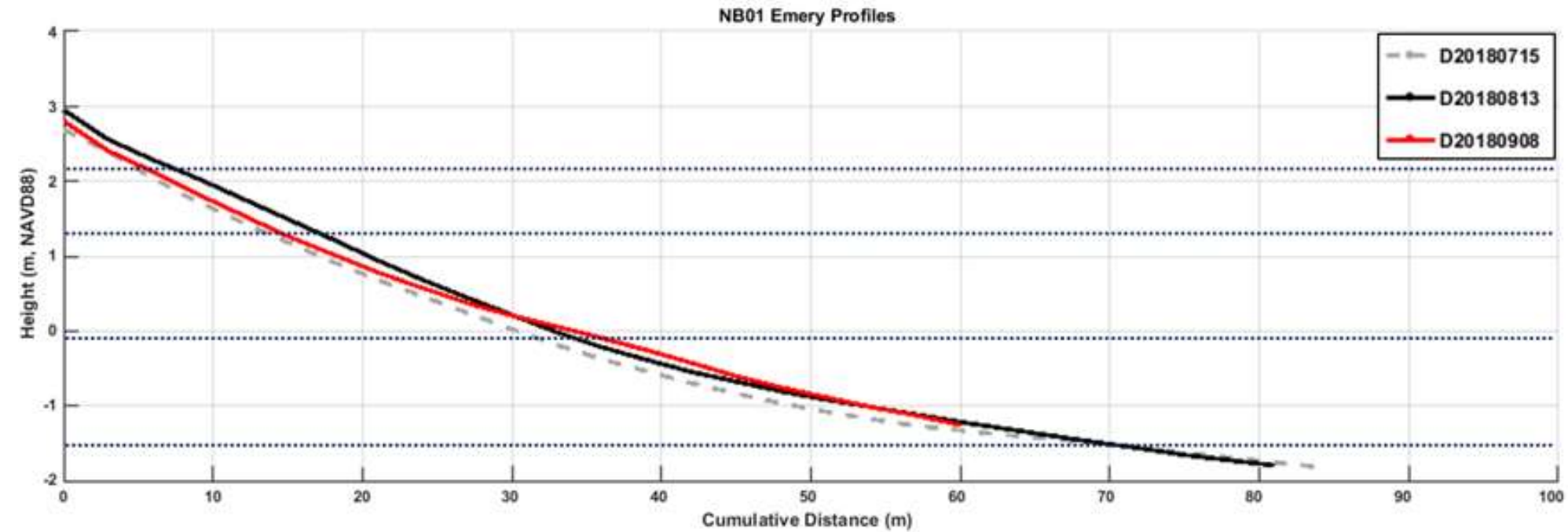

Figure NB01-16. Beach elevation profiles for NB01 on July 15, 2018, August 13, 2018, and September 8, 2018. 


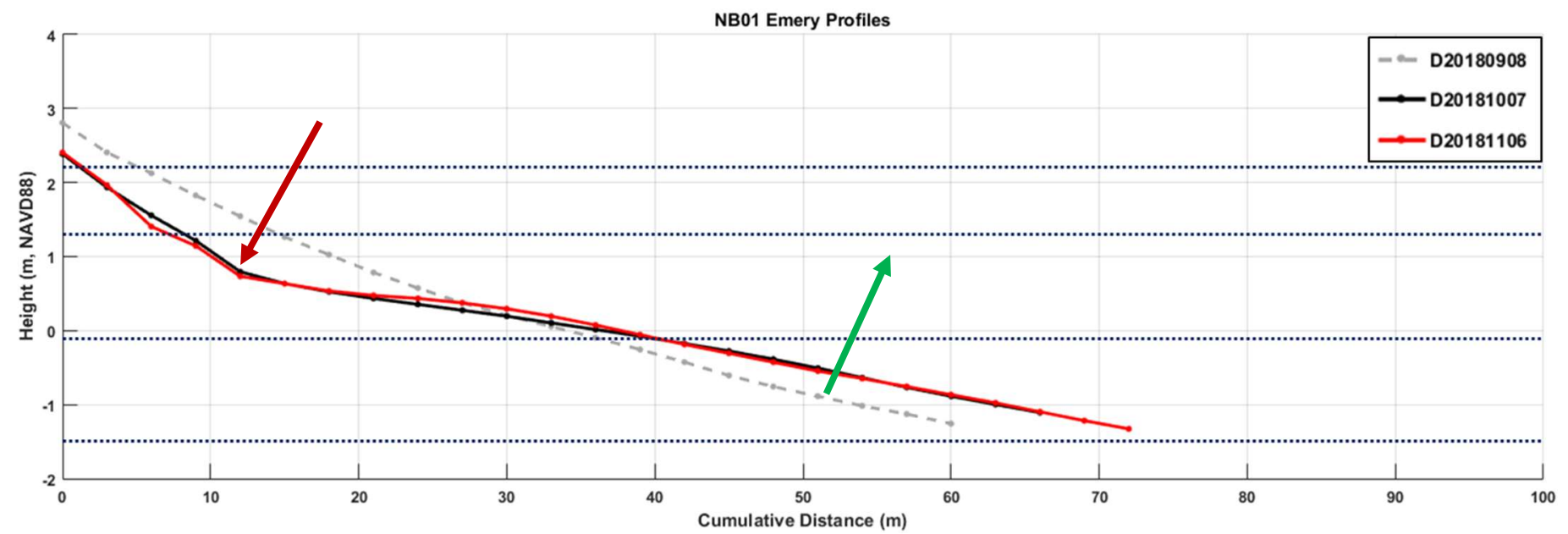

Figure NB01-17. Beach elevation profiles for NB01 on September 8, 2018, October 7, 2018 and November 6, 2018. Sediment was eroded from the upper profile (red arrow) and was deposited on the lower profile (green arrow). The October and November profiles appear to be more in equilibrium.

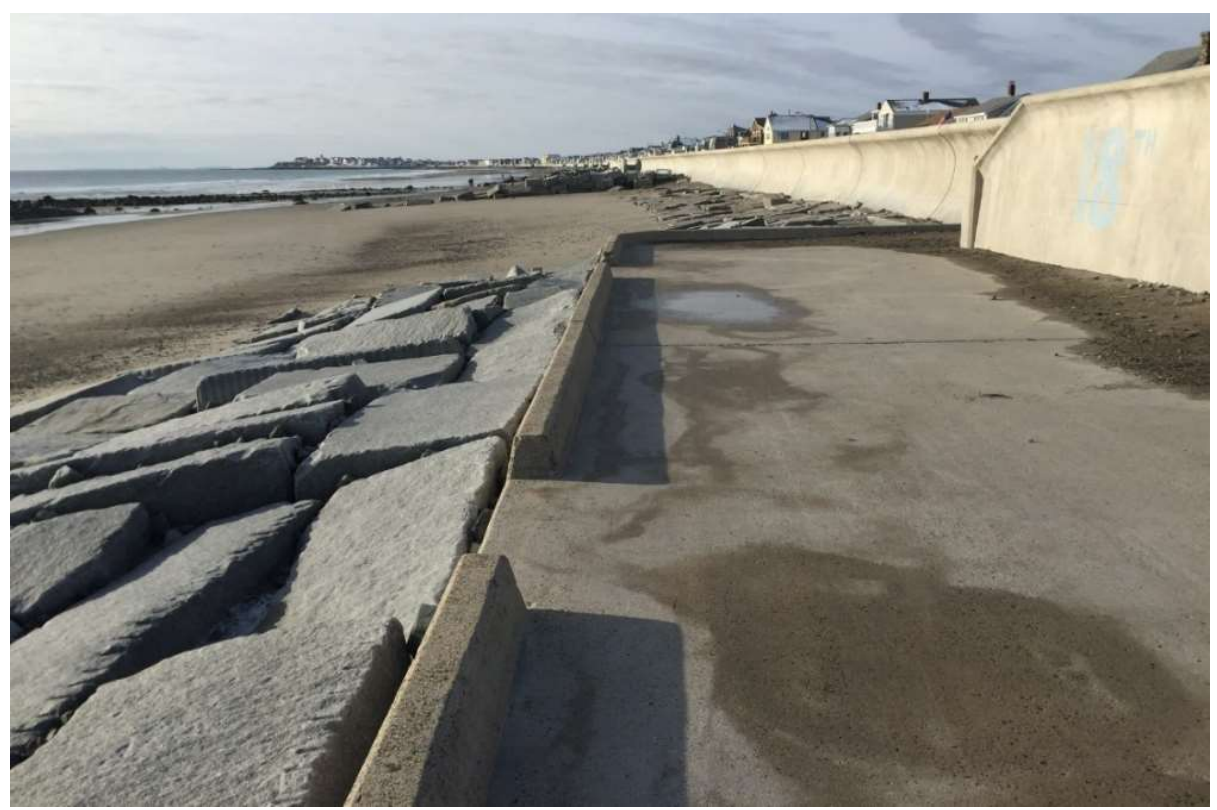

Figure NB01-18. Granite slabs at base of seawall and concrete landing at station NB01. In addition, the

landing is exposed which is more typical for NB01.

Photo taken on February 23, 2019. 
The beach continued to accrete and erode over the next several months through winter and into spring 2019 (Figures NB01-18 and NB01-19). However, the overall mean elevation and sediment volume remained relatively constant over this period (Figures NB01-14). It appears the sediment was again simply redistributing.

Somewhat surprisingly, major erosion and elevation loss occurred on May 16, 2019 (Figure NB01-20), apparently the result of an unnamed storm event with relatively large waves from the east (Table 33). The beach profile rebounded by June 7 and continued to accrete through August reaching the maximum elevation and volume measured during this study on August 4, 2019 (Figures NB01-14, NB01-21, NB01-22, and NB01-23). The beach at NB01 underwent major erosion and loss of sediment volume in late August and September 2019 as seen in the October 26 and November 23 profiles (Figures NB01-24 and NB01-25). Interestingly, the beach started to rebound again with increased volume and elevation by December 23, 2019, where the elevation profile clearly shows a large ridge migrating onto the lower beach (Figure NB01-26). However, the beach eroded in January and remained relatively low through March 13, 2020 (Figure NB01-14). 


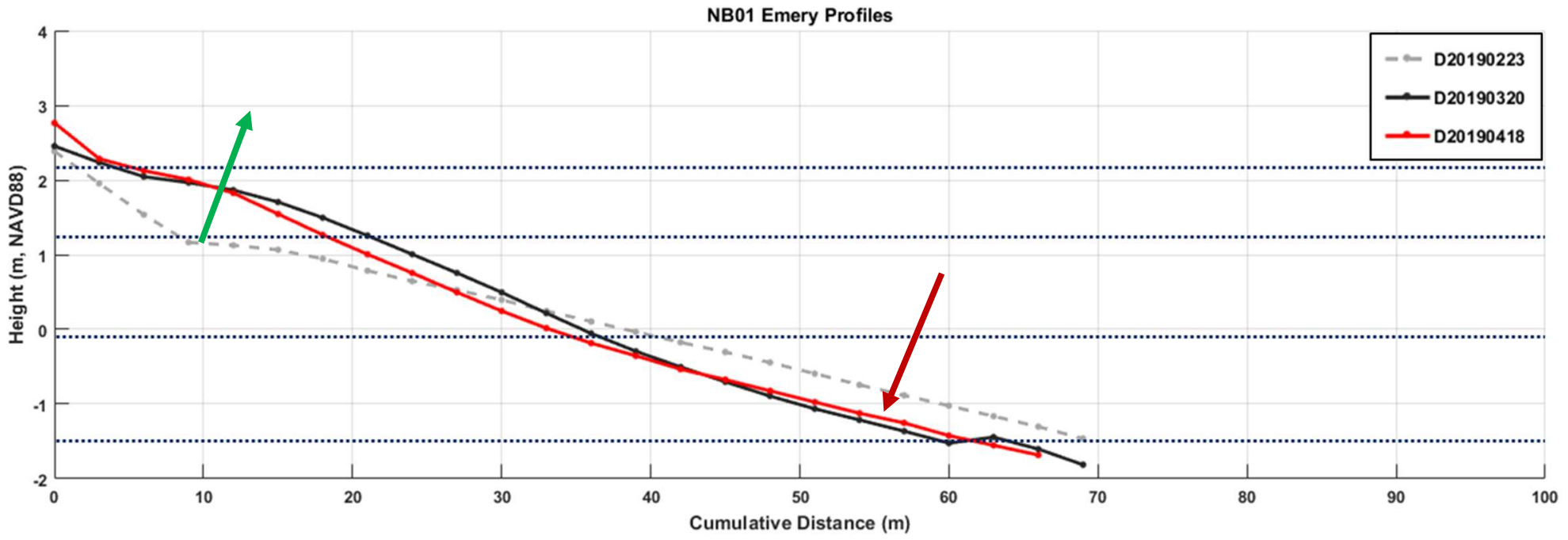

Figure NB01-19. Beach elevation profiles for NB01 on February 23, 2019, March 20, 2019, and April 18, 2019. Note the accretion of the upper profile (green arrow) and the erosion of the lower profile (red arrow).

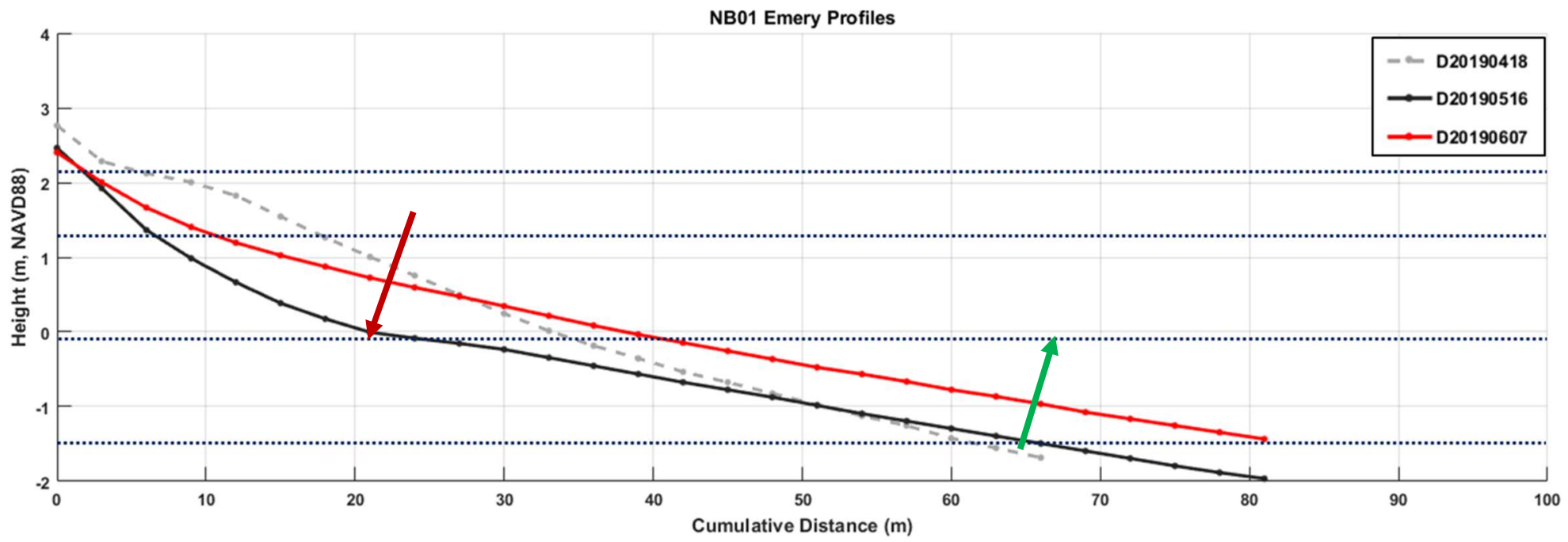

Figure NB01-20. Beach elevation profiles for NB01 on April 18, 2019, May 16, 2019, and June 7, 2019. Note the major erosion from April 18 to May 16 (red arrow), followed by major accretion between May 16 to on June 7 (green arrow). 


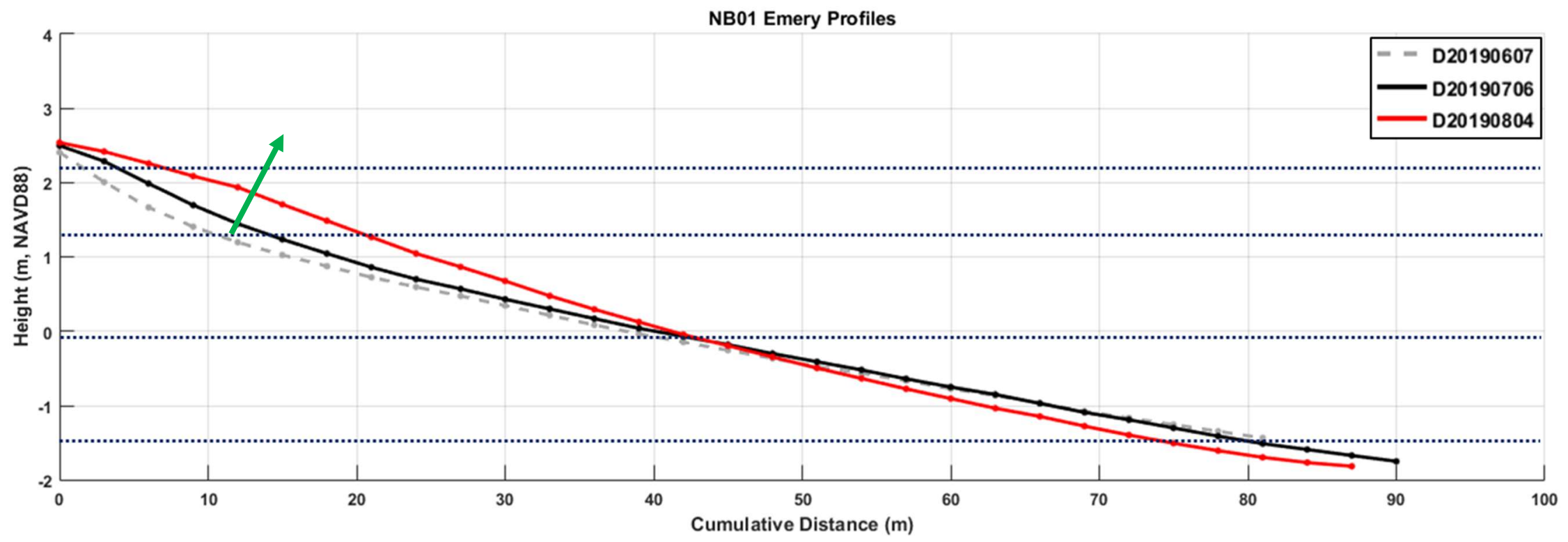

Figure NB01-21. Beach elevation profiles for NB01 on June 7, 2019, July 6, 2019, and August 4, 2019. The rapid accretion that was seen on June 7 continued in July and August (arrow). The August 4 profile is the maximum volume and mean elevation for the study period at NBO1. 


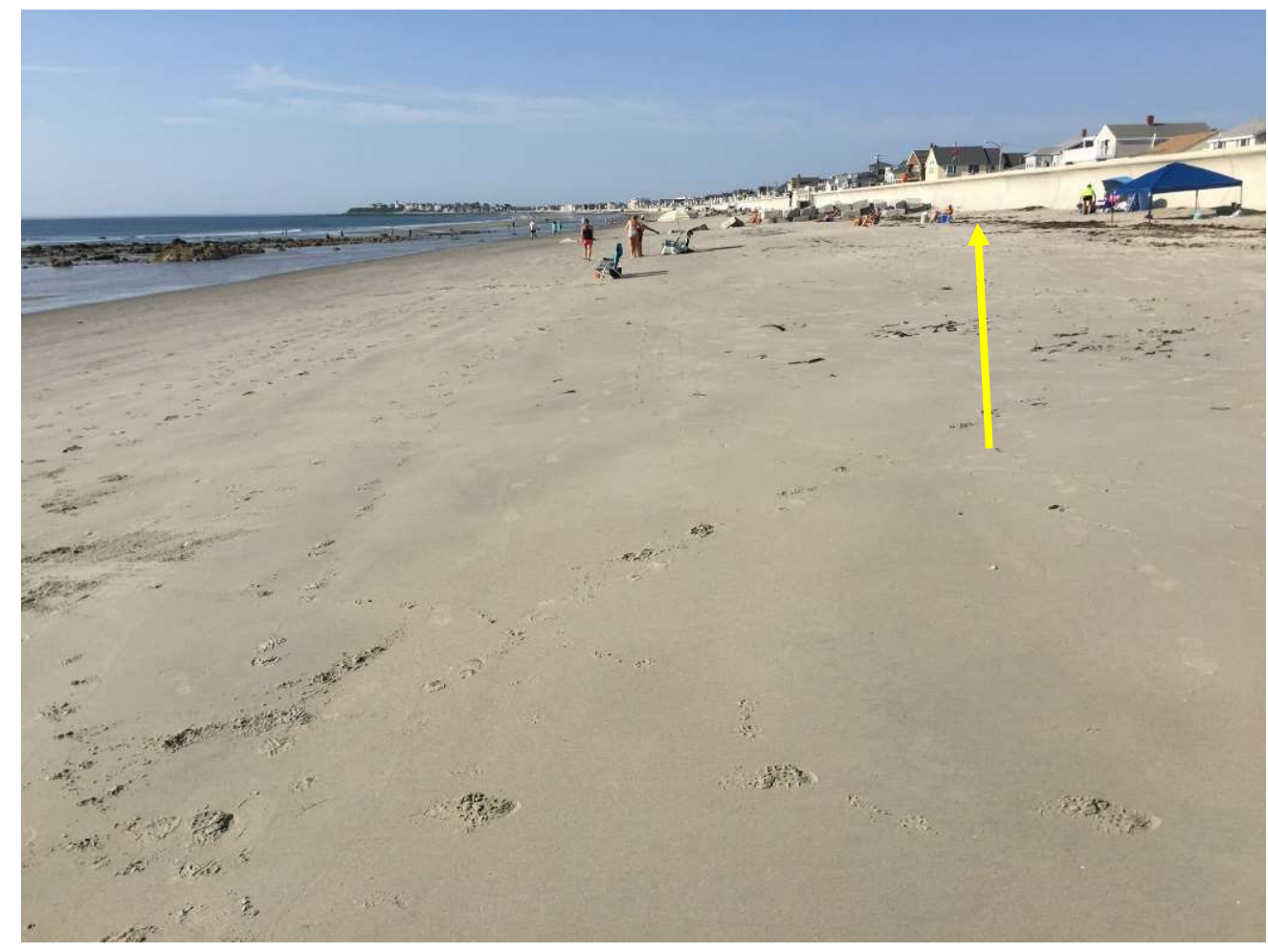

Figure NB01-22. The beach at station NB01 looking south on August 4, 2019, which was the maximum average elevation and sediment volume measured during the study period. Sand has buried the cobbles and boulders that are often exposed and has also covered the granite slabs at the seawall (arrow).

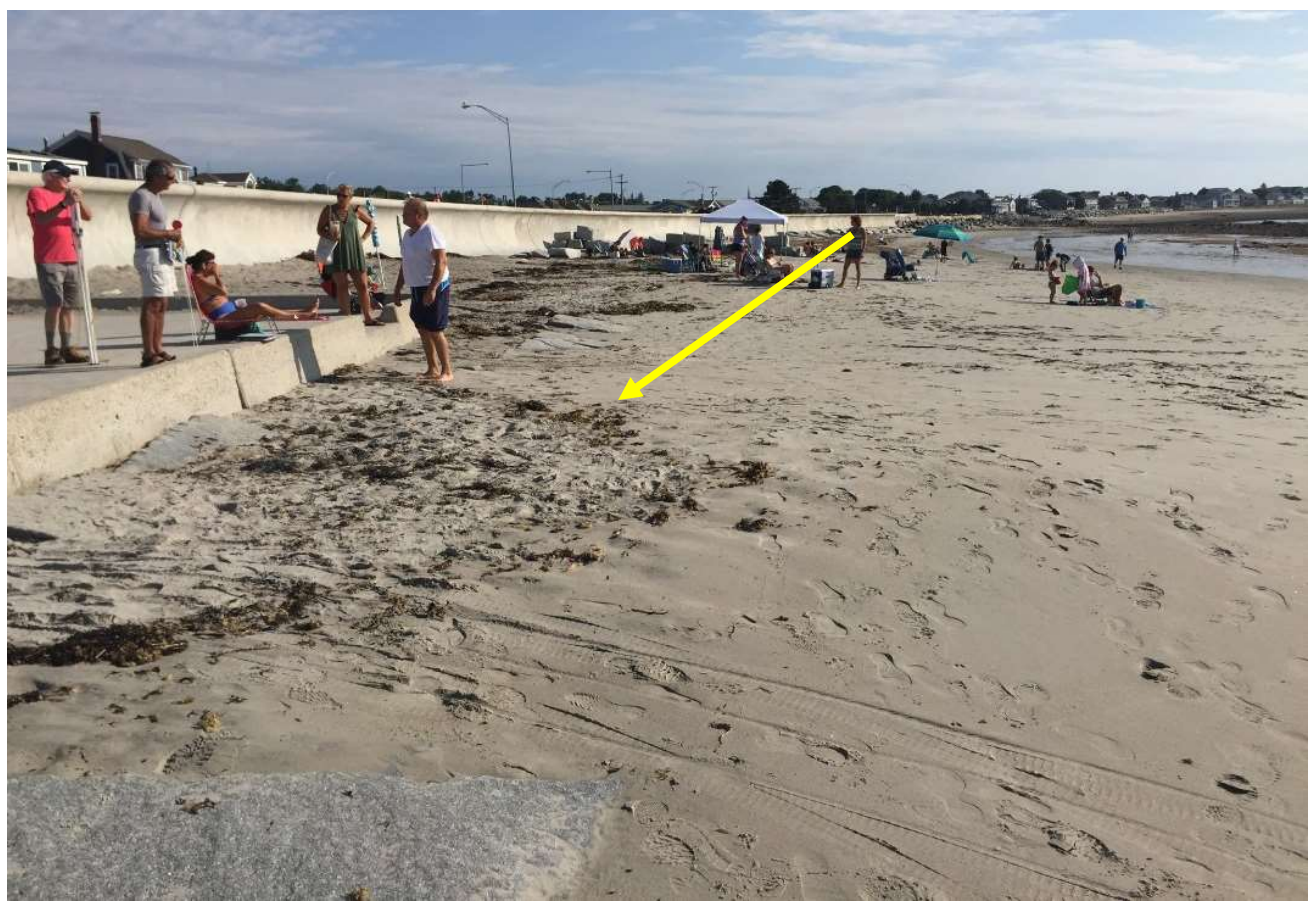

Figure NB01-23. The beach at station NB01 looking north on August 4, 2019, which was the maximum average elevation and sediment volume measured during the study period. Note the granite slabs at the base of the concrete platform are buried (arrow). Compare to the photo in Figure NB01-18. 


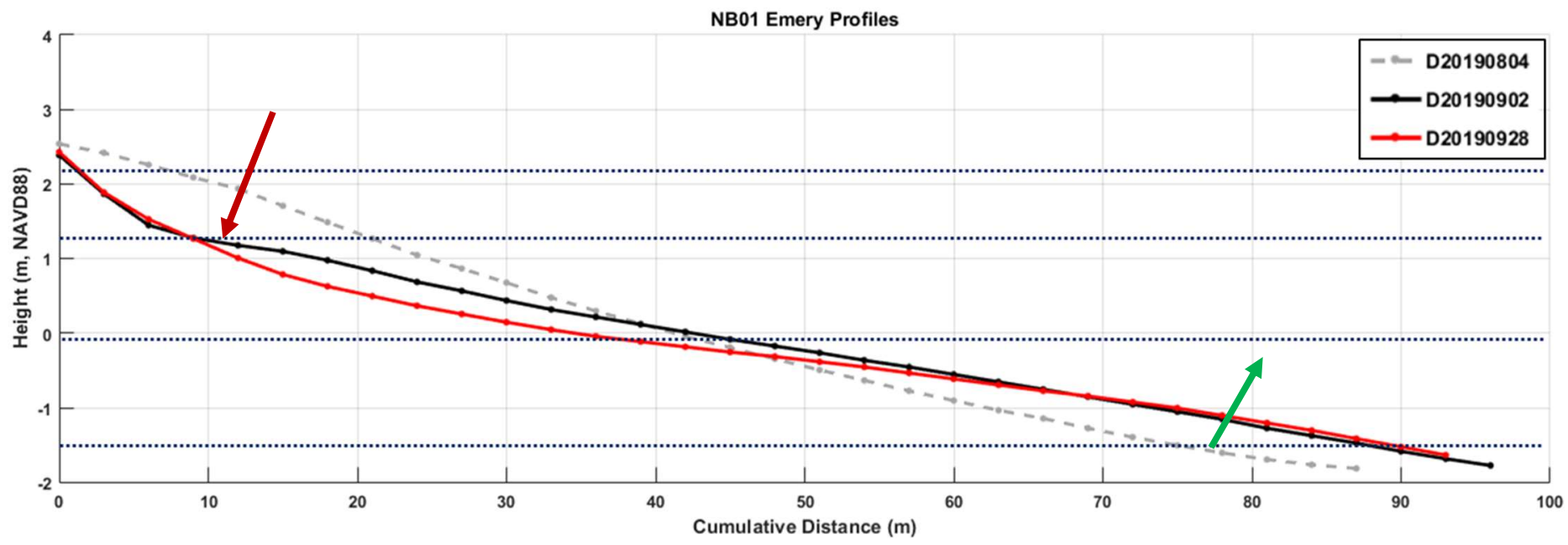

Figure NB01-24. Beach elevation profiles for NB01 on August 4, 2019, September 2, 2019 and September 28, 2019. Note the August 4 profile was the highest measured at NBO1 during the study period. In September, the upper profile was eroded (red arrow), and the lower profile accreted (green arrow). However, there was a net loss of sediment.

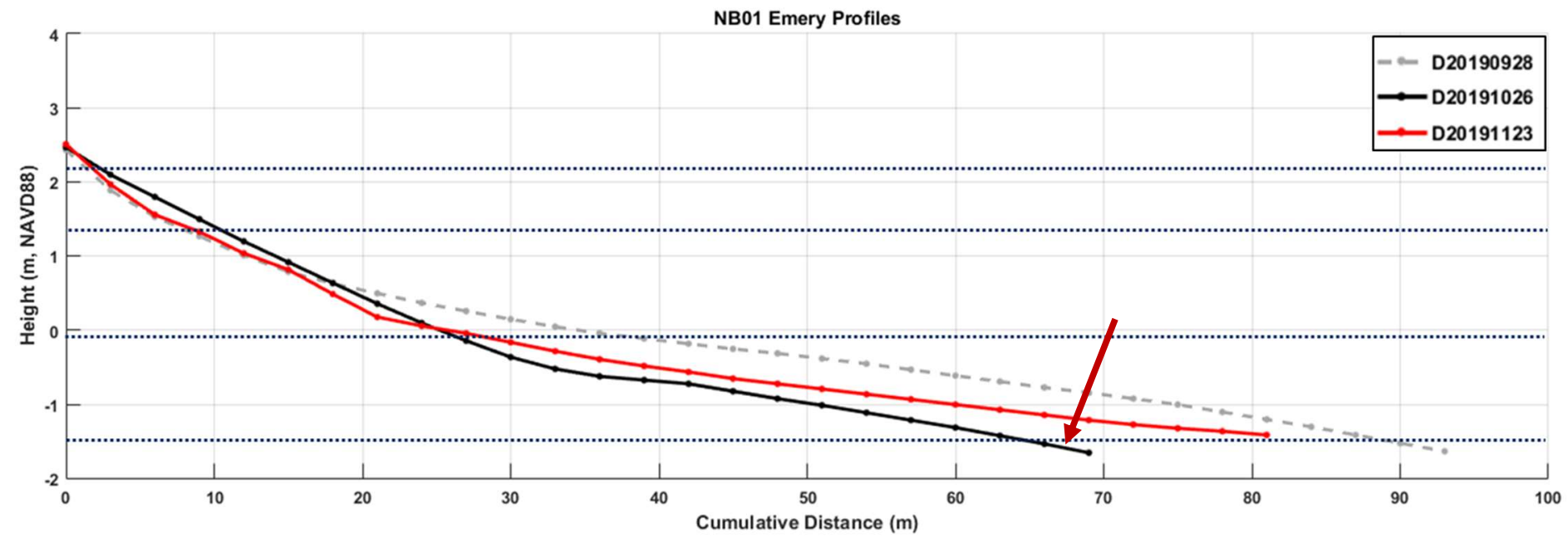

Figure NB01-25. Beach elevation profiles for NB01 on September 28, 2019, October 26, 2019 and November 23, 2019. Major erosion which started in October continued in September 2019 (arrow). 


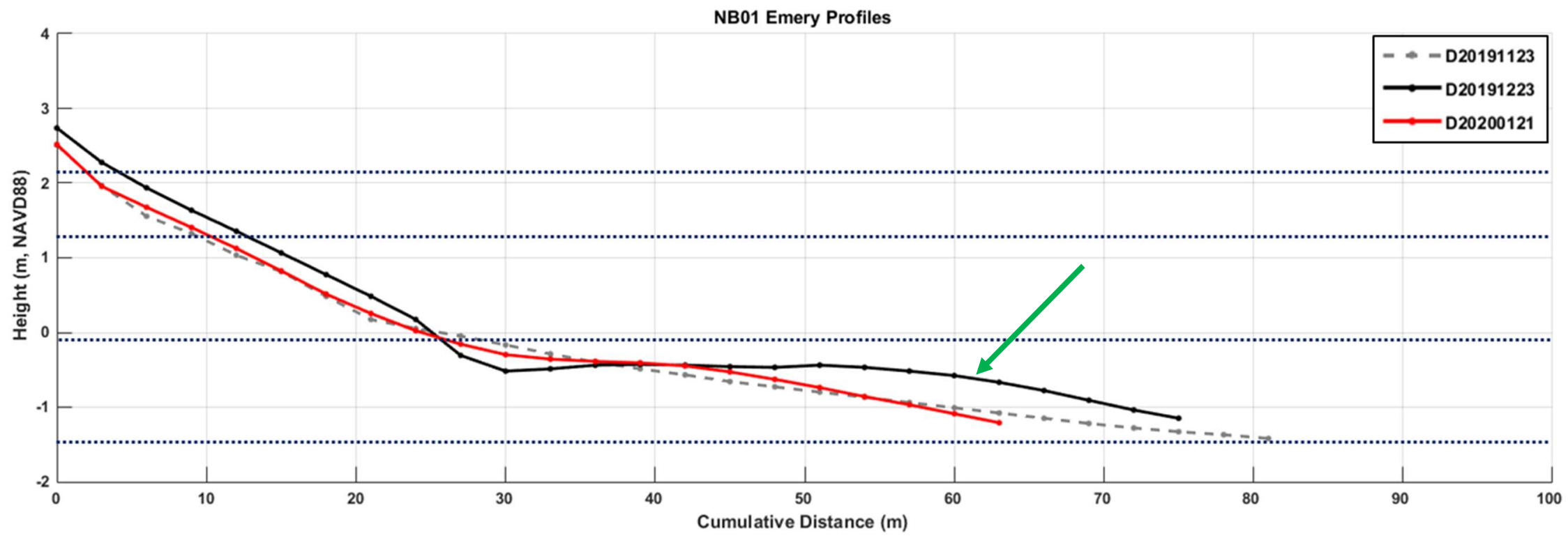

Figure NB01-26. Beach elevation profiles for NB01 on November 23, 2019, December 23, 2019 and January 21, 2020. The beach at NB01 started recovering from the erosion that occurred in November as shown by the large ridge or sand bar migrating landward on the lower beach (arrow). 


\section{Results for Station at Mid North Beach: NB02}

Overview. Profile station NB02 is located approximately in the center of North Beach $\sim 1.2 \mathrm{~km}$ south of the headland and $\sim 1.5 \mathrm{~km}$ north of Great Boars Head (Figures NB-1 and NB02-1). The profile extends seaward from a concrete staircase built into the seawall (Figures NB02-2 and NB02-3). Granite slabs (one or two meters in length and width) are located along the base of the staircase and seawall to prevent wave scour (Figure NB02-1). A gravel ramp is frequently, if not always, present at the base of the seawall. The landward two to three meters of NB02 traverses the granite blocks (Figure NB02-4). The beach at NB02 is bimodal with the gravel ramp forming the landward portion of the beach, while the lower beach is typically sandy (Figure NB02-5). Following erosional periods, the entire beach can be covered with pebbles (Figures NB02-6 and NB02-7).

Summary. The beach at NB02 was extremely eroded by the late winter 2018 nor'easters as reflected by the shortest profile lengths, lowest elevations, and smallest sediment volumes measured during the entire study at this location on April 18 and May 20, 2018. Unfortunately, there is a major gap in the monitoring record due to logistical problems (July - September 2018). It appears a second period of erosion occurred in late winter and spring 2019, but the beach again recovered by summer reaching the maximum volume and average elevation measured at this station on August 17, 2019. Similar to NB01, the beach at NB02 is very dynamic with losses and gains of elevation and movement of sediment. However, the overall elevation of North Beach is low, so even rebuilding the beach still leaves it extremely vulnerable to storms. Also, like NB01, the beach is very susceptible to erosion, flooding, and storm damage.

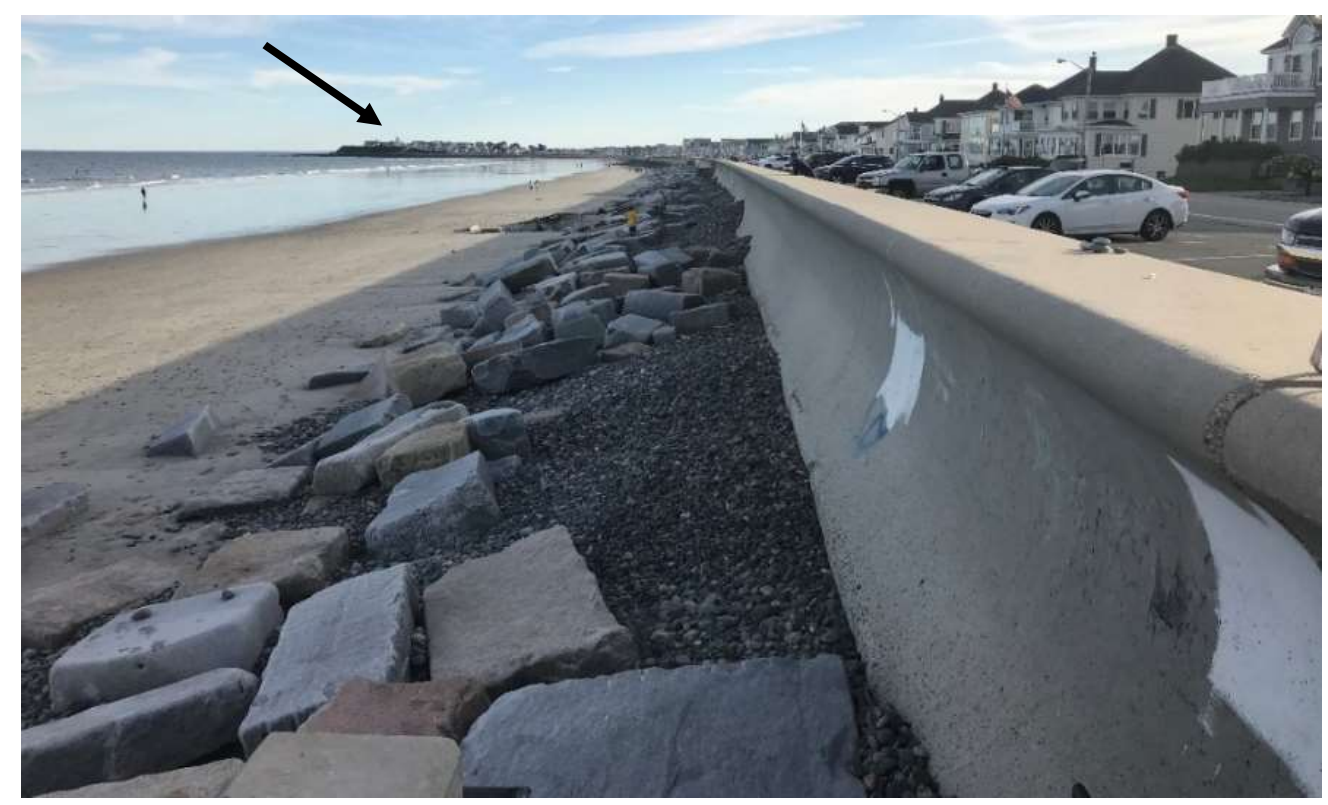

Figure NB02-1. The beach south of station NB02 on September 29, 2019. Great Boars Head is $1.5 \mathrm{~km}$ to the south (arrow). Note granite slabs at the base of the large concrete seawall placed in an effort to protect the wall from wave attack. Also note the gravel against the seawall transported by wave action. 


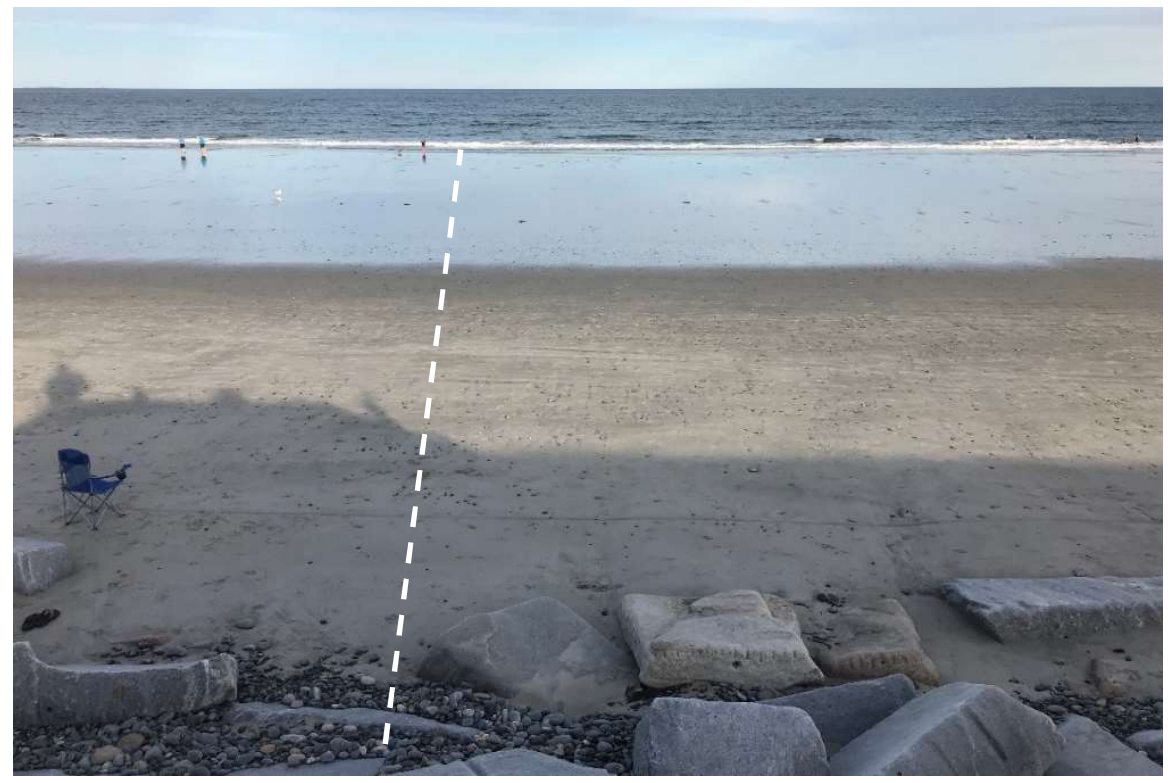

Figure NB02-2.

Location of beach elevation profile for NB02. The profile extends from the base of the concrete stairwell built into the seawall to the low tide line (white dashed line). The photograph was taken on September 25, 2019.

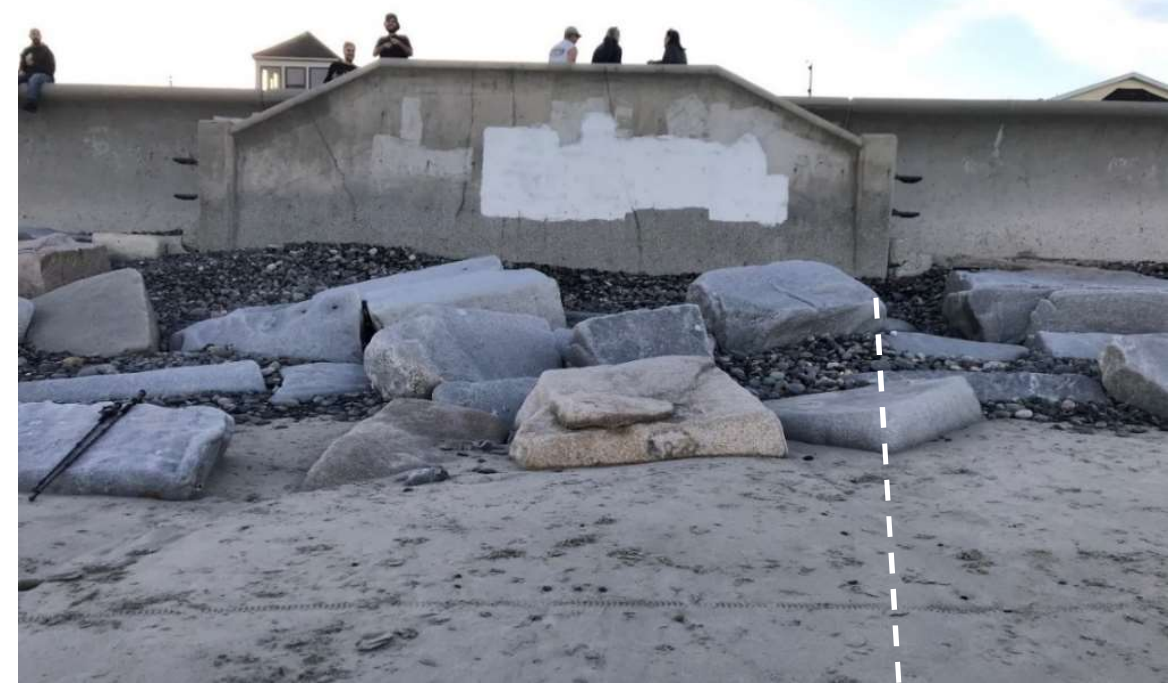

Figure NB02-3.

Stairwell (part of seawall), gravel ramp, and granite slabs at base of seawall at station NB02. Photo taken on September 29, 2019. White dashed line shows start of the beach elevation profile.

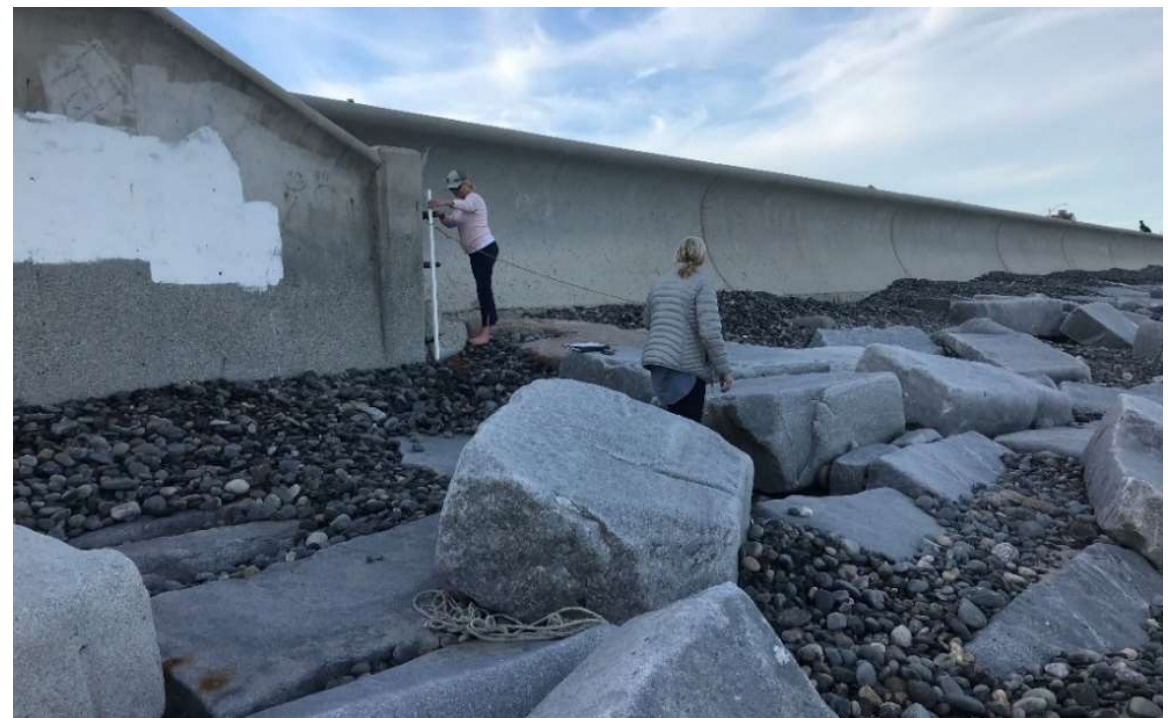

Figure NB02-4. The beach elevation transect at NB02, which extends from the base of the stairwell seaward to the low water line. The photograph was taken during profiling on September 29, 2019. 


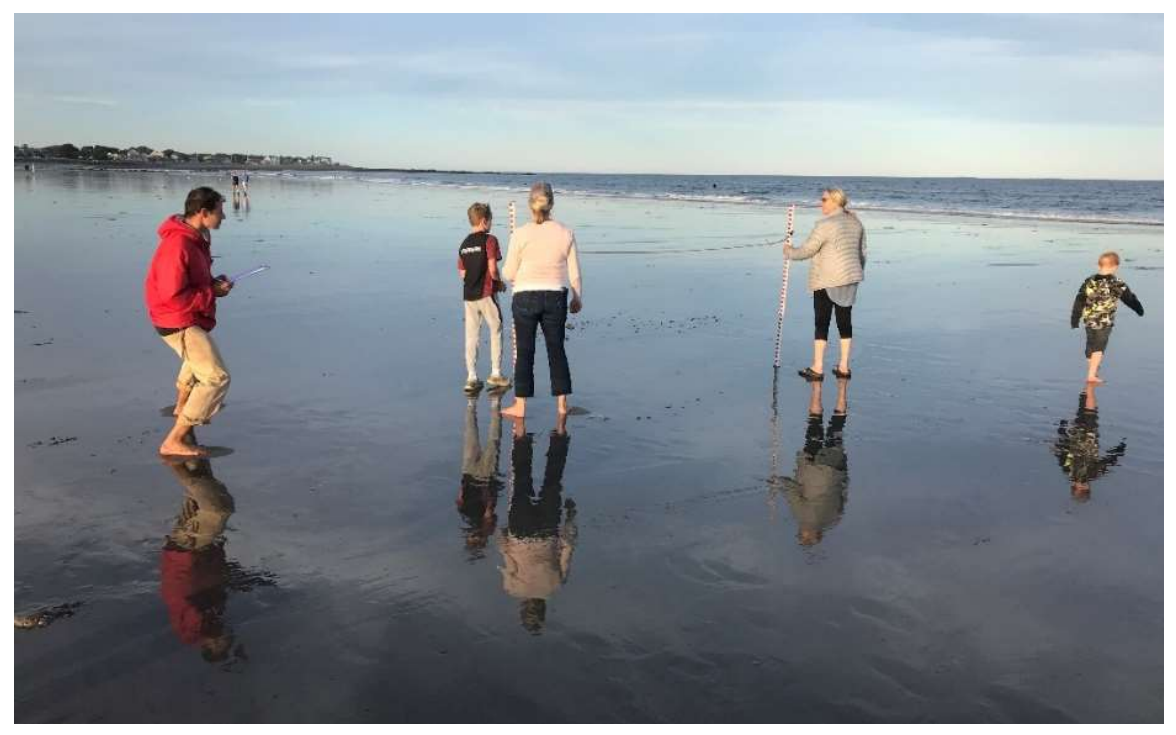

Figure NB02-5.

Profiling North Beach at NBO2 on September 29, 2019. The beach is in an accretional condition and the lower beach is dominantly sandy.

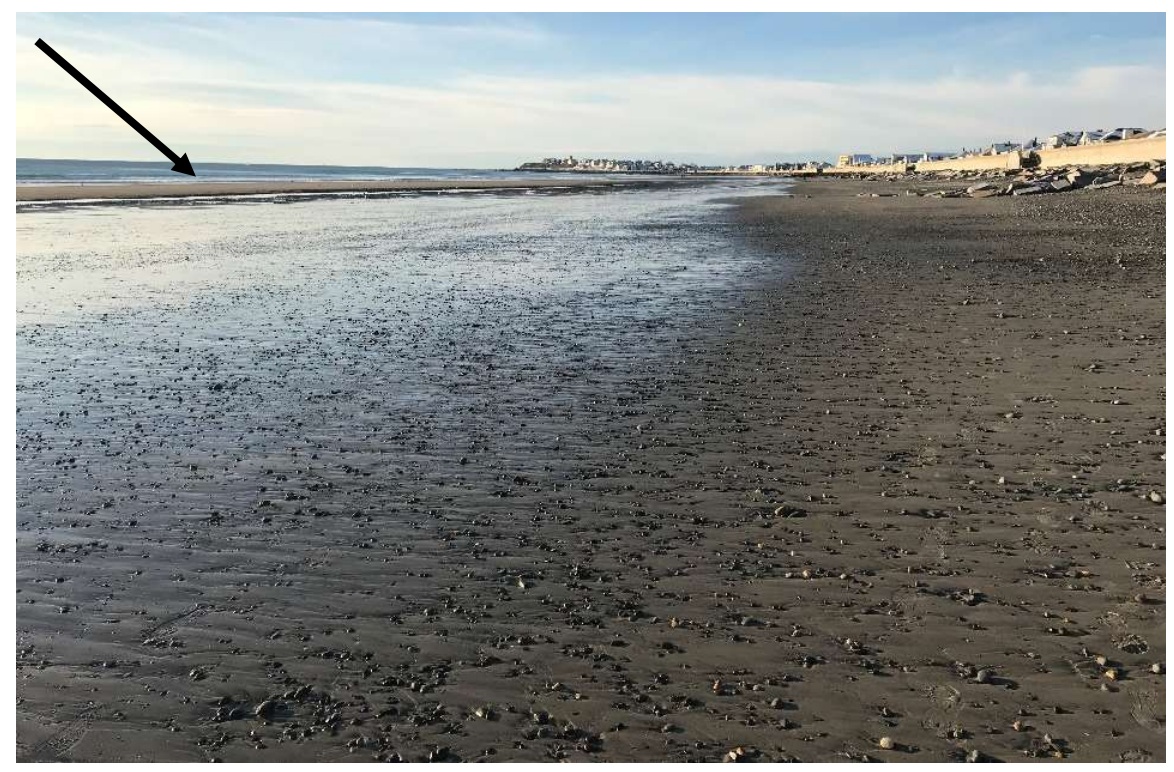

Figure NB02-6. Mid and lower beach at NB02 on February 22, 2019. The beach was recently eroded as evidenced by the scattered pebbles on the surface of the sand. However, the beach is undergoing accretion as shown by the presence of a lowamplitude ridge (arrow) on the lower beach which is migrating landward.

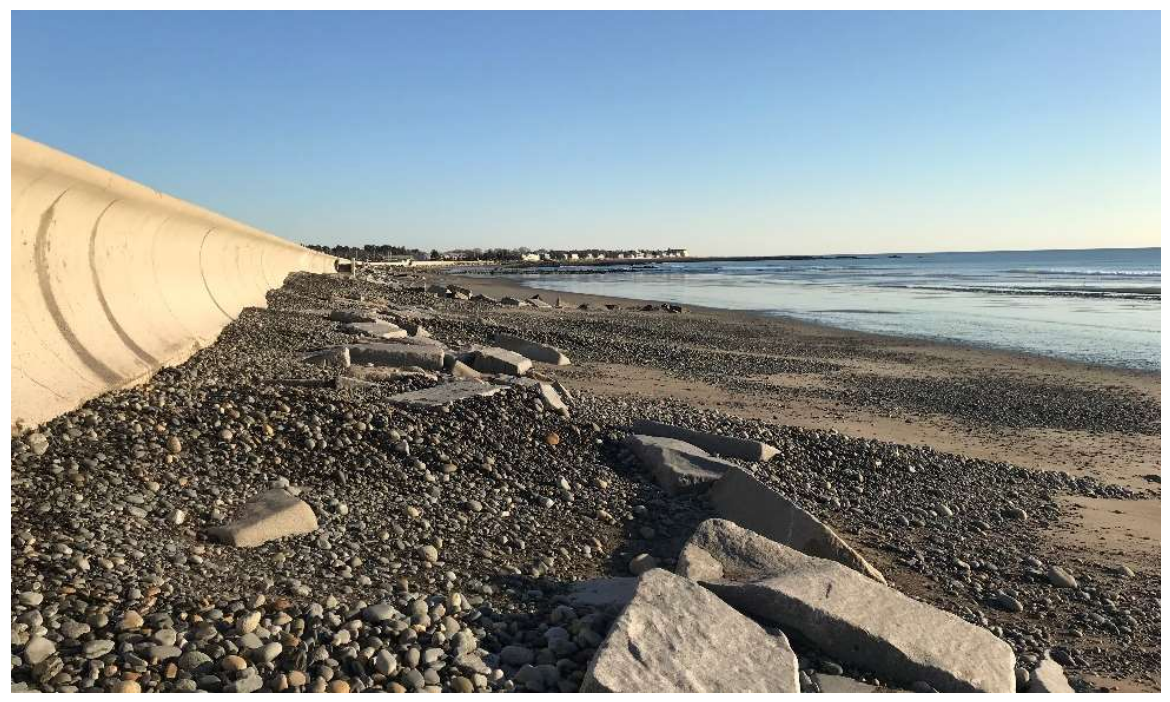

Figure NB02-7. Upper beach at NB02 on February 22, 2019. The beach was recently eroded as evidenced by the scattered pebbles on the surface of the sand. 
General Profile Characteristics. The beach profile at NB02 was run twenty-one times between April 18, 2018 and March 13, 2020. All plotted beach profiles can be found in Appendix C(8). Monitoring of this location was initiated later than the rest of the profile stations along the NH coast. In addition, there are gaps in the record (i.e. July - September and December 2018). However, with these exceptions the station was profiled at near-monthly intervals.

The beach profiles ranged in length from $\sim 45 \mathrm{~m}$ on April 18 and May 20, 2018 to $117 \mathrm{~m}$ on September 29, 2019 (Figure NB02-8). The profiles from April 18 and May 20, 2018 are extremely short due to the late winter 2018 nor'easters which severely eroded most of the beaches along the $\mathrm{NH}$ coast. The elevation profile is typically very steep near the seawall, becoming flatter around $\sim 20$ to 30 m seaward during accretional periods.

Examination of the sweep zone shows the elevation of the beach varied by $\sim 1.0 \mathrm{~m}$ in the upper beach by the seawall, $\sim 1.2$ to $\sim 1.8 \mathrm{~m}$ near mid beach, and $\sim 0.7 \mathrm{~m}$ in the lower beach (Figure NB02-8). Comparison of the maximum elevation profile (which occurred on August 17, 2019) with the minimum average elevation profile (which occurred May 20, 2018) shows no elevation loss in the upper beach but rapidly increasing to $\sim 1.8 \mathrm{~m}$ at the mid beach ( $45 \mathrm{~m}$ seaward) (Figure NB02-9). However, it is likely that the elevation difference was significantly greater in the lower beach, but it could not be measured as the profile became subtidal. 


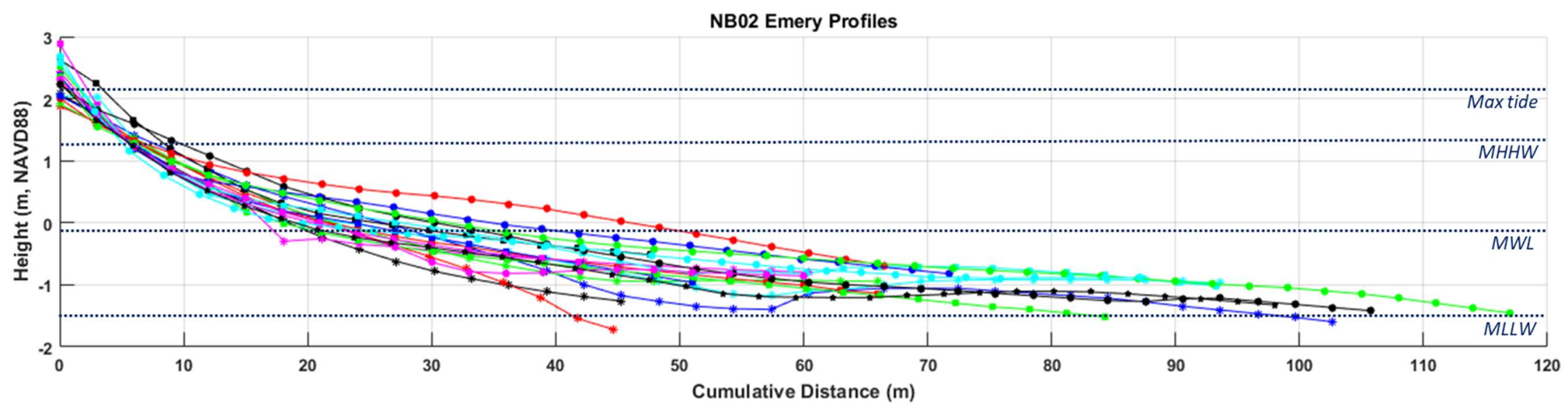

Figure NB02-8. All twenty-one beach elevation profiles measured at station NB02 between April 18, 2018 and March 13, 2020. Maximum tidal elevation (max tide), mean higher high water elevation (MHHW), mean water level (MWL), and mean lower low water elevation (MLLW) are indicated by the dotted lines.

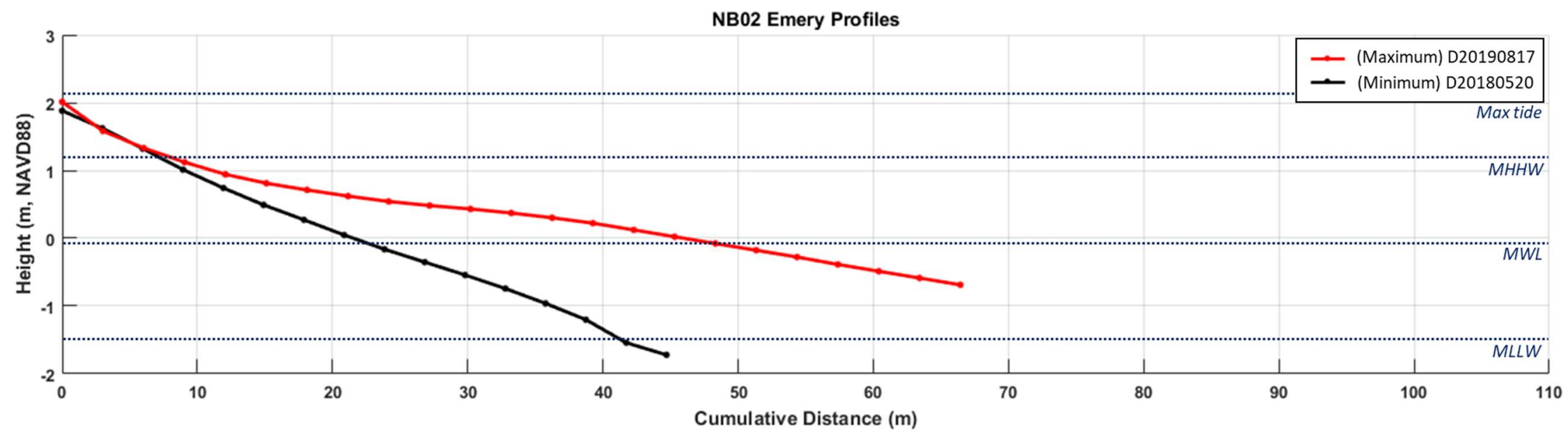

Figure NB02-9. Maximum (August 17, 2019) and minimum (May 20,2018) beach elevation profiles for the study period at station NB02. Note that this is not the impact of a single event as the profiles are not consecutive monitoring dates; rather this comparison looks at the extreme of differences of beach elevation profiles over the entire study period. 
Storm Effects, Beach Erosion, and Recovery. Although there are no profiles to document the beach elevation, width, and sediment volume prior to the late winter 2018 nor'easters (Riley: March 1-4, Quinn: March 6-9, and Skylar: March 12-14), NB02 was obviously significantly eroded during these intense storms as evidenced by the April 18, 2018 profile (Figure NB02-10). The profile is very steep and extends only $\sim 45 \mathrm{~m}$ seaward before reaching the swash zone at low water (Figure NB02-11). The beach was still highly eroded through May but did start to show some major recovery of elevation and length in the lower beach by June 17 with the formation of a very large ridge and runnel system (Figures NB02-10 and Figure NB02-12).

The extreme variability in the length of the profile at NB02 over the study period (Figure NB02-8) hampered the calculation of average sediment volume gains and losses and mean elevation changes. However, to best estimate the changes for a reasonable width of the beach, the shorter profiles were extended to reach $70 \mathrm{~m}$ by assuming the profile continued seaward at the same slope as the last 9 to $18 \mathrm{~m}$ of the profile. This was done at all profile stations to some degree, as explained in the methods section, but the extensions were longer and more frequent at NB02. Therefore, care must be taken in interpreting the volume calculations and the results are considered preliminary.

The lowest sediment volumes measured during the entire study at NB02 were measured in April and May 2018 directly following the late winter 2018 nor'easters (Figure NB02-13). By the next month, on June 17 , the sediment volume significantly increased and the average elevation for the landward $70 \mathrm{~m}$ of the beach increased by $0.4 \mathrm{~m}$. However, as noted previously, logistical limitations in late winter 2018 precluded the monitoring of this station and the overall recovery rate and process as a result of these storms is unknown. 


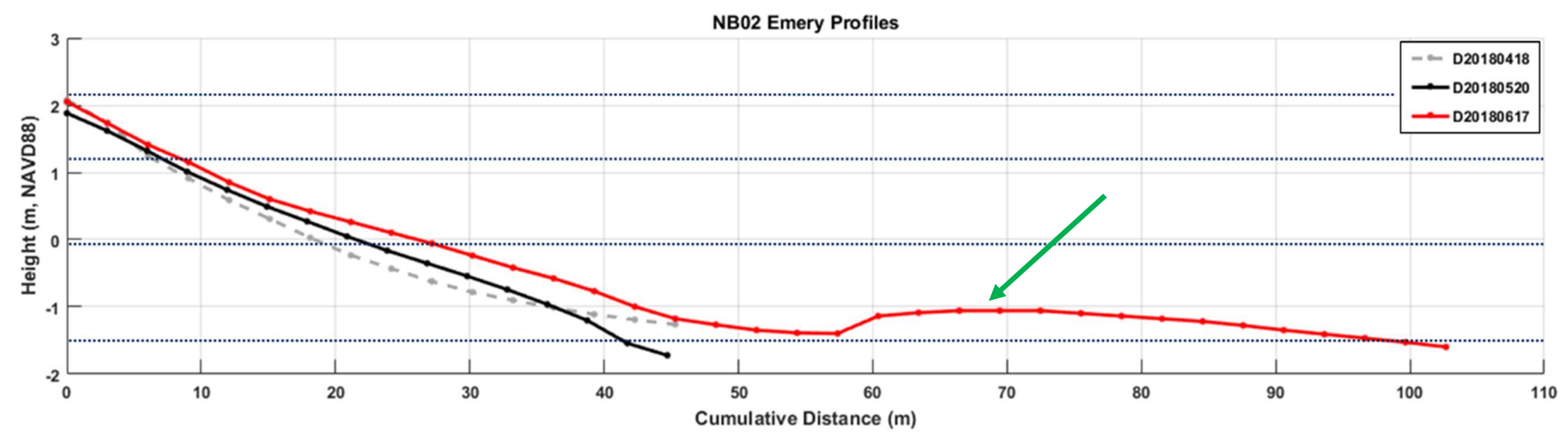

Figure NB02-10. Beach elevation profiles for NB02 on April 18, 2018, May 20, 2018 and June 17, 2018. The beach was highly eroded by the late winter 2018 nor'easters resulting in the very short and low elevations profiles on April 18 and May 20. However, by June 17 the beach had recovered in length, elevation, and sediment volume. Note the large ridge migrating landward up the beach on the June elevation profile (arrow). 


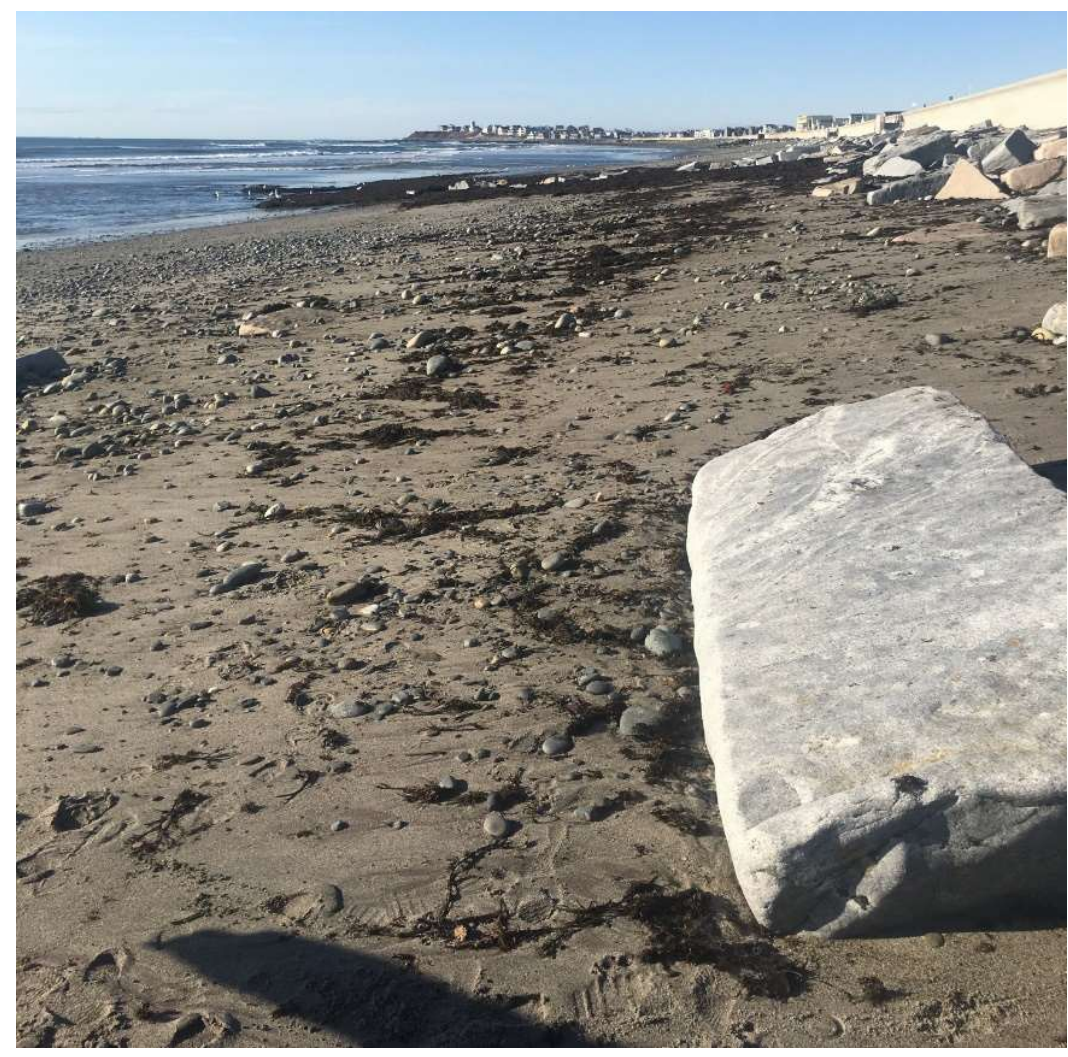

Figure NB02-11. Eroded beach at station NBO2 with exposed pebbles following the late winter 2018 nor'easters. Photograph taken on April 18, 2018.

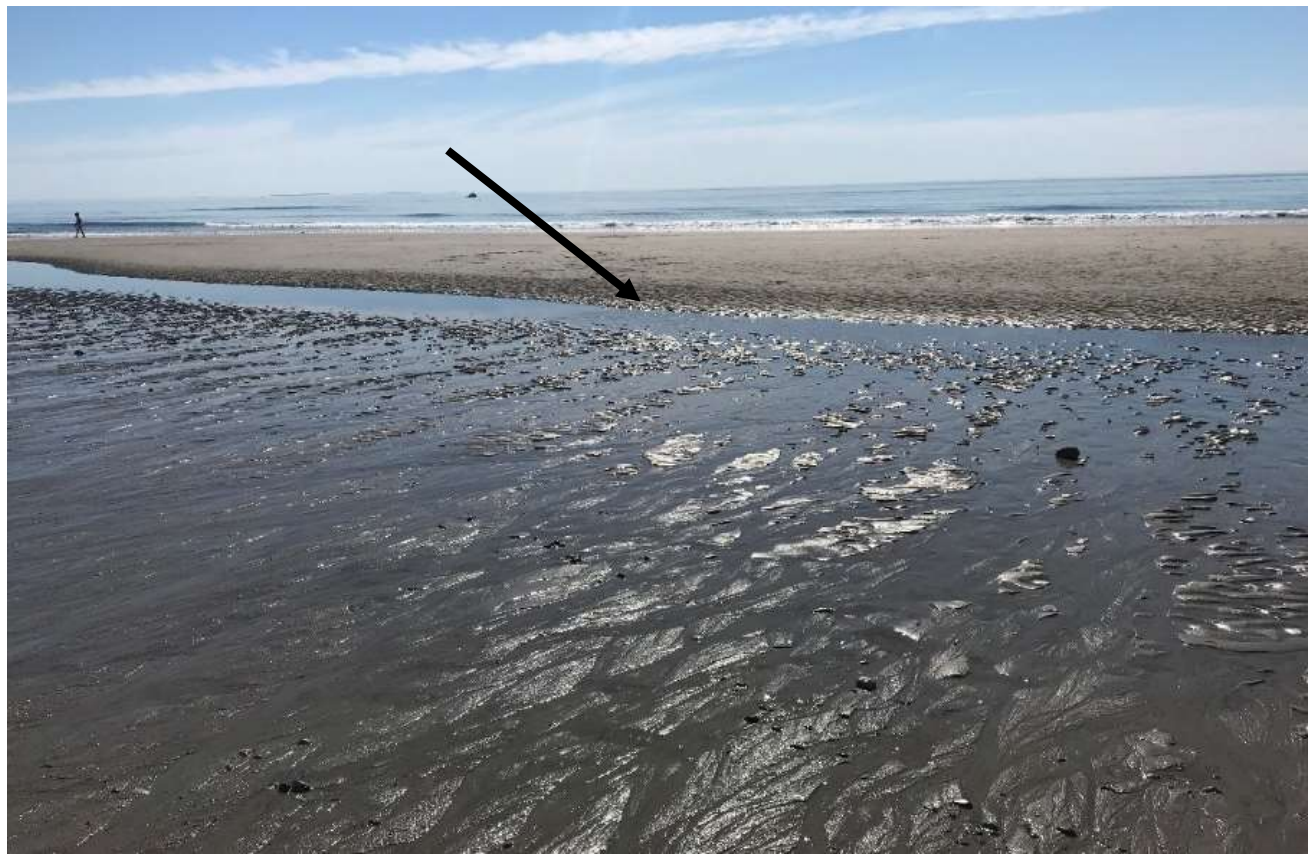

Figure NB02-12. Lower beach at NBO2 on June 17, 2018. The beach was previously eroded as evidenced by the scattered pebbles on the surface of the sand. However, the beach is undergoing accretion as shown by the very large ridge (arrow) on the lower beach. Ridge formation is indicative of sand being transported landward onto a beach following an erosional event. 

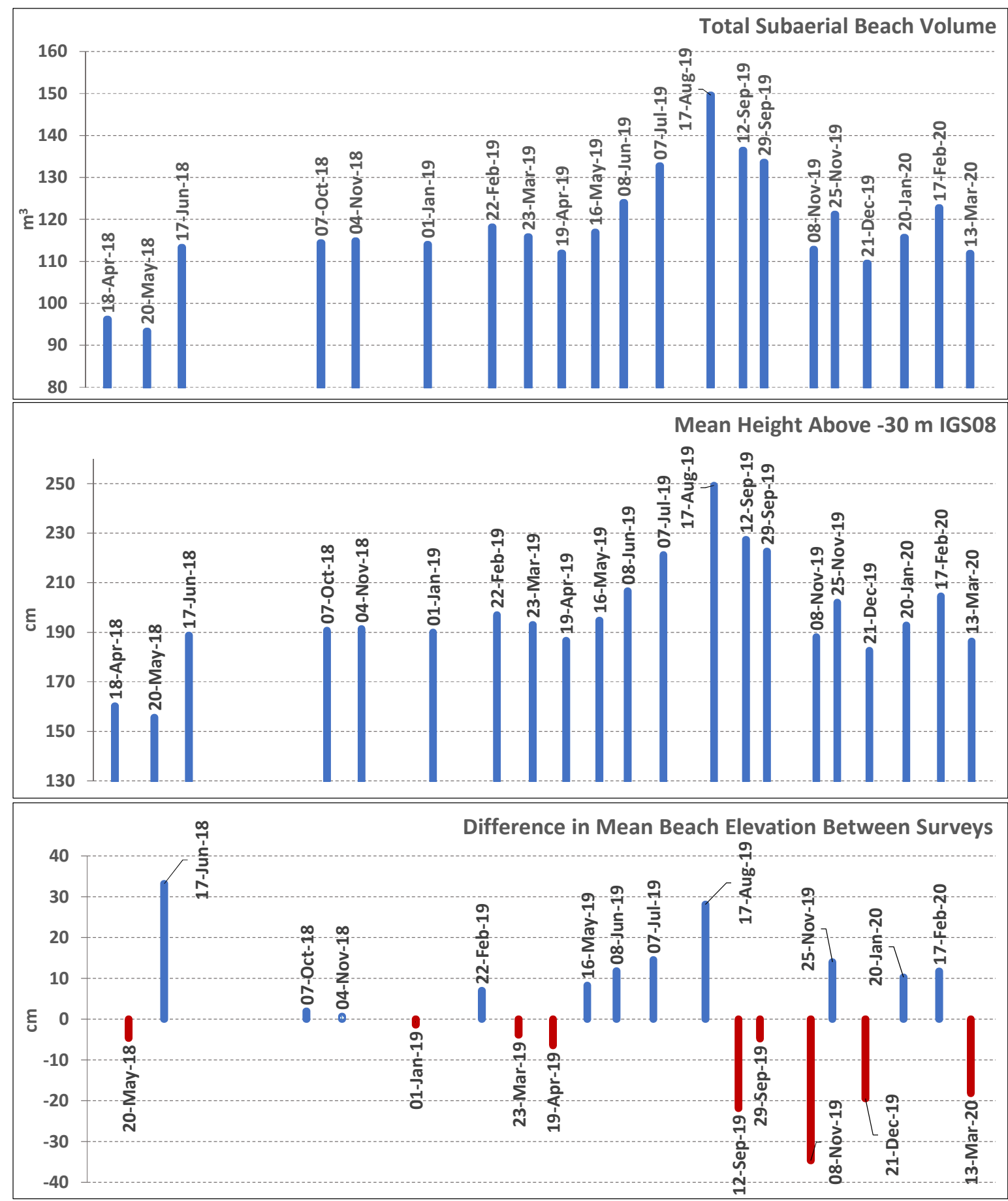

Figure NB02-13. Calculated sediment volume, mean profile elevation, and mean elevation change for the beach profile at station NB02. These parameters were calculated from 0-60 m of the profile length. Five of the twentyone elevation profiles were shorter than the "standard profile length" for the station $(60 \mathrm{~m})$. These profiles were extended using the procedure described in Chapter 2: Methods. Two of the profiles were extended less than $10.0 \mathrm{~m}$ which is considered negligible. Two of the longest extensions (14.7 m on April 18, 2018 and $15.3 \mathrm{~m}$ on April 20,2018) occurred following the severe nor'easters of March 2018 when the beach was extremely eroded. The longest extension (18.1 m on May 16, 2019) occurred following a period of erosion. 
The sediment volumes and elevations were relatively consistent and low through fall and winter 2018 and spring 2019 (Figures NB02-13, NB02-14 and NB02-15). There was a small increase in average elevation of the profile on January 27, 2019 of $\sim 0.2 \mathrm{~m}$, but the profile was very short and the results not reported here. The increase is likely due to erosion of the lower beach and the sediment being transported landward by wave action. In fact, the beach elevation profile measured on January 27 followed a major nor'easter (Harper) that occurred from January 19-21, 2019 (Table 3-3). Therefore, the likely scenario is the lower beach was heavily eroded and the coarser sediment (gravel) was pushed landward to the upper beach giving the false indication of accretion during what was an overall erosional event for the beach. Unfortunately, due to logistical problems, the lack of longer profiles and gaps make this impossible to resolve.

The beach began rebuilding and recovering from the winter storms in late spring and summer 2019. For example, the beach elevation profile for June 8, 2019 has a very large ridge and runnel on the lower beach which was transporting sediment landward (Figure NB02-16). The ridge and runnel system continued to move landward, and the beach at NB02 accreted and reached its maximum elevation and sediment volume on August 17, 2019 (Figures NB02-13 and NB02-17).

Following the maximum elevation and sediment volume profile on August 17, the beach consistently eroded through December 21, 2019 (Figure NB02-13), likely due to the effects of subtropical storm Melissa (Oct 11-13), a fast-moving unnamed nor'easter (Oct 16-17), and a king tide coastal flood (October 28) (Table 3-3). Although the erosion of the beach in the fall and winter is not unusual, the lowering of the elevation and sediment volume makes the beach more vulnerable to potential winter storms. However, the beach slightly accreted or remained unchanged after December 21, 2019 into February 2020 (Figure NB02-13) despite a few winter storms with strong easterly winds and high waves including Ezekiel (Dec 2-4, 2019) and Gage (Dec 30-31). A slight decrease in volume was seen by March 13, 2020, likely a result of two unnamed winter storms in late February-early March 2020 (Feb 27-28 and Mar 6-7, 2020).

As stated previously, the beach at NB02 eroded and rebuilt several times during the monitoring period. However, the elevation of the beach remains very low and very susceptible to erosion. 


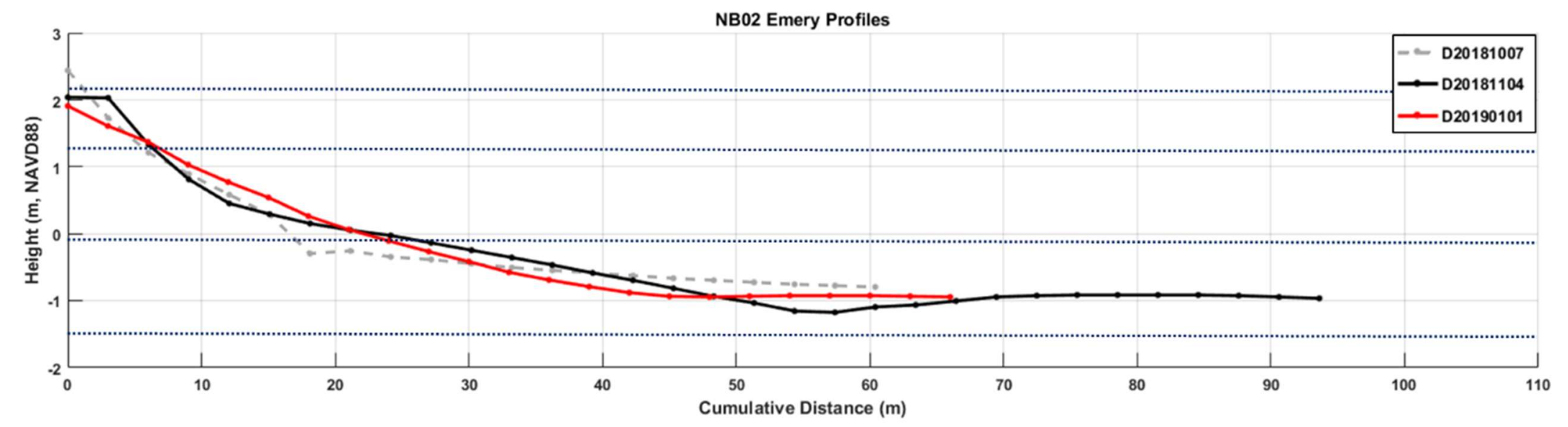

Figure NB02-14. Beach elevation profiles for NBO2 on October 7, 2018, November 4, 2018 and January 1, 2019.

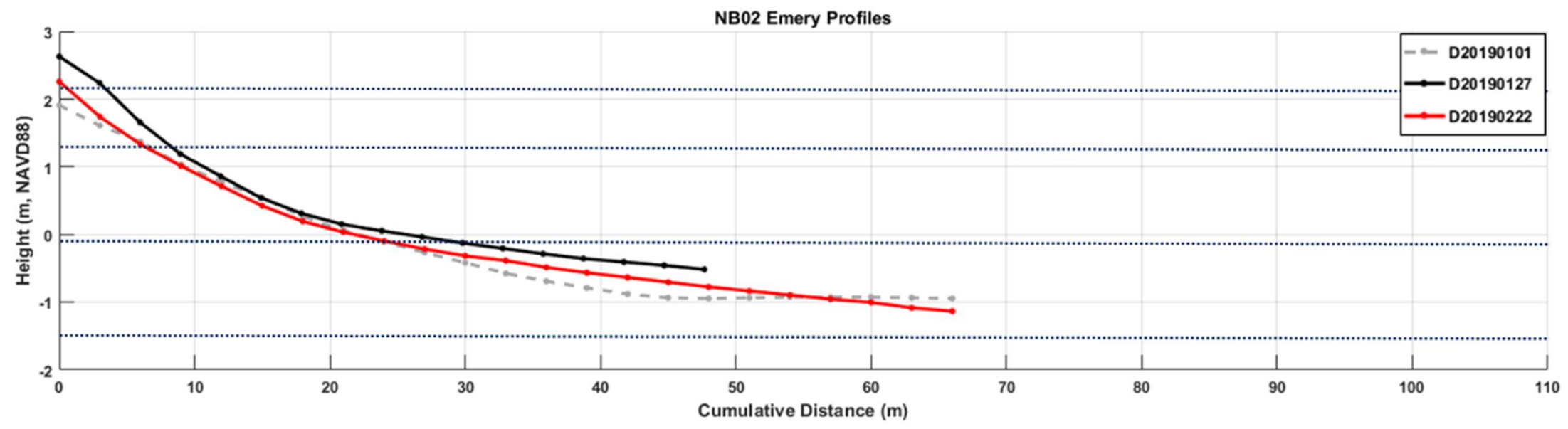

Figure NB02-15. Beach elevation profiles for NB02 on January 1, 2019, January 27, 2019 and February 22, 2019. The beach elevation profile run on January 27 followed a major nor'easter and likely was severely eroded and below the low tide level. The upper beach on January 27 shows accretion because sediment eroded from the lower beach was likely thrust landward. However, the overall beach likely lost a significant amount of sediment. 


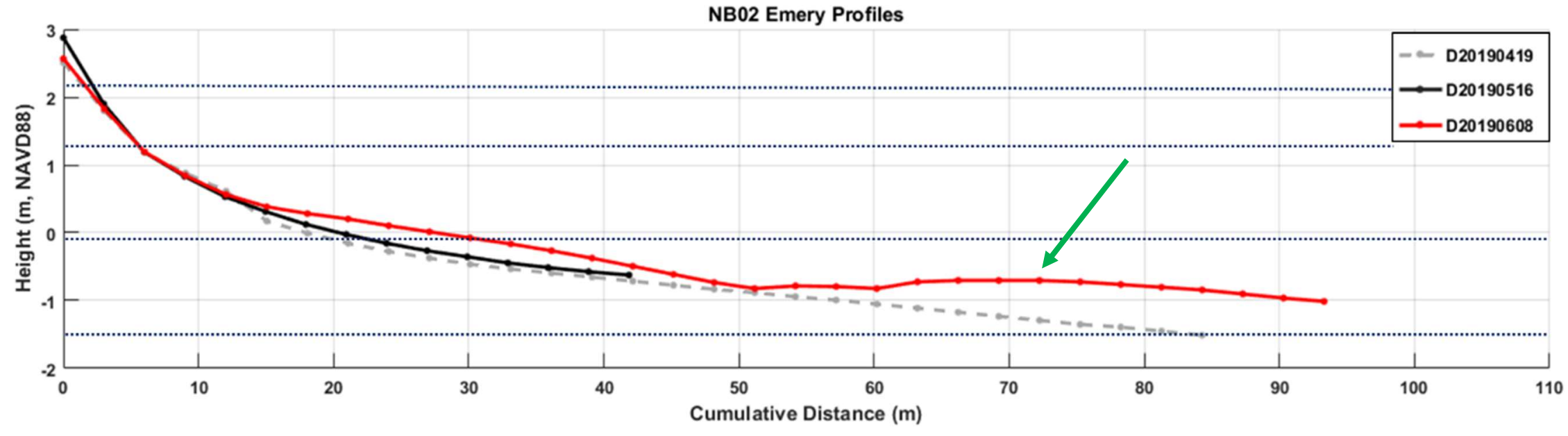

Figure NB02-16. Beach elevation profiles for NB02 on April 19, 2019, May 16, 2019 and June 8, 2019. Note large ridge and runnel on the lower beach on June 8, 2019 indicative of sediment being transported landward and building the beach (arrow).

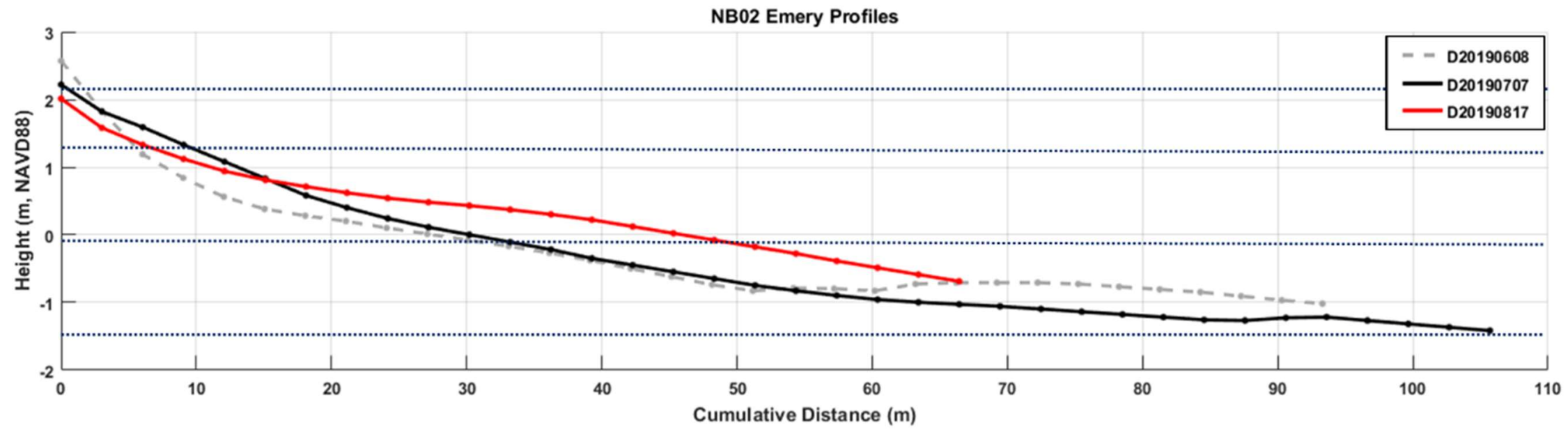

Figure NB02-17. Beach elevation profiles for NBO2 on June 8, 2019, July 7, 2019 and August 17, 2019. The beach profile on August 17 was the highest mean elevation and maximum sediment volume during the study period. 


\section{Introduction to Hampton Beach, Hampton, $\mathrm{NH}$}

Hampton Beach is a barrier spit extending $\sim 2.7 \mathrm{~km}$ from Great Boars Head southward to the jetty at Hampton Harbor Inlet (Figure HB-1). Great Boars Head, a glacial drumlin composed of till, forms the northern boundary and in the past, supplied sand to the beach (Figure HB-2). However, today riprap and other coastal defense structures placed at the base of Great Boars Head have slowed down erosion and cut off the sediment supply. The large cobble and boulder platform that extends seaward from Great Boars Head also likely cuts off any sediments being transported from the beaches from the north.

The barrier is $\sim 0.6 \mathrm{~km}$ in width at its widest location (from the lower beach to the edge of the backbarrier salt marsh). The intertidal beach is wide and extends 150 to $200 \mathrm{~m}$ seaward from the seawalls, buildings, or dunes. Hampton Beach is heavily developed with a thriving business district geared towards tourism, numerous vacation homes, and permanent dwellings. The beach area seaward of Ocean Boulevard is a NH State Park and a favorite tourist destination. Concrete seawalls extend from Great Boars Head $\sim 2.0 \mathrm{~km}$ southward (Figure HB-3). At the end of the seawall, homes and other buildings are largely unprotected, but the beach is relatively wide in this area (Figure HB4). The southern $0.4 \mathrm{~km}$ of Hampton Beach adjacent to the jetty has a large dune system that was restored with dredged sediment from Hampton Harbor in 1934-1935 (Figures HB-5 and HB-6). Hampton Harbor Inlet jetty was built in 1934-1935 and extended in 1966. 


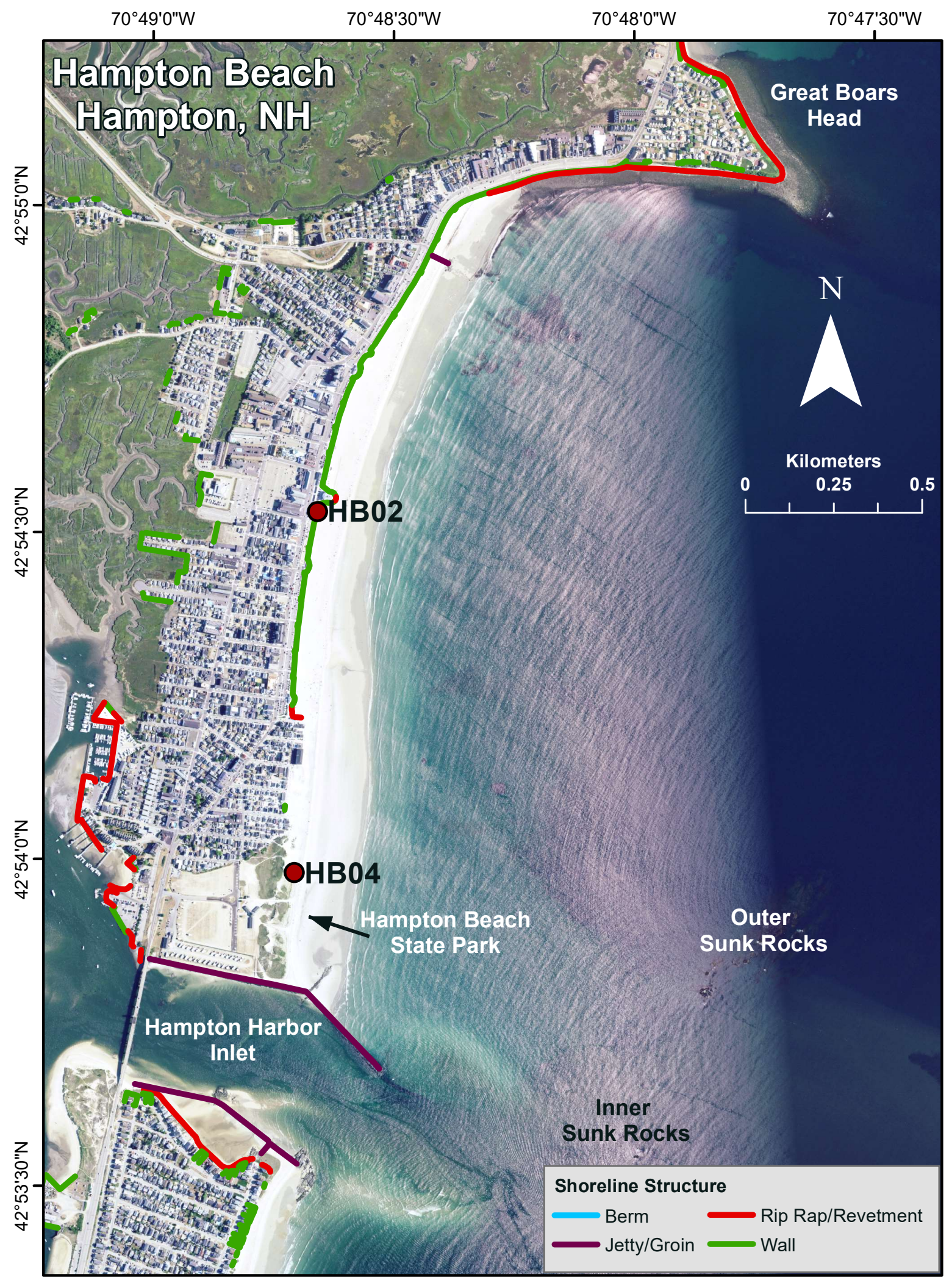

Figure HB-1. Location map of Hampton Beach with stations, geographic features, and shoreline structures. 


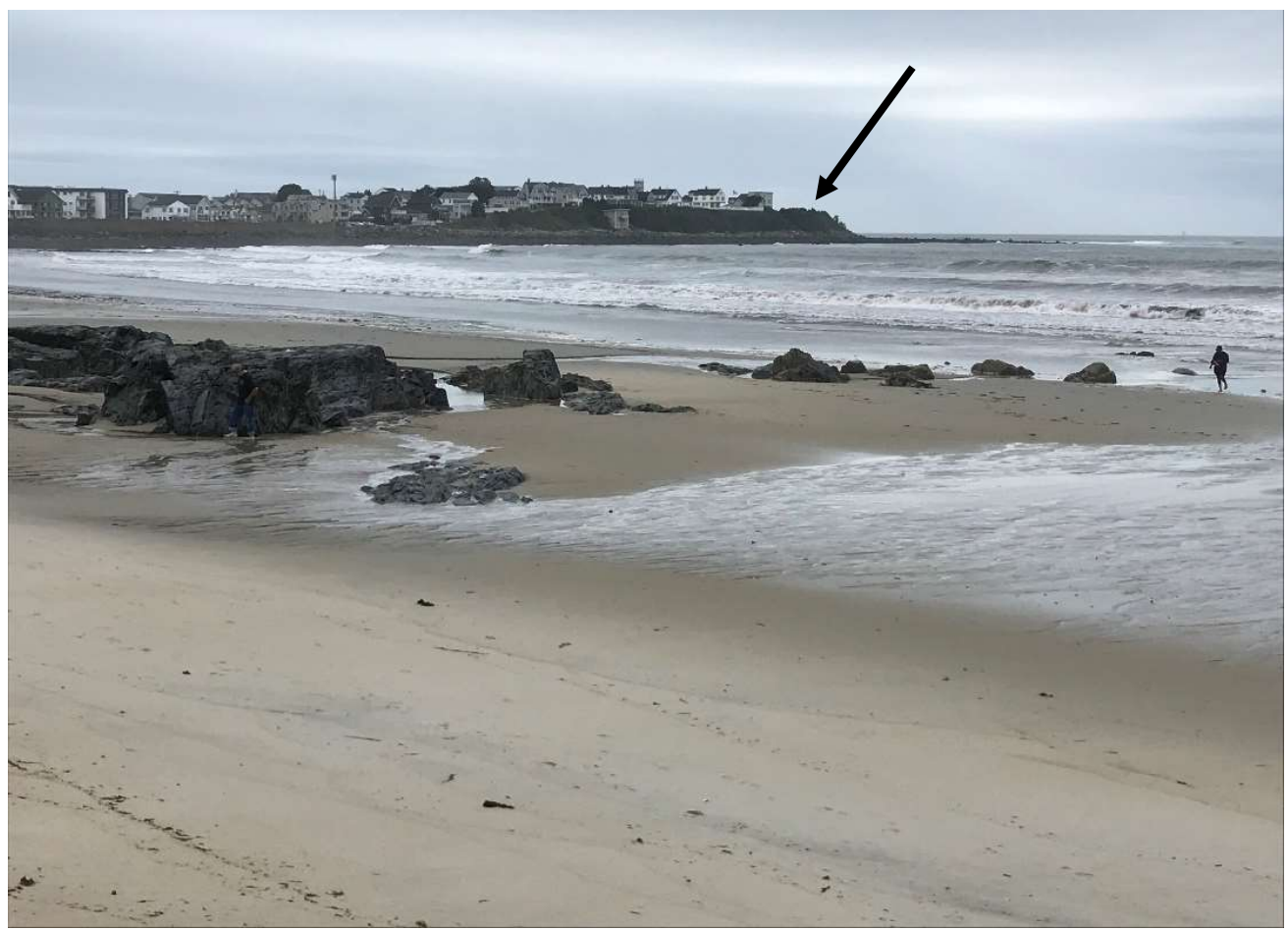

Figure HB-2. Great Boars Head (arrow), which forms the northern boundary of Hampton Beach. Note bedrock outcropping in the foreground. The photograph was taken on September 12, 2018.

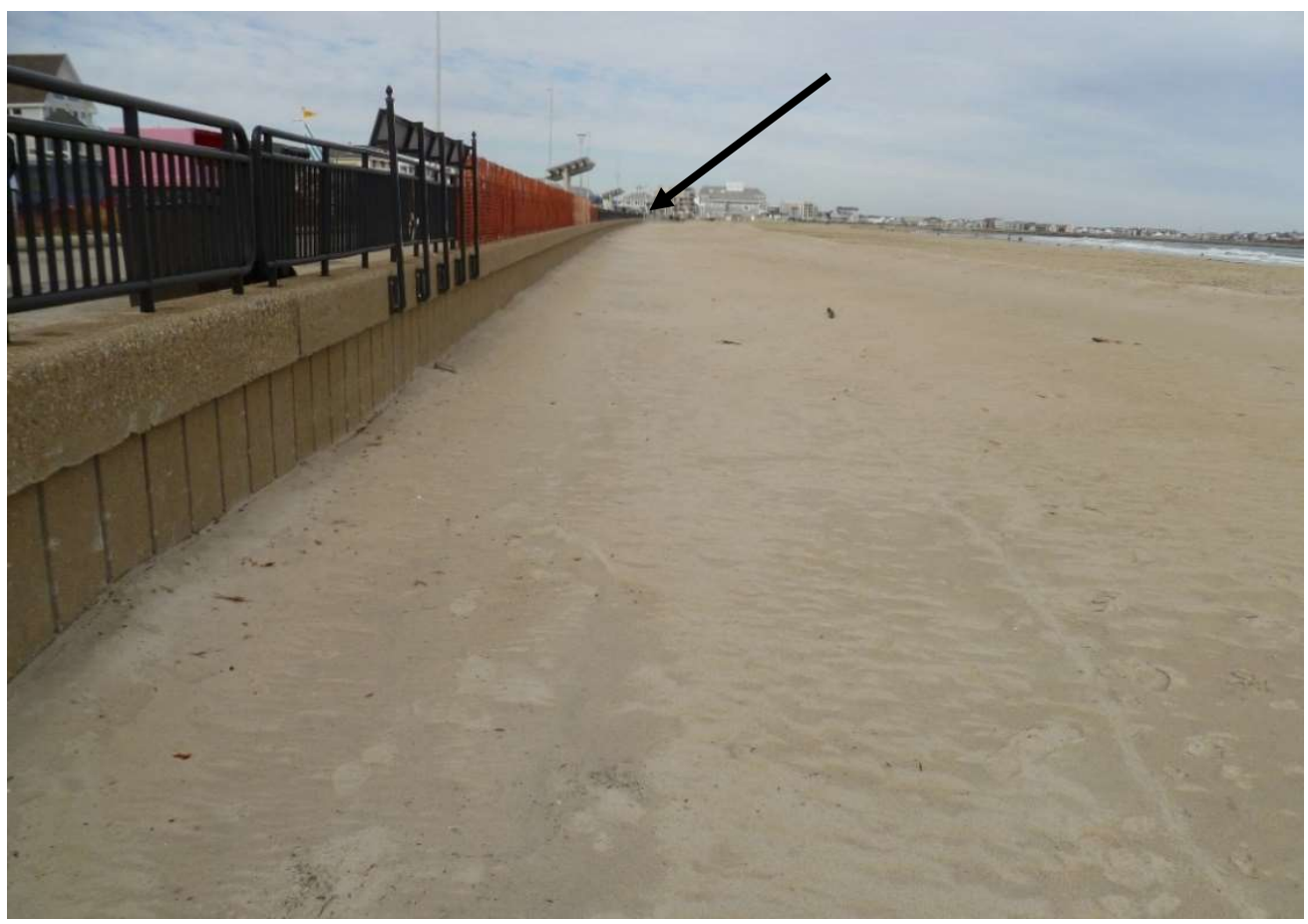

Figure HB-3. Concrete seawall which backs Hampton Beach. The photograph was taken on February 26, 2018 and is looking north from the about mid-Hampton Beach. Profile station HBO2 is at the top of the photograph (arrow). 


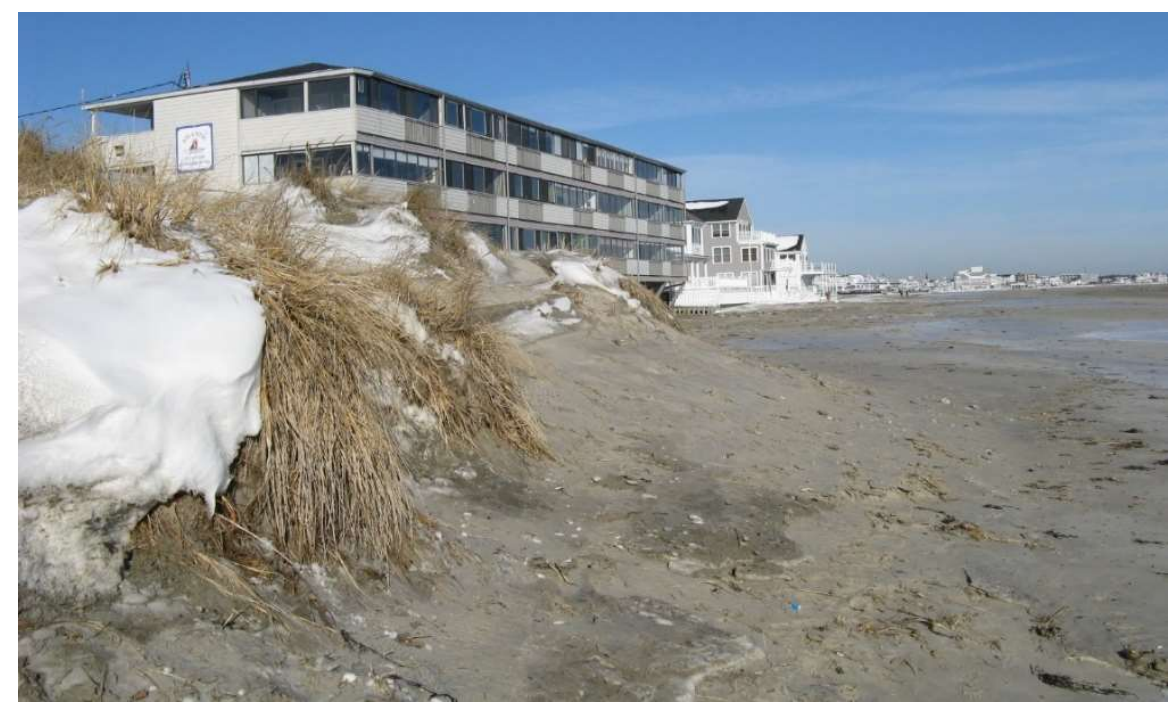

Figure HB-4. North of the large dune field at the southern end of Hampton Beach where there is a section without dunes or a seawall. The photograph is looking north from the end of the dune field on January 5, 2014 following a stormy period.

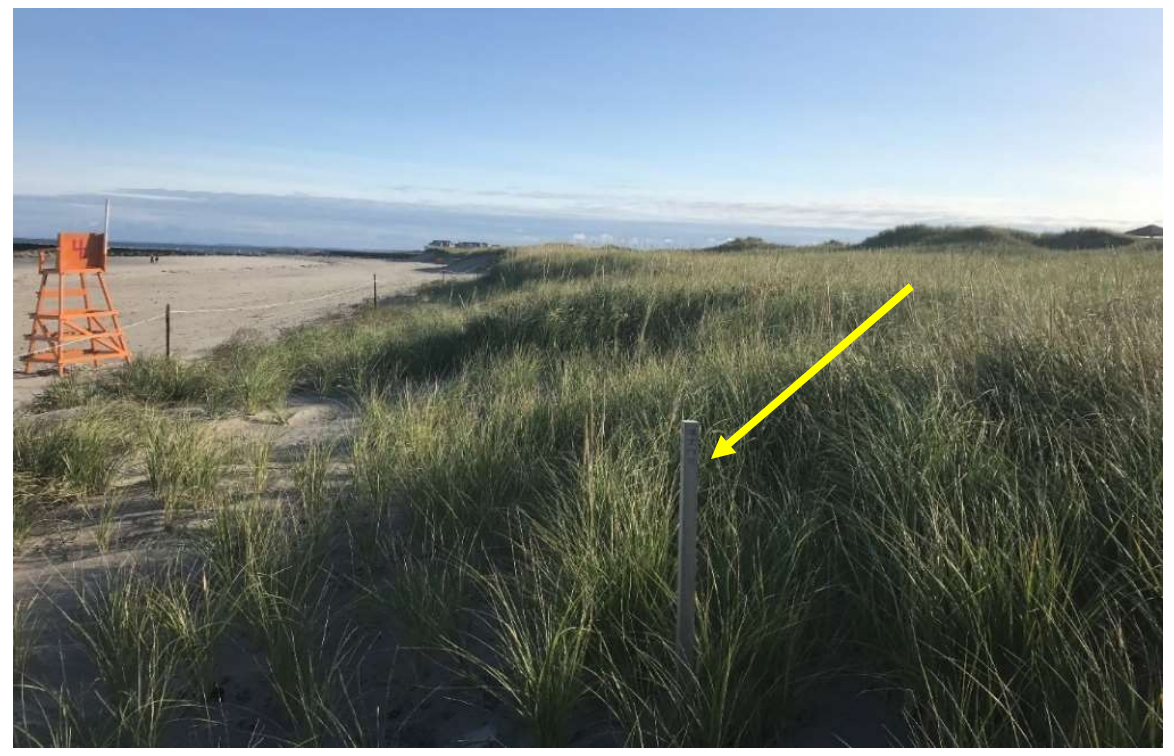

Figure HB-5. Dunes located on the southern end of Hampton Beach. The photograph is taken from the profile station HBO4 (arrow pointing to station marker) looking south on September 12, 2019.

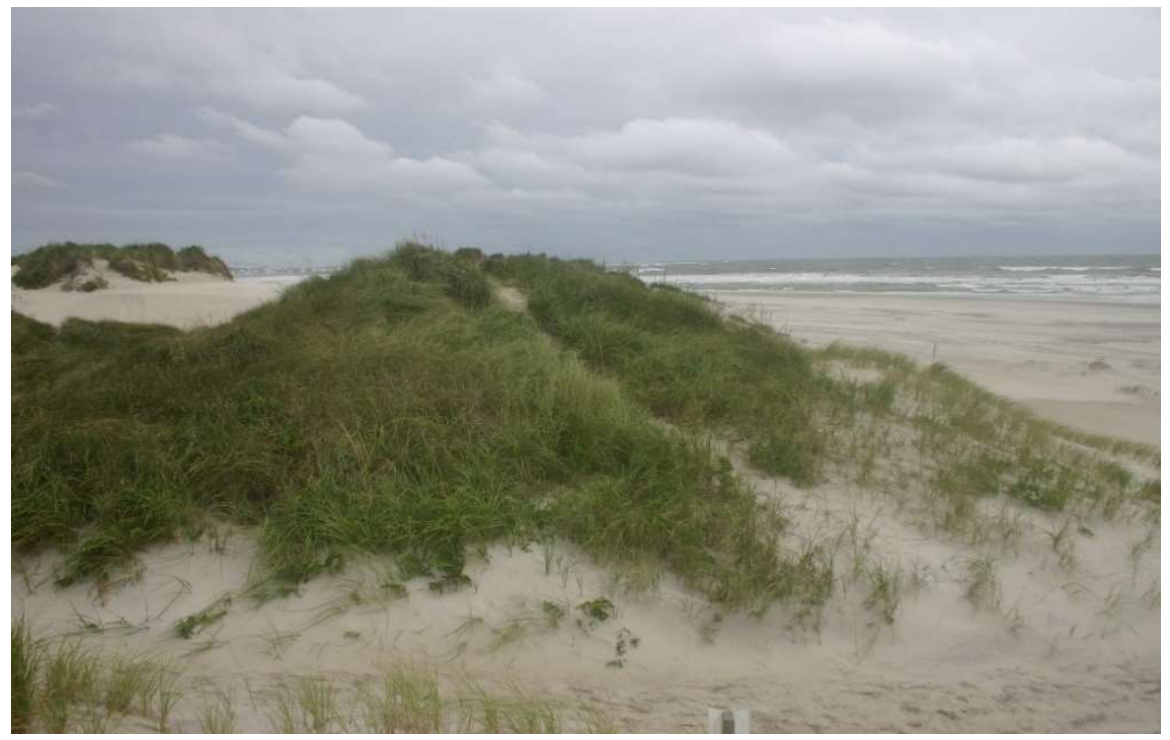

Figure HB-6. Large dune mounds located on the southern end of Hampton Beach. The photograph is looking north on October 3, 2015. 
The northern $0.3 \mathrm{~km}$ of Hampton Beach is a megaclast platform composed of cobbles and boulders formed by the erosion of Great Boars Head (Figure HB-7). The rest of the barrier spit is largely sand and occasional scattered pebbles (Figure HB-3). However, bedrock outcrops can be found on the beach at the northern end of the barrier (Figure HB-8). A groin has been constructed extending between the outcrop and seawall (Figure HB-9). Bedrock also outcrops at the southern end of Hampton Beach offshore of Hampton Harbor Inlet (e.g., Inner Sunk Rocks, Outer Sunk Rocks; Figure HB-1) and at the edge of the inlet adjacent to and attached to the jetty (Figure HB-10 and Figure HB11).

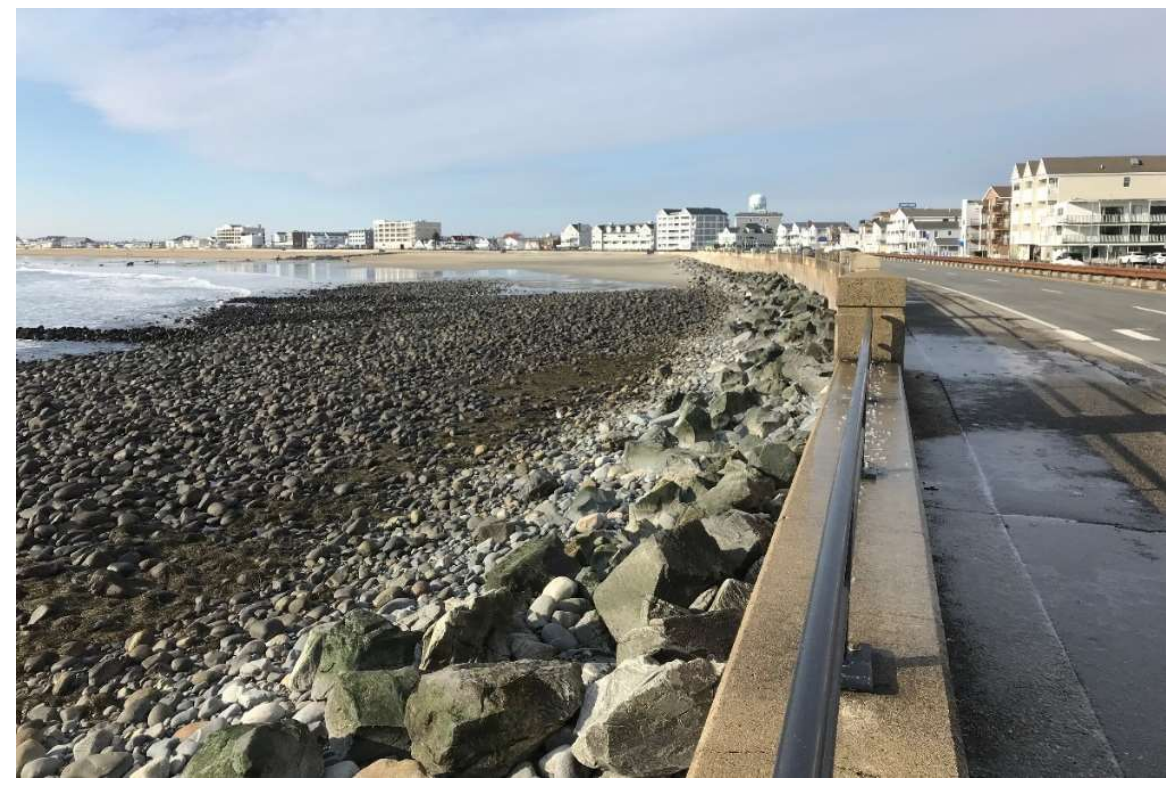

Figure HB-7. Cobble and boulder or megaclast platform at the northern end of Hampton Beach a short distance from Great Boars Head. The photograph was taken on January 27, 2019 looking south. Note the riprap at the base of the concrete seawall, placed for protection from wave attack.

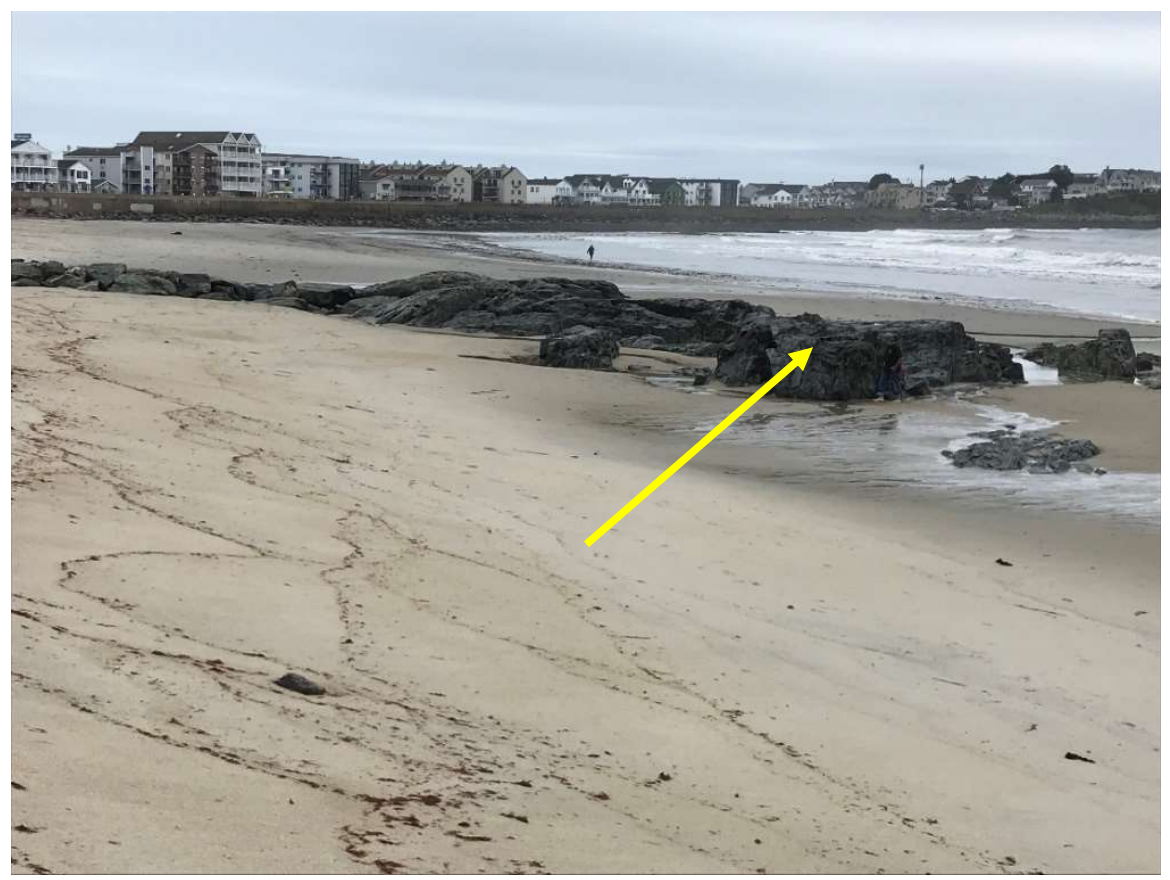

Figure HB-8. Bedrock outcrop on the northern end of Hampton Beach (arrow). The photograph is looking north on September 12, 2019. The bedrock anchors a rock groin extending landward to the seawall shown in Figure HB-9. 

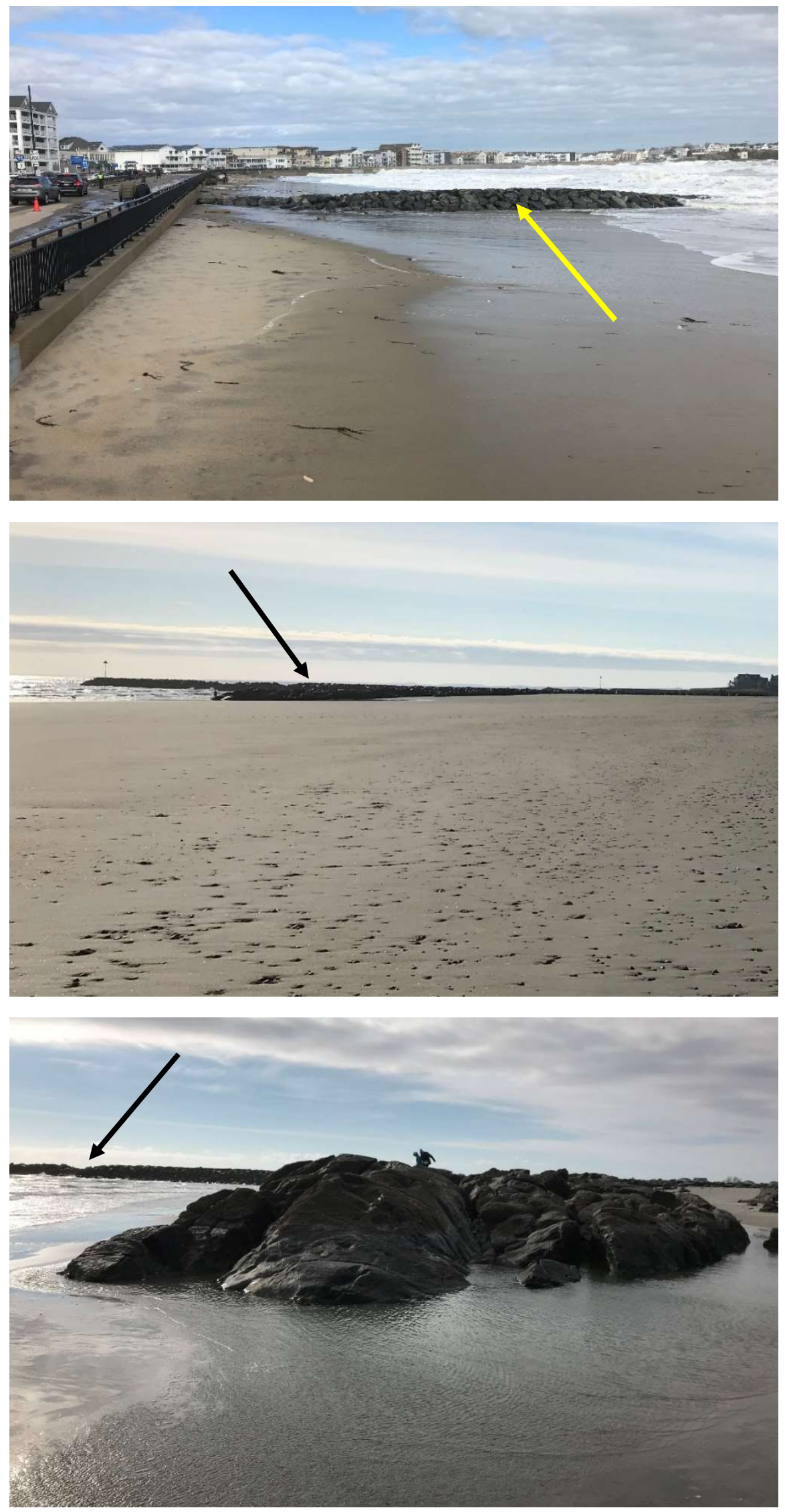

Figure HB-9. Groin on the northern end of Hampton Beach (arrow). The sea is stormy and the waves large as this photograph was taken on March 3, 2018 at the end of Nor'easter Riley.
Figure HB-10. Large bedrock outcrop (arrow) at the southern end of Hampton Beach. The photograph was taken on September 27, 2019. Note the seaward end of the jetty behind the bedrock outcrop.
Figure HB-11. Close-up of the large bedrock outcrop at the southern end of Hampton Beach. The photograph was taken on September 27, 2019. The jetty at the end of Hampton Beach can be seen in the background (arrow). 
In contrast to the $\mathrm{NH}$ beaches north of Great Boars Head, which tend to be relatively flat with moderate-size morphologic features such as berms, Hampton Beach has a very wide upper beach or backshore (Figure HB-12), a well-defined berm with a steep berm face (Figure HB-13), and a wide, flat lower beach or low tide terrace (Figure HB-14). However, at the southern end of Hampton Beach where the dunes are located, the beach is wider and flatter than the middle and northern end (Figure HB-15), largely due to sediment trapping by the large stone jetty at Hampton Harbor Inlet. The buildup of sediment at the southern end of the barrier indicates the net longshore drift is towards the south at Hampton Beach. This contrasts with all the other NH beaches north of Great Boars Head which tend not to have a net longshore drift direction.

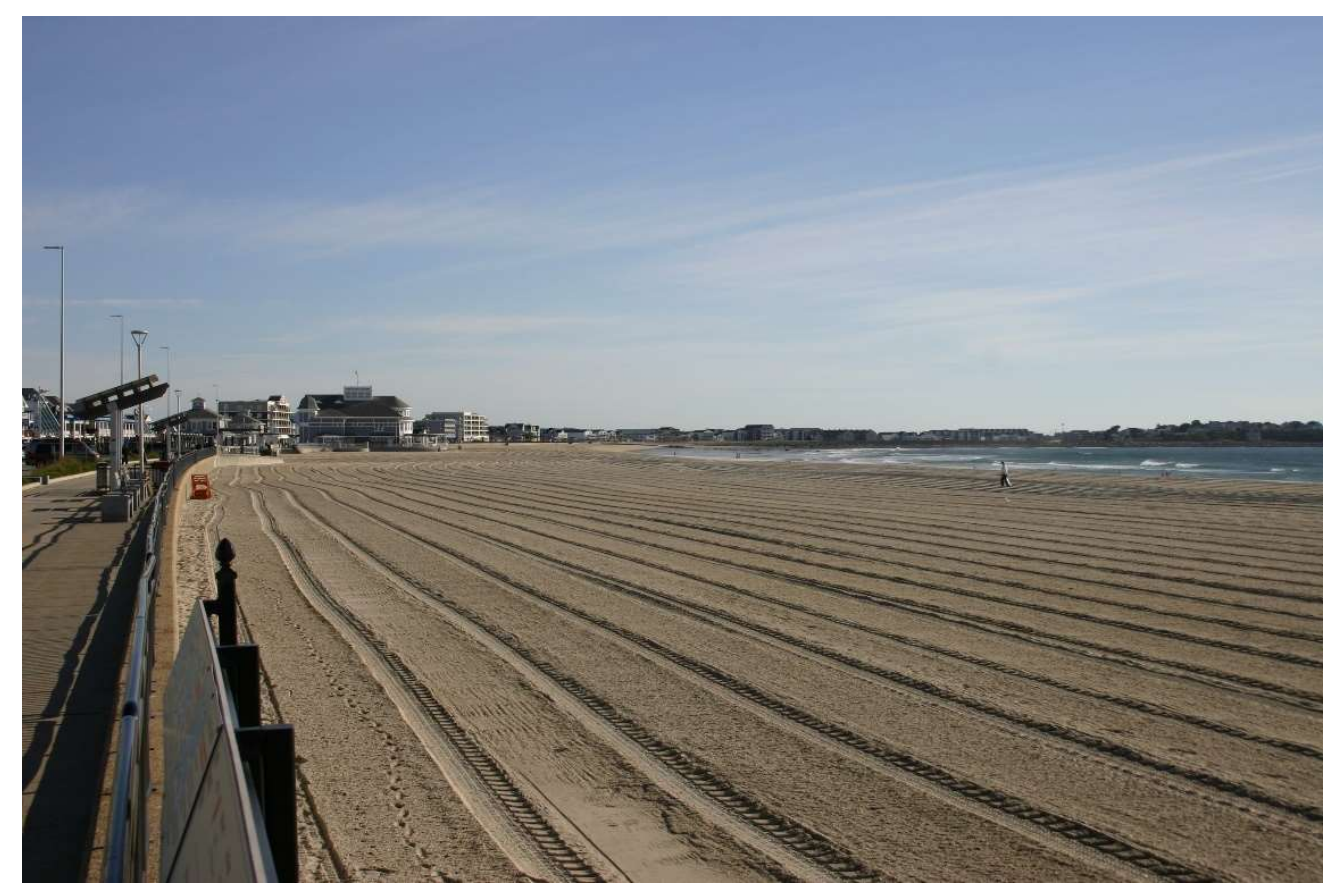

Figure HB-12. A large portion of Hampton Beach has a very wide backshore as shown in the photograph taken on June 17, 2015. The photograph is looking north. Hampton Beach is frequently graded and cleaned in summer. Note the tire tracks. 


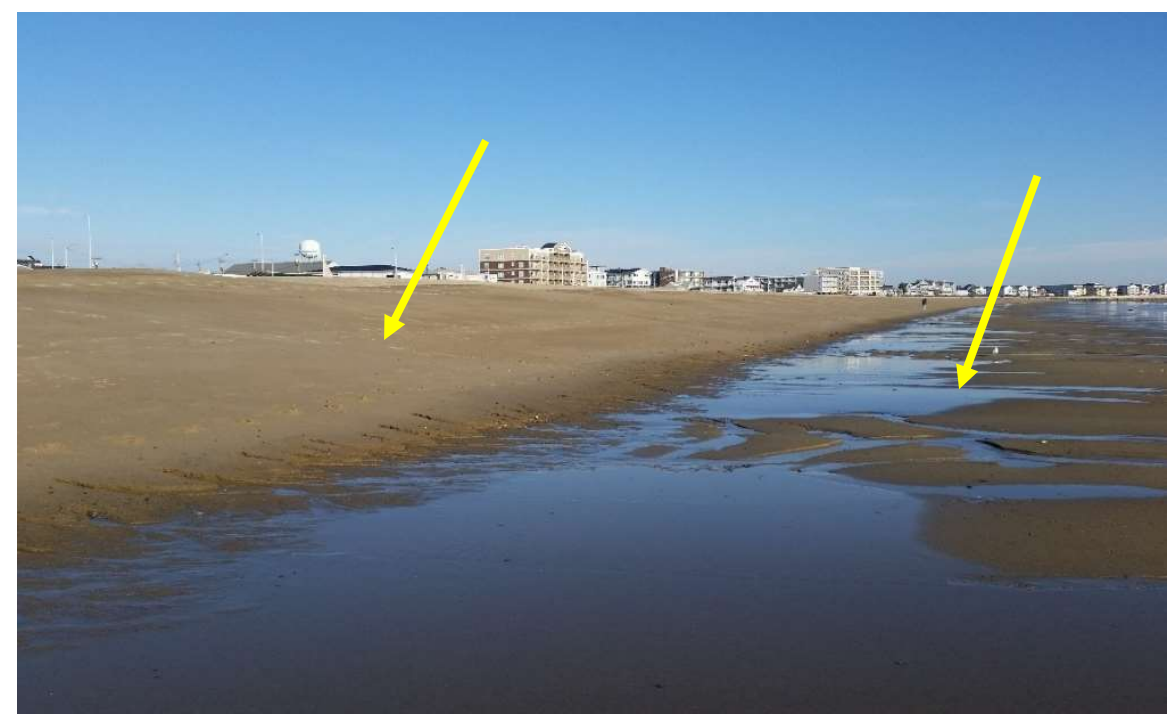

Figure HB-13. Much of Hampton Beach has a very distinctive berm and a steep beach face (left arrow) fronted by a wide low tide terrace (right arrow) as seen here. The photograph is looking south and was taken near the $\mathrm{HBO} 2$ profile on January 30 , 2016.

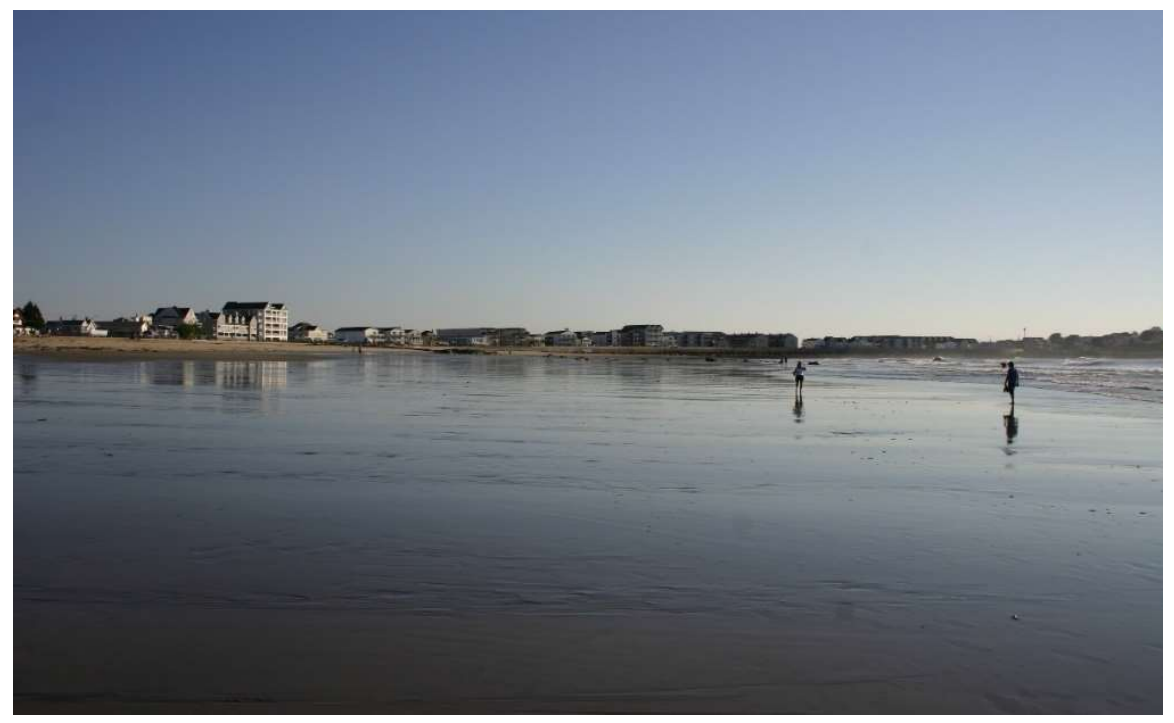

Figure HB-14. Hampton Beach often has a wide, flat lower beach or low tide terrace as seen in this photograph looking north taken on August 4, 2016 from the HBO2 profile transect.

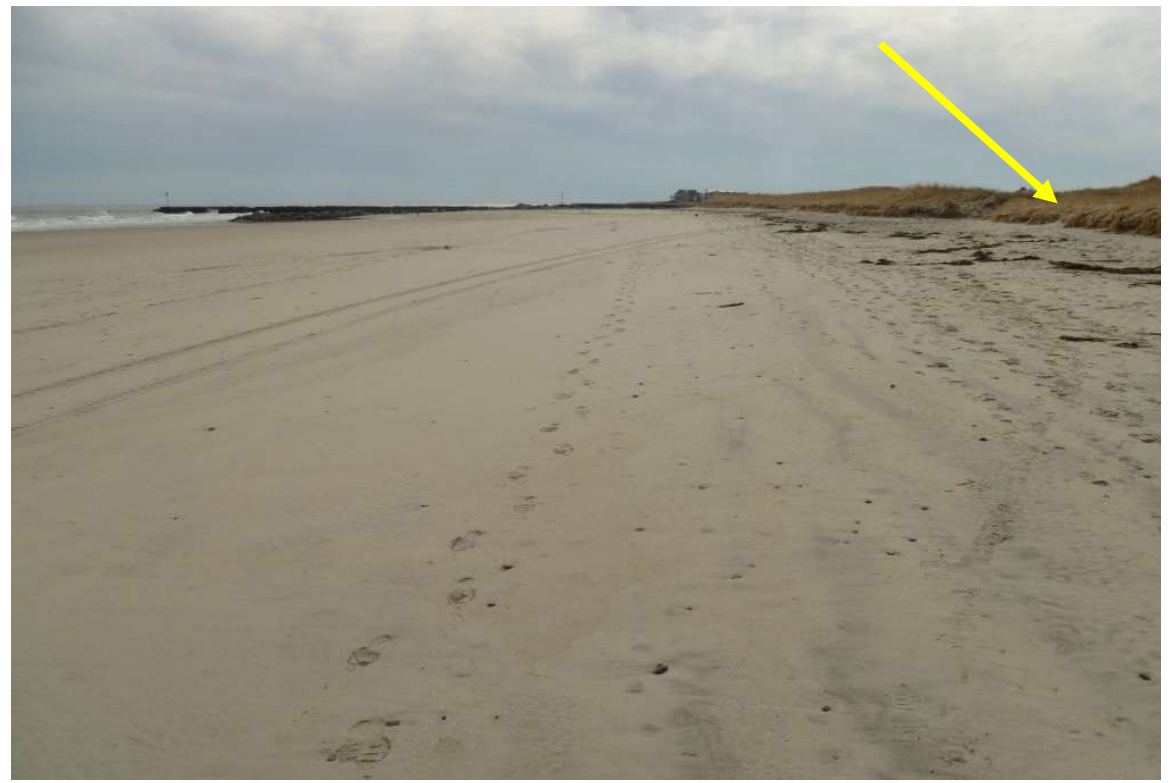

Figure HB-15. The southern end of Hampton Beach which has a large dune field (arrow) is typically very wide and flat. It does form berms and ridge and runnel systems, but in general the features are more subdued as shown in this photograph looking south from station HB04 on February 26, 2018. 
Presently, coastal defense structures limit sand from reaching the back-barrier (Figures HB-7, HB-12, and HB-16), although Ocean Boulevard is frequently overwashed causing flooding and sand to be deposited in the streets and walkways. However, undoubtedly in the past before the barrier was heavily developed, overwash was an important process moving sand from the seaward beaches to the back-barrier and creating overwash fans. Presently, a continuous series of seawalls extend 2.0 $\mathrm{km}$ from near Great Boars Head southward to a series of private homes (Figure HB-1). Much of the Hampton Beach area is heavily manipulated by the NH Division of Parks and Recreation including daily grooming and raking during the late spring and summer months from approximately May to September (Figure HB-12), periodic beach nourishment (Figure 2-4), and seasonal building of sand storm barriers or berms (Figure HB-17).

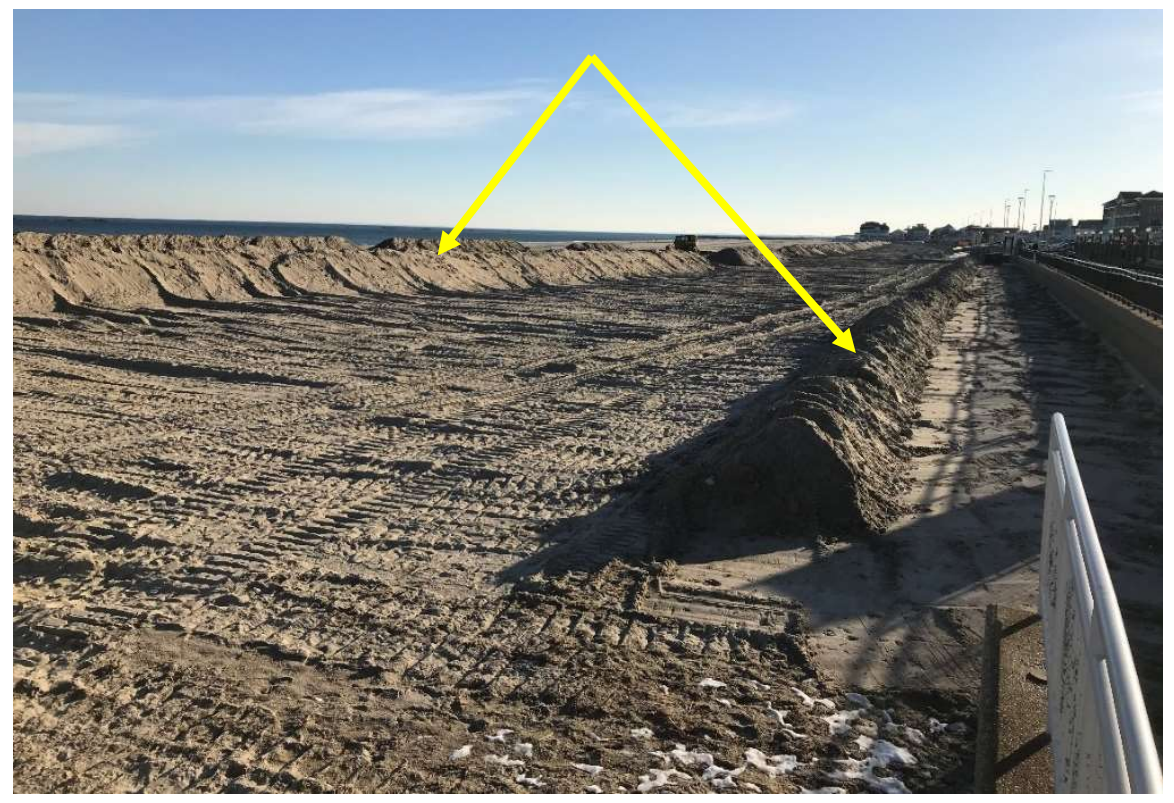

Figure HB-16. Large manmade berms (arrows) at Hampton Beach which serve as protection against storm waves and surges. The photograph above was taken on December 23, 2019 looking south from near station HBO2.

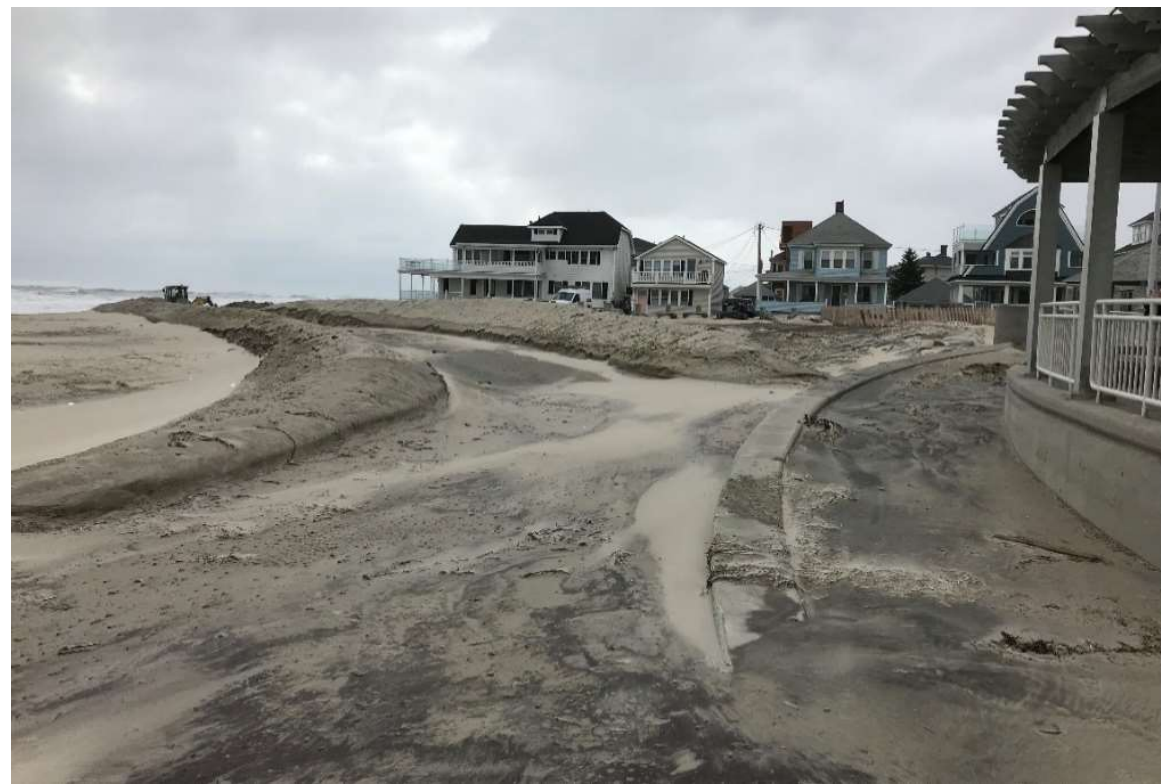

Figure $H B-17$.

Manmade berms being built on Hampton Beach. The photograph was taken on March 3, 2018 following Nor'easter Riley to help mitigate wave erosion and overwash. 


\section{Results for Station at Hampton Beach State Park: HBO2}

Overview. Profile station HBO2 is located approximately in the middle of Hampton Beach $1 \mathrm{~km}$ from Great Boars Head and 1.4 km from the northern jetty at Hampton Harbor Inlet (Figure HB-1). HB02 was one of the three original stations of this study and was first profiled in December 2016. The beach is wide with a well-developed berm and is composed of sand (Figure HB02-1). HBO2 is significantly impacted by storm events when overwash of the beach occurs, which moves sand and water into the street and business district (Figure HBO2-2). Additionally, the beach at HBO2 is frequently (approximately daily) raked to remove trash and debris during the summer (Figures HB-12 and HB021). Sand is also moved and graded to change slopes, fill low areas, or reshape the beach for recreational or safety reasons (Figures HB02-3 and HB02-4).

Summary. Understanding morphologic changes and erosion and accretion patterns at Hampton Beach at HBO2 is extremely challenging due to a number of complexities. The supporting database of beach elevation profiles made over a forty-month period (December 9, 2016 to March 12, 2020), sediment volume calculations for each of these profiles, and accompanying ground photography show a number of consistent and expected trends. However, there are a number of unexpected results with losses or gains in sediment elevation and volume that cannot be easily explained by storms, large waves, or anthropogenic effects (i.e., manmade alterations to the beach). For example, HB02 was significantly eroded over several months (February to April) by the series of storms that occurred in winter 2017 (Table 3-3). In contrast, the series of severe nor'easters in 2018 had a somewhat different effect on HB02. Riley, clearly the most destructive storm during the entire study period, caused major erosion to the beach and significant sediment volume loss in March 2018. However, unlike most other beaches in $\mathrm{NH}$, the following two storms in late winter 2018 had almost no impact on HBO2 and the beach quickly recovered. Also, somewhat unexpectedly, the highest profile elevations and sediment volumes of the entire study period occurred in winter 2019. Admittedly, the winter was relatively mild in comparison to 2017 and 2018, but it is still somewhat surprising.

Part of this variability is natural, especially in view of the extensive offshore bedrock outcrops and other shoals that create complex wave refraction patterns. In addition, the beach at HBO2 is wide with a large backshore with high elevation resulting in a sediment volume that is large (in comparison to many of the other beaches in $\mathrm{NH}$ ). Therefore, measuring relatively small changes in the computed sediment volume can be difficult. However, part of this somewhat complex pattern may also be related to the frequent (daily in the summer season, periodically throughout the year) manipulations of the beach by the NH Division of Parks and Recreation including mechanical raking or cleaning and smoothing the backshore, grading of the beach to maintain a desired profile, and the addition of sand onto the beach. These actions are not necessarily negative, but certain to have an impact on the beach profile. 


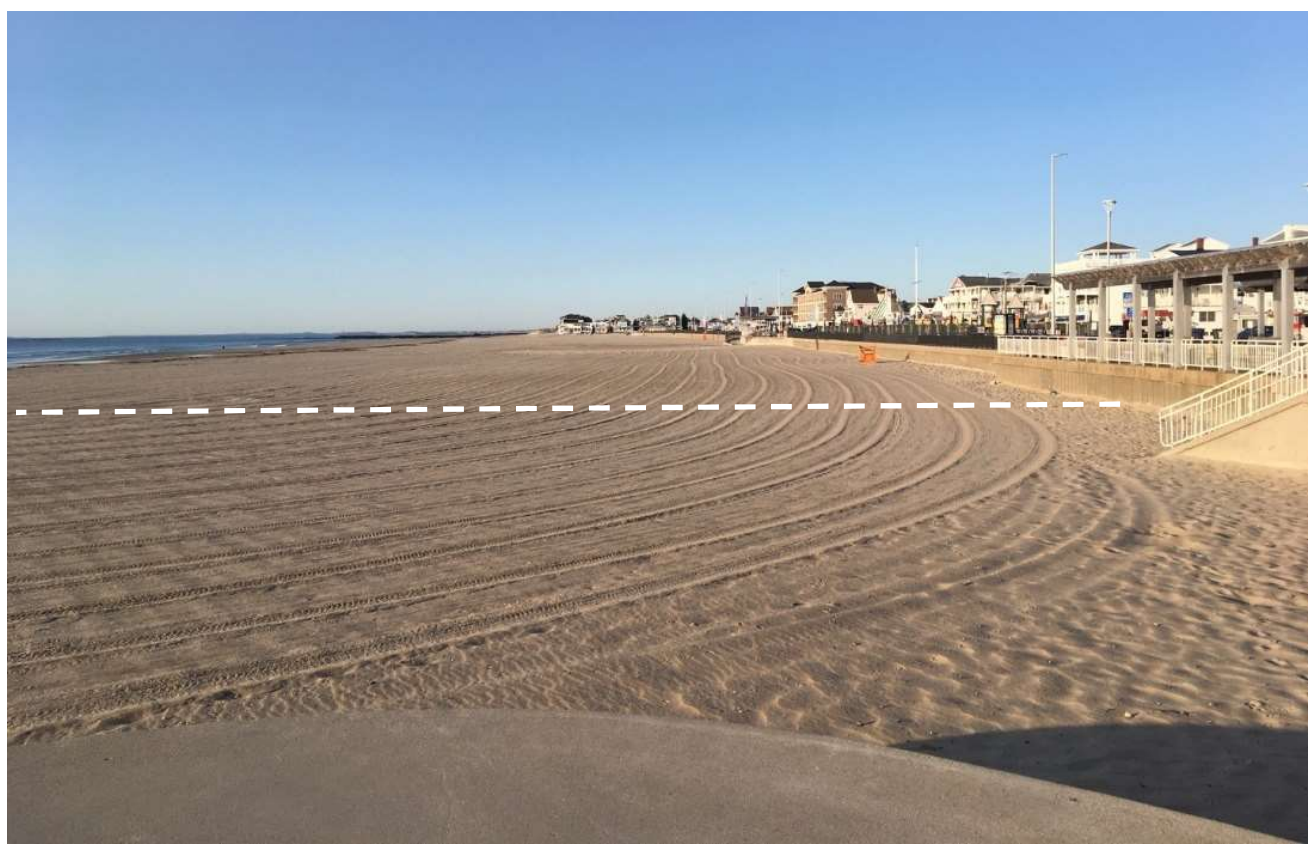

Figure HBO2-1. Beach elevation profile at HBO2, which is located approximately in the middle of Hampton Beach (white dashed line). The photograph above was taken from a short distance north of the station on June 4, 2019. Note the beach was groomed earlier in the day.

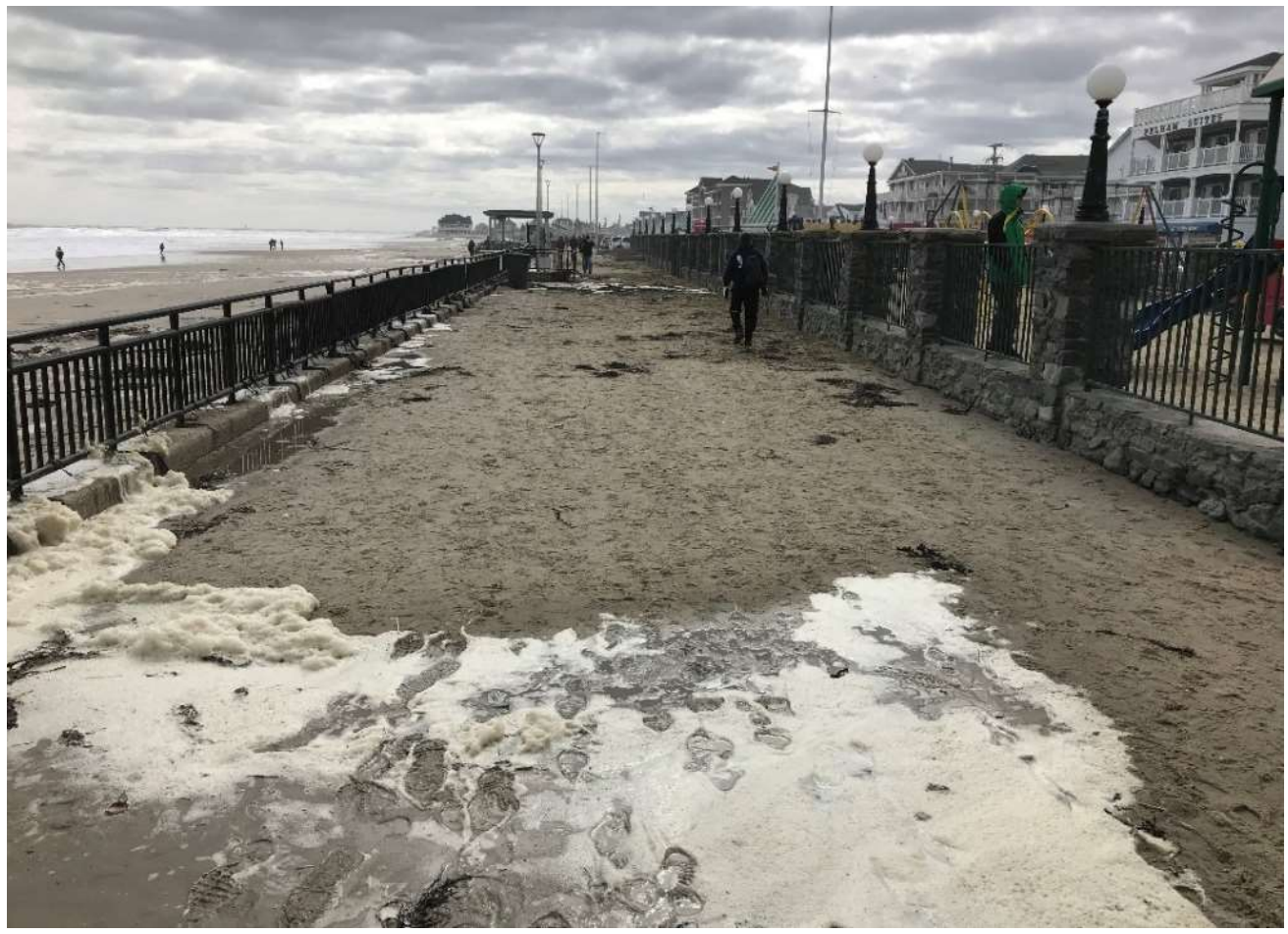

Figure HBO2-2. Following severe storms, sand can be washed into the sidewalks, streets, and business district behind Hampton Beach as seen here on March 5, 2018. Much overwash occurred after the intense Nor'easter Riley hit in late winter 2018. 


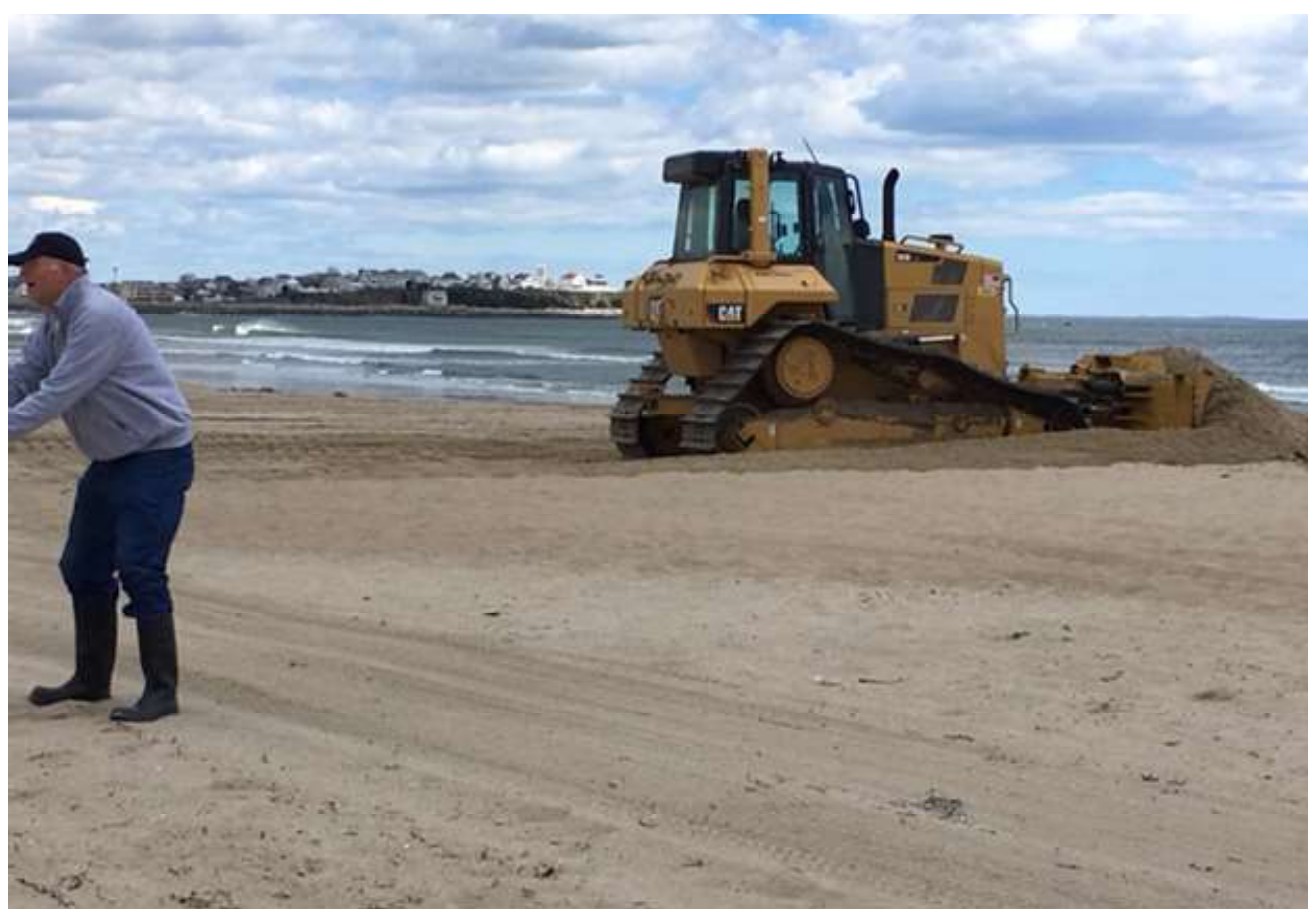

Figure HBO2-3. Hampton Beach is regularly altered using bulldozers (seen here) and similar equipment to level the upper beach, build storm berms, and for other purposes. The photograph above was taken at station $\mathrm{HBO2}$ on May 3, 2017. One of the volunteer beach profilers can be seen on the left. The change in shape of the beach due to this manipulation is discussed below.

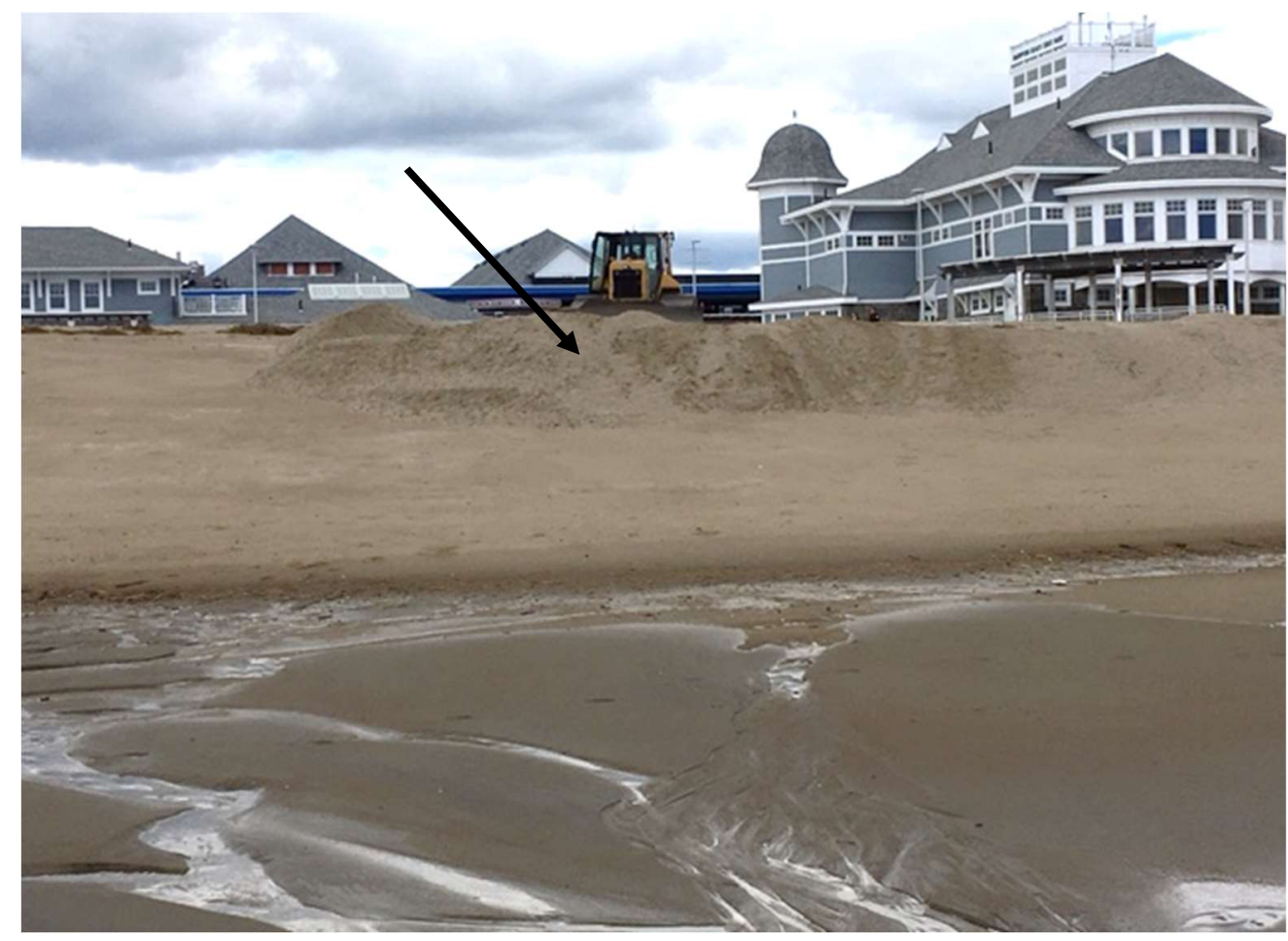

Figure HB02-4. Hampton Beach is regularly altered using bulldozers and similar equipment, as seen here where the upper beach is being extended and sand pushed down the berm (arrow). The photograph above was taken at station HBO2 on May 3, 2017. 
General Profile Characteristics. The beach was profiled forty-seven times between December 9, 2016 and March 12, 2020 (Figure HB02-5). All plotted beach profiles can be found in Appendix C(9). The profile is wide and extends 140 to $190 \mathrm{~m}$ seaward. The backshore or upper beach landward of the berm crest is wide and flat, normally ranging from 70 to $90 \mathrm{~m}$ in width from the seawall to the berm crest. This is unusual for NH beaches which tend to have narrow or no backshore area. The beach has a distinctive berm with a steep berm face that typically drops 3 to $4 \mathrm{~m}$ in elevation over a 20 to $40 \mathrm{~m}$ distance between the berm crest and the lower beach. The low tide terrace is also wide and relatively flat, extending seaward 40 to $60 \mathrm{~m}$.

Examination of the sweep zone shows the elevation of the beach varied less than $\sim 0.7 \mathrm{~m}$ in the backshore, but between $\sim 2.0$ to $\sim 2.2 \mathrm{~m}$ on the berm crest and lower beach or low tide terrace. (Figure HB02-5). Over the study period the berm crest migrated $\sim 55 \mathrm{~m}$ from the most seaward to the most landward positions due to erosion and accretion.

Comparison of the beach elevation profile with the highest average elevation and sand volume during the study period to the profile with the lowest average elevation reveals the largest differences between individual profiles. The maximum elevation profile occurred on January 25, 2019 and depicts the beach during an accretional period with features such as a wide backshore, well-developed berm and berm face, and a large ridge or sand bar moving onshore to the low tide terrace. The lowest mean elevations occurred on two dates: March 8, 2017 and March 6, 2018. The beach elevation profile measured on March 8, 2017 was measured following a series of winter storms (Table 3-3), and the berm was $\sim 1 \mathrm{~m}$ lower than the maximum accretion profile from January 25, 2019 but was not displaced landward. However, the low tide terrace was $2.0 \mathrm{~m}$ lower (Figure HB02-6). Conversely, comparison of the March 6, 2018 beach elevation profile with the maximum elevation profile (January 25, 2019) shows a very different pattern from March 8, 2017 (Figure HB02-7), despite also occurring after a series of winter storms. On March 6, the berm was $\sim 40 \mathrm{~m}$ landward of the January 25 profile and $\sim 2.0 \mathrm{~m}$ lower. In addition, the berm had flattened out. Interestingly, the low tide terrace was not substantially lower than the maximum accretion profile. It is speculated that the large volume of sand eroded from the berm seen on March 8 was transported both landward (which increased the elevation of the backshore and spilled over the seawall) and seaward (which became stored on the low tide terrace). This is discussed in more detail in the following section.

The large changes in morphology seen in the beach profiles are primarily caused by storm erosion and recovery, but also to some degree by the maintenance efforts from the NH Division of Parks and Recreation. Periodically, these manipulations significantly alter the morphology of the beach by flattening or extending the berm (discussed below). 


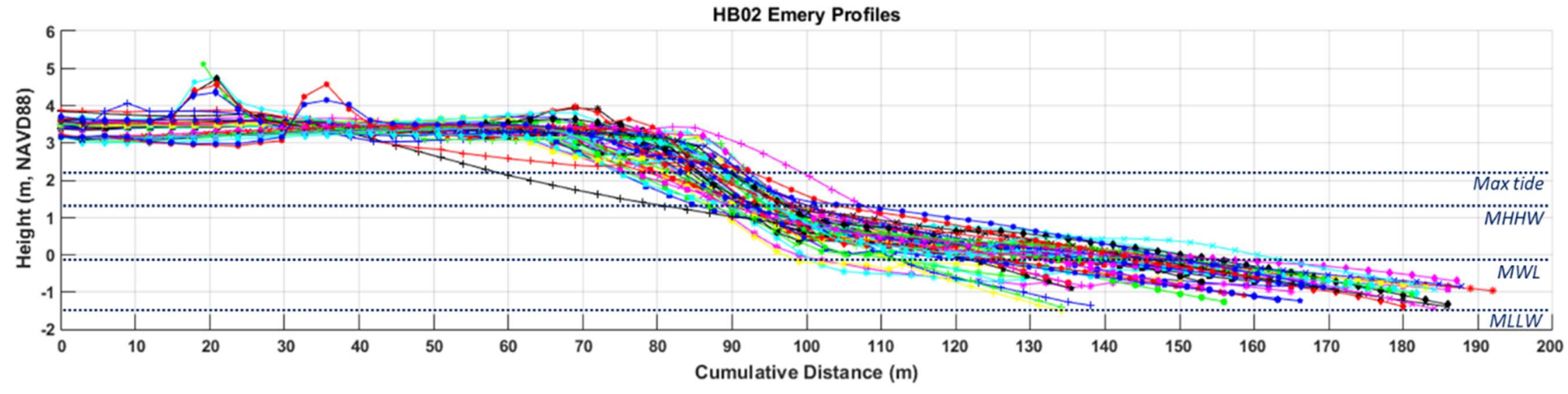

Figure HB02-5. All forty-six beach elevation profiles run at HBO2 between December 9, 2016 and March 12, 2020. Maximum tidal elevation (max tide), mean higher high water elevation (MHHW), mean water level (MWL), and mean lower low water elevation (MLLW) are indicated by the dotted lines. 


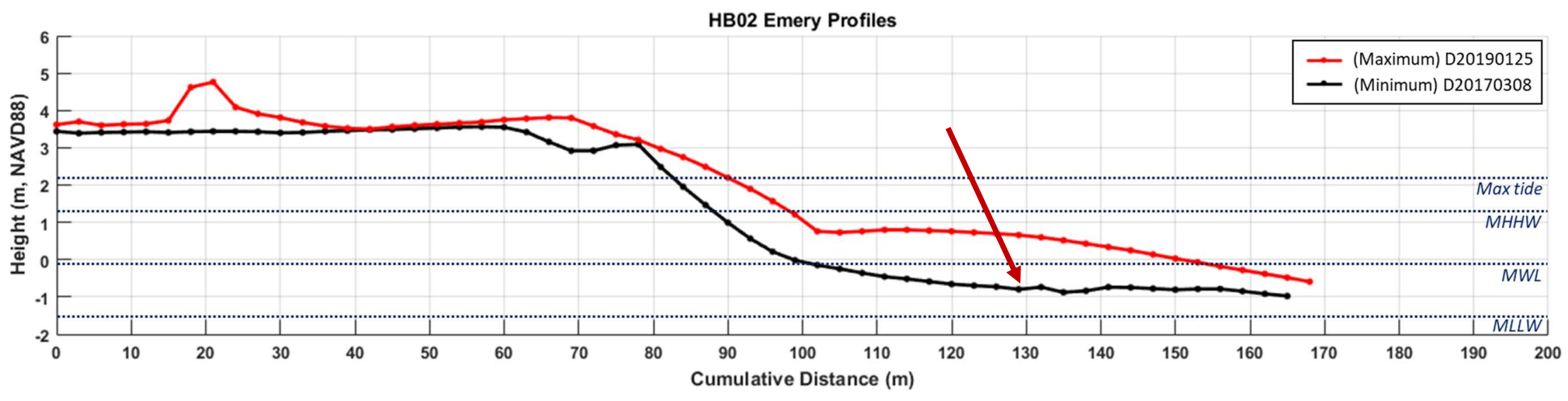

Figure HB02-6. Comparison of the maximum (January 25, 2019) and the first of the two minimum beach elevation profiles following a series of winter storms in early 2017 on March 8 for station HBO2. Note that this is not the impact of a single event as the profiles are not consecutive monitoring dates. Rather this comparison looks at the extreme of differences of beach elevation profiles over the entire study period. Also note how eroded the low tide terrace is on the March 8 profile compared to the maximum profile for the study period (arrow).

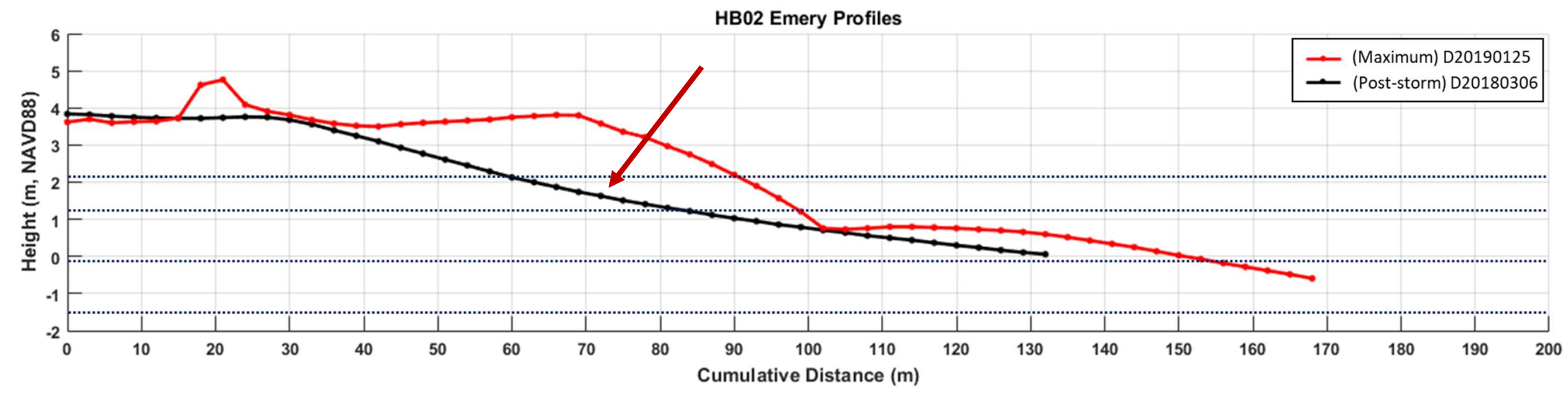

Figure HB02-7. Comparison of the maximum (January 25, 2019) and the second of the two minimum elevation profiles following the severe Nor'easter Riley on March 6, 2018 at station HB02. Note how eroded the berm is on the March 6 profile compared to the maximum profile for the study period (arrow). 
Storm Effects, Beach Erosion, and Recovery. HB02 was significantly eroded in late winter and early spring 2017 by a series of winter storms including Nor'easter Niko (Feb 5-7), an unnamed event with large waves likely related to Niko (Feb 9-10), Orson (Feb 12-13), Pluto (Feb 15-16), Stella (Mar 14-15) and Theseus (Mar 31-Apr 2) (Table 3-3). The beach profiles from February 21 to April 10, 2017 show the berm crest retreated landward $\sim 10 \mathrm{~m}$ and was lowered $\sim 0.8 \mathrm{~m}$ during the storms (Figures HB028 and HB02-9). The berm rebuilt somewhat on March 8 , but the entire lower beach was lowered by $\sim 0.7 \mathrm{~m}$. It is likely the increase in the berm resulted from sand being eroded from the lower beach and pushed landward by waves. However, the overall effect was a loss of elevation. The beach showed signs of recovery on March 17 and April 18 by the presence of a ridge and runnel system (Figures HB02-9, HB02-10 and HB02-11). Examination of the sediment volume calculated for a $1 \mathrm{~m}$ wide swath from the seawall to $140 \mathrm{~m}$ seaward reflects the impact of the storms. The sediment volume decreased significantly, and the average elevation of the beach decreased by $\sim 0.3 \mathrm{~m}$ following the winter storms (Figure HB02-12). The beach recovered with relatively consistent increases in volume and average elevation during spring and summer 2017. This sequence is best displayed by examination of the sediment volumetric calculations and changes in mean elevation, both of which sharply decreased during the stormy period in winter 2017 and then recovered by late summer (Figure HB02-12).

An anomaly in the changes of the beach elevation profile occurred on May 31 during an accretional period (Figure HB02-13). A first examination of the May 31 profile indicates that the beach underwent severe erosion with lowering of elevation and berm retreat. However, given the flatness of the decline in elevation it is likely that this is a product of the beach being graded by NH Division of Parks and Recreation. Subsequently, beach elevation profiles returned to a more normal configuration for accretional conditions (Figures HB02-13 and HB02-14). This is discussed in the next section (Beach Manipulation by Management). 


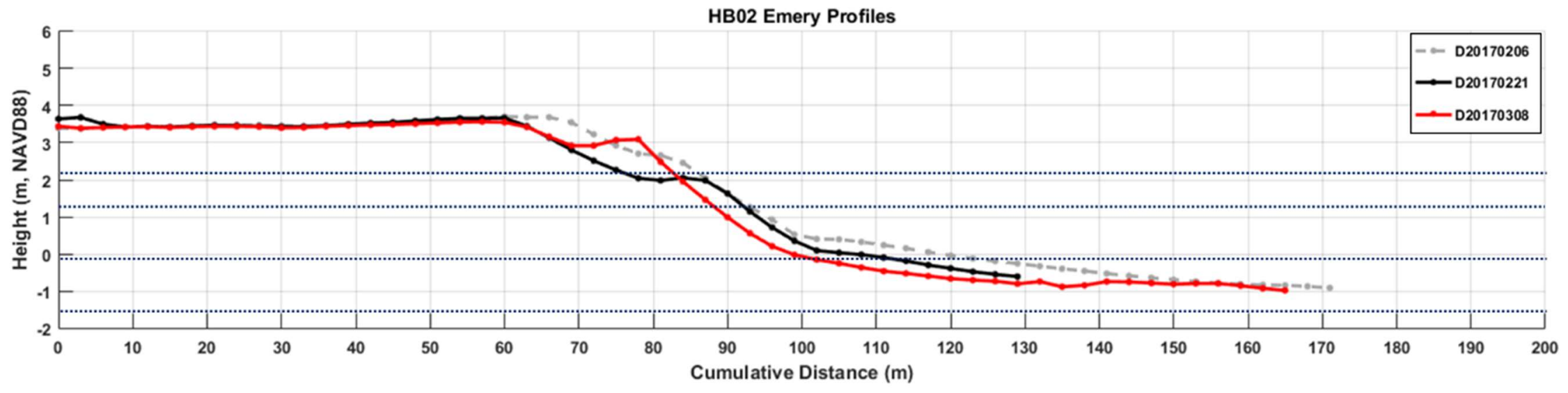

Figure HB02-8. Beach elevation profiles for HB02 on February 6, 2017, February 21, 2017 and March 8, 2017.

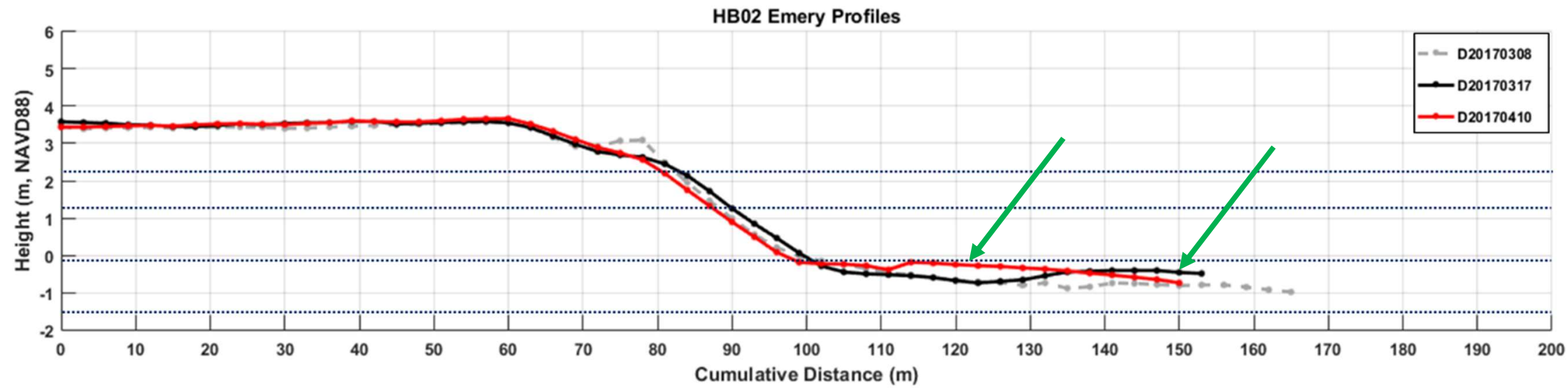

Figure HB02-9. Beach elevation profiles for HBO2 on March 8, 2017, March 17, 2017 and April 10, 2017. Note the presence of a ridge on the lower beach on March 17 and April 18 (arrows). The ridge migrated landward by about $25 \mathrm{~m}$. 


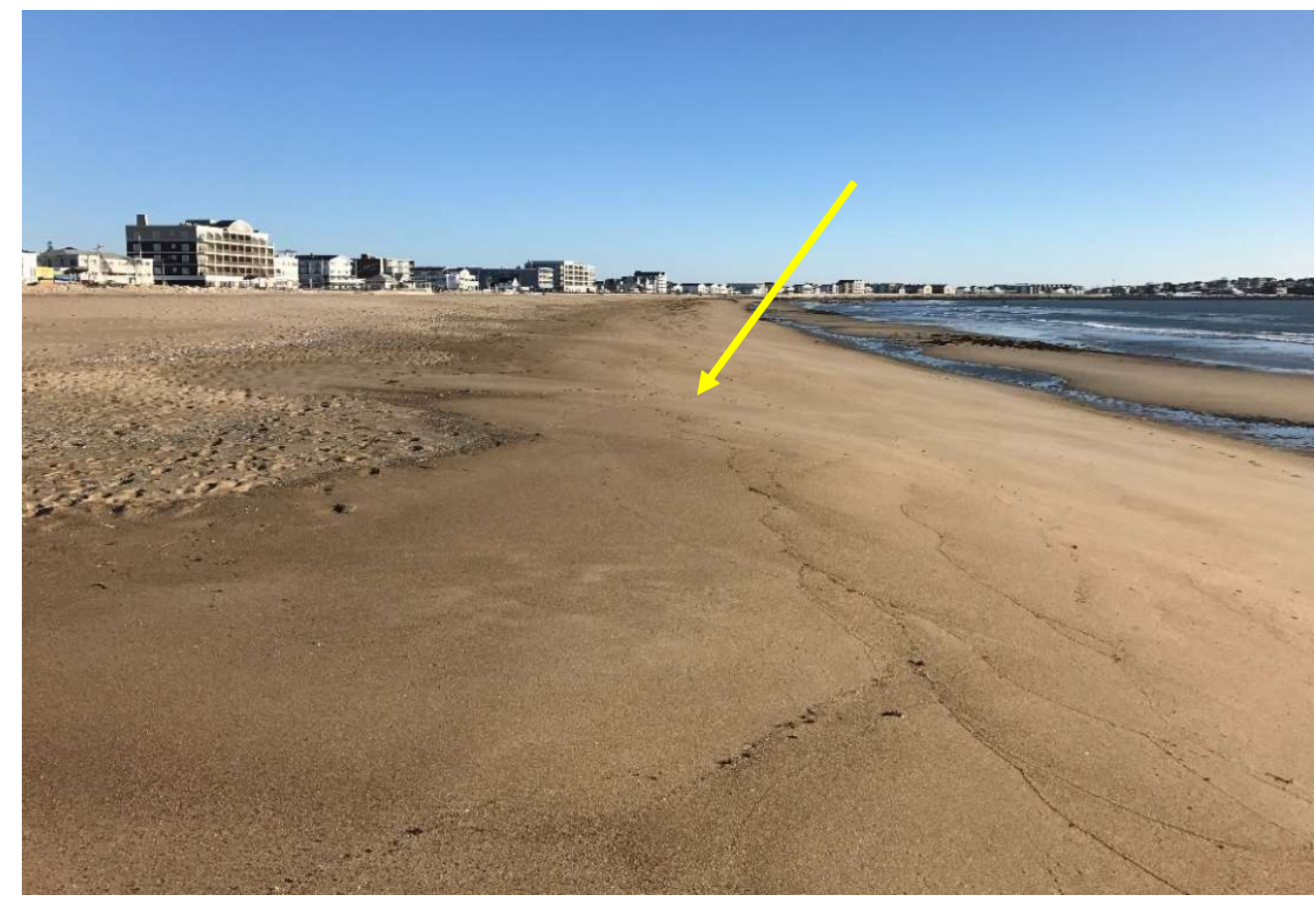

Figure HB02-10. Hampton Beach at HBO2 looking north on March 18, 2017 following a series of nor'easters. Note the berm has been flattened and eroded (arrow). The elevation profile is shown in Figure HB02-9.

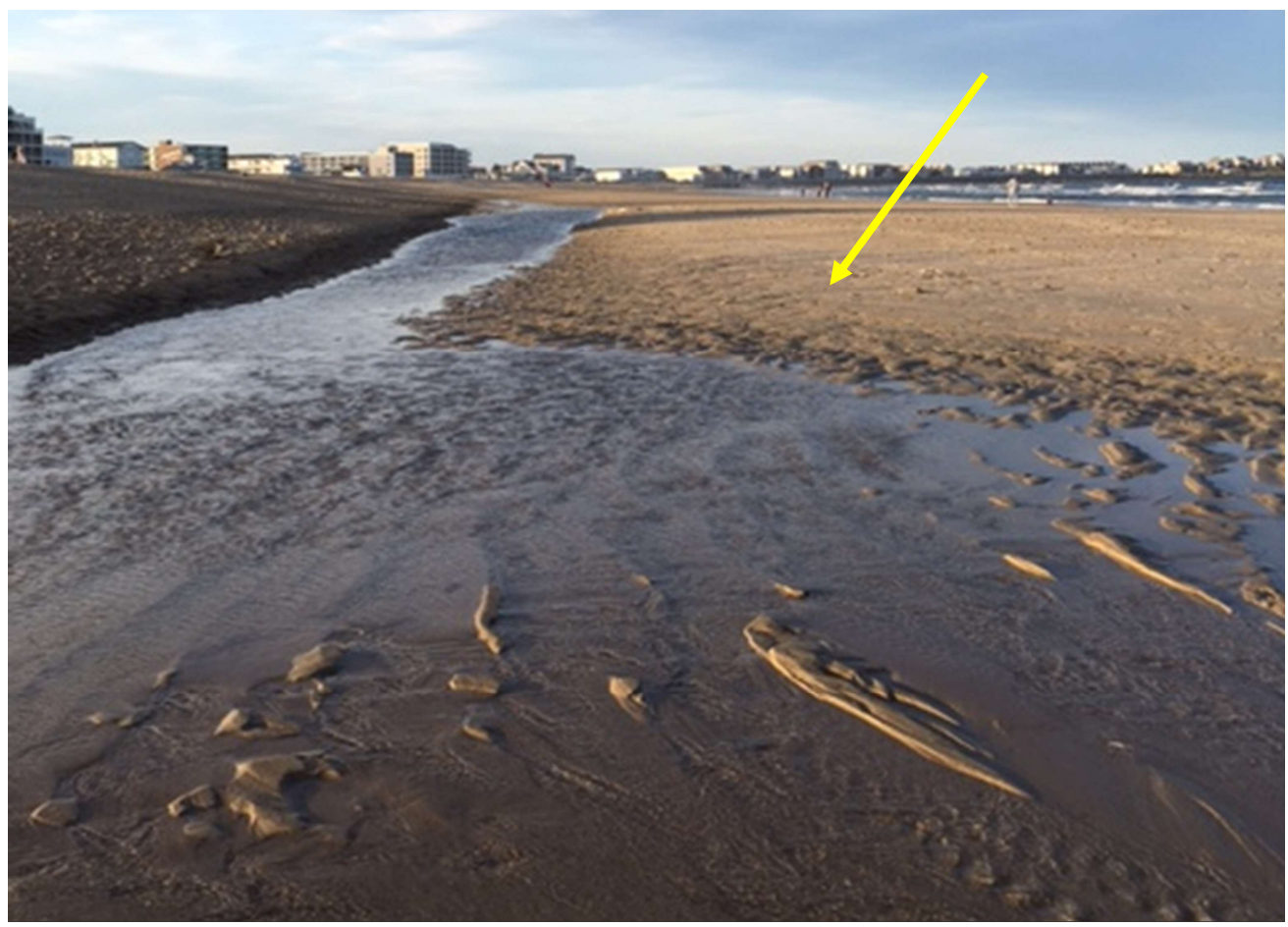

Figure HB02-11. Ridge or sand bar (arrow) migrating across the lower beach at HBO2 on April 10, 2017. The photograph is looking north from the HBO2 elevation profile. The beach elevation profile that correspond to this photo are shown in Figure HBO2-9. 

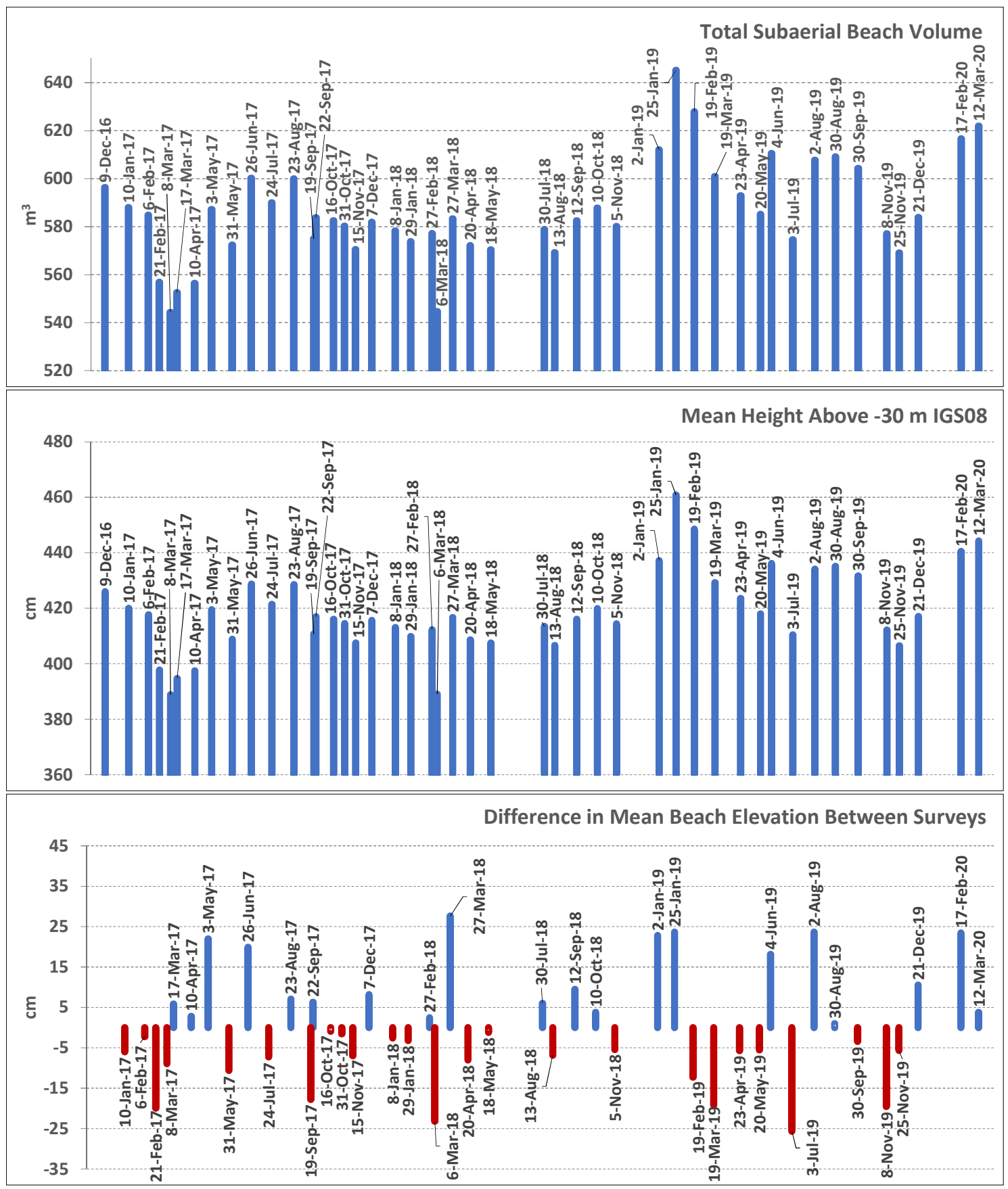

Figure HB02-12. Calculated sediment volume, mean profile elevation, and mean elevation change for the beach profile at station HB02. These parameters were calculated from 0-140 $\mathrm{m}$ of the profile length. Twelve of the forty-six elevation profiles were shorter than the "standard profile length" for the station $(140 \mathrm{~m})$. These profiles were extended using the procedure described in Chapter 2: Methods. However, all but four of these were extended less than $10.0 \mathrm{~m}$ which is considered negligible (five were less than or equal to $5.0 \mathrm{~m}$ ). Two of the longer extensions (11.0 m on February 21, 2017 and March 27, 2018) occurred following major storms when the beach was extremely eroded. One of the largest extensions $(14.0 \mathrm{~m}$ on September 22, 2017) was needed after the large wave field created by Hurricane Jose eroded the beach. The other larger extension $14.0 \mathrm{~m}$ on July 30, 2018) occurred following the period of erosion in later winter 2018 when the lower beach was still in recovery. 


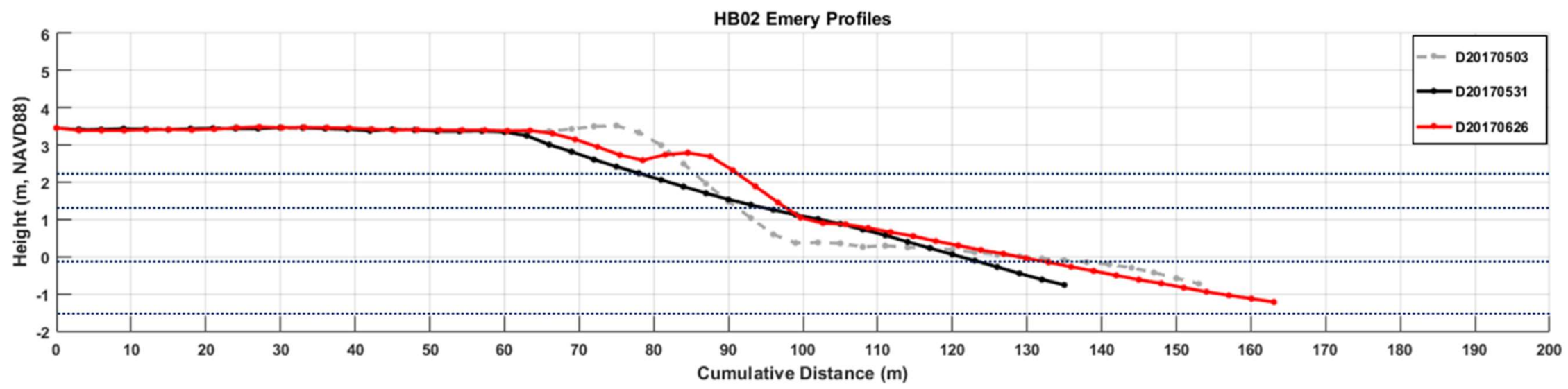

Figure HB02-13. Beach elevation profiles for HBO2 on May 3, 2017, May 31, 2017 and June 26, 2017.

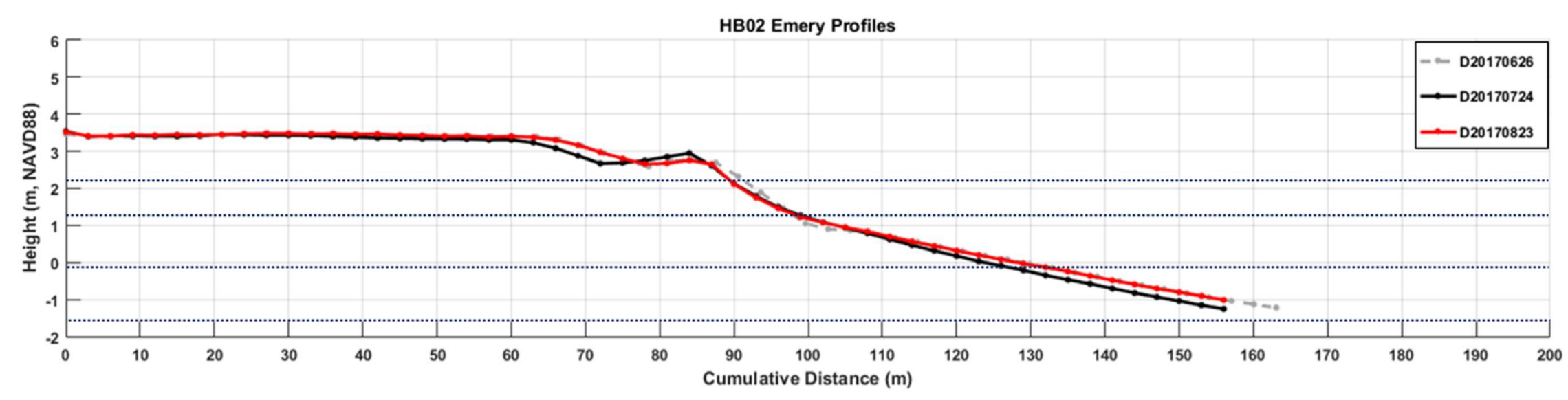

Figure HB02-14. Beach elevation profiles for HBO2 on June 26, 2017, July 24, 2017, and August 23, 2017. 
Starting in fall 2017, the profile elevation at HBO2 decreased, the berm retreated, and the sediment volume decreased. The cause of these changes is not entirely clear but appear to be at least partially the result of the large wave field created by Hurricane José that effected the NH coast from September 21-22, 2017 (Table 3-3). The berm that had built up following the flattening of the beach by the NH Division of Parks and Recreation was removed (Figure HB02-15). A series of winter storms including Philippe (Oct 29-30, 2017), Grayson (Jan 3-5, 2018), Inga (Jan 17-18) and an unnamed winter storm (Jan 29-31) further eroded the beach at HB02 causing a lowering of elevation and the berm to retreat (Figure HB02-16).

As a result of the beach already being lower and narrower, HBO2 was significantly eroded by the intense Nor'easter Riley in late winter 2018 (Mar 1-4). During Riley, the berm crest retreated $30 \mathrm{~m}$ landward and lowered $\sim 1.4 \mathrm{~m}$. In addition, the backshore increased in elevation by $\sim 0.3 \mathrm{~m}$ due to the storm surge transporting sand from the lower beach to the upper beach (Figure HB02-17). Sediment volume calculations indicate $\mathrm{HBO} 2$ lost a significant volume of sand and the average elevation of the beach from the seawall to $140 \mathrm{~m}$ seaward (approximately MLLW) decreased $0.2 \mathrm{~m}$ (Figure HB0212). Following Riley, the beach rapidly rebuilt with the berm increasing in elevation by $\sim 1.4 \mathrm{~m}$ and migrating 50 m seaward by March 27 (Figure HB02-18). The sediment volume increased, and the mean elevation increased by $\sim 0.3 \mathrm{~m}$.

Interestingly, the sequence of severe storms that followed Riley including Quinn (Mar 6-9, 2018) and Skylar (Mar 12-14), as well as unnamed storms with significant wave heights (Mar 21-23 and Apr 1517) seemingly did not have a major impact on $\mathrm{HBO2}$, even though they continued to significantly erode most other beaches in $\mathrm{NH}$. However, this may be misleading as indicated by the elevation profiles from March 27 and April 20 (Figure HB02-18). These elevation profiles do not extend as far seaward as normal due to these areas becoming subtidal, which is an indication that the low tide terrace may have been severely eroded. Therefore, it is likely these events at HB02 caused erosion of the lower beach, but also deposition and an increase in elevation of the upper beach (Figure HB0218). The seaward migration and increase in elevation of the berm by $\sim 1.8 \mathrm{~m}$ is likely the result of wave action eroding the lower beach and the storm surge pushing the sand to the backshore. Unfortunately, this cannot be accounted for in the volume calculations. 


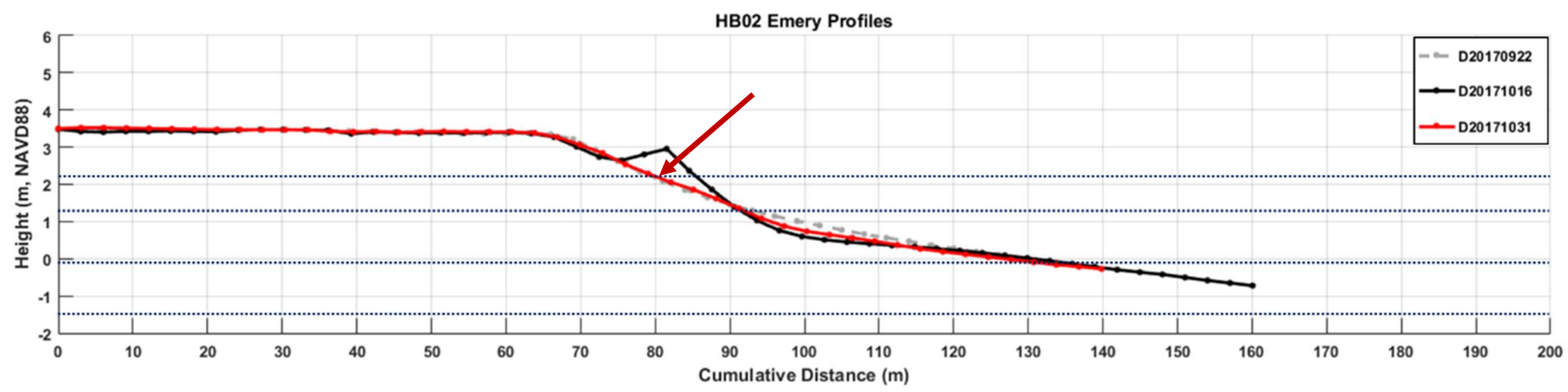

Figure HB02-15. Beach elevation profiles for HB02 on September 22, 2017, October 16, 2017, and October 31, 2017. Note the berm retreat that was occurring (arrow).

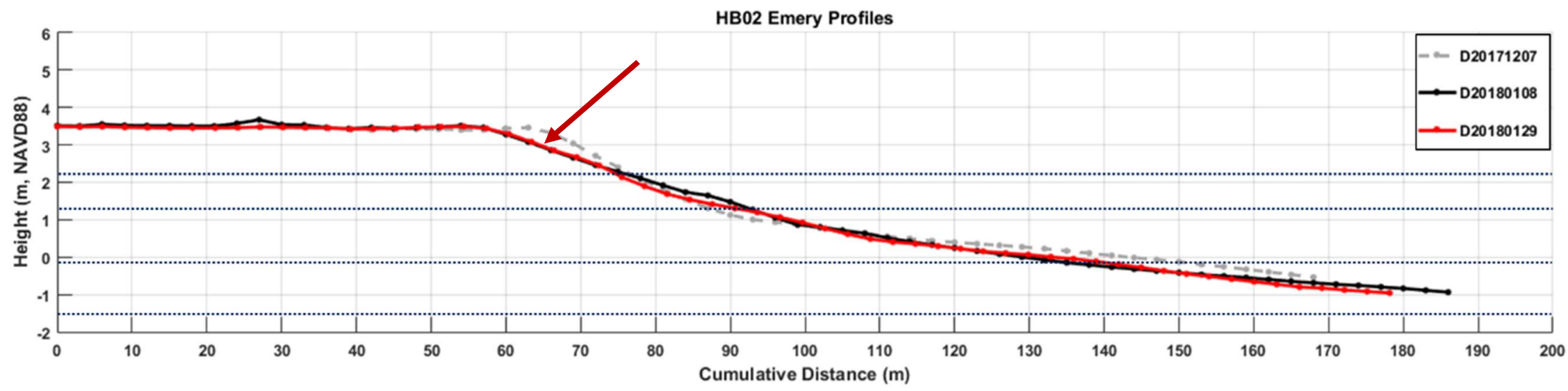

Figure HB02-16. Beach elevation profiles for HBO2 on December 7, 2017, January 8, 2018, and January 29, 2018. Note the berm retreat that was occurring (arrow). 


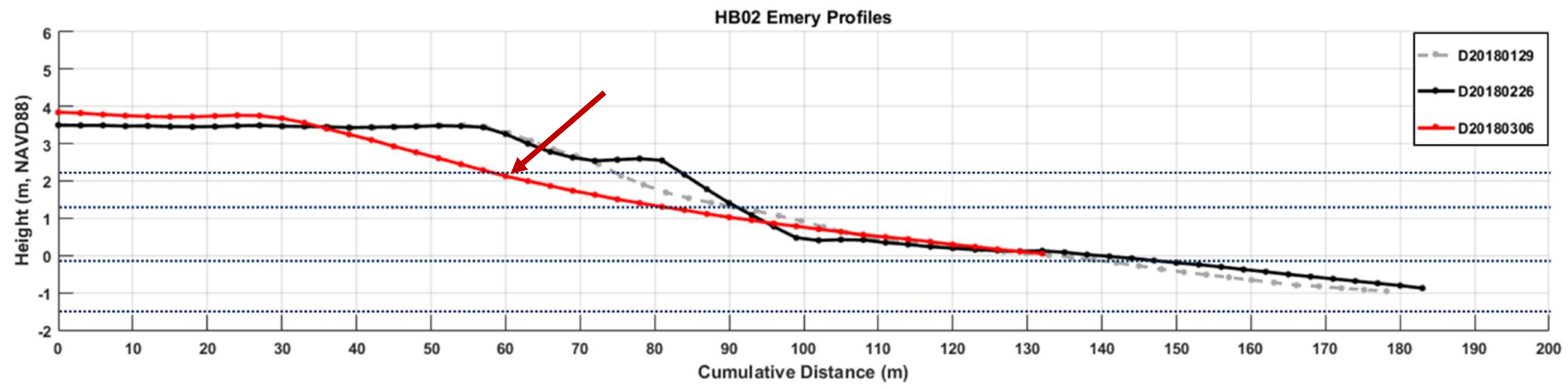

Figure HB02-17. Beach elevation profiles for HB02 on January 29, 2018, February 26, 2018, and March 6, 2018. Note the erosion of the berm that occurred following Nor'easter Riley (arrow).

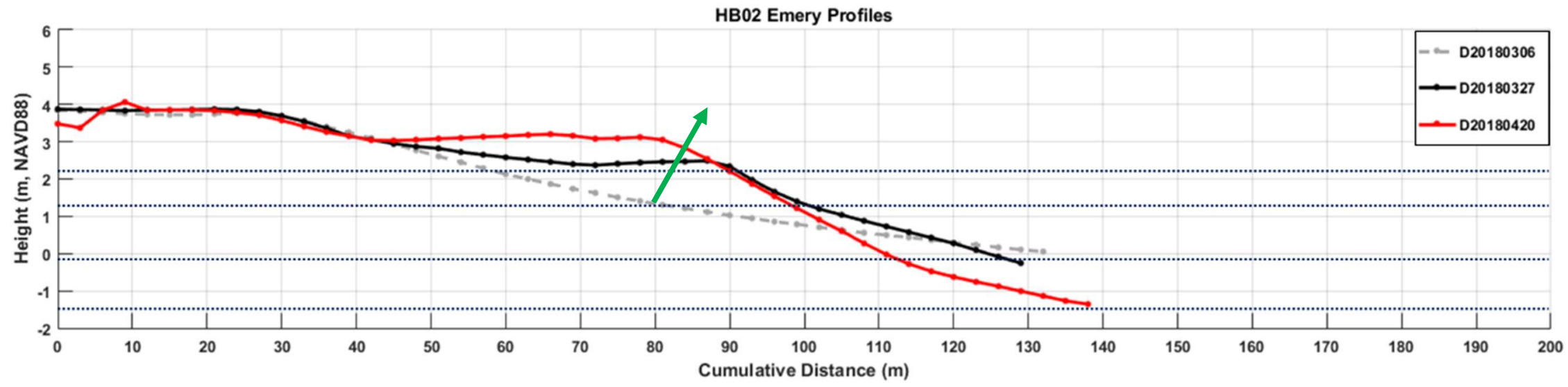

Figure HB02-18. Beach elevation profiles for HBO2 on March 6, 2018, March 27, 2018, and April 20, 2018. Note the apparent recovery of the beach after the series of winter storms in March 2018 (arrow). This may be a result of redistribution of sand that had initially been displaced after these storms. 
The beach profile, elevations, and sediment volumes at HBO2 remained relatively low for Hampton Beach, but consistent over summer and fall 2018 (Figure HB02-12; Appendix C). In winter 2019 the beach increased in elevation and volume reaching maximum values on January 25 and February 19, 2019 (Figures HB02-12 and HB02-19). The increase in elevation and volume largely resulted from the landward migration and welding of a large ridge and runnel system onto the berm. The NH Division of Parks and Recreation also constructed a large berm near the seawall to prevent a repeat of the overwash that occurred during the severe nor'easters in late winter 2018 (Figure HB02-20). However, the human-made berm was constructed from sand from the upper beach and did not likely change the sand volume calculations significantly. It is unclear why the beach would show accretion during winter 2019 as several major storms occurred which eroded other $\mathrm{NH}$ beaches, including the Nor'easters Harper (Jan 19-20, 2019) and Maya (Feb 12-13). This is something that will have to be further evaluated in the future.

Following the highest sand volume and mean elevation for the entire study on January 25, 2019, the beach at HB02 lost elevation and sediment volume in late winter through early summer 2019 (March 19 to July 3) with June 4 being the only exception (Figure HB02-12). On June 4, the berm had built seaward which added some sand volume to the beach (Figure HB02-21). Although there was some erosion on July 3 , the beach maintained an accretionary profile until fall 2019. However, the impact of subtropical storm Melissa (Oct 11-13), a fast-moving unnamed nor'easter (Oct 16-17), and a king tide coastal flood (October 28) eroded HBO2 with berm retreat, loss of profile elevation, and loss of sediment volume seen in the November 8 and 25, 2019 profiles (Figures HB02-12 and HB02-22). The beach stayed relatively low through the end of 2019, but in the beginning of 2020 another humanmade berm was constructed on the upper beach which resulted in a large increase in elevation and volume once more, although not quite as large as seen in the beginning of 2019.

Beach Manipulation by Management. An example of management manipulating Hampton Beach can be seen on the May 30, 2017 profile. On May 3 the beach had significantly recovered from the winter 2017 storms and had built a large berm (Figure HB02-13). However, the berm was removed, the berm face flattened, and the beach face slope reduced with a bulldozer (Figures HB02-3 and HB02-4). Calculation of the volume of sediment on May 30 shows a loss of sediment in the landward $140 \mathrm{~m}$ (Figure HB02-12). However, this material likely was just moved further seaward and not lost from the beach. Interestingly, and as an example of how dynamic Hampton Beach is at HBO2, a large berm had reestablished by June 26 and the sand volume had increased to levels higher than before the manipulation of the beach (Figure HB02-12, HB02-13, and HB02-14). It is likely that the flattened profile that resulted from the sand being bulldozed and the berm being removed was out of equilibrium for this location and the beach quickly adjusted its profile. 


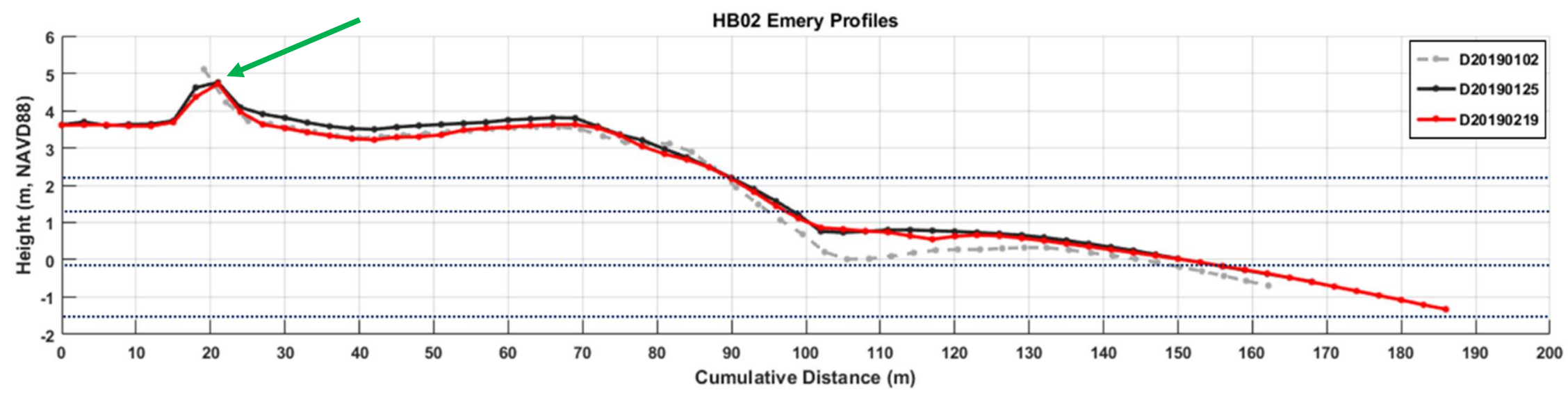

Figure HB02-19. Beach elevation profiles for HB02 on January 2, 2019, January 25, 2019, and February 19, 2019. Note the artificial berm constructed by the NH Division of Parks and Recreation to protect against possible storm damage (arrow).

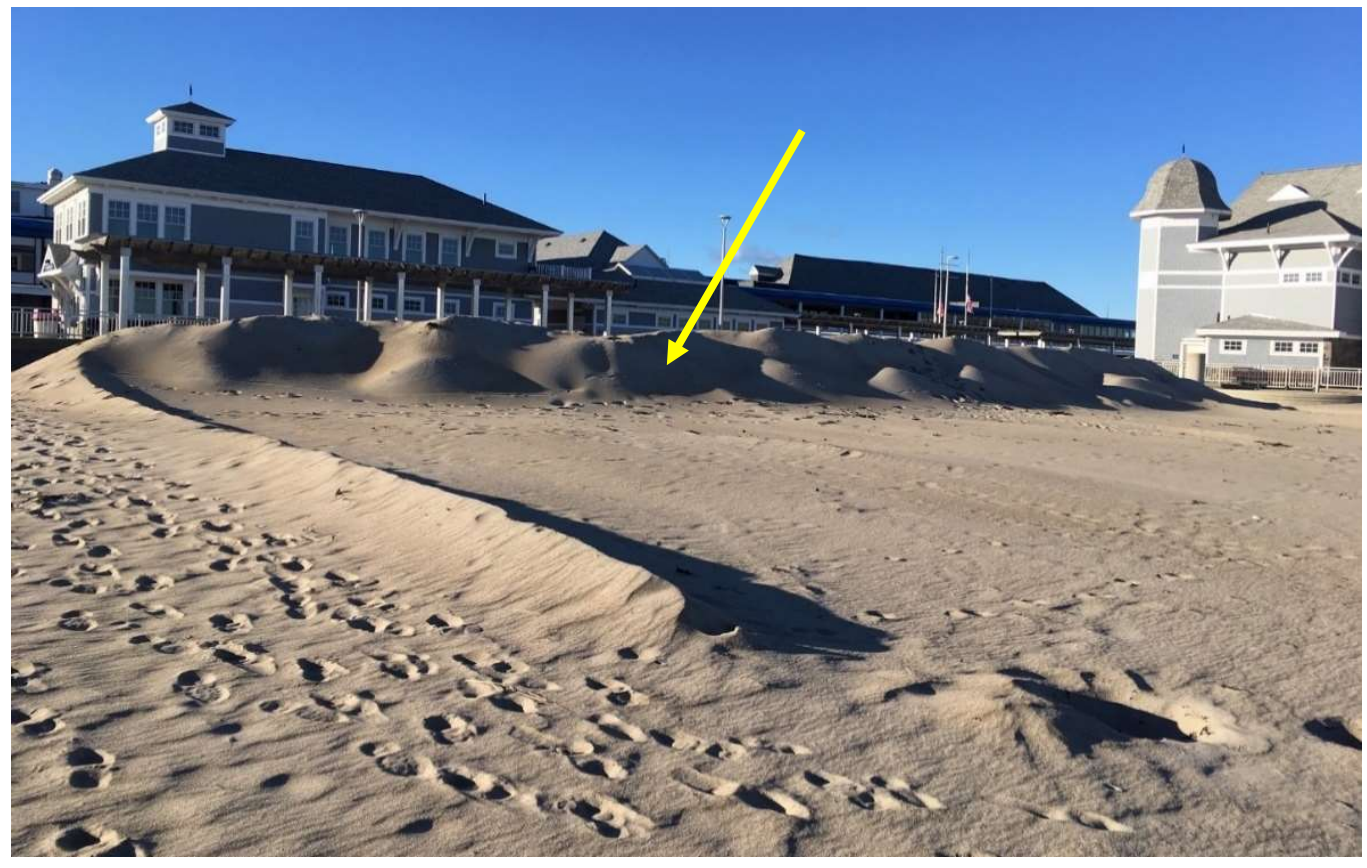

Figure HB02-20. Large berm (arrow) constructed near the seawall at HBO2 to prevent overwash (also seen in the beach profiles in Figure HB02-19 above). Photo taken on December 4, 2018 


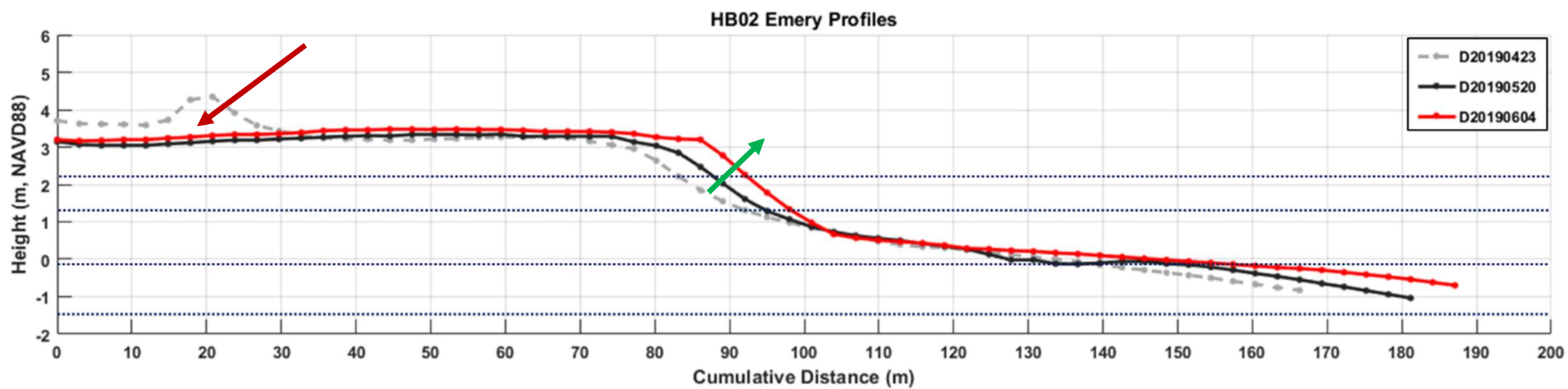

Figure HB02-21. Beach elevation profiles for HBO2 on April 23, 2019, May 20, 2019, and June 4, 2019. Note the human-made berm seen in Figure HB0219 has been removed (red arrow) through natural redistribution, and the lower berm is building seaward (green arrow).

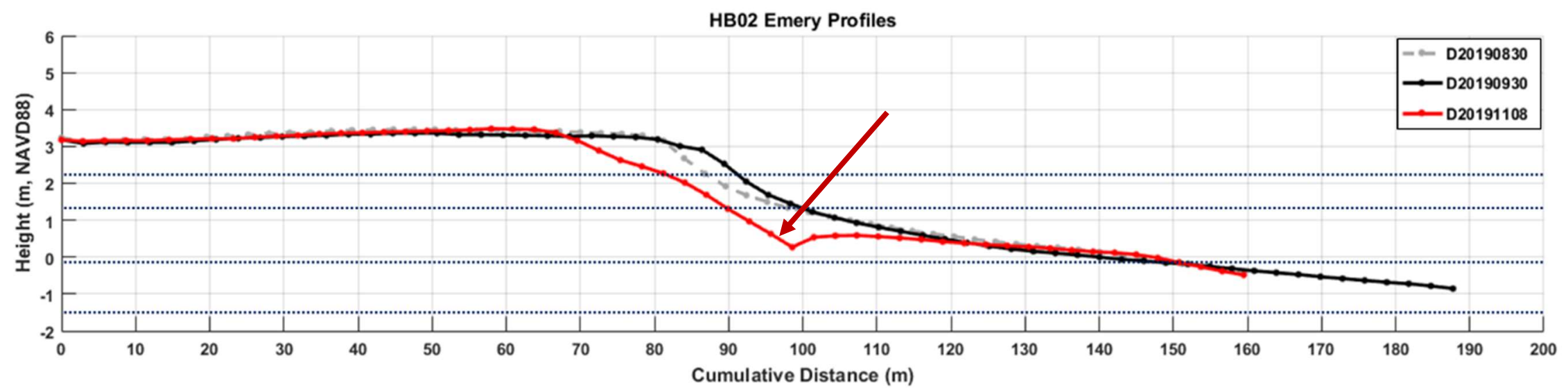

Figure HB02-22. Beach elevation profiles for HBO2 on August 30, 2019, September 30, 2019, and November 8, 2019. Note the berm retreat that occurred following a series of storms and a coastal flood in fall 2019 (arrow). 


\section{Results for Station at Hampton Beach State Park: HB04}

Overview. Profile station HBO4 is located on the southern end of Hampton Beach $\sim 0.3 \mathrm{~km}$ from the jetty at Hampton Harbor Inlet (HB-1). The beach is backed by a large dune system that is $\sim 0.1 \mathrm{~km}$ wide (Figures HB-5 and HB04-1). The beach itself is wide and relatively flat in contrast to the middle and northern reaches of Hampton Beach (Figures HB-15 and HB04-2). In general, the beach at the southern end of Hampton Beach is wider due to the net southerly longshore drift and trapping of sand by the jetty. The sediments are primarily sandy with scattered pebbles after stormy periods. The profile extends from the foredunes to the low water line (Figure HB04-3). The original seaward location marker (wooden stake) in the foredunes was lost during Nor'easter Riley in early March 2018 (Figure HB04-4). Scarps exceeding $3 \mathrm{~m}$ were eroded into dunes south of HB04 nearer the jetty (Figure HB04-5). Subsequent profiles were run from the back stakes set further into the dunes until a new front stake was reestablished and leveled (Table 3-1). Afterward, all profiles were adjusted to the new starting position. In November 2019 the southern end of Hampton Beach adjacent to the jetty was nourished with sand dredged from Hampton Harbor. Approximately 24,465 $\mathrm{m}^{3}$ ( 32,000 $\mathrm{yds}^{3}$ ) of dredged sand was placed near the jetty and spread northward with a bulldozer (Figure 2-4).

Summary. Unfortunately, the database for HB04 is incomplete with gaps in the monitoring record due to logistical issues. However, several trends in the data are consistent with observations at other stations and are consistent with observations of environmental conditions (e.g., storms). The station at the southern end of Hampton Beach at HBO4 sharply contrasts the middle and northern end of the barrier spit. The beach at $\mathrm{HBO} 4$ is very wide and typically fairly flat with a slight convex-upward profile. Nevertheless, HBO4 had elevation changes of between $\sim 0.9$ to $1.5 \mathrm{~m}$ which are very significant considering the low elevation of the beach. Evidence of these extreme changes was seen during the late winter 2018 nor'easters which caused major erosion of the beach and dunes. Afterwards the beach experienced major rebuilding, reaching a maximum sediment volume for the study period in the late summer and fall 2019. During this time large ridge and runnel systems aided in the recovery of the beach, which appear to be a major natural mechanism for rebuilding Hampton Beach. Following this rebuilding episode, the beach was again eroded by winter storms in 2019. In fall 2019 the southern end of Hampton Beach had a large amount of sand placed near the jetty. Although it was placed 200 to 300 m south of the study site at HB04, there seems to be some indication that the sand was added to the profile. However, by the end of the study period in March 2020 no effect of sand placement was apparent. 

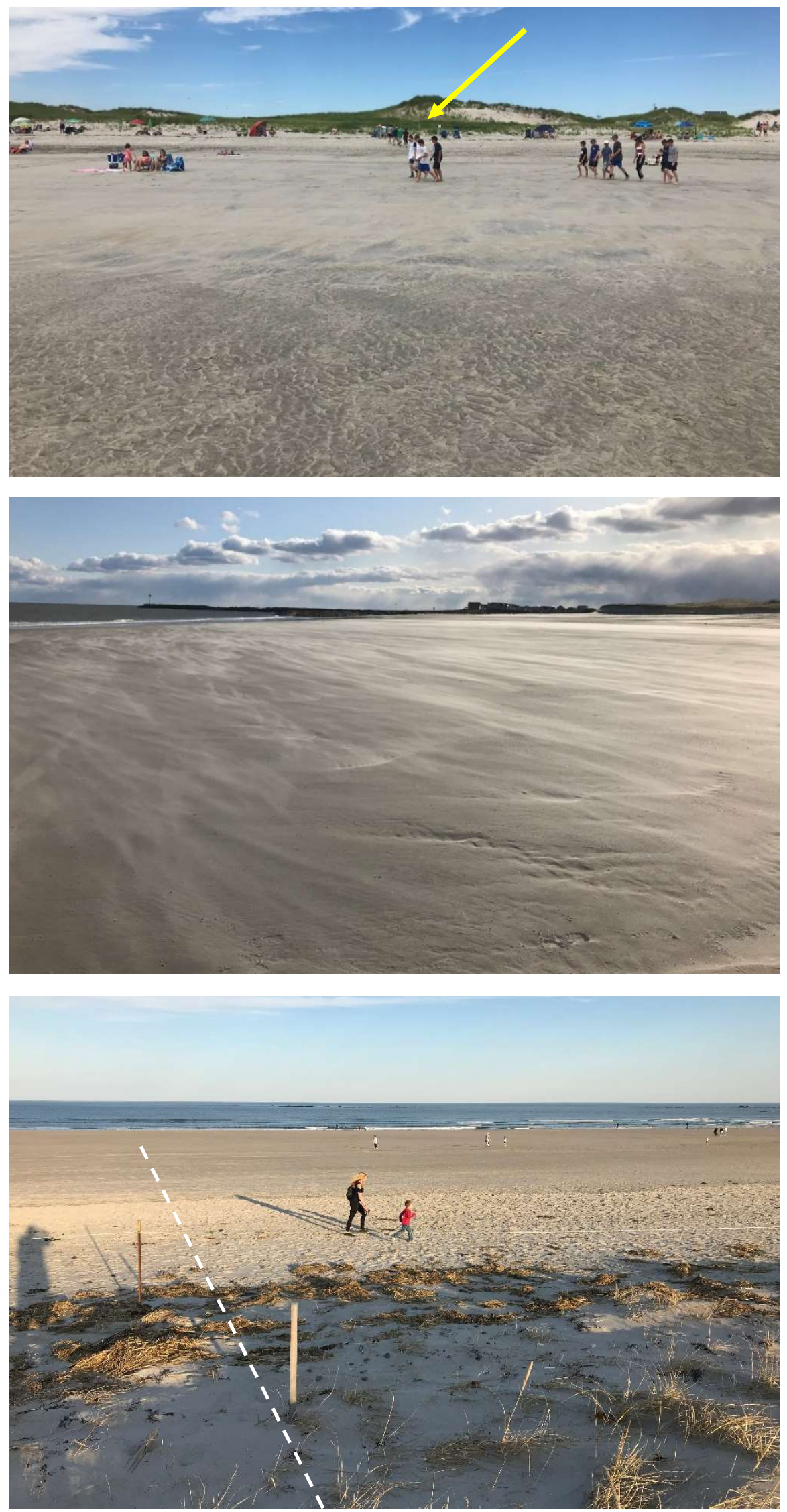

Figure HB04-1.

Extensive dune system that backs the southern $\sim 0.4 \mathrm{~km}$ of Hampton Beach. This photograph taken on July 8, 2019 shows the dunes directly behind station HB04. The station marker is in the foredunes (arrow).

Figure HB04-2. The beach at HBO4 is typically wide and flat as shown here on November 8, 2019. Note the sand blowing across the beach on a very windy and cold day.
Figure HB04-3. Approximate position of HB04 Beach elevation profile (dashed line), beginning at the station marker post. The photograph was taken on March 9, 2020. 


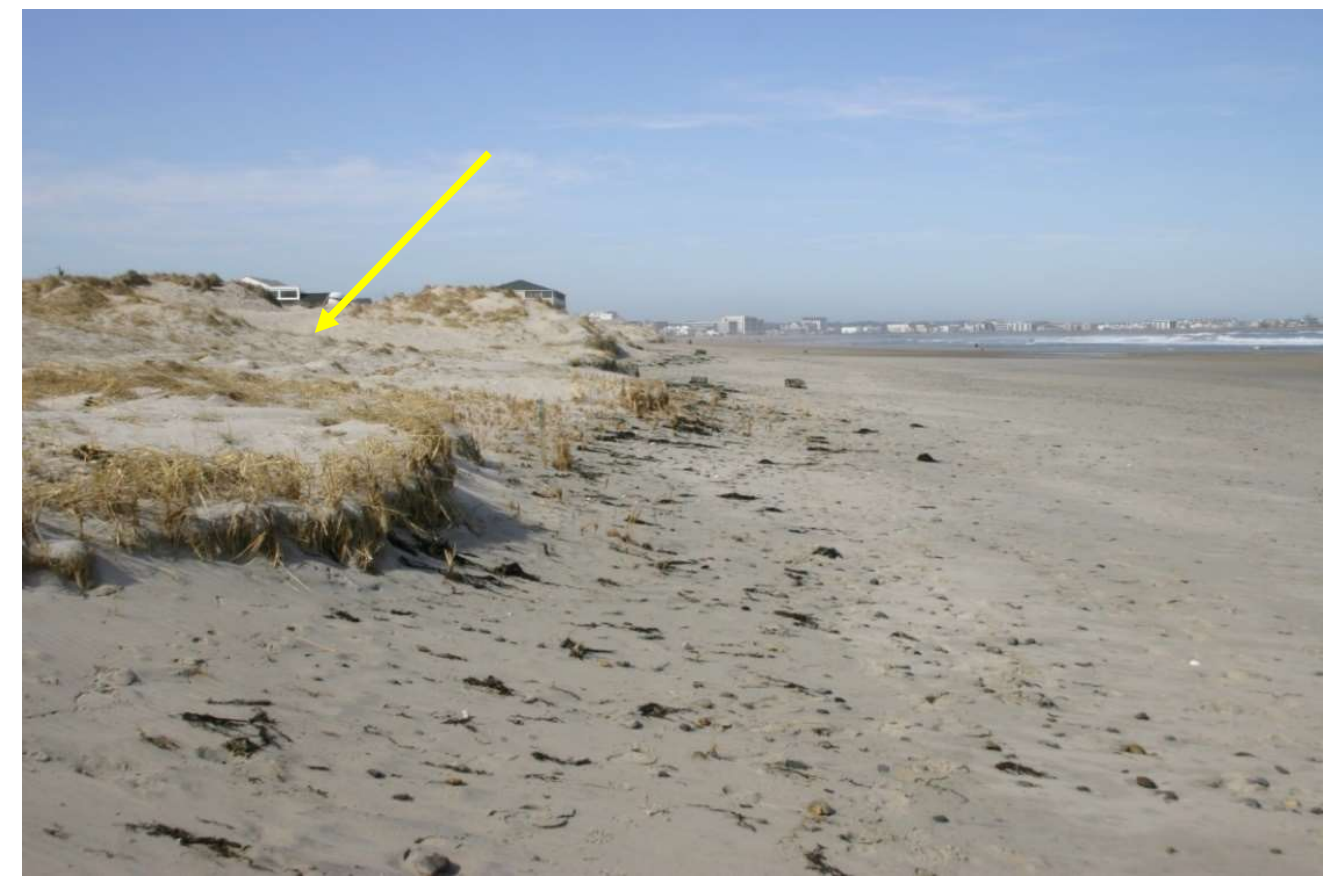

Figure HB04-4. Station HBO4 following the severe nor'easters of March 2018. The photograph was taken on March 28, 2018 and is looking north where the station marker stakes were located. The back stake can be seen (arrow), but the front stake was eroded in the foredunes and was lost in the storms.

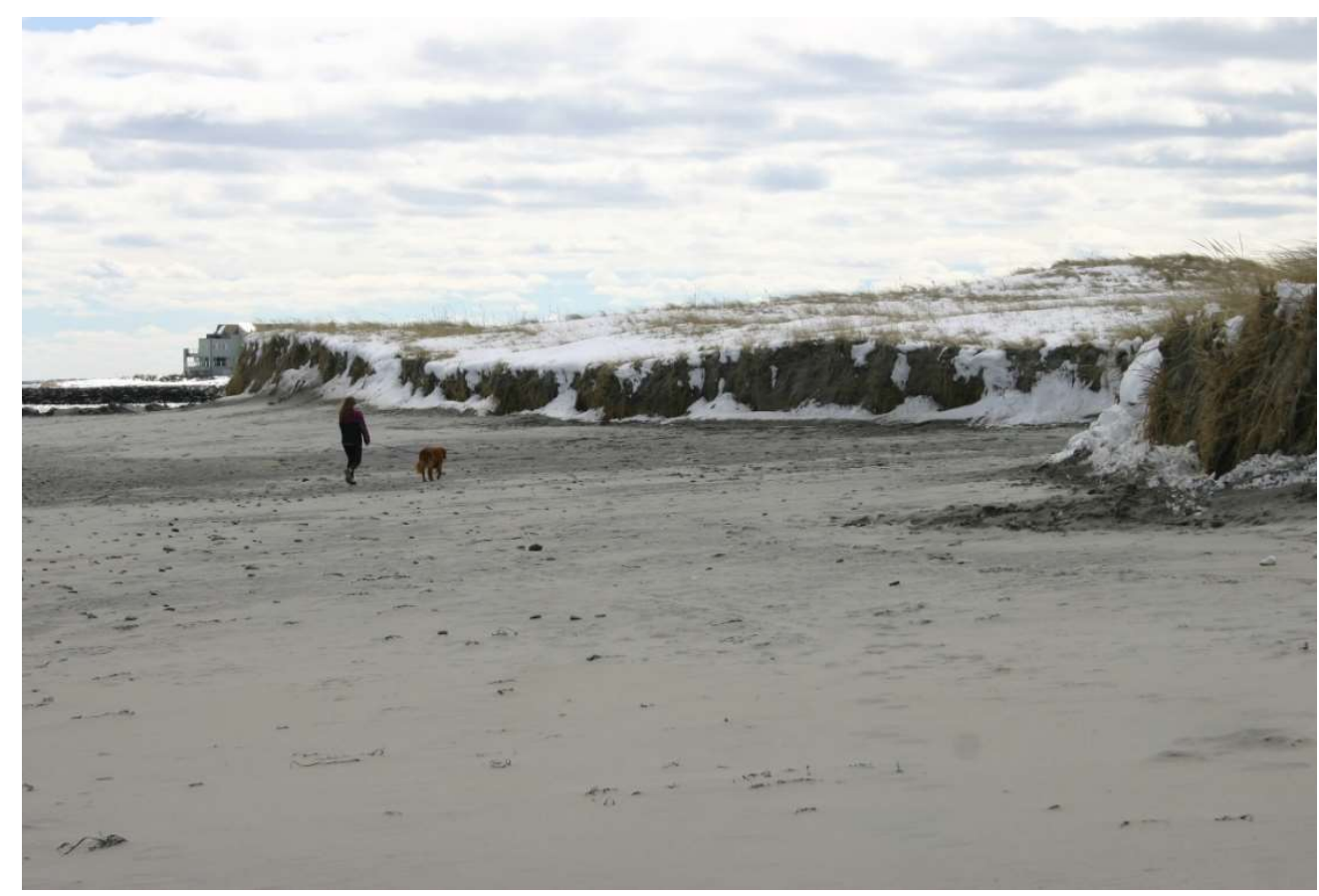

Figure HB04-5. Eroded dunes south of station HBO4 (southern end of Hampton Beach) after the March 2018 nor'easters. The photograph is looking south on March 15, 2018. 
General Profile Characteristics. The beach elevation profile at HBO4 was measured twenty-three times between February 28, 2018 and March 9, 2020. All plotted beach profiles can be found in Appendix $C(10)$. Unfortunately, due to a number of logistical problems the profile was not run consistently at three- to four-week intervals over the approximately twenty-two-month period and several gaps exist in the database including the five-month period between April to August 2018 and the months of May and October 2019. Part of the extended period in summer 2018 was due to the nesting of piping plovers (Charadrius melodus) in the dunes near the station. Plovers are a threatened species at the federal level and an endangered species in $\mathrm{NH}$; therefore, they are legally protected and profile stations near plover nesting sites are coordinated with NH Fish and Game during nesting season. Summer 2019 profiles were able to be conducted without data gaps as a result of the timing and location of plover nesting activities that year. Photographs of plover nests can be found in the next section on Seabrook Beach at SB04.

The beach elevation profiles at HB04 were typically 140 to $170 \mathrm{~m}$ in length. Examination of the sweep zone shows the elevation of the beach varied $\sim 1.2 \mathrm{~m}$ close to the dunes in the upper beach, $\sim 1.6 \mathrm{~m}$ at the berm, $0.9 \mathrm{~m}$ at mid-beach, and $\sim 1.6 \mathrm{~m}$ at low water (Figure HB04-6). Considering the general flatness of the beach at $\mathrm{HBO4}$, these are large elevation changes and reflect significant changes in the beach due to erosion and accretion processes. Comparison of the minimum average elevation profile (which occurred on March 12, 2018) with the maximum average elevation profile (which occurred on September 17, 2018) shows an average difference of $\sim 0.7 \mathrm{~m}$ ranging from $\sim 1.5 \mathrm{~m}$ at the berm and $\sim 0.9 \mathrm{~m}$ near low water (Figure HB04-7). Again, considering how flat the beach typically is at HB04, a 1.6 m difference is extremely large. At the lower elevation the entire intertidal beach would be inundated leading to dune erosion. 


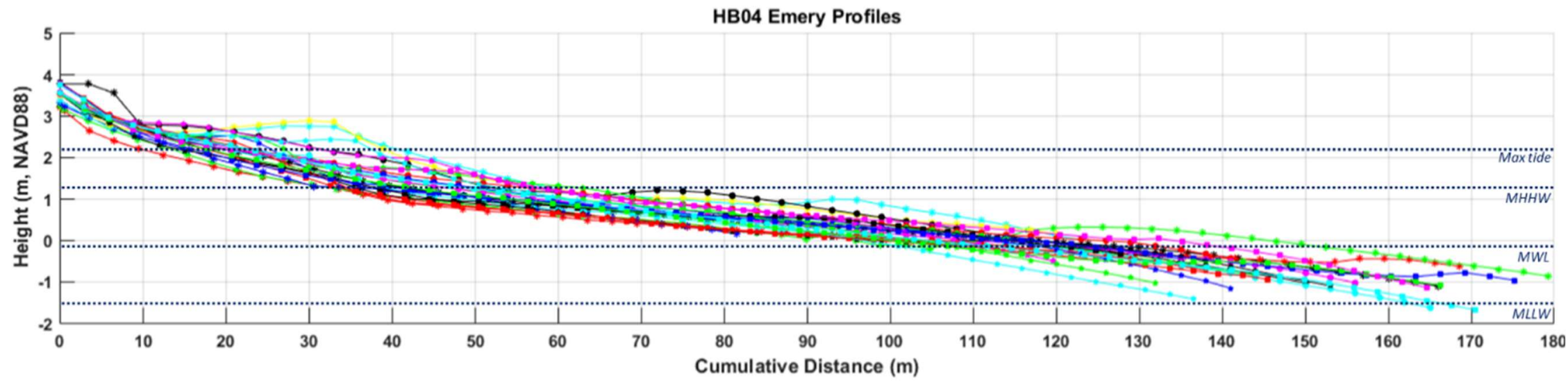

Figure HB04-6. All twenty-three beach elevation profiles measured at station HB04 between February 28, 2018 and March 9, 2020. Maximum tidal elevation (max tide), mean higher high water elevation (MHHW), mean water level (MWL), and mean lower low water elevation (MLLW) are indicated by the dotted lines.

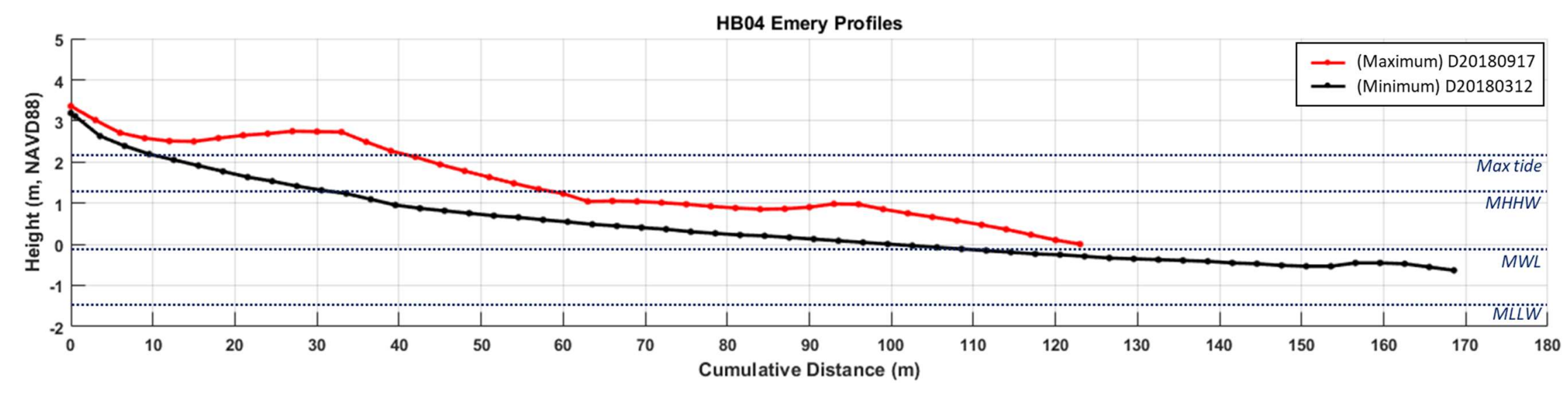

Figure HB04-7. Maximum (September 17, 2018) and minimum (March 12, 2018) beach elevation profiles from the study period at station HB04. Note that this is not the impact of a single event as the profiles are not consecutive monitoring dates. Rather this comparison looks at the extreme of differences of beach elevation profiles over the entire study period. 
Storm Effects, Beach Erosion, and Recovery. The beach profile at the start of the study on February 28, 2018 was relatively low and featureless and indicative of erosional conditions. This notion is reinforced by the associated sediment volume calculation which was relatively low prior to the storms (Figure HB04-8). Therefore, when the series of severe nor'easters occurred in late winter 2018 including Riley (Mar 1-4), Quinn (Mar 6-9), and Skylar (Mar 12-14) (Table 3-3), the beach at HBO4 was already at a low elevation. During Riley and Quinn, the beach profile lost $\sim 0.7 \mathrm{~m}$ of elevation near the foredunes (Figure HB04-9) and an average elevation loss across the entire profile of $\sim 0.3 \mathrm{~m}$ (Figure HB04-8). Interestingly, despite the storms, a ridge and runnel was developing on the lower beach indicative of sand returning to the beach (Figure HB04-10).

The sediment volumes following these storms were the lowest computed for the study period at this station (Figure HB04-8). As noted above, the foredunes at the beginning of the profile were eroded back several meters, removing the station marker, and leaving an approximately $0.5 \mathrm{~m}$ high scarp at the beginning of the profile. Evidence that the beach was starting to recover from the nor'easters can be seen on the beach elevation profile on March 29, 2018 with the development of a large ridge and runnel system on the lower beach (Figures HB04-9, HB04-10, and HB04-11). Ridge and runnel systems form as a result of landward transport of sand across the beach as the profile rebuilds. Unfortunately, the station was not profiled again until almost fall 2018 and evidence of the timing of recovery of the beach at HBO4 was not measured. A partial profile was run on April 22, but only the upper half of the beach was covered. 

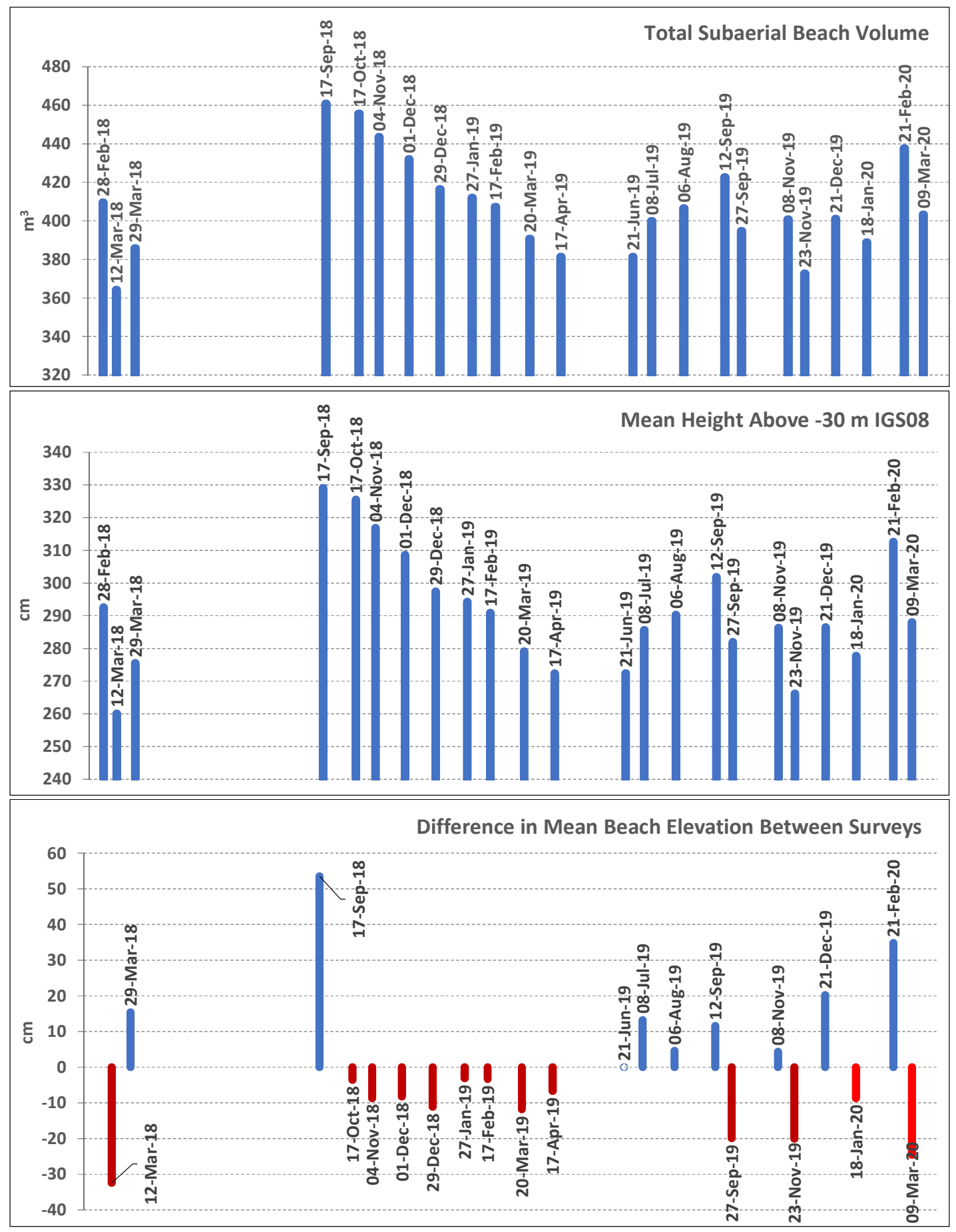

Figure HB04-8. Calculated sediment volume, mean profile elevation, and mean elevation change for the beach profile at station HBO4. These parameters were calculated from 0-140 $\mathrm{m}$ of the profile length. Eight of the twenty-three elevation profiles were shorter than the "standard profile length" for the station (140 m). These profiles were extended using the procedure described in Chapter 2: Methods. Four of the profiles were extended less than $8.0 \mathrm{~m}$ which is considered negligible (three were five meters or less). The largest extensions (12.3 $\mathrm{m}$ on September 17, 2018, $17.0 \mathrm{~m}$ on October 17, 2018, $20.4 \mathrm{~m}$ on September 12, 2019, and $20.0 \mathrm{~m}$ on Nov 8, 2019) occurred during neap tides when the water level did not drop as much as during spring tides. 


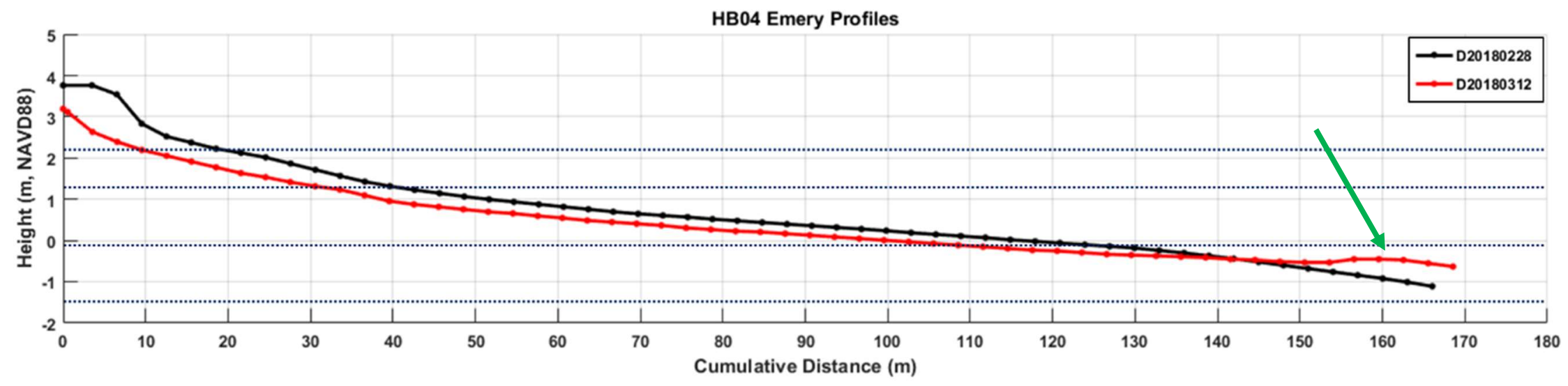

Figure HB04-9. Beach elevation profiles for HBO4 on February 28, 2018 and March 12, 2018. The March 12 profile reflects the severe erosion that occurred during two March 2018 nor'easters (Riley and Quinn). However, a third nor'easter occurred starting on March 12 (Skylar). Note that a small ridge (arrow) has formed in the lower intertidal shown in Figure HB04-10.

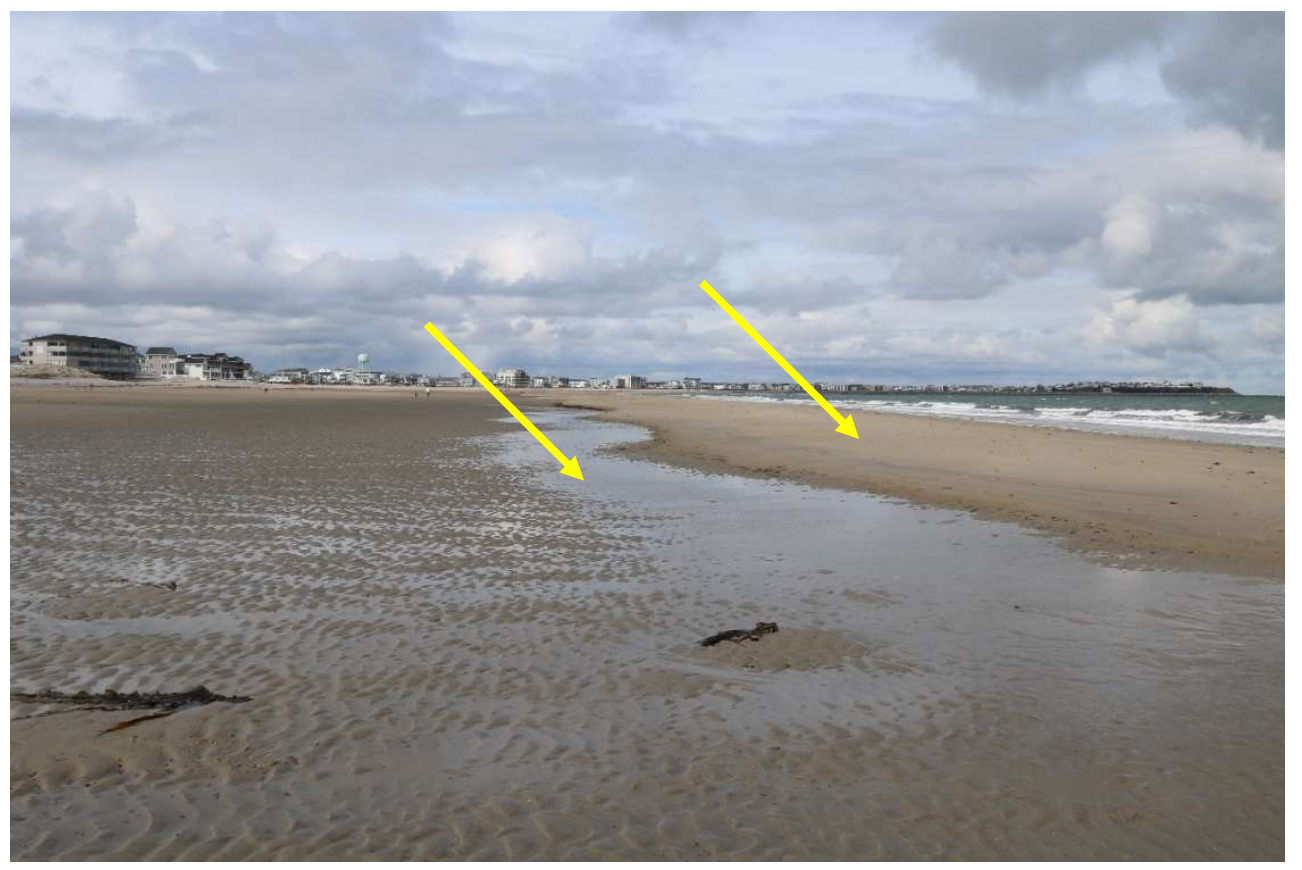

Figure HB04-10. Ridge and runnel on lower beach at HB04 on March 12, 2018. The photograph is looking north. Ridges are sand bars migrating landward (right arrow). The runnel is the low area landward of the ridge (left arrow). The ridge and runnel can be seen on the beach elevation profile shown in Figure HB04-9. 


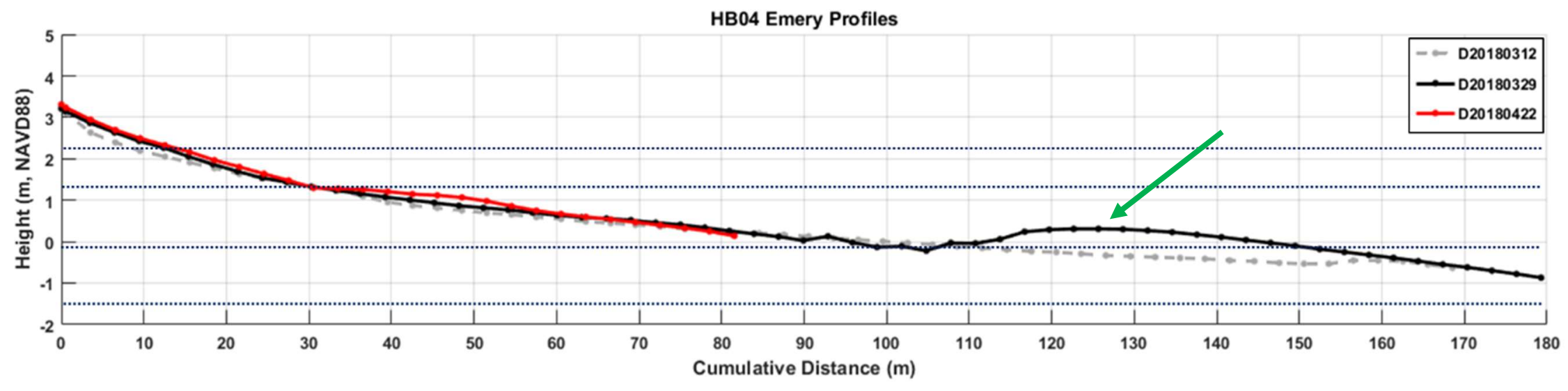

Figure HB04-11. Beach elevation profiles for HB04 on March 12, 2018, March 29, 2018, and April 22, 2018. A large sand bar or ridge (arrow) formed on the lower beach on March 29 indicative of sand being transported landward. 
Clearly the beach area at HBO4 rebuilt over the spring and summer 2018. The elevation profile measured on September 17 shows $\sim 1.5 \mathrm{~m}$ of accretion on the upper beach with the formation of a well-developed berm (Figures HB04-12 and HB04-13). The lower beach accreted $\sim 0.9 \mathrm{~m}$ and a ridge and runnel system was present. The beach maintained the accretional profile through the October 17 profile. Examination of the sediment volume and mean beach elevation calculations for September 17 and October 17, 2018 are at a maximum for the study period (Figure HB04-8).

HB04 profile elevation, sediment volume, and mean elevation steadily declined from fall to winter 2018 and spring 2019 (Figures HB04-8 and HB04-14). The somewhat strikingly consistent decline in elevation and sediment volume likely resulted from the string of storms and unnamed high wave energy events starting with Winter Storm Avery (Nov 15-16, 2018) and including the Nor'easters Harper (Jan 19-20, 2019) and Maya (Feb 12-13) (Table 3-3). The sand volume and average elevation continued to decline until April 17, 2019 (Figures HB04-8 and HB04-15). The beach rebuilt over the summer months reaching the highest sediment volume and mean elevation for 2019 on September 12 (Figure HB04-16). However, the elevations and volumes were significantly below those measured in late summer and early fall 2018. The sand volumes from September 2019 through March 2020 varied going through periods of erosion and accretion with no real trends developing (Figure HB048).

In November 2019, 24,465 $\mathrm{m}^{3}$ ( 32,000 yds ${ }^{3}$ ) of sand added to the southern end of Hampton Beach with material dredged from Hampton-Seabrook Harbor. Surprisingly, no clear signal was seen at HBO4 which is about 200 to $300 \mathrm{~m}$ north of the sand nourishment site. There was some increase in sand volume at HBO4 on December 21, 2019 that likely was a result of the beach nourishment, as well as a major increase in sand volume on February 21, 2020 (Figure HB04-8). However, there is not enough information to determine if this was related to the sand placed on the beach in late fall 2019. Regardless, no further impact was seen by the March 9, 2020 monitoring (Figure HB04-8). 


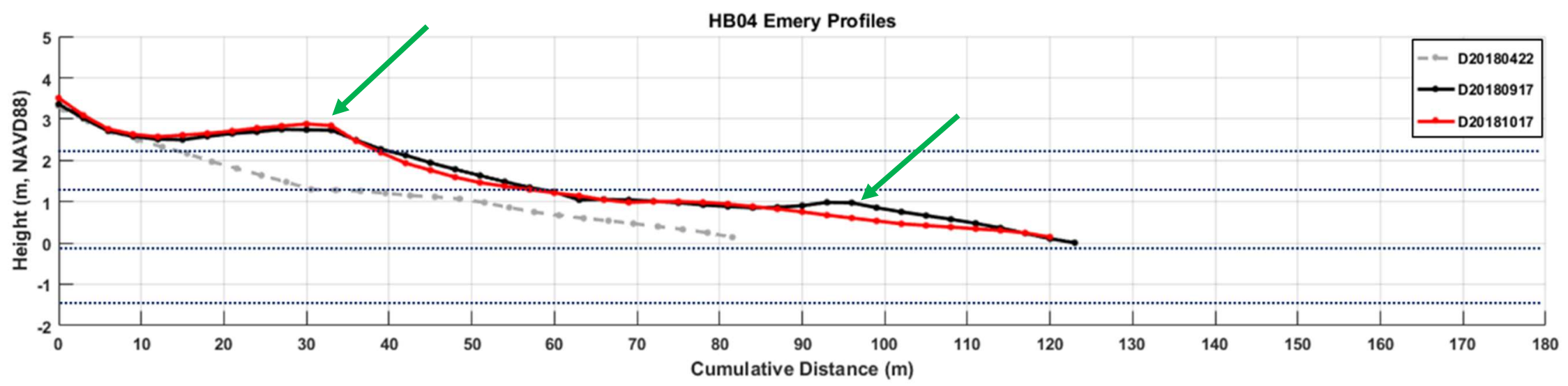

Figure HB04-12. Beach elevation profiles for HBO4 on April 22, 2018, September 17, 2018, and October 17, 2018. Note the large berm on the upper beach (left arrow) and the ridge and runnel on the lower beach (right arrow).

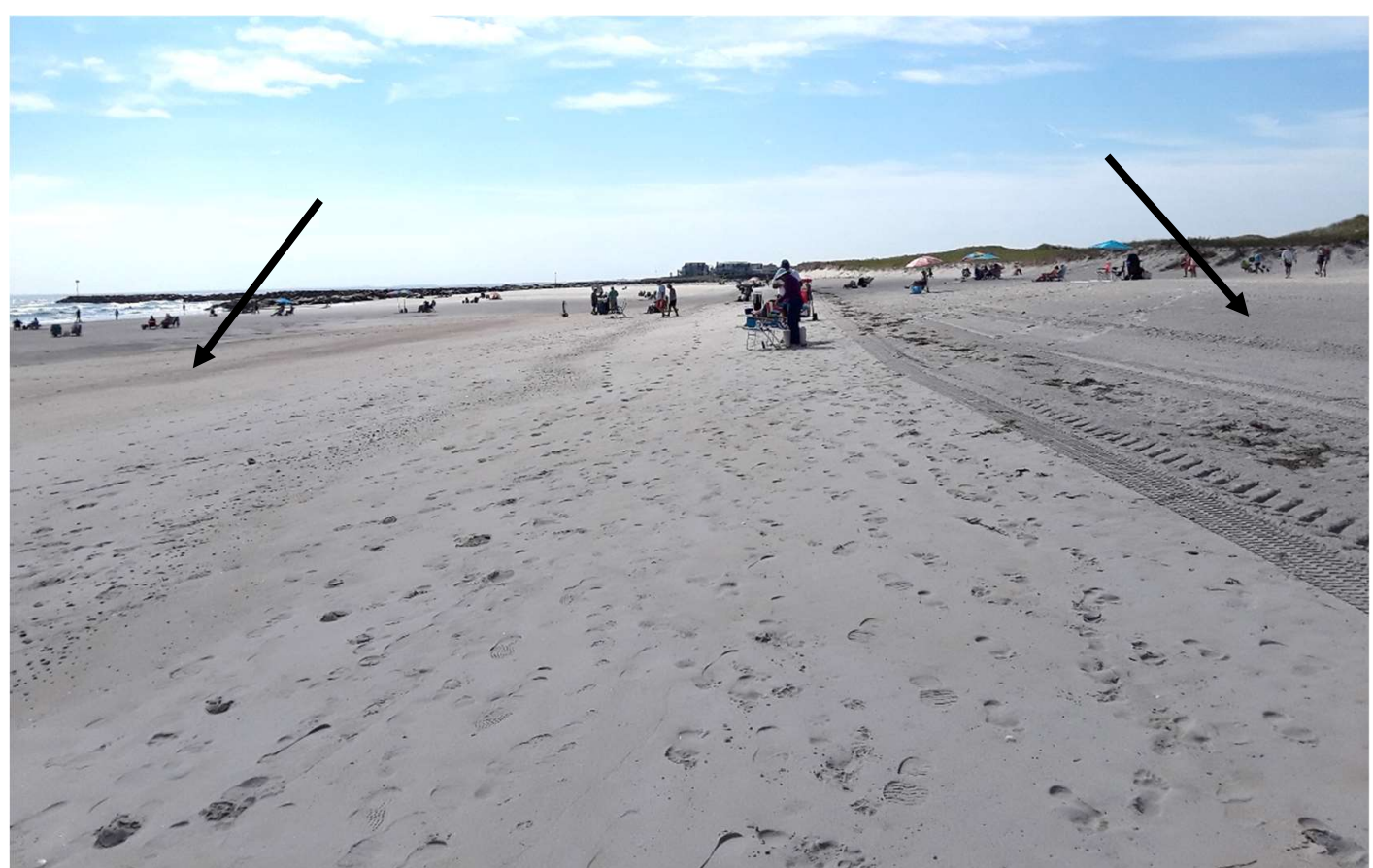

Figure HB04-13. Highly accretional beach at HB04 on September 17, 2018. The photograph is looking south. Note the large berm on the upper beach (right arrow) and the ridge and runnel on the lower beach (left arrow). Both of these features can be seen above in Figure HB04-12 with the same color arrows. Also note the upper beach has been groomed (tire tracks). 


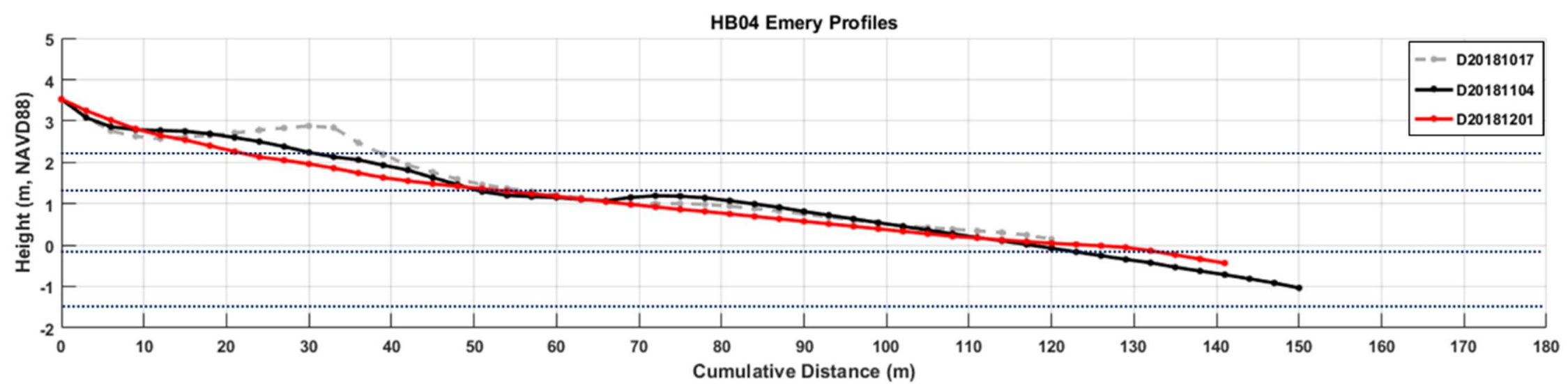

Figure HB04-14. Beach elevation profiles for HBO4 on October 17, 2018, November 4, 2018, and December 1, 2018. During this period the beach underwent continuous erosion and a loss of elevation.

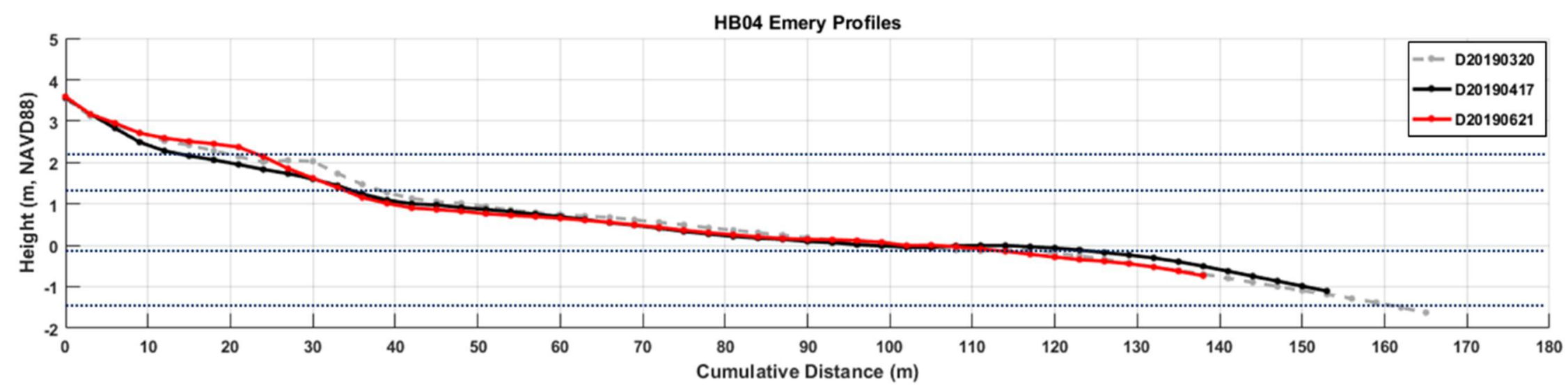

Figure HB04-15. Beach elevation profiles for HBO4 on March 20, 2019, April 17, 2019, and June 21, 2019. 


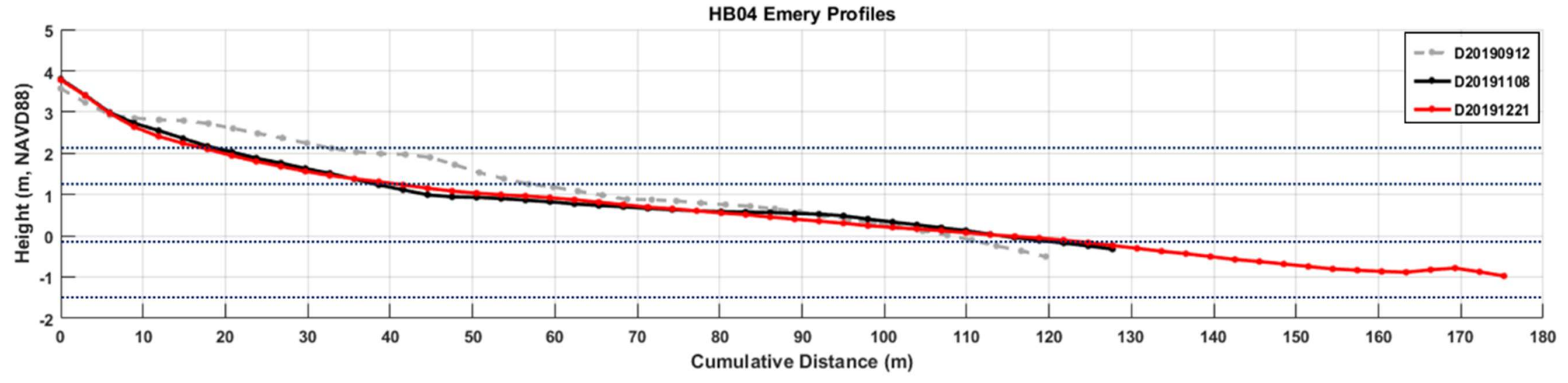

Figure HB04-16. Beach elevation profiles for HB04 on September 12, 2019, November 8, 2019, and December 21, 2019. 


\section{Introduction to Seabrook Beach, Seabrook, NH}

Seabrook Beach, NH and Salisbury Beach, MA are part of the same barrier island that extends $7.8 \mathrm{~km}$ from Hampton Harbor Inlet to the entrance of the Merrimack River. Seabrook Beach is the northern $\sim 2.3 \mathrm{~km}$ of the barrier stretching from the southern jetty at Hampton Harbor Inlet to the NH-MA border (Figures SB-1 and SB-2). The northern half of Seabrook Beach is relatively wide ( $0.7 \mathrm{~km}$ at the inlet) in comparison to the barrier further south ( $0.3 \mathrm{~km}$ at the NH-MA border). Examination of aerial photographs indicate that large overwash deposits occur on the landward side of the barrier suggesting that in the past the barrier was inundated, and sand was pushed into the back-barrier (see back-barrier region in photograph in Figure SB-2 opposite stations SB02, SB04 and SB05).

Unlike almost all the beaches in $\mathrm{NH}$, the Seabrook-Salisbury barrier island has a large dune system that starts $0.8 \mathrm{~km}$ south of the jetty at Hampton Harbor Inlet near the end of Hooksett Street and extends nearly $3.5 \mathrm{~km}$ to the south into Salisbury Beach (Figure SB-2). The dune system in Seabrook varies in width from $\sim 50 \mathrm{~m}$ to $\sim 150 \mathrm{~m}$ (Figures SB-3 and SB04). The Seabrook Beach dunes were restored from 1993 to 1994 by the town of Seabrook (who also owns the dunes) to replace the natural dunes that were removed or damaged in the past. Here the houses are set back from the beach and are afforded protection from storm surges and overwash by the dunes. The $\sim 0.8 \mathrm{~km}$ of the beach north of the dunes to the southern jetty at Hampton Harbor Inlet are comprised of private homes, most with some sort of seawall separating the homes from the beach (Figure SB-5). However, with the exception of a small section $100 \mathrm{~m}$ in length (Figures SB-2 and SB-6), the homes are not protected by dunes.

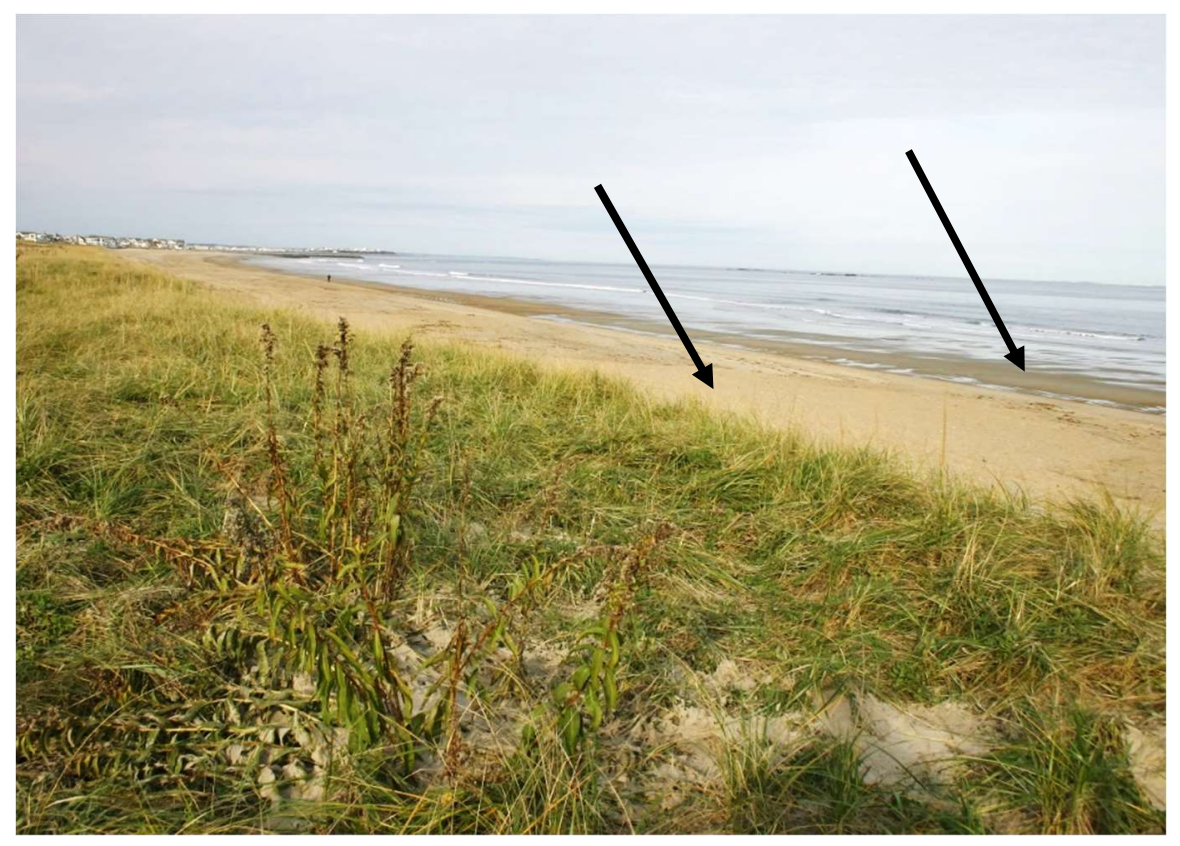

Figure SB-1. Seabrook Beach, NH, which is the northern half of the Seabrook-Salisbury Beach barrier island. The photograph is looking north from station SBO4 and was taken on November 1 , 2017. Note the wellestablished dunes, narrow backshore (left arrow), steep beachface and wide low tide terrace or lower beach (right arrow). 


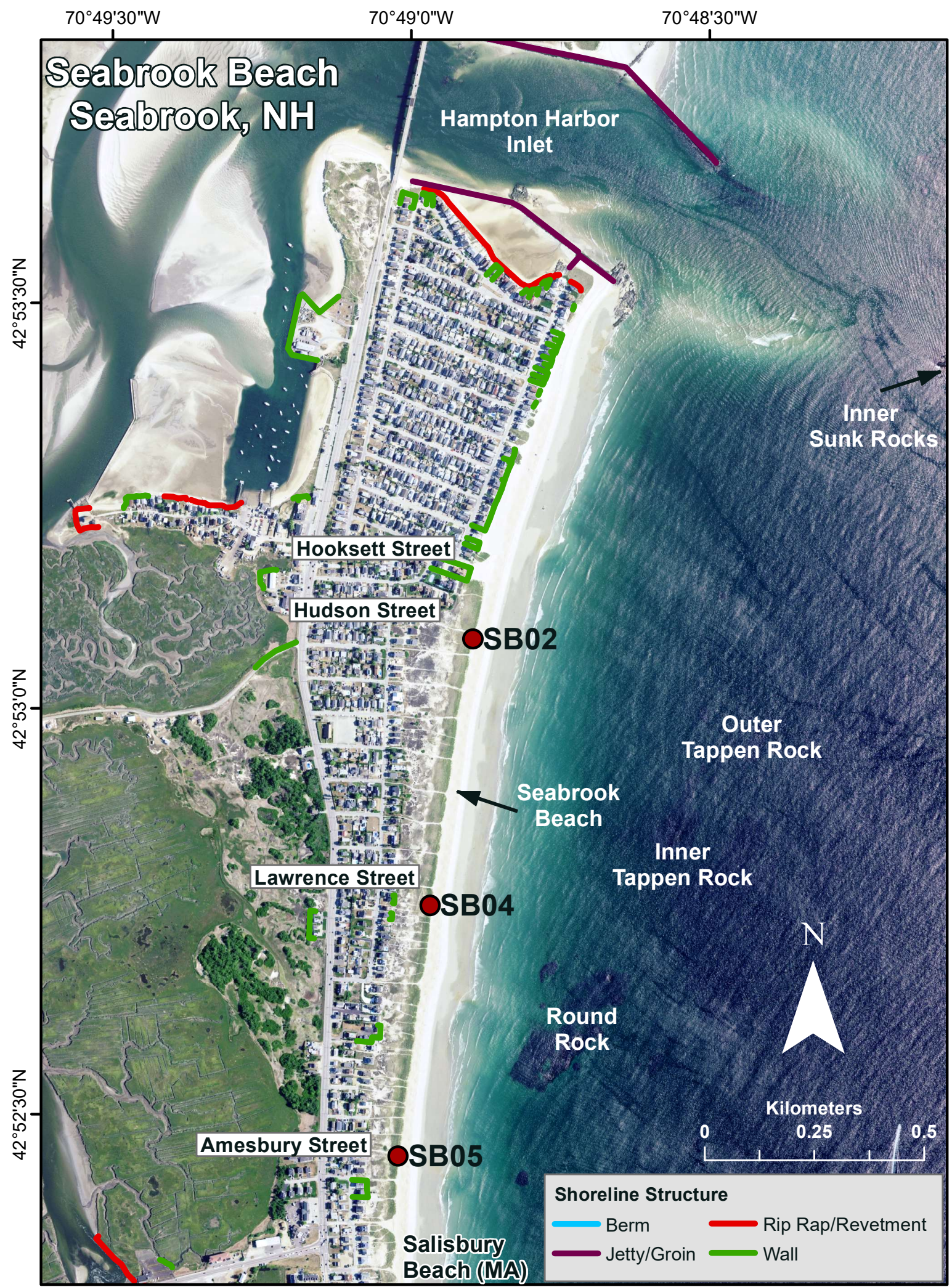

Figure SB-2. Location map of Seabrook Beach with stations, geographic features, and shoreline engineering structures. 
The northern $0.8 \mathrm{~km}$ north of Seabrook Beach under accretional conditions typically has a relatively wide backshore landward of a distinct berm, a steep berm face and a wide flat lower beach or low tide terrace (Figure SB-7). Undoubtedly, part of the reason the beach and barrier island is wider here than further south is due to the effects of the jetty, offshore bedrock outcrops, and the ebb tidal delta or shoals which dampen wave energy from the northeast and cause wave refraction and drift reversal allowing the beach to build higher and wider via sand deposition. Starting at the location of the dunes at Hooksett Street, the backshore is narrower (Figures SB-1 and SB-8), but still has a distinctive berm, steep beach face, and a flat lower beach or low tide terrace. However, after stormy periods and erosion, the beach remains steep, but it narrows and has a minimal or no low tide terrace. Small pebbles and granular sediments as well as shell fragments become exposed as well. Seabrook Beach is predominantly composed of sand. Bedrock outcrops are found near the jetty and offshore of Hampton Harbor Inlet, as well as offshore of the profile stations (i.e., Inner Sunk Rocks, Outer Tappen Rock, Inner Tappen Rock, and Round Rock) (Figure SB-2). There are some small bedrock outcrops offshore of the beach, as well as in the lower intertidal near the jetty (Figures SB-9 and SB-10).

An extremely interesting feature observed on March 18, 2018 after a period of extensive erosion followed by accretion was the presence of a small tombolo in the lower intertidal just north of SB05 apparently related to Round Rock or some unmarked offshore bedrock outcrop or glacial deposits (Figure SB-11). Wave refraction and a reduction of longshore transport of sand usually lead to the development of a tombolo. Typically, the tombolo, if present, is mostly subtidal. However, it does illustrate the interplay of offshore features such as bedrock or megaclast deposits and the beach.

Presently Seabrook Beach (like Hampton Beach) has a relatively large volume of sand and higher elevation compared to all of the $\mathrm{NH}$ beaches north of Great Boars Head. The cause of this accumulation is not clear, but trapping of sand by the well-developed dune system likely contributed to the large volume of sediment. In addition, the periodic sand nourishment from material dredged from Hampton-Seabrook Harbor is likely a factor (discussed below).

A benefit of the dune system at Seabrook Beach, in addition to its role as a buffer against storm erosion and flooding, is its value as a habitat. For example, piping plovers (Charadrius melodus) often nest in the dunes. As discussed earlier, plovers are a threatened species at the federal level and an endangered species in $\mathrm{NH}$ and are protected. A plover nest was noted in June 2019 near station SB04 (Figure SB-16). 


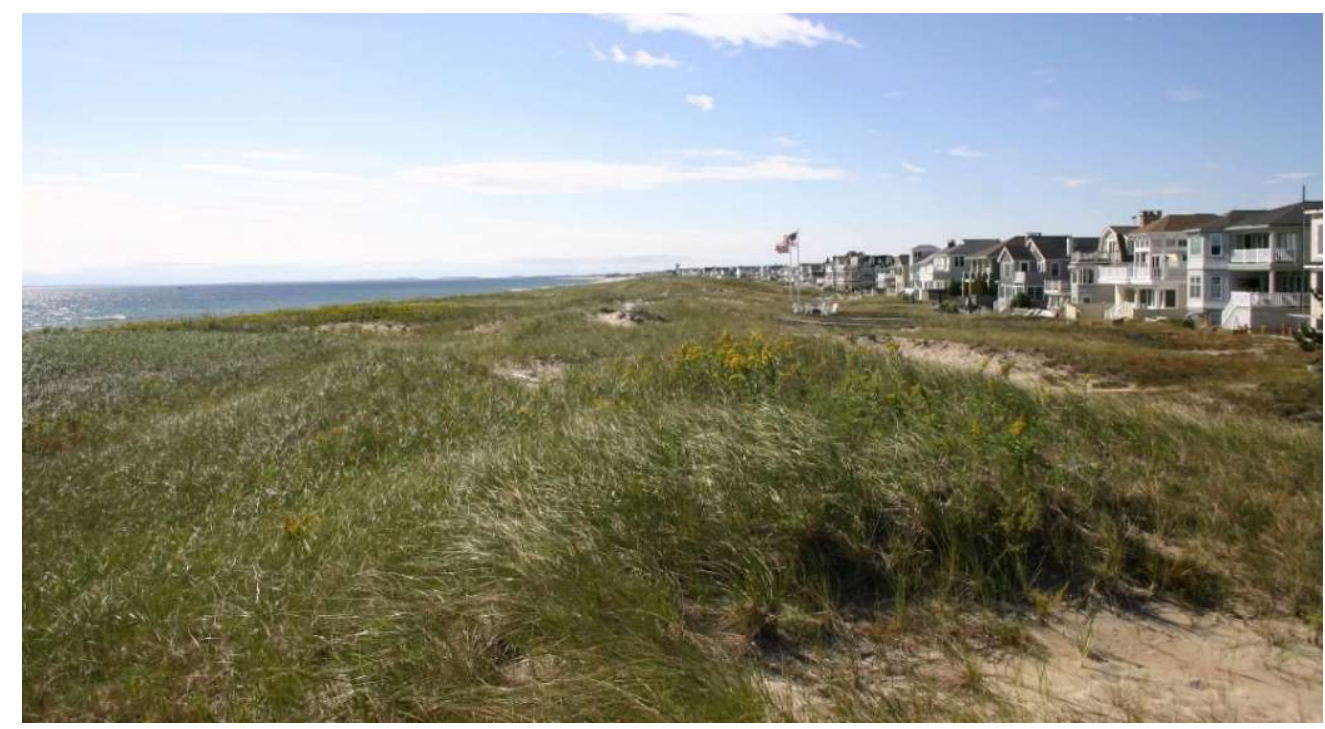

Figure SB-3. Seabrook beach dunes, the largest dune system in NH, looking south from near station SB04 on September 20, 2015.

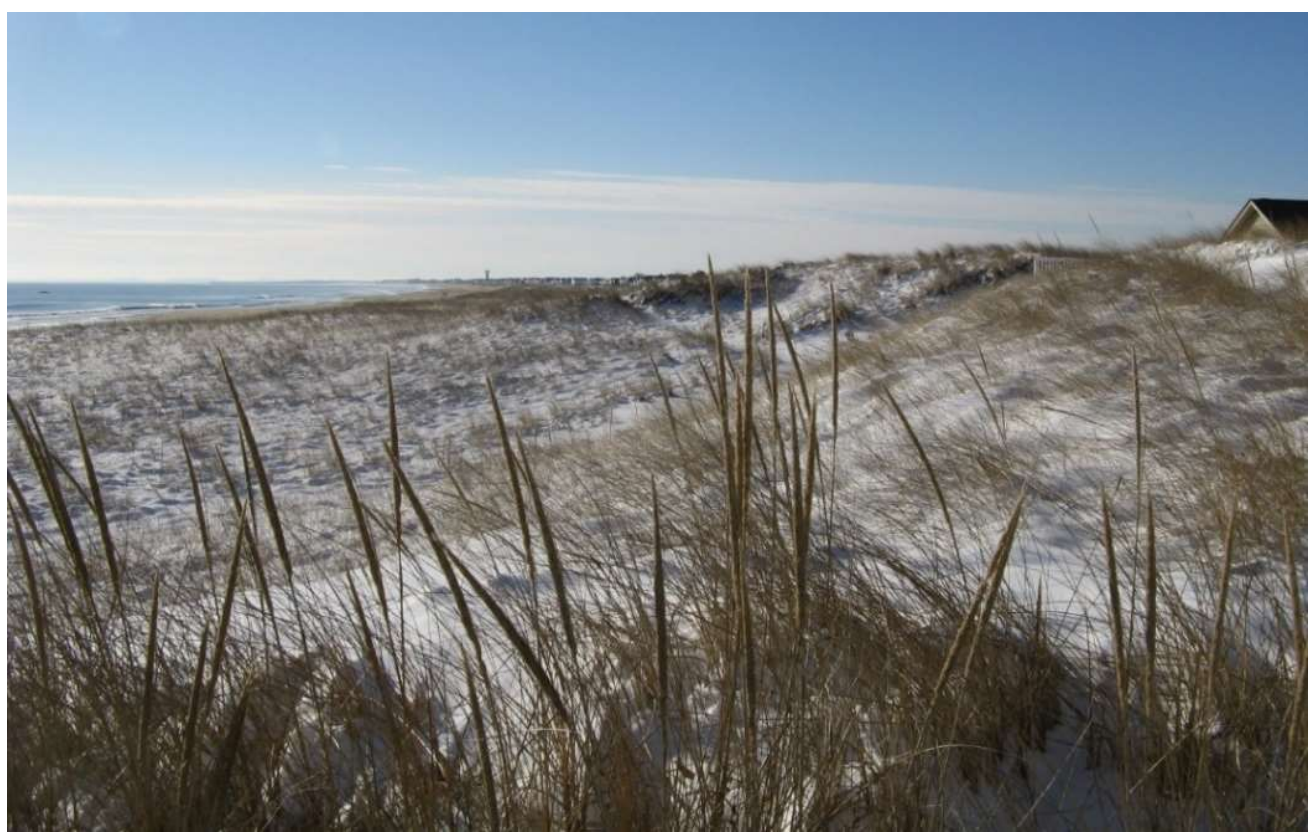

Figure SB-4. Dune grasses at Seabrook Beach in winter. The photograph is looking south from station SBO2 on January 5, 2014. The dunes are a natural storage site for sand and provide protection against erosion and flooding. 


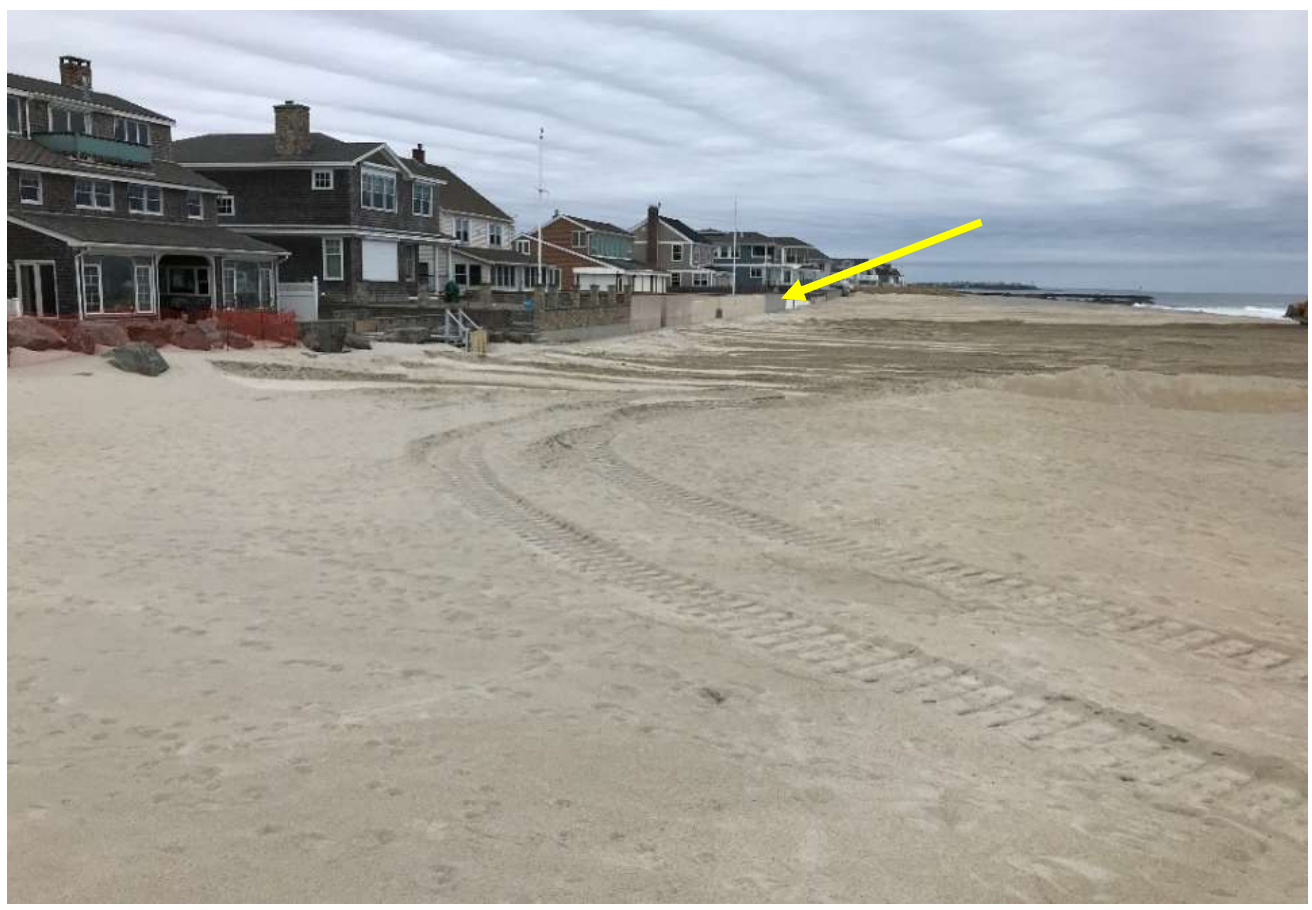

Figure SB-5. Homes north of the major dunes on Seabrook Beach, which are typically protected by a seawall (arrow) as shown in this photograph looking north from Hooksett Street on February 4, 2020. Sand dredged from Hampton-Seabrook Harbor was placed on the beach in the late fall 2019 and can be seen here.

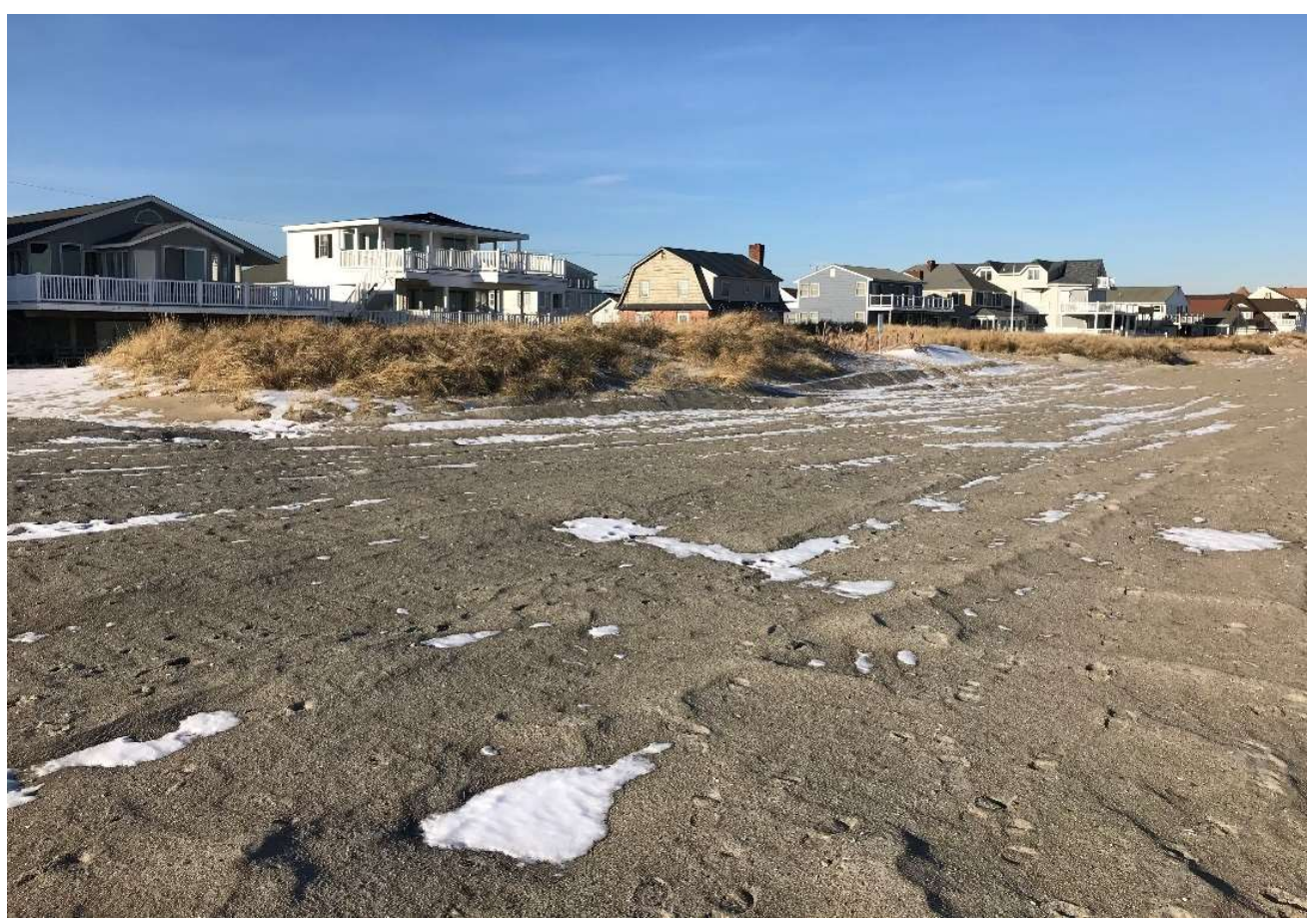

Figure SB-6. The small section of northern Seabrook Beach where there is no seawall, but instead dune grasses grow in front of homes. The dune grasses afford protection from wave attack during storms. This photograph was taken on November 23, 2019 and shows the beach after nourishment efforts that occurred that fall. Sand was spread with a bulldozer causing the rough surface seen in front of the dunes. 


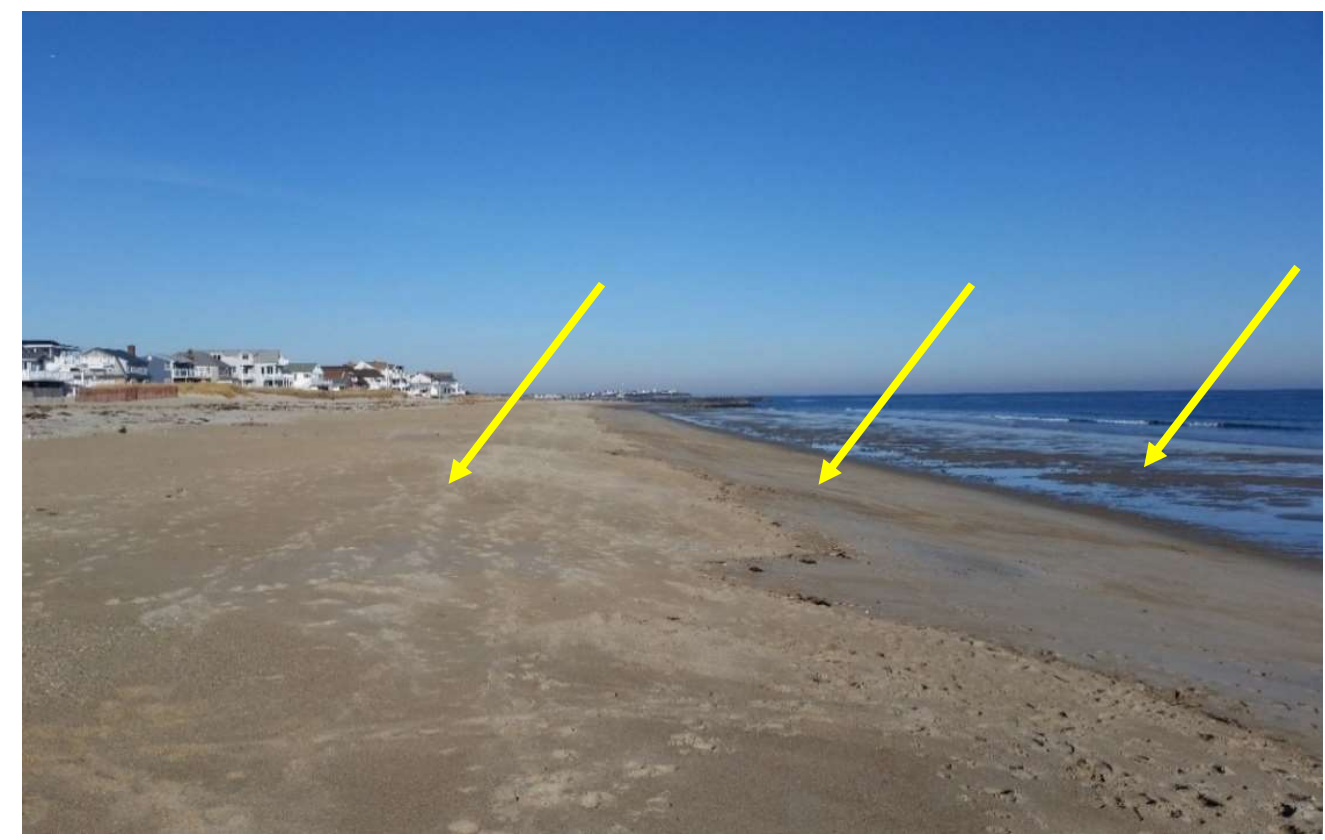

Figure SB-7. Seabrook Beach north of Hooksett Street. The photograph was taken on December 6, 2015 and shows the general features of the beach in that area. Note the wide backshore (left arrow), steep berm face (middle arrow), and wide lower beach or low tide terrace (right arrow).

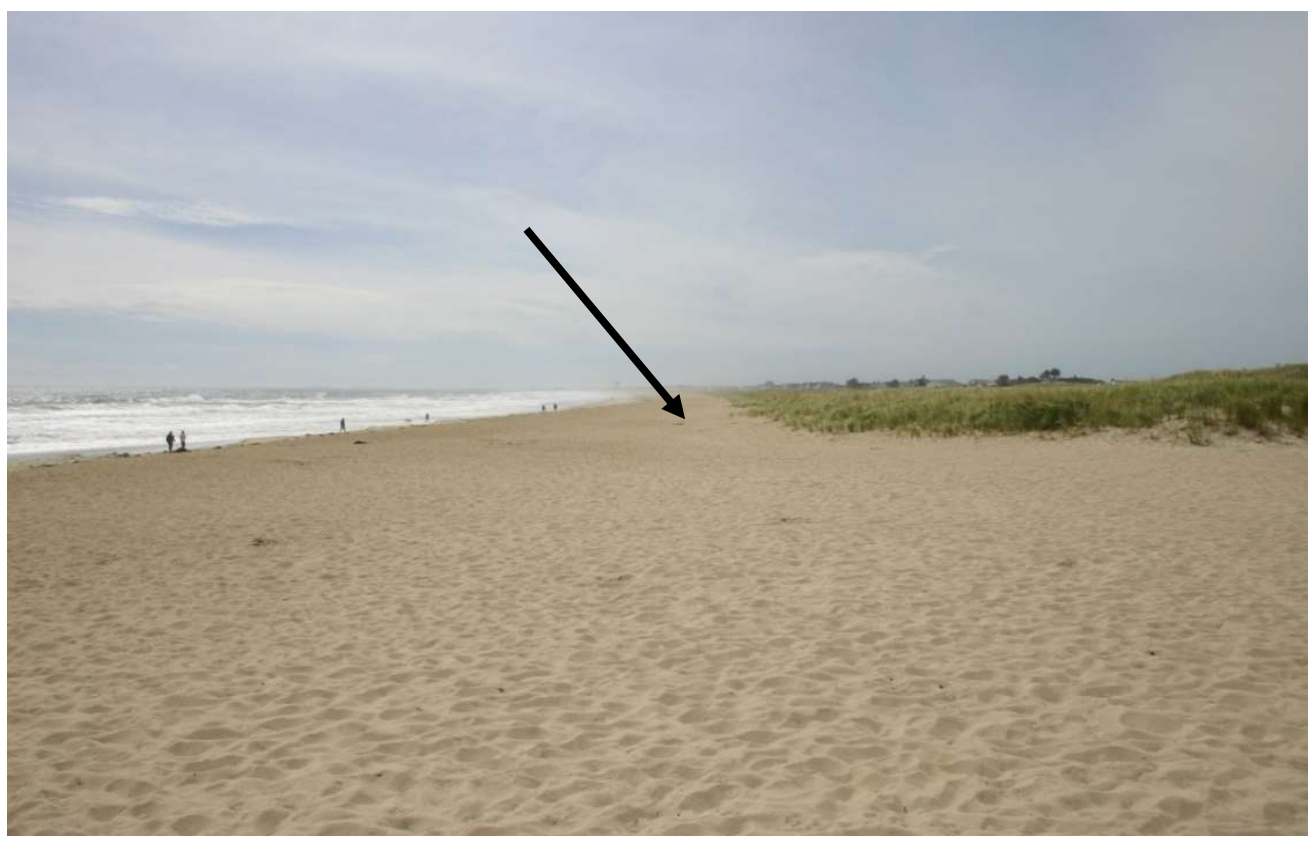

Figure SB-8. Seabrook Beach on September 5, 2016 looking south from near Hooksett Street. Note the upper beach or backshore tends to be narrower (arrow) than the beach to the north. Part of the reason is due to the presence of the dunes which extend seaward. However, Seabrook Beach would likely begin to naturally narrow at this location as the sheltering effect of the jetty to the north and the offshore shoals would have diminished. The dunes are an extremely valuable habitat that provide protection against storm surge and erosion to the landward infrastructure. Restoration and preservation of dunes is an extremely valuable strategy to increase coastal resilience. 


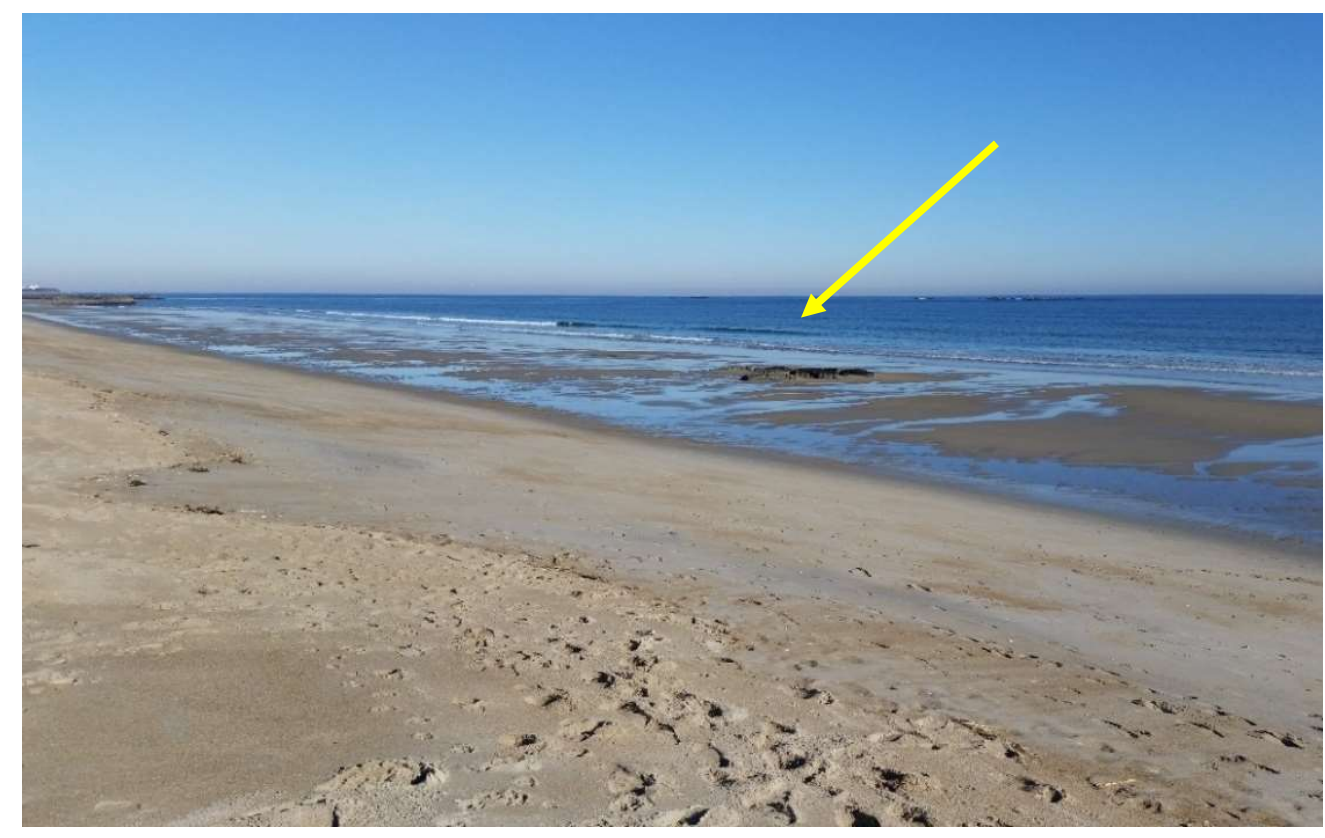

Figure SB-9. Seabrook Beach north of Hooksett Street on December 6, 2015, showing the bedrock outcrops that are present in that area on the low tide terrace (arrow).

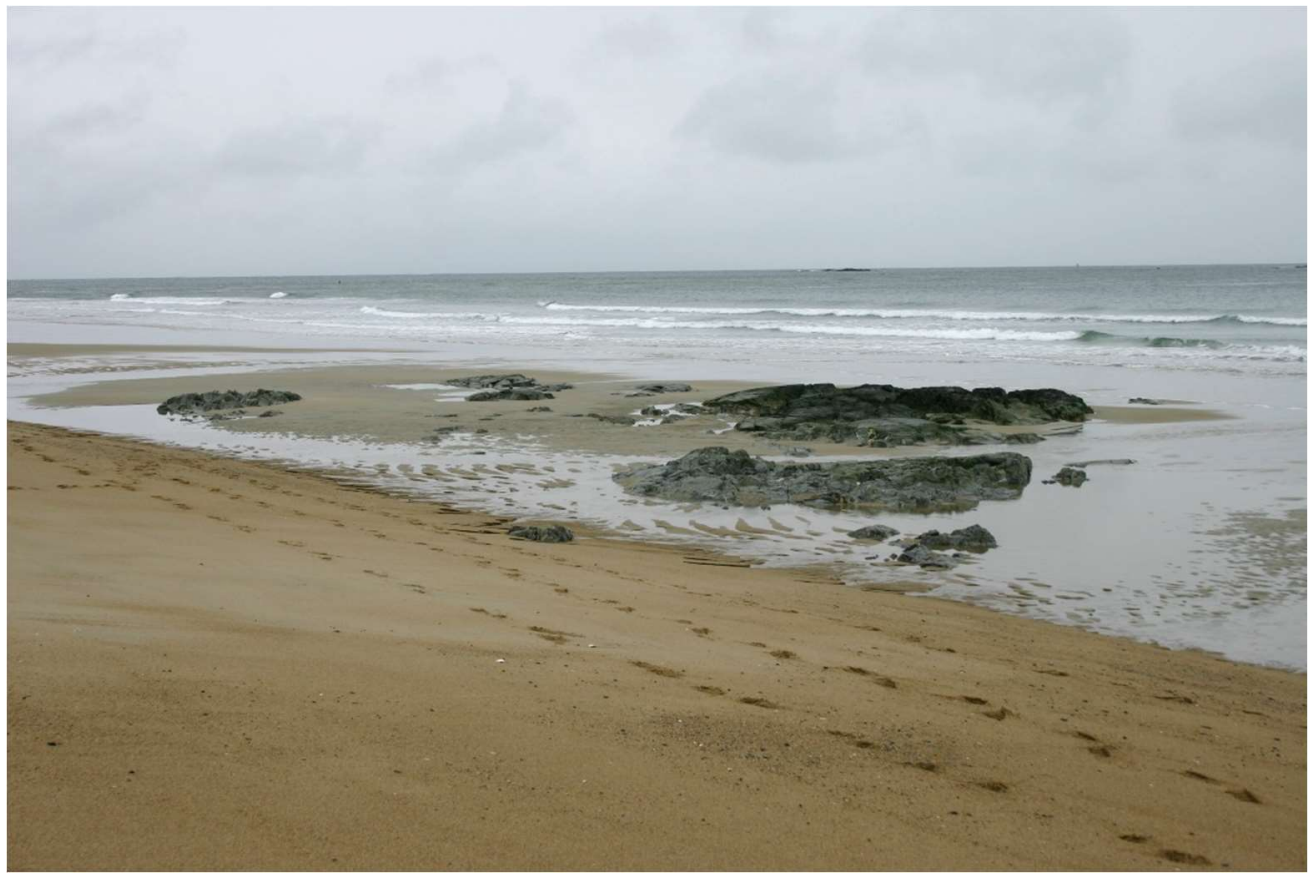

Figure SB-10. Bedrock outcrop on the low tide terrace on Seabrook Beach. The photograph was taken on March 10, 2017 (see Figure SB-9). 


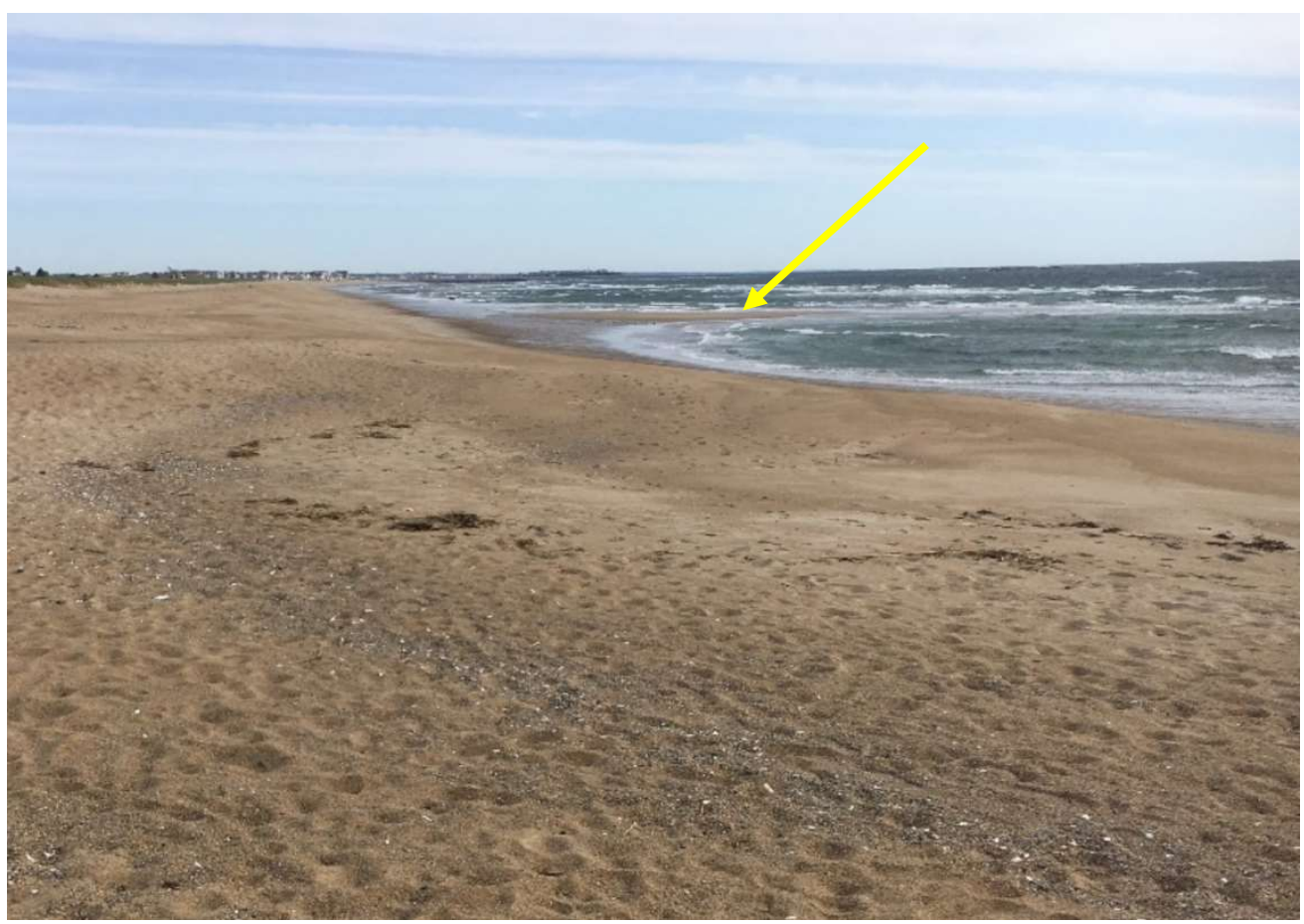

Figure SB-11. Small tombolo (arrow) located behind Round Rock (see Figure SB-2) or a similar offshore bathymetric feature.

One source of sediment to both beaches is beach nourishment. Due to the need for HamptonSeabrook Harbor to be dredged for navigation purposes, sand is placed on Seabrook Beach and Hampton Beach, largely due to economic reasons. This occurred as recently as 2019 with $\sim 91,750 \mathrm{~m}^{3}$ $\left(120,000 \mathrm{yd}^{3}\right)$ and 2012 with $\sim 92,000 \mathrm{~m}^{3}\left(120,330 \mathrm{yd}^{3}\right)$ of sand placed on Seabrook Beach (see section on Beach Nourishment in Chapter 2: Description of the New Hampshire Coast). The sand was hydraulically dredged from the Harbor to improve navigation channels and anchorages and transported via a pipe onto Seabrook Beach (Figure SB-12). The nourishment area extended from close to the northern end of the jetty to Hooksett Street (Figure SB-13). The sand is introduced to the beach through an outfall, where it is spread with a power shovel and bulldozer (Figures SB-14 and SB15). Periodically, the pipe is extended down the beach to facilitate the distribution of the sand. 


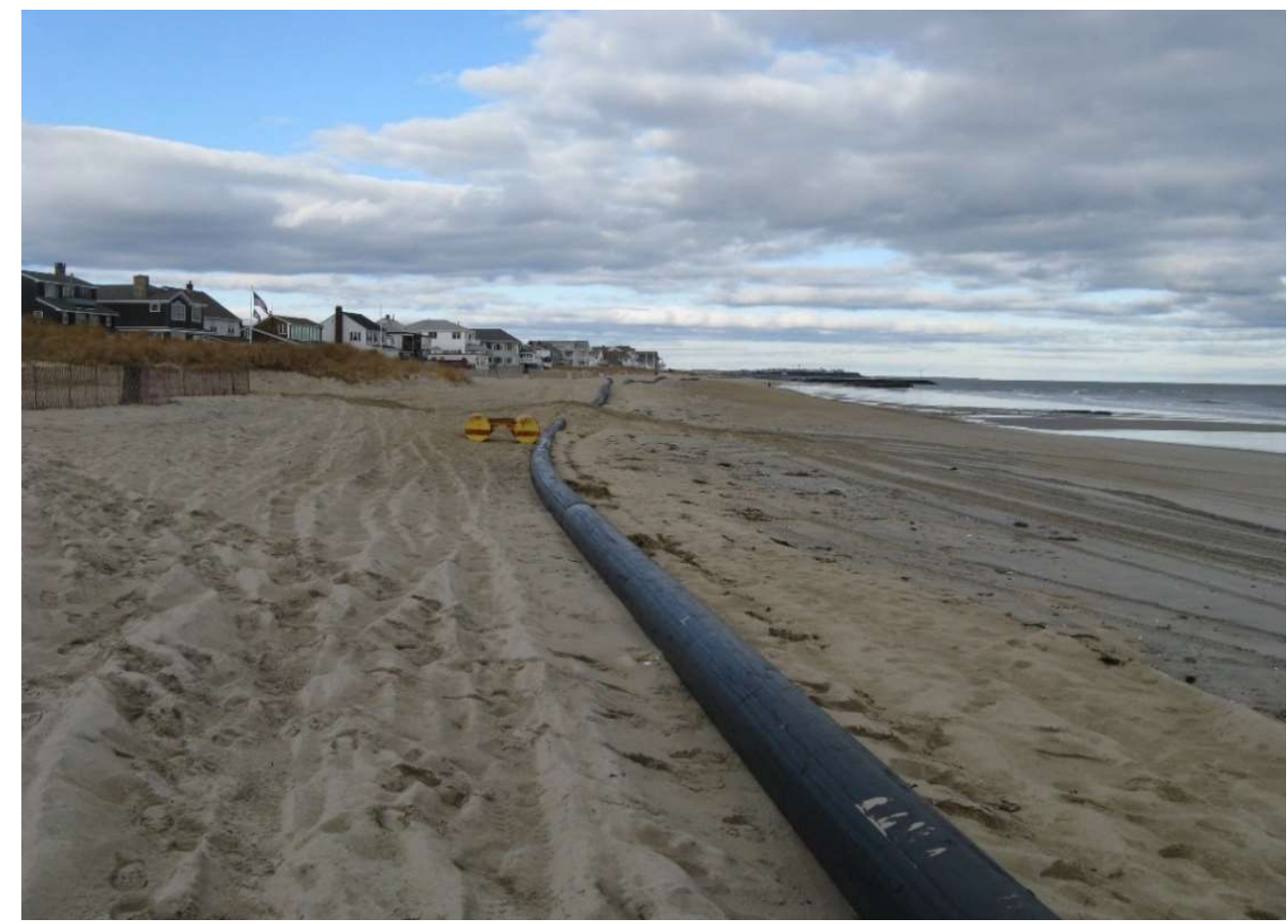

Figure SB-12. Pipeline running from the dredging operation in Hampton-Seabrook Harbor to Seabrook Beach. The photograph is looking north on December 11, 2019.

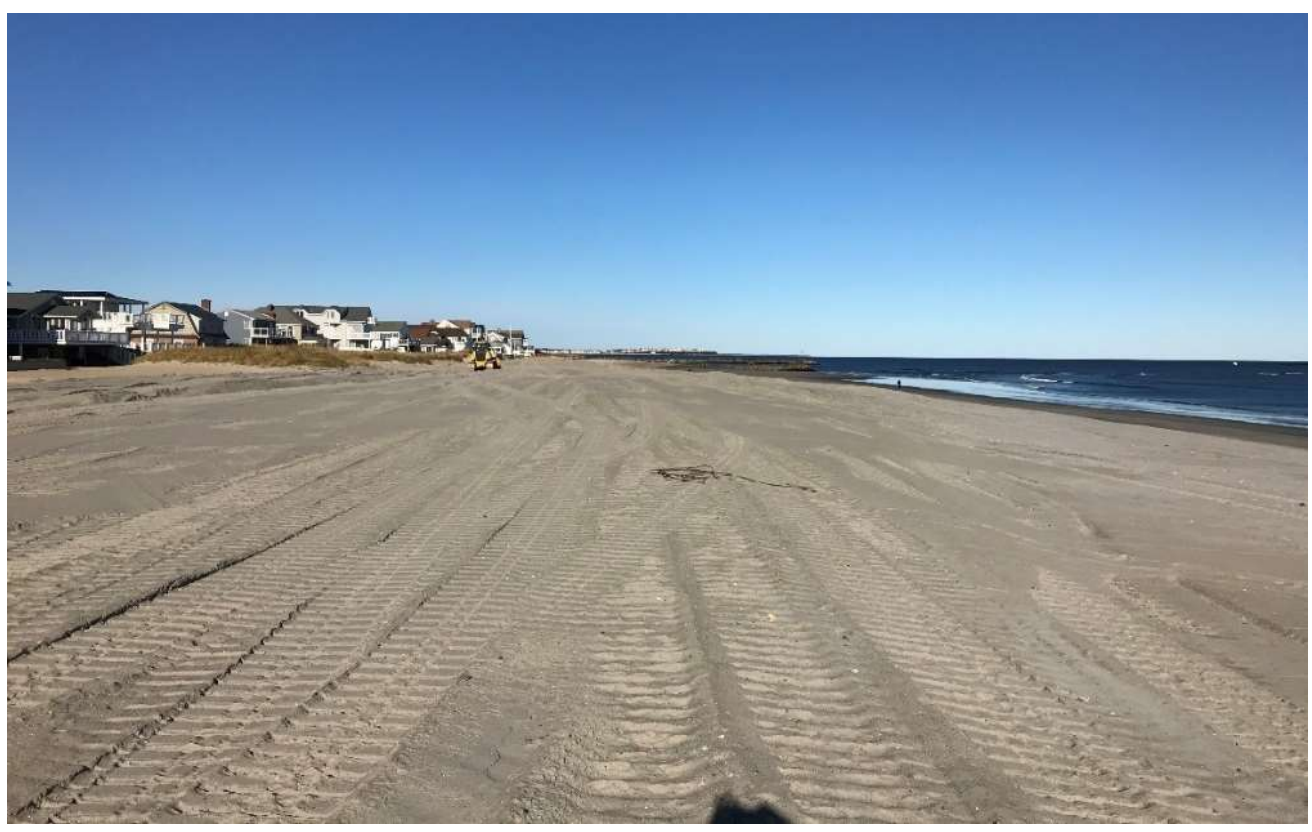

Figure SB-13. The sand placed on the beach during the beach nourishment project from the nearby harbor was graded with bulldozers. The photograph above shows the backshore of the northern end of Seabrook Beach south of the jetty on November 23, 2019. 

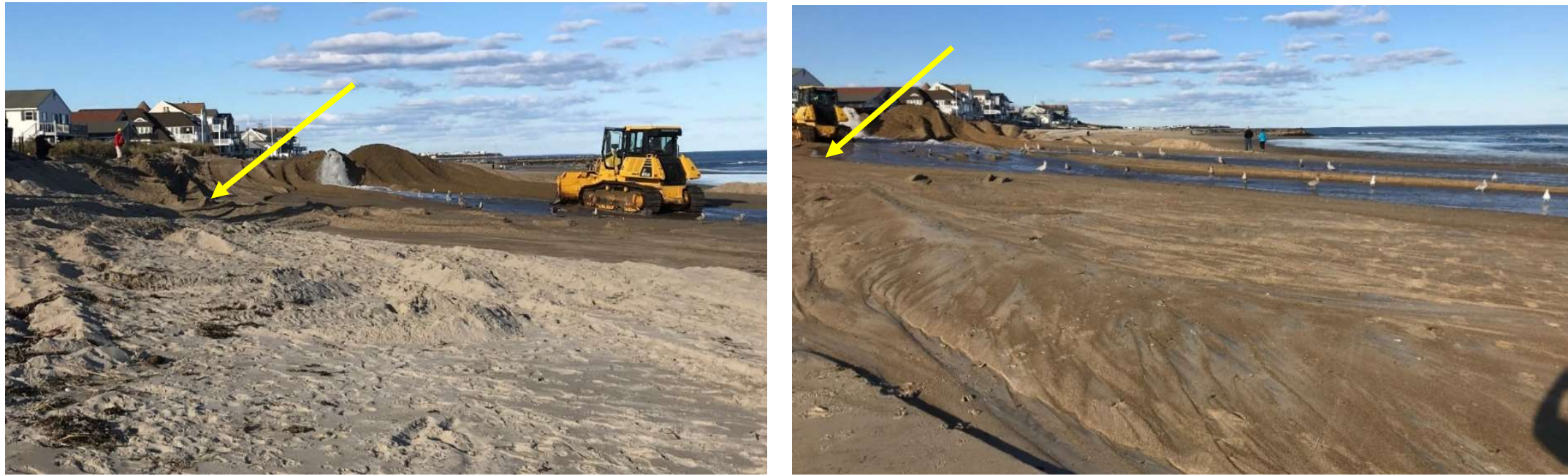

Figure SB-14. Dredge pipe outfall (arrows) and sand buildup on Seabrook Beach on October 26, 2019, where the sand is pumped onto the beach and then distributed by the power shovel and bulldozer.
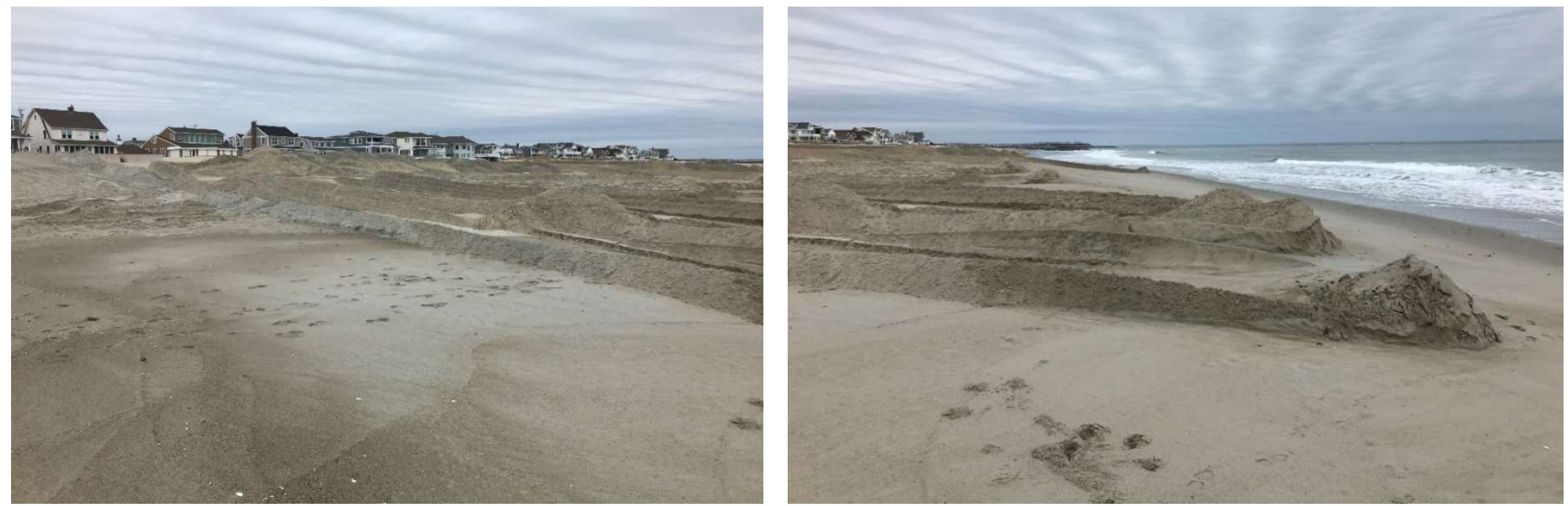

Figure SB-15. Redistribution of sand by power shovel and bulldozer continued into early 2020, as seen in these photographs taken on February 4, 2020. 

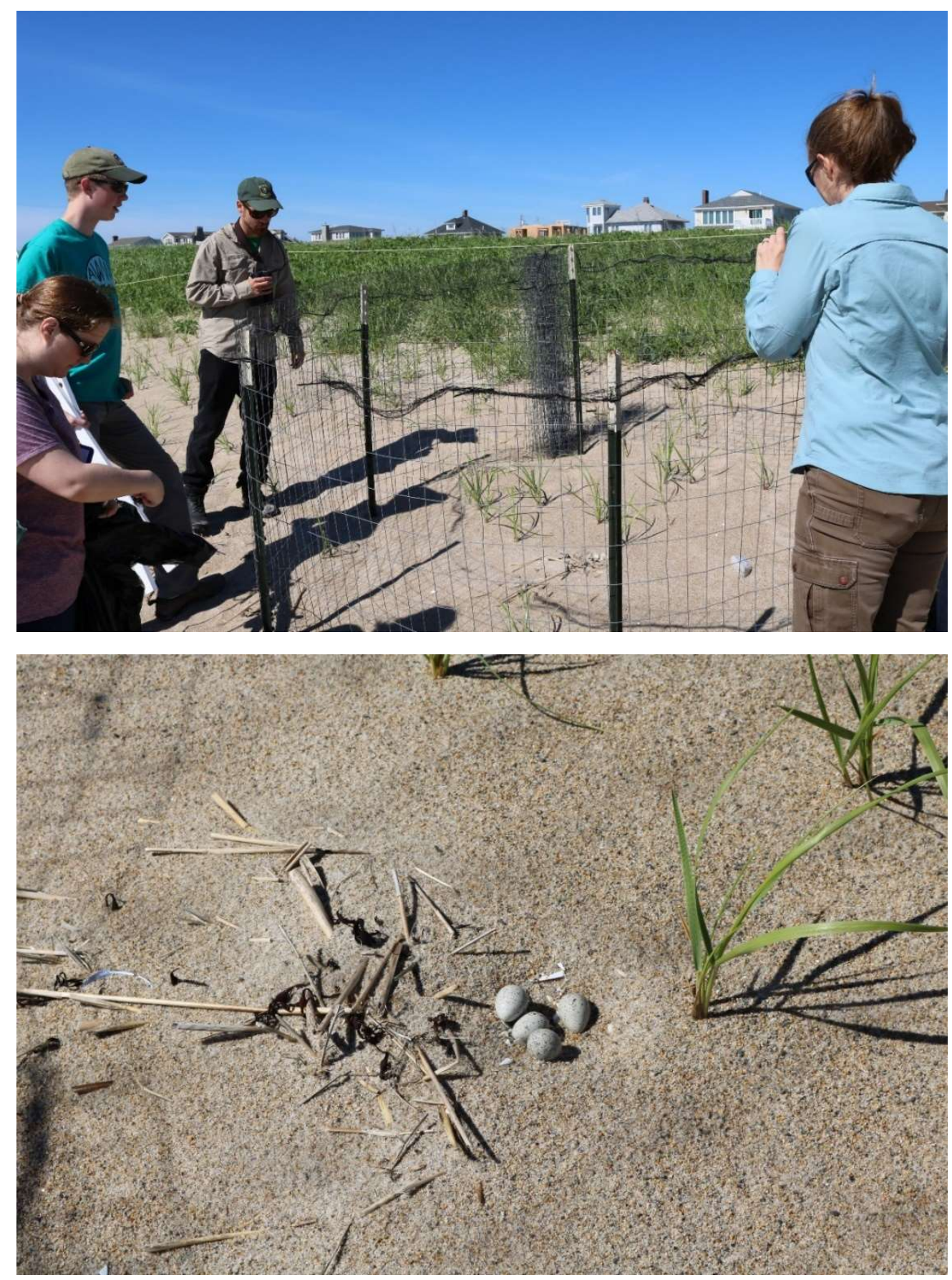

Figure SB-16. Piping plovers (Charadrius melodus) nest (top) and unhatched eggs (bottom) on Seabrook Beach near SB04 on June 6, 2019. 


\section{Results for Station at Northern Seabrook Beach: SB02}

Overview. Station SB02 in located $\sim 0.9 \mathrm{~km}$ from the southern jetty at Hampton Harbor Inlet near the beginning of the dune system on Seabrook Beach and seaward of Hudson Street (Figure SB-1). The dune system at SBO2 is very well-developed and is $\sim 130 \mathrm{~m}$ in width. The beach is largely sand and granule, with occasional scattered pebbles after storms. The beach elevation profile transect extends $\sim 130$ m seawards from the foredunes to the low tide line (Figures SB02-1 and SB02-2). The station is marked by wooden stakes. During accretional conditions, the beach tends to have a narrow backshore, a well-defined berm and steep berm face, and a flat lower beach or low tide terrace (Figure SB02-3). Ridge and runnels can be very distinctive. Following storms, the whole beach becomes narrower, loses morphologic definition, and has a concave-upward profile (Figure SB02-4).

In November and December 2019, the beach north of station SB02 received $\sim 91,750 \mathrm{~m}^{3}\left(120,000 \mathrm{yd}^{3}\right)$ of sand dredged from Hampton-Seabrook Harbor via a pump and piping system (Figures SB-11 to SB16). The sand was graded with a bulldozer and then left to redistribute by natural processes. The entire beach north of Hooksett Street increased in size and elevation due to the beach nourishment project. Although the sand was not directly placed on SB02 (the added sand terminated about $175 \mathrm{~m}$ north of station SB02), it is safe to assume that some portion of the sand was transported by wave action to the study site. There is some evidence of this in the beach profiles, but unfortunately the time interval between profiling dates was not frequent enough to verify the impact on the beach at SB02. In addition, the termination of the field program in March 2020 due to the pandemic reduced the length of the observation period.

Summary. As stated previously, it is important to determine trends by looking at changes over several months, rather than using only single measurements, to access overall decreases or increases in beach elevation and sediment volume. SB02 underwent two cycles of erosion and recovery over the profiling period. There was a major period of general beach erosion in late winter and early spring 2018 following three major nor'easters (Riley, Quinn, and Skylar). However, the beach recovered to accretional conditions with respect to beach profile elevation and sediment volume by late fall and early winter 2018. SB02 maintained the accretional profile for the rest of the study period with the exception of a relatively minor period of erosion in late winter and spring 2019. However, this later period was close to the level of the estimated uncertainty of the methodology for determining elevation and sediment volume.

In contrast to the trends for SB02 discussed here, the other two stations on Seabrook Beach (SB04 and SB05) had two major periods of erosion and recovery. While SB02 showed only minor erosion, SB04 and SB05 showed significant loss of elevation and sediment volume during late winter and spring 2019 (discussed below). It is not clear what drove these differences along the beach, but it is very likely related to the beach nourishment near SB02 in fall 2019. The addition of 91,750 $\mathrm{m}^{3}$ $\left(120,000 \mathrm{yd}^{3}\right)$ of sand immediately north of station SB02 undoubtedly provided sediment via longshore drift. The ebb tidal delta at Hampton Harbor Inlet may also have affected wave approach, 
and longshore drift reversals cannot be ignored. However, it is beyond the scope of this study to address these notions.

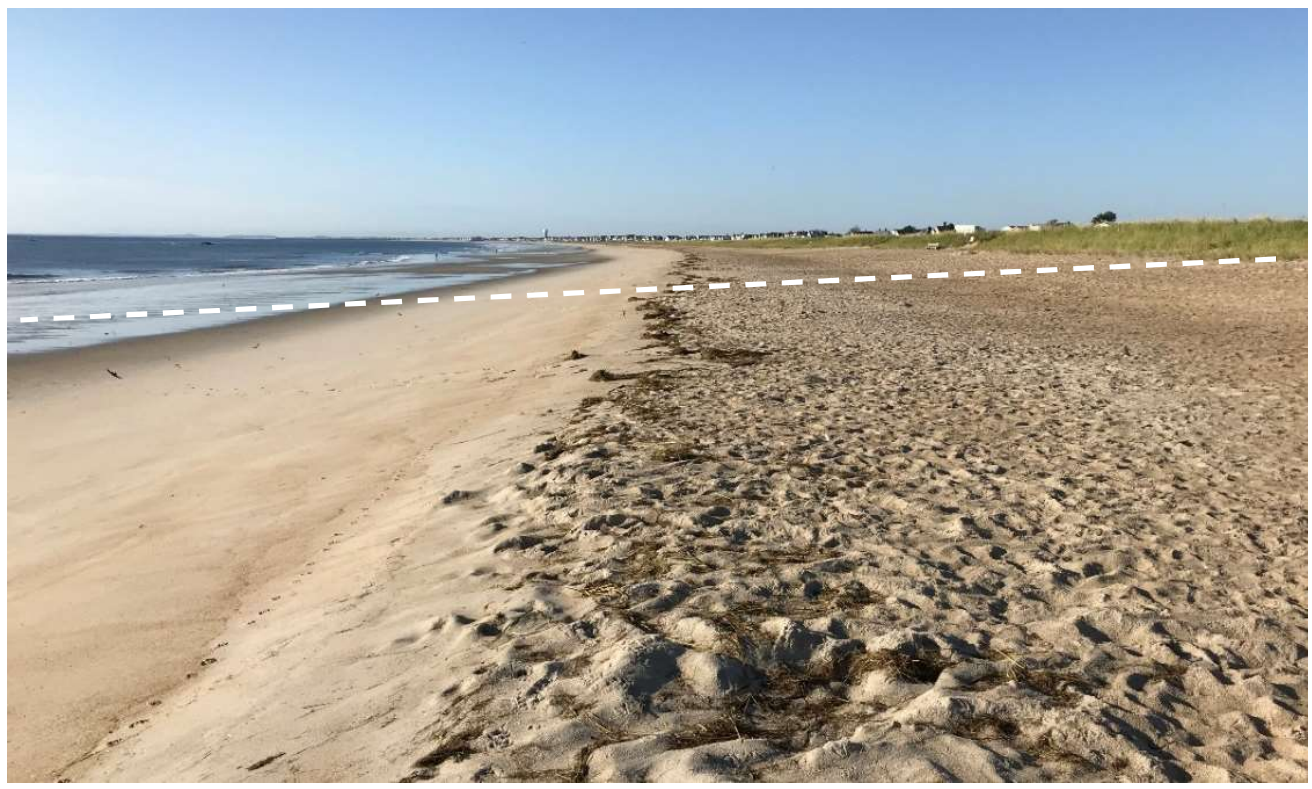

Figure SB02-1. Beach elevation profile transect for station SBO2 on Seabrook Beach looking south (white dashed line). The photograph was taken on September 3, 2019.

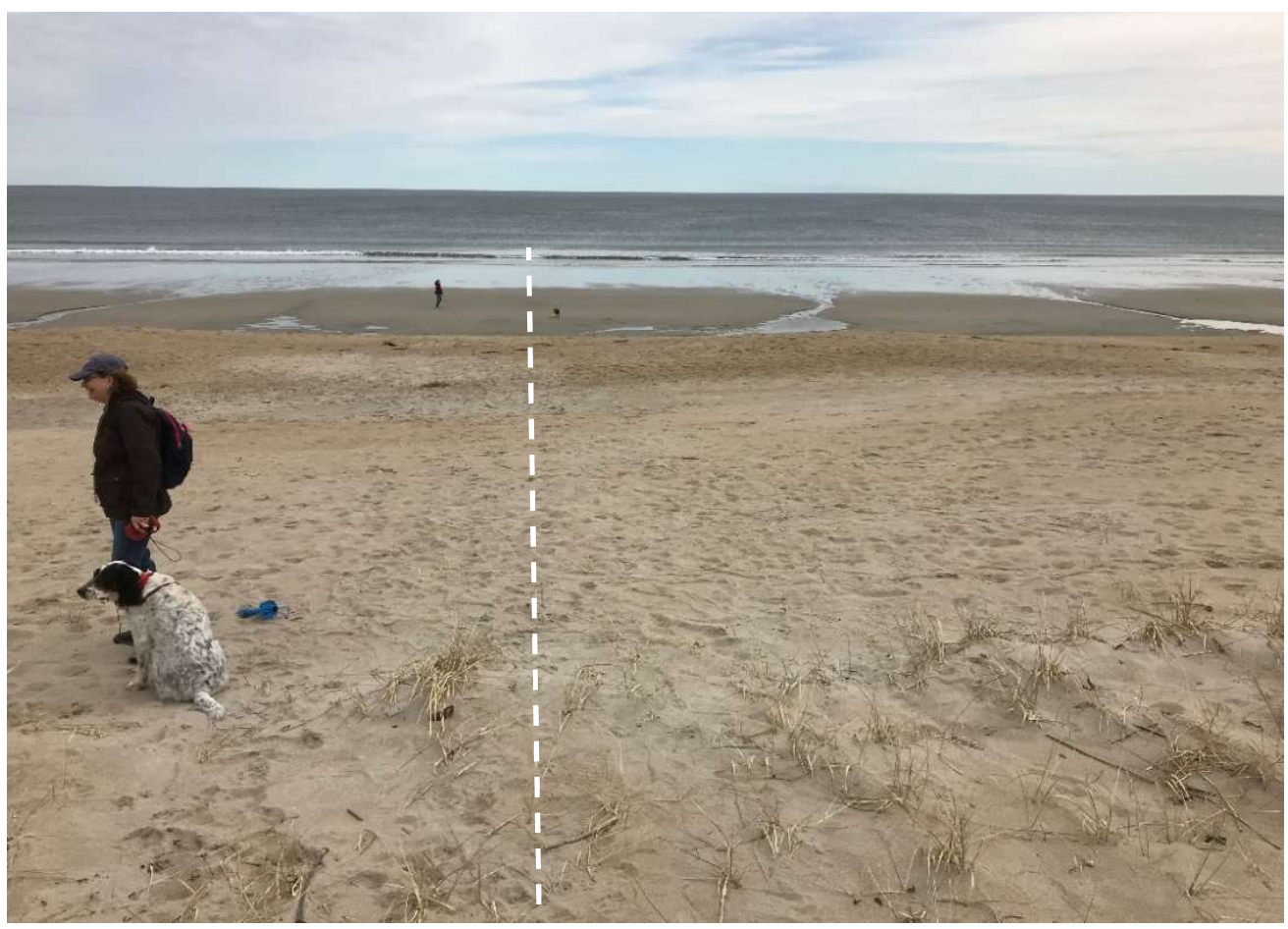

Figure SB02-2. Beach elevation profile transect for station SBO2 on Seabrook Beach looking east (white dashed line. The photograph was taken on February 24, 2018. 


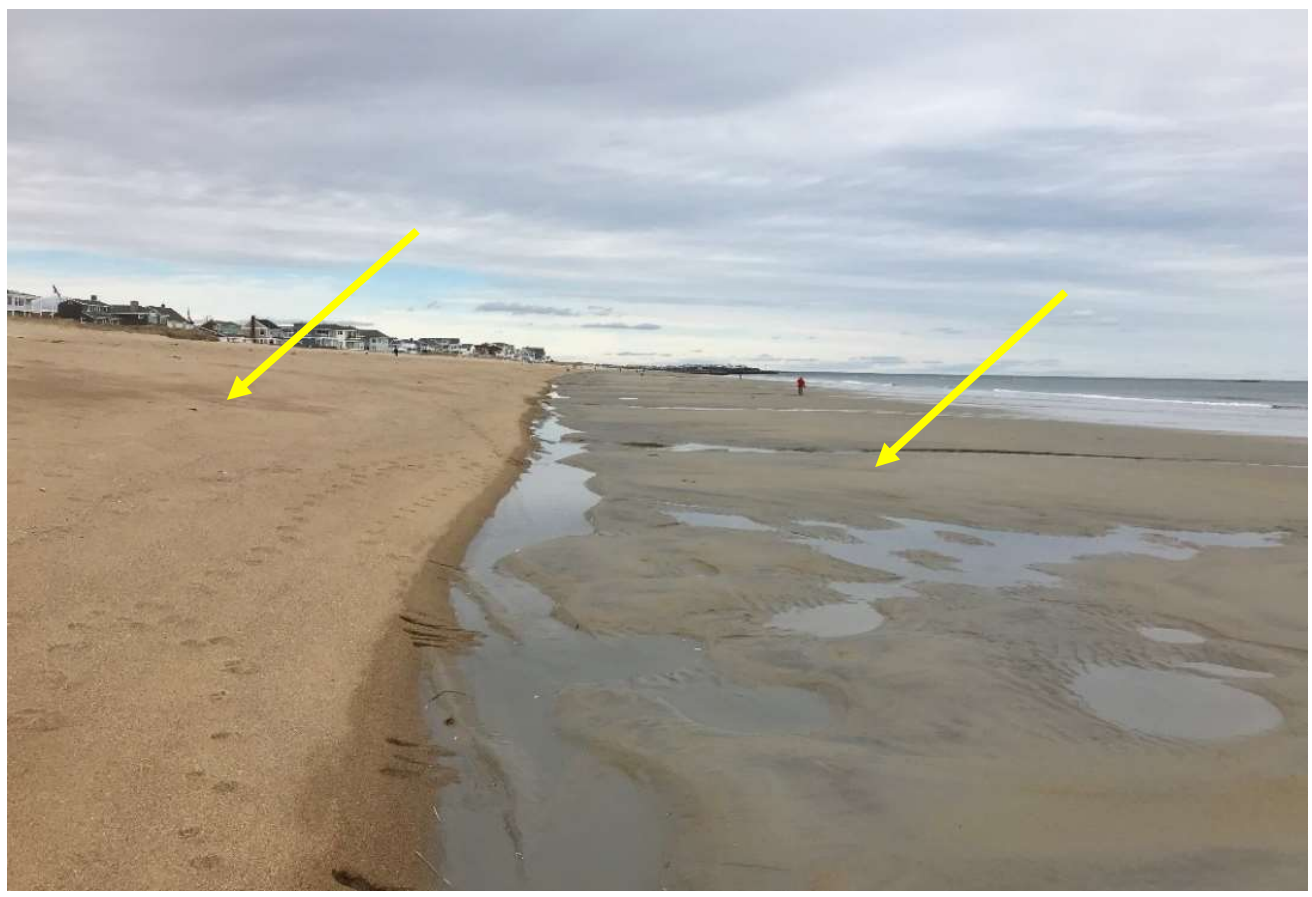

Figure SB02-3. Mid and lower beach at station SBO2 on February 24, 2018. Note the steep berm face (left arrow) and the wide, flat low tide terrace (right arrow). The photograph is looking north from the SBO2 profile transect.

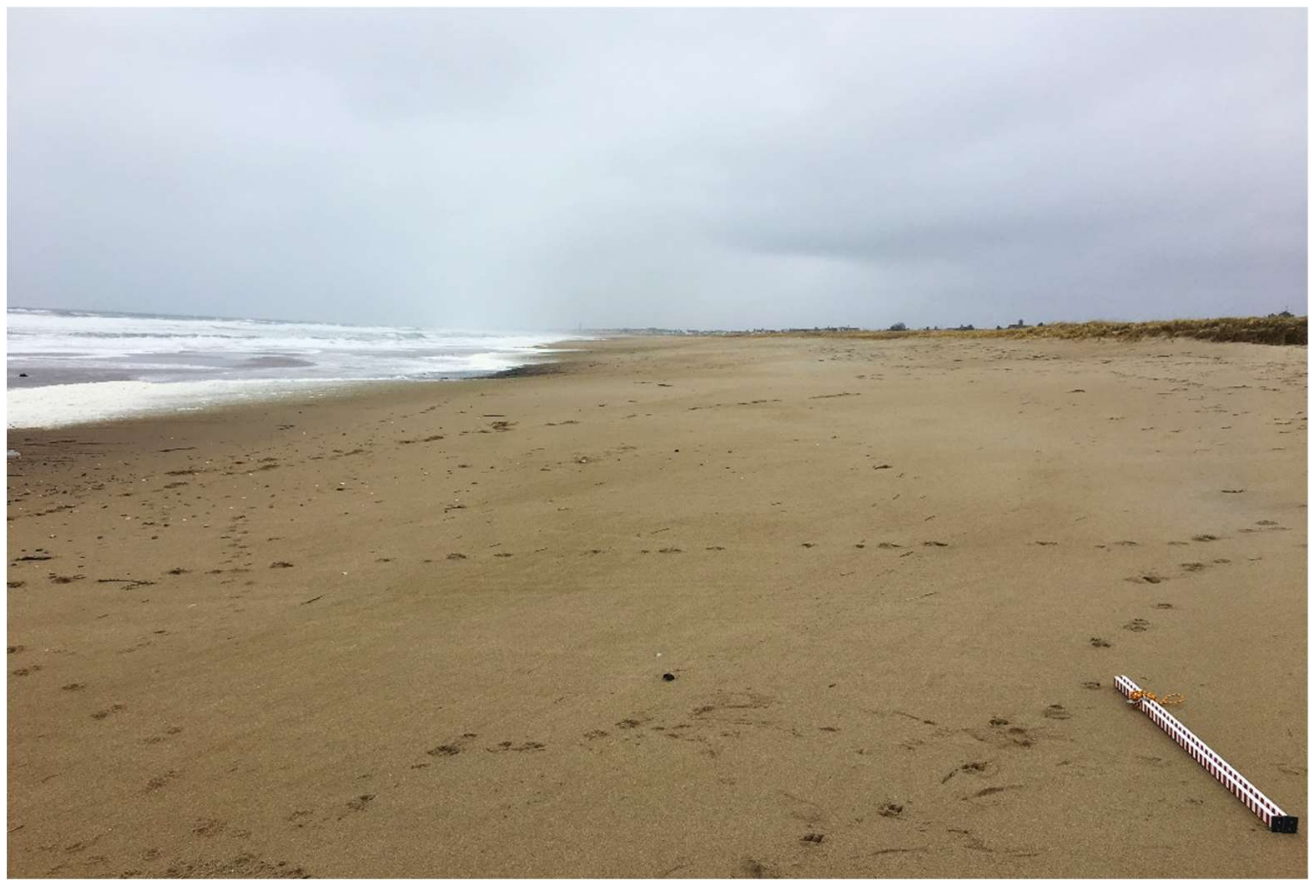

Figure SB02-4. Seabrook Beach at station SB02 looking south on March 7, 2018 following Nor'easter Riley. Note the beach is very flat with few morphologic features. 
General Profile Characteristics. SB02 was profiled thirty-two times between January 29, 2018 and March 9, 2020. All plotted beach profiles can be found in Appendix C(11). The upper and mid beach elevation profile is extremely steep. The profile, which starts in the foredunes, extends between 65 $\mathrm{m}$ to $\sim 130 \mathrm{~m}$ seaward (Figure SB02-5). The shorter profiles follow storm events after the beach has been eroded. For example, the shortest profiles $(66 \mathrm{~m})$ occurred on two dates (May 18 and July 13, 2018) following the late winter 2018 nor'easters. The longest profiles ( $130 \mathrm{~m}$ ) occurred several times as well (March, September, and December 2019, and March 2020) during accretional conditions and very low tides.

Examination of the sweep zone shows the elevation of the beach varied $\sim 0.6 \mathrm{~m}$ just seaward of the foredunes, $\sim 2.1 \mathrm{~m}$ at the berm, $\sim 2.2 \mathrm{~m}$ on the lower beach (occurred following storms), and $\sim 0.7 \mathrm{~m}$ on the lower beach when the profiles exceeded $120 \mathrm{~m}$ (occurred during accretional conditions). The range might be even greater, but the lower beach was subtidal after the major storms in March 2018 and could not be profiled. Comparison of the maximum average elevation profile (which occurred on August 3,2019 ) with the minimum average elevation profile (which occurred on May 18, 2018) shows an average difference of $\sim 1.3 \mathrm{~m}$ but ranged from $\sim 0.5 \mathrm{~m}$ or less on the upper beach to $\sim 2.0 \mathrm{~m}$ on the lower beach (Figure SB02-6). There are also several elevation profiles that have similar low volumes and elevations to the May 18 profile (Figure SB02-7). These are discussed below as they show different patterns of erosion to the beach. 


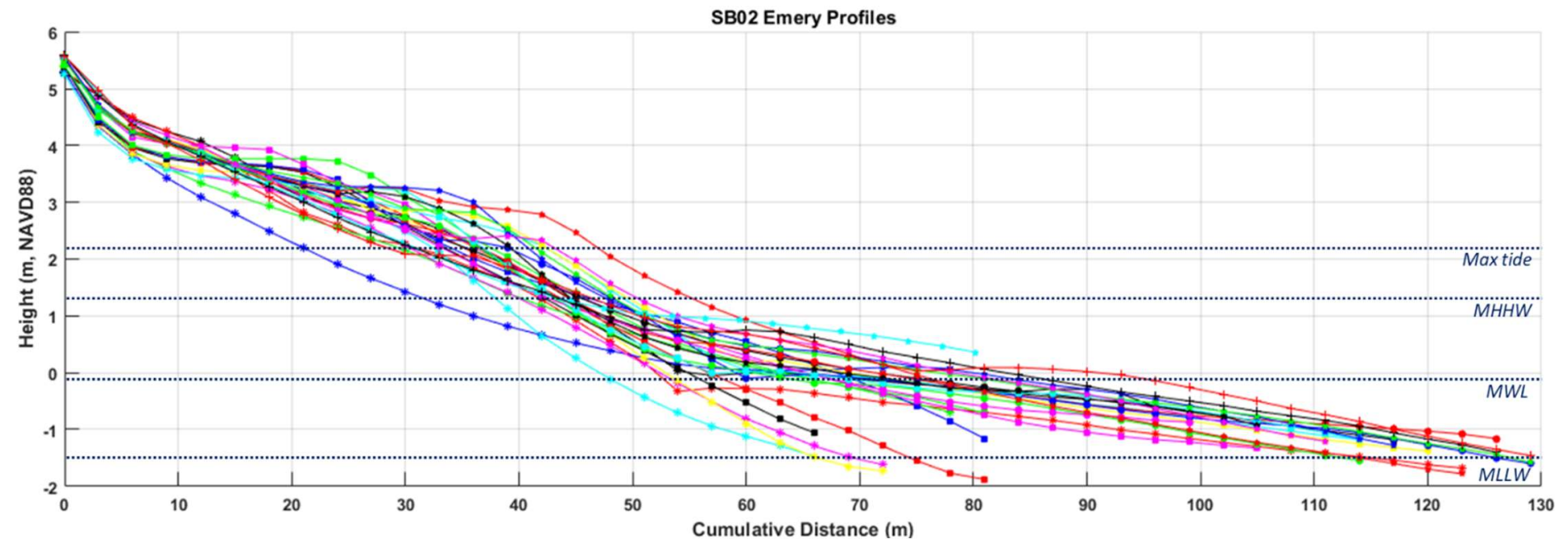

Figure SB02-5. All thirty-two beach elevation profiles measured at station SB02 from January 29, 2018 to March 9, 2020. Maximum tidal elevation (max tide), mean higher high water (MHHW), mean water level (MWL), and mean lower low water elevation (MLLW) are indicated by the dotted lines.

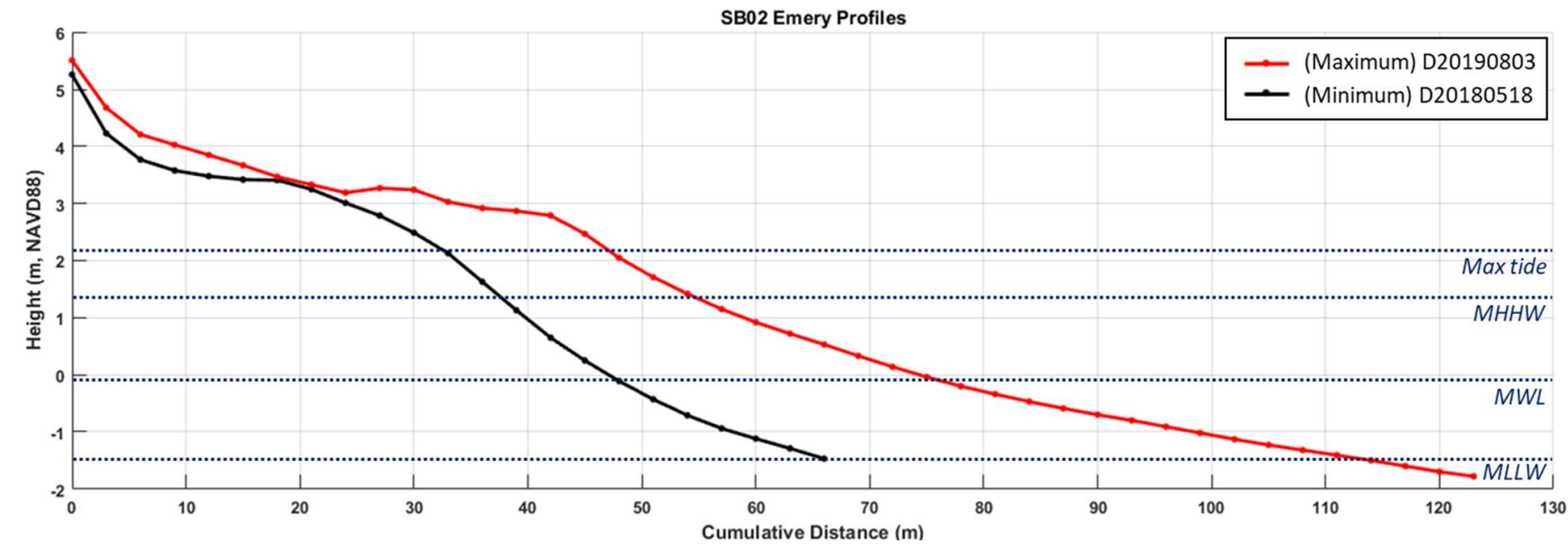

Figure SB02-6. Maximum (August 3, 2019) and minimum (May 18, 2018) profiles from the study period at station SB02. Note that this is not the impact of a single event as the profiles are not consecutive monitoring dates. Rather this comparison looks at the extreme of differences of beach elevation profiles over the entire study period. 

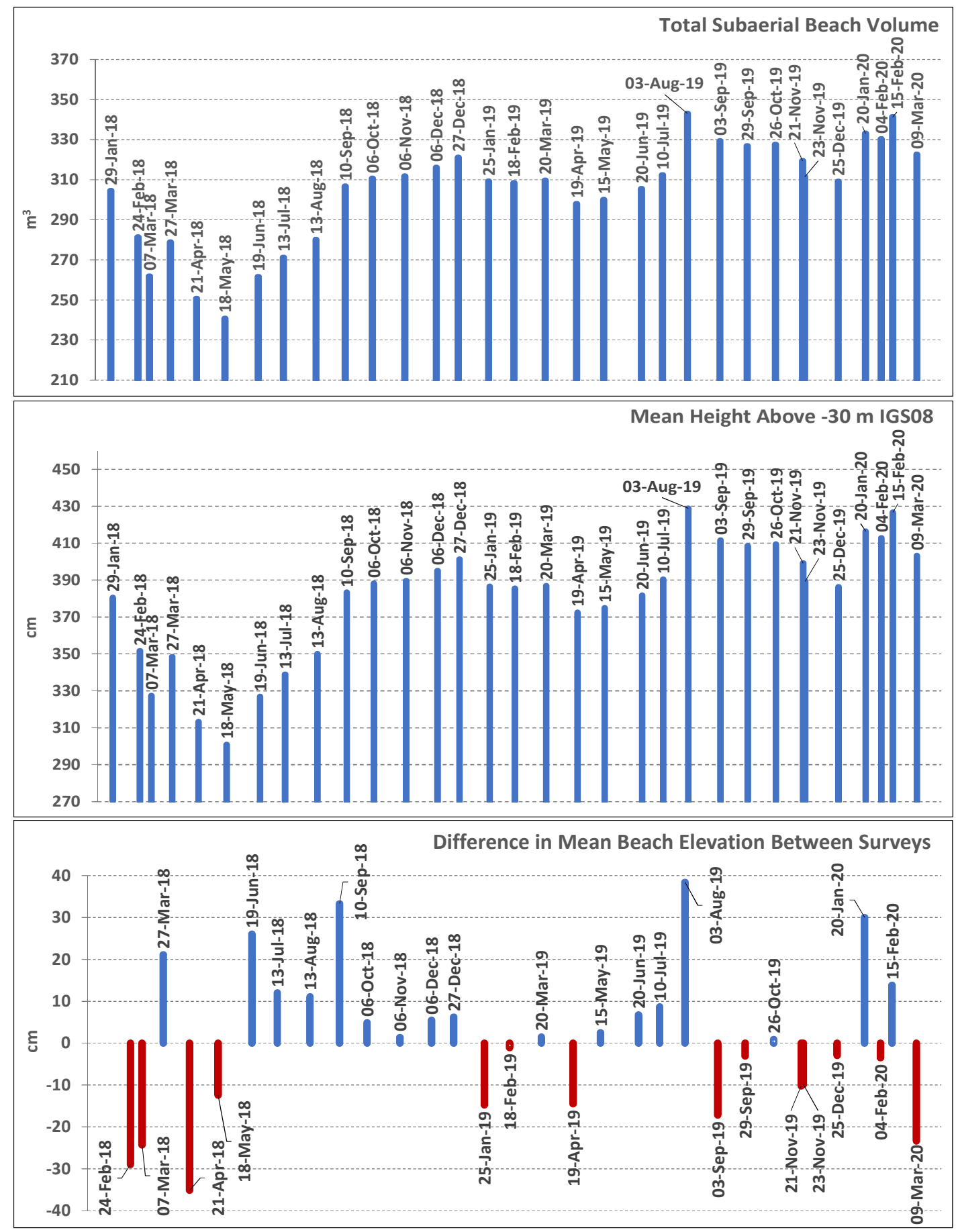

Figure SB02-7. Calculated sediment volume, mean profile elevation, and mean elevation change for the beach profile at station SB02. These parameters were calculated from 0-80 m of the profile length. Six of the thirtytwo elevation profiles were shorter than the "standard profile length" for the station $(80 \mathrm{~m})$. These profiles were extended using the procedure described in Chapter 2: Methods. Four of the profiles were extended less than 8.0 $m$ which is considered negligible (two were $2.0 \mathrm{~m}$ ). One of the larger extensions $(14.0 \mathrm{~m}$ May 18, 2018) was due to the late winter and early spring 2018 storms which eroded the lower beach. The $14.0 \mathrm{~m}$ extension on July 13 likely was due to the profile being run nearly 90 minutes after low tide and a rapid rise of the tide. 
Storm Effects, Beach Erosion, and Recovery. The beach at SB02 was exposed to several winter storms in January and February 2018 including Grayson (Jan 3 -5), Inga (Jan 17-18), an unnamed period of high waves (Jan 29-31), Liam (Feb 7-9), and Noah (Feb 16-18) (Table 3-3). This series of storms, although not overwhelming in strength, with perhaps the exception of Grayson and the unnamed wave event, undoubtedly eroded the beach and lowered the overall elevation as shown by the sediment volume calculations and beach profiles on January 29 and February 24 (Figures SB02-7 and SB02-8).

Consequently, the beach was more susceptible to erosion by the time the series of severe nor'easters in late winter 2018 arrived including Riley (Mar 1-4), Quinn (Mar 6-9) and Skylar (Mar 12-14), and high wave energy events (which occurred on Mar 21-23 and Apr 15-17) (Table 3-3). For example, the elevation profile measured on March 7, 2018 shows the impact of the first of these three nor'easters (Figure SB02-9). The beach was significantly eroded in the upper profile leaving a scalloped or convexupward appearance with some of the sediment deposited on the lower beach or the low tide terrace. The force of the waves, along with the high tides and storm surge (Figure SB02-10), eroded the upper beach and pushed sand into the dunes with each storm (Figures SB02-11 to SB02-14).

The elevation profile measured on May 18, 2018 after all three nor'easters and additional storms (discussed below) shows the upper beach not eroded as badly as on March 7, but the lower part of the beach is highly eroded (Figure SB02-15). These features make it the minimum average elevation profile of the study period. It appears the additional nor'easters further eroded the lower beach (Figure SB02-16) with some of the sediment pushed to the upper beach and likely into the dunes. The impact of the storms is also apparent from the sediment volume. The volume and elevation calculations show a large loss of sand volume and elevation starting with the February 24 profile and reaching the minimum on May 18 before the beach starts to recover (Figures SB02-7). The exception to this is the slightly higher March 27 profile which is likely due to the overall limited length of the area of calculation and because it does not include the lowest part of the beach. The beach started to recover and rebuild its sediment volume and elevation throughout the summer, fall, and very early winter reaching a maximum for the year on December 27, 2018 (Figure SB02-7). 


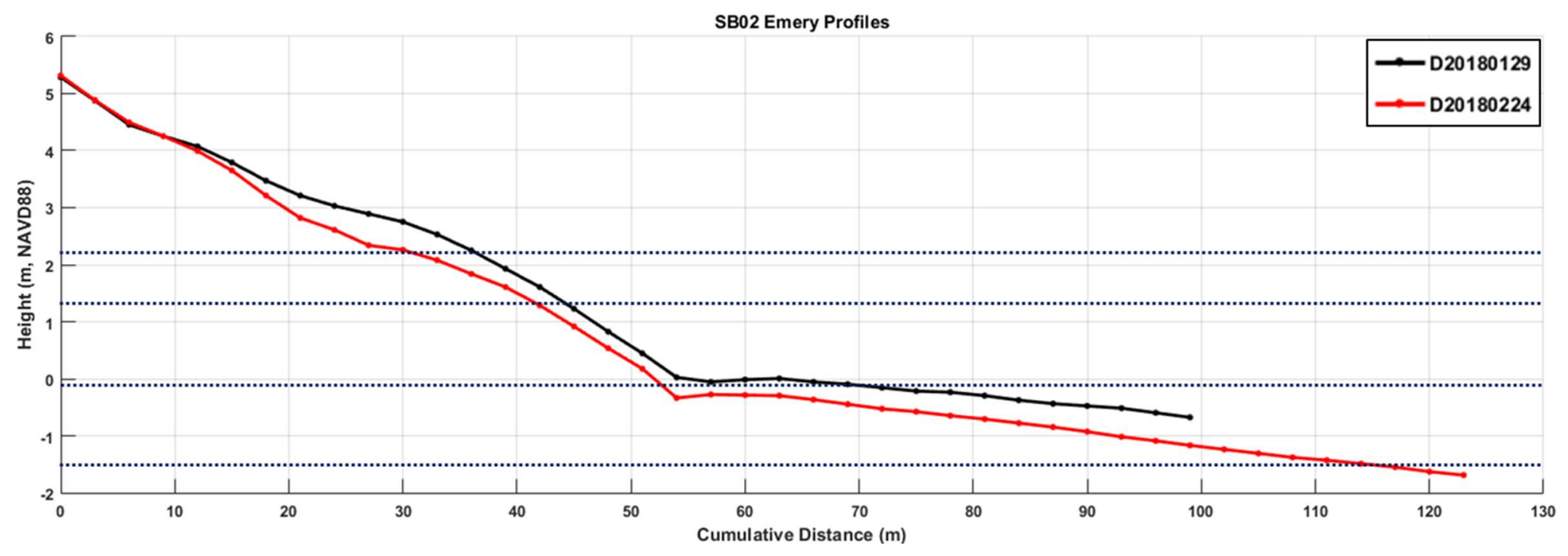

Figure SB02-8. Beach elevation profiles for SBO2 on January 29, 2018 and February 24, 2018.

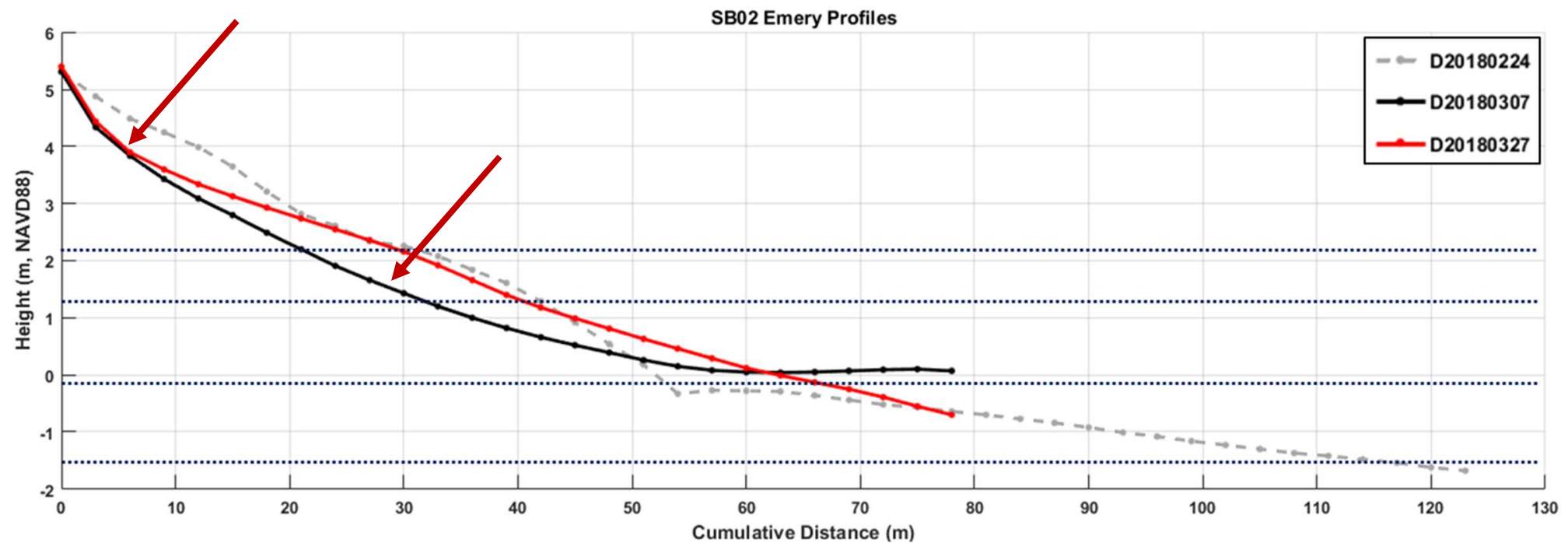

Figure SB02-9. Beach elevation profiles for SBO2 on February 24, 2018, March 7, 2018, and March 27, 2018. Note the significant erosion that occurred in the upper and middle beach in March after the nor'easters (arrows). Also, the lower beach has been totally eroded and is now subtidal. 


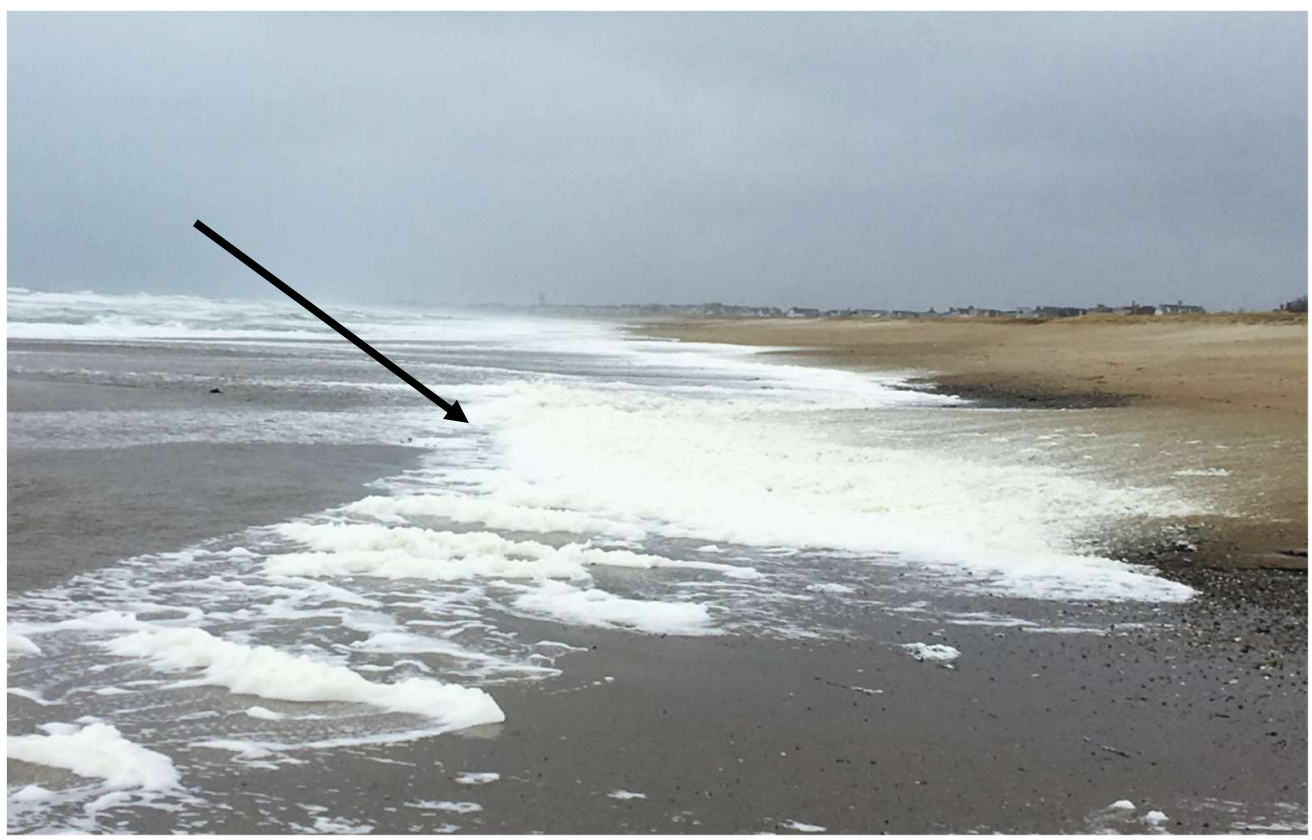

Figure SB02-10. Swash zone at low tide at SBO2 on March 7, 2018 during a stormy period. The strong backrush (seaward flow) of the swash can erode the lower beach. The photograph is looking south.

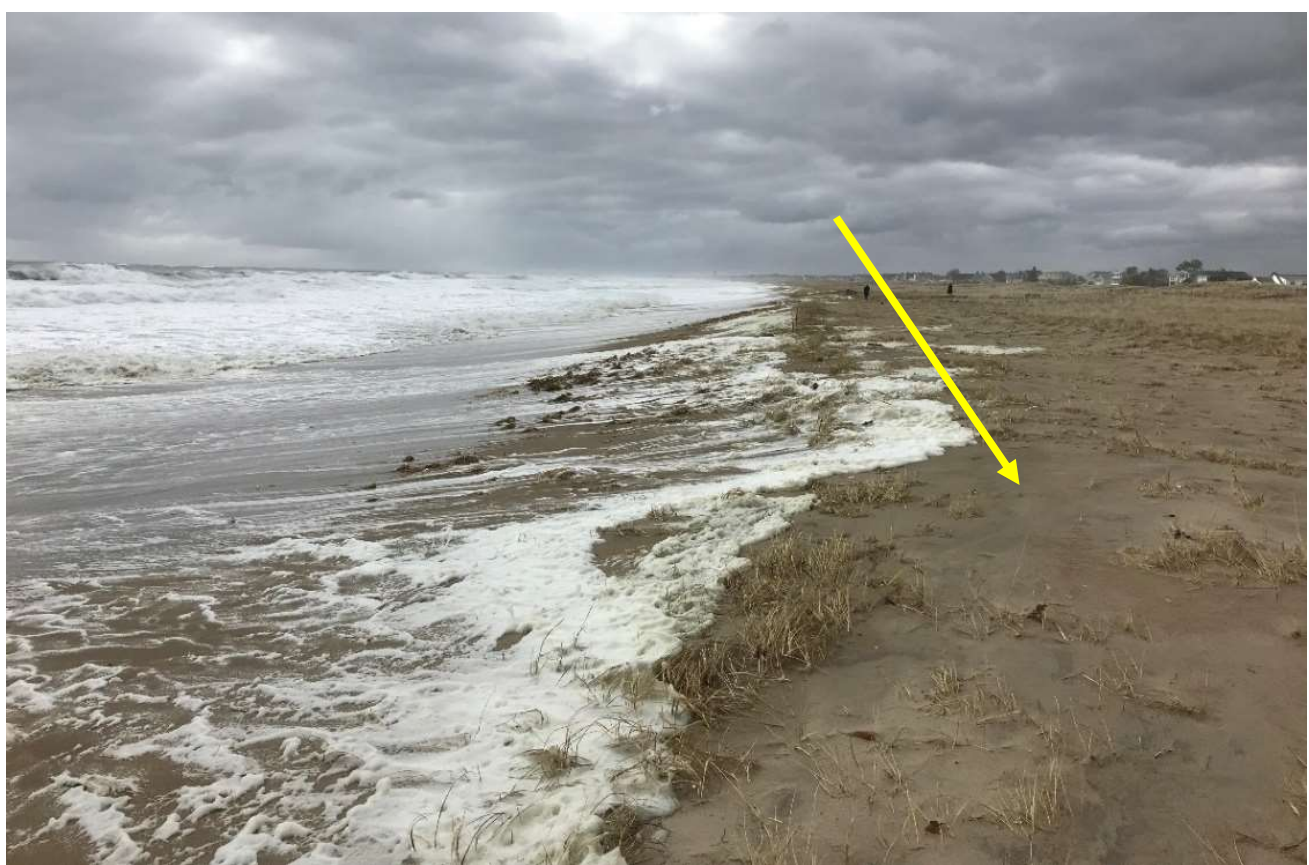

Figure SB02-11. Dune erosion and overwash that occurred during Nor'easter Riley. The photograph taken on March 3, 2018 from close to SBO2 shows the waves eroding the beach and foredune and forcing sand into the dunes (arrow). 


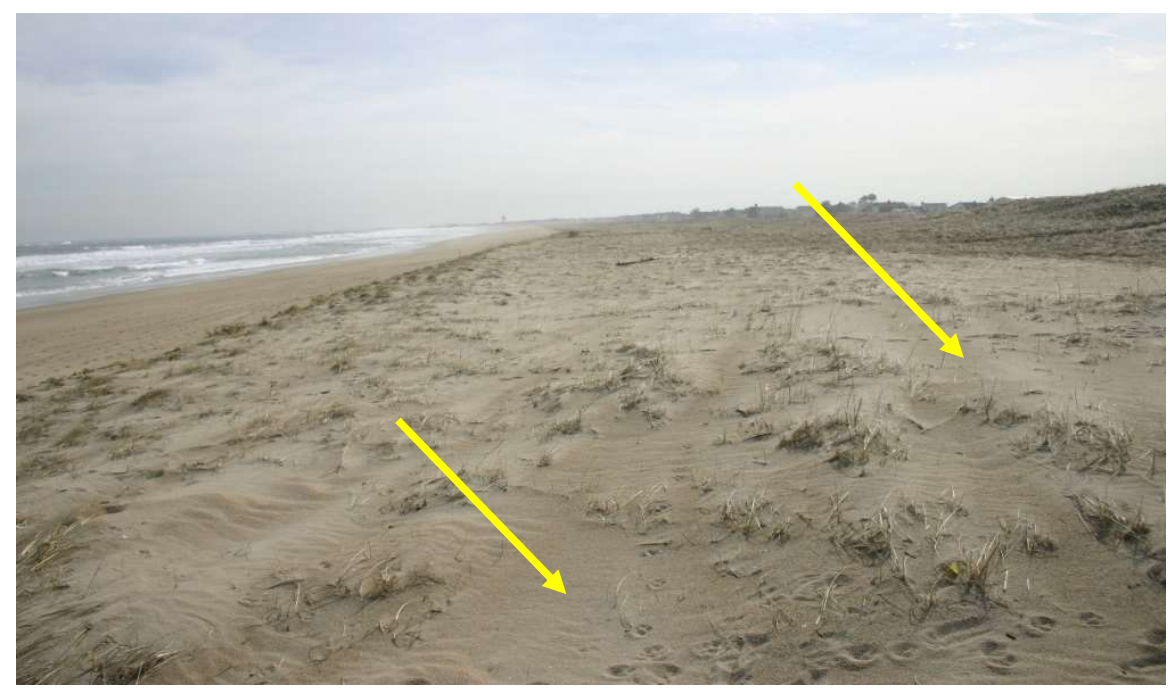

Figure SB02-12. During the March 2018 severe nor'easters the foredunes were eroded and sand transported further into the dunes (arrows). The photograph was taken from near SBO2 on March 28, 2018 and is looking south.

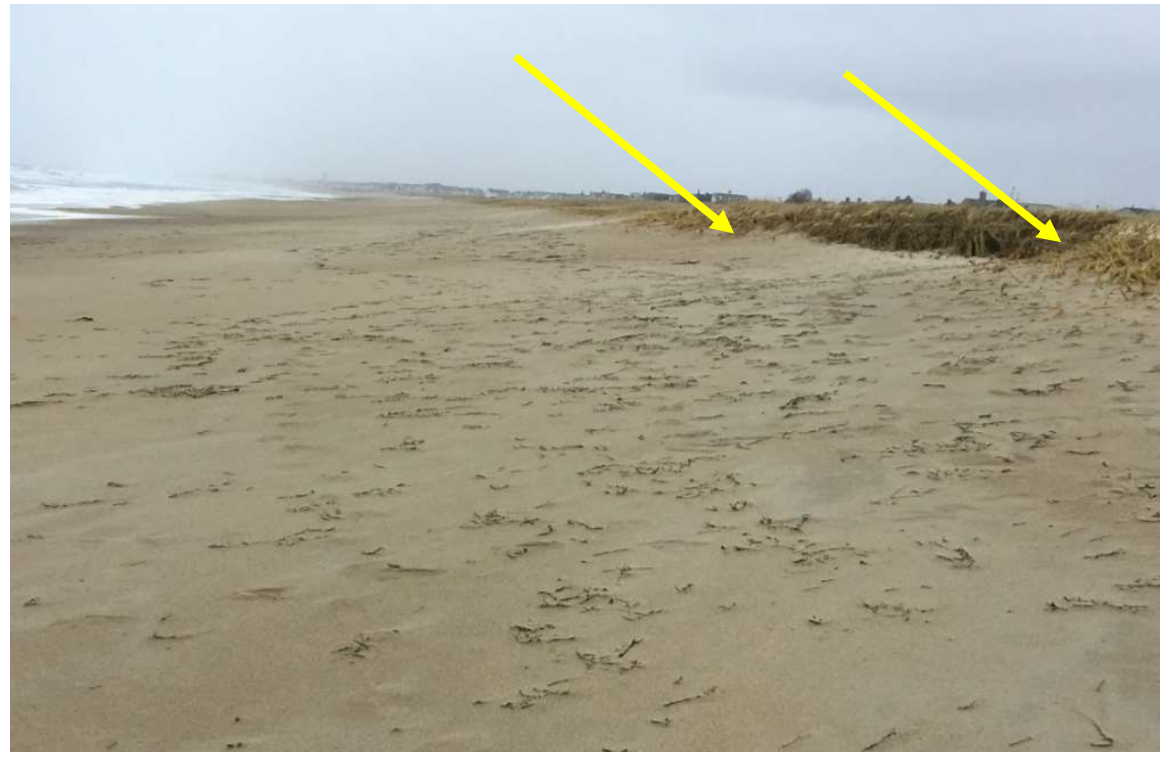

Figure SB02-13. Upper beach near station SB02 on March 7, 2018 following Nor'easter Riley. The beach has been highly eroded and is relatively flat. Note the scarps in the dunes (right arrow) and signs of overwash (left arrow). The photograph is looking south.

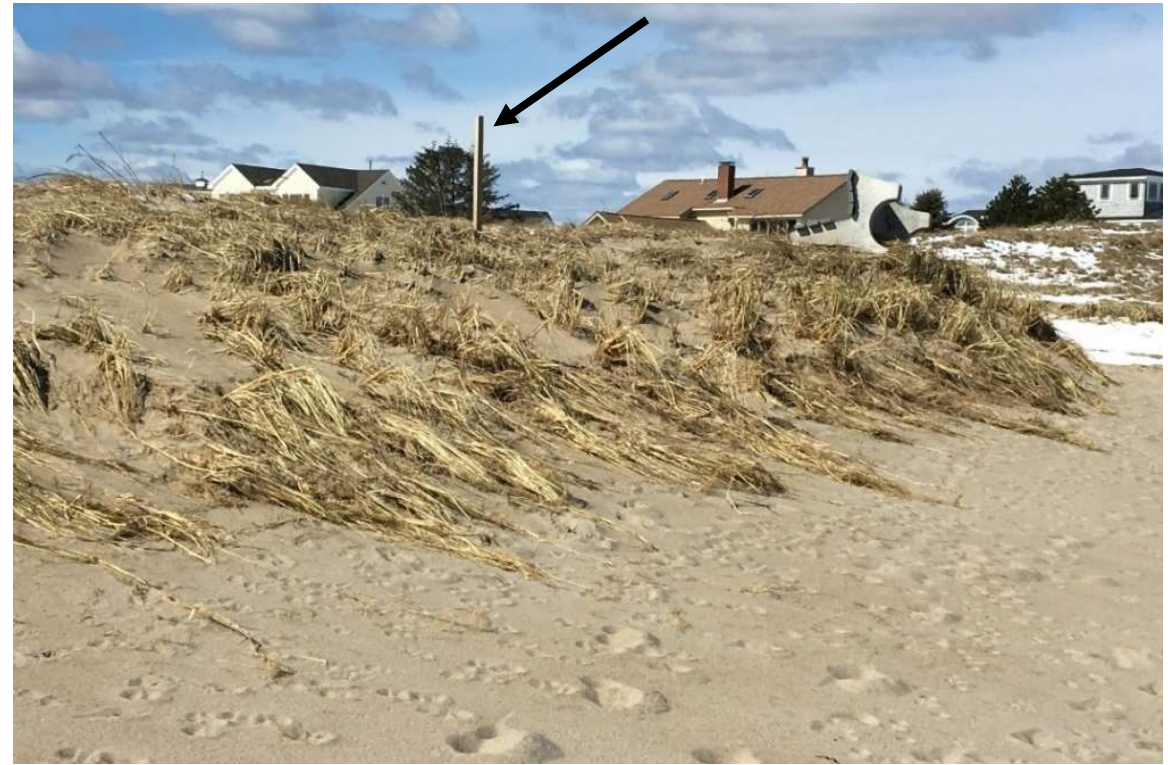

Figure SB02-14. Eroded foredunes at SB02. The photograph was taken on March 11, 2018. The front post (station marker) for the beach elevation profile transect is shown by the arrow. 


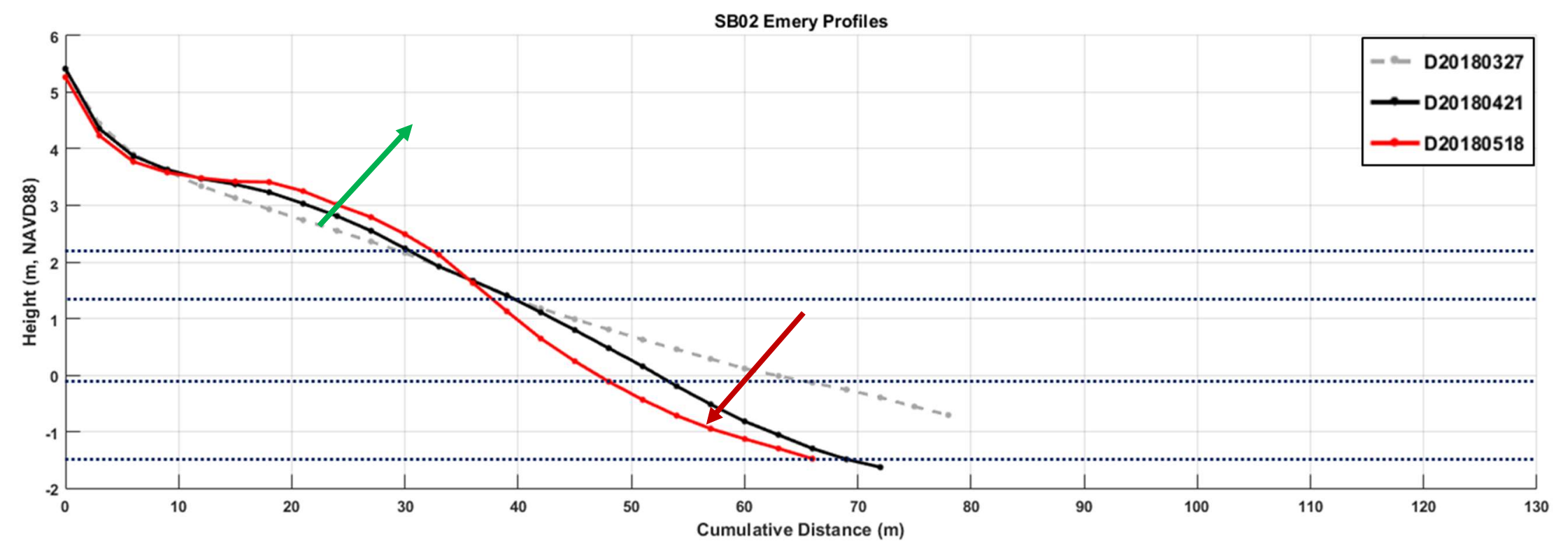

\begin{tabular}{l|l|}
$\begin{array}{l}\text { Figure SB02-15 (above). } \\
\text { Beach elevation profiles for } \\
\text { SB02 on March 27, 2018, } \\
\text { April 21, 2018, and May 18, } \\
\text { 2018. Note the slight } \\
\text { increase in elevation of the } \\
\text { upper-middle beach (green } \\
\text { arrow) but the severe } \\
\text { erosion that occurred in } \\
\text { the lower beach in April } \\
\text { and May (red arrow). }\end{array}$ & $\begin{array}{l}\text { Figure SB02-16 (right). } \\
\text { Rills formed on the low } \\
\text { tide terrace after an } \\
\text { erosive period at } \\
\text { station SB02. The } \\
\text { photograph is looking } \\
\text { south and was taken on } \\
\text { May 18, 2018. }\end{array}$ \\
\hline
\end{tabular}

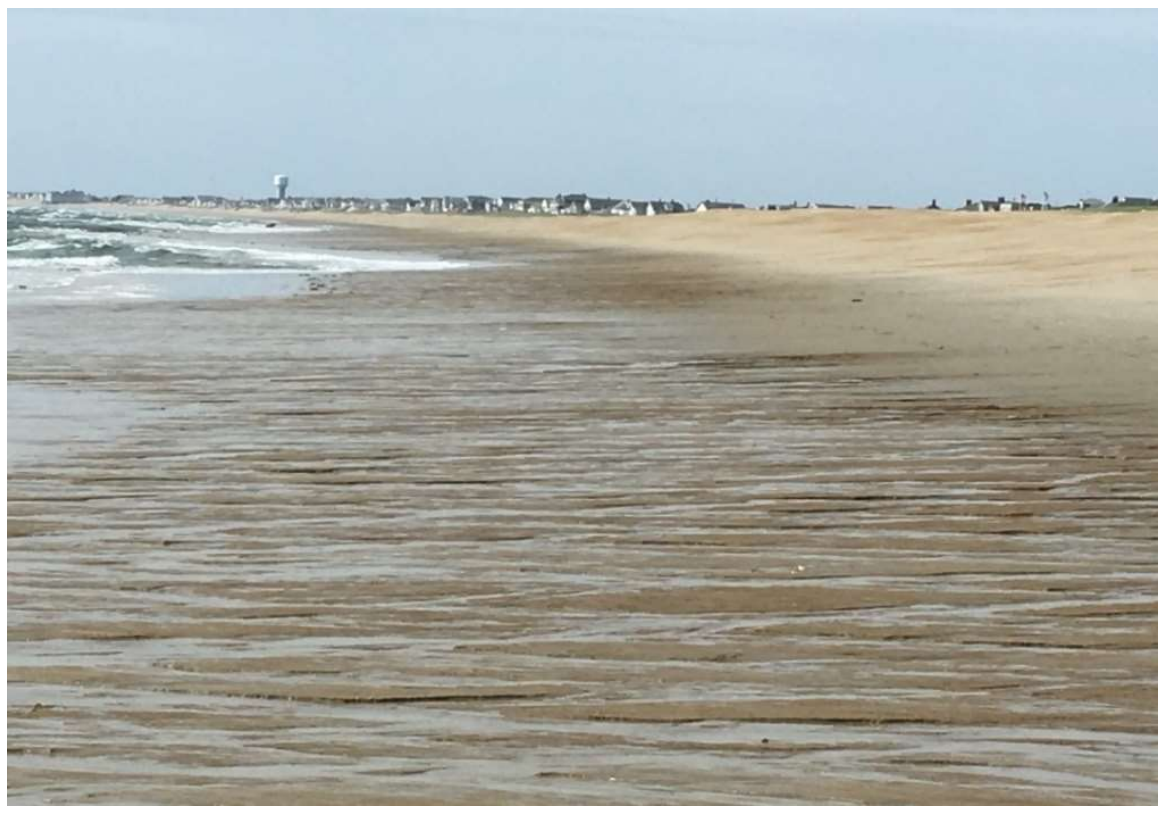


A second period of decline in elevation and loss of sediment volume occurred in 2019 starting in January and reaching a minimum on April 19 and May 15 (Figure SB02-17), although the losses were minimal in comparison to late winter 2018 (Figure SB02-7). In fact, the losses are close to the uncertainty of the measurements and calculations. However, the decline appears to be persistent over several months. Following this decline, the beach returned to what appears to be summer equilibrium conditions reaching the maximum for the study period on August 3 (Figures SB02-7 and SB02-18). During fall 2019, the beach maintained its elevation and volume (Figure SB02-19), despite losses at the other stations on Seabrook Beach. This in part may be due to the proximity of the beach nourishment project taking place adjacent to the station site. There was a slight loss of volume in November and December 2019, but the losses were minimal (Figure SB02-7).

Following the small losses in volume and elevation in December 2019, the beach began to accrete sediment as evidenced by a ridge and runnel seen on the December 25, 2019 profile (Figure SB0220). The ridge is evident in the next four profiles completed in January and February 2020 along with an increase in sediment volume and elevation (Figures SB02-7 and SB02-21 to SB02-24). The beach at SB02 increased in volume and mean elevation reaching a near maximum on February 15, 2020. Again it is likely the increase in sand volume and mean elevation at SB02 resulted from the beach nourishment project and the placement of sand on the beach just north of the station. Longshore drift likely transported some of the sediment south which was deposited at SB02. However, the increase appears to have diminished in March 2020, but lack of continued monitoring due to the pandemic precludes a final determination of the impact of the beach nourishment. 


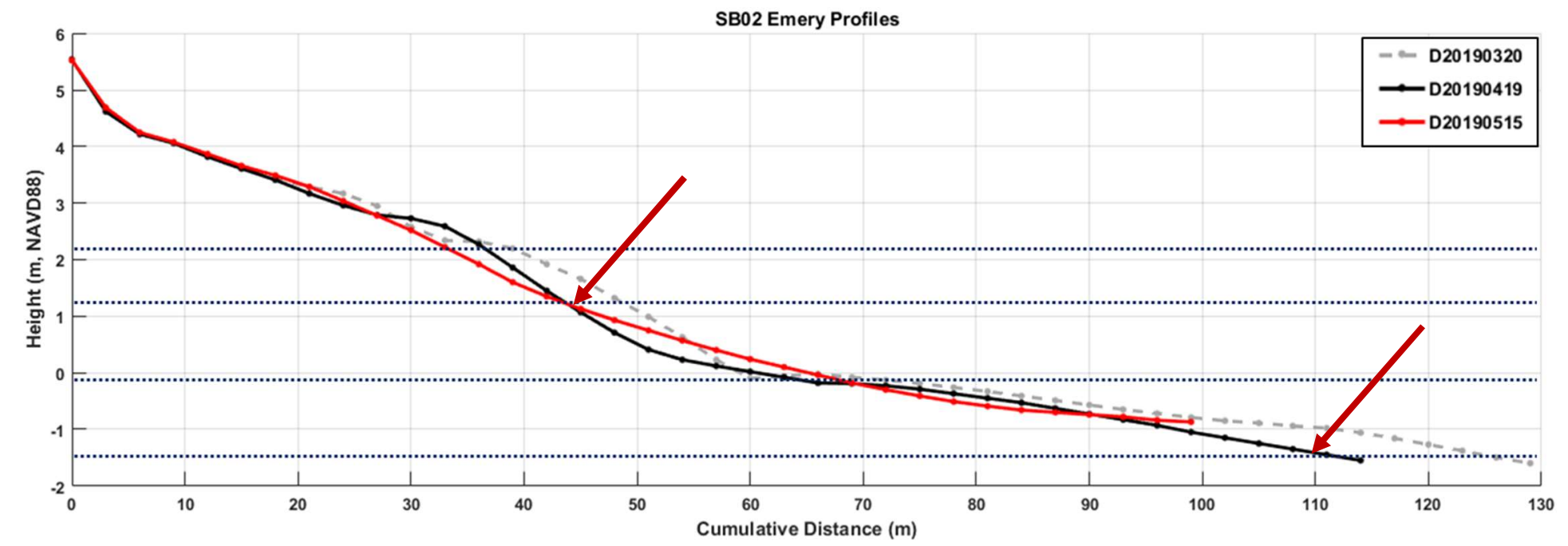

Figure SB02-17. Beach elevation profiles for SBO2 on March 20, 2019, April 19, 2019, and May 15, 2019. Note the slight erosion in the upper-middle beach (left arrow) and on the low tide terrace (right arrow).

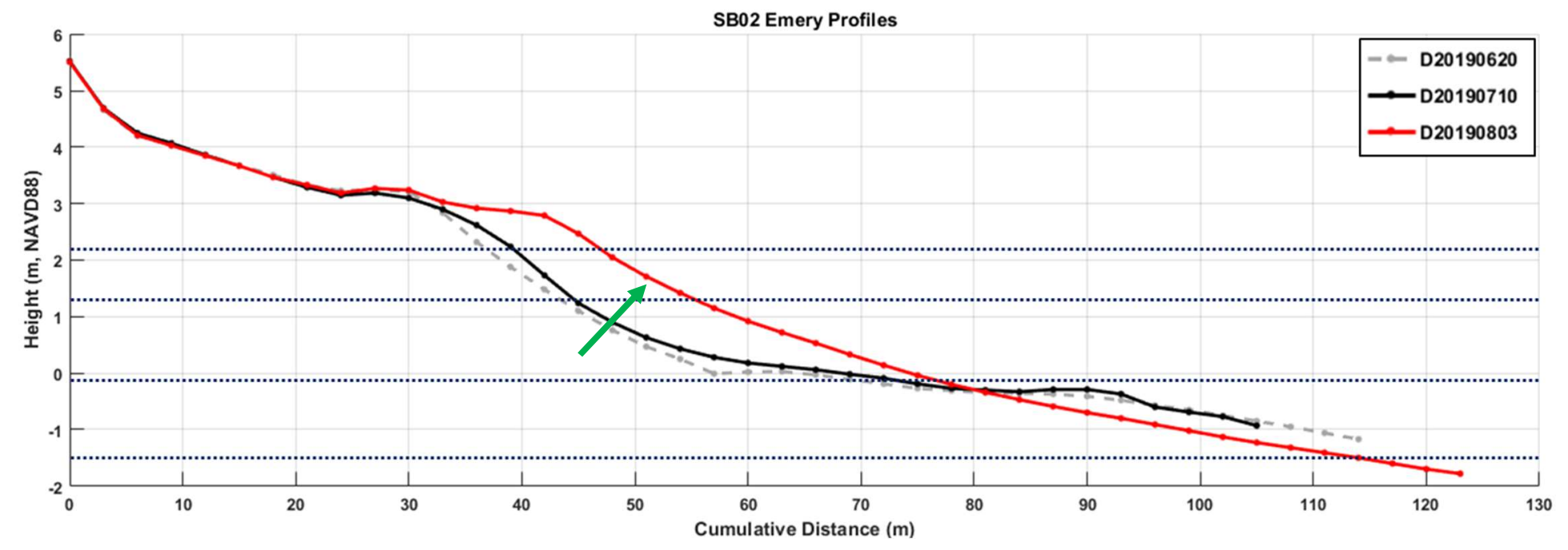

Figure SB02-18. Beach elevation profiles for SBO2 on June 20,2019, July 10, 2019, and August 3, 2019. Note the recovery of the upper-middle beach as seen by the profile on August 3 (arrow), which was the profile with the maximum elevation and volume of the entire study period. 


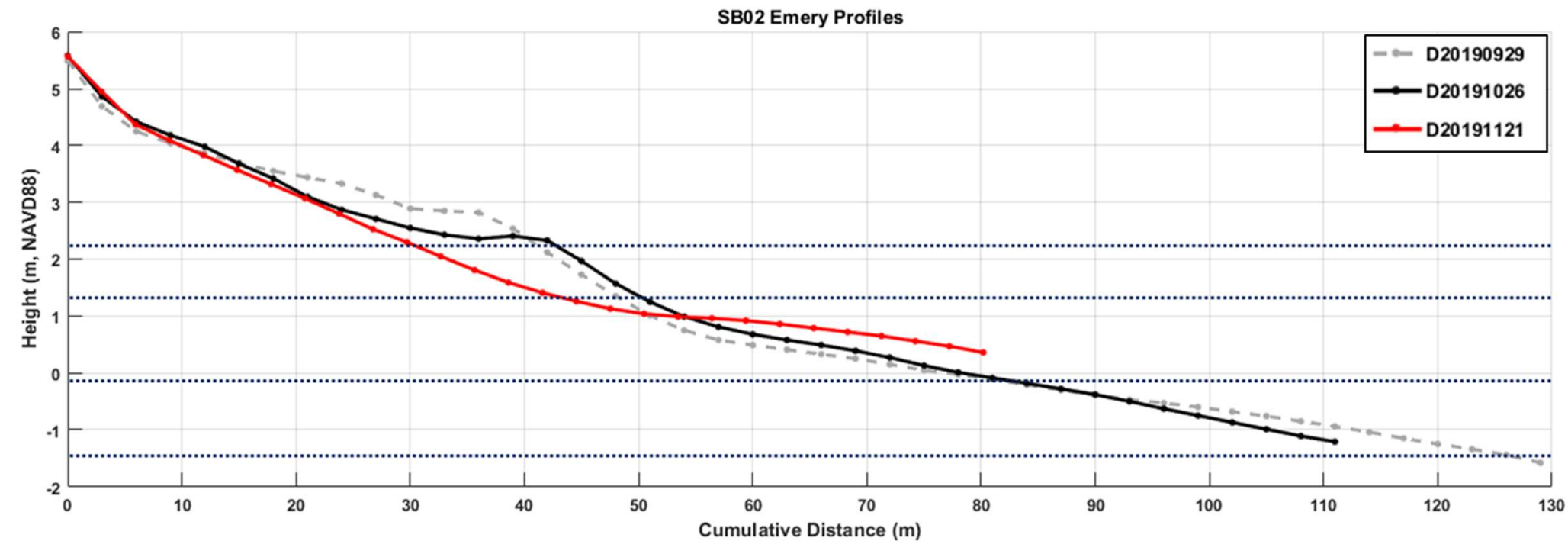

Figure SB02-19. Beach elevation profiles for SB02 on September 29, 2019, October 26, 2019, and November 21, 2019.

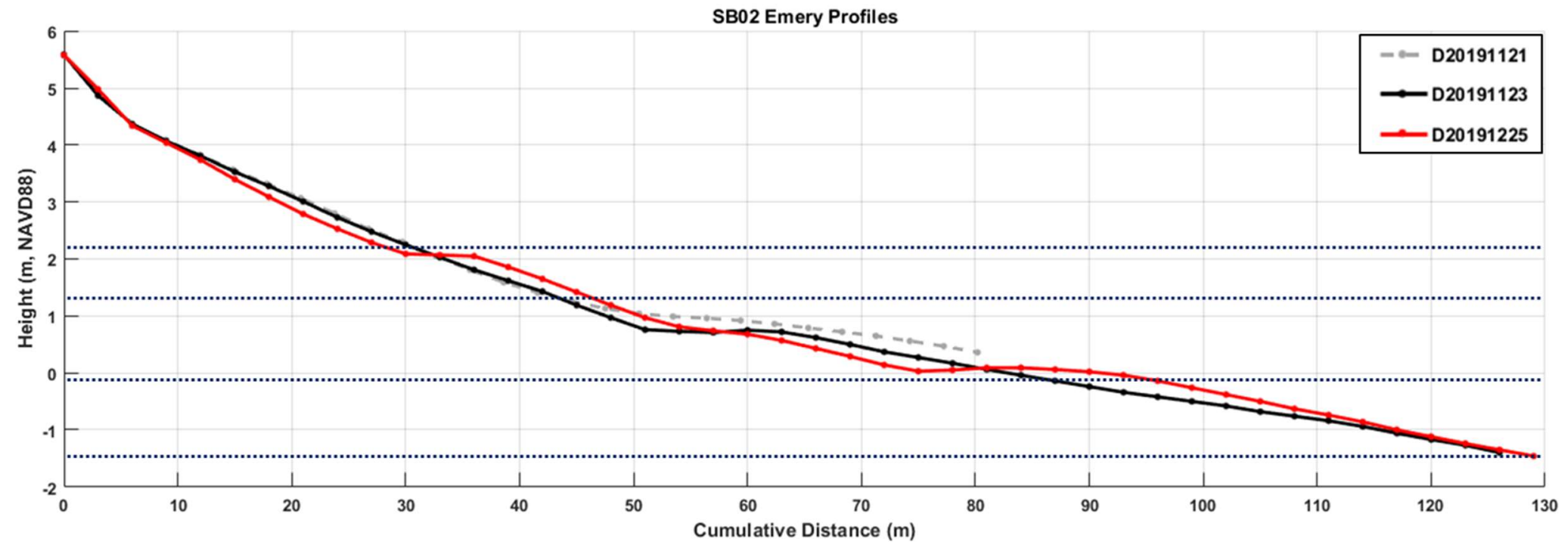

Figure SB02-20. Beach elevation profiles for SB02 on November 21, 2019, November 23, 2019, and December 25, 2019. 


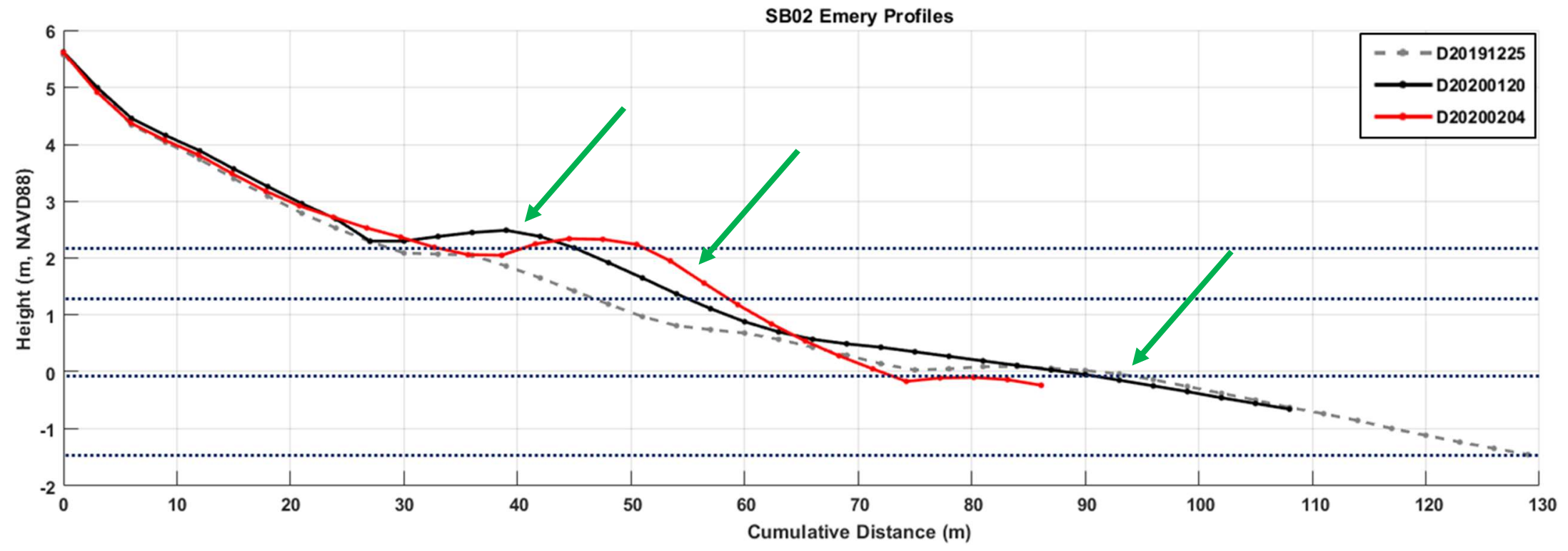

Figure SB02-21 (above). Beach elevation profiles for SB02 measured on

December 25, 2019, January 20, 2020, and February 4, 2020. Note the ridge and runnel system that began to form in December 2020 (right arrow) and continued to move landward in January (middle arrow). It is not clear how the large berm formed in February (left arrow), but it appears to be a modification of the ridge, either natural or by humans.
Figure SB02-22 (right). Ridge and runnel system (arrow) that started to form on the low tide terrace at station SB02. The photograph is looking north and was taken on December 25, 2019.

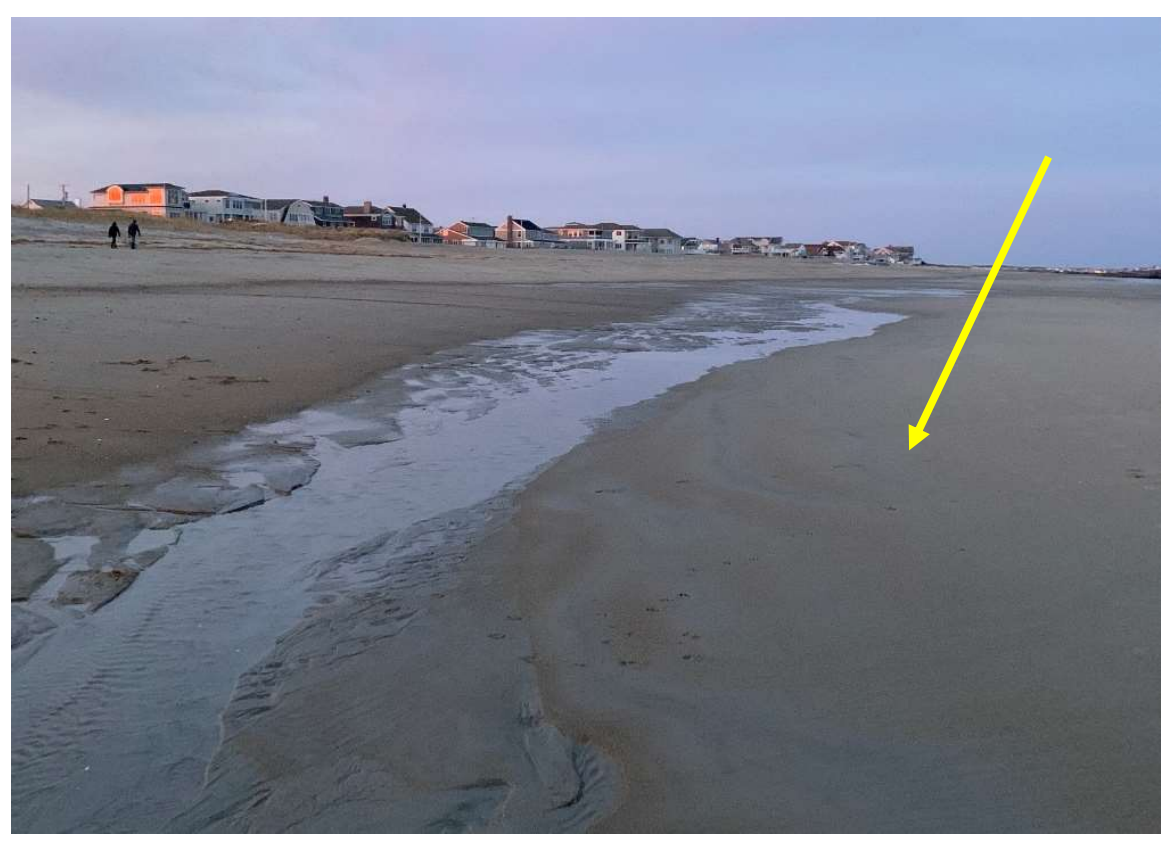




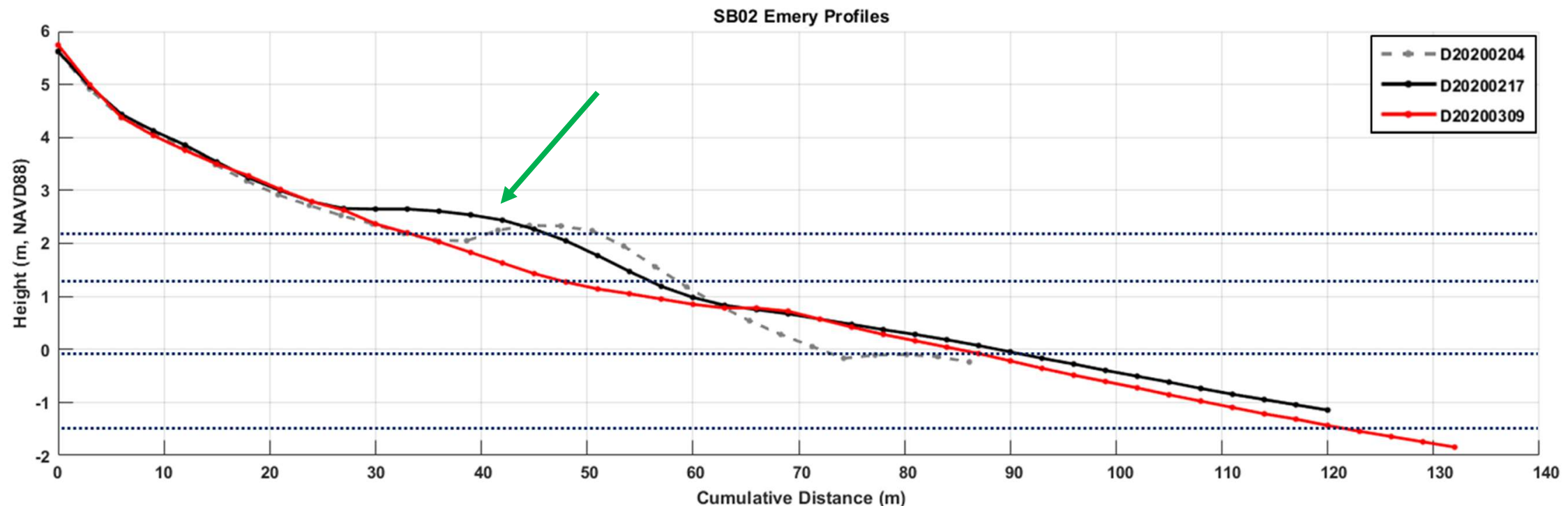

Figure SB02-23 (above). Beach elevation profiles for $\mathrm{SBO2}$ on February 4, 2020, February 17, 2020, and March 9, 2020. The ridge and runnel system seen in Figure SB02-21 continued to move landward and rebuilt the berm as seen on February 17 profile (arrow). However, an erosive event removed the berm by March 9. Note that this profile extends to $140 \mathrm{~m}$, rather than the standard $130 \mathrm{~m}$ for other SB02 profile plots.
Figure SB02-24 (right). Ridge and runnel system (arrow) that continued to move landward on the beach at station SB02. The photograph is looking south and was taken on February 4, 2019.

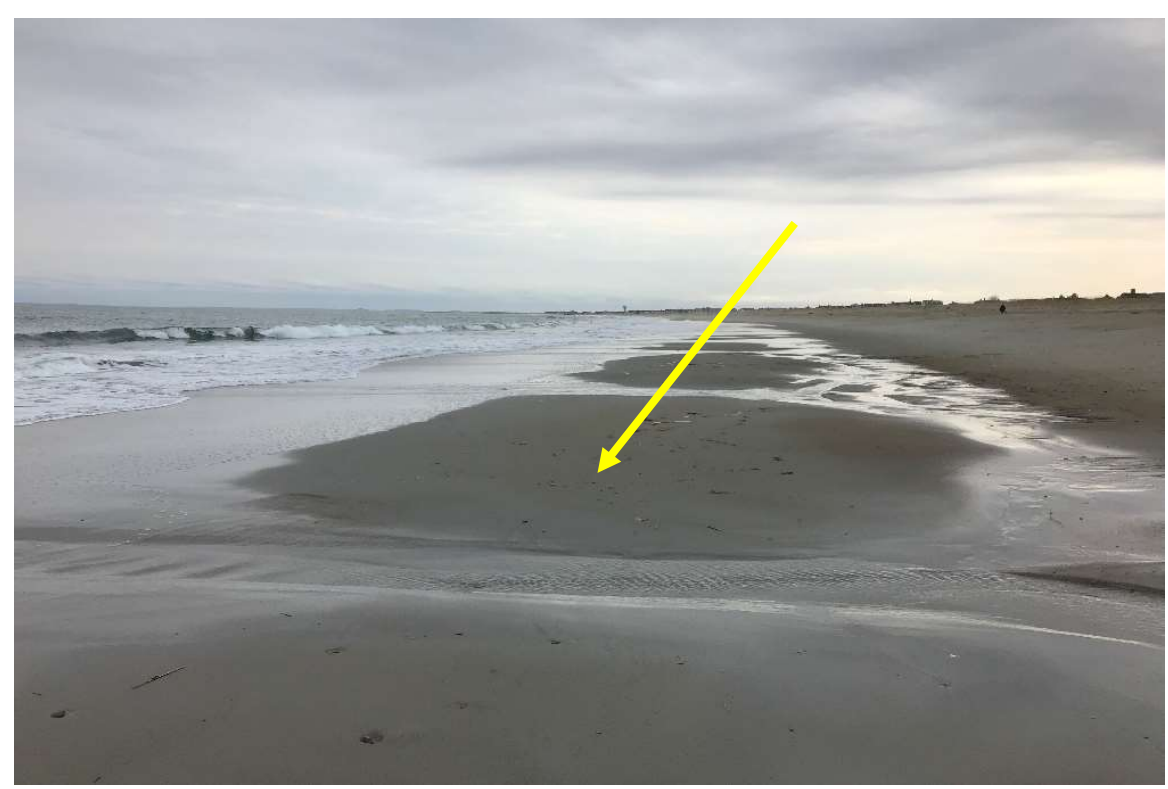




\section{Results for Station at Mid Seabrook Beach: SB04}

Overview. Station SB04 is located $\sim 1.5 \mathrm{~km}$ south of the jetty at Hampton Harbor Inlet, $\sim 0.6 \mathrm{~km}$ south of SB02 and seaward of Lawrence Street (Figure SB-1). The beach tends to have a relatively narrow backshore, a well-defined berm and steep berm face (Figure SB04-1), and a flat lower beach or low tide terrace during accretional conditions (Figure SB04-2). Ridge and runnels can be relatively common (Figures SB04-3 and SB04-4). However, the beach becomes narrower, loses morphologic definition, and has a concave-upward profile following erosive events (Figure SB02-5). Landward of the profile are well-developed dunes 90 to $100 \mathrm{~m}$ in width (Figure SB04-6). All private homes and infrastructure are landward of the dune system and therefore are well protected from storm surge and erosion at the present time. During major storms with significant storm surge and waves, sand is eroded from the beach and pushed into the dunes during overwash events (Figures SB04-7 and SB048).

The beach elevation profile transect extends $\sim 90 \mathrm{~m}$ to $110 \mathrm{~m}$ seawards from the foredune ridge (Figures SB04-9 and SB04-10) to the low tide line (Figure SB04-11). The station is marked by wooden stakes. Unlike other stations on the $\mathrm{NH}$ coast the dunes between the landward stake and seaward stake were also profiled along with the beach at SB04 (SB05 as well). The results of this work will be reported elsewhere. Here we focus on the intertidal beach from the foredunes to the low tide swash. Similar to most of Seabrook Beach, sand and granule dominate the sediments. After storms, pebbles may be scattered across the beach. Unlike the other two Seabrook Beach stations, a small bedrock outcrop is found offshore and to the north of station SB04. However, the bedrock does not appear to have a major impact on the beach.

Summary. The elevation profiles and sediment volume calculations show that the beach went through three periods of erosion and accretion during the study period: late February to June 2018; April to June 2019; and November 2019. Ignoring small profile-to-profile changes, the trends indicate that the beach underwent major erosion and a change in morphology as a result of the series of powerful nor'easters in late winter 2018. Unfortunately, logistical problems prohibited complete documentation of this period. However, it is clear that the lower beach was significantly eroded causing the width of the beach to become much narrower. However, an important observation between May and June 2018 was that major deposition occurred on the upper beach and in the dunes (due to overwash). The buildup of sediment gave the false impression that the beach was undergoing accretion due to high sand volume calculations on May 18, 2018. However, this did not take into account loss of sediment on the lower beach due to constraints of the method to determine volumes. Recovery of the beach at SB04 did not occur until late summer 2018. The second period of erosive conditions (April to June 2019) occurred due to winter storms, but was not as severe as the late February to June 2018 period. However, both of these events lasted several months which is also an important consideration. A low sediment volume or eroded elevation profile that occurred during only one observation period can be caused by a number of forcings (or even an issue with the field observations), and does not necessarily represent a trend. This is the case for the third erosion period 
in November 2019 which has the lowest volume for the study period but lasted only one month, and therefore the impact to the beach is negligible.

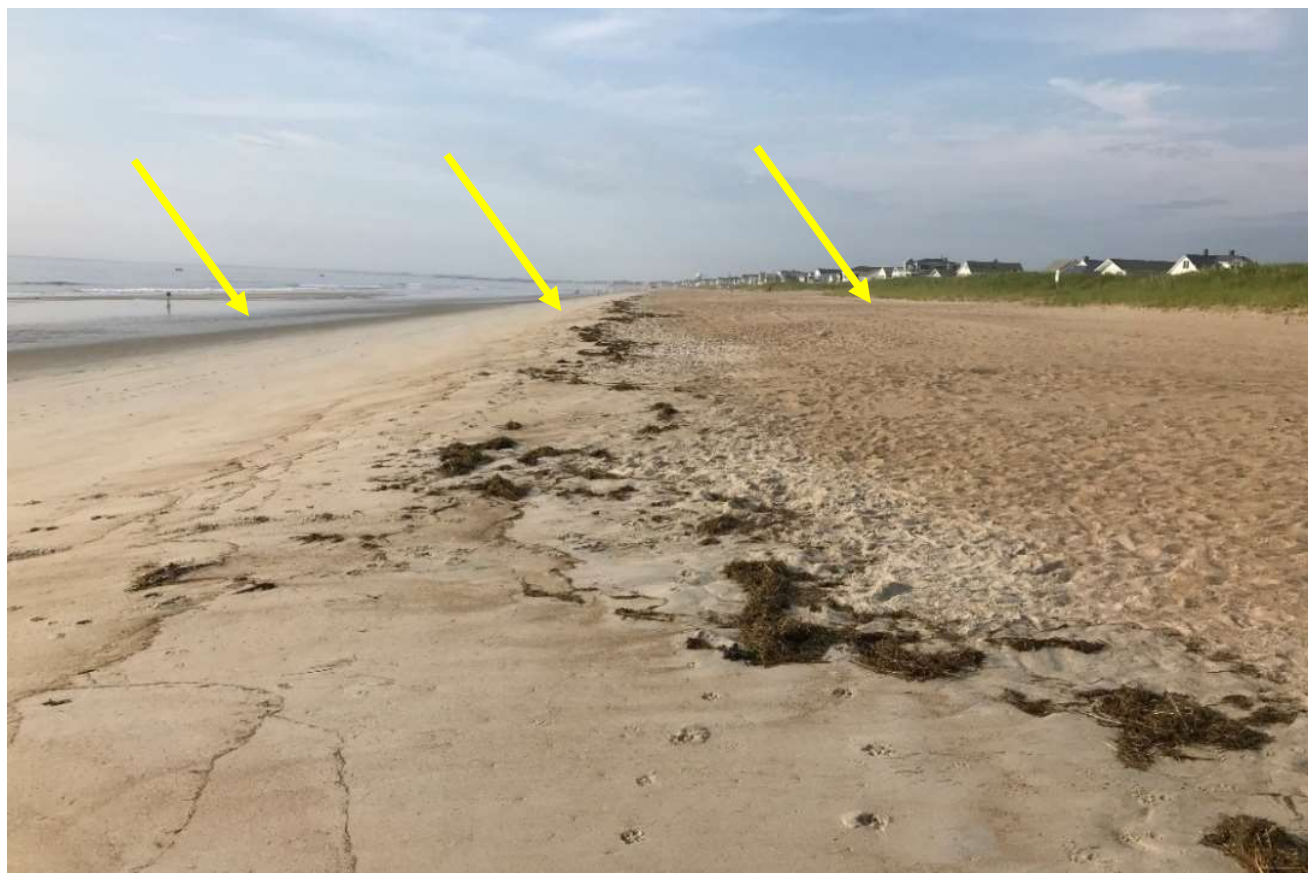

Figure SB04-1. The upper and mid beach at SBO4 under accretional conditions has a flat backshore (right arrow), distinct berm and steep berm face (middle arrow), and a wide flat lower beach or low tide terrace (left arrow). The photograph was taken on August 3, 2019 and is looking south from SBO4.

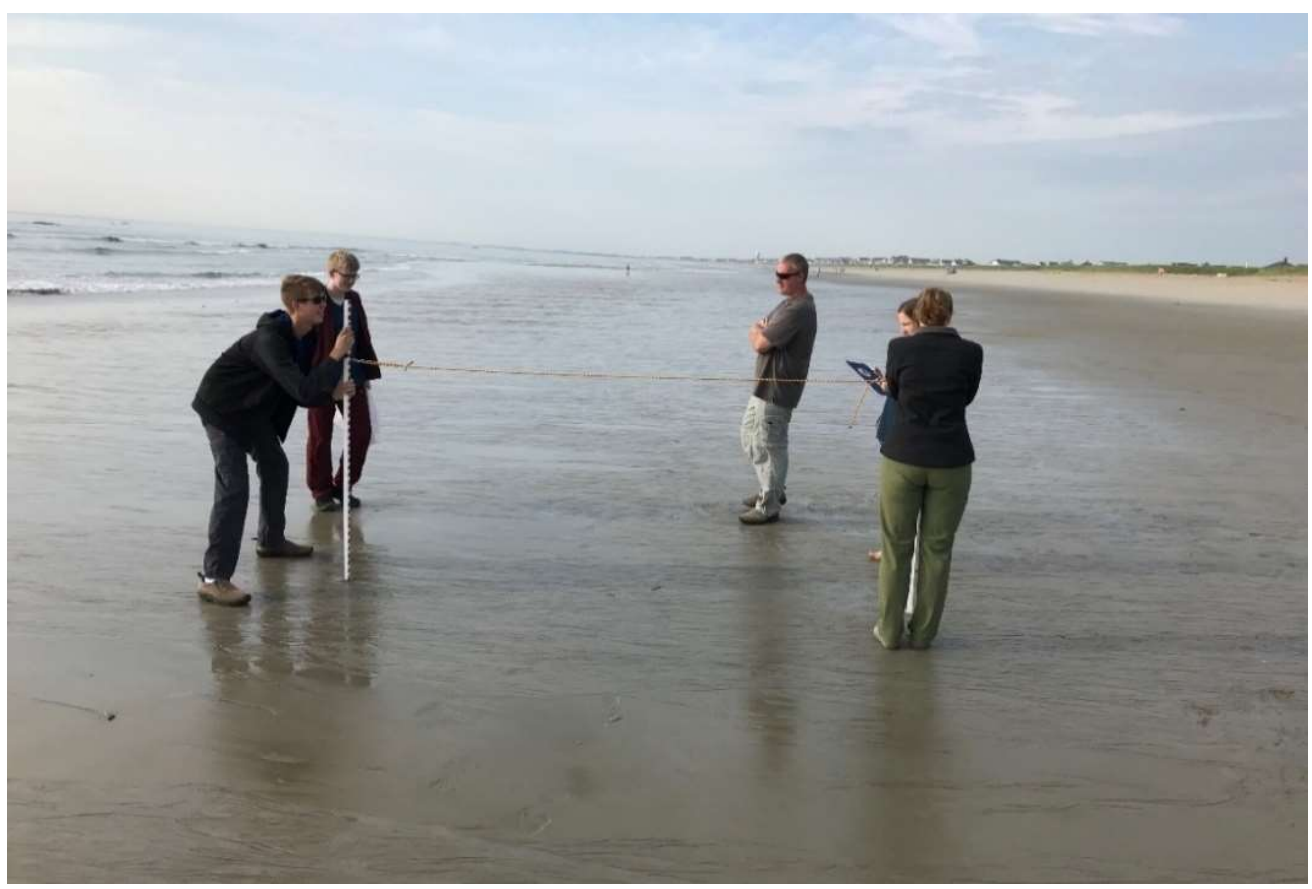

Figure SB04-2. The lower beach at SBO4 under accretional conditions has a wide flat or low tide terrace as seen in the photograph taken on August 3, 2019, looking south. The volunteers are running the profile. 

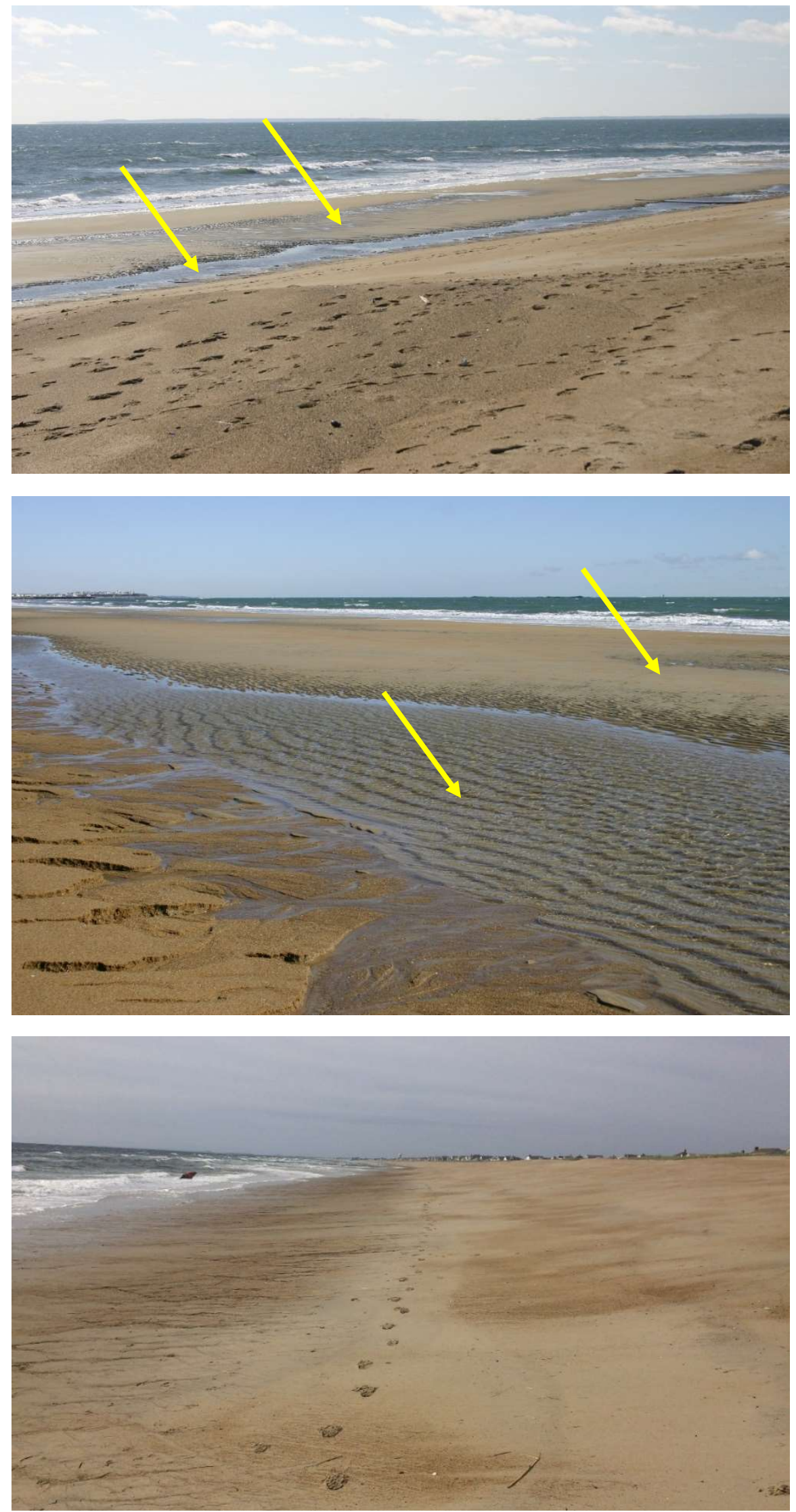

Figure SB04-3. The beach at $\mathrm{SBO} 4$

frequently has large ridge (right arrow) and runnel (left arrow) systems migrating across the beach. The photograph was taken from SB04 on March 18, 2017.

Figure SB04-4. Large ridge (right arrow) and runnel (left arrow) system on SB04. The photograph was taken on March 18, 2017 and is looking north.
Figure SB04-5.

Following storm events the beach often has a steep beachface with a concave-up profile as seen here at SB04 on May 18, 2018. 

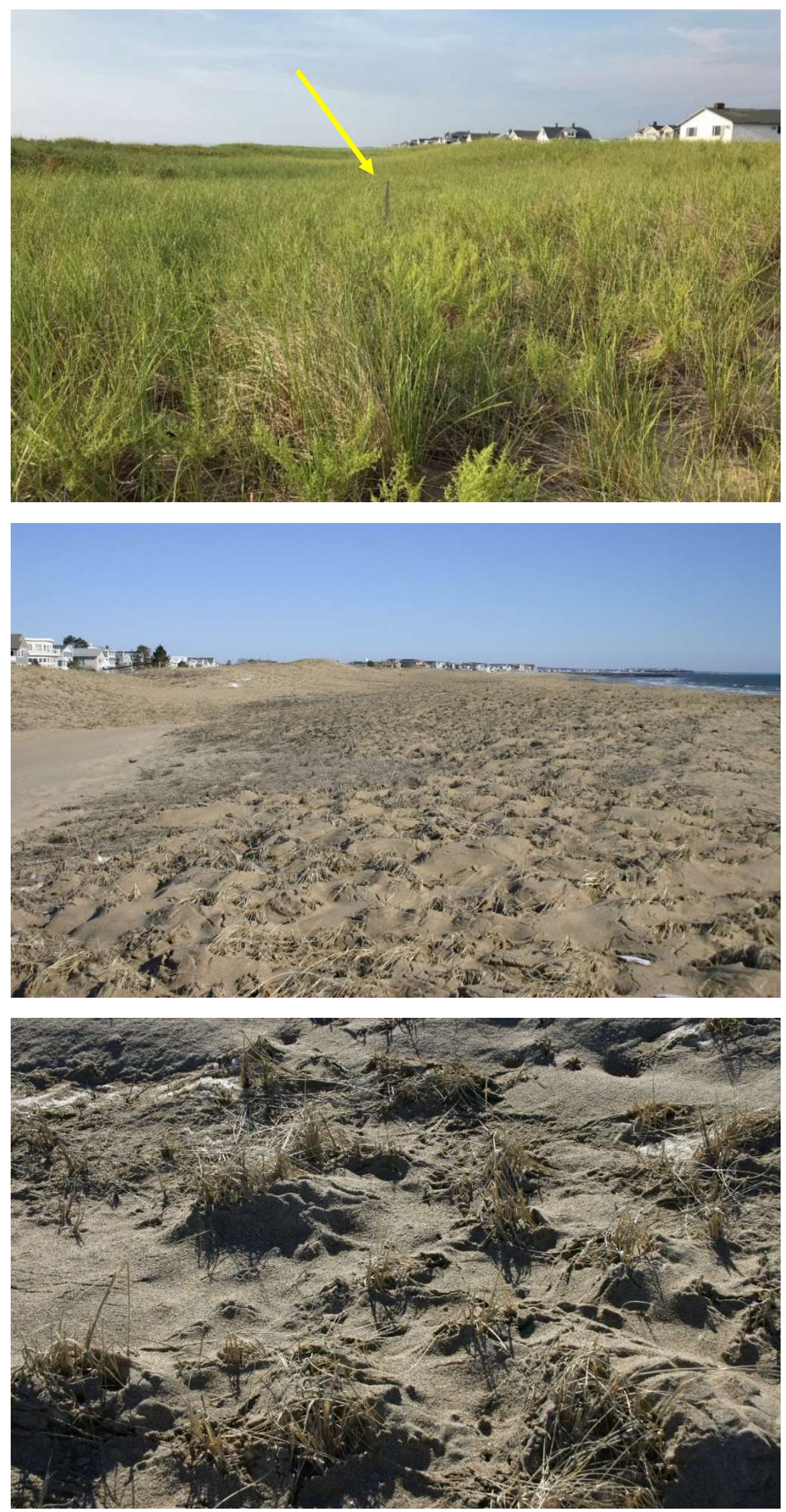

Figure SB04-6. Dune system on Seabrook Beach at SB04 on August 3, 2019. The back stake for the station markers is shown by the arrow.

Figure SB04-7. Sand overwashed into dunes by winter storms, looking north from SB04 on March 18, 2017.

Figure SB04-8. Close-up of sand overwashed into dunes by winter storms, taken on March 18, 2017. 


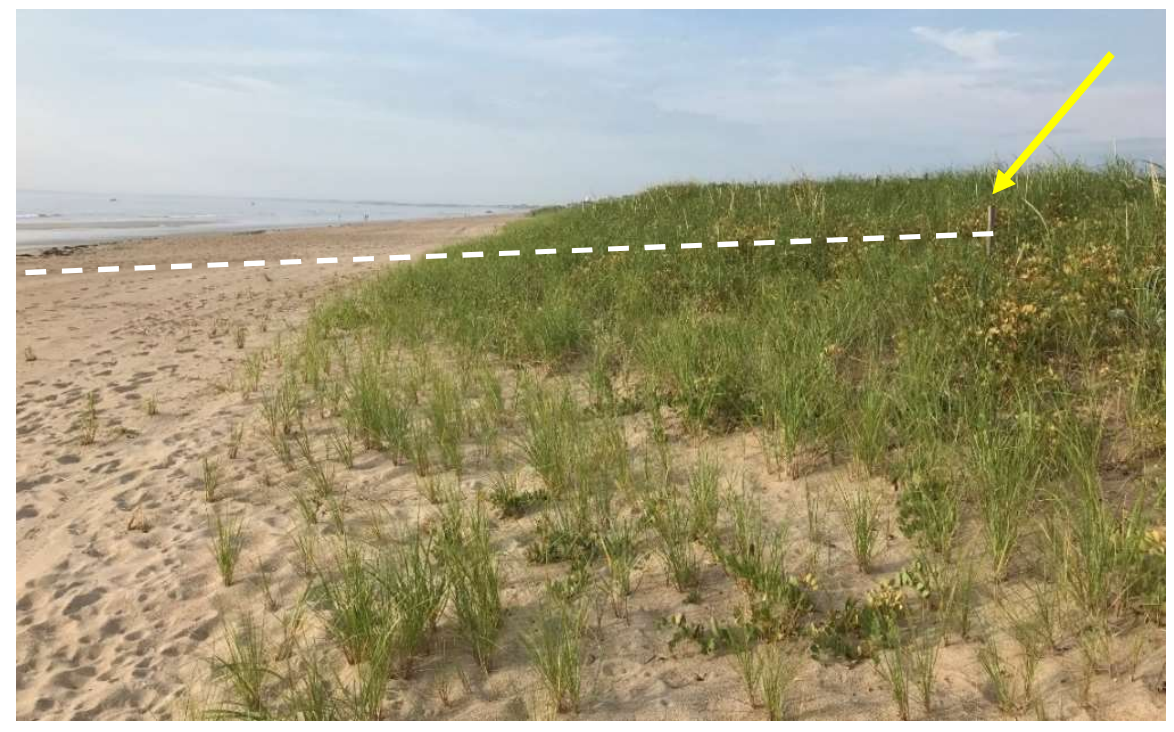

Figure SB04-9. The beach elevation profile at SBO4 looking south. The transect starts at the stake in the foredune ridge and is shown by the dashed line in the photograph taken on August 3, 2019. Note front stake (arrow) that serves as one of two station markers.

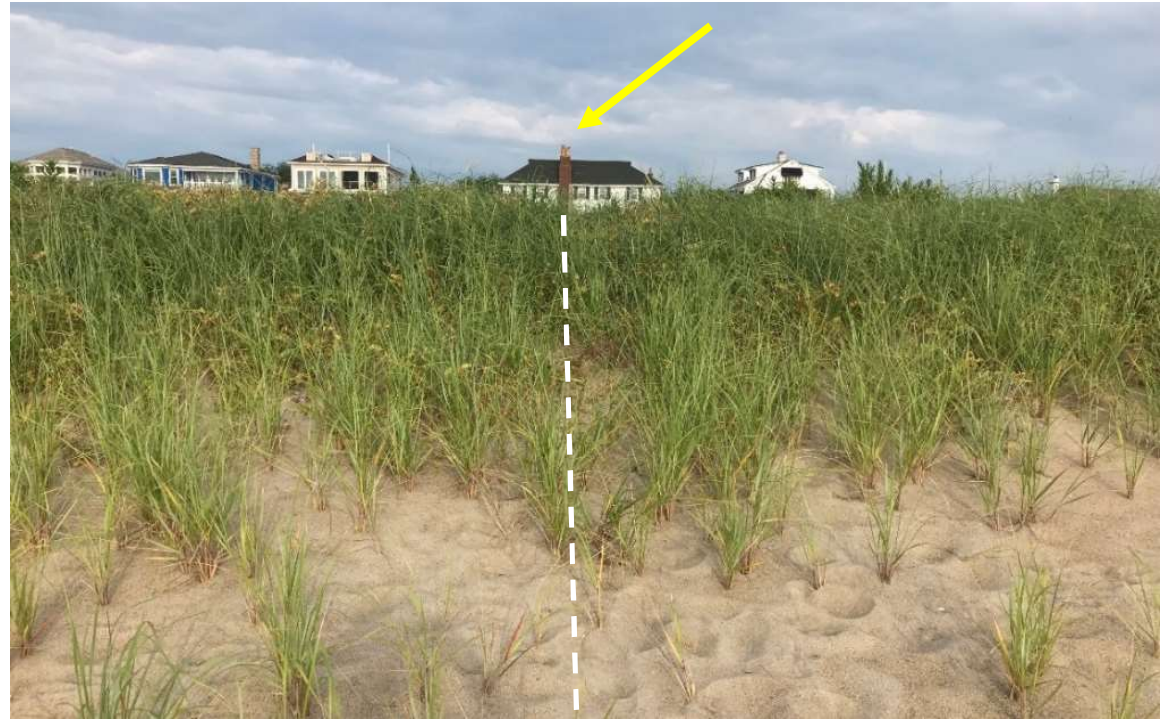

Figure SB04-10. The beach elevation profile at SB04 looking west toward the dunes. The transect starts at the stake in the foredune ridge and is shown by the dashed line in the photograph taken on August 3, 2019.

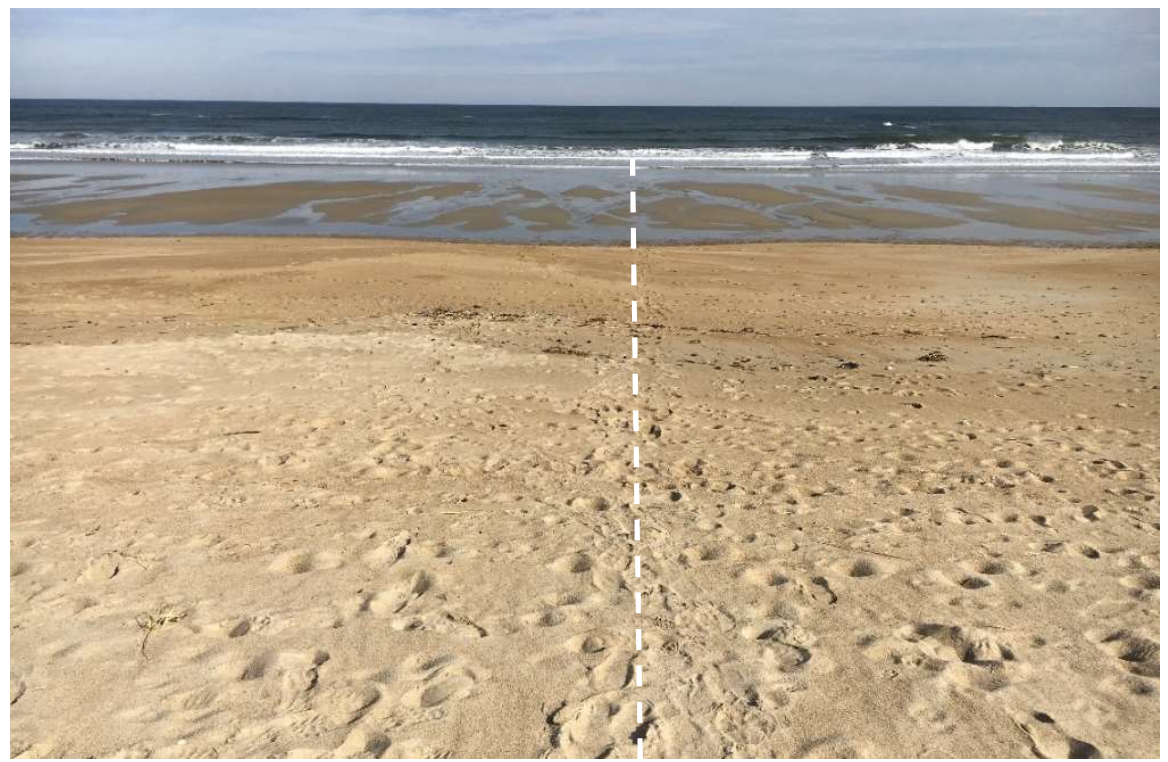

Figure SB04-11. The beach elevation profile at SB04 looking east (dashed line). The photograph was taken on August 3, 2019. 
General Profile Characteristics. The beach elevation profile at SB04 was measured twenty-seven times from January 29, 2018 to March 9, 2020. All plotted beach profiles can be found in Appendix $C(12)$. Unfortunately, the station was not measured during March and April 2018 following three severe nor'easters due to logistical problems and thus the immediate effects of the storms were not measured. However, profile data have been collected at three- to four-week intervals at this station for the remainder of the study period.

The upper and mid beach is extremely steep while the lower beach is flat. The elevation profiles range in length from $\sim 70$ to $100 \mathrm{~m}$ with the longer profiles occurring during periods of accretion (Figure SB04-12). The maximum length was $\sim 112 \mathrm{~m}$ measured on February 26, 2018 just prior to a series of nor'easters that severely eroded NH beaches. The shortest profile was measured on September 7, 2018 due to profiling too long after low tide. May 18 and June 18, 2018 were also very short, but due to beach erosion. Examination of the sweep zone shows a very small variation in the elevation of the beach close to the foredunes in the upper profile (less than $\sim 0.3$ to $0.4 \mathrm{~m}$ ), but a much larger variation in the area of the berm and mid-beach (up to 1.2 to $1.4 \mathrm{~m}$ ). On the lower beach, the differences in elevation range from $\sim 0.9$ to $1.3 \mathrm{~m}$. However, this range probably underestimates the actual differences because the lower beach was subtidal after major storms and could not be measured.

The maximum average elevation profile occurred on August 3, 2019 and the minimum average elevation occurred on November 25, 2019 (Figures SB04-13 and SB04-14). There was a small difference in the upper profile $(\sim 0.3 \mathrm{~m}$ ), but the berm and mid beach were consistently $\sim 1.0 \mathrm{~m}$ lower on November 25 than on August 3. However, as also seen at SB02 and HB02, the lower beach was higher (by about $\sim 0.6 \mathrm{~m}$ ), indicating deposition. Apparently, sand was eroded from the upper beach on November 25 and deposited on the lower beach giving the profile a scalloped appearance. If further erosion occurred, it is likely the lower beach would be eroded as well. This appears to be a common pattern on the barrier beaches in $\mathrm{NH}$. 


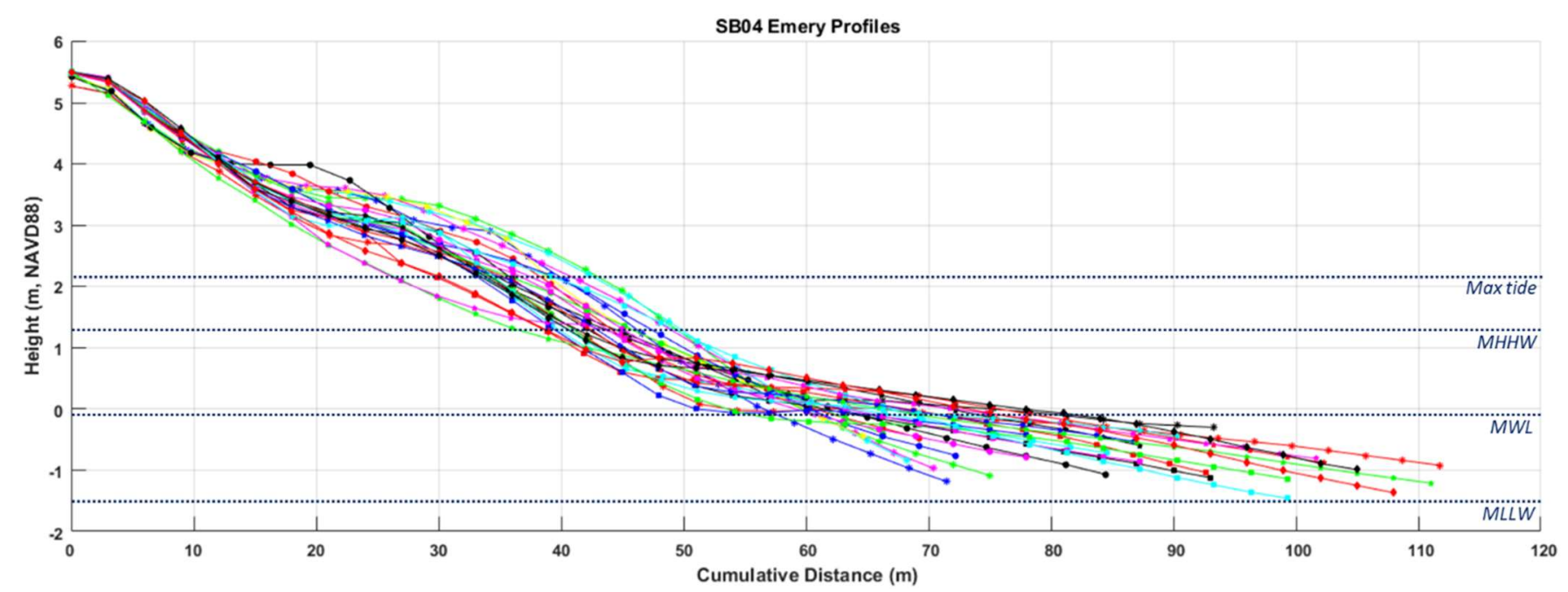

Figure SB04-12. All twenty-seven elevation profiles measured at station SB04 from January 29, 2018 to March 9, 2020. Maximum tidal elevation (max tide), mean higher high water elevation (MHHW), mean water level (MWL), and mean lower low water elevation (MLLW) are indicated by the dotted lines.

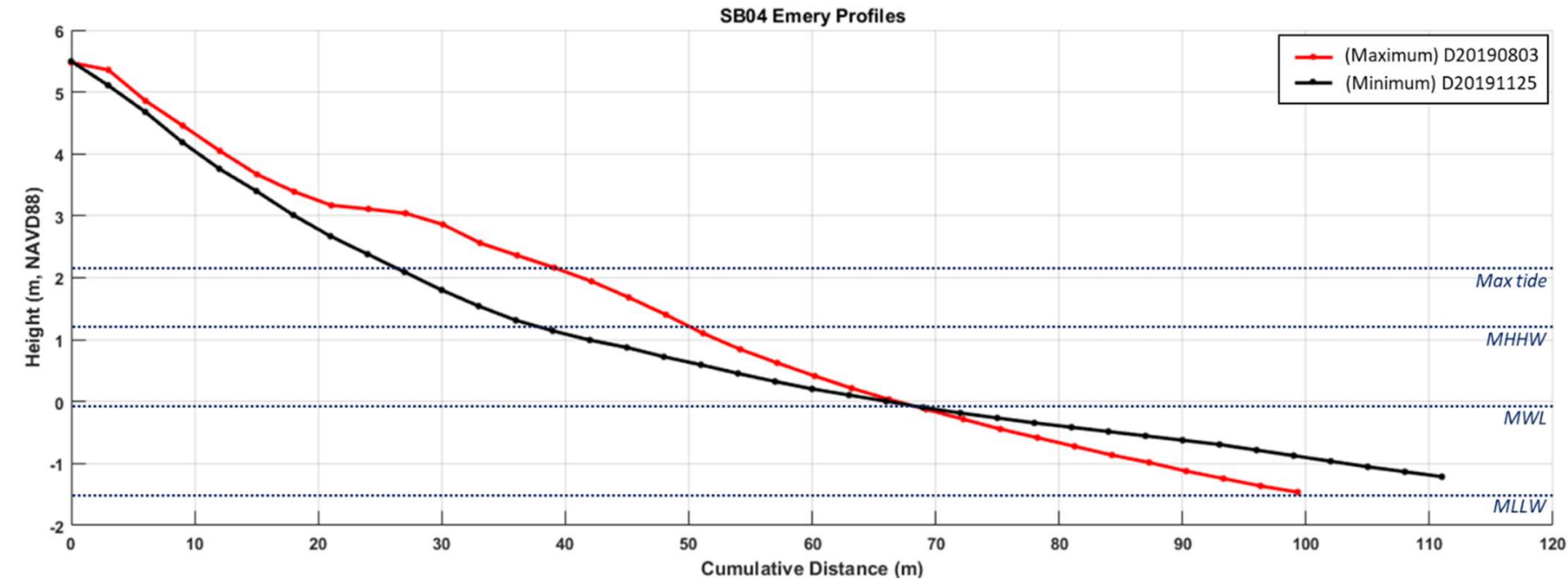

Figure SB04-13. Beach elevation profiles at SBO4 with the highest mean elevation (August 3, 2019) and with the lowest mean elevation (November 25, 2019) measured at station SBO4. 

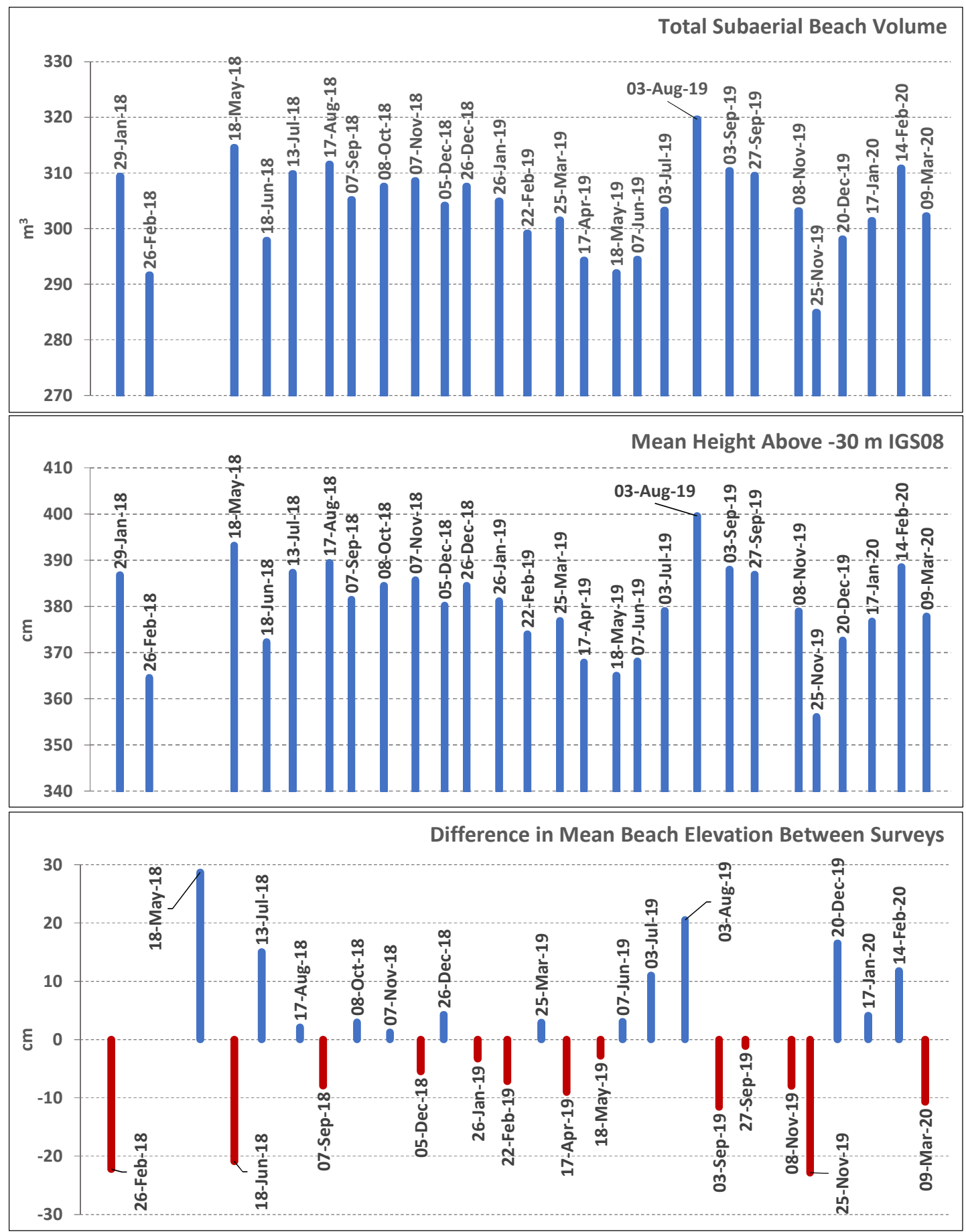

Figure SB04-14. Calculated sediment volume, mean profile elevation, and mean elevation change for the beach profile at station SB04. These parameters were calculated from 0-80 $\mathrm{m}$ of the profile length. Ten of the twentyseven elevation profiles were shorter than the "standard profile length" for the station $(80 \mathrm{~m})$. These profiles were extended using the procedure described in Chapter 2: Methods. Six of the profiles were extended less than $10.0 \mathrm{~m}$ which is considered negligible (three were less than or equal to $5.0 \mathrm{~m}$ ). The longer extensions in 2018 (11.8 $\mathrm{m}$ on August 17, $15.4 \mathrm{~m}$ on September $7,10.8 \mathrm{~m}$ on November 8, and $13.8 \mathrm{~m}$ on December 5) were likely due to the lower beach being eroded with the sediment pushed to the upper beach shortening the profiles but maintaining the overall volume. 
Storm Effects, Beach Erosion, and Recovery. The elevation profile at the beginning of the study in January 2018 indicates that the beach had a wide accretional profile with the lower beach having the highest elevations seen during the study period (Figure SB04-15). Apparently, the winter storms including Grayson (Jan 3-5, 2018) and Inga (Jan 17-18) (Table 3-3) that appear to have eroded the other two Seabrook stations (SB02 and SB05) had little effect on SB04. However, the profile was eroded by winter storms and higher wave energy in late January and February 2018, likely by an unnamed period of high waves (Jan 29-31) and Winter Storms Liam (Feb 7-9) and Noah (Feb 16-18). The elevation profile measured on February 26 was eroded over the entire length, although the lower beach or low tide terrace was extremely wide (Figures SB04-15, SB04-16, SB04-17 and SB04-18). This could either indicate that sediment eroded from the upper beach had been transported to the very lower intertidal area, or that the profile may have just been measured during a very low tide. Similarly, the sediment volume suggests the beach was in an accretional phase on January 29 but had undergone erosion by February 26 (Figure SB04-14). The average elevation over the first $80 \mathrm{~m}$ was lower by $\sim 0.2 \mathrm{~m}$ between the January 29 and February 26, 2018 profiles.

Due to these events and the lowering of the beach, SB04 was likely significantly eroded during the three severe nor'easters in late winter 2018 including Riley (Mar 1-4), Quinn (Mar 6-9) and Skylar (Mar 12-14), as well as high wave energy events on March 21-23 and April 15-17 (Table 3-3). Although the response of the beach was not observed, as discussed above, the beach profiles measured on May 18 and June 16 show dramatic changes to the beach with the upper profile built up vertically $\sim 0.8$ to $1.2 \mathrm{~m}$. However, the lower beach profile lost up to $\sim 1.3 \mathrm{~m}$ in elevation and became much narrower (Figure SB04-19). It appears that the lower beach was highly eroded (Figure SB04-5) and at least some if not a large amount of this material was pushed up onto the mid and upper beach and into the dunes by overwash processes (Figures SB04-20 and SB04-21). Clearly, the beach was heavily impacted by the March 2018 storms with large amounts of sediment lost to the intertidal beach. However, volume calculations showed a major increase on May 18, despite the beach elevation profile showing the beach was significantly eroded. The reason for this is addressed in the following paragraph. 


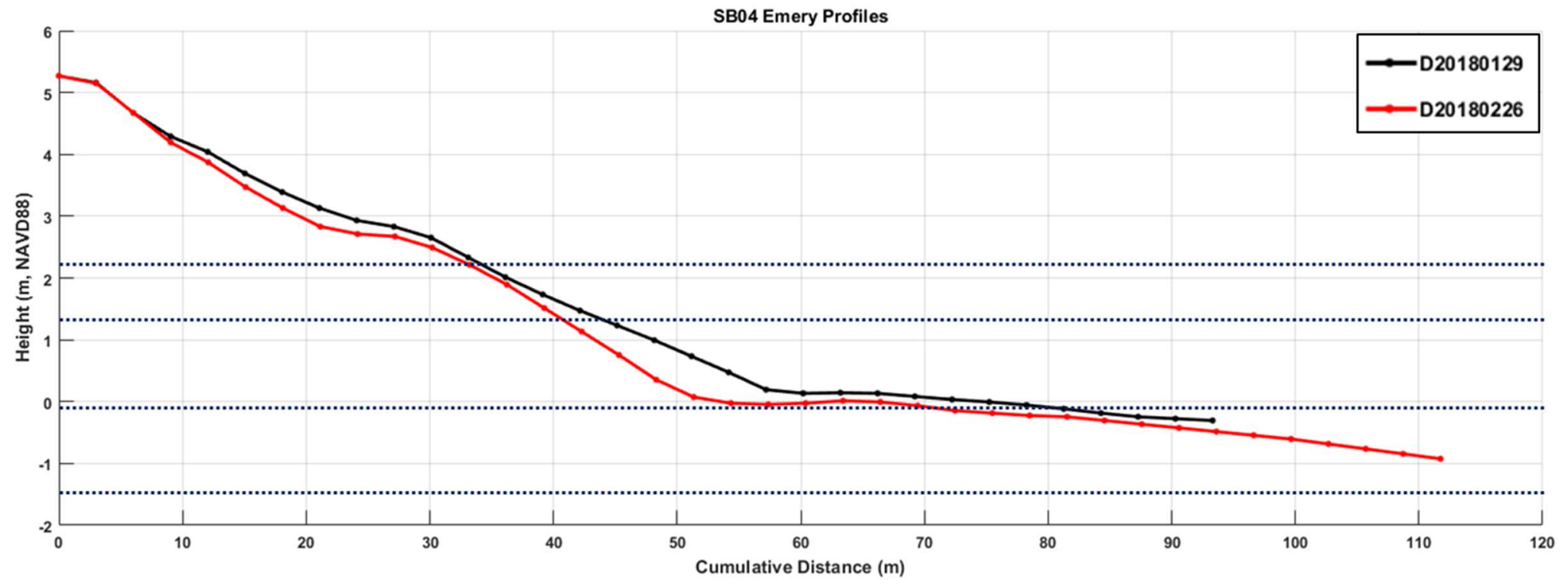

Figure SB04-15
(above). Beach
elevation profiles
measured at SB04 on
January 29, 2018 and
February 26, 2018.
The beach had
significantly eroded by
the February 28
profile.

Figure SB04-16 (right) Seabrook Beach at SB04 on February 26, 2018. The beach is steep and featureless due to a recent period of erosion.

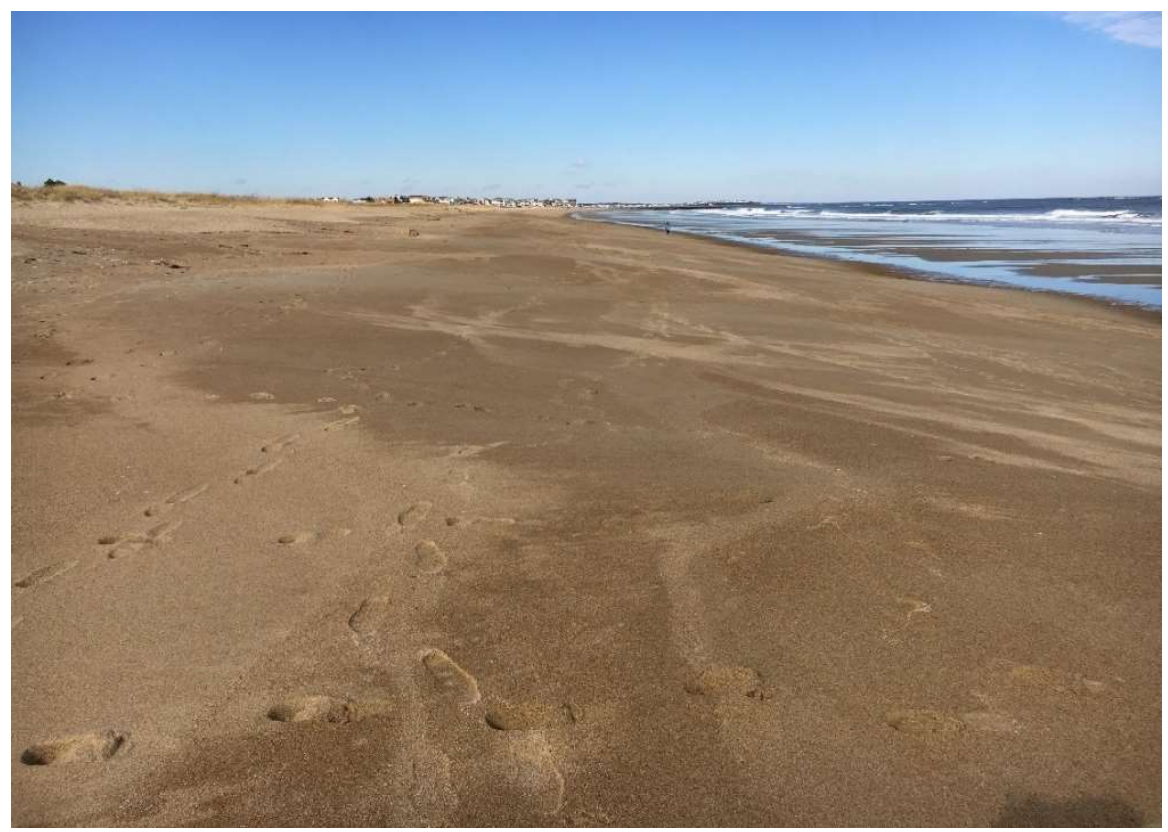




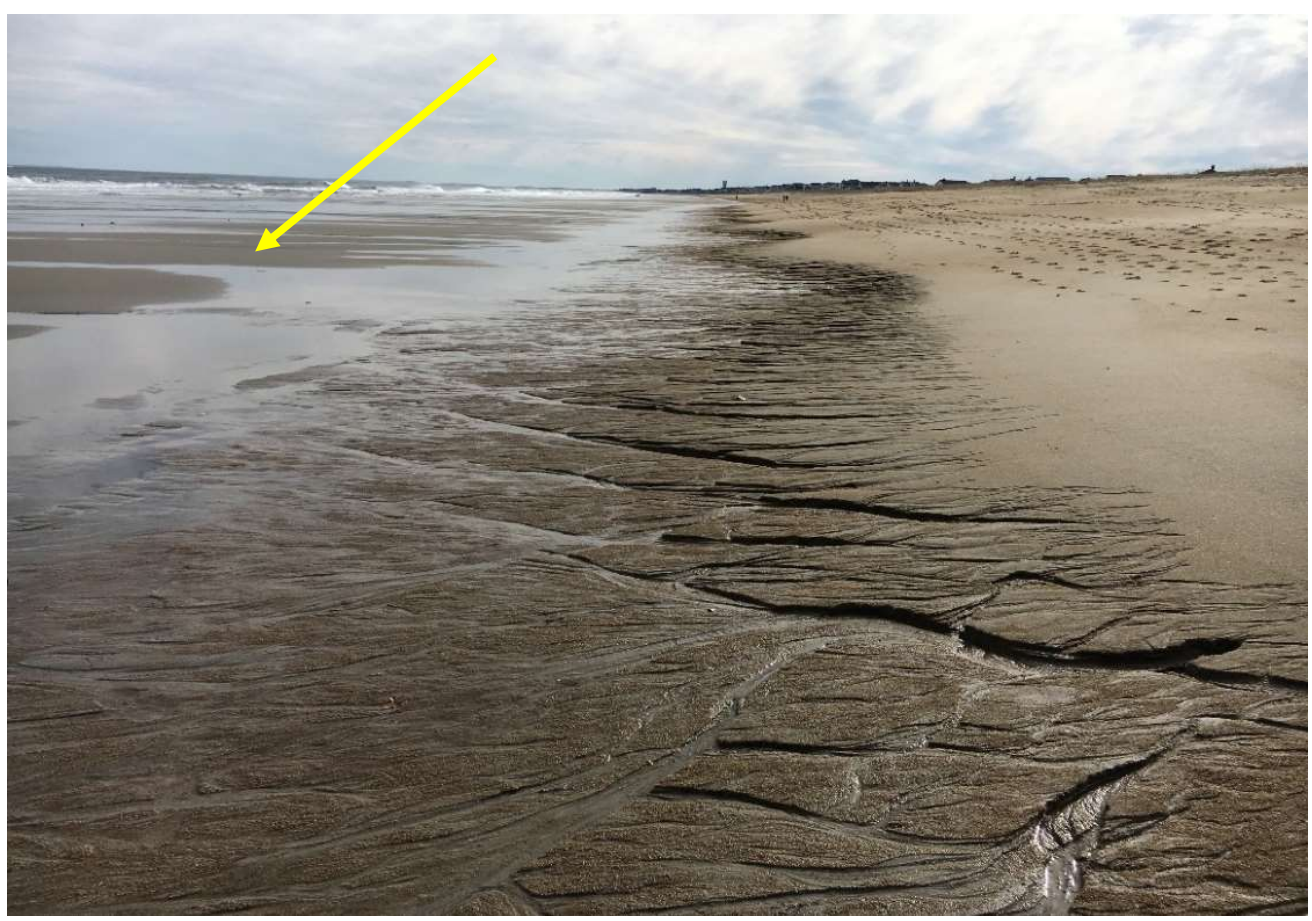

Figure SB04-17. Seabrook Beach at SBO4 on February 26, 2018. The bottom of the berm face has been eroded due to a recent period of erosion. Note a small ridge (arrow) migrating onto the beach indicating the beach is beginning to recover.

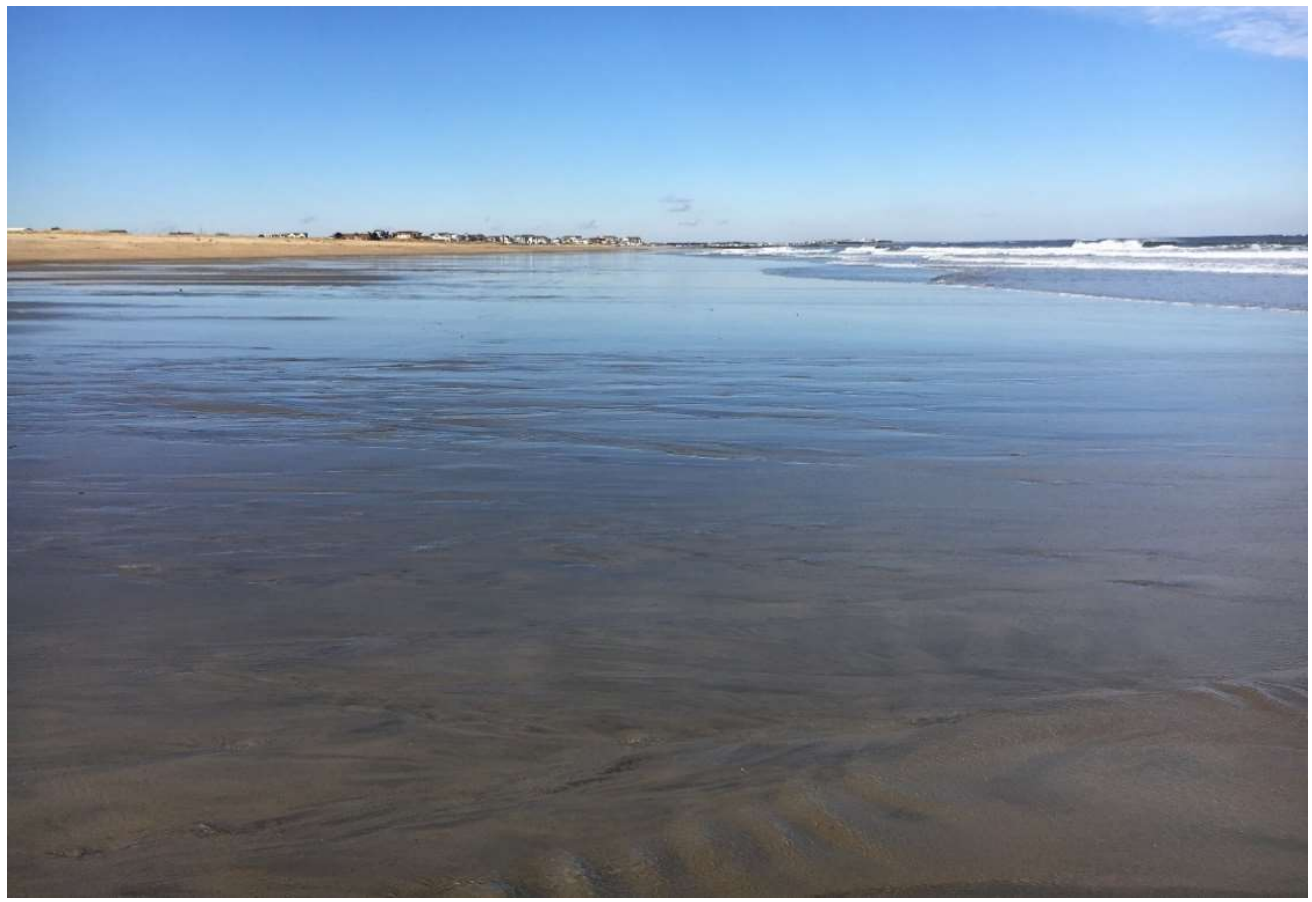

Figure SB04-18. The low tide terrace at station SBO4 on February 26, 2018. The beach was recently eroded. 


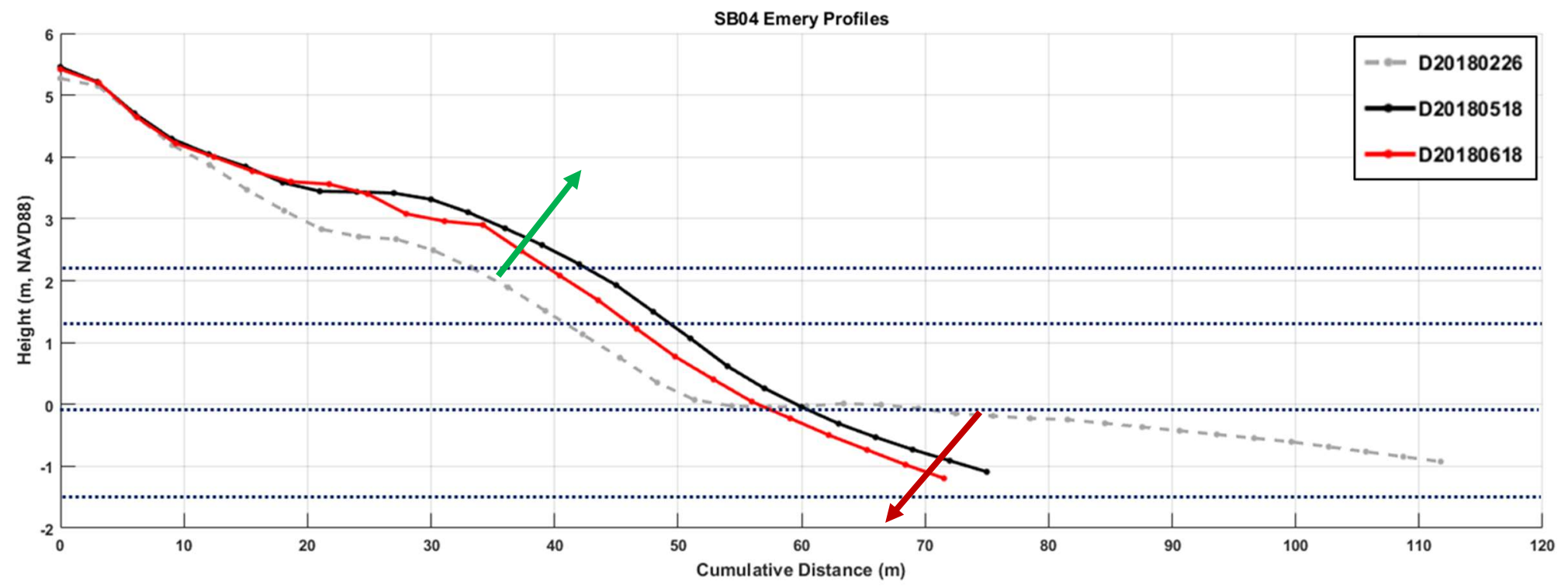

Figure SB04-19 (above). Beach profile sequence for SB04 on February 26, 2018, May 18, 2018, and June 18, 2018. Note how the upper beach had built up (green arrow) but the lower beach had eroded significantly (red arrow).

Figure SB04-20 (right). The upper beach and dunes at SBO4 after they were overwashed during the storms in late winter and early spring 2018. Sand was transported into the dunes as can be seen in this photgraph taken on May 18, 2018. Note the recent sand deposition on and around the dune vegetation (arrow).

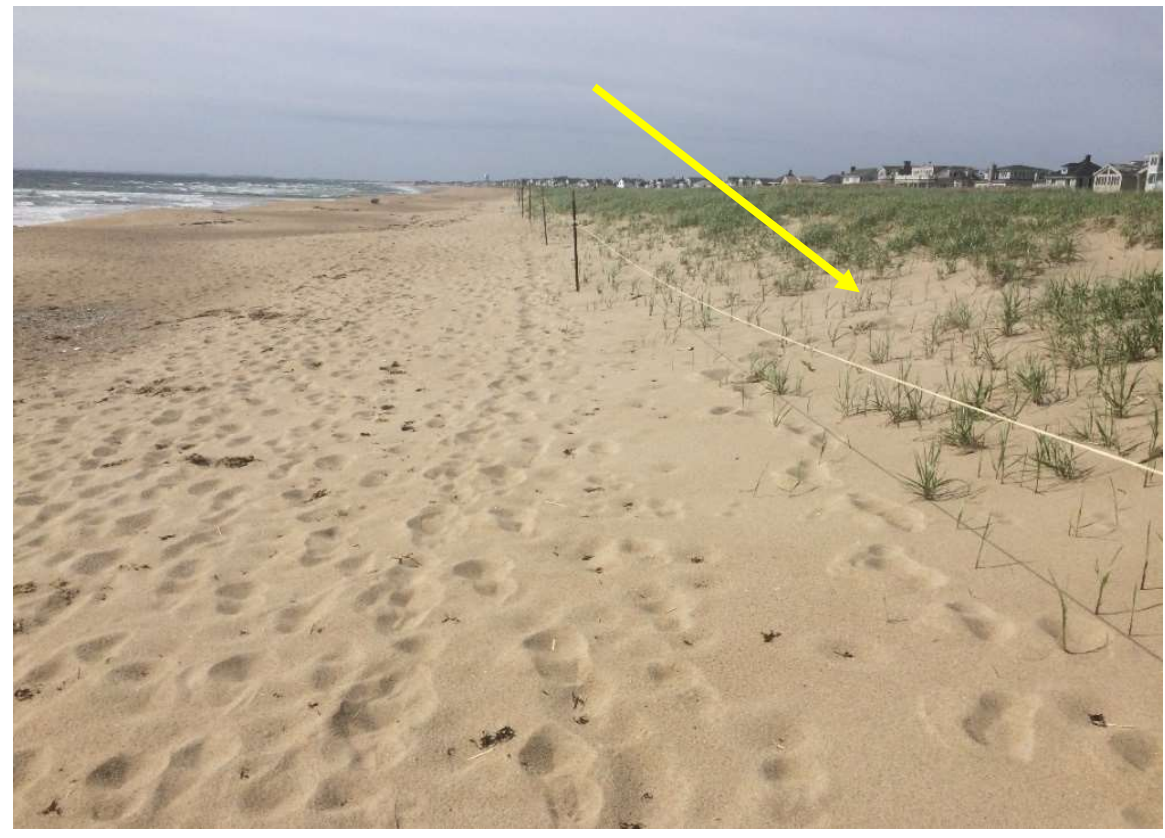




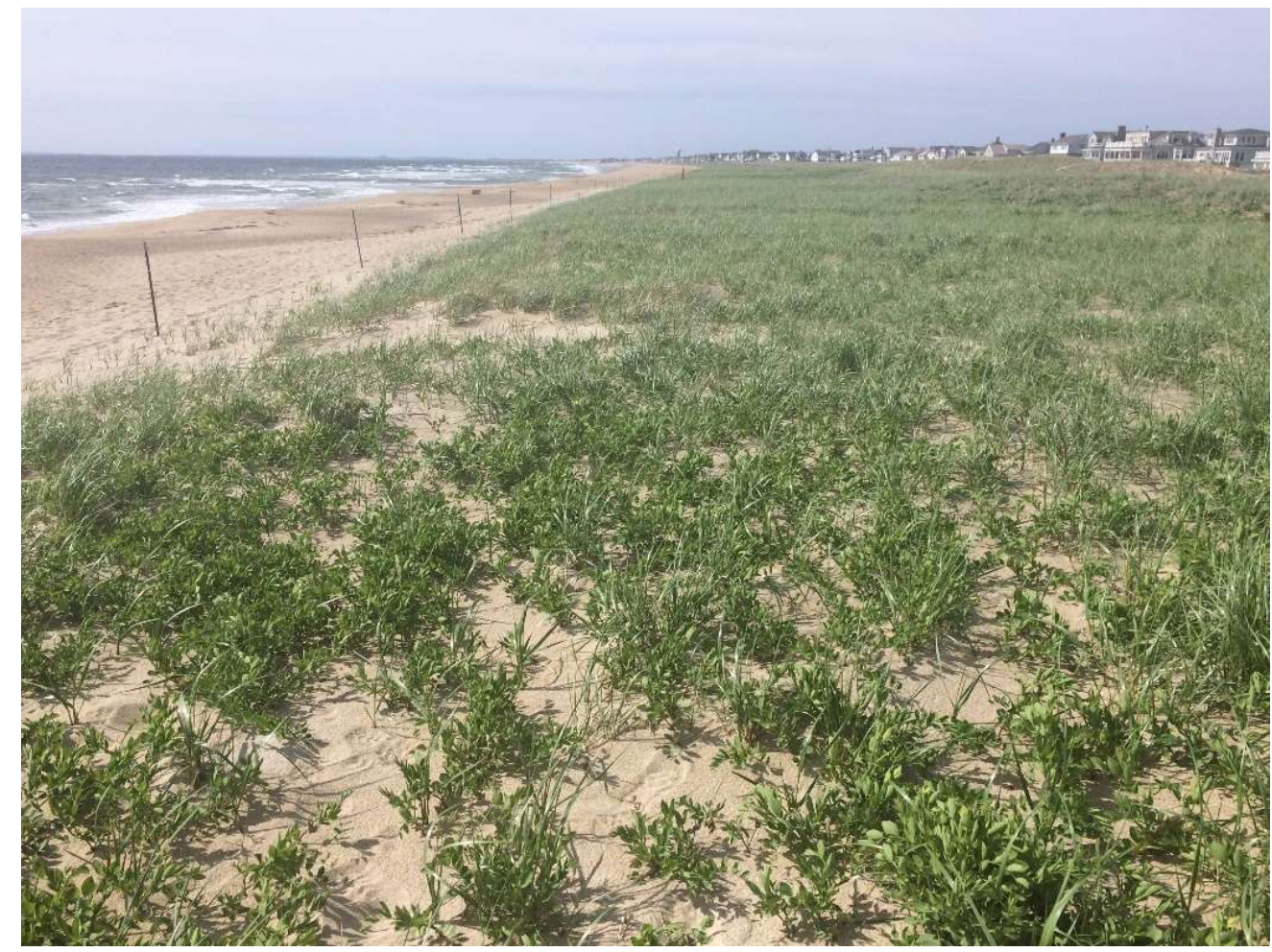

Figure SB04-21. The dunes at SBO4 after they were overwashed during the storms in late winter and early spring 2018. Sand was transported into the dunes as can be seen in this photograph taken on May 18, 2018.

An important point to address here is the relationship between the beach elevation profiles and the sediment volume calculations. In most cases the relationship is strong and the volume calculations and associated average elevations reflect the changes in beach profiles. But in the case discussed above, the volume calculations are made for the first $80 \mathrm{~m}$, not the entire length of the elevation profile. The sediment calculations cannot be made further seaward because the elevation of the lower beach is below the low tide and cannot be profiled using the method employed in this study (Emery Profile Method). On May 18, 2018 it appears that sediment eroded from the lower beach was pushed to the mid and upper beach, within the first $80 \mathrm{~m}$ of the profile where the sediment calculations are made. Consequently, the loss of sediment in the lower beach is not considered. Therefore, the sediment volume in the landward $80 \mathrm{~m}$ of the beach increased dramatically. However, if a longer length of the elevation profile could be used for all of the profiles, the results would be very different and the May 18, 2018 volume would be low in comparison to more accretional profiles. Therefore, it is important to consider what the volume calculations represent before drawing conclusions when comparing time periods.

The elevation profiles at SB04 maintained a similar profile with a well-developed upper beach, but small lower beach through summer and early fall. However, by October 8, 2018, the upper beach returned to a more typical accretional profile (Figure SB04-22). A small backshore and berm had developed with a steep berm face and the lower beach had built upward. 
In late winter and early spring 2019 (Figure SB04-23) the second period of erosion occurred at SB04 with the beach profile losing elevation and sediment volume through May 18 and June 7, 2019 (Figure SB04-24). However, during this period the lower profile did not change appreciably indicating only the upper profile was eroded. The beach recovered from this erosion cycle in summer 2019 reaching a maximum on August 3, which was the highest accretional sediment volume measured at SB04 during the entire study period (Figures SB04-25 and SB04-14). This is the same time that SB02 reached a sand volume maximum for the entire study period (Figure SB02-7).

During fall 2019 (from September through November 2019) the beach eroded during another period of elevation and sediment volume loss after some early fall storms including far field effects from Hurricane Dorian (Sept 6-7), Subtropical Storm Melissa (Oct 11-13), an unnamed nor'easter (Oct 1617) with large wave heights, and a king tide coastal flood on October 28 (Table 3-3). The lowest mean beach elevation and sediment volume for the entire study period occurred on November 25 (Figures SB04-26 and SB04-27). However, this must be viewed in the context that the beach was not profiled following the severe nor'easters of March 2018. Nevertheless, the beach elevation confirms this was a major erosive event (Figure SB04-27). Following this erosional period, the beach steadily increased in volume until February 2020, despite a few winter storms with strong easterly winds and high waves including Ezekiel (Dec 2-4, 2019) and Gage (Dec 30-31, 2019). In March 2020, however, the beach started to erode again, possibly due to two unnamed winter storms in late February-early March 2020 (Feb 27-28 and Mar 6-7: Table 3-3). 


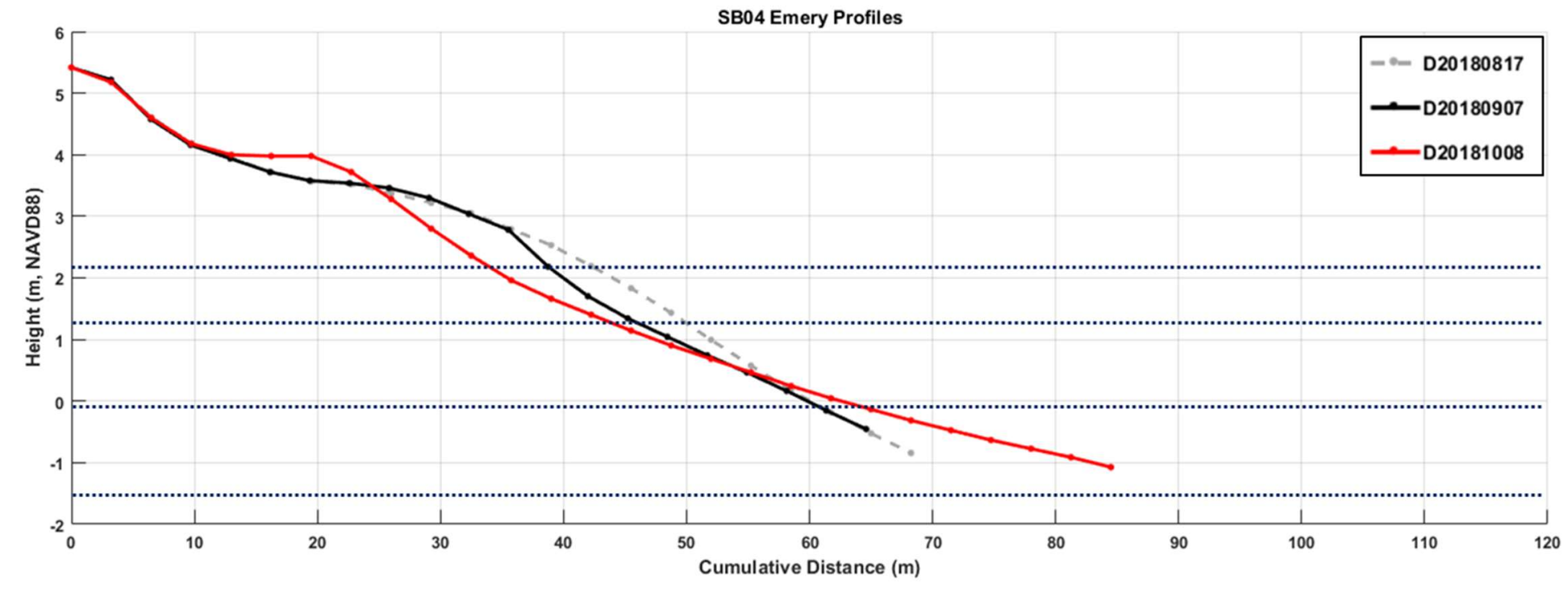

Figure SB04-22. Beach elevation profiles for SB04 measured on August 17, 2018, September 7, 2018, and October 8, 2018.

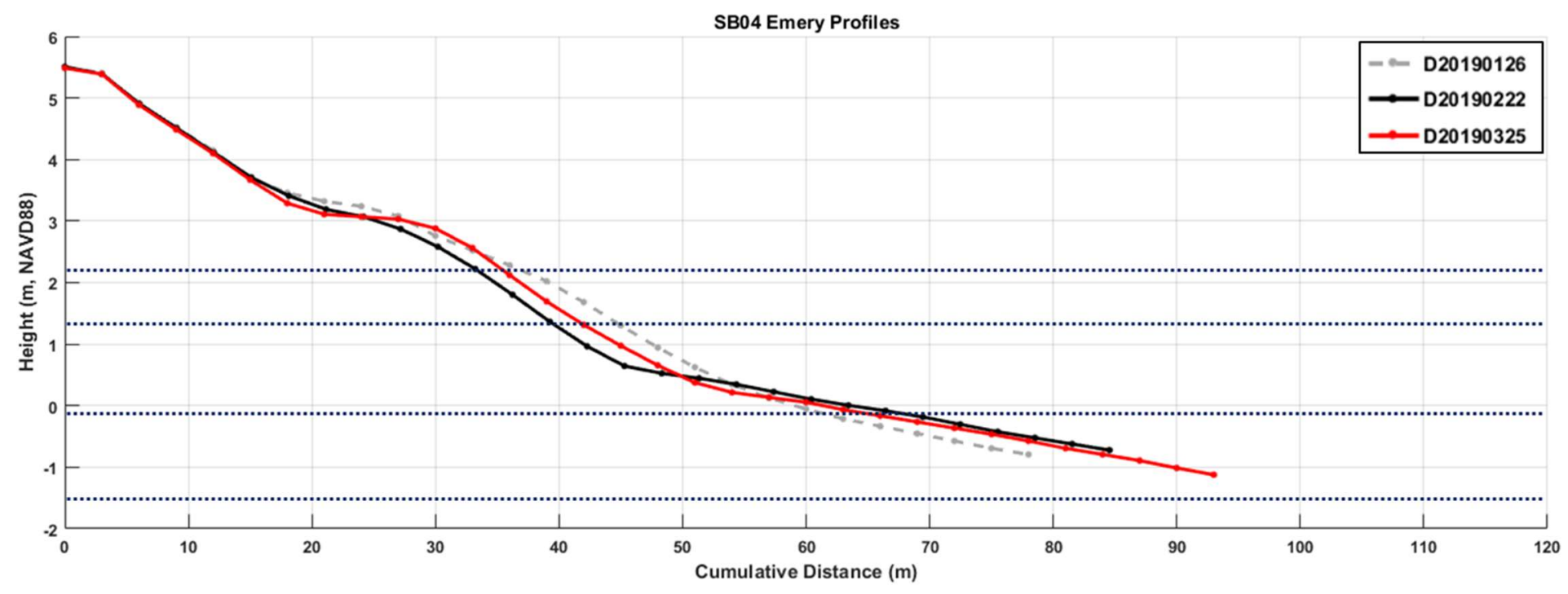

Figure SB04-23. Beach elevation profiles for SB04 measured on January 26, 2019, February 22, 2019, and March 25, 2019. 


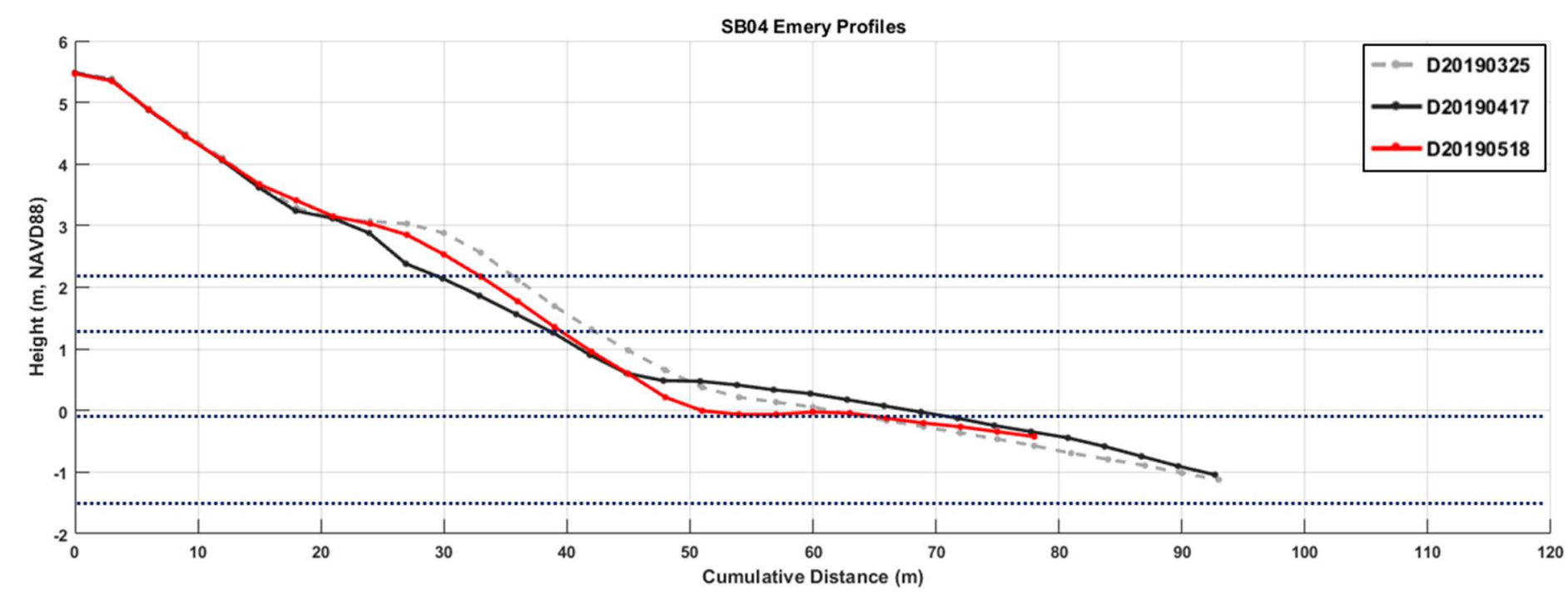

Figure SB04-24. Beach elevation profiles for SB04 measured on March 25, 2019, April 17, 2019, and May 18, 2019.

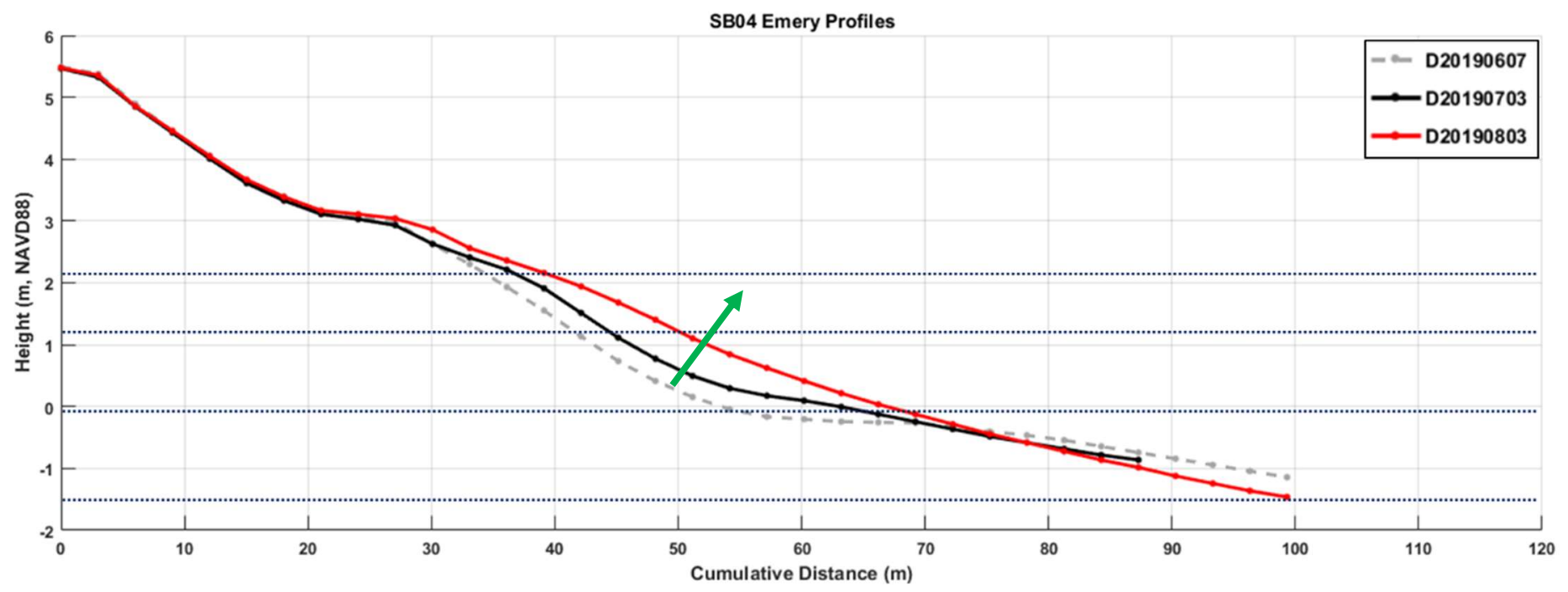

Figure SB04-25. Beach elevation profiles for SBO4 measured on June 7, 2019, July 3, 2019, and August 3, 2019. Note how the beach built up by August 3 (arrow), which was the maximum volume and elevation profile measured during the study period. 


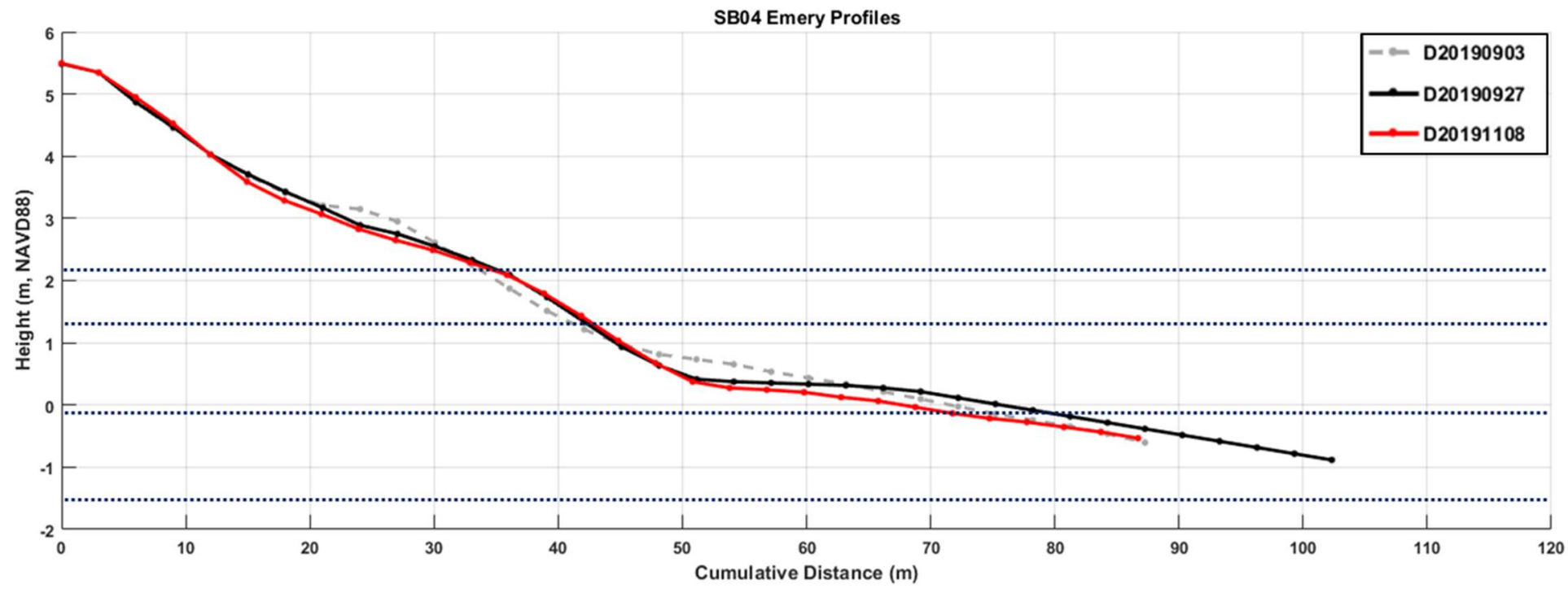

Figure SB04-26. Beach elevation profiles for SBO4 measured on September 3, 2019, September 27, 2019, and November 8, 2019.

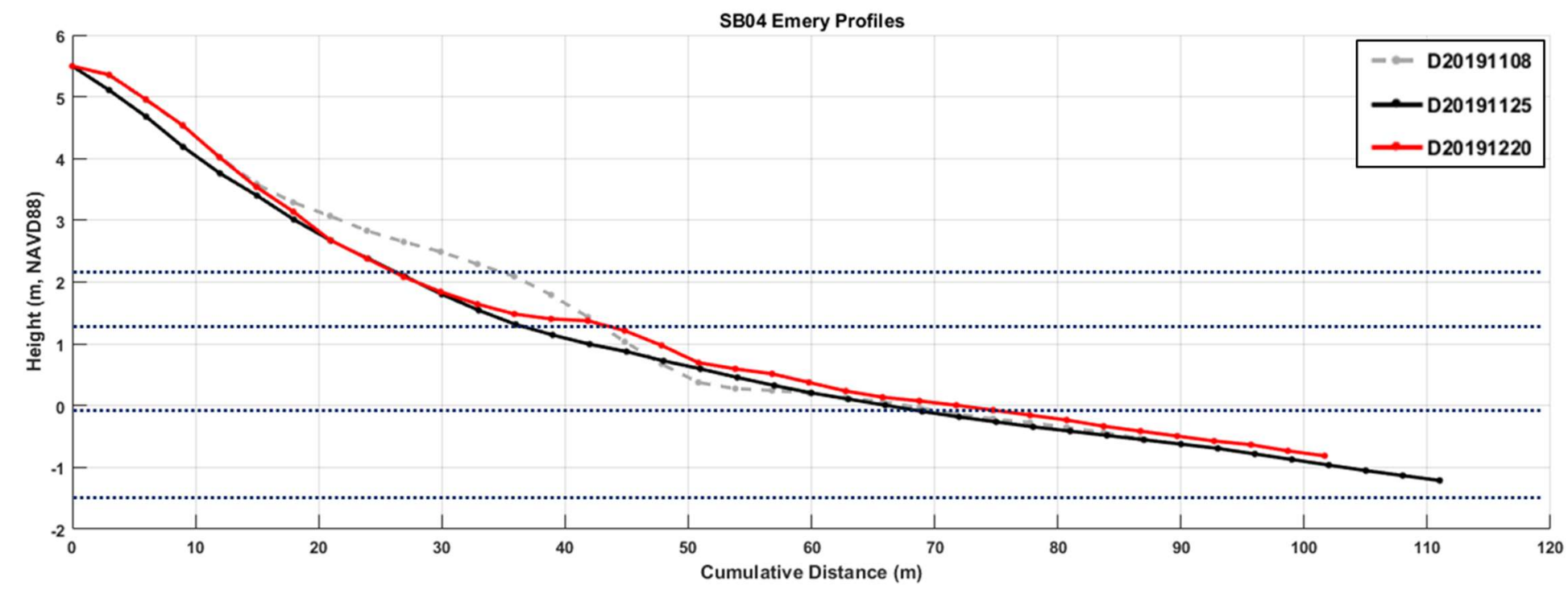

Figure SB04-27. Beach elevation profiles for SBO4 measured on November 8, 2019, November 25, 2019, and December 20, 2019. 


\section{Results for Station at Southern Seabrook Beach: SB05}

Overview. SB05 is located $\sim 2.1 \mathrm{~km}$ south of the Hampton Harbor Inlet jetty close to the NH-MA state line and $\sim 0.6 \mathrm{~km}$ south of station SB04, and directly seaward of Newbury Street (Figure SB-1). The dune system is somewhat narrower here ( $70 \mathrm{~m}$ ) than further north on Seabrook Beach (Figure SB051). However, as elsewhere, the dunes provide protection against storm surges and erosion for the homes and infrastructure found landward. The beach elevation profile at SB05 originates in the foredune ridge (Figure SB05-2) and extends across the beach to the low water line (Figure SB05-3). The station is marked by wooden stakes. The dunes landward of the station markers were profiled in addition to the beach at both SBO4 and SB05. The results of this work will be reported elsewhere. Here we focus on the intertidal beach from the foredunes to the low tide swash.

During accretional conditions the beach tends to have a relatively well-defined backshore (Figure SB05-4), a well-defined berm and steep berm face (Figure SB05-5), and a flat lower beach or low tide terrace during accretional conditions (Figure SB04-6). However, the beach becomes narrower, steeper, loses morphologic definition, and may have a concave-upward profile following erosive events (Figure SB04-7). Also, during major storms with significant storm surge and waves, overwash can occur where sand is eroded from the beach and pushed into the dunes (this is discussed below in detail in "Storm Effects, Beach Erosion, and Recovery"). The beach is largely composed of sand and granular sediment. However, following storms the beach often has large patches of shells (fragments and whole) and scattered pebbles (Figure SB05-07), and seaweed on the lower beach (Figure SB0508).

An extremely interesting feature observed on March 18, 2018 after a period of extensive erosion followed by accretion was the presence of a tombolo in the lower intertidal just north of SB05, which was apparently related to Round Rock or an unmarked offshore bedrock outcrop or glacial deposit (Figure SB05-9). Wave refraction and a reduction of longshore transport of sand usually lead to the development of a tombolo. If present, the tombolo typically is mostly subtidal.

Summary. As stated previously, it is important to determine trends by looking at changes over several months, rather than single measurements, to assess overall decreases or increases in beach elevation or sediment volume. At the start of the study period, it appeared that SB05 had been eroded as indicated by the upper and mid elevation profile and sediment volume calculations. However, an extended low tide terrace was present. The sequence of three severe nor'easters in late winter 2018 caused significant erosion to SB05, entirely removing the low tide terrace. The beach had recovered by May and with the exception of one erosion episode, maintained the overall accretional conditions through November 2018. An extended period of lower elevations and sand volumes began in December 2018 and continued through December 2019. However, cycles of small amounts of accretion, followed by erosion, have occurred in approximately six-month intervals with peaks in sand volume and elevation in January and August 2019. The beach at SB05 eroded as a result of fall and early winter 2019 storms, lowering elevation and sand volume and leaving the beach vulnerable to winter 2020 storms. As a result, SB05 reached the lowest volume during the study period in March 
2020 (although the profile was much longer than when the beach was eroded from the late winter 2018 storms).

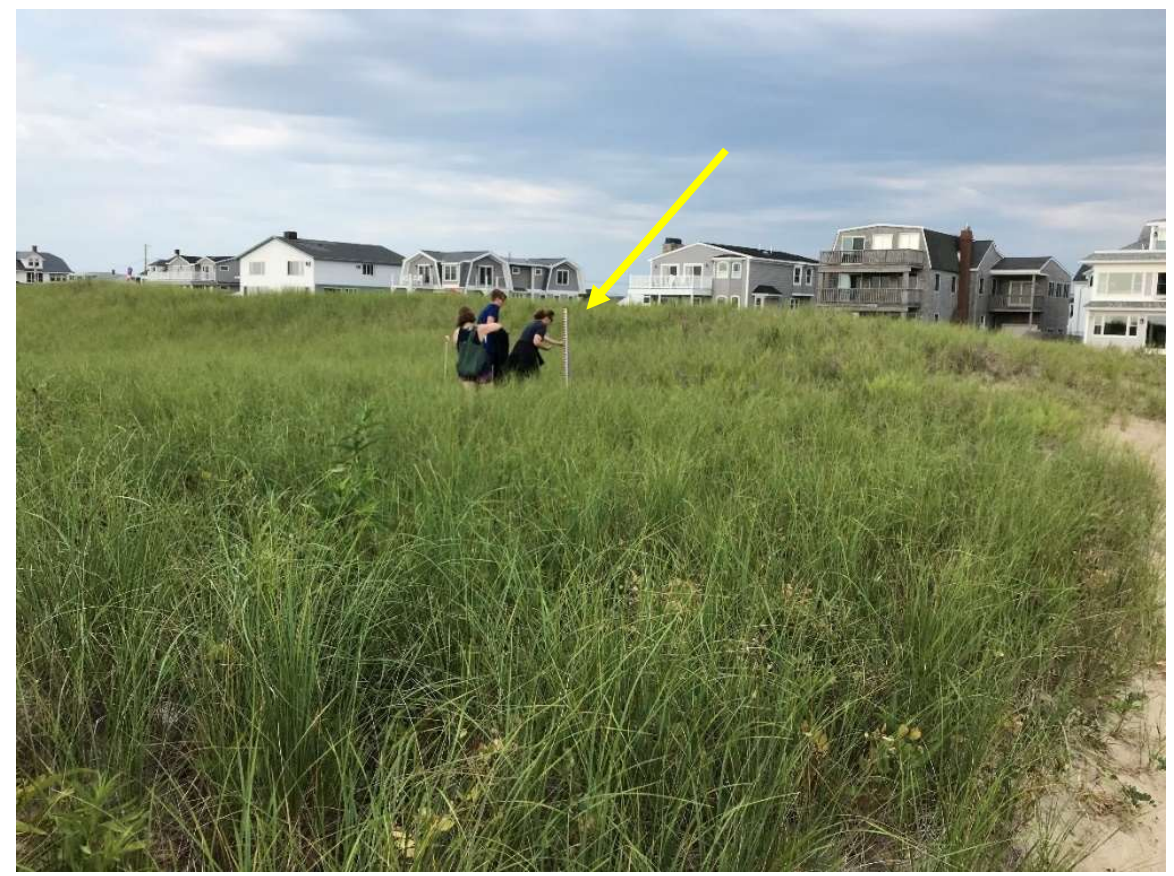

Figure SB05-1. The dune system at $S B 05$, which is narrower than those at stations SBO2 and SB04. However, the dunes still provide important protection for the local infrastructure against storm surges and erosion. The volunteers are measuring the back stake height (arrow) to run a beach elevation profile on August 3 , 2019. The photograph is looking south.

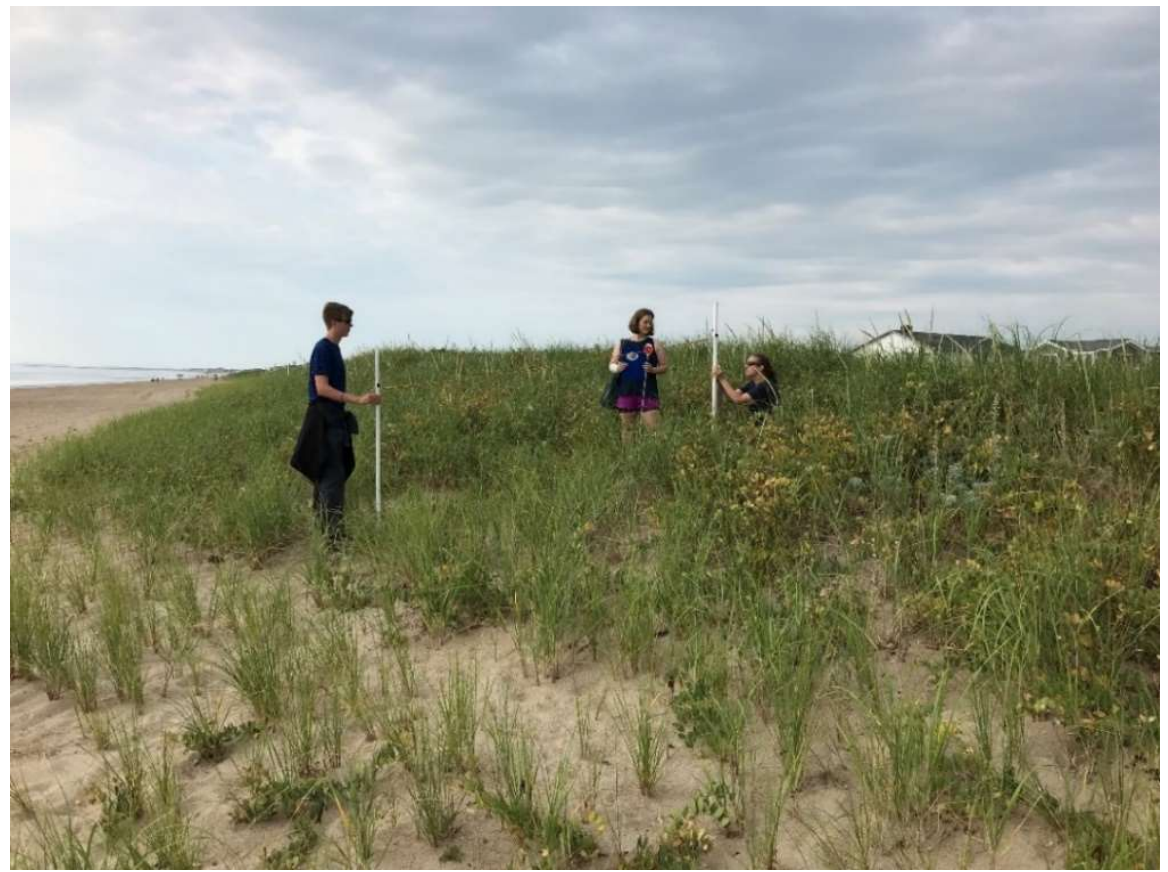

Figure SB05-2. The beach elevation profile at SB05, which starts in the foredunes. The volunteers are running the beach profile here on August 3, 2019. 


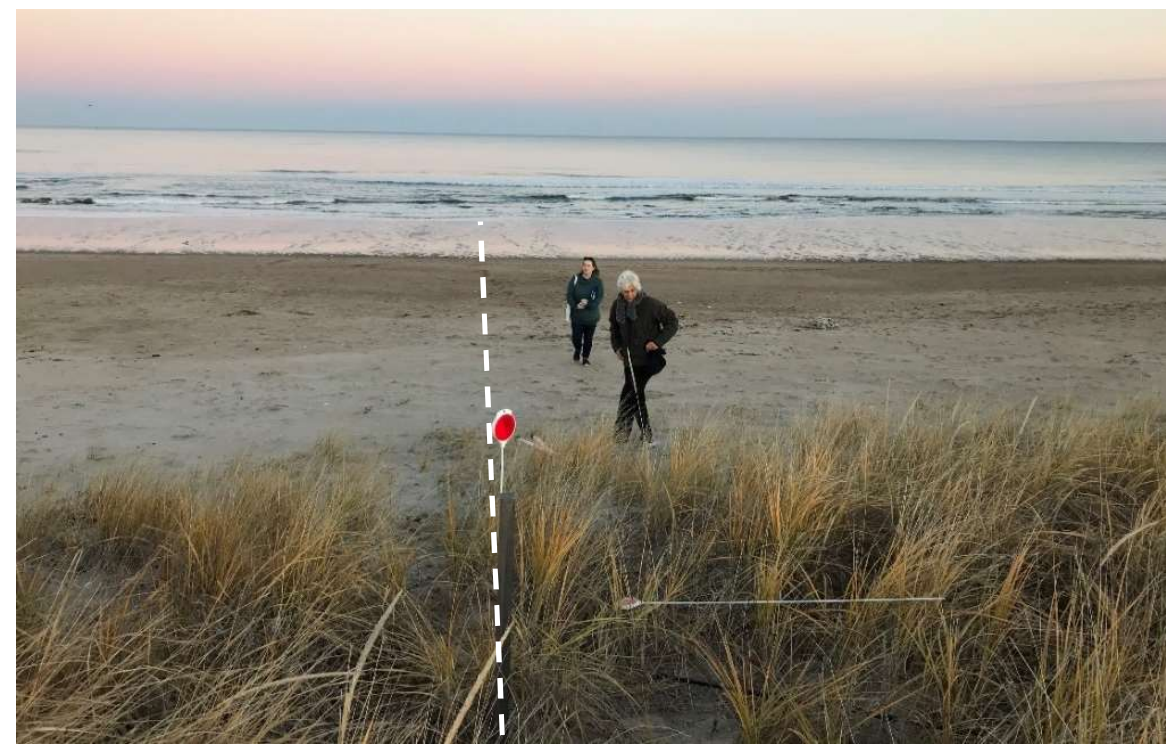

Figure SB05-3. The beach elevation transect at SB05, which starts at the seaward stake in the foredunes and ends at the water's edge. The photograph was taken on November 25, 2019.

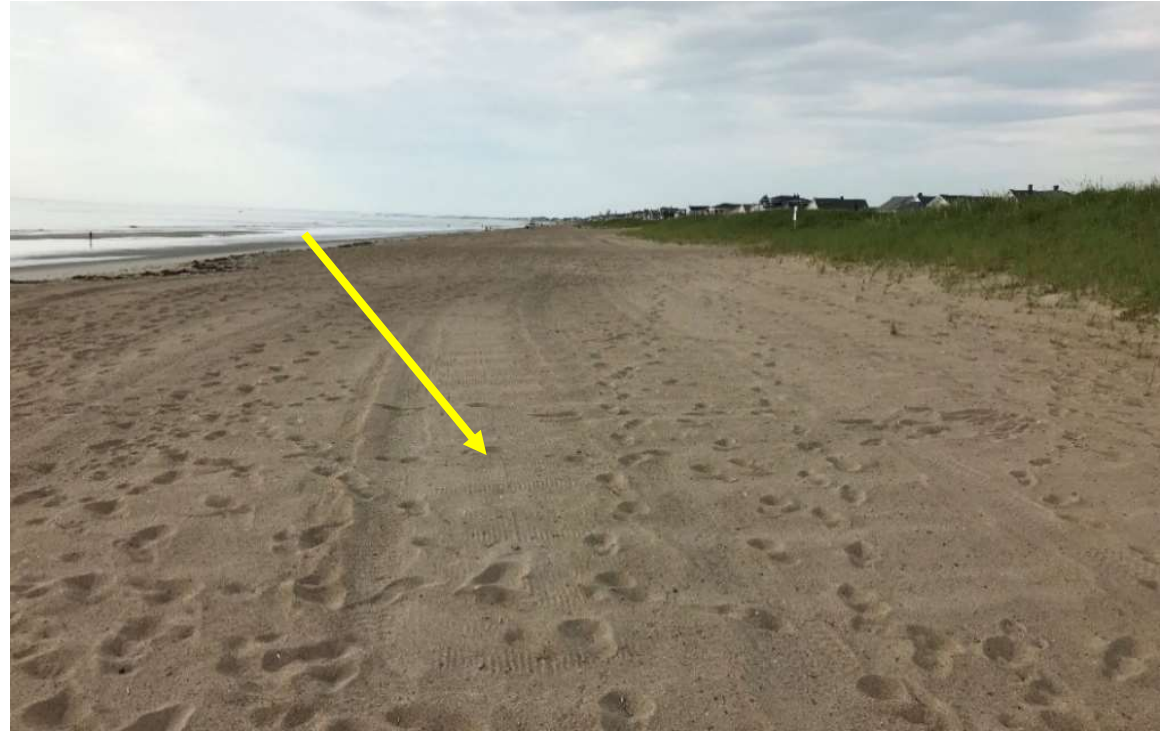

Figure SB05-4. The beach at SB05 during accretional conditions, when it often has a relatively wide backshore (arrow) and a well-defined berm. The photograph shows the wide backshore at SB05 on August 3, 2019 after being graded as indicated by the tire tracks.

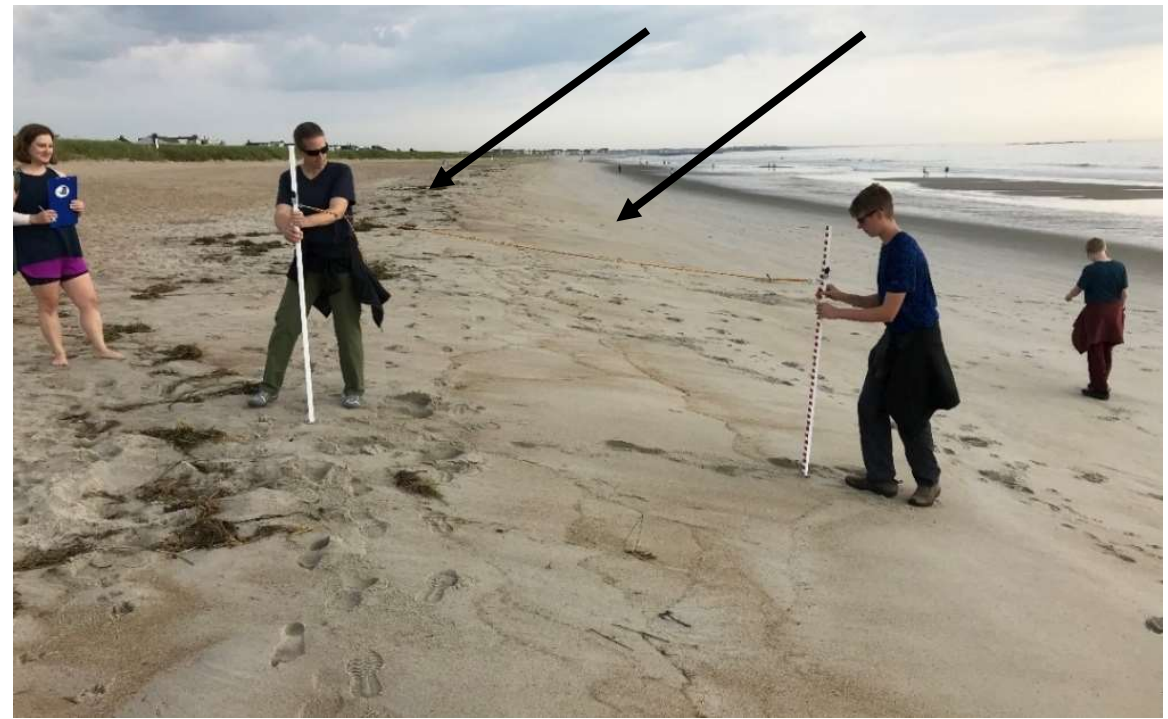

Figure SB05-5. During accretional conditions the beach at SBO5 often has a well-defined berm (left arrow) and steep berm face (right arrow) as seen here on August 3, 2019 . 


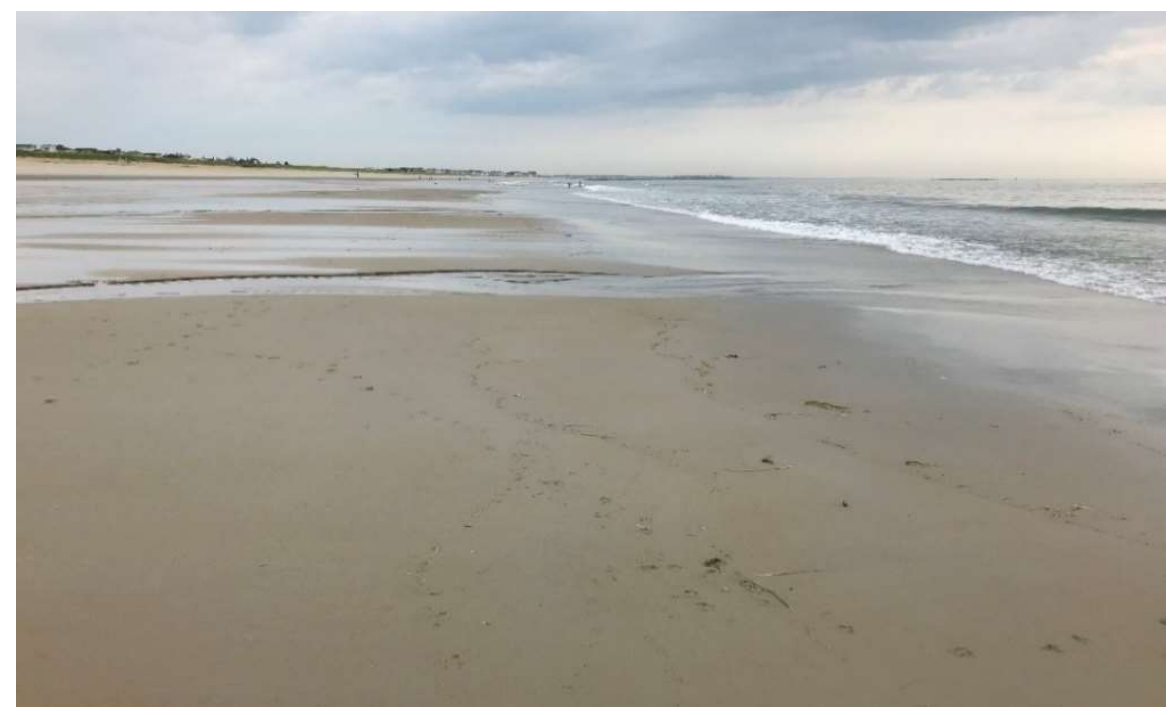

Figure SB05-6. The beach at SB05 often has $a$ wide and flat lower beach or low tide terrace as shown here on August 3, 2019. The photograph is looking north.

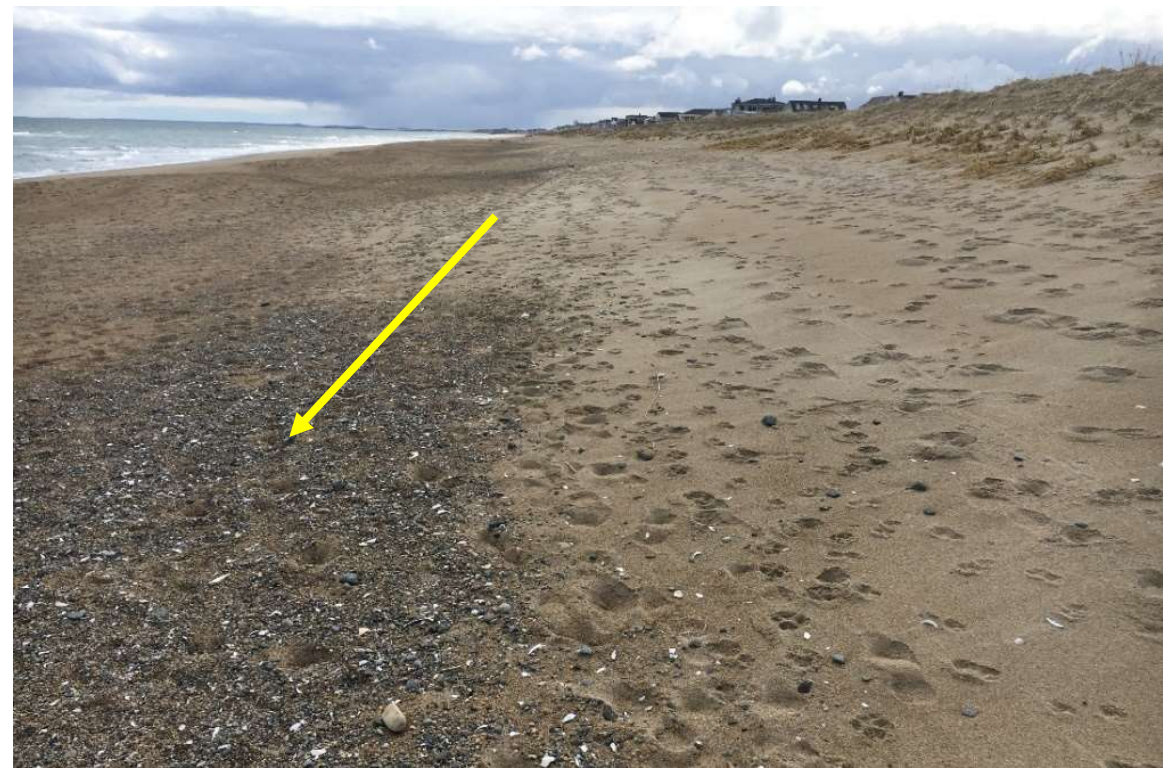

Figure SB05-7.

Following storms the beach at SBO5 often has patches of shells and pebbles (arrow) as seen here on March 12, 2018 following a series of storms. The beach is also flat with few morphologic features which is typical for post-storm profiles at Seabrook Beach.

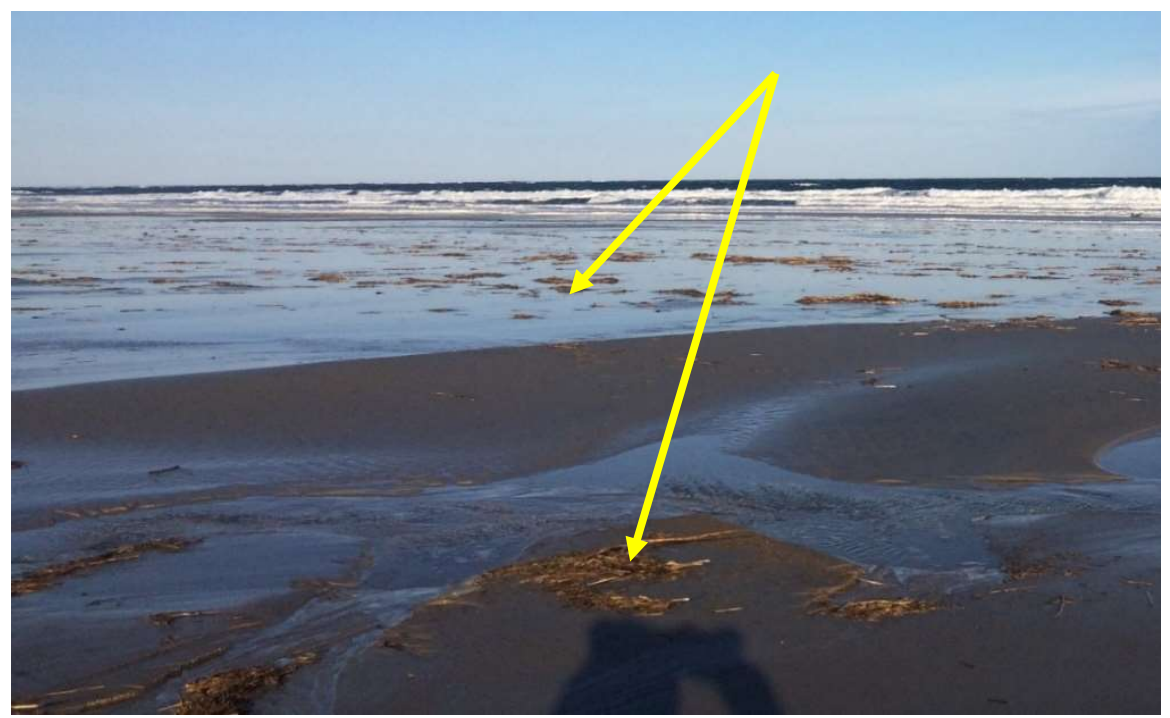

Figure SB05-8. Seaweed washed up on the lower beach at SB05 (arrows) on January 29, 2018 following stormy conditions. 
General Profile Characteristics. The beach elevation profile was measured thirty times from January 29, 2018 to March 9, 2020. All plotted beach profiles can be found in Appendix C(13). SB05 has an extremely steep elevation profile in the upper and mid beach before becoming relatively flat on the lower beach or low tide terrace (Figure SB05-9). However, the low tide terrace was frequently absent after erosive events. The elevation profile was typically $\sim 60$ to $80 \mathrm{~m}$ wide following stormy periods (no low tide terrace). Conversely the profile was $\sim 90$ to $120 \mathrm{~m}$ in length when the lower beach had built up through sediment accretion. The longer profile with the larger low tide terrace is considered an accretional beach. The sweep zone varied $\sim 0.3$ to $0.4 \mathrm{~m}$ close to the foredunes at the beginning of the transect, $\sim 1.6$ to $1.9 \mathrm{~m}$ at the berm and berm face, and $\sim 1.2 \mathrm{~m}$ on the lower beach (Figure SB059).

In order to compare the differences in morphology and elevation between accretional or "built up" beach profiles to highly eroded, post-storm profiles, two comparisons were chosen based on maximum average beach elevation versus minimum average beach elevation (Figure SB05-10). At SB05, two profiles have very similar low mean elevations and are within the calculation's uncertainty; however, these two post-storm erosional profiles have different morphologies and show differences in the beach's response. Both comparisons are shown here as they display different patterns for poststorm or eroded beach profiles at SB05 (and for all of Seabrook Beach). Comparing the minimum average elevation profile which occurred on March 9, 2020 to the maximum average elevation profile that occurred on August 17, 2018 shows a large difference in elevation, approaching $\sim 2.0 \mathrm{~m}$ at its maximum point (Figure SB05-11). The accretional profile has a relatively wide backshore, welldefined berm, and a steep berm face. However, the lower beach is not present which is puzzling, but appears to be simply built up with sediment. The March 9, 2020 elevation profile is very steep starting at the foredunes and extending across the beach. However, there is a berm which is also unexpected. The lower beach has evidence of a small ridge indicating that the beach was beginning to recover. In contrast, comparing the August 17, 2018 beach elevation profile with the March 12, 2018 post-storm profile shows a very different erosional profile (Figure SB05-12). The beach on March 12 is very steep extending from the foredunes, but then has a slight convex-upward shape. However, the lower beach or low tide terrace is missing, likely because it is highly eroded and subtidal. It appears that sediment is eroded from the low tide terrace and transported to the mid and upper beach and into the dunes; however, the overall effect is major beach erosion. 


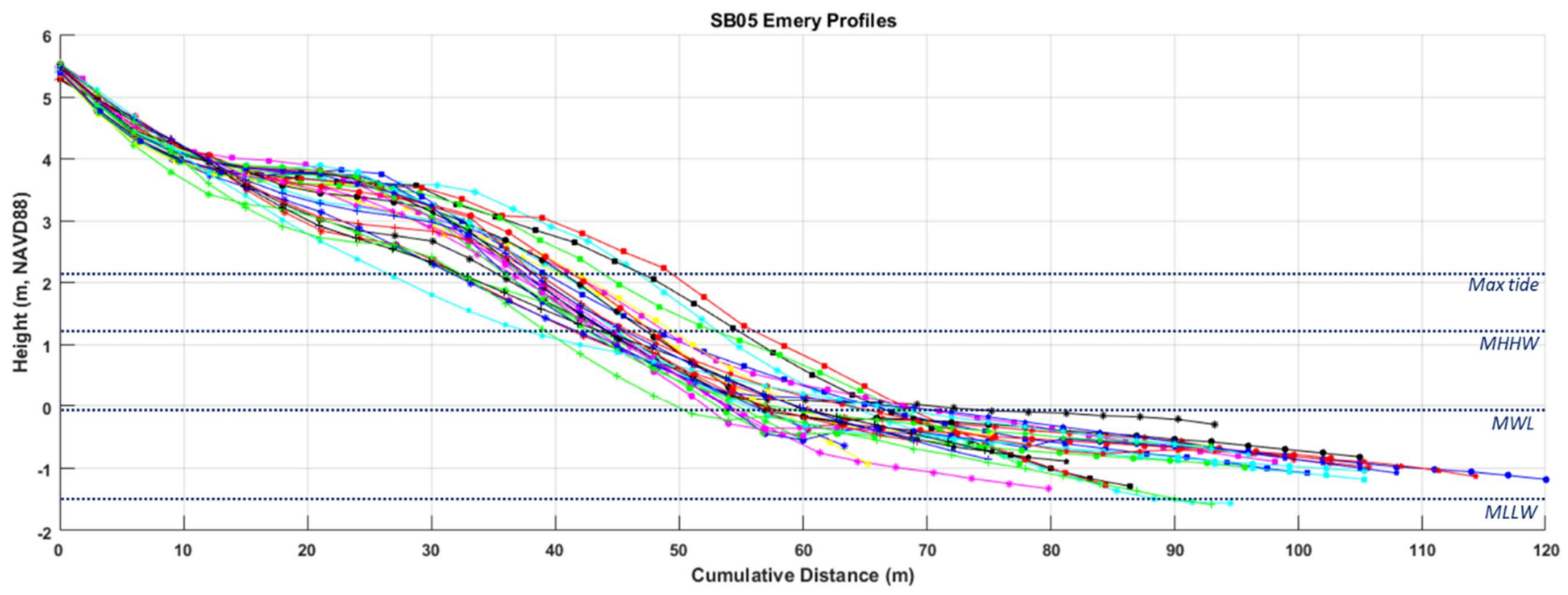

Figure SB05-9. All thirty profiled dates at station SB05 from January 29, 2018 to March 9, 2020. Maximum tidal elevation (max tide), mean higher high water elevation (MHHW), mean water level (MWL), and mean lower low water elevation (MLLW) are indicated by the dotted lines. 

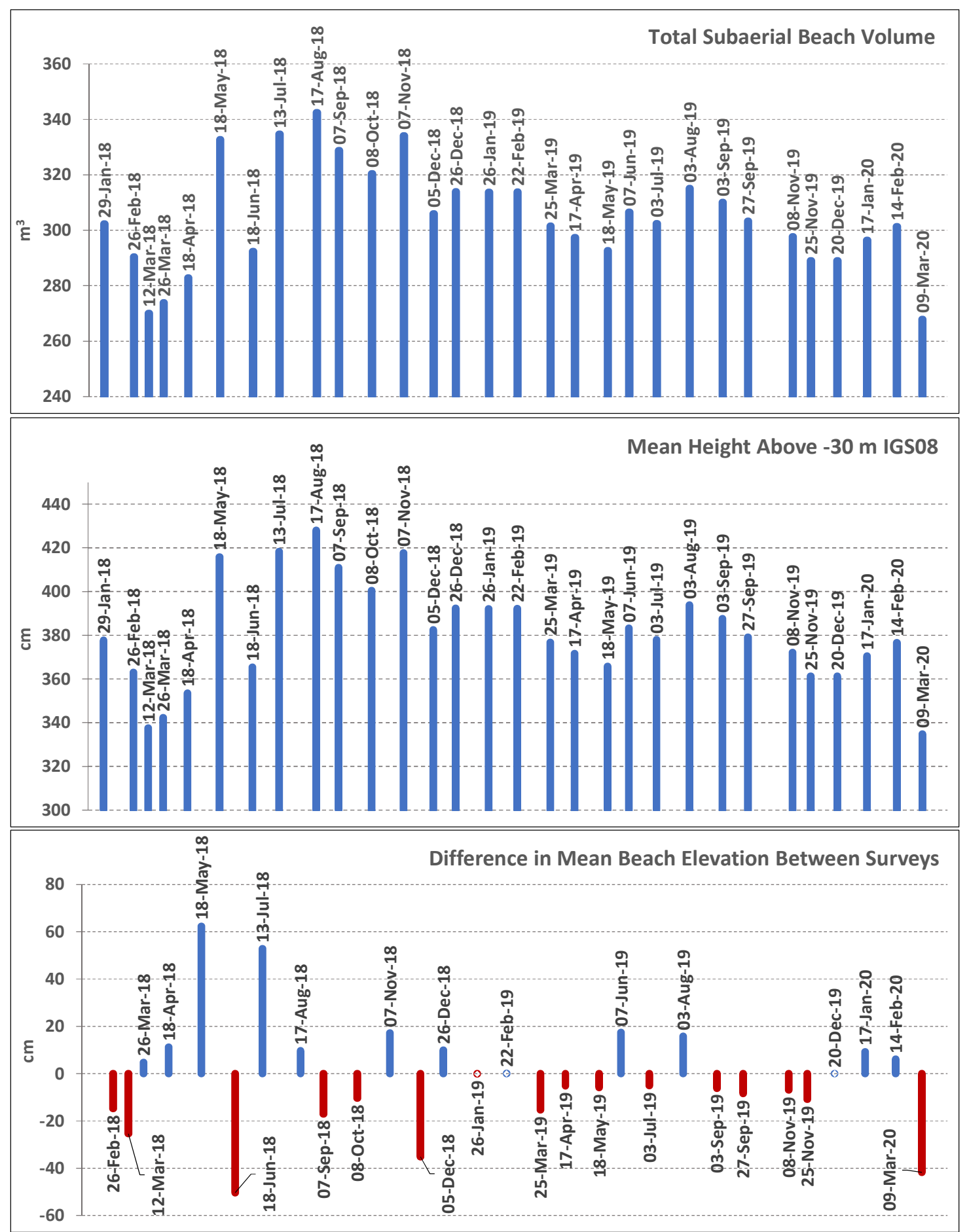

Figure SB05-10. Calculated sediment volume, mean profile elevation, and mean elevation change for the beach profile at station SB05. These parameters were calculated from 0-80 $\mathrm{m}$ of the profile length. Eleven of the thirty elevation profiles were shorter than the "standard profile length" for the station $(80 \mathrm{~m})$. These profiles were extended using the procedure described in Chapter 2: Methods. However, five of the profiles were extended 5.3 $\mathrm{m}$ or less which is considered negligible. Four of the longest extensions (16.8 m on March 26, 2018, $20.0 \mathrm{~m}$ on March 12, 2018, $20.0 \mathrm{~m}$ on May 18, 2019, and $10.8 \mathrm{~m}$ on January 17, 2020) followed winter 2018 and 2019 storms and subsequent beach erosion. 


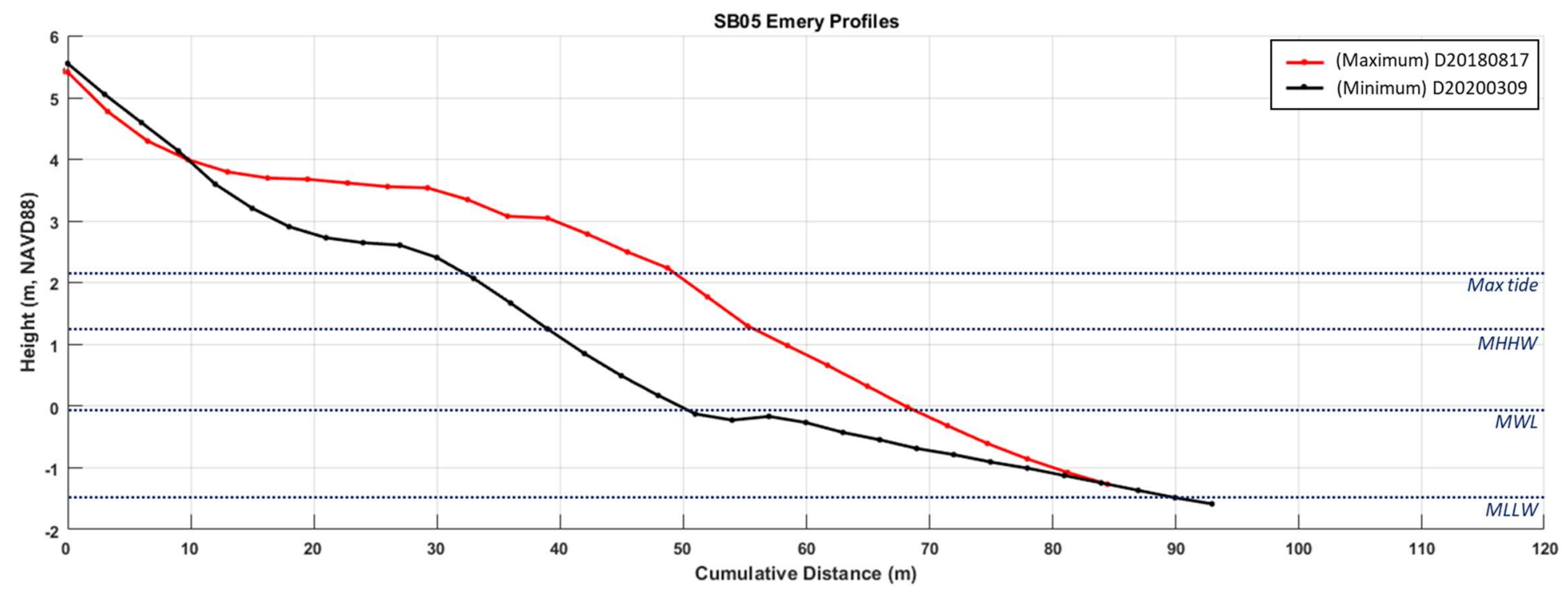

Figure SB05-11. Maximum (August 17, 2018) and minimum (March 9, 2020) profiles for the study period at station SB05.

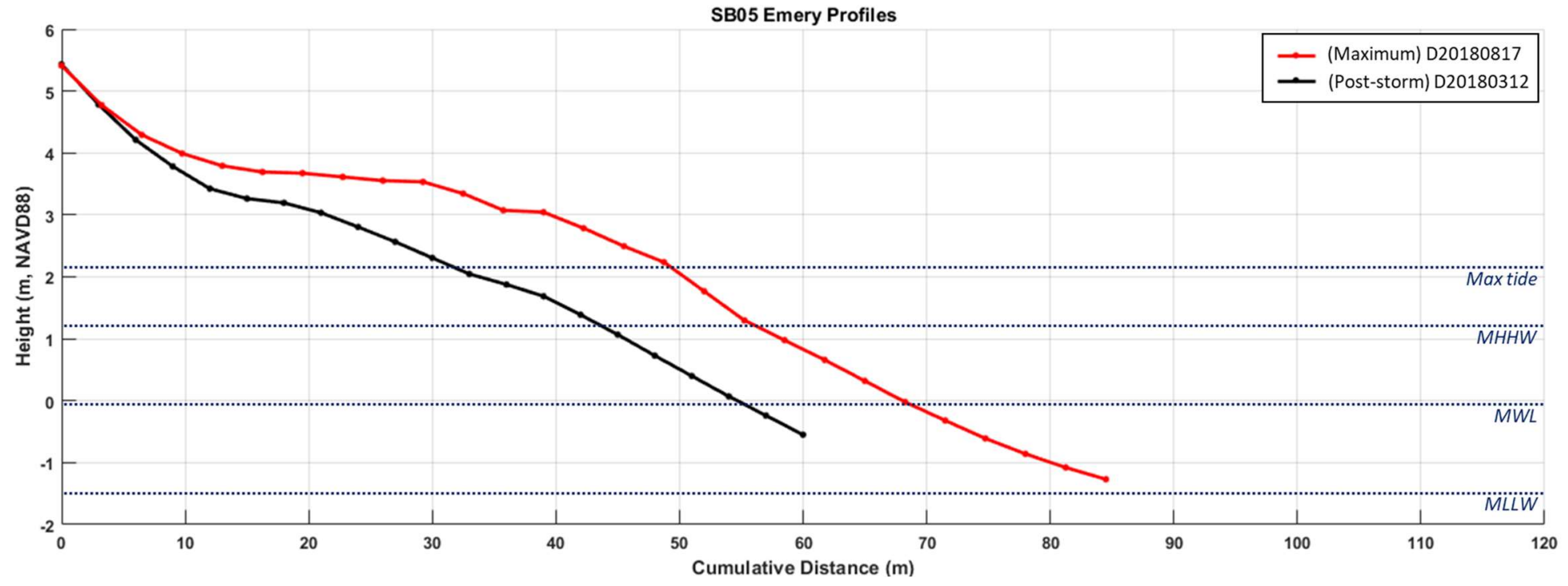

Figure SB05-12. Maximum (August 17, 2018) and post-storm (March 12, 2018) profiles for the study period at station SB05. 
Storm Effects, Beach Erosion, and Recovery. The beach at SB05 appears to have been eroded at the beginning of the study period on January 29 and February 26, 2018 due to several winter storms including Grayson (Jan 3-5), Inga (Jan 17-18), an unnamed period of high waves (Jan 29-31), Liam (Feb 7-9), and Noah (Feb 16-18) (Table 3-3). The upper and mid beach at SB05 had a very steep profile in January and February and was at one of the lowest elevations measured during the study period (Figure SB05-13). However, both elevation profiles had a wide, flat low tide terrace that had the highest elevations measured during the study for the lower beach. Since these are the first profiles measured during the study at this site, it is speculative, but it is likely that the early winter storms in January and February 2018 eroded the upper beach and deposited the sediment on the lower beach, which was subsequently removed by the severe nor'easters in late winter 2018 including Riley (Mar 1-4), Quinn (Mar 6-9) and Skylar (Mar 12-14). Following these storms, the profiles were very short and at some of the lowest elevations for the study period (Figure SB05-14). The beach face was steep with no morphologic features while the lower beach was eroded below low water level (Figure SB0515). As was seen at the other Seabrook Beach stations, the dunes were overwashed and sand transported into the dunes (Figures SB05-16 and SB05-17). The dune grasses quickly grew up through the sand, though, adding height and width to the dunes (Figure SB05-18).

The sand volume and mean elevation also reflect this dramatic loss (Figure SB05-10). This is consistent with one of the patterns that seem to characterize Seabrook Beach, whereby the upper beach is eroded, and the sediment transported to the lower beach. If successive storms occur, then the lower beach also becomes eroded. A second pattern can then emerge where material from the lower beach is eroded and pushed onto the mid and upper beach and into the dunes via overwash processes. 


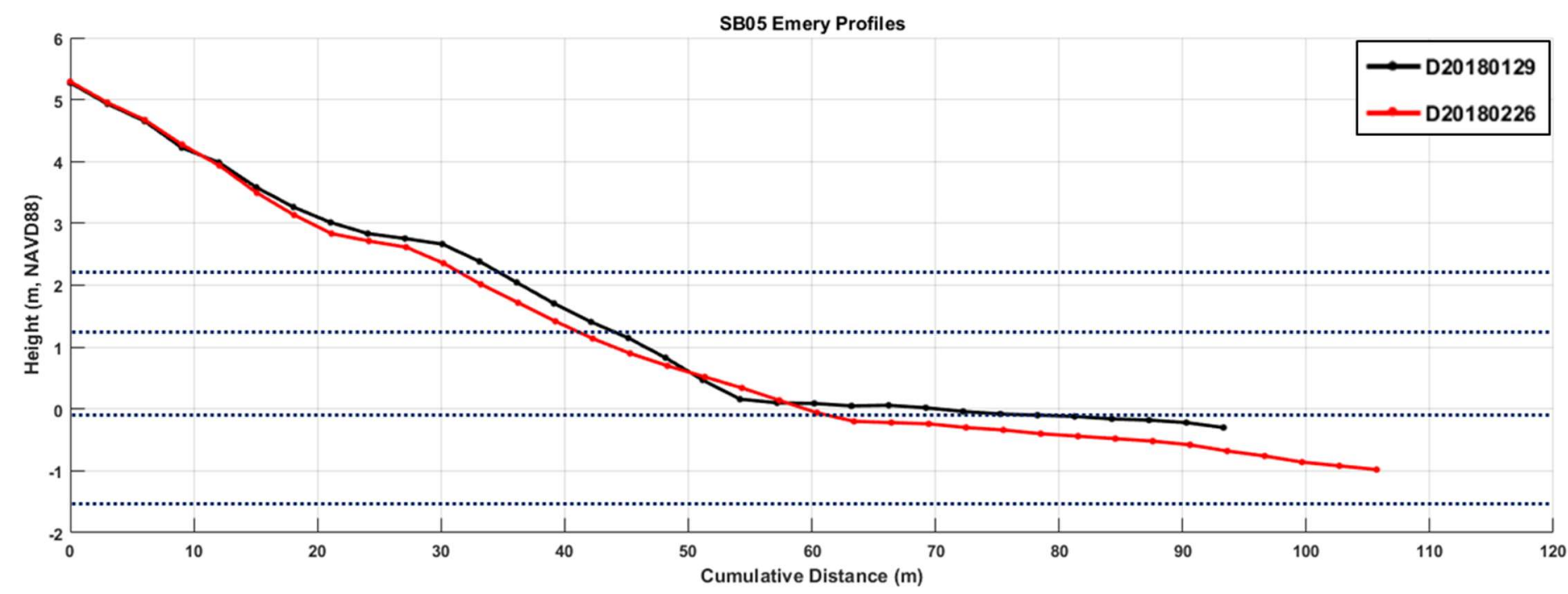

Figure SB05-13. Beach elevation profiles for SB05 measured on January 29, 2018 and February 26, 2018.

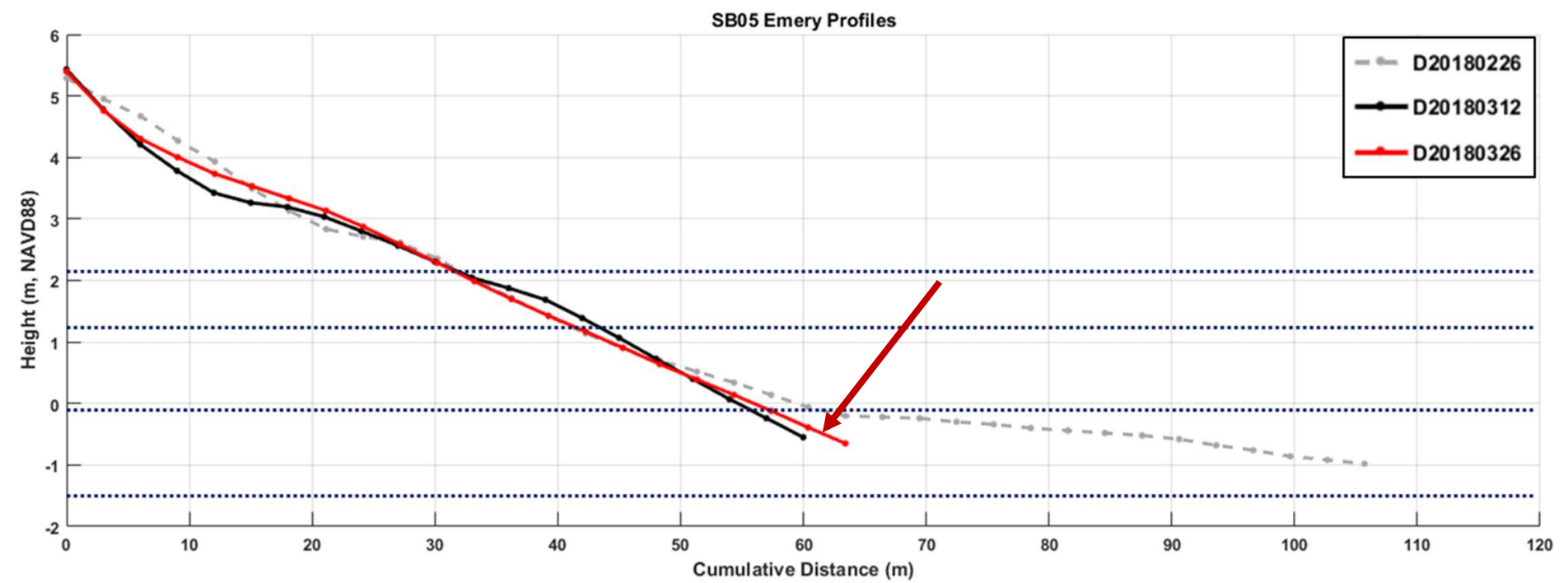

Figure SB05-14. Beach elevation profiles for SB05 measured on February 26, 2018, March 12, 2018, and March 26, 2018. Note how short the post-storm profiles are (arrow). 


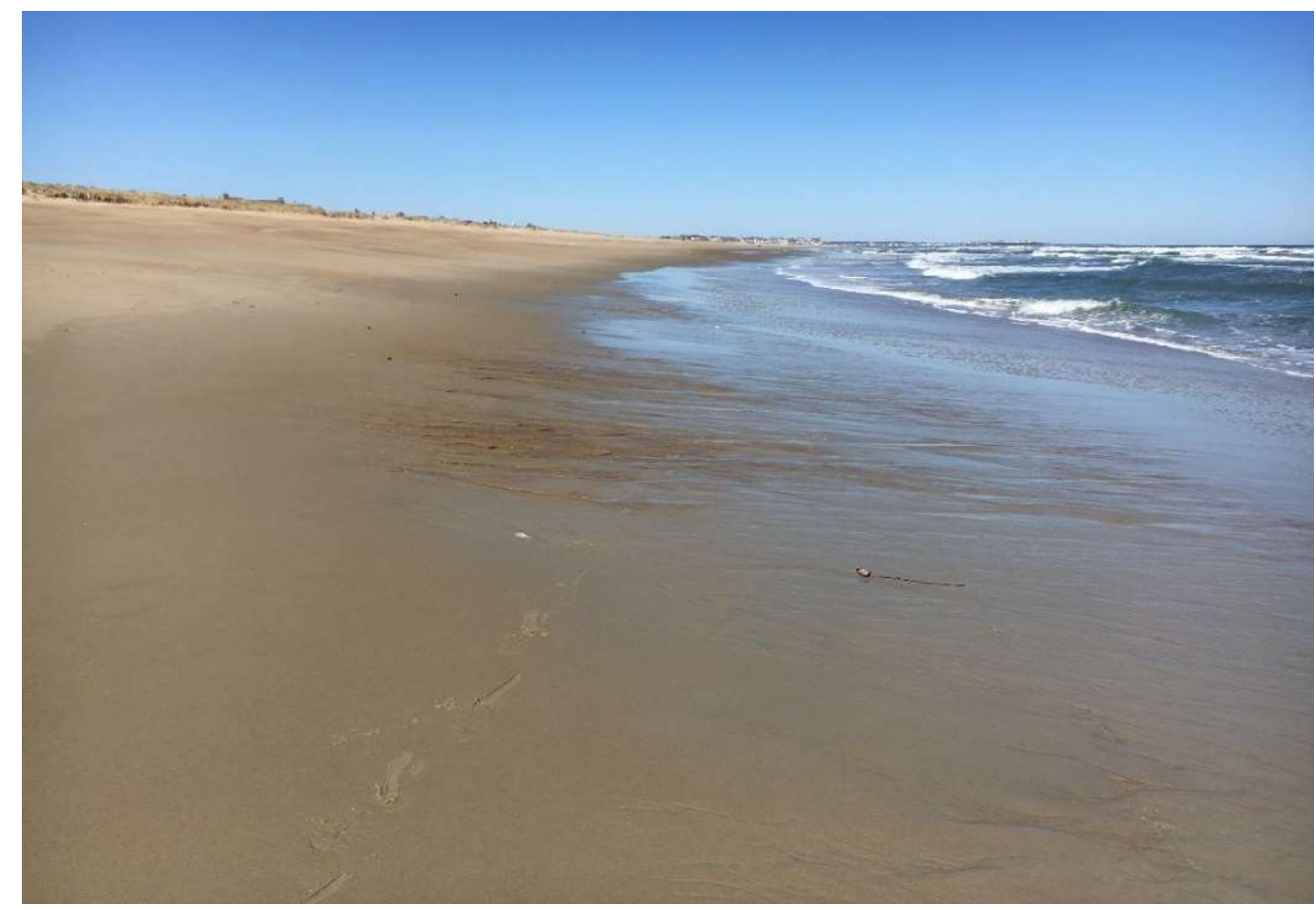

Figure SB05-15. During the nor'easters in March 2018 Seabrook Beach was severely eroded as seen here. In this photograph taken on March 26, 2018 looking north from station SB05, the beach was narrow, steep, and featureless. The low tide terrace is largely missing.

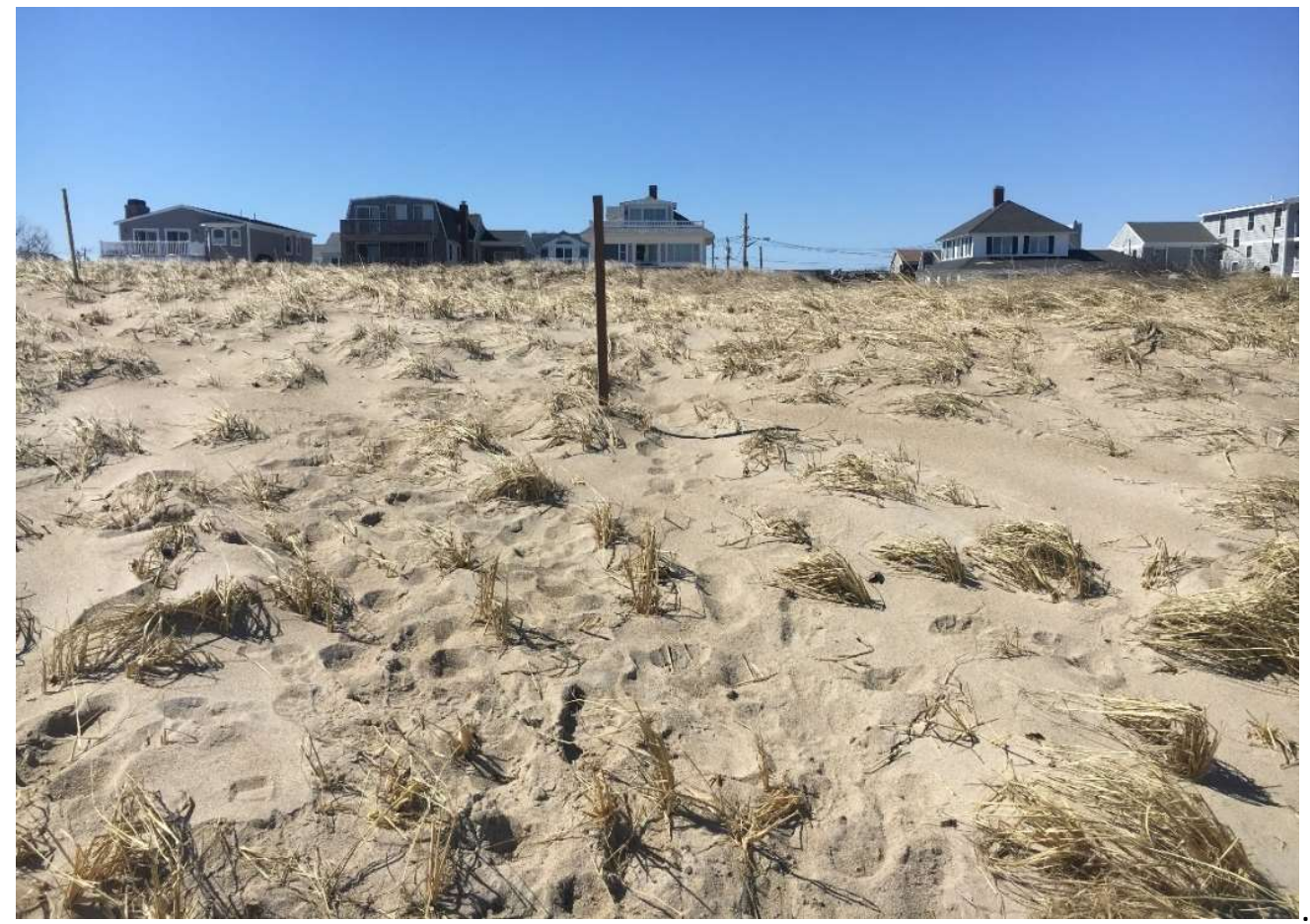

Figure SB05-16. Extensive overwash and a large amount of sand was brought into the dunes after the severe nor'easters in March 2018. The seaward stake/station marker for SB05 is seen in this photograph taken on March 26, 2018. Note the sand burying the vegetation in the foredunes. 


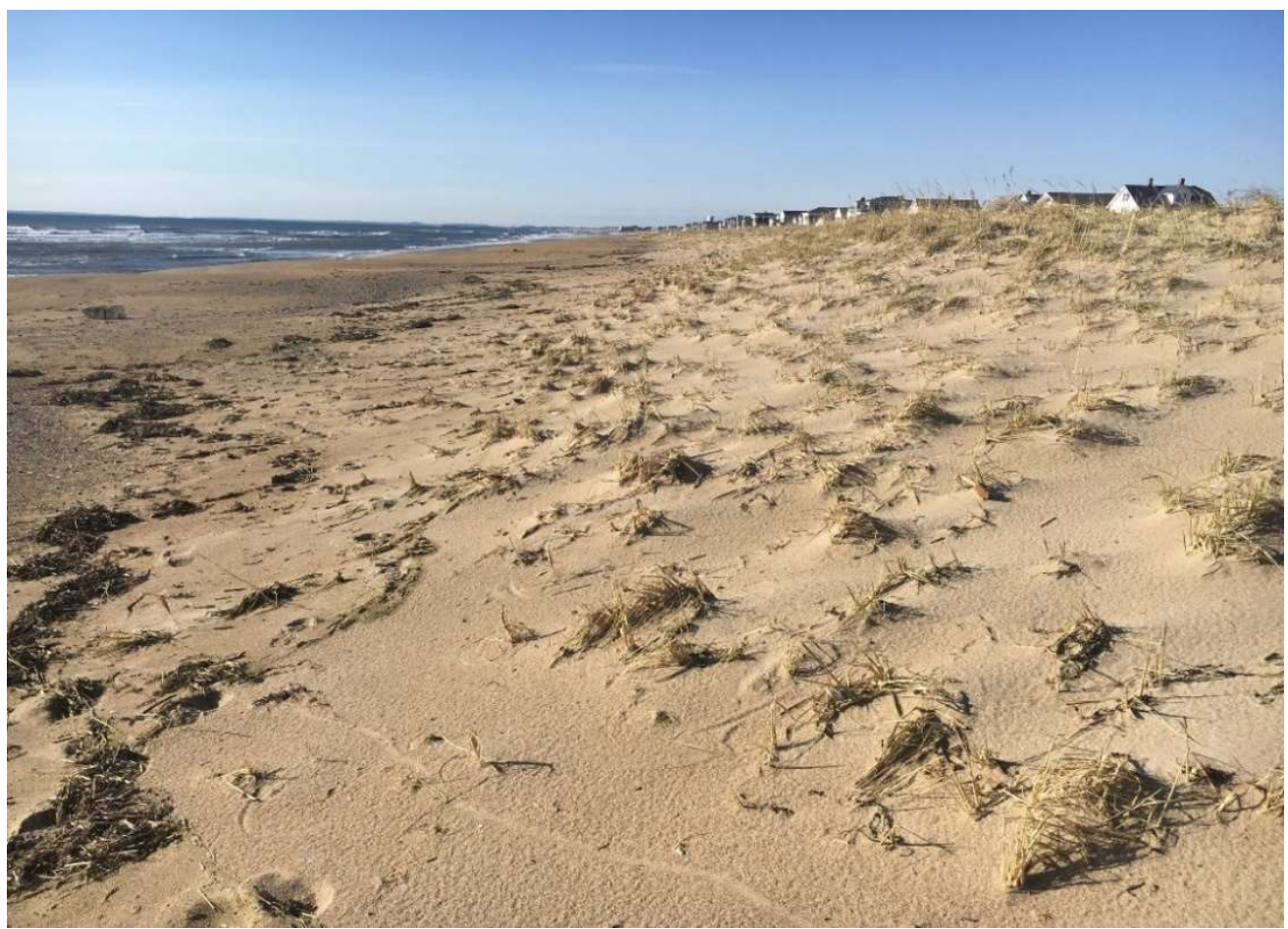

Figure SB05-17. Extensive overwash of the dunes at SB05 caused by the severe nor'easters in March 2018. Note the sand burying the vegetation in the foredunes on April 18, 2018.

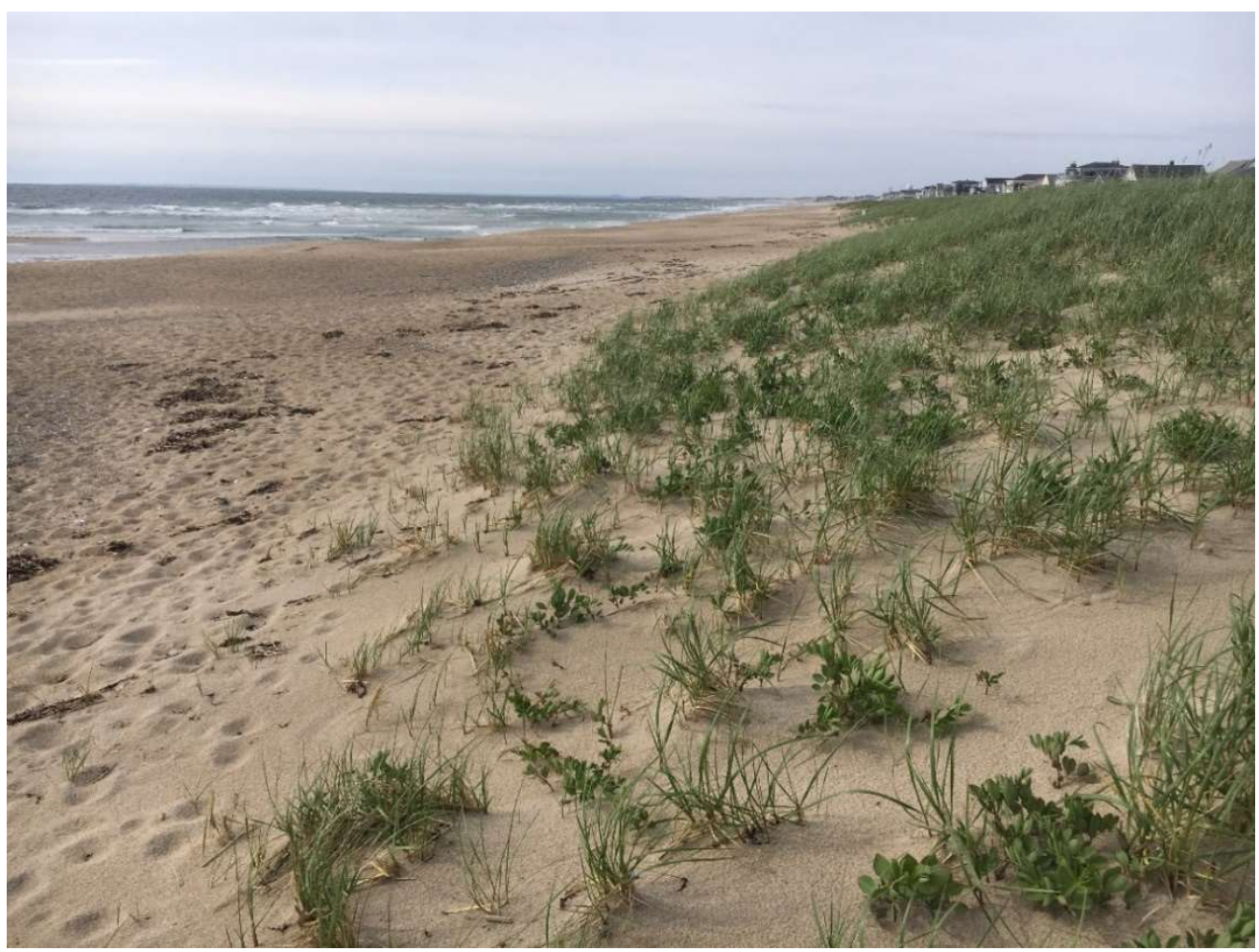

Figure SB05-18. The dune grasses grew quickly through the sand that was transported into dunes by storm surges during the nor'easters in March 2018, as seen here. The photograph was taken on SBO5 on May 18, 2018. 
The beach elevation at SB05 began to recover in April 2018 and by May extensive deposition of sand had occurred over the upper and mid profile (Figures SB05-19 and SB05-20). The elevation profile measured on May 18 showed the entire beach had built seaward and upward. Approximately $1.3 \mathrm{~m}$ of deposition occurred on the upper beach, $\sim 1.5 \mathrm{~m}$ at mid beach and at least $\sim 1.2 \mathrm{~m}$ on the lower beach (Figures SB05-21, SB05-22, and SB05-23). The profile at SB05 maintained this elevation and sediment volume until fall 2018 with the exception of the June 18 observations. A significant loss of sand and elevation occurred between May 18 and June 18 (Figure SB05-20). It is not clear what caused this apparent erosion and sand loss as examination of weather and wave histories do not indicate any high energy event. Also, review of data quality reveals no obvious issues. Therefore, it is assumed that this was a real event. Regardless, the beach had returned to the accretional conditions observed on May 18 by July 13 and maintained them through August 17, which was the highest elevation and sand volume measured during the study period. Following this maximum profile, the beach was moderately eroded in September and October.

Several higher energy events including Winter Storm Avery (Nov 15-16, 2018) and an unnamed high wave period (Nov 27) caused the lower beach to erode along with a loss of sediment as seen on the December 5 elevation profile. However, these were relatively small perturbations, but the overall effect was to lower the beach elevation. Other high energy events in early 2019 such as the Nor'easters Harper (Jan 19-20) and Maya (Feb 12-13) caused the elevation profile and sand volume to remain depressed though February 22, 2019, although the low tide terrace remained relatively wide (Figure SB05-24). Large waves on February 25 continued this period of extended erosion of the beach with elevation and sediment loss from March through July 2019 (Figure SB05-10), with some recovery in August (Figure SB05-25).

Fall 2019 saw a decline in elevation and sand volume with a series of storms including Melissa (Oct 11-13), an unnamed nor' easter (Oct 16-17), and a king tide coastal flood on October 28 (Figure SB0510; Table 3-3). A slight increase in volume was seen from December 2019 through February 2020, but by March 2020 the beach at SB05 was badly eroded down to the lowest volume and elevation seen during the study period. This may have been a result of a couple storms with strong easterly winds and high waves that had occurred since the last profiling period (a winter storm from February 27-28 and a nor'easter from March 6-7, 2020). Some erosion was seen at a number of other stations and beaches in March 2020, but this was the most significant loss and the only station which reached a minimum volume and elevation for the study period during this month. The only other station which experienced a similar extreme drop in volume was at NHB01, but in late January rather than March, and it saw recovery by the next month. 


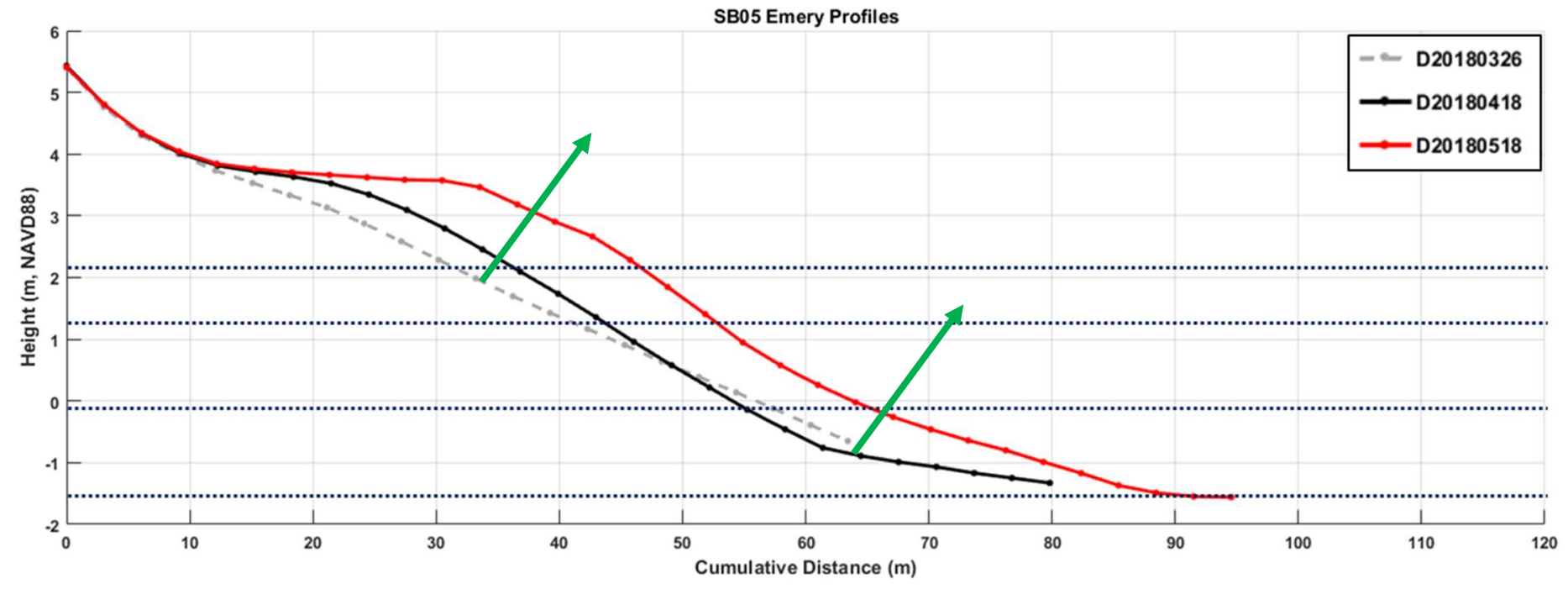

Figure SB05-19. Beach elevation profiles for SB05 measured on March 26, 2018, April 18, 2018, and May 18, 2018. Note the accretion throughout the length of the beach (arrows).

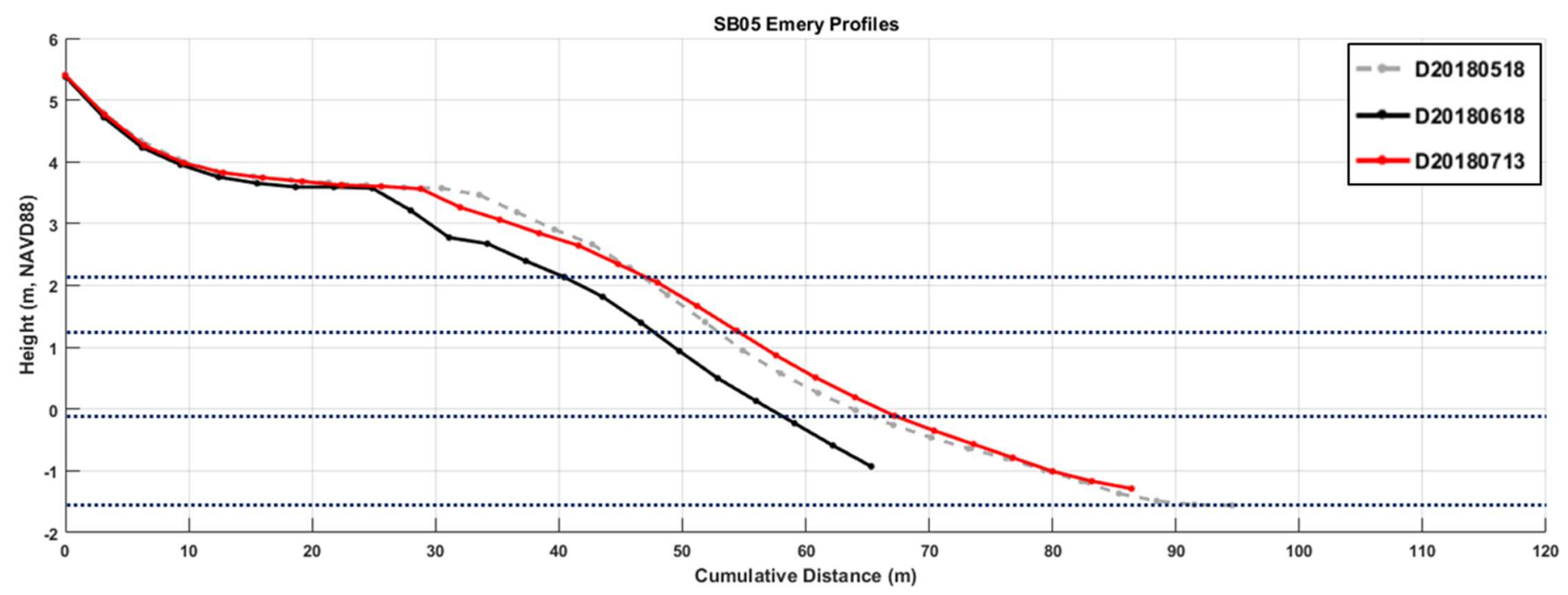

Figure SB05-20. Beach elevation profiles for SB05 measured on May 18, 2018, June 18, 2018, and July 13, 2018. 


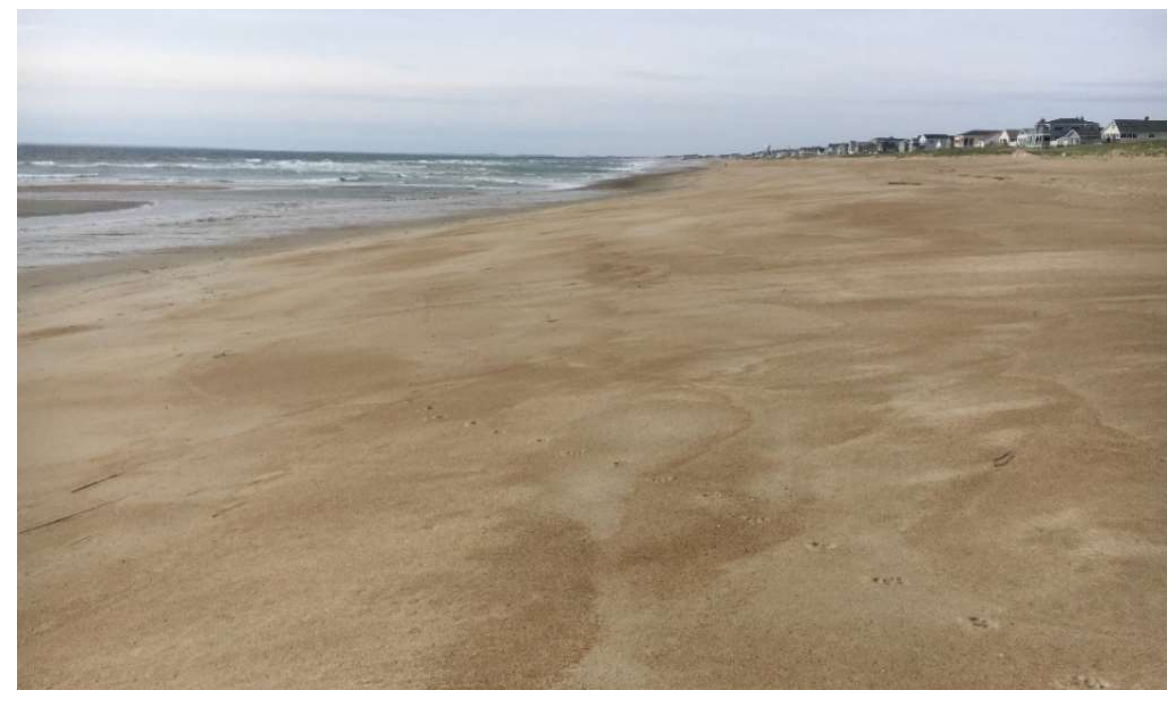

Figure SB05-21. The beach at SB05 had a large volume of sand deposited on the mid and upper beach by May 2018 as shown in the photograph taken on May 18, 2018. The beach had been severely eroded in March 2018 by a series of nor'easters.

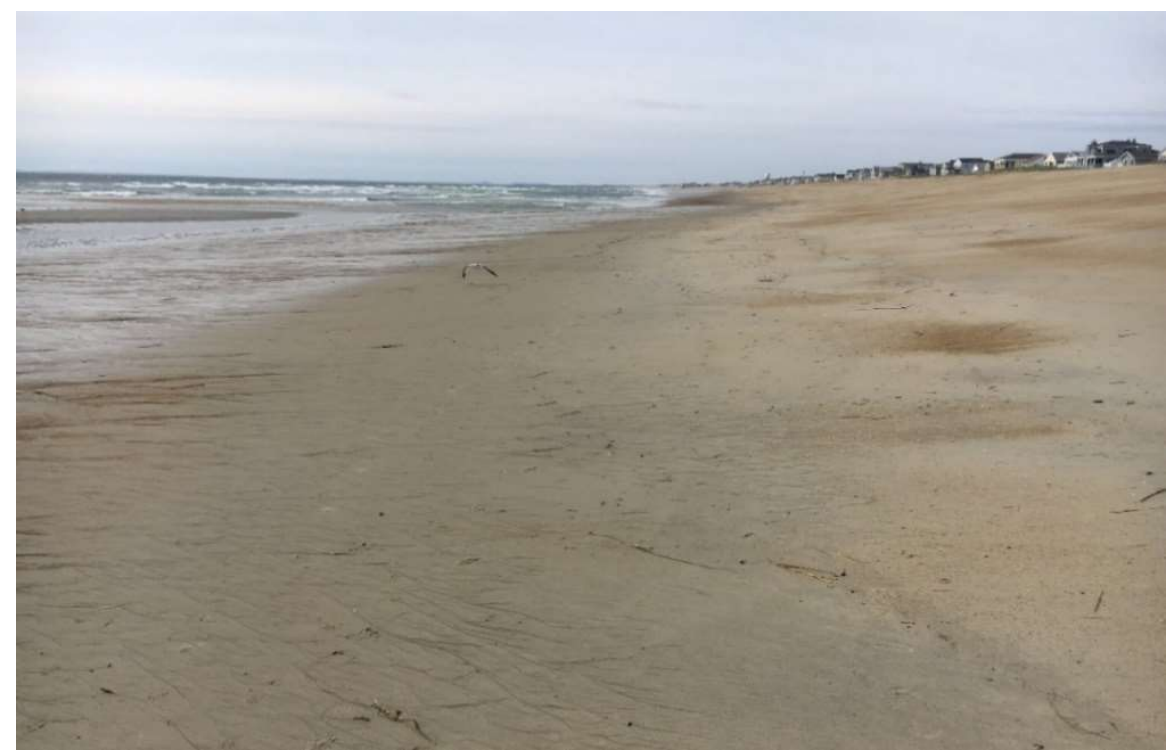

Figure SB05-22. The beach at SB05 had rebuilt by May 2018 as shown by the large volume of sand deposited on the mid and lower beach on May 18, 2018.

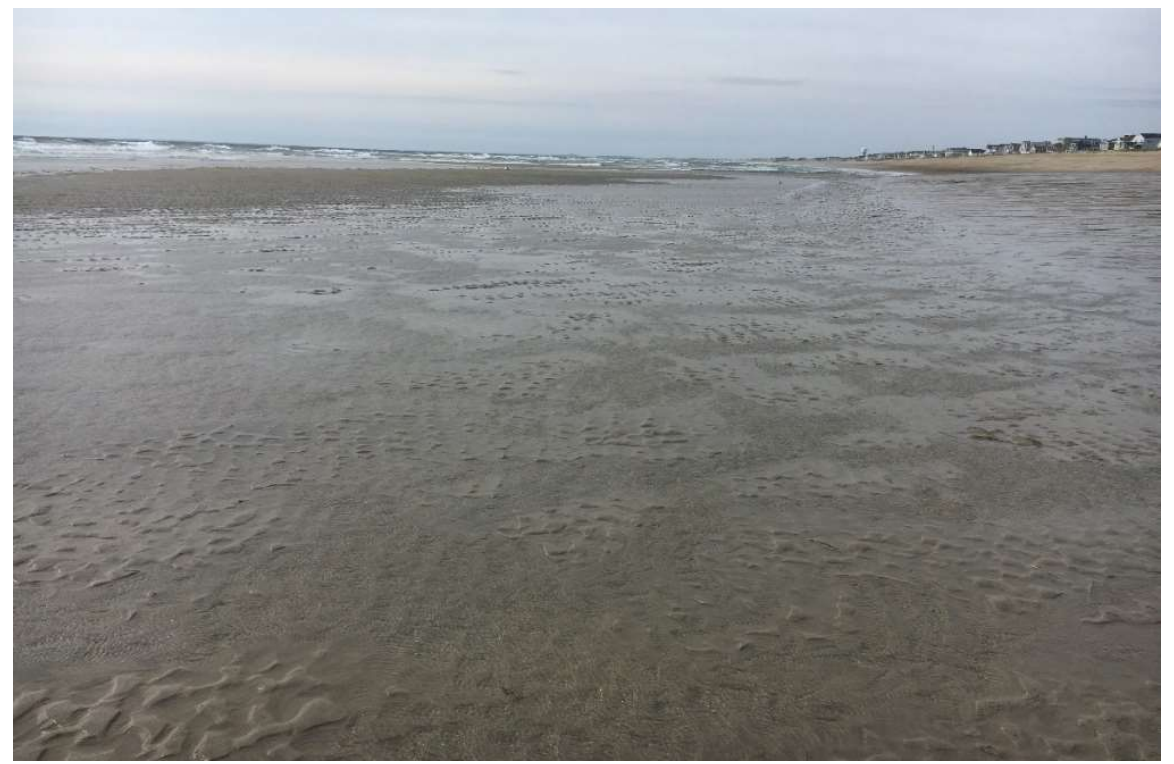

Figure SB05-23. The lower beach or low tide terrace at SB05 had rebuilt by May 2018 as shown in the photograph taken on May 18, 2018. 


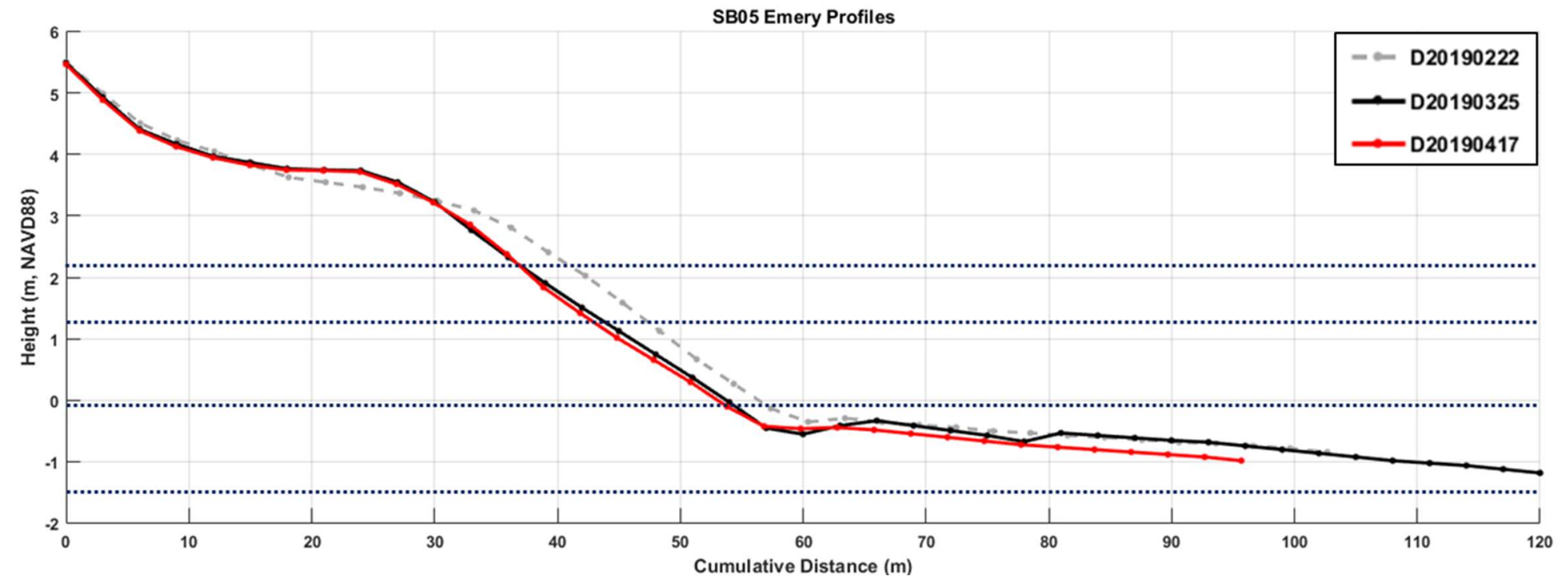

Figure SB05-24. Beach elevation profiles for SBO5 measured on February 22, 2019, March 25, 2019, and April 17, 2019.

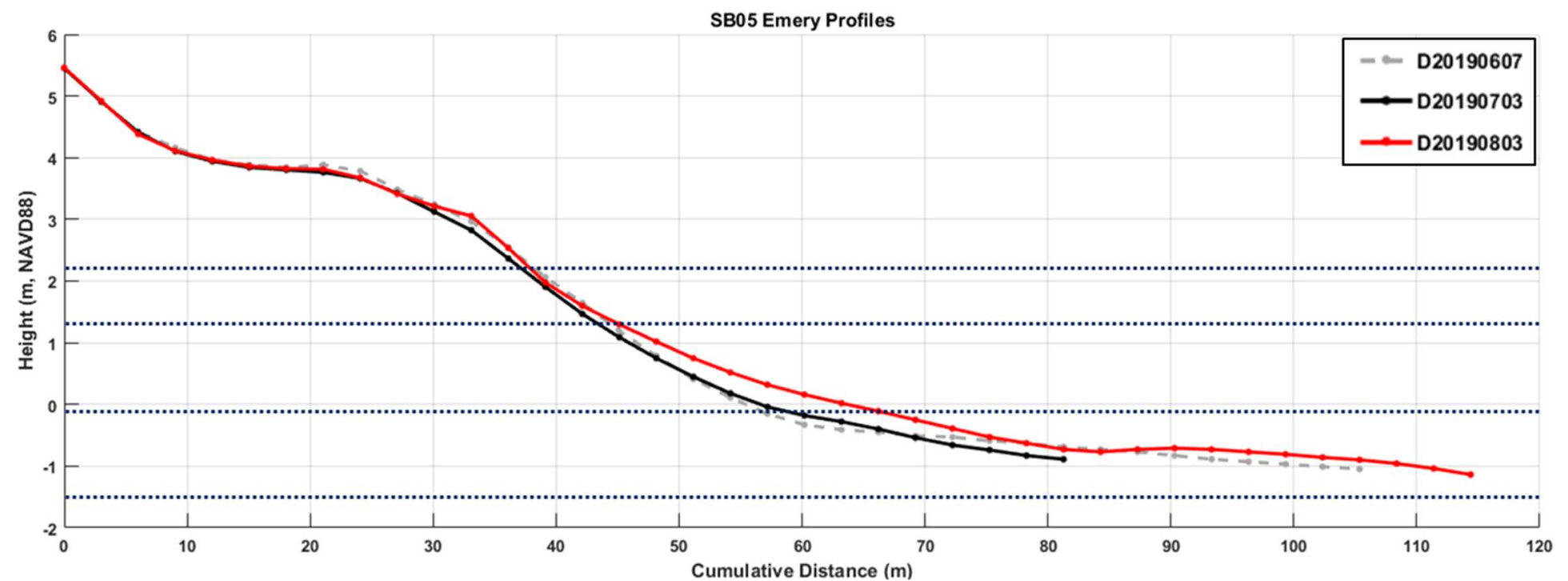

Figure SB05-25. Beach elevation profiles for SB05 measured on June 7, 2019, July 3, 2019, and August 3, 2019. 


\section{References}

Ashtech, 1998. Precise Differential Navigation and Surveying, PNAV. Magellan Corporation.

Betts, A.K., 2011. Seasonal climate transitions in New England. Weather, Vol. 66, No. 9, pp. 245-248.

Birch, F.S., 1984. A geophysical study of sedimentary deposits on the inner continental shelf of New Hampshire: Northeastern Geology, volume 6, number 4, pp. 207-221.

Blondin, H., 2016. New Hampshire Inventory of Tidal Shoreline Protection Structures, New Hampshire Coastal Program No. R-WD-16-09, New Hampshire Department of Environmental Services, Portsmouth, New Hampshire.

Eberhardt, A.L. and Burdick, D.M., 2008. Hampton-Seabrook Estuary Restoration Compendium, PREP Reports \&Publications. 76. https://scholars.unh.edu/prep/76

Emery, K.O., 1961. A simple method of measuring beach profiles. Limnology and Oceanography 6, 90-93.

Goldthwait, J.W., Goldthwait, L., and Goldthwait, R.P., 1925. The Geology of New Hampshire. New Hampshire Academy of Science Handbook Number 1, 86 p.

Haddad, T.C. and Pilkey, O.H., 1998. Summary of the New England Beach Nourishment Experience (1935-1996). Journal of Coastal Research 14, 1395-1404.

Harrison, W. and Lyon, C.J., 1963. Sea-level and crustal movements along the New England-Acadian Shore 4,500-3,000 B.P. The Journal of Geology 71:96-108.

Himmelstoss, E.A., Kratzmann, M.G., Hapke, C., Thieler, E.R., and List, J., 2010. The national assessment of shoreline change: A GIS compilation of vector shorelines and associated shoreline change data for the New England and Mid-Atlantic Coasts, USGS Open-File Report 2010-1119. https://doi.org/10.3133/ofr20101119.

Huang, H., Winter, J.M., and Osterberg, E.C., 2018. Mechanisms of abrupt extreme precipitation change over the northeastern United States. Journal of Geophysical Research: Atmospheres, 123, 7179-7192. https://doi.org/10.1029/2017JD028136.

IPCC (Intergovernmental Panel on Climate Change), 2014: Climate Change 2014: Synthesis Report. Contribution of Working Groups I, II and III to the Fifth Assessment Report of the Intergovernmental Panel on Climate Change [Core Writing Team, R.K. Pachauri and L.A. Meyer (eds.)]. IPCC, Geneva, Switzerland, 151 pp.

Kottek, M., Grieser, J., Beck, C., Rudolf, B., and Rubel, F., 2006. World Map of the Köppen-Geiger climate classification updated. Meteorol. Z., 15, 259-263. https://doi.org/10.1127/09412948/2006/0130.

Kirshen, P., Wake, C., Huber, M., Knuuti, K., and Stampone, M., 2014. Sea-level Rise, Storm Surges, and Extreme Precipitation in Coastal New Hampshire: Analysis of Past and Projected Future 
Trends (No. RSA 483-E). Science and Technical Advisory Panel, New Hampshire Coastal Risks and Hazards Committee.

Leo, M.E., 2000. The Geomorphology, Sedimentology, and Storm Response of Beaches along the Glaciated Coast of the Western Gulf of Maine (New Hampshire and Southwestern Maine). MS Thesis, University of New Hampshire, Durham. 123 pp. plus CD.

Lyon, C.J. and Harrison, W., 1960. Rates of submergence of coastal New England and Acadia. Science 132:295-296.

McKenna, L.A., 2013. Patterns of Bedform Migration and Mean Tidal Currents in Hampton Harbor Inlet, New Hampshire, USA. Unpublished MS Thesis, University of New Hampshire Durham, $106 \mathrm{p}$.

McPherran, K.A., 2017. Seasonal Changes in Geomorphology and Sediment Volume of New Hampshire Beaches: Insights into a Highly-Engineered, Paraglacial, Bedrock Influenced Mixed Sand and Gravel Coastal System. Unpublished MS Thesis, University of New Hampshire Durham, 149 p. https://scholars.unh.edu/thesis/1105

National Oceanic and Atmospheric Administration (NOAA), National Ocean Service (NOS). Vertical Datum Transformation. https://vdatum.noaa.gov/. Accessed January 2020.

National Oceanic and Atmospheric Administration (NOAA), Center for Operational Oceanographic Products and Services (CO-OPS). Tides \& Currents. URL https://tidesandcurrents.noaa.gov/. Accessed January 2020.

National Oceanic and Atmospheric Administration (NOAA), National Centers for Environmental Information (NCEI). Storm Events Database. URL https://www.ncdc.noaa.gov/stormevents/. Accessed January 2020.

National Oceanic and Atmospheric Administration (NOAA), National Data Buoy Center (NDBC). URL https://www.ndbc.noaa.gov/. Accessed January 2020.

National Oceanic and Atmospheric Administration (NOAA), National Weather Service (NWS), National Weather Service Forecast Office Gray/Portland. NOWData- NOAA Online Weather Data. URL https://w2.weather.gov/climate/xmacis.php?wfo=gyx. Accessed January 2020.

New Hampshire Coastal Risk and Hazards Commission, 2016, Preparing New Hampshire for Projected Storm Surge, Sea-Level Rise and Extreme Precipitation. URL http://www.nhcrhc.org/wp-content/uploads/2016-CRHC-final-report.pdf

New Hampshire State Parks. Jenness State Beach Redevelopment Project. https://www.nhstateparks.org/news-events/improving-state-parks/jenness-state-beachredevelopment-project. Accessed June 2020.

Olson, N.F. and Chormann, F.H., 2016, New Hampshire Beaches: Shoreline Movement and Volumetric Change: BOEM/New Hampshire Cooperative Agreement (ContractM14ACO0010) Technical Report Department of Interior, Bureau of Ocean Energy 
Management, Marine Minerals Division, 45600 Woodland Road, Sterling, VA, 20166, 15 pp. $\mathrm{ftp}: / / \mathrm{ftp}$.granit.sr.unh.edu/pub/GRANIT_Data/Vector_Data/Oceans_and_Coasts/dbeachshorelinechange/BOEM_Rept_Change_Analysis_Olson_D20160129_NFO_final.pdf

Sallenger, A.H. Jr., Doran, K.S., Howd, P.A., 2012. Hotspot of accelerated sea-level rise on the Atlantic coast of North America. Nature Climate Change 2: 884-888.

Sinclair, S.N., Licciardi, J.M., Campbell, S.W., and Madore, B.M., 2018. Character and origin of De Geer moraines in the Seacoast region of New Hampshire, USA. Journal of Quaternary Science, 33(2):225-237, ISSN 0267-8179. https://doi.org/10.1002/jqs.3017

Takasu, T., 2013. RTKLIB: An Open Source Program Package for GNSS Positioning. URL http://www.rtklib.com/. Accessed January 2020.

United States Army Corps of Engineers (USACE), 1954. Hampton Beach, N.H. Beach Erosion Control Study. 83 Congress, 2nd Session, H Doc 325.30 p., plus plates.

United States Army Corps of Engineers (USACE), 1962. Shore of the State of New Hampshire, Beach Erosion Control Study. 87/2, H Doc 416. 156 p, plus plates.

United States Army Corps of Engineers (USACE), 2016a. Hampton Beach Shore and Bank Protection Project [WWW Document]. U.S.Army Corps of Engineers. URL https://www.nae.usace.army.mil/Missions/Civil-Works/Shore-Bank-Protection/NewHampshire/Hampton/

United States Army Corps of Engineers (USACE), 2016b. Wallis Sands State Beach Shore and Bank Protection Project [WWW Document]. U.S. Army Corps of Engineers. URL https://www.nae.usace.army.mil/Missions/Civil-Works/Shore-Bank-Protection/NewHampshire/Wallis-Sands/

University of California San Diego, California Sea Grant. CoAST SB: Community Alliance for Surveying the Topography of Sandy Beaches. https://caseagrant.ucsd.edu/project/coast-sbcommunity-alliance-for-surveying-the-topography-of-sandy-beaches. Accessed February 2020.

University of Maine, Maine Sea Grant. Southern Maine Volunteer Beach Profile Monitoring Program. https://seagrant.umaine.edu/extension/southern-maine-volunteer-beach-profilemonitoring-program/. Accessed February 2020.

Wake, C., Burakowski, E., Kelsey, E., Hayhoe, K., Stoner, A., Watson, C., and Douglas, E., 2011. Climate Change in the Piscataqua/Great Bay Region: Past, Present, and Future, in: Carbon Solutions New England. University of New Hampshire, Durham, NH, p. 54.

Wake, C., Knott, J., Lippmann, T., Stampone, M., Ballestero, T., Bjerklie, D., Burakowski, E., Glidden, S., Hosseini-Shakib, I., Jacobs, J. (2019). New Hampshire Coastal Flood Risk SummaryPart I: Science. Prepared for the New Hampshire Coastal Flood Risk Science and Technical Advisory Panel. Report published by the University of New Hampshire, Durham, NH. https://scholars.unh.edu/cgi/viewcontent.cgi?article=1209\&context=ersc 
Ward, L.G., McPherran, K.A., McAvoy, Z.S., and Vallee-Anziani, M., 2016, New Hampshire beaches: Sediment characterization: BOEM/New Hampshire Cooperative Agreement (Contract M14ACO0010) Technical Report, Department of Interior, Bureau of Ocean Energy Management, Marine Minerals Division, 45600 Woodland Road, Sterling, VA, 20166, 37 pp. https://dx.doi.org/10.34051/p/2021.29

Ward, L.G., Corcoran, N.W., McAvoy, Z.S., and Morrison, R.C., 2021, Seasonal Changes in Sediment Grain Size of New Hampshire Atlantic Beaches: BOEM/New Hampshire Cooperative Agreement (Contract M14ACO0010) Technical Report, Department of Interior, Bureau of Ocean Energy Management, Marine Minerals Division, 45600 Woodland Road, Sterling, VA, 20166, 208 pp. https://dx.doi.org/10.34051/p/2021.33 


\section{Appendix A: Glossary of Terms}

Note: The definitions presented here are frequently modified or simplified to describe concepts or calculations presented specifically for this study. In some instances the definitions given here differ from other definitions for a term.

Accrete, Accretional, Accretion: Increase in sediment on a beach.

Attached Barrier: Elongated sand ridge built by the action of waves, currents, and winds that rises above the high-tide level and extends generally parallel with the shore but separated from it by a lagoon or marsh. It is attached to the mainland or a headland at both ends.

Back-barrier: Area of land between a barrier island, barrier spit, or attached barrier (barrier beach) and the mainland.

Backrush: Seaward flow of the swash.

Backshore: Upper or landward zone of the shore or beach lying between the high-water line of mean spring tides and the coastline. Acted upon by waves or covered by water only during exceptionally severe storms or unusually high tides. It is essentially horizontal or slopes landward and is divided from the foreshore by the crest of the most seaward berm. Usually dry under normal conditions.

Barrier Island: Elongated sand ridge built by the action of waves, currents, and winds that rises above the high-tide level and extends generally parallel with the shore but separated from it by a lagoon or marsh. It is unattached to the mainland.

Barrier Spit: Elongated sand ridge built by the action of waves, currents, and winds that rises above the high-tide level and extends generally parallel with the shore but separated from it by a lagoon or marsh. It is attached to the mainland or a headland at one end.

Bedrock: General term for the rock that is part of the crust. It is not unattached such as boulders. Can be buried by sediment or exposed.

Berm: Low, impermanent, nearly horizontal shelf on the backshore of a beach formed of material transported by waves. It is generally bounded on the seaward side by an increase in slope towards the sea (berm crest). Many beaches have no berms, others have one or several.

Berm Crest: Seaward or outer limit or edge, and generally the highest part, of a berm on a beach.

Berm Face: Seaward sloping beach starting at the berm crest and extending to the low tide terrace or where the beach becomes noticeably flatter.

Datum: Reference system or an approximation of the Earth's surface against which positional measurements can be made (e.g., latitude, longitude, and elevation). See geodetic datum.

Bimodal: Beaches composed of sand and gravel.

Diurnal Inequality (referring to tides): Difference in height between successive high tides and low tides. 
Diurnal Tide: One high tide and low tide every lunar day.

Downcut Limit: Critical elevation below which there is little to no vertical erosion.

Drumlin: A low, smoothly rounded, elongated and oval hill, mound, or ridge of compact glacial till, built under the glacial ice and shaped by its flow. The longer axis is parallel to the direction of movement of the ice. Composed of a large range of sediment from boulders to mud.

Dune: Accumulations of sand deposited primarily by the wind at the landward edge of beaches. Can be bare or covered with vegetation. Provides a barrier to water and sand sweeping inland. Acts as a natural storage site for sand.

Dune Grass: A stout grass growing in the dunes.

Ellipsoid: A flattened sphere used to represent the geometric model of the Earth (e.g. the Earth is not completely round and is slightly flattened at the poles); a mathematical model of the Earth to represent horizontal positions on maps and charts (versus the topographic or actual visible surface of the earth).

Emery Method: A simple method for measuring the profile of a beach by using two graduated rods, whose alignment and reading of the intersection with the horizon allow for the determination of differences in level along the profile.

Erode (for beaches): To remove sediment by the action of current, waves or wind.

Erosional (for beaches): A trend or condition where sediment is being eroded by the action of current, waves, or wind.

Esker: A long, low, narrow, sinuous, steep-sided ridge or mound composed of irregularly stratified sand and gravel that was deposited by a subglacial or englacial stream flowing between ice walls or in an ice tunnel of a continuously retreating glacier, and was left behind when the ice melted. Eskers, unlike drumlins, are stratified accumulations of gravel, sand, and waterworn stones.

Foreshore: The gradually seaward-sloping zone of the shore or beach found in the intertidal zone (between high tide and low tide), and usually lying between the crest of the most seaward berm on the backshore (or the upper limit of wave wash at high tide) and the ordinary low-water mark. The zone regularly covered and uncovered by the rise and fall of the tide, or the zone lying between the ordinary tide levels.

Foredune or Foredune Ridge: A coastal dune or dune ridge oriented parallel to the shoreline of an ocean or large lake, occurring at the landward margin of the beach (or along the shoreward face of a beach ridge) or at the landward limit of the highest tide, and more or less completely stabilized by vegetation. The most seaward dune ridge.

Geoid: The zero surface as defined by Earth's gravity; the true zero surface for measuring elevations. This surface cannot actually be seen and therefore cannot actually be measured, so it must be modeled. Mean Sea Level is a close approximation. 
Geometric Datum: Coordinate system with a reference surface (such as sea level) that serves to provide known locations to begin surveys and create maps.

GNSS (Global Navigation Satellite System): A general term describing any satellite constellation that provides positioning, navigation, and timing (PNT) services on a global or regional basis. GPS is the most prevalent GNSS.

Granule (Sediment grain size): sediment grain size class that ranges from 2 to $4 \mathrm{~mm}$.

Groin (Groyne): An engineering structure that is usually a low, narrow, rigid wall constructed of timber, stone, concrete, or steel, usually extending roughly perpendicular to the shoreline, designed to protect the shore from erosion and to trap sediment.

Horizontal Datum: Measures positions or latitude and longitude.

IGS08: Geodetic datum used by surveyors, engineers, and mapping professionals to measure locations (latitude and longitude) and elevations to the Earth's surface throughout the world. Referenced to an ellipsoid.

Intertidal: Area of a beach between high water and low water. Also called foreshore.

Jetty: An engineering structure extending seaward at the edge of a river or inlet designed to stabilize the location or stop migration. It is often built in pairs on either side of a harbor entrance or at the mouth of a river.

Lag Deposits: Coarse-grained material that is left behind after currents or waves have winnowed or washed away the finer material.

Longshore Sediment Transport or Drift: The transportation of sediment along the coast parallel to the shoreline by waves.

Low Tide Terrace: A relatively horizontal or flat area of the beach near the low-water line.

Maximum Average Elevation Profile: The single beach elevation profile for a station that has the highest overall elevations. It is determined from the average profile elevation for a standard profile length for that beach.

MHW (Mean High Water): Average height of all the high waters recorded at a given place over a 19year period (epoch) or a computed equivalent period.

MHHW (Mean Higher High Water): Average height of all the highest high water levels recorded at a given place over a 19-year period (epoch) or a computed equivalent period.

MLLW (Mean Lower Low Water): Average height of all the lower low water levels recorded at a given place over a 19-year period (epoch) or a computed equivalent period.

MLW (Mean Low Water): Average height of all the low water levels recorded at a given place over a 19-year period (epoch) or a computed equivalent period. 
MSL (Mean Sea Level): Average height of the surface of the sea for all stages of the tide over a 19year period (epoch) at a given place.

MTR (Mean Tidal Range): Calculated as the difference in height between mean high water (MHW) and mean low water (MLW).

MWL (Mean Water Level): Average height of the surface of water.

Megaclast: Larger fragments in a variable matrix of a sedimentary rock. Usually refers to cobbles and boulders.

Megaclast Platform: Flat or gently sloping surface extending seaward from the shore composed of megaclasts.

Minimum Average Elevation Profiles: The single profile for a station that has the lowest overall elevations. It is determined from the average profile elevation for a standard profile length for that beach.

Mixed Semidiurnal Tides: Two high and two low tides of different range every lunar day.

Morphology: Shape of the Earth's surface. The external structure, form, and arrangement of landforms.

NAD83 (North American Datum of 1983): Geodetic datum used by surveyors, engineers, and mapping professionals to measure locations (latitude and longitude) and elevations to the Earth's surface in the United States. Referenced to an ellipsoid.

NAVD88 (North American Vertical Datum of 1988): Vertical datum used by surveyors, engineers, and mapping professionals to measure and relate elevations to the Earth's surface.

Neap Tide: A tide occurring at the first and third quarters of the moon when the gravitational pull of the sun opposes (or is at right angles to) that of the moon, and having an unusually small or reduced tide range (usually $10-30 \%$ less than the mean range).

Overwash: Flow of water and sediment over a coastal dune or beach crest during storm events or other situations with high water.

Platforms (Pebble/Cobble/Boulder): Flat or gently sloping underwater erosional surface extending seaward or lakeward from the shore.

Prograde: advance of the coastline or beach seaward due to the accumulation of sediment.

Projection: Process which uses the latitude and longitude which has already been 'drawn' on the surface of the Earth using a datum to then be 'drawn' onto a 'flat piece of paper' or map.

Ramp: Low gradient slope that extends seaward from a seawall or some type of engineering structure. The ramp is likely formed by the erosion of the lower beach during the stormy periods and the storm surge, along with wave run-up, pushing sand up against the seawall. The ramp can be composed of sand or gravel. 
Ridge: Sand or dune ridge located inland from the modern beach due to the seaward building of the beach.

Ridge and Runnel: The ridge is a sand bar moving landward across the intertidal beach being moved by wave bores and swash. If no storms occur, the ridge will continue to migrate landward and weld onto the berm. It is a major mechanism for the natural recovery of a beach following an erosional period. The Runnel is a trough-like area at the landward edge of the ridge. It carries the water drainage off the beach as the tide retreats and is flooded as the tide advances.

Rills: small channels formed on a beach that form from seaward flow of swash or groundwater.

Riprap: Rock debris used to stop erosion from waves or currents.

\section{Runnel: See Ridge and Runnel}

Seawall: Engineering or human-made structure built at the landward edge of the beach primarily to prevent erosion and other damage to the upland by wave action.

Sediment: Fragmental material that originates from erosion of rocks (e.g. sand, gravel, silt, mud).

Semidiurnal Tide: Two high tides and low tides nearly equal in range every lunar day.

Shingle Beach: a beach composed of pebbles and small to medium sized cobbles (instead of sand)

Shoaling (Sediment): Buildup of sediment due to deposition.

Shoaling (Waves): Alteration of a wave as it proceeds from deep water into shallow water, and evidenced by an initial decrease in height of the incoming wave, followed by an increase in height as the wave arrives on the shore.

Shore-normal: A line at a right angle to the coast or upland.

Significant wave height: Average height of the highest one-third of all waves.

Spring Tide: Larger than average tides that occur twice each month at or near the times of new moon (conjunction) and full moon (opposition) when the gravitational pull of the sun reinforces (or acts in the same direction as) that of the moon.

Standard Elevation Profile Length or Standard Profile Length: Profile length chosen to calculate all volume parameters for an individual beach station. The minimum length that captures most of the profiles determined from reviewing all the profiles from that station from all dates.

Storm Surge: An abnormal, sudden rise of sea level along an open coast during a storm, caused primarily by onshore wind stress, or less frequently, by atmospheric pressure reduction, resulting in water piled up against the coast. It is most severe when accompanied by a high tide.

Subsidence: Sinking of the Earth's crust relative to the surrounding area.

Swash: Rush of water up onto the beach following the breaking of a wave. 
Swash Zone: Sloping part of the beach that is alternately covered and uncovered by the uprush of waves.

Sweep Zone: Envelope encompassing the entire horizontal and vertical area occupied by all of the beach elevation profiles measured at a station when plotted together. It defines the highest and lowest elevations (extremes) of all points on the profile transect that have occurred during the entire period the profile has been monitored. An upper or lower boundary is rarely defined by a single profile from a given day. This definition is adapted for this study from the coastal literature which includes the intertidal beach and subtidal nearshore to the depth of closure.

Tidal Datum: Standard elevation framework used to track local water levels as measured by a tidal gauging station.

Tidal Inlet: An inlet through a barrier beach which water flows alternately landward with the rising tide and seaward with the falling tide.

Till or Glacial Till: Unsorted and unstratified sediment deposited by a glacier. Generally unconsolidated, deposited directly by and underneath a glacier without subsequent reworking by water from the glacier, and consisting of a heterogeneous mixture of clay, sand, gravel, and boulders varying widely in size and shape.

Uplift: Rising of the Earth's crust relative to the surrounding area.

Vertical Datum: Measures elevation above a reference surface.

Washover Deposit: Sediment deposited by overwash.

WGS84 (World Geodetic System 1984): Geodetic datum used by surveyors, engineers, and mapping professionals to measure locations (latitude and longitude) and elevations to the Earth's surface throughout the world. Referenced to an ellipsoid. 


\section{Appendix B: Complete Storm History}

Detailed storm history of the New Hampshire coast from December 2016 to March 2020. Wind data was calculated from the buoy at the Isles of Shoals, NH (Station IOSN3; 42.967 N 70.623 W) and wave data was calculated from the Jeffreys Ledge buoy (Station $44098 ; 42.798$ N 70.168 W) (NOAA NDBC, accessed January 2020). Storm details have been downloaded from NOAA's Storm Events Database (NOAA NCEI, accessed January 2020). Times are in UTC. Average wind speed was calculated by averaging over a chosen period when winds were highest (generally when above $10 \mathrm{~m} / \mathrm{s}$ ), and which corresponded to the known storm dates. Wind gust range was calculated by finding the maximum and minimum wind gust from the chosen period. Average significant wave height was calculated by averaging over a chosen period when waves were highest (generally when above $2 \mathrm{~m}$ ), and which corresponded to the known storm dates. Peak significant wave heights were calculated by averaging the period of the highest waves.

Definitions of terms used in Appendix B (from NOAA NDBC, accessed January 2020):

- Significant wave height $(\mathrm{Hs})$ : average height of the highest one third of all wave heights during a 20-minute sampling period, reported every half hour

- Wave direction: the direction from which the waves at the dominant period are coming, and is reported every half hour

- Wind speed: averaged over a two-minute period (because Isles of Shoals is a land station) and is reported hourly

- Wind direction: averaged over a two-minute period and reported every hour

- Wind gust: the peak 5- or 8-second gust speed measured during the two-minute period, and is reported every hour

Note: In order for the tables to be complete and include the needed information, the lettering is small. Therefore, the tables in Appendix $B$ are best viewed at least $125 \%$ enlargement. 


\begin{tabular}{|c|c|c|c|c|c|c|c|c|c|c|c|}
\hline \multicolumn{4}{|c|}{$2016-2017$} & \multicolumn{3}{|c|}{$\begin{array}{l}\text { Wind } \\
\text { (Isles of Shoals Station IOSN3) }\end{array}$} & \multicolumn{5}{|c|}{$\begin{array}{c}\text { Waves } \\
\text { (Jeffrey's Ledge Station 44098) }\end{array}$} \\
\hline Dates & Name & Type & Snow & $\begin{array}{c}\text { Average Wind } \\
\text { Speed }\end{array}$ & Wind Gust Range & Wind Direction & \begin{tabular}{|c|} 
Peak Wave \\
Hs (Significant Wave Height)
\end{tabular} & $\begin{array}{c}\text { Average } \\
\text { Hs (Significant Wave Height) }\end{array}$ & $\begin{array}{c}\text { Range } \\
\mathrm{Hs}\end{array}$ & \begin{tabular}{|c|} 
Average \\
Ts
\end{tabular} & \begin{tabular}{|c} 
Dominant \\
Ts
\end{tabular} \\
\hline \multirow[t]{2}{*}{ Dec 28-30 } & Fortis & Winter Storm & $<2^{\prime \prime}(<5 \mathrm{~cm})$ & $13.8 \mathrm{~m} / \mathrm{s}(30.9 \mathrm{mph})$ & $8.9-19.0 \mathrm{~m} / \mathrm{s}(19.9-42.5 \mathrm{mph})$ & SSE, then WSW & $3.4 \mathrm{~m}(\mathrm{SE})$ & $2.8 \mathrm{~m}(\mathrm{SE}$, then $\mathrm{W})$ & $2.1-3.7 \mathrm{~m}$ & $5.6 \mathrm{~s}$ & $6.5 \mathrm{~s}$ \\
\hline & & & & Dec $29(18: 00)$ to Dec 31 & $1(06: 00)$ & & Dec $30(00: 00$ to $04: 00)$ & Dec $29(22: 00)$ to Dec $30(17: 00)$ & & & \\
\hline \multirow[t]{2}{*}{$\tan 3-5$} & & & & $13.4 \mathrm{~m} / \mathrm{s}(30 \mathrm{mph})$ & $8.0-21.8 \mathrm{~m} / \mathrm{s}(17.9-48.8 \mathrm{mph})$ & ENE, then W & $4.8 \mathrm{~m}$ (ESE) & $4.0 \mathrm{~m}$ (ESE) & $2.2-5.3 \mathrm{~m}$ & $7.5 \mathrm{~s}$ & $9.7 \mathrm{~s}$ \\
\hline & & & & $\operatorname{Jan} 3(08: 00)$ to $\operatorname{Jan} 4(09$ & $9: 00)$, and $\operatorname{Jan} 4(22: 00)$ to $\operatorname{Jan} 5(20: 00)$ & & $\operatorname{Jan} 4(02: 00$ to $10: 00)$ & $\operatorname{Jan} 3(18: 00)$ to $\operatorname{Jan} 4(16: 00)$ & & & \\
\hline \multirow[t]{2}{*}{$\tan 7-8$} & Helena & Nor'easter & & $11.4 \mathrm{~m} / \mathrm{s}(25.5 \mathrm{mph})$ & $8.1-17.7 \mathrm{~m} / \mathrm{s}(18.1-39.6 \mathrm{mph})$ & NNE, then NNW & $3.1 \mathrm{~m}(\mathrm{E})$ & $2.8 \mathrm{~m}(\mathrm{E})$ & $2.0-3.2 \mathrm{~m}$ & $6.5 \mathrm{~s}$ & $8.7 \mathrm{~s}$ \\
\hline & & & & $\operatorname{Jan} 7(13: 00)$ to $\operatorname{Jan} 8(09$ & 9:00) & & $\operatorname{Jan} 8(03: 00$ to $12: 00)$ & $\operatorname{Jan} 7(22: 00)$ to $\operatorname{Jan} 8(21: 00)$ & & & \\
\hline \multirow[t]{2}{*}{$\operatorname{Jan} 17-19$} & Jupiter & Winter Storm & $5-8 "(13-20 \mathrm{~cm})$ & $10.8 \mathrm{~m} / \mathrm{s}(24.1 \mathrm{mph})$ & $9.3-14.5 \mathrm{~m} / \mathrm{s}(20.8-32.4 \mathrm{mph})$ & ENE & \multirow{2}{*}{\multicolumn{5}{|c|}{ (data not available) }} \\
\hline & & & & $\tan 17(22: 00)$ to $\operatorname{Jan} 19$ & $(05: 00)$ & & & & & & \\
\hline \multirow[t]{2}{*}{ Feb 5-7 } & Maya & Winter Storm & 6" $(15 \mathrm{~cm})$ & $11.6 \mathrm{~m} / \mathrm{s}(26.0 \mathrm{mph})$ & $10.4-17.6 \mathrm{~m} / \mathrm{s}(23.2-39.4 \mathrm{mph})$ & WSW & (no peak) & $1.6 \mathrm{~m}$ (WSW) & $1.3-2.1 \mathrm{~m}$ & $4.3 \mathrm{~s}$ & $5.2 \mathrm{~s}$ \\
\hline & & & & Feb $5(14: 00)$ to Feb $6(1$ & 11:00) & & & Feb $5(15: 00)$ to Feb $6(17: 00)$ & & & \\
\hline \multirow[t]{2}{*}{ Feb 7-9 } & Niko & Nor'easter & $10-15^{\prime \prime}(25-38 \mathrm{~cm})$ & $13.6 \mathrm{~m} / \mathrm{s}(30.4 \mathrm{mph})$ & $8.0-18.7 \mathrm{~m} / \mathrm{s}(17.9-41.8 \mathrm{mph})$ & ENE & $4.0 \mathrm{~m}$ (WSW) & $3.1 \mathrm{~m}$ (WSW) & $2.0-4.6 \mathrm{~m}$ & $6.7 \mathrm{~s}$ & $8.4 \mathrm{~s}$ \\
\hline & & & & Feb $7(13: 00)$ to Feb $8(0$ & $06: 00)$ & & Feb $8(01: 00$ to $7: 00)$ & Feb $7(16: 00)$ to Feb $8(16: 00)$ & & & \\
\hline \multirow[t]{2}{*}{ Feb 9-10 } & & & & $14.1 \mathrm{~m} / \mathrm{s}(31.5 \mathrm{mph})$ & $10.9-22.8 \mathrm{~m} / \mathrm{s}(24.4-51.0 \mathrm{mph})$ & NE, then WNW & $4.2 \mathrm{~m}(\mathrm{NE})$ & $3.4 \mathrm{~m}(\mathrm{NE}$, then $\mathrm{WNW})$ & $2.1-4.8 \mathrm{~m}$ & $6.2 \mathrm{~s}$ & $7.7 \mathrm{~s}$ \\
\hline & & & & Feb $9(09: 00)$ to Feb 10 & $(20: 00)$ & & Feb $9(22: 00)$ to Feb $10(04: 00)$ & Feb $9(12: 00)$ to Feb $10(13: 00)$ & & & \\
\hline \multirow[t]{2}{*}{ Feb 12-13 } & Orson & Winter Storm & 6-16" $(15-41 \mathrm{~cm})$ & $14.0 \mathrm{~m} / \mathrm{s}(31.4 \mathrm{mph})$ & $11.9-18.4 \mathrm{~m} / \mathrm{s}(26.6-41.2 \mathrm{mph})$ & ENE, then NNW & $4.5 \mathrm{~m} \mathrm{(E)}$ & $3.6 \mathrm{~m}(\mathrm{E})$ & $2.5-5.2 \mathrm{~m}$ & $6.9 \mathrm{~s}$ & $9.9 \mathrm{~s}$ \\
\hline & & & & Feb $12(18: 00)$ to Feb 14 & $4(02: 00)$ & & Feb $13(06: 00)$ to Feb $14(04: 00)$ & Feb $12(06: 00)$ to Feb $14(13: 00)$ & & & \\
\hline \multirow[t]{2}{*}{ Feb 15-16 } & Pluto & Winter Storm & & $10.3 \mathrm{~m} / \mathrm{s}(23.0 \mathrm{mph})$ & $7.4-14.7 \mathrm{~m} / \mathrm{s}(16.6-32.9 \mathrm{mph})$ & SSE, then $\mathrm{E}$ & $3.0 \mathrm{~m}(\mathrm{E})$ & $2.8 \mathrm{~m}(\mathrm{E})$ & $2.3-3.3 \mathrm{~m}$ & $6.4 \mathrm{~s}$ & $8.9 \mathrm{~s}$ \\
\hline & & & & Feb 15 (09-22:00), and Fe & Feb $16(04-13: 00)$ & & Feb 16 (11:00 to 15:00) & Feb 16 (06:00 to 19:00) & & & \\
\hline \multirow[t]{2}{*}{ Mar 14-15 } & Stella & Nor'easter & $12-20 "(30-51 \mathrm{~cm})$ & $19.5 \mathrm{~m} / \mathrm{s}(43.7 \mathrm{mph})$ & $10.5-30.7 \mathrm{~m} / \mathrm{s}(23.5-68.7 \mathrm{mph})$ & $\mid \mathrm{NE}$ & $6.3 \mathrm{~m}$ (ESE) & $4.6 \mathrm{~m}$ (ESE) & $2.9-7.1 \mathrm{~m}$ & $8.2 \mathrm{~s}$ & $12.0 \mathrm{~s}$ \\
\hline & & & & Mar 14 (13:00) to Mar 15 & $5(04: 00)$ & & Mar $14(20: 00)$ to Mar $15(02: 00)$ & Mar 14 (17:00) to Mar 15 (23:00) & & & \\
\hline \multirow[t]{2}{*}{ Mar 19-21 } & & & & $10.1 \mathrm{~m} / \mathrm{s}(22.6 \mathrm{mph})$ & $6.9-15.4 \mathrm{~m} / \mathrm{s}(15.4-34.4 \mathrm{mph})$ & $\mathrm{NE}$, then variable & $3.8 \mathrm{~m}$ (ESE) & $3.1 \mathrm{~m}$ (ESE) & $1.9-4.1 \mathrm{~m}$ & $6.9 \mathrm{~s}$ & $9.5 \mathrm{~s}$ \\
\hline & & & & Mar $19(05: 00)$ to Mar 20 & $0(17: 00)$ & & Mar 20 (06:00 to 15:00) & Mar 19 (12:00) to Mar 21 (03:00) & & & \\
\hline \multirow[t]{2}{*}{ Mar 31-Apr 2} & Theseus & Winter Storm & 6" $(15 \mathrm{~cm})$ & $12.5 \mathrm{~m} / \mathrm{s}(27.9 \mathrm{mph})$ & $8.8-20.0 \mathrm{~m} / \mathrm{s}(19.7-44.7 \mathrm{mph})$ & $\mathrm{NE}$ & $4.1 \mathrm{~m}$ (ESE) & $3.3 \mathrm{~m}$ (ESE) & $2.0-4.6 \mathrm{~m}$ & $7.0 \mathrm{~s}$ & $9.0 \mathrm{~s}$ \\
\hline & & & & April 1(00:00) to April 2 & $2(05: 00)$ & & April 1(13:00) to April 2 (01:00) & April 1 (07:00) to April 2 (17:00) & & & \\
\hline \multirow[t]{2}{*}{ May 14-15 } & & & & $11.7 \mathrm{~m} / \mathrm{s}(26.2 \mathrm{mph})$ & $7.8-19.5 \mathrm{~m} / \mathrm{s}(17.4-43.6 \mathrm{mph})$ & NNE, then WNW & $3.1 \mathrm{~m}(\mathrm{E})$ & $2.6 \mathrm{~m}(\mathrm{E})$ & $2.0-3.3 \mathrm{~m}$ & $5.9 \mathrm{~s}$ & $8.4 \mathrm{~s}$ \\
\hline & & & & Mar $14(07: 00)$ to Mar 15 & $5(23: 00)$ & & May 14 (19:00 to 23:00) & May $14(09: 00)$ to May $15(16: 00)$ & & & \\
\hline \multirow[t]{2}{*}{ May 25} & & Coastal Flood & & $12.3 \mathrm{~m} / \mathrm{s}(27.6 \mathrm{mph})$ & $6.4-21.5 \mathrm{~m} / \mathrm{s}(14.3-48.1 \mathrm{mph})$ & $\mathrm{NE}$ & $2.6 \mathrm{~m}(\mathrm{E})$ & $2.2 \mathrm{~m}(\mathrm{E})$ & $1.4-2.9 \mathrm{~m}$ & $5.9 \mathrm{~s}$ & $7.5 \mathrm{~s}$ \\
\hline & & Storm surge: 0. & $35 \mathrm{~m}$ & May $25(13: 00)$ to May 26 & $26(18: 00)$ & & May $25(22: 00)$ to May 26 (06:00) & May $25(18: 00)$ to May $27(01: 00)$ & & & \\
\hline \multirow[t]{2}{*}{ Jun 5-7 } & & & & $12.2 \mathrm{~m} / \mathrm{s}(27.3 \mathrm{mph})$ & $8.5-18.1 \mathrm{~m} / \mathrm{s}(19.0-40.5 \mathrm{mph})$ & $\mathrm{NE}$ & $3.7 \mathrm{~m} \mathrm{(E)}$ & $2.9 \mathrm{~m}(\mathrm{E})$ & $2.0-4.0 \mathrm{~m}$ & $6.7 \mathrm{~s}$ & $8.5 \mathrm{~s}$ \\
\hline & & & & June $5(18: 00)$ to June 6 & (19:00) & & June $6(14: 00$ to $19: 00)$ & June $6(04: 00)$ to June $7(11: 00)$ & & & \\
\hline \multirow[t]{2}{*}{ Sept 19-22 } & Jose & Hurricane & & $11.1 \mathrm{~m} / \mathrm{s}(24.9 \mathrm{mph})$ & $7.4-18.7 \mathrm{~m} / \mathrm{s}(16.6-41.8 \mathrm{mph})$ & NNE & $4.2 \mathrm{~m}(\mathrm{E})$ & $3.6 \mathrm{~m}(\mathrm{E})$ & $2.8-4.6 \mathrm{~m}$ & $7.0 \mathrm{~s}$ & $9.3 \mathrm{~s}$ \\
\hline & & & & Sept $19(11: 00)$ to Sept 2 & $23(08: 00)$ & & Sept 22 (07-10:00, 19-22:00) & Sept $21(12: 00)$ to Sept $23(01: 00)$ & & & \\
\hline \multirow[t]{2}{*}{ Oct 29-30 } & Philippe & Tropical Storm & & $16.4 \mathrm{~m} / \mathrm{s}(36.6 \mathrm{mph})$ & $10.9-35.0 \mathrm{~m} / \mathrm{s}(24.4-78.3 \mathrm{mph})$ & ESE, then SW & $4.9 \mathrm{~m}$ (SE) & $3.9 \mathrm{~m}$ (SE) & $2.4-5.6 \mathrm{~m}$ & $7.6 \mathrm{~s}$ & $10.7 \mathrm{~s}$ \\
\hline & & & & Oct $29(18: 00)$ to Oct 30( & $(22: 00)$ & & Oct $30(09: 00$ to $19: 00)$ & Oct $30(03: 00)$ to Oct $31(08: 00)$ & & & \\
\hline \multirow[t]{2}{*}{ Dec 5-6 } & & & & $13.5 \mathrm{~m} / \mathrm{s}(30.2 \mathrm{mph})$ & $7.2-21.2 \mathrm{~m} / \mathrm{s}(16.1-47.4 \mathrm{mph})$ & $\mathrm{s}$ & $3.4 \mathrm{~m}(\mathrm{SE})$ & $2.8 \mathrm{~m}(\mathrm{SE})$ & $2.0-3.8 \mathrm{~m}$ & $6.0 \mathrm{~s}$ & $7.3 \mathrm{~s}$ \\
\hline & & & & $\operatorname{Dec} 5(13: 00)$ to $\operatorname{Dec} 6(1$ & 12:00) & & Dec $6(05: 00$ to 08:00) & Dec $5(18: 00)$ to $\operatorname{Dec} 6(14: 00)$ & & & \\
\hline Dec 23-24 & Dylan & Winter Storm & $1-4 "(3-10 \mathrm{~cm})$ & $8.2 \mathrm{~m} / \mathrm{s}(18.4 \mathrm{mph})$ & $5.8-13.6 \mathrm{~m} / \mathrm{s}(13.0-30.4 \mathrm{mph})$ & WNW & (no peak) & $1.9 \mathrm{~m}$ (ESE, then WNW) & $1.6-2.3 \mathrm{~m}$ & $5.4 \mathrm{~s}$ & $6.9 \mathrm{~s}$ \\
\hline & & & & $\operatorname{Dec} 23(20: 00)$ to Dec 24 & $4(18: 00)$ & & & Dec $23(02: 00)$ to Dec 24 (12:00) & & & \\
\hline Dec 25-26 & & & & $13.4 \mathrm{~m} / \mathrm{s}(30.0 \mathrm{mph})$ & $9.9-20.3 \mathrm{~m} / \mathrm{s}(22.1-45.4 \mathrm{mph})$ & NE, then WSW & $3.9 \mathrm{~m}$ (ENE) & $2.9 \mathrm{~m}$ (ENE, then WSW) & $1.9-4.4 \mathrm{~m}$ & $5.8 \mathrm{~s}$ & $7.3 \mathrm{~s}$ \\
\hline & & & & Dec $25(01: 00)$ to Dec 26 & $6(20: 00)$ & & Dec 25 (13:00 to 18:00) & Dec $25(06: 00)$ to Dec $26(12: 00)$ & & & \\
\hline
\end{tabular}




\begin{tabular}{|c|c|c|c|c|c|c|c|c|c|c|c|}
\hline \multicolumn{4}{|l|}{2018} & \multicolumn{3}{|c|}{$\begin{array}{l}\text { Wind } \\
\text { (Isles of Shoals Station IOSN3) }\end{array}$} & \multicolumn{5}{|c|}{$\begin{array}{c}\text { Waves } \\
\text { (Jeffrey's Ledge Station 44098) }\end{array}$} \\
\hline Dates & Name & Type & Snow & $\begin{array}{c}\begin{array}{c}\text { Average Wind } \\
\text { Speed }\end{array} \\
\end{array}$ & Wind Gust Range & Wind Direction & $\begin{array}{c}\text { Peak Wave } \\
\text { Hs (Significant Wave Height) } \\
\end{array}$ & $\begin{array}{c}\text { Average } \\
\text { Hs (Significant Wave Height) } \\
\end{array}$ & $\begin{array}{c}\begin{array}{c}\text { Range } \\
\mathrm{Hs}\end{array} \\
\end{array}$ & \begin{tabular}{|c} 
Average \\
Ts \\
\end{tabular} & \begin{tabular}{|c} 
Dominant \\
Ts
\end{tabular} \\
\hline $\operatorname{Jan} 3-5$ & Grayson & Nor'easter & $10-15 "(25-38 \mathrm{~cm})$ & $16.65 \mathrm{~m} / \mathrm{s}(37.2 \mathrm{mph})$ & $13.5-27.9 \mathrm{~m} / \mathrm{s}(30.2-62.4 \mathrm{mph})$ & NE, then WNW & $6.3 \mathrm{~m}$ (ENE) & $5.0 \mathrm{~m}$ (ENE) & $3.0-7.8 \mathrm{~m}$ & $7.5 \mathrm{~s}$ & $10.3 \mathrm{~s}$ \\
\hline & \multicolumn{3}{|c|}{ Storm surge: $0.85 \mathrm{~m}$} & \multicolumn{3}{|c|}{$\operatorname{Jan} 4(11: 00)$ to $\operatorname{Jan} 7(13: 00)$} & $\operatorname{Jan} 4(19: 00)$ to $\operatorname{Jan} 5(00: 00)$ & \multicolumn{4}{|l|}{$\operatorname{Jan} 4(14: 00)$ to $\operatorname{Jan} 5(11: 00)$} \\
\hline \multirow[t]{2}{*}{$\operatorname{Jan} 12-16$} & & & & $11.8 \mathrm{~m} / \mathrm{s}(26.4 \mathrm{mph})$ & $7.4-19.9 \mathrm{~m} / \mathrm{s}(16.6-44.5 \mathrm{mph})$ & $S, W N W$, then NNE & $3.5 \mathrm{~m}(\mathrm{SSE}), 3.2 \mathrm{~m}(\mathrm{E})$ & $2.7 \mathrm{~m}$ (SSE, then $\mathrm{E})$ & $1.9-3.8 \mathrm{~m}$ & $6.8 \mathrm{~s}$ & $9.1 \mathrm{~s}$ \\
\hline & & & & \multicolumn{3}{|c|}{$\operatorname{Jan} 12(15: 00)$ to Jan $15(03: 00), \operatorname{Jan} 15(02: 00)$ to Jan $16(07: 00)$} & \multicolumn{5}{|c|}{\begin{tabular}{|l|l|l}
$\operatorname{Jan} 13(13-16: 00), \operatorname{Jan} 16(06-08: 00)$ & $\operatorname{Jan} 13(04-21: 00), \operatorname{Jan} 15(17: 00)$ to $\operatorname{Jan} 16(22: 00)$ \\
\end{tabular}} \\
\hline $\operatorname{Jan} 17-18$ & Inga & Winter Storm & $4-8 "(10-20 \mathrm{~cm})$ & \multicolumn{3}{|c|}{\begin{tabular}{|c|} 
Low winds recorded at Isles of Shoals \\
\end{tabular}} & \multicolumn{5}{|c|}{ Low waves recorded at Jeffrey's Ledge } \\
\hline \multirow[t]{2}{*}{$\tan 29-31$} & & & & $11.7 \mathrm{~m} / \mathrm{s}(26.2 \mathrm{mph})$ & $9.4-16.9 \mathrm{~m} / \mathrm{s}(21.0-37.8 \mathrm{mph})$ & NNE, then variable & $4.2 \mathrm{~m}(\mathrm{E})$ & $3.4 \mathrm{~m}(\mathrm{E})$ & $2.3-4.5 \mathrm{~m}$ & $6.8 \mathrm{~s}$ & $9.5 \mathrm{~s}$ \\
\hline & & & & $\operatorname{Jan} 29(10: 00)$ to $\operatorname{Jan} 30$ & $(21: 00)$ & & $\tan 30(16: 00$ to $22: 00)$ & $\operatorname{Jan} 30(01: 00)$ to $\operatorname{Jan} 31(09: 00)$ & & & \\
\hline \multirow[t]{2}{*}{ Feb 7-9 } & Liam & Winter Storm & $5-12 "(13-30 \mathrm{~cm})$ & $10.85 \mathrm{~m} / \mathrm{s}(24.3 \mathrm{mph})$ & $7.5-15.6 \mathrm{~m} / \mathrm{s}(16.8-34.9 \mathrm{mph})$ & WNW & $2.2 \mathrm{~m}(\mathrm{NW})$ & $1.8 \mathrm{~m}$ (ESE, then NW) & $1.4-2.4 \mathrm{~m}$ & $4.9 \mathrm{~s}$ & $6.0 \mathrm{~s}$ \\
\hline & & & & Feb 8 from 05:00 to $15: 00$ & & & Feb $8(06: 00$ to $10: 00)$ & Feb $7(20: 00)$ to Feb $8(16: 00)$ & & & \\
\hline \multirow[t]{2}{*}{ Feb 16-18 } & Noah & Winter Storm & 6-9" $(15-23 \mathrm{~cm})$ & $10.8 \mathrm{~m} / \mathrm{s}(24.2 \mathrm{mph})$ & $7.1-15.9 \mathrm{~m} / \mathrm{s}(15.9-35.6 \mathrm{mph})$ & SW, NW, then SSE & $2.1 \mathrm{~m}$ (variable winds) & $1.7 \mathrm{~m}$ (variable winds) & $1.1-2.2 \mathrm{~m}$ & $4.8 \mathrm{~s}$ & $5.9 \mathrm{~s}$ \\
\hline & & & & Feb $15(20: 00)$ to Feb 16 & $(04: 00)$, Feb $17(00-13: 00)$, Feb $18(00-0$ & 05:00) & Feb $17(05-06: 00)$, Feb 18 (10-12:00) & Feb 17 (00:00-08:00), Feb 18 (06:00 & $0-21: 00)$ & & \\
\hline \multirow[t]{2}{*}{ Mar 1-4 } & Riley & Nor'easter & Flooding & $16.24 \mathrm{~m} / \mathrm{s}(36.3 \mathrm{mph})$ & $10.0-28.3 \mathrm{~m} / \mathrm{s}(22.4-64.3 \mathrm{mph})$ & NNE & $7.2 \mathrm{~m}(\mathrm{E})$ & $5.9 \mathrm{~m}(\mathrm{E})$ & $4.0-8.4 \mathrm{~m}$ & $9.5 \mathrm{~s}$ & $13.5 \mathrm{~s}$ \\
\hline & & Storm surge: 0 . & $79 \mathrm{~m}$ & Mar $2(01: 00)$ to Mar 4 (1. & $5: 00)$ & & Mar 3 (01:00 to 10:00) & Mar 2 (16:00) to Mar 5 (01:00) & & & \\
\hline \multirow[t]{2}{*}{ Mar 6-9 } & Quinn & Nor'easter & $10-18 "(25-46 \mathrm{~cm})$ & $14.63 \mathrm{~m} / \mathrm{s}(32.7 \mathrm{mph})$ & $8.6-23.9 \mathrm{~m} / \mathrm{s}(19.2-53.5 \mathrm{mph})$ & NE, then NNW & $6.6 \mathrm{~m}(\mathrm{E})$ & $5.1 \mathrm{~m}(\mathrm{E})$ & $3.0-7.4 \mathrm{~m}$ & $8.1 \mathrm{~s}$ & $10.4 \mathrm{~s}$ \\
\hline & & & & Mar 7 (06:00) to Mar 8 (1 & & & Mar 8 (06:00 to 12:00) & $\operatorname{Mar} 7(22: 00)$ to $\operatorname{Mar} 8(20: 00)$ & & & \\
\hline \multirow[t]{2}{*}{ Mar 12-14 } & Skylar & Nor'easter & $24 "(61 \mathrm{~cm})$ & $15.59 \mathrm{~m} / \mathrm{s}(34.9 \mathrm{mph})$ & $7.9-23.7 \mathrm{~m} / \mathrm{s}(17.7-53.0 \mathrm{mph})$ & $\mathrm{NE}$, then WNW & $6.5 \mathrm{~m}(\mathrm{E})$ & $5.1 \mathrm{~m}(\mathrm{E})$ & $2.9-7.6 \mathrm{~m}$ & $8.3 \mathrm{~s}$ & $11.9 \mathrm{~s}$ \\
\hline & oastal floo & ga at Hampton a & d Rye) & Mar $12(21: 00)$ to March & $14(02: 00)$ & & Mar $13(16: 00)$ to March 14 (02:00) & Mar $13(06: 00)$ to March $14(16: 00)$ & & & \\
\hline \multirow[t]{2}{*}{ Mar 21-23 } & & & & $12.5 \mathrm{~m} / \mathrm{s}(28 \mathrm{mph})$ & $7.8-18.5 \mathrm{~m} / \mathrm{s}(17.4-41.2 \mathrm{mph})$ & NNE, then NNW & $5.1 \mathrm{~m}(\mathrm{E})$ & $4.0 \mathrm{~m}(\mathrm{E})$ & $2.5-5.2 \mathrm{~m}$ & $7.5 \mathrm{~s}$ & $10.2 \mathrm{~s}$ \\
\hline & & & & Mar $21(06: 00)$ to Mar 22 & $(17: 00)$ & & Mar 22 (11:00 to 16:00) & Mar 21 (22:00) to Mar 23 (03:00) & & & \\
\hline \multirow[t]{2}{*}{ Apr 15-17 } & & & & $13.8 \mathrm{~m} / \mathrm{s}(30.9 \mathrm{mph})$ & $11.8-21.3 \mathrm{~m} / \mathrm{s}(26.4-47.6 \mathrm{mph})$ & ENE & $5.1 \mathrm{~m}(\mathrm{E})$ & $4.0 \mathrm{~m}(\mathrm{E})$ & $2.8-5.5 \mathrm{~m}$ & $7.2 \mathrm{~s}$ & $9.5 \mathrm{~s}$ \\
\hline & & & & Apr 15 (06:00) to Apr 17 (1) & $03: 00)$ & & Apr 16 (18:00 to 22:00) & Apr $16(07: 00)$ to Apr $17(11: 00)$ & & & \\
\hline Sept 18 & Florence & Hurricane & & & w winds recorded at Isles of Sho & & & ow waves recorded at Jeffrey's & 's Ledge & & \\
\hline Oct 12 & Michael & Hurricane & & & w winds recorded at Isles of Sho & & & ow waves recorded at Jeffrey's & 's Ledge & & \\
\hline \multirow[t]{2}{*}{ Oct $27-28$} & & & & $17.2 \mathrm{~m} / \mathrm{s}(38.5 \mathrm{mph})$ & $10.8-28.9 \mathrm{~m} / \mathrm{s}(24.2-64.6 \mathrm{mph})$ & & $6.2 \mathrm{~m}$ (ESE) & $4.5 \mathrm{~m}$ (ESE) & $2.6-6.5 \mathrm{~m}$ & $8.1 \mathrm{~s}$ & $10.3 \mathrm{~s}$ \\
\hline & & & & Oct $27(09: 00)$ to Oct $28(1$ & $11: 00)$ & & Oct $27(22: 00)$ to Oct $28(03: 00)$ & Oct $27(16: 00)$ to Oct $28(19: 00)$ & & & \\
\hline \multirow[t]{2}{*}{ Nov 10-11 } & & & & $13.3 \mathrm{~m} / \mathrm{s}(29.8 \mathrm{mph})$ & $9.1-19.7 \mathrm{~m} / \mathrm{s}(20.4-44.1 \mathrm{mph})$ & ENE, then W & $3.9 \mathrm{~m}(\mathrm{E})$ & $2.9 \mathrm{~m}(\mathrm{E}$, then $\mathrm{W})$ & $2.0-4.1 \mathrm{~m}$ & $6.0 \mathrm{~s}$ & $7.5 \mathrm{~s}$ \\
\hline & & & & Nov $10(00: 00)$ to Nov 11 & $(16: 00)$ & & \begin{tabular}{|l|l} 
Nov $10(08: 00$ to $12: 00)$ \\
\end{tabular} & Nov $10(03: 00)$ to Nov $11(07: 00)$ & & & \\
\hline \multirow[t]{2}{*}{ Nov 15-16 } & Avery & Winter Storm & 5-8" $(13-20 \mathrm{~cm})$ & $17.1 \mathrm{~m} / \mathrm{s}(38.3 \mathrm{mph})$ & $14.4-22.0 \mathrm{~m} / \mathrm{s}(32.2-49.2 \mathrm{mph})$ & ENE & & (data not available) & & & \\
\hline & & & & Nov 16 from $05: 00$ to $18: 0$ & & & & & & & \\
\hline \multirow[t]{2}{*}{ Nov 20} & & Snow Storm & $3-8^{\prime \prime}(8-20 \mathrm{~cm})$ & $10.4 \mathrm{~m} / \mathrm{s}(23.3 \mathrm{mph})$ & $9.4-13.5 \mathrm{~m} / \mathrm{s}(21.0-30.2 \mathrm{mph})$ & NE, then NNW & & (data not available) & & & \\
\hline & & & & Nov 20 from 10:00 to 23:0 & & & & (adta nol dvalladie) & & & \\
\hline \multirow[t]{2}{*}{ Nov 27} & & Coastal Flood & & $15.7 \mathrm{~m} / \mathrm{s}(35.1 \mathrm{mph})$ & $11.7-21.6 \mathrm{~m} / \mathrm{s}(26.2-48.3 \mathrm{mph})$ & ENE, then $S$ & $5.6 \mathrm{~m}(\mathrm{E})$ & $3.8 \mathrm{~m}(\mathrm{E})$ & $2.5-6.2 \mathrm{~m}$ & $7.1 \mathrm{~s}$ & $10.1 \mathrm{~s}$ \\
\hline & & & & Nov $26(22: 00)$ to Nov 27 & $(16: 00)$ & & Nov 27 (10:00 to $14: 00)$ & Nov $26(22: 00)$ to Nov $28(02: 00)$ & & & \\
\hline Dec 16-19 & & & & $12.7 \mathrm{~m} / \mathrm{s}(28.4 \mathrm{mph})$ & $9.0-23.2 \mathrm{~m} / \mathrm{s}(20.1-51.9 \mathrm{mph})$ & WNW & $3.6 \mathrm{~m}$ (ESE) & $2.9 \mathrm{~m}(\mathrm{ESE}$, then NW) & $1.9-4.1 \mathrm{~m}$ & $6.1 \mathrm{~s}$ & $8.1 \mathrm{~s}$ \\
\hline & & & & Dec $17(20: 00)$ to Dec 19 & $(10: 00)$ & & Dec 17 (07:00 to 13:00) & Dec $16(21: 00)$ to Dec $18(23: 00)$ & & & \\
\hline Dec 21-23 & & & & $12.5 \mathrm{~m} / \mathrm{s}(28.0 \mathrm{mph})$ & $8.3-21.3 \mathrm{~m} / \mathrm{s}(18.6-47.6 \mathrm{mph})$ & SSE, then WNW & $3.1 \mathrm{~m}(\mathrm{SE})$ & $2.4 \mathrm{~m}(\mathrm{SE}$, then variable $)$ & $1.2-3.3 \mathrm{~m}$ & $6.1 \mathrm{~s}$ & $9.2 \mathrm{~s}$ \\
\hline & & & & $\operatorname{Dec} 21(13: 00)$ to $\operatorname{Dec} 23$ & $(21: 00)$ & & Dec 21 (19:00 to 22:00) & Dec $21(13: 00)$ to $\operatorname{Dec} 23(19: 00)$ & & & \\
\hline
\end{tabular}




\begin{tabular}{|c|c|c|c|c|c|c|c|c|c|c|c|}
\hline \multicolumn{4}{|l|}{2019} & \multicolumn{3}{|c|}{$\begin{array}{l}\text { Wind } \\
\text { (Isles of Shoals Station IOSN3) }\end{array}$} & \multicolumn{5}{|c|}{$\begin{array}{c}\text { Waves } \\
\text { (Jeffrey's Ledge Station 44098) }\end{array}$} \\
\hline Dates & Name & Type & Snow & \begin{tabular}{|c|} 
Average Wind \\
Speed \\
\end{tabular} & Wind Gust Range & Wind Direction & \begin{tabular}{|c|} 
Peak Wave \\
Hs (Significant Wave Height)
\end{tabular} & $\begin{array}{c}\text { Average } \\
\text { Hs (Significant Wave Height) }\end{array}$ & $\begin{array}{c}\begin{array}{c}\text { Range } \\
\mathrm{Hs}\end{array} \\
\end{array}$ & $\begin{array}{c}\text { Average } \\
\text { Ts }\end{array}$ & \begin{tabular}{|c}
$\begin{array}{c}\text { Dominant } \\
\text { Ts }\end{array}$ \\
\end{tabular} \\
\hline \multirow[t]{2}{*}{$\operatorname{Jan} 1-2$} & & & & $12.4 \mathrm{~m} / \mathrm{s}(27.7 \mathrm{mph})$ & $5.9-26.6 \mathrm{~m} / \mathrm{s}(13.2-59.5 \mathrm{mph})$ & SSE, then WNW & $3.0 \mathrm{~m}(\mathrm{SE})$ & $2.3 \mathrm{~m}(\mathrm{SE}$, then $\mathrm{NW})$ & $1.3-3.2 \mathrm{~m}$ & $5.5 \mathrm{~s}$ & $6.7 \mathrm{~s}$ \\
\hline & & & & $\operatorname{Dec} 31(23: 00)$ to $\operatorname{Jan} 2($ & $(10: 00)$ & & $\operatorname{Jan} 1$ (09:00 to $15: 00)$ & $\operatorname{Jan} 1(02: 00)$ to $\operatorname{Jan} 2(09: 00)$ & & & \\
\hline \multirow[t]{2}{*}{$\operatorname{Jan} 19-20$} & Harper & Nor'easter & $8-12 "(20-30 \mathrm{~cm})$ & $15.1 \mathrm{~m} / \mathrm{s}(33.8 \mathrm{mph})$ & $13.1-21.2 \mathrm{~m} / \mathrm{s}(29.3-47.6 \mathrm{mph})$ & $\mathrm{NE}$ & $3.9 \mathrm{~m} \mathrm{(E)}$ & $3.1 \mathrm{~m}(\mathrm{E}$, then $\mathrm{NW})$ & $1.8-4.0 \mathrm{~m}$ & $6.2 \mathrm{~s}$ & $8.1 \mathrm{~s}$ \\
\hline & & & & $\operatorname{Jan} 20$ from $03: 00$ to $18: \mathrm{C}$ & & & $\operatorname{Jan} 20$ (11:00 to 20:00) & $\operatorname{Jan} 20(06: 00)$ to $\operatorname{Jan} 22(13: 00)$ & & & \\
\hline \multirow[t]{2}{*}{ Feb 12-13 } & Maya & Nor'easter & $4-8 "(10-20 \mathrm{~cm})$ & $9.5 \mathrm{~m} / \mathrm{s}(21.3 \mathrm{mph})$ & $12.6-19.6 \mathrm{~m} / \mathrm{s}(28.2-43.8 \mathrm{mph})$ & ENE & $4.3 \mathrm{~m} \mathrm{(E)}$ & $3.2 \mathrm{~m}(\mathrm{E})$ & $2.1-4.9 \mathrm{~m}$ & $6.9 \mathrm{~s}$ & $9.1 \mathrm{~s}$ \\
\hline & & & & Feb $12(23: 00)$ to Feb 13 & $3(14: 00)$ & & Feb 13 (09:00 to 12:00) & Feb $13(03: 00)$ to Feb $14(02: 00)$ & & & \\
\hline \multirow[t]{2}{*}{ Feb 25} & & High Wind & & $17.0 \mathrm{~m} / \mathrm{s}(38.0 \mathrm{mph})$ & $15.2-27.2 \mathrm{~m} / \mathrm{s}(34.0-60.8 \mathrm{mph})$ & WNW & $4.4 \mathrm{~m}$ (ESE) & $2.8 \mathrm{~m}$ (ESE) & $1.3-4.4 \mathrm{~m}$ & $6.2 \mathrm{~s}$ & $7.8 \mathrm{~s}$ \\
\hline & & & & Feb $25(09: 00)$ to Feb 27 & $7(06: 00)$ & & Feb 24 (21::00) (some data gaps) & Feb $24(11: 00)$ to Feb 25 (04:00) (so & ome data gaps & & \\
\hline \multirow[t]{2}{*}{ Mar 3-4 } & Scott & Snow Storm & $4-8 "(10-20 \mathrm{~cm})$ & $10.1 \mathrm{~m} / \mathrm{s}(22.6 \mathrm{mph})$ & $8.9-15.1 \mathrm{~m} / \mathrm{s}(19.9-33.8 \mathrm{mph})$ & NNE, then SSE & $2.7 \mathrm{~m} \mathrm{(E)}$ & $2.4 \mathrm{~m}(\mathrm{E})$ & $1.3-3.1 \mathrm{~m}$ & $6.8 \mathrm{~s}$ & $8.6 \mathrm{~s}$ \\
\hline & & & & Mar 2 (11:00-21:00) and & $\operatorname{Mar} 3(20: 00)$ to Mar $4(03: 00)$ & & Mar 2 (19:00) to Mar 3 (03:00) & $\operatorname{Mar} 2(14: 00)$ to $\operatorname{Mar} 3(22: 00)$ & & & \\
\hline \multirow[t]{2}{*}{ Apr 3-9 } & & & & $12.0 \mathrm{~m} / \mathrm{s}(26.8 \mathrm{mph})$ & $5.8-25.7 \mathrm{~m} / \mathrm{s}(13.0-57.5 \mathrm{mph})$ & W, then NE & $2.7 \mathrm{~m} \mathrm{(E)}$ & $2.2 \mathrm{~m}(\mathrm{E})$ & $0.7-2.9 \mathrm{~m}$ & $5.6 \mathrm{~s}$ & $7.7 \mathrm{~s}$ \\
\hline & & & & Apr $3(19: 00)$ to Apr $4(11$ & 1:00), Apr 8 (06:00) to Apr $9(04: 00)$ & & Apr 4 (00-06:00), Apr 8 (15-23:00) & Apr 3 (05:00) to Apr 4 (20:00), Apr 8 & $8(08: 00)$ to Apr & $(15: 00)$ & \\
\hline \multirow[t]{2}{*}{ Apr 19-21 } & Haza & ardous Weather Out & tlook & $12.9 \mathrm{~m} / \mathrm{s}(28.9 \mathrm{mph})$ & $9.3-17.5 \mathrm{~m} / \mathrm{s}(20.8-39.1 \mathrm{mph})$ & & $2.2 \mathrm{~m}(\mathrm{SE})$ & $1.9 \mathrm{~m}(\mathrm{SE})$ & $1.5-2.3 \mathrm{~m}$ & $5.6 \mathrm{~s}$ & $7.8 \mathrm{~s}$ \\
\hline & & & & Apr 19 (14:00) to Apr 21 & $(03: 00)$ & & Apr $19(04: 00$ - 07:00) & Apr $19(01: 00)$ to Apr $21(15: 00)$ & & & \\
\hline \multirow[t]{2}{*}{ Apr 26-28 } & & & & $10.9 \mathrm{~m} / \mathrm{s}(24.4 \mathrm{mph})$ & $5.9-17.1 \mathrm{~m} / \mathrm{s}(13.2-38.3 \mathrm{mph})$ & $E$, then $W$ & $2.8 \mathrm{~m}(\mathrm{SSE})$ & $2.2 \mathrm{~m}(\mathrm{SSE})$ & $1.5-3.1 \mathrm{~m}$ & $5.7 \mathrm{~s}$ & $8.0 \mathrm{~s}$ \\
\hline & & & & Apr $26(10: 00)$ to Apr 28 & $(05: 00)$ & & Apr 27 (00:00 to 06:00) & Apr $26(17: 00)$ to Apr $28(08: 00)$ & & & \\
\hline \multirow[t]{2}{*}{ May 13-15 } & & & & $9.9 \mathrm{~m} / \mathrm{s}(22.1 \mathrm{mph})$ & $6.7-14.7 \mathrm{~m} / \mathrm{s}(15.0-32.9 \mathrm{mph})$ & ENE & $3.1 \mathrm{~m}(\mathrm{SW})$ & $2.5 \mathrm{~m}(\mathrm{SW})$ & $1.4-3.4 \mathrm{~m}$ & $6.6 \mathrm{~s}$ & $8.9 \mathrm{~s}$ \\
\hline & & & & May $13(13: 00)$ to May 15 & $15(04: 00)$ & & May $14(12: 00)$ to May $15(07: 00)$ & May 13(20:00) to May 15(21:00) & & & \\
\hline \multirow{3}{*}{\begin{tabular}{|l|} 
Aug 26 \\
Sept 6-7 \\
\end{tabular}} & & Rip current risk & & & ow winds recorded at Isles of Shoe & & & Low waves recorded at Jeffrey's & 's Ledge & & \\
\hline & Dorian & Hurricane & & $12.5 \mathrm{~m} / \mathrm{s}(28.0 \mathrm{mph})$ & $10.9-17.1 \mathrm{~m} / \mathrm{s}(24.4-38.3 \mathrm{mph})$ & $\mathrm{NE}$, then variable & $3.7 \mathrm{~m}(\mathrm{E})$ & $2.7 \mathrm{~m}(\mathrm{E})$ & $1.4-4.2 \mathrm{~m}$ & $6.7 \mathrm{~s}$ & $8.8 \mathrm{~s}$ \\
\hline & & & & Sept $6(20: 00)$ to Sept 7 & $(15: 00)$ & & Sept $7(19: 00)$ to Sept $8(02: 00)$ & Sept $6(23: 00)$ to Sept $8(13: 00)$ & & & \\
\hline \multirow[t]{2}{*}{ Sept 20} & Humberto & Hurricane & & & ow winds recorded at Isles of Shoe & & $2.7 \mathrm{~m}$ (ESE) & $1.9 \mathrm{~m}$ (ESE) & $1.1-3.0 \mathrm{~m}$ & $10.3 \mathrm{~s}$ & $13.2 \mathrm{~s}$ \\
\hline & & & & & & & Sept $20(20: 00)$ to Sept $21(00: 00)$ & Sept $20(15: 00)$ to Sept $21(17: 00)$ & & & \\
\hline \multirow[t]{2}{*}{ Oct 11-13 } & Melissa & Suptropical Storm & & $13.6 \mathrm{~m} / \mathrm{s}(30.4 \mathrm{mph})$ & $9.8-21.1 \mathrm{~m} / \mathrm{s}(21.9-47.2 \mathrm{mph})$ & & $5.4 \mathrm{~m}(\mathrm{ESE})$ & $4.0 \mathrm{~m}$ (ESE) & $1.7-6.6 \mathrm{~m}$ & $8.0 \mathrm{~s}$ & $11.5 \mathrm{~s}$ \\
\hline & & & & Oct $9(06: 00)$ to Oct $12(1$ & 14:00) & & Oct $11(18: 00)$ to Oct $12(08: 00)$ & Oct $9(16: 00)$ to Oct $13(14: 00)$ & & & \\
\hline \multirow[t]{2}{*}{ Oct 16-17 } & & Nor'easter & & $15.6 \mathrm{~m} / \mathrm{s}(34.9 \mathrm{mph})$ & $10.3-29.9 \mathrm{~m} / \mathrm{s}(23.0-66.9 \mathrm{mph})$ & $E$, then WSW & $5.4 \mathrm{~m}(\mathrm{SE})$ & $3.5 \mathrm{~m}(\mathrm{SE})$ & $1.8-6.8 \mathrm{~m}$ & $6.5 \mathrm{~s}$ & $9.4 \mathrm{~s}$ \\
\hline & & & & Oct $16(19: 00)$ to Oct 18 & $(07: 00)$ & & Oct $17(07: 00$ to $11: 00)$ & Oct $17(01: 00)$ to Oct $18(09: 00)$ & & & \\
\hline \multirow[t]{2}{*}{ Nov 18-19 } & & & & $13.3 \mathrm{~m} / \mathrm{s}(29.8 \mathrm{mph})$ & $11.8-17.0 \mathrm{~m} / \mathrm{s}(26.4-38.0 \mathrm{mph})$ & NNE & $4.3 \mathrm{~m}$ (ESE) & $3.8 \mathrm{~m}$ (ESE) & $2.8-4.8 \mathrm{~m}$ & $7.7 \mathrm{~s}$ & $11.1 \mathrm{~s}$ \\
\hline & & & & Nov $18(03: 00)$ to Nov 19 & $9(05: 00)$ & & Nov $18(19: 00)$ to Nov $19(05: 00)$ & \begin{tabular}{|l|} 
Nov $18(10: 00)$ to Nov $19(15: 00)$ \\
\end{tabular} & & & \\
\hline \multirow[t]{2}{*}{ Nov 24-25 } & & & & $15.2 \mathrm{~m} / \mathrm{s}(34.0 \mathrm{mph})$ & $11.3-25.2 \mathrm{~m} / \mathrm{s}(25.3-56.4 \mathrm{mph})$ & NNE, then WNW & $3.4 \mathrm{~m}$ (ENE) & $2.9 \mathrm{~m}(\mathrm{ESE}$, then $\mathrm{WNW})$ & $1.9-3.9 \mathrm{~m}$ & $5.7 \mathrm{~s}$ & $7.0 \mathrm{~s}$ \\
\hline & & & & Nov $24(14: 00)$ to Nov 25 & $5(10: 00)$ & & Nov 25 (00:00 to 02:00) & \begin{tabular}{|l|l|} 
Nov $24(17: 00)$ to Nov $25(12: 00)$ \\
\end{tabular} & & & \\
\hline \multirow[t]{2}{*}{ Nov 28-29 } & & & & $12.8 \mathrm{~m} / \mathrm{s}(28.6 \mathrm{mph})$ & $9.8-20.1 \mathrm{~m} / \mathrm{s}(21.9-45.0 \mathrm{mph})$ & NNW & $3.8 \mathrm{~m}$ (NE) & $3.3 \mathrm{~m}(\mathrm{NE})$ & $2.2-4.2 \mathrm{~m}$ & $6.3 \mathrm{~s}$ & $8.9 \mathrm{~s}$ \\
\hline & & & & Nov $28(10: 00)$ to Nov 29 & $9(09: 00)$ & & Nov $29(00: 00$ to $06: 00)$ & \begin{tabular}{|l|} 
Nov $28(14: 00)$ to Nov $29(17: 00)$ \\
\end{tabular} & & & \\
\hline \multirow[t]{2}{*}{$\operatorname{Dec} 2-4$} & Ezekiel & Winter Storm & $12-16 "(30-41 \mathrm{~cm})$ & $15.4 \mathrm{~m} / \mathrm{s}(34.4 \mathrm{mph})$ & $10.8-22.1 \mathrm{~m} / \mathrm{s}(21.2-49.4 \mathrm{mph})$ & NNE, then NW & $5.8 \mathrm{~m}(\mathrm{E})$ & $5.0 \mathrm{~m}(\mathrm{E})$ & $3.1-6.3 \mathrm{~m}$ & $7.8 \mathrm{~s}$ & $10.6 \mathrm{~s}$ \\
\hline & & & & $\operatorname{Dec} 2(01: 00)$ to $\operatorname{Dec} 4(0$ & $02: 00)$ & & $\operatorname{Dec} 2(19: 00)$ to $\operatorname{Dec} 3(11: 00)$ & $\operatorname{Dec} 2(10: 00)$ to $\operatorname{Dec} 4(02: 00)$ & & & \\
\hline \multirow[t]{2}{*}{ Dec 14} & & Flooding & & $12.4 \mathrm{~m} / \mathrm{s}(27.7 \mathrm{mph})$ & $3.7-20.5 \mathrm{~m} / \mathrm{s}(8.3-45.9 \mathrm{mph})$ & ESE & $3.3 \mathrm{~m}(\mathrm{SE})$ & $3.0 \mathrm{~m}$ (SE, then variable) & $2.5-3.6 \mathrm{~m}$ & $6.4 \mathrm{~s}$ & $8.6 \mathrm{~s}$ \\
\hline & & & & Dec $14(08: 00)$ to Dec 14 & $4(18: 0)$ & & Dec 14 (13:00 to 16:00) & Dec $14(10: 00)$ to Dec $16(04: 00)$ & & & \\
\hline \multirow[t]{2}{*}{ Dec 30-31 } & Gage & Winter Storm & $4-8 "(10-20 \mathrm{~cm})$ & $13.6 \mathrm{~m} / \mathrm{s}(30.4 \mathrm{mph})$ & $11.0-20.8 \mathrm{~m} / \mathrm{s}(24.6-46.5 \mathrm{mph})$ & ENE & $4.6 \mathrm{~m}(\mathrm{E})$ & $3.6 \mathrm{~m}(\mathrm{E})$ & $2.4-5.1 \mathrm{~m}$ & $7.0 \mathrm{~s}$ & $9.1 \mathrm{~s}$ \\
\hline & & & & Dec $30(09: 00)$ to Dec 31 & $1(18: 0)$ & & Dec 31 (09:00 to 18:00) & Dec $30(14: 00)$ to $\operatorname{Jan} 1(03: 00)$ & & & \\
\hline
\end{tabular}




\begin{tabular}{|c|c|c|c|c|c|c|c|c|c|c|c|}
\hline \multicolumn{4}{|l|}{2020} & \multicolumn{3}{|c|}{$\begin{array}{l}\text { Wind } \\
\text { (Isles of Shoals Station IOSN3) }\end{array}$} & \multicolumn{5}{|c|}{$\begin{array}{c}\text { Waves } \\
\text { (Jeffrey's Ledge Station 44098) }\end{array}$} \\
\hline Dates & Name & Type & Snow & $\begin{array}{l}\text { Average Wind } \\
\text { Speed }\end{array}$ & Wind Gust Range & Wind Direction & $\begin{array}{c}\text { Peak Wave } \\
\text { Hs (Significant Wave Height) }\end{array}$ & $\begin{array}{c}\text { Average } \\
\text { Hs (Significant Wave Height) }\end{array}$ & $\begin{array}{c}\text { Range } \\
\text { Hs }\end{array}$ & $\begin{array}{c}\text { Average } \\
\text { Ts }\end{array}$ & \begin{tabular}{|c} 
Dominant \\
Ts
\end{tabular} \\
\hline \multirow[t]{2}{*}{$\tan 16-18$} & Jacob & Winter Storm & $4-8 "(10-20 \mathrm{~cm})$ & $12.3 \mathrm{~m} / \mathrm{s}(27.5 \mathrm{mph})$ & $8.8-19.6 \mathrm{~m} / \mathrm{s}(19.7-43.8 \mathrm{mph})$ & NW & $3.1 \mathrm{~m}$ (variable) & $2.6 \mathrm{~m}$ (variable) & $2.0-3.2 \mathrm{~m}$ & $5.4 \mathrm{~s}$ & $6.5 \mathrm{~s}$ \\
\hline & & & & $\operatorname{Jan} 16(17: 00)$ to $\operatorname{Jan} 18$ & (06:00) & & Jan $17(07: 00$ to $10: 00)$ & $\operatorname{Jan} 16(21: 00)$ to Jan $18(00: 00)$ & & & \\
\hline \multirow[t]{2}{*}{$\tan 25$} & Mabel & Winter Storm & & $14.3 \mathrm{~m} / \mathrm{s}(32.0 \mathrm{mph})$ & $9.8-23.7 \mathrm{~m} / \mathrm{s}(22.0-53.0 \mathrm{mph})$ & E & $3.5 \mathrm{~m}$ (ESE) & $2.8 \mathrm{~m}$ (ESE) & $2.1-3.7 \mathrm{~m}$ & $6.5 \mathrm{~s}$ & $8.3 \mathrm{~s}$ \\
\hline & & & & $\operatorname{Jan} 25(19: 00)$ to $\operatorname{Jan} 26$ & $(06: 00)$ & & Jan 26 (06:00 to 09:00) & $\operatorname{Jan} 25(21: 00)$ to $\operatorname{Jan} 26(18: 00)$ & & & \\
\hline \multirow[t]{2}{*}{ Feb 6-7 } & Kade & Winter Storm & $2-6^{\prime \prime}(5-15 \mathrm{~cm})$ & $12.2 \mathrm{~m} / \mathrm{s}(27.3 \mathrm{mph})$ & $7.7-22.7 \mathrm{~m} / \mathrm{s}(17.2-50.8 \mathrm{mph})$ & $\mathrm{NE}$, then $\mathrm{W}$ & $3.6 \mathrm{~m}$ (ESE, then $\mathrm{W}$ ) & $2.4 \mathrm{~m}(\mathrm{ESE}$, then $\mathrm{W})$ & $1.7-3.9 \mathrm{~m}$ & $5.7 \mathrm{~s}$ & $7.4 \mathrm{~s}$ \\
\hline & & & & Feb $6(12: 00)$ to Feb 9 ( & 1:00) & & Feb $7(22: 00)$ to Feb $8(02: 00)$ & Feb $6(15: 00)$ to Feb $8(10: 00)$ & & & \\
\hline \multirow[t]{2}{*}{ Feb 27-28 } & & Winter Storm & $2-4 "(5-10 \mathrm{~cm})$ & $15.4 \mathrm{~m} / \mathrm{s}(34.4 \mathrm{mph})$ & $9.8-24.2 \mathrm{~m} / \mathrm{s}(21.9-54.1 \mathrm{mph})$ & $E$, then W & $4.0 \mathrm{~m}(\mathrm{E}$, then WSW $)$ & $3.0 \mathrm{~m}(\mathrm{E}$, then WSW $)$ & $2.0-4.2 \mathrm{~m}$ & $5.9 \mathrm{~s}$ & $7.3 \mathrm{~s}$ \\
\hline & & & & Feb 27 (07:00) to Feb 28 & $(20: 00)$ & & Feb $27(13: 00$ to 17:00) & Feb $27(09: 00)$ to Feb $28(15: 00)$ & & & \\
\hline \multirow[t]{2}{*}{ March 6-7 } & & Nor'easter & & $14.1 \mathrm{~m} / \mathrm{s}(31.5 \mathrm{mph})$ & $8.8-22.1 \mathrm{~m} / \mathrm{s}(19.7-49.4 \mathrm{mph})$ & NNE, then variable & $5.0 \mathrm{~m}(\mathrm{E})$ & $3.8 \mathrm{~m}(\mathrm{E})$ & $1.8-5.3 \mathrm{~m}$ & $7.5 \mathrm{~s}$ & $10.6 \mathrm{~s}$ \\
\hline & & Offshore) & & Mar 6 (20:00) to Mar 8 & 2:00) & & Mar 7 (13:00 to 17:00) & Mar 6(22:00) to Mar 8(11:00) & & & \\
\hline \multirow[t]{2}{*}{ Mar 23-24 } & Quincy & Winter Storm & 4-6" $(10-15 \mathrm{~cm})$ & $12.0 \mathrm{~m} / \mathrm{s}(26.8 \mathrm{mph})$ & $8.2-20.6 \mathrm{~m} / \mathrm{s}(18.3-46.1 \mathrm{mph})$ & E, then variable & $3.3 \mathrm{~m}$ (ESE) & $2.8 \mathrm{~m}$ (ESE) & $1.9-3.5 \mathrm{~m}$ & $6.6 \mathrm{~s}$ & $8.7 \mathrm{~s}$ \\
\hline & & & & Mar $23(12: 00)$ to Mar 2 & $(13: 00)$ & & Mar 24 (07:00 to 17:00) & Mar 23 (22:00) to Mar 25(02:00) & & & \\
\hline \multirow[t]{2}{*}{ Apr 3} & & Coastal Flood & & $12.9 \mathrm{~m} / \mathrm{s}(28.9 \mathrm{mph})$ & $9.8-20.1 \mathrm{~m} / \mathrm{s}(21.9-45.0 \mathrm{mph})$ & NNW, then NNE & $6.0 \mathrm{~m}(\mathrm{E})$ & $4.3 \mathrm{~m}(\mathrm{E})$ & $2.3-6.5 \mathrm{~m}$ & $8.4 \mathrm{~s}$ & $11.6 \mathrm{~s}$ \\
\hline & & & & Apr 2 (13:00) to Apr 4 (1) & & & Apr 3 (12:00 to 20:00) & Apr $3(00: 00)$ to Apr $5(08: 00)$ & & & \\
\hline \multirow[t]{2}{*}{ Apr 9-10 } & & Winter Storm & & $11.8 \mathrm{~m} / \mathrm{s}(26.4 \mathrm{mph})$ & $8.2-18.5 \mathrm{~m} / \mathrm{s}(18.3-41.4 \mathrm{mph})$ & SSE, then W & $2.7 \mathrm{~m}(\mathrm{SE})$ & $2.1 \mathrm{~m}(\mathrm{SE}$, then $\mathrm{W})$ & $1.3-2.9 \mathrm{~m}$ & $5.1 \mathrm{~s}$ & $6.1 \mathrm{~s}$ \\
\hline & & & & Apr 9 (10:00) to Apr 11 (1 & & & Apr 9 (23:00) to Apr $10(02: 00)$ & Apr $9(14: 00)$ to $\operatorname{Apr} 10(19: 00)$ & & & \\
\hline \multirow[t]{2}{*}{ Apr 13} & & High wind & & $15.2 \mathrm{~m} / \mathrm{s}(34.0 \mathrm{mph})$ & $10.3-24.7 \mathrm{~m} / \mathrm{s}(23.0-55.3 \mathrm{mph})$ & ssw & $4.0 \mathrm{~m}$ (SSE) & $2.8 \mathrm{~m}$ (SSE) & $1.9-4.6 \mathrm{~m}$ & $6.3 \mathrm{~s}$ & $8.8 \mathrm{~s}$ \\
\hline & & & & Apr 13(10:00) to Apr 14 & $(11: 00)$ & & Apr $13(23: 00)$ to Apr 14 (02:00) & Apr 13 (15:00) to Apr 14 (14:00) & & & \\
\hline
\end{tabular}




\section{Appendix C: Beach Profile Sequences}

Beach profile sequences for all profiled dates at all beaches.

Appendix C(1): WS01 beach profiles from December 9, 2016 to March 12, 2020.

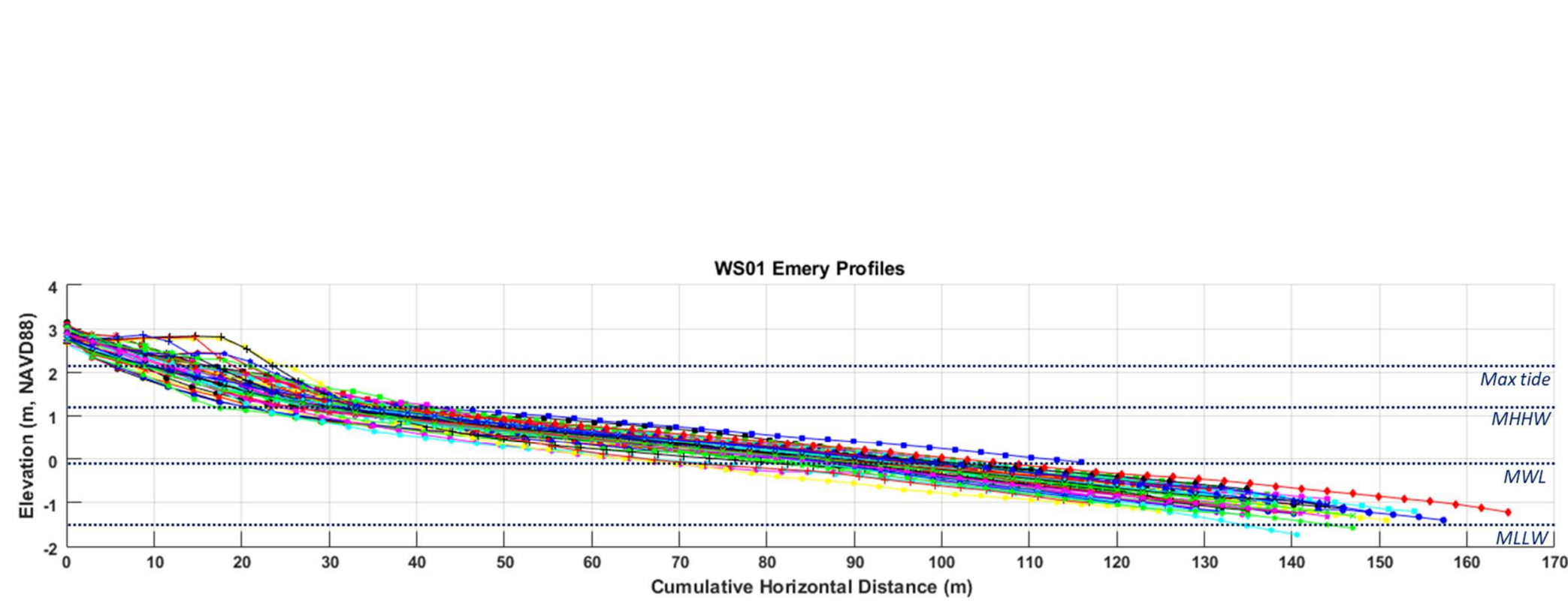

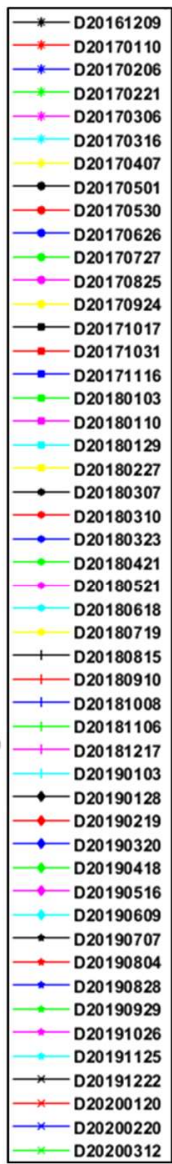



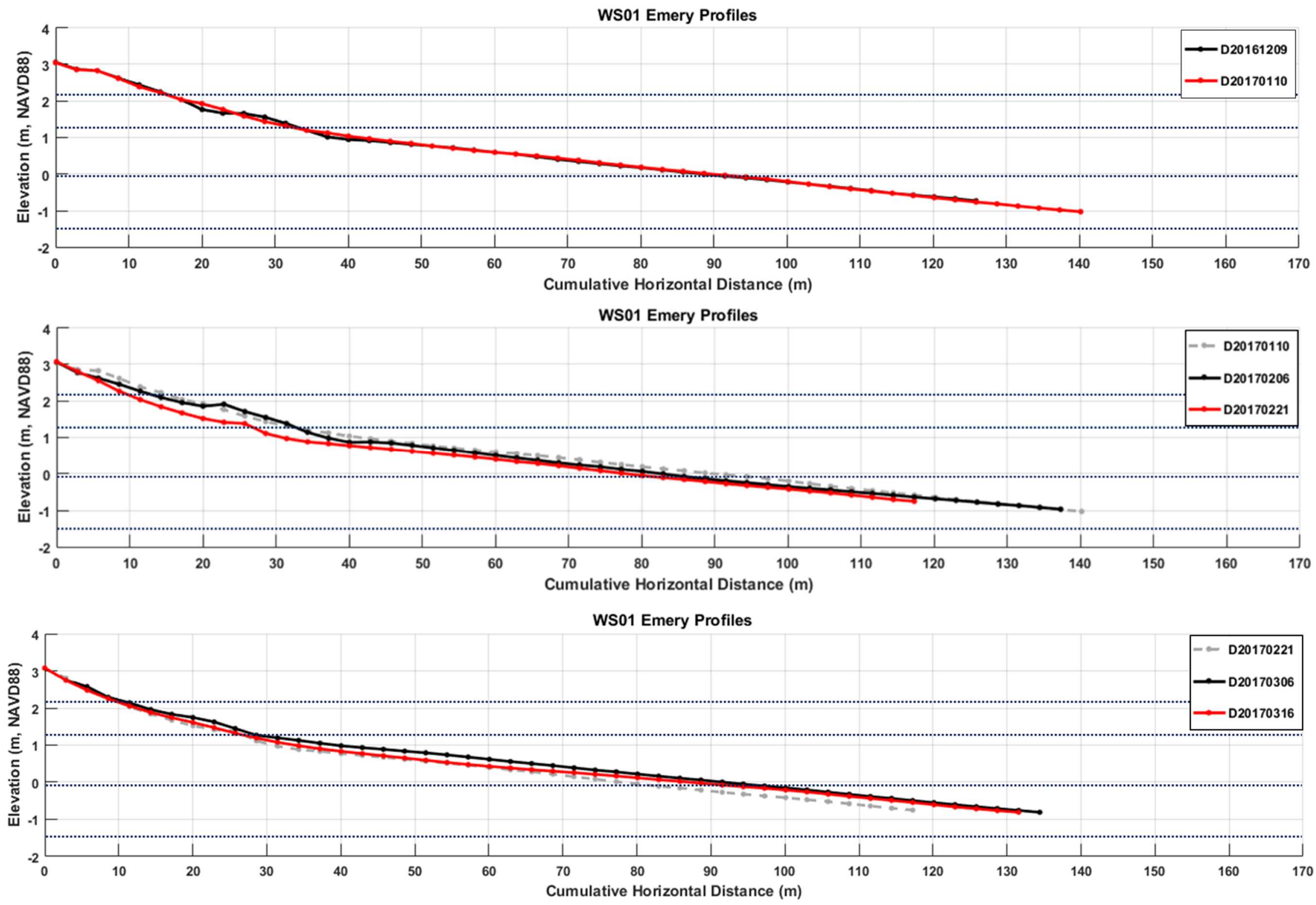

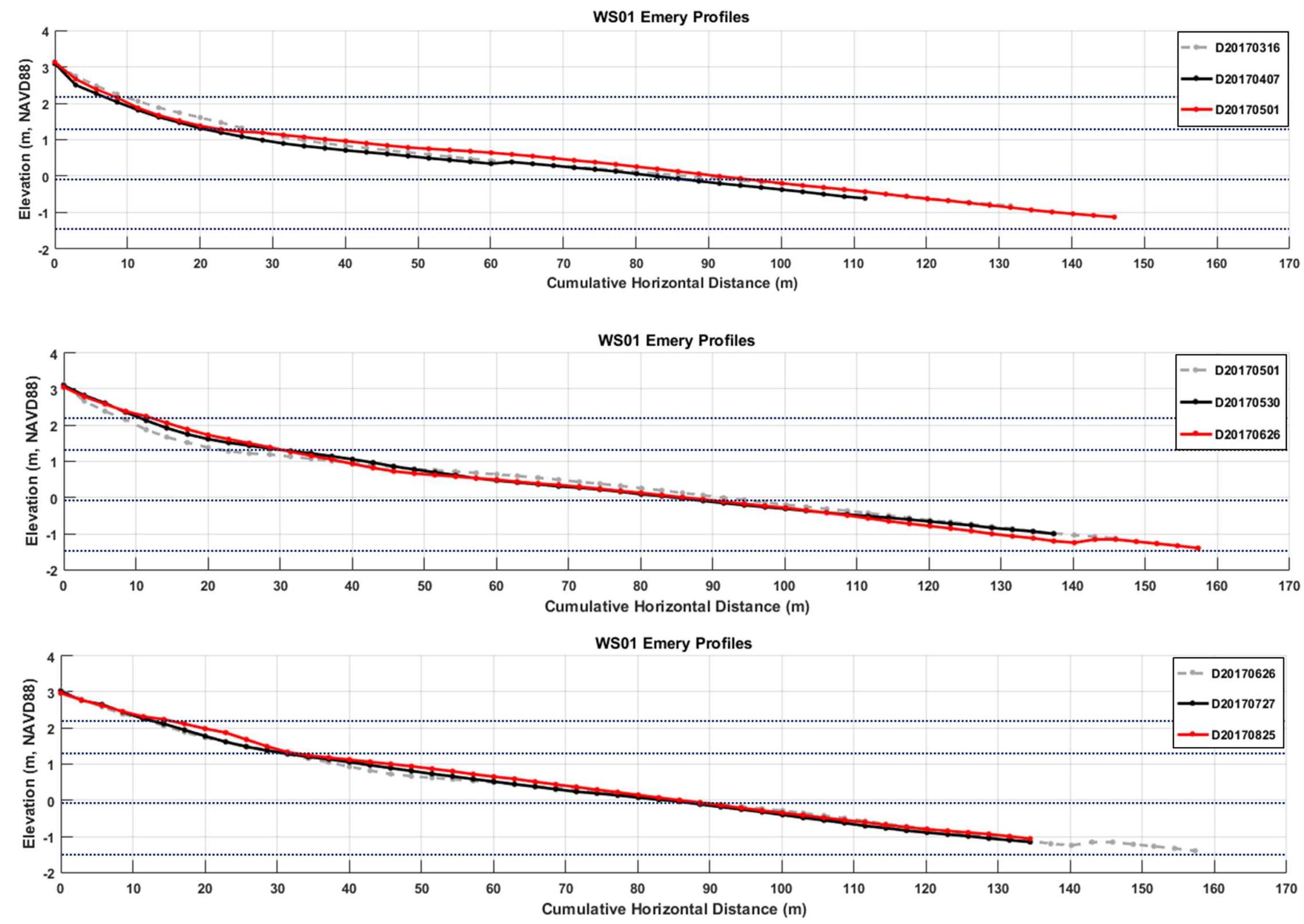


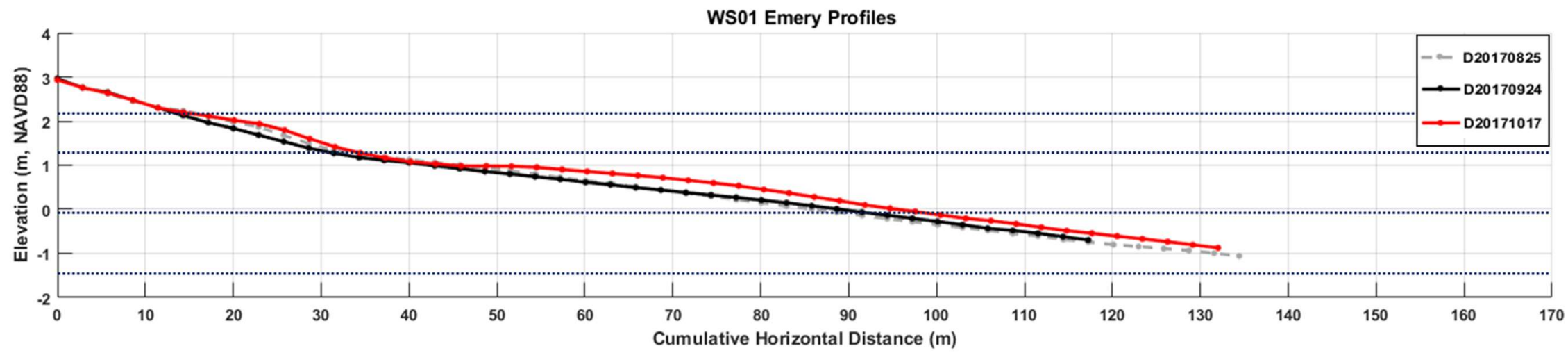

WS01 Emery Profiles

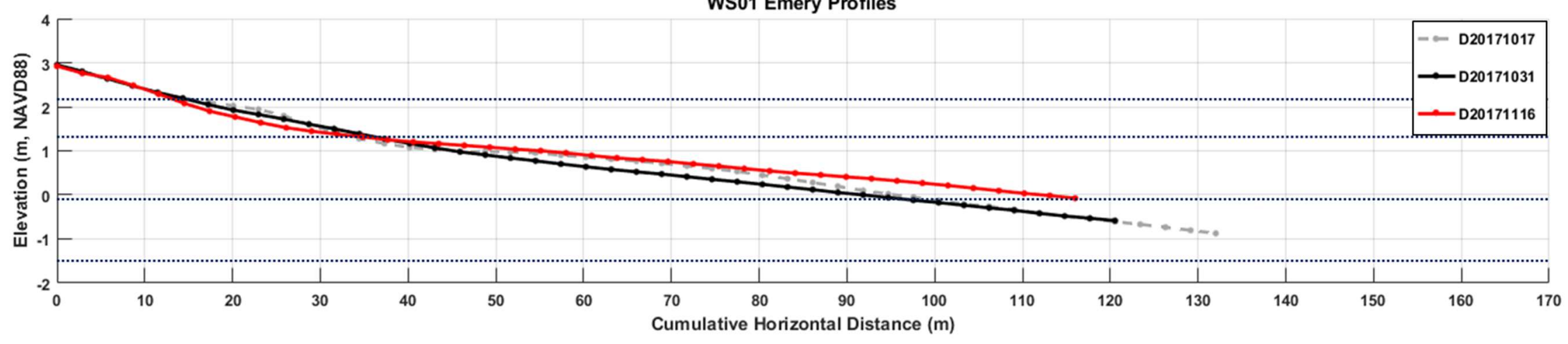

WS01 Emery Profiles

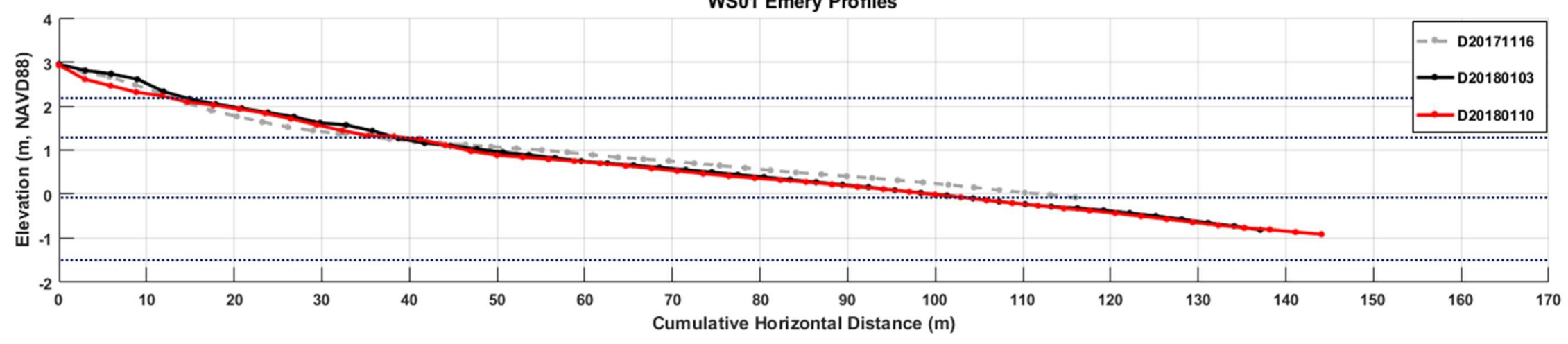



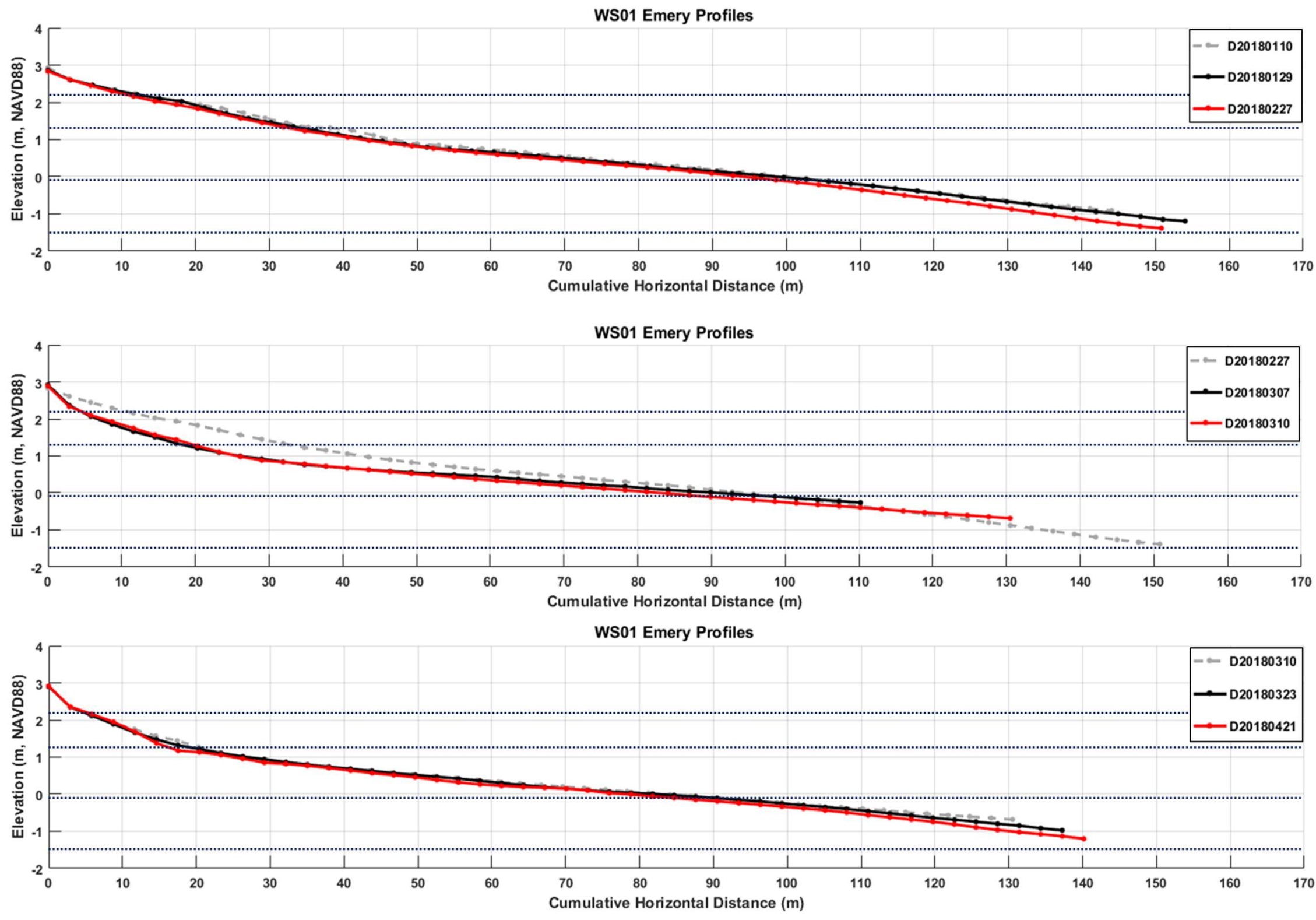


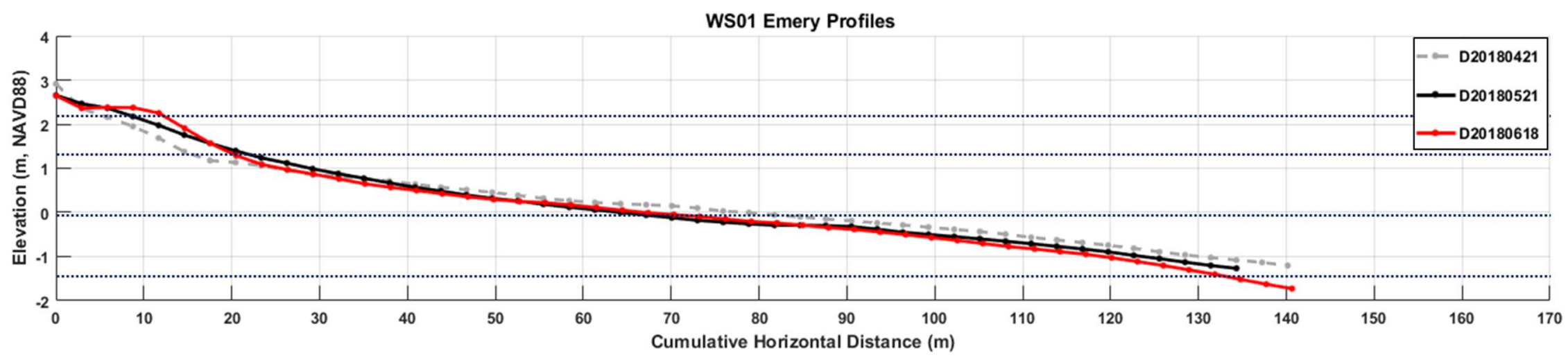

WS01 Emery Profiles

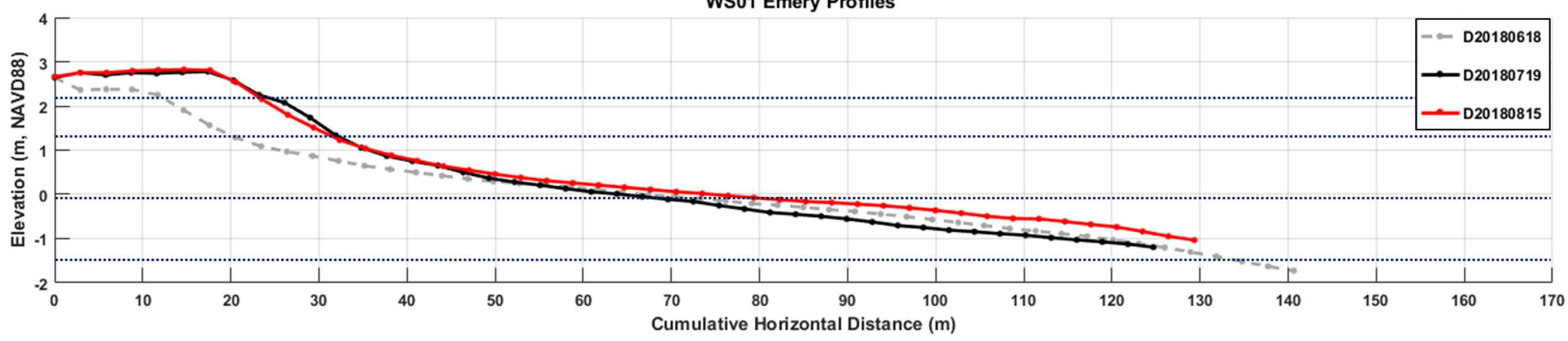

WS01 Emery Profiles

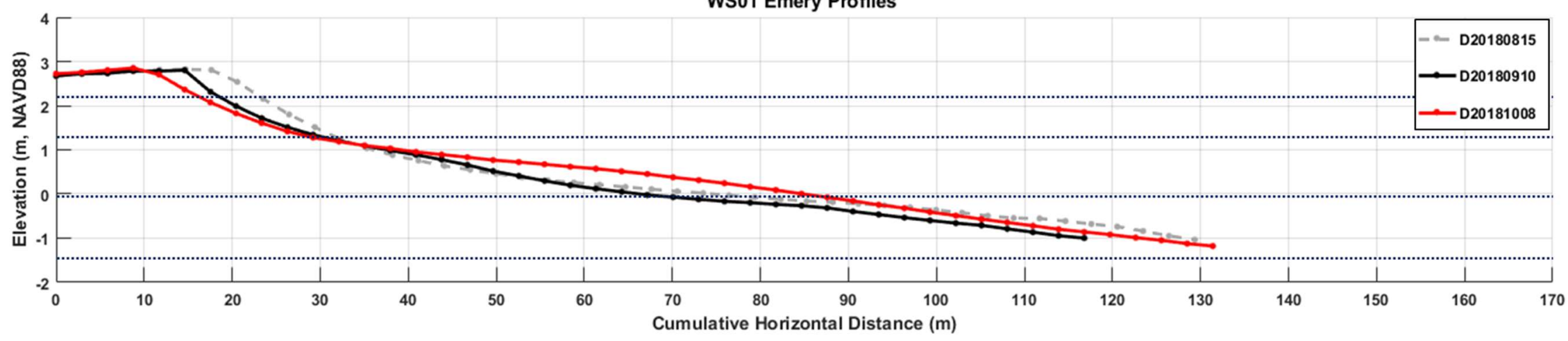



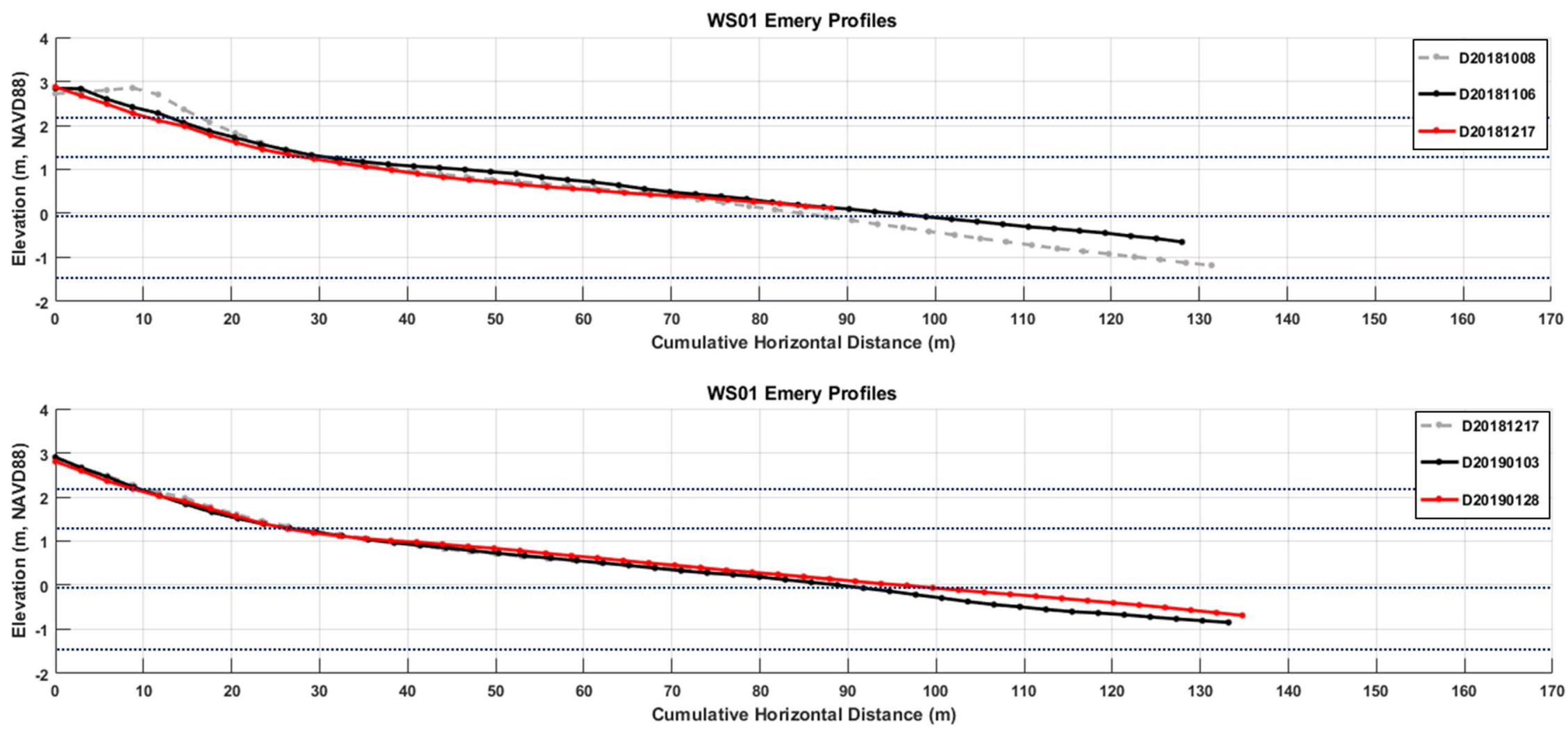

WS01 Emery Profiles

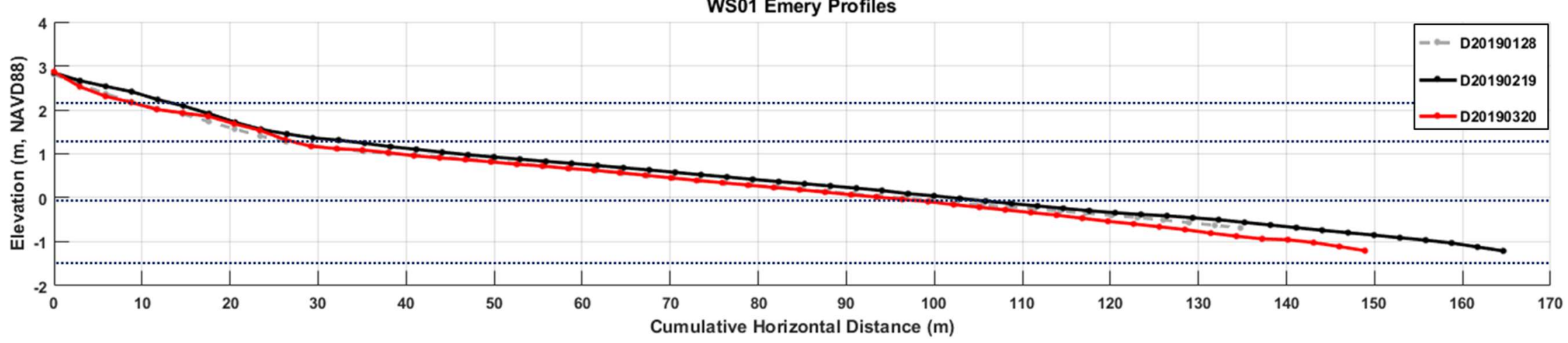



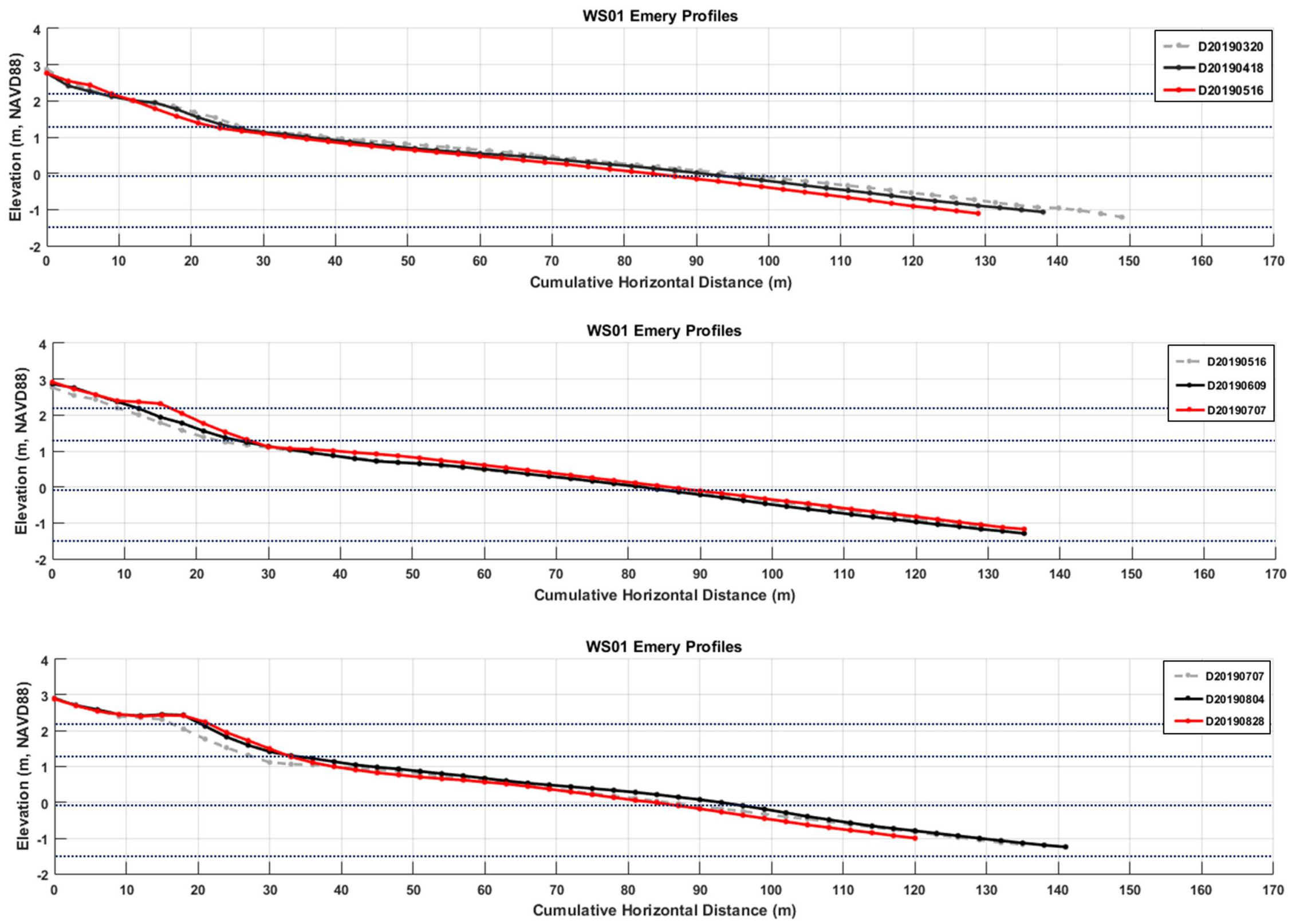

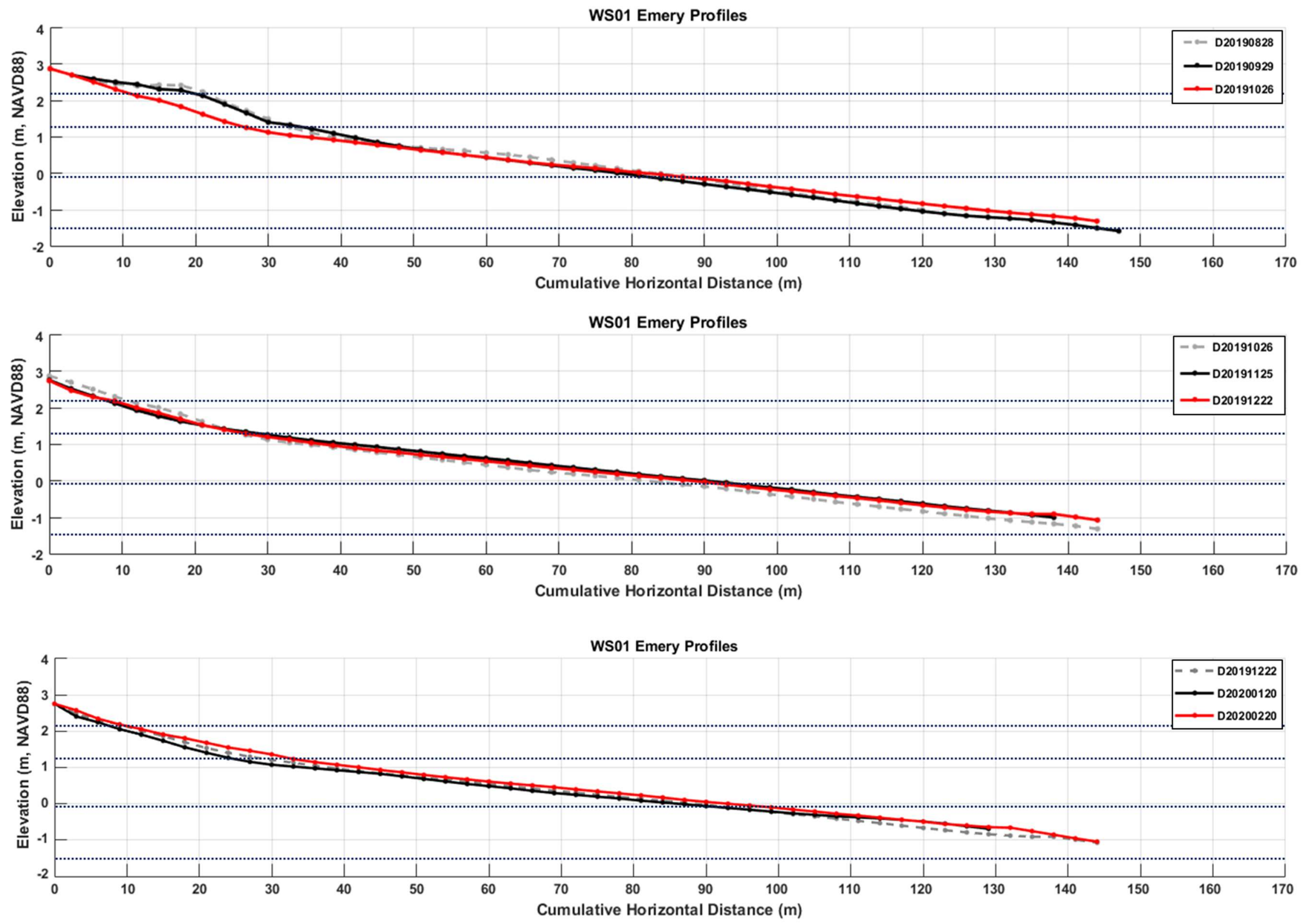
WS01 Emery Profiles

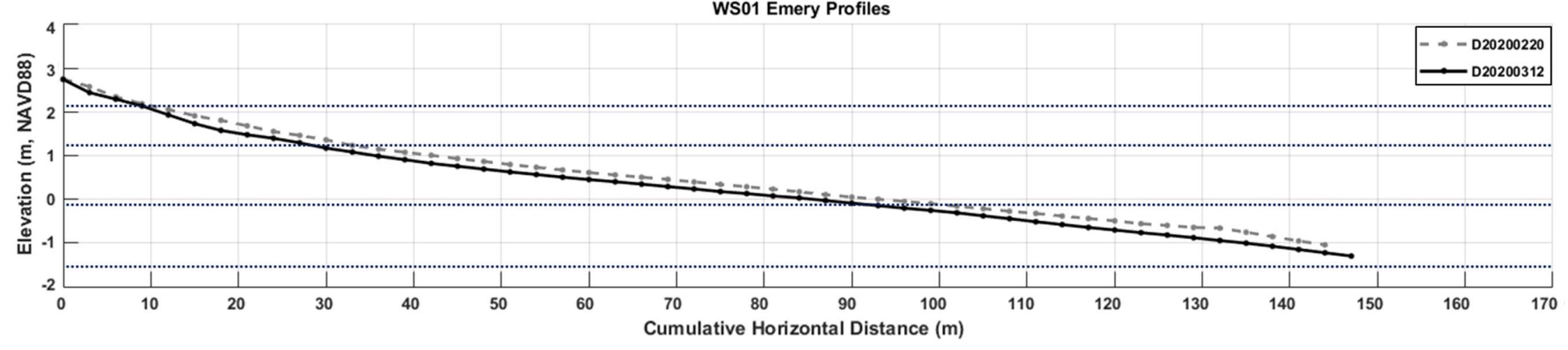


Appendix C(2): WS02.5 beach profiles from January 30, 2018 to March 14, 2020.
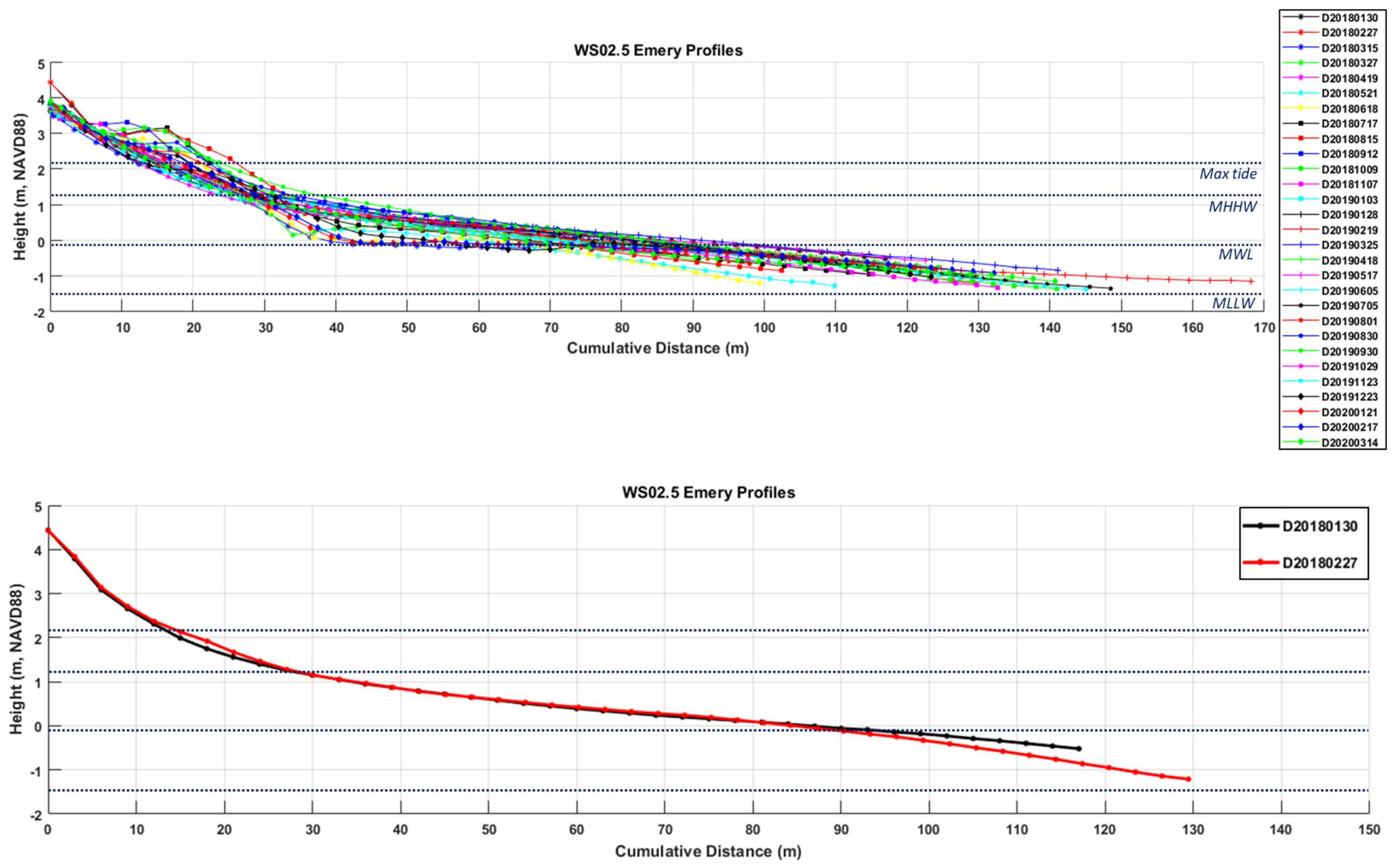

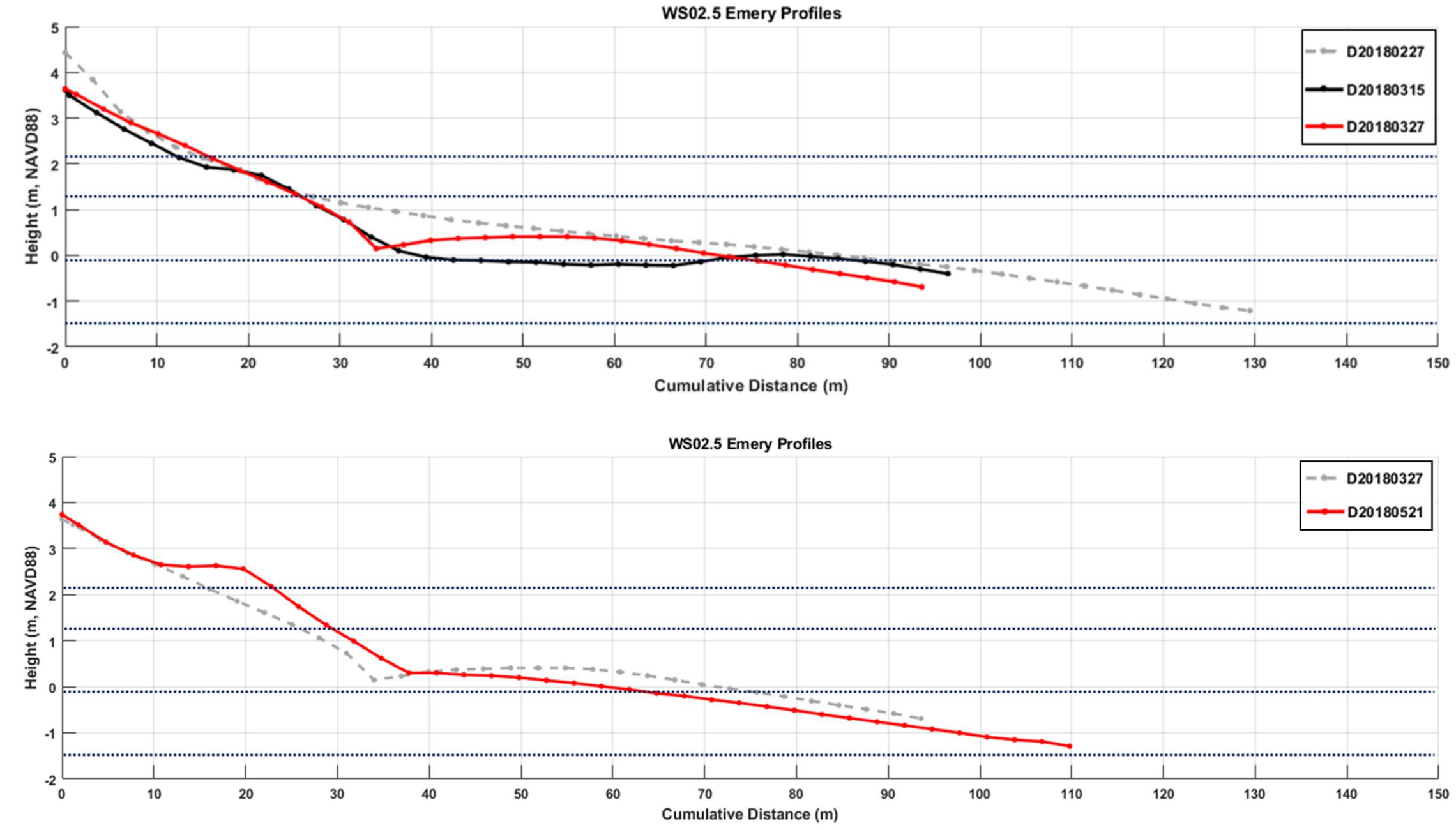

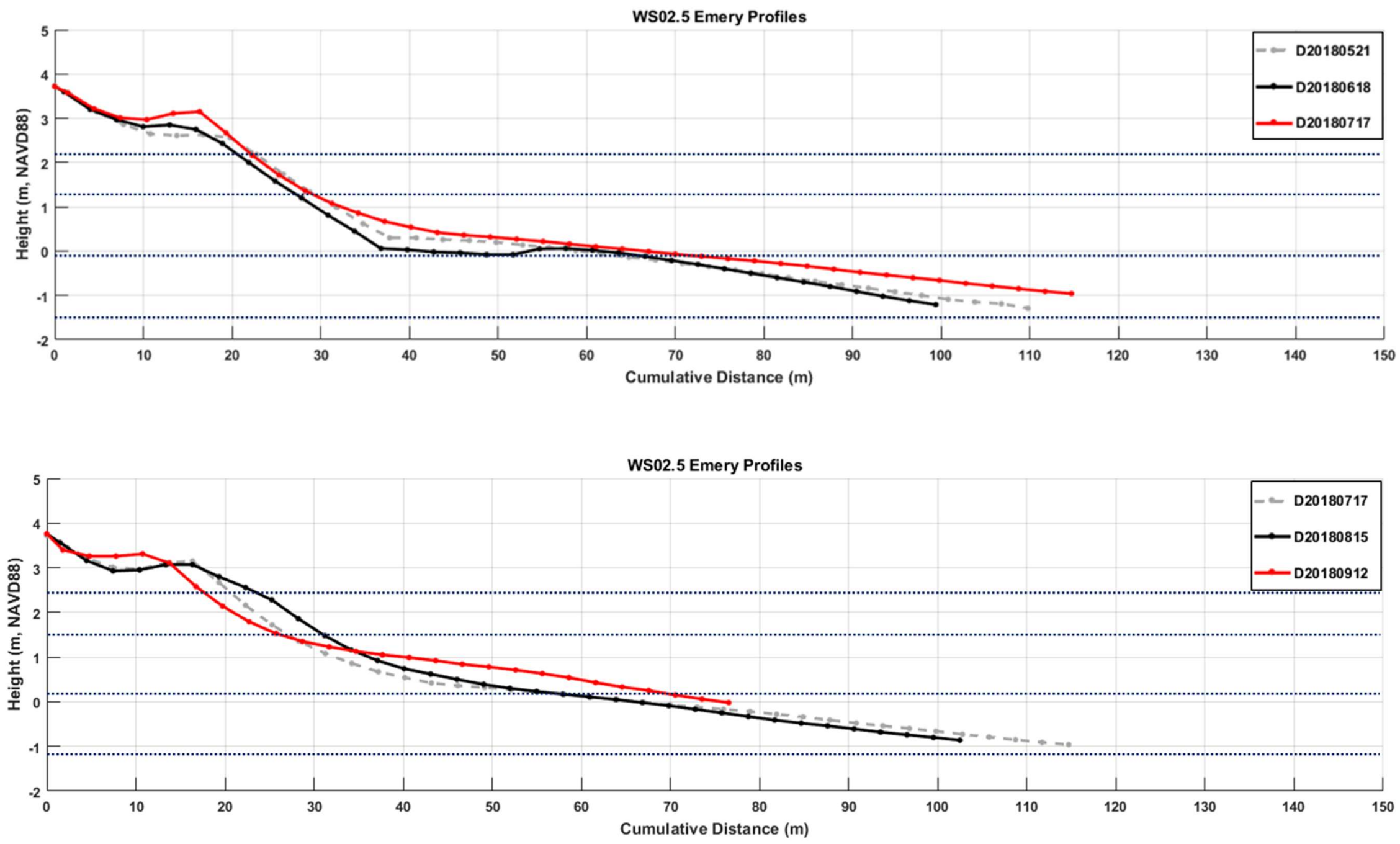

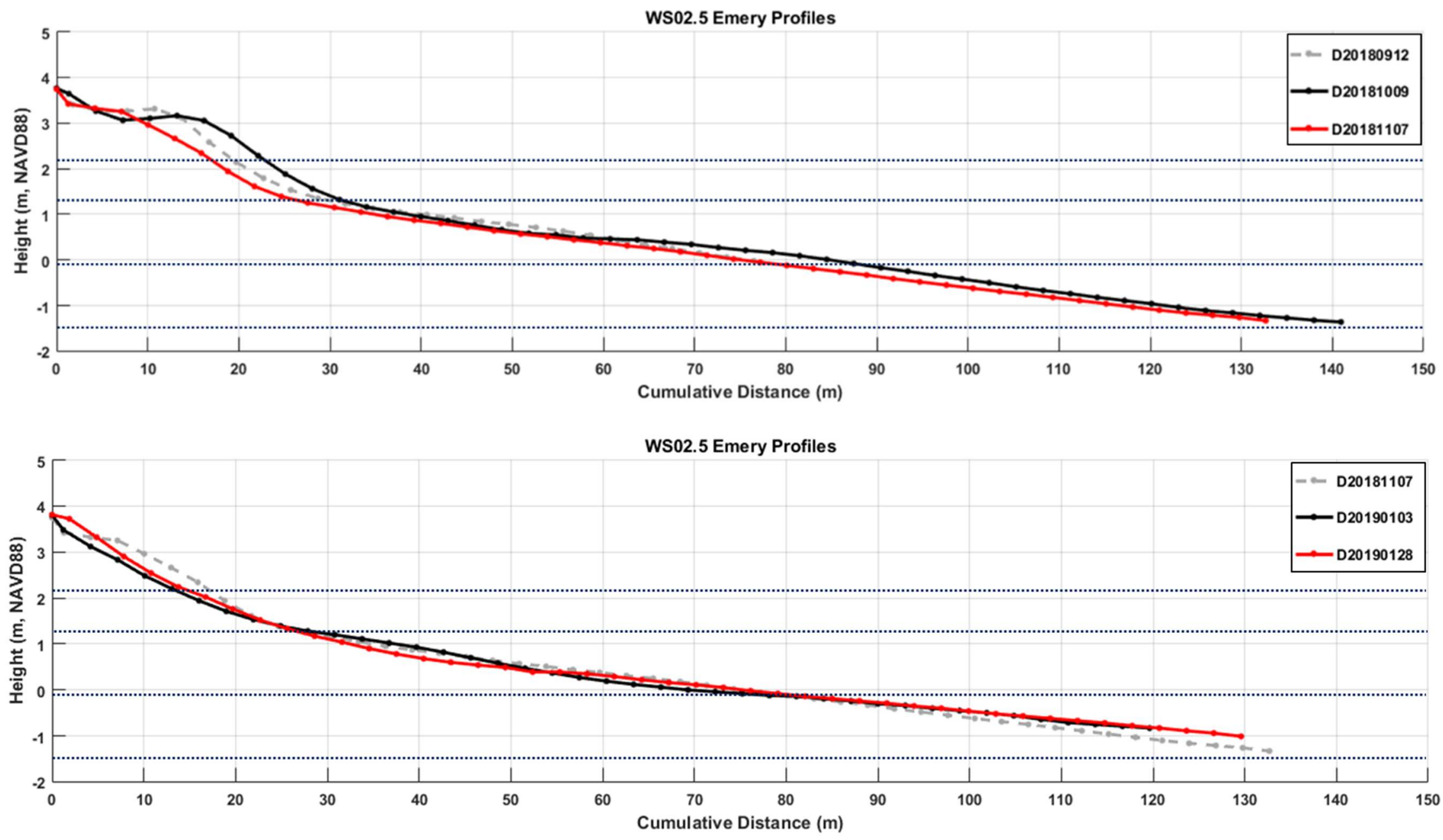


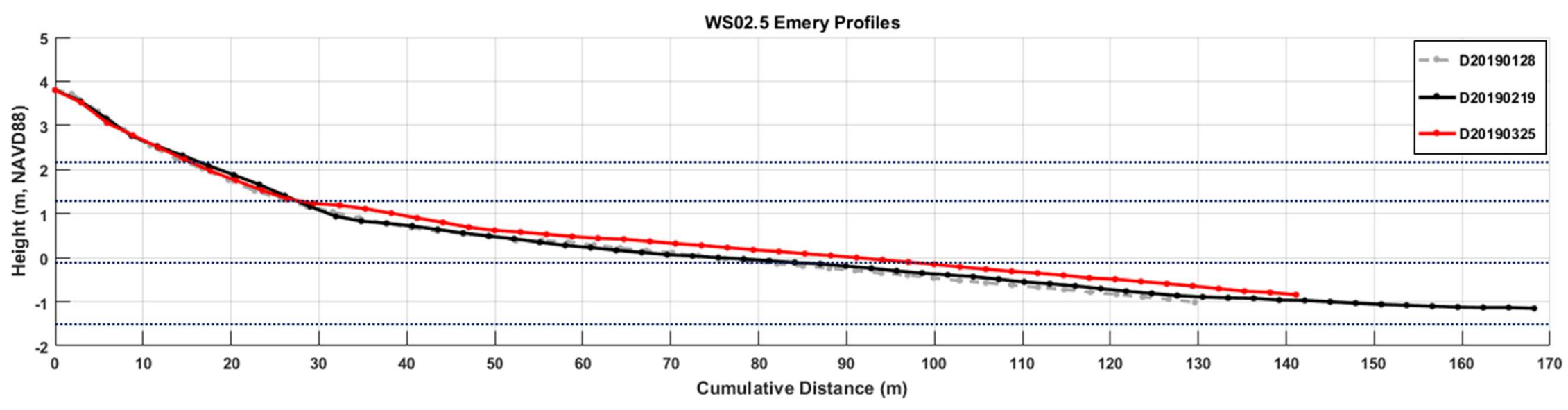

*Plot above extends to $170 \mathrm{~m}$, rather than $150 \mathrm{~m}$

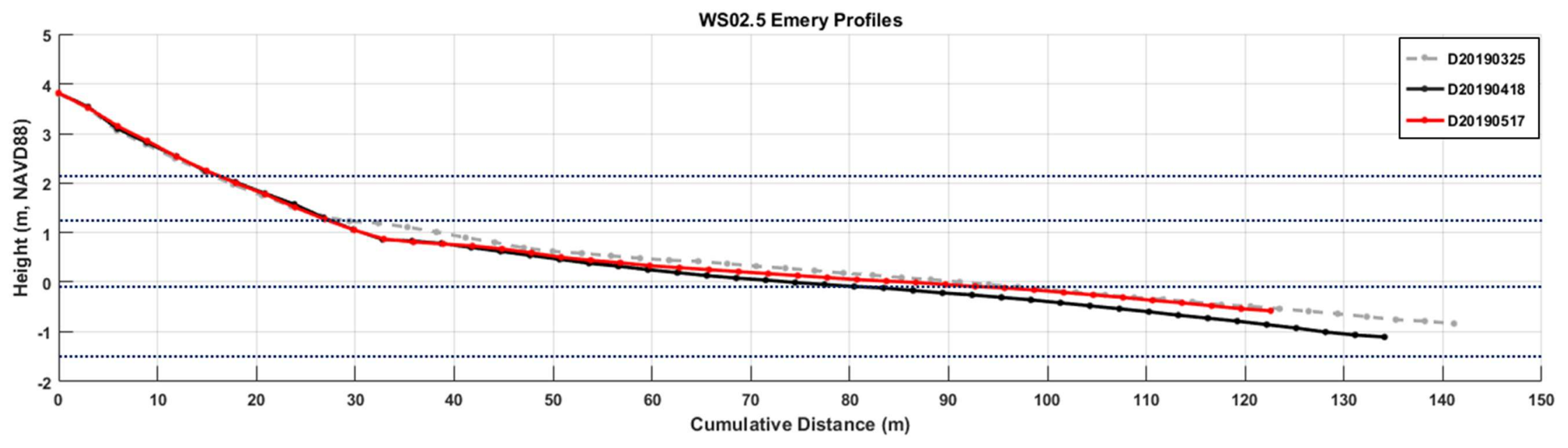



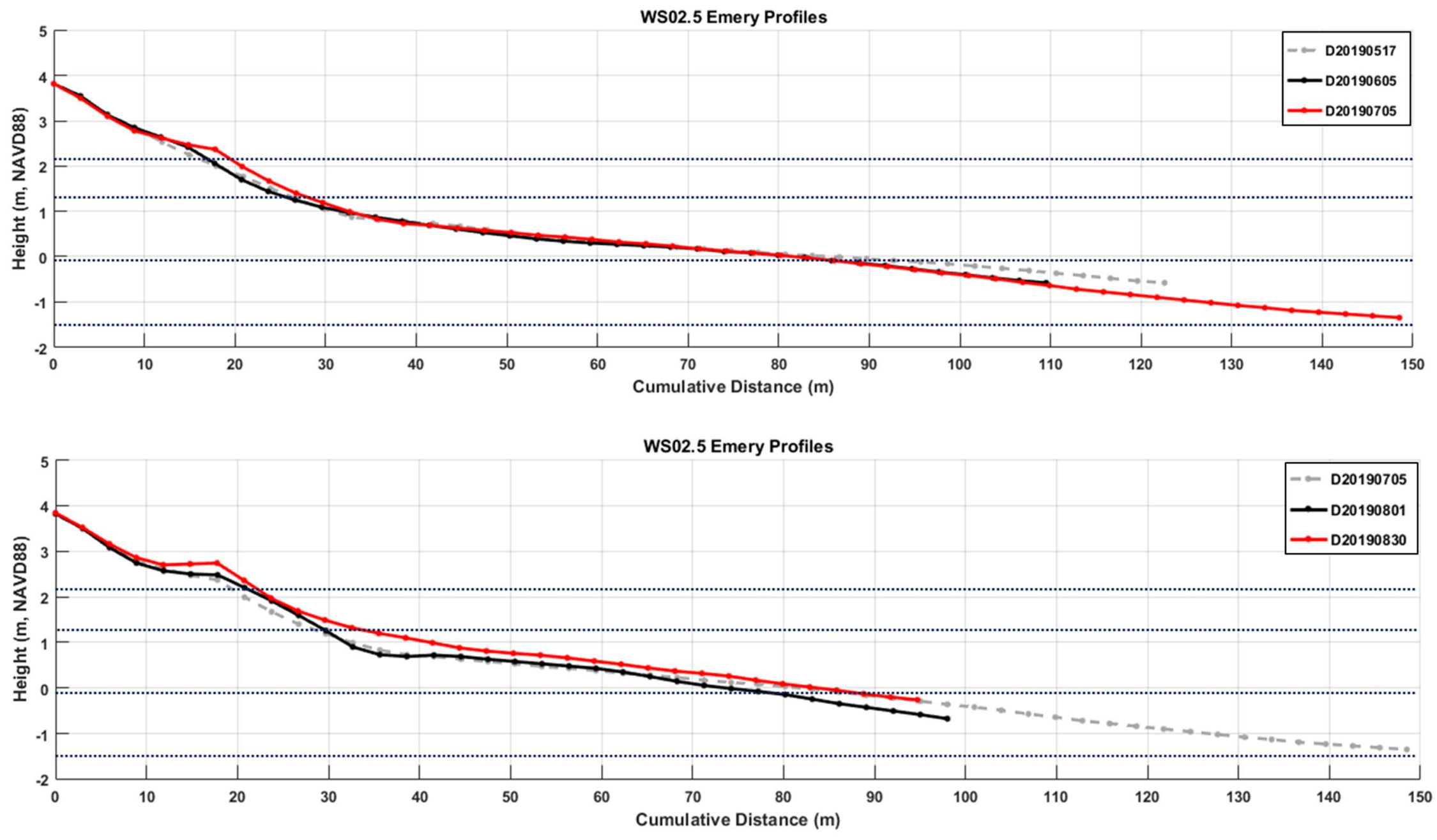

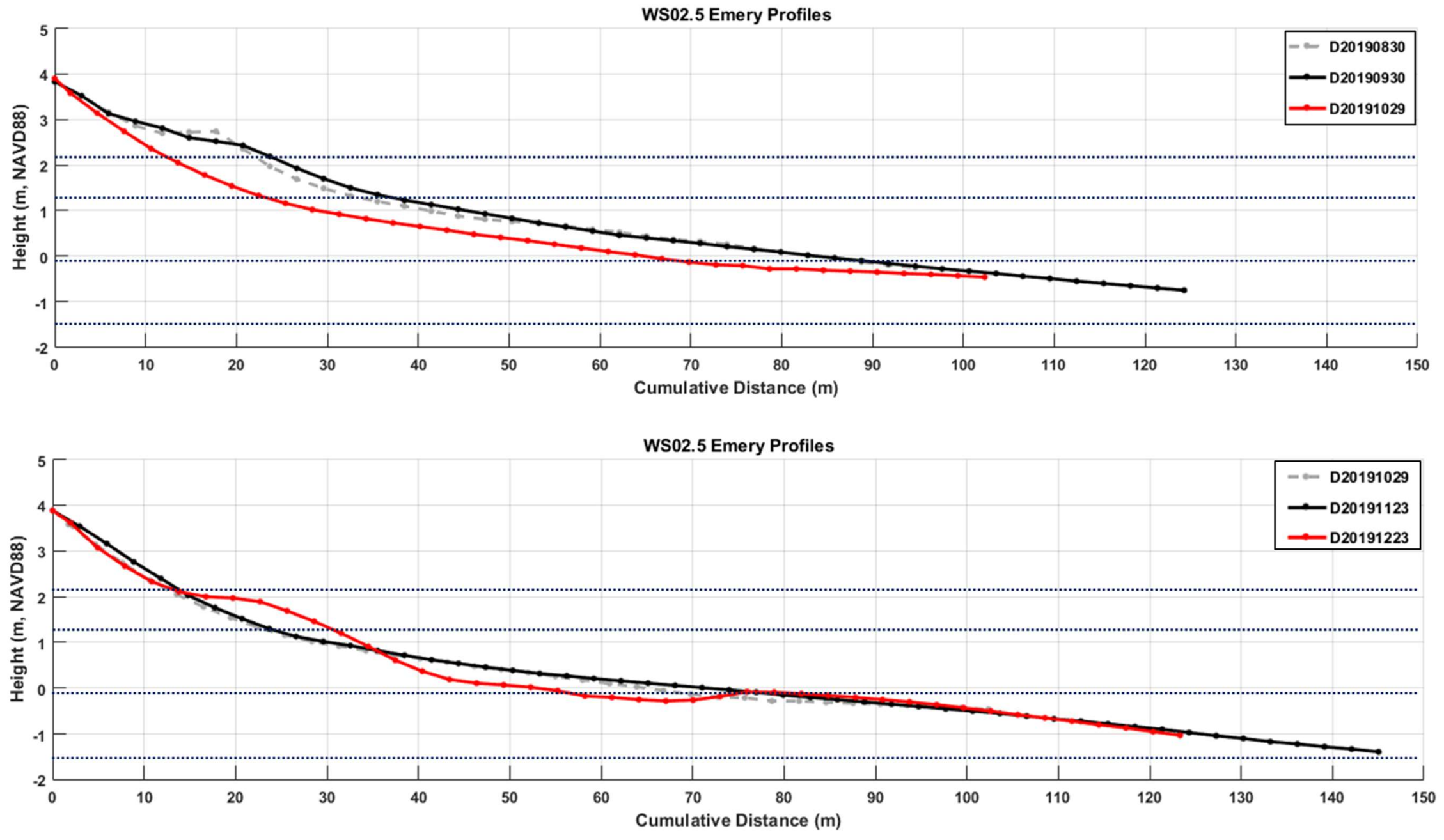

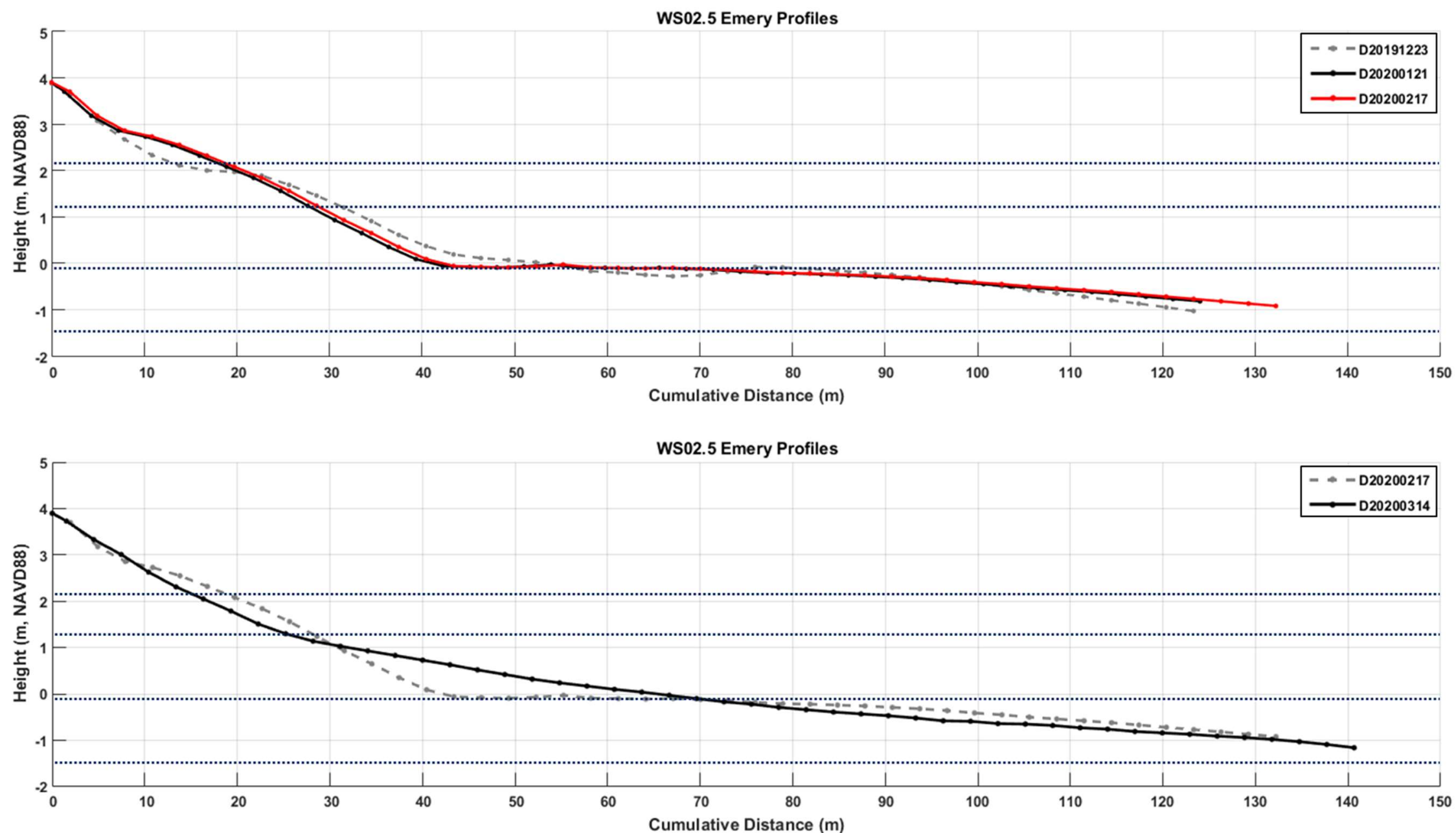
Appendix C(3): JB01 beach profiles from January 28, 2018 to March 14, 2020.
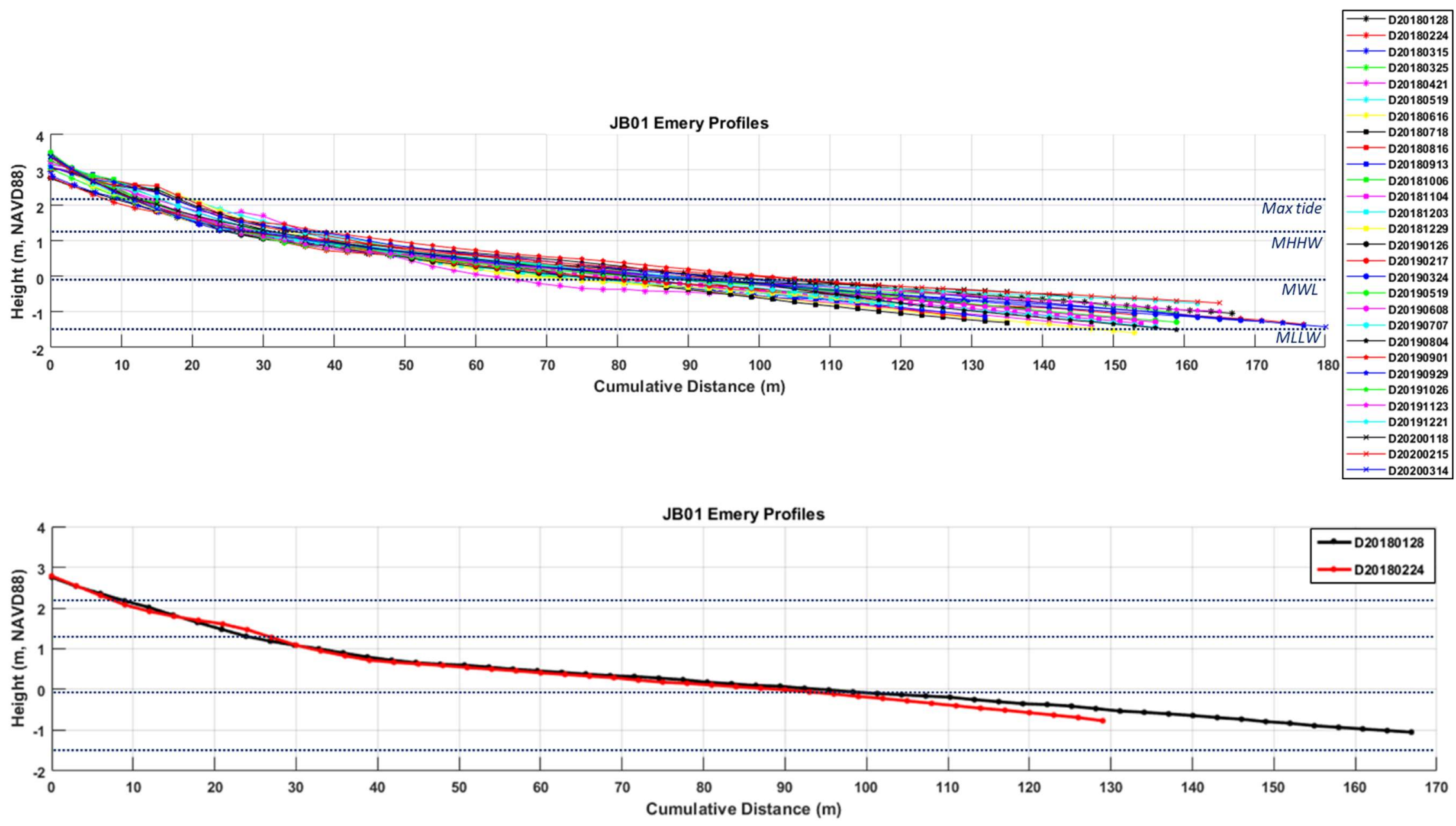

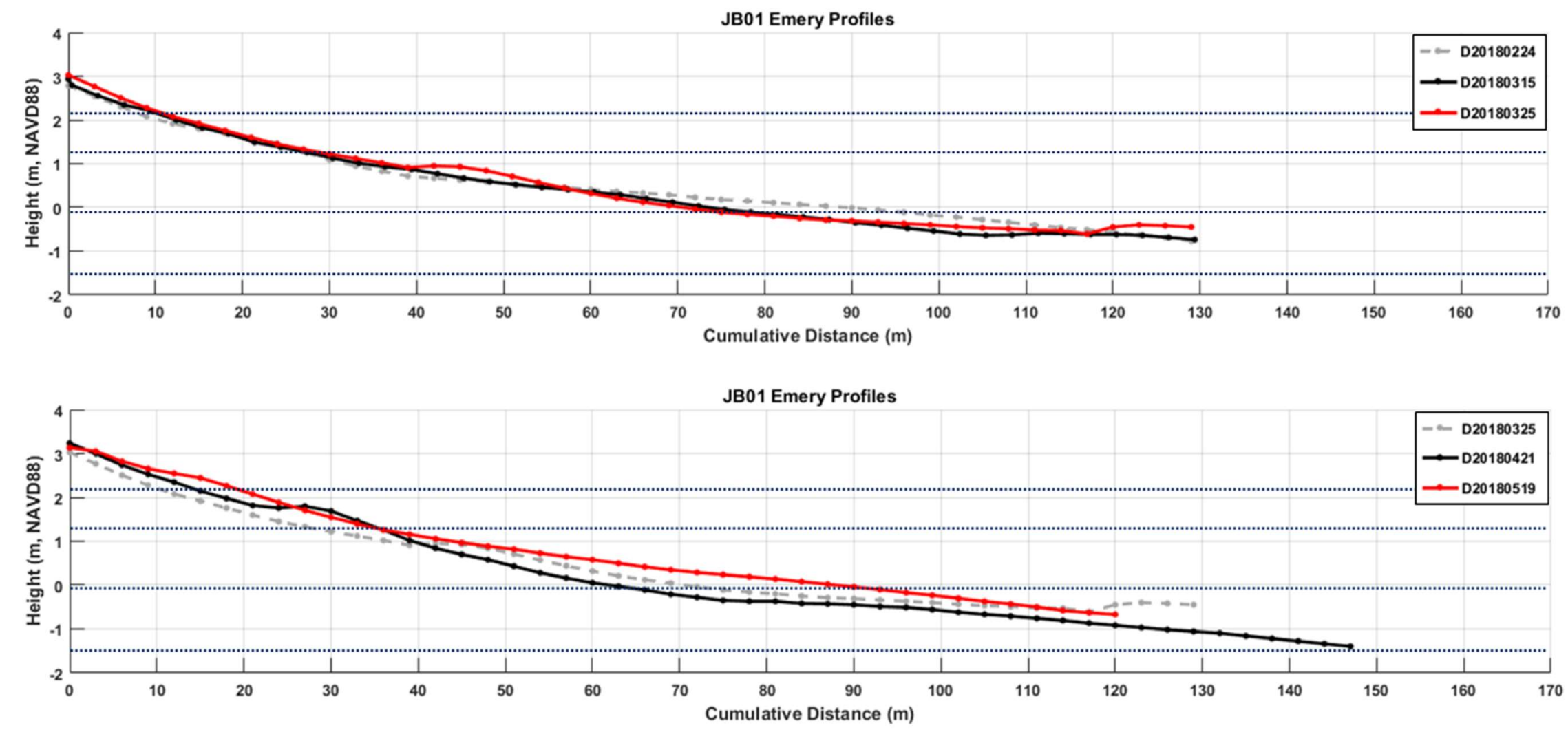

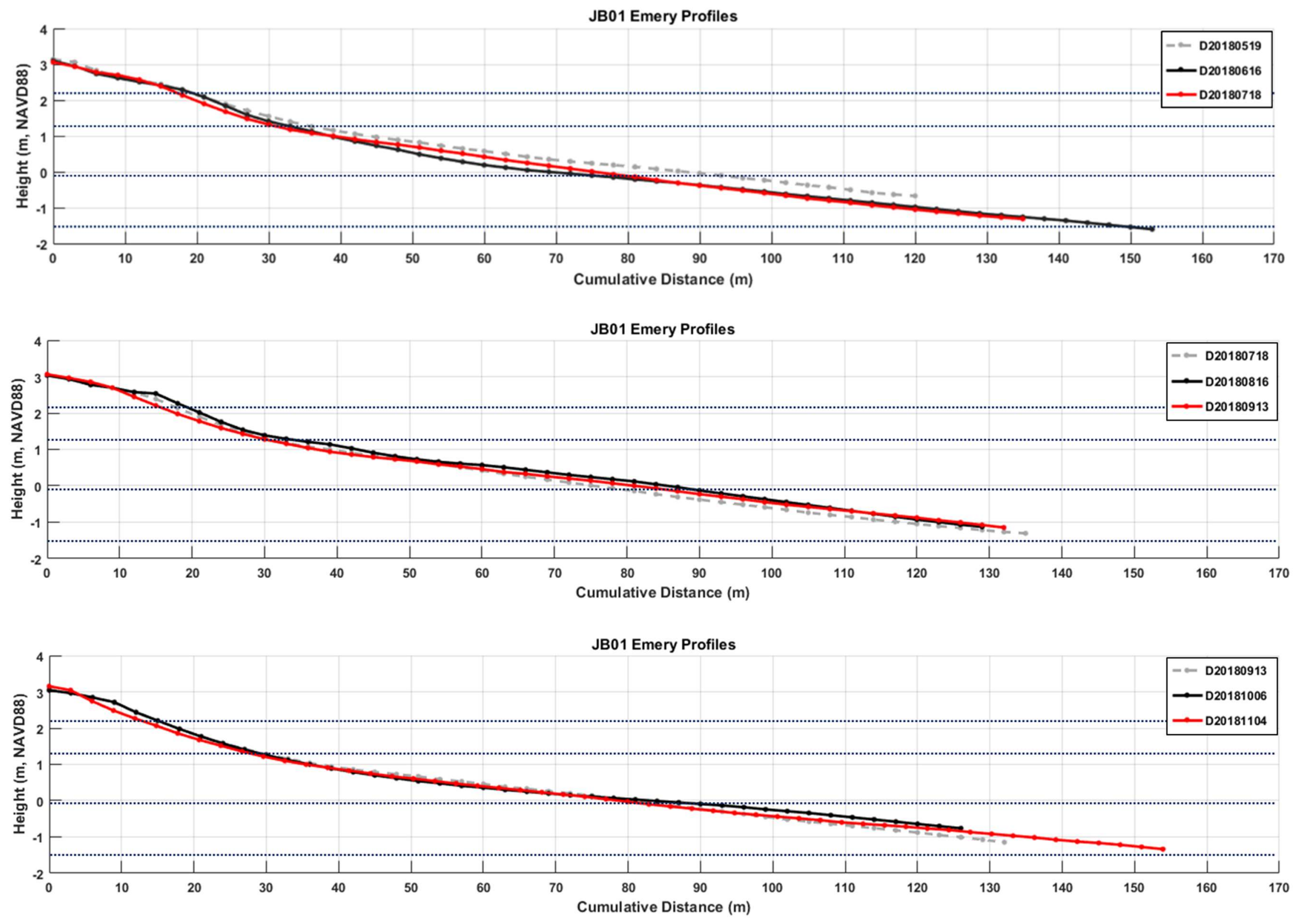

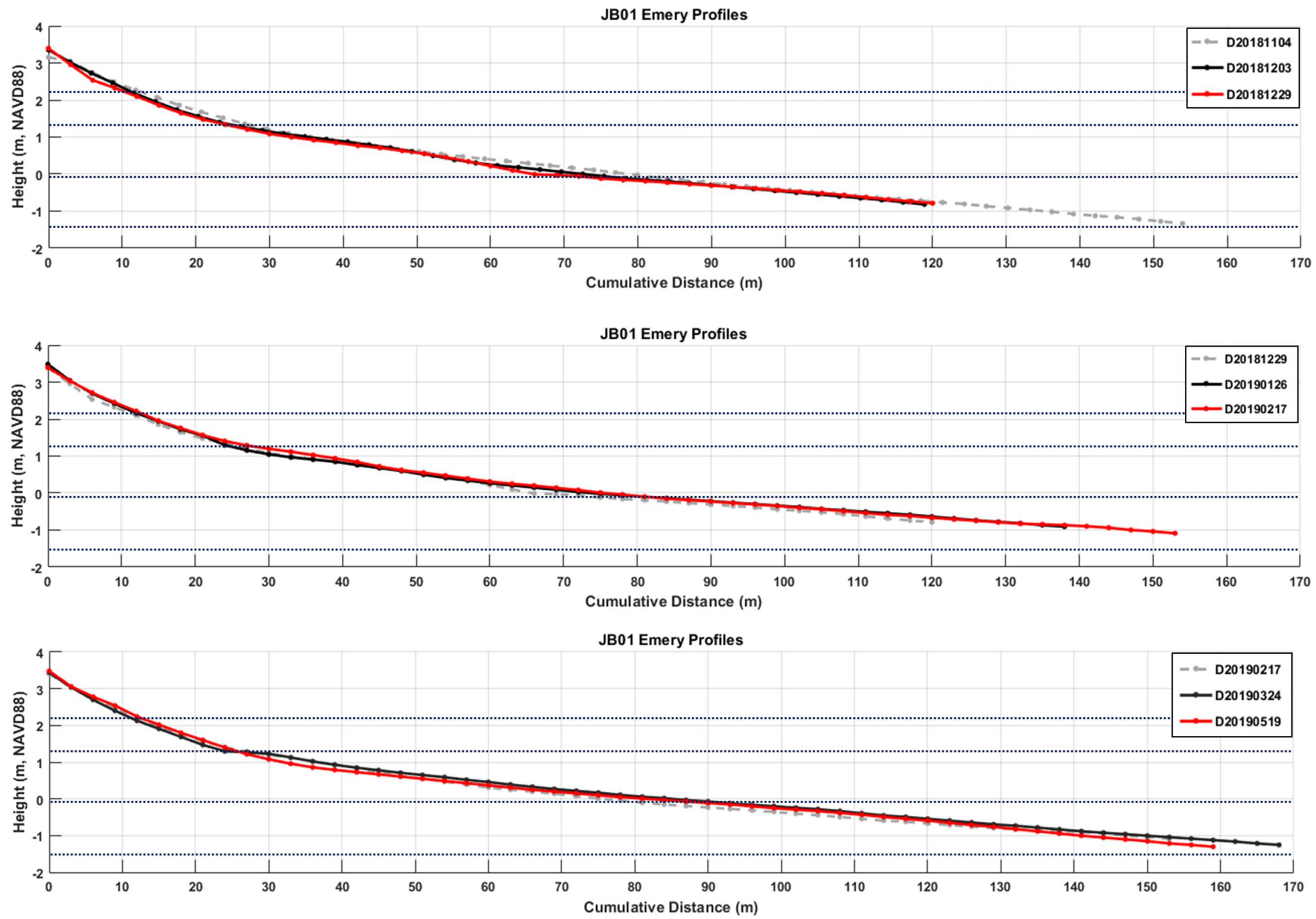

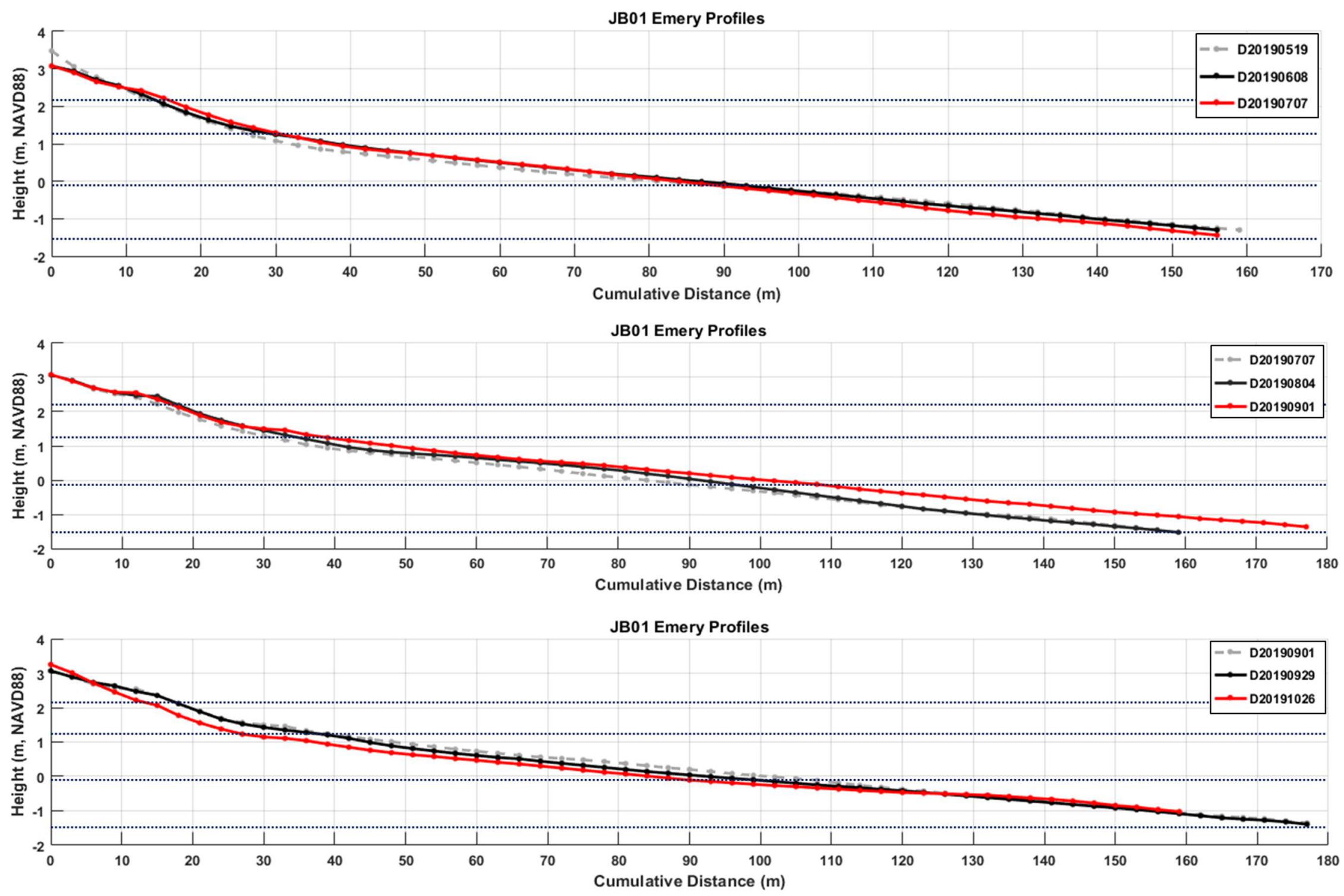

*Plots above extend to $180 \mathrm{~m}$, rather than $170 \mathrm{~m}$ 

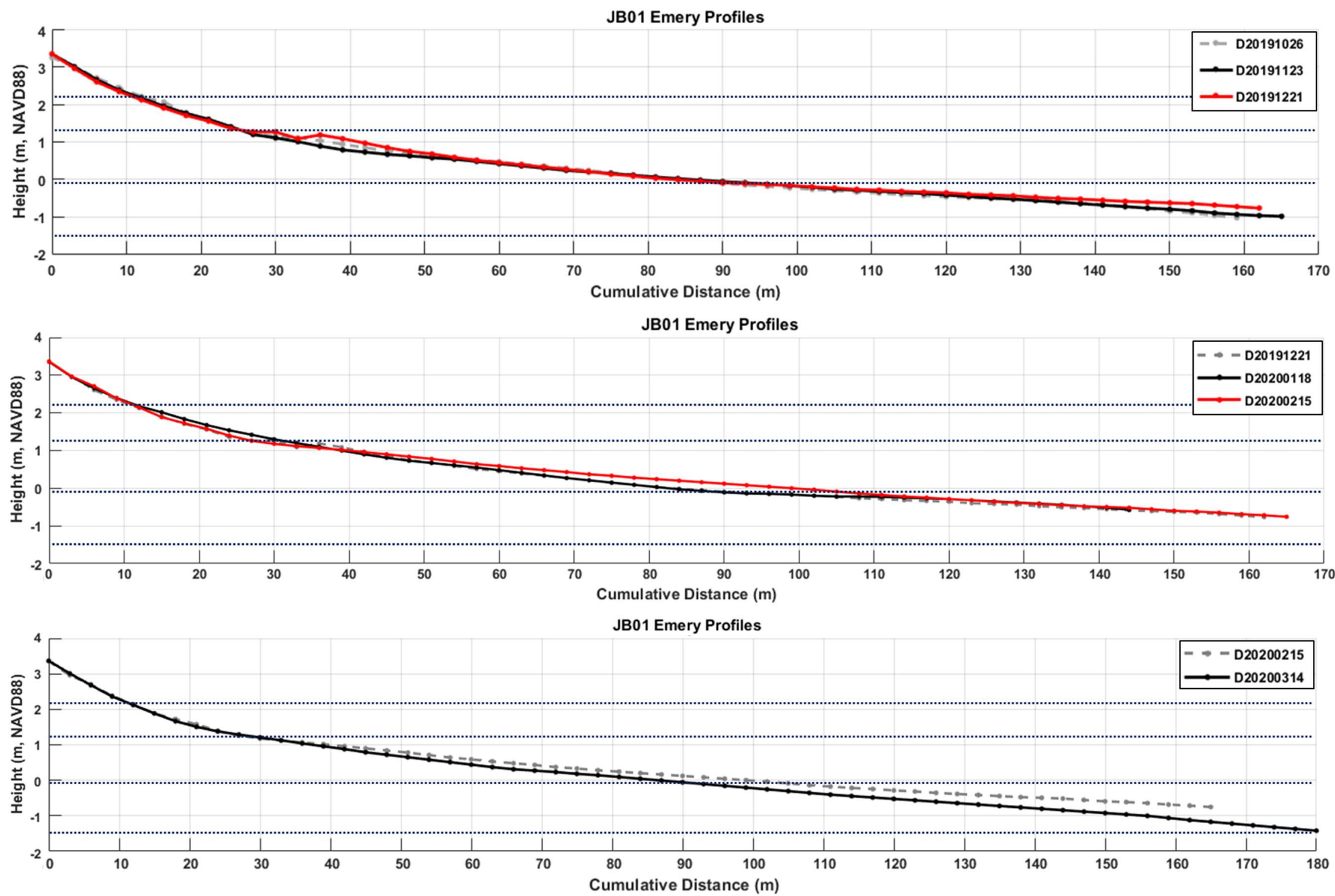

*Bottom plot, above, extends to $180 \mathrm{~m}$, rather than $170 \mathrm{~m}$ 
Appendix C(4): JB02 beach profiles from December 8, 2016 to March 12, 2020.

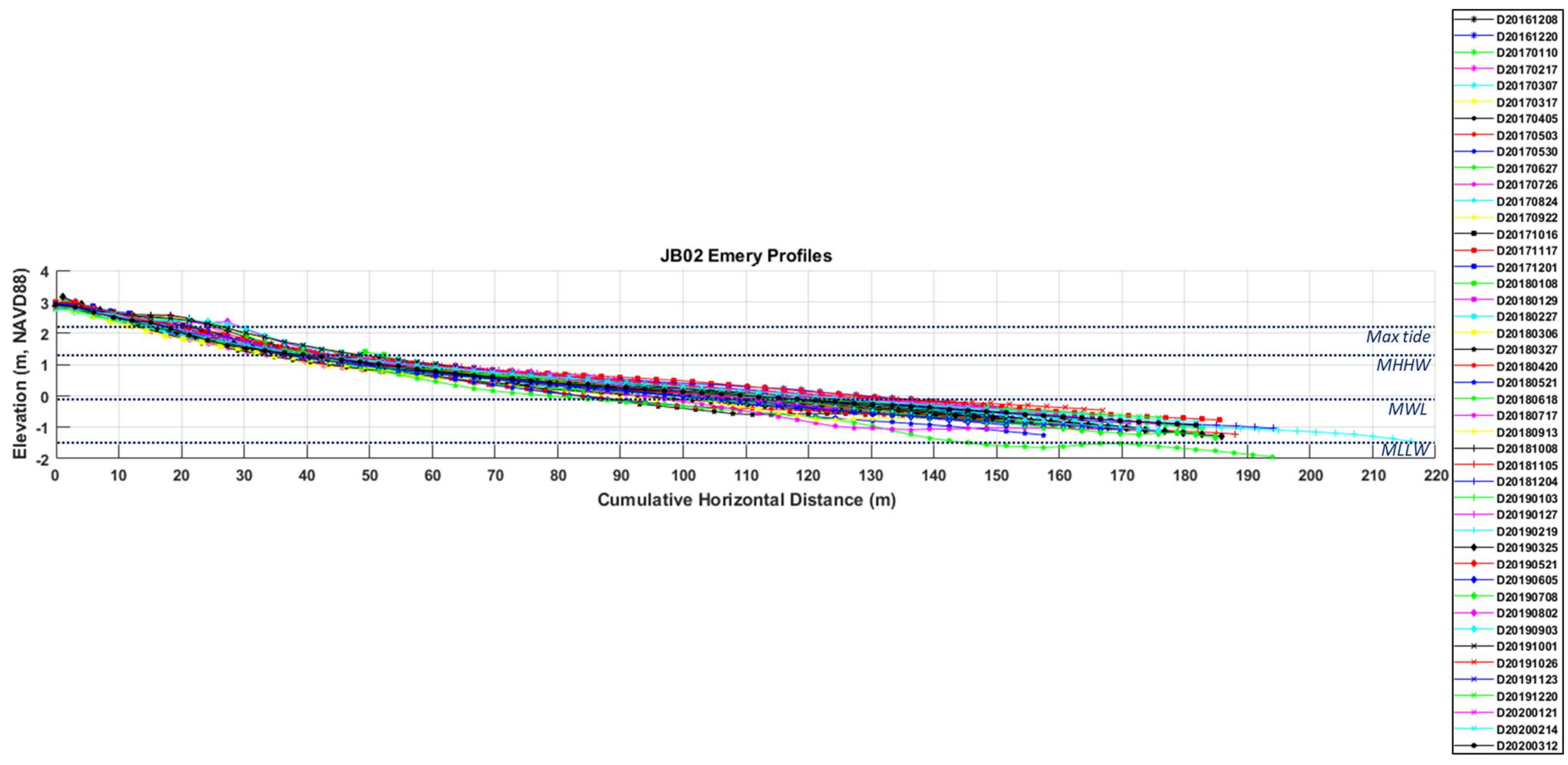



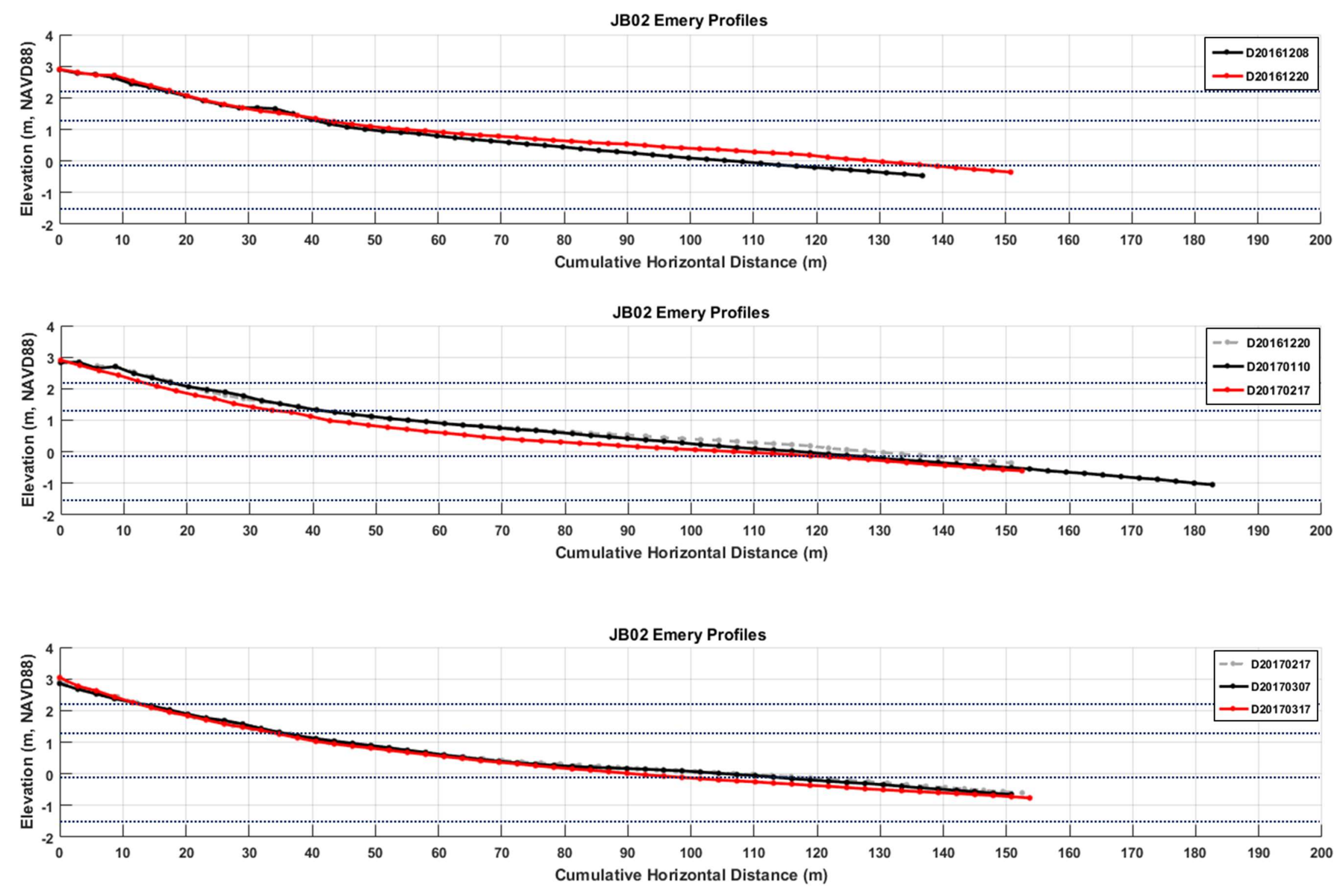

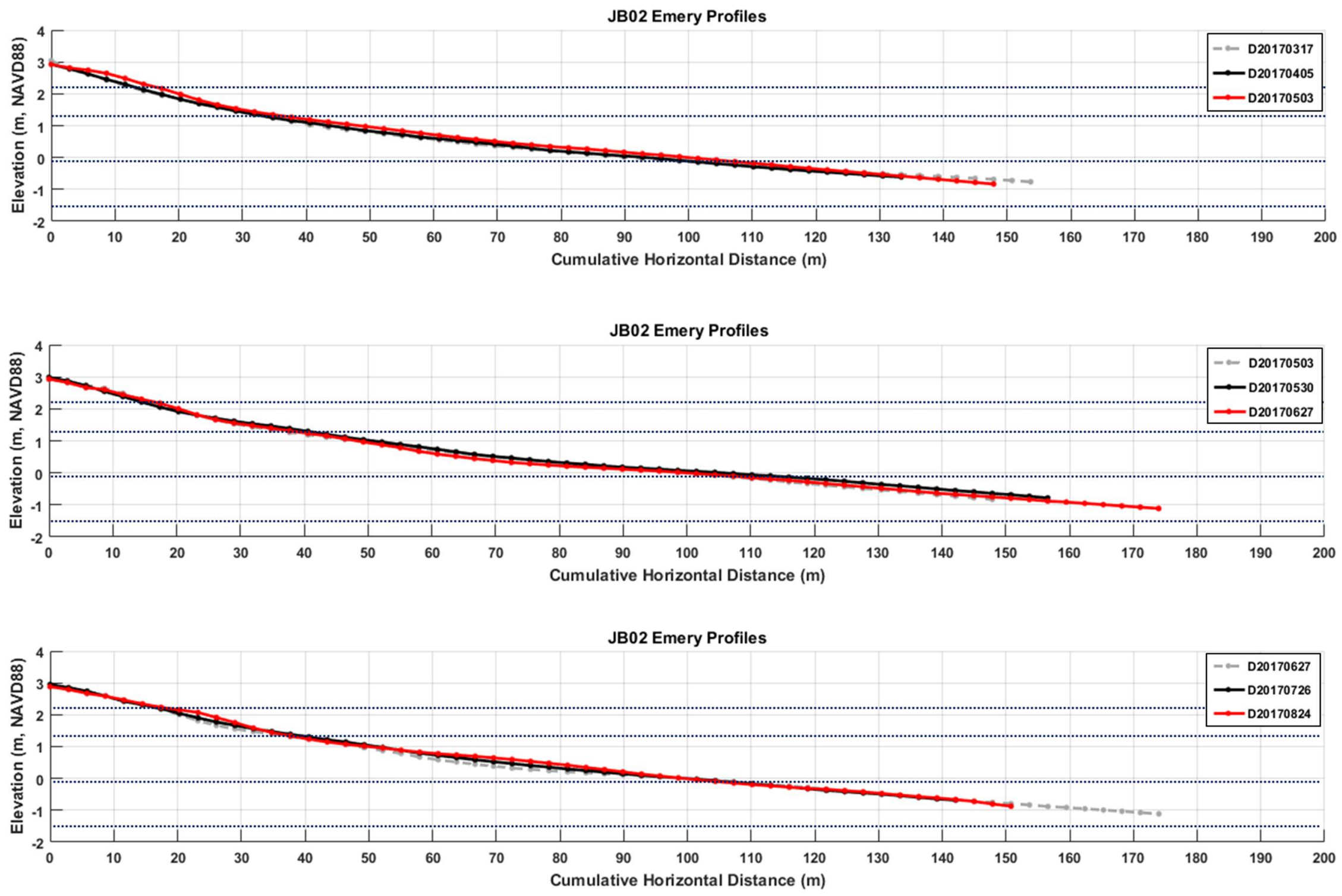


\section{JB02 Emery Profiles}
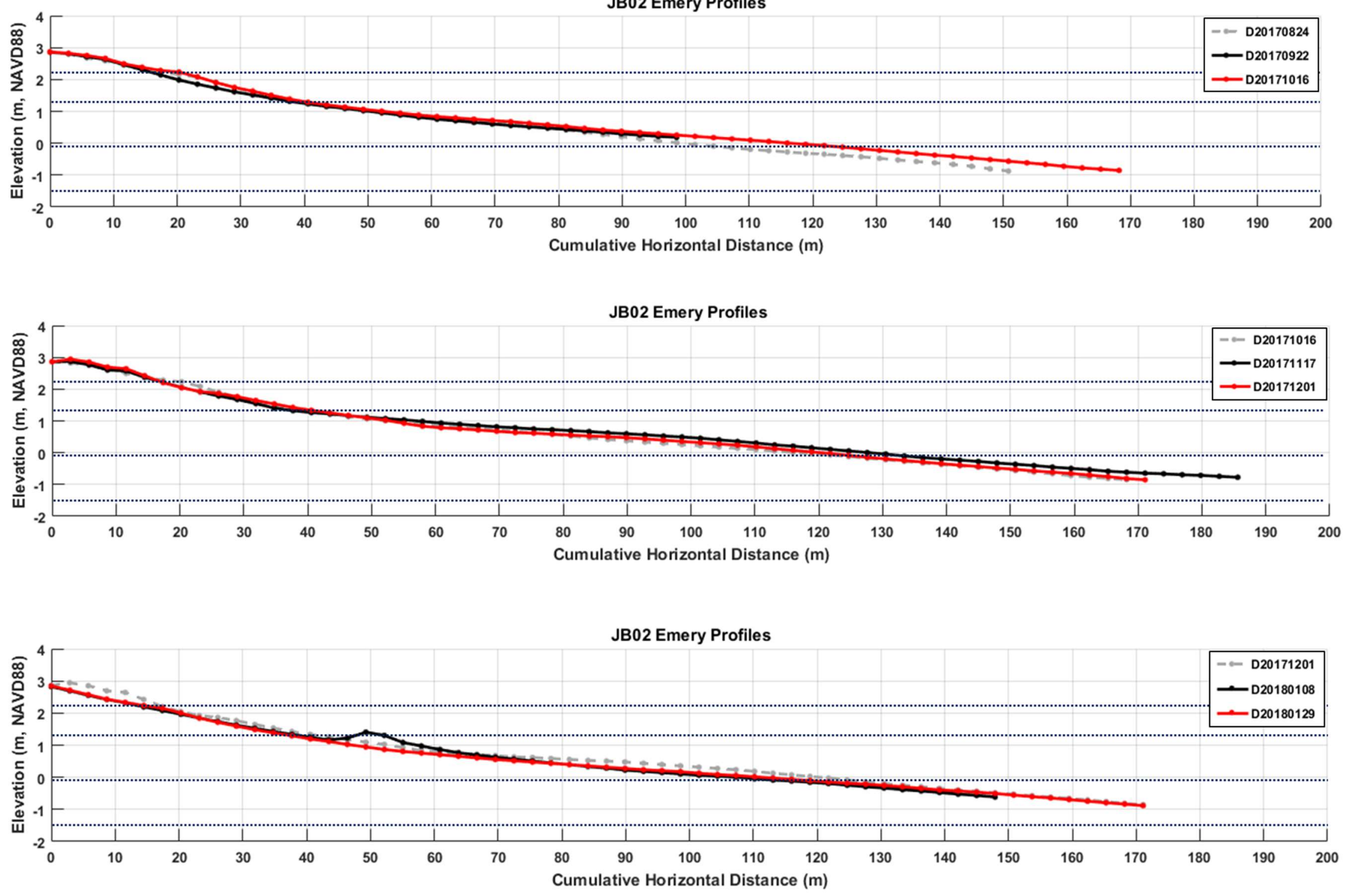

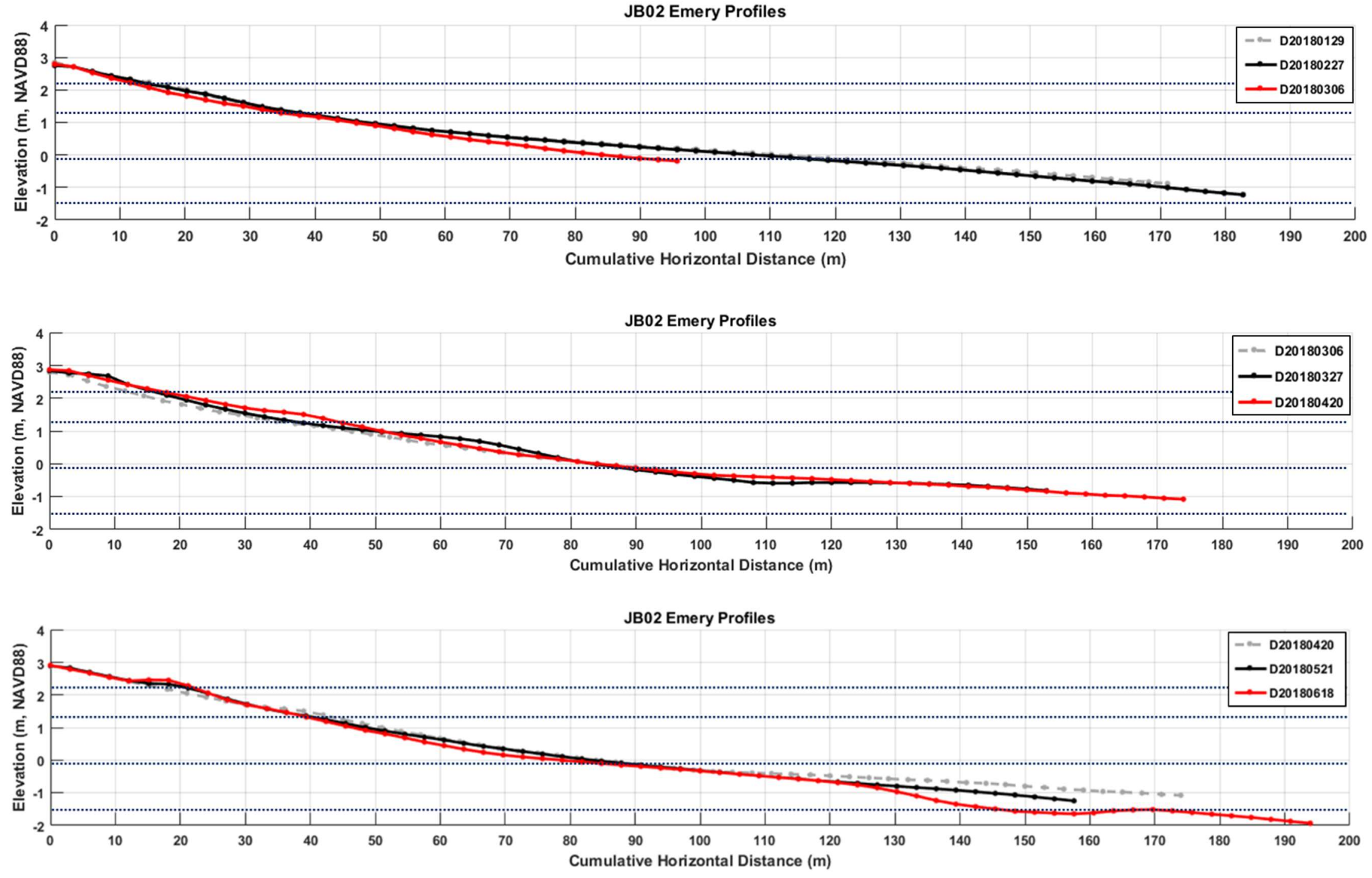

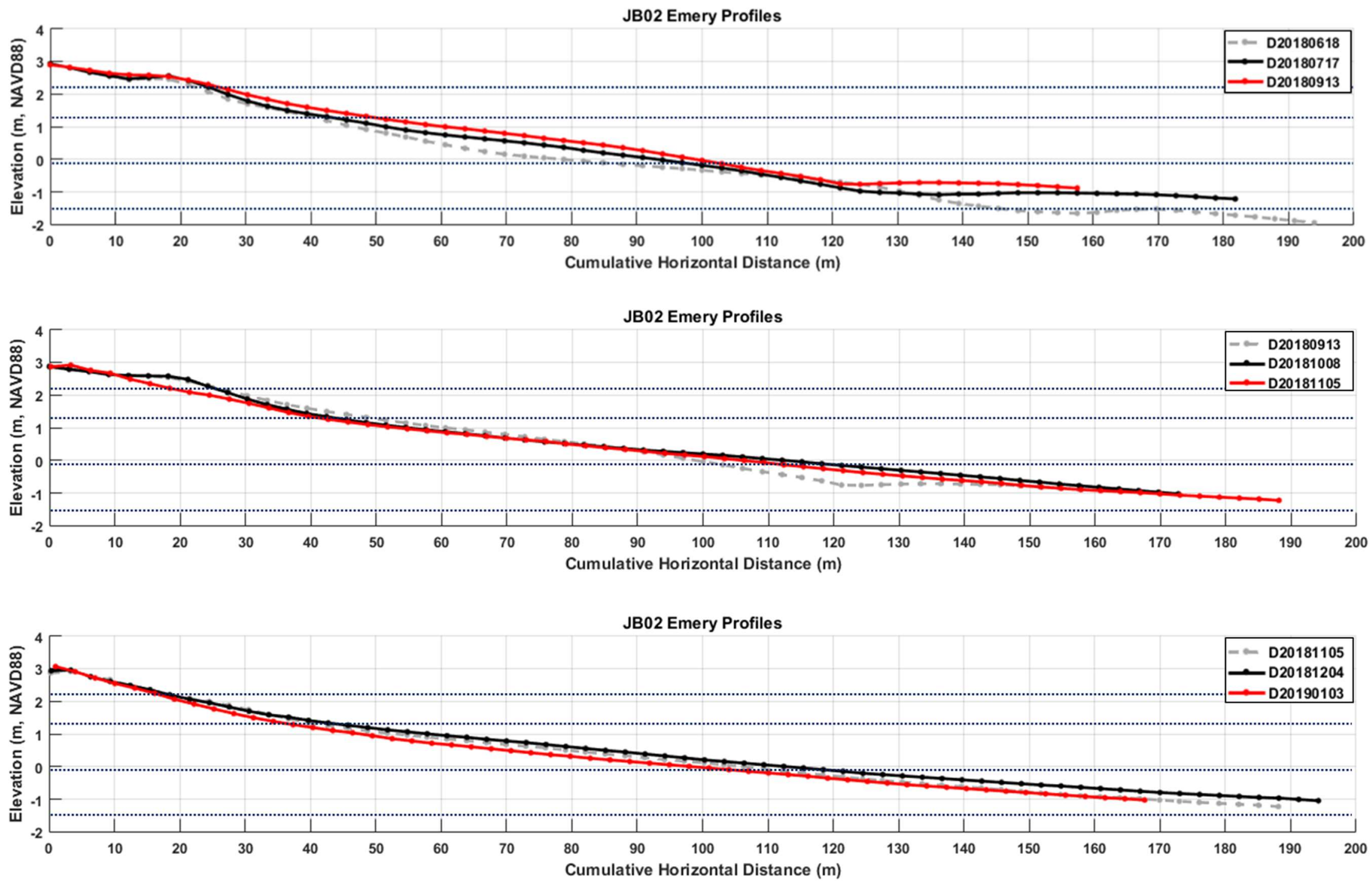

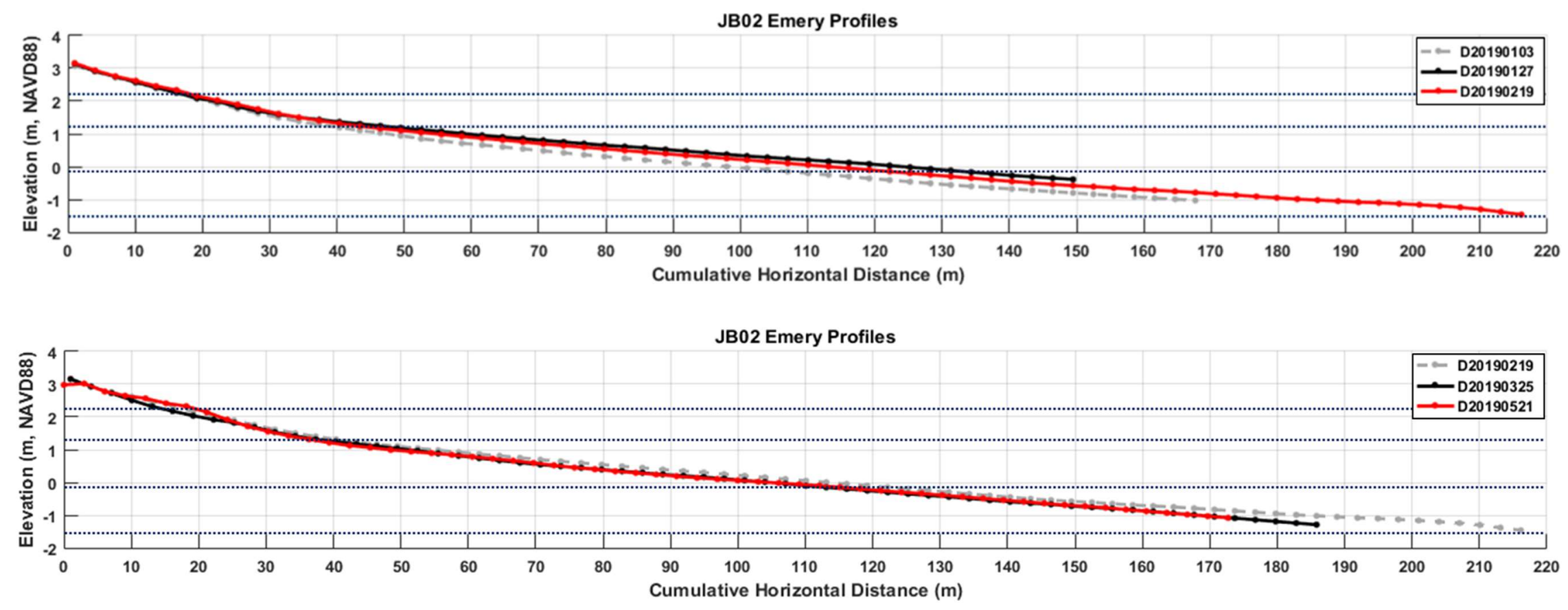

*The top and middle plots, above, extend to $220 \mathrm{~m}$, rather than $200 \mathrm{~m}$

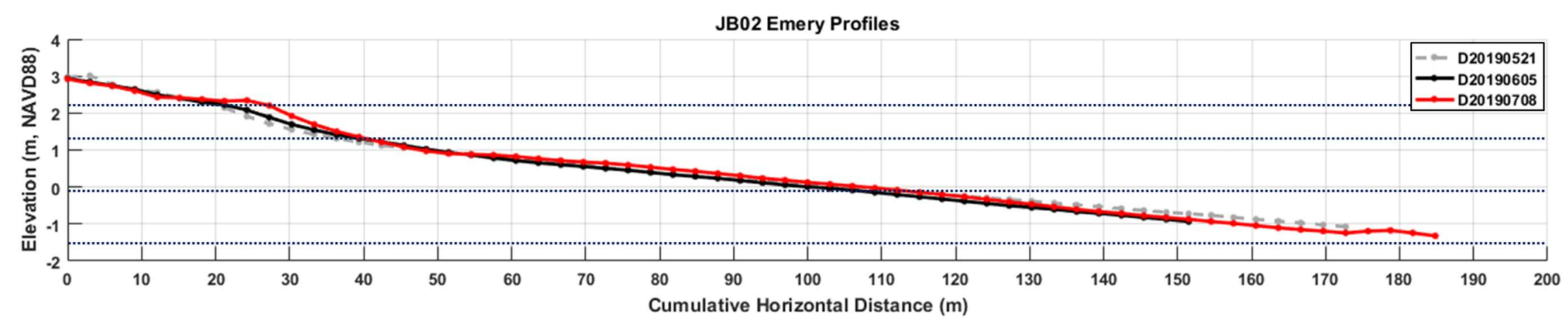



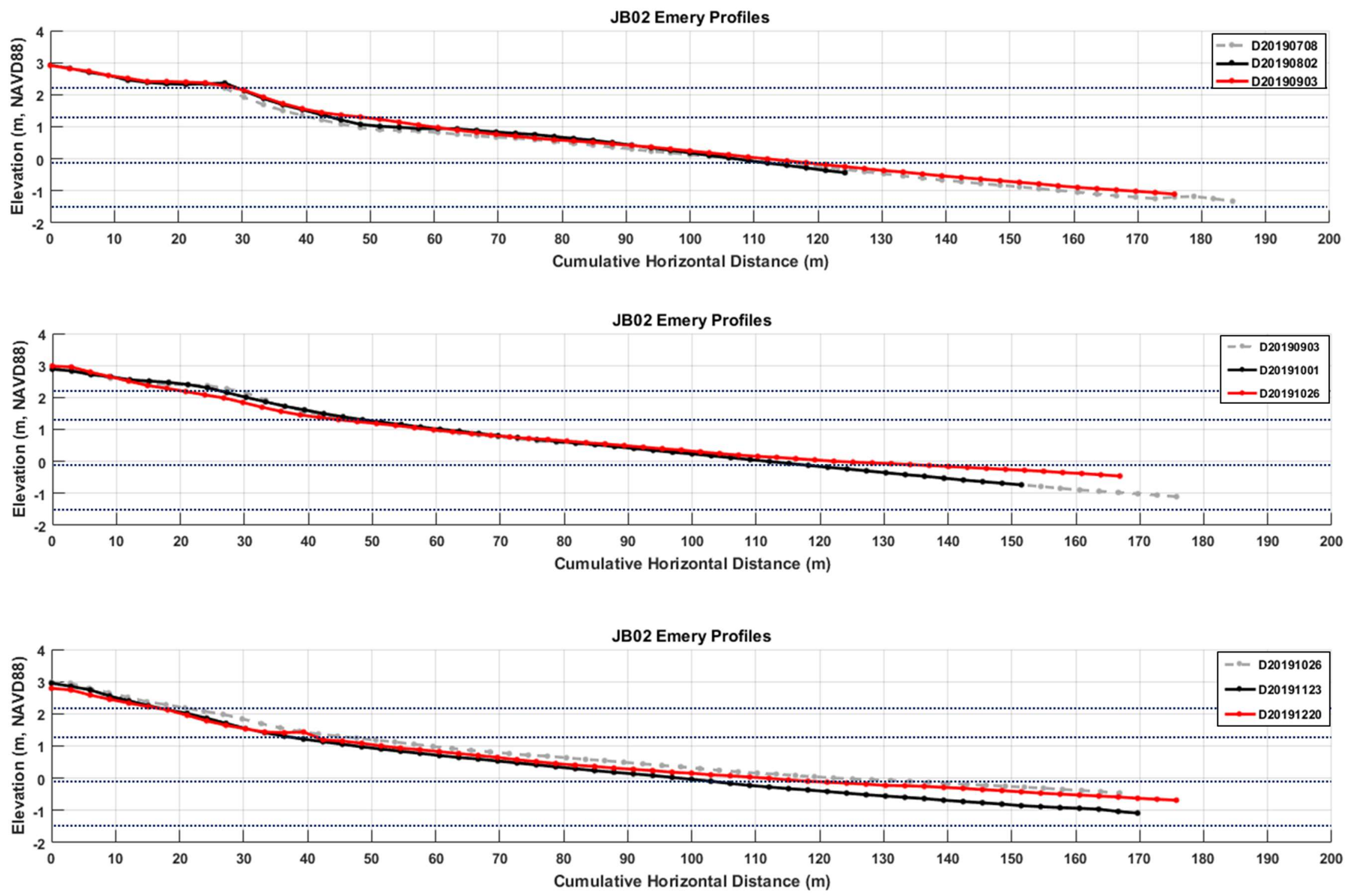

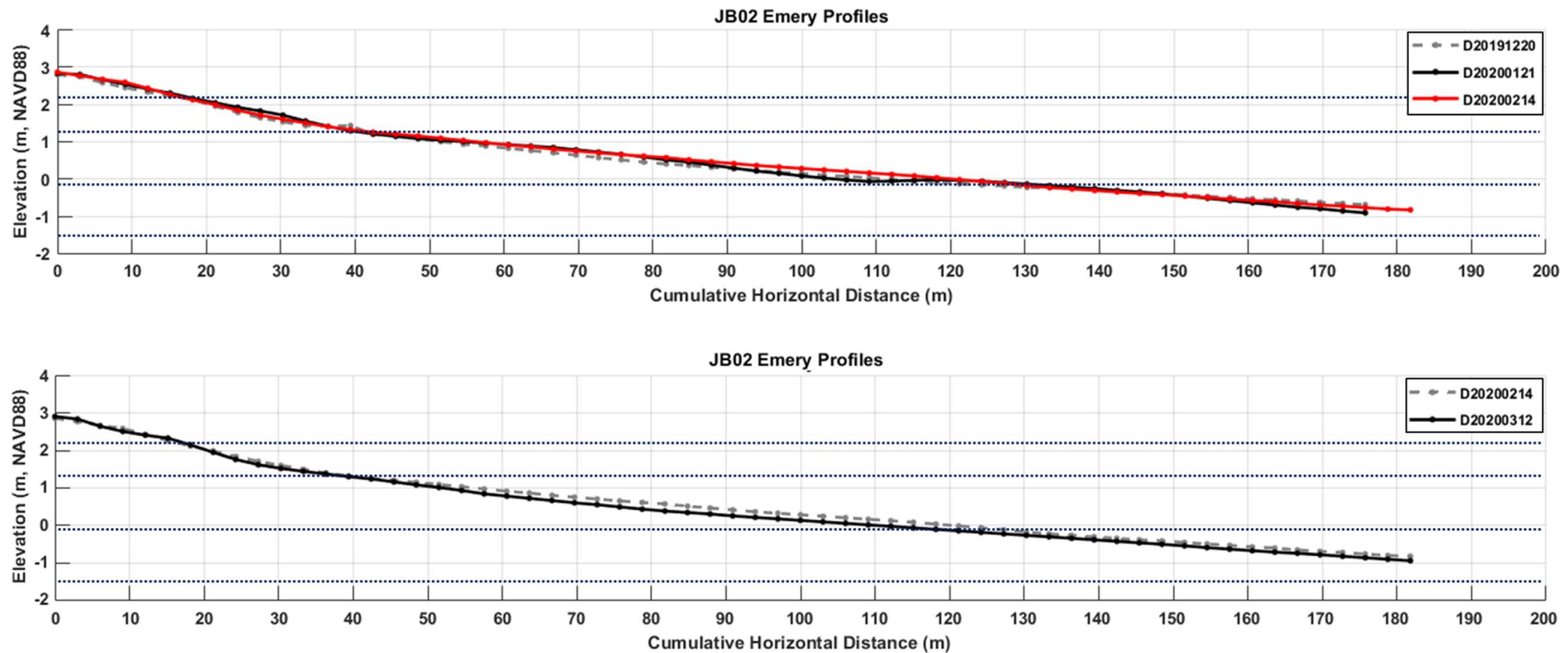
Appendix C(5): NHB01 beach profiles from January 27, 2018 to March 14, 2020.

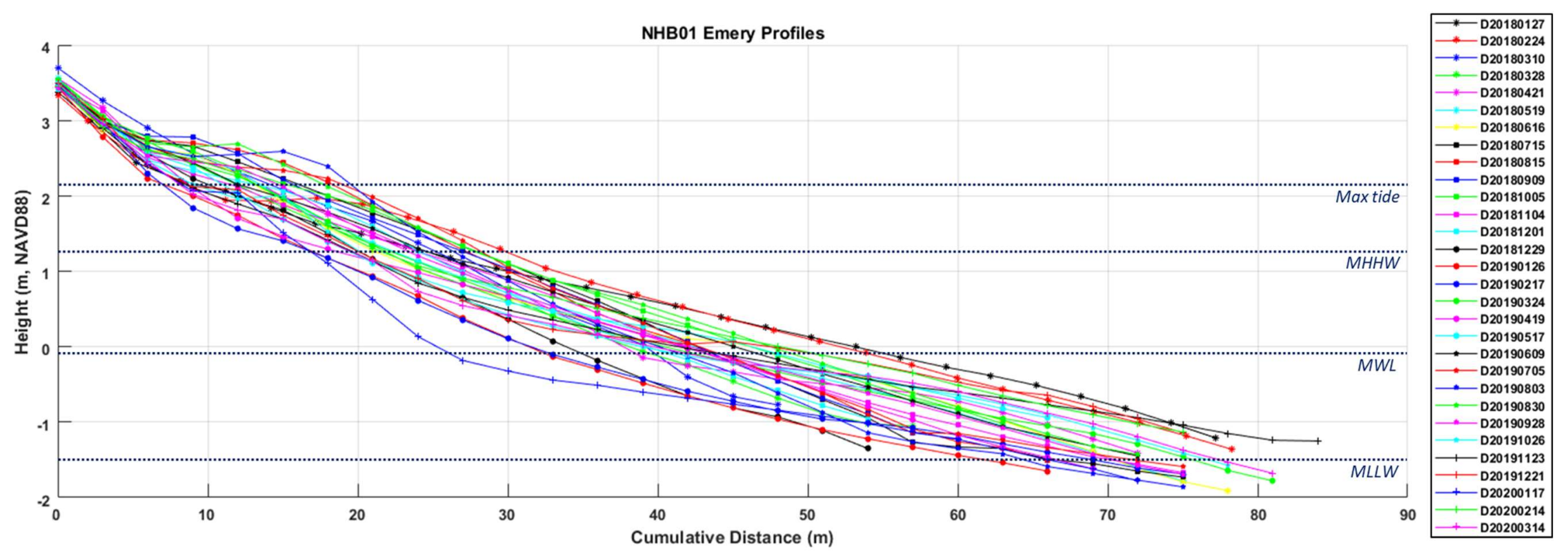



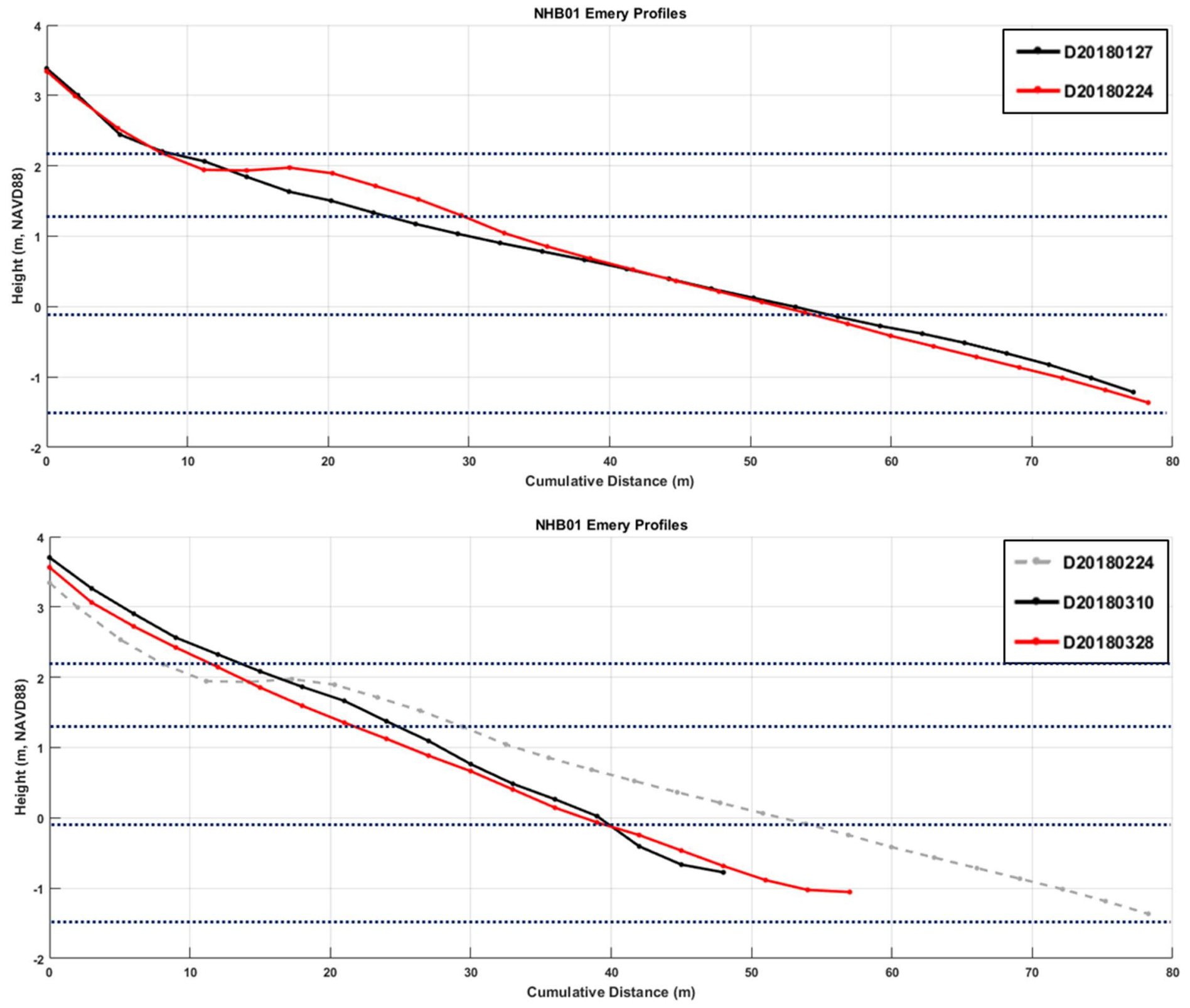

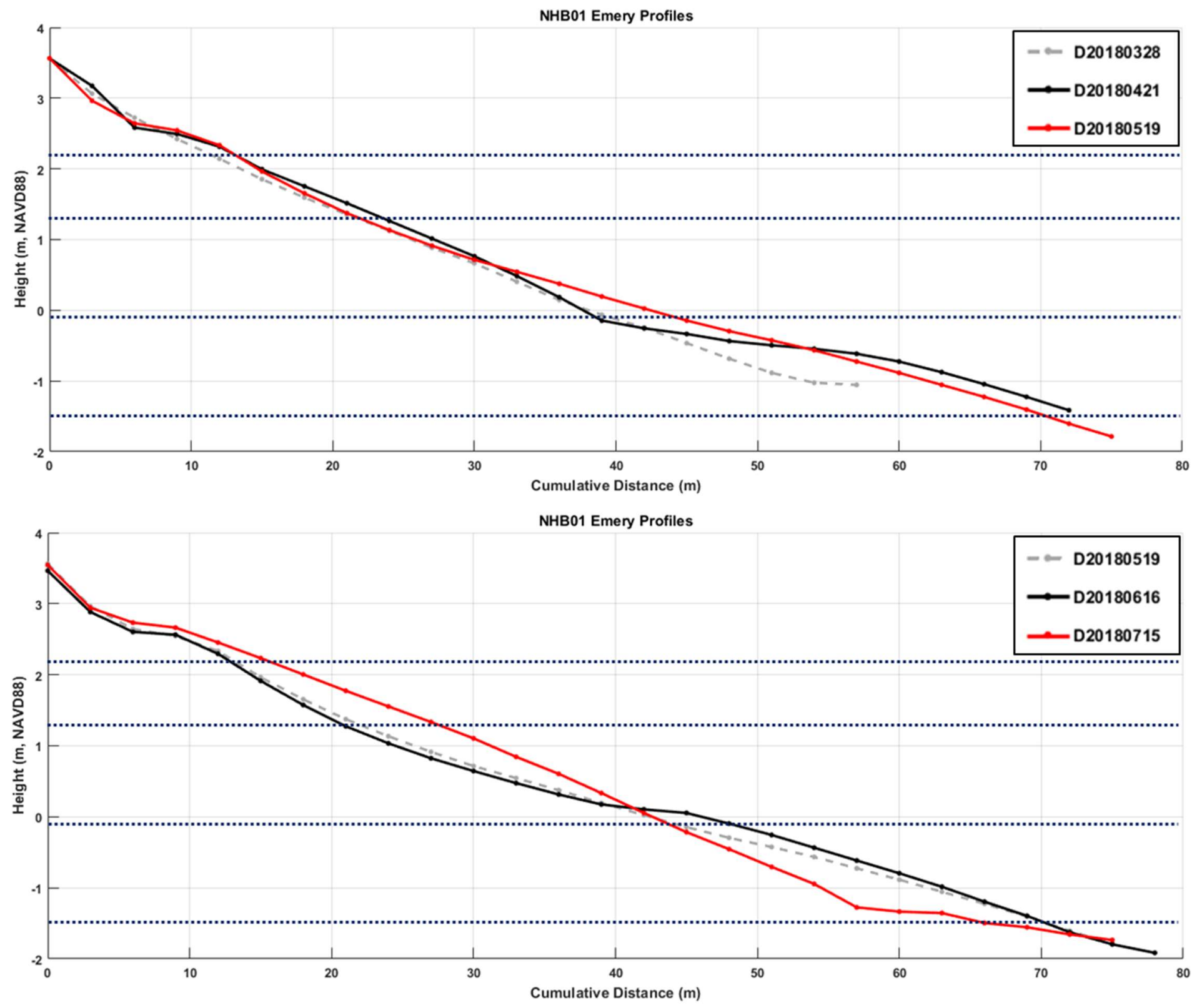

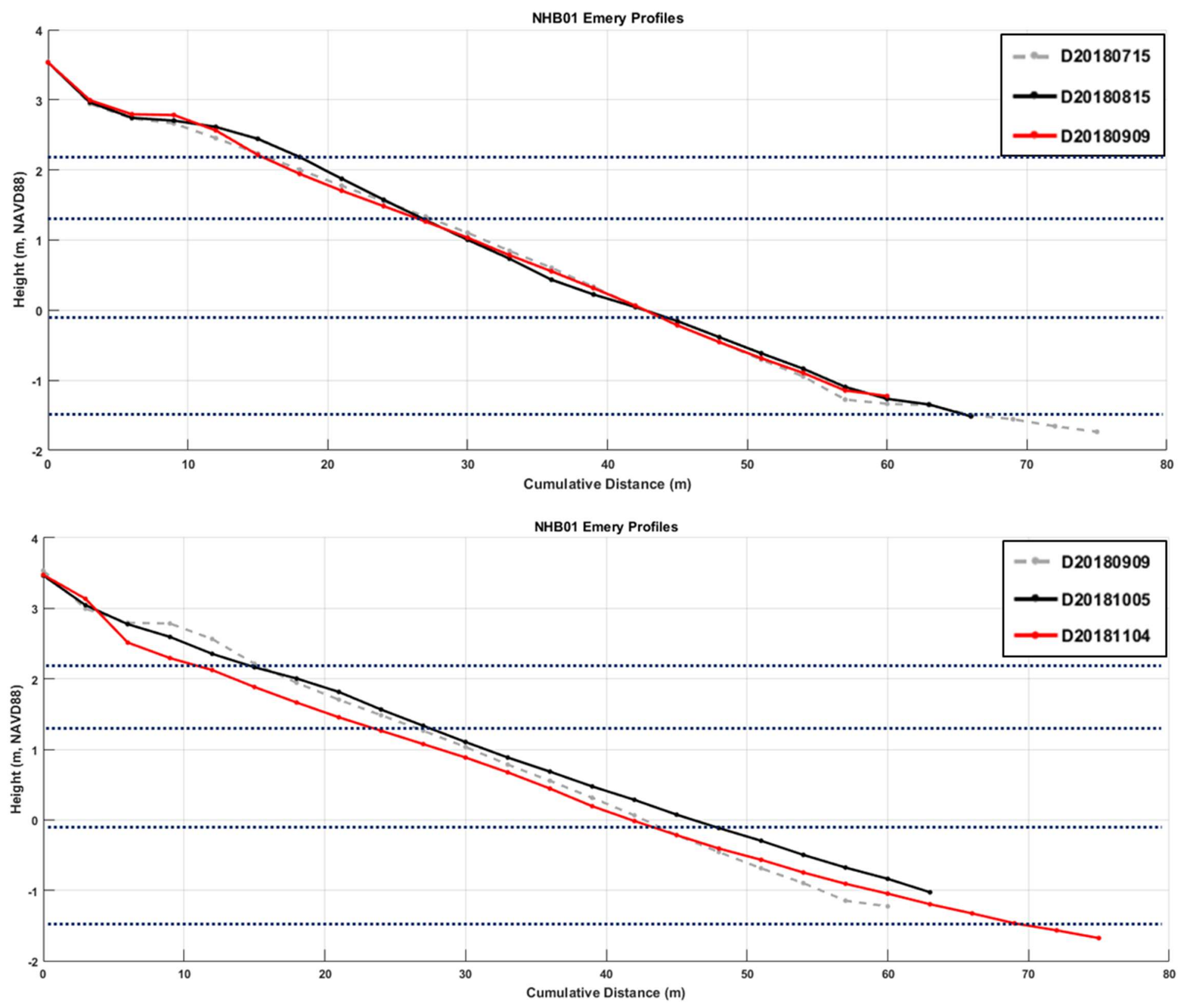

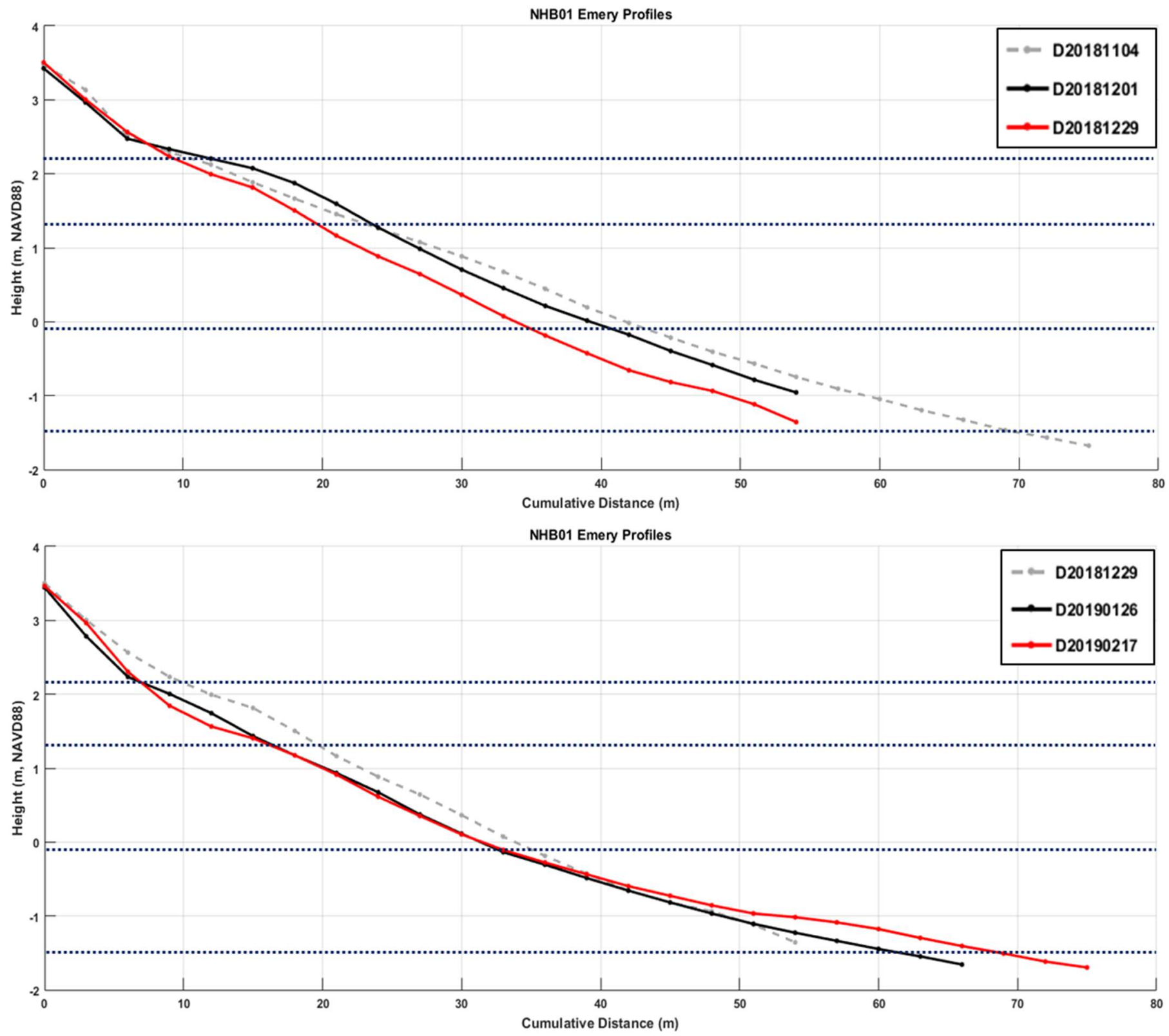


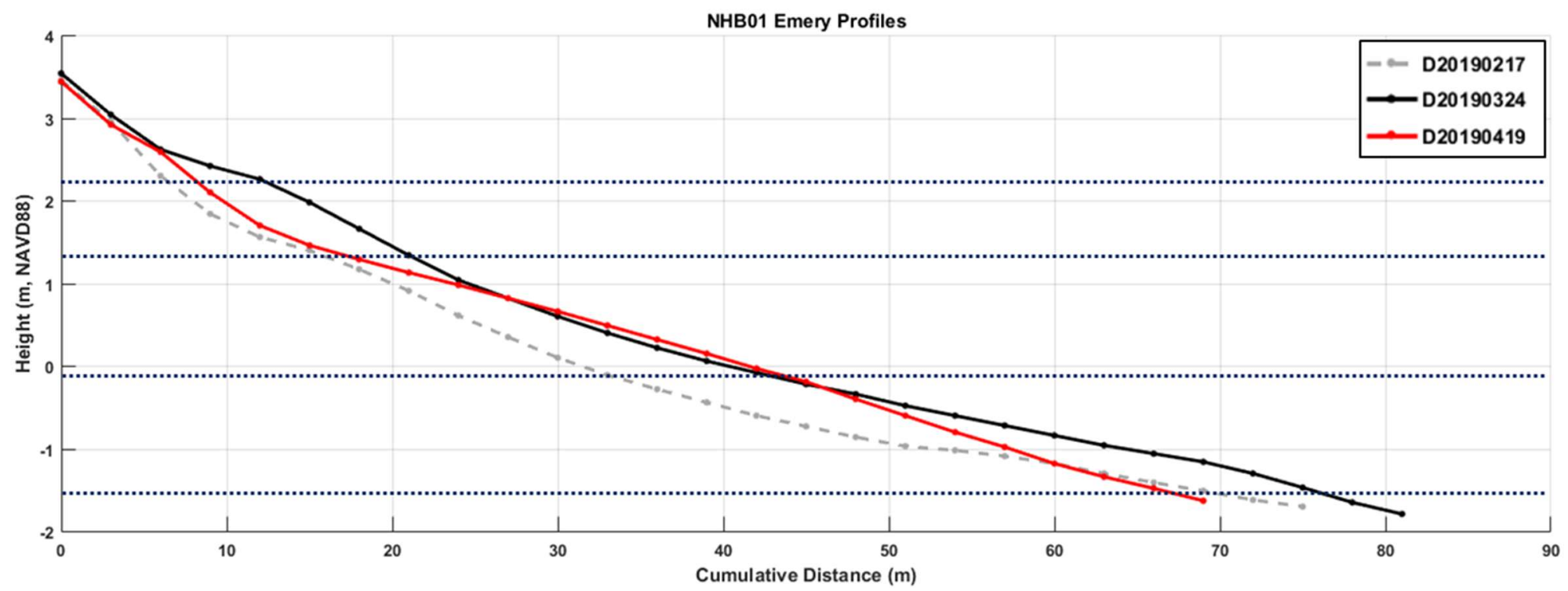

*The plot above extends to $90 \mathrm{~m}$, rather than $80 \mathrm{~m}$

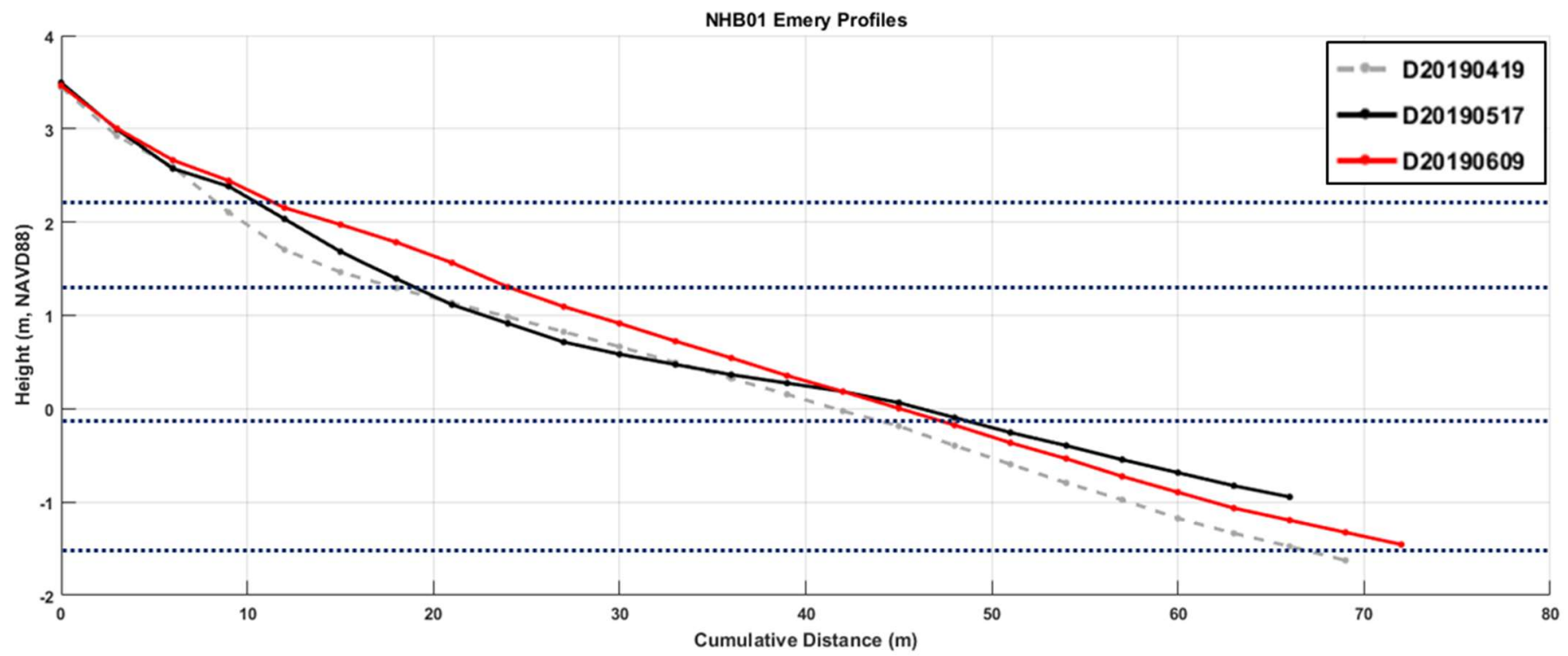



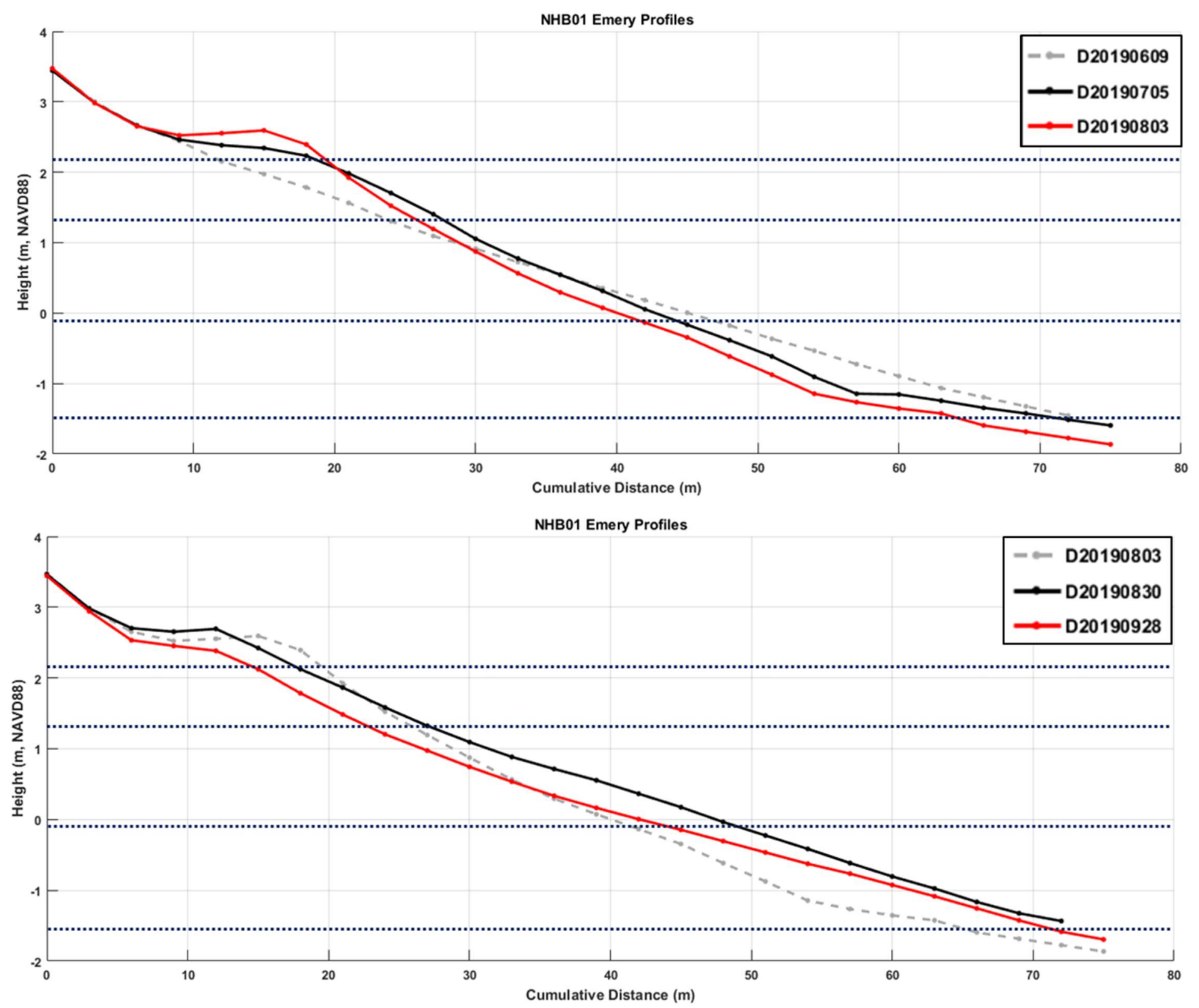

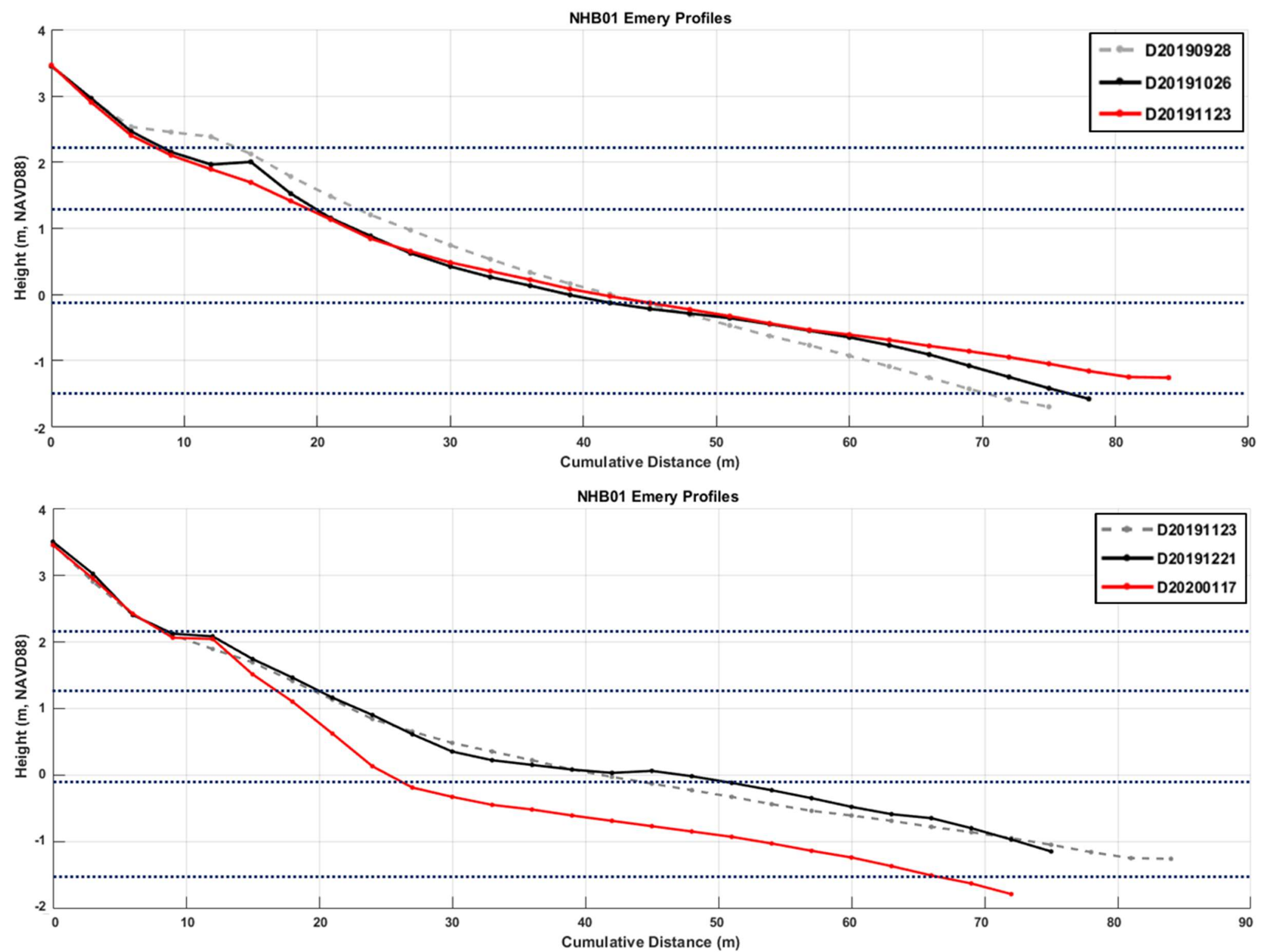

*The plots above extend to $90 \mathrm{~m}$, rather than $80 \mathrm{~m}$ 


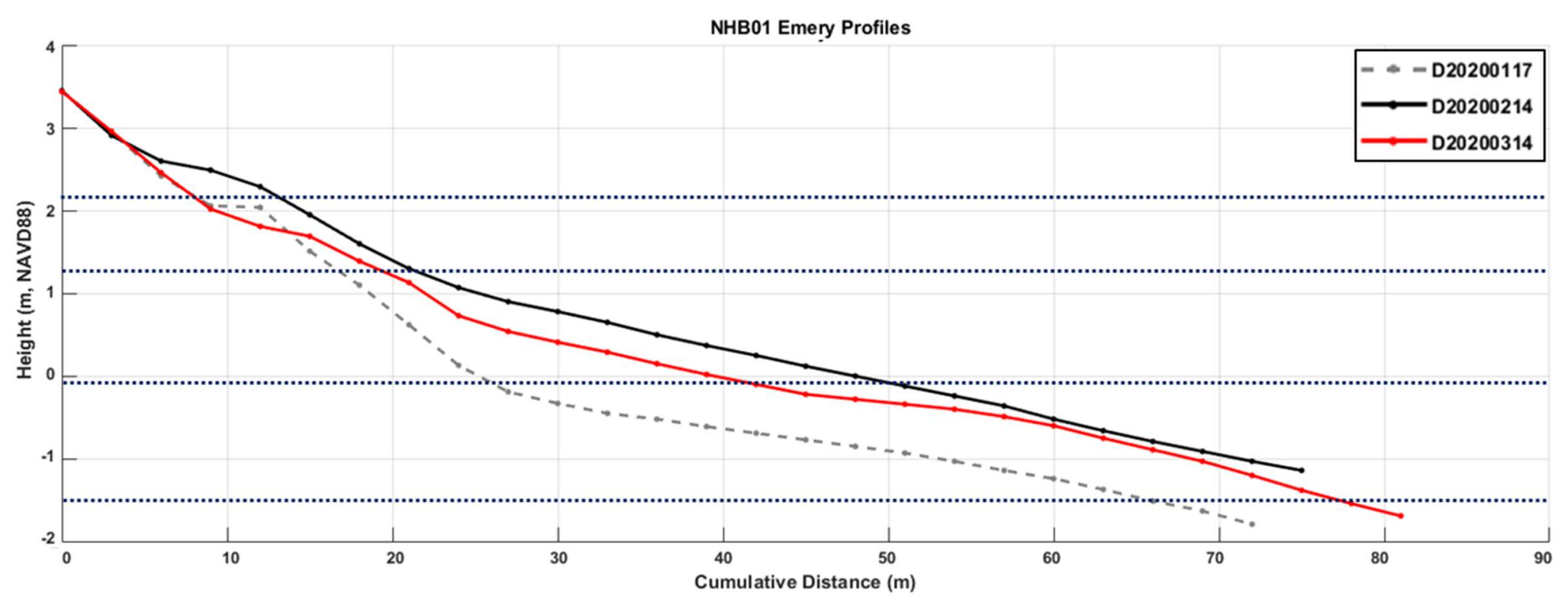

*The plot above extends to $90 \mathrm{~m}$, rather than $80 \mathrm{~m}$ 
Appendix C(6): NHB02 beach profiles from January 27, 2018 to March 14, 2020.

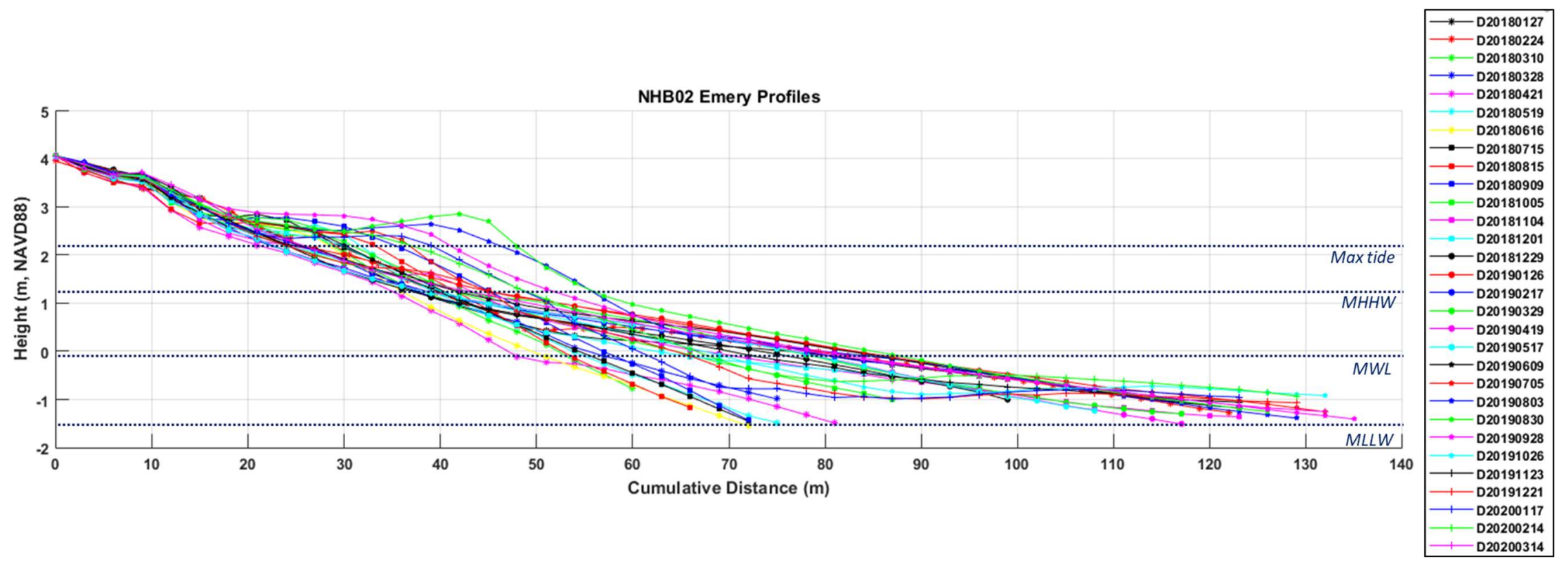



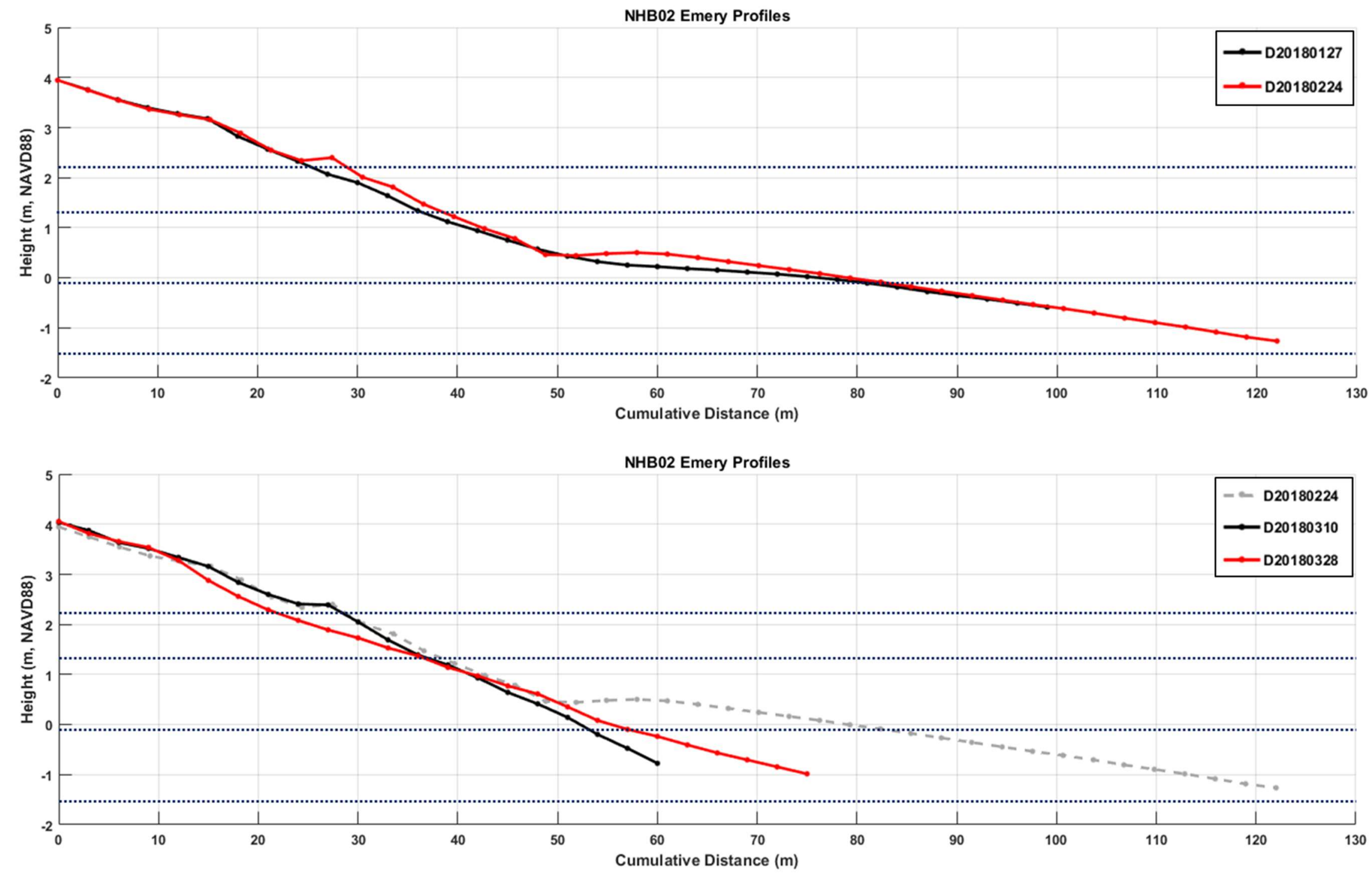

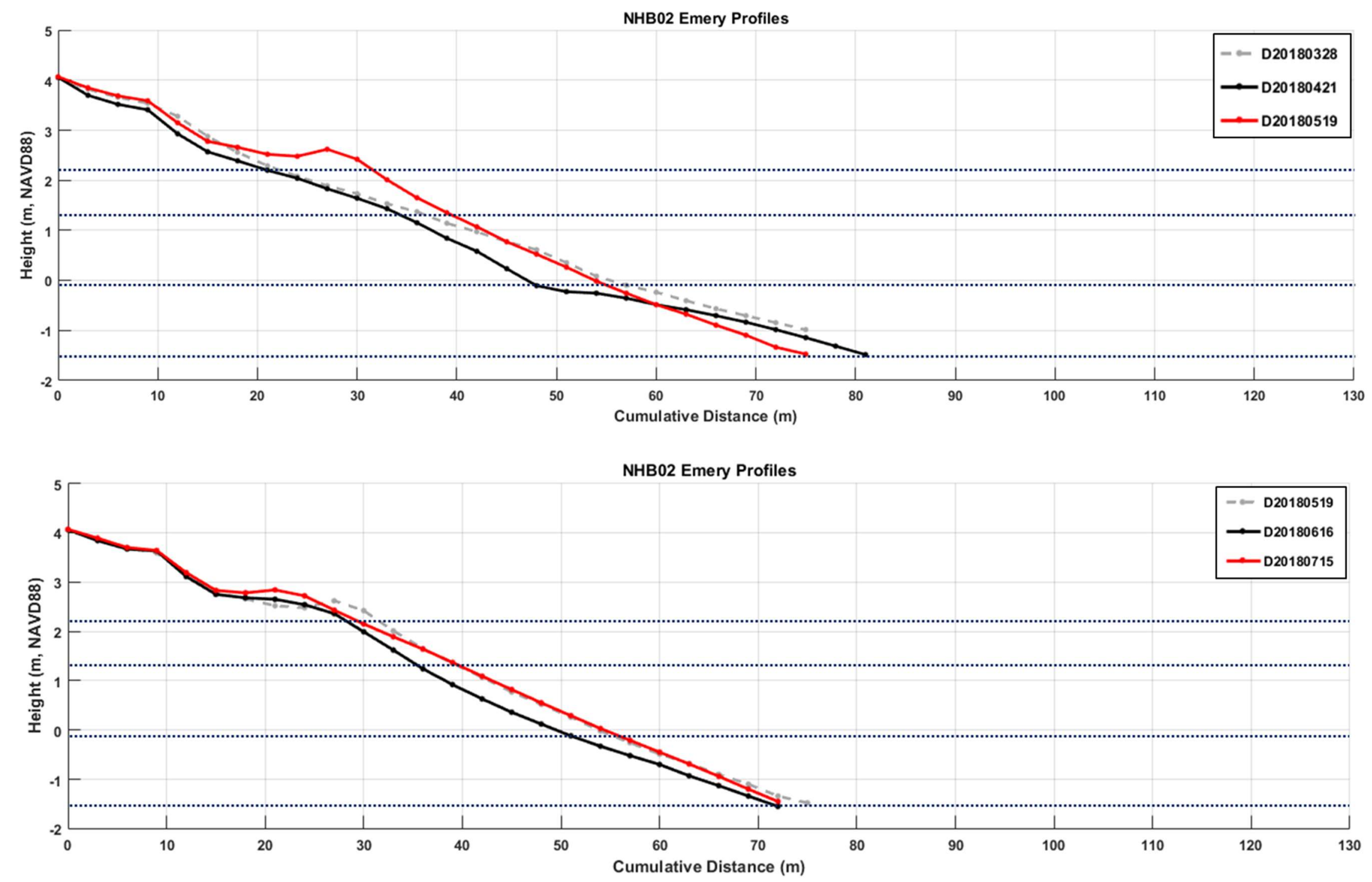

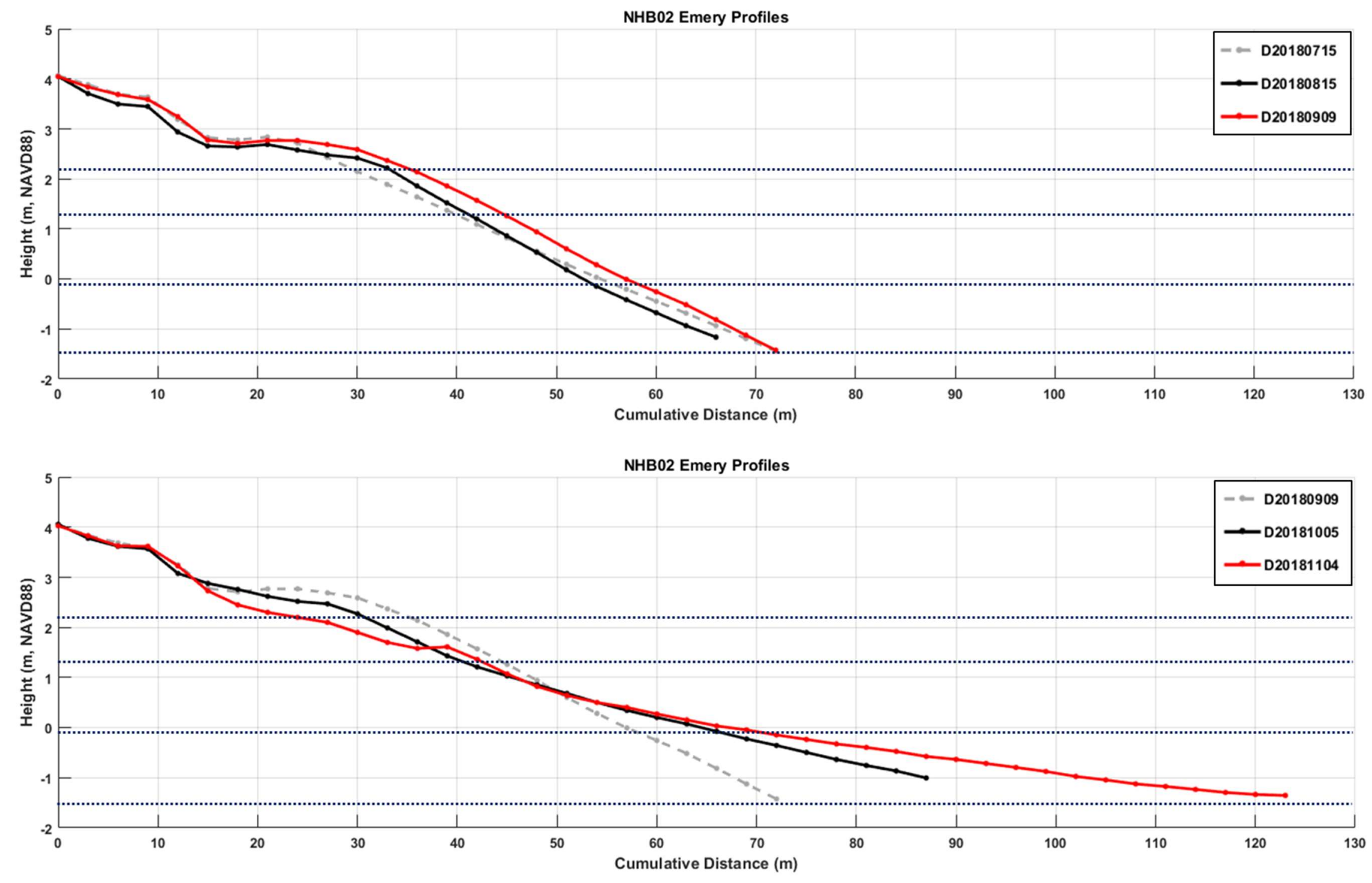

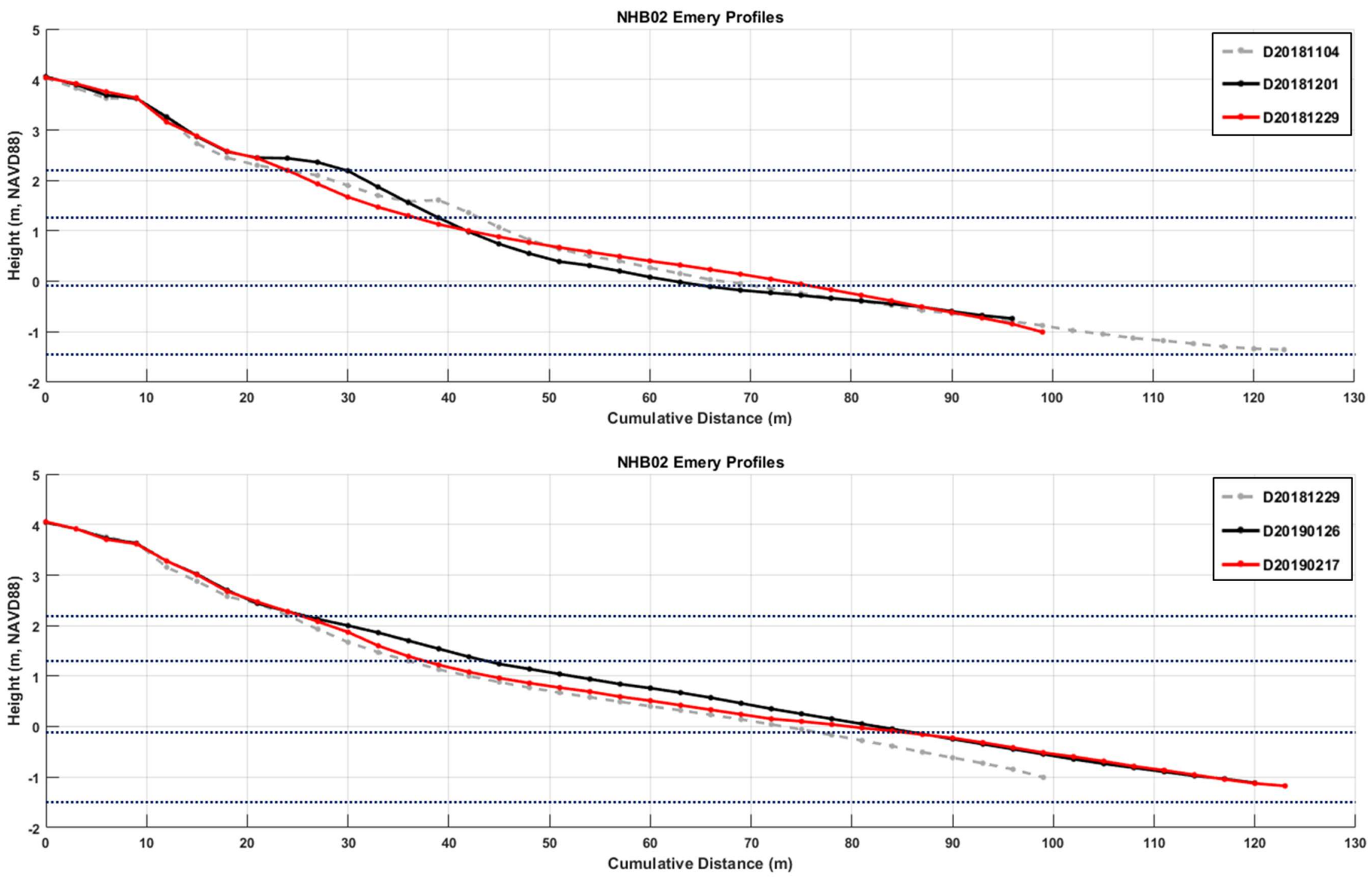

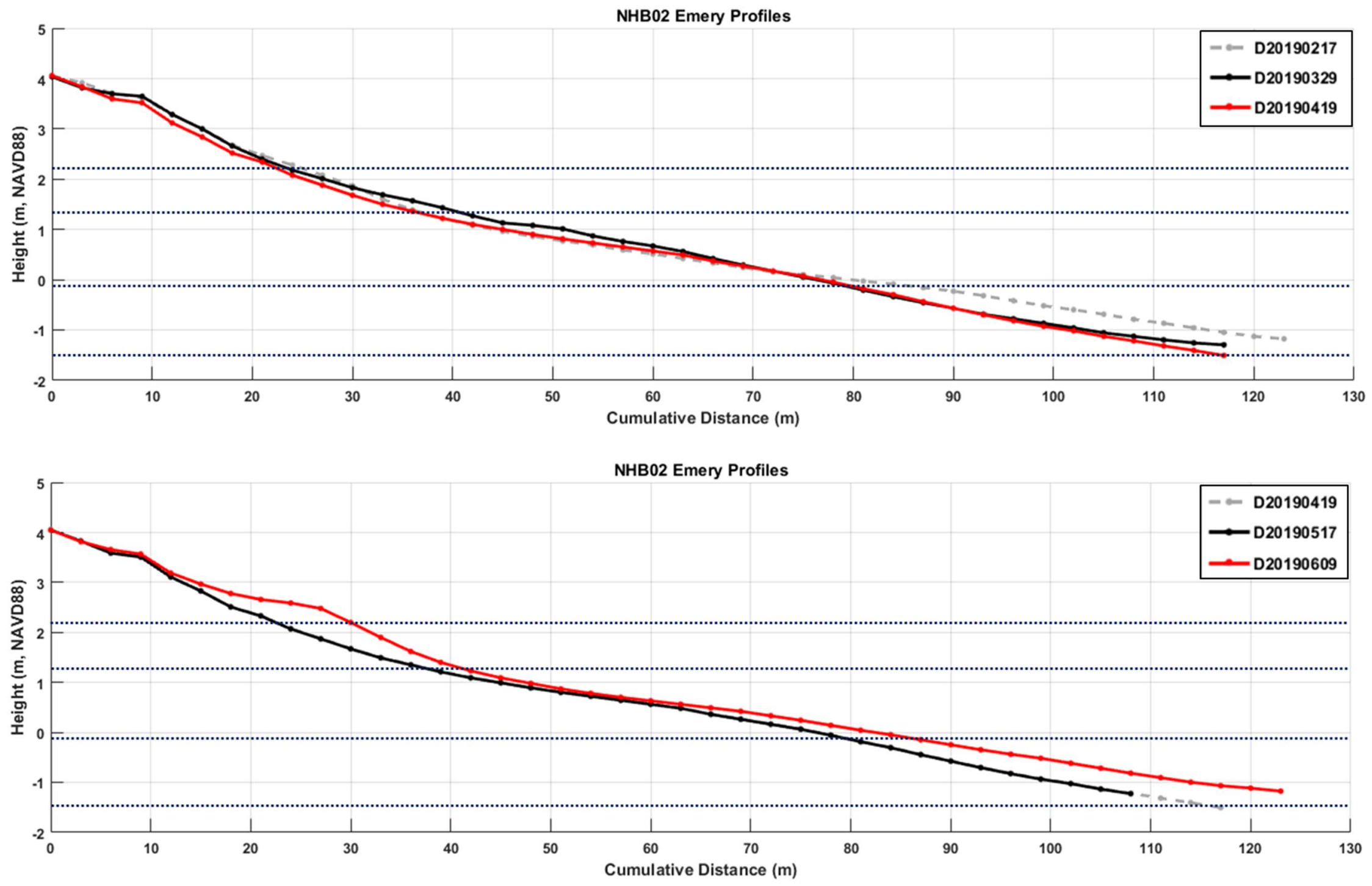

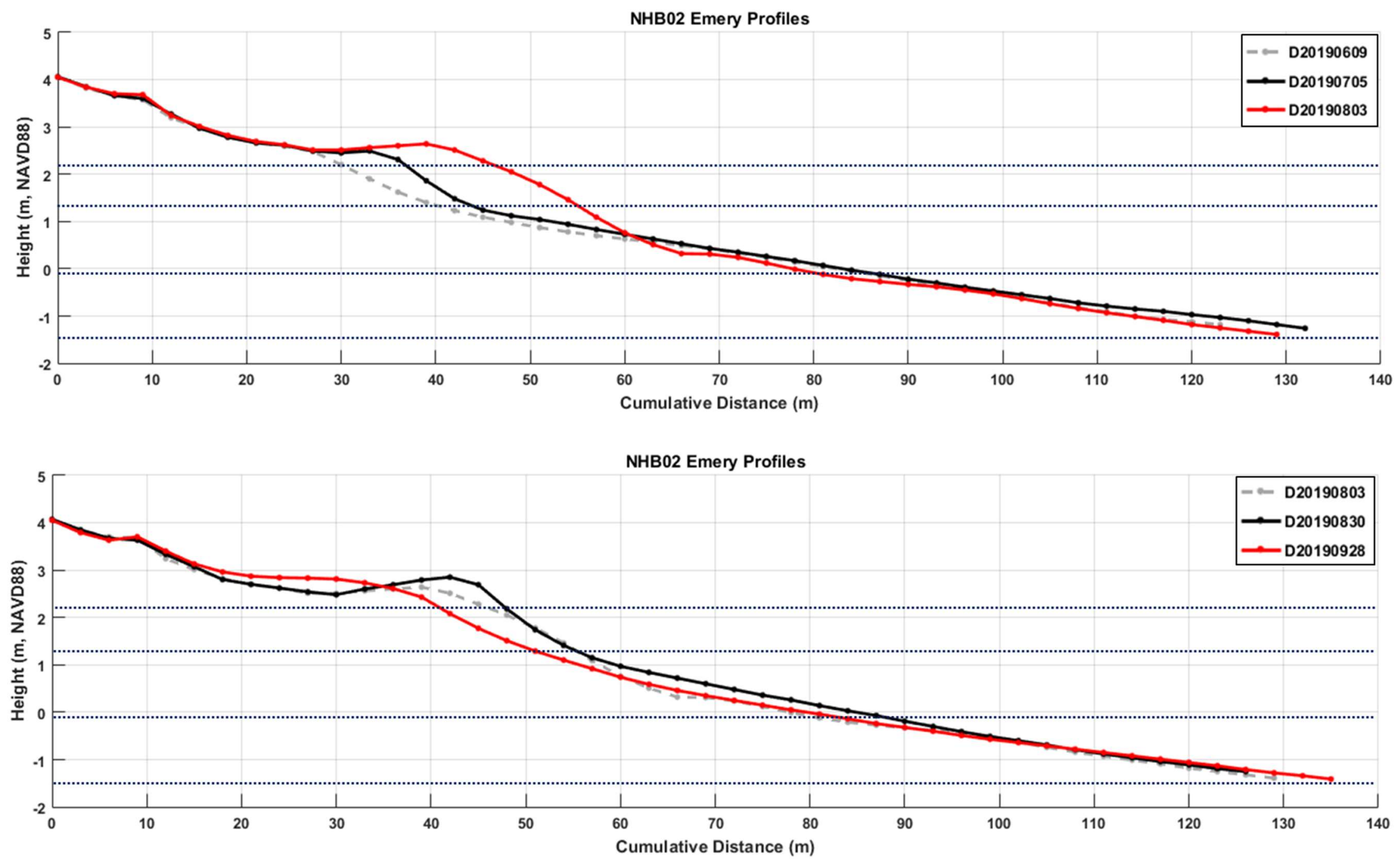

*The plots above extend to $140 \mathrm{~m}$, rather than $130 \mathrm{~m}$ 


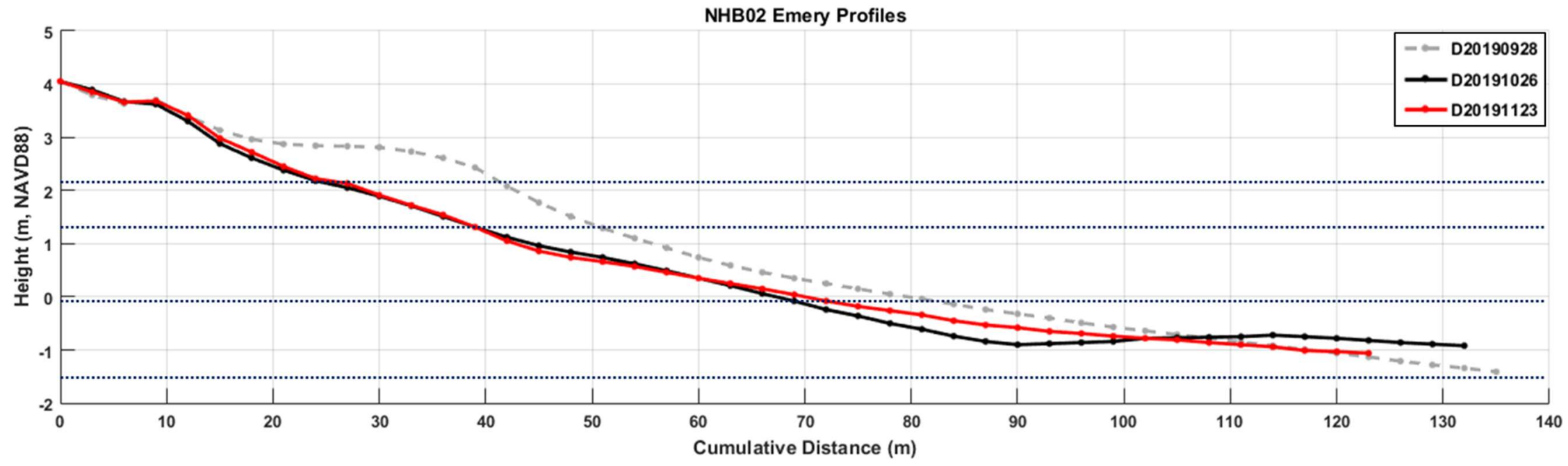

*The plot above extends to $140 \mathrm{~m}$, rather than $130 \mathrm{~m}$

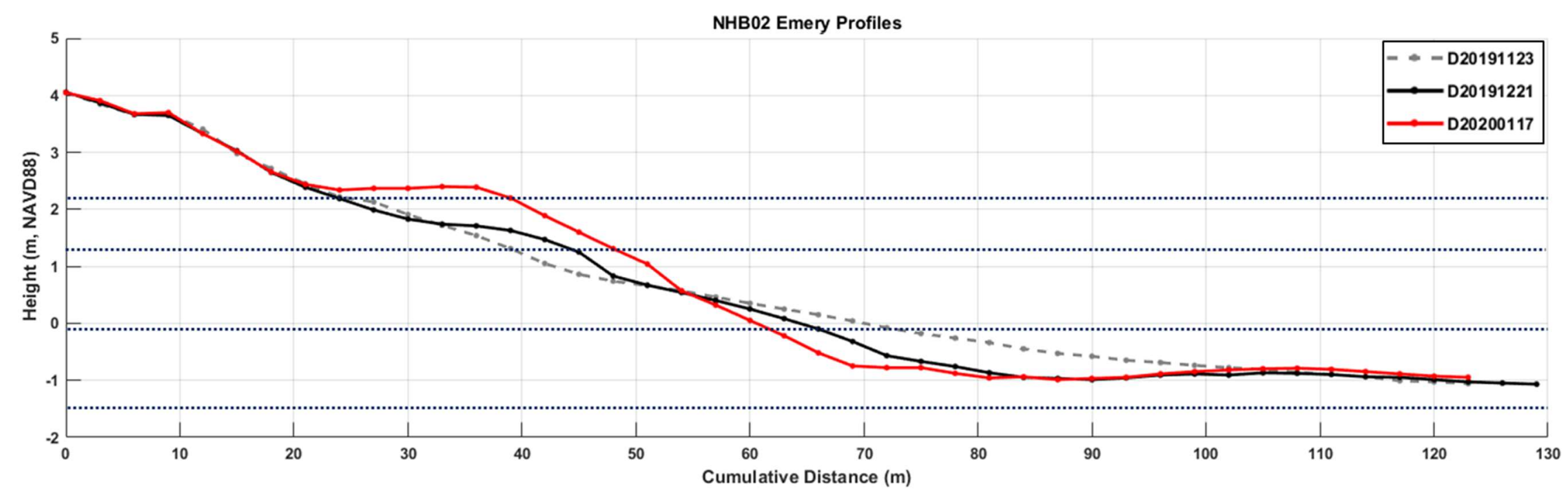




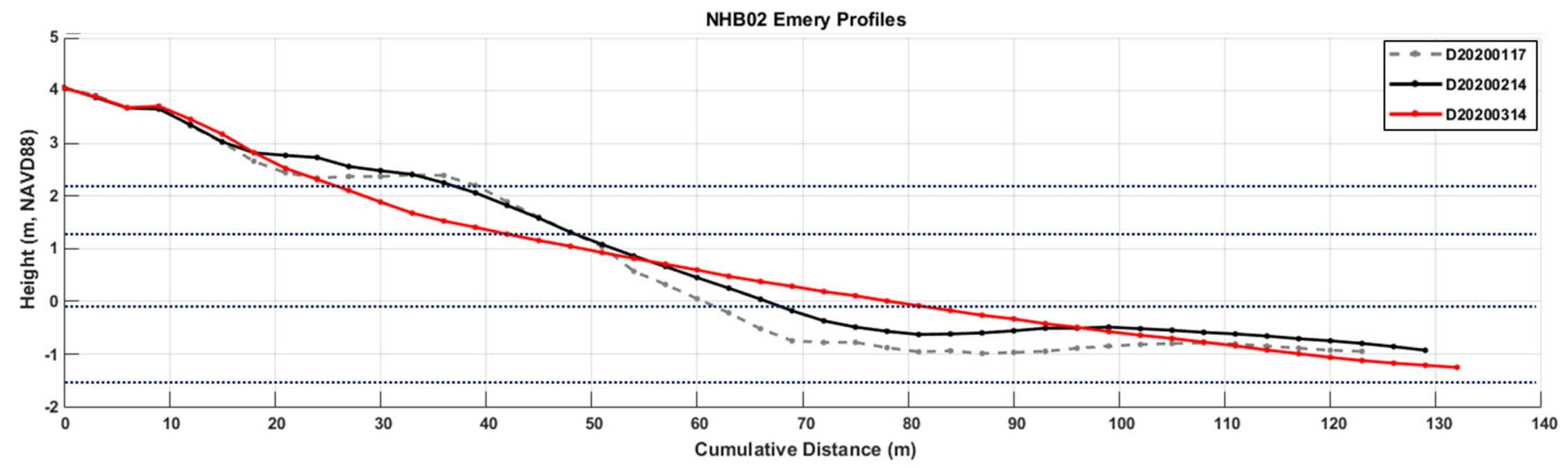

*The plot above extends to $140 \mathrm{~m}$, rather than $130 \mathrm{~m}$ 
Appendix C(7): NB01 beach profiles from January 27, 2018 to March 13, 2020.

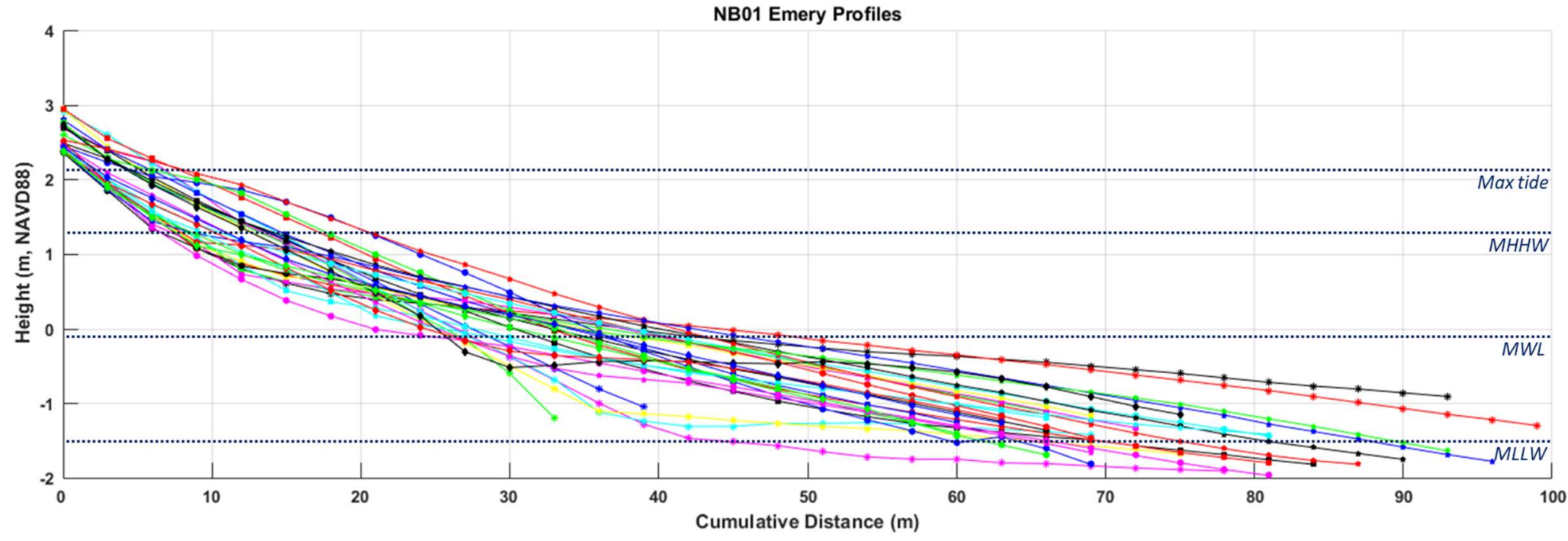



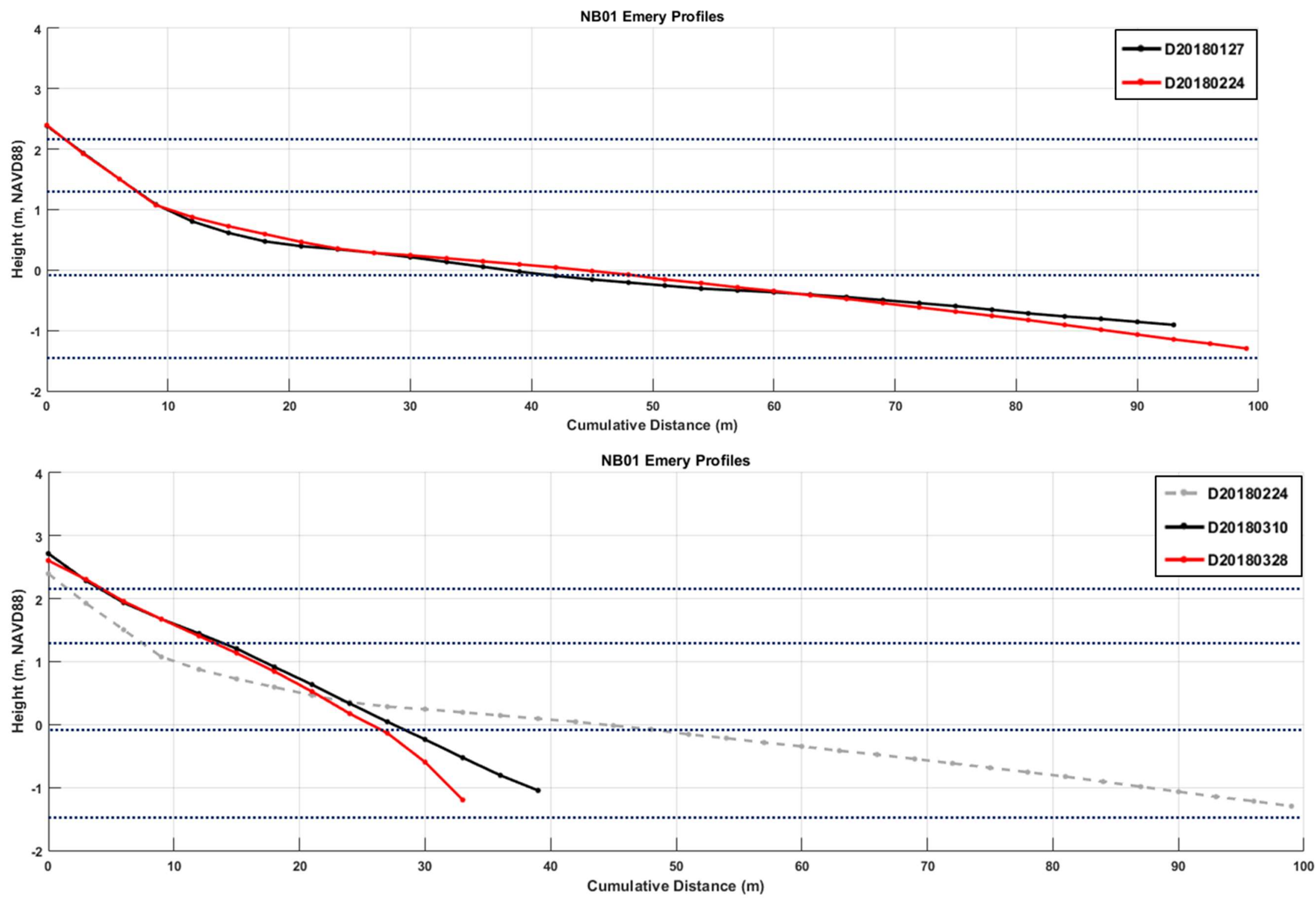

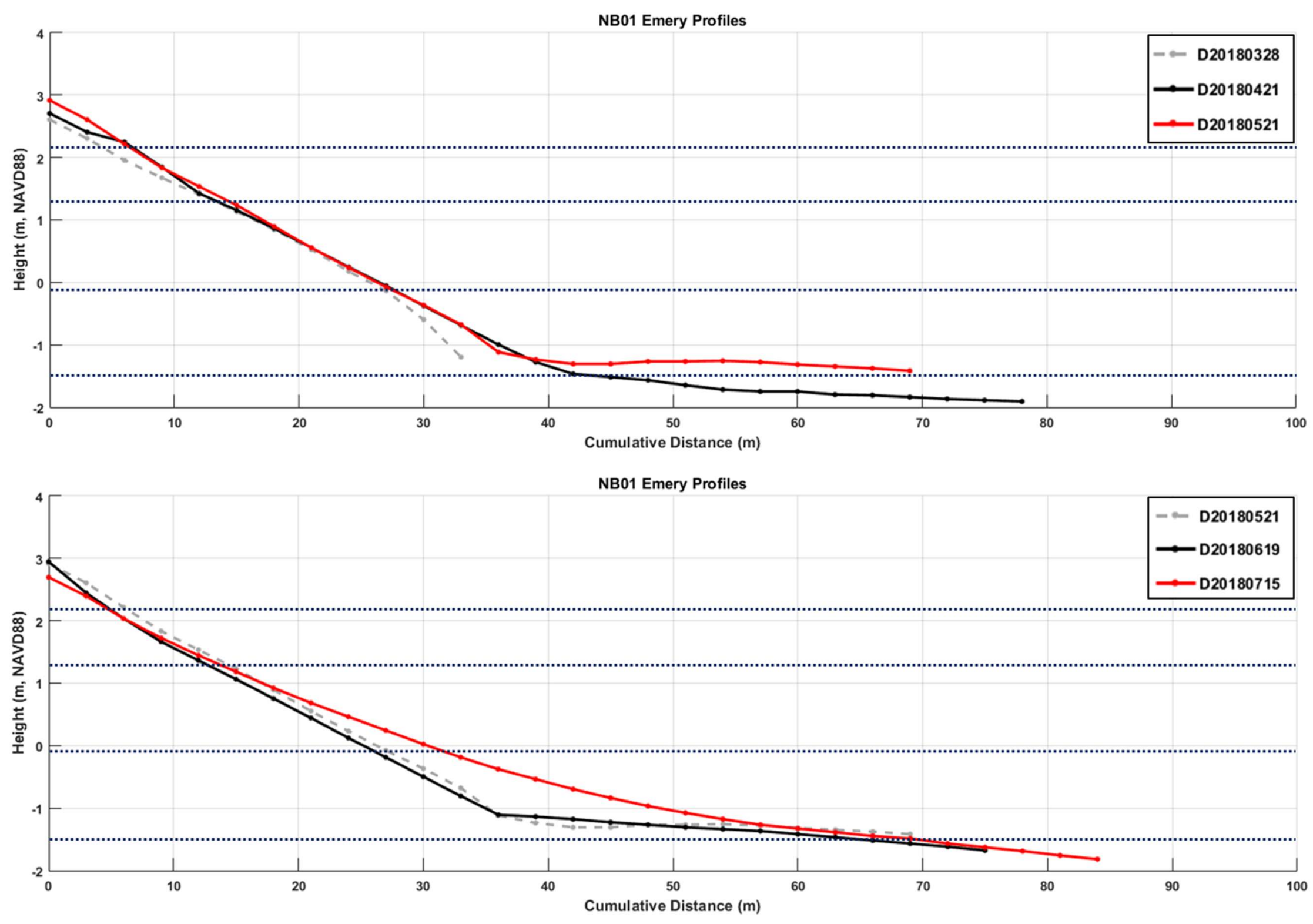

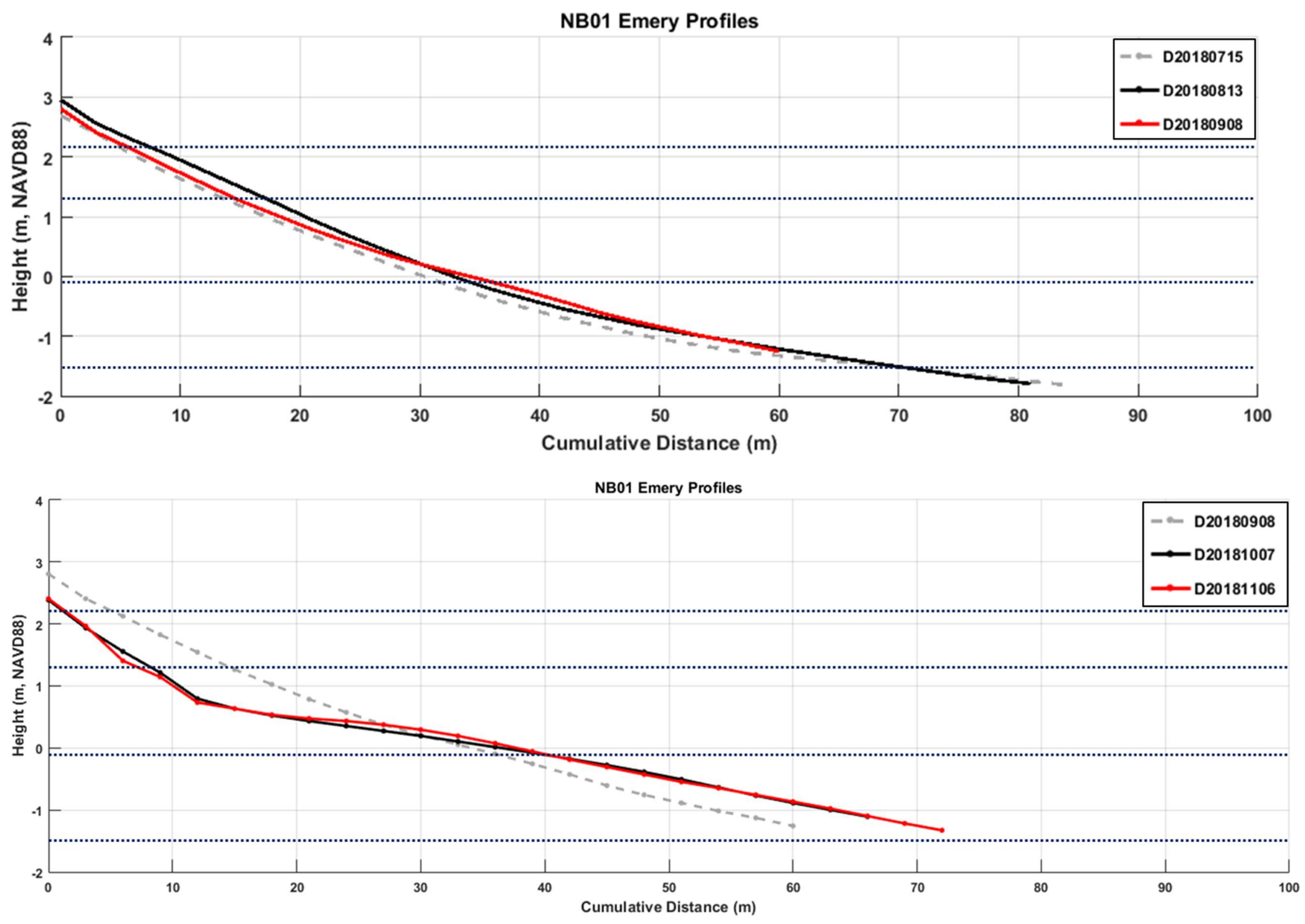

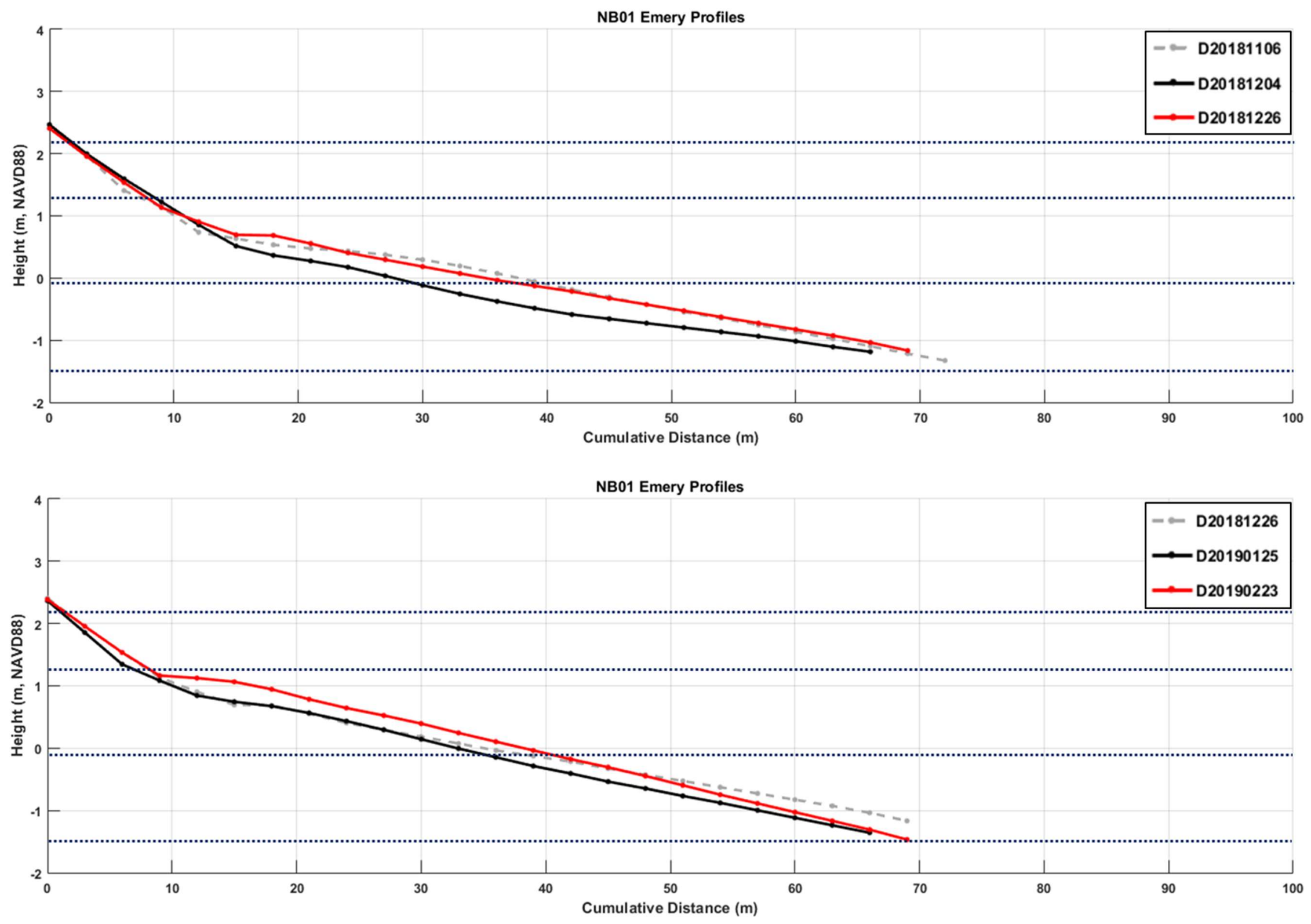

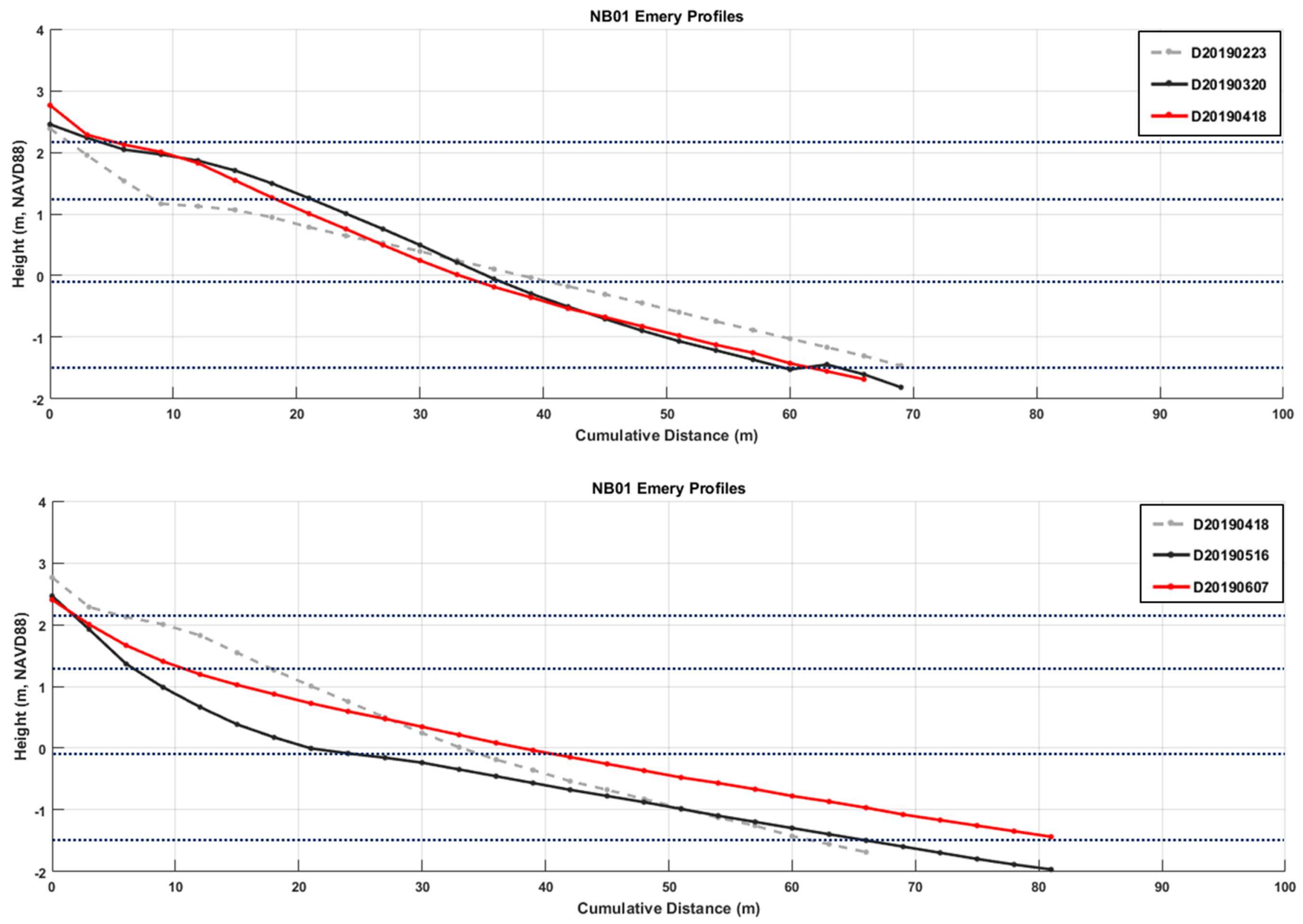

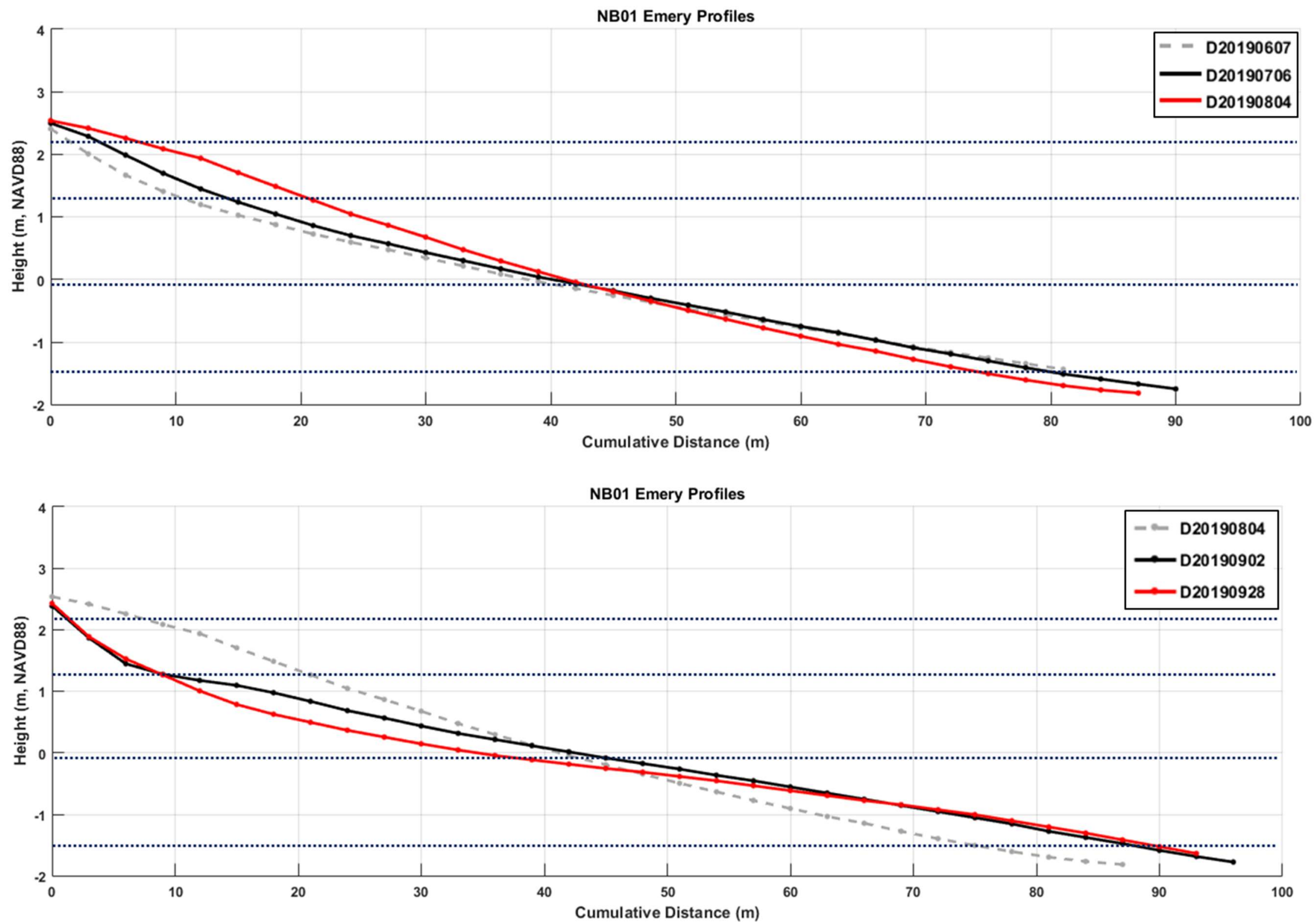

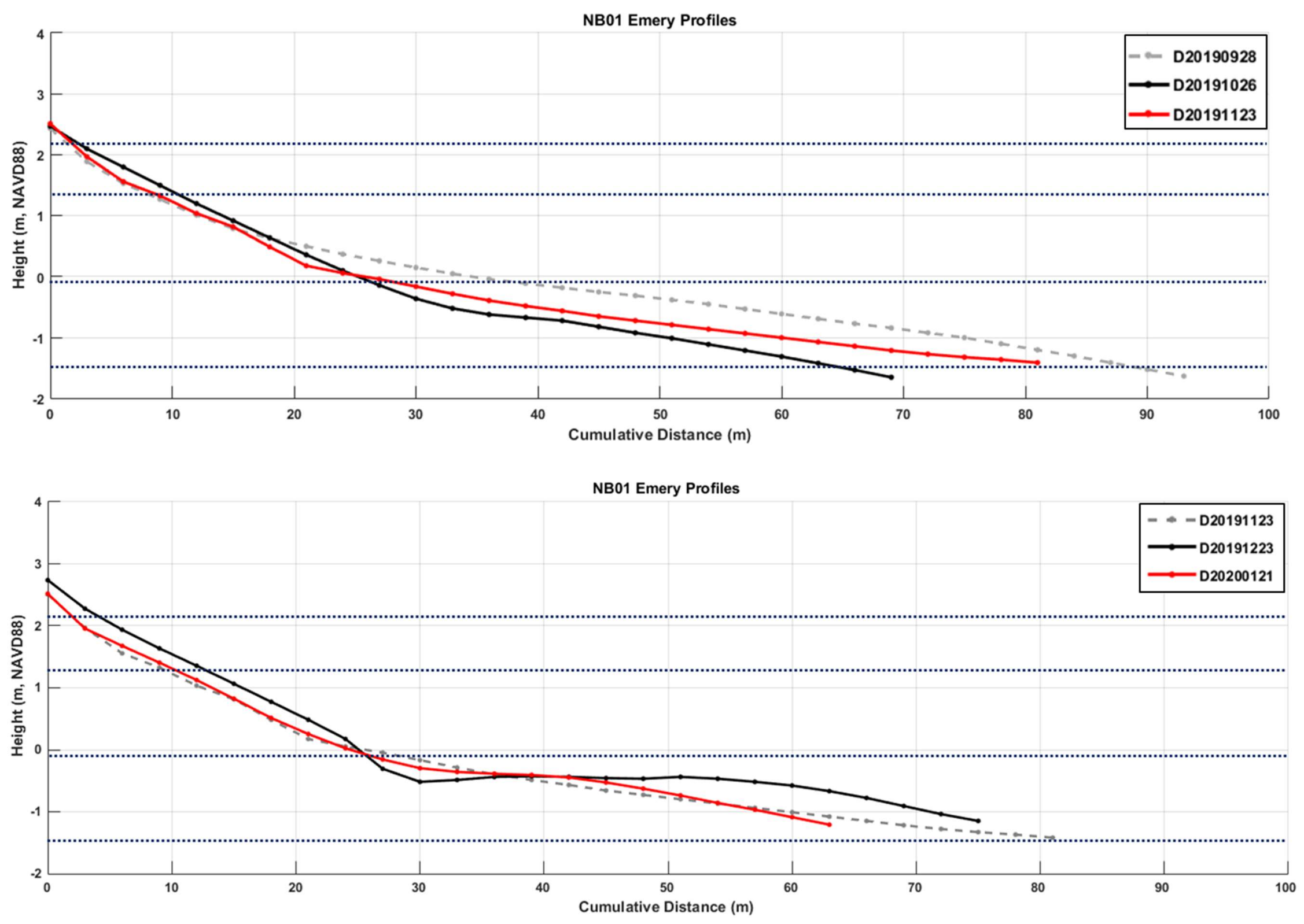


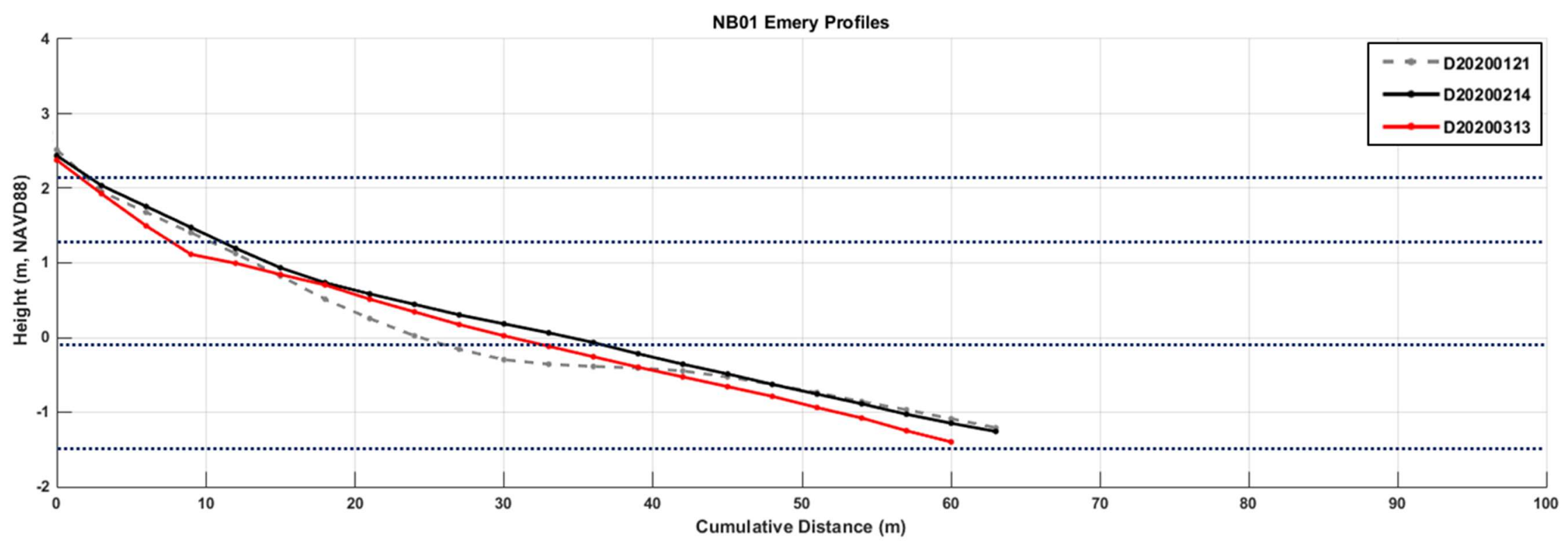


Appendix C(8): NB02 beach profiles from April 18, 2018 to March 13, 2020.
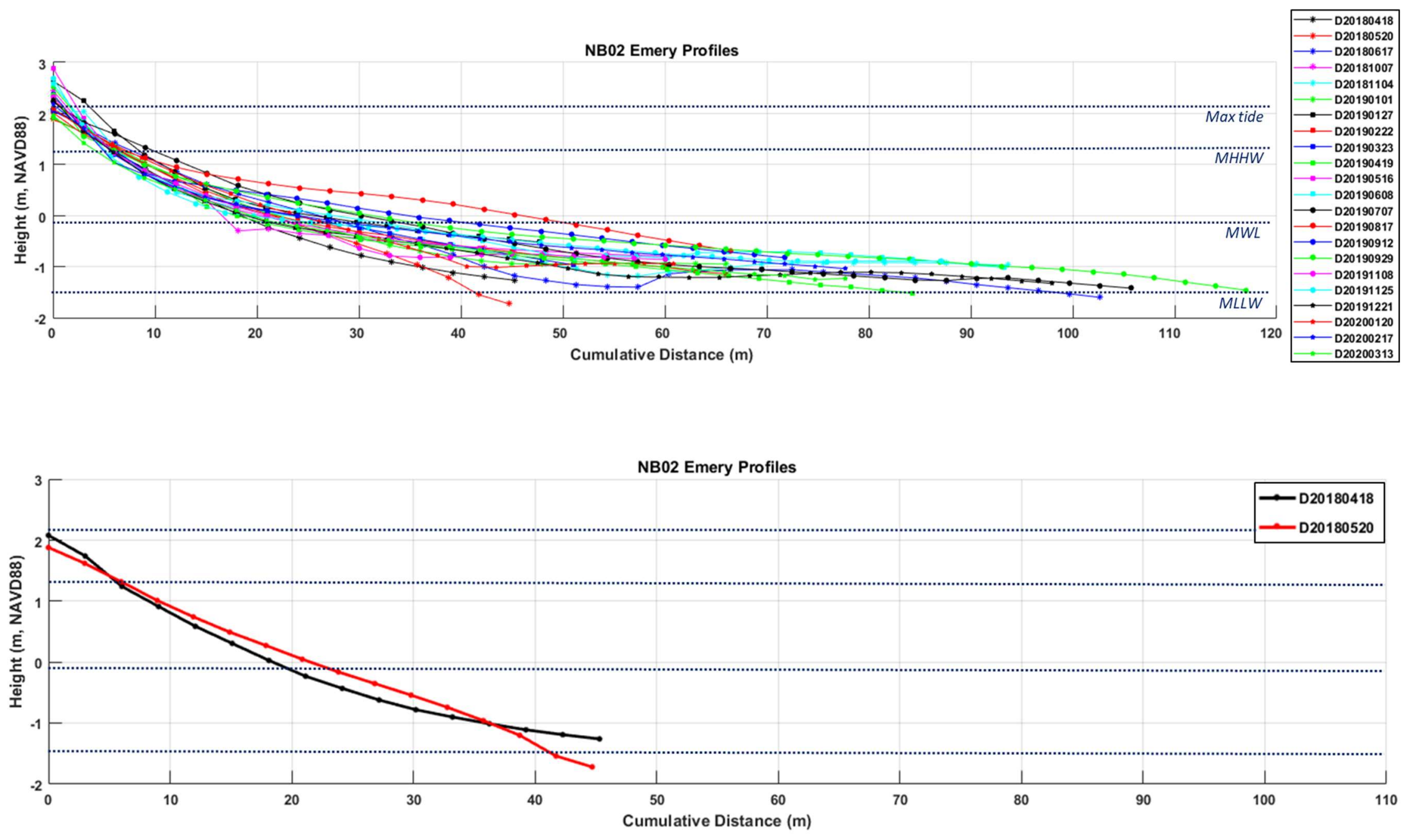

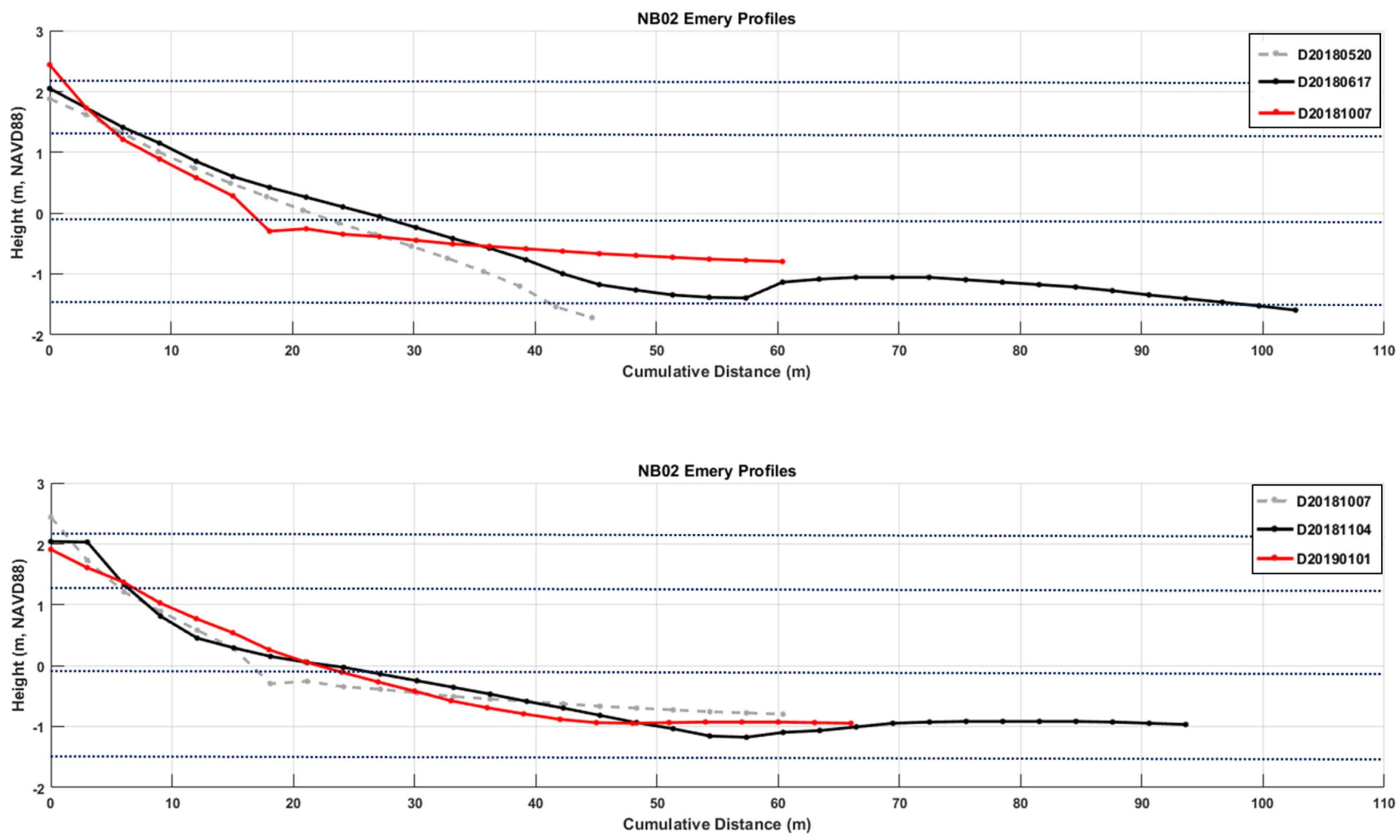

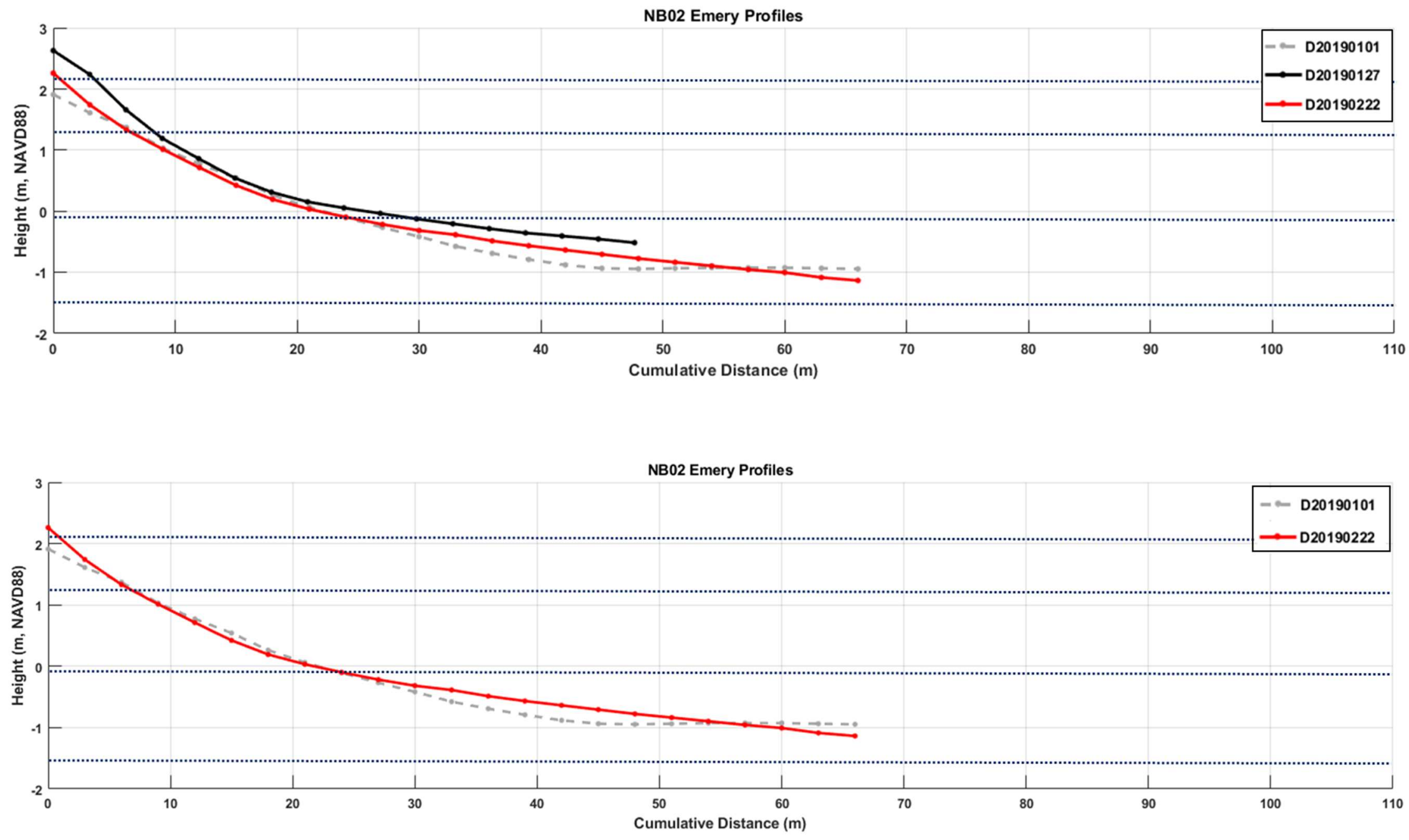

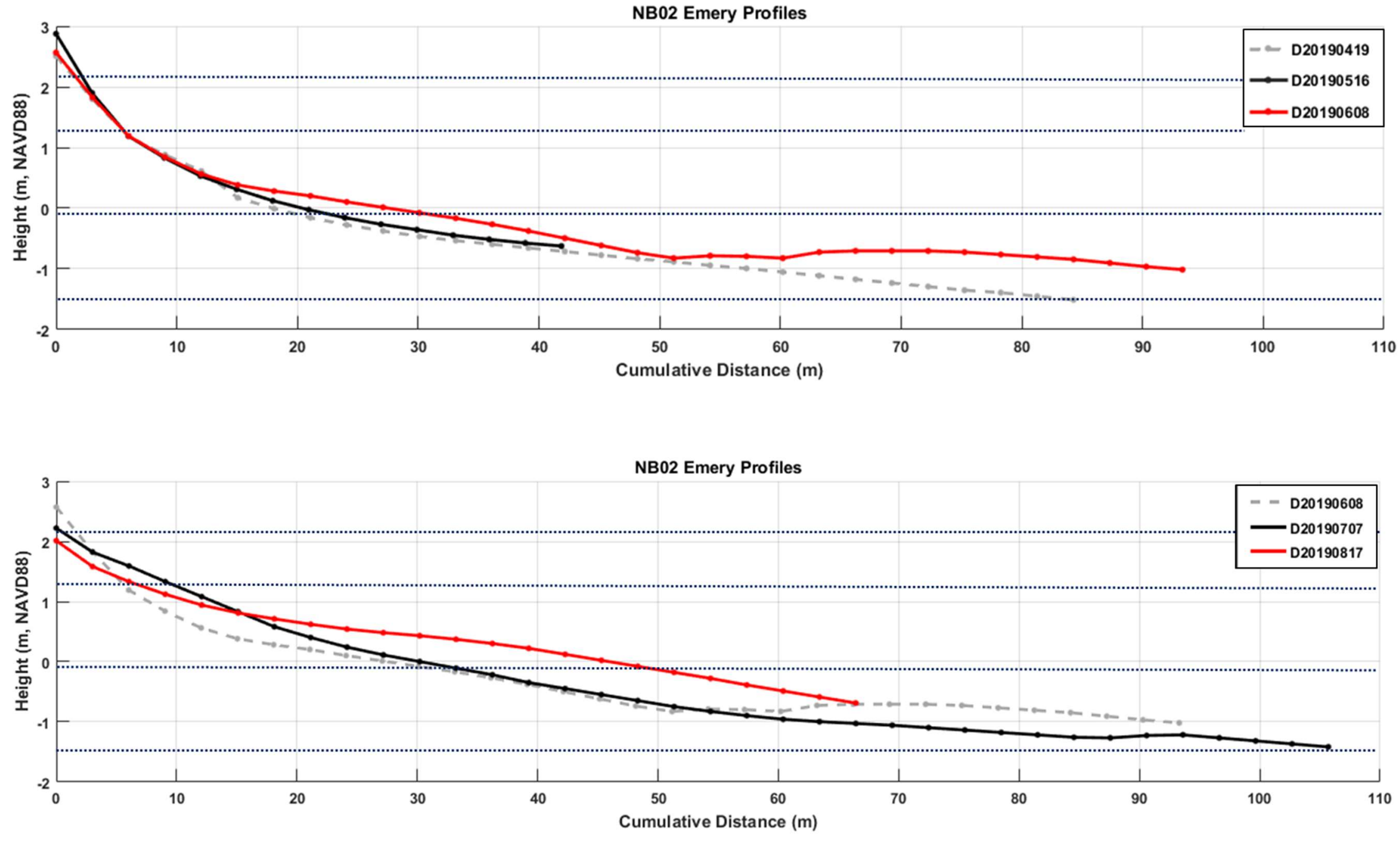

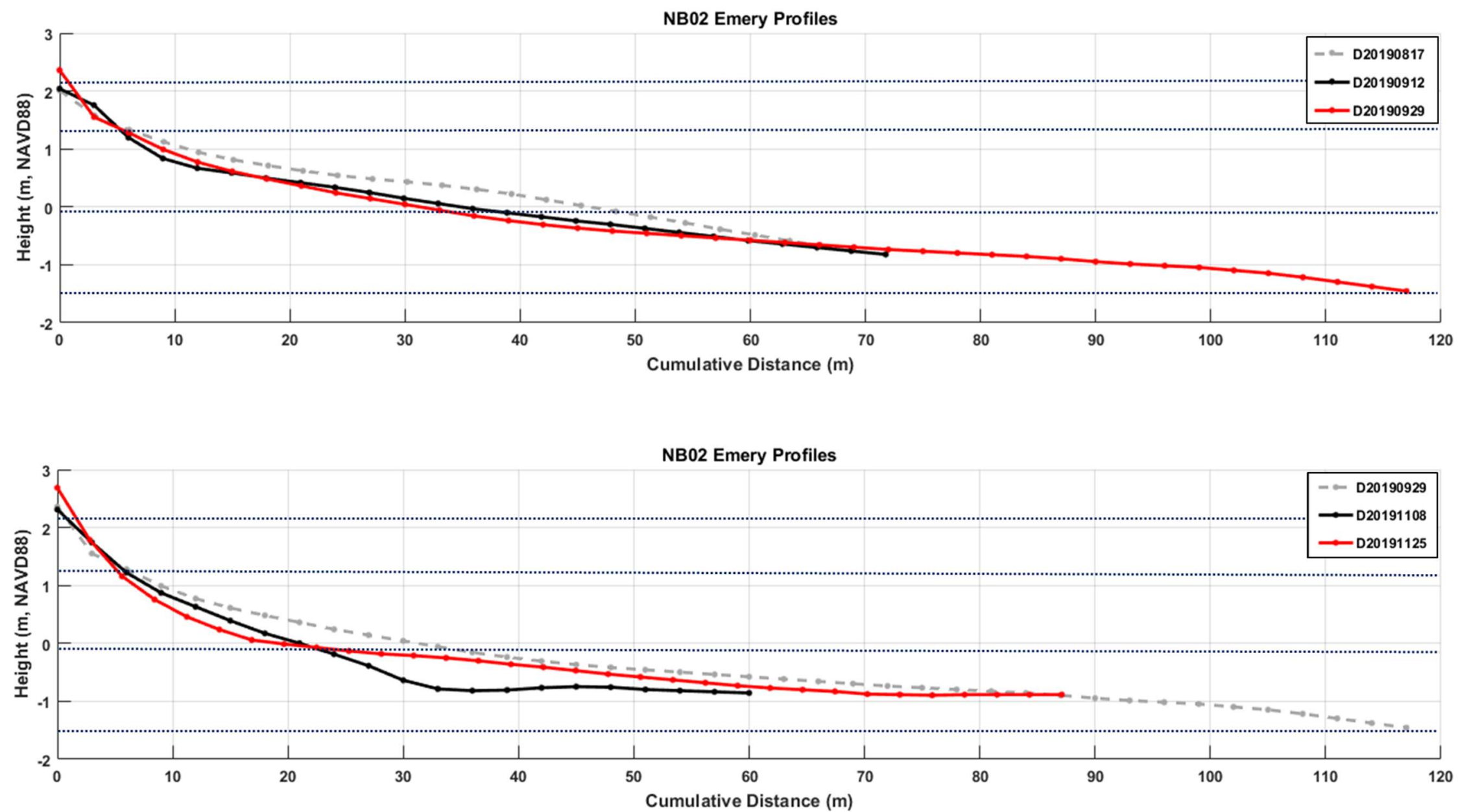

*These plots extend to $120 \mathrm{~m}$, rather than $110 \mathrm{~m}$ 

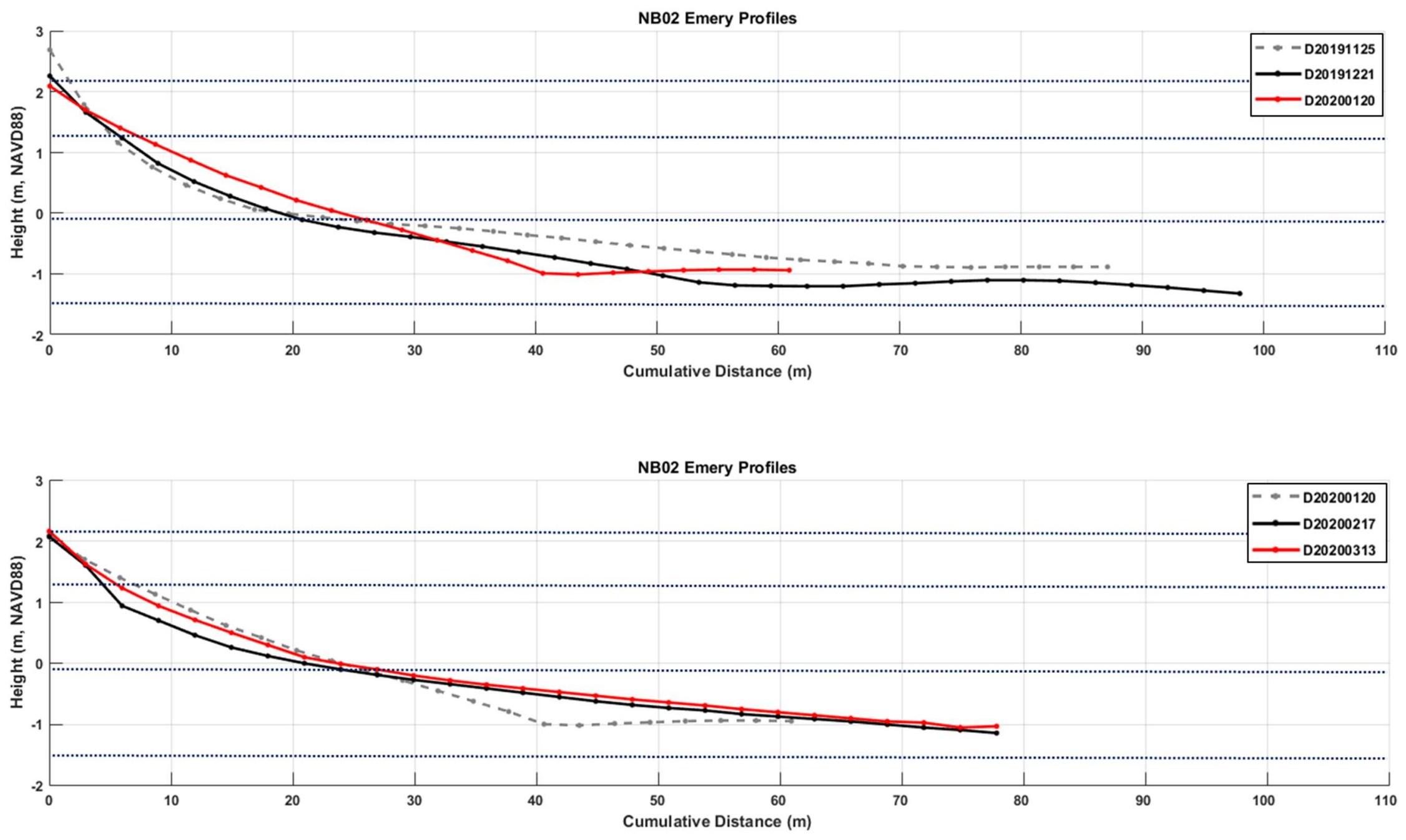
Appendix C(9): HB02 beach profiles from December 9, 2016 to March 12, 2020.

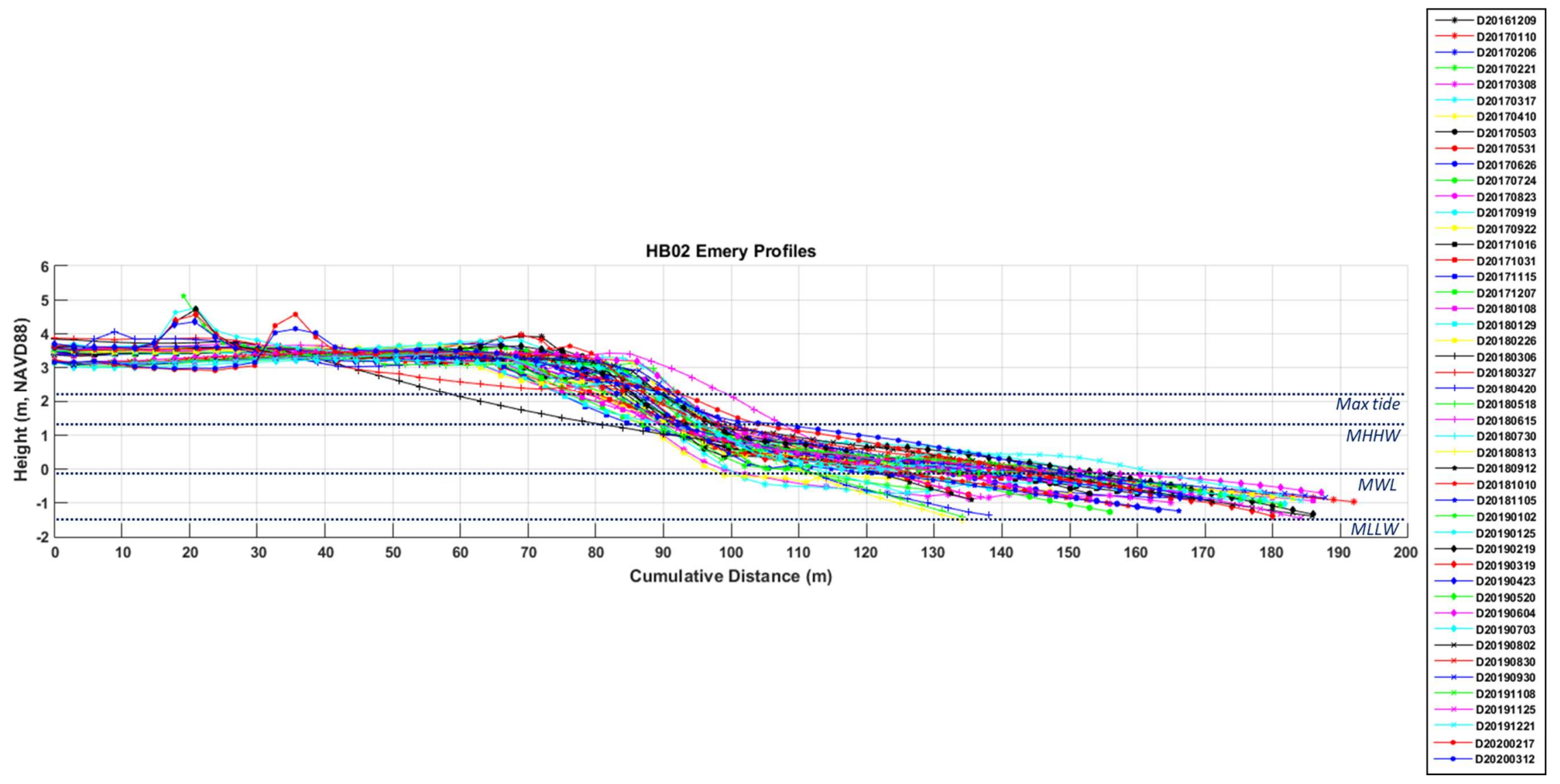



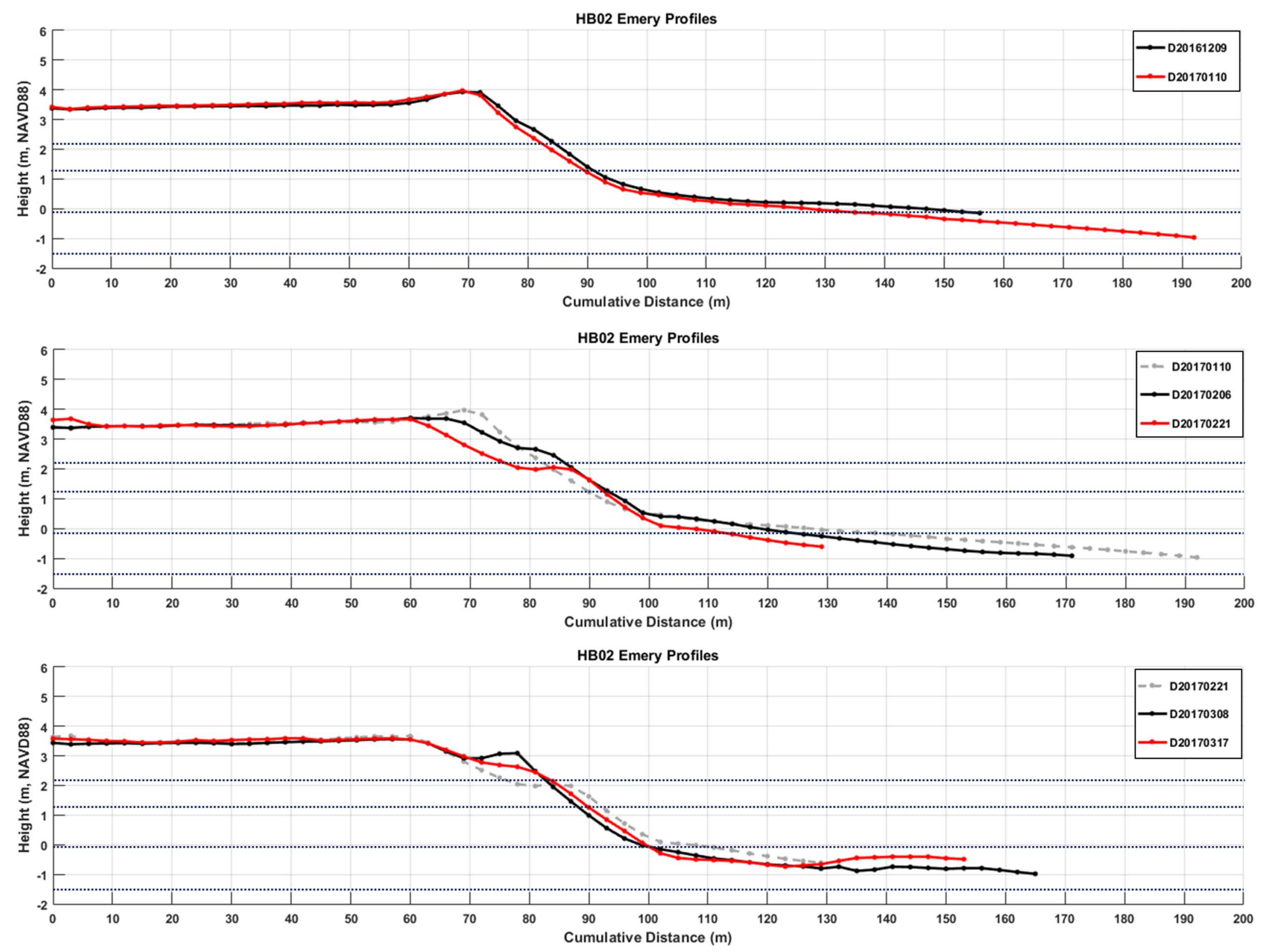

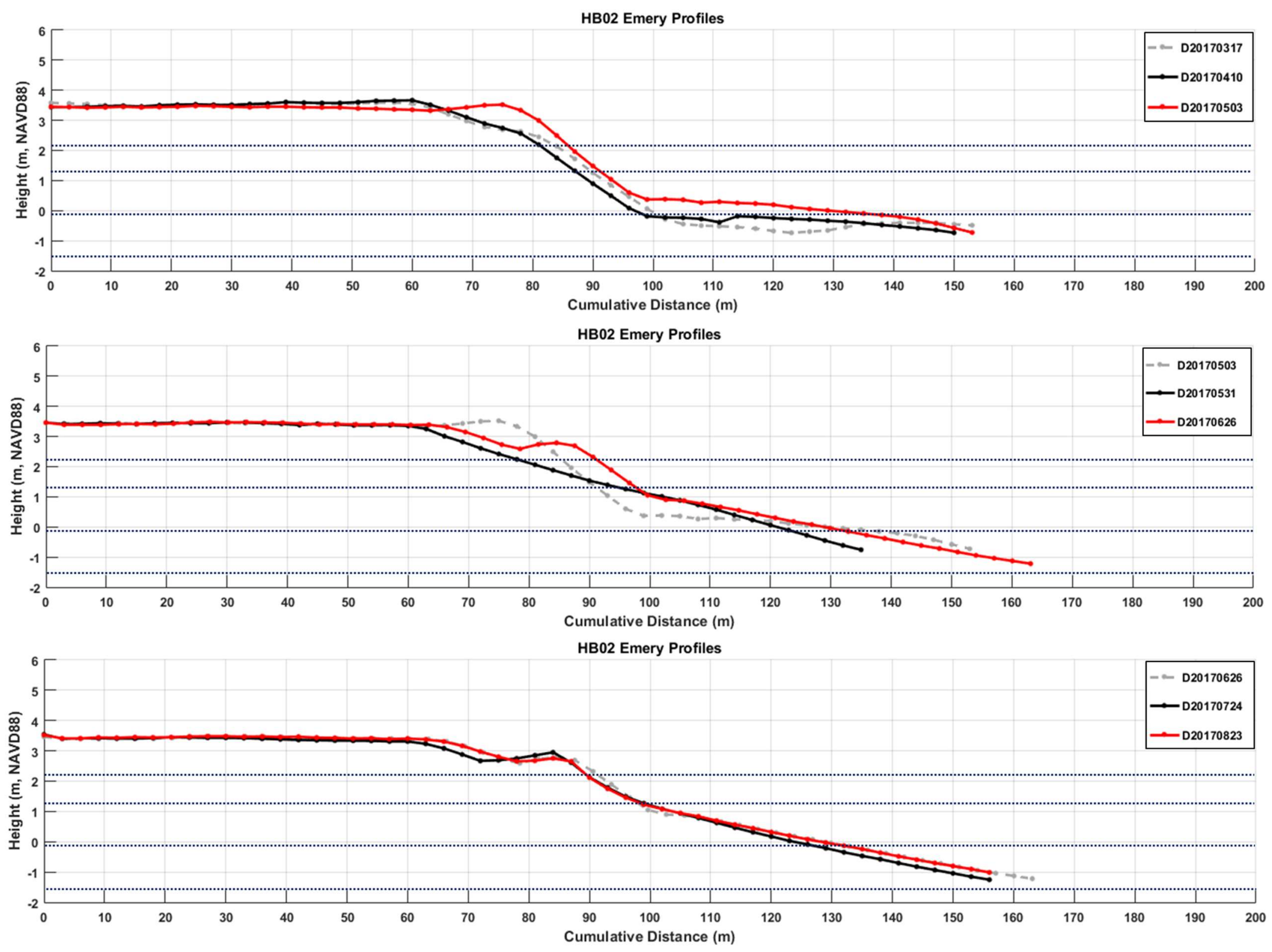

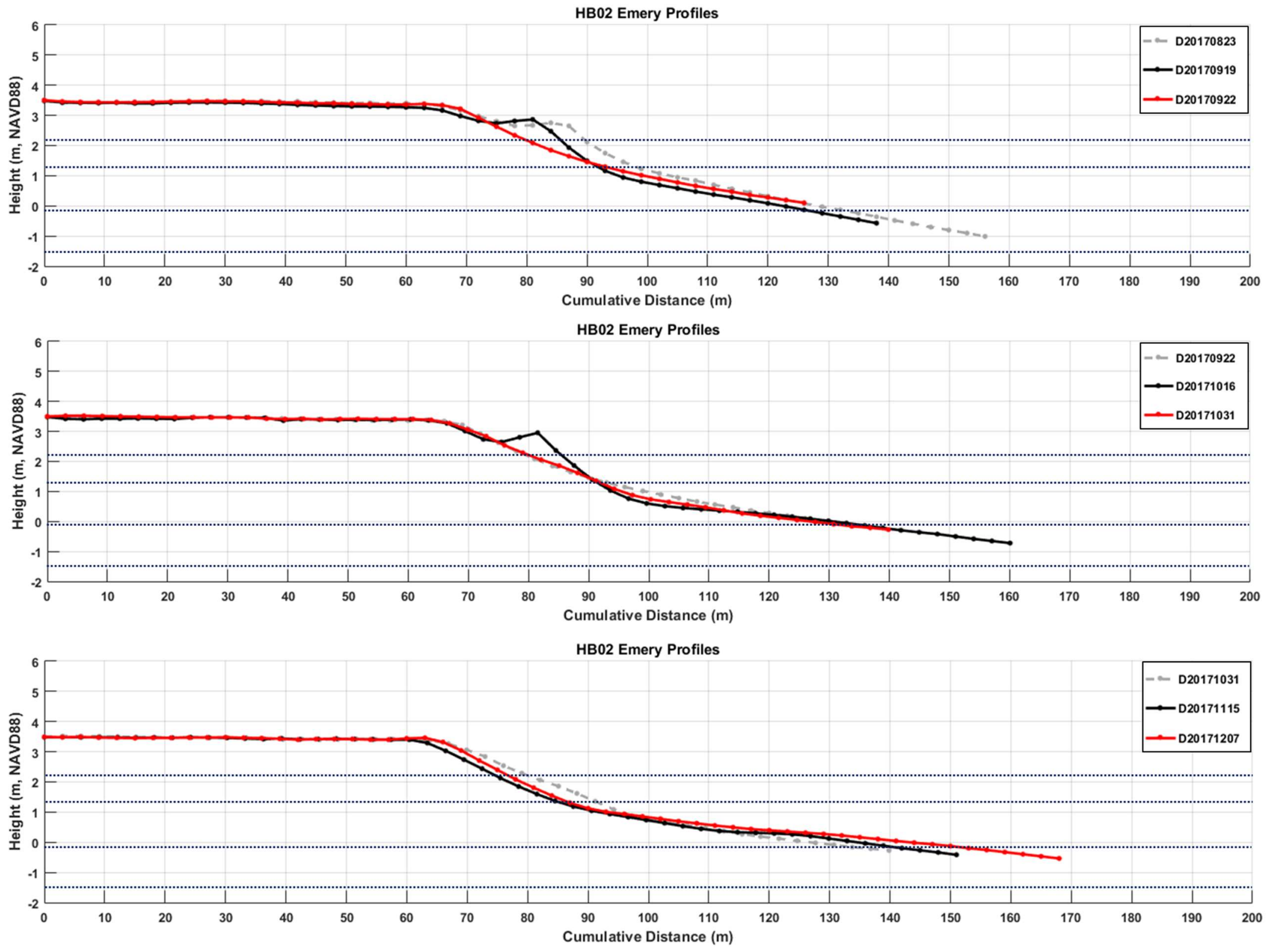

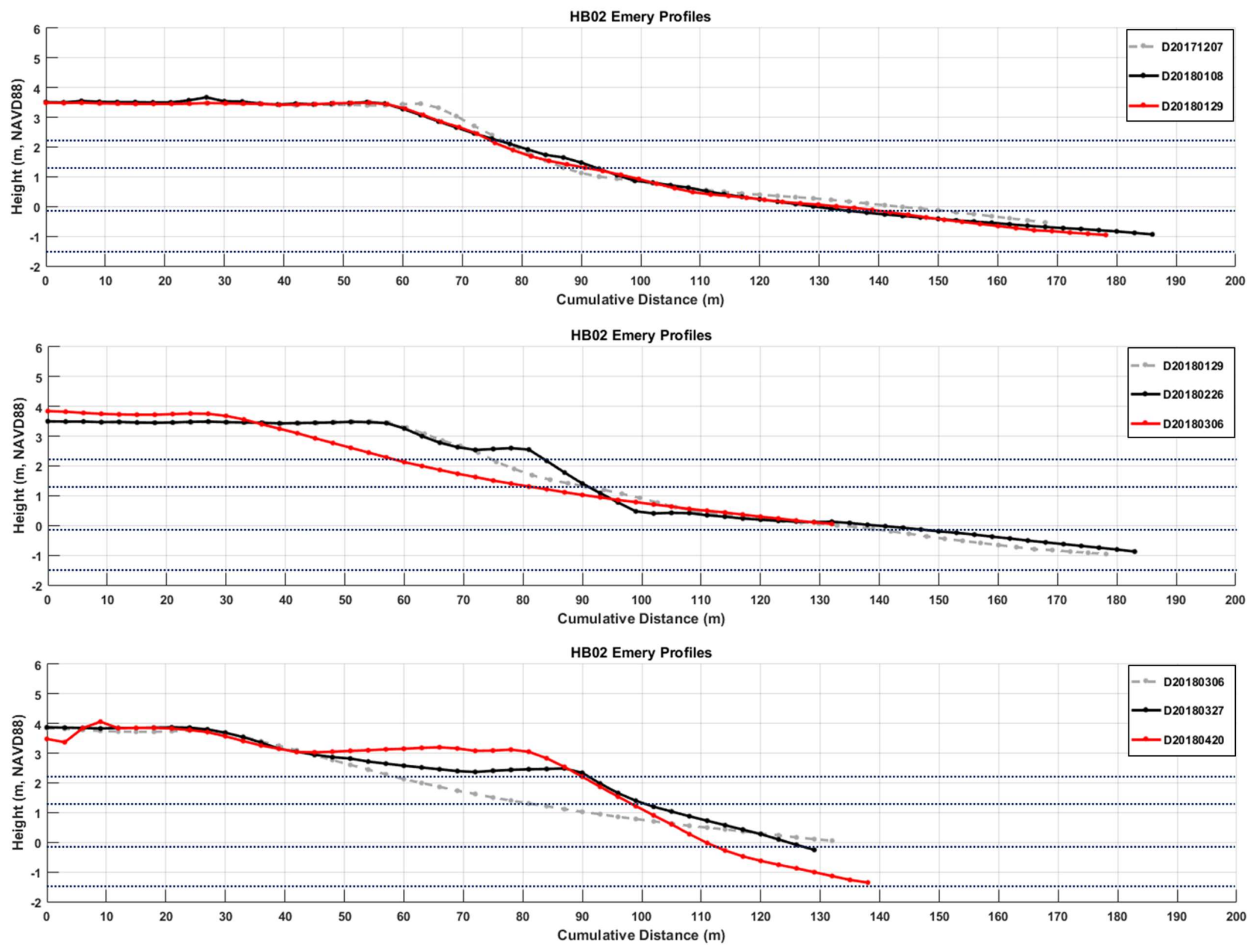

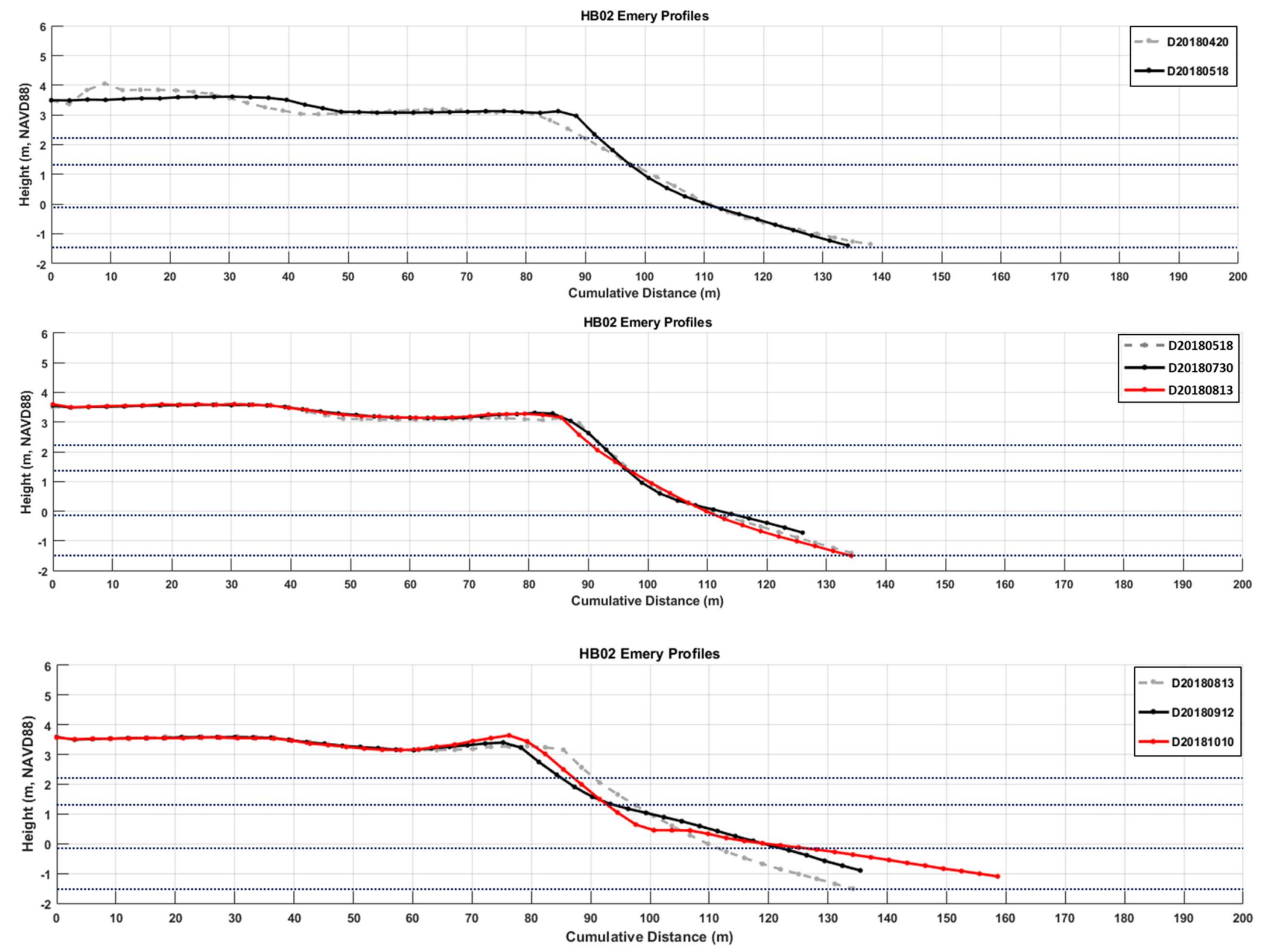

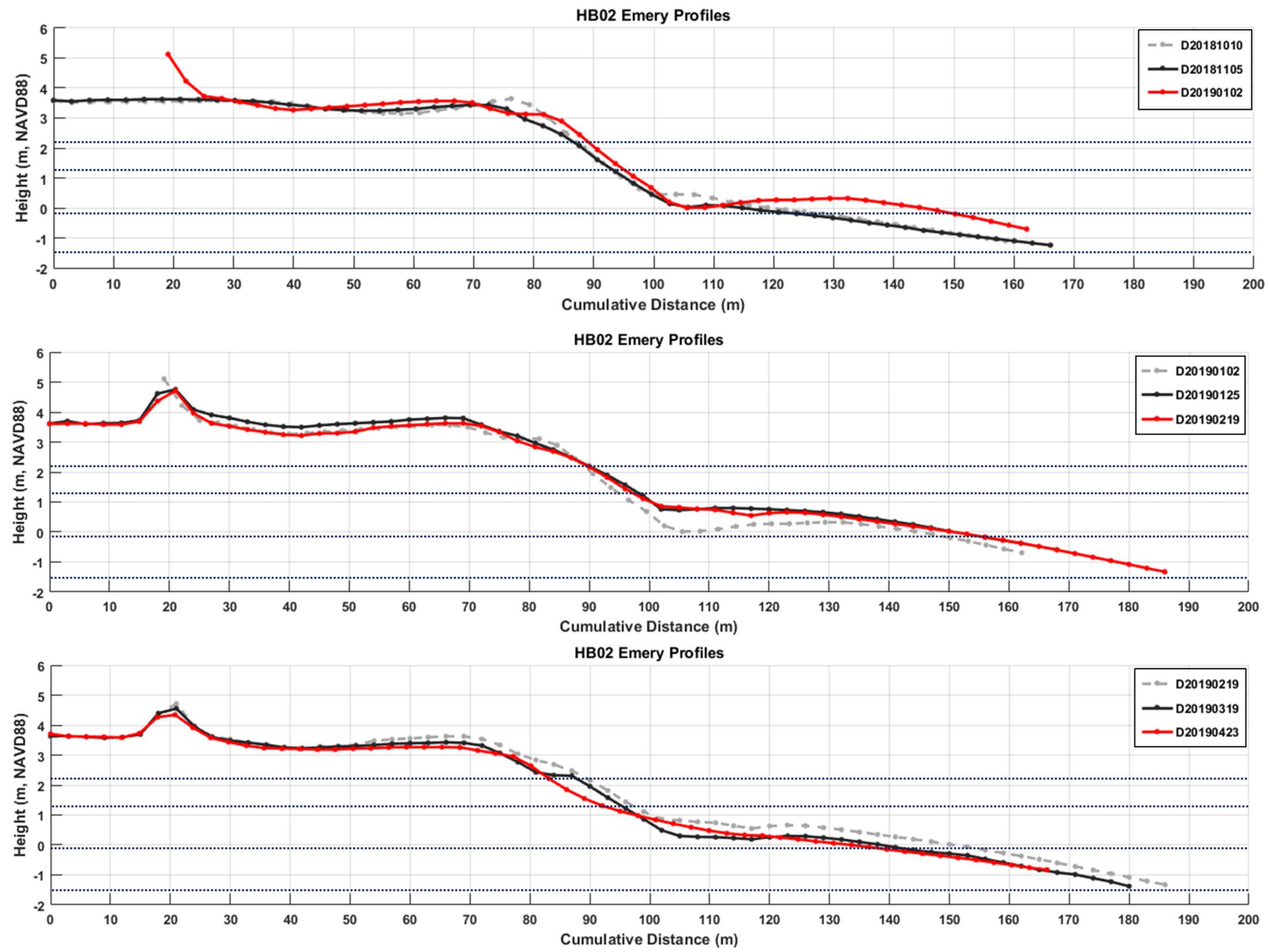

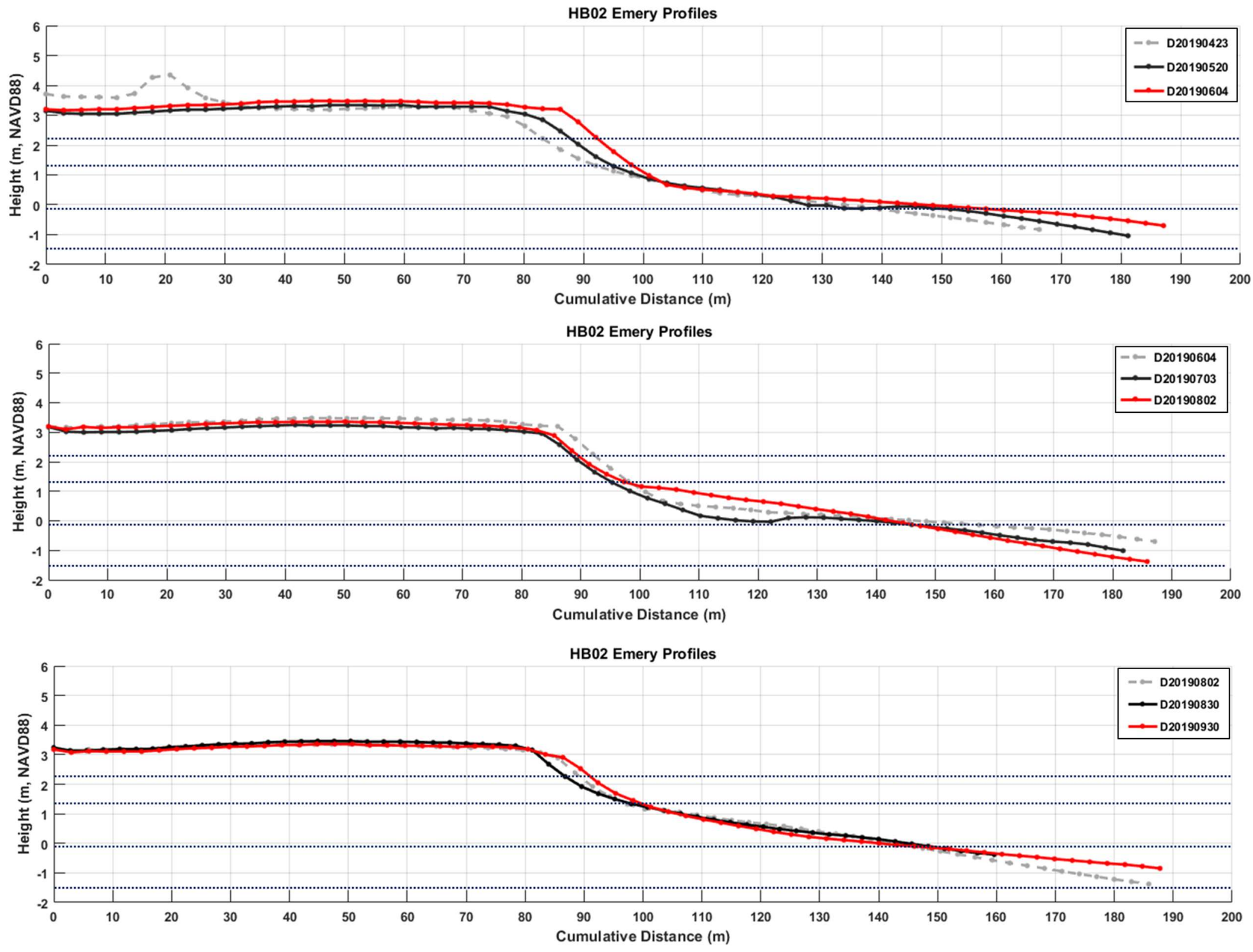

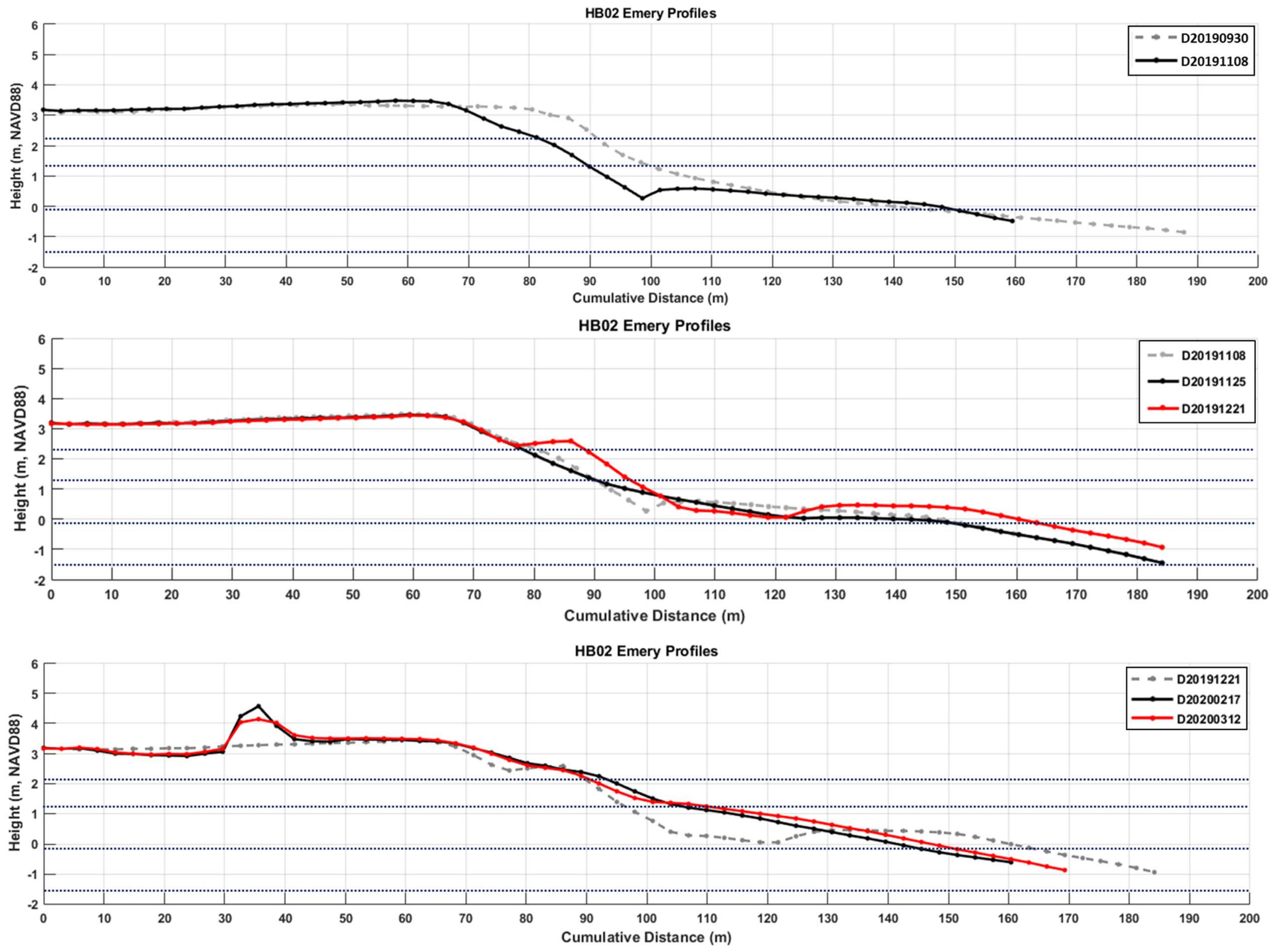
Appendix C(10): HB04 beach profiles from February 28, 2018 to March 9, 2020.
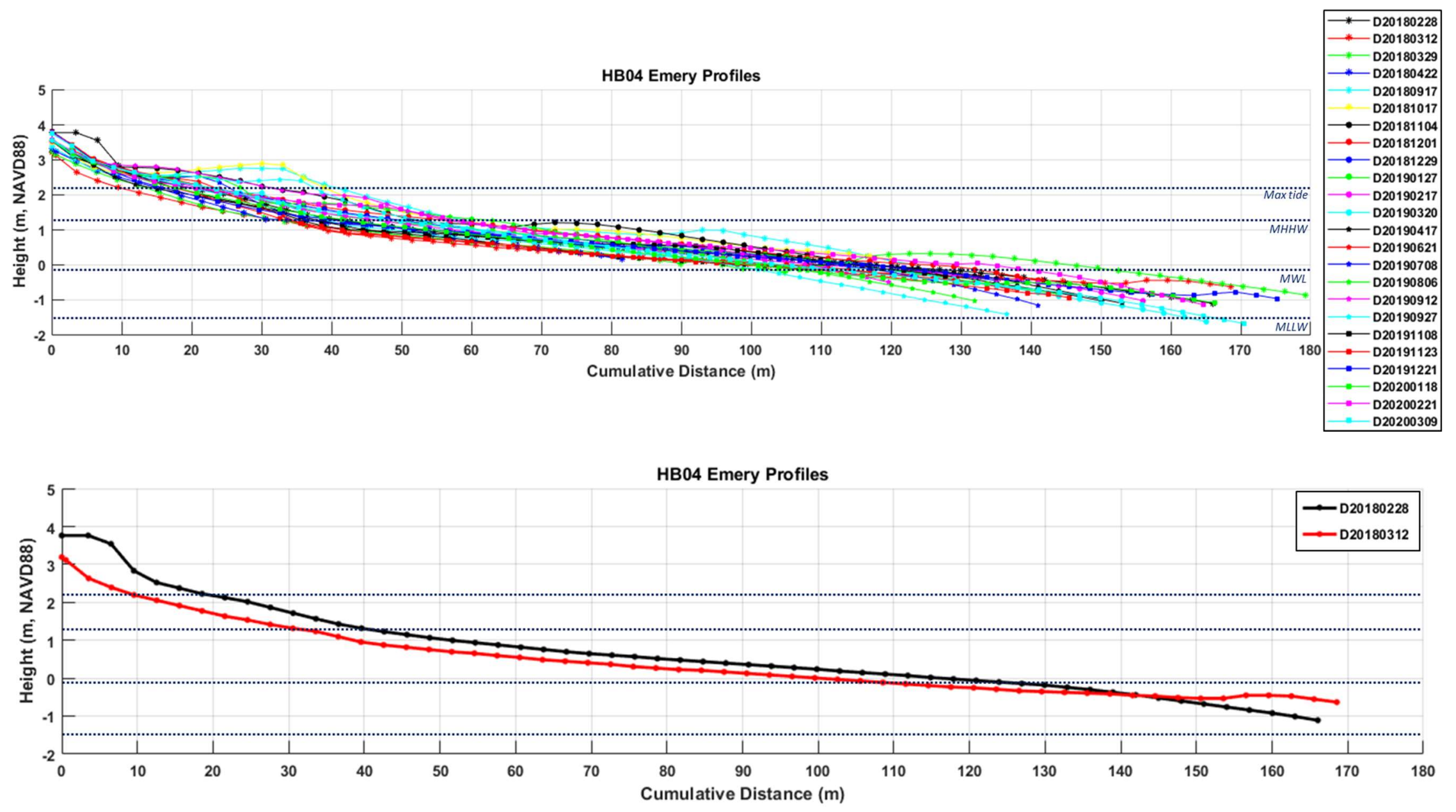

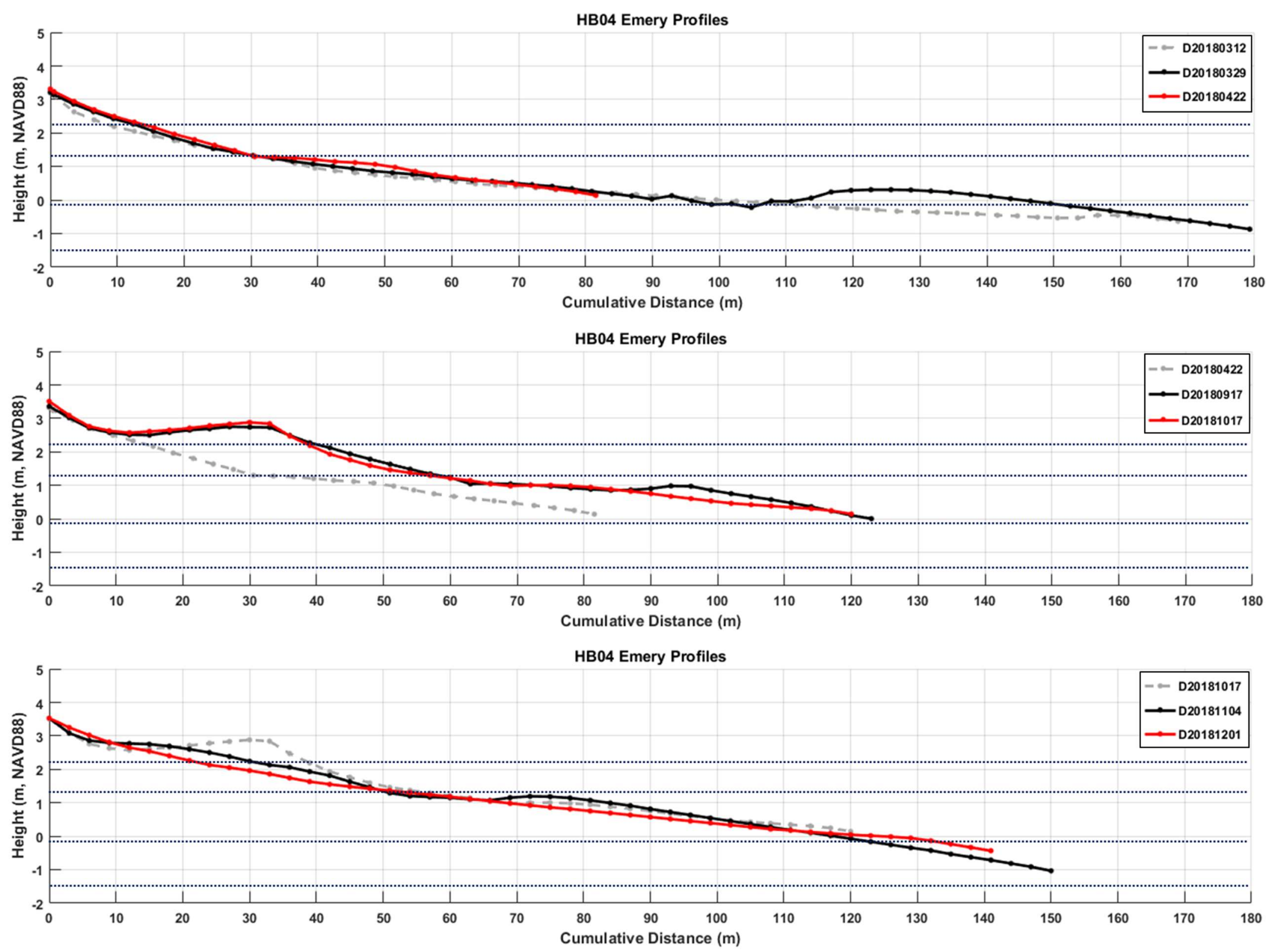

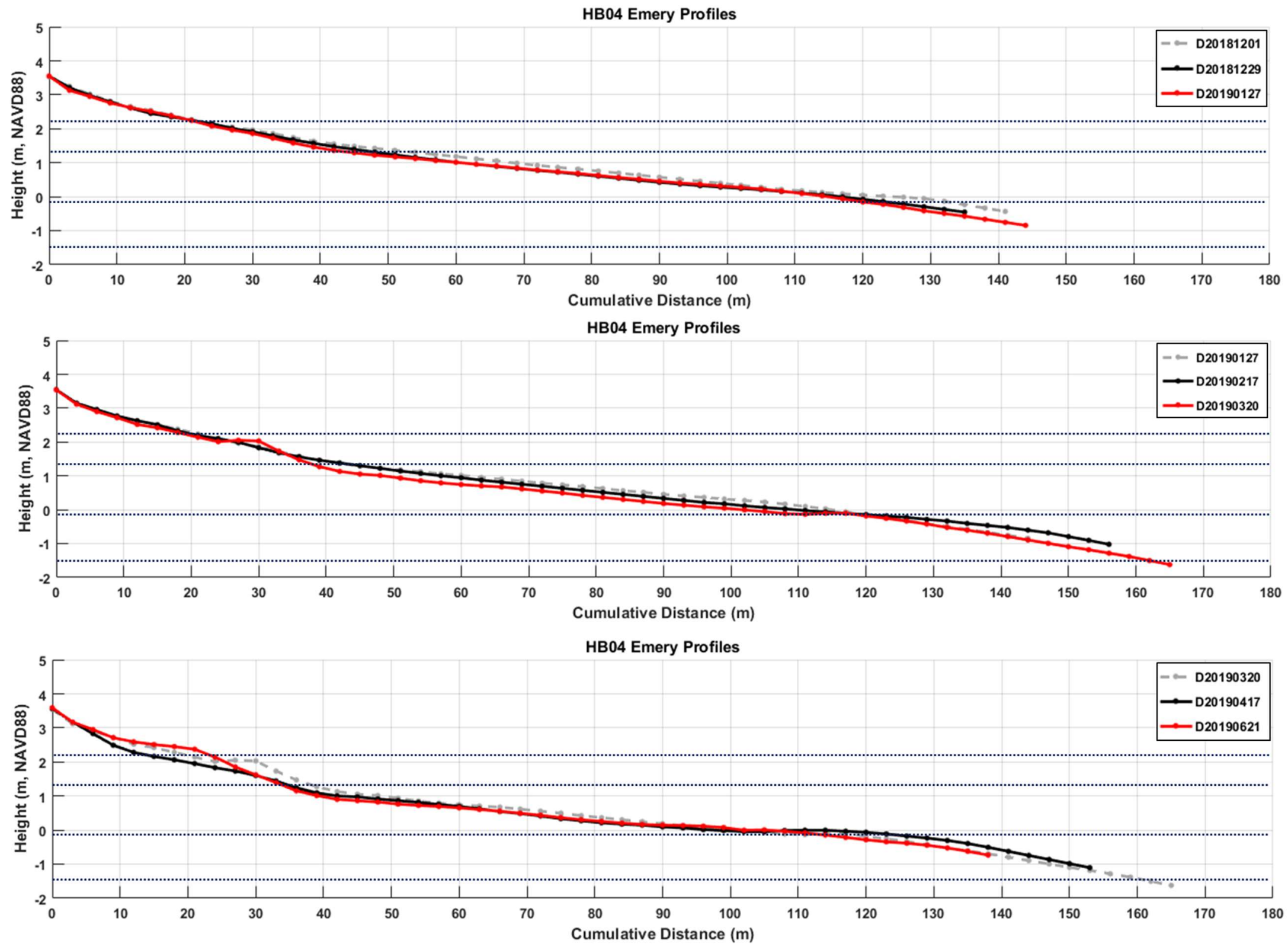

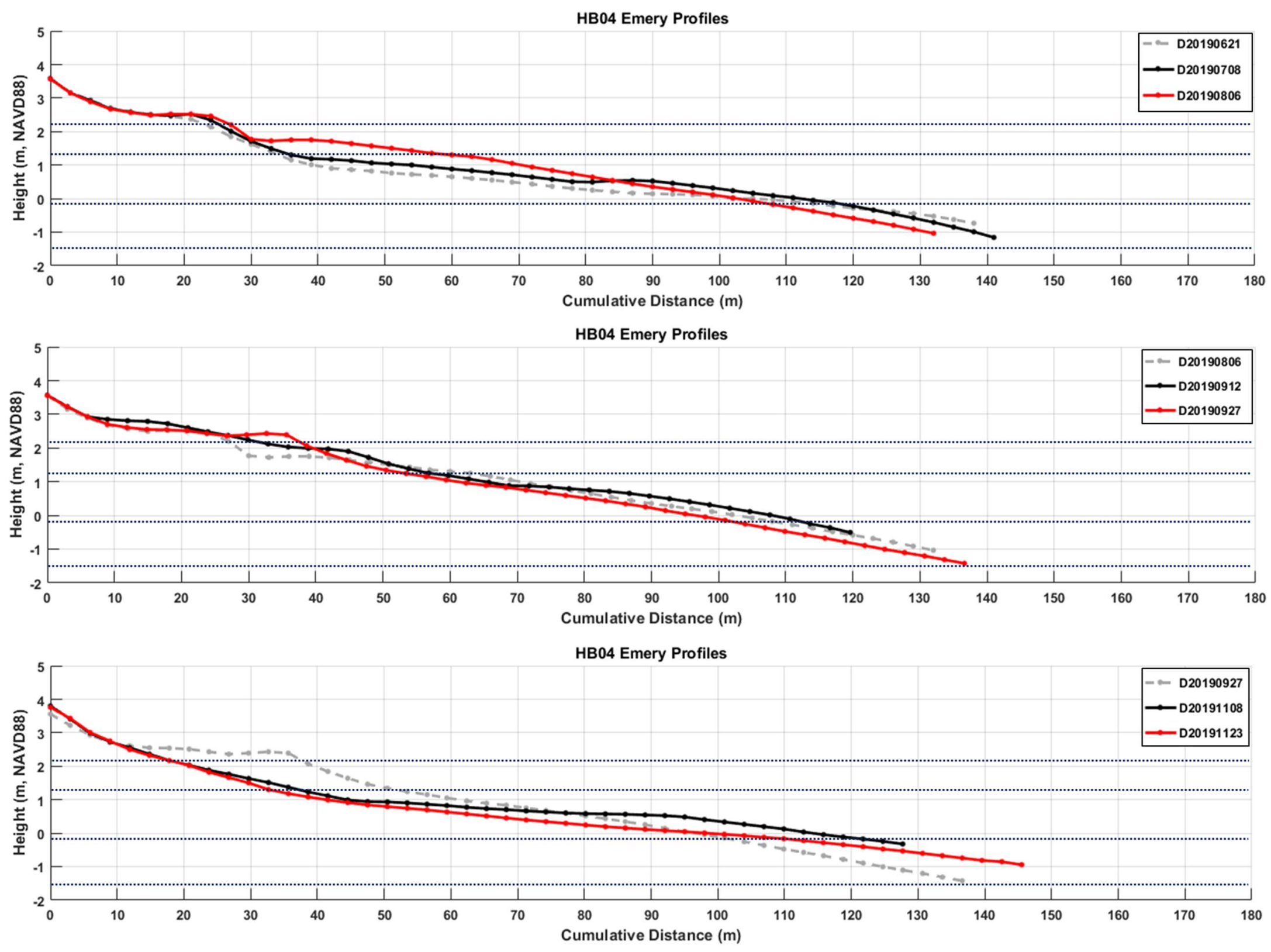

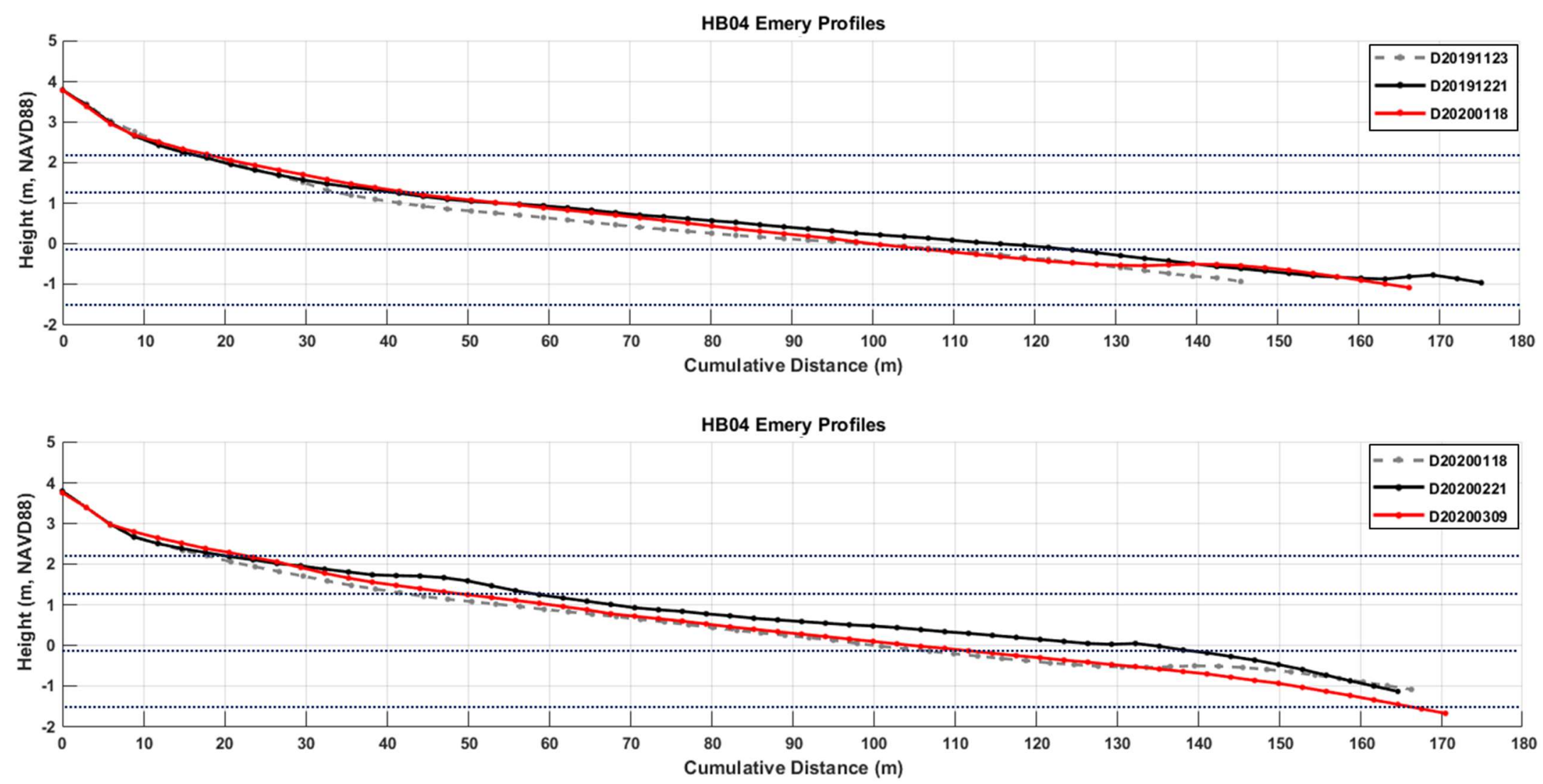
Appendix C(11): SB02 beach profiles from January 29, 2018 to March 9, 2020.

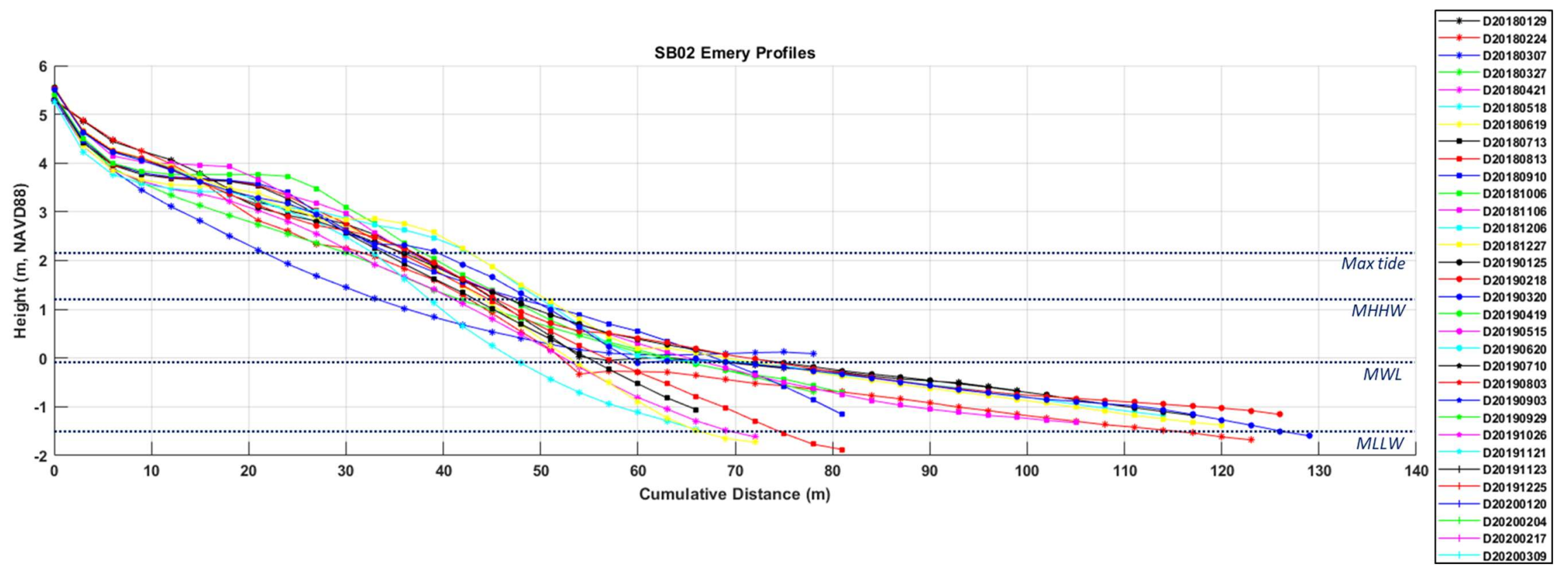



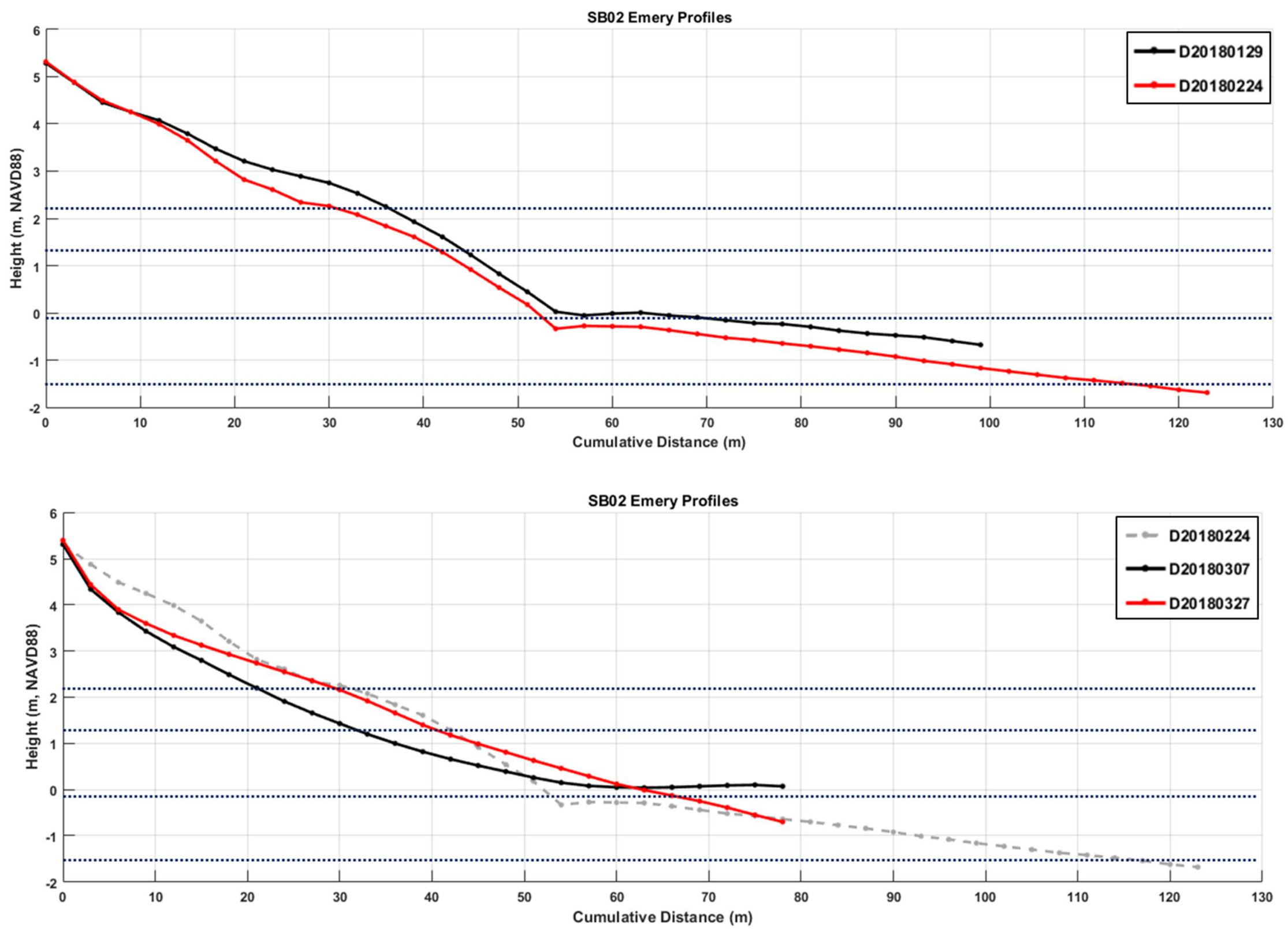

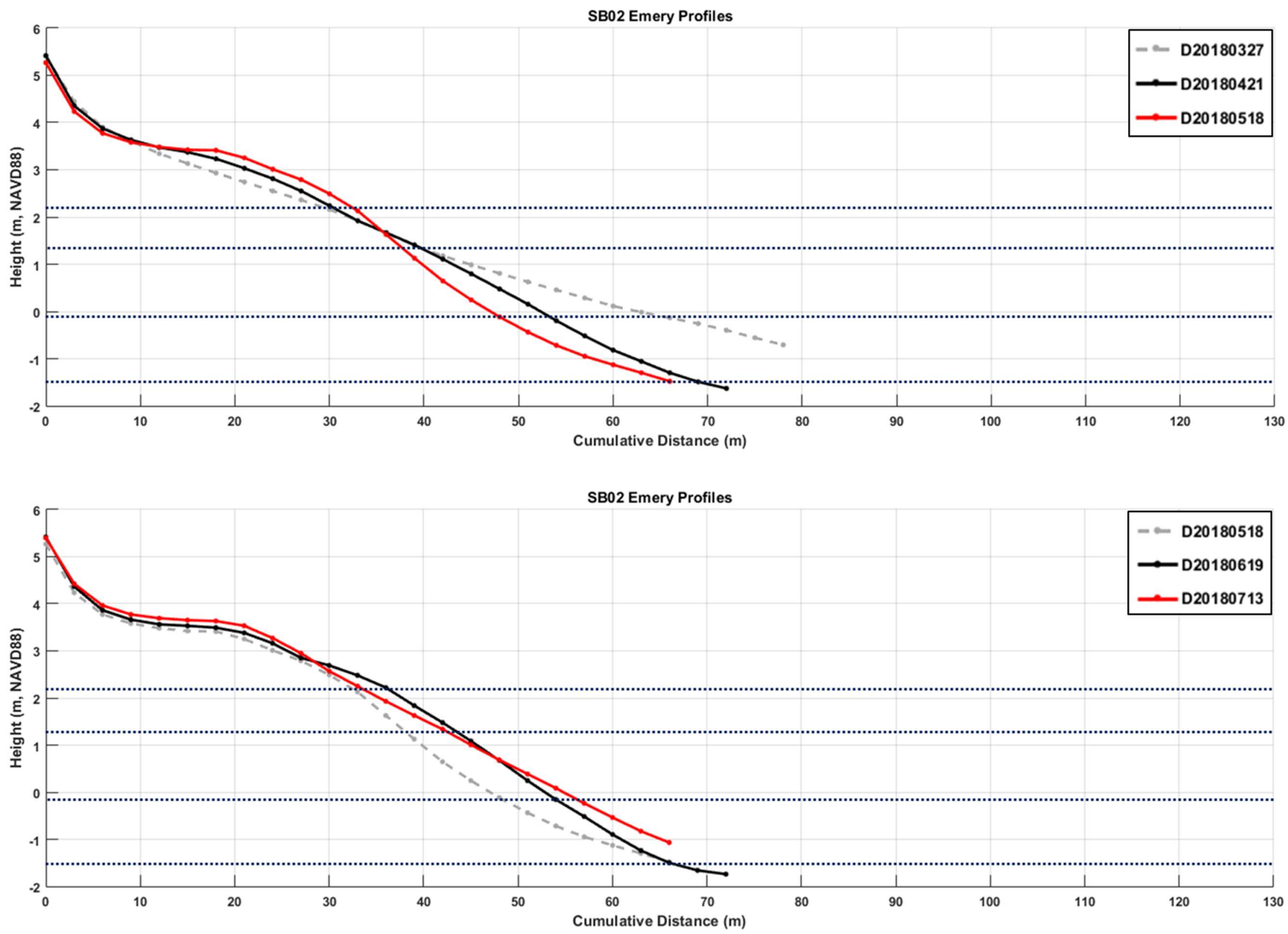

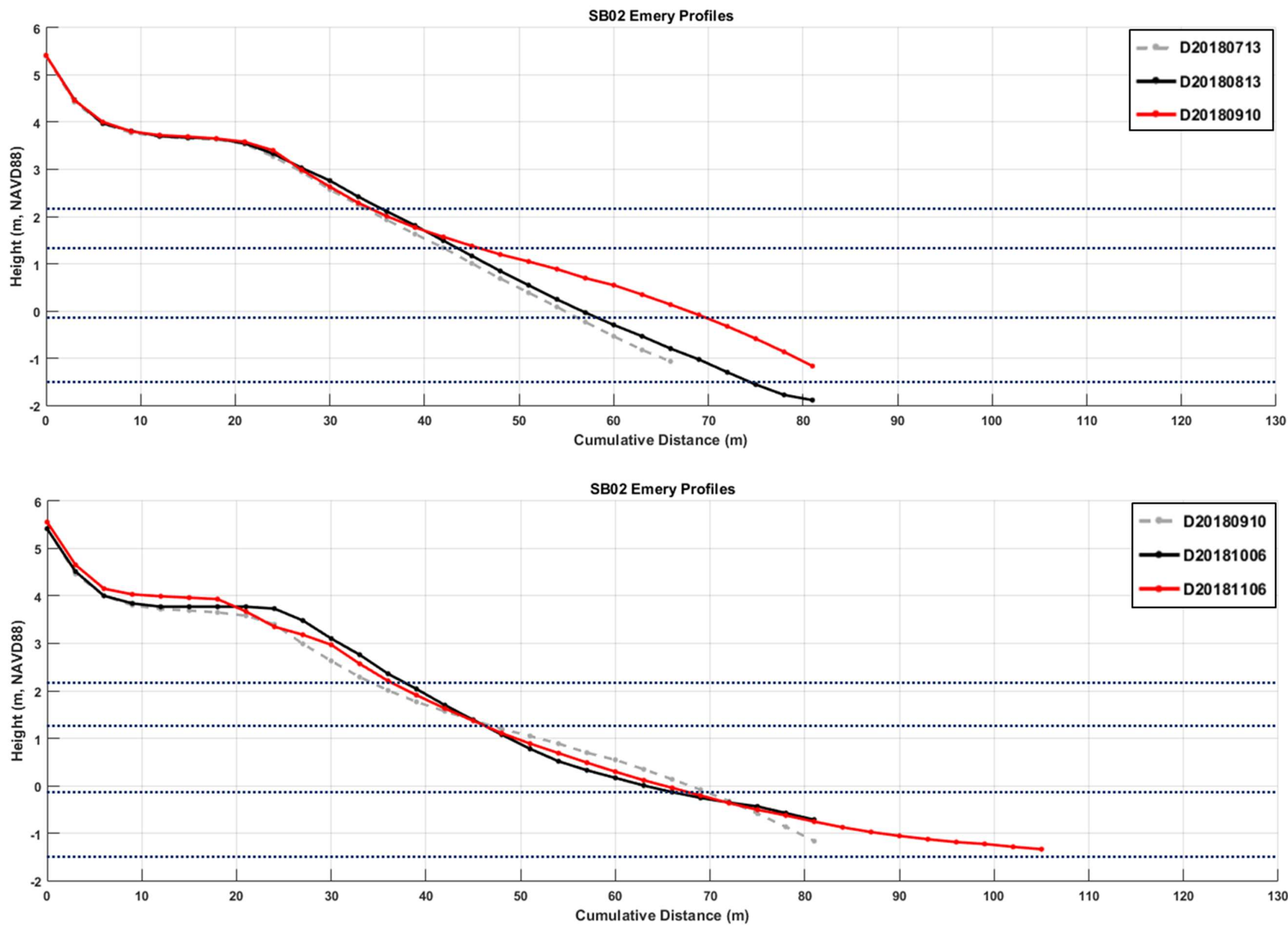

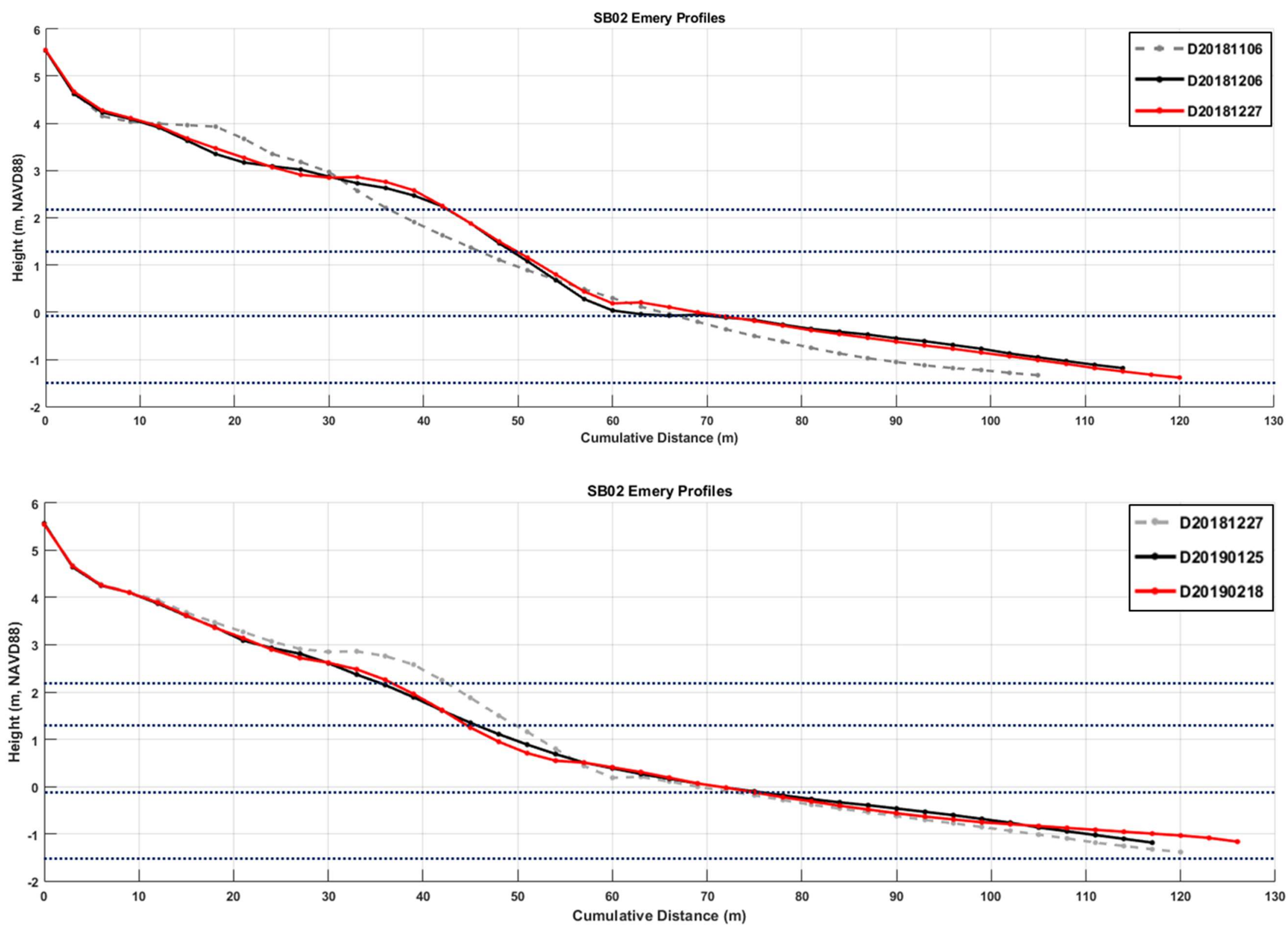

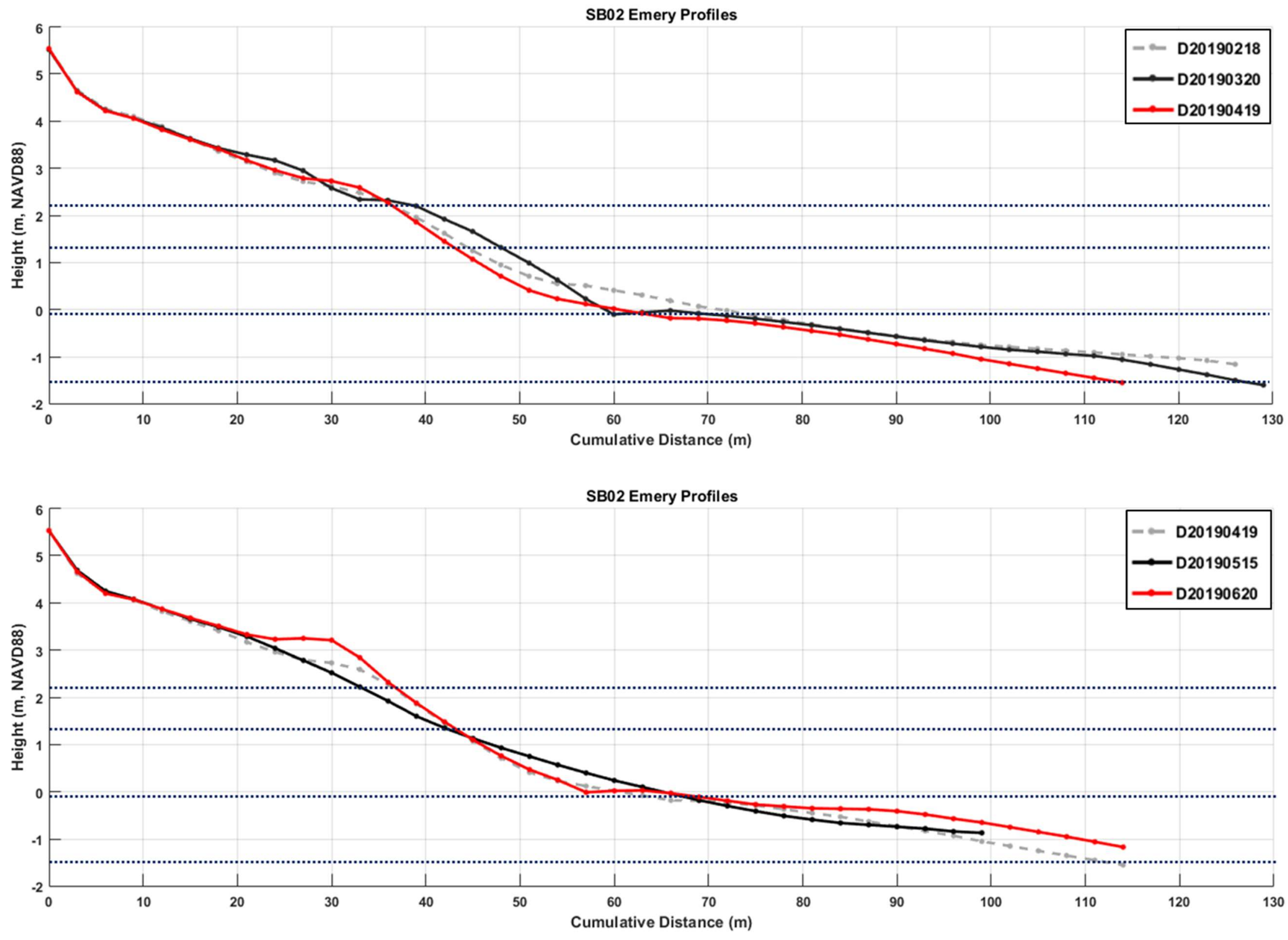

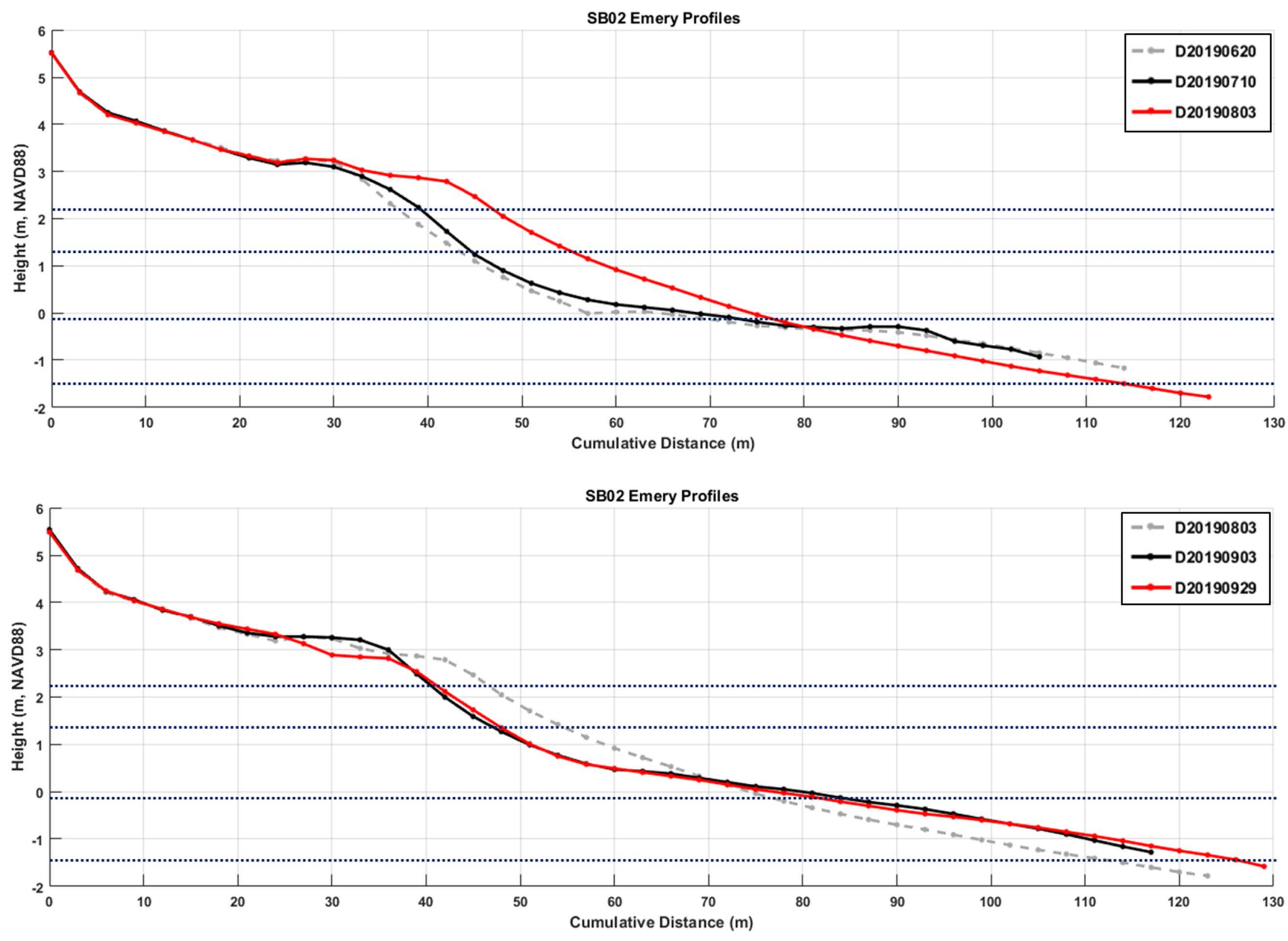

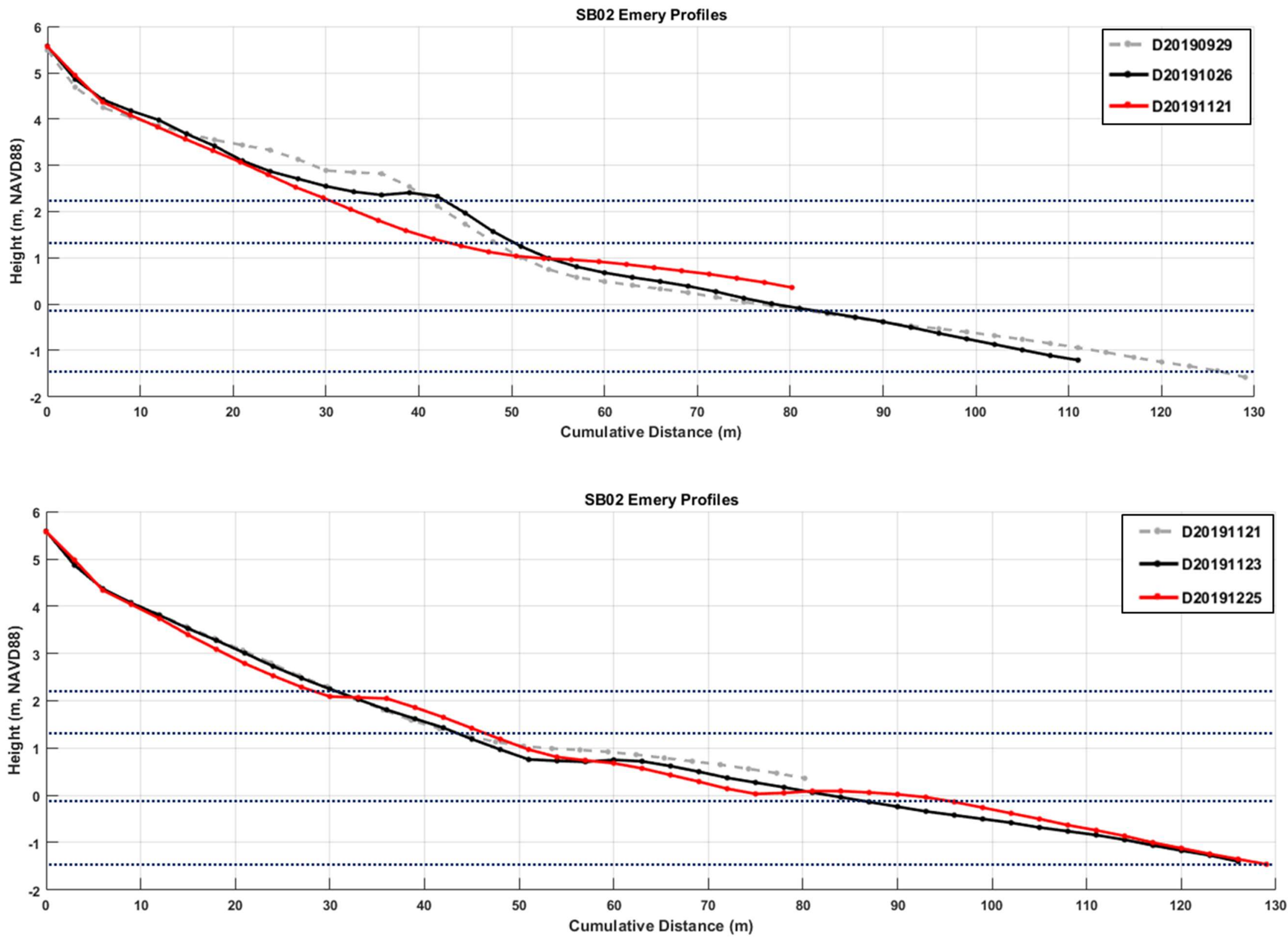

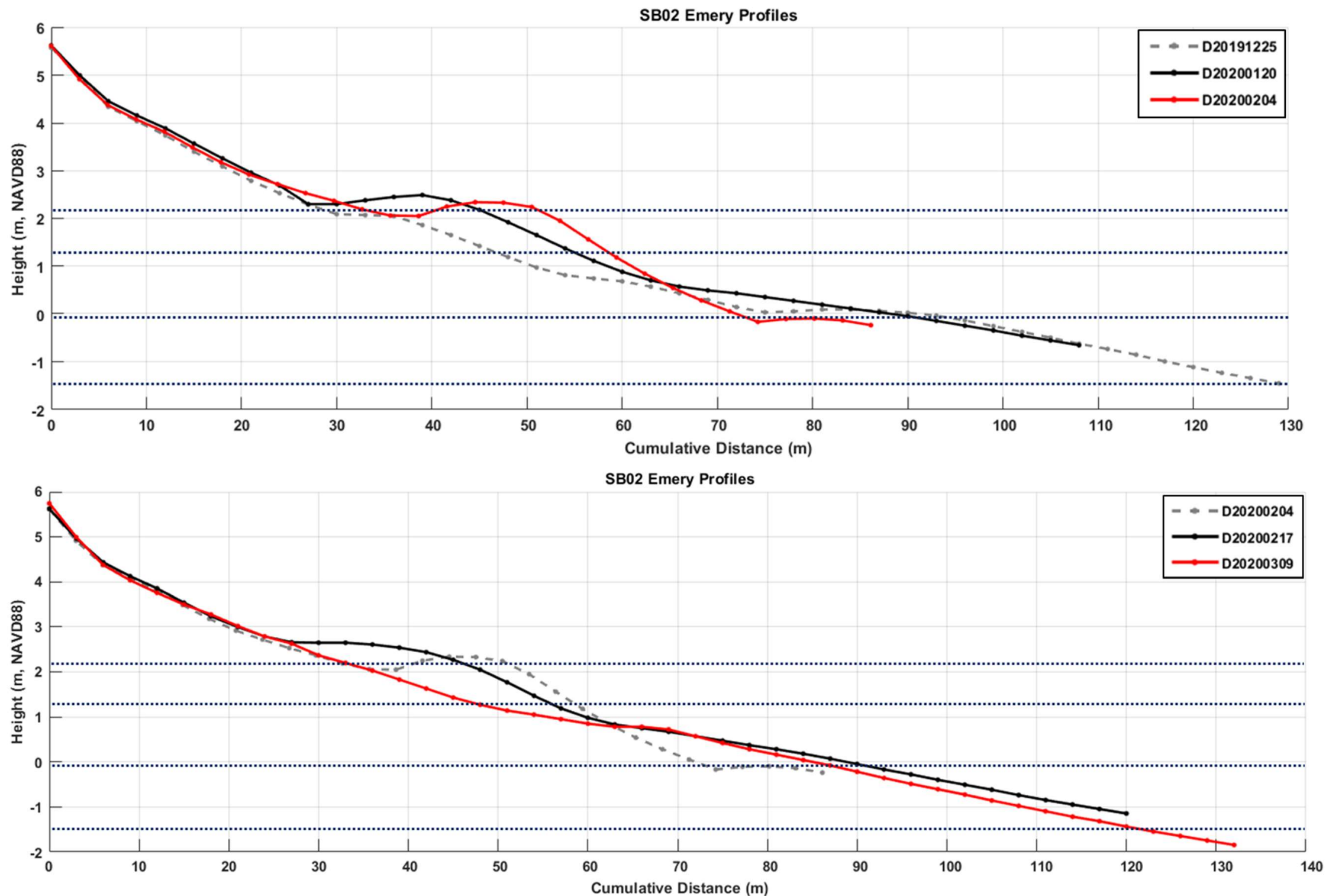

*Plot above extends to $140 \mathrm{~m}$, rather than $130 \mathrm{~m}$ 
Appendix C(12): SB04 beach profiles from January 29, 2018 to March 9, 2020.

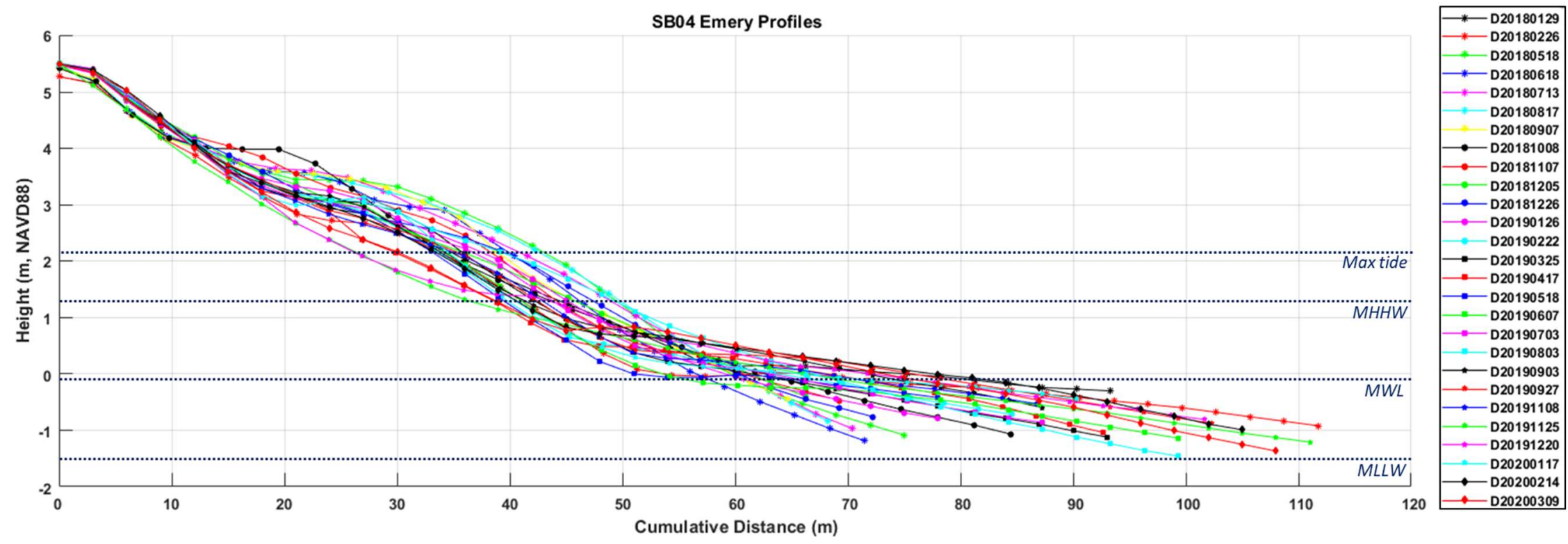



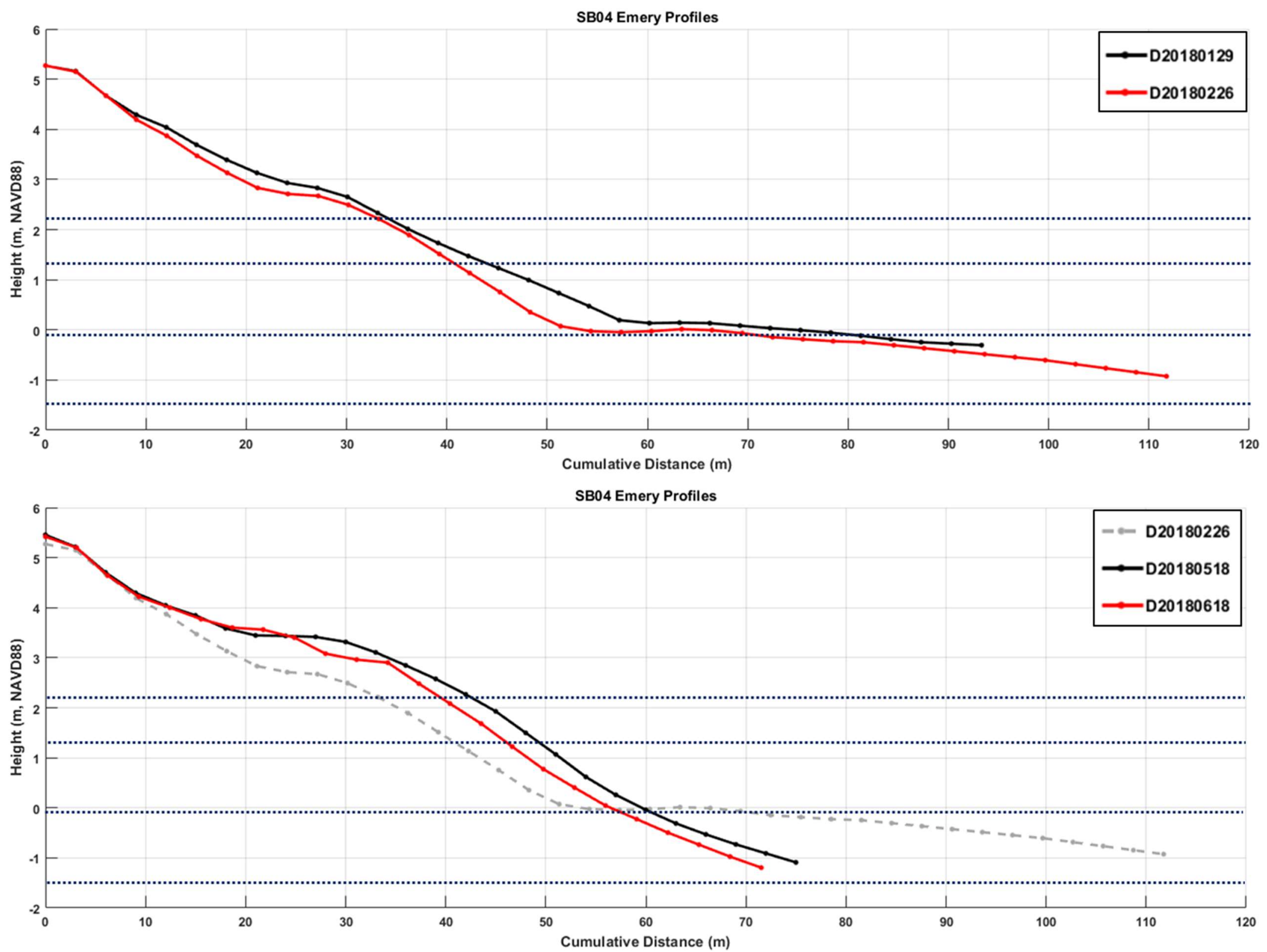

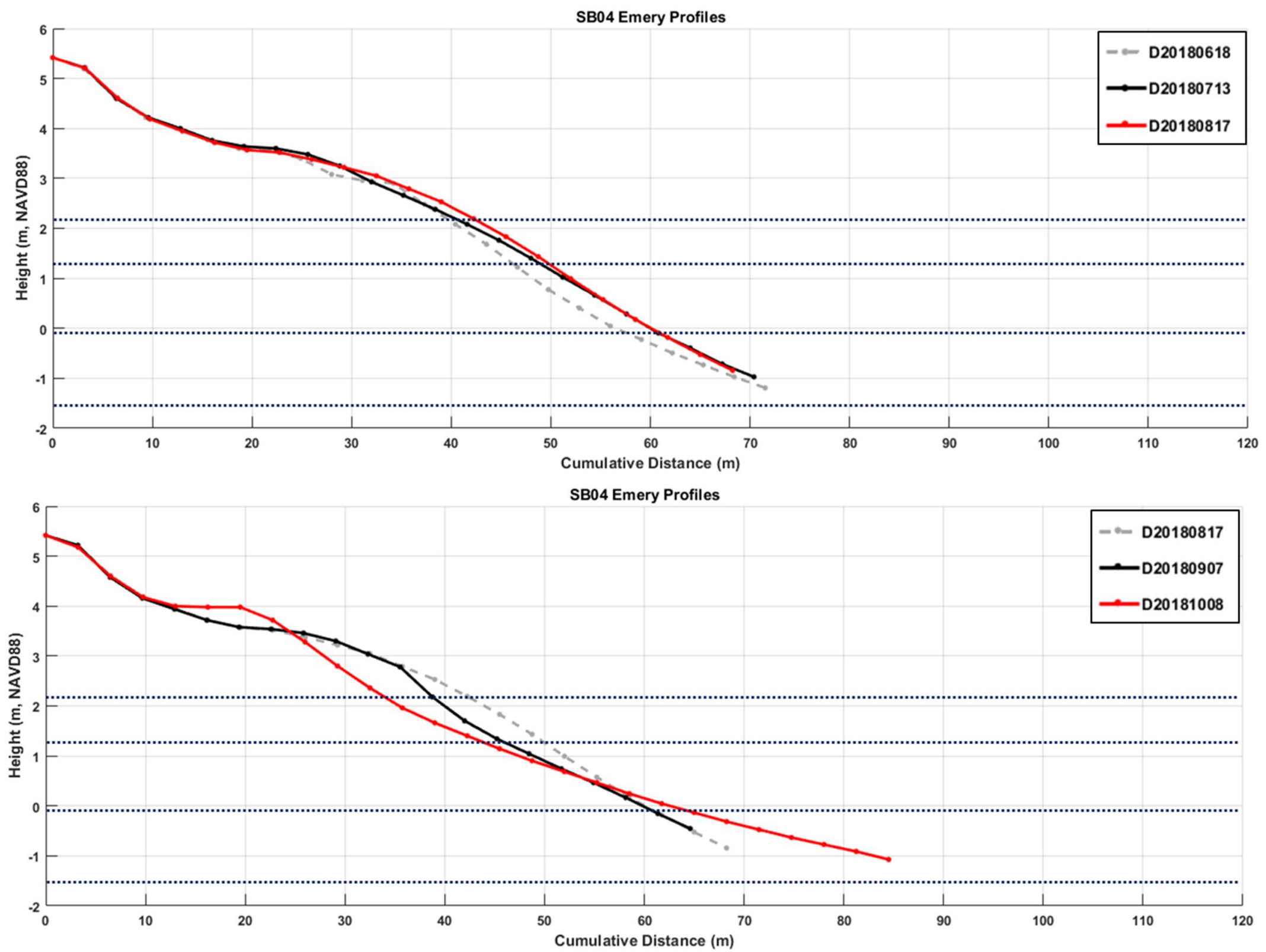

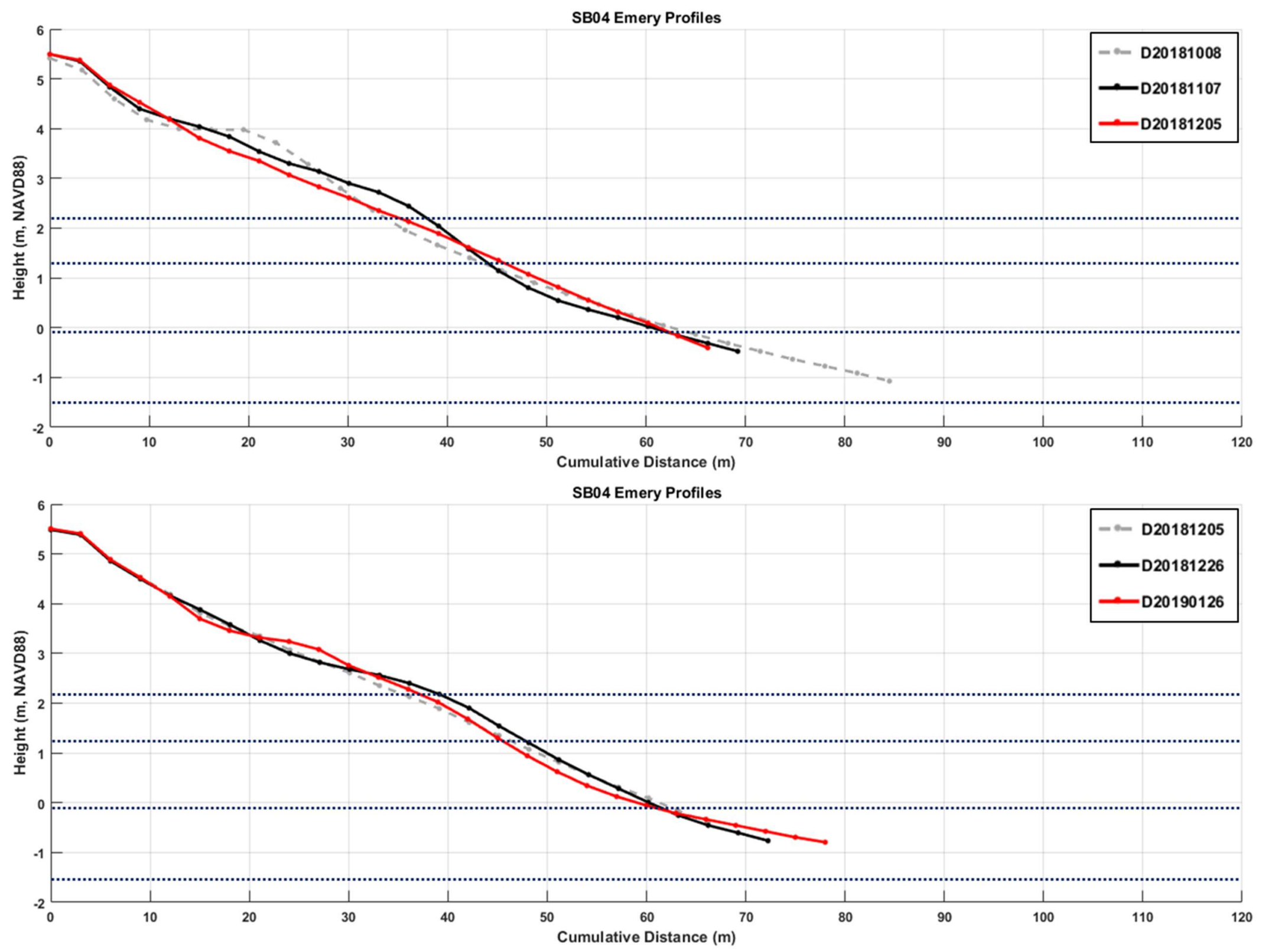

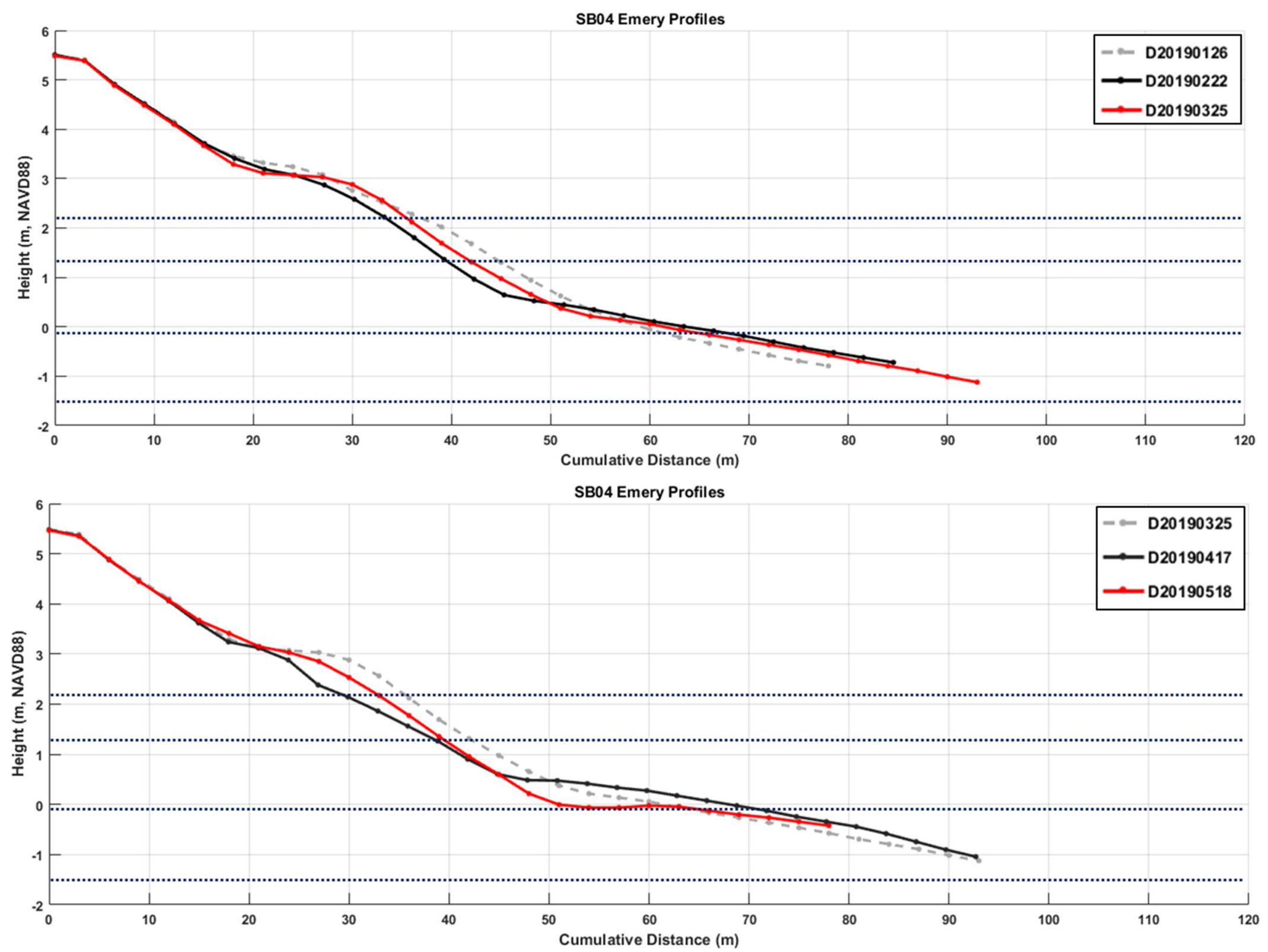

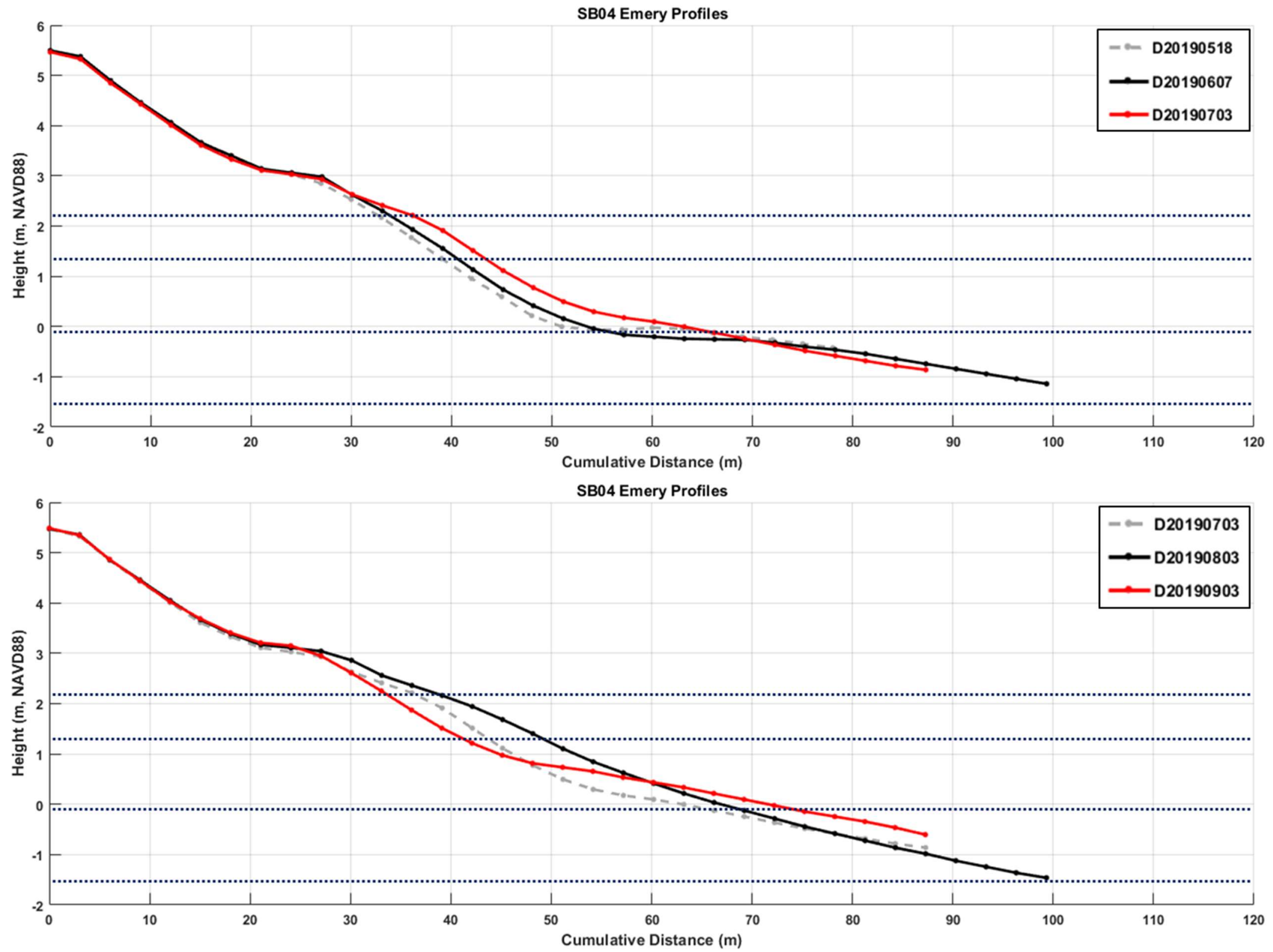

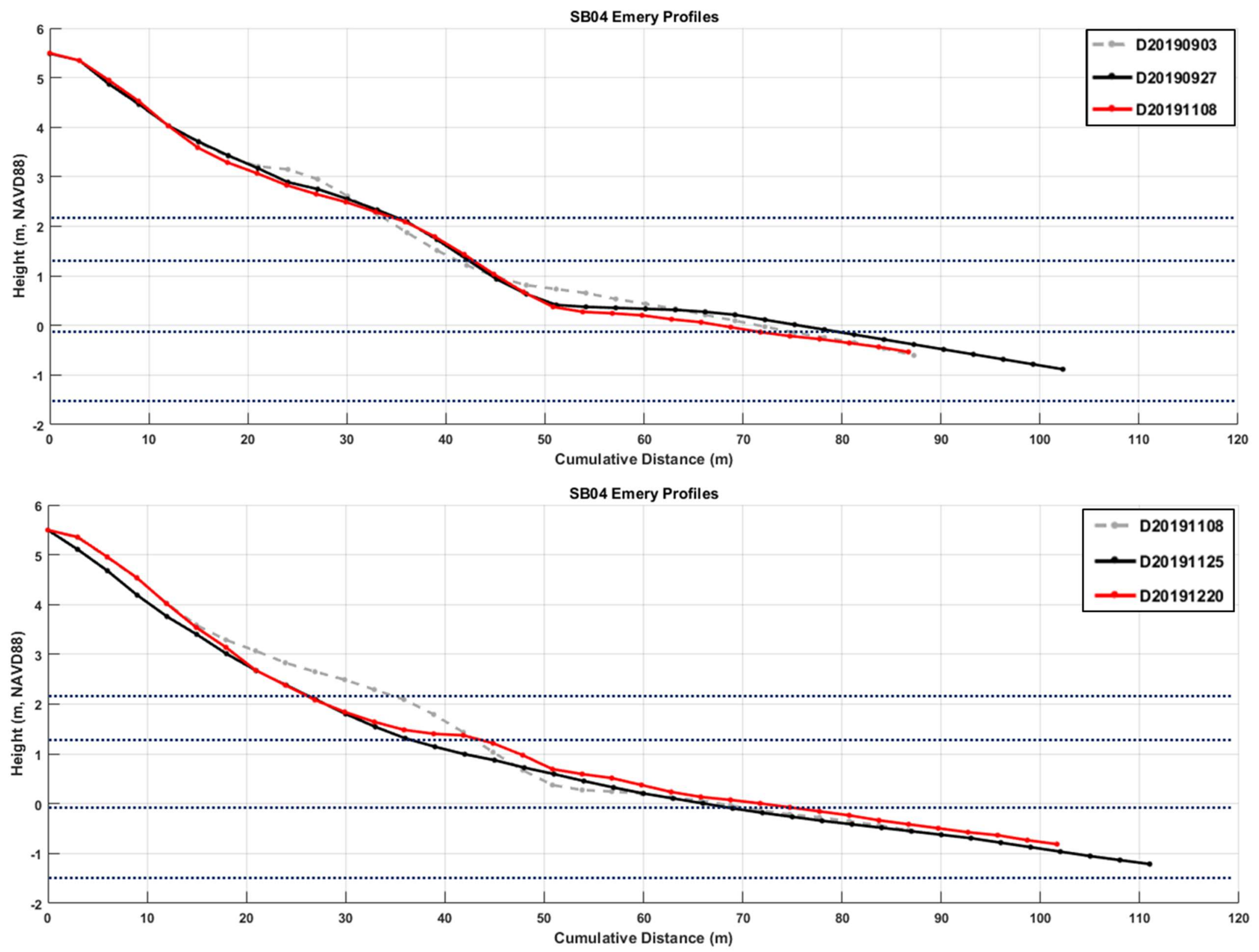

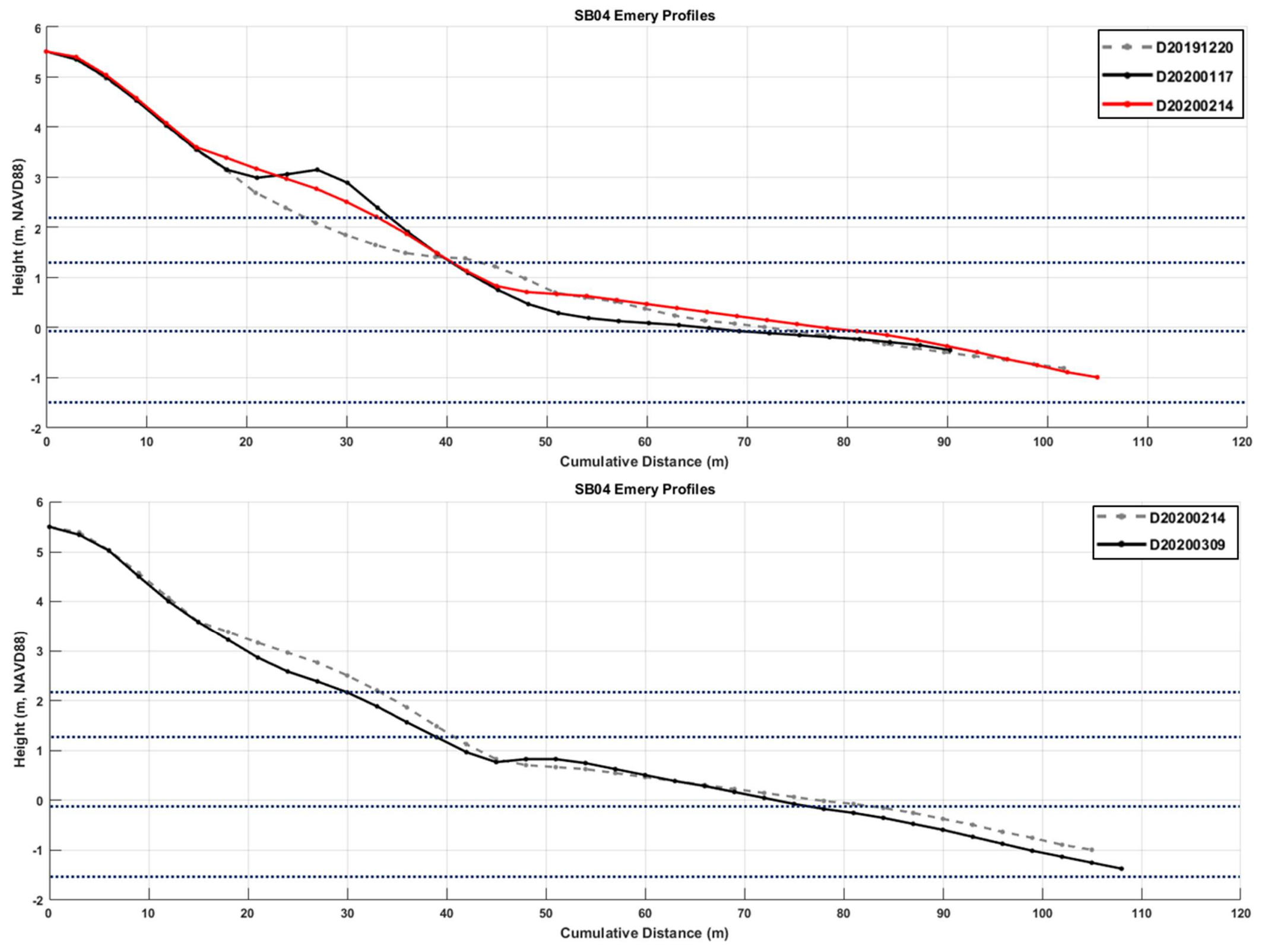
Appendix C(13): SB05 beach profiles from January 29, 2018 to March 9, 2020.

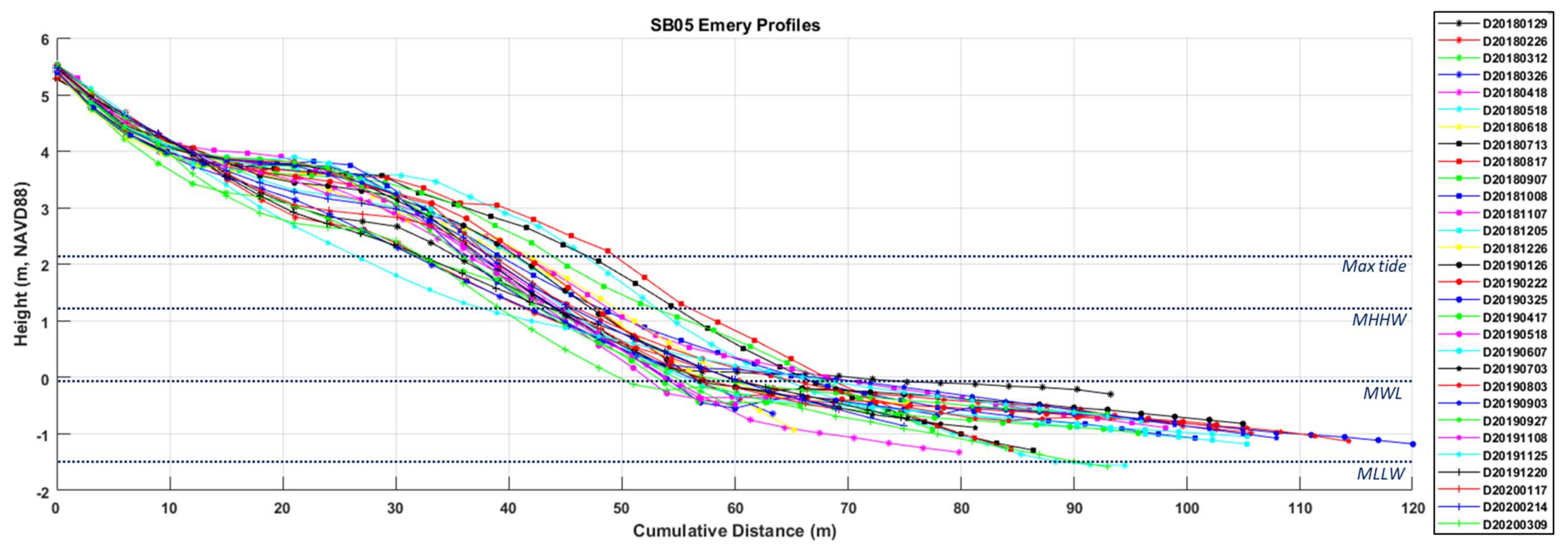



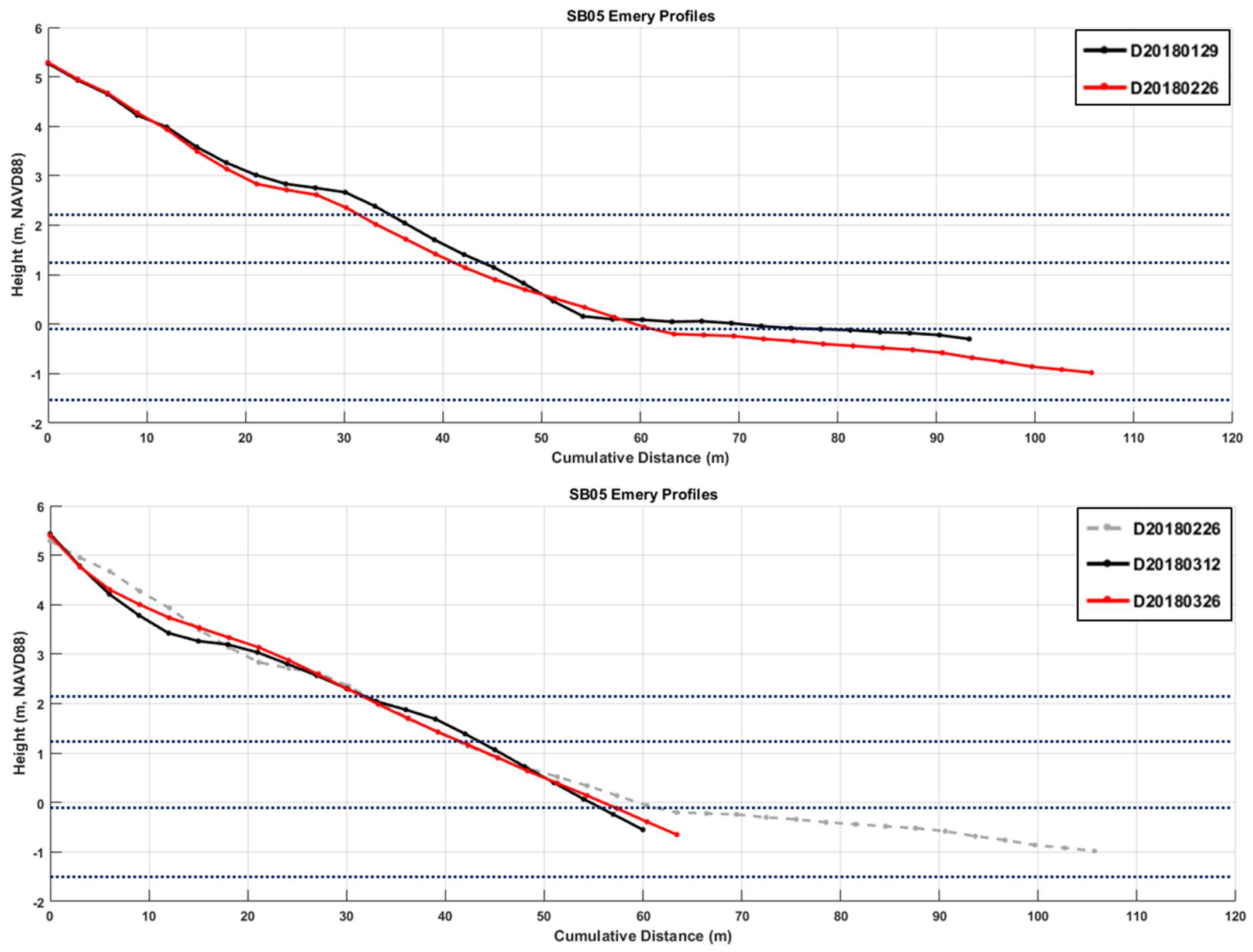

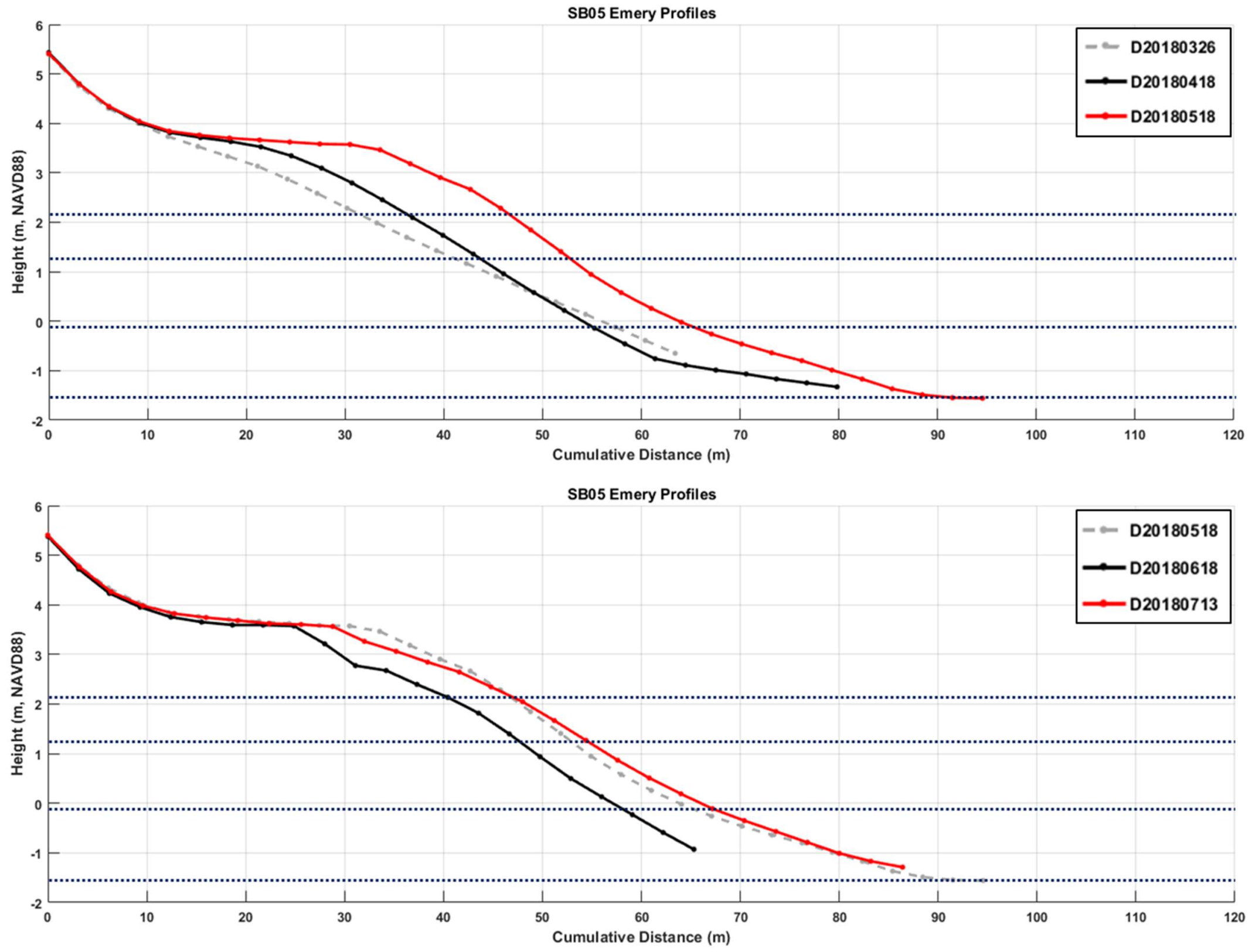

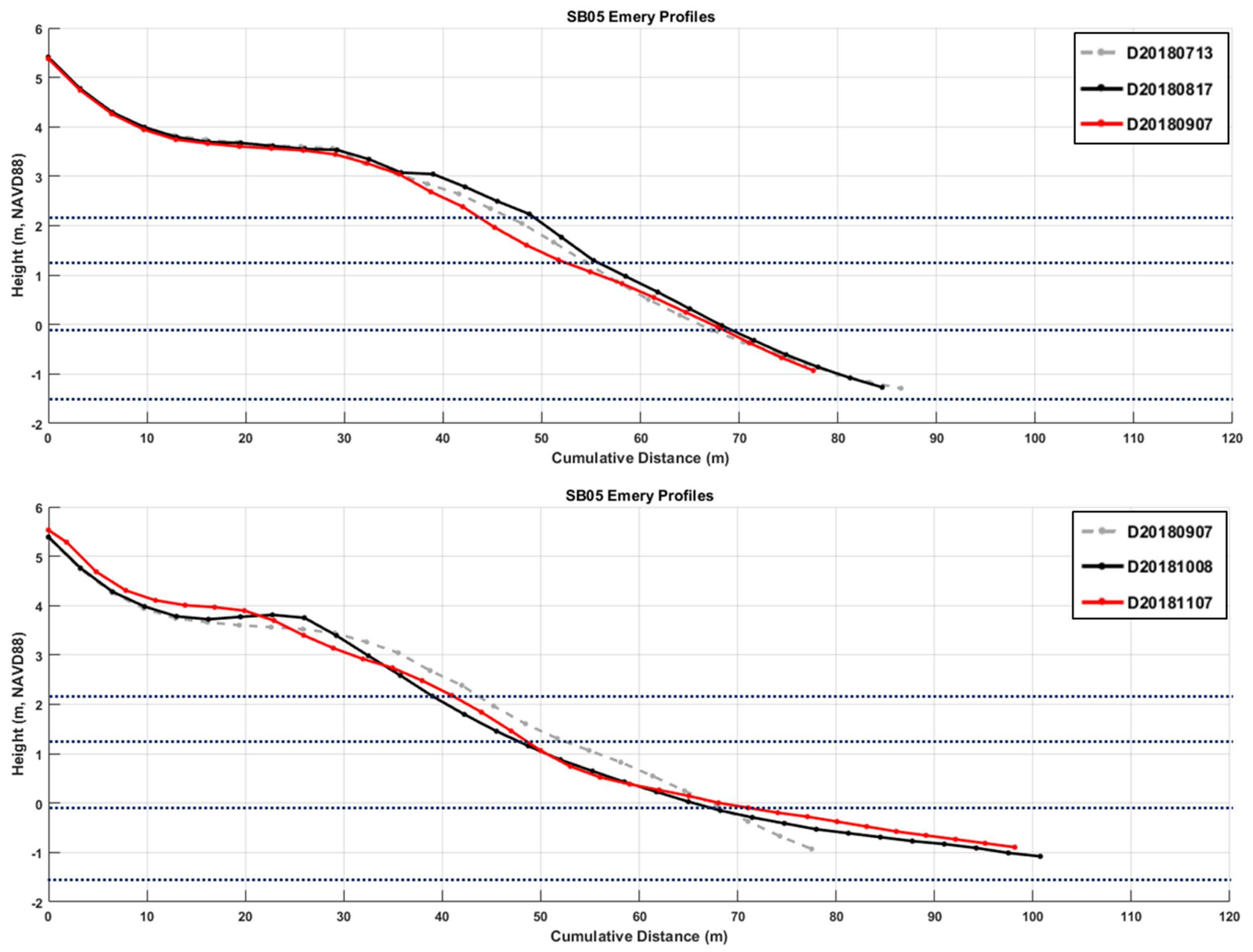

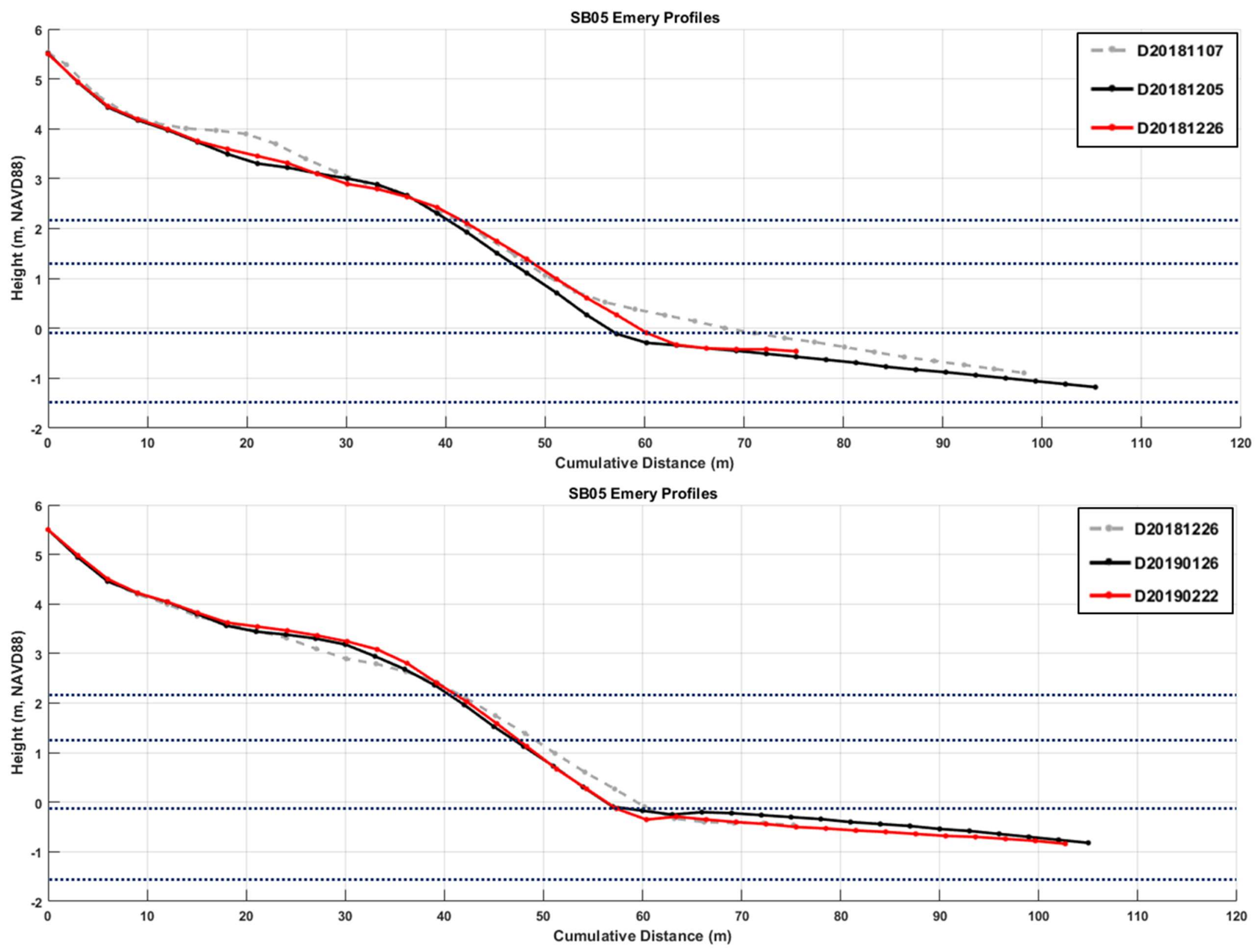

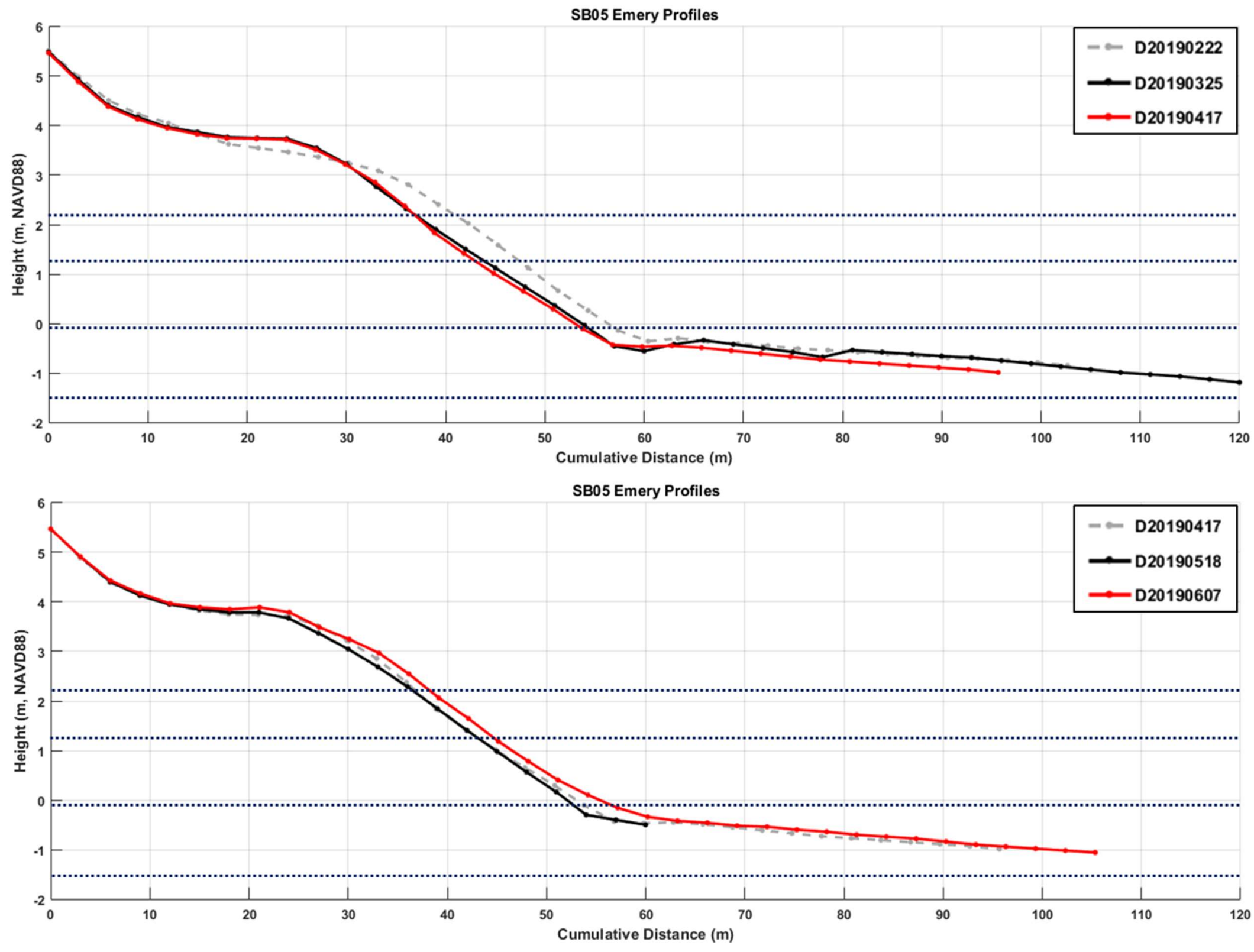

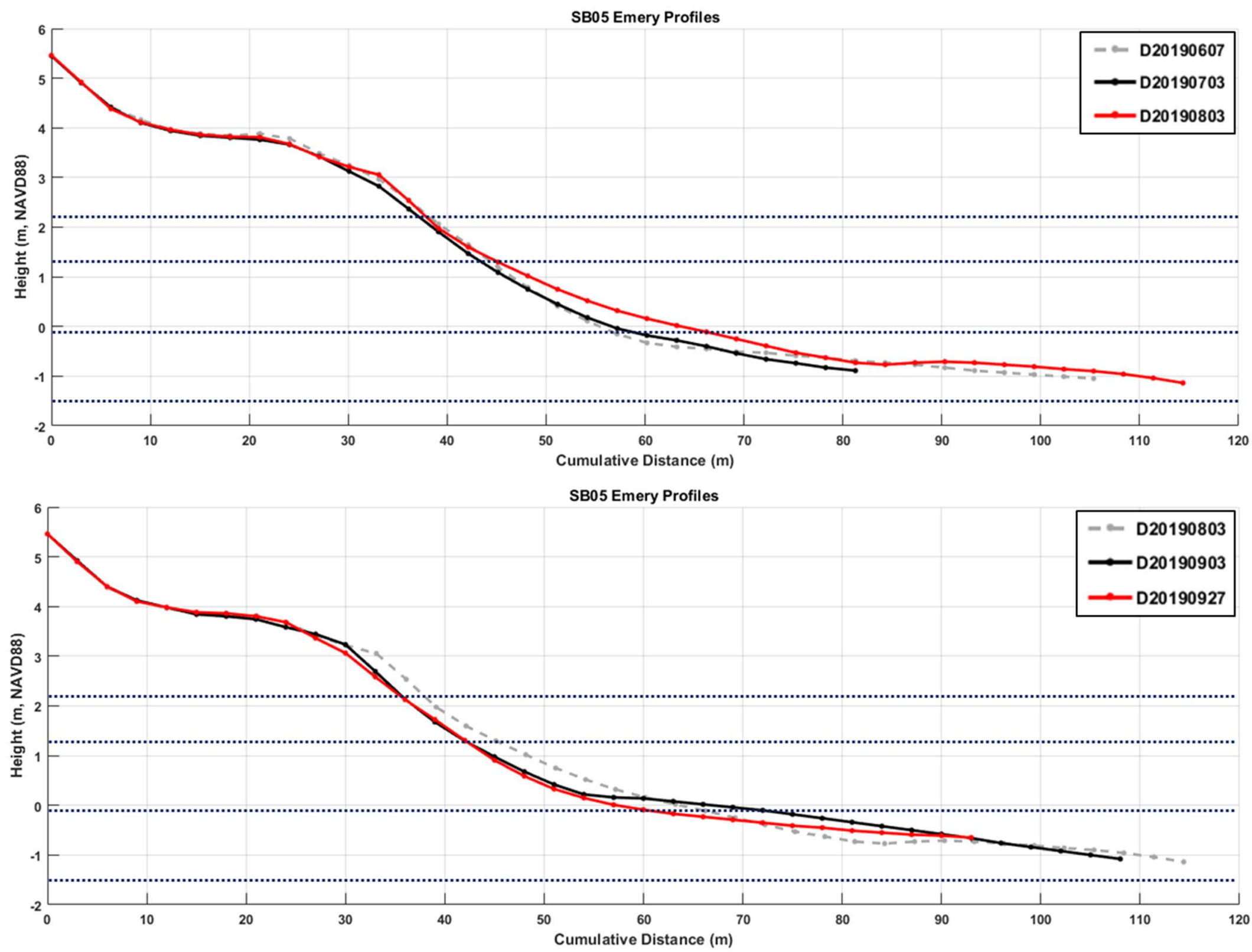

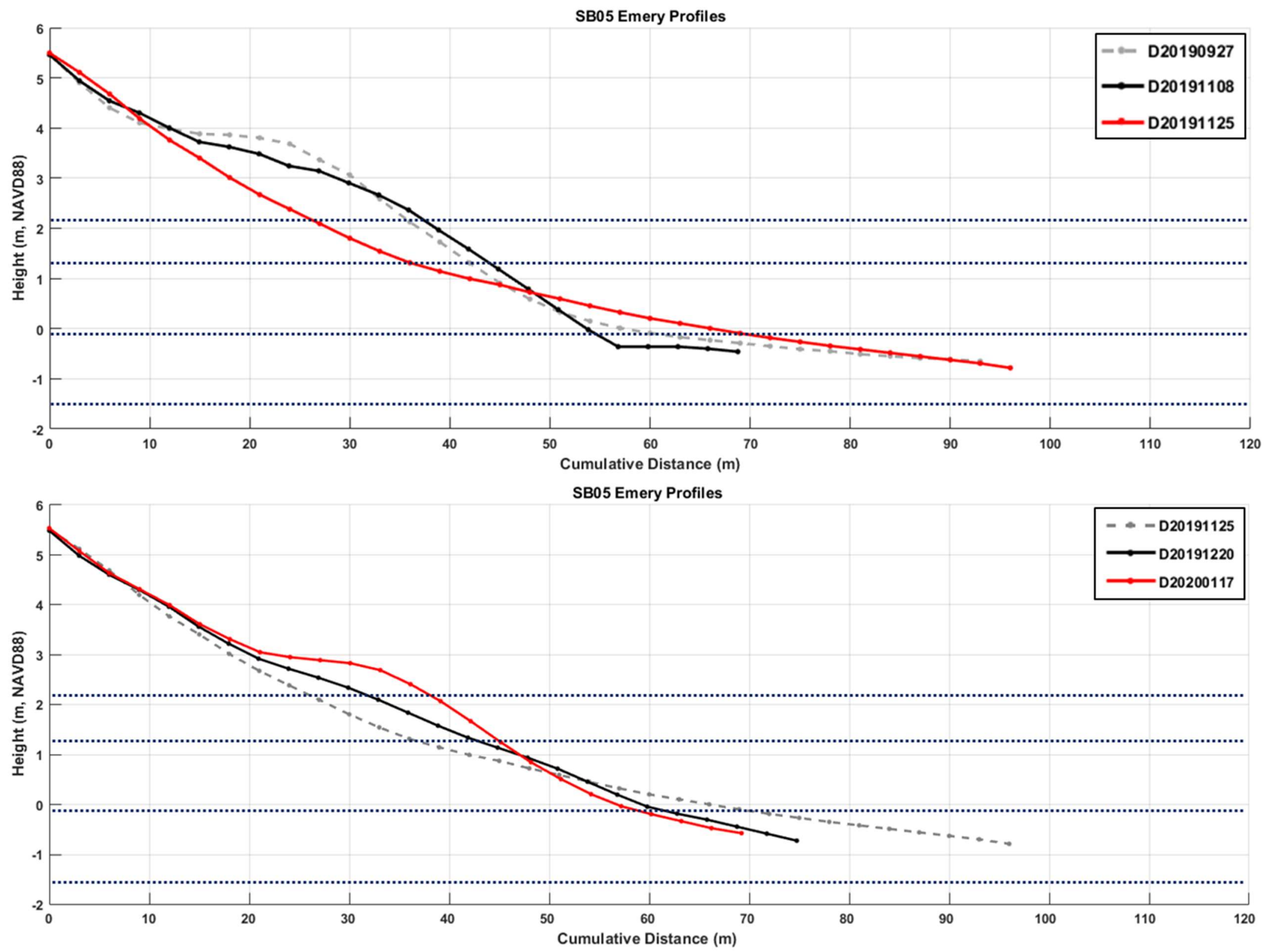


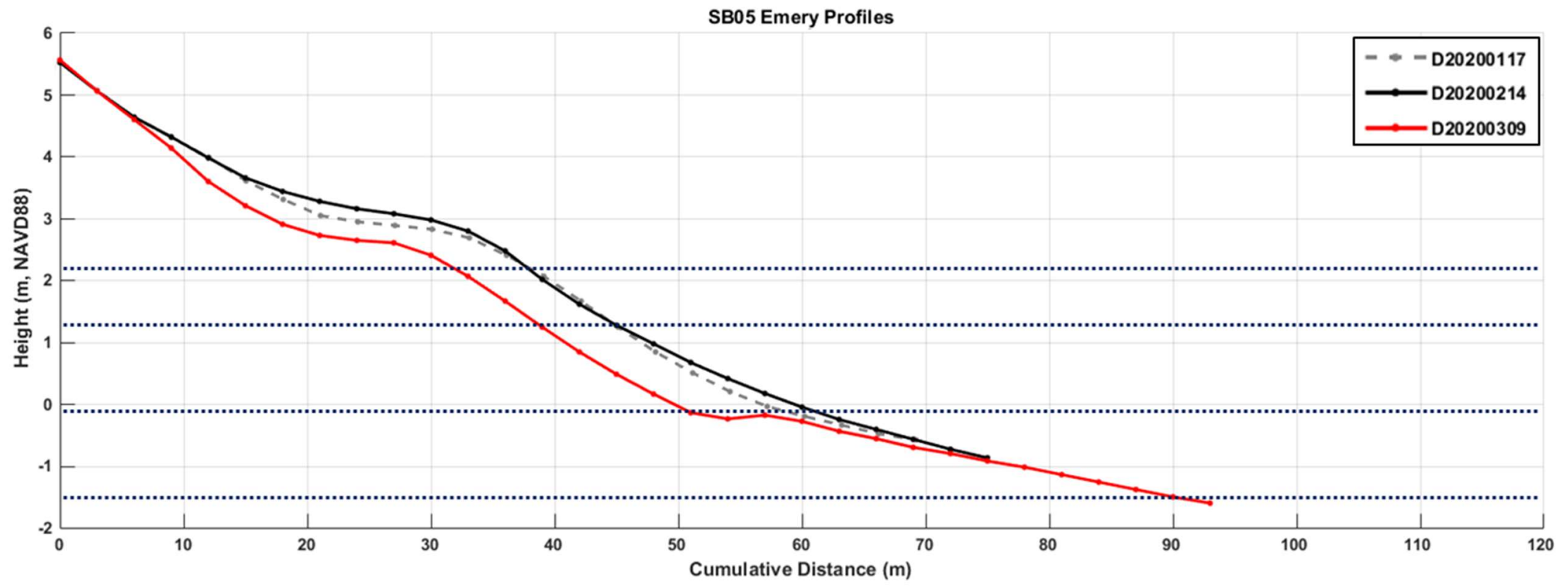

